Florida International University

FIU Digital Commons

\title{
Outlaw Citizenship in Artistic Cities: Local Artistic Communities and Citizen Participation
}

Amelia A. Pridemore

Florida International University, aprid004@fiu.edu

Follow this and additional works at: https://digitalcommons.fiu.edu/etd

\section{Recommended Citation}

Pridemore, Amelia A., "Outlaw Citizenship in Artistic Cities: Local Artistic Communities and Citizen Participation" (2019). FIU Electronic Theses and Dissertations. 4025.

https://digitalcommons.fiu.edu/etd/4025

This work is brought to you for free and open access by the University Graduate School at FIU Digital Commons. It has been accepted for inclusion in FIU Electronic Theses and Dissertations by an authorized administrator of FIU Digital Commons. For more information, please contact dcc@fiu.edu. 


\title{
FLORIDA INTERNATIONAL UNIVERSITY
}

Miami, Florida

\section{OUTLAW CITIZENSHIP IN ARTISTIC CITIES: LOCAL ARTISTIC COMMUNITIES AND CITIZEN PARTICIPATION}

\author{
A dissertation submitted in partial fulfillment of the \\ requirements of the degree of \\ DOCTOR OF PHILOSOPHY \\ in \\ PUBLIC AFFAIRS \\ by
}

Amelia A. Pridemore 
To: Dean John F. Stack, Jr.

Steven J. Green School of International and Public Affairs

This dissertation, written by Amelia A. Pridemore, and entitled Outlaw Citizenship in Artistic Cities: Local Artistic Communities and Citizen Participation, having been approved in respect to style and intellectual content, is referred to you for judgment.

We have read this dissertation and recommend that it be approved.

$\begin{array}{r}\text { Sukumar Ganapati } \\ \hline \text { Matthew D. Marr } \\ \hline \text { Milena I. Neshkova } \\ \hline \text { N. Emel Ganapati, Major Professor }\end{array}$

Date of Defense: March 26, 2019

The dissertation of Amelia A. Pridemore is approved.

Dean John F. Stack, Jr. Steven J. Green School of International and Public Affairs

Andrés G. Gil

Vice President for Research and Economic Development and Dean of the University Graduate School

Florida International University, 2019 
C Copyright 2019 by Amelia A. Pridemore

All rights reserved 


\section{DEDICATION}

I dedicate this dissertation to my parents, Mike Pridemore and Maggie Gore

Pridemore; my best friends, Josh Hunter, Marie Hall-Booth, and Martha Snyder-Sheehan; my late maternal grandmother, Kathleen Howell Gore Hatfield; my late paternal grandfather, Joe Lewis Pridemore; my late journalism colleague, Dan Stillwell; and my darling cat, Domino. I would never be the person I am and would have never reached this point without the influence of these amazing and inspiring fellow outlaws. Thank you. 


\section{ACKNOWLEDGMENTS}

I wish to first thank my dissertation chair, Dr. N. Emel Ganapati, for all of her guidance, support, and being the person who somehow strikes that balance of allowing me to pursue research topics and methods that are outside-the-box and finding ways to help me make it into solid scholarship. She knows when to let me run or rein me in, which is a testament to her intuition, brilliance, and, most certainly, her patience. Taking in someone who was certainly not a typical Ph.D. candidate, certainly did not have a typical research interest for Public Affairs, and definitely did not have a typical modus operandi took some serious courage on her part, too. I am so honored to have had such an amazing scholar who is also an amazing person beside me through all of this.

I also want to extend my gratitude toward my three committee members, Dr. Sukumar Ganapati, Dr. Milena I. Neshkova, and Dr. Matthew D. Marr. Each of you has provided outstanding insight that provided an amazing toolkit, per se, when I entered the field in Austin and New Orleans. More importantly for me, though, I always say that my committee members were the first ones to take a chance on a rather unconventional scholar and topic. For that, I am forever in their debt.

I certainly will never forget my roots and want to give credit is due, there. I want to thank Dr. Robert Behrman, Dr. Marybeth Beller, Dr. Cheryl Brown, Dr. George Davis, and Dr. Jamie Warner of the Department of Political Science at Marshall University,

where I earned my master's degree. I entered their program with no intentions of earning a Ph.D. afterward to have them make me fall in love with academic research and demonstrate how to transition from being a consumer of knowledge to a creator of 
knowledge and how incredible that is. They never held me back and always encouraged my creativity and imagination in everything I did.

I must also thank Dr. Ralph Turner, professor emeritus, from the W. Page Pitt School of Journalism and Mass Communications at Marshall. With Dr. Turner's guidance, I launched my professional career during my undergraduate program. Dr. Gordon Crews, now chair of the Department of Criminal Justice at the University of Texas-Rio Grande Valley, also helped me further develop my research during my master's program. All of my Marshall professors were willing to take a gamble on a firstgeneration student from the West Virginia coalfields region who had serious ambition but had a steeper learning curve. I joked that I needed to keep a toothbrush in their offices because I was there so often, but they never turned away a student who truly wanted to learn and just needed a little extra time.

I am grateful to Dr. Joaquin Herranz Jr., associate professor of Public Policy and Governance at the Daniel J. Evans School of Public Policy at the University of Washington-Seattle. My conversation with him when this dissertation topic was very much in its infancy really helped me find that "in" that would make more in the public policy realm notice the work I was doing and how this work could both fit in our discipline's context while still being novel. Like my professors at FIU and Marshall, he also combined being a brilliant scholar with being a wonderful person.

I certainly want to thank those who provided fellowships that made this research possible. I would like to thank the Florida International University's University Graduate School for its Dissertation Year Fellowship and Doctoral Evidence Acquisition fellowship. I also want to thank the Florida International University Steven J. Green 
School of Public and International Affairs for awarding me the Morris and Anita Broad Research Fellowship. I also want to express my gratitude toward the American Society for Public Administration for choosing me for its 2019 Founder's Fellows program. I also want to acknowledge the Corporation for National and Community Service for its education award after I served one year as an AmeriCorps VISTA.

I also want to express my gratitude to Alice in Chains, my all-time favorite band. Not only has their music inspired my work and pushed me onward even when it seemed all hope was lost, but also their survival through so much adversity is breathtaking. Seeing Alice in Chains live in 2010 ultimately inspired me to enter academia. Alice in Chains demonstrates the epitome of raw honesty, something I always strive to do in my writing, my music, and my scholarship. During this journey, I also discovered Halestorm, whose music also keeps my head up when it feels like the weight of the world is on my shoulders. I want to acknowledge them, as well. Getting congratulatory hugs from four musicians I so tremendously respect when I had the chance to meet them shortly after earning candidacy is definitely one of my life's greatest highlights.

And I certainly want to thank the people of Austin and the people of New Orleans. You welcomed a stranger into your cities — and you beloved street corners, bars, and coffee shops — and you treated her as one of your own. You demonstrated such raw honesty and shared your amazing stories about how you fight to keep your cultures and institutions alive. I will forever carry the imprint of your streets on my feet and the imprint of your hearts on my soul. 


\section{ABSTRACT OF THE DISSERTATION \\ OUTLAW CITIZENSHIP IN ARTISTIC CITIES: LOCAL ARTISTIC COMMUNITIES AND CITIZEN PARTICIPATION \\ by}

Amelia A. Pridemore

Florida International University, 2019

Miami, Florida

Professor N. Emel Ganapati, Major Professor

Artistic communities are under threat from rapid development leading to an affordability crisis and social tension from new residents. Those in the fine arts could be forced to leave, and the cities' beloved older third place arts venues could shutter. However, they face numerous participation barriers. They are a largely disaffected population, with many turning to "outlaw citizenship", such as protests and online organizing. Given these communities' contributions to economies, culture and history, and quality of life, determining their participation barriers and how to break them is critical.

I undertook a qualitative study in Austin and New Orleans with methods such as unstructured interviews and participant observations. One finding was place being critical for constructive conversation, particularly in casual, level third places. A major hindrance was artistic communities' constantly working to afford rising costs could rarely participate. These findings may help government agencies and scholars working to engage disaffected populations. 


\section{TABLE OF CONTENTS}

CHAPTER

PAGE

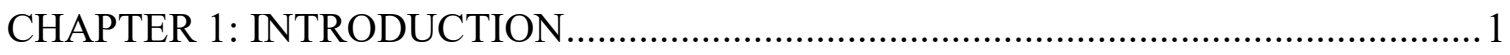

Part 2: What we know from the literature ......................................................... 7

Part 3: Summary of Literature Gaps — What We Do Not Know ......................... 17

Part 4: Research Questions ................................................................................ 19

Part 5: Case Study Cities ................................................................................ 20

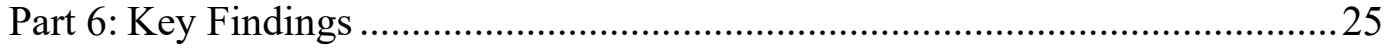

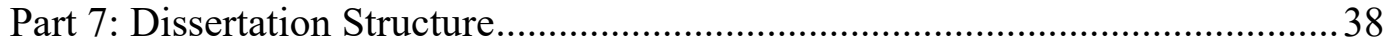

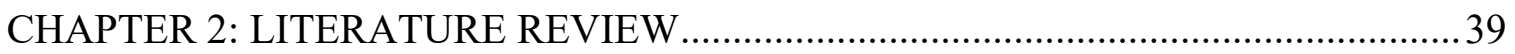

Citizen Participation: Introduction ........................................................ 40

Classic Participation Classification and Warnings for the Future ........................ 41

Outlaw Citizenship and a Dangerous Political Environment ............................. 48

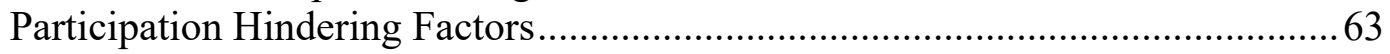

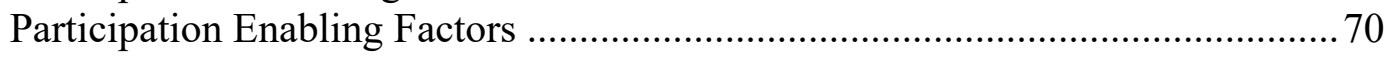

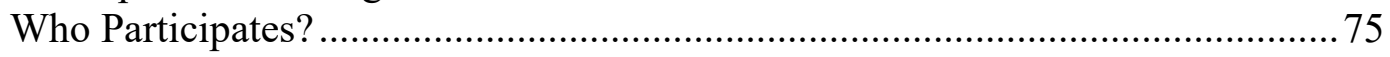

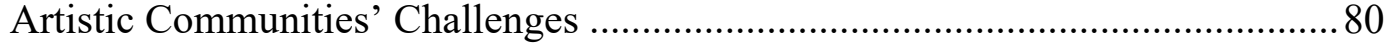

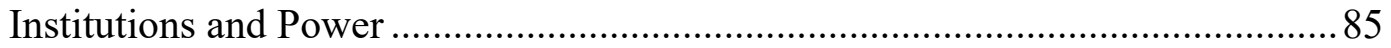

Artistic Communities' Preferred Communication Styles .................................... 96

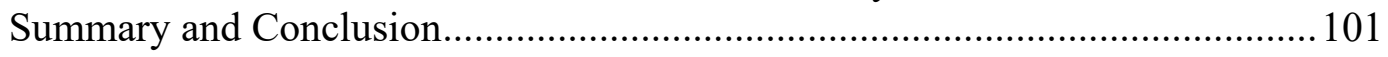

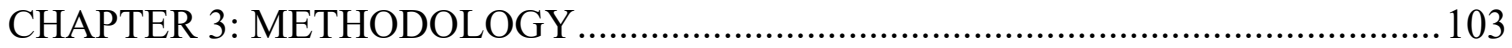

Qualitative Approach............................................................................. 103

Case Study City Selection and Elimination Criteria ........................................ 105

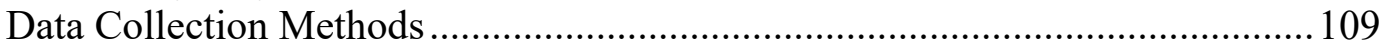

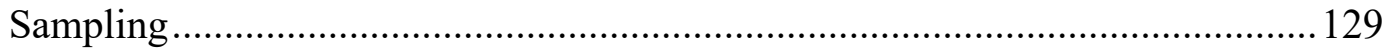

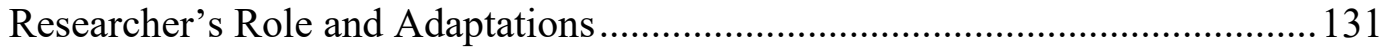

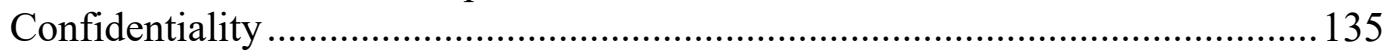

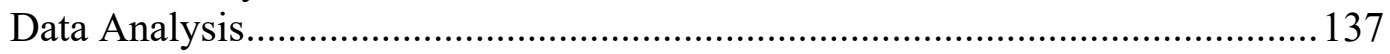

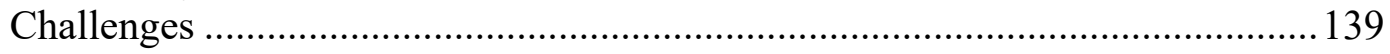

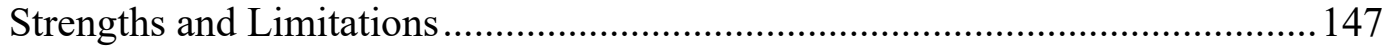

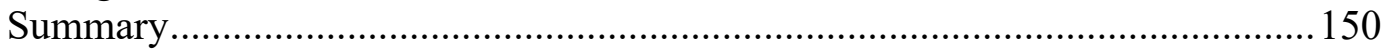

CHAPTER 4: NEW ORLEANS' PARTICIPATION HINDERING FACTORS .......... 153

Barriers to Traditional Participation ................................................................... 155

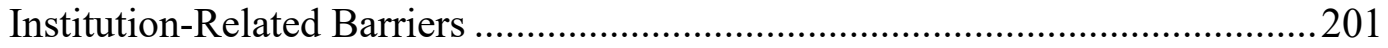

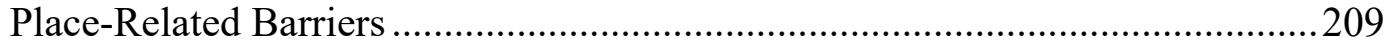

Barriers Related to Other Community Stakeholders .......................................2 218

Barriers Related to Artistic Communities .....................................................223

Barriers to Non-Traditional Participation......................................................2256

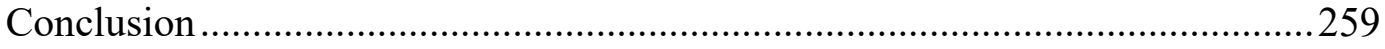


CHAPTER 5: NEW ORLEANS' PARTICIPATION ENABLING FACTORS ............261

Enabling Factors Related to Traditional Participation ....................................263

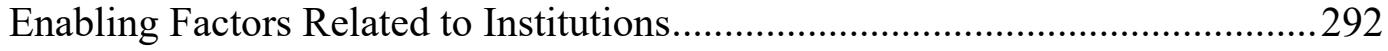

Enabling Factors with the Artistic Community .................................................. 310

Enabling Factors Related to Non-Traditional Participation ...............................316

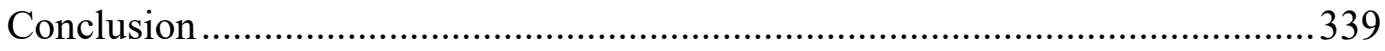

CHAPTER 6: NEW ORLEANS AND DECIDING WHO PARTICIPATES .................342

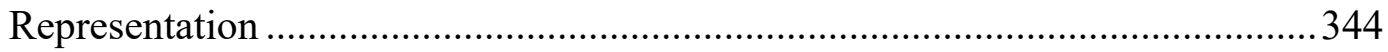

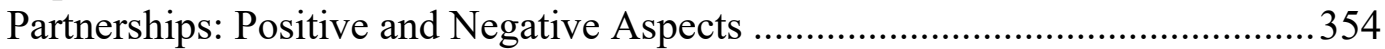

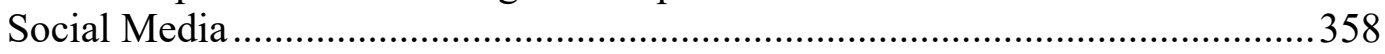

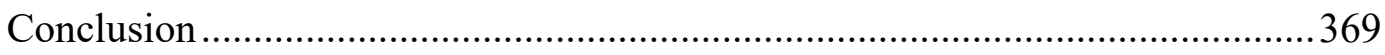

CHAPTER 7: AUSTIN'S PARTICIPATION HINDERING FACTORS .....................371

Hindering Factors Related to Traditional Participation................................... 374

Hindering Factors Related to Institutions ................................................ 425

Hindering Factors Related to Place ..............................................................442

Hindering Factors Related to Other Community Stakeholders .........................466

Hindering Factors Related to Artistic Communities ......................................510

Hindering Factors Related to Non-Traditional Participation ...........................539

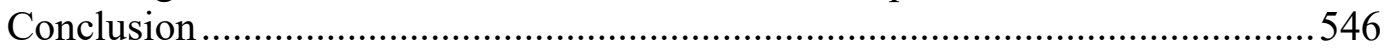

CHAPTER 8: AUSTIN'S PARTICIPATION ENABLING FACTORS .......................551

Enabling Factors Related to Traditional Participation ....................................557

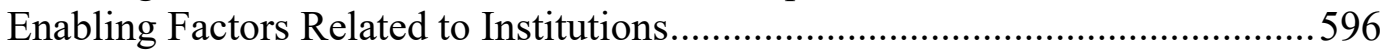

Enabling Factors Related to Place .....................................................................613

Enabling Factors Related to Other Community Stakeholders ............................649

Enabling Factors Related to the Artistic Community........................................663

Enabling Factors Related to Non-Traditional Participation ..............................687

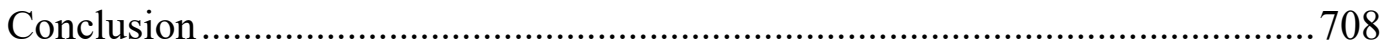

CHAPTER 9: AUSTIN AND DECIDING WHO PARTICIPATES ............................714

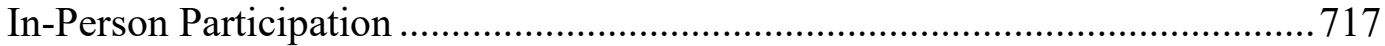

Problems with who participates (in person) ........................................717

Solutions to who participates (in person) ....................................... 728

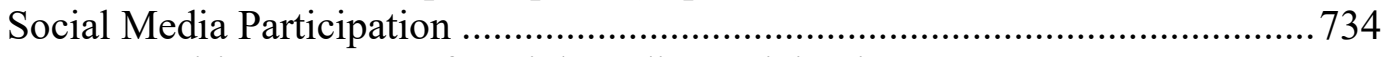

Positive Aspects of Social Media Participation................................... 736

Negative Aspects of Social Media Participation .................................... 741

Consensus: Social media better for notification, not engagement ..........779

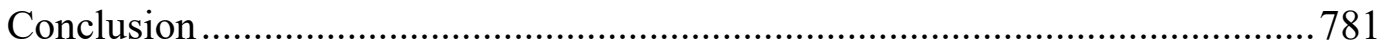




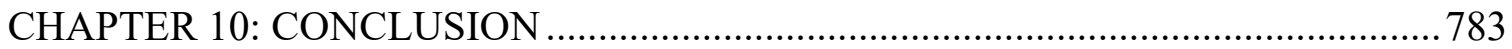

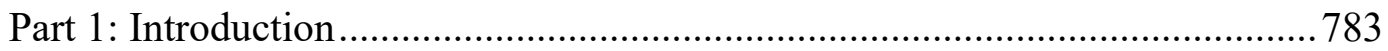

Part 2: Summation of Findings (Artistic Communities)....................................785

Part 3: Policy Conclusions......................................................................... 792

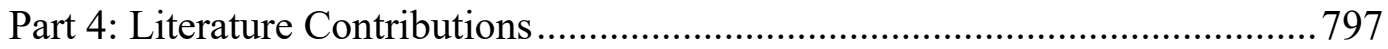

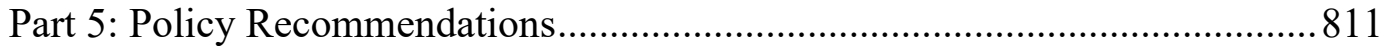

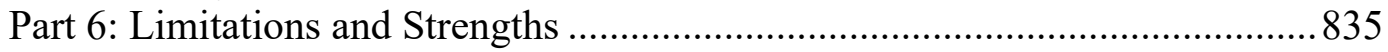

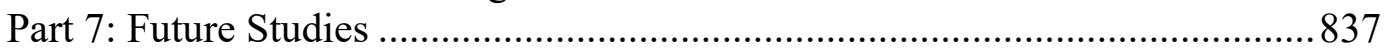

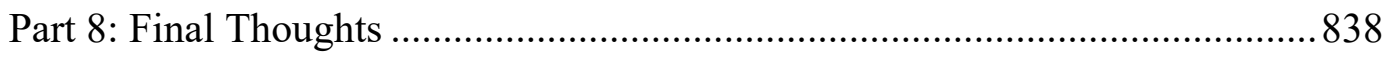

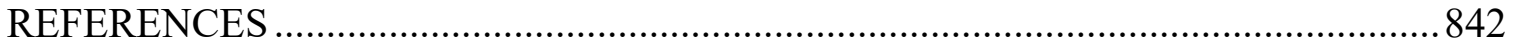

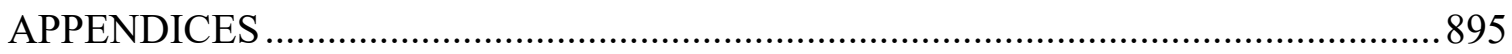

VITA 


\section{LIST OF TABLES}

TABLE

PAGE

Table 3.1: Participants' Primary Roles.

Table 3.2: Participants' Noteworthy Secondary Roles. 116

Table 3.3: Participant Gender

Table 3.4: Participant Race.

Table 3.5: Participant Age 117

Table 3.6: Participant Educational Level 118

Table 3.7: Participants' Time in Their Respective Cities. 118

Table C1: Austin, Hindering Factors, Data Analysis . .906

Table C2: Austin, Enabling Factors, Data Analysis .906

Table C3: Austin, Who Participates?, Data Analysis. 907

Table C4: Austin, Breaking Participation Barriers, Data Analysis . .907

Table C5: New Orleans, Hindering Factors, Data Analysis...... .907

Table C6: New Orleans, Enabling Factors, Data Analysis .908

Table C7: New Orleans, Who Participates?, Data Analysis .908

Table C8: New Orleans, Breaking Participation Barriers, Data Analysis. .909 


\section{LIST OF FIGURES}

FIGURE

PAGE

Figure 3.1: Participant Draws Narrative Map (Pridemore, 2018) .................................. 124

Figure 3.2: Participant Draws Narrative Map (Pridemore, 2018) ................................ 124

Figure 4.1: Krewe Du Vieux float, mayor as stripper (Pridemore, 2018) ...................... 169

Figure 4.2: Krewe Du Vieux pimp walking group (DeMocker, 2018a) ........................ 169

Figure 4.3: Krewe Du Vieux float, people in floodwater (Pridemore, 2018)................. 170

Figure 4.4: 1880s street performance cartoon (as cited in City of New Orleans, 2013).174

Figure 4.5: Storyville shutdown and Satan (as cited in Karst, 2017) .......................... 181

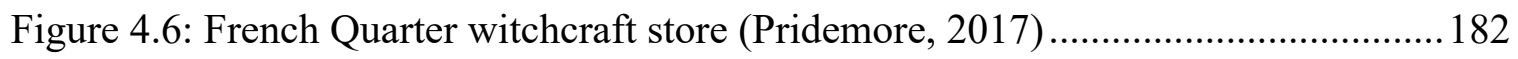

Figure 4.7: French Quarter occult store (Pridemore, 2017) ..................................... 182

Figure 4.8: French Quarter gay bar with Christmas décor (Pridemore, 2017)............... 184

Figure 4.9: French Quarter Christmas décor (Pridemore, 2017) ................................. 184

Figure 4.10: Closed store, rent is too damn high meme (Pridemore, 2017)................... 192

Figure 4.11: Giant band tip bucket, Bourbon (Pridemore, 2017)................................ 194

Figure 4.12: Street band with giant tip buckets (Pridemore, 2018).............................. 195

Figure 4.13: Near-empty council chambers at meeting's end (Pridemore, 2018).......... 197

Figure 4.14: Narrative Map (Reality/Inset): Alicia, New Orleans visual artist.............. 199

Figure 4.15: Narrative Map (Reality/Inset): Frank, New Orleans street musician.......... 199

Figure 4.16: Narrative Map (Reality/Inset): Lee, New Orleans street musician .............200

Figure 4.17a: Noise Zones (Music and Culture Coalition of New Orleans, 2016a) .......204

Figure 4.17b: Decibel Chart (Music and Culture Coalition of New Orleans, 2016a) .....205

Figure 4.18: Krewe Du Vieux float, mayor as man of feces (Pridemore, 2018)............212 
Figure 4.19: Krewe Du Vieux walking group feces hat (Pridemore, 2018)...................213

Figure 4.20: FIX MY STREET high heel shoe (Fix My Streets NOLA, 2015) ............215

Figure 4.21: Damaged bicycles at city hall bike racks (Pridemore, 2017)....................217

Figure 4.22: Krewe Du Vieux float, 300 years of ineptitude (Pridemore, 2018)...........228

Figure 4.23: Krewe Du Vieux float, New Orleans report card (Pridemore, 2018) ........229

Figure 4.24: Narrative Map (Reality): Lucius, street musician ...................................233

Figure 4.25: Narrative Map (Reality): Kingsley, NOPD supervisor.............................236

Figure 4.26: Street poem about my cat (Identity withheld per IRB restrictions, 2017) ..244

Figure 4.27: People holding giant snakes on Bourbon Street (Pridemore, 2017) ..........247

Figure 4.28: Narrative Map (Reality): Anthony, street musician...............................257

Figure 5.1: Cat food for stray at NOPD precinct (Pridemore, 2017) ...........................276

Figure 5.2: Street performer's chained bicycle (Pridemore, 2017) ..............................279

Figure 5.3: Street performer's chained tip bucket (Pridemore, 2018) ..........................279

Figure 5.4: Narrative Map (Ideal): Frank, New Orleans street musician .......................281

Figure 5.5: Narrative Map (Ideal): Kingsley, NOPD supervisor .................................282

Figure 5.6: Narrative Map (Reality): Frank, New Orleans street musician ...................286

Figure 5.7: Narrative Map (Reality): Lee, New Orleans street musician.......................285

Figure 5.8: Narrative Map (Reality/Inset): Lee, street musician ..................................28

Figure 5.9: Katrina X spraypainted on house (Stokes, 2010)....................................295

Figure 5.10: Katrina X décor on coffee machine (Pridemore, 2017) ..........................296

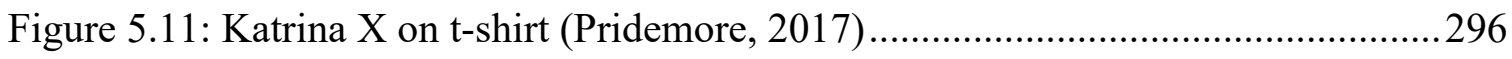

Figure 5.12: NOLA BJJ, Katrina X school patch (NOLA BJJ, 2018b) ..........................297 
Figure 5.13: Mr. Bill smashed in earthquake (Saturday Night Live, 2018 [1981]) .......299

Figure 5.14: Krewe Du Vieux 2006, Fix Everything My Ass! (Cockroach, 2006d) ......301

Figure 5.15: Krewe Du Vieux 2006, FEMA Beads on the Way (Cockroach, 2006a) ....302

Figure 5.16: Krewe Du Vieux 2006, Home is Where the Tarp Is (Cockroach, 2006c) ..303

Figure 5.17: Krewe Du Vieux 2006, FEMA condom (Cockroach, 2006b) .................... 304

Figure 5.18: Trumpet player at Lee statue removal (DeMocker, 2017a) ......................320

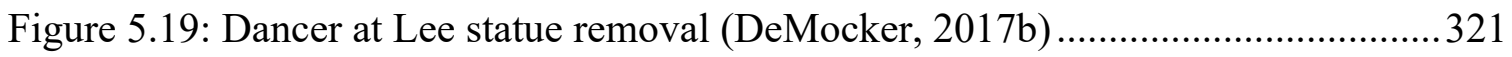

Figure 5.20: Krewe Du Vieux Marie Antoinettes at parade arrival (Pridemore, 2018) .. 327

Figure 5.21: Krewe Du Vieux bearded Marie Antoinette (DeMocker, 2018b) ..............327

Figure 5.22: Krewe Du Vieux, Let them eat, pink fan (Pridemore, 2018).....................328

Figure 5.23: Krewe Du Vieux Spanktuary City Lady Liberty butt (Pridemore, 2018)...329

Figure 5.24: Krewe Du Vieux Lady Liberty spanks back (Pridemore, 2018)................330

Figure 5.25: Krewe Du Vieux, poop deck boat float (Pridemore, 2018) ....................... 332

Figure 5.26: Krewe Du Vieux, NOLA underwater at 400 (Pridemore, 2018) ................ 333

Figure 5.27: Krewe Du Vieux, scuba diver with Rouses bag (Germer, 2018)...............333

Figure 5.28: Krewe Du Vieux, scuba divers in walking group (DeMocker, 2018c).......334

Figure 5.29: Krewe Du Vieux, Let them eat Donald Trump float (Pridemore, 2018) ....336

Figure 5.30: Prohibition beers, Bourbon Street (Pridemore, 2017) ..............................338

Figure 5.31: Street preacher on Bourbon Street (Pridemore, 2017) ..............................338

Figure 5.32: Judge not, pedi-cab driver (Pridemore, 2017) .......................................339

Figure 6.1: Threats (as cited in Music and Culture Coalition of New Orleans, 2016)....362

Figure 6.2: Kill Wish (as cited in Music and Culture Coalition of New Orleans, 2016) 363

Figure 6.3: Walk over their dead bodies, Facebook comment (Stevenson, 2016) ..........364 
Figure 6.4: God sent a warning in Katrina, Facebook comment (Reilly, 2017) 364

Figure 6.5: Post-Charlottesville Facebook taunting (Pendley, 2017a, 2017b) ...............365

Figure 6.6: Facebook insults, racist meme (Callahan, 2017a, 2017b) .........................366

Figure 7.1: Elevated Austin city council seats (Rodrigues, 2015) ................................384

Figure 7.2: Elevated Austin city council seats (back view) (Unknown Photographer, 2015) 384

Figure 7.3: Elevated Austin city council seats (council view) (Rodrigues, 2014) ..........385

Figure 7.4: Narrative Map (Reality): Percy, Austin musician......................................391

Figure 7.5: The Nook, with Westin hotel in the background (Anderson, 2017) ............404

Figure 7.6: Austin February 2018 city government org chart (City of Austin, 2018g) .. 409

Figure 7.7: Interim chief, new city manager, bombing (KTBC FOX 7 Austin, 2018) ...417

Figure 7.8: Narrative Map (Reality): Penelope, Austin journalist 423

Figure 7.9: Narrative Map (Reality): Nymphadora, film festival organizer in Austin....424

Figure 7.10: (Koch and Fowler, 1928, as cited in Austin American-Statesman, n.d.)....431

Figure 7.11: (Koch and Fowler, 1928, as cited in Austin American-Statesman, n.d.)....433

Figure 7.12: Fuck Trump, Fuck (epithet) stairwell vandalism (Pridemore, 2017).........436

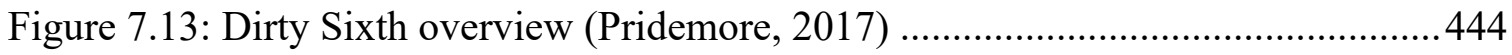

Figure 7.14: New Orleans logo on Sixth Street bar (Pridemore, 2017) ........................447

Figure 7.15: Sixth Street animal masks in window (Pridemore, 2017)........................449

Figure 7.16: My Capital Metro route screenshot (Pridemore, 2018) ............................462

Figure 7.17: Overview: Red River bars and hotel locations (Pridemore, 2018) ............471

Figure 7.18: Cheer Up Charlie's and two hotels over it (Pridemore, 2018) ..................473

Figure 7.19: Cheer Up Charlie's, Hyatt, and rock wall (Google Street View, 2018) .....474 
Figure 7.20: Cheer Up Charlie's outdoor stage, rock wall (Austin Chronicle, n.d.).......475

Figure 7.21: Narrative Map (Reality): Hermione, Austin musician.................................479

Figure 7.22: Downtown Austin construction cranes (Pridemore, 2018) ...........................482

Figure 7.23: Luxury real estate signs (Pridemore, 2018) .............................................483

Figure 7.24: Luxury real estate sign covered in tags (Pridemore, 2018).........................483

Figure 7.25: Six sign-up sheets for one meeting (Pridemore, 2018) ……………….......530

Figure 7.26: Sign up sheet close-up (Pridemore, 2018) ……………………..............531

Figure 7.27: Santa caps at tax bill protest (Pridemore, 2017) ……………………….....541

Figure 7.28: Santa at tax bill protest (Pridemore, 2017) ……………………………....541

Figure 7.29: Lump of coal for senator at Christmas protest (Pridemore, 2017) .............542

Figure 7.30: InfoWars at Christmas protest (Pridemore, 2017) ……….........................545

Figure 8.1: Narrative Map (Ideal): Nymphadora, film festival organizer in Austin .......590

Figure 8.2: City music workshop, parking validated (City of Austin, 2018e) ................596

Figure 8.3: CodeNext Game Night board, documents (Pridemore, 2018) ......................605

Figure 8.4: CodeNext Game map (Glasshouse Policy \& Austin Monitor, 2018)............607

Figure 8.5: CodeNext Game rubric (Glasshouse Policy \& Austin Monitor, 2018) ........609

Figure 8.6: CodeNext Game Night completed game board (Pridemore, 2018)..............611

Figure 8.7: Mohawk, All Are Welcome sign (Pridemore, 2018) ...................................615

Figure 8.8: Mohawk, taxidermy bear in rhinestone suit (Pridemore, 2018) ..................616

Figure 8.9: When in Rome, when in Hell, bathroom vandalism (Pridemore, 2018).......617

Figure 8.10: Cheer Up Charlie's lit-up sign (Pridemore, 2017)....................................619

Figure 8.11: Cheer Up Charlie's outside mural (Pridemore, 2017) .................................620 
Figure 8.12: Cheer Up Charlie's rainbow bar area (Pridemore, 2017) .........................620

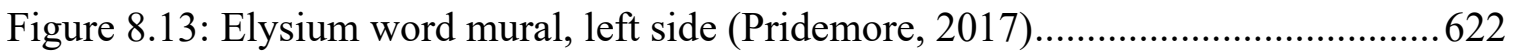

Figure 8.14: Elysium word mural, right side (Pridemore, 2017) ................................623

Figure 8.15: Austin Central Library's auditorium (City of Austin, n.d.c) .....................628

Figure 8.16: Super casual venue for CodeNext Game Night (Pridemore, 2018)...........629

Figure 8.17: Daniel Johnston's frog drawing (Johnston, n.d.) .....................................636

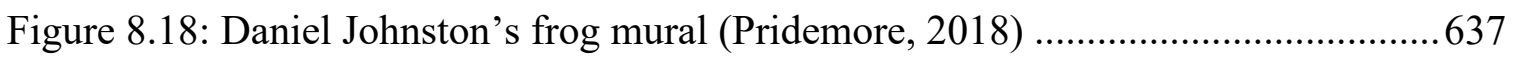

Figure 8.19: Daniel Johnston's frog at bottom of SXSW mural (Pridemore, 2018)......638

Figure 8.20: Hi, How Are You Day sign, with frog (Pridemore, 2018) .......................639

Figure 8.21: Hi, How Are You Day frog cake (Pridemore, 2018) .................................640

Figure 8.22: Overview, Mohawk, Hi How Are You Day (Pridemore, 2018) ................641

Figure 8.23: Ground level concert pit, Mohawk (Pridemore, 2018) .............................642

Figure 8.24: Band and crowd, Mohawk, Hi How Are You Day (Pridemore, 2018) ......643

Figure 8.25: Mayor, organizers, Hi How Are You Day (Pridemore, 2018)...................645

Figure 8.26: Johnston's art, auction (Pridemore, 2018) ............................................646

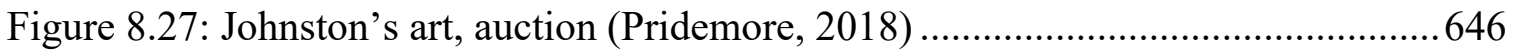

Figure 8.28: South-By-Southwest green music lanyard (Pridemore, 2018) ..................655

Figure 8.29: South-By-Southwest orange interactive lanyard (Pridemore, 2018) ..........655

Figure 8.30: South-By-Southwest blue film lanyard (Pridemore, 2018) ......................656

Figure 8.31: South-By-Southwest gray platinum lanyard (Pridemore, 2018)................656

Figure 8.32: South-By-Southwest access gates (Pridemore, 2018) .............................657

Figure 8.33: South-By-Southwest British rock photographer (Pridemore, 2018)..........661

Figure 8.34: SXSW, first photo, Hendrix and Jagger (Pridemore, 2018) ......................662 
Figure 8.35: Red River district map, venues circled (Google Maps, 2019) 668

Figure 8.36: Save Our Spaces protest casket (D.B. Hall, 2016)

Figure 8.37: Save Our Spaces, dancer rises (Austin American-Statesman, 2016) .694

Figure 8.38: Save Our Spaces protest, dancer comes out of casket (D.B. Hall, 2016) ...694

Figure 8.39: We Are the Weird in Austin (as cited in D.B. Hall, 2016) .......................696

Figure 8.40: Save Our Spaces protest, Jester (as cited in D.B. Hall, 2016) 697

Figure 8.41: Dog walker and dancer (as cited in D.B. Hall, 2016)..... 698

Figure 8.42: Texas gas station gun T-shirt (Pridemore, 2017) 705

Figure 8.43: Texas gas station gun, God, America, T-shirt (Pridemore, 2017) ..............705

Figure 9.1: Narrative Map (Ideal): Draco, city boards/commissions member..... .723

Figure 9.2: Facebook Live’s viewer counter (as cited in City of Austin, 2018) .738

Figure 9.3: Facebook Live's real-time emojis (as cited in City of Austin, 2018) .739

Figure 9.4: Eight Thousand Retweets (Alliance for Securing Democracy, 2018c) ........748

Figure 9.5: Chance the Rapper tweet, Austin bombings (Chance the Rapper, 2018) .....749

Figure 9.6: Russians, bombings, race (Alliance for Securing Democracy, 2018d) ........750

Figure 9.7: Russians, bombings, Trump (Alliance for Securing Democracy, 2018b) ....751

Figure 9.8: Russians, bombings, race (Alliance for Securing Democracy, 2018a)........751

Figure 9.9: Chance the Rapper's tweet replies (Kane, Heffler, Wendigobeach, 2018) .. 752

Figure 9.10: Racism or Not (Jean, Ramsey-Ford, West, Vasquez \& Appice, 2018) ......753

Figure 9.11: Sugar coating, poo emoji (Boudreaux, 2018) ........................................ 754

Figure 9.12: Facebook Austin bombing comment, media attack (Barnes, 2018) .......... 754

Figure 9.13: Facebook, media, bombings (Cox, Blakely, Bolton, \& Macry, 2018) .......756 
Figure 9.14: (Bennett-Ashcraft, Bynum, Parkhill, Lenhart, Garza, \& Schell, 2018)......757

Figure 9.15: Russians, white nationalism (Alliance for Securing Democracy, 2018e)...759

Figure 9.16: Russians, fanaticism (Alliance for Securing Democracy, 2018g) ............. 759

Figure 9.17: Russians, conservative (Alliance for Securing Democracy, 2018f) ..........759

Figure 9.18: Accused Russian (Garza, Schell, \& Epps, 2018) .................................... 760

Figure 9.19: Repeated posting (as cited in City of Austin, 2018d) ..............................765

Figure 9.20: Repeats drown out relevant (as cited in City of Austin, 2018d) ................767

Figure 9.21: Self-promotion (as cited in City of Austin, 2018d) ................................ 769

Figure 9.22: More self-promotion (as cited in City of Austin, 2018d) ........................ 770

Figure 9.23: Not sure what you're talking about (as cited in City of Austin, 2018d) .....771

Figure 9.24: Panelist fan love (as cited in City of Austin, 2018d) ............................... 771

Figure 9.25: Fan love for panelist on Twitter (Cam Mysterio, 2018b) ..........................772

Figure 9.26: Sharp political comments (as cited in City of Austin, 2018a) ...................773

Figure 9.27: Asking is it over (as cited in City of Austin, 2018d) .............................. 774

Figure 9.28: Broadcast cutting out (as cited in City of Austin, 2018d)........................775

Figure 9.29: Frustrated Twitter user, laptop gif (Cam Mysterio, 2018a) .......................776

Figure 9.30: Tech problems, video goes black (as cited in City of Austin, 2018d) ........777

Figure B1: Map of Red River district and Dirty Sixth (Google Maps, 2018)................901 


\section{CHAPTER 1: INTRODUCTION}

Though I was shivering from the drenching rain in January 2018, I saw New

Orleans' French Quarter come to life with a spectacular, hilarious, and biting display with its delightfully over-the-top Krewe Du Vieux Mardi Gras parade floats, brass bands, and second-line parade dancers that included women and bearded men dressed as Marie Antoinette. The dazzling Maries, as well as sparkling dancers dressed as the Statue of Liberty, mermaids, pigs, and scuba divers pulled spectators into the crowd to dance with them along the way. The floats took dead aim at the city government after residents had endured months of flooding and drainage problems from malfunctioning pumping stations (Brasted, 2017). Atop one of the floats sat an effigy of the then-mayor as a man who was literally a pile of feces. Dancers with hats that resembled giant piles of feces with sparkling purple plumes at the top — gleefully followed.

Just as the city did not stop for a measly little flood warning that evening, the street performers continued their "hustle", simply finding awnings where they continued to play their hearts out as the more faint of heart believed they would melt like the Wicked Witch of the West. Crowds in pink wigs and sparkling makeup began gathering well in advance of the parade. On the steps of a house that instructed passersby to stay off the steps, a small group of young women walked onto the steps and took selfies. New Orleans was a city that would have a good time but would also not stop hard work and not stop fighting back.

Weeks before, I had been in Austin, where a sign reading "All Are Welcome" at the Mohawk live music venue in the Red River district greeted visitors at the door. I spent quality time with a dead stuffed bear in a vintage sky blue suit — as well as a crowd 
ranging from young people in scruffy flannel shirts to professionals and government officials - as we stood in an outdoor concert pit in near-freezing weather. The gathering was to further promote mental health awareness and destigmatize, and raise funds to treat mental illness (Hi, How Are You Project, 2018), something that friendly people I met readily shared that they had struggled with but survived.

I climbed onto the Mohawk balcony to watch the crowd ranging from twentysomethings to elderly men with long white beards so I could check the notepad I had hidden while in the crowd. I noticed the neighboring Cheer Up Charlie's across from me. There, a rainbow motif also lets those who walk inside know that all are welcome there too, regardless of sexual orientation or gender identity. I had visited Cheer Up's, as the locals call it, and immediately made friends for the evening in this comfortable and casual locale's outdoor seating area, even though we were shivering outside that night, as well. Like Poseidon was no match for New Orleans, Jack Frost would not stop Austin.

Both nights in the Red River district, though, I glanced upward to see two high-end hotels looming over the beloved, humble outdoor live music venues and their developers closing in on them.

The sounds of these spirited cities, with their music in the open air, dancing in the streets, shabby and yet comfortable and beloved arts spaces, colorful costumes even when it is not Halloween, diversity, carefree laughter, and where one has the license to be as weird as the heart desires, though, could be silenced. 
Artistic communities*, the core of historically arts-oriented cities that historically march to the beat of their own drums, are under threat. Rapid development, gentrification, and skyrocketing rents are making it almost impossible to afford both living in their cities or owning their businesses (Long, 2010; Personal Communication, 2017, 2018; Timberg, 2015). Besides their homes and livelihoods being at stake, their cities' beloved third places (Oldenburg, 1999) such as older bars that play live music, small art galleries, and fringe theaters, could be forced out of the cities — if they have not been forced out already.

On top of this, social tensions have arisen from new residents or elegant businesses seeking to temper historically boisterous entertainment neighborhoods and cultural activities (Curtin, 2017a; Findell, 2017a, 2017c, 2017d, 2017e; Rainey, 2014; Personal Communication, 2017, 2018; Woodward, 2014). Because these communities, businesses, and spaces are critical elements of a city's culture, history, quality of life, and economic base, it is imperative that policy solutions that can preserve these communities and spaces be workable and implemented.

While this situation may seem like a market problem, this is very much rooted in public policy and public policy scholars and practitioners should definitely take heed. Typically, the opposing parties, like wealthy developers and new residents, work to quell artistic communities through pushing for policies, like stricter noise ordinances, that can curb or even stop artistic activities and businesses (Beyer, 2016). If culture, through these policy mechanisms, becomes restricted to the point where artistic communities cannot

*This definition is different from Richard Florida's "creative class" (Florida, 2014a, 2014b), which includes, amongst others, technology workers along with fine arts occupations. This study's definition, derived from Markusen and Schrock (2006) and Personal Communication (2015), only refers to the fine arts. 
properly do their jobs, if at all, the culture will die. Those opposing the artistic communities often have much more money and societal and political power over oftenstruggling artistic communities, creating a serious power imbalance in policy debates (Gaventa, 1980; Warner, 2001, 2011).

In historically arts-oriented cities, the cultural roots are much deeper — some, going back for centuries (City of New Orleans, 2013) — than in cities that have undertaken arts development initiatives in recent years, making the losses a punch to the face and what remains being at risk sparking feelings of anger, betrayal, and hurt. In terms of both quality of life and cultural access in cities, the artistic community members, venues, and activities being threatened (Beyer, 2016) are most often ones providing those accessible and affordable activities critical for having a vibrant city with a good quality of life (Berson, 2007; Jacobs, 1992 [1961]; Oakes \& Warnaby, 2011; Oldenburg, 1999), such as dive bar concerts and fringe theater performances. Arts and culture matter not just to a certain segment of the population but also to all citizens.

It should be noted that some scholars have argued that development and income inequality, not artistic communities, are responsible for their plight. Markusen (2014) writes, "A free-market property rights system and an active development industry in cities drive gentrification, not artists per se, even if some artists are caught in its fastchanging web. Contemporary cultural observers understand this and are questioning the pervasiveness of artist-led gentrification" (p. 570). Florida (2014a, 2017) has pointed to income inequality, which has become even more severe than during previous gentrification cycles (2017) and (2014a) the "enduring legacy of race and poverty at the bottom of the socioeconomic order..." (p. 202). 
Nonetheless, artistic communities are not giving up the culture and spaces they hold dear and the communities they have created without a fight. They are now entering citizen participation processes, but because of the current situation combined with years of longstanding tensions stemming from disputes like ones over noise and cultural practices and events considered nuisances, artistic communities are entering the citizen participation process as a disaffected population. This presents a challenge in itself, but another is that artistic communities, as scholars have noted is often the case for historically disadvantaged groups (Fung, 2006, 2015; Laurian, 2004; Rimmerman, 2011), face numerous barriers in trying to participate.

Disaffected artistic communities working to enter local policymaking processes are now often engaging in the increasingly unconventional and often-adversarial "outlaw citizenship" (as cited by C.S. King \& Nank, 2015; Faires, 2016; Personal Communication, 2015; Rimmerman, 2011; Woodward, 2014) that disaffected populations favor. Outlaw citizenship involves eschewing more traditional citizen participation such as participating in traditional public hearings for activities such as protests and online organizing (Rimmerman, 2011). Rimmerman (2011) notes that such forms of participation are "often deemed necessary by groups that are located at the margins of American society" (p. 94) who believe they have no other options and will not be heard otherwise. Outlaw citizenship's goal is not working with government but against it, with participants working to disrupt policies they believe are unjust. In artistic communities' outlaw citizenship, they are often utilizing their crafts such as music and theatrical performances that both communicate their situations and relationships with 
their governments (Frith, 1996; Litten, 2016; Love, 2006; Rainey, 2014; Woodward, 2014, 2016).

Given their significant contributions to overall urban vitality (Oakes \& Warnaby, 2011; Oldenburg, 1999), losing artistic communities and their spaces would be majorly detrimental to the public that public administration serves. However, to help craft public policy with artistic communities" first-hand knowledge as a valuable contributor (Elias \& Alkadry, 2011) that could keep the musicians artists in the cities and save their spaces, public administrators need to determine what artistic communities' participation barriers are, what could help them overcome any barriers, and who among artistic communities should participate.

The structure of this chapter is as follows. First, I will summarize what we do know from relevant literature, such as how participation inequality can result. Then, I will summarize the gaps, what we do not know from the literature. I will then present the research questions I formulated — 1) What factors hinder artistic communities' participation in local government? 2) What factors enable artistic communities' participation in local government? (3) Who among artistic communities should participate? Afterward, I will present information regarding the two case study cities I chose, Austin and New Orleans and some key similarities and differences between the two. I will then follow by summarizing my dissertation's key findings, such as the importance of place in either having a comfortable and conducive environment that creates constructive participation or intimidating ones that outright silence artistic communities. I will close with providing the rest of my dissertation's structure. 


\section{Part 2: What we know from the literature}

One of my core arguments in summarizing pre-existing literature is that despite citizen participation's ideals of creating greater democracy and equality (Arnstein, 1969; Denhardt \& Denhardt, 2015; Frederickson, 1997a; Fung, 2006, 2015; C.S. King \& Nank, 2015), its traditional structures and venues actually create greater inequality in the end (Fung, 2006, 2015). This is largely rooted in citizens' access to participation forums, and that access or lack thereof determines who will be the "winners and losers" in policy debates (Fung, 2006, 2015). That access is often rooted more in social and economic power and how society at-large views certain groups (Miller, 2012; Schneider \& Ingram, 1993).

Groups such as racial and ethnic minorities and those with lower socioeconomic status are often literally or figuratively shut out of traditional public hearings (Fung, 2006, 2015; Rimmerman, 2011). The key is that that when they do not attend these meetings, it is not because of apathy but instead, inability to attend (Laurian, 2004). Often, the reasons why they cannot attend include barriers such as work schedules and family responsibilities (Laurian, 2004) and societal barriers such as those from lower socioeconomic groups being intimidated by public hearings and not being trained in their social strata in how to speak in a way that government officials would favor (Rimmerman, 2011).

As a result, the policies that are created in the end favor the more privileged (Fung, 2006, 2015). Government officials prefer the more so-called "polished" communications styles from wealthier citizens, and wealthier citizens are less intimidated in those traditional participation venues (Rimmerman, 2011). In the end, citizen participation 
structures create greater inequality (Fung, 2006, 2015) when they were ironically designed to do the opposite (Arnstein, 1969; Denhardt \& Denhardt, 2015; Frederickson, 1997a; Fung, 2006, 2015; C.S. King \& Nank, 2015). Seminal pieces such as Sherry R. Arnstein's (1969) “A Ladder of Citizen Participation” warned that powerholders often manipulate citizen participation structures, even those on her figurative ladder's higher rungs, so that less powerful citizens are still silenced. Arnstein (1969) also noted that citizens were learning the "Mickey Mouse game" (p. 218) of how government worked in reality and preparing to fight back. Citizens who fight back often do so with outlaw citizenship (Pridemore, 2018; Rimmerman, 2018).

In this section, I will summarize multiple sets of literature that guided my study. First, I will discuss scholarship involving outlaw citizenship. Second, I will discuss participation hindering factors identified in public administration literature. Third, I will identify participation enabling factors public administration scholars have identified, and I will follow with a summation of what they have written about deciding who should participate, particularly in terms of how restricted or diffuse participation should be.

Afterward, I will discuss what the literature has revealed regarding institutions and power structures, particularly multi-dimensional power structures that are not direct and observable. The final literature set I will summarize involves artistic communication.

\section{Outlaw citizenship}

Outlaw citizenship (as termed by C.S. King \& Nank, 2015) often erupts when citizens are in negative situations, and, when approaching government for remedies, they literally or figuratively have doors shut in their faces (Pridemore, 2018; Rimmerman, 2011). The major point about outlaw citizenship that practitioners and scholars should 
know is that it is not spontaneous. Rather, it is the result of grievances built up over time that often erupts when citizens reach a breaking point (Akram, 2014; Pridemore, 2018). Often major events such as police shootings and labor strikes are those breaking points (Akram, 2014; Pridemore, 2018; U.S. Department of Justice, 2015). When administrators find themselves facing outlaw citizenship, it should not be a shock. They should have seen it coming.

What makes this situation even worse is that neither administrators nor citizens want to take "the high road" because citizens increasingly do not want to partner with government and administrators desire citizen deference (C.S. King \& Nank, 2015, p. 1112). Furthermore, administrators still prefer traditional participation venues like public hearings when citizens increasingly prefer outlaw citizenship (C.S. King \& Nank, 2015; Pridemore, N.E. Ganapati, \& Revell, 2019; Rimmerman, 2011). Over time, online outlaw citizenship has spiked (Rimmerman, 2011), which concerns some scholars because they believe in-person interaction, in whatever format, is critical for conducive community development (Rimmerman, 2011). This is especially concerning with the rise of social media (Allcott \& Gentzcow, 2017; Sunstein, 2017), a subject for which public administration citizen participation study is in a relative infancy (Pridemore, N.E. Ganapati, \& Revell, 2019).

\section{Participation Hindering Factors}

Public administration scholars have identified other hindering factors besides those mentioned earlier about participation structures creating greater inequality in the end (Fung, 2006, 2015). One major hindering factor is negative social construction. Social construction is how the public at-large views certain populations, for better or worse 
(Schneider \& Ingram, 1993). Those who are viewed favorably are targets for more favorable policy that will benefit them. Conversely, populations that are viewed negatively in the public eye could either have little to no policies benefitting them or even have policies implemented that work to their detriment.

Power is a major element in social construction as well, but powerful groups could be viewed negatively and positively alike, as can less powerful ones (Schneider \& Ingram, 1993). This creates a more complex situation in policymaking. Policies targeting the powerful but negatively viewed tend to have benefits that are largely hidden or even appear to hurt when they actually help. For favorably viewed but less powerful groups, officials will appear to show great concern but not allocate many resources, often having lower government levels or the private sector handle their needs.

Low public trust can be a major hindering factor for governments working to create constructive citizen participation, especially when they are working to move past extreme conflict and other crises (Bland, 2011; Goldie \& Murphy, 2015). Past citizen participation forums that, in citizens' minds, failed also erodes that trust and ultimately becomes a hindering factor (C.S. King \& Nank, 2015; Morin, 2016).

\section{Participation Enabling Factors}

Local-level organizing, such as at the municipal or neighborhood level, has been a participation enabling factor the public administration literature has identified (Pridemore, N.E. Ganapati, \& Revell, 2019). One example of how this can work well is that decentralized policymaking and with more citizen input allows more officials and citizen groups who understand culture and society unique to a given locality (Fischer, 2006). Striking the right balance between administrators' specialized expertise and 
citizens' first-hand experiential knowledge is also a critical enabling factor, as well (Brydon \& Vining, 2016; Fischer, 2006; Geurtz \& Van de wijdeven, 2010; Hong, 2015; Lawton \& Macaulay, 2014; Thijssen \& Van Dooren, 2016; Wagenaar, 2007).

Citizens and administrators alike overcoming fear of societal change is another enabling factor scholars have identified (Mucha, 2015). Mucha (2015) notes that as cities change and inevitably face new challenges, both governments and citizens face situations that are both uncomfortable and highly consequential. However, citizens also demand action when problems arise, and that often requires the very change they fear. The key in administrators successfully handling these situations and getting citizens involved in a conducive partnership is administrators positively framing issues that citizens may initially fear.

Public administration scholars have identified technology as an enabling factor (Pridemore, N.E. Ganapati, \& Revell, 2019), but a major factor in whether or not it will work in the end is that technology's user-friendliness and functionality (S. Ganapati, 2011; Zheng, 2015).

\section{Who Participates?}

In deciding who participates, public administration scholars have worked to weigh the balancing act (Emerson \& Nabatchi, 2015) between being inclusive and having diverse participants that represents the public being served (Fung, 2006) and having participation becoming to excessive, leading to incoherent noise and/or outright mob rule (Alexander Hamilton, Jay, \& Madison, 2001 [1787]; Hirschman, 1970). Balancing participation, Rimmerman (2011) writes, means handling the dilemma of balancing "participation, civility, and stability" (p. 3). 
Fung (2006) writes that if policymakers, for reasons such as lacking knowledge or resources, cannot make particular decisions, then whether or not citizen input can fill the gaps largely depends on which particular citizens participate (p. 67). Questions that should be answered in terms of who participates include whether or not participants truly represent either the relevant population or general public, if "important interests and perspectives" are included or excluded, "possess information and competence to make good judgments and decisions", and are "responsive and accountable to those who do not participate" (p. 67).

When scholars have worked to answer the question of who participates, they have portrayed online participation as problematic, namely because it opens the door so widely to an extremely diffuse group (Bryer, 2013; Kurniawan \& de Vries, 2015; Yetano \& Royo, 2017). Bryer (2013) contends that this can actually hurt citizens in the end. He examined online comments used in the federal rulemaking process and found most were "emotional, illogical, and lacking in credibility" (p. 263). What happens afterward is that

policymakers disregard such comments because they are of no use. After this, the citizens whose comments were disregarded "may experience diminished trust, diminished efficacy, and diminished perceptions of government legitimacy" (p. 276).

\section{Artistic communities' challenges}

In this chapter's introduction, I have provided an overview of artistic communities challenges, such as affordability (Timberg, 2015) and tensions from those working to temper boisterous entertainment neighborhoods (Beyer, 2016). However, I do want to further explain third places (Oldenburg, 1999) literature that both explores both what 
many artistic communities hold dear, what they stand to lose, and what drives much of their citizen participation.

Oldenburg (1999) refers to casual community gathering spaces such as bars, bookstores, and coffee shops as "third places". These are spaces away from home and work, and some scholars (Jacobs, 1992 [1961]; Oldenburg, 1999) argue that these are critical pieces of a healthy urban environment. They are often older structures in older neighborhoods, where a mix of strangers gave cities their unique identities (Oldenburg, 1999). A key point about third places is that they are what Oldenburg calls "levelers", where all people, regardless of social standing, are on the same social footing as opposed to stifling hierarchal structures like workplaces. People can also express themselves freely in ways they never could at home or work.

These older structures housing these accessible third place venues are frequently maligned because some may not see them as valuable - until it is too late (Oldenburg, 1999). Even structures that may be shabby have value, Oldenburg (1999) argues, writing, "The beer joint in which the middle-class American takes no pride can be as much of a third place as the proud Viennese coffeehouse" (p. 20). When a third place is lost, Oldenburg (1999) writes, "It is much like the death of a beloved first citizen. The community no longer feels the same; much of its character and charm seems to have depended on that place" (p. 206).

\section{Institutions and Power}

\section{Institutions}

North (1990) describes institutions as society's "rules of the game" and "humanly developed constraints shaping human interaction" (p. 3). These can be formal, such as 
written policy, or informal, such as societal gender roles. Informal ones are often much stronger, staying in place even after formal ones change. A challenge with institutions is that both formal and informal ones may not always be positive. Deep-seated culture and heritage keep informal institutions alive, and they have "great survival tenacity" (North, 1990, p. 37).

Some scholars warn, though, to not become too comfortable with institutions. While they may be strong, they are not indestructible (Bachrach \& Baratz, 1962). North (1990) writes that those seeking institutional change often do so by first changing formal ones. Once formal institutions, like public policies, are changed, this keeps related informal institutions from thriving and, eventually, the informal institutions wear down. Power

Institutions require examination of what is inside them — "ordered systems of power" or "power structures" (Bachrach \& Baratz, 1962, p. 947). How power is exercised is not always, if almost never, cut and dry. In this study, I present three dimensions of how power works in society, and most important for this dissertation, how that power works to either enable or stifle citizen participation.

The First Face of Power is largely straightforward but also requires multiple presumptions. In the First Face, A (the powerful) has the power over B (the powerless) to force B to do something that B would not normally do (Gaventa, 1980; Warner, 2001, 2011). A major element is that it has to be observable. If no resistance is readily visible, "silence automatically means happiness" (Warner, 2011, p. 1) or consent (Warner, 2001). "Grievances are" presumed "to be recognized and acted on", and "participation is" presumed "to occur within decision-making arenas, which are, in turn" presumed to be 
“open to virtually any organized group" (Gaventa, 1980, p. 5). In this approach, nonparticipation on citizens' parts is not seen as a problem and equated with consensus. Relationships between those with low socioeconomic status and low participation, Gaventa (1980) writes, "gets explained away as apathy, political inefficacy, cynicism, or alienation of the impoverished" (p. 7). With the First Face, Gaventa argues (1980), victims are blamed for their own conditions.

Other scholars, though, have argued that power exercises are not always direct, observable marching orders. Instead, they are likened to a game in which the powerful who may or may not be government officials with legal authority — control the rules and, consequently, the outcomes (Bachrach \& Baratz, 1962; Gaventa, 1980; Warner, 2001). With the Second Face of Power, Warner (2011) writes, exercises include "picking rules of the game", "manipulating agendas", and "ignoring and not making decisions (non-decisions)" (p. 1). These exercises are not always observable, with Warner (2011) noting that exercising power in private, such as done in non-disclosure agreements, can be especially effective. Likewise, it can become more readily observable through A bringing private conflicts into the open.

A key point for both the First and Second faces of power is that B, the less powerful or outright powerless, is aware of what A is doing (Gaventa, 1980; Lukes, 1974; Warner, 2001, 2011). Power exercise dimensions go even further with the Third Face of Power, in which B may not know who is responsible, with others shaping his/her sense of reality and using this to again prevent B from fighting A's actions. Warner $(2001,2011,2018)$ notes that while the first two faces focus on the powerful's actions, the Third Face examines the powerless' actions more. It aims to answer an often-asked question in the 
social and political arena of why anyone would consent to something that is against his/her best interests (Warner, 2001, p. 119). The Third Face may begin with B, after A continually defeating it through the First and Second Faces, withdrawing over time and feeling powerless (Gaventa, 1980).

Also over time, the powerless may become more vulnerable to manipulation, often through myths and symbols and sometimes to the point where they do not know who is actually responsible (Gaventa, 1980). Some tactics powerholders use to make this a reality, Gaventa (1980) explained, can include playing on existing strong traditional beliefs among the powerless, like religion. The powerholders could equate people or activities that would help the powerless — and threaten the powerholders' positions with something that attacks those deeply held beliefs. In a deeply Christian community, for example, powerholders sending messages that those who seek to help hate God would make the powerless turn against a potential ally (Gaventa, 1980). If challenging powerholders means going against those traditions and values, the powerless will not resist.

Just as institutions can fall apart, though, so can power structures. The task is extremely difficult, especially when considering deeply ingrained mantras the powerful enforce, but it is not impossible. Gaventa (1980) writes that for B to overcome A, B must mobilize and act upon issues that overcome A's “mobilization of bias against B's actions" (p. 24). B must also "develop its own resources" and mobilize others with the same "clearly conceived and articulated" grievances (p. 24). In other words, B must take action on its own, gather other like-minded people, and counter A's inevitable messaging against what B will do. 


\section{Artistic Communication}

Artistic communication became the preferred communication style for historically disenfranchised groups namely because of longstanding inequity (Love, 2006). Love (2006) writes that when societies transitioned from oral to literate, the rational argument communication style of white men became more privileged in the social and political dialog. Opening that dialog to include those who use artistic expression then creates a more democratic, and equal society. Communication using artistic expression can be either realistic or idealistic. In realistic communication, the artist or musician explicitly states his/her problem or situation (Floeckher, 2010). For idealized artistic communication, the artist or musician shows the audience what he/she wants or even who he/she wants to be (Frith, 1996). If this is not the person's reality, they become goals that the person will work to accomplish.

\section{Part 3: Summary of the Literature Gaps — What We Do Not Know}

\section{Outlaw citizenship}

More needs to be known about outlaw citizenship, in general, because the public administration discipline has not explored non-traditional participation much. Because the literature indicates its roots lie with disaffected citizens (Akram, 2014; C.S. King \& Nank, 2015; Pridemore, 2018; Rimmerman, 2011), we need to connect with those citizens and find out what the specific roots are for specific populations - artistic communities, in this study. Because internet-based outlaw citizenship is on the rise (Rimmerman, 2011), this needs to be further explored and with a particular focus on social media. Public administration scholarship involving social media rather than government websites is in a relative infancy (Pridemore, N.E. Ganapati, \& Revell, 2019). 
Furthermore, an overall major gap involving public administration's outlaw citizenship literature is consideration of the turbulent and sometimes-poisonous social and political dialog of the present day. Scholars have begun to further examine this dialog, overall (Box, 2017), even though it is extremely new, shocking, and ever-changing. Given that this situation will not likely end soon and possibly become worse, this should definitely be explored more.

Participation hindering factors

The literature has identified hindering factors for citizen participation, overall, but more needs to be done to explain what stands in the way for disaffected citizens. An even more specific literature gap is what stands in the way of artistic communities' citizen participation.

\section{Participation enabling factors}

A literature gap is what factors enable artistic communities participation, specifically, as well as what enables participation for disaffected populations, as a whole. Furthermore, a literature gap is also determining how to start a dialog with a group that blames government for their plight.

\section{Who participates?}

In general, a literature gap is who should participate among artistic communities. Within this area, a major gap is social media participation, given its extremely diffuse nature and how it opens the doors to anyone with an Internet connection. Social media participation is extremely new in public administration scholarship, overall (Pridemore, N.E. Ganapati, \& Revell, 2019), as are studies involving non-governmental web platforms. 


\section{Artistic communities' challenges}

One key point involving artistic communities' challenges is how third places (Oldenburg, 1999) theory becomes a reality and how they could, as Oldenburg (1999) writes, create a freer and socially level atmosphere. Furthermore, an additional gap is determining what roles they could play in possibly enabling artistic communities' citizen participation.

Institutions and Power

A major literature gap involving power is how to overcome, in real time, barriers that seem impossible to break, and, specifically, how artistic communities could do this. Likewise, finding out exactly how these repeated exercises of power could lead to outlaw citizenship is another major factor.

\section{Artistic communication}

A literature gap involving artistic communication is determining how this could work in practice in public administration policymaking. Also, if administrators do use and favor the more privileged rational argument, which historically disenfranchised groups have had less ability to learn, both artistic communities and administrators alike must then work to translate a figurative language barrier (Herranz, 2015).

\section{Part 4: Research Questions}

Question 1: What factors hinder artistic communities' participation in local government and how? With this, which aspects are (a) artistic community related, (b) policymaker-related, and (c) institutional? 
Question 2: What factors hinder artistic communities' participation in local government and how? With this, which aspects are (a) artistic community related, (b) policymaker-related, and (c) institutional?

Question 3: Who among artistic community members gets to participate and why?

\section{Part 5: Case study cities}

For this study, I undertook a qualitative comparative case study in Austin and New Orleans. Before I arrived on the ground and immersed myself in both cities, I had classified Austin as a positive extreme case study and New Orleans as a negative extreme. This was based on my pre-IRB approval review of secondary sources. Once I began my fieldwork and interacting with the cities' locals, though, I found that neither city totally fit the mold for either of the labels.

The initial review showed that Austin's situation with its local government and artistic community was more amicable. I based my initial positive extreme classification for Austin on factors such as the city government presenting largely accessible participation methods targeting artistic community members, garnering extremely high responses, and work to create policy to help the artistic community based on that participation (City of Austin, 2015; City of Austin, 2016b; Dinges, 2016).

Austin did present some major positive findings, such as its artistic community's strong in-group relationships and even former rivals putting aside differences for very successful citizen-initiated policy change. On the flipside, some interviewees informed me that work done from the aforementioned multiple citizen participation initiatives, which tend to repeat themselves, rarely leads to implemented policy in the end. 
Government inaction on these initiatives and in general was identified as a major participation hindering factor in Austin.

New Orleans was classified at the onset as a negative extreme based on factors such as the artistic community and city government having a longstanding acrimonious relationship, which includes citizen mistrust stemming from notorious government corruption (Daily Mail Reporter, 2013; Hoye, 2014; Karst, 2016; Kushner, 2010; Lane, 2016; Rainey, 2016; Simerman, 2016) and extreme social tension that includes wealthy elite citizens' attempts to use public policy such as noise ordinances to temper longstanding entertainment neighborhoods (Beyer, 2016; Freund, 2014a, 2014b; Rainey, 2014; Times-Picayune, 2014).

As I expected, I found some especially negative findings in New Orleans, such as that corrupt past still influencing citizen relationships for the worse and citizens believing, with evidence, that the New Orleans city and Louisiana state governments would continue this behavior. Artistic communities in-group relationships, I found, were fraught with serious infighting and tribalism and with a mixture of longstanding and emerging disputes ranging from resistance to new artistic genres being a part of the music and arts scenes and constantly seeing fellow artistic community members as competition to old personal spats.

Another issue in New Orleans, which was a unique divergence from Austin (or, likely, most American cities), was the methods employed when state government cracked down on New Orleans city government or citizens. Texas state officials would work to erode local control or eliminate certain Austin policies, like its plastic bag ban (Lindell, 2018a, 2018b) and an ordinance meant to help low-income renters with federal housing 
vouchers (Watson, 2018). Though many Austinites essentially saw these measures as dirty tricks meant to intrude on local control and their way of life (Personal Communication, 2017, 2018), these were still done through established policy processes like court rulings or bills passed in the legislature (Lindell, 2018a, 2018b; Watson, 2018).

This was a different story in New Orleans. Both decades ago and during my own study period, the Louisiana state government sent armed personnel to "restore order" in New Orleans and, even by standards of unleashing armed personnel on a city, these incidents were bizarre and extreme. In 1934, Huey Long, a former Louisiana governor and sitting U.S. senator with presidential ambitions, ordered 2,500 state National Guard soldiers to storm the New Orleans city voter registration office (Karst, 2016a, 2016b, 2016c; Kushner, 2010; Times-Picayune, 2011). He claimed city government corruption was rampant (Karst, 2016). Long's goal was to strip New Orleans' then-Mayor T. Seemes Walmsley, a political ally-turned-foe who had beaten a mayoral candidate from Long's political machine, of power over the city police department and establish his own tax assessment entity.

Eighty-three years later, in 2017, Louisiana Attorney General Jeff Landry deployed a special task force to New Orleans, saying it was to combat the city's crime (O’Donoghue, 2017). The sticking point was that Landry's task force was working independently and not in the New Orleans Police Department's command structure (Personal Communication, 2017; O’Donoghue, 2017). Landry's efforts were not only seen as purely political because of his being a likely opponent against the incumbent governor (O’Donoghue, 2017), but also extremely dangerous because of his officers working alone (Personal Communication, 2017). 
However, New Orleans had some serious positive findings, too. One was the artistic community's unwillingness to back down when threatened and often doing so in bold, attention-grabbing ways (Cockroach, 2006a, 2006b, 2006c, 2006d; Krewe Du Vieux, 2006; Krewe Du Vieux, 2018; Observation, 2018). Artistic community members also partnered with other disaffected groups with similar grievances like service industry (Nolan, 2010; Personal Communication, 2017; Stromquist, 2017) and adult entertainment workers (Archer, 2018; Music and Culture Coalition of New Orleans, 2017b; Morris, 2018; Personal Communication, 2017). They even showed kinship with old enemies, like the local police, and both some artistic community members and the police showed a willingness to work with one another on common concerns like the city's violent crime (Personal Communication, 2017). Some Austin interviewees, though their city was the one initially classified as a positive extreme, praised the New Orleans artistic community's outlaw citizenship activities and suggested that they should follow suit.

So while the positive and negative extreme classifications in terms of artistic community/local government relationships were not a perfect fit for either city, Austin and New Orleans did exhibit an element for which the cities had different extremes time.

Interviewees in Austin informed me that the city was moving at an extremely rapid pace, particularly with its new development and related social and economic change. It was so rapid that it left the artistic community and city, as a whole, spinning because it seemingly never knew what direction the city would take next. For the artistic community, it seemed as if they could never be secure because, even after policy victories that both reduced noise complaints and enabled them to boost their revenues, 
another challenge would emerge such as a music venue's property taxes doubling or a theater losing its lease. I was also informed that, during most of my study period, the city having gone without a permanent city manager and having multiple department heads in the interim made that uncertainty even worse. New developers and wealthy new residents, I was informed, directly or indirectly causing detrimental situations for longstanding artistic community members and creative spaces was a major point of contention.

On the positive side, though, Austin was not closed off to positive change, either, and largely welcomed ideas from those who could create that (Personal Communication, $2017,2018)$. The city's social environment was not especially stratified or closed off to outsiders, meaning that someone with merit could find an "in" with policymaking, the artistic community, and the city as a whole.

For New Orleans, the city seemingly could not emerge from its troubled past and a troubled past that began well before Hurricane Katrina struck in 2005 (Personal Communication, 2017). These included anything from police officers murdering people, with two former city police officers on death row for killing citizens in the 1990s and within five months of each other (Hoye, 2014; Mustain, 2014; Simerman, 2016), to the shutdown of Storyville in 1917. Storyville was a legalized prostitution district that was seen, even to the present day, as a place of black empowerment from black women earning good money they used to start businesses and black entertainers rising to prominence (Daily Mail Reporter, 2013; Karst, 2017; Landau, 2014; Personal Communication, 2017; Pope, 2017). This and numerous other factors added to the city's longstanding racial divisions and inequality, interviewees informed me. 
Past elements that interviewees believed would never end also included the influence of a wealthy, closed-circle elite on city government, with some of the government/elite collaborations going as far as policymaking being done behind closed doors at elites' private gatherings and dubious, at best, financial relationships with city government. The society was so stratified and closed-off, as a whole, I was told, that even new wealthy residents interested in starting businesses could not get past this and eventually took their money and possible economic opportunity for longtime residents elsewhere.

However, that past element also presented some positive findings for New Orleans. One was its fierce devotion to its culture and history, and its unyielding fight to maintain its positive cultural institutions (Personal Communication, 2017). Quite often, they used these institutions to battle those from inside and outside the city who sought to shut down these practices and spaces. In doing this, they were also unafraid of being what could, elsewhere, be seen as offensive (Observation, 2018), and given the wrongdoing that hit citizens from the past to the present alike (Brasted, 2017; Daily Mail Reporter, 2013; Granger, 2017a, 2017b; Kettl, 2007; Krewe Du Vieux, 2006; Krewe Du Vieux, 2018; Kushner, 2010; Hoye, 2014; Lane, 2016; Mustain, 2014; Simerman, 2016), such displays — that included extremely large and colorful satirical Mardi Gras floats — could be seen as justifiable (Observation, 2018).

\section{Part 6: Key findings}

\section{Outlaw citizenship}

Some of my findings involving outlaw citizenship provided challenges to existing literature on the subject. One is that, as mentioned above with the New Orleans Mardi 
Gras floats, displays that could be widely considered offensive can be empowering, fighting back against a government that has wronged the artistic community and citizenry as a whole with an equal bite. Another challenge is that, especially in the present-day political environment, outside agitators like counterprotestors or people who just want to make participants snap can cause a negative image for outlaw citizenship more than any in-group behavior.

Outlaw citizenship, I found, is not necessarily adversarial. Rather, some nontraditional and even especially unconventional participation can be done to create a bridge between artistic communities and government officials, as well as the public atlarge who could join their causes. These included performing their work outside artistic spaces and demonstrating first-hand to officials and the public at-large what the artistic communities had to offer and, likewise, what could be lost without greater support.

On the lighter side, outlaw citizenship can provide a more fun and interesting participation experience that helps sustain participation. Being able to freely express oneself, especially if it involves the arts, can be much more enjoyable than public hearings. This, interviewees said, keep participants interested when they are needed to attend the drier hearings.

\section{Hindering Factors}

Artistic communities' work schedule and affordability crisis link

Artistic communities found themselves in a figurative rat race, working constantly to afford the rising rents and, therefore, being unable to take the time to engage with government officials. One crisis fed another, with the unaffordability and participation inequality making each other worse. 
Traditional public hearing format just does not work for disaffected citizens and artistic communities

Two main reasons why this was the case were detrimental participation venue choices, namely government buildings, and these meetings being extremely long. Traditional public hearing venues, like government buildings or hearings done in elegant locations, caused intimidation and overall discomfort for artistic communities, particularly for minorities and groups coming from lower socioeconomic backgrounds. Heavier police presence was one of the chief barriers for minority participation. Furniture placement, such as officials seated well above participants visually and psychologically created and reinforced an uneven power dynamic. Extremely long meetings, sometimes lasting the entire day and even through the night — well past midnight in some cases kept those with work obligations and transportation issues from being heard. Those coming from more privileged backgrounds could stay and be heard.

\section{Transportation and infrastructure}

Transportation became a hindering factor for artistic communities participation because they either could not physically reach some participation forums or transportation issues in getting to and affording parking for gigs added to the disaffectedness. Factors such as expensive parking or inadequate public transportation create more participation and economic equity issues. Citizens with lower socioeconomic status, I found, struggle with this much more. Infrastructure, a rather unexpected finding, was practical but was mostly one that added to citizen ire. When artistic communities found themselves dealing with extremely dangerous street pavement in New Orleans or equally hazardous sidewalks in Austin's Red River district, they were at government's 
mercy because these are literally illegal for citizens to repair on their own. In the case of New Orleans' problematic and even failing pumping stations and flooding, this sparked outrage and, consequently, outlaw citizenship (Granger, 2017a, 2017b; Krewe Du Vieux, 2018; Observation, 2018).

\section{Trust issues}

Trust issues were a major finding of mine and namely because they did not just involve citizens' trust in government, on which other citizen participation studies have focused (Pridemore, N.E. Ganapati, \& Revell, 2019). Trust and mistrust, as I found in this study, went in multiple directions that namely included government agencies, nonprofit advocacy organizations, and artistic community members. Sometimes, government was the entity that struggled with determining who to trust, especially when multiple individuals and organizations claimed to be spokespersons or even the spokesperson for the local artistic community.

This also shed light on previous studies involving partnerships, as well, because most previous citizen participation studies have focused on their positive sides and how to further build them (Pridemore, N.E. Ganapati, \& Revell, 2019). Here, I found that partnerships could be a negative, depending on who that potential partner is. Such problems that interviewees mentioned was individual and organizational self-interest, partnerships hinging on going against personal or organizational ethics, and, for artistic communities, potential partners wanting to use popular local entertainers as mere spokespersons but doing nothing to help those entertainers or their fellow artistic community members. Just as government agencies found some outside groups untrustworthy, some advocacy organizations found themselves breaking partnerships 
with government agencies because partnerships hinged on the advocacy organizations, interviewees told me, going against their organizational or personal ethics.

\section{Leadership gaps}

The key findings involving leadership for this study deal with relationships and stability. Austin and New Orleans both found themselves with prolonged leadership gaps during the study period. Austin, which has a council-manager system, had gone about year without a permanent city manager (Hernandez, 2017; Personal Communication, 2017, 2018), and New Orleans, which has a strong mayor government, had about a sixmonth transition period between its city elections and new mayor and council taking office (Litten, 2017e).

Leadership transitions being long and with prolonged uncertainty, left artistic communities in limbo as to whether or not officials with whom they had managed to build positive relationships would remain in their positions when new leaders came on board. Stability came into play because the rapidly transitioning Austin and New Orleans needing positive change overall made the situation even more chaotic because the artistic communities and cities as a whole did not know who would guide them and when that person would begin guiding them.

\section{Negative social construction}

Negative social construction was another hindering factor, and a key addition this study makes it that social construction (Schneider \& Ingram, 1993) can apply to places just as it does with people, and as a result, can be targeted for negative or positive public policy depending on that perception. Elements that added to negative social construction of people included race, personal appearance, (Personal Communication, 2017, 2018) 
and, in the case of New Orleans, outsider derision that led to negative actions from the state or federal governments (Cooperman, 2005; MSNBC, 2005; O’Donoghue, 2017; Personal Communication, 2017).

With place, problems that namely included crime also eroded social construction (Schneider \& Ingram, 1993) about given neighborhoods and artistic spaces. This made certain areas targets for negative policies such as noise restrictions or street performer curfews or, for certain spaces, shutdown.

Negative in-group relationships and tribalism

This was a finding I namely found in New Orleans. Negative in-group relationships and tribalism within the artistic community kept it from organizing as well as it could or caused some organizing efforts to fall apart. Some of the reasons behind it ranged from competition for gigs, tension between those doing traditional art forms and more contemporary ones, or simply longstanding personal feuds.

\section{Enabling Factors}

\section{Participation venue (Third Places)}

As Oldenburg (1999) indicates, artistic community interviewees found third places to be much more ideal and conducive places to meet government officials. The reasons were that they provided casual, socially level environments that were not intimidating, as opposed to government buildings and elegant locations, which tended to have higher police presence. The results were even and open conversations and ones that were constructive. 


\section{Participation sustainment measures}

The keys to participation sustainment that I found were providing results and having participation activities that are more fun and engaging (generally achieved in outlaw citizenship) and having specific forum scopes. When citizens work to craft a policy, it is important for it to be implemented and be one that is not a watered-down version that has no effect. Also, specific forum scopes are critical because, as I will further explain in the following section about who should participate, if someone shows up for a forum that does not interest them, they will believe their time is wasted and not show up for one that would interest them more. Also, as I will further explain in discussing outlaw citizenship findings, activities that are more fun can counter problems with traditional participation being, for many people, extremely boring. Bureaucracy that "gets it" and working as language barrier "translators"

Having bureaucracy members that either have experience as working artistic community members or work to learn about their world can create much better relationships with artistic communities. They not only understand the artistic communities' specific and unique needs, but they can also work to translate the figurative "language barriers" (Herranz, 2015) between artistic communities and other government officials.

Civil service integration for arts bureaucracy office employees

Any government arts offices being integrated into the civil service versus being a political initiative was seen as a major enabling factor. Much like the issues with leadership, the reason was stability. Civil service protection and integration meant that employees' jobs and entire offices were far less vulnerable to political whims, as was the 
case with arts offices in Austin. Conversely, ones that were a political initiative could be shut down if and when elected officials or even just a single elected official decides they are no longer wanted, as is the case with New Orleans' cultural economy office.

\section{Positive social construction}

Positive social construction was a major enabling factor, and this provided two additions to social construction literature - one with a flipside. Just as people can be targeted for positive social construction and, subsequently, public policy benefitting them (Schneider \& Ingram, 1993), the same can apply to place. Spaces such as third place (Oldenburg, 1999) venues that the city as a whole adores can be a target for policy that works in their favor, like the extended hours in Austin's Red River district. Appearance was a factor in social construction, but, in Austin, it worked in reverse, somewhat. While New Orleans interviewees decried casually dressed artistic community members who were also targets for police and the city's elite, Austin's more casually dressed artistic community members, particularly ones that had a "rock and roll" aura, were seen as being true to self and not being fake.

Positive in-group relationships

Positive in-group relationships were another enabling factor, because when relationships were already harmonious, artistic communities were ready to organize if facing a policy challenge and do so without serious risk of their organizing efforts falling apart.

Positive out-group relationships

Just as relationships within artistic communities being positive was a major enabling factor, so were the artistic communities relationships with other key groups. One 
of my more interesting findings in this area was that old enemies, like rival bar owners, could become serious allies. Other disaffected populations that share the same grievances can be that, as well. Furthermore, having such relationships in advance can save artistic communities and businesses when they are threatened. These can include a business' neighbors or community organizations to which businesses can loan their space.

\section{Self-sufficiency}

Being one's own spokesperson and with one's own evidence-based arguments was a major enabling factor. This helped artistic community members avoid the pitfalls of any potentially non-constructive partnerships and find themselves gaining more positive attention from those in power. In this, interviewees told me, their arguments needed to be rooted in facts and evidence rather than emotion, which they could not only provide, but they could also have officials learn from their first-hand experience.

\section{Who Participates?}

Diversity needed

Interviewees indicated that having diverse participants, particularly from racial and ethnic minorities, was critical in having a more equal and more representative participation effort. Especially when considering minority residents and artistic community members were feeling the pain and rising costs from new development more than others, this was especially critical.

\section{Conciseness needed}

On the flipside, interviewees indicated conciseness was needed in both their messages and number of participants. One ideal situation interviewees in Austin mentioned was having the stakeholder groups involved in a given situation, like a music 
festival's security, first meet among themselves and decide on talking points. Then, each group sends a spokesperson to meet with city officials and other stakeholders. This eliminated chaotic town hall style meetings where, quite often, the meeting turned to incoherent shouting, and nothing was achieved.

Specificity

Besides having specific forums about specific topics to sustain participation, something else that must be considered in choosing who participates is having specific people who are affected by a given policy the most being the participants. Otherwise, not narrowing down the participant pool hurts participation in the long run. I was informed that if someone shows up for a forum about a topic that does not affect them or they do not care about, they will find it — and participation in general — a waste of time. Then, that person will not show up for a forum that involves policies that do affect them more and for which that person has valuable first-hand experience.

\section{Too many speakers}

One of the major problems that made the hindering factor of long meetings worse was having too many speakers for a meeting. Because underrepresented groups often have to leave before their chance to speak if a meeting drags onward, excessive numbers of speakers ultimately hurts democracy in the end. Likewise, overrepresented groups are then thought to be the representative for all citizens' viewpoints, in some officials' eyes. Officials, namely in Austin, were working to control meeting length in general and speaking times, but the meeting length, with too many speakers being a major root cause, was still a major problem. 


\section{Social media}

Social media was a finding of note because it opened the participation door at the local level to anyone with an Internet connection - local or not. One positive is that social media can make information from government more accessible and, digitally speaking, reach artistic communities where many of them already gather. However, social media presented numerous problems such as trolling and general bad behavior (Personal Communication, 2017, 2018), and even serious security situations in both cities (Alliance for Securing Democracy, n.d.; Evans, 2017b, 2017c, 2017d; Herrera, 2018a; Kinchen, 2016; Personal Communication, 2017; Rainey, 2017a; Webster, 2017). The overall consensus from interviewees was that social media was a positive for notifying people and doing initial organizing, but that participation had to move offline and inperson to be effective.

\section{Artistic communities' challenges}

One of the desires most artistic communities had that they believed would seriously help them were market-oriented, private sector-oriented solutions over ones related to the nonprofit sector. Most did not want more funding but, rather, policies that enabled them to make more money or stopping policies that would erode their profits and ultimately threaten their survival even more. Another solution was, as mentioned above, meeting officials in third place (Oldenburg, 1999) venues. Besides the comfort and conducive conversation factors mentioned above, artistic community members believed that officials seeing what they experience first-hand led to better policy in the end. Officials also noted that coming to artistic communities where and when they gathered already 
meant that they could more readily reach a group that is difficult to organize because of their schedules and eliminate intimidation factors from buildings like police stations.

\section{Institutions and Power}

\section{Institutions}

Three major findings involving institutions are that not all are positive, institutions can fall, and because formal ones are indeed how those seeking power will target first, this means that fair and workable policies are both needed and need to be updated constantly as cities change. Institutions, though strong (North, 1990), are particularly vulnerable when societies are in flux (Personal Communication, 2017, 2018) and with unprecedented socioeconomic inequality (Florida, 2017). Those with far greater financial capital than those who have gentrified neighborhoods in the past present a greater threat economically and socially, should their economic power sway officials, interviewees indicated. Some interviewees also pointed out that negative institutions should be dismantled, though, particularly when those institutions include cutting minorities out of the social and political dialog.

Power

Multi-dimensional power exercises demonstrated how non-govermental actors with no direct policymaking power still exerted authority over less powerful artistic community members. As is done with the Second Face of Power (Bachrach \& Baratz, 1962; Gaventa, 1980; Warner, 2001, 2011), interviewees informed me that wealthy elites will manipulate policymaking and the overall "rules of the game" to work in their favor or refuse to make decisions that would work in their favor. Findings involving the Third Face of Power show how hopelessness and even withdraw from participation has 
happened after continual defeat or how in-group messaging among less powerful groups that government is the enemy, which historically have been started by powerholders (Gaventa, 1980), has kept the less powerful from participating.

However, I also found out how these power structures can be overcome. Gaventa (1980) writes that the less powerful must mobilize with other less powerful groups and strongly enough that they overcome the powerholders' inevitable messaging against them and do so with their own resources and "clearly conceived and articulated" grievances (p. 24). This happened, particularly when the Austin Red River district owners employed this strategy during an ultimately successful policy measure that gave them extended hours for playing live music, despite some powerful opponents (Findell, 2017a, 2017e, 2018; Personal Communication, 2017, 2018). Interviewees noted, though, that overcoming these structures was extremely difficult, particularly when working to counter the abovementioned deeply ingrained in-group messaging against participation before facing challenges from more powerful outside groups.

\section{Artistic communication styles}

One of my findings is that artistic communities utilized artistic expression not because, as the literature has previously found (Love, 2006) they lacked ability to or preferred not to speak in traditional rational argument. Rather, they were demonstrating the value of their arts institutions, places, and activities to officials and the public at-large (Personal Communication, 2017, 2018; Rude Mechs, 2017, 2018). This was being done to remind the public as to what they have and what is at risk of being lost. It was particularly useful in gaining attention and doing so in a bold manner. 
One of the main differences in terms of how many government officials and artistic communities communicated was not necessarily their type of preferred speech (Love, 2006) but, rather, how they organized their group communications. Artistic communities were more accustomed to free-form collaborative structures (or lack of structure, rather), while governments preferred more structured, hierarchal methods. This, artistic community members told me, created a barrier.

\section{Part 7: Dissertation Structure}

My dissertation's structure is as follows. In Chapter 2, I provide the literature review, and for Chapter 3, I explain my methodology.

Then, I present the New Orleans case. In Chapter 4, I explain the factors that hinder New Orleans' artistic community's participation, and I explain enabling factors for New Orleans in Chapter 5. In Chapter 6, I explore the question of who should participate among New Orleans' artistic community.

After that, I present the Austin case study. In Chapter 7, I explain factors that hinder Austin's artistic community's citizen participation, and in Chapter 8 , I do the same for factors that enable it. For Chapter 9, I explore the question of who should participate in Austin's artistic community.

In Part 4, I provide a closing chapter, which will include my major literature contributions and final thoughts. I will provide appendices in the reference section that include regularly occurring topics and unique aspects of both Austin and New Orleans culture for reference, as well as charts further detailing my data analysis and a list of participants, identified by their pseudonyms, their cities, and their roles. 


\section{CHAPTER 2: LITERATURE REVIEW}

I review four sections of literature themes - citizen participation, outlaw citizenship, artistic communities' challenges, institutions and power, and artistic communities' preferred communication styles — in this chapter. Artistic communities' citizen participation, with their hindrances, enablers, and barriers that can be broken are largely absent from the public administration literature. While the citizen participation literature provides an excellent starting point, material from urban studies that gives context to artistic communities' present-day situation, power theory that shows even deeper roots for citizen participation inequities, and musicology that provides insight into artistic communities' preferred communication will bolster this review.

However, I will go further and note that citizen participation on the part of disaffected groups in general is relatively absent from public administration literature as well. Furthermore, the literature is minimal in terms of determining how to engage disaffected citizens, which will provide additional and considerable challenges to public administration practitioners. Knowing this is especially critical in the present-day fractious and confrontational political environment, especially as technology and social media continually evolves. While this dissertation's focus is on the case of artistic communities, I will build upon this literature to show a broader appeal in that much of it applies to disaffected populations, as a whole.

Citizen participation literature will begin this review. Given its multiple facets and caveats, this will have multiple subsections as follows: Classical Texts and Warnings for the Future, Outlaw Citizenship, Hindering Factors, Enabling Factors and determining who participates. The section involving artistic communities' challenges will come 
afterward. The institutions and power section will follow, beginning with a discussion on institutions and followed by three dimensions of power that ultimately affect who "wins and loses" in the political and social realm. The artistic communities' preferred communication section will follow that. I will then conclude with a summation and reiterate how this dissertation will fill the gaps.

\section{Citizen Participation: Introduction}

My main argument in this section is that despite citizen participation's ideals of creating greater democracy and equality, this is not the reality. Democracy and social equity are citizen participation's tenets (Arnstein, 1969; J.V. Denhardt \& R.B. Denhardt, 2015; Frederickson, 1997a; C.S. King \& Nank, 2015; Fung, 2006, 2015). However, citizen participation forums are not equal, and actually, do the opposite of participation ideals (Fung, 2006, 2015). This is largely rooted in citizens' access to participation forums. Citizens' access or lack thereof to their governments determines who will be the "winners and losers" in policy debates (Fung, 2006, 2015), and that access is often rooted more in social and economic power and how society at large views certain groups (Miller, 2012; Schneider \& Ingram, 1993).

These practices have created a strikingly disaffected citizenry, who are lashing out with outlaw citizenship — citizens engaging in non-traditional participation methods such as protests and online organizing (C.S. King \& Nank, 2015; Pridemore, 2018; Rimmerman, 2011). Because governments in both the United States and abroad are facing major social upheavals from disaffected citizens (Pridemore, 2018; Rimmerman, 2011; Simeonova, 2005) and those who seize upon those attitudes to rise to power (Box, 
2017), it is critical that this discipline understands disaffectedness' roots in participation inequality and works to remedy them. Otherwise, the consequences can be severe.

\section{Classic Participation Classification and Warnings for the Future}

When examining the "classics" in citizen participation scholarship more closely, outlaw citizenship's warning signs were evident even then. In this section, I will focus on citizen participation ideals from the United States' founders, particularly those related to citizen participation and the civil service's role. Then, I will move to Sherry R. Arnstein's seminal "A Ladder of Citizen Participation" from 1969 — and with that, emphasizing the nuances, caveats, and power imbalance on which, I argue, she spends far more time than her more-often-cited ladder that typifies citizen participation outlets.

The Constitutional framers sought a limited role for citizens in public affairs, with citizens' ability to participate limited to voting in elections (C.S. King, 2015; Rimmerman, 2011). Two chief concerns were the new government's stability and societal stability, with the latter on the framers' minds in light of Shay's Rebellion in 1786 (Rimmerman, 2011). These concerns were namely echoed in The Federalist Papers. In the Federalist No. 51, Madison pointed out that while citizens were government's primary control, officials "must first enable the government to control the governed" (2001 [1787], p. 269). The reasoning was not only the need to prevent rebellion against the government but also to have government prevent citizens from taking the rights away from one another. Citizen groups naturally have different interests, according to Madison, and if the majority is "united by a common interest, the rights of the minority will be insecure" (p. 270). 
Madison (2001 [1787]) noted that powerful citizens can stomp the rights of citizens with less power, even if the powerful are the minority in the "Federalist No. 10". Liberty is saved when liberty is controlled, in this view. One concern Madison (2001 [1787]) puts forward is development of what he calls "factions" — a group of citizens who may or may not be the majority who are "united" through "some common impulse of passion, or of interest" that is "adverse to the rights of other citizens or to the permanent and aggregate interests of the community" (p. 43). Factions can be a majority of people, an especially loud and/or powerful minority, and even "an obnoxious individual" (p. 46). Even if factions are a majority, Madison writes that even threats on a minority group are a threat to liberty itself.

Essentially, a society that factions rule is one governed by the loudest, not necessarily the majority, according to Madison (2001 [1787]). A "pure democracy", which Madison writes is a "small group of citizens who assemble and administer the government in person", can have "a common passion or interest" that results from government itself - with "nothing to check the inducements to sacrifice the weaker party" (p. 46). The problem is that one remedy, outright abolishing liberty, is detrimental for society, even though liberty sparks factions. He elaborates:

Liberty is to faction, what air is to fire, an ailment, without which it instantly expires. But it could not be less folly to abolish liberty, which is essential to political life, because it nourishes faction, than it would be to wish the annihilation of air, which is essential to animal life, because it imparts to fire its destructive agency (p. 43).

The question that Madison (2001 [1787]) works to answer is how to temper these factions, especially if they truly are threats to liberty. Factions' causes cannot be removed 
because people will naturally develop different and opposing passions. The only relief, then is buffering society from its effects. This is done, even if a faction is the majority, through having a government enable it to "sacrifice" that passion or interest" for "both the public good and the rights of other citizens" (p. 45).

Just as the founders envisioned a limited role for citizen participation, they also had the same ideal for administrators who would make the new government work (Frederickson, 1997b). With that same stability concern in mind, they "gathered civil servants of modest, gentlemanly demeanor who would not stir up the riffraff" with "roughly 65 percent of the highest-level" federal appointees coming "from the landed gentry, merchant, and professional classes" (p. 211).

More than two hundred years later, scholars still pointed out the dangers of societal power imbalance. However, some of them advocated for more citizen input in public policymaking, especially during and after the civil unrest of the 1960s and 1970s. Sherry R. Arnstein's 1969 “A Ladder of Citizen Participation” is considered a seminal, if not the seminal piece regarding citizen participation in government, with it being "reprinted more than eighty times and translated into at least five languages" (American Association of Colleges of Osteopathic Medicine, 2015). This also coincided with and was a major piece in what C.S. King (2015) calls the "second-wave" of citizen participation, sparked by the societal unrest of the 1960s.

The key point that I will focus on most is that the piece requires a closer review not for Arnstein's (1969) often-cited eight figurative ladder "rungs" that represent public involvement levels, but, rather, her acknowledgement and, arguably, greater focus on how citizen participation systems are extremely complex, especially when considering 
participation barriers and sinister motives of those with greater societal power who abuse participation venues to create more power for themselves. These sinister motives, according to Arnstein (1969), manifest themselves even in participation seemingly designed to give citizens actual decision-making ability. I will be utilizing Arnstein's (1969) work often throughout this literature view and subsequent chapters, given both its standing in the citizen participation canon and, I argue, Arnstein's (1969) oftenoverlooked greater points she makes about participation's complexity and darker sides.

Arnstein (1969) presents a typology with an eight-rung ladder, with citizen involvement in policymaking rising with the ladder's rungs. Going further, she uses three categories for the rungs' levels: non-participation, tokenism, and citizen power (p. 217). Non-participation levels, "manipulation" and "therapy", are "contrived" to "substitute for genuine participation." The actual intent is not allowing citizens to have a voice in policymaking but to instead "enable powerholders to 'educate' or 'cure' participants." (p. 217).

The three "tokenism" levels — informing, consultation, and placation — on Arnstein's (1969) mid-range rungs represent ones in which less powerful citizens do have a voice but those who hold power still make final decisions (p. 217). In these cases, citizens are heard, but that does not mean that any changes that they indicate will improve their situations will be made at all.

Arnstein's (1969) “citizen power” rungs — partnership, delegated power, and citizen power - are ones in which citizens actually have some degrees of decisionmaking power. One key aspect of partnership that is especially relevant to this dissertation is that its roots are citizen anger, not government initiation, in most cases. 
Pointing to examples from problematic neighborhood improvement initiatives, Arnstein (1969) writes that partnerships "were triggered by citizens who had been enraged by previous forms of alleged participation" (p. 222).

Though the ladder may provide a framework for typifying citizen participation formats, Arnstein (1969) herself points out major nuances — arguably doing this through much more of the piece. Citizen participation, according to Arnstein (1969), is extraordinarily complex and those who hold power can manipulate even the highest participation levels so that their interests triumph over groups such as the poor and racial minorities. She put the ladder forward as a way to recognize not only participation levels but to also understand the less powerful's demands for a greater voice in crafting polices that will have a direct effect on them and how the powerful reacts to those demands often manipulating certain participation venues so that their interests still dominate.

In terms of complexity, Arnstein (1969) notes three major caveats. The first, one of the most critical for this dissertation, is that the typology does not analyze "the most significant roadblocks" for certain groups" "genuine participation" (p. 217). Those who have greater societal power may resist that power being redistributed to those on society's margins, (closely resembling King and Nank's 2015 argument), and their resistance to giving less powerful citizens more power can also be rooted in racism and paternalism. Those on the opposite end of the power spectrum may face more longstanding barriers such as poorer communities lacking "political" and "socioeconomic infrastructure" and knowledge base, and on top of that, longstanding negative attitudes toward those in power are a major roadblock because "have-nots" also face "difficulties 
of organizing a representative and accountable citizens' group in the face of futility, alienation, and distrust" (p. 217).

Arnstein (1969) urges caution when examining her own typology, namely, because many more rungs could both exist and overlap. Furthermore, powerful people with sinister motives can manipulate participation methods for their own gain. She elaborates:

Depending on their motives, powerholders can hire poor people to co-opt them, to placate them, or to utilize the have-nots' special skills and insights. Some mayors, in private, actually boast of their strategy in hiring militant black leaders to muzzle them while destroying their credibility in the black community (p. 218).

...Unfortunately, this chicanery is not a unique example. Instead, it is almost typical of what has been perpetuated in the name of high-sounding rhetoric like "grassroots participation." This sham lies at the heart of the deep-seated exasperation and hostility of the have-nots toward the powerholders (pp. 217218).

Furthermore, divisions between the powerful and those with less power are not purely dichotomous, with a single hard line between those who hold it and those who do not, Arnstein (1969) notes. Within the powerful's and less powerful's sides of a figurative sphere, neither are "homogeneous blocs," with both groups having "a host of divergent points of view, significant cleavages, competing vested interests, and splintered subgroups". She justifies the use of the more dichotomous terminology, though, because those with less power 'really do perceive the powerful as a monolithic 'system', and powerholders actually do view the have-nots as a sea of 'those people', with little comprehension of the class and caste differences between them” (p. 217).

Still, the ones with less societal power are not outright powerless and should not be discounted, Arnstein (1969) writes. They can find ways to act and demand action, with 
this portion of Arnstein's (1969) echoing outlaw citizenship scholarship years later

(Akram, 2014; Box, 2017; C.S. King \& Nank, 2015; Pridemore, 2018; Rimmerman,

2011). Arnstein (1969) notes:

One hopeful note is that, having been so grossly affronted, some citizens have learned the Mickey Mouse game, and now, they too know how to play. As a result of this knowledge, they are demanding genuine levels of participation to assure them that public programs are relevant to their needs and responsive to their priorities (p. 218).

\section{Classic Citizen Participation Literature’s Gaps}

Given the age of these texts, the surface literature gaps from them are determining how they apply to the present day and what ramifications any of them had. The key is that scholars are still examining the same problems, and now, those problems' severe consequences.

When examining the classic pieces, the key, as I will further point out through this chapter, is that despite them being decades' or even centuries' old, practically no one worked to heed these writers' warnings. If anyone did address these writers' recommendations or philosophies, they either chose the ones that led to many citizens not being heard (Frederickson, 1997b; C.S. King \& Nank, 2015) or in the case of the Arnstein (1969) piece, not paying attention to serious disclaimers and nuance.

In my dissertation, I will work to address the gaps through pointing out the consequences of not heeding the classic writers' warnings or following any of their misguided principles and what can be done to at least begin to remedy the situation. Furthermore, I will point out the less-explored nuances writers such as Arnstein (1969) 
and how they manifest themselves in present-day citizen participation issues. Likewise, I will provide recommendations as to how to move past any related barriers, as well.

\section{Outlaw Citizenship and a Dangerous Political Environment}

Nearly fifty years after the Arnstein piece's publication, her warnings were not heeded. Governments both in the United States and globally are now feeling disaffected citizens' wrath (C.S. King \& Nank, 2015; Pridemore, 2018; Rimmerman, 2011). “Outlaw citizenship" is the result. Outlaw citizenship (as termed by C.S. King \& Nank, 2015; Pridemore, 2018) is when citizens eschew traditional participation methods such as speaking at public hearings and opt for non-traditional ones such as protests and online organizing. The key in outlaw citizenship is that those who engage in it are doing so because they do not believe they will be heard otherwise (Rimmerman, 2011). This is rooted in inequality, often in citizen participation practices (C.S. King \& Nank, 2015), and the situation is not spontaneous but is, rather, longstanding frustration built up until citizens reach a breaking point (Akram, 2014; Pridemore, 2018; Simeonova, 2005). In this subsection, I will give an overview of outlaw citizenship and how it has evolved, particularly in the United States, over time, especially as technology has advanced.

In the United States, the government and citizens began separating themselves from each other during and in the aftermath of the 1960s' and 1970s' social upheavals (C.S. King \& Nank, 2015; Frederickson, 1997a). These upheavals created a greater push for citizen participation in public administration (C.S. King, 2015; Frederickson, 1997a) and federal mandates requiring agencies to give the public more input in policymaking (C.S. King \& Nank, 2015). However, King and Nank (2015) write that local officials 
believed citizen participation threatened their power base, and therefore, any movement toward greater citizen participation was brief (p. 10)

Government officials increasingly viewed citizen participation as a negative, and traditional citizen participation venues became all but useless (C.S. King, 2015; C.S. King \& Nank, 2015). When officials saw their power base as threatened, citizen participation "lived on here and there ... usually through largely ineffective public hearings" (C.S. King \& Nank, 2015, p. 10) - the problematic structure that other scholars have identified as a participation hindrance (Fung, 2006, 2015; Rimmerman, 2011). Citizen participation was viewed as a "cost of doing business". C.S. King and Nank (2015) further write:

It was during this time that citizens became seen as clients or consumers - as passive recipients of governmental services. Requirements for citizen participation were generally treated in administrative agencies as a cost of doing business instead of as an asset to effectiveness or responsibility worth carrying out for its own sake. At best, citizens were viewed as a constituency, the source of important political support. One result of this perception of citizen participation as a cost of doing business was that public participation began to be viewed negatively. It was no longer seen as enhancing administrative processes, especially when participation detracted from administrative expertise (pp. 10-11).

This administrator attitude of "treating citizens as a business cost" led to an increasingly disaffected citizenry (C.S. King \& Nank, 2015) that scholars warned would create, at best, angry citizens (Frederickson, 1997a; Fung, 2015). Fung (2015), focusing again on participation structure and as a point for practitioners, writes:

It is important to design participation in ways that its outcomes are meaningful to participants. Frustration, cynicism, or apathy can be the results of a poorly designed public engagement process in which participants hopes for learning, working, or accomplishing some goal are disappointed by a process that is futile, in which the relevant decisions have been made elsewhere by someone else, or in which the choices and stakes are trivial (p. 513). 
Practitioners' actions that did the opposite of what Fung (2015) urged progressively made citizens turn to outlaw citizenship (C.S. King \& Nank, 2015; Rimmerman, 2011). A key aspect of outlaw citizenship is that its participants do not want to work with government but against government to disrupt policies the participants believe are unjust (Pridemore, 2018; Rimmerman, 2011). Another important point about outlaw citizenship is that it is not spontaneous (Pridemore, 2018), but, rather, a buildup of longstanding grievances that eventually reach a breaking point, often sparked by a major event such as a police shooting or catastrophic natural disaster. When public administrators encounter outlaw citizenship, it should not be a shock.

Akram (2014) saw this while examining 2011 riots in the United Kingdom after police shot and killed a man, and Akram (2014) developed a theoretical framework, in the context of riots, based on Pierre Bourdieu's "habitus", which is a person's understanding of how to behave and interact.

A person's upbringing and social class is habitus' main influence, with a person's earliest experiences being a major part of the societal actor he/she eventually becomes, and this is very difficult to change (Akram, 2014; Pridemore, 2018). Two elements compose a person's habitus, the unconscious and — the most important one for understanding why citizens revolt — preconscious. Unconscious is a largely forgotten personal history that still shows itself through "second nature" (as cited in Akram, 2014; Pridemore, 2018).

The preconscious, though, is not forgotten (Akram, 2014). A person clearly remembers all of the experiences that compose the preconscious element of his/her 
habitus. Some of those experiences can be negative life events, such as job loss or experiencing racism and other forms of social inequality (Pridemore, 2018). Habitus' stability prevents people from acting on their preconscious' grievances — at least for a while (Akram, 2014; Pridemore, 2018). The final step in Akram's (2014) framework is one of motivation and habitus change. Riots happen, Akram argues, because underlying grievances rupture habitus. Riots are the end of a process and not simply a single, spontaneous event. A major event such as a police shooting will push citizens into action, but those citizens likely had major grievances long before this happened.

Data related to police shootings, for one example, support this theory. A recent example is the civil unrest in Ferguson, Missouri, after a white police officer shot and killed Michael Brown, a young black man, in 2014 (U.S. Department of Justice, 2015). However, citizens' interactions with its police department were extremely negative long before the Brown shooting. The U.S. Department of Justice's report (2015) on its Ferguson Police Department investigation showed that citizens, the vast majority of them black, were targeted by aggressive policing, municipal court practices, and racial bias long before Brown was killed. Just some of the examples in the report included that, between 2012 and 2014, black people were eighty-five percent of vehicle stops, ninety percent of citations, and ninety-three percent of arrests for Ferguson P.D. officers, even though black residents are only sixty-seven percent of the population. The report also indicated Ferguson officers "frequently detain people without reasonable suspicion and arrest people without probable cause" (p. 16).

A major clash between administrators and citizens is that, according to C.S. King and Nank (2015), neither wants to take the "high road" — with citizens who do not want 
to partner with government and administrators desiring citizen deference. Citizens have little reason to take the "high road" and partner with government to put the public interest ahead of their own private desires when they see themselves as not citizens, but mere consumers (C.S. King \& Nank, 2015, p. 11-12) Simultaneously, administrators have little reason to take the "high road" either. C.S. King and Nank further explain their view of administrators:

Administrators see the ideal citizen as one who understands citizenship as being a follower, supporter, and ratifier of government action, conforming to administratively defined mandates. There is little prompting for administrators to take the high road and put the public interest(s) ahead of their professional interests. Public administrators see themselves as professionals, experts with a certain level of autonomy who are tasked with making tough decisions about getting things done in an environment of vague statutes, conflicting mandates, and an angry, discontented citizenry. Although a professionalized view of work provides dignity and boundaries to administration, it does little to encourage collaboration with citizens (especially those scary, angry citizens!). Relationships with citizens are instrumental. Citizen participation is simply a means to satisfy statutes, and administrators are often relieved when few show up for mandated public meetings (pp. 11-12).

Arguably, a combination of older core public administration values of efficiency and economy (Frederickson, 1997a) and new movements emphasizing market-oriented principles such as neoliberalism have contributed to present-day outlaw citizenship (Box, 2015; C.S. King \& Nank, 2015). Movements such as New Public Management and Reinventing Government have encouraged citizen input but that input desired is more like a private-sector consumer satisfaction survey (C.S. King \& Nank, 2015). Neoliberalism, Box (2015) explains, is a market-based philosophy with "liberalism" not being political liberalism, but rather, economic liberalism — with emphasis on limited government intervention and free-market principles. When this philosophy is applied to the public 
sector, citizen participation and how much the public is or is not involved depends on how profitable and costly it is. Box (2015) writes:

If this prescriptive litmus test is followed, the public will or will not be involved depending on whether an efficiency conscious administrator determines it does not cost too much. ... In public administration, the neoliberal emphasis on economic rationality has taken form in "new public management" and related concepts, with accompanying stress on quantification of performance and measurement of whatever can be measured. (pp. 65-67).

During these market-oriented movements that presumed citizens want "results" and "productivity" and not policy change or different relationships with their governments, citizens were once again viewed as consumers (C.S. King \& Nank, 2015). Their input was valued, but from a managerial perspective because their input would, in theory, improve performance, service, and "products". The idea, C.S. King and Nank (2015) write, is “as old as ... Frederick Taylor's scientific management (1967 [1911])" (C.S. King \& Nank, 2015, pp. 12-13).

Simultaneously, citizens have created movements of their own, on both the Right and Left, and grassroots organizing is on the rise (C.S. King \& Nank, 2015; Rimmerman, 2011). Whether this is a positive or a negative is debatable, and it can go to extremes of either side of the political spectrum. Rimmerman (2011) points out that outlaw citizenship can prompt "meaningful policy responses from governing elites", especially with non-violent civil disobedience, "the deliberate breaking of an 'unjust' law" (p. 67). However, Rimmerman (2011) also points to the militia movement, of which those responsible for the 1995 Oklahoma City bombing were associated. He elaborates broadly, on how certain forms of outlaw citizenship, especially if they are violent, can be a threat to civil policy debate. He writes: 
The contemporary American scene is littered with groups on both the left and right whose members embrace unconventional politics and factious activity as a response to those in power. At a bare minimum, these groups contribute to the growing incivility and breakdown of community increasingly associated with American politics. To the extent that they endorse and encourage violence, they threaten overall system stability (p. 67).

Outlaw citizenship, like Arnstein's (1969) points, is extremely nuanced and almost always has certain categories overlapping. Building on literature from Pridemore (2018) and Rimmerman (2011), I will explain some of the multiple scales in which outlaw citizenship is classified and with examples. It should be noted that these levels often have very wide ranges and intersect with one another.

\section{Legality}

1. Illegal (Non-violent civil disobedience or violent protests and terrorism)

2. Legal (Permitted protest, with participants following governing body's ground rules)

\section{Intensity/Violence}

1. Peaceful demonstration

2. Non-violent civil disobedience

3. Confrontational protest or confrontational counter-protest

4. Violent protest (Riots, vandalism, property destruction, physical altercations)

5. Terrorism

I argue that outlaw citizenship encompasses a wide spectrum not so relevant in terms of their liberal or conservative ideology but, most importantly, their levels of extremity. That extremity is very related to how well outlaw citizenship works - either rallying more people for their cause and creating positive policy change or doing nothing and even turning the public and governments against them and their causes (Rimmerman, 2011). Legality is not necessarily a factor as to whether or not a particular outlaw citizenship activity will be positively viewed and/or creates positive change. This is especially true when outlaw citizenship activities garner widespread media coverage. 
Rimmerman (2011) uses the United States Civil Rights Movement as a positive example, namely because of its use of non-violent civil disobedience, activities that were illegal at the time, in contrast to outraged whites and violent police actions that were all shown in media coverage. A modern-day version of illegal, non-violent civil disobedience largely viewed favorably is the protest at the Standing Rock Sioux Tribe's Native American reservation in North Dakota (Levin, 2017; Pridemore, 2018). A major contrast is the legally permitted actions of the vehemently anti-gay Westboro Baptist Church, whose activities include extremely inflammatory protests at funerals for hate crime victims and fallen soldiers and coal miners (Associated Press, 2006; Gregory, 2011; Morton, 2011; Theroux, 2007). Although the church's activities are legal, the church and its members are widely despised, with its members the subject of the BBC documentary The Most Hated Family in America (Theroux, 2007).

The internet, especially with the advent of social media, has created a whole new level of outlaw citizenship and has made this phenomenon much faster, easier, less costly, and much more global (Pridemore, 2018; Rimmerman, 2011). It is also more attractive for younger populations. Long before online communication's advent, disaffected populations networked with like-minded groups abroad, such as some of those involved in the U.S. Women's Suffrage movement meeting the United Kingdom's suffragettes and adopting their more militant tactics (Adickes, 2002). Even before social media took hold, disaffected groups such as those involved in the 1999 Seattle WTO protests organized online and used this medium to connect with like-minded people in other countries (Pridemore, 2011; Rimmerman, 2011). 
Present-day online communication, especially social media, has both enabled and transformed outlaw citizenship. One prime example is the January 2017 Women's March. Certain studies (Crockett, 2017) showed Facebook motivated more women to attend the national march in Washington, D.C. and numerous "sister marches" nationwide than friends or family. Also, such communication allowed the event to easily become global, inspiring sister marches abroad in cities such as Sydney, Berlin, Nairobi, and Cape Town" in solidarity with American women who opposed the Trump administration (Smith-Spark, 2017). The communication's ease not only mobilizes, but it allows groups, like-minded or not, to learn new tactics in an easier, faster, and less-costly manner. One tactic U.S. groups such as women and immigrants have utilized is general strikes - a practice borrowed from Europe (Crockett, 2017; Prose, 2017). General strikes are days during which no one in that group goes to work, shops, or spends money to demonstrate citizens' political and economic power. While Crockett (2017) acknowledges that factors such as declining union strength in the United States mean that general strikes could not be as large as those in Europe, she did note that some city governments, school districts, and other organizations did shut down for the March 8, 2017, "Day Without a Woman".

The internet and social media, particularly in terms of how it has changed the public discourse, has very sharp critics. Social media scholarship in public administration is relatively in its infancy, with Pridemore, N.E. Ganapati, \& Revell (2019) finding only three empirical public administration articles published between 2006 and 2016 that explicitly mentioned social media or a social media platform in the title. However, other 
scholars' most recent works have sharp critiques of social media and the internet, in general (Rimmerman, 2011; Sunstein, 2017).

Sunstein (2017) likened social media to a very modern, very isolationist echo chamber. This is a very modern version of an older theory — that opinions people form highly, if not totally, depend on what they are fed. Political scientist V.O. Key, in his 1968 book The Responsible Electorate, wrote that the American electorate's voice comes from an "echo chamber" (as cited in Ansolabehere \& Iyengar, 1996, p. 101). The echo chamber's output inevitably and invariably resembles the input, and people's choices can be no more than reflections of what is presented to them - being echoes of the information they see.

A major element of the social media echo chamber is that it can be both majorly widened and severely restricted at the same time. While numerous people are building large, diverse communities through social media, they are also building very narrowly tailored ones for people with common interests and ideologies (Sunstein, 2017).

Likewise, people are both interacting with larger, diverse groups and constraining their interactions to shrinking, narrow and usually like-minded individuals as well. In the latter example, people with the same viewpoint are usually talking with one another, and firing one another up. They can also block stories and viewpoints that do not interest them by alternating their feed preferences.

This is especially concerning when the information being spread on social media is false. The 2016 U.S. presidential election brought this major social media flaw to light. Allcott and Gentzcow's (2017) database in their study involving fake news during the 2016 election contained "115 pro-Trump fake stories shared on Facebook a total of 30 
million times, and forty-one pro-Clinton fake stories shared a total of 7.6 million times" (p. 212). This and other instances of fake news, such as an altered video purportedly showing eight "supernatural car crashes", where "ghost cars" were shown as colliding with an invisible force (Evon, 2018), are especially concerning, especially when Allcott and Gentzcow's (2017) database showed thirty-eight million fake news shares translating to 760 million instances of users (about three fake news stories for every American adult) clicking through and reading a fake news story. They note that ideologically aligned inferences that fake news stories are true, equal for both Republicans and Democrats, are stronger for people with ideologically segregated social media networks.

Even when information passed along on social media is true, scholars are also concerned that increased time online also means that more people spend far less time interacting with people face-to-face, which has deleterious effects on community development (Rimmerman, 2011). Rimmerman (2011), noting that the Internet's full effects on citizen participation remain to be seen, writes:

Citizens do not have the opportunity to talk to and listen to one another directly. As a result, they are not held accountable for their positions and do not have the benefit of learning from others through the give and take of the discussion process.

Technological innovation cannot substitute for the kind of community building and participatory experiences associated with face-to-face democracy and the participatory democratic vision. A further worry is that people (especially the young) who are constantly using instant messaging, texting, e-mail, and cell phones (We must all be connected, all of the time!) find it increasingly difficult to concentrate on the moment at hand. In this way, these new technological forms of progress serve as distractions and undermine the ability of people to concentrate and focus for sustained periods (p. 131). 
C.S. King and Nank (2015) had a strong warning for administrators as to what can result if governments do not engage disaffected citizens, but noted that figuring out how to do so was difficult.

If we don't engage citizens, they will practice forms of participation that stymie or limit the ability of government to do the work of the public good. If we don't engage citizens, possibilities of despotic-democratic governments increase. If we don't engage citizens, we are not going to be successful at working to ameliorate the wicked problems of our times. Therefore, we must practice engagement - but how do we do so? (p. 14)

Even when compared to the time of C.S. King and Nank's 2015 publication, the political and social environments have drastically changed, with scholars debating whether or not a despotic, and specifically, "fascist" government is gradually emerging - and even currently in place (Box, 2017). Whether or not this is the case, outlaw citizenship has become even more pronounced and, defying earlier notions of outlaw citizenship (even ones published during the current decade), with citizens engaging in "outlaw" activities that support the federal administration as well as state and local governments and even some in the federal bureaucracy joining outlaw citizens who oppose the federal executive branch's actions, becoming "outlaw governments".

Like previous outlaw citizenship movements, the current environment is not spontaneous. Sarlin, Petulla, and Peterson (2016), in their quantitative and qualitative analysis of Donald Trump's earliest supporters who ultimately propelled him into his position, found that this relatively small but vocal bloc were largely people whose economic conditions were worse after the Great Recession's economic recovery, had very low educational attainment, felt disconnected and abandoned for many years, and uncomfortable with an increasingly diverse nation. Most notably in this situation, they 
were disillusioned with mainstream candidates from both major parties, supporting “ 'outsider' candidates like Ron Paul or Ross Perot in the past" - meaning that such an attraction already existed.

Box (2017) points out that, although scholars have often have sharply different views as to whether or not the Trump administration's ideals and actions can be labeled "fascist", there is widespread agreement that disaffected citizens, often acting with behaviors including (but certainly not limited to) belief over knowledge, widely accepting "strange, even bizarre ideas" — and the current president, Box (2017) argues, using "such ideas in an apparent attempt, often successful, to destabilize the concept of an identifiable reality" (p. 581). As has been the case with outlaw citizenship movements in the past (Rimmerman, 2011), the effects of this, especially in the long-term, is debatable (Box, 2017). Box (2017) distinguishes between the rancorous debates just a few years ago and the marked differences with the current one, the latter of which, he argues, has both given those with more extreme views a platform and more social acceptance. He writes:

Even before the recent presidential campaign made misinformation, conspiracy theories, and false claims an everyday occurrence, it was a commonplace notion that the public was politically polarized and skeptical about government, especially the federal government. Now, knowledge, rationality, and facts are tarnished concepts in public discourse. Belief, even when grounded in clearly nonfactual material from social media and right-wing and alt-right figures, today allows people to feel comfortable in voicing views that would not have been heard so openly only a short time ago (p. 589).

Even in this case, though, Box (2017) points out that these very dark clouds do have serious silver linings for both practice and research. In practice, state and local governments can create progressive policies running counter to the federal 
administration's, as they have done in past "regressive eras" (p. 590). Effectively they can become outlaw governments. As of this writing, eleven state governments are suing the Trump administration over its "zero tolerance" immigration policy (Kamb, 2018), and local officials in the city of Austin, Texas, and Travis County, Texas, where the majority of the Austin city limits are located, are pushing back against both the federal and Texas state governments on immigration policy, despite state officials' actual and threatened retaliation (Jarvie, 2017). Also, members of the federal bureaucracy have resisted the Trump administration through filed complaints, media leaks, and rogue social media accounts (Eilperin, Rein, \& Fisher, 2017).

For scholars and practitioners, Box (2017) writes:

Not all impacts on public administration need be negative or troublesome. Scholars may respond to conditions in this new era with ideas that inspire reevaluation of the role of public administration in society. They may also document and elaborate on useful management innovations that are generated either because of or despite conditions in the broader society. As public professionals feel the effects, positive or negative, of policy shifts and organizational changes created by political leaders enacting regressive values, they may develop variations on processes and techniques that become lasting additions to the management toolkit (pp. 589-590).

\section{Outlaw Citizenship Literature Gaps}

Outlaw citizenship, itself, represents a major literature gap in public administration. Most of empirical work in public administration has focused on traditional participation outlets such as government meetings (Pridemore, N.E. Ganapati, \& Revell, 2019), but this non-traditional participation, which Rimmerman (2011) argues is what citizens prefer most, is relatively missing in the public administration literature. This examination, especially when examining Box's 2017 piece written describing the 
especially abnormal political and social environment American society has entered, is one that is especially crucial for public administration scholars to undertake.

Another major gap in public administration literature, as King and Nank (2015) has noted is a problem in practice too is that most citizen participation empirical studies focus on administrators and what goes on inside public organizations (Pridemore, N.E. Ganapati, \& Revell, 2019). As Box (2017) notes, political environments eventually permeate public organizations. Therefore, more work needs to be done in which researchers connect with citizens, especially disaffected ones who resort to outlaw citizenship. Just as artistic communities' citizen participation, in general, is relatively absent, public administration also needs to examine its particular outlaw citizenship outlets and methods, as it would in any study involving disaffected citizens' outlaw citizenship methods.

A third major gap is further understanding social media's potentials and pitfalls, particularly in the case of artistic communities. The public administration citizen participation literature, as mentioned above, is still extremely limited on social media (Pridemore, N.E. Ganapati, \& Revell, 2019). Given the serious implications mentioned above, such as the proliferation of fake news and stoking outrage (Allcott \& Gentzcow, 2017; Sunstein, 2017), social media definitely deserves further examination.

This dissertation will further examine outlaw citizenship and, specifically, how disaffected groups utilize it and why. In this dissertation's specific case population, it will look at how artistic communities use it. I will also examine how this is being utilized in the present-day fractious political and social environments, and for better and worse and how that outlaw citizenship permeates the day-to-day work of administrators who must 
confront it. Furthermore, this dissertation will focus more on the citizens in citizen participation instead of public administration's traditional focus on administrators or organizations. Given that so much of the literature points to how outlaw citizenship is the result of citizens not being heard, it is critical, then, to hear from the citizens and see what drives them to engage in outlaw citizenship. This dissertation will also further examine social media practices in general, with a particular focus on how it is used in outlaw citizenship.

\section{Participation Hindering Factors}

Scholars are publishing on the same problems (C.S. King \& Nank, 2015;

Pridemore \& N.E. Ganapati, \& Revell, 2019) that Arnstein (1969) identified — likely because little to nothing has been done to remedy the problems of participation roadblocks and citizen discontent (C.S. King \& Nank, 2015). In this section, I will discuss factors still hindering citizen participation (Laurian, 2004; Fung, 2006, 2015; Rimmerman, 2011). These include problematic citizen participation structures, certain groups' negative social construction, and lack of trust in government.

\section{Problematic Citizen Participation Structures}

Traditional participation's structure is one of citizen participation's main hindering factors. Although citizen participation progress has been made in both theory and practice (Fung, 2006, 2015; Kovalick, Walts \& Wells, 2015; Mucha, 2015), traditional citizen participation structures, such as the dominant public hearing format, create greater social inequality in the end (Fung, 2006, 2015; Laurian, 2004; Rimmerman, 2011). Fung (2015) writes that citizens who utilize traditional participation like the dominant public hearing format "are frequently more socioeconomically advantaged" ( $p$. 
515), and that participation venues favoring the politically, socially, and economically powerful can "secure policies and public actions that reinforce their economic or political positions" (p. 519).

In contrast, disadvantaged groups participate in traditional forums less not because of apathy but because of longstanding, social, economic, and educational inequality (C.S. King, 2015; Laurian, 2004; Rimmerman, 2011), just as Arnstein (1969) pointed out was a hindering factor for the less powerful $(1969$, p. 217). This was evident in the above-mentioned public hearing format (C.S. King, 2015; Rimmerman, 2011). Those with greater socioeconomic standing not only have their status as backing, but also, their communication styles are more privileged in traditional formats (Jewell \& Bero, 2007; Love, 2006; Rimmerman, 2011). In Beyond Adversary Democracy, Jane Mansbridge writes that groups such as the wealthy and more educated are "more likely to participate in town meetings because they feel less inhibited about expressing their views" (as cited in Rimmerman, 2011, p. 28).

Perceived sophistication and perceived intelligence can boost more advantaged groups during meetings and even in written comments. Jewell and Bero (2007) examined business community comments that demonstrated more technical knowledge that would likely appeal more to the specialized bureaucracy. Others mainly relied more on personal experience or moral arguments. Jewell and Bero questioned how democratic public comment periods are if certain groups' perceived knowledge and language are more appealing to the bureaucracy. 
Rimmerman's (2011) and Laurian's (2004) work further points out that apathy is not the reason why disadvantaged groups participate in traditional formats less often. Rimmerman (2011) writes:

Those who subscribe to the democratic theory of elitism believe that citizens have little interest in politics, have minimal knowledge of what is happening politically, and fail to participate because they perceive that the system is working well enough as it is. But those who embrace the more participatory democratic perspective challenge the notion of civic indifference by identifying various ways that citizens have become more meaningfully involved politically in their communities. Citizens do care, and they struggle in all sorts of ways to find opportunities to have their voices heard in decisions at all levels of government that affect their lives (p. 60).

When examining public hearings during a toxic waste situation, Laurian (2004) found that the vast majority of those who did not attend the hearings did so because they could not attend, with reasons such as lack of awareness and meeting times conflicting with work schedules. Only nine percent did not attend because they believed they could not affect positive change.

Negative Social Construction

Even when certain groups can access traditional participation formats, participation barriers - often very sinister ones — still exist. These barriers are rooted in how the public views certain groups. Schneider and Ingram (1993) put forward social construction theory, which they define as "cultural characterizations or popular images of the persons or groups whose behavior and well-being are affected by public policy" ( $\mathrm{p}$. 334). This involves "portraying groups in positive and negative terms through symbolic language, metaphors, and stories" (p. 334). Schneider and Ingram (1993) contend that social construction has a powerful effect on public officials, shaping policy agendas, and 
actual policy design. Social construction also defines particular groups as to who is deserving of government's help and who is not — even going as far as creating policies that punish unfavorably viewed groups.

Social construction can seep into citizen participation because it can affect who is invited to participate in policymaking and who is not (Schneider \& Ingram, 1993). This reflects Arnstein's (1969) assertion that, among other reasons, negative social views like racism are reasons why powerholders resist shifting that power to less powerful groups. Schneider and Ingram (1993) write that certain groups on which policies may have a significant and negative effect may not participate because messaging those target populations receives encourages passivity or withdraw. Likewise, other target populations receive messages encouraging them to, through participation, combat policies that could affect them negatively. Which direction this will take depends on how others will approve or disapprove of certain groups who are policy targets.

Schneider and Ingram (1993) give examples of groups often viewed favorably, such as the elderly and veterans, and those viewed negatively, such as convicted felons and those addicted to controlled substances. Polices with negative effects on negatively viewed groups may receive widespread support. One example both Schneider and Ingram (1993) and Miller (2012) used is the term "drug addict". Miller (2012) points out that the public discourse often bombards people with slogans such as "drug addict", "welfare recipient", or "War on Drugs" to either gain support for or demonize polices or even certain people. This, in turn, fuels public support or public outcry and subsequently affects policies implemented. 
Power is also a critical element of Schneider and Ingram's (1993) framework as well. Favorably viewed groups can be seen as either powerful or powerless, and unfavorably viewed groups can also viewed as both, as well. Examples would include groups such as veterans as favorably viewed and powerful, and children as ones who are viewed favorably but are considered powerless. On the other side, the rich may be seen as viewed unfavorably but powerful, and convicted felons may be seen as both viewed unfavorably and powerless. These two elements intersecting can also create policy outcomes that work to help or hurt certain groups, particularly the powerful who are viewed favorably and the powerless viewed unfavorably. Helping the former would boost public support, and punishing the latter would gain the same.

In the case of negatively viewed but powerful groups, policymakers have an especially problematic situation (Schneider \& Ingram, 1993). For the negatively viewed but powerful, policymakers opt for benefits that largely hidden or even appear to hurt when they actually help, writing, "(Policymakers) will prefer policies that the public and the media believe will inflict burdens on powerful, negative groups but that actually have few, if any, negative effects" (p. 338).

While policymakers may not have to wade through a figurative public opinion minefield as they do with the powerful but disliked groups, any work with those viewed favorably but less powerful is still difficult. The main problem is this case is resources. Although "officials want to appear to be aligned with their interests", "their lack of political power makes it difficult to direct resources toward them" (p. 338). Therefore, symbolic policies allow officials, particularly elected ones, "to show great concern but relieve them of the need to allocate resources" (p. 338). Often, this group's needs are 
either handled by lower government levels or even passed to the private sector, and the group has "little control over the design of the policies" (p. 338). Such groups, namely women and children, "have been viewed as the responsibility of families, churches, and the private sector".

However, an empirical study from Neshkova and Guo (2016) showed that whether or not a group is viewed favorably has a greater effect than power. They examined the four agencies' constituencies that would fall under one of the four different combinations from Schneider and Ingram (1993) of power and public image (Example: Corrections' departments constituents being viewed negatively and as powerless.) (p. 9), and how open those agencies were to public input. Of their results, Neshkova and Guo (2016) write:

Further, our data support the presence of an interaction mechanism between social construction of policy targets and their political power: the effect of political power is significant only for positively constructed target groups but loses its significance if the target population has a negative social image. In other words, the social construction trumps the effect of power in the decision-making calculus of public managers. It can be argued that administrators are concerned more with the positive projection and legitimacy of their actions than with the possible retaliation from a powerful but negatively constructed target group (p. 23)

\section{Lack of Trust in Government}

Another major hindering factor is citizens mistrusting their governments, creating

a barrier between the two, especially when mistrust has been longstanding (Choi, 2007;

Goldie \& Murphy, 2015; Hazell, Bourke, \& Worthy, 2012; Pascaru \& Ana Butiu, 2010;

Pridemore, N.E. Ganapati, \& Revell, 2019; Schatz, 2013; Worthy, 2010).

Low public trust can be a major hindering factor when governments work to create constructive citizen participation, especially when governments are working to 
move beyond extreme conflict (Goldie \& Murphy, 2015) and other crises (Bland, 2011). Goldie and Murphy (2015), pointing to the case of Belfast, Northern Ireland, emphasize that even with positive public sector reform on paper, per se, public administrators must understand often-complicated and still-tense situations that remain the public's reality if administrators try to have their jurisdictions emerge from major conflict. Likewise, scholars must understand the reality of how policy acts "in practice and the challenges and paradoxes" that local government-level conflict resolution entails. "Politically aware public managers" and the role of "informal organizational networks" are "vital to conflict management" and "even in an environment where reform is illustrated and embedded" (p. 483). This should be done even when this work is "not sufficient to result in conflict prevention and a reawakening of tension and violence" (p. 483).

Past citizen participation forums that, in citizens' minds, failed also erodes trust and ultimately becomes a hindering factor. Citizens, in reality, either make no change or get a "false sense of security" (Morin, 2016, p. 104) or, like King and Nank (2015) described earlier, governments only invite citizens to comply with legal requirements (Morin, 2016; Royo, Yetano \& Acerete, 2013). In some cases, governments use participation methods to gain more power for themselves rather than giving it to citizens (Linde \& Karlsson, 2013; Pascaru \& Ana Butiu, 2010; Yang \& Wu, 2013), just as Arnstein (1969) wrote years before that powerholders often do to those with far less power.

Hindering Factors' Key Literature gaps

The major literature gap is finding the answer to C.S. King and Nank's (2015) above-mentioned question - finding out what stands in the way of engaging disaffected 
citizens, in particular. The literature has identified hindering factors for the citizenry in general, but, in comparison, not much has been written on what hinders disaffected citizens. This will come with considerably more challenges for public administrators, and it is critical that scholars in the field examine it.

Also, when working to identify hindering factors in any disaffected group's citizen participation, not just artistic communities', is finding out the specific reasons for any group's disaffectedness and each group's own specific hindering factors. Because of outlaw citizenship being a buildup and not spontaneous, one must find the root of the problem before finding out any particular solution, and likewise, find out the particular obstacles that certain groups face. This is especially true for any policymakers seeking input from a selected constituency.

This dissertation will work to fill those gaps through examining what hinders disaffected citizens, specifically, which will be disaffected artistic communities in the particular population I will examine. This will look at both practical obstacles and more deep-seated, longstanding ones such as negative social construction that stand in the way.

\section{Participation Enabling Factors}

Public administration literature does paint a largely grim picture of citizen participation (Pridemore, N.E. Ganapati, \& Revell, 2019). Although public administration empirical studies involving citizen participation hindering factors greatly outnumber those about enabling factors (Pridemore, N.E. Ganapati, \& Revell, 2019), not all studies involve roadblocks. Some administrators are realizing that citizens with firsthand knowledge as to how certain policies affect them or could affect them can provide 
valuable insight — which can, in turn, create more effective policies (Elias \& Alkadry, 2011; Emerson \& Nabatchi, 2015).

Particularly in instances involving local-level government and decentralization and technology, public administration literature has pointed to how citizen participation can be enabled (Pridemore, N.E. Ganapati, \& Revell, 2019).

\section{Local-Level Organizing}

Public administration studies involving participation's enabling factors have focused on the local-level organizing, whether it is through municipal governments or neighborhoods and other smaller communities. Mucha (2015) and Kovalick, Walts, and Wells (2015) both emphasize this, with the latter writing that "individuals in communities are often the eyes and ears of government agencies" (p. 126).

Mucha (2015) notes that meaningful citizen participation involves give-and-take from both citizens and administrators alike. For citizens and administrators to together create positive change, citizens must change behaviors over time, and administrators can take a leading role - through making changes in how they operate, as well. Using the example of municipal government, he writes:

This cannot be done by changing the way one governs and administers; citizens will also have to change their behaviors over time, with the city employees as role models and facilitators to help move citizens to a place of empowerment and belief in their ability to affect change. This requires significant changes in employee skills, attitudes, and the systems used to get things done (p. 177).

Using the case of the city of Olympia, Washington, and its work to combat climate change, Mucha (2015) points out that as cities change and inevitably face new challenges, both government and citizens face a situation that is both initially 
uncomfortable and majorly consequential over time. On one hand, many people initially fear change. On the other, citizens demand action when problems arise - which often requires that change they fear.

The key in administrators successfully handling these situations and getting citizens involved in a productive partnership is issue presentation (Mucha, 2015). Fear can lead to withdrawing and seeking refuge in the familiar or outright denial of a problem. However, the public's response may be different if something is framed in terms of opportunity and leadership. Mucha (2015) writes:

Therefore, it's essential to lead ... efforts through what people value, particularly at the community level. ... This is the beginning of the next wave of public management reform with the potential to restore and renew relationships among and between citizens and their governments - we might even begin trusting each other again (p. 175).

Pridemore, N.E. Ganapati, \& Revell (2019) write that bringing citizen participation to smaller government forms or even areas within governments, particularly neighborhoods, has been shown as a positive in most citizen participation studies that involved local control and decentralization (Geurtz \& Van de wijdeven, 2010; Fenwick \& McMillan, 2012; Jun \& Bryer, 2016; Thijssen \& Van Dooren, 2016; Wagenaar, 2007). Local governments and citizens, in these cases, were working together to solve complex, novel problems. Striking the right balance between administrators' specialized expertise and citizens' firsthand experiences became a major enabling factor itself (Brydon \& Vining, 2016; Fischer, 2006; Geurtz \& Van de wijdeven, 2010; Hong, 2015; Lawton \& Macaulay, 2014; Thijssen \& Van Dooren, 2016; Wagenaar, 2007). 
Fischer's (2006) study of the Science for the People movement in Kerala, India, provides telling examples involving decentralization and striking that balance. Science for the People was part of an initiative that decentralized planning authority, giving it to local governments who enlisted citizens in planning. This often challenged wealthy landowners. Once that power was given, those involved struck the right balance between expertise and firsthand knowledge.

During community based mapping activities, for example, local volunteers worked on the ground with which they were familiar to map locations of roads and other infrastructure and gather demographic data such as income and household size from fellow citizens (Fischer, 2006). This work that partnered them with people using more sophisticated technology and skills also avoided the language barriers present in the preceding section. The information presented was "presented in local rather than scientific terminology. They were formulated in ways that helped people understand in their own lay languages the findings and their economic and social implications" (p. 33). Once the volunteers' mapping was done, the movements' expert members from the Center for Earth Science Studies, "an institution long engaged in scientific research related to resource management and planning" (p. 32), overlaid data from the volunteers with some of their own mapping of resources like underground water, which were not readily visible. This resulted in lengthy development reports combining reports of local social and cultural history combined with assessments of various resources. These were used to further develop action plans that worked to solve the problems identified.

Technology is, in some of public administration's literature, also seen as an enabling factor with citizen participation (Brydon \& Vining, 2016; Carrizales, Melitski, 
Manoharan, \& Holzer, 2011; Ferretti \& Lener, 2008; S. Ganapati, 2011; Ivanovic, 2012; Manoharan \& Bennett, 2013; Robbins, Simonsen, \& Feldman, 2008; Zheng, 2015). One of the major caveats in determining whether or not technology is an enabling factor is user-friendliness and functionality.

Zheng (2015) discovered that functionality was a major positive factor in citizens' electronic participation and motivated them to use this format more (p. 423). Tools available needed to be well-designed, have methods of contacting public officials, and enable both citizens' self-expression and ability bring up relevant policy issues. Also, they need to be convenient, lower-cost, and efficient (p. 428). When citizens experience websites with "difficulty in navigation or inability to find information" those who offer eparticipation "cannot hope to foster civic participation" (p. 428). Another factor in how technology has enabled citizen participation is that certain technologies' continual development has made them more user-friendly. S. Ganapati (2011) found that this was the case with Geographic Information Systems (GIS) technology, noting, "The waves represent progression of the GIS technology from being an elite field of expert professionals to that of ordinary citizens" (p. 431). Barriers in utilizing GIS, he noted, "are less likely to be technological and more likely to be institutional" (p. 432).

\section{Enabling Factors' Literature Gaps}

The key literature gap I have identified after examining public administration's literature on citizen participation's enabling factors is finding out more about how to engage disaffected populations, and ones within artistic communities specifically. While this subject has been explored and in recent years (Elias \& Alkadry, 2011; Emerson \& Nabatchi, 2015), the current social and political environment has morphed so much and 
so quickly (Box, 2017) that even studies published during this decade may only provide a starting point for engaging present-day disaffected populations. Furthermore, enabling factors for artistic communities are largely absent from public administration literature, and this needs further explanation, as well.

This dissertation will explore what factors enable artistic communities' participation, particularly when the community is a disaffected one. This will also provide context of the current, fractious political environment during which any engagement between disaffected citizens and government will take place, and how this work can be done despite any conflict.

\section{Who Participates?}

Another major consideration that must be taken into account in citizen participation is the question of who participates. Whether or not citizen input in policymaking actually contributes to better policies in the end depends "in large measure" on who participates (Fung, 2006, p. 67). Leaders in both government and advocacy groups must decide exactly how inclusive they want to be (Emerson \& Nabatchi, 2015; Fung, 2006). Excessive participation can lead to incoherent noise and/or outright mob rule (Alexander Hamilton, Jay, \& Madison (2001 [1787]); Hirschman, 1970). Likewise, too much constraint or the wrong kind of restraint can exclude needed perspectives or have a population that is not representative of the public being served (Fung, 2006). Rimmerman (2011) noted that balancing "participation, civility, and stability" is a dilemma (p. 3).

Fung (2006) puts forward a citizen participation framework called "The Democracy Cube", a three-dimensional model with three intersecting scales of 
"participant selection, "communication and decision mode" (what level of voice citizens will have), and "authority and power" (how much power citizens will have in final policy decisions made). For the purposes of this dissertation and this section, I will focus most on the participant selection scale.

If policymakers "lack the knowledge, competence, public purpose, resources, or respect" to make certain decisions, then whether or not citizen input can remedy these "deficiencies depends on large measure on who participates" (Fung, 2006, p. 67). Questions that need to be answered in terms of who participates include determining whether or not potential participants are "appropriately representative of the relevant population or the general public", if "important interests or perspectives" are included or excluded, "possess the information and competence to make good judgments and decisions", and are "responsive and accountable to those who do not participate" (p. 67).

Fung (2006) identifies five selection mechanisms. The first is the least restrictive participant selection, used by the vast majority of citizen participation venues. It begins with the diffuse, public sphere level, in which the venue is open to anyone who wants to come. "Complete openness has an obvious appeal" (p. 67), but this is not the reality. The reality is that, in this scenario, the slightly more restrictive open, self-selected participant selection happens. Like Rimmerman (2011) and King (2015) pointed out was problematic about traditional government meetings, most of those who choose to participate in these venues tend to be wealthier and better-educated and are "frequently unrepresentative of any larger public" (Fung, 2006, p. 67).

Fung (2006) then presents two different selection methods to potentially remedy this problem. Some participation venues that remain open to the public at-large will also 
selectively recruit people from population segments that are less likely to engage with their governments. Examples include initiatives involving policing or urban planning utilizing "community organizers to publicize meetings in low-income and minority communities" (p. 67). This is done to attract people who care more about or have a higher stake in certain issues, particularly if these populations are disadvantaged. Issues such as crime "are less urgent for the wealthy" (p. 67). The problem with this setup is that groups with particular interests in a particular issue "may nevertheless exploit the open-to-all character" of meetings that remain open to the public at-large to stack participation in their favor. Therefore, Fung (2006) argues, randomly selecting participants from among the general population — and restricting participation to that group only — "is the best guarantee of descriptive representativeness" (Fung, 2006, pp. 67-68). Examples of such initiatives are deliberative polling or citizens' juries.

Further along Fung's (2006) scale, which becomes more restrictive as it progresses, is engaging "lay stakeholders". This is a group of "unpaid citizens who have a deep interest in some public concern and thus are willing to invest substantial time and energy to represent and serve those who have similar interests or perspectives but choose not to participate" (p. 68). Groups such as neighborhood associations, for one example, are composed of lay stakeholders. Then, Fung's (2006) scale moves into both more restrictive and more professionalized levels. The next step is engaging "professional stakeholders", who are "frequently paid representatives of organized interests and public officials" (p. 68). Such stakeholders are often utilized during governance matters such as "regulatory negotiation, grassroots environmental management, and collaborative planning" (p. 68). 
The final levels of Fung's (2006) scale restrict decision-making to state actors. Professional politicians, who win in "competitive elections" and "supposedly represent our interests" (p. 68) are at the second-highest level. Expert administrators, members of the professional civil service who, in traditional public administration thought, have "technical", specialized expertise are at the top of a scale, meaning that decisions reserved to only them are considered to be ones with the least public input. Fung (2006) notes that "many (perhaps most) public policies" are determined through "the technical expertise of officials whose training and professional specialization suits them to solving particular problems" (p. 69). This mode, that usually does not involve citizens at all, is typically restricted to public employees such as planners, regulators, and police officers.

For the most part, empirical studies in public administration show mixed to negative findings about citizen participation efforts that worked to bring more people into the policymaking process (Pridemore, Ganapati, \& Revell, 2019). Public administration scholars also urged policymakers to carefully consider who and how many should participate (Musso, Weare, Bryer, \& Cooper, 2011; Rossmann \& Shanahan, 2012).

As scholars cautioned in the outlaw citizenship section, some public administration scholars portrayed online participation as problematic (Bryer, 2013; Kurniawan \& de Vries, 2015; Yetano \& Royo, 2015). Bryer (2013), Jimenez (2013), and Kurniawan and de Vries (2015) all pointed out that opening the door too much or at the wrong time could hurt citizens themselves, not just hinder the work of the bureaucracy. Most of the time, according to the literature, too much noise meant that citizens' voices were figuratively drowned out or eventually disregarded (Bryer, 2013). For citizens, these forums they first perceived as empowering may have been disempowering in the end. 
One example Bryer (2013) used was online comments in the rulemaking process on Regulations.gov, a website that has "democratized the federal rulemaking process by making it easier for citizens to search, read, and comment on proposed rules” (p. 263). His qualitative analysis showed that the comments tended to be "emotional, illogical, and lacking in credibility" (p. 263). Using the examples such as a Department of Health and Human Services proposed rule change, he showed how most participants made erroneous presumptions about the rule and provided only "emotion-driven" comments. He contends that when citizen participation methods become especially easy, this hurts citizens in the end.

"Say, for instance, that the nearly 20,000 citizens who participated in the HHS rule comment process thought they could make a difference through their submissions and activism. The quality of their commentary, however, was such that it was of little or no use for decision-makers, thus leading regulatory and administration staff to make a determination based on other evidence more relevant to the issue at hand. When this happens, citizens who participated but whose words were not meaningful for decision-makers may experience diminished trust, diminished efficacy, and diminished perceptions of government legitimacy" (p. 276).

\section{Literature gaps in determining who participates}

One key gap is determining, among artistic communities, who will participate. If local governments are to bring this population subgroup to the literal or figurative table, it must decide who does or does not need to be there. Furthermore, in answering the question of who participates, in any subgroup of any population, scholars need to further explore the social media conundrum. Social media is a "diffuse, public sphere" level to an extreme, and yet, only three empirical studies Pridemore, N.E. Ganapati, and Revell (2019) found in their extensive public administration literature review explicitly 
mentioned social media or a social media platform in the title. Therefore, anyone working to answer this question should definitely take social media into account.

With this dissertation, I will explore who among artistic communities should participate and how wide the participation window should be. A major element addition in addressing literature gaps will be its examination of social media's relatively uncharted territory, in which the participation window is an extreme, and it is increasingly becoming the norm.

\section{Artistic Communities' Challenges}

Policy, market, and social forces in longstanding artistic cities are pushing artistic communities, their cores, out (Markusen, 2014; Long, 2010; Timberg, 2015; Florida, 2017). This population is both critical for residents' quality of life (Jacobs, 1992 [1961]; Oldenburg, 1999) and a major economic development driver (Florida, 2014a; Florida, 2014b; Rushton, 2013).

Cities' artistic communities most vital contributions are greater quality of life, community cohesion, and more vibrant cities for all residents. Oldenburg (1999) refers to places such as bars, bookstores, and coffee shops as "third places", community gathering places away from home or work. Spaces devoted to community gathering, in general, are critical for having a healthy urban environment (Jacobs, 1992 [1961]; Oldenburg, 1999). Those spaces are often older structures in older neighborhoods, where a mix of strangers intermingling gave a city its unique identity (Oldenburg, 1999). That day-to-day intermingling builds what Jacobs (1992 [1961]) calls a "web of public respect and trust", which is a "resource in the time of personal or neighborhood need" (p. 56). 
Adding music and other cultural attractions to these community spaces creates an even healthier and more vibrant atmosphere, with Oakes and Warnaby (2011) noting that activities that are in the open and free or low-cost make culture both more accessible and democratic. Such accessible arts activities are prevalent in third places, like historic music venues. Oldenburg (1999) notes that another social benefit of third places is that they are "levelers", where all people, regardless of social standing, are on the same social footing as opposed to stifling hierarchal structures like those in workplaces. They are also places where people can express themselves freely in ways they never could at home or at work, and he argues that people need such outlets. He writes:

Here, individuals may uncork that which other situations require them to bottle up. The timidity which the workplace imposes upon those with families to support does not extend to the third place. Here, one may bellow like a street preacher or wail like a new widow, boast with gusto or assume the authoritarian pomp of a high court judge.

The mundane world subdues us... It encourages us to be image-conscious and self-conscious. ... ....For people with spirit (or who need spirit), this is too stifling and vapid. ... (In the third place), the stage is available, and it's a wonderful stage, for the audience appreciates the actor no matter how bad the act (pp. 5859).

Artistic activities and third place venues most seriously threatened are the ones that, like Oakes and Warnaby (2011) and Oldenburg (1999) described, are more accessible and affordable for local residents. These include generally (if not very) affordable dive bar concerts, street performances, and fringe theater shows (Berson, 2007; Beyer, 2016; Jacobs, 1992 [1961]; Oakes \& Warnaby, 2011; Oldenburg, 1999). Such threats, besides more market-oriented affordability, include public policy 
mechanisms such as more restrictive noise ordinances (Rainey, 2014; Woodward, 2014), curfews, and stricter code enforcement (Berson, 2007).

These policy mechanisms are almost always tied to the development-related social tensions. Development and population influxes have also brought in new, wealthier populations turned off by lively artistic scenes and the unique people and gritty, older places in them (Beyer, 2016; Personal Communication, 2017, 2018). Those wealthy new residents then turn to local governments and advocate for policies that could seriously temper those historically boisterous neighborhoods (Beyer, 2016; Personal Communication, 2017, 2018). Well-established artistic cities have often held that identity for decades, if not centuries (City of New Orleans, 2013; Long, 2010). The artistic roots have been in place much longer and are much deeper than in other cities. This devotion to local culture and history and to the crafts artistic community members love is the driving force for artistic communities' participation that includes outlaw citizenship (C.S. King \& Nank, 2015; Long, 2010; Raeburn, 2007; Pridemore, 2018; Rimmerman, 2011).

Local-level public policy, in the end, almost always determines artistic communities' survival (Berson, 2007; Long, 2010; Personal Communication, 2017, 2018; Timberg, 2015). Combined with the residential housing situation, beloved old performance venues like gritty, unique dive bars are either endangered or being forced to close (Berson, 2007; Long, 2010; Timberg, 2015). The older structures housing some of these more accessible venues are frequently targeted and maligned because they are not seen as valued - until it is too late (Oldenburg, 1999). Oldenburg (1999) elaborates:

The beer joint in which the middle-class American takes no pride can be as much of a Third Place as the proud Viennese coffeehouse. It is a fortunate aspect of the 
Third Place in that its capacity to serve the human need for communion does not much depend upon the capacity of a nation to comprehend its virtues (p. 20).

Such places are rarely appreciated as much as they should be while they are still operating. When a place such as this burns down, however, it is much like the death of a beloved first citizen. The community no longer feels the same; much of its character and charm seems to have depended on that place (p. 206).

When cities become "cool" — and as a result, more expensive — because of their attractive music and arts scenes, scholars assert that artistic communities are not the ones to blame for their situation. Rather, scholars point to development profits and income inequality. Markusen (2014) writes, "a free-market property rights system and an active development industry in cities drive gentrification, not artists per se, even if some artists are caught in its fast-changing web. Contemporary cultural observers understand this and are questioning the pervasiveness of artist-led gentrification" (p. 570). Richard Florida (2014a, 2014b, 2017), known for his "Creative Class" theory, acknowledges he has been blamed for this crisis (2017). Florida (2014a, 2017), though, points to longstanding inequality that has become far worse in recent years.

Florida (2017) writes that while gentrification is not a new phenomenon, presentday gentrification's impacts are far more cataclysmic. For decades, neighborhoods have shifted from wealthy to poor and back to wealthy, with the cycle continually repeating itself. The problem now is that the wealthier groups moving into urban neighborhoods in the "back to the city" movement are far more affluent and privileged than before, with, between 2000 and 2014, the most likely group to move back into densely populated urban areas being the wealthiest ten percent of United States households. While urban socioeconomic divides are nothing new, either, the current situation tilts the balance of 
urban inequality much further. The poorest ten percent of households were the most likely to leave American cities between the above-mentioned time frame of 2000 and 2014 (Florida, 2017, p. 62). Even younger residents moving into urban areas are coming from wealthier backgrounds, with Florida writing, “.... any way you slice it, it’s a privileged subset of young people that is headed back to cities" (p. 63).

Florida (2017) further elaborates on his re-examination of urban policy, particularly with a greater focus on inequality, in The New Urban Crisis. He writes:

Although some of the more personal attacks stung, this criticism provoked my thinking in ways I could never have anticipated, causing me to reframe my ideas about cities and the forces that act on them. As techies, professionals, and the rich flowed back into urban cores, the less advantaged members of the working and service classes, as well as some artists and musicians, were being priced out. ... I began to see the back-to-the-city movement as something that conferred a disproportionate share of its benefits on a small group of places and people. I found myself confronting the dark side of the urban revival I had once championed and celebrated.

...Ultimately, the very same force that drives the growth of our cities and economy broadly also generates the divides that separate us and the contradictions that hold us back (pp. xvi-xvii).

\section{Artistic Communities Challenges’ Literature Gaps}

The urban studies literature provides insight on why artistic communities' spaces and activities are critical components of public life and why these spaces and activities are held dear. The literature also points to the strain the artistic people and spaces are under in terms of affordability and some of the social and market forces behind them, especially the more exacerbated ones of the modern era.

However, the urban studies literature has, for the most part, only recently moved toward working to find remedies to artistic communities' affordability crisis, and a major 
gap even in that is discovering how to engage this group. Likewise, it must go further even in that and ask questions mentioned above of who participates, what hinders and enables their participation, and who participates. Also, a major gap is finding out how to start a dialog with a disaffected population with the additional challenge of artistic communities possibly viewing urban administrators and scholars as the ones to blame for their plight, as Florida (2017) said was the case for himself.

This dissertation will further the discussion of artistic communities challenges, which are just now entering the figurative scholarly conversation with publications such as ones highlighting creative class policy’s ramifications (Florida, 2017; Timberg, 2015) being very recent. This will also address the additional challenge policymakers would likely have in creating a dialog with a disaffected population who sees the policymakers as responsible for their problems.

\section{Institutions and Power}

Theory involving institutions and Faces of Power, which demonstrate, for this dissertation, the three different dimensions in which power is exercised, can provide a framework that counters any longstanding belief that disaffected groups do not participate because of apathy but because they face roadblocks. Faces of Power, especially its latter dimensions, can provide background for both those roadblocks and how more powerful members of society create them.

\section{Institutions}

North (1990) described institutions as societal "rules of the game" and "humanly developed constraints shaping human interaction" (p. 3). Institutions can be formal, such as written policy, or informal, such as societal gender roles. Informal ones are often much 
stronger, staying in place even after formal ones change. Further complicating the situation is different groups' practice-acquired "tacit knowledge", which can only be partially communicated.

The challenge with institutions, though, is that both formal and informal ones alike may not always be positive. The Civil Rights Movement of the 1960s provides examples on formal institutions. Jim Crow laws during the segregation era were formal institutions. So was the Civil Rights Act that legally ended Jim Crow. The city of Austin provides examples on informal ones and how they are longstanding, for better and worse alike. Austin's commitment to environmental protection, despite challenges from development and state government, is seen as an institution (Ankrum, 2010; Lindell, 2018a, 2018b; Swearingen, 2010; Wynn, 2011). Likewise, Austin's racial segregation with Interstate 35 as an east/west boundary is also seen as an institution (Balli \& Texas Monthly, 2013).

Those institutions, formal and informal and positive and negative alike, can both enable and hinder voice. While they are not the only factor, institutions and their different typologies are key factors in showing why groups who want to be heard will either go the route of traditional participation, non-traditional outlaw citizenship, or remain silent.

Constraints, North (1990) writes can keep informal institutions alive, and constraints "are a part of the heritage we call culture" (p. 37). North (1990) also points out that institutional changes are difficult to sustain, and deep-seated cultural elements have "great survival tenacity".

However, another key point about institutions is that, while they are strong, presuming they are indestructible is erroneous, Bachrach and Baratz (1962) warn. North 
(1990) notes that those who seek institutional change often do so by first changing formal institutions. Once formal institutional change, like those in public policy, keep informal institutions from thriving, those informal institutions gradually wear down. Bachrach and Baratz (1962) and other scholars (Gaventa, 1980; Schattschneider, 1983 [1960]; Warner, 2001; Warner, 2011) whose work I will use further below describe how those with greater societal power have this greater ability to create this institutional change than less powerful ones have when trying to preserve institutions.

Institutions require examination of what is inside of them, as well. Within every institution, there is "an ordered system of power, a "power structure" (Bachrach \& Baratz, 1962, p. 947). How power is exercised is not always, if almost never, cut and dry. In this section, I will present three dimensions of how power works in society and, most important to this dissertation, how that power works to either enable or stifle citizens voices - especially when citizens' power or lack thereof is taken into account. First Face of Power

The First Face of Power is, on the surface, very straightforward, but also requires numerous presumptions. In the First Face, A (the powerful) has the power over B (the powerless) to force B to do something that B would not normally do (Gaventa, 1980; Warner, 2001, 2011). For example, if a restaurant manager told an employee to clean the business' public toilets, the employee would likely do it not because he/she wanted to clean the toilets but because the manager had the ability to fire him/her. A major element of the First Face is that it has to be observable. If no resistance is readily visible, "silence automatically means happiness" (Warner, 2011, p. 1) or consent (Warner, 2001). In the 
case of the restaurant employee, cleaning the toilets without objection would likely exhibit consent.

Gaventa (1980) and Warner (2001) show how the First Face's presumptions from political scientists Robert Dahl and Nelson Polsby play out in citizen participation. First, "grievances are" presumed "to be recognized and acted on", and "participation is" presumed "to occur within decision-making arenas, which are, in turn" presumed to be “open to virtually any organized group" (Gaventa, 1980, p. 5). In this approach, nonparticipation or inaction on the citizens' part is not seen as a problem, and is instead seen as citizens exhibiting consensus.

Relationships between those with low socioeconomic status and low participation, Gaventa (1980) writes, "gets explained away as apathy, political inefficacy, cynicism, or alienation of the impoverished" (p. 7). In this First Face view, Gaventa (1980) argues, the victim is essentially blamed for his/her own condition.

\section{Second Face of Power}

Other scholars have pointed to the Second Face of Power, developed by political scientists Peter Bachrach and Morton S. Baratz (Bachrach \& Baratz, 1962; Gaventa, 1980; Warner, 2001), which describes power dimensions that act not as direct, observable marching orders but are likened to a game in which the powerful control the rules and, subsequently, the outcomes. Warner (2011) explains that, in this approach, "A has the power over B to the extent that A can refuse to make a decision that is in B's interest or manipulates the agenda so that B's interests cannot be heard" (p. 1).

The Second Face involves power exercises such as "picking rules of the game" and "ignoring and not making decisions (non-decisions)" (p. 1). Exercise of the Second 
Face is not always observable (Warner, 2011). "In fact, privatizing power is a very effective way to wield power" (Warner, 2011, p. 1). One example of this is nondisclosure agreements, which require those who sign them to remain silent about the more powerful person's actions. Likewise, it can become more readily observable through A bringing any private conflict into the open. Schattschneider (1983 [1960]) writes that doing this brings more people into a negotiation until a "balance of forces" works in A's favor (p. 39). In regards to socialization as a power exercise, Schattschneider (1983 [1960]) writes: "The moral of this is: If a fight starts, watch the crowd because the crowd plays the decisive role" (p. 3).

If powerholders can keep the less powerful's issues from arising, this, in theory, prevents the less powerful from acting (Gaventa, 1980). In this view, one must examine who gets what and how and, likewise, who loses what and how — and how these two are interrelated. According to Schattschneider (1983 [1960]), Gaventa (1980), and Warner (2001, 2011), one reason is suppressing the less powerful. Schattschneider (1983 [1960]) writes:

It is profoundly characteristic of the behavior of the more fortunate strata of the community that responsibility for widespread nonparticipation is attributed wholly to the ignorance, indifference, and shiftlessness of the people. This has always been the rationalization used to justify the exclusion of the lower classes from any political system.

There is a better explanation. Abstention reflects the suppression of the options and alternatives that reflect the needs of the nonparticipants. It is not necessarily true that the people with the greatest needs participate in politics most actively. Whoever decides what the game is about decides to also who can get into the game (p. 102) 
Warner (2001) illustrates how the Second Face can work in action and presents a real scenario in which the First Face's logic was faulty — and outlaw citizenship erupted. In 1958, Warner (2001) writes, Dahl had written a book titled Who Governs? He described power distribution during New Haven City Council meetings and tallied each time he observed power being exercised. From his observation, he concluded that no one exerted power over others on major issues, and "therefore, every group must have, by definition, consented to the council decisions". Warner (2001) explains what happened soon thereafter and why:

Two weeks after the book was published, New Haven erupted into race riots. Obviously, not everyone had given their consent on "key" issues and was happy with the outcomes. What Dahl's First Face of Power had missed was the power of the executive board to limit the council agenda to non-confrontational items, items to which everyone consented. Confrontational topics, such as anything involving racial issues, were either tabled or pre-emptively excluded from the discussion. Powerful members of the council had manipulated to their advantage and had exercised the power of non-decision and non-action, their power to do nothing (Warner, 2001, p. 117)

\section{Third Face of Power}

A key point in both the First and Second Faces of Power is that B, the less powerful or outright powerless, is aware of A's actions (Gaventa, 1980; Lukes, 1974; Warner, 2001, 2011). Power exercise dimensions go even further with the Third Face of Power, in which B may not know who is responsible — with others shaping his/her sense of reality and, most importantly in the citizen participation context, using this to again prevent B from fighting A's actions. Warner $(2001,2011,2018)$ notes that while the first two faces focus more on the powerful's actions, the third face examines the powerless more. It aims to answer a question asked often in the social and political arena, "How and 
why would one ever consent to something that is not in one's best interest, that is against one's desires?" (Warner, 2001, p. 119).

Basically, the powerless in the Third Face of Power are, in effect, beaten into submission. The Third Face may begin with B, after A continually defeating it through using the First and Second faces, withdrawing over time and that withdraw leading to an "unconscious pattern of withdraw, maintained not by fear of power of $A$, but by a sense of powerlessness within B, regardless of A's position" (Gaventa, 1980, p. 17). That sense of powerlessness can manifest itself in such forms as extensive fatalism (Gaventa, 1980). The constant defeat, Gaventa (1980) writes:

...gives rise not only to the conscious deferral of action but also to a sense of defeat, or a sense of powerlessness, that may affect the consciousness of potential challengers about grievances, strategies, or possibilities for change. Participation denied over time may lead to acceptance of the role of non-participation, as well as to a failure to develop the political resources - skills, organization, consciousness - of political action. Power relationships may develop routines of non-challenge, which require no particular action on the part of the powerholders to be maintained... (Gaventa, 1980; as cited by Warner, 2001)

The Third Face becomes even more powerful if B internalizes and adopts the powerful's ideology, sometimes entering the participation arena on A's behalf working against themselves (Gaventa, 1980; Warner, 2001, 2011). Those engaging in citizen participation often have a greater awareness of their own situation because of a figurative two-way street - those who are aware of their own situation not only participate more, but those who participate more develop greater awareness (Gaventa, 1980). The problem is that those denied access to participation arenas cannot "engage actively with others in the determination of their own affairs" and also "might not develop political consciousness of their own situation or of broader inequalities" (p. 18). 
The powerless being silent may then give the powerful's ideology legitimacy (Gaventa, 1980). Over more time and through more exercises of the first and second faces, the powerless' conscious may be malleable and vulnerable to manipulation often through myths and symbols and sometimes to the point to where they do not know who is actually responsible. A major point in this is that, when B recognizes a grievance, it may act against a wrong target. Gaventa's (1980) work explains how that can happen.

Gaventa (1980) examined the Third Face of Power empirically in the case of an extremely poor mining town of Tennessee in his book Power and Powerlessness: Quiescence and Rebellion in an Appalachian Valley (Gaventa, 1980; Warner, 2001). Gaventa, Warner (2001) writes, wanted to know why people living in such horrible conditions "did not lobby the mining company or the local government for better working and living conditions or why they did not just leave to find a better life elsewhere" (Warner, 2001, p. 119).

Some of the tactics powerful people in the community utilized were ones that spoke to the miners' and mining families' strong traditional beliefs, like religion or patriotism (Gaventa, 1980, p. 254). For example, elites created a new enemy Communists, but the powerful's manipulated version of Communists - when they believed disaffected miners would rebel and receive assistance from outside the community (Gaventa, 1980). The message that the local elite put forward was that Communism, "an evil brought in" by both foreign and American outsiders, included dogma such as "hatred of God", "dictatorship" with "headquarters in Moscow" and "destruction of all forms of representative and democratic government and the rights of liberty guaranteed under the American Constitution...” (p. 110). Labels such as 
"Communist" or "outsider" were effective in quelling discontent when outside help from people they, thanks to the messaging from the elite, believed worked against everything they held dear and in favor of what they had, in their traditions, taught to abhor.

Therefore, challenging those closely held traditional values and beliefs were not an option to them (p. 254). If resistance meant joining people who fought against their traditions and values, they would not resist.

Warner (2001) uses the example of domestic violence to further demonstrate why someone would stay in what an outside observer would believe is a situation that someone should obviously leave. She writes:

Often, the abuser mixes together the acts of the first face (actual violence) and the second face (manipulative agenda-setting like control of the financial and social situation) over a long period of time. Instead of presuming that the B has consented to the situation (or else, she would just leave, wouldn't she?), the third face forces us to look at how these repetitive acts impact the ability of the victim to know her own interests at the rational level. Why doesn't the victim just leave? Instead of presuming a conception of identity based on the first face (silence implies consent), the third face tries not to blame the victim. The third face tells us, instead, that B might have internalized the situation at the level of the self, that she might have begun to believe that she deserved the violence, that it was her fault, that there was no other viable options, or, simply, that this is just the way life is. A, in this situation, has manipulated the environment so that B is no longer aware of her objective interests, although someone outside the immediate situation, like a case worker or relative, could see that B's objective interests were not being met (pp. 121-122).

\section{Breaking power structures}

Like institutions, power structures are extremely strong and can be exceptionally difficult to dismantle (Gaventa, 1980; North, 1990; Warner, 2001). Just like institutions, power structures are not indestructible, either. Gaventa (1980) provides insight on how this can happen, and how the powerless can defeat the powerful. 
Power shifts, whether it comes from B gaining power or A losing power, can challenge power structures and even spark rebellion (Gaventa, 1980). Even when those challenges emerge, B must take several steps to overcome powerlessness "before the conflict is on competitive ground" (pp. 23-24). Much of what B has to do is a combination of self-reliance and partnerships (Gaventa, 1980). It involves organizing with other people who have the same grievances, mobilizing, clearly identifying problems, anticipating what A will do to retain power and fight back, and taking action on its own and with a course it develops on its own. One of the biggest challenges is also breaking out of thought patterns, namely that potential allies are enemies, which A has created through the Third Face of Power. Gaventa (1980) elaborates:

B must go through a process of issue and action formulation, by which B develops consciousness of the needs, possibilities, and strategies of challenge. That is, B must counter both the direct and indirect effects of power's third dimension. And B must carry out the process of mobilization of action upon issues to overcome the mobilization of bias of A against B's actions. B must develop its own resources - real and symbolic - to wage the conflict. Only as the obstacles to challenge by B in the second and third dimensions are overcome can the conflict which emerges in the first dimension be said to reflect B's genuine participation - i.e. self-determined action with others similarly affected upon clearly conceived and articulated grievances.

This formulation of the steps of effective challenge provides further understanding of the means by which A may prevail... A may respond at any point along the process of issue emergence. That is, the powerless may face barriers to effective challenge in the process of the formulation of issues, of the mobilization of action upon issues, or in the decision making about issues - any or all of which may affect the outcome of the conflict. What are for B barriers to change are, for A, options for the maintenance of the status quo.

But ... as the barriers are overcome, ... A's options for control lessen. ... Once patterns of quiescence are broken upon one set of grievances, the accumulating resources of challenge - e.g., organization, momentum, consciousness - may become transferable to other issues and other targets. ... A will act to thwart challenges by B regardless of whether or not they appear...... For once the patterns are broken, the likelihood of further action by B increases and the options 
for control wielded by A decrease. ... B must ally with (another) B for the emergence of effective challenge against A... (pp. 24-25)

\section{Institutions and Power Literature Gaps}

The key gap in the literature involving power is how, in real time and for artistic communities, to overcome barriers that seem impossible to break. If there are multiple levels of "games" that powerholders create, then a key gap is finding out how to effectively play in the arena one is given or find a way to, figuratively, destruct that arena. Likewise, finding out exactly how these repeated exercises of power could lead to outlaw citizenship is another major factor. One can presume, when combining theory involving power and outlaw citizenship, that the power exercises are outlaw citizenship's roots. The gap is that the power literature largely points to how rebellions are quelled, not sparked. Therefore, it would be pertinent to see how power theory, especially its ideals on mobilization to overcome power structures, comes into play in situations when disaffected citizens may not see any other options but outlaw citizenship.

One major contribution this dissertation will have in addressing these gaps is pointing to how certain power structures and institutions can be overcome and conversation can be sparked, not just the participation barriers that institutional and power structure issues cause. Furthermore, this dissertation will address the literature gaps involving less visible power structures, namely the Second and Third faces, to challenge older participation scholarship in showing how presumed apathy or even happiness is often false. 


\section{Artistic Communities' Preferred Communication Styles}

Artistic communities' preferred communication styles are significant for two main reasons in this dissertation. It is not only the preferred style for the specific group being studied, but its arts-oriented techniques are also the preferred communication for disaffected groups, in general (Floeckher, 2010; Love, 2006).

The roots of both this communication preference — and participation inequality for historically disenfranchised groups, political scientist Nancy S. Love (2006) argues, is when societies transitioned from oral to literate. Rational argument became the preferred communication style in the political discourse. Groups such as women and minorities who, because of historical disenfranchisement, could not access what they needed to learn such communication styles. As a result, communication styles of wealthier white men became the preferred voices in the political spectrum. This kept many other voices, namely those of women and minorities, out (p. 6). Fraser (1997) writes that because of that imbalance, economic injustice and "cultural injustice" are very much intertwined (as cited in Love, 2006, p. 7).

Including art forms such as music in the political dialog, Love (2006) argues, creates a more "inclusive democratic discourse", "pluralizing" the voices in it (p. 11). "Song lyrics frequently represent political views and cultural identities" (p. 11). They “define and expand relationships between groups and challenge established identities and institutions" (p. 11). Musical communication often comes in two different forms I will define — "realistic", in which musicians explicitly state their current situations or their histories (Floeckher, 2010), and "idealistic", in musicians explain what they want their situations to be, even if it is not yet their reality (Frith, 1996). Storytelling from musicians 
provides not only an accessible and alternative lens (Farmer, 2010) but one that is especially suited for examining historically disenfranchised and disaffected groups because of its historical roots (Love, 2006).

This approach from musicology provides a sharp contrast to traditional public administration thought, in terms inclusivity and the number of voices in the social and political discourse. While music-related theory calls for more voices (Love, 2006), this runs counter to traditional public administration thought that advocated a neutral, insulated bureaucracy. In Woodrow Wilson's 1887 “founding” piece on administration, he argued for less public involvement, writing:

Bureaucracy can exist only where the whole service of the state is removed from the common political life of the people, its chiefs as well as its rank and file. Its motives, its objects, its policy, its standards, must be bureaucratic (p. 217)

Examining musical expression can include historically disenfranchised groups' often-dark realities and music some of the angriest citizens prefer. Lyrics and music that speak to the reality of a person's situation can be both cathartic and empowering for listeners (Floeckher, 2010). Floeckher (2010) uses the example of metal and the subject of war. Metal's lyrics are often not overtly political, but they can serve a concrete and ultimately political purpose. "By providing uncompromising, in-your-face commentary on war that contradicts the doublespeak of politicians and pundits, heavy metal lyrics lend an angry voice to those whose voice goes unheard in the mainstream media" ( $p$. 233). Metal provides an unflinching commentary (Floeckher, 2010) at a time when public administration scholars such as Gooden (2014) argue that apprehension in discussing sensitive topics is problematic and prevents meaningful dialog that can lead to solutions. 
Floeckher (2010) provides examples from songs like Metallica's "One" and Alice in Chains' "Rooster" that present the agonizing accounts of people who have experienced war and compares them to a comparatively sanitized news report about the subject, which was characterized by euphemistic language. Floeckher (2010) explains how the music, in this case, more accurately told the war survivors' stories:

These are just a few of countless examples of euphemisms that disguise the brutality of war and render its victims, soldiers and civilians alike, alone with the reality of what has happened to them. When the news media abandon their responsibility to use language that accurately describes the brutality of war, what is left is a chasmal physical, psychological, and emotional divide between the victims of war and those of us who only read about them. Indeed, euphemistic language turns war crimes into mere abstractions and, contributing to the already impersonal nature of modern warfare, cleverly transfers culpability away from the aggressor and onto the victims themselves (p. 235).

One example of how realistic communication works is through the music of Rage Against the Machine, which frequently invokes powerful, force lyrics depicting egregious racial and economic inequality. This was displayed in one of the band's signature songs, "Killing in the Name", which decried police use of excessive force against minorities with the lyrics of:

Some of those who work forces

Are the same that burn crosses

...Those who died are justified, for wearing the badge

They're the chosen whites (Commerford, de la Rocha, Morello, Wilk, 1992).

Tom Morello, the band's lead guitarist (now lead guitarist for rap-metal band Prophets of Rage), said his music comes from his own experiences as a black man who has experienced racism that includes racial profiling by police (Spanos, 2015). He 
emphasized that when he played at a concert in Ferguson when telling interviewers he was not merely a celebrity with a conscience. He said:

A few years ago, I was walking home from a bar... ...Two squad cars pulled over and handcuffed me in the streets of my hometown. Their excuse was that someone had been breaking into cars. Countless times pulled over in my old van in Beverly Hills when I first moved [to L.A.]... It's not a foreign concept. It's not like I'm flying in to go see what racism is like. It still remains a prevalent, underlying fact of American life. The more we continue to resist it, the better it's going to be (as cited in Spanos, 2015).

The "realistic" form of musical communication can state the problem. The "idealistic" form can then move to proposing a solution. Frith (1996) argues that music can both express identity but create it as well. Music, in this sense, provides a figurative two-way street between music and its fans. Music goes beyond reflecting its musicians' and fans' social views and identities. It goes further by actually creating them, as well. Frith (1996) argues that music is a way of living ideals instead of only expressing them. Musical lyrics and even non-verbal aspects of it such as performance can be expressions related to identities such as gender or race. Those identities conveyed in music can be ideals that may not necessarily reflect who a listener is at the time, but they become ideals that they then want to become and identities they want to attain for themselves. Then, they work toward accomplishing that goal. Frith (1996) gave the example of people who try to make themselves look like their favorite celebrities or fictional characters.

Music gives people a real experience of what the ideal could be (Frith, 1996). People can express and lose themselves in musical participation. This process of both relating to music and realizing an identity, Frith (1996) points, out, can happen from 
being exposed to "high art" music, such as classical, as well as often-derided "low art" music like punk rock or pop. Different styles of music may produce different identities, but the process they use to form identities is the same. One example is Halestorm's "I Am the Fire", which both lyrically and with its production, demonstrate Frith's (1996) identity transition and movement of self. The lyrics of "I Am the Fire" come from the perspective of a wounded person desiring and working toward becoming powerful, despite initially questioning if this could even happen. The lyrics include:

Am I brave enough?

Am I strong enough?

...To push away my fear

To stand where I'm afraid

I am through with this

'Cause I am more than this

...I am the fire

I am burning brighter

Roaring like a storm

And I am the one I've been waiting for

...Alive and burning brighter

I am the fire (Hale, Hottinger, \& Stevens, 2015)

The band's lead guitarist Joe Hottinger pointed to both the lyrical content and

vocalist Lzzy Hale's not having any backing vocals on the song as both major

contributors to the song's message (Stocks, 2015). He said:

I think the lyric that sums up the whole song best is, "I am the one that I've been waiting for." It's the idea that nobody is holding you back except yourself. So, be the fire. If you listen to the song closely, there's no doubled vocals or harmonies or anything like that. It's all Lzzy on her own, owning it. $I$ am the fire. There is nobody else. That's the message of this song (as cited in Stocks, 2015). 


\section{Artistic communities' communication styles' literature gaps}

While musicology provides a lens as to how the arts can provide a more inclusive dialog, it remains to be seen as to how this can work in practice in public policymaking. Furthermore, it reveals another problem that needs to be solved. If administrators do use and favor the more privileged rational argument, which historically disenfranchised groups have had less ability to learn, both artistic communities and administrators alike must then work to translate a figurative language barrier (Herranz, 2015). It also begs the question of, should a "translator" be chosen, who that person or group would be.

This dissertation will examine both the problems and opportunities that artistic communities' preferred communication styles present. In this, I will work to address the literature gaps of how these styles become or could enter or at least spark policymaking. Furthermore, it will also address the gap of how to overcome language barriers between administrators utilizing rational argument and artistic communities, who like disaffected populations in general, favor artistic communication styles.

\section{Summary and Conclusion}

In this review, I have presented citizen participation's challenges and ideals, with the challenges being exceptionally dire in the face of outlaw citizenship and the current political environment. With the literature involving artistic communities' challenges and preferred communication styles, I have added both the challenges artistic communities face and their communication styles and the context of that. The institution and power theory has provided even deeper context into how society in all of these realms creates winners and losers — and keeps the winners on top. 
Through this dissertation, I will work to fill the gaps involving artistic communities' participation, particularly its hindering factors, enabling factors, and determining who participates. I will address gaps that include building dialog between disaffected citizens and the policymakers they may very well blame for their grievances, how multi-faceted power structures work as both participation barriers and how to possibly overcome them, having more citizens' viewpoints as well administrators', the effects of social media in the citizen participation sphere, and how language barriers between groups with very different communication styles can be overcome.

Furthermore, I will work to show a broader appeal of this work by filling the gap of figuring out how to engage disaffected citizens as a whole, focusing on citizens as much as I do administrators, and examining social media's new and evolving role in citizen participation in government — both its opportunities and major challenges. 


\section{CHAPTER 3: METHODOLOGY}

This chapter provides the roadmap I utilized to carry out this dissertation. The following chapter details why I undertook a qualitative study, why I selected the cities of New Orleans and Austin, and why this work is important. Following that discussion, I provide insight into my multiple, triangulated data collection methods such as performance ethnography-rooted observations and unstructured interviews and how I situated myself in the field when in situations ranging from traditional government meetings to Mardi Gras. I then demonstrate how I analyzed the data and note the multiple and sometimes extreme challenges, such as multiple natural disasters, I faced during this research period. I will conclude by noting my study's strengths and limitations and how these methods can provide a roadmap for others who seek to do research with disaffected populations.

\section{Qualitative Approach}

The research questions I utilized combined with factors involving my study population and incomplete official numerical data necessitated this all-qualitative approach.

My research questions - 1) Who among artistic communities should participate and why? 2) What factors enable and hinder artistic communities' participation in local government and how? 3) How can artistic communities overcome participation barriers? — were the main determinant. The questions namely ask "how" and "why", meaning they require the deeper explanation that qualitative methods provide (B.L. Berg \& Lune, 2012). Furthermore, previous researchers' work with both artistic communities and disaffected populations and incomplete and problematic official numerical data also 
necessitated that the work I did had to entail deeper engagement, in-person work inside communities, and taking a more holistic approach.

One method I could not use was surveys. Surveys repel disaffected populations, according to Arnstein (1969). Therefore, if I were to reach a challenging population as it was, I could not do so in a way that automatically repels them. Surveys are one of the most common methods in the "consultation" ladder rung that invites citizen input (Arnstein, 1969, p. 219). This method is a serious point of contention with disaffected populations, with citizen frustration increasing when surveys are done repeatedly, often about the same topics, and especially when none of them produce results that tangibly makes their lives better. It is perceived as "window-dressing participation" (p. 220), with one of Arnstein's (1969) interviewees stating: "Nothing ever happens with those damned questions, except the surveyor gets $\$ 3$ an hour, and my washing doesn't get done that day" (p. 219). Even though my dissertation would not be actual government participation itself, the problem is that if I were to do a survey, I would be doing what irritates disaffected populations the most and would get nowhere.

Besides avoiding methods that repelled my study population, existing numerical data was too unreliable for this population. Markusen \& Schrock (2006) note that most people in artistic communities do their art for secondary income or as an avocation. This means that they are an underground population, per se, and missed in official occupational data counts at the federal level. Both cities in this study undertook data collection methods in regards to their artistic communities (City of Austin, 2012; City of Austin, 2015; City of New Orleans, 2016), but issues such as the cities combining those working in the culinary arts or gaming industry with the artistic community population 
boundaries I chose to utilize, per the Markusen and Schrock (2006) definition, meant that I would be analyzing populations outside of my study's parameters if I used this data.

\section{Case Study City Selection and Elimination Criteria}

My two case study cities in Austin and New Orleans were excellent venues for conducting my research because they were simultaneously similar enough to avoid an "apples to oranges" comparison, per se, but had enough divergence to show a clear comparison. In this section, I will both justify my use of comparative case studies, period, but I will also justify choosing Austin and New Orleans.

Comparative case studies are both designed to examine the readily visible and the deep, contextual material lurking in the background, alike — producing a full portrait. They also allow researchers to explore the interlinkages between different actors. Context and a phenomenon under observation may not be disconnected, and case studies work to examine both (Yin, 2014). Case studies also work to show a broader story or message through a more intense focus on a single situation. For example, wealthy, predominantly white newcomers have worked to temper boisterous existing cultural practices in multiple gentrifying cities and these cultural practices are often linked to local culture and history — particularly for minorities (Fayyad, 2017). However, examining such practices more intensely in two cities produced richer results that also worked to convey that broader message.

Austin's and New Orleans' local artistic communities are both facing similar challenges, such as affordability, and are both entering — or cannot enter, in some cases — local policymaking. They are both very similar in terms of geography and political/social situations because both are in the Southern United States and states 
bordering each other. Both, especially Austin, have sharp policy and societal divergence with their more conservative region, state governments, and, since Donald Trump took office, federal government (Clark, 2017; Jarvie, 2017; O'Donoghue, 2017). This, in both cities, has resulted in major clashes with both state and federal government officials and citizens in other areas of their respective states. Austin and New Orleans were both undergoing major policy and leadership changes — on top of rapid development during this study, which gave me the ability to actually see the evolution and challenges in the urban studies literature and how that connected to artistic communities and their participation.

Although both cities' artistic communities were largely underground populations, available data did bolster my use of Austin and New Orleans as case studies. In Austin, the music, film, non-profit arts, visual arts and music-related tourism sectors had an economic output of $\$ 2.7$ billion in 2010 (City of Austin, 2012). These sectors brought in an estimated $\$ 48.1$ million in city tax revenue the same year. For New Orleans, jobs in entertainment, literary production, design, and visual arts are some of its top employers (City of New Orleans, 2016). Although, as mentioned before, official employment data does not include avocational work, both cities had some of the highest concentrations of arts and entertainment employment in the United States for larger cities outside of the major metropolises of New York and Los Angeles (City of Austin, 2012; City of New Orleans, 2016; U.S. Department of Labor, 2017).

One note I will make is that, before I got on the ground and immersed myself in both cities, I had classified Austin as a positive extreme case study and New Orleans as a negative extreme. This was based on my pre-IRB approval review of secondary sources. I 
found that neither totally fit the mold for either label when I was able to enter the field and interact with the locals. The initial review had showed that Austin's situation with its local government and artistic community was more amicable, and New Orleans' was especially fraught.

For Austin, I based this positive extreme classification on factors such as the city government presenting largely accessible participation methods targeting artistic community members, garnering extremely high responses, and work to create policy to help the artistic community based on that participation (City of Austin, 2015; City of Austin, 2016b; Dinges, 2016). An example is the Austin Music Census in 2015, a city government-initiated survey for its music community that garnered almost four thousand responses (City of Austin, 2015) that showed that the music community members were in a severe economic and affordability crisis. The city government then announced work to solve this crisis for the music community, as well as those in other disciplines (City of Austin, 2016a), with work that included city staff then recommending solutions in the later-published Music and Creative Ecosystem Stabilization Recommendations (City of Austin, 2016b). I based New Orleans' negative extreme classification based on factors such as the artistic community's long, extremely acrimonious relationship with its city government that includes citizen mistrust stemming from notorious government corruption (Daily Mail Reporter, 2013; Hoye, 2014; Karst, 2016a; Kushner, 2010; Lane, 2016; Rainey, 2016; Simerman, 2016), and fraught social tension that includes wealthy citizens' attempts to use public policy such as noise ordinances to temper longstanding entertainment neighborhoods (Beyer, 2016; Freund, 2014a, 2014b; Rainey, 2014; TimesPicayune, 2014). 
As I later discovered, though, there were some especially negative findings in Austin, such as artistic community ire over stalled city government initiatives (including ones related to the above-mentioned music survey), as well as very positive ones in New Orleans, such as certain government officials working to reverse longstanding extremely acrimonious relationships. Nonetheless, the combination of Austin and New Orleans and their extreme situations for better or worse both demonstrated what could facilitate a more amicable solution that produces meaningful results and acrimonious ones that continually erode.

Before I began this study, there was concern that New Orleans may be too exceptional of a case because of the city still reeling from Hurricane Katrina. As I found in both my secondary source review and on the ground in the city, serious issues affecting artistic communities' citizen participation were taking place long before Katrina. This included Louisiana machine politics (Karst, 2016a; Times-Picayune, 2011), racism (Personal Communication, 2017), and city police officers murdering citizens (Hoye, 2014; Mustain, 2014; Simerman, 2016). While the Katrina aftermath did permeate my findings, the New Orleans interviewees indicated that most of what they faced was very longstanding and happening before Katrina struck in 2005. Some of these dated back to eras such as slavery, the Civil War, and Prohibition.

The situation artistic communities are facing is not unique to Austin and New Orleans, and I, therefore, considered several other historically arts-oriented cities. Elimination criteria namely included too much policy and social divergence, especially with cities outside the United States. These cities included Seattle; Nashville; Toronto; Sydney; Huntington, West Virginia; and Asheville, North Carolina. One of the United 
States examples, Nashville, has a city-county consolidated government (Bucy, n.d.). Unlike most of the other U.S. cities I considered most, Seattle is working with a state government that, for example, has legalized retail marijuana and is fighting the federal government's immigration policies, and is almost as progressive as the city itself (Black, 2018; Kamb, 2018). Besides the overall social and political divergence of a city in Australia, Sydney has elements at play in artistic community's policymaking needs, like building codes, being decided at the federal level (City of Sydney, 2013) rather than the local level, like most United States cities.

\section{Data Collection Methods}

\section{Local-Level Field Research}

To successfully do this work, I also knew that I would have to be on the ground in both cities as much as possible, no matter what method I would be utilizing at the time. Jackson, Herranz, and Kabwasa-Green (2003) write that accurately documenting cultural practices and participation levels in arts and culture is a challenge, but more promising work is coming from local-level research. Typically, arts research participation levels have been measured through counting filled seats at arts-specific venues, namely at nonprofit organizations (M. Jackson, Herranz, \& Kabwasa-Green, 2003; Rushton, 2013). The result, according to M. Jackson, Herranz and Kabwasa-Green (2003) has been a major undercounting in arts participation levels because the more traditional studies miss amateur and "unincorporated" arts — art performed outside of nonprofit and for-profit arts organizations. This would include activities such as street performance. When researchers have gone into cities and neighborhoods, they have managed to find a much 
larger and much more diverse artistic community, especially among minorities and lowincome residents.

Therefore, being on the ground in Austin and New Orleans was critical, and, as I found out after obtaining IRB approval and could begin making contacts in both cities, I found out this was crucial not only because of past research but because of the study population's and the two cities' social environments. Participants in both cities, but especially in New Orleans, indicated they were frustrated with outsiders, which included academic researchers, coming into the cities, taking from them, and leaving. Actually showing the people in both cities that my intentions were sincere was absolutely necessary. Some participants in both cities insisted that any interaction take place inperson and in their respective cities. Also, as Markusen and Schrock (2006) point out, most people involved in the arts pursue their creative ventures as an avocation or secondary income and are therefore left out of official occupational data. This meant that I had to find and observe the artistic communities where and when they gathered.

\section{In-Depth Unstructured Interviews}

I conducted a total of thirty-seven in-depth unstructured interviews lasting a combined seventy-seven hours in both cities. In Austin, I conducted twenty-three, lasting a combined fifty hours, and fourteen of the same in New Orleans lasting a combined twenty-seven hours. These interviews were a critical component of the study, namely because it allowed me to hear about the situation directly from the people involved, and the unstructured format allowed me to adjust my questioning for the divergent groups and to show understanding and respect for local culture. All interviews except for one were individual interviews. The single group interview, done in New Orleans, had two people. 
Unstructured interviews allow an open exchange and allow researchers to "explore areas, cultural domains, or topics of interest in great depth without presupposing any specific responses or conclusions" (B.L. Berg \& Lune, 2012, p. 5). It should be noted that those working with unstructured formats do not come unprepared. Rather, they are encouraged to keep a written list of topics they want to be covered (B.L. Berg \& Lune, 2012). Even when dealing with complex subjects such as decibel levels in noise ordinances, I was still able to use the unstructured format.

The first consideration I made, after sampling procedures mentioned above and having an interviewee agree to participate, was interview setting. In almost all situations, I allowed the interviewee to choose the setting so that he or she was most comfortable and because several had transportation issues, so that the interview was a place that he or she could easily reach. I did exert some control, however, because I asked interviewees to please not choose locations that were extremely loud, like a live music venue during performance times, because I would not be able to pick up the interview on my voice recorder. The most common interview sites were coffee shops (ten), but interview sites ran the gamut from private offices to bars, art galleries, a hallway, sidewalks, and inside a car. I conducted ten over the phone, even when in interviewees' respective cities, when participants told me it was more convenient for them.

The unstructured format became critical because I was able to adjust my questioning and language to fit the interviewee. For example, New Orleans typically refers to its artistic community as "culture bearers", and Austin refers to its own as "creatives." I inferred that, with New Orleans, its historical traditions are considered so dear and longstanding, that a more exalted term was being used. Harry (pseudonym), a 
cultural community advocate in New Orleans, noted that certain longtime performers in the city are practically royalty in New Orleans society. For Austin, Creative Class (Florida, 2014b) policy and language is very commonplace, both from those who enthusiastically subscribe to it and deride it. Furthermore, this is likely a result of the tech industry's rise in the city and, as one city native interviewee indicated, the city's overall cultural shift when the South-by-Southwest festival began including technology along with music and film. The unstructured format allowed me to interchange the terms. Some interviewees were far more laid-back than others, particularly artistic community members in Austin and younger interviewees in both cities as opposed to current and former policymakers in both cities. I was able to adjust my language and tone to either formal or more relaxed.

My personal background as a musician, writer, and former journalist also helped during these interviews, in terms of building a positive rapport, and the unstructured format allowed for this. I also had to consider occupations and occupational lingo and demonstrate understanding of such. For example, one challenge the artistic community members, particularly musicians, faced that had a public policy link was difficulty in transporting gear, especially if it was very large. Noting that my newest acoustic guitar (widely considered one of the easier instruments to transport) weighs around twenty pounds while in its hardshell case, I was able to ask musicians in both cities who played instruments like tubas or drums about issues involving parking and, in New Orleans, severely deteriorating streets. Likewise, my being a former police beat reporter helped me relate to police and journalist interviewees, and my being a public administration scholar certainly aided me when interviewing current or former policymakers. 
Rather unexpectedly, my time as a server whose primary income was tips helped me relate to certain artistic community members more, particularly street performers. One New Orleans street poet, identified under the pseudonym "Ginny", talked about the kinship she felt with other disaffected and low-paid populations, particularly those in the service industry. This is an exchange I had with her.

Ginny: ...Minimum wage in New Orleans is, like, four bucks or something for a server. It's like three or four bucks, and everybody lives off of tips. ... ...

Amelia: I used to be a server myself. Not everybody tips. I've lived it. Ginny: Right on.

I will note that several interviewees having multiple relevant backgrounds was a major plus. For example, some in the private and nonprofit sectors were former government officials, and some government and nonprofit sector officials were former full-time artistic community members or private-sector entertainment industry professionals. Therefore, certain interviewees had multiple perspectives.

\section{Focus Group}

I conducted one focus group with New Orleans musicians during this study. The key purpose for having focus groups as part of this study was to not only garner answers for the research questions but to also witness group dynamics in the artistic communities - a key factor in how successful artistic communities will be in organizing for any participation efforts.

My group in New Orleans consisted of six brass band musicians who largely supported themselves in the tip-based cash economy. Surviving in a cash economy as self-employed artistic community members often do is a major gap in the literature involving arts and cultural policy that tends to focus more on nonprofit arts organizations. 
As I will further explain in the challenges section, finding and organizing potential focus groups was extremely difficult in both cities. However, this one group and our exchange with one another was invaluable, especially considering I had a follow-up interview the next day when I was able to make one major connection between the city's artistic community and the local bureaucracy.

The setting for this group activity, a city sidewalk in cold weather, was not exactly comfortable, but it was very conducive and important. The reason was that, as I worked to do with interviewees, I wanted to ensure all participants were in a familiar and (psychologically) comfortable place. The group participants told me, when I was thanking them for their time, that discussing policy related issues they face on city sidewalks is something they do often in their day-to-day lives. This was an exchange I had with a group member identified as Garrick, where I also gave a nod to the fact that they were also allowing me, still an outsider even though I was also a musician, into their realm.

Amelia: Thank you so much.

Garrick: We're often hanging around afterwards talking about things like this anyway (Laughter ensues among group members).

Amelia: So it's just a party that the West Virginia girl gets to join this time, right? Garrick: We're not preaching to the choir this time, so yeah!

The group exchange was also key because certain group members added valuable additional information to points others brought up. For example, the focus group members talked about transportation problems in the city, particularly the sparse to nonexistent parking and the extremely poor road conditions. The group members backed one another up. A key element that came out of the focus group was also a discussion about tribalism within the city's artistic community, on which certain group members would 
back up one another. With that backup, this added more credence to a single person's statement and having multiple focus group members back up a single topic also helped bolster some of the individual interviewees' claims.

Although I made multiple attempts, I was not successful in gathering a focus group for Austin. The main reason was the fact that neither I nor any other interviewees with pre-existing connections within the artistic community who assisted me could find any single convenient day and time that would work for a group. To make up for the resulting deficit in the number of participants, I did more individual interviews in Austin than I did in New Orleans. This let me end with twenty-three total participants for Austin and twenty-one for New Orleans, once participants in individual and group interviews and the focus group for the latter city were combined.

\section{Participant Data}

Tables 3.1 and 3.2 break down data for the interview and focus group participants in both cities that include occupations, as well as demographics such as race, gender, and educational level. Any line marked with an asterisk $(*)$ means that it is a subgroup of an above-mentioned population (i.e., musicians within the artistic community). I also made note of how long they had lived in their respective cities and relevant former or secondary roles, such as when someone had previously worked in government or also, as a secondary side job or avocation, was an artistic community member.

Table 3.1: Participants' Primary Roles

\begin{tabular}{|l|l|l|}
\hline & Austin & New Orleans \\
\hline $\begin{array}{l}\text { Artistic community } \\
\text { members (total) }\end{array}$ & 7 & 11 \\
\hline
\end{tabular}




\begin{tabular}{|l|l|l|}
\hline *Music & 5 & 8 \\
\hline *Theater/Film & 1 & 1 \\
\hline *Visual Arts & 0 & 1 \\
\hline *Writing & 0 & 1 \\
\hline *Multi-Disciplinary & 1 & 0 \\
\hline City official (Bureaucracy) & 4 & 2 \\
\hline $\begin{array}{l}\text { City official } \\
\text { (Boards/Commissions) }\end{array}$ & 2 & 0 \\
\hline City official (Elected) & 1 & 0 \\
\hline State/Federal Official & 1 & 0 \\
\hline $\begin{array}{l}\text { Private-sector arts and } \\
\text { entertainment (total) }\end{array}$ & 2 & 3 \\
\hline *Bar/Nightclub & 1 & 2 \\
\hline *Festival & 1 & 0 \\
\hline *Art Gallery & 0 & 1 \\
\hline Journalist & 2 & 0 \\
\hline Academic & 0 & 1 \\
\hline Advocate & 4 & 4 \\
\hline
\end{tabular}

Table 3.2: Participants' Noteworthy Secondary Roles

\begin{tabular}{|l|l|l|}
\hline & Austin & New Orleans \\
\hline Former government official & 3 & 0 \\
\hline Former artistic community & 3 & 0 \\
\hline $\begin{array}{l}\text { Also artistic community } \\
\text { member }\end{array}$ & 1 & 2 \\
\hline
\end{tabular}




\begin{tabular}{|l|l|l|}
\hline Also academic & 1 & 1 \\
\hline Also business owner & 1 & 1 \\
\hline
\end{tabular}

Table 3.3: Participant Gender

\begin{tabular}{|l|l|l|}
\hline & Austin & New Orleans \\
\hline Male & 10 & 11 \\
\hline Female & 13 & 9 \\
\hline No answer & 0 & 1 \\
\hline
\end{tabular}

Table 3.4: Participant Race

\begin{tabular}{|l|l|l|}
\hline & Austin & New Orleans \\
\hline White & 16 & 15 \\
\hline Black & 1 & 4 \\
\hline Hispanic/Latino & 3 & 0 \\
\hline Multi-Racial & 2 & 0 \\
\hline No answer & 1 & 2 \\
\hline
\end{tabular}

Table 3.5: Participant Age

\begin{tabular}{|l|l|l|}
\hline & Austin & New Orleans \\
\hline $18-29$ & 4 & 5 \\
\hline $30-39$ & 5 & 9 \\
\hline $40-49$ & 7 & 3 \\
\hline
\end{tabular}




\begin{tabular}{|l|l|l|}
\hline $50-59$ & 3 & 3 \\
\hline 60 or older & 2 & 1 \\
\hline No answer & 2 & 0 \\
\hline
\end{tabular}

Table 3.6: Participant Educational Level

\begin{tabular}{|l|l|l|}
\hline & Austin & New Orleans \\
\hline Some College & 0 & 5 \\
\hline Associate Degree & 1 & 1 \\
\hline Bachelor's Degree & 13 & 7 \\
\hline Master's Degree & 5 & 4 \\
\hline $\begin{array}{l}\text { Doctoral or other Terminal } \\
\text { Degree }\end{array}$ & 4 & 3 \\
\hline $\begin{array}{l}\text { No answer } \\
\text { No }\end{array}$ & 0 & 1 \\
\hline
\end{tabular}

Table 3.7: Participants' Time in Their Respective Cities

\begin{tabular}{|l|l|l|}
\hline & Austin & New Orleans \\
\hline $1-5$ years & 5 & 6 \\
\hline $6-10$ years & 3 & 3 \\
\hline $11-19$ years & 5 & 4 \\
\hline $20+$ years & 5 & 1 \\
\hline Lifelong resident & 4 & 5 \\
\hline $\begin{array}{l}\text { Non-resident with vested } \\
\text { interest }\end{array}$ & 1 & 2 \\
\hline
\end{tabular}




\section{Observations and Performance Ethnography}

My fieldwork included about 165 hours of observations, during which I took 1,473 photos and forty videos. Out of the forty-one observations I did, thirty were participant observations, nine were non-participant, and two were a mix of both. The latter emerged during situations when I would visit multiple settings, such as multiple sessions during a festival. I took field notes and wrote a narrative for each observation when finished.

Deciding what my role would be in each was very important during the observations. I adopted different roles during these observations because these were done in sharply different environments, in terms of who attended them, activities done, and behavioral expectations for anyone attending (both written and unwritten). In certain settings, particularly lively ones like concerts when the audience participates just as much as the performers (as done in subcultures like metal, punk, and hip-hop), it was appropriate that I fit in more. Being muted and off-to-the-side, as opposed to headbanging during a metal show or (badly, in my case) twerking, a rump-shaking dance style in New Orleans bounce hip-hop, would make me stand out more and disrupt the setting more because I would be looked upon as a creepy voyeur. Just as someone would be thrown out of a Shakespeare theater performance for loudly cheering, even during a swordfighting scene, a person would be viewed just as negatively for quietly and passively watching a metal show. In others, such as government meetings, it was more appropriate that I remain seated and quiet. Not doing so would literally mean I could find myself ejected from the meeting. 
During my observations, I utilized the earlier-mentioned performance ethnography (Dennis, 2009; Denzin, 1997; Marshall \& Rossman, 2011; Snyder-Young, 2010). Besides viewing all people, including the researcher, as actors in a socially constructed world, a major element is viewing all situations, artistic performance or not, as a performance and ones potentially relevant to the subject being researched.

Through these techniques, I was able to move beyond textual sources (which Snyder-Young (2010) argued could disrupt dominant hegemony and Love (2006) argued could create a fuller, more democratic discourse) and examine non-textual elements in the field. This either lead toward findings I never would have discovered otherwise, backed up other research methods, or be the findings themselves. These included but were certainly not limited to the way that government officials behaved toward citizens during meetings. In numerous situations, I had to take into account the context in which an event was happening to both determine my appropriate role, especially as to whether or not I would participate in an observation and, if so, how. In doing that, I also had to consider myself as an actor in that environment.

Snyder-Young (2010) recommends arts-based techniques such as focusing on audiences, taking "aesthetic cues" from those in a research setting, and examining "a wider range of professional performances for aesthetic inspiration" (p. 889). Such a perspective was a major element during my observations. The major aesthetic cue I found useful in this situation was non-verbal communication, and in artistic and non-artistic settings alike. Non-textual cues included behavior such as people either turning their backs toward or leaning closer to one another, tone of voice (comforting, infuriated, sarcastic, etc.) or actions like angrily slamming objects to show discontent or 
spontaneously jumping onto buckets and behaving like an evangelist while singing religious hymns to build community within an audience. The aesthetic cues also included furniture positioning, such as that in meeting rooms that indicated how level government officials and citizens were. In some locations, officials were seated behind large podiums situated above citizens' heads, indicating a more stratified and closed-off environment. At others, officials sat at the same tables as citizens, creating the opposite effect.

While I was a participant during most observations, some situations required nonparticipant observation. This was namely at government meetings, where non-muted behavior can get a person ejected, but also because this is where issues such as intense political, socioeconomic, and racial divides were especially evident and, quite often, those separated into those factions are in the same room. This was especially the case during a public hearing I attended in New Orleans. Another factor was that, given those circumstances, I did not want to appear as if I were "siding" with a particular faction especially if a particular faction member were white, like me. After I had working in both cities for some time, I was often recognized as "the researcher", given my contacts with artistic community members and public officials. If I were seen approaching people after a tense meeting and asking them if they would like to talk to me, I would be seen as being on "that side" and a member of a rival group. Therefore, I took care to not even so much as speak, during and sometimes even after meetings, except to ask someone where I could find an agenda.

As mentioned above, though, I utilized participant observations most often, particularly because several settings, like concerts or entertainment districts, were especially lively and, in many cases, audiences perform as much as performers do. If I 
were exhibiting muted behavior in a place such as a hip-hop dance club on a weekend night, not participating with others in the setting would make me stand out more. So to fit in and therefore avoid disrupting the setting by having others wonder why I was merely standing quietly and watching, I made sure to play board games with others at a game night, stood in the middle of a concert pit (an area in front of the stage with no seating, where audience members stand) rather than outside the pit or in the very back, attempted to dance along at a hip-hop performance even though I looked totally ridiculous, and exhibited other such behavior like headbanging or singing along with songs I knew that demonstrated I was "all in" and not an obvious outsider. This was especially critical in settings that did not involve huge crowds.

\section{Narrative Mapping}

I utilized mapping techniques with seventeen participants during the course of this study, and I specifically used a technique known as "narrative art". Narrative art, as Lapum, et. al. (2015) define it, is a different approach than traditional textual mapping that can include designing or constructing an art piece using techniques that include drawing. The technique emerged from both the more textual mapping methods as well as the "highly visual arts-informed research methods of photo elicitation, collage, and portraiture" (pp. 2-3). Much like performance ethnography, this method is one that can allow researchers to go beyond text analysis and have richer, more contextualized data to analyze, and it can "probe further into participants' narratives" (p. 11). Lapum, et. al., (2015) note that it is important for those who undertake visual narrative mapping is to treat it as a part of a "organic process that emerges" from a combination of researchers' data and analytic discussions. 
My plans for mapping activities during this dissertation took an unexpected turn. Originally, I had planned to only do these as a starter activity for focus groups, which would only contain artistic community members. As I will further explain, an opportunity arose to utilize narrative mapping to allow others, including those outside artistic communities, to express themselves beyond traditional narrative. That opportunity became so successful that I utilized narrative mapping at every available chance I had. I did seven mapping exercises with Austin participants and ten in New Orleans. During these exercises, I asked artistic community participants to first draw a picture of their actual relationships with their city governments. All of those who did the mapping exercise were given a box of twenty-four crayons, and, when such items were available, a pen. Once they were finished with the drawings, I asked them to explain what they drew to add confirmability to any conclusions I might draw from examining the picture on my own as Lapum, et. al. (2015) did among their research team. I would ask questions such as why certain elements were a particular color, why certain items or people were positioned higher than others, or why particular drawing elements were larger than others. I followed by asking participants to flip over the paper to draw their ideal relationships with their city governments. I then asked the same questions as I did about their depictions of actual situations. Figures 3.1 and 3.2 show certain participants drawing, with their faces not shown to protect their identities. I took these photos with the participants' permission. 
Figure 3.1: Participant Draws Narrative Map (Pridemore, 2018)

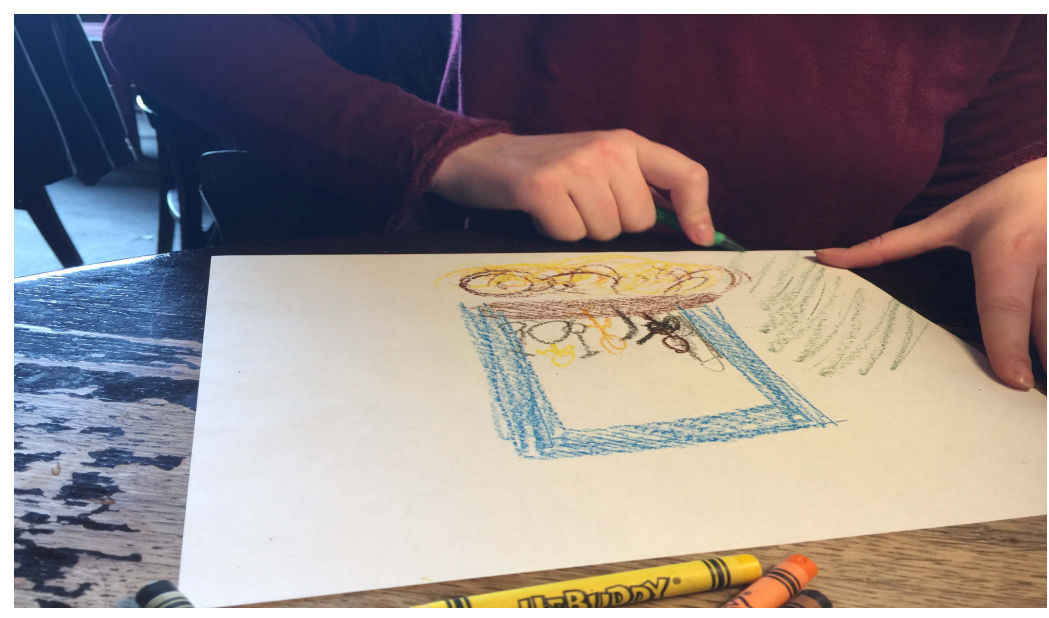

Figure 3.2: Participant Draws Narrative Map (Pridemore, 2018)

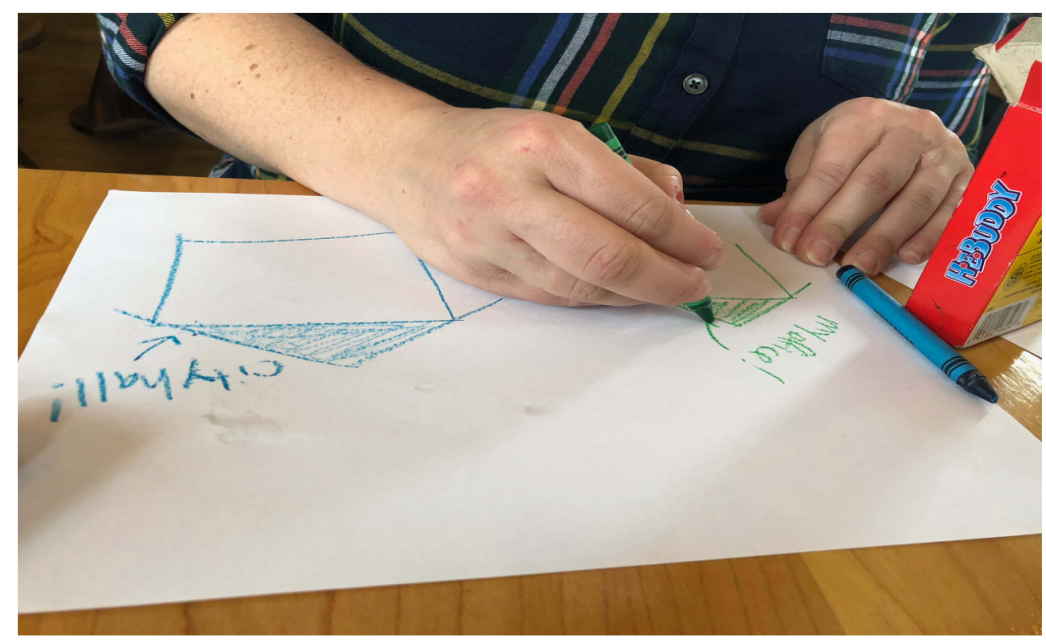

This followed both the Lapum, et. al. (2015) suggestion, as well as a performance ethnography goal (Dennis, 2009) of displaying idealized situations — what something could be, and, possibly, research that identifies solutions and not just problems. I also wanted to expand the overall dialog (Love, 2006) through allowing artistic expression to come through the findings. When I was able to do the mapping activity, I started the activity as soon as I obtained informed consent. This also gave the interviewees and focus group participants the chance to start conversations themselves and demonstrate to me 
their particular areas of concern, such as racial inequality or policies such as restrictive noise ordinances that sought to temper boisterous artistic scenes. This allowed me to build on the interviewees' and focus group participants' particular organic expertise and allow them to make their own unique contributions to this dissertation.

Acting on a hunch, I decided to expand narrative mapping's use. This happened after the focus group with New Orleans street musicians, who frequently depicted negative encounters with police. However, a few also demonstrated in the drawings that they had empathy for the police officers because they saw the police officers as ones who have to carry out orders coming directly or indirectly from wealthier and more powerful people - a common oppressor in some eyes. A few also depicted better relationships with police as their ideals.

Coincidentally, I had an interview with a New Orleans city police supervisor the following day. I mentioned some of what the focus group members had to say and some of what they drew, and Kingsley, the police supervisor, noted the he and other police officers had shared concerns with the street performers, such as the city's high murder rate. Just as I asked the street performers to do, I, to his surprise, asked Kingsley to draw his own "real" and "ideal" pictures, only showing his department's actual relationship with the artistic community and then its idealized one. Also, I noticed that he skipped the option of using a pen and utilized the crayons and multiple colors, something that some artistic community members in this study did not do. When I asked him why he did this, he told me that the different colors allowed him to convey situations and ideals that a regular pen or text would not allow — as some artistic community participants throughout the course of this study did. He noted that he appreciated the chance to do 
something that is definitely not a part of his day-to-day activities, saying, "I never thought $I$ would ever see my art published" as I was leaving.

Besides the fact that others outside the artistic communities enjoyed the mapping activity, the subset that enjoyed it the most was a surprise as well. Musicians in both cities, as a whole, adored the activity and also noted that it was very similar to their dayto-day activities. Freelance musicians in both New Orleans and Austin told me that they would frequently color their packaging for home-burned CDs of their music while waiting for gigs to start. The musicians were also the ones much more likely to utilize multiple colors in a drawing and use color to describe a situation, person, or group, such as a New Orleans musician drawing himself as green because he felt like an alien, or an Austin musician using different flesh-toned colors in her hand at the same time to depict her desire for more racial and ethnic representation. I had first believed visual artists would enjoy the activity more, but while the visual artists did not express displeasure, they were definitely not as enthusiastic as the musicians.

The main reason some participants did not get to do the mapping exercise was because their interviews were done over the phone. Therefore, they may have not had crayons or other items on hand, and I certainly did not want to create any expenses for them. Also, I would not be able to observe them drawing and ask questions while the person was present with a drawing. Other conditions included being in a space where there was no room for anyone to draw, such as when I interviewed a New Orleans musician in her car that was loaded with her gear. 


\section{Physical artifact examination}

Physical artifact examination was a major component of this study, but I will note that it became both a larger element than I had planned, and the artifacts I found myself examining were, most often, not artifacts I believed I would examine most. Yin (2014), while not dismissing their use, writes that "physical artifacts have less potential relevance in the most typical kind of case study" but when they are relevant, they can be a very important component (p. 117). For me, that was definitely the case.

My early, pre-fieldwork presumption was that I would examine artistic items such as visual art pieces and musical instruments. This presumption was not erroneous, as I did examine such relevant items. Satirical Mardi Gras floats and related parade walking groups' costumes in New Orleans were major. Doing a physical artifact examination of the floats and walking groups' costumes after following the Krewe Du Vieux parade to parking lot where it ended allowed me to spend more time examining the floats and costumes and catch valuable details participants were communicating that I would have otherwise missed by only watching from my parade view and for whatever short time they were in sight. The parade floats and costumes namely depicted the participants' (and many citizens' inside and outside the artistic community) extreme frustration with the city's pumping stations and resulting flooding and drainage problems.

However, most physical artifacts that communicated the cities' sentiments were found in merchandise and décor items like T-shirts, bumper stickers, jewelry, and personalized restaurant equipment and graffiti. The merchandise, especially massproduced ones marketed toward tourists, may seem superficial, but, especially as the findings unfolded, I found that if someone decided a sentiment was something locals so 
widely held that it was a marketable T-shirt or bumper sticker, that person may be on to something that I should consider myself. Furthermore, this was reinforced when I would see the same themes in other such merchandise and décor. A common recurring theme in Austin were items that displayed a desire to retain its local and state culture in the face of high development influxes and in-migration, and, for New Orleans, the city's survivalist attitude as it continued to recover from Hurricane Katrina.

Review of Secondary Sources

I began my research into the more contemporary issues facing artistic communities in general and especially into the situations in my case study cities through reviewing secondary sources. These included local mainstream and alternative newspapers, books on local history, reports from government agencies and arts/culture advocacy organizations, and local social media channels. I monitored all of these on an ongoing basis, especially considering the rapidly changing environments in both research sites, and, to be further explained in the challenges section, extreme events that happened in both cities during my fieldwork. The alternative newspapers, publications that are not a city's official paper of record and tend to cover edgier and less-mainstream topics, and social media channels such as Facebook groups where the two cities' artistic communities congregate were two of the best mediums for examining the contemporary issues, especially because alternative newspapers seemingly covered both cities' artistic communities more and because social media channels provided insight directly from citizens inside and outside the cities' artistic communities themselves. Likewise, they also provided insight from outside agitators who made the artistic communities situations more complex. 
For the more contextual elements, the mainstream newspapers, especially very old editions, and the local history books proved to provide the greatest insight. These included World War II-era letters to the editor and 1880s political cartoons in New Orleans newspapers that reflected the present-day attitudes artistic community members told me they still faced. The local history books provided insight into certain local eras and events, such as Austin becoming a music and "hippie" mecca in the 1970s (Long, 2010), which created the cities' arts-oriented identities and simultaneously derided and beloved gritty cultures.

\section{Reporting Back}

To aid in the study's confirmability, I reported back to all interviewees and focus group participants with a summation of my major findings via e-mail. This summation first presented the major findings for both cities, and then, specific findings for the participants' respective cities. Out of the combined forty-four participants, thirteen responded. Eight were from Austin, and five were from New Orleans. Five commented that the findings were accurate, one commented that they were "mostly accurate", and the rest could only acknowledge their receipt and thank me for sending it because their schedules did not allow them to respond back.

\section{Sampling}

I recruited participants through a combination of judgment and snowball sampling. Originally, I had planned to identify gatekeepers in both cities with judgment sampling, and continue through snowball sampling. While I still utilized snowball sampling, conditions in the field, as I will further explain below, necessitated and justified more use of judgment sampling. 
One method I utilized to begin the judgment sampling was finding social media channels where artistic communities gathered and through local media coverage of issues relating to the cities' artistic communities. The problem arose when I quickly discovered some infighting amongst people in the same subset (i.e., other artistic community members, other advocacy groups, etc.). After making a judgment call that I should talk to a given, for example, two people, I would find out that those two people as individuals and/or group members seriously disliked the other person or group. If I had only worked through a few select organizations or individuals, I would only have their allies' perspectives and perspectives that could not be applied to the cities' artistic communities as a whole. Furthermore, the infighting problem was a finding itself. Another issue was my desire to include the perspectives of historically disenfranchised groups such as racial and ethnic minorities, and representatives of emerging or smaller subcultures in both cities, such as musicians in the hip-hop, punk rock, and extreme metal genres, and I had to make judgment calls while working to find people in those groups.

Therefore, I had to utilize judgment sampling much more often than snowball sampling referrals, usually through the above-mentioned venues of social media and local news media as well as during special events and going to venues artistic communities frequent such as live music venues and art galleries. Besides having a more representative sample in the end, the judgment calls helped me reach rival groups or individuals frustrated with the rivalry and wanting to not associate with any of the groups. Such an approach also helped me learn more about the infighting problems and about the specific concerns minorities and smaller or emerging subcultures had. 


\section{Researcher's Role and Adaptations}

When entering the field into any situation, especially for interviews, focus groups, and observations, I had to consider every aspect of my own role. These included how I dressed or groomed myself, what language I would or would not use, how I would tactfully approach sensitive topics, and what aspects of my own background I would or would not reveal. This allowed me to integrate myself in local culture and build more connections, show sensitivity and respect to certain populations and the two cities, and build a more comfortable rapport with my participants.

Especially when considering that I found appearance — both dressy and more casual alike — was a major element in both negative and positive social construction, my own appearance became an even more critical piece of my fieldwork than I had imagined it would be. The key was balancing out a consideration for the different situations I was entering and avoiding being obviously fake. Both would be considered insensitive and off-putting. I documented what I was wearing — clothing, makeup, jewelry, and hairstyle — for each situation when I was in the field.

The biggest overall consideration I had to make was whether or not I would readily identify myself as a musician and writer and to what degree, followed by how casually or formally I would dress. Typically, I did not wear anything such as a small treble clef necklace I own that readily identified myself as a musician if I were interviewing people such as policymakers whose agencies had conflicts with the artistic community. I did not want to risk readily identifying myself as someone who could be viewed as an adversary. However, I would wear such jewelry or something like a band Tshirt or a Harry Potter sweater if I interviewed artistic community members to show that I 
was someone who could identify with their concerns and create a comfortable rapport. This was helpful in not only building a positive rapport with artistic community members but especially with disaffected ones who may have had reservations about trusting someone doing academic research.

How formally or casually I dressed depended more on the city, not the occasion or person. I quickly learned that in New Orleans culture, dressing especially sharp is a part of the traditional culture, with longstanding cultural community members known for wearing very stylish, matched, and bold clothing even during seemingly casual events like street performances. Given that I later found how certain artistic community members heavily decried others who were very casual, it was important to demonstrate and respect that cultural understanding in how I dressed. The situation was reversed in Austin, where I found that dressing casually and exhibiting somewhat of a "rock ' $n$ roll" look (i.e., men with long hair) is not only seen as acceptable but also preferable much of the time, given the city's historically laid-back vibe in the artistic community and how it is seen as creating gravitas and being true to oneself. Just as I did in New Orleans, I wanted to demonstrate and respect Austin's local culture, as well.

I had to consider my own role with far more than fashion while in the field, though. I also had to consider what I would or would not reveal about myself, local and/or ethnic cultural sensitivities, professions, and local lingo during field interactions in both cities. This became especially thorny when a topic was extremely sensitive but absolutely had to be addressed. For both cities, such a topic was definitely race, and I especially had to be sensitive, namely because I am white, while interviewing people who are racial and ethnic minorities. As Gooden (2014) indicates, discomfort and fear that one 
will be labeled a racist or "race-baiter" keep meaningful conversations about race from happening, which in turn, prevent meaningful solutions. I did not want to dance around a subject that was related to so many of my major findings, and I did not want to make the grave mistake of avoiding a subject for purely comfort's sake.

However, I did not want to make another grave mistake of being an outsider who automatically presumes she knows exactly what it is like to be part of another group. I had encountered this myself in the past when meeting certain (not all) scholars from outside Appalachia who specialized in Appalachian studies. I had heard their very erroneous presumptions about my homeland and had sometimes even been lectured on how they believed what I knew and personally experienced from my own homeland's culture was false. Given that experience and how raw I felt afterward, I absolutely did not want to do the same to others.

I usually broached the subject by starting with extremely broad questions or even by acknowledging that by being white, I would never truly know what it is like to be black, Hispanic, or Asian and in interviewees' respective cities. When utilizing the latter, I would tell that person that because I would never know, I especially needed him/her to tell me. Sometimes, I would relay my own above-mentioned stories to demonstrate that I have personally experienced what it is like for outside "experts" to tell me I am wrong about myself, so I could better demonstrate my intentions of having a meaningful and non-distorted conversation. One interviewee, who is black, agreed to an interview after such a conversation with me when he had initially distrusted me.

Besides dealing with the "r-word", I also had to consider the "K-word" in New Orleans. Hurricane Katrina was another very sensitive subject, especially because of the 
intense outside media coverage and derision from outsiders during the aftermath (TimesPicayune Staff, 2005) and through the city's work to recover. I handled that situation namely by not asking interviewees about Katrina unless or until they mentioned it first. This was crucial, given that multiple interviewees had very traumatic experiences from Katrina. Revelation of personal details also factored into any discussion of Katrina also because of my own time in the city during the Katrina aftermath as a military embedded reporter. I had the double risk of both bringing up a sensitive subject and that I was one of the outside news media personnel and alongside a security agency in the city during that time.

Luckily, the interviewees who I sensed would view my experience favorably did that. I usually made the call to reveal my first time in New Orleans when someone would say something like, "If you had been here in 2005..." This was especially helpful during my interview with the city police supervisor, identified by the pseudonym Kingsley, who worked in New Orleans during the aftermath too. He received me warmly at the onset, but he switched to being enthusiastic once he knew about my particular Katrina experience. He seemed to appreciate some of my gritty experiences similar to some of his own, like my having to rip a mat out of my hair with my bare hands (His response: "Now that's gangsta!"). More importantly, my mentioning that when leaving New Orleans in 2005, I had vowed to return and subsequently kept my promise further showed people I had genuine care and concern for the city and its people that was so crucial to demonstrate. I also showed knowledge of his occupation's challenges when I mentioned my time as a police beat reporter, and I noticed him leaning in closer to me when I based 
a question relating to that subject on what I witnessed while covering a police officer's murder in the line of duty. At the end of that conversation, he said:

Kingsley: I really appreciate the opportunity to have these conversations with you to kind of think through some of the things that we do but maybe don't think about why we do it. And I really want your published dissertation.

\section{Confidentiality}

All participants were given anonymity and throughout this dissertation, and they will only be identified through pseudonyms. The pseudonyms were derived from the Harry Potter series, and they were randomly assigned. No pseudonyms used match either the name of the person to whom they were assigned as well as any other participants' real names. A list of participants, identified by their pseudonyms and their occupations, is in Appendix D.

Photos were a major aspect of this dissertation's confidentiality concerns. This particular dissertation needed to have visual depictions of the situation at hand, like photos showing exactly how close high-end hotels were being built relative to preexisting outdoor live music venues in Austin. This presented a challenge because multiple participants were prominent public officials or entertainers and even if I tried to avoid taking their photos at events, the fact that both cities host large-scale events with massive crowds means that there was a chance someone could be in a picture's background, and I would not recognize it. Therefore, on all consent forms, I made sure to let participants know that I would be taking photographs for publication and that, should they be in any photos, they would not be identified as a participant. 
Furthermore, I followed media-related laws, which apply to the general public and not only press, regarding photographs, and this was a part of my approved IRB application. Photos were only taken at public events and in public places. In such places and during such events, there is no reasonable expectation of privacy, per mass communications law (Estrin, 2012). For example, if I were to go onto a person's private property and take photos of him or her inside their home, I would be violating their privacy, as well as trespassing or even committing a home invasion. But if a person has chosen to enter the public realm, such as joining in street festival and entertainment district revelry, taking their photograph while I am in the public realm myself is allowed. Therefore, taking photos that included other people who may have not been given informed consent, especially when doing so at events like Mardi Gras and South-bySouthwest where it would be physically impossible, is permissible if people are in places where there is no reasonable expectation of privacy.

Also, I have kept certain details about participants vague throughout this study. The reason is that, aside from those working in the two cities' police departments, almost all participants were either self-employed or working in organizations or divisions public, private, and nonprofit - with less than ten employees. This became even more complicated when a person was, for example, the only or only one of a few minority or female employees or that person had a very specific artistic style. Therefore, certain details regarding participants' current or former employers or artistic styles, have been omitted throughout this dissertation because of confidentiality concerns. 


\section{Data Analysis}

I utilized the computer-assisted qualitative data analysis software NVivo 11 to organize material, code data, generate themes, determine how often certain themes occurred, and draw comparisons between the two case study cities.

I merged all above-charted demographic information. I transcribed focus group and interview recordings word-for-word, with the exception being instances when I had to make edits to protect a person's confidentiality. For example, some stated very specific details about their employers or even their own names. The transcripts are identified by each person's pseudonym, city, primary role, and date of focus group or interview. I wrote out accounts of all observations, and took photographs during observations and physical artifact examinations.

\section{Coding}

I began analyzing the data through inductive coding. Inductive approaches typically use research questions to typically narrow the study's scope and also generating new theory based on data collected (Gabriel, 2013). Also, inductive coding is routinely used when exploring "new phenomena or looking at previously researched phenomena from a different perspective" (Gabriel, 2013). Given this study involved a population that previous public administration scholarship has rarely touched, a more exploratory approach was needed.

With NVivo software, I began with four nodes underneath each city that represented my research questions of who participates, factors hindering participation, factors enabling participation, and how participation barriers can be broken. Using that, I coded textual and visual data answering those questions and created child nodes 
underneath them for frequently recurring themes that represented the questions' answers. This coding procedure not only sorted the data, but through using NVivo, I was able to see how often certain themes arose and how often in one city versus another (if at all in the other). As needed, I created more child nodes to go underneath particular findings that were especially complex, such as the negative social construction finding that had many frequently occurring sub-areas like race and socioeconomic power.

During the coding, I would create memos to make notes of connections to other material, or some of the most profound statements participants made so that I would be sure to include them in the main document. I also utilized NVivo's memos to make note of key differences between Austin and New Orleans. I created word clouds for coded material I gathered in both cities for the individual cities and both cities combined to see how the cities compared to each other in terms of recurring words and compared to the data as a whole. One major NVivo coding item I relied on heavily was also NVivo's counts for references to a given code and the number of sources from which it came. I paid closer attention to the number of sources because, for example, one interviewee may bring up a certain topic much more than others. That means there would be several references but only one source count because of the references coming from a single transcript. However, if certain codes — and answers to research questions - are coming from numerous transcripts, observation accounts, and physical artifacts, that may be more widely held attitude and a more pertinent finding.

I will note, however, that I did use discretion and did not merely rely on numbers or clouds in my analysis. Certain findings may not have been mentioned more frequently than others, but they arguably carry much more weight. An example is New Orleans' 
egregious history of government corruption and misconduct, particularly within the city's police department. Given that this sordid past includes an armed standoff between a former governor's National Guard troops and city police officers (Karst, 2016a, 2016b, 2016c) and, literally, police officers murdering citizens (Hoye, 2014; Mustain, 2014; Simerman, 2016), this finding was especially significant, even though it did not occur most frequently in the computer-aided analysis.

Charts with my most frequently occurring codes are available in Appendix C.

\section{Challenges}

During the course of this dissertation, I experienced numerous anticipated challenges that were even more precarious than I had expected and several unanticipated, unusual, and extreme ones. I have indicated what the challenges were and how I handled them to the best of my ability below.

\section{Racial and social tension}

This challenge was especially evident in New Orleans, where despite the city having a majority-black population, the sample I had in the end was majority-white. This was clearly not by design. Numerous attempts to increase my sample's size and diversity, such as going to historically minority cultural spaces, did not produce many results. This turned out to be a finding for New Orleans, in the end, because interviewees, both black and white, told me about how the city's black residents have grown to seriously mistrust white outsiders and newcomers. This has been a challenge for either sincere advocacy groups or black artistic community members who have been taken advantage of by those with ill intentions. 
Interviewees pointed to a major media influx in the city during and after Katrina, with many researchers, social entrepreneurs, commercial entertainment entities such as movies and TV shows, and commercial book authors wanting to experience or take from — depending on who you ask — the city's arts and cultural community. The interviewees also pointed out that some of these outsiders have heavily distorted or exaggerated the situation in New Orleans, and one person who angrily declined my interview request told me this and the fact that she resented academic studies that compared New Orleans to other cities. Although I lost an interview, I was honest with her when I explained Austin also was included in the study because I believed it would certainly be unethical to withhold this information and deceive her in the end. While I did make some inroads in working to show my sincerity, concern for the cities, and commitment to having accurate research, I still paid for others' sins in the end.

\section{Disaffectedness and general citizen anger}

Reaching out to disaffected groups as the main purpose of one's dissertation is far easier said than done. While some disaffected citizens were pleased to hear that someone truly wanted to listen to them, others did not welcome me with open arms. Because, as I discovered through my fieldwork, the roots of disaffectedness are frequently linked to citizens being let down in the end by people who say they want to help, some citizens did not want to talk to yet another person who claimed to have sincere intentions.

Besides the above-mentioned situations in New Orleans involving longstanding racial and social tension, I encountered some reactions of, “This isn't going to help me. Nothing has helped before when I participated" in Austin. One of my findings for Austin was that artistic community members believed their government would make grand 
promises to let them down in the end with inaction. So, even though I was not a part of the local government, some believed that my research was akin to what they had seen from their government and, as a result, did not want to participate in this study, either.

\section{Weather and natural disasters}

Extreme weather wreaked havoc on this dissertation. Throughout the course of this research, multiple off-the-charts weather events struck in or near both cities and affected my research activities. The weather was especially consequential because many, if not most, of the locations where I needed to work were totally or mostly outdoors, like the Red River district live music venues. These all inhibited my ability to meet people where they normally congregated and especially as I worked to diversify my sample.

New Orleans' situation with its malfunctioning pumping stations, pumps that are designed to remove water from the below-sea-level city after rains, kept me out of the city more than once and made travel and fieldwork there precarious when I was able to go. Parts of the city were severely flooded three times in late July 2017 and early August 2017 (Brasted, 2017). Given the drainage problems and the fact that these floods struck without warning, I had to be ready to leave New Orleans at any time once I did manage to get back into the city. Thankfully, my relocation for fieldwork meant that I had a doable, eight-hour drive, but the driving that took away from field time was necessary so that I could hurry and leave if the city suddenly flooded again and not be at the mercy of an airline. The final piece of the fieldwork, the Krewe Du Vieux Mardi Gras parade, was at high risk of being abandoned because of flood warnings earlier in the evening.

Thankfully for the city's, the parade's, my own, and my dissertation's sake, the warnings were cancelled, and I was able to complete my fieldwork. 
Hurricane Harvey striking the Gulf Coast in August 2017 seriously affected my work in both cities and for almost the entire duration of the fieldwork. Austin was in grave danger of flooding, and because Harvey was expected to move east, so was New Orleans. In the very short term, the night Hurricane Harvey's outer bands bore down on my Austin home shut down a planned observation in the Red River district. While the Austin area dodged a major bullet, especially because the Colorado River that flooded farther south runs through the downtown, it still sustained a blow from Harvey in the form of gasoline shortages and shortages on some food items. I also had to cancel planned travel to New Orleans around this time because even a weaker version of Hurricane Harvey would have devastated the city because of the pumping stations, but fortunately for New Orleans, Harvey's remnants moved north of the Gulf Coast before reaching it.

Hurricane Harvey was still not done wreaking havoc on this dissertation even in October. While Austin and New Orleans were largely spared from Harvey, the route between them in areas like Houston and Texas' eastern I-10 corridor were decimated. Following another cancelled trip to New Orleans when there was a possibility even part of Hurricane Irma in September 2017 could flood the city again thanks to the pumping station problems - when the only way out was north thanks to Harvey damage to the west and Irma to the east - I thought it was finally safe to be on the ground in New Orleans again. Although all road condition reports indicated Interstate 10 was re-opened, I found myself stranded east of Houston when a piece of Harvey debris struck my car. The down time cost me a fieldwork day, and I also had to sleep in my car underneath the canopy of an abandoned gas station in Louisiana. To avoid the Harvey damage when 
going back to Austin, I had to take a two-day trip through Louisiana and Texas, during which I had to sleep in my car again beside a second abandoned building. This time, it was located somewhere in east Texas and near a cow pasture. Needless to say, this also took away valuable time in the field.

Extreme temperatures also affected the fieldwork, with my conducting research outdoors in temperatures ranging from around thirty degrees in January 2018 to at or near 110 degrees in July and August of 2017. The heat was certainly uncomfortable, but the extreme cold that happened later, complete with snow in both of my Southern research cities, was far worse in terms of it affecting my work. Red River Free Week in January 2018 was off limits because the venues are mostly outdoors, and temperatures were as low as the teens. The weather became so unseasonably cold in Austin that wild animals seeking shelter burrowed into people's walls, as a raccoon did in my own walls. New Orleans was struck with what locals called the "Deep Freeze" around that same time, with roads freezing over. Two people were killed in related car accidents during that time (Litten, 2018a).

\section{Other extreme events}

The weather was not the only extreme event during this study. Just as the Austin data collection was ending, a serial bomber struck the city. During this time, not only was the entire city on edge, but the city also experienced Russian online trolls working to stir up tensions in Austin (Herrera, 2018a) — which filtered into my findings involving social media. Furthermore, constant extreme political shifts at the national level, caused sharp reactions in both of my case study cities, such as New Orleanians having a march against white supremacy after the Summer 2017 violence at a white supremacist rally in 
Charlottesville, Virginia, and Austin activists engaging in a Christmas carol protest of the Republican tax bill in Congress in December 2017.

\section{Rapidly changing environments}

Both cities were in the midst of major changes during my study period. Although this did provide a major lesson in how cities are or are not handling social, economic, and political shifts, the overall situation shifting repeatedly through the course of this study was a serious challenge. Two major examples are the Austin city manager search and the New Orleans mayoral election.

\section{Target population's constraints}

While this was one of my major findings for this entire dissertation, the fact that the artistic communities of both cities are constantly working, taking on extra gigs or multiple jobs outside of their crafts, also hindered their ability to spend time with me. I made sure to let anyone who was interested in participating know that I was available on any day or time that worked for them, even if it were extremely early or late, and at whatever location they desired. My flexibility and ability to be that flexible was critical doing this work, but some people were in situations so dire that no amount of flexibility on my part would allow them to participate. Furthermore, other elements of some extraordinarily severe conditions the artistic community faced became a challenge. A New Orleans tap dancer I met could not break to talk because rent was due when I found him, and he had no phone on which I could call him later.

When I quickly realized just how bad the affordability situation was affecting the artistic communities, I not only worked to find out about the problem for my research produced but find ways to better accommodate those who I needed for the research 
process. One method that was much more fruitful was planning meetings with artistic community members in the middle of the month, when they are less likely to find themselves "hustling" for rent money. I had met the New Orleans tap dancer, for example, on the last day of that month. I tended to schedule meetings with others, like government officials, around the beginning or end of a given month.

\section{Explicit Language and Art}

A challenge I faced as I began transcribing and analyzing data was determining how to handle very explicit language in interview and focus group transcripts and in works of visual and performance art. With one exception, I decided to include the actual words spoken and actual images and performances shown. A major problem this dissertation repeatedly states is a problem is that people are angry and not being heard. I have made the judgment call that if I were to sanitize my study population's expression, I would be silencing them or not allowing them to express the gravity of their situations. Furthermore, because this is a population that, as a whole, is deeply opposed to any form of censorship, sanitizing would be looked upon even more unfavorably and likely seen as offensive.

The one exception, though, involved racial slurs and other epithets describing historically disenfranchised populations. One black interviewee in New Orleans and a biracial interviewee in Austin used the n-word during our conversations. This was not a purely gratuitous use because both were strongly expressing their experiences of being black in their respective cities. For example, the New Orleans interviewee used it to describe how he felt during Hurricane Katrina. However, I know that as a white writer, my using such a word in full would not be viewed the same way, even if I were relaying 
what a black person directly told me. To balance out this consideration, I put a censored version of this word and others like it in the transcripts or in any related images I used.

\section{Intoxication}

To participate in this study as an interviewee or focus group participant, one had to be given informed consent. I could not ethically obtain consent from an intoxicated person. Because I knew at least more than half of my research sites in both cities would serve alcohol and festivals were notorious for any other legal or illegal controlled substance, I had intoxication as an exclusionary criteria on my IRB application. Until I entered the field, though, I had absolutely no idea how large of a challenge intoxication would be.

Often, I would try to talk to people after performances, but some would consume some type of controlled substance before I had the chance. This happened during two failed attempts to have a focus group, for example, when one group moved to another location and began smoking marijuana and another began heavily consuming alcohol before I could ask either of them. One performer excluded himself before leaving the stage, much less before I could ask, when he shouted, "Who's drunk tonight? I'm drunk!"

To avoid the intoxication challenge as much as possible, I tried to go to as many performances or gatherings as I could during daytime and early evening hours when alcohol and marijuana are usually not consumed as much. This did certainly help. However, one visual artist had to be excluded because he removed his sunglasses to show bloodshot eyes and chugged from a concealed whiskey bottle around 3 p.m. on a busy street. I sometimes had to be more explicit in avoiding the intoxication issue, such as when I would sit closer to people to make sure I did not readily smell alcohol on their 
breath and even flat-out ask whether or not someone was sober and request that they remain that way.

These situations pointed to other serious problems both cities artistic communities are facing, as well. Interviewees in both cities, particularly health advocates, told me that substance abuse (namely alcohol) and mental health are serious problems facing the artistic communities in both cities, and these are linked to the affordability crisis and other economic and social conditions they face. On a more positive note, I witnessed some artistic community members and government officials in Austin recognizing this as a common concern that they both wanted to address.

\section{Strengths and Limitations}

\section{Strengths}

One of the major strengths that this research design had was multiple, triangulated methods. Not only did multiple methods produce richer findings, but the approach also aided in study credibility (B.L. Berg \& Lune, 2012). For example, the observation during which I saw the councilwoman turn her back to a citizen speaker pointed to repeated interview data of artistic community members saying their government does not listen. My interviewees' opportunity to report back on my findings plus my asking participants questions during the drawing exercise rather than solely interpreting the artwork on my own adds to confirmability. Also, the unstructured format allowed for follow-up questions, which aids confirmability, because that gave me the chance to clarify anything that may have not been clear or, when interviewees revealed seriously negative or surreal situations, be absolutely certain of what is being said. 
Although there were serious challenges, the qualitative approach was a major strength in that it let me access an underground population and one whose story is obscured in most official data sets. Those data sets are also problematic in some regards, too. I also would have never been able to reach a disaffected population had I undertaken methods like surveys because the artistic community members who talked to me really wanted someone to listen rather than simply hand them a sheet of paper. Some explicitly expressed frustration about surveys.

My personal background as a longtime musician and writer is a major strength that informs this study, but as I found out, other aspects of my background I did not believe would be as relevant were certainly that. This includes my time in the service industry as a tipped employee, my time as a police beat reporter, my witnessing some scholars distorting my homeland's story, and my military embed experience in New Orleans during the Hurricane Katrina aftermath. While I had to be very choosy as to what I revealed, to whom, and to what extent, I found that I had multiple ways of reaching different groups and showing them that while our experiences may not be identical, but they may have common ground.

I believe such an approach would be critical in any situation where a researcher is working to build a trusting relationship with a disaffected population. Saying, "I totally get it," and with no evidence will make people angry. Saying, "You're right. I don't totally get it. But through this experience, I can at least get an idea of where you're coming from. Please tell me more," is a much better approach. Given how this study brings light to attention disaffected citizens as a whole have and provides methods for 
making inroads with disaffected citizens that scholarship has missed and needs to include makes it very transferable.

The Austin/New Orleans combination's strength went beyond the fact that the two are historically arts-oriented cities with affordability crises. I found that as the situation at the federal level unfolded, this two-city combination provided a look at local government resiliency and resistance during deeply uncertain times. Both also have sharp policy and social differences as opposed to their states, region, and federal administration and both local governments are fighting to hold firm, whether the issue is banning plastic bags or protecting undocumented immigrants. This adds to the study's transferability, as well.

Although, as I will further describe in the limitations section, I ended with a majority-white sample in both cities, my use of more judgment sampling helped me have a final sample that had multi-faceted viewpoints, have representation from certain underrepresented groups, and, most importantly, avoid an extremely unrepresentative sample that only included a particular person's or group's allies. This was critical given the problems with infighting in some circles.

\section{Limitations}

The largest limitation this study has is the majority-white sample, particularly in New Orleans. While I have worked to make sure issues involving race are definitely represented, even if I had to pull from secondary sources more than I had planned, the participant sample not reflecting the New Orleans population is a limitation.

A limitation I expected — but had no idea what the extent would be — was the shifting situations in both cities. I knew both were on the verge of major policy and social 
changes. However, I did not anticipate events such as ones like New Orleans' repeated pumping station-related flooding, the 2017 hurricane season, and the Austin serial bombings. I handled this through setting firm cutoff times for data collection — Mardi Gras 2018 for New Orleans and South-by-Southwest 2018 in Austin — because there were simply no other natural stopping points. This meant cutting off data collection when New Orleans was in a mayoral transition and strippers had begun protesting city government actions (with artistic community members as allies, in some instances) and Austin had at last hired a city manager, who became part of the team responding to the serial bombings. The cities are still changing rapidly as of this writing — but this dissertation had to be written.

Another limitation is that the study only has two case study sites. While the combination of New Orleans and Austin was a strong one, they are still only two American cities. Furthermore, my comparing apples to other apples begs the question of, "What about the oranges?" Similar research should be done in other arts-oriented cities experiencing the same crises as Austin and New Orleans and also take some of their own unique aspects into account, as well.

\section{Summary}

This chapter has provided an overview of how I conducted this qualitative comparative case study dissertation. Through multiple, triangulated methods, paying attention to local cultural cues, and through utilizing my own organic knowledge, I was able to produce a dissertation that reached a group public administration scholarship has not reached. Furthermore, this work has shown serious transferability potential, especially as the public administration practice and academic discipline enter very 
uncertain times and largely because administrators are feeling citizens' wrath so much more.

My dissertation's fieldwork threw me numerous challenges, some of which I could have never expected. I believe a key contribution this dissertation will have, along with the results it has produced, are lessons for future researchers who will want to reach not only artistic communities, but disaffected populations as a whole.

Doing such research can be an outright minefield, and if one is not careful, the most well-intentioned and well-designed research proposal can be destroyed. Even if one presumes that a disaffected citizen will be pleased to tell someone about his or her grievances, that does not mean a disaffected citizen will be willing to do so with an academic researcher - someone who could be perceived as disconnected or elitist and possibly because of negative encounters with not only previous researchers, but also government officials, entertainment outlets, and the news media. Approaching disaffected citizens takes serious cultural sensitivity — to not only demographic issues such as race and income levels, but also to ones involving occupations, subcultures such as artistic genres, and overall local context. One must learn and pay attention to cultural and social cues as research progresses and take these cues into account even when deciding what to wear, how to speak, and where to meet. If these factors are not taken into account and researchers are inflexible both when entering and progressing through the field, they will fail.

Even though the work is difficult, it is not impossible. The keys are flexibility, listening, and creative problem-solving skills. If challenges are recognized early, then researchers can determine what cannot be changed and what can — and devise solutions 
to get past the latter. When encountering any mistrust, researchers can find out what their study populations' concerns are and adjust as much as possible. Researchers must also be more than willing to step outside of academia's or at least their own disciplines' traditional boxes. Through taking such steps, all researchers can eventually begin to reach populations they may have never reached before and produce a fuller picture of how their disciplines reflect and affect society as a whole. 


\section{CHAPTER 4: NEW ORLEANS' PARTICIPATION HINDERING FACTORS}

An especially egregious corruption history, unequal and often-sinister power structures, vexing and ambiguous public policy, and divisions among the artistic community members are just the tip of the iceberg when it comes to factors hindering New Orleans' artistic community's participation in its local government. In this chapter, I explore findings for this case that I classified as a negative extreme at this dissertation's onset.

Multiple findings in this chapter both address literature gaps and present challenges to conventional scholarship. First, it does address the challenges artistic communities face in local government participation and demonstrates how they have utilized artistic communication styles in policy debates. It also demonstrates how multidimensional power structures and exercises, particularly the Second Face works to have powerholders manipulate situations to work in their favor over a less powerful group and with that less powerful group knowing who is responsible (Bachrach \& Baratz, 1962; Warner, 2001; Warner, 2011). These were not surprises, given that examining artistic communities' participation was my overall goal at the onset and my pre-fieldwork secondary source reviews pointed to Second Face of Power exercises in New Orleans policymaking (Freund, 2014a, 2014b; Webster, 2014a, 2014b).

Somewhat unexpected findings, though, had a broader appeal and provided challenges to elements of public administration scholarship's canon and conventions. Existing literature has addressed trust issues when political and social conflict and corruption have been atrocious, but almost none of these empirical studies have used an extreme case in the United States (Pridemore, N.E. Ganapati, \& Revell, 2019). This 
presents a likely flipside to not only public administration scholarship, but also some notions of American exceptionalism. This case takes into account the impact of not only tension between citizens and governments, but also more about how any citizen in-group tension and infighting ultimately affect participation and policy outcomes. It shows the impact of citizens' economic pressures on having a constructive dialog with government and on government outreach activities. In regards to non-traditional participation's hindering factors, most previous studies have pointed to activities that create public backlash, such as hate speech and violence (Pridemore, 2018; Rimmerman, 2011). In this chapter, I will show how another hindering factor is that, when citizens believe no positive change happens from traditional and non-traditional participation, alike, they become demoralized and less likely to participate in both traditional and non-traditional forums again.

The chapter's structure is as follows. First, I will discuss traditional citizen participation barriers, which include factors relating to public officials such as the city's hyper-political environment and wealthy citizens' greater access to officials and greater influence on policymaking. Next, I will discuss institutional-related factors that namely include pushes to both utilize outdated and troublesome public policy or change those policies to make them more restrictive and quell boisterous entertainment neighborhoods and cultural practices. Place-related barriers will come afterward, with discussion about hindering factors related to the city's infrastructure and flooding and transportation problems. Following that, I will present hindering factors related to other community stakeholders, namely powerful business interests, who pressure artistic community members to stay silent or face retribution. 
I will then proceed with presenting factors related to artistic communities themselves, namely their lack of trust in the local government because of its corruption history and their continued trauma and heated dialog after Hurricane Katrina. I will also include a discussion about in-group hindering factors such as infighting and tribalism. Then, I will present hindering factors for non-traditional outlaw citizenship, namely in that people who engage in it all for no change to occur in the end find their efforts to be futile before concluding.

\section{Barriers to Traditional Participation}

Numerous factors related to traditional citizen participation, such as public hearings, created citizen participation barriers for New Orleans' artistic community. Through my interviews and focus groups, I discovered that artistic community members and their advocates found traditional participation outlets practically useless, with material namely from my observations and secondary source reviews backing up their claims. Even some members of the city bureaucracy saw major problems involving traditional citizen participation forums.

Barriers included ones related to public officials, which included the city's hyperpolitical environment and an especially long transition period, public officials' collaborations with the city's wealthy and elite that included crafting and deciding on public policy at private gatherings, and negative social construction of certain artistic community members. Formal participation mechanisms presented problems with extremely long meetings scheduled at inconvenient times, artistic communities' work schedules related to the affordability crisis keeping them from attending these meetings, 
and a general dissatisfaction with the traditional mechanisms when artistic communities can make it to and speak at these forums.

\section{Hyper-Political Environment}

New Orleans politics was a major hindering factor not only in terms of its history of government corruption. Historically and in the present-day, the city is very hyperpolitical. The political environment's effects were namely a trickle-down to the artistic community, but even then, its effects, real and potential, were significant.

How this namely translated into hindering factors for the artistic community's participation was that the extremely high political influence and pressure on the bureaucracy, such as a greater ability for and greater likelihood of major personnel changes and even eliminating certain offices meant that this had the potential to alter or even end relationships street-level bureaucrats or mid-level management had built with the artistic community and other disaffected groups. It also meant that needed policy overhauls, namely revisions for the problematic sixty-year-old noise ordinance, were stalled because elected officials did not want to make major changes before an election. What made this situation even worse during the study period is that the mayoral and city council elections that took place during this time had an extremely long, six-month transition period between the election and the new mayor and council taking office.

Its direct effects though, namely involved an artistic community who did not want to get involved in what they saw as outright deranged environment and who was left in a long limbo, questioning how their relationships would change through the long transition. 


\section{Background: Nuances of the 2017 Election and Transition}

One of the most relevant features of the New Orleans city elections during this study period was the six-month time frame between the times its current mayor, LaToya Cantrell, was elected and took office, making for an exceptionally long transition. The reason for this was, in 2013, the League of Women Voters successfully lobbied Louisiana's state legislature to move elections for parishes with more than 300,000 people from early winter to fall to line up elections with statewide races (Litten, 2017e). Before that was changed, Orleans Parish voters cast ballots during Mardi Gras season. New Orleans city voters approved a charter change in 2014 to move the mayoral and city council inauguration dates closer to the new election dates. However, those changes were not slated to take effect until 2022, leaving 2018 as the "odd year out" (as cited in Litten, 2017e) when it would take six months for the newly elected mayor and council to take office. This also came at a time when the city would definitely have a new mayor because then-Mayor Mitch Landrieu was term-limited.

The October 2017 primary election with eighteen mayoral candidates did not produce a winner with fifty percent or more of the vote, meaning that the top two candidates, Cantrell, a city councilwoman at the time, and Desiree Charbonnet, a former judge, moved to a runoff election in November 2017 (Litten, 2017d). The primary election alone made history because it guaranteed the city would have its first female mayor in its 300-year history, and Cantrell emerged victorious.

Furthermore, because more positions and even some entire offices were directly or indirectly subject to political whims, that meant work being done and relationships being built were in limbo. Adding the six-month transition period meant that, even after 
New Orleans knew who would be in its new government — also after council elections that were replacing five of seven council seats - no one knew what the new government would do and how it would affect those relationships, work, and any needed policy changes for just short of half a year.

To make matters stay in limbo indefinitely, allegations emerged that Cantrell improperly used a city credit card during her time as a councilwoman (Rainey, 2017f). A related investigation and the overall controversy then became tied to other state and local political figures that included Louisiana Attorney General Jeff Landry, who had seriously battled New Orleans city leaders just months before (to be explained in a later section). Landry was given the task of the credit card investigation (LaRose, 2018b; O'Donoghue, 2017; Rainey, 2017f). This meant that some of my corruption history-weary participants wondered how long Cantrell would be in office or if she would even take office at all while that long transition was taking place.

My participants informed me, though, that elections and electoral politics in New Orleans were already problematic, even without this one election with an exceptionally long transition, for both the artistic community and those in the bureaucracy who were working to build or repair relationships with them. Even the potential of a special election, much less a scheduled one where a new mayor was a guarantee, meant that elected officials would not take action on needed major policy changes and those in the bureaucracy and artistic community both found themselves dealing with especially problematic policies, like the noise ordinance. 


\section{Bureaucracy/Artistic Community's Relationships and Long Transition}

The key impact the New Orleans city elections and long transition period had on the artistic community, advocates, and bureaucracy members building relationships with them was the potential to alter or even sever relationships they had built or had made inroads in repairing and the transition keeping them all guessing for six months as to whether or not this would happen.

Kingsley, a New Orleans Police Department supervisor, held law enforcement civil service protection for his job and related civil service rank, but his specific leadership role was one of several in NOPD that was an appointed one. He and the others held the position at the will and pleasure of the department's superintendent, who serves at the will and pleasure of the elected mayor. Olympia, an employee in the city's health department, had civil service protection, but her department's director was in an appointed position, which he had only held for a short time period before the transition began. Uncertainty during the long transition was already affecting the department's work - and she and others who had worked on programs such as Sound Check that made inroads with the artistic community may leave.

Olympia: There's a lot of uncertainty, and I will say that I have not decided whether or not I will stay for the transition. I may choose to leave depending on who Cantrell brings in. So the long period is nice because you can start applying for jobs and have plenty of time to make that transition. However, it also means that a lot of people are leaving, and instead of filling those positions, people are just given more duties.

This came at a time when the health department's responsibilities were also becoming more urgent and priorities were having to shift, Olympia said, namely because of the opioid epidemic reaching New Orleans, with opioid emergency response calls for 
2017 anticipated to double 2016's. Sound-related issues were not being outright abandoned, but the spike in opioid responsibilities combined with the stalled problematic noise ordinance and long transition meant that they were largely on hold.

Relationships being in limbo, Harry, an artistic community advocate, said, provided potential problems and opportunities, but no one would know what any of those were for months. One measure he was taking was, after at least knowing the election results, contacting incoming elected officials and working to build relationships with them in advance.

Harry: So there is a great chance that some of our connections will be gone. We've built a good relationship with the Eighth District (of NOPD). That's the French Quarter, Marigny - where the bulk of the street performance is. So, we're hoping that the people who are in place there stay, but who knows? We're working under the thought that everything changes in May. ... For us, it's relationship building and making sure we're in when they transition. It's also a period of opportunity that we can get things moving and get things on board. The incoming mayor is someone with whom we have a relationship already. Hopefully, that's helpful.

For the rest... We'll find out. There's nothing we can really do but hope for the best and try to make sure we're in a position where, whatever happens, we still have our relationships, institutionally, as much as possible.

Harry also noted the city's Office of Cultural Economy, itself, was in limbo after the election and also during the entire study period. The problem was that, even before the election, artistic community members I interviewed knew little to nothing about what the office even did. The Mayor's Office of Cultural Economy, according to its official website, has a mission of creating economic and entrepreneurial activities for the artistic community that will benefit the city's residents as a whole (City of New Orleans, 2018c). Landrieu created the office as a mayoral initiative situated under the umbrella of his 
office. Being that it was a political initiative, Landrieu or any mayor who came after him had the authority to shut down the office.

Some street performers I interviewed told me they believed the cultural economy office may have been involved in having wrongly issued citations against them dismissed, but that they largely dealt with a local nonprofit organization in that. However, Michael, a longtime musician, and Rolanda, an art gallery owner who had experience in public arts funding, had no idea what the office even did, despite both attempting to find out. Michael said:

Michael: Nobody knows. I'm not being crass in saying this. Nobody does. I'm up here, and I don't know. What do you think the dude at the corner of Royal and Conti knows? ... I can't even tell you what it is that they do other than put out brochures every six months talking about how many people are employed with the cultural community. I don't know where they get their numbers. I've been trying to figure it out since 2011. I can't tell you to this day.

Harry said that the cultural economy office is likely behind some situations for the artistic community not being worse than what they already are. It is just that because the office, in his opinion, needs to do more public outreach, not many people actually see any positive work they have done. However, a single new mayor can stop whatever that work may be. (Note: Cantrell kept the cultural economy office after the transition.)

Although he had anonymity, Kingsley chose not to fully discuss the political situation, given that the specific civil service law by which he must abide forbids open political activity and discussion, and he wanted to abide by those standards, regardless. However, the long transition still left certain things in question, namely whether or not he and others would stay in their positions. The only things he could do besides wait was prepare for another person to possibly take his position and, if and when that happened, 
work with his replacement and encourage his replacement to maintain relationships he had built with the artistic community and build a dialog as early as possible.

Kingsley: If I'm replaced and my staff is replaced, then I would say I would do everything I could to help the new people coming in to maintain those relationships and to give them guidance as to who they should reach out to.... I think it might be just too early because the new administration needs to be in place to give them new mission-based decisions. They don't make a decision on police chief on Day One. There's so much going on until all of that is settled. I can't tell you what the transition will look like, but whatever it is, I'll work to help whoever comes after me. We could certainly be left here to do the work that we're doing. But if somebody takes over that, I'll do what the person who had my position before me did, which is tell me who's involved in outreach and encourage building relationships that we've had there.

\section{Politically charged environment}

Even without the problem that the 2017 election's long transition period created, New Orleans being especially hyper-political regardless of the situation was still a major problem. These problems included needed policy overhauls being stalled because of political vulnerability (real or perceived), citizens or bureaucracy members dealing with the effects of political feuds (particularly between Louisiana state and New Orleans city government officials), multiple controversies becoming intertwined to make all situations worse and some elected officials' or more powerful citizens' pressures on the bureaucracy. All of this left important work stalled or made citizens far less willing to work with their local government, even with the civil service employees, because they did not want to be involved in something they saw as chaotic.

In an interview before the election took place, Olympia said the reason why the noise ordinance had been stalled was not only the (somewhat) regularly scheduled election, but, before the 2016 presidential election was decided, Landrieu was rumored to 
be on Hillary Clinton's shortlist for a cabinet position. Should Clinton have won and Landrieu been appointed, this would have triggered a special election. This was also during ongoing controversies involving the city's strip clubs. This left the problematic sixty-year-old ordinance in place when, although proposed remedies varied wildly, practically no one wanted it, the bureaucracy could not enforce it, and the artistic community and business owners could not truly look toward it for guidance in staying within the law. I mentioned my working to sort through at least two proposed noise ordinance documents, and Olympia said, "Neither of those will pass."

Olympia: When council first gave us this money to start (Sound Check), we were told, "You start this project, bring us your ideas, and then we'll re-pass this ordinance." But then the stripper ordinance came up, and you can't do two controversial things in the French Quarter back-to-back. And then the election... ... Things were put on hold, and they are still on hold. So at this point, no one wants to address the sound issue because it's controversial.

Olympia provided multiple examples of how someone in the city's bureaucracy who is doing a job in public service and is working to do so based on evidence, such as decibel levels deemed safe and unsafe in empirical studies, and not political belief has to do so in hyper-political climates, both in dealing with elected officials and with those mentioned earlier who have (or want) power and money.

Olympia: It's extremely difficult. That is my goal. It is still my goal. The daily fights... And it's a fight within city hall.

...So, for example, there's talk about how this noise stuff relates to the crime on Bourbon Street. We've seen a rise in shootings this year. ... It came up like, "If you could just, if we could keep the noise down and then if you couldn't hear it on the street, people wouldn't be hanging out on the streets, and they'd be inside venues, and you'd have less crime." I don't know why that would mean less crime, but other things will get thrown in there or people will say, "Well, I just don't like their music, and this is impacting me because I'm annoyed by that. This is my quality of life. And I say, "But I'm the health department." 
...It's a fight within when I meet with the mayor's office or meet with other people to say, "Wait, but I'm the health department." There's a lot of, "Well, are you addressing these pieces?" And I say, "No, that has nothing to do with health. If you want that addressed, talk to a different department."

When first introducing Sound Check, she and other health department personnel unveiled it first to representatives of three groups likely to be affected most — musicians, residents living near entertainment venues, and business owners - and in three separate meetings before it was announced to the public at-large. The meetings with the musicians and residents went well, and they were very constructive. That was not the case with the business representatives who "were coming in, cussing us out, and leaving." The business owners took great offense to the fact that their meeting was the last of the three when the meetings' order was simply a scheduling matter, not one of preference. She explained:

Olympia: Clearly, they felt, we didn't want to hear from them because we waited, and that was their attitude. Their attitude was, "You're just going to listen to the musicians and residents when we're actually the ones that you should be listening to because we pay more taxes than them, and we're what keeps your city's tourism economy going.

...So honestly, what they believed was that because they bring in more tax revenue for the city, they should get whatever they want. And I just said that may work in the mayor's office, but that doesn't work in the health department. So that's part of the problem.

While some interviewees indicated new leadership was needed to create positive change in New Orleans, Lavender, an artistic community advocate, disagreed. Lavender pointed to the street-level bureaucrats in the city who she (and other interviewees) believed were the ones best suited for building or rebuilding constructive relationships, 
saying, "We need to support the mid-level staffers who dedicate their lives to making things better."

\section{Public-Elite Collaboration}

While the artistic community faced severe economic pressures that hindered their participation, those who fought to silence them had a major wealth advantage. Artistic community members, venue owners, and advocates informed me that those who advocated for measures such as stricter noise ordinances, street performer curfews, and venue restrictions had enough money that they could easily defeat much poorer artistic community members or small, neighborhood venues in policy debates and legal challenges - even when the numbers of artistic community members and their supporters fighting them were higher. Sometimes, the artistic community members and their supporters had a difficult fight even when an opponent was just one wealthy person. This became even worse when wealthy elites would meet with public officials at private gatherings, where policy was created and/or decided on before public meetings that lessprivileged artistic communities and their allies could only try to fight policies that have major negative effects on them when decisions were already made.

The issue of elite/public collaboration mirrored previous scholarship involving multi-dimensional power. These situations operated like the Second Face of Power (Bachrach \& Baratz, 1962; Warner, 2001; Warner, 2011), specifically, in that powerholders who do not and, in this case, cannot actually give observable orders but

manipulate a situation to make themselves victorious over those with less power - and that the less powerful who feel the effects clearly know who is behind it. 
Multiple interviewees, secondary source reviews, and focus group participants pointed to opponents who have had serious wealth advantages that have tipped policy debates in their favor, such as when they have had the means to hire high-profile attorneys or public relations firms (Freund, 2014a, 2014b; Webster, 2014a, 2014b, 2014c). Observations, physical artifact examinations, and secondary source reviews backed up statements involving what interviewees and focus group participants told me about wealth and the desire for more that creates an extremely unequal power structure.

Two examples interviewees and focus group participants provided include attorney Stuart Smith and businessman Sidney Torres, wealthy and powerful individuals they believed had undue and questionable influence on city government and in public policy debates. Smith, whose profile includes a $\$ 1$ billion judgment against Exxon Mobil in 2001 (UPI, 2001), supported controversial noise ordinance revisions that sparked the January 2014 brass band protest. The first proposal was withdrawn two days after the protest (Freund, 2014a, 2014b; Webster, 2014a). During the controversy, Smith was accused of trying to intimidate two public officials (Freund, 2014a, 2014b; Webster, 2014c). He pled guilty to a misdemeanor cyberstalking charge in September 2014 after sending a threatening text message to a Bourbon Street business owner and state public official for supporting a second compromise ordinance, which also failed in January 2014 after a tie vote from city council (Freund, 2014a, 2014b).

Before the noise ordinance that sparked the brass band protest was withdrawn, Smith also sent an email to then-Councilwoman Kristin Gisleson Palmer (Palmer was again elected to council during the fieldwork period, but she had not yet taken office before the fieldwork concluded.) that, according to a statement from Palmer, "appeared 
... to be an improper attempt to influence my vote on sound legislation" (as cited in

Webster, 2014c). The e-mail from Smith to Palmer, which Palmer said was "bulls---“ in an emailed response to him (as cited in Webster, 2014c) reads:

If any of this is true, you won't be electable as a dog catcher by the time I am finished with you. I really can't believe it but now have 2 investigators [sic] on it and intend to depose (the business owner and state official) under oath. I sincerely hope none of this is true. You only promised me one thing when (another local business figure) and I got you elected. I expect you to stop these people who are attacking me personally and pass this legislation. Your victory party was at my house for Christ's sake, and after all that, a strip club owner has become your confidant and spokesperson (as cited in Webster, 2014c).

Torres, though, was the figure interviewees and focus group participants brought up most often. Torres' influence and involvement in city politics and municipal services were ones interviewees and focus group participants found dubious, at best. Torres, a multi-millionaire with a CNBC reality show, rose to prominence as a "celebrity trash king" (as cited in Larino, 2016) after bringing trash services back to New Orleans after Katrina (Larino, 2016; LaRose, 2018c). Some interviewees and focus group participants were incensed about his impact on the artistic community's activities that included suing a local live music venue for disturbing him and then opening an entertainment venue of his own that amassed neighborhood complaints (Litten, 2017f; Personal Communication, 2017). Torres also provided financial backing - $\$ 300,000$ in 2015 and another $\$ 100,000$ in 2016 - for the French Quarter Task Force, which is an off-duty security patrol of city police officers (Bullington, 2015; Bullington, 2016). Using Torres as an example, Michael, a musician, pointed to issues of both wealthy elites' influence and power and those elites' questionable relationships with government officials. He explained: 
Michael: Sidney is another example of someone who was a multi-millionaire, comes from old money, became another millionaire on top of the millions he already had thanks to city government who gave him... The guy never dealt with sanitation services before, and he suddenly winds up with multi-, multi-milliondollar contracts for the city. I remember, after Katrina, I was like, "Damn, why didn't anyone call me and ask me if I could submit a bid, even though I've never been a damn garbage man before? I could buy a truck too." That didn't just happen. His grandmother is the richest white woman in Chalmette. His father is the richest white man in Chalmette.

...He made millions off the city. Then, he went and bought little police cars and scooters for the police department. He funded cars for NOPD, specifically for the French Quarter. ... That's money and power. Do you think I can go to the police department and say, "You know what? I want to buy you fifteen scooters," and just walk away from it? I have to have some power. I'm going to get something out of that. Money and power are the ghosts of New Orleans. The old money ain't going to go nowhere that old money can't control it.

...You think of the advocacy of the musical and cultural community. We can have all of the ideas we want. We know what we need for our community support and economic support in developing our cultural economy. But if you've got folks who've got money, they're going to get their way. That's just New Orleans. It's probably that way in any city. When money talks, bullshit walks.

Krewe Du Vieux floats in 2018 repeatedly invoked the constant problems with the city's pumping stations that have repeatedly flooded the city (to be discussed in further detail in a following section), and that citizens' viewed the city as only concerned with money and power, not helping its citizens. With one float depicting Landrieu as a stripper with cash in his underwear sitting atop a pump — on a float called "Mitchey's Sewer and Water Whores". The float was covered with dollar bills and with walking groups dressed as pimps with dollar bill signs, and the accompanying band played the 1980s pop song "I Want Candy" to further communicate the view that the city government only wanted money. Another float showed miserable citizens in floodwaters, while cash flowed from 
the top of the float. Photos of the floats and walking group are displayed in Figures 4.1, 4.2, and 4.3.

Figure 4.1: Krewe Du Vieux float, mayor as stripper (Pridemore, 2018)

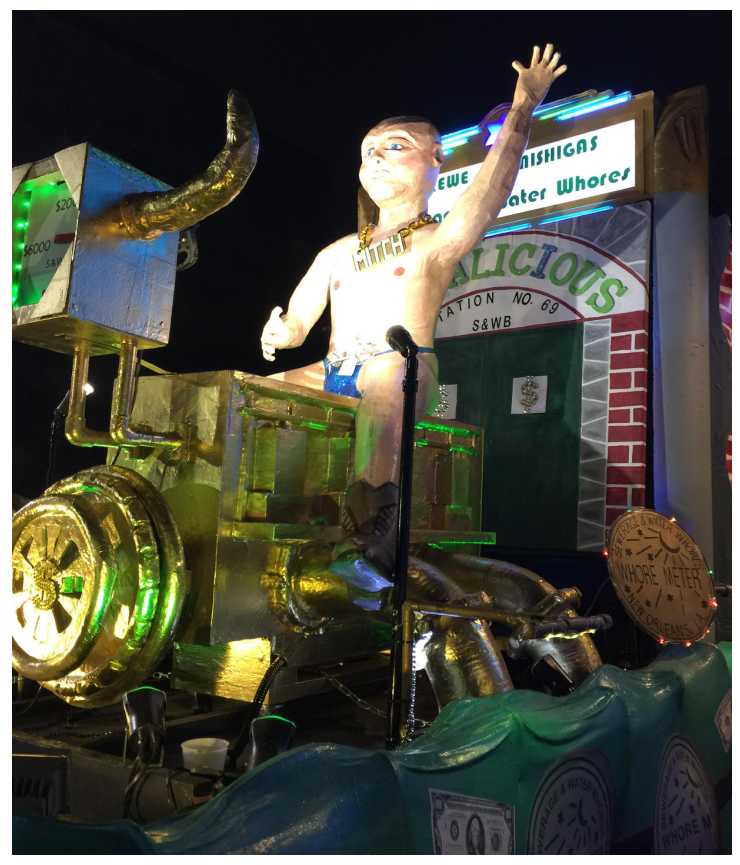

Figure 4.2: Krewe Du Vieux pimp walking group (DeMocker, 2018a)

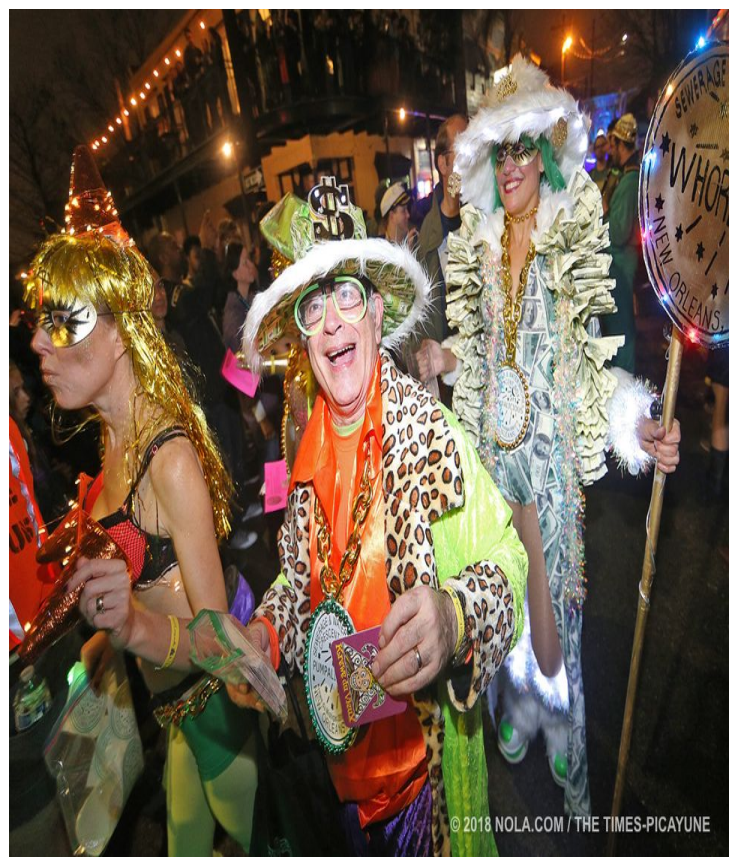


Figure 4.3: Krewe Du Vieux float, people in floodwater (Pridemore, 2018)

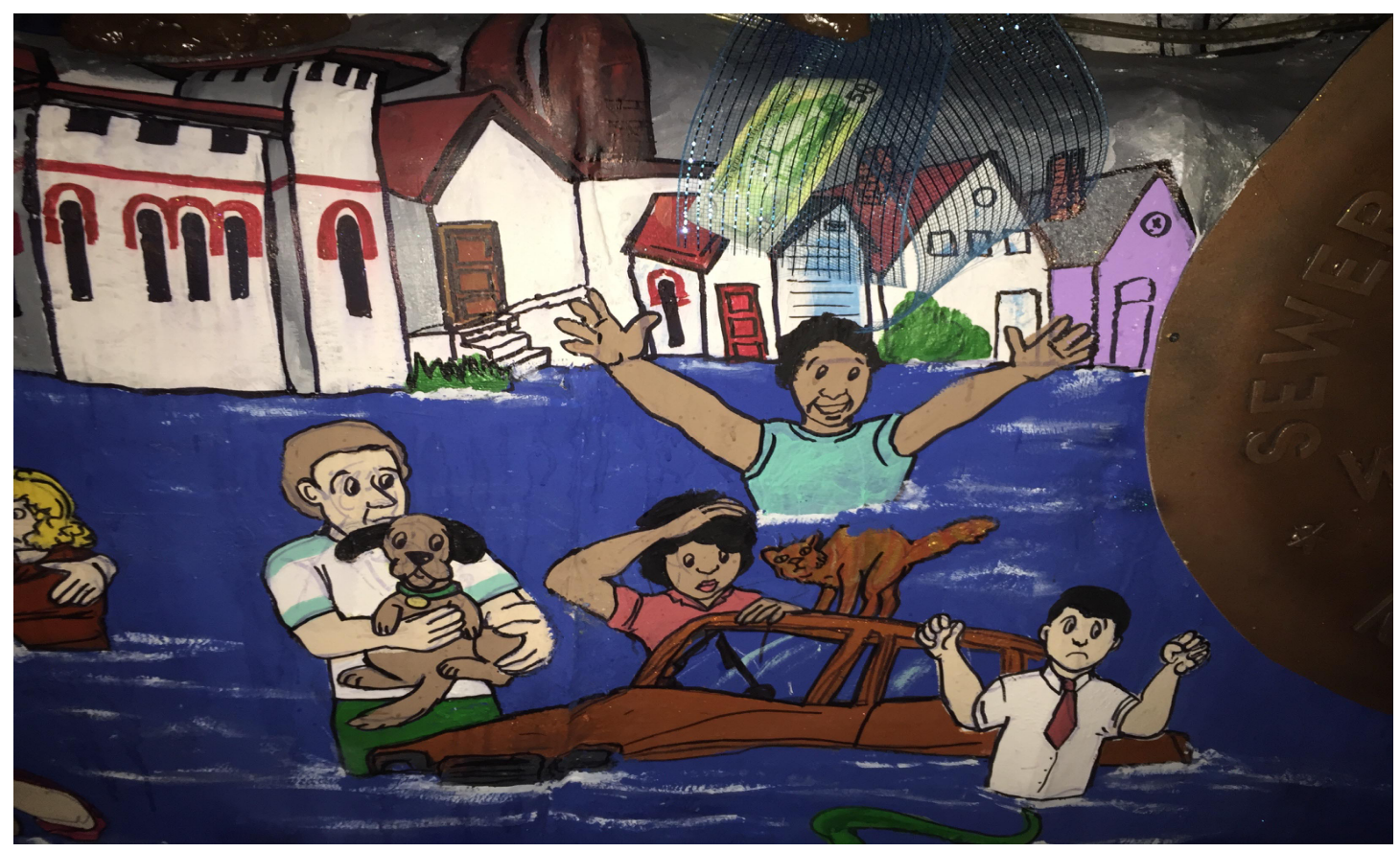

Multiple interviewees that included artistic community members and advocates also pointed to the wealthy not only having greater resources but also greater access to elected officials to the point where policy decision making took place behind closed doors at private gatherings. Susan, an artistic community advocate, used the example of the December 2013 proposed noise ordinance that sparked the brass band marching into city hall in protest the following month. She said that policy decision involving the proposed noise ordinance was made not only during Christmas season, when attention is diverted toward the holiday, but also at private gatherings. She said:

Susan: We were alerted to it and began sort of finding out what we could and discovered it was, again, a very small group of people. There was conversation talking about "Oh, we went to the council member's house and drank wine." Well, I'm sure you did, but that's not the way that policy needs to get written. That's inexcusable. 
The artistic community members and their advocates noted that because policies like this are being crafted and even decided on at gatherings to which they have no access means that these power structures defeat them before they even have the chance to fight. An interview with Harry and exchange I had with the street musician focus group participants illustrated these points.

Harry: It happens a lot behind the scenes. A lot of city council decisions are made before they even get to the meeting. ... A lot of that has happened. It's a reality. ... If (the wealthy) are determined to make something happen, they're going to make it happen. I think that's also real. Sometimes, it doesn't matter. No amount of public pushback is going to kill something.

Lee: Obviously. If we had power and wealth, it would be easy for our opinions to be heard.

Others: Yeah.

Lee: We wouldn't even have to go to a meeting. The people who influence the rules here... They're not going to community meetings either. They're just in closed-door circles with those people with those spheres of influence.

Lucius: People are having things that deal with edicts that are coming from these powerful.

Amelia: So, in other words, even though there are things like the Sunshine Laws, and laws about open meetings... A.K. Rich Guy... I'm just going to give him some kind of name, all right? So, A.K. Rich Guy meets with J.D. Politician at a wine soiree that they're having where people are in evening gowns, and that's where the edicts come from? Not from the meetings...

Lucius: No.

Amelia: ...but when these rich people hang out?

Lucius: Yeah. 
Wealth inequity was made even worse when factoring in that the wealthy generally had much more time on their hands and were able to, even when their official numbers were already fewer, distort the number of people who supported them echoing James Madison's 231-year-old fear in The Federalist Papers of powerful factions, that, besides being the majority, can also be an especially loud minority or an “obnoxious individual” (Alexander Hamilton, Jay, Madison, 2001 [1787]). Harry indicated that "squeaky wheels", not the majority, often dictated public policy. Regulus, a bar owner, dealt with a neighborhood association whose members utilized city policy mechanisms in trying to shut down his bar. The reality, though, was that a single person was doing most of the repeated complaining to city government and claiming to have numerous supporters. The support from city government became stronger when this person managed to get a neighborhood association to work with him, whose numbers even when counting inactive members - were still smaller than those who would come to Regulus' bar on a given busy night. He elaborated:

Regulus: He's spent a lot of time writing to city hall and to the councilperson. He was abusive and insulting to everyone, even people down at city hall. And so if they really thought, "We've got this dude, and it's just him," I think somebody would have shut him down a long time ago. Somebody would have said, "Go F yourself, and if you write me one more letter like this, you will hear from...", but they never did. I think the only reason they never did is because he did a good job of convincing them that somehow he was representing some mythical group that it wasn't just him and himself and that he had this following - and if they made him angry, they would hear from his following.

...So it was almost like a chicken shit way of governing. ... I think that when you allow it to get so skewed to one side, where the neighbors begin to think that it's not an equal thing here, is that fair? Are they the ones who will decide whether or not this business exists? I think that's wrong. ... I think that as long as people all work within the law in running their businesses, and if they're zoned properly and they have all the permits and stuff like that, I think they shouldn't be at the whim of whether or not a neighborhood association likes that. 


\section{Negative Social Construction}

Negative social construction (Schneider \& Ingram, 1993) of the New Orleans artistic community, especially when it came to race, appearance, and perceived criminality plagued the artistic community's participation. In both real and hypothetical situations, interviewees told me that government officials and city elites would automatically view them unfavorably and have their concerns disregarded in traditional citizen participation forums, echoing Schneider and Ingram's (1993) theory. Like the issues involving government corruption, this was also highly intertwined with the city's complex history.

Race

Michael, who is black, said that race automatically turns off white public officials, even for black citizens with higher educational levels and socioeconomic status. He said:

Michael: You know how I would be painted? I would be painted as the angry black man. If I were chosen to be the voice and the advocate, I will come across as the angry black man. I'm well-educated and well-traveled. I own a very successful business, and I have been an educator for twenty years. I'm not wet behind the ears. I'm passionate about economic development and prosperity for the cultural community. But if I got up and said that in front of a mic, I'm the angry black man.

This mirrors Schneider and Ingram's (1993) construction visuals, which show that while minorities tend to have high political power, society at-large mostly view them negatively. It is the same case for follow-up work (Neshkova \& Guo, 2016) scholars have done when examining Schneider and Ingram's (1993) work and applying it to empirical studies involving citizen participation. 
Negative social construction of the artistic community, and especially when it was tied to race, seemed to be extremely blatant in New Orleans and extremely longstanding.

Figure 4.4 below is an anti-street performance editorial cartoon from the 1880 s from New Orleans' Times-Picayune, reprinted in a report for the city of New Orleans.

Figure 4.4: 1880s street performance cartoon (as cited in City of New Orleans, 2013)

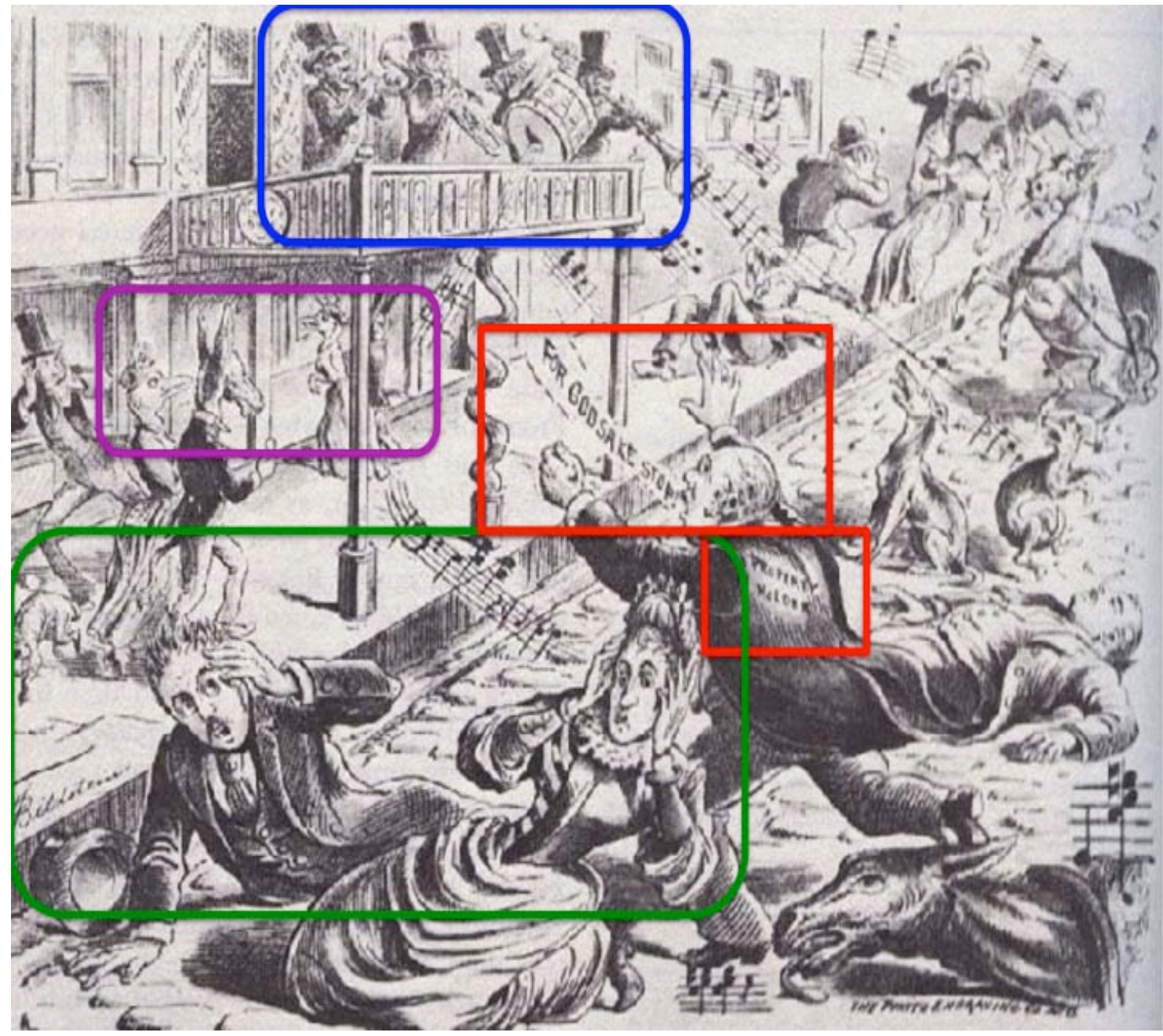

The cartoon depicts the people egregiously suffering, highlighted in the green box, from the street musicians' actions as well-to-do and white. In the blue box, the offending street performers assaulting their "victims" with their music from above are not only viewed as the villain, but they also appear to be black. The "hero" is the older white 
man, in the red boxes, shouting at them to stop — whose long suit jacket also has "property owners" on the back, depicting the ones with more economic and racial capital as the "good guys". In purple, a group mills about the streets seemingly unbothered and they are portrayed as upright-walking animals.

This view continued into the $20^{\text {th }}$ Century when people concerned with the city's "moral fiber" protested and finally shut down Storyville, a district with legalized prostitution beside the French Quarter that, from 1897 to 1917, also provided New Orleans musicians (black jazz performers, in particular), with performance venues (Daily Mail Reporter, 2013; Landau, 2014). New Orleans' glamourous prostitutes and other "loose women" and its related art works became a major part of New Orleans and its cultural activities - either by making the city glamorous or creating an image of a modern-day Sodom or Gomorrah.

Storyville's legacy, particularly its closure, was very evident during interviews, observations, and during the focus group even though the district closed literally one hundred years before my fieldwork began. Relevant details related to Storyville will appear throughout this section (and other parts of this dissertation), but in this section, I will focus on aspects of it tied to race and present-day social construction and tension. White and black musicians alike discussed the racial dynamics involving Storyville.

Michael (black musician): There were musicians performing and making money and receiving accolades and opportunities to perform elsewhere. There were women of color of the night who were able to make money, and in many cases, good money. There were opportunities for some of these women who were able to transition into becoming business owners. So, yes, Storyville had its vice. Storyville was also a place of economic prosperity, specifically for people of color. It also goes against America's greatest hidden secret in that morality is consciously attached to, and that is the white man's love and lust for black bodies. It simply is. 
Garrick (white street musician): In terms of what we're doing, like with the history of busking in this place, it's really weird because back in the days of Storyville, the city wanted to paint such a good picture of covering up how shitty New Orleans was that they would hire white musicians to play in front of the cribs, the really cheap prostitution spots on the street. That way, people would come here and see white musicians and say, "But they're poor. Oh! Wow! New Orleans! It's so creative! And look, the people are working so hard here. It's so great," and they would buy into this whole thing that the city was actually performing for them.

Race-related social construction during and directly after Hurricane Katrina still wounded interviewees. Michael was displaced during the aftermath, and in an area that was not near as racially diverse or accepting as his native New Orleans. In strongly worded terms, he described how he felt because of how he was treated. Because of the current political environment in which hate speech has become more prevalent, such as it was during New Orleans' Confederate monument removals, his treatment and feelings related to Katrina burn even more.

Michael: My daughter is turning eleven. I have a twelve-year-old son, and unfortunately, because of what we have been dealing with in this country and in this city the last year or so, with blunt racism - blunt racism where it is right in your face... It's not even being hidden anymore. I'm a Generation X. I was raised with the sentiment that I would not have to deal with the racial issues that my parents and my grandparents had to deal with. I could honestly say, for the most part, that I don't feel like I dealt with it until Hurricane Katrina, when I suddenly became a refugee. I became, for the first time in my life, a $\mathrm{n}^{* * * *}$. It was because people were willing to say that to my face.

Harry and Michael both likened present-day messages about the New Orleans artistic community from wealthier residents, particularly from white wealthy residents and about black artistic community members, to dated and now-ridiculed propoganda films such as the anti-marijuana Reefer Madness from the 1930s (Gasnier, Hirliman, 
Esper, Hoerl, \& Meade, 1938 [1936]) that they both referenced. As in such films, the wealthier residents' "moral" outrage is used to create or stoke fear of other groups, and, in this case, is very racially coded. Both Harry and Michael elaborated on this language and imagery, with both connecting it to public policy that emerges, as Schneider and Ingram (1993) and Miller (2012) have done.

Harry: There was someone complaining about a club. ... The city was using her and others as witnesses to shut it down. ... She didn't use racial slurs, but it was quoted to that extent. She didn't like that there were women "shaking their backsides to rhythmic music" outside. This was in 2011, right? This was not 1956, but yet these are the same arguments people are making.

It's like Reefer Madness. You see these things happening, like restrictions to stop music at midnight or push music out of neighborhoods. One of the best spots to watch is alcoholic beverage control meetings. A lot of music venues serve alcohol. So when they're taken to trial, often times, it's around noise or music. ... It's oftentimes racially split, in which the bars owned by a working-class black family has a middle-class white family trying to shut them down or limit them. ... The bar owners don't have the means to defend themselves, so they end up getting consent judgments that limit or shut down their music, limit their hours, and other things.... Most recently, in 2016, one fight over a club was clearly another manifestation of that issue. ... It was an almost entirely white group of neighbors, a neighborhood association. They saw what was a black cultural space, and they didn't like it. ... That was early 2016. This wasn't forty years ago. This is what you see from neighbors and what you then see in city policy.

Michael: What's Reefer Madness? It's the white woman (Michael makes an inhaling sound), and the black man... He's (Michael makes a mockingly sinister look on his face). That's what all of our laws are based on. It comes all the way back to these noise ordinance things, etc., etc. Storyville... All of that stuff is... (Claps hands). It ain't rocket science. It's the same stuff we've been seeing forever.

Other proposed noise ordinances that have failed have been perceived as narrowly targeting groups based on race. Harry noted that subsequent noise ordinance proposals introduced decibel limits on what is called C-weighted sound, which is bass, and the 
decibel measurement is the level of the thump it produces — not just pure noise level. Aweighted sound, which is regulated, is the decibel measurement of how loud a device, activity, or person is. Musical genres associated with heavy bass such as reggae, hip-hop, and bounce, an up-tempo hip-hop subgenre native to New Orleans, are often associated with racial minorities. Harry also pointed to dialog about the city's bucket drummers, who are often young black men or black teenage boys.

Harry: I've gone to meetings where people say they have guns in their backpacks. All of that is lies. That's the messaging that a lot of people are putting out there. And there's absolutely a racial component to that.

Regulus, who is black, believes his problems' initial roots were most likely not race-related, but when the controversy continually unfolded, his opponents accused him of "playing the race card" when he did not. His argument was that the neighbors were trying to close a legitimately operating business and control how he operated it if it stayed open. Nonetheless, they used the fact that he was black as way to soften his arguments against them. He noted:

Regulus: They just felt like they should be able to dictate what happens and if you - whether you would be black, white, Chinese, or whatever - are not going to agree to what they had dictated, then they are going to make your life a living hell. That's what I think.

\section{Outsider Derision of New Orleans}

New Orleans and its residents being perceived as lawless and immoral had a major effect on both the city's social tension and policy oriented conflicts with the federal and Louisiana state governments. This affected participation in terms of artistic 
community members believing they had no recourse at all against some power abuses and further stoked a contentious political and social environment.

As was the case with race, much of this is longstanding. This namely affected citizen participation in that political forces namely at the federal and Louisiana state levels used that perception from outsiders to try and score political capital (Clark, 2017; McClendon, 2016b; O’Donoghue, 2017) from those with such perceptions through enacting policies that detrimentally effected New Orleans, in general, including its artistic community. This created an environment that affected participation namely because artistic community members believed that accountability and recourse for these actions were almost non-existent because those outside policymakers were literally out of reach, and they could not fight back. It also further stoked overall anger and discontent, particularly during (and in still-existing memories of) Katrina and its aftermath when tensions were already at a fever pitch. It became even worse when such dialog from outsiders was racially coded, as Michael noted about some media coverage of Katrina. This all combined to continually add to a contentious overall dialog.

Stories both in historical accounts and artistically portrayed show that New Orleans' people and culture, as well as the city as a whole, were simultaneously beloved or derided — seen as either a carefree, boisterous place that warmly accepted societal outcasts or a dank pit of sin and vice. Through secondary source reviews and my interviews, I found that especially when outsiders come to enjoy New Orleans and go home to slam it, this becomes even more infuriating for locals. This has also translated into targeted public policy against the city because, as Schneider and Ingram (1993) note, policies that hurt or even punish undesirable groups are viewed favorably, and as Miller 
(2012) writes, social and political dialog that includes labeling certain groups with derogatory labels determine policies enacted over what is actually needed. Such dialog during the Katrina aftermath was especially poisonous, and this eats at the New Orleans psyche even more.

Historically, New Orleans has been a city where people could let themselves loose in ways that would be very socially unacceptable elsewhere or even illegal. For many New Orleans natives and residents, this is a key part of their identity and culture namely, that of an accepting city where a person can be free to be who he or she is. Certain outsiders, though, have branded New Orleans with a figurative Scarlet Letter that has filtered into social and policy debates involving the city. Secondary source reviews provided insight into the outsiders' views, but interviews with locals, especially those who were lifelong New Orleans residents, provided great insight on how this is a cloud hanging over New Orleans to this day and affects dialog within the city.

New Orleans natives take pride in their lively second-line parades, jazz funerals, and other cultural practices — with some even being proud of its loose, free atmosphere (City of New Orleans, 2013). These were especially dear to residents because they blended the city's European, African, and Caribbean roots (Kunian, 2007; Driscoll, 2012) and paid tribute to those who survived horrific injustices such as slavery and those who helped those groups escape and survive (Oliver, 2007; Personal Communication, 2017).

Outsiders, though, began to literally view New Orleans as the home of the devil himself. Ultimately, outsider derision shut down Storyville. When the United States entered World War I in 1917, military presence spiked because of New Orleans being a port city. The federal government banned prostitution within five miles of military bases 
(Pope, 2017). Despite many locals, including a madam going by the name of Gertrude Dix who "won all hearts" fighting the closure, the city complied with a request from the U.S. Secretary of the Navy. A 1917 newspaper editorial cartoon from the New Orleans Item (a now-shuttered newspaper) shown below in Figure 4.5 displayed the view of Storyville, and many of New Orleans', detractors — that the closure stopped the work of Satan himself.

Figure 4.5: Storyville shutdown and Satan (as cited in Karst, 2017)

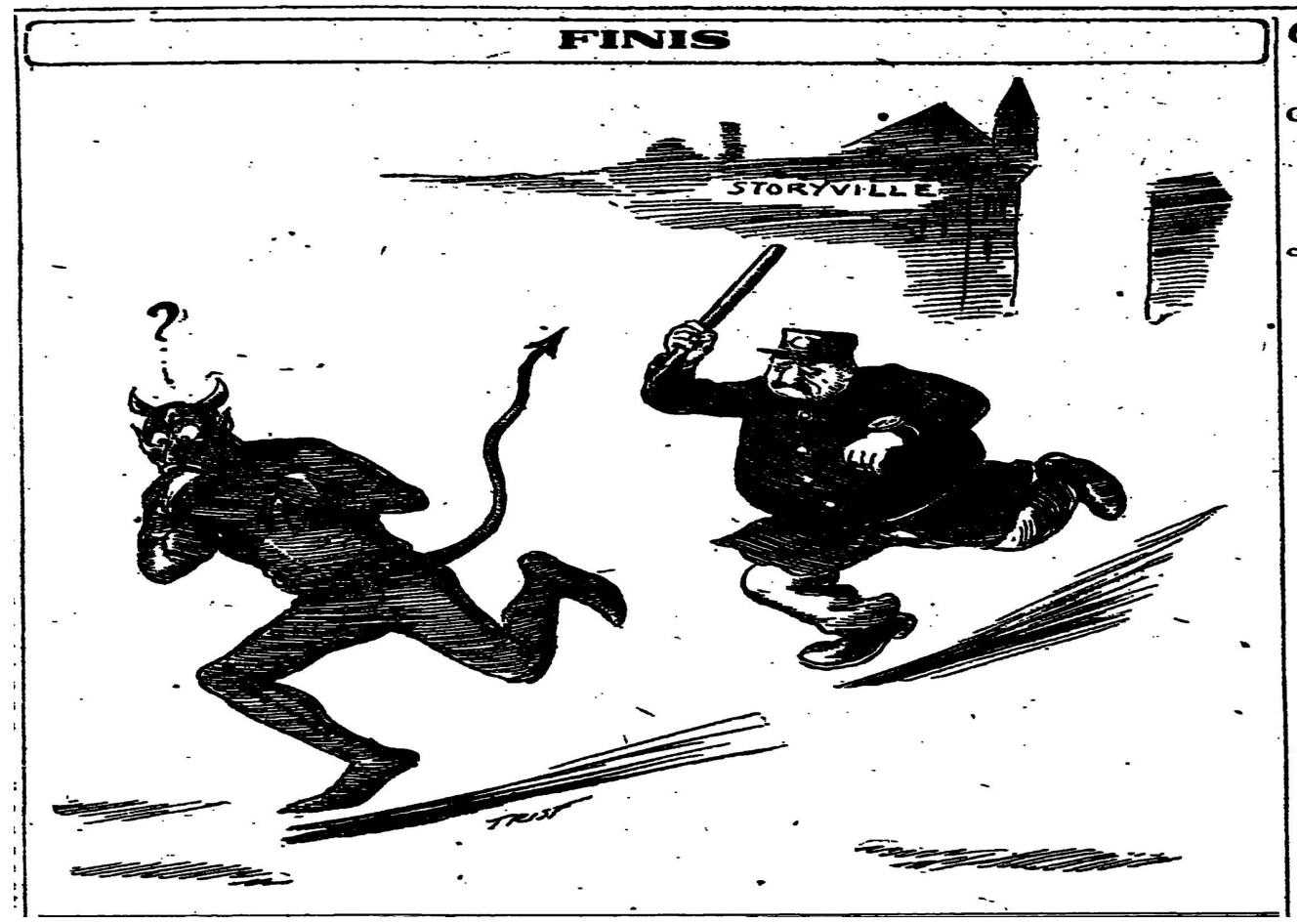

Imagery of the occult and voodoo are parts of New Orleans culture

simultaneously celebrated or condemned. Besides voodoo's link to the end of jazz funeral celebrations (Kunian, 2007; Oxford Acoustics, 2013), voodoo is still a prevalent piece of New Orleans culture, as are its Catholic, African, and European roots. During observations in the city, I found businesses devoted to voodoo and the occult in the open, in very busy areas of the French Quarter, shown below in Figures 4.6 and 4.7. 
Figure 4.6: French Quarter witchcraft store (Pridemore, 2017)

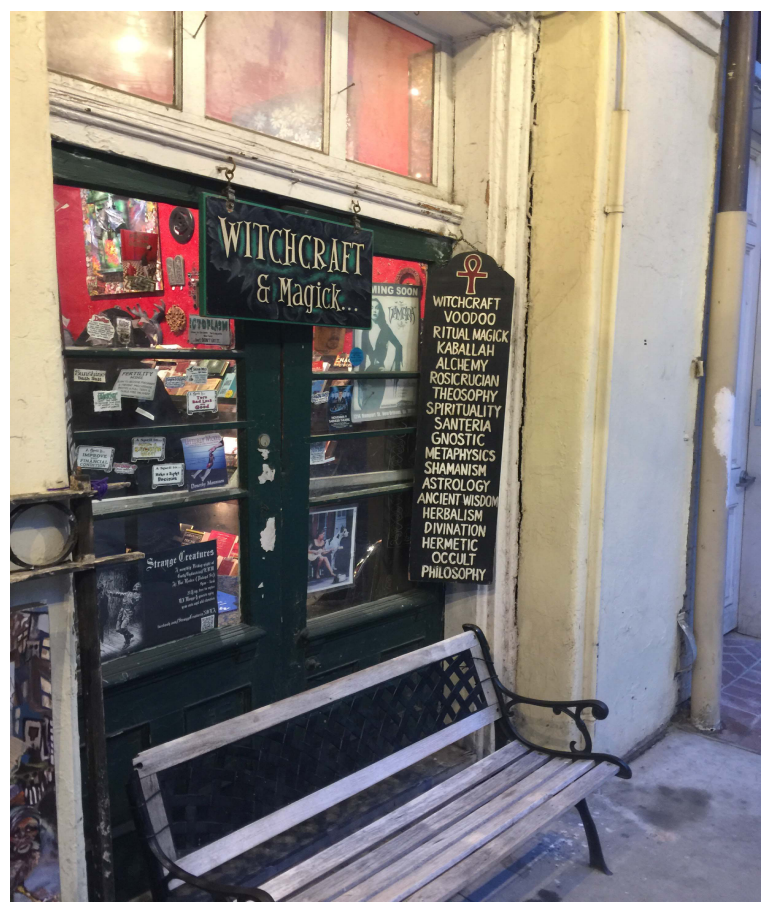

Figure 4.7: French Quarter occult store (Pridemore, 2017)

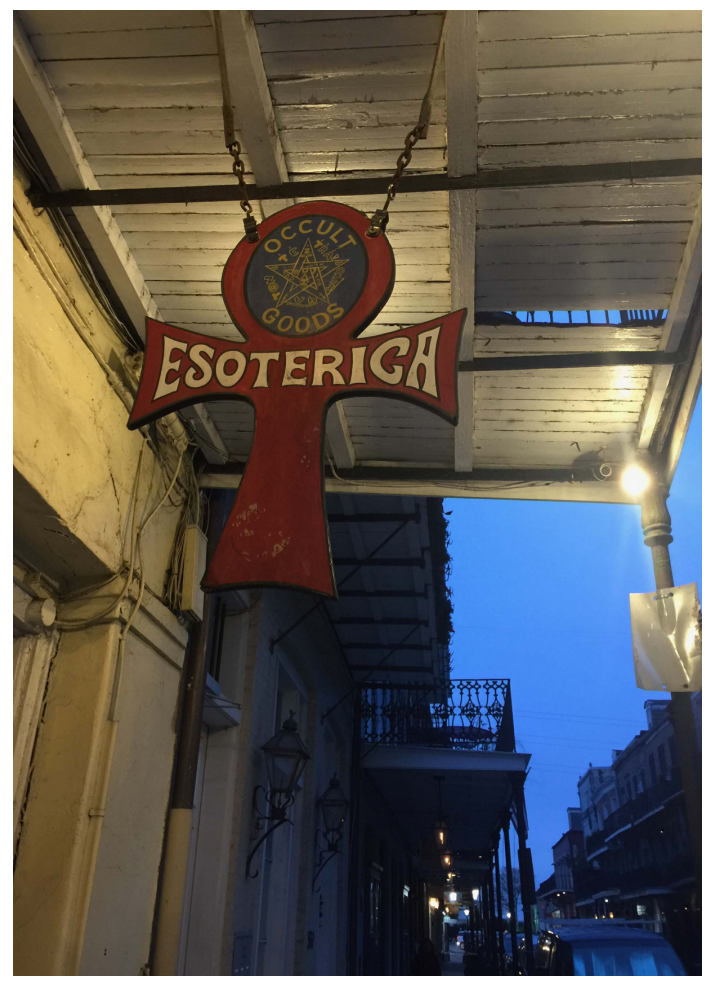


For locals, this shows that the city is accepting and welcoming even for society's biggest outcasts, which was further backed when reviewing sources from the city's LGBT community and its signature Pride festival, Southern Decadence (Mott-Smith, 2014; Southern Decadence, n.d.). Black LGBT community members were also largely responsible for the rise of New Orleans bounce music. While these groups were definitely not as well-established as the brass bands, they considered themselves very in tune with New Orleans because they represented societal outcasts that no one elsewhere understood or wanted to understand. On Southern Decadence's official website, organizers explain: "...New Orleans has marched to the beat of its own drum. For two centuries, those in control of the Louisiana state government have tried in vain to impose their prejudices on a city that is French, Spanish, Creole, African, Catholic, pagan, and very gay (in both senses of the word). If nothing else, New Orleans knows how to throw a party, from the world-famous Mardi Gras to other, more specialized celebrations" (Southern Decadence, n.d.).

While observing just outside of Café Lafitte in Exile on Bourbon Street, which bills itself as the oldest continuously operating gay bar in the United States (Café Lafitte, n.d.), I saw the mix of Christian culture with the derided. Just before I saw two witcheraft stores a few streets over, I saw Café Lafitte in Exile, shown in Figure 4.8, and the surrounding area, shown in Figure 4.9, fully decorated for Christmas. 
Figure 4.8: French Quarter gay bar with Christmas décor (Pridemore, 2017)

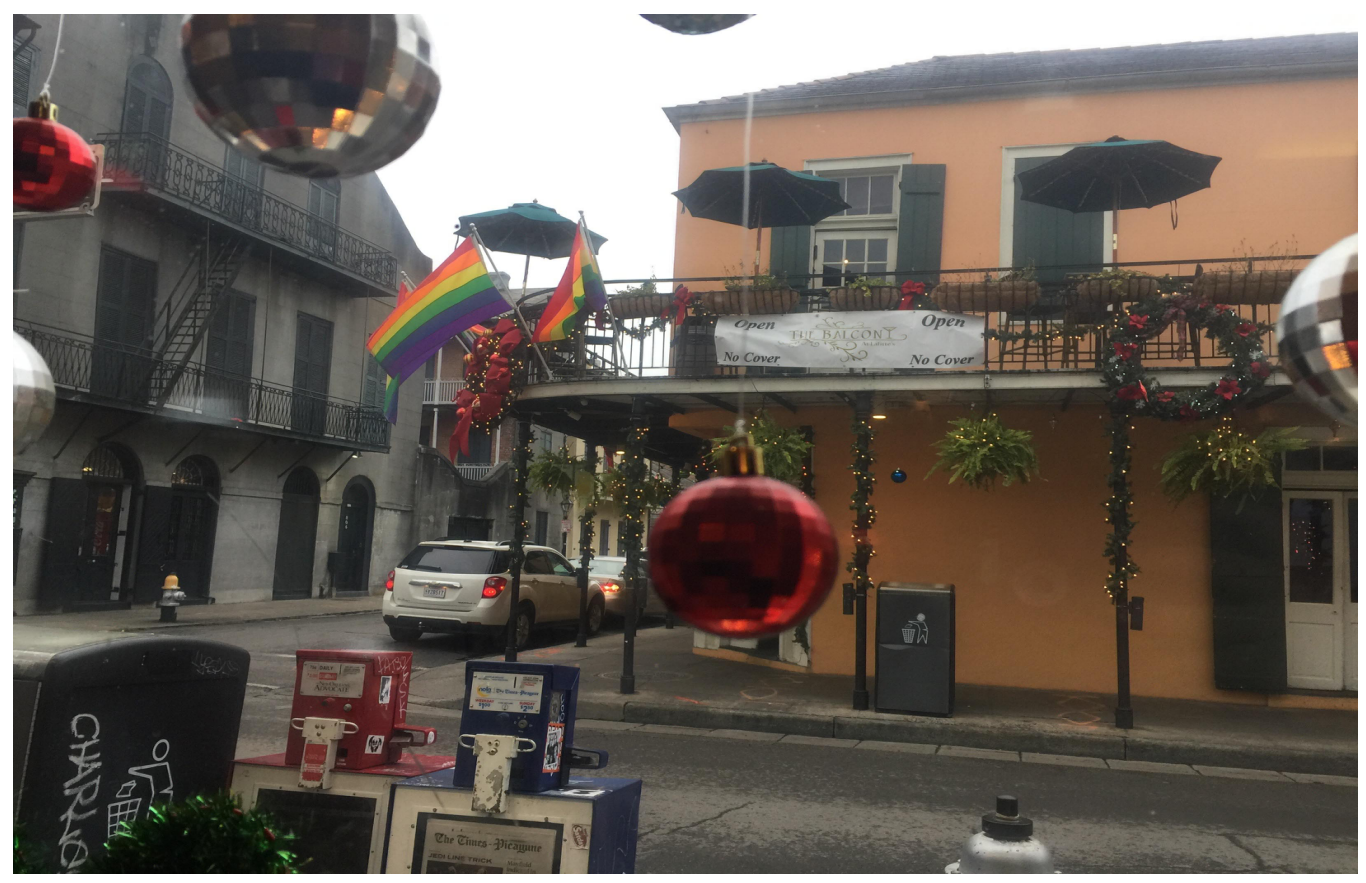

Figure 4.9: French Quarter Christmas décor (Pridemore, 2017)

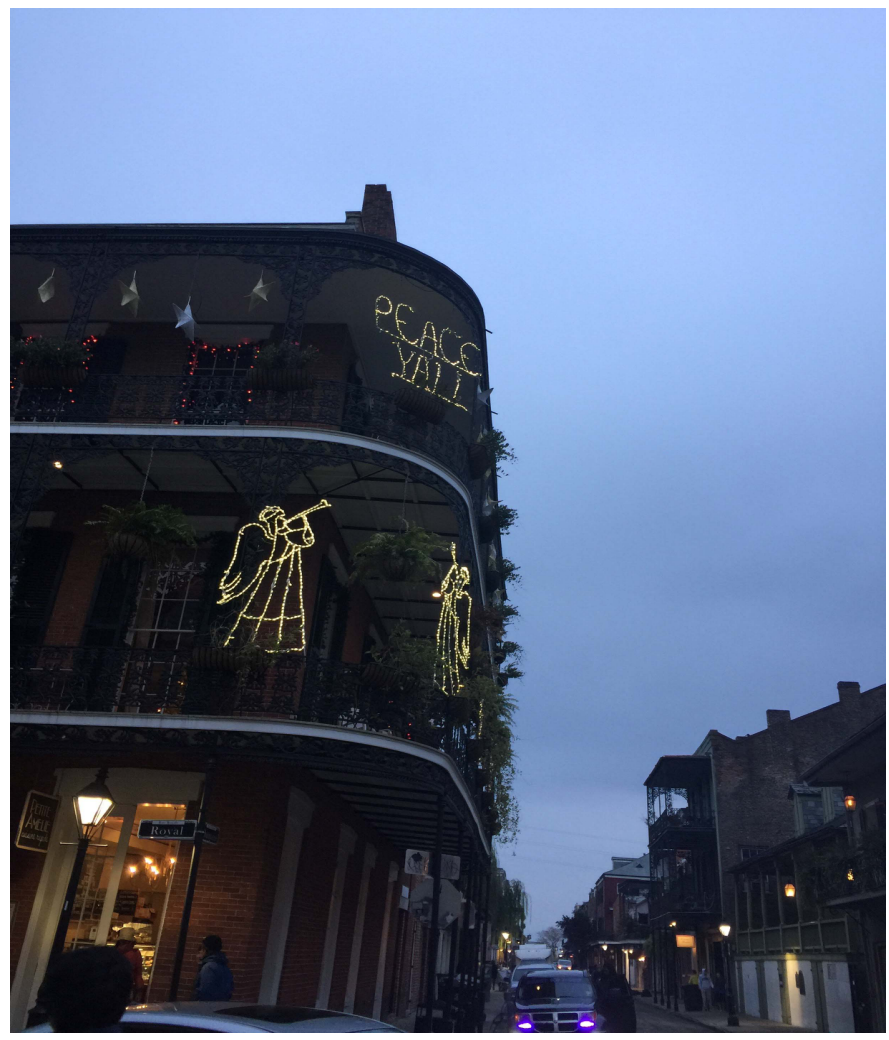


This mixture of the divine with the damned, though, was too much for outsiders to handle, and this long history of New Orleans' openness to the outcasts and its detractors reached a fever pitch during the immediate Katrina aftermath (Cooperman, 2005; MSNBC, 2005). The fact that the Southern Decadence was originally scheduled during the time Katrina struck did not help matters in this regard (Cooperman, 2005). Opinion leaders, namely very influential religious ones like the Rev. Franklin Graham, made statements that Katrina was God's punishment for its seedy reputation, with Graham saying:

This is one wicked city, OK? It's known for Mardi Gras, for Satan worship. It's known for sex perversion. It's known for every type of drugs and alcohol and the orgies and all of these things that go on down in New Orleans. There's been a black spiritual cloud over New Orleans for years. They believe God is going to use that storm to bring revival (MSNBC, 2005).

This translated to public policy debates, with then-U.S. House Speaker Dennis Hastert saying it made "no sense" to spend billions of dollars to rebuild a city that is under sea level, when discussing federal assistance after Katrina (Associated Press, 2005; as cited in Jewson \& Maldonado, 2015). This was despite the fact that fifty-one percent of urbanized areas in the New Orleans metro area were above sea level, most of them being the oldest parts of the city like the French Quarter (Jewson \& Maldonado, 2015) where Southern Decadence happens to take place (Mariano, 2017b).

Kingsley discussed how outsiders view New Orleans — but noted their misconceptions and how locals believe the same detractors also happily partake of the vibrant city when they visit. He said:

Kingsley: We're not lazy party people, and I know that the rest of the country seems to think that we're like America's mistress and not its wife. But you'll keep 
coming back to us, right? And maybe you don't want to admit that you enjoy us as much as you do and maybe you come here and you're allowed to be yourself.

...We will allow you to be who you want to be here. So, I think that we are a little hurt that the rest of the country all of a sudden thought of us as, you know, from Mars.

...After the storm, I think that we realized that we are much more dependent on America seeing us as Americans and humans than we wanted to think that we were. We realized that there were people in other parts of the country who were openly discussing why we would rebuild an American city. Can you imagine it if another city got flooded? What if Los Angeles got an earthquake? The Speaker of the House from Illinois questioned why it should be rebuilt, and there was really a feeling of, "We're still a part of this country even though we might be a little quirky, and we feel like we're part of the northern Caribbean sometimes more than we feel like we're a part of the American South."

The New Orleans Times-Picayune, as part of its Katrina coverage that earned it the 2006 Pulitzer Prize for Public Service, released a scathing editorial directed at the rest of the United States for its derision in New Orleans' crisis (Times-Picayune, 2005). In it, the writers discuss how the rest of the United States wanted the oil and gas drilled offshore in Louisiana, how food is shipped through New Orleans ports, and wanting to "share in our spirit" and "sample the joyous beauty of our jazz and our food". The city was "happy to oblige them" (as cited in Times-Picayune, 2005). Federal officials, the writers said, told New Orleans the levees were safe when they were not. New Orleans needed the rest of the nation's help — a return of the favor — to both protect it from future storms as it continues the economy that provides so much to the entire country. Instead, the attitude toward New Orleans was, the writers wrote:

They act as if we are a burden. They act as if we wore our skirts too short and invited trouble (Times-Picayune, 2005). 
Despite what the city provides to the rest of the nation, the federal and Louisiana state governments have targeted New Orleans for its perceived misdeeds and lawlessness in the present day. One example is U.S. Attorney General Jeff Sessions targeting New Orleans and sparring with city officials for New Orleans' "sanctuary city" policy that, for New Orleans, includes forbidding city police officers from questioning crime witnesses or victims about their immigration statuses (Clark, 2017; Evans, 2017a). Landry, before he became involved in the Cantrell credit card investigation, deployed a special task force to New Orleans, saying it was to curb the city's crime (O’Donoghue, 2017). The sticking point, though, was that Landry's task force members were working independently and not in the unified command structure of New Orleans Police Department and the multiple other law enforcement agencies that work with the city police in that command structure, namely the Louisiana State Police (O’Donoghue, 2017). Landry's efforts were not only seen as purely political, with the Republican Landry being a likely opponent against incumbent Democratic Louisiana Governor John Bel Edwards in 2019, but also extremely dangerous because of his officers working alone.

Social media traffic indicated Landry's task force members harassed New Orleans street performers, with the Music and Culture Coalition of New Orleans advocacy group posting to Facebook that it had confirmed such reports and noted the task force was working outside the NOPD command structure (Music and Culture Coalition of New Orleans, 2017a). Among other comments on this Facebook post, one an account from someone claiming such harassment, saying that a task force member behaved unruly and tried to force them to leave their spot because "a clarinet case was sticking out just a little further than ideal” (Music and Culture Coalition of New Orleans, 2017a). 
Landry's task force's work ended during my first week in the field in New

Orleans. Kingsley provided details on how dangerous the situation was, especially when considering that Landry's officers were not distinguishable as law enforcement officers because of their plainclothes black shirt and khakis outfits and unmarked cars while openly carrying guns. The command structure is critical in any security situation both within an organization and especially when working with others. To show an example of how much needs to be clearly spelled out in all partnerships and command structures, Kingsley held up the four-inch-thick document that is his agency's intricate mutual aid agreement with the Louisiana State Police, as well as other huge documents with plans for major events like festivals and hurricanes. These plans detail all parties' specific responsibilities so that everyone knows their own tasks and what others are doing and consider local community and lead agencies' standards. This is especially crucial during catastrophic events.

Kingsley: I appreciate outside help. How am I going to turn down extra officers helping us? But they have to do it in a coordinated fashion with us. They've got to know where our problems are, and a lot of those officers that they sent down here are former New Orleans police officers. But they have got to know where I am having, maybe, a pattern of armed robberies and with the description of who that armed robber is.

They've got to know what our expectations for our community are. So, we don't chase cars unless they're committing violent felonies, and they're at imminent risk to public safety. We don't chase cars for traffic violations because the risk/reward is so unbalanced. OK. Great. I can catch you and get you for reckless driving, but you ran into a family of four and killed them. Right? It's just... There's no... That doesn't make any sense.

So, they're not readily recognized by my citizens. So if some bunch of guys jump out of a car in a, maybe a dark Charger with tinted windows, and they run at you with guns, and they're not dressed like police officers, how do you know that they're the police? So they have the potential for that to become a very dangerous situation, very quickly. And then my officers may not recognize them as officers 
because of what they wear. There's got to be a level of coordination with outside agencies.

The focus group members and Harry noted the problems namely with multiple state and federal law enforcement agencies, combined with private guards, who all patrol the French Quarter along with the city police. This created a major problem with accountability and recourse, if the artistic community were to try and get that. One problem was the sheer number - fourteen known security agencies from the city, state, and federal governments, as well as private organizations, even after Landry's task force left. To get this number, Kingsley, who works with them all to different extents, had to write out a list to keep track of them. Not all are headquartered locally, creating a geographic logistical challenge if the artistic community wanted to fight their actions.

This was a related exchange from the street musician focus group.

Lucius: The state police are very often the ones to cause problems for us. To address that problem, we would have to go to Baton Rouge or Baton Rouge would have to come here, which is almost impossible to even conceive.

Rubeus: Yeah.

Lucius: Unfortunately, it's not quite as simple as getting local government involved, specifically with the police problem. They even have Homeland Security running around sometimes. I've never seen them bothering musicians, but it doesn't create an atmosphere of comfort or peace and security.

\section{Appearance}

Appearance was also a hindering factor related to social construction in New Orleans, but not just in relationships between government and the artistic community. Oftentimes, it affected relationships within the artistic community, particularly between 
those who were older or younger or New Orleans' traditional performers and ones engaged in more contemporary art forms.

During my observations, I noticed that many of those playing traditional brass music and jazz, particularly if they were older and/or black, dressed very sharply in outfits that included bow ties or elegant hats, even for seemingly casual gigs like playing on street corners. Many other artistic community members, particularly if they were younger, dressed very casually. Some focus group members called themselves "scruffy" in describing how they are looked down upon just because they have a casual appearance, and some said they are even thought to be criminals or dangerous as a result. This often happens when they come in contact with people who are wealthy and white. The situation is the case even if the artistic community member in question is white, but it is even worse for minority artistic community members. Ginny, a street poet, said:

Ginny: I think that there's a perception that even if the time could be scraped up, not much would be heard. There is an association with homelessness and other criminalized behaviors. So from the get-go, whatever request we have, the logic and sensibility of those requests are overshadowed by the appearance of the people making the request.

Michael believed that "looking the part" was critical in being taken seriously, and he believed that one way the situation for artistic community members could be improved is by teaching them professionalism, in general. This can include how to properly dress, as well as business acumen and responsible financial management. Some are not taught that, often because of social equity reasons like race and poverty. Part of teaching professionalism and creating a positive image for oneself, he said, needs to involve appearance. 
Michael: My dad is a professional. I'm comfortable looking professional because I've been wearing suits and ties since I was a kid. You have some musicians who show up to events, and they look homeless. You can't demand the pay that you might deserve if you don't look the part. That's important. You have to have someone to teach you. You have to have someone to tell you there's a time and a place for everything. If I were at a government meeting, I would have on a suit and tie. I was taught that. I am comfortable with that.

\section{Barriers Related to Formal Participation Mechanisms}

The artistic community members and their advocates, during focus groups and interviews, expressed serious dissatisfaction with traditional participation mechanisms, namely government meetings and public hearings. As they did in pointing out elites and officials had crafted and decided on policy privately before public meetings, the artistic community members and their advocates said meeting times made it impossible to attend. This was especially true if the meetings were extremely long. What made the situation far worse was artistic communities' having to work constantly, taking extra gigs, staying on the streets longer, and taking jobs outside of the arts because the affordability crisis itself necessitated that. This created a figurative rat race in that the artistic community could not advocate for policy solutions that could solve a major problem because of the problem itself. When they could attend traditional forums, they did not believe officials wanted to even try to understand their concerns.

Artistic Community's Schedules, Economic Pressures

The most common hindering factor I found throughout this entire dissertation was the problem of a figurative cultural rat race. Because of the skyrocketing rents and affordability issues, artistic community members were constantly working — "the hustle" as many called it, through taking on extra gigs, spending extremely long hours 
performing or selling their work on the streets, and working other jobs outside of the arts. This, especially for those working in New Orleans' cash economy (earnings coming from tips or gigs), put them on a much lower power position as opposed to many who worked to snuff them out.

My first fieldwork foray into New Orleans began the road toward this finding because of interviews I did not get. I discovered that I came to New Orleans at the worst possible time - toward the end of the month. Rent would be due at the week's end. During an observation in the French Quarter, I quickly saw a consequence of the rising rents when I passed by the window of this shuttered business shown in Figure 4.10, where someone was using a popular viral Jimmy McMillan meme to communicate the situation.

Figure 4.10: Closed store, rent is too damn high meme (Pridemore, 2017)

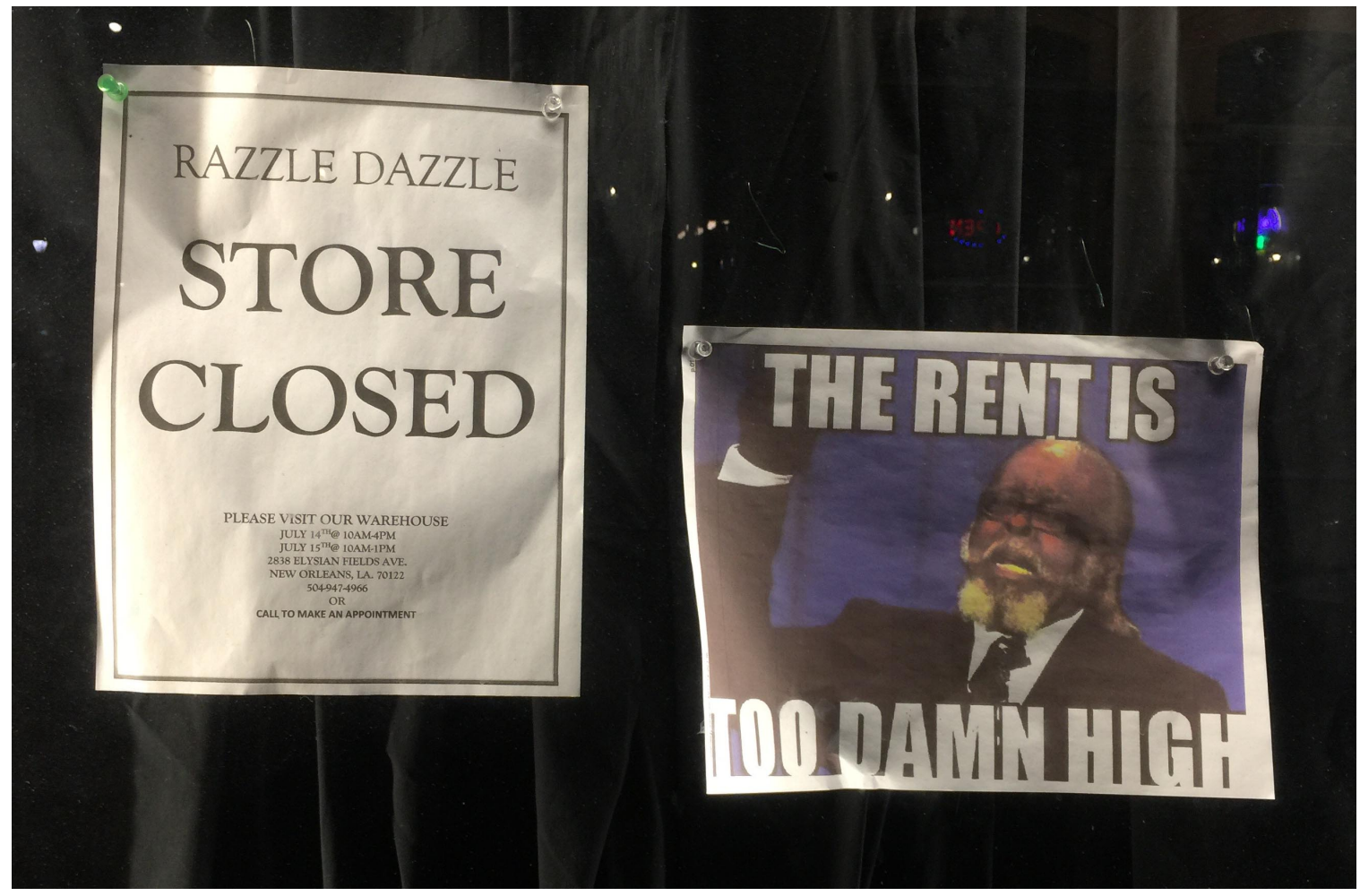


One street musician who had earlier agreed to an interview later told me she could not talk because she was short on rent money and had to hustle more. I noticed a man tap dancing on the street for hours, rhythmically singing the lyrics, "It's hard work, but it's honest work," as he endlessly pounded the pavement. I managed to briefly talk to him the second night I found him, when he had his infant daughter in his arms, telling me, "I do this for her." He was pleased to hear about my work, but he could not stop tapping even for just a very short conversation because stopping for even just a few minutes meant lost tips.

This made me question if the affordability crisis itself kept artistic community members from participating in government because if they had to work nonstop, that begged the question of whether or not they could attend a sometimes hours-long government meeting. Interviewees and focus group participants confirmed this was indeed the case. Fleur, a street musician, said she often spends twelve to fourteen hours per day playing on the streets, and the focus group of other street musicians were doing the same. Multiple other artistic community members inside and outside of music and multiple advocates said artistic community members were forced to choose constant work to literally keep a roof over their heads over working to either combat negative policies or work to create policies that would improve their situations.

Fleur and Regulus both also noted that many artistic community members must do this on top of handling family responsibilities such as raising children or caring for aging parents. Harry, an artistic community advocate, further explained the situation.

Harry: It's really hard to sustain people's involvement in pushing for systemic change when they're trying to get by, day-to-day, every day. If you're barely 
making your rent, it's really difficult to show up to a meeting that would change the zoning ordinance.

...If you're working three jobs or out hustling for tips so you can pay your rent, you don't have time to worry about policy change. You're worried about keeping a roof over your head or food on the table. That's certainly very real around a lot of street performers and a lot of gigging musicians.

Other observations further illustrated this point. When observing multiple nightclub gigs, performers kept large to extremely large and prominently marked containers with them for tips, as shown in Figure 4.11. Some performance groups would beckon audience members to tip them or even send a member out into the audience with these containers to personally ask for tips. One vocalist, while collecting tips, said, “We'll take cash, credit cards — hell, we'll even take EBT!" Street performers' tip containers, as shown in the band photo below in Figure 4.12, were generally very large buckets with prominently drawn dollar signs on them. (Note: The street performers in Figure 4.12 were not interviewees or focus group participants.)

Figure 4.11: Giant band tip bucket, Bourbon (Pridemore, 2017)

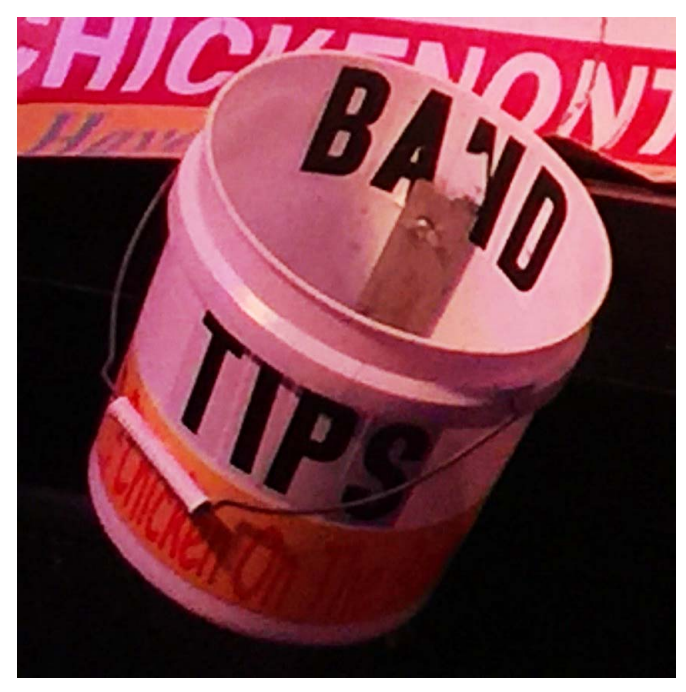


Figure 4.12: Street band with giant tip buckets (Pridemore, 2018)

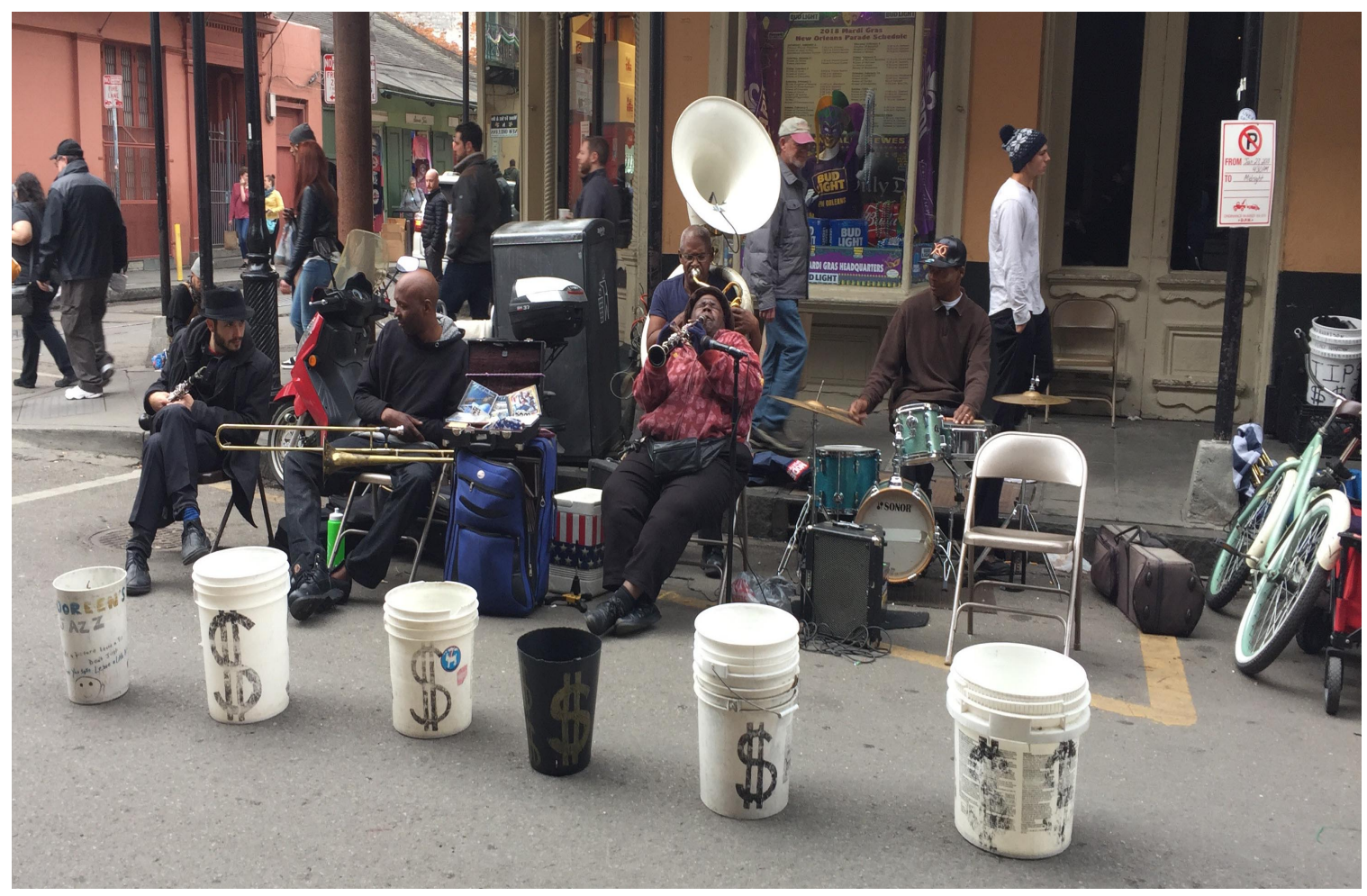

Even if someone's artistic business had its own brick-and-mortar location, this was also a problem. Rolanda, an art gallery owner who, like others, works by herself, already had to move her business. Her first location's landlord informed her, two days after Katrina struck, that he was going to raise her rent by $\$ 2,000$ on the month. She is now in a space that does not have a restroom. This means that she already has to temporarily close her business any time she has to go across the street to use the toilet. The majority of her business comes from tourists, most of whom find her gallery while strolling by. On top of that, she and others in the visual art market are facing the challenge of anxiety over the current national political and economic environment. Because art is a very discretionary purchase, such purchases are usually eliminated from personal budgets during periods of economic anxiety. The majority of her business 
coming from tourists means that she is dependent on another highly discretionary part of people's incomes. The international political situation, such as with the travel ban involving Muslim-majority countries, makes things even more volatile because although most of her business comes from American tourists, international tourists tend to buy more when they do come. She said:

Rolanda: We are singing for our supper. Literally. If you own your own business, you are so dependent on whoever walks through the door, and you just have to be there when that happens. Someone might say, "Hey, do you want to go to lunch?" I haven't had a lunch in twenty years!"

\section{Formal Participation Forums' Inconvenient Scheduling, Length}

Formal participation forums' scheduling in New Orleans, typically during daytime hours on weekdays, made them extremely difficult to attend. This was especially true for daytime-working business owners, street performers working for cash tips particularly during the daytime Royal Street Pedestrian Malls, and artistic community members who had jobs both inside and outside the arts that were during regular business hours. The meetings being extremely long also made them often impossible to fit into someone's schedule.

I observed the city council's public comment period for the Master Plan amendments, which was put at the end of a regular council meeting that began at 10 a.m. and had already lasted for about four hours. The city website did note that the hearing would not likely start any earlier than 1 p.m., but the Master Plan hearing did not begin until around 2:30 p.m.

Multiple citizens left before they had the chance to speak as I watched people continually file out of the meeting room and signed-up speakers being called after they 
were already gone — with more and more already-departed speakers' names called as the meeting dragged onward. When I first arrived, I could barely move because the room was so packed. By the time the meeting was near-finished, I managed to take this panoramic shot shown in Figure 4.13 that shows the few who had manage to hold out until sometime after 4 p.m. Even council members' frustrations were evident, with one repeatedly putting her head in her hands and running her fingers through her hair. One councilman acknowledged how the time had dragged on during an exchange with a citizen speaker who said she had been there "all day". The councilman said, "That's because we're all approaching tomorrow.” The meeting finally ended around 5 p.m., with the few remaining (myself included) either rushing or staggering out.

Figure 4.13: Near-empty council chambers at meeting's end (Pridemore, 2018)

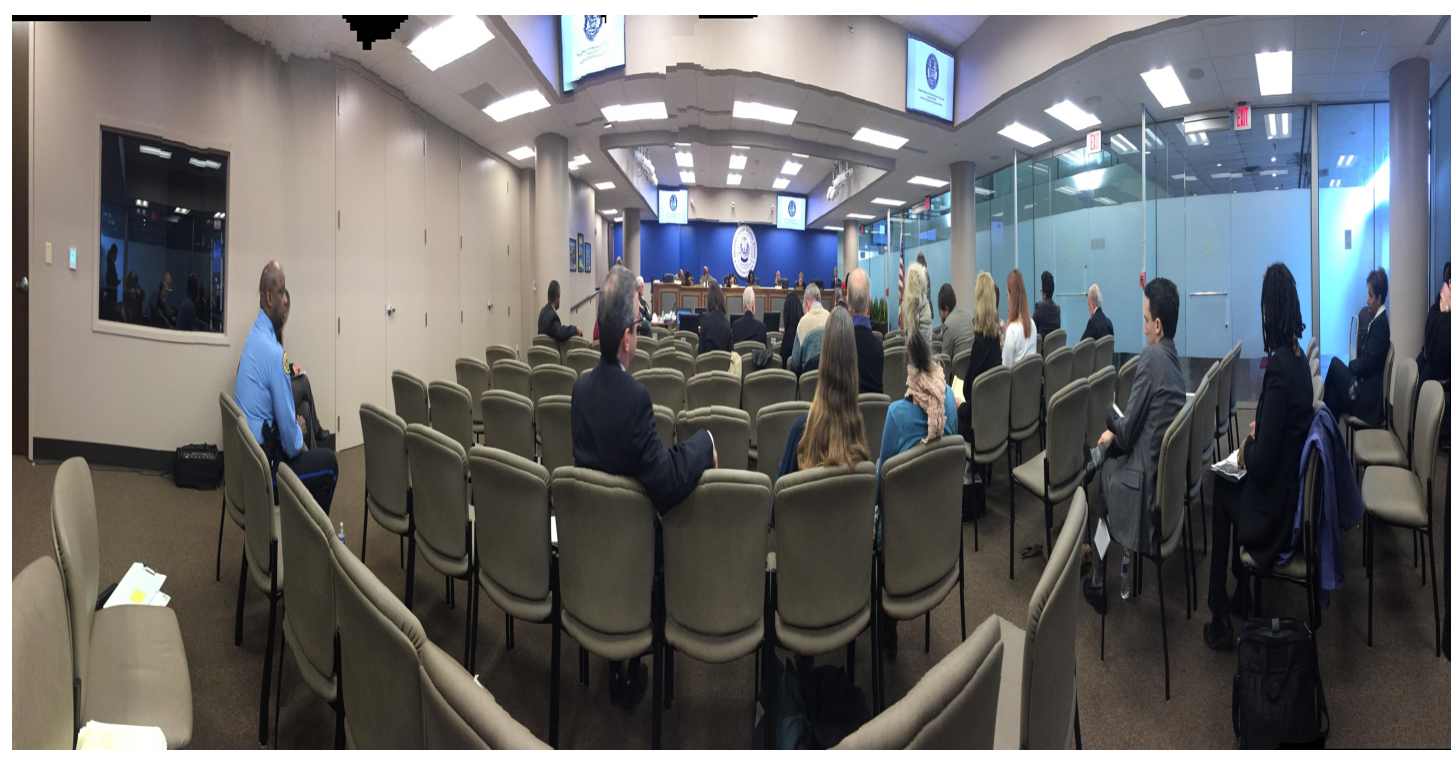

An issue that further complicated matters was that the majority of New Orleans government entities had their public meetings during daytime hours, such as the city council meeting at 10 a.m. or planning commission meeting at 1:30 p.m. Rolanda, specifically referring to the 10 a.m. city council meetings, said, "Who can go to that? I 
can't. I have to be here." Fleur, pointed to the meetings' length, saying, "Who has time for that? I don't have time for that." Further compounding the situation, though, was the fact that artistic community members are quite often working both day and night, making any evening meeting attendance impossible, as well. Michael illustrated these points:

Michael: If you've got cats who... Like, these meetings would be held in the evening, around 6 p.m. or something like that. They would be for an hour or an hour and a half. But if you've got cats who have evening gigs, like your Bourbon Street bands, they can't attend those. You have some musicians who unfortunately play until two or three o'clock in the morning. During the day, they're resting or they have day jobs. You have a lot of people who don't have a lot of flexibility on their jobs, where they can leave and go take care of business. You can't just leave work, saying, "I've got a council meeting at one o'clock." Those aspects keep people from participating. There's no fix for it all. Most council meetings take place during the day. For people who work... I've been blessed because I've always had employment opportunities that have given me flexibility. ... A lot of people don't have that flexibility.

\section{Dissatisfaction with Traditional Participation Mechanisms}

Multiple interviewees from the artistic community who were able to participate in traditional forums found their efforts futile. Beside the factor of the odds already being stacked against them because of elite/public official collaboration, they believed their efforts were in vain because officials tuned them out or were outright hostile, often at the elites' urging. The pictures below in Figures 4.14, 4.15, and 4.16 are selections taken from narrative maps that Alicia, a visual artist, and Frank and Lee, two street musicians, drew. They portray government officials and the powerful as malicious. 
Figure 4.14: Narrative Map (Reality/Inset): Alicia, New Orleans visual artist

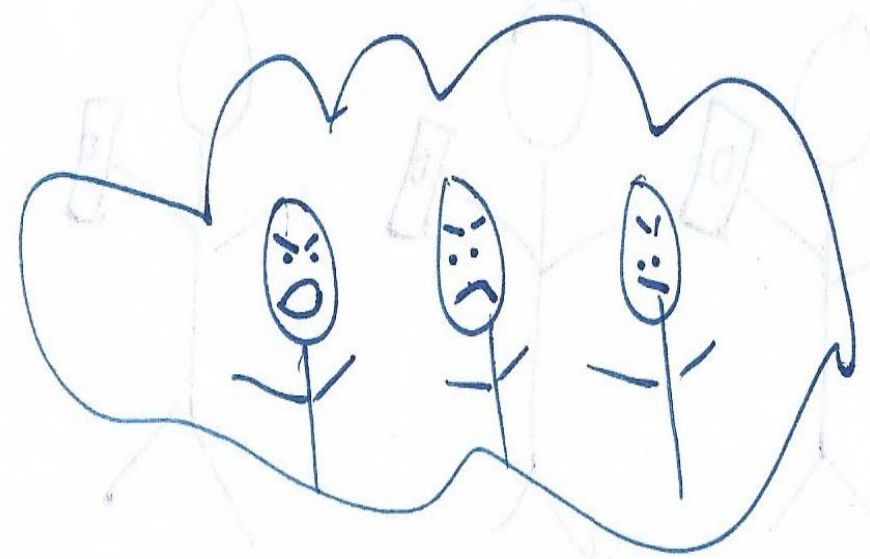

Figure 4.15: Narrative Map (Reality/Inset): Frank, New Orleans street musician

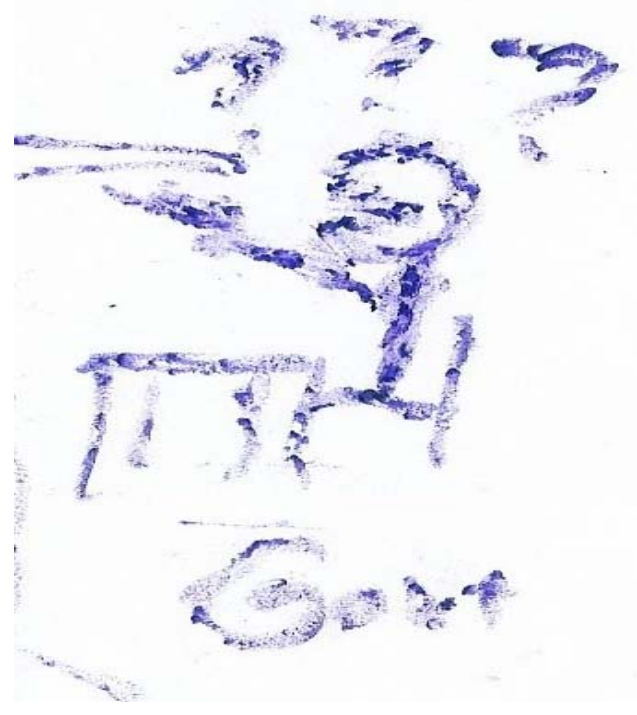


Figure 4.16: Narrative Map (Reality/Inset): Lee, street musician

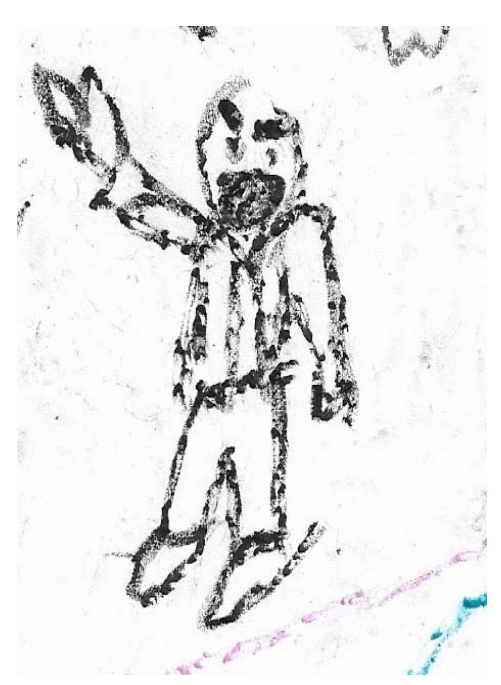

I saw very glaring evidence of this sentiment and backing for their claims during the last days of my New Orleans fieldwork in late January 2018. This first happened at the above-mentioned Master Plan public hearing, even before the meeting's time dragged into the early evening. Before the hearing had even begun, multiple citizens in the thenpacked audience who had also been sitting through the preceding city council meeting were rustling in their seats and talking amongst themselves. One man angrily slammed a chair with his 20-page city council agenda. Some council members left before the hearing, which made the entire meeting last for about seven hours.

A key moment was, while a citizen was speaking and noting the city government's past misdeeds, a councilwoman had her high-back chair's back turned toward him, creating a figurative wall. When the councilwoman turned around to face the audience again, I saw her talking on her cell phone at her desk. This was when the citizen was mentioning his frustration with New Orleans' political processes, saying, “Things have not been done properly for years here in New Orleans." 
All of the focus group participants said they had been to traditional government meetings, and some had spoken at them. However, they did not believe voicing their concerns in such forums helped their situation, in part because of the earlier-mentioned issues involving public/elite collaboration and the issues involving economic resentment that will appear later in this chapter. This was an exchange I had during the focus group with Lucius, who had spoken at one of the meetings.

Amelia: What did you feel like when you were speaking? Were people looking down at their phones or something like that, or do you feel like they were actually listening to you?

Lucius: I feel like I was being heard but not listened to.

Amelia: Why is that?

Lucius: Well, they were making eye contact and seemed interested, but I'm not even sure they really understood what I was saying. Their vision of reality and the way they think things ought to be are so different from mine. I can speak as clearly as possible, and everyone else in the room can agree. But they literally can't even conceive what I'm talking about because if it's not good for the quarterly fiscal course and it's not good for tax revenue, it doesn't exist.

\section{Institution-Related Barriers}

Institutions provided participation barriers for artistic communities working to participate, namely in that they faced precarious policy situations - both on the books and proposed - that could have shut them down. How institutions came into play to both create and aggravate this situation and stand in the way of artistic communities from being heard in these policy debates is first, as North (1990) argues, those with greater power worked to change institutions both formal (such as policy) and informal (New Orleans' longstanding cultural practices) alike through first changing formal institutions. The practices also mirrored literature namely on the Second Face of Power, in which 
those using power structures rooted in institutions (Bachrach \& Baratz, 1962) (such as deference to elites) to manipulate a situation to work in their favor and to the less powerful's detriment (Warner, 2001; Warner, 2011) and in a way in which the less powerful cannot fight back.

What made the situation worse for the artistic community members, their advocates, and some in the bureaucracy was that old policies that were severely outdated, had unconstitutional elements, could not be enforced, or were extremely confusing and convoluted - namely the noise ordinance - were still on the books, with hardly any hope for positive change. The elites, though, pushed proposed noise ordinance revisions that would have severely limited or even shut down certain cultural practices and worked to do so in a way that would avoid opposition. While groups such as neighborhood associations did not have direct authority to give artistic communities observable orders, as the First Face of Power (Warner, 2001; Warner, 2011) requires, they utilized the Second Face to change a formal institution that would then curb and could eventually change an informal one.

\section{Tricky policy mechanisms}

Precarious policy mechanisms, whether they came from existing and oftenoutdated and unconstitutional policies still on the books or ones being proposed, created further problems with unequal power structures. Participants that namely included advocates, business owners, and a government official pointed to current and proposed policies that were vague or confusing, directly and negatively target artistic communities, or cannot even be enforced. Further complicating the situation was when needed policy did not exist, leaving regulation to legally unenforceable social contract. 
The first problem involved policies that existed and certain groups manipulating situations to use those to their advantage. The largest sticking point for all parties involved in disputes involving the artistic community was the city's current noise ordinance and music and culture-related zoning ordinances. The noise ordinance, Olympia and Harry informed me, was originally passed during the 1950s, with modifications in the 1980s. Olympia said the biggest problem her department has with its Sound Check program and sound issues, in general, is the ordinance, which "desperately needs to be updated".

The Music and Culture Coalition of New Orleans (Music and Culture Coalition of New Orleans, 2016a) created a street performer reference guide in an effort to, as much as possible, clearly explain parts of the noise ordinance and zoning ordinances that affect them. The city has seven different zones in the French Quarter and the neighboring Marigny neighborhoods alone with different sound limits allowed at different times. There are three more — bringing the total to ten — for the rest of the city. This does not include an exception for a buffer zone during religious services at St. Louis Cathedral in Jackson's Square and night sound level limits in the Square and other neighboring areas. On top of this, there are further regulations that include how loud amplification can be and from how far away, and street performers have to be mindful as to whether or not any crowds they attract are blocking public right-of-ways. Figures $4.17 \mathrm{a}$ and $4.17 \mathrm{~b}$, shown below, portions of MACCNO’s guide (2016a), display maps of the French Quarter and Marigny, with the different zones and noise levels allowed. In some cases, only one short, narrow street separates two different zones, as is the case with neighboring Bourbon and Royal streets. 
Figure 4.17a: Noise Zones (Music and Culture Coalition of New Orleans, 2016a)

\section{SOUNDLEYELSBYRECEINNGLANDUSE}

If someone complains about the sound level of your performance, the decibel measurement needs to be taken

from the property of the person reseiving the sound (person who complained) and not from the swures of tha soundl

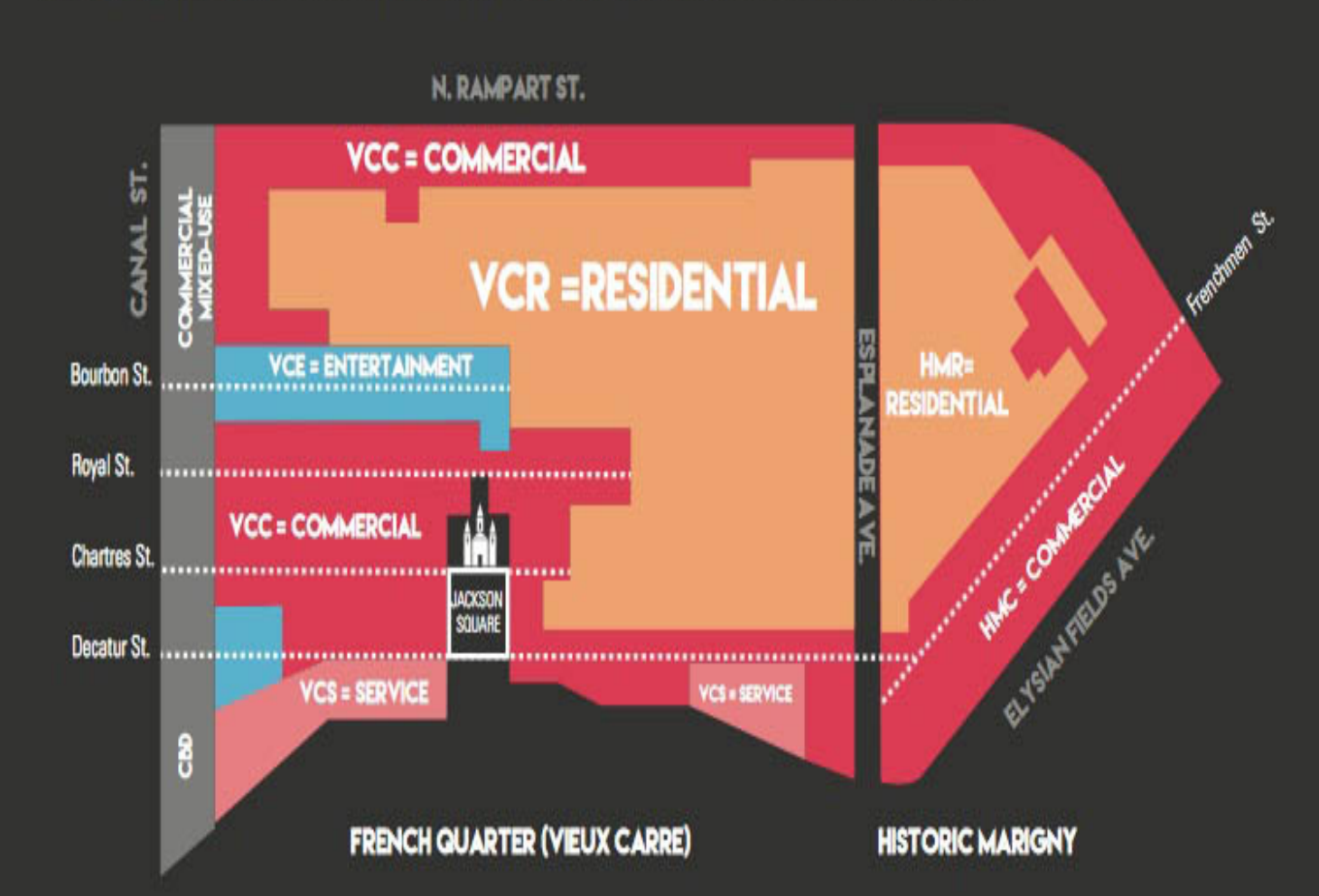


Figure 4.17b: Decibel Chart (Music and Culture Coalition of New Orleans, 2016a)

\section{SEC. $66-202$}
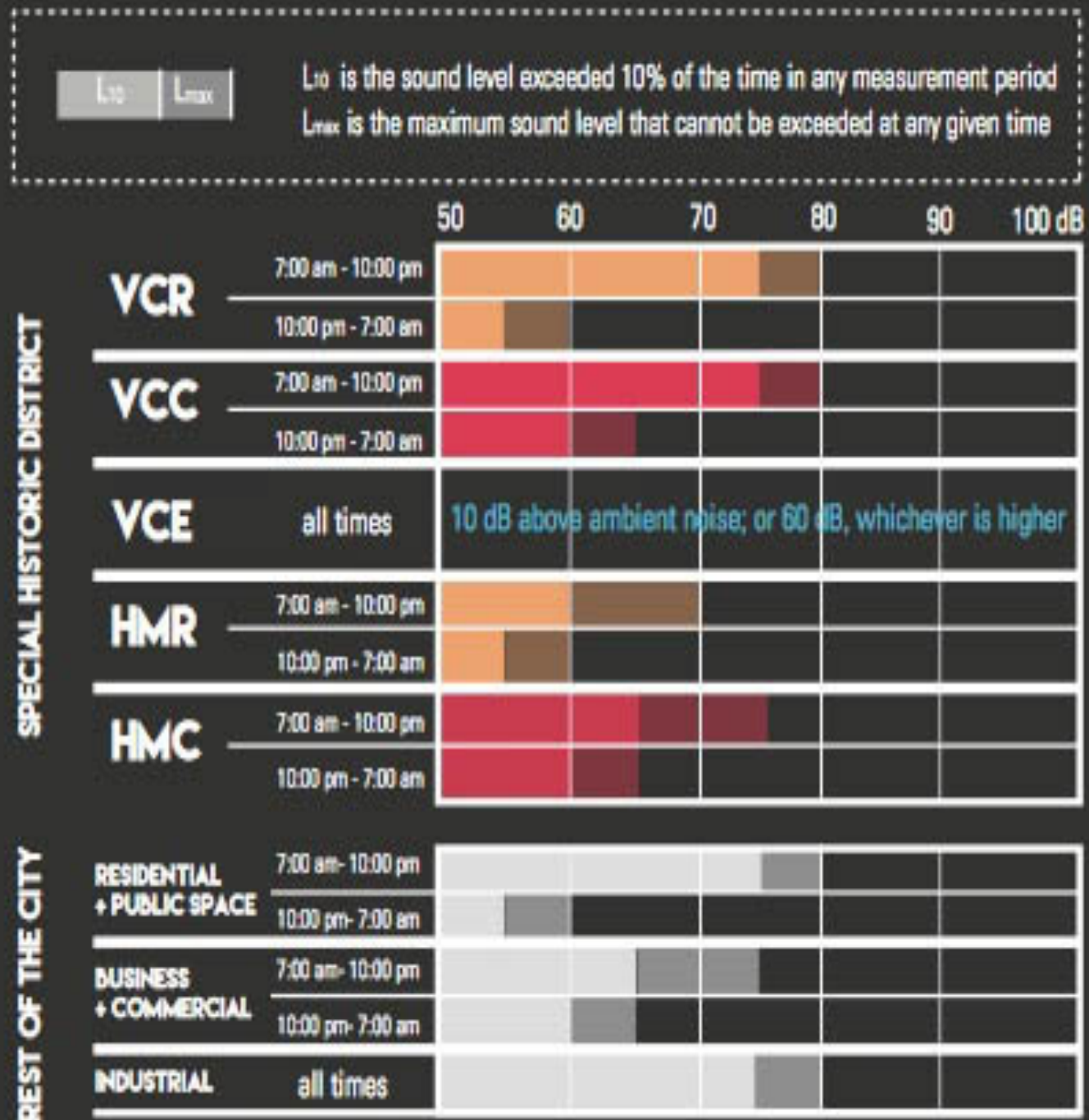

Also, the noise ordinance contains a curfew provision stating street musicians must stop at 8 p.m. (Times-Picayune, 2014). In 2014, the New Orleans city attorney deemed the curfew unconstitutional. "Until the ordinance is revised, the police are 
supposed to regulate noise around the clock" (as cited in Times-Picayune, 2014) and city council had not, as of this writing, been able to pass any revised regulations.

Olympia said that the ordinance remaining as it is all but keeps her hands tied, because of unconstitutional measures in the ordinance that namely include ones narrowly targeting music, the ordinance barely touching any other disturbing noise such as construction or barking dogs, or because certain calls she gets, often related to callers' personal tastes, would not be violations of the current or any future well-designed ordinance. One example she gave to demonstrate the current ordinance's ambiguity was regulations on noise from animals, like dogs barking, which state that someone is in violation if the noise would disturb a "reasonable" person. That begs the question of what is "reasonable", and therefore, she said, that part of the ordinance would not stand up in court.

Olympia: I would say that for eighty to ninety percent of the calls we get, we can do nothing about them. ... Once we have a workable ordinance, we can do some things. I have to argue with people every day. They call me saying, "But the ordinance says..." And I say, "But the ordinance is wrong," like it is unconstitutional or whatever the reason is.

...We get a lot of complaints about people who don't like the music that a bar is playing. They're things like, "They're listening to rap music, and it has profanity. I've got kids, and blah, blah, blah." Most of our street performer complaints are that the street performer only knows two or three songs, and they just play them over and over again, when whatever business or resident just wants them to play something different. But we constantly are letting people know that we can only enforce decibel limits, not the type of music that someone's playing or what someone is saying.

Harry, Susan, and Dean, a bar owner, noted how the current policies, even if they are not being enforced, still being on the books threaten the artistic community and 
businesses, especially because subsequent leaders could later decide to enforce these. Susan elaborated:

Susan: This is kind of the crux of our work, dealing with the ways that culture is treated under the law, and it's not pretty. I mean, legally, music is not allowed in most buildings in the city because of the pattern of zoning laws, which is completely fucking insane.

Dean added that the earlier-mentioned wealth structures could also lead to enforcing these still-existing problematic policies, and, like Olympia, also noted how ambiguous laws leave too many questions as to what is permitted and what is not. This is especially problematic for business owners like himself who want to obey the law - but cannot understand what the law is and are dealing with a law that even government officials cannot explain to them. This becomes especially problematic when anyone working to use those policies against someone like him has greater financial backing.

Dean: You're going to have the people that are on the side of the rich and powerful. That's kind of a normal thing. You're going to see that anywhere, no matter what the issue is. But when you have ambiguity, then how do you translate that into a definitive way of dealing with it? The ambiguity muddies the water. You have the people over here that are against music, citing the ambiguity as defense against the music. And then you've got these people here that don't understand it going, "Really? That's what it says? OK. I guess I don't know what to do with that, then. And the problem is that, then, you need somebody else who can translate what that really means or what it could mean.... And why do I have to play by different rules than the guy across the street?

New policy mechanisms proposed just before and during the study period created even more problems, sometimes ones artistic community members and advocates believed were even worse than the ones on the books. One example was the December 2013 noise ordinance that the brass band protested in January 2014. Besides its origins in unofficial and private policymaking forums, these groups pointed to parts that would 
essentially shut down live entertainment. One of the most significant changes, which would have affected the entire city and not just the French Quarter and Marigny, was that the proposed ordinance dictates that sound measurements be taken at the complaint source's property line (Webster, 2014a). Harry noted that in urban historic districts like the French Quarter, structures have to be built to the street — putting their property lines practically right where entertainers are performing and easily making an entertainment venue be over the limit should such an ordinance pass. Violations of any kind jeopardize liquor licenses, and this could shut down a venue altogether or have a venue choose to no longer offer live entertainment because of that risk. Therefore, such a policy measure would have put live entertainment in jeopardy.

Regulus, during his negotiations with city officials and the neighborhood associations, would have the neighborhood associations present what they called compromises that would have actually made his business create more problems — giving them greater ability to shut him down. One request the association made was to have people only exit the bar through the front door. The parking lot is in the building's rear. This means that those attending a large show with two hundred to 250 people would have to go around the building and through the neighborhood to reach their cars, creating a greater disturbance than if they simply walked out the back door and directly to their cars. He said:

Regulus: That's when I put my foot down because I knew there was no way that could happen. If they were going to close me if I wouldn't agree to that and that would be the straw that broke the camel's back... But if I agreed to that, they would be closing me down in no time anyway. So I said, "No, no, no. I'm not going to agree to that." 


\section{Place-Related Barriers}

This was a rather unexpected finding, but I quickly found out that a serious hindering factor was place-related, namely involving the city's transportation and infrastructure problems. These included but were certainly not limited to the city's flooding and drainage issues from its severe pumping station problems, crumbling and dangerous street pavement, and having severely limited parking. The transportation and infrastructure issues created a two-pronged problem — low attendance and high rancor. This kept artistic community members from going to functions like government meetings or community organizing forums at all or made it extremely difficult. The pavement, in particular, damaged bicycles and cars and equipment such as musical instruments being hauled on it. Both the drainage and pavement issues created major safety hazards, and, especially during the city's multiple flooding incidents, ate into their scarce incomes because of lost gigs and performance time. The transportation and infrastructure problems not only literally stood in the way of artistic community's participation, but it figuratively did so by creating even more resentment.

\section{Pumping Stations and Flooding}

The city's multiple pumping station-related flooding and constant drainage problems and related controversies with the city's Sewerage and Water Board (S\&WB) during the study period stood in the way of a meaningful dialog between the artistic community — and much of the citizenry as a whole — and the city government. The situation, namely according to my secondary source reviews, observations, and physical artifact examination were endemic of what citizens believed was a government 
neglecting citizens' basic needs and only caring about money and caused major public safety problems and economic losses.

For more than one hundred years, New Orleans has had a system of pumping stations to drain water from the low-lying city when it rains (Brasted, 2017; Pridemore, 2005). It has twenty-four stations with 120 pumps, with the pumps varying in their capacity (Brasted, 2017). There are also more than 68,000 catch basins for drainage throughout the city, and as of July 2017, the city had a backlog of 2,500 open service requests for clogged catch basins. I noticed this problem myself while in the city in January 2018, when the city was under flash flood watches just before Krewe Du Vieux began.

In late July 2017, parts of New Orleans flooded when a slow-moving storm dumped more than four inches of water on the city, and floodwaters reached some homes, cars, and businesses in Mid-City (Brasted, 2017). Two weeks later in early August 2017, another storm flooded multiple neighborhoods, with floodwater levels reaching "thigh height" on some streets as little as a half-hour.

While these may be considered freak acts of nature, the saga unfolded to reveal government failures that were both immediate and longstanding. S\&WB officials initially reported that the city's pumps were working in full capacity during the August flooding (Brasted, 2017). It was later revealed that sixteen pumps were not operating - once the number had been amended three times from reports of seven, then eight, then fourteen pumps. During the flooding, it took Landrieu's office three hours to release detailed information about which intersections were closed, with bumper-to-bumper traffic from people trying to flee. Also, the S\&WB power plant is more than 100 years old and 
operates on a 25 -hertz cycle electrical system that became obsolete before World War II. The local electric utility supplies a 60 -hertz cycle, meaning that the S\&WB cannot simply connect to the city power grid. It has to create its own electricity to power the pumps. Infuriated citizens showed their frustration during a hearing at city hall by shouting at officials, holding signs reading "LIES!" and spreading purple brooms and plungers on the city hall steps (Granger, 2017a, 2017b; Sayre, 2017b).

The situation put the city on edge even more during the 2017 hurricane season, even when the devastating Hurricanes Harvey and Irma did not directly strike New Orleans. After Harvey struck Texas in late August and began moving east, some pumps were still not working (Rainey, 2017d). Irma in early September was arguably even more dangerous because, if evacuations were necessary, the extensive Harvey damage on Texas' Interstate 10 corridor to the west and Irma directly striking at the east meant the only way out was north (Schleifstein, 2017).

Citizens utilized the arts and New Orleans culture to express their anger and frustration during Krewe Du Vieux, where the flooding and drainage problems dominated most of the parade's content. Besides floats showing longstanding citizen frustration with government, in general, they also included the earlier-mentioned float of Landrieu as a stripper accompanied by a pimp walking group, numerous different walking groups in S\&WB work vests, people wearing scuba gear, and a float with a boat called "NOLA's Ark". Arguably, the most scathing display was the "Mitch's Poo Poo Factory" float invoking purposeful toilet humor that displayed Landrieu as a man made of feces - a literal piece of poop - seated in front of an outhouse and atop a pump, complete with a plunger and a lifesaver with the S\&WB name on it. Walking groups that followed wore 
S\&WB work vests complete with cone-shaped feces hats with Mardi Gras-colored adornments and sparklers. The float and one of the hats are shown in the two physical artifacts shown in Figures 4.18 and 4.19, below.

Figure 4.18: Krewe Du Vieux float, mayor as man of feces (Pridemore, 2018)

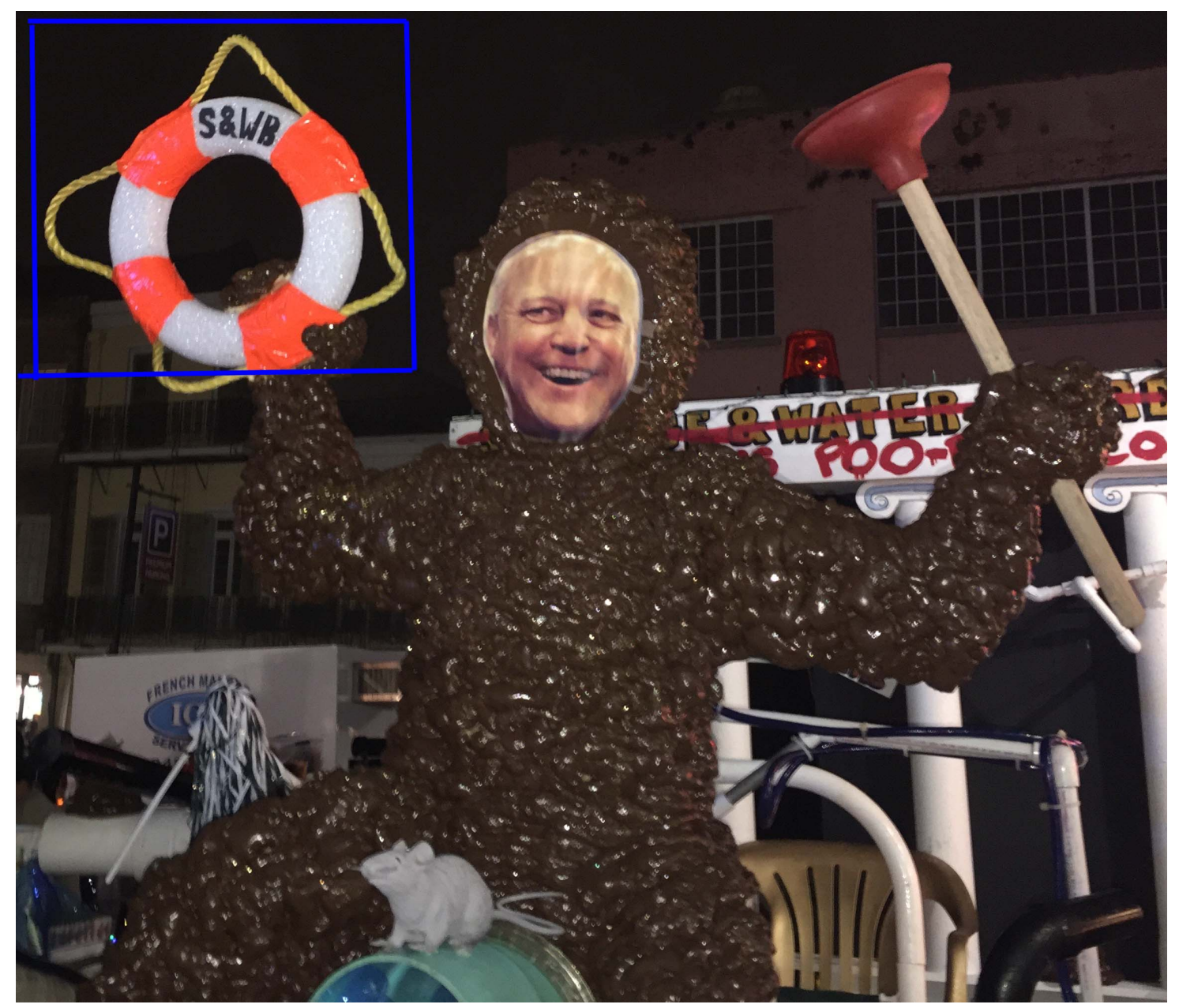


Figure 4.19: Krewe Du Vieux walking group feces hat (Pridemore, 2018)

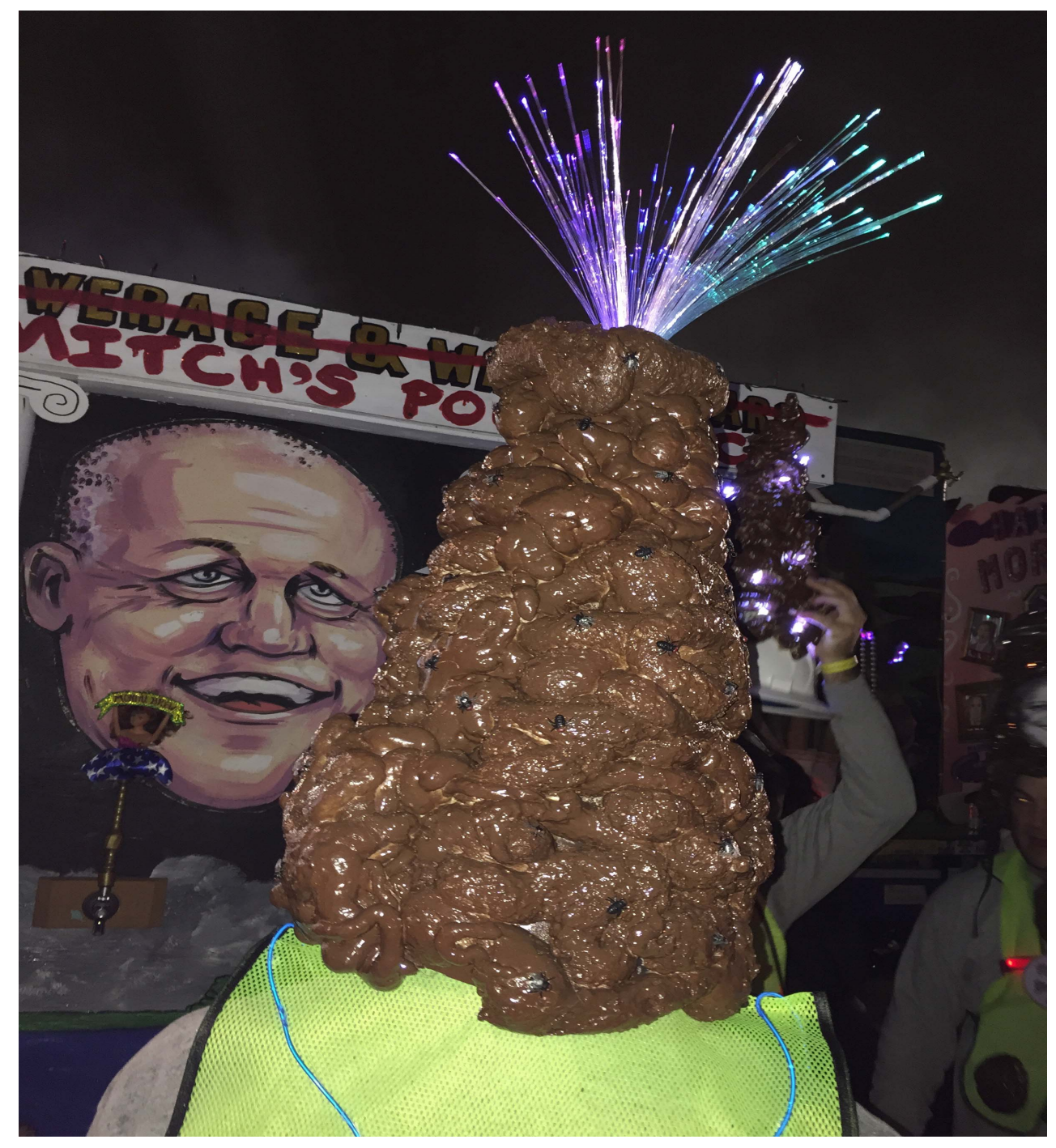

Krewe Du Vieux's annual newsletter, Le Monde de Merde (Translated from

French: The World of Shit), provided confirmation of the parade group's intentions in its discussion of a more explicit float I have chosen not to visually display. It invoked Katrina, the French heritage, the sewage, drainage and flooding, purposeful toilet humor given the nature of the situation - and the overall sentiment that the government abused it citizens. 
We even learned that, sometimes, even our levees need to take a leak. More than ten years after the greatest flush in New Orleans history, though, we thought we had plumbed the depths of that problem and come out the better and drier for it.

But no. Our Sewerage and Water Board, the master plumbers of New Orleans itself, have taken the city's No. 1 priority and done a royal No. 2 of it.

And so as a summer rain slowly rose up, New Orleans could see a swirl of promises go down the drain. The wee wee people, the mere citizens of the city, were wee wee'd on yet again by the powers that pee (Krewe Du Vieux, 2018).

\section{Transportation}

Transportation problems plagued the artistic community, with the chief concerns being horrendously crumbling street pavement and treacherous road conditions and little to no parking. I both learned this during interviews, my focus group, observations, and physical artifact examinations. I also had to pull from secondary sources because every attempt I made to personally photo-document some of the most atrocious pavement with some roads having more holes than driving space — was either ruined by the pavement nearly throwing my phone out of my hands or myself out of a seat during car rides or, besides the inherent reckless hazard of taking cell phone photos while driving anywhere, the fact that driving on the city streets alternated between feeling like I was in a Jeep Wrangler commercial from the ruggedness or James Bond movie from dodging giant holes.

The transportation issues not only made it extremely difficult for artistic community members to get to policy oriented venues like government meetings or community organizing forums but also be able to do their jobs. The pavement conditions constantly damaging cars and bicycles, as well as equipment like musical instruments, added to both their economic woes and frustration with city government even more. The 
practically non-existent parking created or exacerbated the same problems, especially when parking conditions necessitated less-than-ideal transportation methods.

Figure 4.20: FIX MY STREET high heel shoe (Fix My Streets NOLA, 2015)

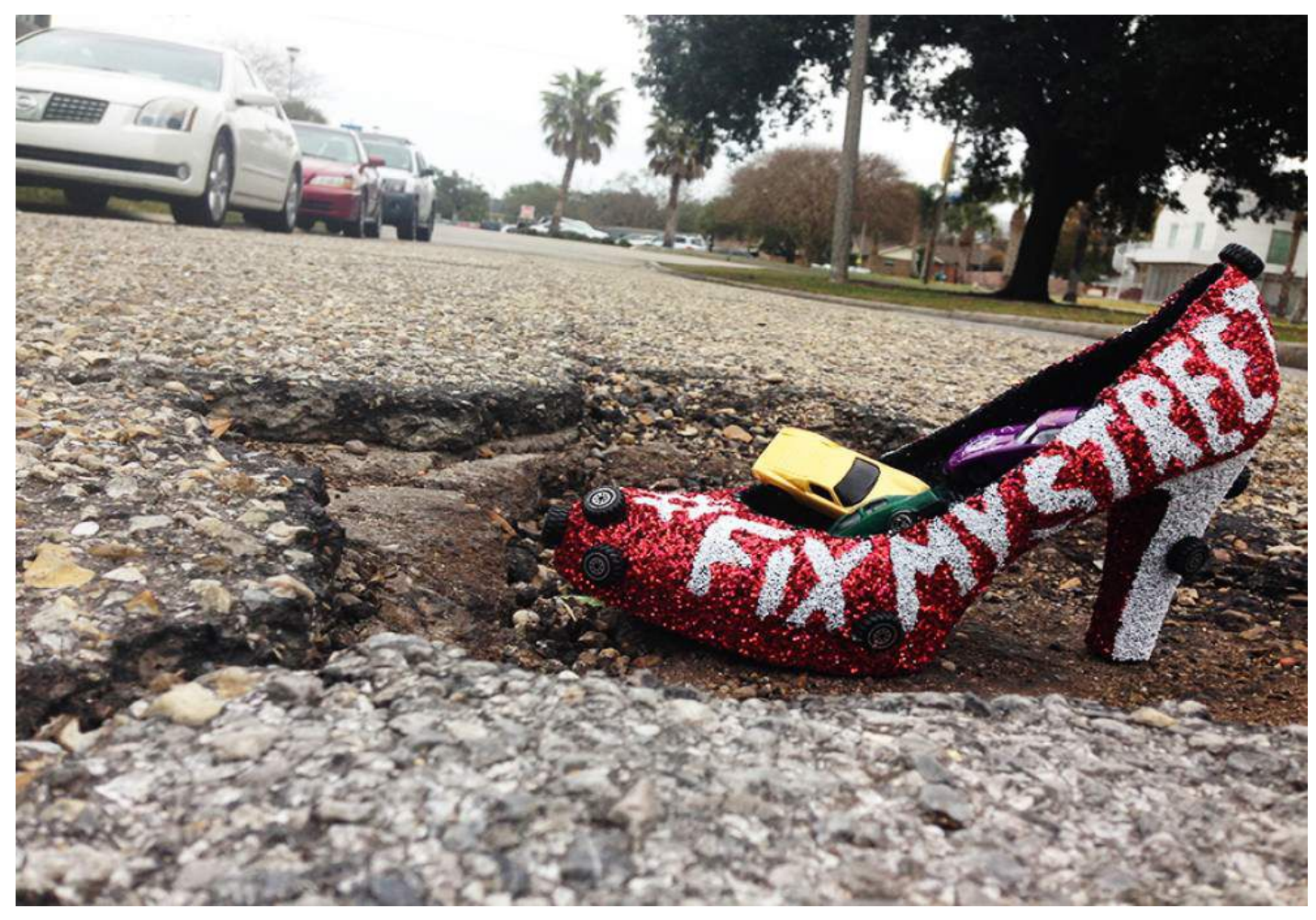

The secondary source photo above in Figure 4.20 shows a badly damaged New Orleans street, with frustrated residents utilizing colorful visual décor as protest. During my time in New Orleans, I regularly encountered potholes along with missing chunks of pavement covered with gravel. I quickly stopped wearing dress shoes in New Orleans after just two days of fieldwork because the sidewalk conditions on which people are both walking and riding bicycles were too dangerous and instead opted for running shoes or, when anticipating heavy rainfall on top of this, heavy work boots even when going to more formal occasions. One Lyft driver informed me that he had lost tires and, in one incident, a car bumper to the potholes. 
Multiple interviewees in both city government and the artistic community pointed to the severe lack of parking. The focus group members shined a light on how this and the pavement situation combined create a transportation nightmare for them. Most of the musicians, they said (which I also observed myself, later), use "bike carts" when going to any place where they have to or want to bring their instruments because they cannot find parking, and maneuvering a car during major events like Mardi Gras parades would be impossible, anyway. The bike carts are very small, often wooden and apparently homemade trailers attached to bicycles that people were using to haul instruments as large as tubas or drum sets. This becomes very dangerous for their instruments, personal safety, and livelihood when they either risk wrecking their bicycles on the pavement or find themselves eaten with repair costs for instruments and bicycles. The only saving grace in terms of biking being easier is the city and most of its streets being rather compact.

Garrick: You get a lot of exercise on your bike (The group members laugh.)

Lee: Well, my tuba is in the bike cart and rattling around back there. It's getting damaged because of the means I need to transport it. This city is great for biking, but not necessarily because of any intentionality. It just sort of happened that way. It's easy to get around. Things are kind of close, but the conditions of the street are literally going to damage my instrument, while I'm just trying to move it from my house to get to the gig.

Lucius: Or you can wreck on the streetcar track and break your ribs.

Lee: ...If I only moved my tuba in a bike cart and didn't play it, but I only moved it three times a month - getting somewhere and not getting to play it... If I were do that three times a month... At the end of the year, that tuba would need to be repaired just because of the amount of... The streets. They're really, really rough. 
Bicycles I observed throughout New Orleans, especially when members of the artistic community were riding them, were not only high in numbers but also tended to be in extremely rough shape. I took the photo in Figure 4.21 below of the bike racks directly in front of city hall, a specific location where interviewees told me the severe parking problems hurt citizen participation. Besides the bicycles' rough conditions that include heavily taped seats (as circled in pink) items such as baskets, racks, and a child seat on the back of a bike (in blue square boxes) showed how a lot of people have to rely on bicycles for so much of their daily activities and in a place where transportation conditions are certainly not ideal. I found another bicycle with a missing seat and wheel chained right beside the main crosswalk going to city hall's front entrance.

Figure 4.21: Damaged bicycles at city hall bike racks (Pridemore, 2017)

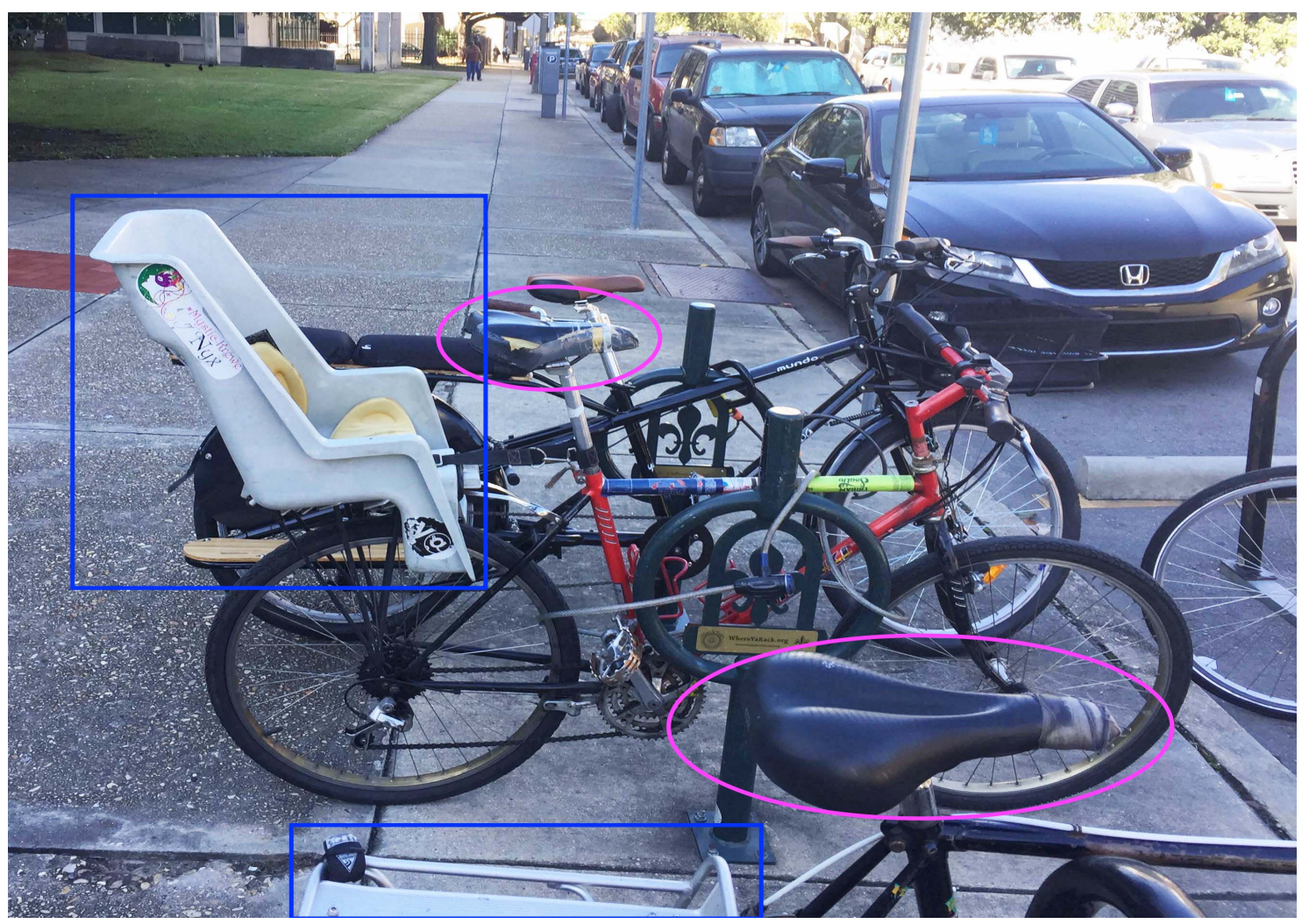


Krewe Du Vieux's 2018 newsletter also pointed to the transportation problems, as well as ones involving infrastructure, reading in part:

Also marching will be many of the city's top brass bands. Showcasing the local brass band talent is one of the few Krewe Du Vieux traditions that don't need to be unclogged, repaved, or otherwise completely repaired (Krewe Du Vieux, 2018).

As was the case with many of the other issues in this chapter, the focus group participants told me that the street pavement was only a piece of a larger, more systematic and longstanding problem of a government that ignores or abuses its citizens, especially ones who create what the government promotes so heavily.

Lee: I'm not even necessarily complaining about the streets. It's just sort of like we come to this question of the authority - the government - over you. The streets? That's a government issue. That's their bag, and they're not taking care of that and a bunch of other things. It's really hard. You always feel like... If you're looking at these situations, you're looking at yourself as one entity, the government as another entity, or whatever, it's, "What's the mutual give and take here?" If you're constantly just getting yelled at all the time, and you're trying to bike home, and you hit a pothole, and your front tire blows out, you drop your things... All of a sudden, it's like, BAM! "You're hassling me about something, and you're not even doing the thing you're supposed to be doing." That's very frustrating.

\section{Barriers Related to Other Community Stakeholders}

Others in New Orleans outside of government and artistic communities created major participation hindering factors, namely when they had tremendous economic power over artistic community members. These included not only further attempts to temper boisterous entertainment areas, but they also put major pressure on artistic community members to stay silent on policy matters the artistic community favored. In some cases, the artistic community members were forced to publicly oppose policies they 
actually supported. The consequences included losing ones job, being blacklisted and not getting any more gigs, and their workload combined with economic pressures keeping them from having a voice kept them from working to participate in policymaking processes that would help them. On top of this, the same parties and work situations responsible for this situation caused artistic community members to endanger their health and their entire careers just to financially survive. This affected the bureaucracy's outreach efforts because certain artistic community members were in situations where they could not collaborate or receive help from the bureaucracy, preventing further dialog.

\section{Attempts to Temper Boisterous Entertainment Areas}

One of the major controversies involving the New Orleans (as well as other cities') artistic communities is wealthy newcomers' attempts to significantly quiet down or even shut down historic, longstanding boisterous entertainment districts, entertainment venues, and cultural practices. The fact that anyone would move into a neighborhood well known for entertainment or beside an entertainment venue and then complain about the noise in trying to alter the neighborhoods' characters was simultaneously confusing and infuriating for artistic community members, venue owners, and their advocates. This was especially true for those on the receiving ends of the resulting policy measures.

Olympia, and Dean, who had a wealthy resident try to shut down his business, illustrated this point.

Olympia: There's mixed feelings about this, but if you bought a house on Bourbon Street, like...

Amelia: In other words, if you wanted your peace and quiet... 
Olympia: You should not have moved to Bourbon Street.

Dean: We always use the airport analogy, right? If you move next to an airport, and you know it's an airport, well, then you can't complain about the noise from the airplanes that are flying over your property.

\section{Pressure from powerholders not to voice opinions on favorable policies}

Interviews with artistic community advocates, one musician, and one government official pointed to artistic community members being not only forced to stay silent on policy matters that would benefit them, but it went further in that some were forced to speak against policies they favored. The parties responsible, the interviewees said, included some government entities and employers such as certain venue owners. Otherwise, they would lose their jobs or be blacklisted from being booked for more gigs. This pressure translated into hindering further dialog with certain bureaucracy members because they were not allowed to speak with or receive help from the bureaucracy during outreach efforts.

The artistic community's economic pressures eroded their power position even further because, artistic community members, advocates, and one government official said entities such as entertainment venues and government entities pressured them not to voice their support for policies that would benefit them — or even threaten their livelihoods if they did so.

They used the example of city health officials and advocates working to ban indoor smoking at venues, where entertainers were working sometimes seven hours at a time in smoke-filled rooms. Lavender told me that many artistic community members, 
namely musicians, privately told her they supported the ban because of their health and encouraged her to fight for it, saying, "Please. You have got to help us. We have to keep our jobs here, but for God's sake, make it the law.” However, their employers were going further than merely silencing them and forcing the artistic community members who actually supported the ban to speak against it. Otherwise, they would lose their jobs.

Protecting their livelihoods had already reached the point to where members of the artistic community were literally endangering their health to the point of risking career-ending injuries. Lavender and Parvati, another advocate who is also a medical doctor, said these include but are not limited to dancers breaking their legs and vocalists losing their voices when I interviewed Lavender and Parvati together.

Lavender and Parvati further explained how artistic community members, namely musicians and dancers, hid injuries as well as mental health conditions and continued to work while injured to save their jobs. Those whose employers provided health coverage would not use that coverage because, by going through claim forms, employers would know who has a medical condition and not allow that person to work. They said:

Lavender: A young dancer said to me, "Nobody plays with the broken doll."

Parvati: I think that's what's so different, if you look at athletics versus performing arts. In athletics, it's not that unusual for injuries to occur. The game stops, they run out, they take the person...

Lavender: Yeah, and there's, like, 40 million people there, and he just broke his collarbone.

Parvati: But everyone's like, "Great, we're going to get him back. We got these therapists. We have all this stuff." It's not the same as musicians and dancers hiding injuries, even from their friends. They don't because it's just so... Nobody wants to be injured, an athlete or an artist, but when the artists are injured, they can't speak about it. They're still so suspicious even when we're trying to help them because it means that then you're branded as, "Oh, the injured one, and 
you're always out, and I can't..."You don't get cast and when you don't get cast, and you get looked over year after year...

Such an environment also undermined city employees' outreach to the artistic community as well. Olympia also pointed out that certain artistic community working conditions put entire careers at risk in the long term. The city's health department has an initiative called "Sound Check", which promotes healthy sound levels at entertainment venues and promotes hearing protection for musicians working in loud conditions (Personal Communication, 2017). Olympia noted that while most musicians were receptive and wanted to wear hearing protection, some venue owners were not allowing musicians to wear earplugs while playing at their venues. She said:

Olympia: Some people really like what we're doing. We'll have some musicians come up and say like, (whispers) "Can you talk to our drummer?" They'll come over, like really quietly, and be like, "I don't want anyone else to know I told you this, but can you come talk to our drummer? He gets really loud, so then the rest of us have to get loud and it's getting out of control." Some musicians are fully aware that they've lost their hearing or that they're starting to lose their hearing, but playing music and making sound is what they do. It's not only their livelihood, but it's their passion. Some of them feel like we're taking that away from them. There are also immediate needs versus long-term needs, right? So, their hearing might go, but is that five years away, ten years away, or twenty years away versus, "I need to eat today. I need to pay my rent tomorrow." You have to consider that people have what they need and their livelihoods. ... But are there some out there whose minds I can change? Probably. We also have a lot of people who are employed directly by businesses who have said, "I can't talk to you. I want to wear earplugs, but I've been told I'm not allowed to."

Another power-related economic pressure artistic community members have is being blacklisted if they voice an opinion on an issue that is in opposition to a more powerful entity's - meaning they could very well lose gigs from more than one venue if they speak out. Michael explained: 
Michael: In today's time, the first thing is, "What are they going to dig up on me?" This is also probably highly unspoken, but if I do get up there and I do want to say that things are not working toward my benefit, how is that going to hurt me economically? How many gigs am I going to lose? That's one reason why there are very few musicians who participate in the political arena, even if it's just advocating for themselves. It's simply because, "How is this going to hurt me economically?"

...Take the Convention and Visitors' Bureau. They're one of the most powerful entities in this city because it's tourism. It's their job to promote and get tourism, right? ... Let's just say I decide to go to the city council and say that I don't agree with the noise ordinance and that I believe musicians should be able to perform at Canal and Bourbon streets because it's on a public street just like any other street - as long as they're not blocking the roadway, they should have the right to perform. ... So, let's say I go to say that, and they have spoken out saying that they don't want bands. Now, I am going against them. Now, the political arm says, "Who is this guy? We need to shut him down." The first thing is that you're blackballed. So those bigger gigs that might come through that organization? You ain't getting them no more. You ain't getting booked no more. So, if you put your name in the political hat - your festivals... "He's on that (blacklist). We're not booking him." That's a reality. It's an unspoken reality, but it's a reality.

\section{Barriers Related to Artistic Communities}

Major participating hindering factors were also related to the artistic community, as well. One involved their mistrust of government officials, namely the city police department and elected officials, because of an egregious history of corruption and crimes that go all the way to police officers' murdering citizens. Continued ramifications and traumatic memories of Hurricane Katrina was a contributor. That deep mistrust made artistic community members hesitant or unwilling to work with government officials.

Serious problems existed within the artistic community itself, with factors such as infighting, tribalism, longstanding feuds, intense competition, old social orders, and clashes between those participating in traditional and contemporary culture standing in the way of not only working with city government but also with one another. Some 
artistic community members decried this situation, noting that a divided artistic community meant that it would eventually fall without putting aside their differences. Without a united front, participation efforts would either not work or never so much as materialize.

\section{Not Trusting Government Officials}

New Orleans' sordid past with government corruption has created not just a divide. It has created a chasm between the artistic community (and citizenry as a whole) and the local government. Some of the most atrocious actions have some from the city's police department, but its elected officials in both the city and state of Louisiana being embroiled in corruption scandals have certainly contributed to citizen mistrust. The continued ramifications and trauma from Hurricane Katrina have exacerbated the situation.

\section{Corruption History Part 1: Political Corruption}

The history of general government corruption, especially when factoring in Louisiana state politics and political machines that have affected New Orleans residents, is very longstanding and heinous, with many artistic community members, the citizenry as a whole, and outsiders seeing these government entities as being unjust and preying on citizens rather than serving them. This has not created a divide. It has created a chasm. Corruption scandals involving local, state-level, and federal politicians have added to the mistrust the artistic community has of its government. Essentially, the view among artistic community members is that they do not want to work with public officials who either have sketchy records or, if officials are truly honest now, will eventually become 
corrupt after working in government. This was also reflected in outlaw citizenship displays.

Louisiana was ranked the most corrupt U.S. state in 2013, with the largest number of per capita public corruption convictions according to U.S. Department of Justice data compiled between 2002 to 2011 (Daily Mail Reporter, 2013). Political machines have dominated since the rise of legendary or infamous (depending on who is asked, even to this day) Louisiana populist politician Huey Long (Kushner, 2010), a former governor and sitting U.S. Senator with presidential ambitions when he was assassinated in 1935 (Times-Picayune, 2011).

One of the most notorious chapters in Louisiana and New Orleans history is the dramatic public feud between the state and city governments in 1934 (Karst, 2016a) when Long ordered 2,500 state National Guard soldiers to storm the New Orleans city voter registration office, claiming city government corruption was rampant. Long's goal was to strip New Orleans' then-Mayor T. Seemes Walmsley, a political ally-turned-foe, of power over the city police department and establish his own tax assessment entity. Just a few months before the standoff, Walmsley, of the "Old Regulars" political machine, had also defeated a mayoral candidate from Long's machine. Walmsley responded by having the city deputize "a force of about 500 special police officers, armed with submachine guns, and stationed them outside city hall” (as cited in Karst, 2016a).

Besides political machines' dominance to the present day, a lasting piece of Long's legacy is abuse of power and using public service for personal gain (Kushner, 2010). Another egregious example was the 1991 gubernatorial election, which ended with both candidates going to federal prison. Edwin Edwards, a former governor, was 
already on trial for mail fraud and bribery, and his opponent in the runoff election was former KKK grand wizard David Duke. After a campaign that spawned bumper stickers like "VOTE FOR THE CROOK" (meaning Edwards) because the alternative was a former Klansman, Edwards won a third non-consecutive term, but he and his son went to prison "for selling casino licenses and prison contracts". Duke also went to prison after being convicted in a "mail fraud scheme that duped thousands of followers into giving him money" (as cited in Kushner, 2010).

This legacy and its very related citizen mistrust continued into much more recent years and continues to add to artistic community members' mistrust of government officials, even when officials portray themselves as do-gooders who want to make positive change. Ray Nagin, the city's mayor during Katrina, is now in federal prison after corruption convictions (Lane, 2016). Nagin was convicted in 2014 on twenty counts "that included wire fraud, conspiracy, bribery, and filing false tax returns" (as cited in Lane, 2016). He is serving a ten-year prison sentence (Lane, 2016; Rainey, 2016), as of this writing. During his trial, Nagin was shown to have taken "hundreds of thousands of dollars in bribes over several years" from "businessmen seeking breaks from his administration" (as cited in Lane, 2016). These bribes included money (Lane, 2016) as well as "gifts, free trips, promises of post-term consulting gigs, and, in one instance, free shipments of granite for his sons' countertop company, from businessmen chasing city contracts or looking to smooth away bureaucratic obstacles" (Rainey, 2016).

Kingsley noted that Nagin is the only New Orleans mayor to have gone to prison, "believe it or not". Neville, a New Orleans filmmaker, pointed out Nagin's conviction and said Nagin's successor, Landrieu, was not well-liked at all toward his term's end, 
either. Neville indicated that New Orleans residents believe that even those who may want to make positive change now will become corrupt once they become embedded in government.

Neville: People used to get elected as anti-corruption. Politicians in the old guard end up being exactly like the people they railed against and end up going to prison just like the people they railed against.

Ray Nagin was elected, basically by saying he wasn't going to be business-asusual and that he was going to put old racial divisions behind. But when he came up for re-election, he had to use those same old racial divisions to get re-elected, and he barely did. ... So the guy who was the do-gooder or good government guy when he's running for office, ends up getting indicted for something. You never know how. That's the reason people don't really trust politicians because "the honest man" becomes the guy in prison sometimes - actually, most of the time.

...It's like, “Ah, he's honest now, but wait until he's done. Just wait, and then, you'll see what he's up to."

Even before the mayor-elect during the study period, Cantrell, had taken office, that above reaction seemed to be the case because of the credit card controversy (LaRose, 2018b; O’Donoghue, 2017; Rainey, 2017f). During the transition, Anthony, a street musician and focus group participant, wondered if Cantrell would actually take office because, "She's got some problems now." (Cantrell did take office in May 2018.). Further citizen mistrust in government was vividly on display during Krewe Du Vieux, which was also a powerful display of outlaw citizenship utilizing the arts. When citizens lash out with outlaw citizenship, according to the literature (Pridemore, 2018; Rimmerman, 2011), it is because they do not believe they will be heard otherwise. Just two days after I witnessed the Master Plan public hearing, I saw Krewe Du Vieux provide a clear-cut example. In the January 2018 parade that noted the city's $300^{\text {th }}$ anniversary, the parade (to be discussed more throughout the New Orleans chapters) displayed 
numerous floats, walking groups, and bands invoking the old French culture that sent the message of, "Three hundred years later, and everything is still terrible", such as shown in this float in Figure 4.22, on which I did a physical artifact examination.

Figure 4.22: Krewe Du Vieux float, 300 years of ineptitude (Pridemore, 2018)

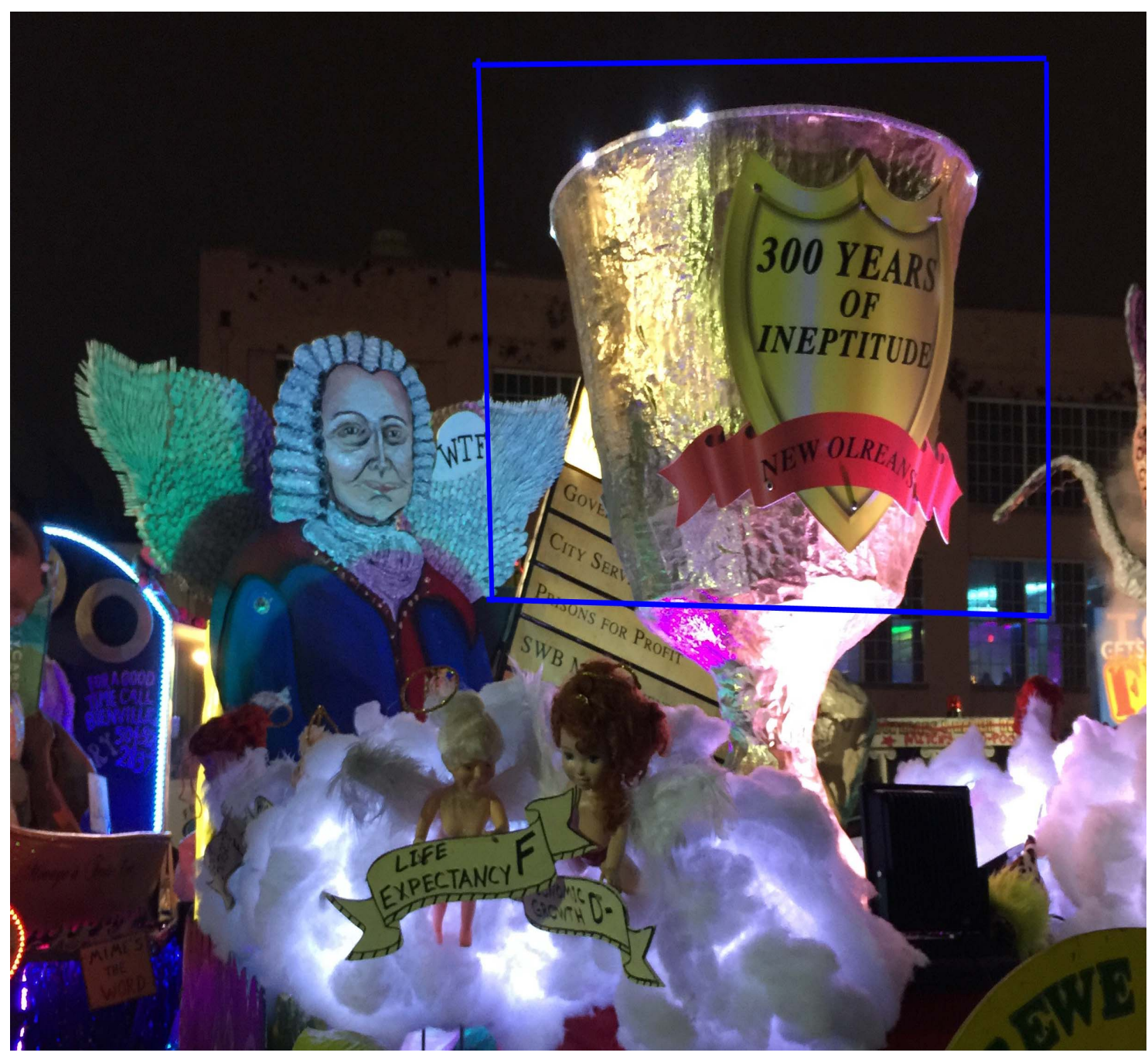


Figure 4.23: Krewe Du Vieux float, New Orleans report card (Pridemore, 2018)

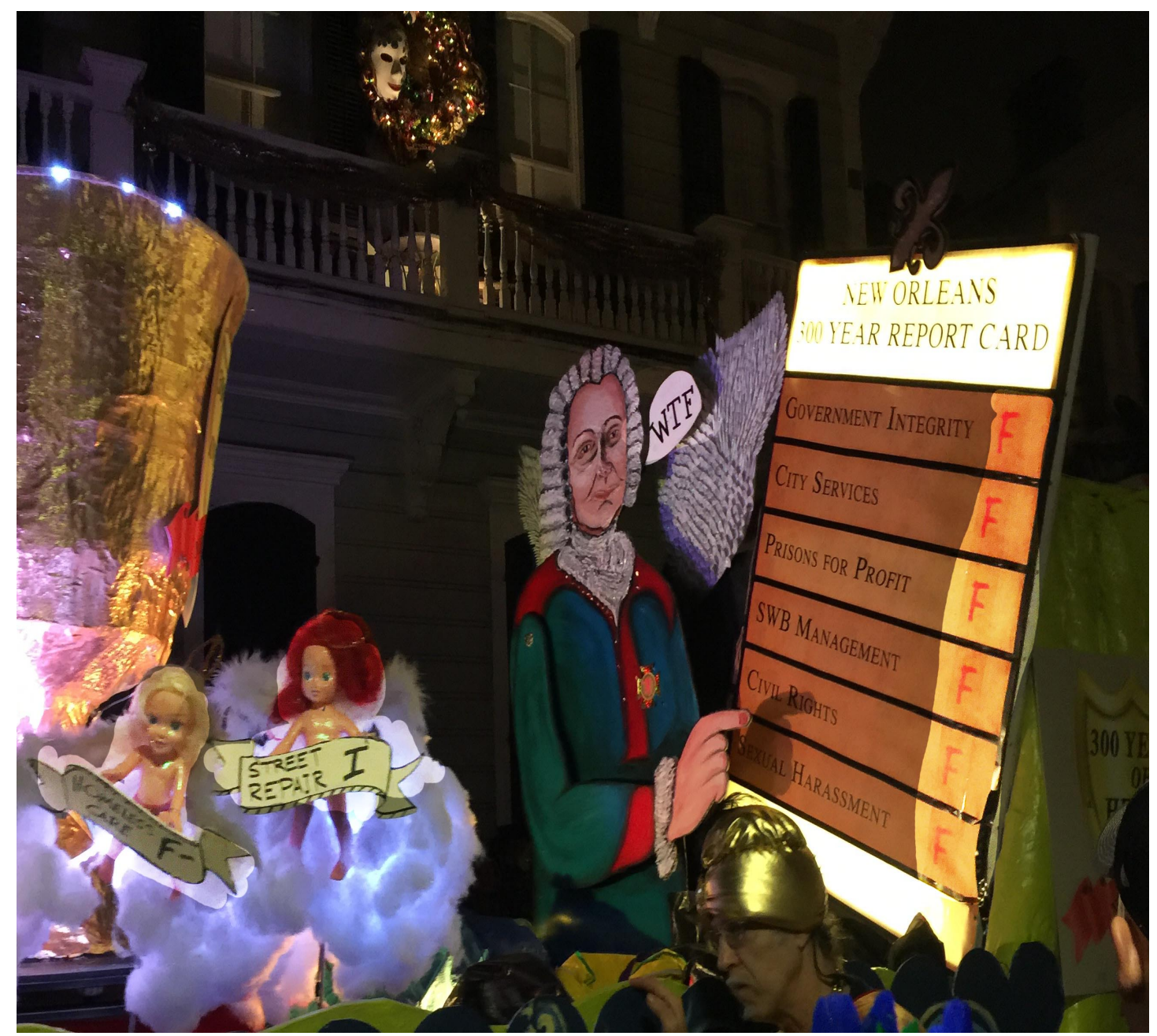

The float shown above in Figure 4.23 depicts Jean-Baptiste Le Moyne, Sieur de Bienville, the French-Canadian explorer and colonizer who founded New Orleans in 1718 (Krewe Du Vieux, 2018; Times-Picayune, 2018) as an angel looking down from the heavens and through the angel-filled clouds at the city he founded with an aghast "What the fuck?!". The parade's overall theme, "Bienville's Wet Dream", was one intended to capture both a relatively short-term and extremely long-term negative 
situation for New Orleans — both to which citizens saw no end because of its political environment.

Krewe Du Vieux, in its newsletter explaining its theme, told an overall story arc of Bienville's dream that became all wet - a dream of a glorious city that, though it became beautiful, was one that unjust powerholders governed for three hundred years and, in doing so, abused its citizens even to the present day (Krewe Du Vieux, 2018). The "wet" theme was also pointing to citizens' fury over the city's malfunctioning pumping stations and related repeated flooding, particularly after promises that they were safe after Katrina's catastrophic flooding.

Krewe Du Vieux's organizers detailed dubious and controversial historic figures and eras the city has lived through, such as slavery, having Confederate monuments, elites and the longstanding rigid social order (to be explained later in the chapter), and flooding and storms including but certainly not limited to Katrina (Krewe Du Vieux, 2018). The overall message, though, was that nothing had changed. This was namely shown in the "report card" that Bienville is holding that gives the city failing grades for sewer and water management as well as government integrity, city services, and civil rights. The same grades are also displayed with the dolls throughout the clouds, giving the city an "incomplete" grade on services such as street repair. Floats I examined such as one skewering the Cantrell credit card controversy and one showing the city completely underwater by the time its $400^{\text {th }}$ anniversary comes shows how some citizens believed the government culture would never change or even make their lives worse. 


\section{Corruption History Part 2: New Orleans' Police Department}

The New Orleans Police Department's corruption history is the most heinous, with a troubled history that includes murdering citizens, as well as police officers convicted for both corruption and violent crime (Hoye, 2014; Mustain, 2014; Personal Communication, 2017; Public Broadcasting Service, 2010; Simerman, 2016). Two former New Orleans police officers, Len Davis and Antoinette Frank, are on death row for murdering citizens, just five months apart, during the 1990s (Hoye, 2014; Mustain, 2014; Simerman, 2016). Just during the week after Katrina struck in 2005, officers shot at least ten people with "nearly a dozen" officers involved in the shooting and subsequent cover-up of the bloody Danziger Bridge incident facing criminal charges (Grimm, 2015).

The U.S. Department of Justice initiated an investigation into NOPD in 2010 for alleged misconduct, with a written report issued the following year documenting the DOJ's “finding of a number of patterns and practices of unconstitutional conduct and details DOJ's concerns about a number of NOPD policies and practices” (U.S.

Department of Justice, 2012). The city police department voluntarily entered the consent decree in 2012, with it being finalized in 2013 (Personal Communication, 2017; U.S. Department of Justice, 2012). Kingsley explained that the consent decree "gives a very broad oversight of the New Orleans Police Department to a monitoring team that directly reports to a federal judge."

Kingsley readily acknowledged his department's troubled past and how that would deeply affect its relationship with not only the city's artistic community but also all New Orleans citizens. 
Kingsley: I mean, I tell my wife it's a different world if a New Orleans police officer kills somebody. We're talking about murders. We've murdered people in the past. It's one thing when a criminal kills another citizen. It's a completely different thing when it's an entity of the government, right?

So think about it when the New Orleans police kill a citizen. That happens in North Korea. That happens in Putin's Russia. You set the expectations that extrajudicial killings don't happen in America.

... So it certainly creates a barrier if I ask a member of the community to trust me. Why the hell should they?

Kingsley, a New Orleans native, said that he used to get upset when people would talk about Len Davis and Antoinette Frank because those incidents happened while he was in high school and before he even joined the department, and in the hometown he deeply loved, saying, "That's not my New Orleans." Then, he was on duty during Katrina, both personally experiencing the horrors of the storm in his home and while other officers were involved in the Danziger Bridge incident. This changed his perspective, consent decree or not. Many of the problems were related to hiring practices, supervision, discipline, and belief that misconduct would go unpunished.

Artistic community members and other citizens had not forgotten NOPD's past, either. During a focus group I conducted with street musicians in the city, the participants told me about their negative encounters with city police, and some visually depicted these in their narrative maps. This particular map, shown in Figure 4.24, from Lucius, one of the focus group street musicians, shows a police officer standing in the way of his freedom, creativity, and livelihood and keeping him in poverty. 
Figure 4.24: Narrative Map (Reality): Lucius, street musician

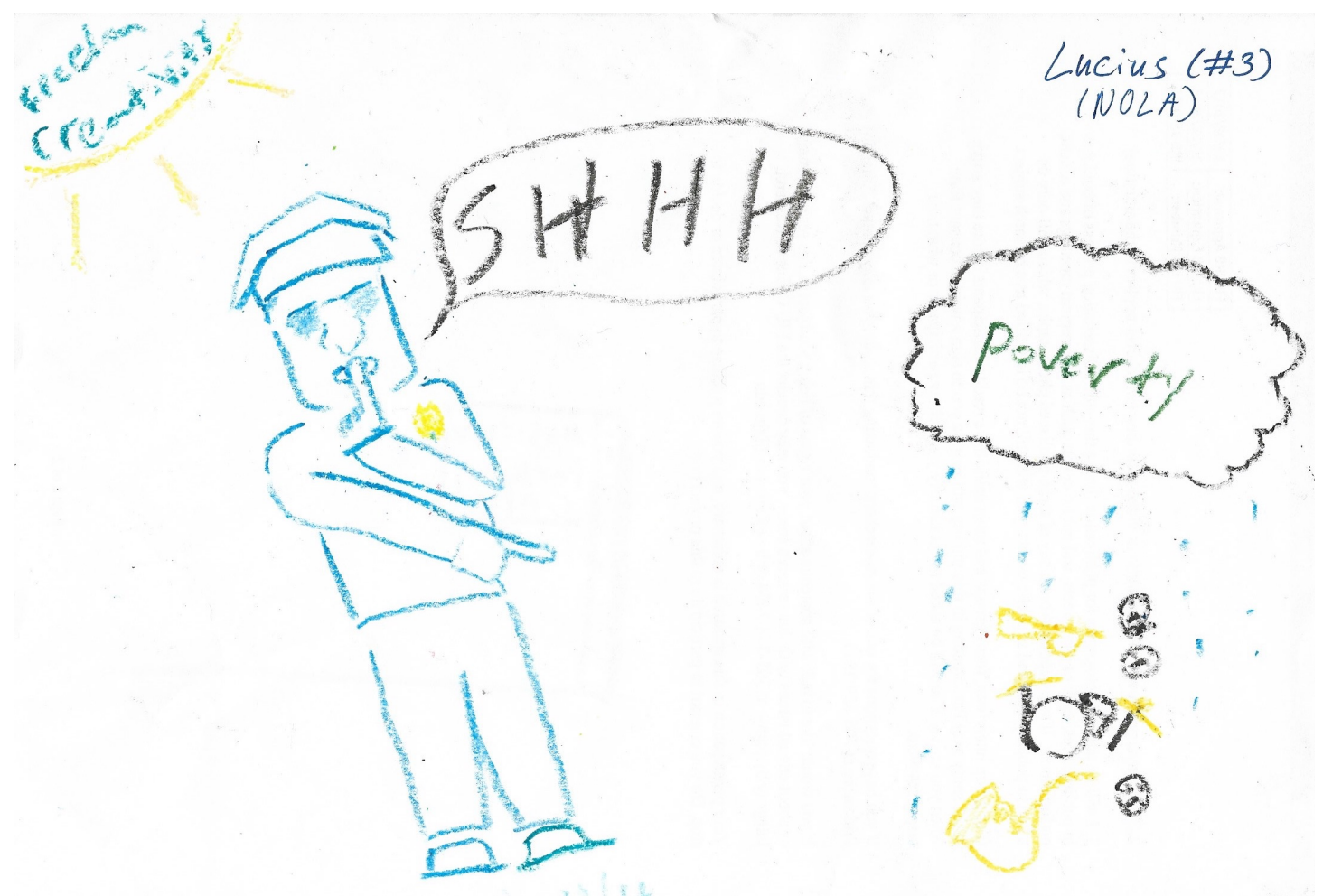

The focus group street musicians described their frustrations about and lack of faith in NOPD, noting the consent decree and the fact that the city ranked third for murders in the United States in 2017 (CBS News, 2018). Personally for them, they said they have received multiple tickets for "obstructing" sidewalks that have cost them as much as $\$ 150$ or time spent in court fighting tickets when they could be on the streets earning more money. The current murder rate was very distressing for them, given they are both on the city streets and usually have cash tips on hand. The latter especially makes them a target. This was an exchange I had with them.

Lee: I don't think NOPD has an image that can be tarnished by people who are often, maybe less, doing frustrating things. That's my opinion. 
Garrick: Well, yeah. They've been so corrupt and feeling like they're above everything that they're hiring the federal government to come here and go to the police stations to fire people.

Lucius: That's the consent decree, right?

Lee: Very controversial.

Amelia: So, in other words, you can't tarnish it anymore if they're already under federal investigation, and they've got this long history that goes all the way up to murders of citizens?

Lee: Right.

Garrick: Yeah, and we're already up to competing with Detroit and Baltimore with being the murder capital every year.

Lee: I'm not necessarily a fan. I don't think NOPD does a bang-up job.

Susan pointed to the 2005 St. Joseph's Night holiday incident involving the police, in her words, "brutalizing" Mardi Gras Indians, saying, "I use that as an example as sort of the climate in which music and culture is treated." In 2005, "officers sped through crowds and told Indian chiefs to remove their extravagant suits or go to jail" (Reckdahl, 2010). The Mardi Gras Indians, whose gathering is celebrated on St. Joseph's Night, is a longstanding tradition in New Orleans known as "Masking Indian" (Oliver, 2007). While determining its exact history is difficult, "most agree the ritual song, dance, and costuming began as a way for African slaves" brought to the United States to celebrate their heritage, complete with new suits every year that often cost thousands of dollars in materials and take an entire year to make (Oliver, 2007). One of the possible explanations of its roots is that Native Americans harbored runaway slaves (Oliver, 2007; Personal Communication, 2017). 
Kingsley explained the significance of this tradition and acknowledged the 2005

events — and similar incidents involving St. Joseph's Night before that.

Kingsley: The Mardi Gras Indians... I mean, it's almost magical watching them. ... It's just an unbelievable thing. The New Orleans Police Department didn't understand what that was.

...It's basically African-Americans paying homage to Native Americans who helped them escape the bonds of slavery. This is the symbol that it is. There's real stuff going on there. This is not just an excuse to walk around and drink a beer and wear feathers.

So in the spring of 2005, the police department, when the Indians came out, allowed them to do their thing during the day, and then, at night when the sun went down, we did what we had done previously, which was having everyone turn on their lights and sirens, running police cars on the streets, making everybody spread. They started throwing people in jail for petty things like obstruction of public passage, public drunkenness, and things like that. They're really those charges that police sometimes use to have an excuse to put people in jail. ... The community felt like it was too much, like, "We're tired of being beaten down. It's 2005 . We're tired of this every year, when we're doing this cultural thing."

In his narrative mapping shown in Figure 4.25, Kingsley depicted what his department's current relationship was like with the artistic community. The blue circle represents what he called the police department's "circle of trust". The blue dots inside represent police officers, and the yellow dots inside represent members of the New Orleans artistic community. He chose yellow because he wanted to show the artistic community's vibrancy. Some yellow dots were inside the circle because of inroads the department has made in creating positive change (to be explained in greater detail in a subsequent chapter). However, the yellow dots outside the circle represent artistic community members who still mistrust police, showing that work remains to be done and that Kingsley acknowledges it. 


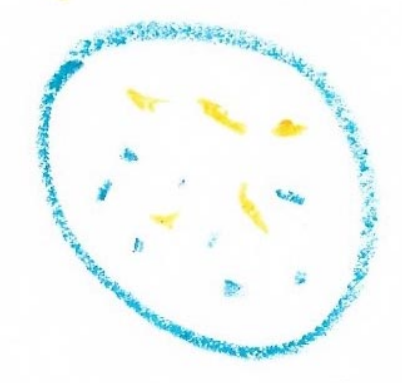

\section{Hurricane Katrina}

Katrina, a theme that will arise often throughout the New Orleans chapters, is also heavily tied to the corruption issue, with Kingsley calling it "the biggest elephant in the room”. Katrina is a major element because the already-notorious government combined with actions of the Louisiana state and federal governments (Krewe Du Vieux, 2006; Kettl, 2007) made a situation that Kingsley described as "hell on Earth" even worse. Most interviewees who were in New Orleans at the time Katrina struck were repulsed, had not forgotten this, and it was yet another reason why they deeply distrusted the local government as a whole and were less likely to want to participate in policymaking.

I observed lingering memories of this while I was searching through the city's library archives in June 2017. I overheard a rather spirited conversation from some young people. One said, "You remember Katrina? If you tried to cross the street, if you tried to cross a bridge, it was BOOM! SHOOTOUT!" Kingsley pointed to the multiple incidents of police misconduct during Katrina, particularly the Danziger Bridge incident. 
Kingsley: The biggest elephant in the room was the atrocities that the New Orleans Police Department committed on citizens during Katrina. There were a lot of New Orleans police officers that are in jail for things they did to people who were trying to get the hell out of here. They were trying to get out of hell on earth. I was here for the storm. I don't take it lightly. I know how difficult it was. I know how trying and stressful it was.

The city government's troubled past, especially during Katrina, has created major challenges for those in the bureaucracy, as well as the artistic community. Olympia, a city health department employee, like Kingsley, said the city's general corruption history has made her work to build positive relationships especially challenging. One present-day example she gave was directly related to the Katrina past.

Olympia: People are skeptical about your motives, about what's going to happen. I see that in my work in emergency management and much more. So to give you an example, in February 2017, we had the tornado in New Orleans East, and I ran one of the shelters. We had a number of people who said, "I don't want to stay here. I stayed in a shelter during Katrina. I don't want to go through that again." I just kept saying, "It's going to be different. That was a whole lifetime ago in the world of emergency management, and a lot of things came out of that. We've learned a lot and, at the end of the day, I wasn't in charge of the shelter you were in, but I'm in charge of this one, and you're going to be safe. No one is going to steal your stuff, and no one's going to get hurt. Here are the rules. Here's what's going to happen." We had one guy who was like, "No! Police, just take me to jail right now."

\section{Economic Resentment}

The economic and public policy challenges and the toxic social environment converge for artistic community members into an economic resentment that I found as a major hindering factor. Even though the artistic community brings in major tourism dollars and what they do is such an enormous part of the city's overall economy, the individual artistic community members' benefits are exponentially less — creating deep resentment, according to my interviews, focus group, secondary source reviews, narrative 
maps, and observations. The city government and business owners utilizing the arts and culture as part of their marketing strategy only infuriates them more. This has caused a two-way situation in which the artistic community members grow increasingly frustrated with their governments and sometimes turn on one another. This combined artistic ingroup and artistic/government strife is a major hindering factor in having a constructive dialog.

In 2014, the city of New Orleans had its best post-Katrina year for tourism, with 9.52 million visitors bringing $\$ 6.81$ billion into the local economy, according to a University of New Orleans Hospitality Research Center report (as cited in Larino, 2015). However, Todd Higgins, a member of the Black Men of Labor Social Aid and Pleasure Club, pointed out a problem with that number (as cited in McClendon, 2015a). The ones who reaped most of the benefits, though, were hotels, and bar and restaurant owners namely clustered in the French Quarter and Central Business District — not the people who produced much of the culture that the visitors came to experience (as cited in McClendon, 2015a).

My participants echoed the same sentiments and said this was a major hindering factor in creating meaningful dialog. Ginny noted the issues with corruption and the constant gigging and hustle that prevents anyone from having time to engage in policy oriented dialog.

Ginny: I feel like that is the case because of the way the city makes all this money that never sees the people who are literally singing and dancing for it. Multiple narrative maps from artistic community members that showed ideal situations were ones in which they had a more equal share in what the city makes from them. The focus group street musicians were especially incensed with this, given 
marketing campaigns they have seen when compared with the earlier-mentioned tricky

policy mechanisms.

Garrick: There's concessions made by the government where it's like, "Oh no. We love our musicians. They keep this city alive." You know, they'll put ads in the paper of something like a picture of a guitar player, and it'll say, "Music is the heartbeat of our city," and then it'll be like, "NOLA Dot Tourism" or whatever.

They'll kind of commodify the aspects of it, and that makes us feel devalued. A lot of the new rules and regulations make it harder to have local music, specifically.

Lucius' ideal situation that he drew was a parking spot reserved for musicians, similar to musician parking and/or loading zones like some other musically oriented cities like Seattle have done (Murray, 2014) because of transportation problems their musicians have faced. The focus group members were familiar with what the other cities did. Lucius and Lee both said that this drawing was a metaphor for something larger — the city actually doing something tangible that would benefit the artistic community rather than only singing its praises.

Lucius: It's a symbol of what government could do instead of just saying that they care or, as we've mentioned, putting ads out in the newspaper or whatnot, saying music is the heart of this town. They could actually do something substantial to show that they have any concern whatsoever. This would be a great thing.

Harry and Lavender both noted that this situation created severe social inequity and for a group on which the city heavily relies.

Lavender: It's a quality of life issue. We view is as actually overcoming the disparities in our community. If you live in a wealthy community like Cambridge, Massachusetts, people are not going to be as focused on the poor musicians and artists who are living in such poverty. But here, they are. And here, they're the backbone. It's the city's Number One engine, which is good, but something's wrong. ... It's a civil rights issue. 
Harry: It's an organizing challenge, but it's not unique to us. It's just particularly apparent. Particularly with New Orleans, which makes billions off the backs of the creative and physical labor of service industry workers and musicians and then pays them less than a living wage... That has to change.... With more of an organizing push, I think that's something that needs to be addressed.

\section{Divisions within Artistic Communities}

Problems not only involved relationships between the artistic community and government, but also inside the artistic community itself. Tribalism, infighting, and longstanding feuds in the artistic community, meaning that certain tight cliques formed that only looked out for one another or even worked to the detriment of others was a major hindering factor in citizen participation. Interviewees that included advocates and artistic community members, the focus group participants, and my observations led to this finding. One major element of this social structure was an economic one. Fellow artistic community members were seen as competition, not comrades. A very connected problem was a mixture of very longstanding or relatively new social orders, meaning that factors such as the length of time one had been in the artistic community and when someone had arrived in the city relative to the time Katrina struck determined how well a person was received and whether or not others would want to work with him or her. Any potential and some actual organizing efforts were derailed because certain individuals and groups simply would not get along.

\section{Tribalism, Infighting, and Feuds}

General infighting was a major hindering factor, with some respondents telling me that, in some cases, no other reason except personal dislike and longstanding feuds 
that often had nothing to do with the arts or public policy between certain individuals and groups stood in the way of any meaningful citizen participation, as Lee, a street musician in the focus group, illustrated.

Lee: A big stumbling block for our involvement as an arts community is maybe... The street musicians' community... All of the obstacles we've been talking about: People having different views of each other, certain amounts of respect or disrespect, lack of ability to meet each other on even terms... All that we've been talking about with musicians and police officers or musicians and business owners... It's also a conversation about musicians and musicians. We don't have a very unified street music scene, I think. We have a lot of different subcultures.

...If we had a more united front that had a more agreed-upon set of morals and values or ethics, then it would be a lot easier for us to have something to present to the institutions that be. But it's sort of a typical progressive fashion. There's a fracturing within the group that, in some ways, prevents it from being able to settle on bigger ideas and pushing those forward instead of bickering about smaller, more specific nuances.

Interviewees and focus group participants pointed out that given New Orleans is a city of about 380,000 , its artistic community is very small when compared to a major metropolitan area like New York or Los Angeles. The situation becomes even more insular when factoring in aspects such as only a few bookers securing gigs at multiple clubs or that an increasingly diversifying group of performers that, on the streets alone, range from traditional New Orleans brass bands to the newer street poets, rappers, dancers, and acrobats are sometimes working just across a very narrow street from one another. Being so insular has created close bonds, but it has also bred enmity, particularly among longtime members whose feuds have lasted for decades. This presented a major challenge for advocates like Harry who were working to organize them.

Harry: You have people who have been in each other's lives for decades. Sometimes, they don't always like each other. They haven't liked each other for decades, like some of the people who have been here for thirty years. What I 
always tell people while working in the cultural community is that you don't get to pick and choose who you work with. You work with who's there already.

That's who you've got. You can't bring in somebody new to be like, "You know what? I need you to be the new musician in town." No. You're working with these people, whether you like it or not.

Harry noted that when the smaller size creates friendships instead of rivalries, another problem that arises then is that friends will only look out for those in their very small groups and exclude others. Some newer arrivals to the artistic community who were very eager to create positive change in New Orleans found themselves learning this situation in a very brutal fashion. Ginny is relatively new to New Orleans and moved from a very progressive region. She wanted to help New Orleans' artistic community be more cohesive and work toward a better reality. She quickly learned that the artistic community had its own issues to solve from within, much less from the outside, and witnessed local nonprofits' organizing forums with the artistic community fall apart.

Ginny: For me, I came here because there's so much to learn from all of these street performers because they're the best of the best. They've really done their craft. ... But the people who have been playing the game have been doing it for so long. It's so entrenched that half of it is logical market competition and half of it is feuds - like nonsensical feuds that, as extensive as they are, have nothing to do with money.

...The other thing that keeps people from getting actively involved is that we're, almost universally by nature, not joiners and that is also a huge impediment. At the end of the day, most of us would rather do our own thing and just make it work - and fight one another rather than trying to come together to find a solution that works for everybody. ... While that does make amazing creativity and discipline, it's not great for political organizing because it doesn't take much.

...That's the one thing about (the nonprofit) meetings that I find both hilarious and sad. They fall apart. Most of the meeting is just trying to keep the meetings on the topic that it was called for and keeping people from getting into these basically aesthetic squabbles. 
Divides, the respondents told me, can be the result of practically anything. Harry gave the example of New Orleans' expanding diversity of street art and performance in recent years. Performers with acoustic music will be on the same street as someone with amplification, which is legal for New Orleans street performers. Certain performers have played for decades, while others are either very new or have come from out of town. The latter, who Lavender and Michael both said are often rich young people whose parents are supporting them, tend to infuriate the locals, especially when they are blamed for the high rents that they leave behind after their temporary stays in New Orleans. Some performers play traditional music or have understated acts while others do acrobatic stunts or rap along with electronic beats on a smartphone. Whether the people in question are understated or boisterous, more traditional performers will quite often look down upon others doing more contemporary art forms or ones like bluegrass music, which are not considered native to New Orleans. Michael made light of the latter, saying, "So when you have 'Johnny and the Hillbilly Five' set up on an opposing corner, I can see that type of tension.”

Street poets who, for a fee type passersby a poem on a manual typewriter and with the subject being the customer's choice, are a very new arrival in the city, relatively speaking. The physical artifact below in Figure 4.26 is a poem I purchased from a street poet - at a negotiated bargain price of a $\$ 5$ haiku versus a $\$ 10$ full poem because of budgetary concerns - that the poet wrote about Domino, my cat who always missed me when I would be gone for fieldwork. 


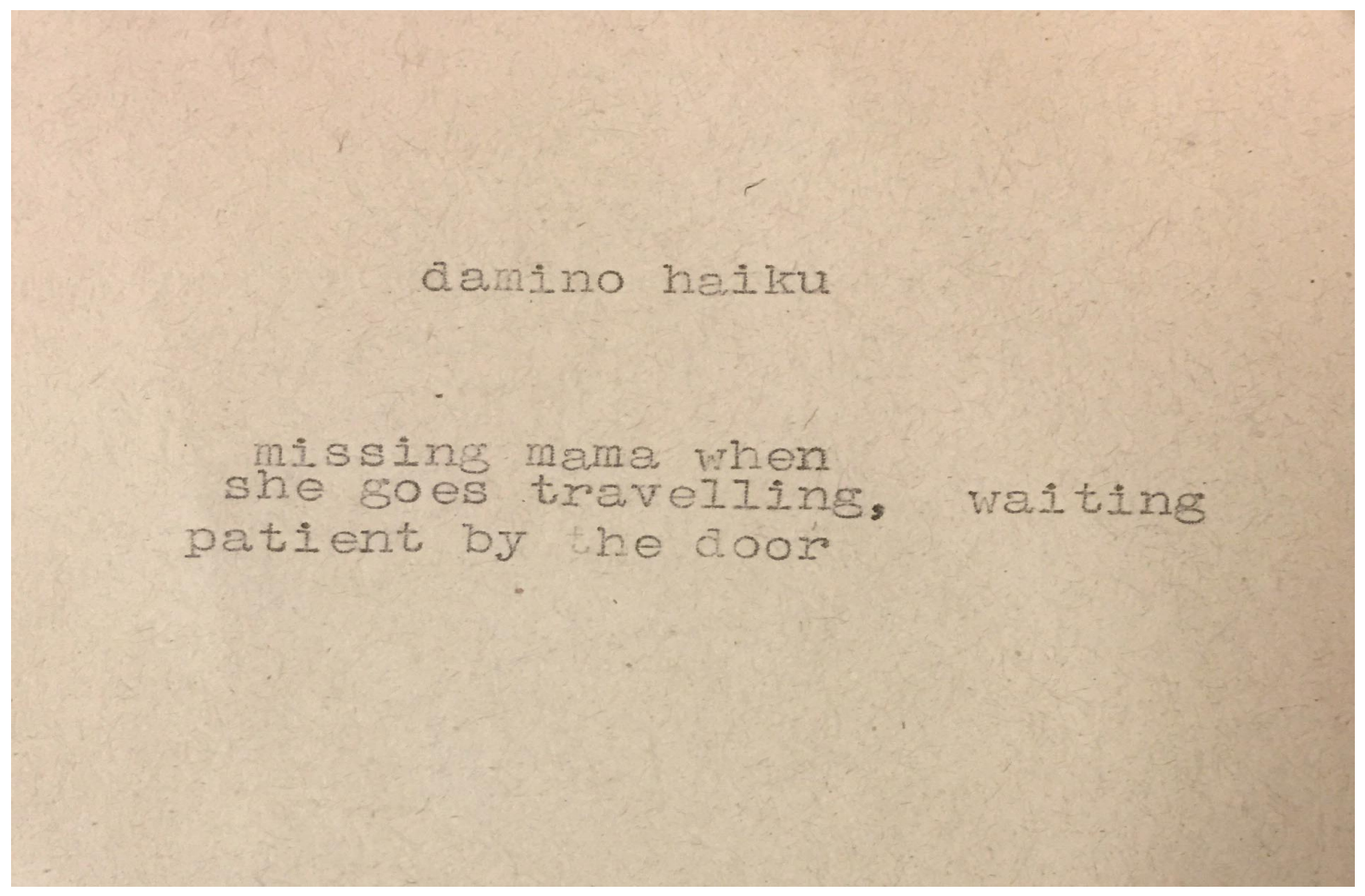

Visual artists have worked on the streets for decades, and some of them consider certain entertainers too loud or just annoying, according to interviewees. On top of this, venues and performers with venue gigs such as ones on Frenchmen Street have clashed with street performers because some of those in the venues believe the street performers either disturb them or take their business. I first observed some of this discord while overhearing two acoustic street musicians happily talking about how a "total asshole" dancer with a loud speaker who used to perform where they usually did had gone elsewhere. Harry said that when working to organize people with such bad blood, this made giving the artistic community a greater voice in policymaking extremely difficult.

Harry: All of these things happen internally — with street performers, gigging musicians, club owners... And then you've got the traditional culture bearers and the new sort of post-Katrina wave of musicians and others like the poets. Even with Mardi Gras, there have been dance krewes that have sprung up that some of the traditional people aren't fond of. There are a lot of issues that come into one. 
One of our challenges is that we have such a big tent, and we try to address all of that. But you can't make everybody happy all the time. So as we move into places that are more social justice-oriented, some of the other side of it falls off for us, and, ultimately, you have to decide what issues are universal that you can tackle.

Participants also indicated this was a problem not only within the artistic community, but also among other disenfranchised groups like service industry workers and even among some of the more powerful people who have worked to quell their activities. Regulus came to a meeting for the neighborhood association opposing his bar during his work to have a constructive dialog with the association. The problem was that neighbors gathered there were fighting amongst themselves too much for anything to move forward.

Regulus: Man, it was the most contentious, acrimonious meeting. It was crazy. I was like, "Oh my Lord!” I was so happy to get out of that place.

Amelia: Was that among themselves or them against you?

Regulus: No, it was among themselves. Before they even heard from me, I was like, "Lord, have mercy!"

\section{Other artistic community members seen as competition}

One of the more troublesome specific reasons for the in-group tension was that members of the artistic community their fellow artists as competition, not comrades. Some of the reasons include the large numbers of performers and venues wanting the same tourist dollars or because certain artistic people consider themselves more deserving of fame or accolades. Such competition has reached the point where not only people will refuse to work with others but also where some will try to undermine one another. 
Michael said competition in such a line of work, whether it is between businesses or individuals, is natural and even if certain people do like each other, any money another musician earns is money he does not, or vice versa. The same goes for one landing a gig when another does not.

Michael: A club owner isn't going to give his competitor five beer sales if he can get those beer sales. My band has a weekly gig. My objective is that everyone walking down that street is coming into the club where I am, not the club next door. I'm going to do that by making sure my band is tight, that we sound good, and that it's going to be a great experience.

Amelia: And if people go to the bar next door...?

Michael: That's money I'm not making. As a performer, my objective, myself, is to use my skill sets and talents to bring people into the club, no matter what club I'm playing in. The more people I'm able to get, the more money I'm able to make. The club has that exact same mindset. If I book you every Sunday, and there's ten people in here... I may be friends with the people next door, but they've got 150 people. So, if 150 people buy three beers a piece, and these ten people bought three beers a piece, who just made what? The club owner is going to say, "I need another band." He wants to make money, also.

This competitive environment was certainly evident during observations, particularly when I spent a Saturday night on Bourbon Street. Because so many nightclubs, individuals working for tips, and businesses like souvenir shops and strip clubs wanted passerby money, they went to some rather outlandish means to get attention. People flashed and even danced with extremely large signs advertising drink specials. A stripper wearing barely any clothing at all stood in the doorway of one of the clubs to get both attention for the club and tips for herself. Nightclub employees would come outside and shout over megaphones, and some entertainers like rappers I observed would briefly step outside and come back in while performing. Two people on Bourbon Street, shown in Figure 4.27 below, had giant snakes draped across their shoulders. 
Figure 4.27: People holding giant snakes, Bourbon Street (Pridemore, 2017)

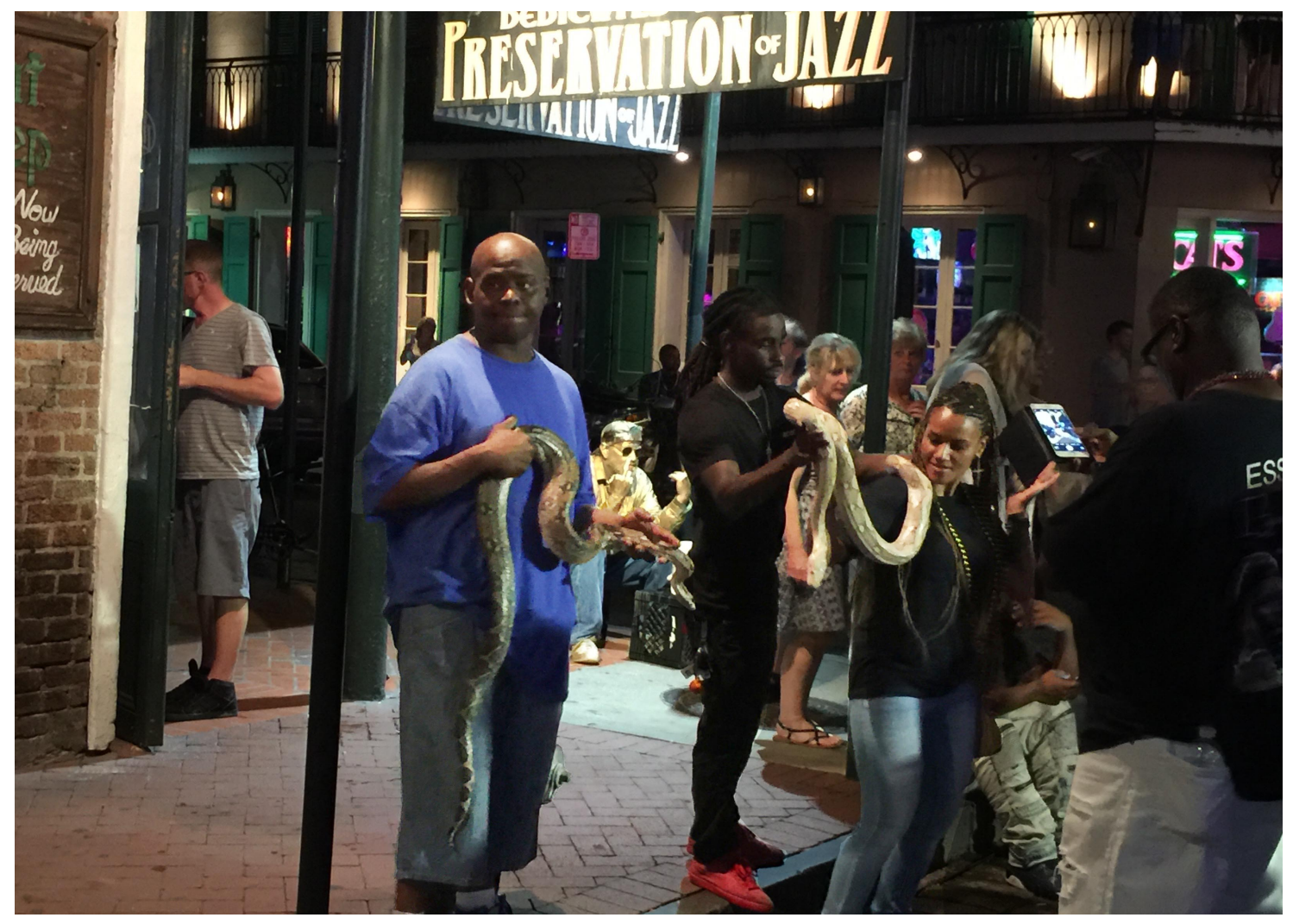

Olympia noted that in her work in dealing with noise issues, the loudest

businesses on Bourbon Street are not the ones with live music. The loudest are ones such as t-shirt stores and daiquiri shops that are blaring music from speakers loudly to draw in customers, part of that highly competitive environment.

The competition was not only for profits but also for accolades and achieving national prominence. Especially when it came to who would get a "big break", this created even more in-group animosity. Neville, a New Orleans native, said this was not always the case. One major change he noted was the advent of the internet, even before social media became prominent, around the late 1990s to early 2000s. Methods for creating and platforms for promoting both became far more accessible with technology. With that, though, came more people both working to become successful artists and 
entertainers and gain attention, accolades, and money — and divisions and rivalries that spurred.

Neville: Like if there were people doing a publication... It was like, "I'm doing it!", "No, I'm better than them!", or whatever. A rivalry between this group and that group... "They don't like us? Well, we don't support them." I noticed that in the early 2000s, very much. It was, "You don't associate with these people because these people don't like us."

...Today, I think what a lot of people realize... I think it's not necessarily between genres or between anybody doing anything. I think the city has become a bit more clique-ish in terms of... "These people are in a band. I want to be in a band too. I want to be the one who breaks out." That's basically the mindset a lot of people have or, "I'm better." Everybody looks at other bands and what they're doing as bigger rivals, and I think that's the wrong way to look at it.

Neville mentioned that another local filmmaker had recently done very well, with his film earning major awards and being shown in international locations. The attitude from other New Orleans filmmakers, Neville said, was “That should be me up there. I should be the one." He has personally found it difficult for him to find people willing to work with him on projects that he leads because certain ones will try to overly dictate what the final product will be so that they can take more credit and gain more prominence for themselves if the project is a success. This type of environment, Neville said, was not conducive at all.

Neville: We should be glad that somebody here was able to do something. If someone here can do it, that means you can. You don't have to be the first one in, you know? If you look at other people as your rivals, and you're just focusing on how to shut other people down, you're not going to be focusing on what you're trying to do.

During my conversation with Neville, I mentioned that, in my past experiences at music venues, musicians would come to another musician's aid even if they did not know 
the other person. I used the example of when I attended an open mic night at Churchill's in Miami and saw a man lend the onstage guitar player he did not know his own guitar when the player onstage broke a string mid-set. In New Orleans, Neville said, that would not have happened unless, perhaps, the guitar player in need was a part of the lender's circle of friends. He said, 'I can’t imagine just helping some guy he's never met. Maybe there was a time when that was the case, but not anymore."

This competition was just as brutal, if not more so, when artistic community members had a full-time job in the arts, such as with a symphony or theater or dance company. Theaters, in particular, usually have understudies waiting in the wings.

Lavender and Parvati had seen this in their own advocacy work, especially when seeing artistic community members trying to hide and work through potentially career-ending injuries rather than treat them.

Parvati: There are five people waiting to have your chair in the symphony or waiting to have your part in the ballet. They're not going to take you on tour if you're like, "Well, I can't really play."

Lavender: There's a school for the performing arts here in New Orleans. At that school, they're taught to be so competitive. They're taught to be so competitive because that's the way to do it. The kids that they honor are the ones who have worked with performing arts medicine, who are big stars in New York. They don't honor the ones with weekly jobs here, who struggle. It's, "Look at what we did. We pushed them out. Look at how great they are. Look at how good they are."

\section{Social Order}

Another aspect of New Orleans' tribalism hindering factor was that of multiple social pecking orders, with most being very longstanding and very tied to the city's culture and history. Participants likened certain citizens such as prominent entertainers to 
a modern-day aristocracy, even royalty. Consequently, anyone else was inferior. A second part of the social order was related to the modern day, and that was how someone was viewed in terms of when that person arrived relative to the time Katrina struck.

Participants indicated that anyone who was seen as trying to figuratively or literally cash in on the Katrina recovery, such as starting social entrepreneurships or being able to say he/she is from New Orleans to boost an entertainment career is viewed very unfavorably. This social structure stood in the way of any meaningful citizen participation.

Some of the social order in the artistic community is linked to how long someone has been working in their discipline or how long their performance group has been together. Garrick's band is three years old. He said he either finds himself dismissed because three years, even when factoring in how long bands typically last overall, is not very long at all compared to how long some New Orleans bands have been together.

Garrick: We quarrel around our own meritocracy on this street. If you talk to a different street band, they'd be like, "Oh (Name of Garrick's band)? They're only three years old." If you talk to someone else, they're like, "Oh man, you've been in a band for three years. That's a long time." If you talk to someone here, it's like, "Pfft!" People here look at us and are like, "Oh, you guys are figuring out this music and figuring out the social contract of this place." It gets in the way all the time.

Racial divides and their continued enforcement are another element of the New Orleans social order. Neville noted the story of the Rose Tattoo bar from 1982. The Ku Klux Klan threatened to bomb the black-owned bar because it allowed a white punk rock band to play (WDSU-TV, 2017 [1982]). The Klan, Neville said, claimed the reason was the punk band's provocative music and performance advertising, such as the band advertising a show as a Charles Manson parole benefit (This was only done to draw 
attention to flyers advertising the show.). The real reason, Neville contends, is because the Klan did not want to see a mixed-race crowd of both the business owners and different performers playing and it used threats to enforce its mantra. Neville further explained:

Neville: The Rose Tattoo was booking white hardcore bands about once a week. They would just have all these white kids in hardcore punk bands play in this black neighborhood bar, and the Ku Klux Klan threatened to blow it up because white kids were playing in a black bar. A couple of guys showed up with baseball bats, came to the owner, and said, "If the show goes on, we're going to blow the place up."

There's always been racial tension and an old white guard. So those shows were things like a hardcore band opening for the Mardi Gras Indians. Only in New Orleans, would you get that. I guess some people didn't like it. They had a problem with this. Some people said it was because these guys would rather be drunk instead of watching these crazy white kids jump around onstage and screaming at the top of their lungs.

To the Klan, this was a problem. They couldn't handle it.

Harry indicated that in New Orleans society, certain longstanding entertainers are viewed as other societies would view royalty. This was almost literal when examining longstanding local culture, particularly Mardi Gras, where parade krewes' guests of honor do not receive titles such as "grand marshal" but are crowned kings or queens instead (Hardy, 2016). Even the Mardi Gras colors of purple, green, and gold are linked to royalty. Mardi Gras' colors are linked to the first Krewe of Rex parade in 1872 when the colors were deemed suitable for a king (Mardi Gras, n.d.). Mardi Gras krewes have historically been very exclusive, with only white men in the highest echelons of society being able to join the five krewes existing before 1900 (Rothman, 2015). In the $20^{\text {th }}$ Century, more people wanted to have their own krewes, too, and the number of krewes 
exponentially increased during that but factors such as race, religion, gender, and ethnicity still divided them.

A city government move to change these krewes' practices became extremely controversial even for those who could benefit because it violated longstanding tradition and social order. Rothman (2015) writes that in the 1990s, the city voted to require krewes to integrate or lose their rights to have parades. Even most black voters, the majority of citizens, opposed this because this would violate tradition.

Though Mardi Gras tradition is beloved and held dear in the city, New Orleans' overall and ingrained elite, aristocratic culture, interviewees indicated, created a social stratification that kept the artistic community from working with one another, not just with the local government. Regulus said this problem, in his opinion, was worse than the government corruption because this ultimately led to a very unequal economic situation, as mentioned above in the power structures section. People, even ones who were already very wealthy, bringing new businesses and employment opportunities to the city who the elite did not accept eventually became frustrated and left, taking those opportunities elsewhere.

Regulus: It wasn't so much about the politicians. You know what it was? It's this sort of old aristocracy. They've got the people here who behave more like European royalty. ... We see this as just like Mardi Gras, and fun, and just make believe, but... It has some meaning.

...They've got these organizations ... that represent the New Orleans elite. So for a very long time, if you came to New Orleans and showed up here and when you bought your business here and you got a couple hundred people working for you... With the New Orleans elite, you seemed like you were not always welcomed and sometimes, they even treated you like a second-class citizen. Even though you've got your degrees from whatever university, own your own business, and got your own money, it's like you still weren't a part of the group. And so it seems like after so many years of that, a lot of people who had that kind 
of weight, instead of coming to New Orleans and being treated like some peon, they just decided to take their ball and go someplace else. That's kind of what happened. It was more of them than the corruption that caused the economic downfall of the place.

\section{Katrina and the Social Order}

Another influence on the local social order in New Orleans is how people are viewed in terms of when people arrived in New Orleans relative to when Hurricane Katrina struck. Because certain people have been viewed as coming into the city only to profit or gain fame and accolades from the high post-Katrina attention on New Orleans — and then leave the city sometimes with higher rents in still in place long after they are gone because of the housing demand — those perceived to be profiting from Katrina are also on the lower end of the social order.

Garrick, one of the street musicians in the focus group, said for those who arrived after Katrina like he did, it can vary depending on one of three times — directly after the hurricane such as those who came to work with a nonprofit organization, about seven years later after the city "reopened", per se, and saw the rise of Frenchmen Street, or in very recent years. Generally, the later the arrival, the worse one is viewed, but that reaction can depend from person to person. If the reaction is negative, no one will want to have a conversation.

Garrick: I mostly feel that at jam sessions. The city is known for that. They're every night. Sometimes, I'll go to one. There is enough of that sort of attitude of meritocracy, where all of these musicians are like, "We're all into the same stuff. We have the same mutual friends. We play in the same kinds of bands. We should be working together. We believe the same stuff, idealistically and ethically, about being a musician." But because some people are newer than others or whatever, it's impossible to get an hour with somebody. 
New Orleans Traditional vs. Outsider and Contemporary Culture

With the new arrivals and as younger generations in the city have been exposed to new art forms, new art forms are continually emerging in the city, as detailed in the first subsection. This tension has gone beyond the street performer issues though and is a major element in the tribalism problem that hinders participation and even determines who is a target for negative policy.

A key example is the issues Regulus had with the neighborhood association that tried to close his bar. Regulus said that even before he opened, he envisioned a place where people regardless of differences such as race, sexual orientation, and personal tastes could gather. He opened the door to other, more contemporary art forms.

Regulus: I don't care who you are. If you come in here and we agree that you're going to do an event, I don't treat anybody like I'm holding my nose and just, "Give me your money and hurry up and leave." ... (Laughs) Now, some times... I am in my fifties, and sometimes the music is a little loud for me, and so sometimes, I am happy with the DJ unplugs (laughs) because my ears are a little more sensitive these days. But other than that, that's what we do.

On another neighborhood association's website (besides the one that was opposing Regulus' bar), I saw that the association desired a new noise ordinance, one that would "protect and promote the music — not noise — for which New Orleans is justly famous" (French Quarter Citizens, 2014). Regulus told me that during his dispute with the neighborhood association opposing his bar, the association seemingly worked against him more when he opened the door to less traditional entertainment, especially if it was popular with or associated with people who are young and black. I mentioned this website statement to him, and he said that the difference between music and "noise" was relative, differing from person to person. 
Regulus: It's all relative. I remember one time I was here, when some dude was doing some electronic music or something. It was the funniest thing because I'm the old man in here, and I didn't realize there was a guy on stage with a little instrument, but he started doing his music, and there was this little guy, the sound guy. He sat next to me, and I kind of jumped back and said, "Hey man, what's the feedback coming from? And he kind of laughed and just pointed out that was his music. It sounded strange to me, but people were sitting here listening to it like they were listening to something cultural or something like that.

...That was one of the points (the neighborhood association) has been making. If you did the kind of stuff they like, then you're OK. If you do some stuff that maybe they don't understand, and that's noise to them, it's like, "Oh man, we don't want that." Well, it's not your club, sir.

...If you leave it up to the neighbors, then if there's something that happens with the neighbors that doesn't make sense to the neighbors - something they don't like or doesn't fit their idea of what good entertainment is - then that means you will probably hear from them.

\section{"Divided We Fall"}

Some interviewees indicated that this environment was especially toxic and was one that could eventually be the artistic community's downfall when it faces powerful opponents. If they fought among themselves, they would all lose in the end.

During the observation when I saw the street performers discussing the dancer they were happy to see gone, a young performer and a newcomer working on Royal Street said that Royal was the "classy" cultural area, while Bourbon was a "frat house". Interviews indicated, though, that other artistic community members and their advocates saw attitudes like these as not only problematic in terms of citizen participation but outright dangerous when already facing unbalanced power structures.

Rolanda said she personally does not visit Bourbon Street, but at the same time, she does not want to work against it because she knows that will not benefit her. In fact, it 
could very well work against her because a person visiting Bourbon Street could also

come to her business, given how tourism-dependent visual art income is.

Rolanda: We are all in this. The only reason I'm here with an art gallery is because of the tourists. Only five percent of my business is from locals... If they come to see Bourbon Street, great. The chances of them wandering past my door are still pretty good. To me, it's all good. There's room for everybody to set up shop and have their own business and whatever draws people here... Who cares? It's fine. I mean, we are inviting people to come here for whatever reason, and we live and die by it. We survive because of it.

So I don't like it when people dog one street or the other. I've got friends who work in the industry over on Bourbon Street, and they make a great living. So, more power to them. ... The more we can do, unified, the better that is for everybody.

When someone comes for a part of the artistic community a fellow artist may dislike, that artist doing nothing or even cheering on a downfall may find themselves in the same situation, some interviewees indicated.

Neville: Let's just say we let them go after Bourbon Street because we're Royal Street. Well, then, they're going to run after Royal Street, and you're like, "Oh crap!” Well, maybe you should have supported Bourbon Street. Now, they're coming for you. ... You're next. Don't think they're not out there. These rich guys are like, "OK. I'm going to shut this place down. Next, I'm going to shut these guys down. I'm going to shut that down." ... This is a prime example. You don't have to go on Bourbon Street. You don't have to like Bourbon Street. But if they go after Bourbon Street, how long will it be before they go after Royal Street? You're definitely going to fall.

\section{Barriers to Non-Traditional Participation}

A major hindering factor for outlaw citizenship, certain interviewees and focus group members told me, is that they believed it accomplished nothing in the end. Furthermore, at least one interviewee believed that outlaw citizenship, particularly if 
done without a coherent message, will make public officials with the ability to make positive changes turn against disaffected citizens, including those in artistic communities.

Anthony, a street musician and focus group member, participated in the January 2014 brass band protest at city hall, and his narrative map drawing shown in Figure 4.28 depicted his experience. It was the image he chose to draw what he believed was city's overall relationship with its artistic community and without any further prompting from me as to what he should draw.

Figure 4.28: Narrative Map (Reality): Anthony, street musician

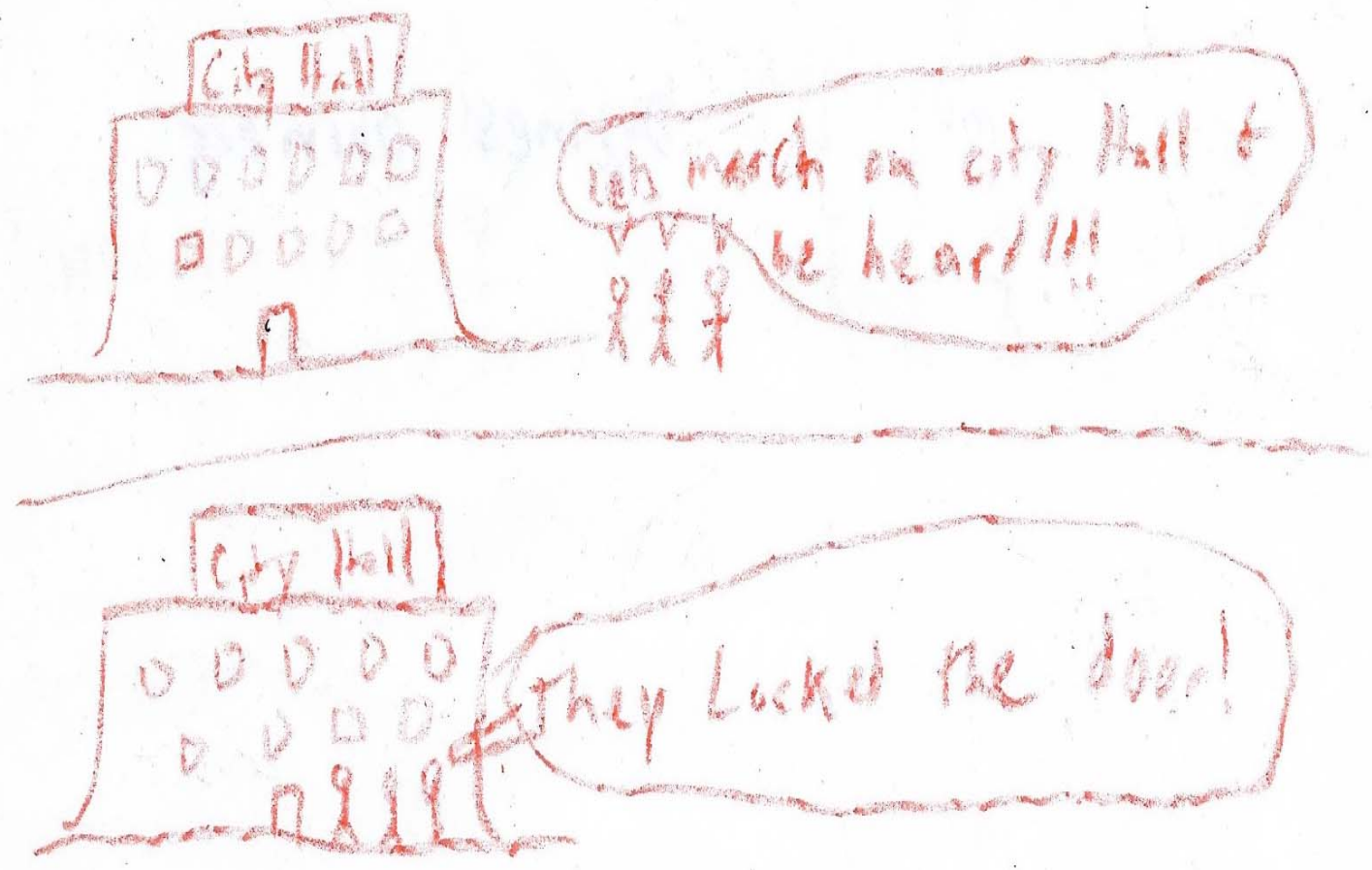

Anthony, as well as some other focus group members and interviewees who participated in this march, said the march started with the band showing up at city hall but to find the doors locked and the public officials they thought would be gathered at a meeting absent. They eventually did their march through city hall and into council 
chambers, and Cantrell, then a councilwoman, came and opened the doors and listened to some of the musicians speak. He said he and others felt excited when they showed up for the march, but believed that in the end, their efforts were in vain. He explained:

Anthony: (Cantrell) didn't actually do anything except kind of make us feel like we're being listened to. She didn't, actually. None of the other council members or policymakers actually showed up. They decided, instead of actually coming to talk to us, to actually close the place down and just not deal with us. She at least opened the door and gave us kind of an empty gesture... But it didn't actually do anything.

...We didn't actually accomplish anything. It was kind of venting stress. ... We were at least supposed to be heard - say something to people who were responsible for controlling policy decisions - and they just didn't show up. That's kind of been the thing. You can't actually talk to anybody. They don't want to.

...The end result was still the same. There was still no being heard.

Michael said that he left the event before it ended once musicians began speaking because he believed it was both fruitless and nonsensical by that point.

Michael: That was a powerful little image with the instruments and the guys walking in. After about thirty minutes, I walked out. After they played and sang and prayed and all of this stuff, they went on the microphone and "Blah, blah blah!" I said, "Man, ain't nothing about to get done. It's a shit show at this point."

Michael said the he believed most consequential hindering factor for outlaw citizenship, at least in this case, produced no positive end result because the problematic noise ordinance is still on the books, and policies set forth in it can seriously hurt the artistic community. Furthermore, such activities, which also include outlaw citizenship's online organizing, can put government officials on the defensive and make them even less likely to help disaffected groups. 
Michael: The image is powerful, and it says something. But at the end of the day, it's about, "What was the outcome?" You can have all the propaganda you want, but at the end, what's the outcome? What are we getting out of this?

Even with that display of protest, the noise ordinance is still on the books. Ain't nothing about it changed. ... If the police decide that the band that plays on the corner of Frenchmen and Chartres seven nights a week - and they've done it before... If the police decide they want to shut that band down, they can come on that corner at any time and shut that band down. If the musician doesn't stop playing, they have the rightful lawfulness to take away instruments. That's on the books. We can march in and out of city hall all we want, but if we're not going to do anything that's going to change the laws that are on the books to benefit what we need, it's rhetoric.

\section{Conclusion}

The hindering factors in New Orleans' artistic community's citizen participation are numerous, egregious, longstanding and can be very peculiar and sinister, especially when considering the complex power structures and social order. In this chapter, I have addressed the hindering factors that include ones related to traditional participation, institutions, place, other community stakeholders, issues within the artistic community, and outlaw citizenship.

Especially when considering these hindering factors have roots that are literally one hundred years old or even older, overcoming them will not be an easy task and will certainly not happen overnight. Some New Orleans findings presented in this chapter confirm earlier studies such as ones on why people resort to outlaw citizenship (C.S. King \& Nank, 2015; Pridemore, 2018; Rimmerman, 2011) or how government misdeeds can erode public trust and citizens' willingness to participate (Pridemore, N.E. Ganapati, \& Revell, 2019). Others provide sharp contradictions or at least, to academia as a whole, that egregious situations and extreme conflict that hinder positive citizen-government dialog do happen in the United States and are worth examining. This is especially true, as 
longstanding grievances have led to the heated American political environment of the present day (Box, 2017; Pridemore, 2018).

In next chapter though, I will present a major flipside that shows New Orleans' enabling factors, as well how its artistic community and government officials alike have worked to determine who participates. Like some of the hindering factors, the enabling factors are also especially unique and especially bold and, like understanding the city itself, often require thinking outside the box to see how they do or could work. Furthermore, they provide insight on how a city can work to build a constructive dialog even when confronting a horrific past. New Orleans also provides exceptional and powerful lessons on how outlaw citizenship can work and do so through utilizing the arts. 


\section{CHAPTER 5: NEW ORLEANS' PARTICIPATION ENABLING FACTORS}

New Orleans' artistic community sharing and acting on common concerns with other disaffected groups — and old enemies — government meeting the artistic community at the artistic community's places and meeting times, and the city's tough-asnails, survivalist, and defiant attitude are major enabling factors for the New Orleans artistic community's participation in its local government. In this chapter, I further explore findings for this case I classified as a negative extreme at this dissertation's onset. Here, I show a positive flipside to a tremendously bleak previous chapter.

This chapter's findings fill critical literature gaps — adding to or providing flipsides to established citizen participation scholarship in both public administration (Pridemore, N.E. Ganapati, \& Revell, 2019) and outside the discipline (Oldenburg, 1999). For example, previous scholarship has examined partnerships between government officials and citizens in working to solve novel problems (Pridemore, N.E. Ganapati, \& Revell, 2019). The findings presented here take that a step further and show how governments can build these working relationships with disaffected citizens, specifically. Previous scholarship has namely addressed the difficulty in working with a fractious political environment and extreme conflict (Pridemore, N.E. Ganapati, \& Revell, 2019). This chapter goes farther in explaining how citizens and governments alike in those situations can reach a positive end. Similar to the previous chapter, this also explores overcoming extreme conflict in an American city rather than an international one.

These findings also add to other disciplines' scholarship, namely Ray Oldenburg's (1999) “third places” scholarship from urban studies. Place was a critical 
element with enabling citizen participation in New Orleans, and the spaces in which the most constructive dialog between the artistic community and government officials took place were third places, not government offices. Artistic communities and government officials alike pointed to the third places' higher personal comfort level, casual environment, iconicity, and physical and social accessibility.

I also challenge some previous assertions involving outlaw citizenship. Rimmerman (2011) writes that negative or potentially offensive displays can make a cause lose followers. The New Orleans situation, though, shows how something that could be widely considered offensive can be empowering and help certain groups gain followers, namely because of it being a major counter to those who have egregiously wronged a community. In New Orleans, these potentially offensive and simultaneously empowering displays included profanity, overtly sexual humor, and in-your-face insults to local government officials and outside detractors alike. Elsewhere, this may be seen as going too far with outlaw citizenship. In New Orleans, a city that has been egregiously wronged by its own government (Daily Mail Reporter, 2013; Kushner, 2010; Lane, 2016) and outsiders (Kettl, 2007; Krewe Du Vieux, 2006) alike, this was a way of biting back.

This chapter's structure is as follows. I will begin through presenting findings related to traditional citizen participation, which include artistic communities uniting with other disaffected populations and "old enemies" in government alike because of common concerns. Next, I will discuss institutional-related factors that namely include the city's tough, survivalist attitude and deep love of its city and culture. Following that, I will discuss enabling factors related to the artistic community such as some of its in-group and out-group community controls — building relationships with one another and with 
outside parties such as business' neighbors. These either kept policy related challenges from happening in the first place or helped less powerful artistic community members when wealthy elites tried to shut them down. Then, I will discuss enabling factors involving non-traditional participation. These include utilizing beloved cultural practices — using them to also demonstrate the value of what is being threatened, the artistic community's and city's being unafraid of being deliberately offensive when the situation warranted it, and using the outlaw citizenship practices to help and unite with other disaffected populations such as service industry workers.

\section{Enabling Factors Related to Traditional Participation}

Traditional citizen participation presented far less enabling factors over the hindering factors mentioned in the previous chapter. For example, this dissertation's New Orleans case had no significant positive findings related to formal participation mechanisms, like government-organized public meetings. Still, not all was bleak.

The enabling factors involving traditional participation had two major common threads - the bureaucracy and place. The city bureaucracy was at the forefront of working to heal gaping, festering old wounds. Artistic community members sometimes saw the street-level bureaucrats like police officers as kindred spirits, with both being at the mercy of elected officials and the city's wealthy elites with whom the elected officials collaborated. Place was a major factor, as well. Bureaucracy employees had their greatest success in building relationships with the artistic community through going to where the artistic community gathers and at the times they gather. For both the bureaucracy and the artistic community, this work was done in more comfortable places, at more convenient times, and in the "level" atmosphere of third places like longstanding music venues 
(Oldenburg, 1999). Artistic community members said they also saw this interaction as a positive, and they wanted to see more of it.

"Old enemies" in the bureaucracy and the artistic community building upon common concerns was another enabling factor presenting itself. This was a rather surprising finding and, as I will further explain below, had the trail leading to it beginning with a plate of cat food. These common concerns included the city's violent crime and murders and mutual interest in youth arts development.

\section{Enabling Factors Related to Public Officials}

Bureaucracy working to heal old wounds

As detailed in the previous chapter, New Orleans' troubled past has created a chasm between its city government and its artistic community. Certain employees in the city's bureaucracy, though, are making great strides in working to heal those old wounds and create positive working relationships with the artistic community. This namely includes the city police department, which arguably has the largest uphill climb.

Kingsley, a New Orleans city police supervisor, said he understood the challenge and the reasons behind it, but he and his department were continually working toward building better relationships with the artistic community. An example he gave was what the police department has done to improve relationships with the Mardi Gras Indians during the past few years. This involved both give and take from both the police and the Mardi Gras Indians.

The police department ended its St. Joseph's Night celebration practices mentioned in the previous chapter, during which police would break up their cultural event and put people in jail for minor offenses. The Mardi Gras Indians adjusted their 
practices as well. Formerly, Kingsley said, the Indians would roam the streets and then, once encountering one another, literally do battle. As a group, the Indians decided that doing a non-violent celebration was better, in general, as well as one that would be viewed in a positive light. Kingsley explained:

Kingsley: In the ensuring years, we kept working toward fixing those relationships that were broken. In some cases, they never even existed. With the police and the Mardi Gras Indians... There wasn't a broken relationship. There was a non-existent adversarial relationship.

I could tell you in the last seven to eight years, there has been a real shift in the way that we, the police department, patrol the Mardi Gras Indians. What we really do is just block off all the streets around their meeting area to make sure that the cars don't come in and just allow them to do this thing.

And there's been a real shift in the way that they do their thing. It used to be that they would roam the streets and when they would encounter one another, they would literally have brawls. They don't do that anymore. Now, they do this beautiful dance with chanting and things like that. They don't carry weapons anymore. They pushed back to the community to say, "Don't bring weapons to our events. We don't want violence in our venture. You're giving us a bad name." So they're giving the same message we're giving. It's, "Let's this be the beautiful cultural event it should be, not the opportunity for violence that a few people would use to kind of get back at their enemies."

And so I think that when you look at the Indians and you have the opportunity to come to St. Joseph's Night, March 19... It's just phenomenal. It's a very, very beautiful experience. And if you think when you're out there next year and you see how peaceful it is, just imagine that piece being broken by lights and sirens and police cars flying up and throwing people in jail and kind of understand how far we've come since 2005 and before.

Harry, a cultural community advocate, backed up Kingsley's statements about how the police have solved many of its issues involving the Mardi Gras Indians and noted that cultural community advocates like himself have strong working relationships with the supervisors in the Eighth District, which includes the French Quarter and 
Marigny. The district's commander, in particular, Harry said, "gets it" and wants to continually build positive relationships.

More positive relationships between the police department and citizens as a whole were also on display during my observations. Just before the Krewe Du Vieux parade came through the streets in January 2018, city police officers used motorcycles to clear crowds from the streets. This is a common practice in policing because motorcycles' smaller size and greater maneuverability can more effectively work past crowds or heavy traffic over a patrol car (New York State Police, n.d.). Once police had cleared the streets but had to remain in position to keep the crowd at bay, the officers chatted with the crowds and allowed people, even ones dressed in colorful Mardi Gras outfits that included pink wigs, pose for photos beside the motorcycles. Police allowed children in the crowd to sit on the bikes. From what I observed in this instance, I really saw the police building a good rapport with the crowds. I was certain that several of them were likely quite intoxicated, but as Kingsley told me, the New Orleans Police Department will allow adults to be adults until they get out of hand.

Kingsley noted other practice changes that the department has done to build better relationships with both the cultural community and citizens as a whole. NOPD adopted practices in the Obama Administration's $21^{\text {st }}$ Century Policing Report that includes what he called "procedural justice", meaning fair, standardized step-by-step procedures for interactions with citizens. This entails, in all encounters, officers introducing themselves upon arrival, explaining why they are there, and explaining what they are doing, allowing the person to ask questions, and explaining what the next steps are. He further elaborated: 
Kingsley: We want to make sure that the person understands that they are going to be treated fairly throughout the process and also treating that person as though they are not being punished. The punishment comes from the courts. We should not be belittling people or dolling out punishment on the streets. That's up to the courts to do, and it sounds so logical, but we really have pushed hard to make sure that our officers are doing those things to the point that they audit our officers via their body worn cameras when they're encountering citizens randomly on traffic stops and things of that nature to see if the officers follow that procedure. When you explain the process to people and explain why they are being stopped, what they did, and then explain to them what the next steps are, they may not like the outcome but if they find that the process feels fair, they will feel like they were treated fairly.

... Not only do we teach it in the academy, but we also teach it in almost all aspects of training throughout the police department. And then we reinforce it by doing these random checks on officers' encounters with citizens via body worn cameras. If they're not doing these procedures, we work to train them and say, "Hey, look, you forgot to explain the process. You forgot to introduce yourself. You've forgotten to allow the person the opportunity to speak." You train them on that and remind them of that. And then if they still don't get it, you can start to take progressive disciplinary action, whether it's a written warning or, eventually, maybe a formal disciplinary investigation. But most officers, once they get used to doing it, it becomes second nature.

...To have that dialog with that person so that it's no longer just, "Give me your license, registration, and insurance," they know why they're being stopped. They know who you are. You have some legitimacy because you have given them a legitimate reason why you stopped doing that just for random reasons, allowed them to voice their concerns because maybe they do have a legitimate reason. "Yes, officer, do you see my wife in the back seat.? She's having a baby." You allow them to explain what happened and then you've explained the process to them so that they know the process has some equity to it.

That is how we have worked to increase the community's confidence in us, especially in communities that have lacked confidence in us because of past prior bad acts by members of this department.

Clearly explaining what will and will not happen and following through as

promised has helped other bureaucracy members working to rebuild public trust with the citizenry at-large, not just the artistic community. This not only leads to greater public trust between the bureaucracy and the citizens with whom it directly interacts but citizens 
also spread the word to other citizens, as well. Olympia, a city health department employee, illustrated this through explaining what happened immediately after her time working with disaffected citizens who had memories of government failures during Hurricane Katrina, while she was working at the 2017 tornado shelter mentioned in the previous chapter. She said:

Olympia: But at the end of that, eight days later, the mayor's chief of staff was there as we were having the last people leave. And this group of them that had been throwing this big fit went to her and said, "We don't like everything the city does, but we really appreciate (Olympia) because she does exactly what she says she's going to do. What we hear from city government is a lot of promises and people not doing things. But with (Olympia), if we asked for something, and (Olympia) couldn't make it happen, she said, 'I don't think I can make that happen. I'll try to work on it.' And if she made a promise about something, she followed that through."

I try really hard to explain to people why we're doing what we're doing - what actions we're taking and why. ... By explaining those things and telling people what we're doing and being an honest and genuine person... I think it helps with that. But that's person by person. That's not what people are seeing on the news.

Clear explanations to elected officials and the public at-large, Olympia said, are more effective also when utilizing evidence-based arguments — ones that are based in empirical research rather than pure emotion. This creates an environment where the bureaucracy's arguments to either politicians or citizens alike have more solid grounding — an attempt to transcend the hyper-political environment mentioned in the previous chapter. This is especially true in the work to revise the noise ordinance, in which Olympia said health department officials are working to base anything they put forward on "scientific data and not just political perceptions and people's thoughts", such as arguments based solely on personal taste or artistic content mentioned in the previous chapter. She mentioned that any government agency, not just hers or other health 
departments, could work to transcend politics through this practice, such as police supervisors using crime data to justify hiring more officers. She said:

Olympia: Here in the health department, our tactic is to bring it back to the science and in looking at research and trying to not make things political. Sometimes, you have to frame them different ways for different people, whether that's the city council or the mayor's office. I think the more often we can say, "Mayor, here is the scientific evidence behind this, and this is why we want to do it," I think the less we can get into the political business.

Another practice Kingsley mentioned is "no silly question" sessions between officers and members of historically disenfranchised groups. He used the example of the transgender community. At the time I interviewed Kingsley, he was working to have an advocate who is transgender to come and meet with officers and allow the officers to ask any question about transgender communities that they have without worrying about being offensive or asking a question that may seem silly. These sessions have a dual purpose in not only providing officers with information but also building a more open, comfortable dialog with members of disenfranchised groups. He elaborated:

Kingsley: We can then have a safe space where people can ask questions like some of what you would think are silly questions I hear. But they're not silly. ... I think I have identified somebody who can answer questions that, on its face, might seem silly. But if one person asks it, there are probably a lot of the people thinking it. I think something like this would probably be more impactful if it were not coming from a two-hour block of instruction at the academy.

As mentioned in the previous chapter, artistic communities favored comfortable, familiar, level, and casual meeting places if they were to interact with city government officials. However, place mattered in this case with Kingsley's planned meeting between the transgender advocate and officers in a reverse sense. Although he wanted the environment to be a safe one for all parties, he wanted to convey to his officers that what 
was happening was something he and the department were taking very seriously and that the officers should take it very seriously, in turn. His plan was to have the meeting in a conference room that he uses for serious functions, like policy meetings and award ceremonies and not routine events such as daily roll calls, so that the room itself is part of what conveys the gravity. He further elaborated:

Kingsley: If it's in a special room and attended by high-ranking members of their districts who say, "Guys, this is important, all right? This is a community that really doesn't trust us. And our job is to get everybody to trust us." So that's one of the things that I'm working on, kind of internally.

\section{Bureaucracy Going to the Artistic Community}

Place was a major factor when discussing enabling factors for the New Orleans artistic community. Some New Orleans city bureaucracy members have gone beyond simply opening a door to the artistic community and have instead gone to the artistic community where the artistic community congregates and at times that work for the artistic community. Bureaucracy interviewees told me this was a critical piece of any inroads they have made because of a combination of overcoming both practical barriers like work schedules and transportation difficulties and social and historical barriers like mistrust that have come with the city government's checkered past. Most artistic community interviewees informed me that they welcomed this interaction and wanted the bureaucracy to do this more. Some who had encountered city officials at the artistic community's gathering places and in casual settings said these interactions in these places have been the most constructive and believed most positive change has come from these interactions. 
When the city's health department prepared to launch Sound Check, Olympia said that, before announcing it publicly, she and other department employees had separate stakeholder meetings with three groups any noise ordinance change would affect the most: musicians, business owners, and residents. During these meetings, the health department personnel would tell those attending what they were thinking about doing but also ask the groups for their feedback. A major aspect of this is that meetings were done where these groups congregate rather than asking the groups to come to the health department. This was namely done to combat three of the obstacles mentioned in the previous chapter: difficult work schedules, intimidation from speaking at formal meetings, and transportation problems. The health department conducted its meetings with musicians at a local bar, a comfortable place. She explained:

Olympia: The first is just logistical as you just saw it is very hard to park and get to city hall. It's just such a logistical challenge that we face when we hold any community meeting. You have to pay for parking. It's not super easy. So one, by meeting at a venue in another part of the city, it's easier for people to get to. But I do think it's less intimidating when we're coming to you. It gives them, I think, maybe a little more confidence to speak and that they know they're going to outnumber us. Yeah, I think it brought more people to the table.

Time and place was another key aspect of not only these stakeholder meetings but also work on the streets with the artistic community and other historically disenfranchised groups in the health department's efforts. Olympia said she and others met with the artistic community where and when they gathered by going to live music venues and other entertainment areas such as Bourbon Street to educate musicians and other club personnel about their efforts to protect hearing. This has been done even at extremely late, odd hours. She said this built positive relationships and fully demonstrated to the 
artistic community and other groups that the health department was taking an interest in them and their well-being. She explained:

Olympia: We've done hearing screenings and educational sessions at 3 a.m., as the bars are closing. There's a service industry group that gets together after they all get off work and have a drink and hang out. We've attended their meetings in the middle of the night because that's the population we're serving. We've never had a morning meeting about Sound Check. Even if it's during business hours, they've been in that right after lunch period where we know people are out but they haven't left for work yet.

...I think direct engagement takes a long time and it's hard work. But I think that's where you have conversations, that make people change, right? When you walk up to someone and they say, (loudly), "But I can't hear you!" And say, "I know. That's why I'm here. Let's talk." We have also found that the easiest way to get people to talk to us is to give out free Koozies. We have cozies with the Sound Check logo and some tips. We give those and earplugs away. Every bouncer or security guy at the front door knows my team by name. Every night, it's "Hey, do you have another set of your earplugs for me?" That's the easiest way to make friends on the streets.

Kingsley said going to the artistic community where it congregates or at places

where and when it congregates has helped the police department build and/or rebuild relationships, as well. The department regularly has community meetings throughout the city, but he understands that some groups, such as undocumented immigrants, that the police do want to reach will not feel comfortable in a police station. He emphasized the importance of going to communities versus asking communities to come to government officials, especially when government officials are working to rebuild tattered relationships. He emphasized that it also has to be a two-way street with artistic community members or any group the department comes to, working to create positive, constructive relationships. He explained:

Kingsley: I tell my officers and I look at myself and say it's not enough for the community to come to me. I work for them. I'm a public servant. It's my job to gain their trust. It's not their job to gain my trust. And again, "the community" is 
so broad. But it usually is one or a small group of officers, sometimes midranking, sometimes high-ranking, sometimes frontline officers who go to that group and say, "Look guys, we're having problems. Tell us what's going on." And that's the building of relationships.

But I don't think that it's the community's responsibility to come to us. The only responsibility I think the community has, is that if we come to them to try and work out a problem, to kind of talk to us to let us know what the problems are, where the solutions are, to work with us, and to not shut us down. Even if you're working against the man, don't work against me, even if you're withdrawn. If you're withdrawn, and if you're building up walls, then I become "the other". There's this demonization that's going on. But if we can at least have dialogue, even if the dialogue is vehemently disagreeing with each other. I mean, at some point, we'll find some common ground that we can start working towards. And you know what? Maybe at the end of the day we'll only find the sliver of common ground, but we can say, "Well, let's at least focus on getting that right and we won't get to the broader issues." But you have to start somewhere and if there's no dialogue, you don't go anywhere. But it's our job as public servants to begin the dialogue, and it's the community's responsibility, I think, to allow us to be in that dialogue.

A local nonprofit advocacy organization, the Music and Culture Coalition of New Orleans (MACCNO), has regular meetings at the Candlelight Lounge in Treme, and Kingsley said either he will go to these meetings or send a representative. The Louisiana State Police, which also patrols the French Quarter and has an extensive mutual aid agreement with the city police, regularly attend as well. He explained how the setting, both during and after the meeting, helped him to build relationships and provided a concrete example of how this led to action taken.

Kingsley: It's an opportunity for musicians to air their grievances with the police or with, just in general, whatever is going on. Every business and citizen group that has a meeting down here, usually in the evening, I attend and I do so to make myself available on that informal setting so that usually they'll ask me to speak and speak for five minutes, but then I stay for the reception because that's where you can really have conversations with people in an informal setting. I feel like we do our best to kind of give everybody the opportunity to talk to us and have their grievances heard and so we can address some of those issues. 
In the last Candlelight Lounge meeting that was put on by MACCNO, which I did not attend, but two of my officers attended... There were concerns about whether we were correctly enforcing a music ordinance on Bourbon Street. Are we incorrectly enforcing a law against businesses using speakers outward facing towards the street in order to bring in customers? In the past, some officers have enforced that law on people that have speakers on the street, performers with speakers and amps on the street. It was a good question because I said, you know what? A: I didn't know that officers are enforcing that. B: I wasn't aware that that was a law that was being enforced incorrectly. So before my officers could say that we're not forcing it, they said, "Let me find out." When we looked into it, reading the ordinances, I put out a message to all the officers that worked for me saying, "This ordinance strictly applies to bars and clubs with out-facing speakers and does not apply to persons using speakers in performance on the street." So we were able to. That was the concern. We really circled back to them to say, "You're right, it should not be being enforced if it's being enforced this way. I will tell all of my officers to make sure it's being enforced properly."

This was not only an approach the government officials I interviewed both favored and have done but also one that artistic community members I interviewed wanted, even without my prompting. Either they desired more of this or, if it were not happening in other situations, they wanted this more.

During the focus group, one of the members made the remark of how he wished government officials could just sit down with them at a casual meeting place and "just have some whiskey and talk." I mentioned a preliminary conversation (Personal Communication, 2015) I had during this research's beginnings that involved Bloomington, Indiana's, city government going to its local music community at a music venue and at a time when those working day jobs would be off from work but before gigs would start. The city was building a new arts district and wanted their input and to give the artistic community as a whole ownership of the project in the end, too. The focus group's street musicians repeatedly said, "Yes!" during this spiel, with one saying: 
Lucius: Can we get them here? Can we somehow import them here?

Artistic community interviewees desired this, as well, with one saying:

Ginny (street poet): Yeah! That would be fabulous. If our government would meet us where we are, that would go such a long way. I think that that the best and most meaningful stuff has taken place when city officials or police or whoever came to our meetings or just stopped to talk to see if I needed help. That's when really good work happens, for sure.

Both advocates and researchers doing work in New Orleans have advocated this approach, with Harry and Minerva, a researcher doing work in New Orleans, meeting with the groups they are trying to reach in comfortable, casual community gathering places, such as those Oldenburg (1999) describes with third places. In these settings, they emphasized that accessibility was greater and intimidation such as that in formal government meetings settings, was decreased. Harry said, "Yeah. That's what we do. It's all about access." Minerva further elaborated:

Minerva: I think place is important. Think of the city hall meetings. I mean, you walk into those meetings, and it's very formal. You have the council members sitting at the desk in their the big, cushy chairs and swinging around, and they're sitting up above the common citizens - the commoners, the citizens, both. I think place is very important, and I think if everyone kind of came to that common space, to a safe space, to a space that's comfortable, open - and to whatever, the evenings, the afternoon... I think that would be interesting.

\section{Old Enemies with Common Causes: The Bureaucracy and Artistic Community}

One of the more surprising findings for this dissertation is that groups whose relationship has been fraught at its best had common causes and deep mutual concerns. This was potential groundwork for a much more constructive relationship overall. The ones who had these common causes with the artistic community were namely employees in the city bureaucracy, such as the city's police department. 
This finding did not obviously present itself. My personal background was key in discovering it for three reasons: my being a musician since I was a teenager, my being a former police beat reporter — and, very unexpectedly, my being a devoted cat owner. The latter is how this path began.

I visited the New Orleans Police Department's precinct in the French Quarter and this plate of cat food in front of the door shown in Figure 5.1 immediately caught my attention.

Figure 5.1: Cat food for stray at NOPD precinct (Pridemore, 2017)

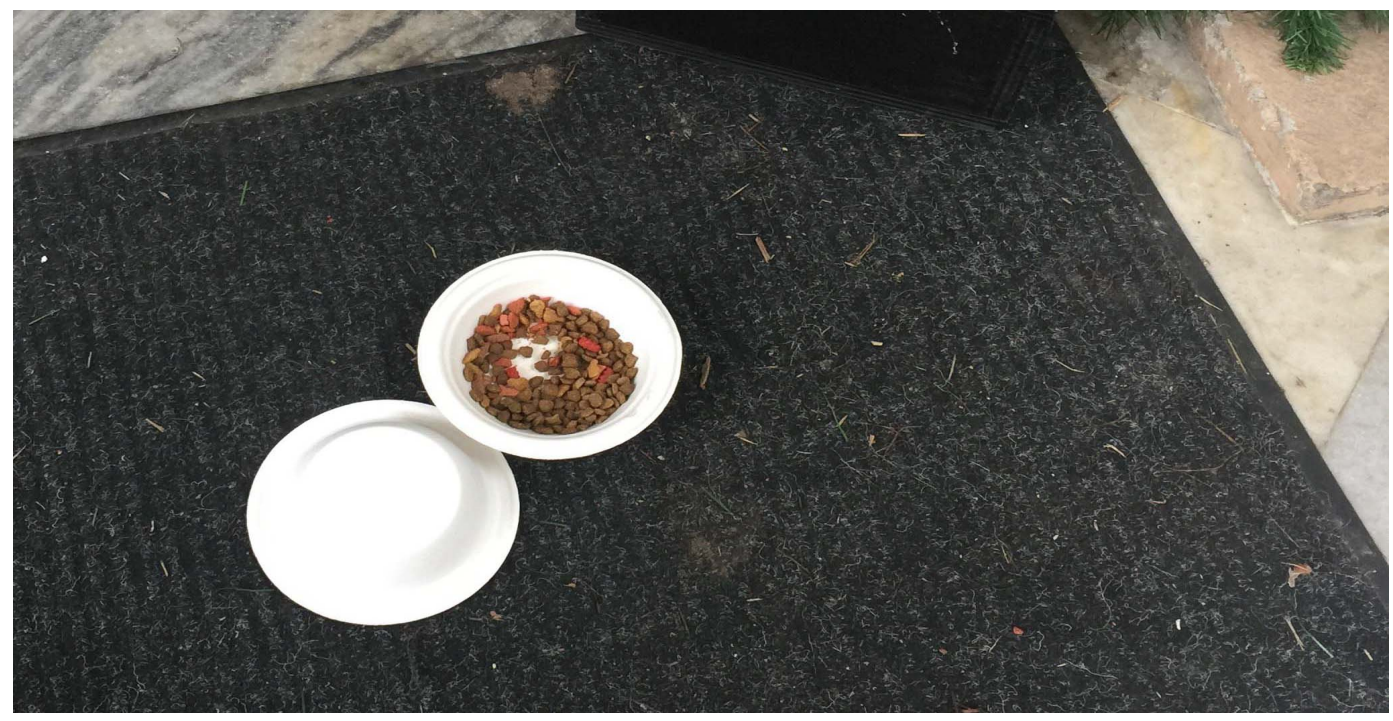

Just out of cat-loving curiosity, I asked a woman at the front desk if the police department employees were caring for a cat. She explained that was the case - for ten years. Smokey, a local French Quarter stray, was a mainstay at the department since a civilian employee had begun feeding him, and since her retirement, others continued to feed Smokey. Multiple artistic community members mentioned how they felt a kinship with other disaffected groups in the city, namely service industry workers (to be further explored in a later section). While visiting a café very close to the police department, I 
overheard the service industry workers and some of their customers talking about Smokey, a regular around the café too.

I asked a server if the café employees also cared for Smokey, and she said they had taken care of him and another cat friend who had joined him named Sammy. The two would frequently play outside of the building and entertain employees and customers. Despite their notoriety, Smokey and Sammy eluded me during my time in New Orleans, when I had hoped to get a photo of these famous felines. Just at that point, a police officer walked in, and I asked her if she had seen Smokey. She smiled and she had not seen him that day, anyway. Still, she knew Smokey, too.

The artistic community members' old rivals, the police, and their kindred spirits, the service industry workers, had come together for a decade because of their common love and concern for Smokey the Cat. This led me to further explore if there were other, more serious common concerns the old rivals had and if this could spark a more constructive dialog, overall. This turned out to be true, and the city bureaucracy employees I interviewed immediately took an interest and told me they wanted to use that opportunity.

The city's violent crime and murders was the most serious common concern between the city government, namely the police department, and the artistic community. As mentioned in the previous chapter, New Orleans was the city ranked third for murders in the United States during 2017 (CBS News, 2018), and street performer interviewees and focus group participants were especially distressed. Artistic community members, namely those working on the streets, in New Orleans namely work in a cash-based economy, and I knew from my time as a police beat reporter that individuals and 
businesses known to have more cash on hand are often targeted for crime more (Pridemore, 2008, 2010).

I asked the street performers how often they had been robbed of their cash tips. Those in the focus group mentioned said that had happened to them constantly — noting that people who rob street performers rob them of not only cash but also instruments, bicycles, and even chairs and buckets on which they sit. Ginny mentioned bicycles are stolen frequently.

Fleur, a street musician interviewee, said she chains her tip buckets, but that still has not prevented some from reaching into the buckets and taking her cash before she can stop playing long enough to empty them, as she does regularly. A street band I observed during a Royal Street Pedestrian Mall had a friend periodically emptying tip buckets throughout their performance. During my interview with Fleur, a friend of hers drove up on a bicycle with one of the "bike carts" - carts, as mentioned in the previous chapter, that are attached to bicycles and used to haul equipment as large as tubas and drums. Fleur's friend had a full drum set in his but needed to step away to use the bathroom. She and I both agreed to keep an eye on it for him, with the man chaining it and saying, "I don't know if I should leave my Cadillac here tonight. I have to do a parade. They're (Thieves) going to knock each other down for it."

The observation photos below of one street performer's bicycle and another's tip bucket in Figures 5.2 and 5.3 show what lengths the New Orleans street performers were taking, namely with chains (often, very thick), to protect their earnings and other belongings. 
Figure 5.2: Street performer's chained bicycle (Pridemore, 2017)

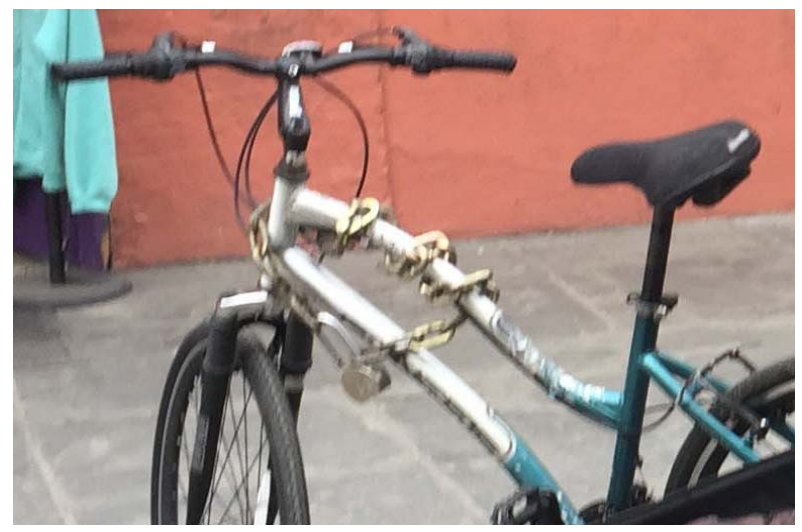

Figure 5.3: Street performer's chained tip bucket (Pridemore, 2018)

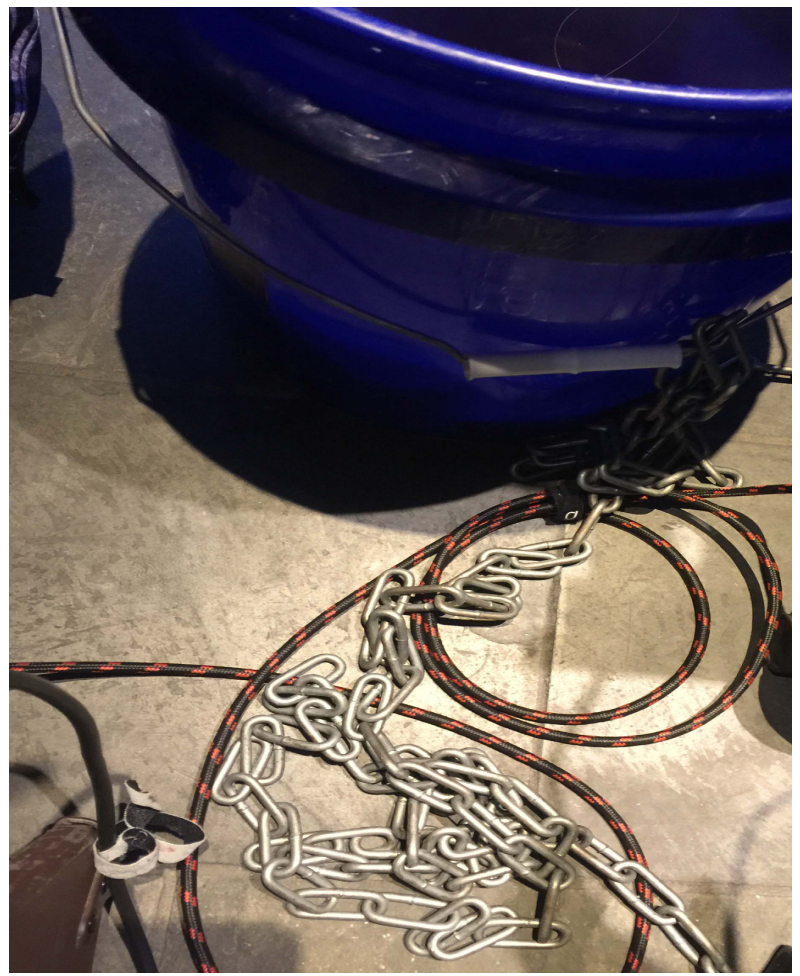

Throughout this dissertation, gender was not a major factor except when discussing crime. Male street performers were guarded and fearful because of New Orleans' crime, but female performers were especially frightened because they believed their gender and, quite often, smaller size meant they would be targeted even more. During an observation, I overheard a female performer mention that she personally stakes 
out a corner across from the police precinct for safety reasons. I asked Fleur during my interview with her what it was like to work as a female street performer knowing about the murder ranking and the crime, in general. One measure she takes besides chaining her tip buckets is forgoing the bicycles and bike carts the male performers who spoke to me used and driving her car to wherever she is playing and only playing at places where she can park her car. This, itself, is very challenging and limits where she can play, given that parking in the French Quarter is all but non-existent. She said:

Fleur: You have to be street smart. ... It's scary — very scary. I should probably be more scared. ... If my car were far away, I wouldn't be doing this. I make sure that my car, when it's after dark, is right there. So when I'm loading up, it's right there. It's all lit. And the police station is one block away. There are always people around.

I interviewed Kingsley the day after I conducted the focus group and mentioned what the street performers had told me about their constantly being robbed and their vulnerability from having cash on hand. I asked Kingsley if he believed this was a starting point in building a constructive relationship with the artistic community, especially with the street performers. This was the exchange we had.

Amelia: Basically, (the street performers) said that after we get done, if we don't get robbed or our instruments don't get stolen, we don't want to get killed going home. ... So I'm just wondering if one common thread that you guys have that you can build on is the fact that you guys both don't want this.

Kingsley: I do. I absolutely do, and I will... I think that's a great opportunity for us to work on some common ground. It's another piece of common ground that we have. I think that is certainly something we can kind of explore with them.

...I can't think of an instance where a performer committed a violent crime down here. And that's really what my focus is. So they might sometimes violate nuisance ordinances and things of that nature, and warnings are helpful in that regard. But my officers' focus has really been on violent crime, and (the street 
performers) are victimized — and I'm sure much like the homeless, much like drug addicts... They're victimized at a much higher rate than they commit crimes.

That's a really good opportunity that I really hadn't realized until now. I'm stealing that one. I'll give you credit. But yeah, that's an opportunity for us to maybe start to close some of those gaps there. I can say, "Hey, we're really working toward the same issue, which is to keep everybody safe. And you guys in the street performer community know about safety issues and are often victimized."

Some artistic community members wanted a constructive dialog with the city government, in general, and they depicted this in some of their narrative mapping. This rather self-explanatory drawing from Frank, a street musician in the focus group, was one such narrative map. This drawing is shown in Figure 5.4.

Figure 5.4: Narrative Map (Ideal): Frank, New Orleans street musician

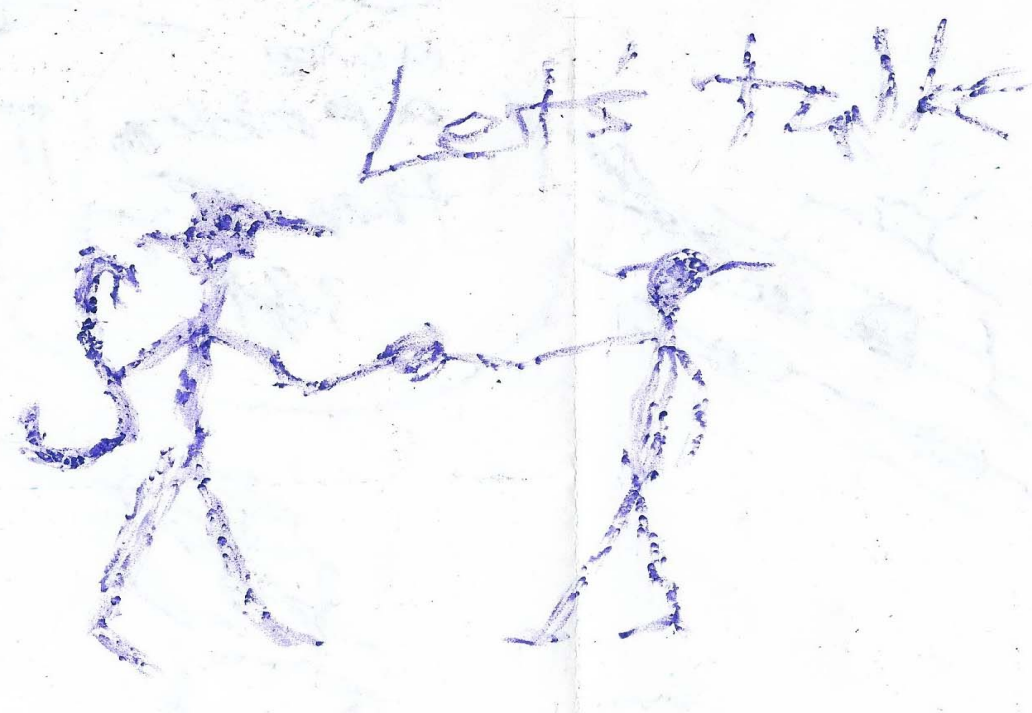

Just as I did with the street musicians in the focus group the day before, I had Kingsley draw a narrative map depicting his department's actual and idealized relationships with the artistic community. The narrative map below in Figure 5.5 shows his idealized one. 


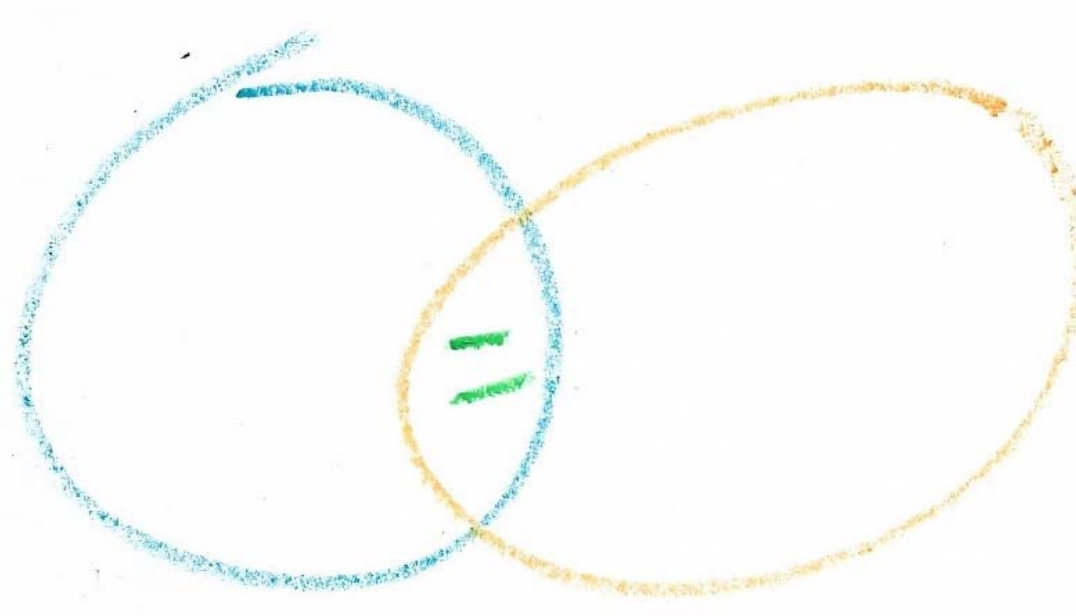

Kingsley explained his idealized drawing as the police, represented by the blue circle, and the cultural community, represented by the yellow circle, coming together. The key is the green equal sign in the middle. Yellow and blue make green, and Kingsley said he wants both groups to come together and have an equal partnership. As he did in the realistic narrative map show in the previous chapter, Kingsley chose yellow to represent the New Orleans cultural community, saying it represents their boldness.

Another major starting point that the officials, in particular, believed was a link in building stronger bonds with the artistic community was youth outreach — passing on artistic and cultural traditions to new generations, encouraging positive expression, and keeping youth occupied with constructive activities. Noting my experience when I started playing guitar (and as the only local girl doing so at the time) as a teenager — when a common complaint among my musician friends was how we were sick of disgruntled individuals shutting us down for minor noise when we were doing something 
constructive, I asked the government officials in particular if working to get more youth involved in the arts and utilizing the artistic community's skills to do it was more common ground.

Kingsley, who said he and his officers would rather see young people involved in the arts over juvenile crime any day, said this was definitely the case — and some New Orleans city officers were already taking an active role. New Orleans' cultural traditions being so beloved helps in making this already attractive to young people and further encourages them to stay out of trouble. He explained:

Kingsley: One of our officers who was a detective under me, and now he's a sergeant... He and his brother do a lot of volunteer work after school with the marching bands in New Orleans. Marching bands here are big. They're really more popular here than I would bet a lot of places because they're such a huge part of Mardi Gras. When you went to a local high school, and then, you see your high school and the band during the eleven days of Mardi Gras - six, seven nights. Out of those eleven nights, you have some pride, and a lot of people get really wrapped up about that. That stirs up a lot of pride in these kids.

And those marching band directors... Those kids don't get into trouble because they know if they get in trouble, they get kicked out of the band, number one. Number two, the directors have worked them so hard when they're at practice, by the time the kids get home, they eat and go to sleep.

So marching bands in New Orleans and our kids being involved in the cultural community is a win, win because we're not having to deal with them in a negative juvenile crime manner. ... I think that a cultural connection between the kids and the police is a win, win.

Kingsley, like Olympia and Harry did in the previous chapter, noted the city's bucket drummers, which are mostly teenagers or young adults. Olympia said the very loud drumming often draws ire from people such as those who own high-end businesses on Royal Street. Certain city policymakers, though, have acted with concern for the drummers namely because they worry for their safety, have seen them out during school 
hours or late at night, and know that some of the drummers lack family structure.

However, Olympia, like Harry did, pointed to the NOPD's eighth district commander who gets to know the drummers personally, educates them on safety, and makes sure the other officers get to know them well, too.

Kingsley pointed out that there are far less constructive things the young bucket drummers could be doing and encouraged those who complain to help the young people find positive mentors and constructive activities rather than simply trying to make them leave. He said:

Kingsley: If you look at my little drummer boy kids, they hide their buckets out at my station, which I think is cute. They lock their bikes up to my station and they come because they know it's safe. So when I get complaints from the business owners on a set of these because they're making loud noise, a lot of times, my response is, "Hey, you should work with MACCNO to develop programs to get these kids involved." I think that's a great opportunity.

...We see young kids right now drumming on a bucket who, maybe by next fall, could be drumming in a school band, where they're getting some formal teaching and some discipline and structure. It might be the only structure they have in their lives. I don't know. And maybe it gives them the opportunity to become Jean Baptiste, as opposed to just becoming a kid who played on the buckets when he was 15 and then, he went off and did something else that wasn't as productive.

Bureaucracy having more in common with artistic community and other disenfranchised groups

Another both realized and potential enabling factor in New Orleans was bureaucracy members having more in common with the artistic community, whether the two groups realized this or not. This was namely because both bureaucracy members and artistic community members were also facing the same affordability and morale challenges as well as both being treated as "the other" in society at-large. Artistic community members also saw city bureaucracy members, namely some police officers, 
as being disenfranchised too, with their livelihoods at the mercy of the city's elite, as detailed in the previous chapter.

Just as the artistic community was concerned with their livelihoods while under pressure from rising costs, so were members of the bureaucracy. Olympia said that her department had faced budget issues that would not allow any additional expenditures or changes from the previous year. This led to a combination of frozen pay raises, certain employees who believed they were being promoted leaving because they did not get the promotion, and employees left behind doing their own jobs combined with the duties of those who have left. During a meeting about the soundscape with French Quarter residents and some groups representing musicians attending, Olympia said she emphasized that the health department was not out to be "the bad guy" — that it understood the importance of people's livelihoods and how it was also linked to the health department's goals. She said:

Olympia: I said that I understand that people losing their business, losing their jobs, and not making money because I shut them down because I enforced exorbitant fines on someone... That's not helping their health, right? People need to be able to afford safe housing. People need to be able to afford food and need to be able to afford health care or health insurance. Those things are just as important to my team as making sure that people don't lose their hearing or making sure neighbors are able to sleep at night. That's part of our holistic approach. Those are things we want to make sure that people understand - that we recognize that.

Artistic community members namely showed this attitude, as well, during the focus group I conducted with street performers. Some of them showed this attitude toward police officers, in particular. During the focus group, some of the group members depicted police officers as kindred spirits, people whose lives were also at the mercy of a 
wealthy elite collaborating with the elected government (as mentioned in the previous chapter). They did so in their narrative mapping drawing exercises, which will be shown below. The first is from Frank, a street musician whose idealized relationship with city government was shown above. His depiction of the actual situation is below in Figure 5.6 .

Figure 5.6: Narrative Map (Reality): Frank, New Orleans street musician

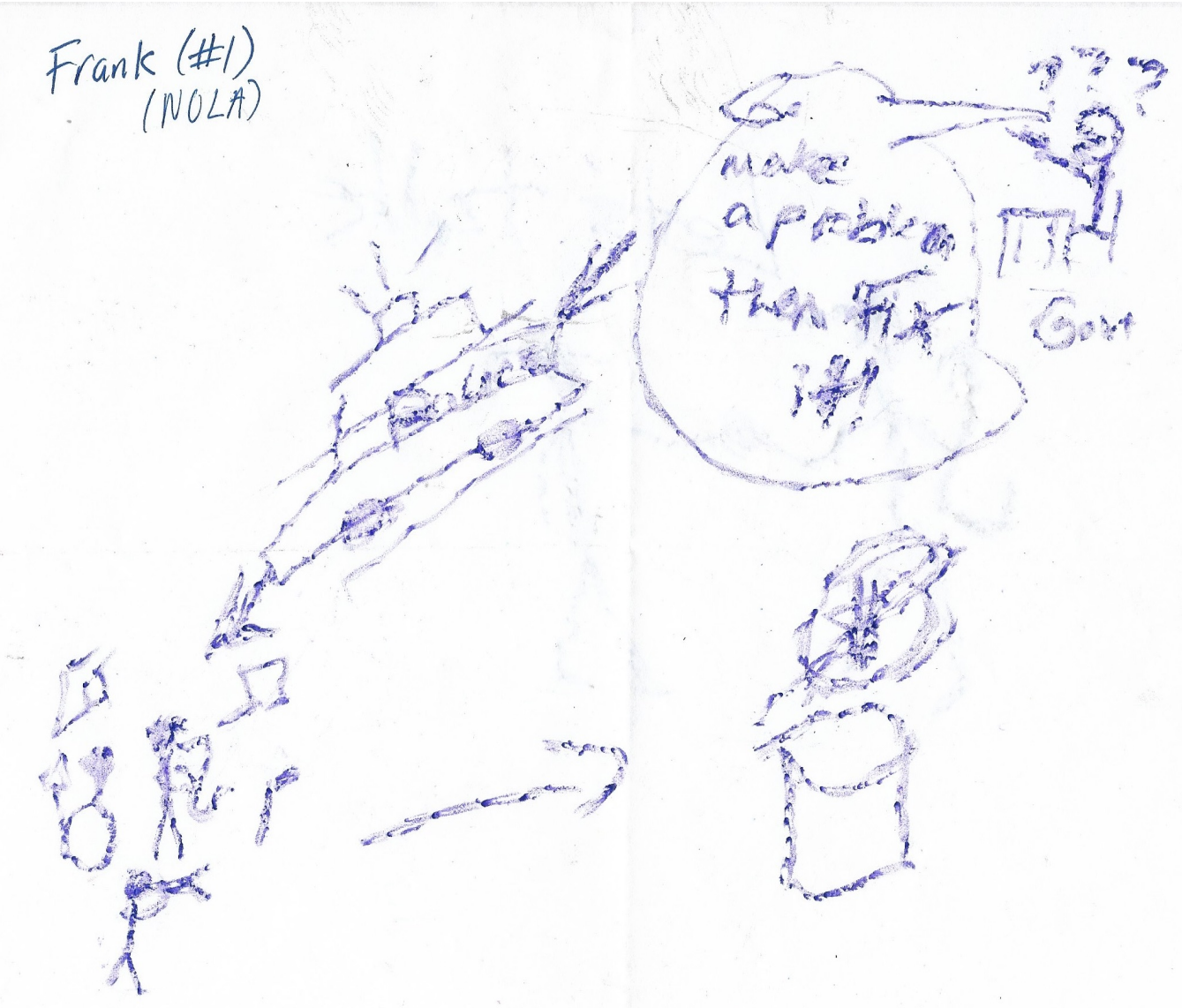

In this depiction, Frank diagrams a process that starts with a city elected official, situated at the top, moving to a police car toward the middle, leading to a street performer, and the street performer's income as represented by the tip bucket at the end of this diagram. Frank said he drew the street performer and the elected official being at 
two different heights because they were not at the same level and he wanted to show a general separation between the two. The key is that the police car is between the two, and the police, he said, have to listen to the elected official's directive, as Frank depicts it, of, "Go make a problem, and then fix it!" He said that although the street performers have good community controls amongst them (to be explored in a later section), government officials will intervene on non-existing problems like perceived disputes over street performance space. All of this, in the end, results in lost income for the street performers.

One key aspect, though, is how the government officials do this - the police. Frank shows how the police are not the ones giving the orders but simply following them - a cog in this system leading to the street performers' income just as the street performers like him are, rather than the actual person causing their grief. Lee, another street musician, also depicted police officers as being at the mercy of elites. I will draw attention to a major aspect of this drawing shown in Figure 5.7 with an inset further below in Figure 5.8. 
Figure 5.7: Narrative Map (Reality): Lee, New Orleans street musician

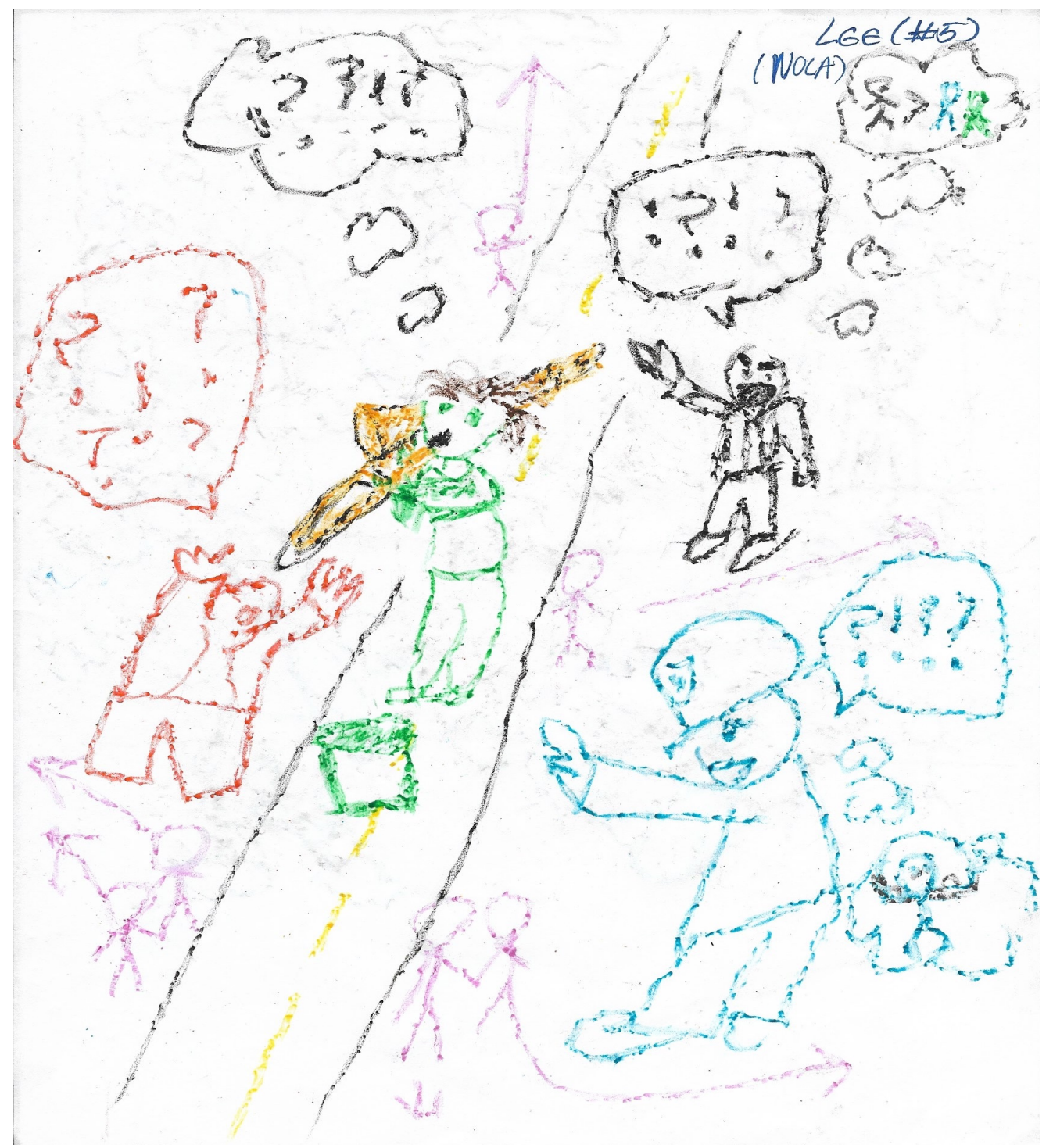

Lee explained his drawing by saying that the green musician in the middle of the street was himself, the person in blue was a police officer, and the person in black was a wealthy business owner. The latter is a group with whom street performers, particularly those on Royal Street, have clashed (Webster, 2015b), with the focus group members telling me that police officers - depending on which of the fourteen agencies in the French Quarter alone that the elites believe will work in their favor — are called to 
intervene. The others in the picture include the orange man, another street vendor, and citizens milling about are the ones in pink. He drew himself as the only person standing in the street while the others stand aside because he believed he and other street performers like him are the only ones who truly understand what is happening on the street. All have thought or voice balloons (or a combination of the two) above their heads of question marks and exclamation points, he said, because they are feeling a mix of anger and confusion.

He only has a thought balloon because, Lee said, he has no voice because he is at the bottom of the social standing of all in this picture. He said he chose green for himself because of the money he is trying to earn. When Lucius and Garrick, another street musician, chimed in regarding use of green, saying that being a street musician is like being "an alien from outer space", Lee agreed with their assessment, as well.

Another side of that picture, though, is shown more closely in the inset below in Figure 5.8.

Figure 5.8: Narrative map (Reality/Inset): Lee, street musician

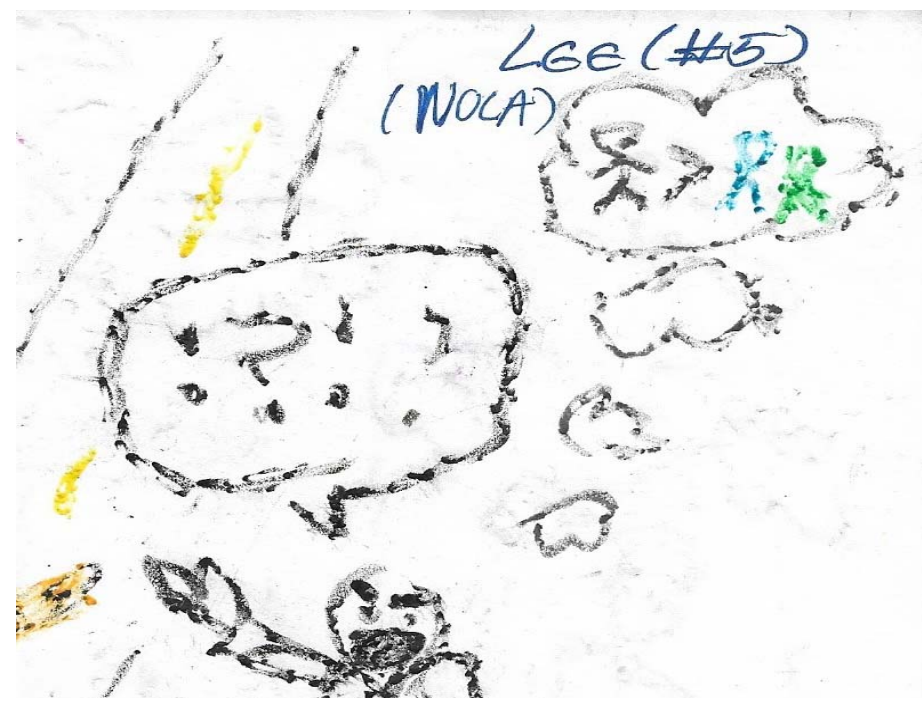


The wealthy business owner in black has a thought balloon in which he is thinking that he is superior to both the green street musician and the blue police officer, and as Lee explained, believes he should control both. An important note is that Lee's and other focus group members' comments regarding the wealthy elites' collaboration with the elected government and how it is used to mistreat them echoes comments from Olympia in the previous chapter about how business owners angrily confronted her, arguing they are in a higher position because of their tax contributions, when she was working to ignore politics in working to promote public health and do so based on empirical evidence.

In this depiction, Lee sees common ground between himself and the police officer, another member of the bureaucracy, because they have a common oppressor in the wealthy elites. Lee explained:

Lee: I've got Mr. Guy in a Suit over here. He's got another thought coming out. He views himself as superior. For example, he has an opinion about me. He's got a business. He's in a higher social strata. So, mentally, (for the man in the suit), we're not equals. He's got a thing that separates himself from me.

And it's the same with the cops. He feels like he's above the cop. The cop has to answer to him because he's financially viable in a way that should mostly be relevant in who gets to say things. He's like, "I have the most money. You are profiting off that. You should be listening to me. I have sway and influence."

While Garrick was not as empathetic as some of the other focus group members, he did believe that the street performers had at least some kinship with the New Orleans city police because he believed that the city police often had to do what they disliked 
because elected officials and wealthy elites collaborating with them tied the officers' hands. He said:

Garrick: There's a very weird tension, I guess, all the time when it comes to law enforcement here because they answer to private businesses and exact government interest, but they are also so against some of the ideas that those same people have that they end up siding with us sometimes on various things. I can tell that they want to protect us. They want to make the entire French Quarter a pedestrian mall, in response to a lot of noise complaint issues that come up here. Of course, no private business wants that.

During my interview with Kingsley the day after I did this focus group and saw drawings like Frank's and Lee's, I mentioned the view some of them had, of the police being an instrument of a more powerful oppressor rather than the police being the oppressors themselves. This is part of the exchange I had with Kingsley.

Amelia: The view some of them had was that of, "They're just doing a job that they have to do." Do you think that's something that a lot of people miss sometimes when it comes to building their view of police officers in general?

Kingsley: I do, and not only for performers but just the public in general. Officers are often responding to complaints made by citizens or calls to 911 or calls to dispatcher of, "Something's happening that I don't like."

...So the officers are just really... They are enforcing the laws written, which is where I kind of went back to the whole... We don't write the laws, right? We just enforced the laws and policies that our lawmakers write. Sometimes people get mad at us because we're just the most visible part of the government because you don't often see your elected officials out here enforcing the laws. That's what our job is. So we have to do so based on how that law was written and what the courts' interpretations of that law are.

During my conversation with Kingsley, I noticed that on two different occasions, he mentioned that New Orleans police officers and the artistic community members are both often viewed as "the other" in society at-large. I picked up on this, and I asked if 
both groups being "the other" was common ground between the police and artistic community. This was his response.

Kingsley: I love that. We had some deep concerns with crimes against the LGBTQ community. I appreciated hearing their concerns, and our LGBTQ coordinator was there.

One person said, "Why is it always that a gay man has to represent the entire spectrum of the LGBTQ community?" But the officer who was there said, "Well, I have three things against me. I'm gay, I'm black — and I'm a New Orleans police officer." The crowd was like, "Yeah. OK. That makes sense."

\section{Enabling Factors Related to Institutions}

To say New Orleans' artistic community and its citizenry as a whole is a force to be reckoned with is a major understatement. Major institutions in the city really pushed the artistic community's citizen participation. The citizens proved themselves to be tough as nails - relentlessly hardworking and in some of the harshest conditions. They also exhibited a survivalist attitude that was defiant against outsiders who criticized it and the elites who worked to control it. This namely showed itself as the city continually emerged from Hurricane Katrina, even taking the infamous FEMA X spraypainted on searched buildings after Katrina throughout the city and making it a visually artistic symbol of pride. These never-say-die attitudes pushed artistic community members into participation venues, both traditional and non-traditional, even when they faced incredible odds against them because of their standing against powerful elites.

Tough as nails

New Orleans is a city that does not back down from a challenge. During my time in the city, I witnessed people weathering conditions that were definitely not for the faint of heart and working extremely hard while doing it. This was a major enabling factor for 
participation because gritty people will not give in to pressures from government or the elite alike without a fight and will make sure their voice is heard.

The artistic community and the city as a whole takes pride in their work ethic that is tough as a brick wall, like the French Quarter tap dancer I observed whose mantra was, "It's hard work, but it's honest work," as he pounded the pavement non-stop for hours. As I was leaving from a break at Woldenburg Park, which is on a hill overlooking the French Quarter, I saw the tap dancer and several bucket drummers working at a relentless pace.

Even terrible weather did not stop some of the artistic community members. I observed and chatted with a street band I met the day before Krewe Du Vieux who came out to the streets before the parade started to earn money from passersby — even though the rain was practically coming down in buckets and flood watches had been issued. While I traveled in a large poncho and waterproof boots, the band simply found an awning and continued to play anyway. In July 2016, House of Blues New Orleans posted a video of a street performer dressed as Darth Vader dancing to Tom Petty's "Free Fallin"” for tips — in the pouring rain (House of Blues New Orleans, 2016).

Kingsley said this spirit is true for New Orleans' citizens as a whole, not just the artistic community. This was something he strongly emphasized when he wanted to counter the outsider derision, particularly during the Katrina aftermath, that was identified as a participation hindering factor in the previous chapter. He explained:

Kingsley: So I'll tell you that there are a lot of hard-working folks in our community. Those skyscrapers that are in the downtown area or one block outside of the French Quarter weren't built by lazy people. All of the hotel rooms get cleaned and scrubbed on a daily basis. If you've ever made a pot of gumbo, you'll know it's not something a lazy person does. 
... I don't think that New Orleanians allow outsiders to say that we are laissez faire, party central, lazy people and cause us to turn into laissez faire, lazy party people. We work hard here, and we have for a long time. We were the reason a lot of the Midwest... All of those hard-working Midwest farmers who grow our produce? It doesn't make it out of the country through New York or LA. It comes through New Orleans. A lot of the gas and oil that this country produces and refines? It comes through Louisiana ports - Port Morgan and Plaquemines.

All that great seafood? That Gulf seafood? Those shrimp don't just jump out of the water into your skillets up in Boston. Those oysters are finding their way up there through us, and all of our buster crabs in Lake Pontchartrain are pulled out from there. They go to Baltimore because we've fished out of our harbor, and that's the hard-working New Orleanians who are pulling that stuff up.

\section{Survivalist, Defiant Attitude}

Throughout New Orleans, I witnessed a powerful survivalist attitude namely in my physical artifact examinations and observations, but also in my interviews and focus groups. This attitude was namely tied to the city surviving Katrina, but it applied to other turbulent eras of its past such as slavery. New Orleanians were often proudly defiant, essentially firing back at naysayers or ones that predicted the city's doom. That attitude enabled participation because, as mentioned above, this attitude was passed onward to public policy matters because the artistic community and the citizens at-large did not take adversity lying down at all.

Physical artifact examination was key here. Throughout the city and on almost every object imaginable, New Orleanians had taken an infamous symbol that invoked its darkest hour - the infamous Katrina Xs - and converted it into visual art that is a symbol of pride. An example of the Katrina Xs from 2005 is below in Figure 5.9. 
Figure 5.9: Katrina $X$ spraypainted on house (Stokes, 2010)

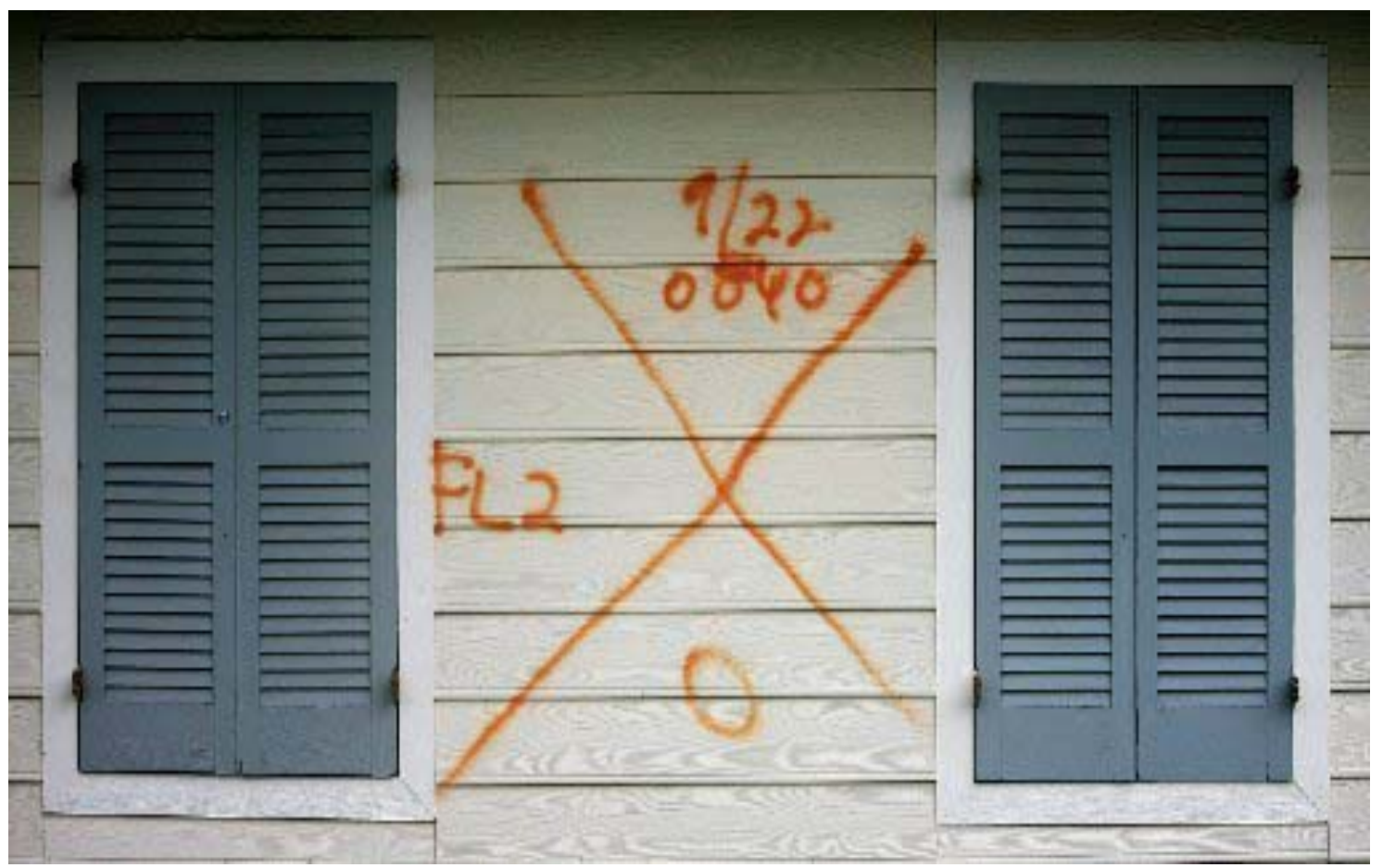

These Xs were spraypainted on houses and other places where people or animals could be found, like vehicles, after they were searched during the immediate Katrina aftermath (Pridemore, 2005). The date the structure was searched is at the top, and the agency that searched it is to the left (Pridemore, 2005; Stokes, 2010; Swenson \& TimesPicayune Staff, 2015). If any hazards were found, such as gas leaks or downed wires, that is spraypainted on the right quadrant (Stokes, 2010; Swenson \& Times-Picayune Staff, 2015). The grimmest number is at the bottom - the number of dead bodies found (Pridemore, 2005; Stokes, 2010; Swenson \& Times-Picayune Staff, 2015). During my time in New Orleans in 2005, I saw a house in the Lower Ninth Ward where eight bodies had been found (Pridemore, 2005).

New Orleanians have taken such a chilling symbol and turned into a source of pride - showing what they have endured and survived. Symbols invoking the Katrina X 
were practically everywhere, especially on merchandise like T-shirts. Figures 5.10 and 5.11 below show a coffee shop's machine and a T-shirt for sale, two of the places that had the Katrina X.

Figure 5.10: Katrina $X$ décor on coffee machine (Pridemore, 2017)

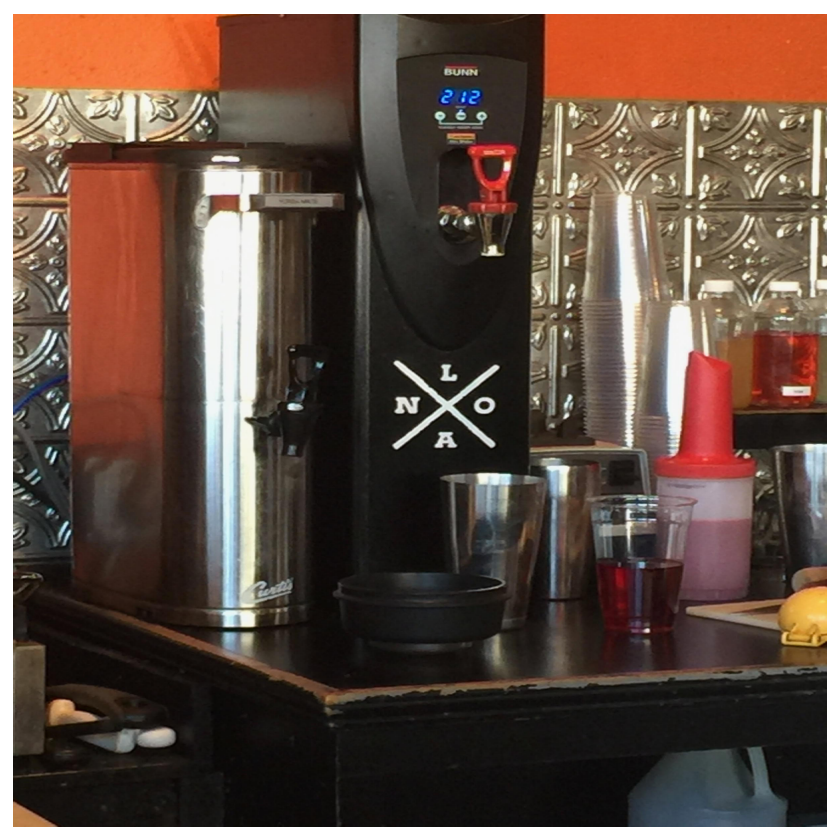

Figure 5.11: Katrina $X$ on T-shirt (Pridemore, 2017)

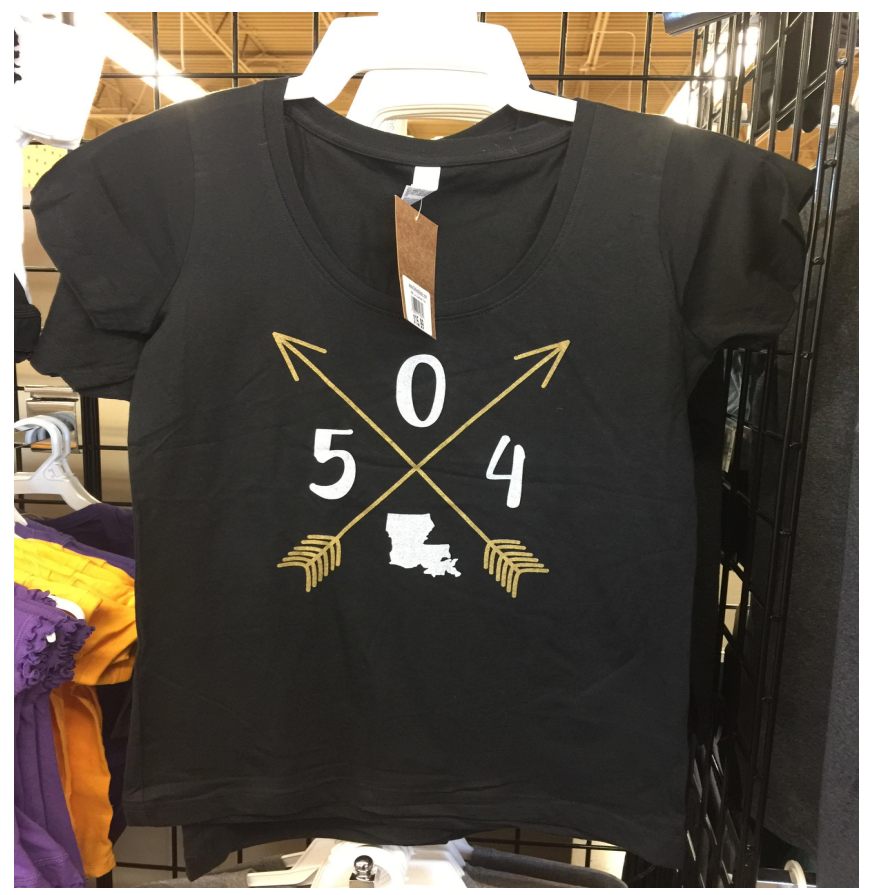


One organization used it as a logo, and its management explained not only what the $\mathrm{X}$ meant to the organization but also the city as a whole. New Orleans Brazilian JiuJitsu (commonly known as NOLA BJJ) adopted a symbol invoking the Katrina X for its school patch (NOLA BJJ, 2018a, 2018b). School patches in martial arts, which students and instructors wear on their gis (kimono-style uniforms) have the school's logo and are typically worn over the heart and on the back (Personal Communication, 2017). NOLA BJJ's logo is below in Figure 5.12 - with the $\mathrm{O}$ at the bottom where the Katrina body counts were spraypainted — as well as an early 2018 explanation from the school's website for what the logo means to the school and what the Katrina X means to New Orleans.

Figure 5.12: NOLA BJJ, Katrina X school patch (NOLA BJJ, 2018b)

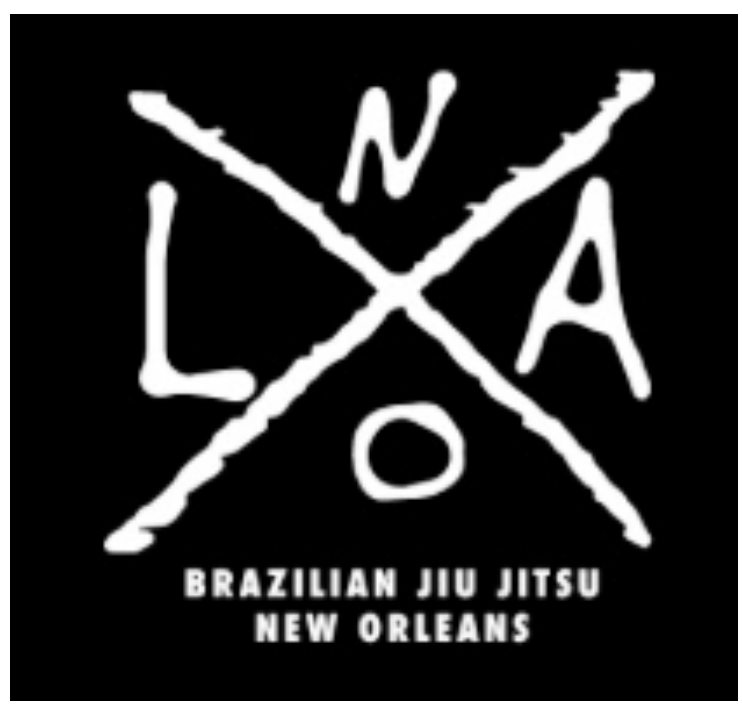

For local residents, this $\mathrm{X}$ has come to represent our city just as much as the Fleur de Lis or Superdome. It has come to symbolize the resilience, undying spirit, and sense of community amongst the citizens of New Orleans. We will never forget what happened that fateful August, but, more importantly, we will never forget that we were able to persevere and overcome. It is for this reason that we adopted this $\mathrm{X}$ as our logo. Our school is a team and a community that can't be broken. We will persevere through whatever hardships lie in front of us, and we shall emerge stronger and closer than before (NOLA BJJ, 2018a). 
Kingsley recalled an event that he said was the beginning of New Orleans bringing back their culture — and re-emerging as a city, in general — after Katrina. It was the Southern Decadence LGBT Pride parade. The parade being originally scheduled when Katrina struck in 2005 led to much of the religiously based outsider derision during the Katrina aftermath (Cooperman, 2005; MSNBC, 2005). That year, Southern Decadence was officially cancelled because of Katrina (Mariano, 2017b). However, a group of "French Quarter holdouts led a small parade through the Quarter, despite the mandatory evacuation then in effect."

This survivalist attitude is strong enough for New Orleanians to react with sarcasm and humor, especially when providing scathing commentary against those who they believe create their misery or make it much worse. This was true even immediately after Katrina. Krewe Du Vieux was the first Mardi Gras parade to roll in 2006, the first Mardi Gras after Katrina (Mardi Gras New Orleans, 2018). Krewe Du Vieux not only kept its biting satirical stance as shown with the flooding and sewer issues in 2018, but it "went there" in 2006 as it made Katrina the center of the parade's theme: "C'est Levee", a nod to the levee failures (Krewe Du Vieux, 2006). A key point in displaying both the parade's humor and city's survivalist attitude was the parade's king being New Orleans comedian and environmentalist Walter Williams, creator of the long-running Mr. Bill segments that began on Saturday Night Live. In these sketches, Mr. Bill, a man made of children's modeling clay, suffers numerous misfortunes including (and certainly not limited to) being sawn in half, run over by cars, electrocuted, and dismembered, while 
voicing his trademark squeal of "Ohhhhh nooooo!" every time. Figure 5.13 below shows Mr. Bill being smashed in an earthquake fault while on an ill-fated trip to California.

Figure 5.13: Mr. Bill smashed in earthquake (Saturday Night Live, 2018 [1981])

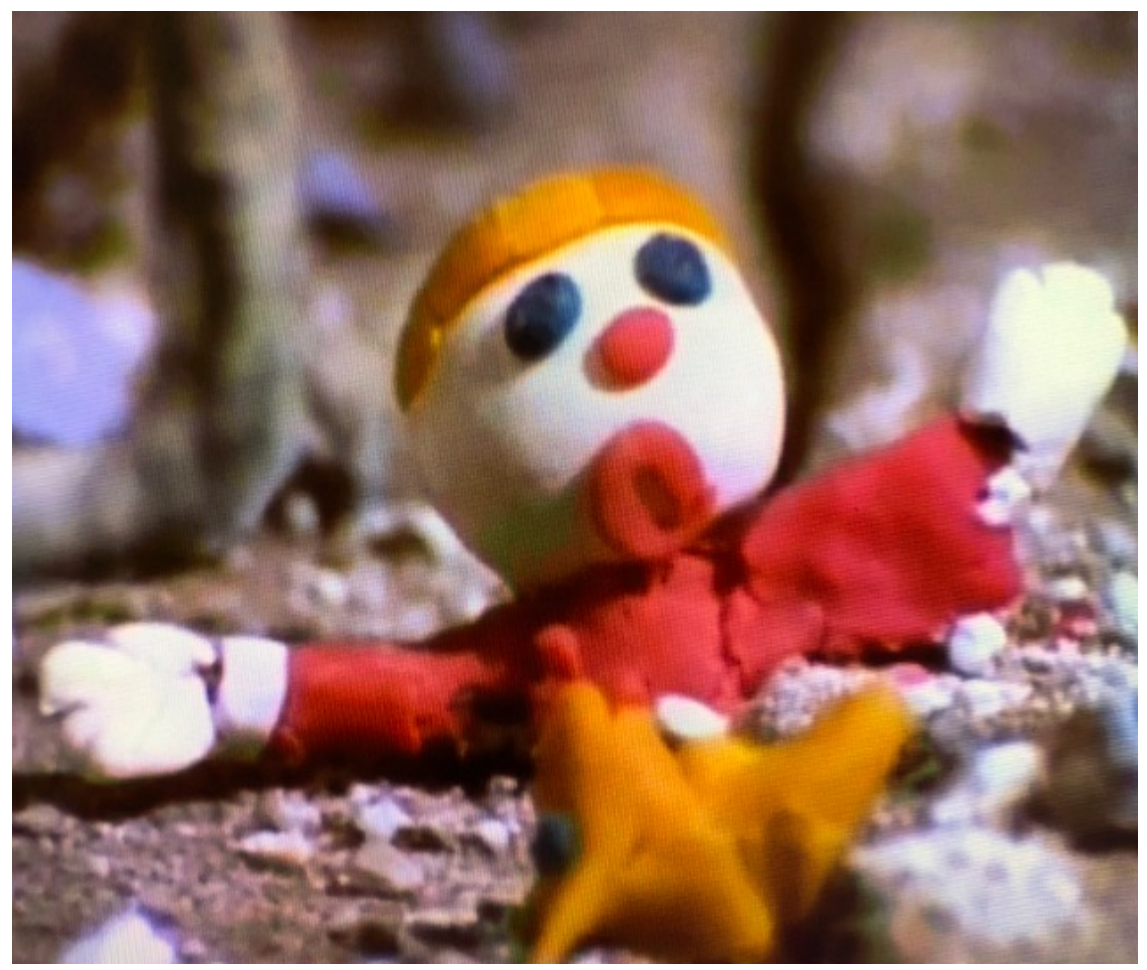

Mr. Bill, though, returns for yet another misadventure every time. Krewe Du Vieux chose Williams because, according to its 2006 newsletter, Mr. Bill was the perfect metaphor for New Orleans' determination to rise again and survive, despite the devastation and its living with the risk of such a storm before and after Katrina. The newsletter read:

If there is a single metaphor for the disaster that has befallen New Orleans as well as our ability to rise back up from the mud, it might be the great Mr. Bill of Saturday Night Live fame and coastal restoration fame. We may scream, "Ohhhh nooooo!" from here to Bayou Adrinque — but once our limbs come back together and the hangover wears off, we're here to fight another day (Krewe du Vieux, 2006, p. 2). 
Parade floats and costumes showed no mercy toward officials at the federal, state, and local levels. Popular targets included then-President George W. Bush, then-Louisiana Governor Kathleen Blanco and then-Mayor Ray Nagin (Cockroach, 2006a, 2006b, 2006c, 2006d; Krewe Du Vieux, 2006). Arguably, the Federal Emergency Management Agency was the topic of the most scathing scorn. Floats and costumes depicted the blue tarps found on numerous houses, mold, hazardous material suits, and what residents believed were the failed responses and broken promises of help from all levels of government, but namely FEMA and its then-director Michael Brown. Photos of that past Krewe Du Vieux are below in Figures 5.14 through 5.17. 
Figure 5.14: Krewe Du Vieux 2006, Fix Everything My Ass! (Cockroach, 2006d)

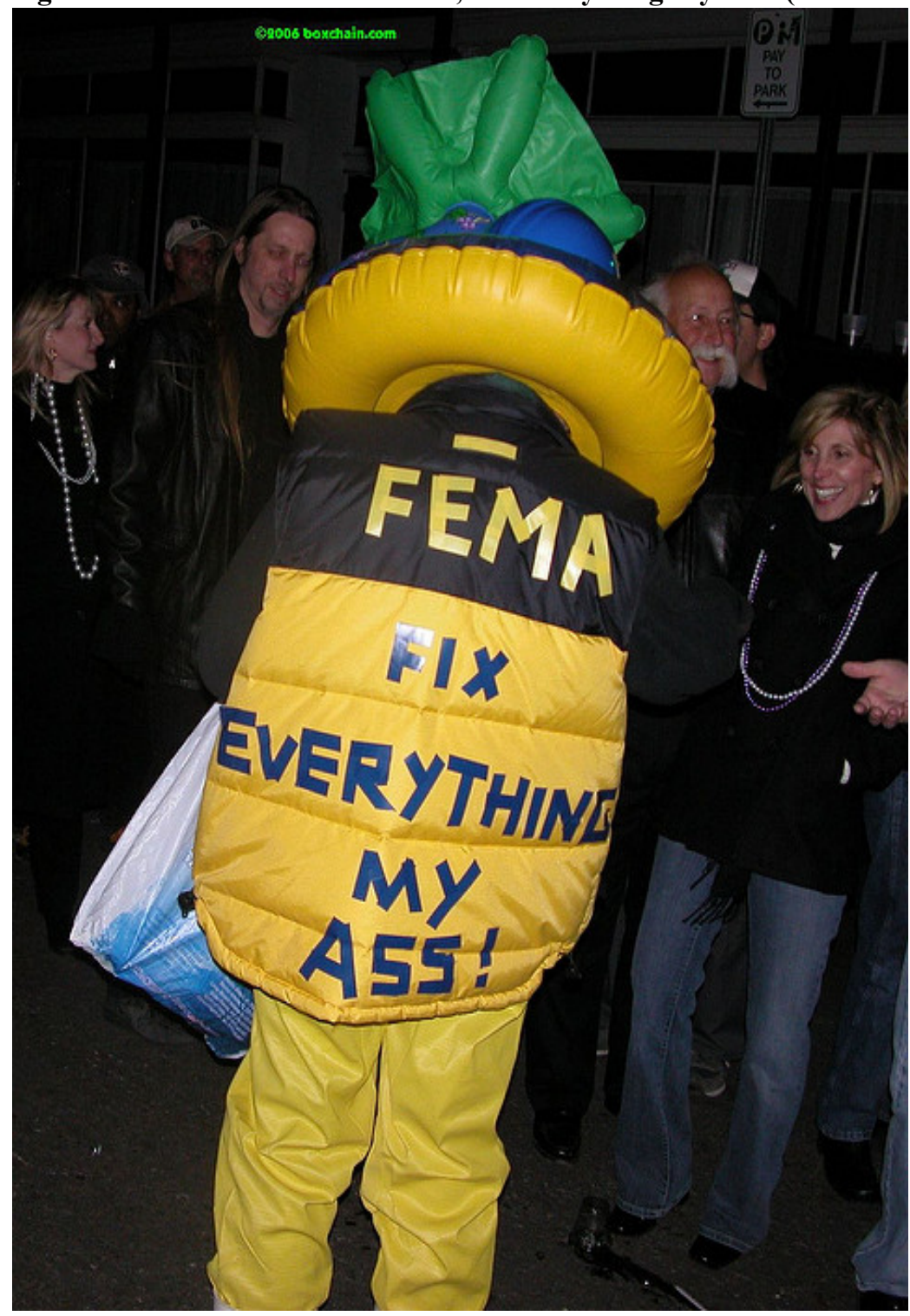


Figure 5.15: FEMA Beads on the Way (Cockroach, 2006a)

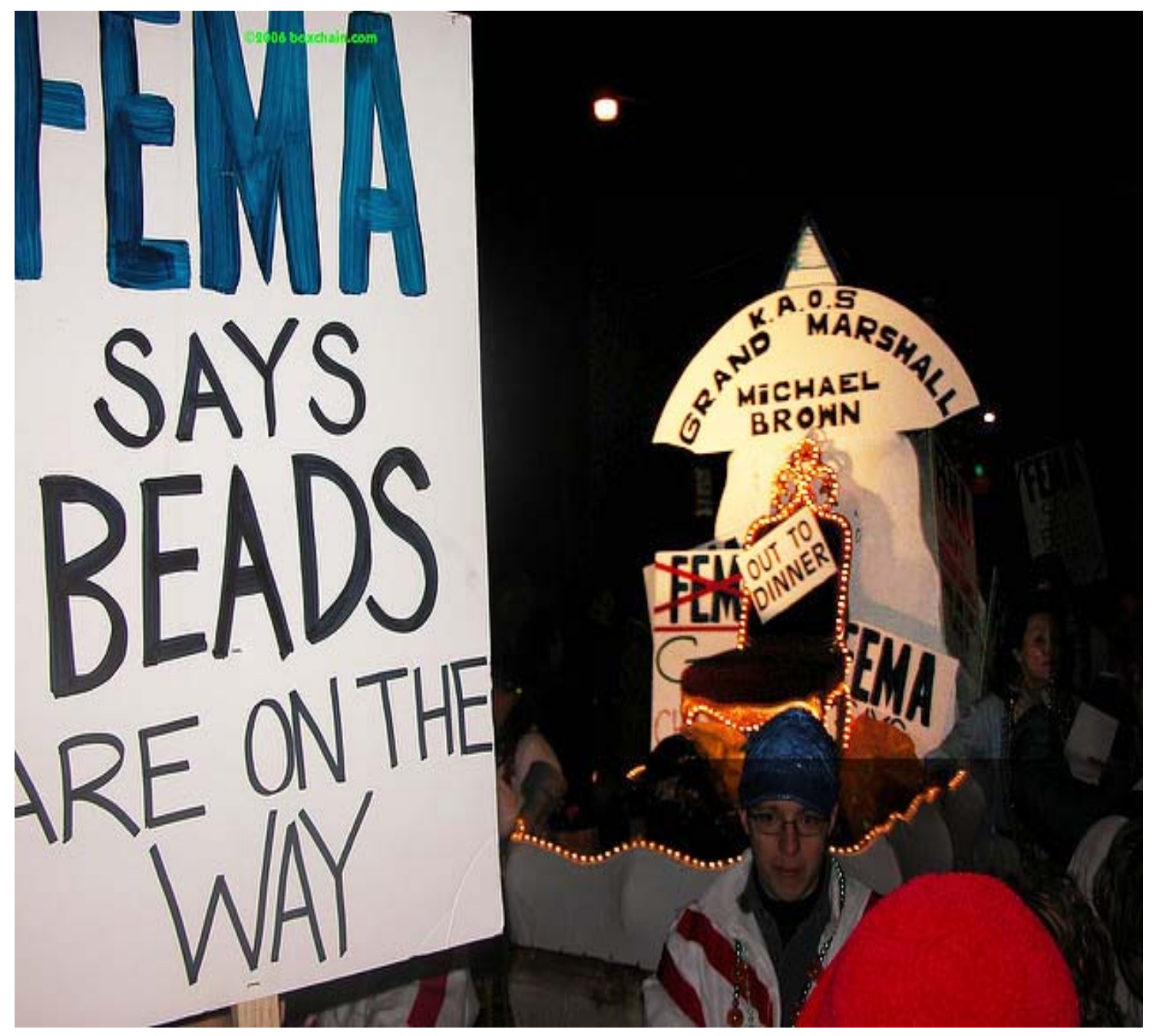


Figure 5.16: Krewe Du Vieux 2006, Home is Where the Tarp Is (Cockroach, 2006c)

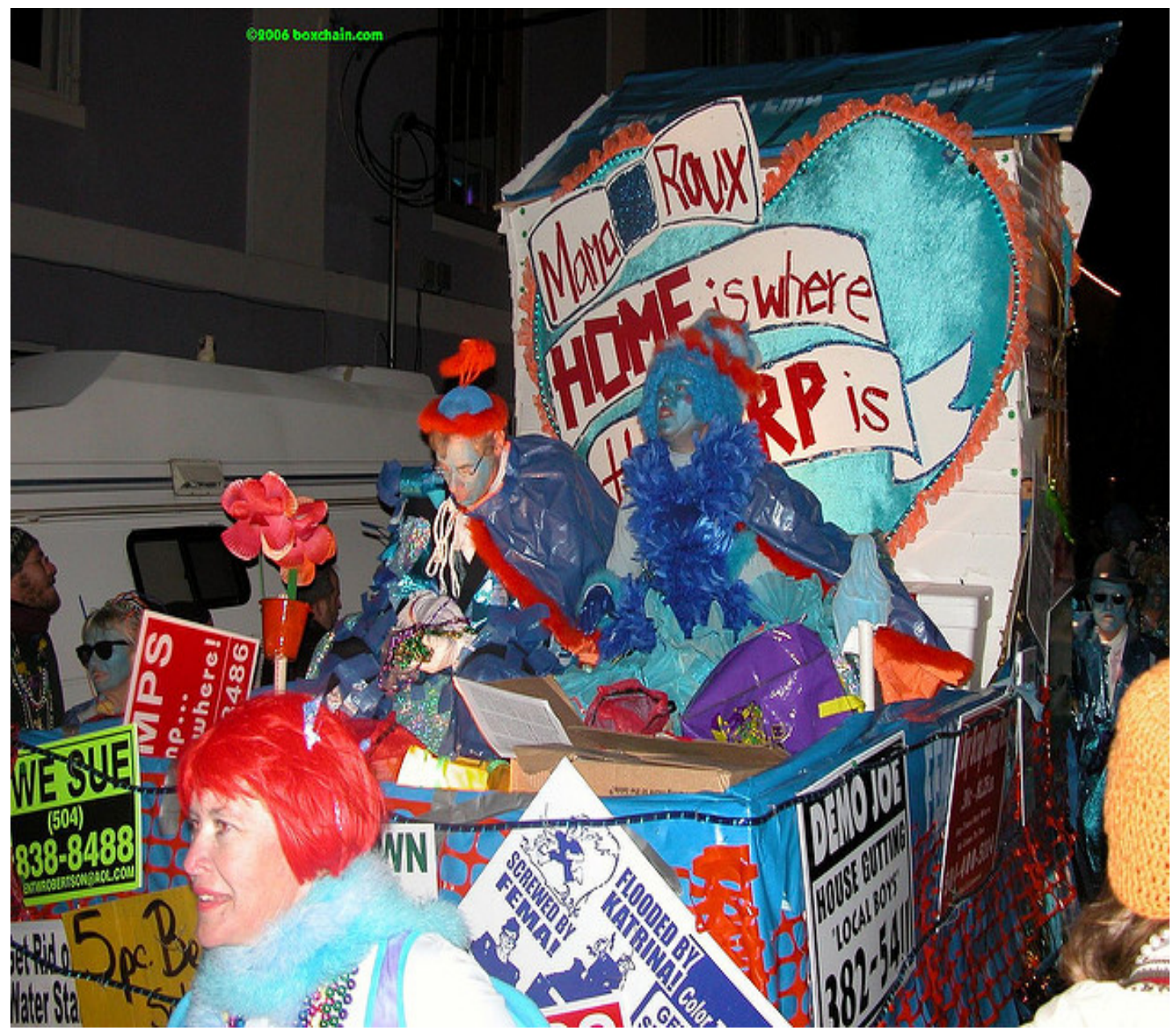


Figure 5.17: Krewe Du Vieux 2006, FEMA condom (Cockroach, 2006b)

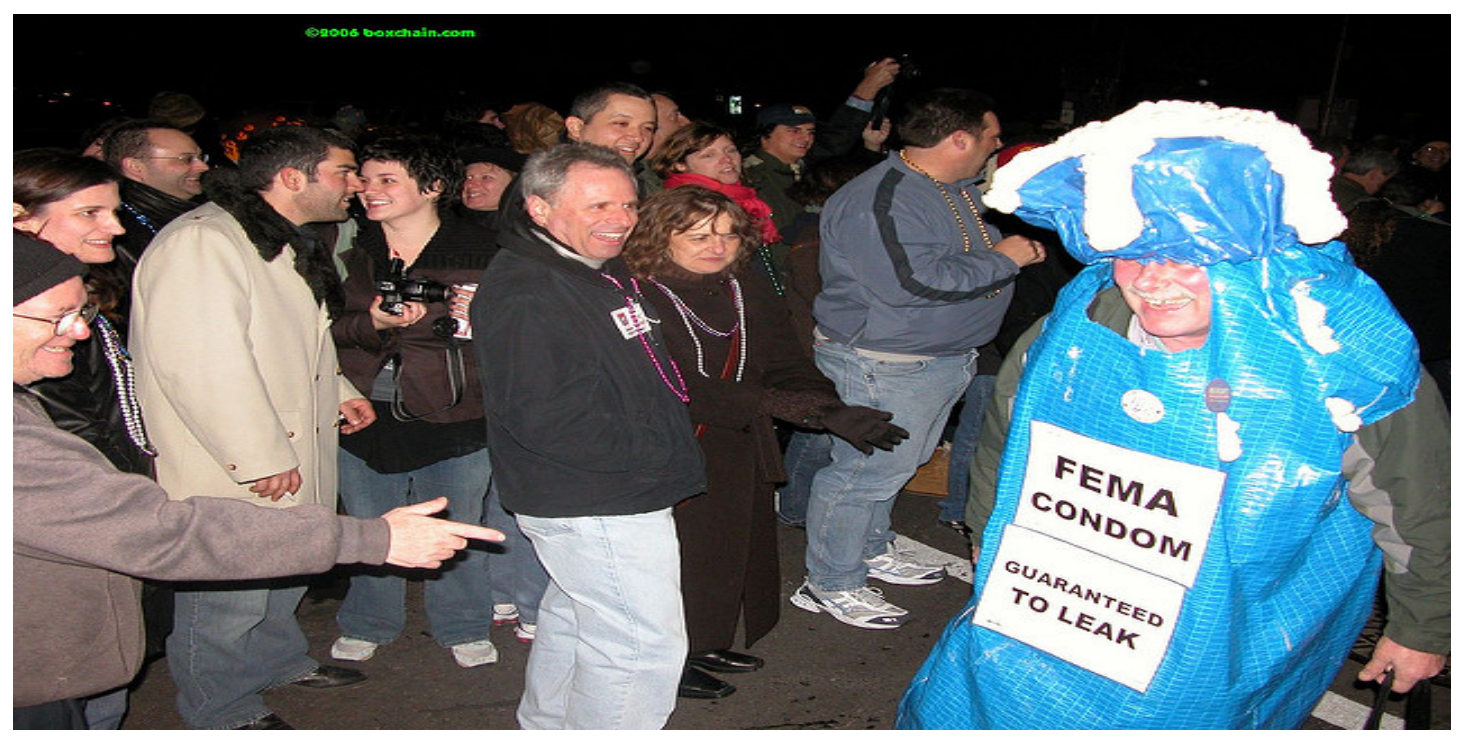

The four photos above all have scathing criticism of FEMA and Michael Brown (Cockroach, 2006a, 2006b, 2006c, 2006d). The first two blast FEMA's response, with the second featuring an empty chair for Brown, which conveyed the float designers' view of agency being missing. The second two show the blue tarps that covered many residents' roofs (Pridemore, 2005) after Katrina, and the photos (Cockroach, 2006a, 2006b, 2006c, 2006d) depict them as both a terrible reality for the residents and ones that do not work, at that. The third photo's blue tarp float, "Home is Where the Tarp Is" also features a sign reading, "Screwed by FEMA" (Cockroach, 2006c).

These photos may, on the surface, show the hindering factors and bad blood prominently featured in the previous chapter. The flipside of the situation, though, is that New Orleans, even in their darkest hour, fought back and fought back against systems that failed them and, specifically toward the national-level public figures who derided them while they were suffering (Cooperman, 2005; MSNBC, 2005). They also fought 
back with humor, which was likely an even more difficult and daring task when some might argue such a display was "too soon".

This fighting spirit persisted to the present day and translated into pushing the artistic community into citizen participation venues. Lavender, another cultural community advocate, said that when she needs the New Orleans artistic community members with whom she works to come out and support her efforts, they will do that, especially when their own livelihoods are on the line. This is a part of my exchange with her.

Lavender: Those who have their livelihoods on the line will show up. It's a civil rights issue.

Amelia: So when you put out the call, they show up?

Lavender: They show up.

Amelia: If you had to take a stab at how many would show up to a given event after you would put out a call, how many would show up?

Lavender: I would say three or four dozen, usually. If I get on the phone and specifically ask them to come and say I want them to speak, they'll do it. We had a whole program saved because I got a brass band to come and speak to the federal regulators that were in town. We got a brass band. The federal regulators were so impressed to have nine African-American musicians speak out about health care that they changed their minds about cutting off a program.

The street musicians in the focus group told me that participating in traditional forums like public hearings — at which almost all had spoken — is daunting because, as mentioned in the previous chapter, that participation is sometimes in vain because decisions are often made in private and in advance with the city's wealthy elites. Many do burn out from this, they said. Nonetheless, they believed it was important to make sure they were being heard, even if the fight is a losing battle. 
Lee: (The meetings) largely feel like a pacification of the masses, and we'll still go because we feel that it's important to do that and yell back. But ultimately, it feels more like a war of attrition, where you feel like your voice or whatever you say probably won't push the needle. It won't do any amount to make it register, but you just have to continue to be a part of the thing if you want to have a valid opinion about the thing. You have to try and participate in the process, even when you know the process probably won't result in any change.

\section{Love of city, home, and culture}

Love for the city and its cultural practices run deep, especially for natives and longtime residents. One question I posed to several interviewees was, "What is New Orleans to you?" They described of not only their personal love for the city and its culture but also the deep affection they had seen from others. That deep affection enabled participation because of the desire to fight for the neighborhoods, communities, and the city that people loved so dearly.

Kingsley said the term "community" is such a broad, general term that could include almost anyone. But for New Orleans, he said, the city is a community that truly revolves around its arts and culture, as well as its food and cooking and family traditions. It is a city, he said, that, despite some flaws, has individuality like no other and a heart like no other. In an exchange I had with him, what he told me about New Orleans had a verbal cue about "widgets" that ran counter to "standardized", "one best way" processes akin to Frederick Taylor's scientific management, which took its cues from mass production (McManus \& Perruci, 2015, p. 77). New Orleans was not mass-produced and could never be completely replicated - marching to the beat of its own drum, just how its people liked it. This was an exchange I had with him. 
Amelia: What is this city for you?

Kingsley: Everything. It is. There was a long time after the storm when I never left New Orleans. Some of it was probably PTSD, and some of it was just because I felt so comfortable here and just so... I say "at home", but it has always been my home. I just felt like there wasn't a reason to leave the city. I was here. I had no reason to go anywhere. I have since discovered the Caribbean beaches. Maybe if I wanted one thing to be added to New Orleans, it would be a really nice beach. Yeah.

New Orleans is everything. It's every part of the world put together in this little, bitty vulnerable area where we don't always get along and where we don't always get it right, but we all understand what a sense of community is. It is really nice living somewhere that feels like it has a soul, where the overarching goal of the day is to not make more widgets. The overarching goal of the day is to live, to enjoy life. I like to cook, like to eat, like to hang out with my friends and family, and I enjoy coming to work and doing the things that I get to do in a city that is just so amazing.

I mean, I've seen the worst that the city has to throw at me, and it's always, always been outweighed by the best that the city has. I'm OK with us being a little small compared to New York and LA and Dallas. I don't need to have eight million people living here. I enjoy feeling like a big neighborhood rather than some "cool" industrialized city.

...We are accepting of other folks, but we are also very protective of our own culture. ... That's a societal norm that we New Orleanians struggle with. I welcome some new ideas to the city every now and then, just as long as you're not trying to change us.

Though he was not a New Orleans native, Dean, a bar owner, had very similar

sentiments, and this was very much related to the city's culture and cultural communities.

Dean: I first visited here in the early ' 90 s, and it was for a music convention. My wife and I owned a music dealership in another state at the time and fell in love with the city. We got an apartment here so that we could come down whenever we could, but we still lived elsewhere.

At a certain point, we realized that we had more friends down here than where we were living at the time. So, we moved here, and we ended up buying this business.

... New Orleans is not without its problems. Like I said before, it's probably the biggest small town there is, or the smallest big town. Either way works. ... 
Despite its warts, I think New Orleans is an amazing place. It's the most European experience you can get without going to Europe. It's a place where the people are amazingly friendly. ... It's an amazing place to live.

It's a 24-hour city. I remember one time when we were still living where we were before, a friend and I were down here visiting. Of course, here, we have go-cups where you can just take a plastic cup, pour your beer in it and just walk outside, walk right down the street, walk between bars, or walk home with a beer in your hand.

We went back, and we were at a bar. They were out of glasses, so they poured the beer in a plastic cup. We had just gotten back from New Orleans, and we just absentmindedly walked outside the bar. It was, "What are you doing?! You can't just walk outside with that!" You know? Damn rules!

The more I travel, the more this becomes home. This is a remarkable place, and we've had so many cool experiences here with people - the spontaneous moments of music that happened and some celebrities that have come in and joined in with a band. ... It's a remarkable thing to be a part of that, to be somebody that's instigating that musical experience in New Orleans rather than somebody just observing it.

Rolanda, an art gallery owner and visual artist, recalled her experiences with Hurricane Katrina — one of multiple traumas she experienced in just a few years' time. Before Katrina, she moved to New Orleans from New York, where she was during the September 11, 2001, terrorist attacks. She lost multiple close friends in the World Trade Center. She recalled her time evacuating from New Orleans as Katrina was ready to strike - literal days on a highway, a car breaking down, heat, and caring for her young daughter and her cat. Her husband also left. She then found herself displaced for a few years. On top of it, she could not bring herself to paint again, feeling as if Katrina had siphoned away her creativity.

Then, she came to visit New Orleans a few years later, and a rather unique, New Orleans-style event drew her back. She recalled: 
Rolanda: It took me eight years to get up the nerve to come back and visit, and I came to bury one of my best friends. That's when I... That was tough, to come back.

But then, we were doing a second-line down through the French Quarter, and I had a python wrapped around my wrist (Laughs). Everything just seemed like, "Wow, this is why I love this place, and we've got to come back."

...It's pretty great. My old neighborhood... I can't drive by my old house. I did it once, and it took me two days to stop crying about it. There are definitely moments when it's tough, but I just love this place. So I'm happy to be back here - completely happy to be back here. There are places where you just drive by, and it's something like, “Oh, I remember that there." And it's sad.

But the city is better than ever. The city looks good. People are happy. There's a vibrancy here. There's a renewed sense of energy here that it didn't have before. It is loved, and you can feel that. People put a lot of heart and soul into getting it back after Katrina, and you can feel it.

Rolanda is also painting again. She recalled the first painting she finished after Katrina, saying, "I burst into tears. I finished the painting, and I just started crying because it was a huge hurdle to get over."

Those with intense struggles in the present day find solace or a release in New Orleans' cultural activities, Lavender said, which also fuels that desire to preserve that culture in the policy arena.

Lavender: What I see as the more common story is that you have a musician who is caring for an elderly relative and is their primary caregiver. They work two jobs, play music, and then, in between gigs, have to go back and forth and change the diapers, give food - do everything they need to do to be the elder's caregiver. It's like the lives of our musicians and dancers. ... The joy that they get from performing gives them one little bit of joy that they get back. I remember talking to an older woman who does African-style dance. She said she was taking care of her mother and raising her great-grandchild. She said if she comes and dances just once a week, she can get through. She has to do it. 
Kingsley recalled that even in some of his intense situations as police officer, he sees New Orleans' devotion to its culture.

Kingsley: I was on a scene where we had a guy cordoned off in the block. I don't know. He had a gun, or he maybe committed a robbery... I don't really remember what it was. I just remember I was standing out there, kind of on the corner. You do a perimeter - get everybody in and then through the block searching for your guy.

I remember, across the street, some kid came out on his front porch. He pulled out his trumpet and started practicing (Laughter). There's a guy with a gun, but this was... He heard the police car. So he came outside to see what we were doing and thinking, "Well, I might as well knock out my practice while I'm out here."

...I can remember the block. I remember thinking that it was so cool that some kid just came out and started practicing on his front porch while we're searching his block. ... This doesn't happen in other places. I loved it.

\section{Enabling Factors with the Artistic Community}

Besides its outlaw citizenship practices that will be discussed in greater detail in the following section, a major enabling factor within the artistic community was in-group and out-group community controls. Within artistic communities, certain members did not resort to the tribalism mentioned in the previous chapter and built relationships with one another. These relationships went beyond friendship and mutual respect in that they would work to police one another, such as controlling some performers' outlandish behavior, to avoid policy oriented challenges like street performer curfews from happening in the first place. The businesses namely discussed their partnerships with neighbors and community organizations and work to be good neighbors and upstanding citizens - before any challenges erupted. When the two bar owners faced legal challenges from wealthy elites, they had ready made coalitions that backed them. 


\section{Community based controls}

During the previous chapter, interviewees pointed to rampant tribalism and competitiveness within the artistic community and wealthy elites working to curtail or stop their activities. However, they also pointed to a major enabling factor of community based controls, both within the artistic community and in its relationships with parties such as businesses and neighbors. While some relationships, as mentioned before, were combative, others worked ahead to build positive relationships with other artistic community members and parties with whom they may have conflicts, like business owners' neighbors. This practice had two major achievements. First, it kept policy oriented conflicts from arising much more often. The other benefit was that, when artistic community members or business owners faced policy oriented challenges from powerful elites, they had already established coalitions willing to support them in citizen participation arenas.

Fleur said that if government entities like the police get involved in a dispute between street performers, all street performers' activities could be curtailed in the end. Therefore, she said, it is best to calmly settle non-criminal, non-violent disputes such as who makes it to a particular corner first amongst themselves. Also, she and other performers will be on the lookout to not only see if they, themselves, are drawing a large crowd that could block sidewalks but will also watch to see if others are doing this too. They will encourage the performers who could spark negative government action for all to stay in line. Being that she has played in New Orleans for over fifteen years, she has come to know the regulars and she is often the mediator. She explained this more as she and I spoke in the French Quarter while multiple acts were performing around us. 
Fleur: (Points to multiple performers) I am friends with these guys, those guys, these guys, those guys - I mean, everybody here. I'm often caught in the middle because sometimes, this band will be too big or too loud and then I'm just waiting. But if they're blocking the sidewalk, I'll help clear the sidewalk just to help. If a business owner gets mad, he's going to go to city council and make life hard for them, which will, in turn, make it hard for me.

...In the French Quarter, we really, over time, get to know each other. I know this gentleman who performs out here, and he is sometimes crazy - crazy like swinging a hammer, cussing - just crazy. But you know, every time he gets worked up, a bunch of us will swarm around him. We'll just be like, "Hey, man. Cool it." And it's fine. Anywhere else in America, he'd be shot for doing that, right? In a tourist area, swinging a hammer, cussing... You know? He'd be shot, for sure.

But because we know him, and we know, deep down, even though he's unhinged at that moment, he's a good person. So we'll come out, and we'll just try to diffuse the situation.

The in-group artistic community controls have also worked when dealing with the crime situation, which, as detailed before, was the only factor in this dissertation in which gender presented itself as a major factor. Fleur said that when the street performers are loading up at the night's end, fellow performers with whom she has built relationships and even some passersby will come to her spot to keep an eye on her. Some have even chased down thieves and retrieved stolen tips for her.

Fleur: I do have friends who will come out and will look out for me. I don't even want them to, but they do. They're like, "Oh, you're by yourself. I'm going to come." And so I'm rarely alone at night. ... I do usually get some people who stop to listen to me, and I feel like they're listening, but they're also eyes and ears for me.

Just as she described with the in-group controls, Fleur noted that she and some other performers do have amicable relationships with some of the local business owners whose shops are near their performance spaces. Just as she does with the street 
performers who may have issues within the group, she also finds herself mediating between other performers and business owners. She believes that business owners, police, other government officials, and street performers alike could cause far less policy oriented controversy in the first place by simply having greater mutual respect and established relationships.

Fleur: OK, so the business owner will get mad at the band that's too loud or too big, and then he'll go to city council and that might turn into an ordinance against me. But through conversations with that original business owner, we're cool. He's like, "You're fine. You're always nice. You always respond to our feedback. You're fine, but all these other people are ruining it for the rest of us."

Fleur, who is non-white, acknowledged the longstanding issues involving race in relationships between the artistic community and the city government, particularly if the artistic community members are black. She also knows some of the tension involving people from outside New Orleans who come to perform on the streets. However, she has played with local black musicians and has experienced no problems, namely because the musicians with whom she has played have also worked to build positive relationships. Likewise, she welcomes the company of visiting musicians who also work to build positive relationships with the locals. She and other musicians I interviewed had all come to know a German trombone player and played with him.

Fleur: I totally know him, and I like talking to him. I asked him to play with me once, and it was fine. Yeah, he was nice. We all like him. If he were a jerk, we probably wouldn't like him as much.

While this would not cure all ills, New Orleans' — or any other cities' — policy conflicts, Fleur believes, could be curtailed if more citizens, police, business owners, and 
government officials built positive working relationships and showed mutual respect. She added:

Fleur: It's just basic kindergarten stuff. ... Go back to kindergarten and learn the ABCs of "please" and "thank you" and "Sharing is caring." ... I think the world would be better. Just pass out the crayons.

For Dean and Regulus, another bar owner, positive relationships with neighbors and working to be a good neighbor and citizen was a major help when they both faced legal challenges from wealthy elites who could have shut down their bars. Before any controversies erupted, Dean took measures to be a good neighbor, such as not having live performances past certain hours and working to make sure his building's structure was not making the bar louder than it should be. He also does not deride other businesses. When a wealthy resident tried to shut down his business, Dean had multiple neighbors rally behind him.

Dean: Almost everything was positive because a lot of the neighbors spoke out and said we had never bothered anybody. "They don't bother us. They're wonderful neighbors."

Amelia: So, you had people in place willing to help you?

Dean: Right. Right. There are places in town that kind of exist on their own, and they don't really try to be partners with their neighborhoods. I think they pay a price for that. We try to be partners with our neighbors to the extent that we can.

Regulus said that when his business faced legal challenges, working to be a partner with both the neighborhood and the citizens of New Orleans as a whole, was key in his keeping the doors open. Besides working to address neighbor concerns, he and his business partner often loaned community groups who were low on funds space when it was needed. 
Regulus: I think we've been good community members when people in the community call and see if there's anything we can do in terms of space or whatever. We have not been the kind of people who are always just about money and how much money you have for us. That's the way we participated in the community. And so because of that, I knew that it wouldn't be as easy as maybe as others thought it would be to try and shut us down.

In fact, when we got to city hall, that's why we had so many people there. Even the attorney didn't charge us anything. He didn't charge us a dime because he saw us that way as well. And I'll be quite honest with you: If we had to go through the whole thing with legal fees and stuff like that, that could have been enough to shut us down, just with paying attorney's fees.

Having that positive community relationship and cultivating a good reputation as a valuable community member, Regulus said, literally paid off for him in the end. Like Dean, he said that if more venues — in New Orleans or elsewhere — did the same, this would seriously help them if they faced significant legal challenges. One of his statements also pointed that allies may not initially present themselves as such and that it pays to not immediately stereotype someone as a likely opponent. When his business was opening, Regulus, who is black, was required to bring a petition to his business' neighbors. One white family with children expressed reservations because of previous bad actors, but he assured them that he would run a reputable business. The family saw him later and thanked him for keeping his word. Another person he thought could create a problem at first glance turned out to have the totally opposite reaction. He said:

Regulus: I went to this one house, and there was a young lady. I found out she was the housekeeper. So I look up and see a wheelchair, and I say, "Hey, well, whoever the owner is, can you call them?" And I'm saying to myself, "Oh Lord. Here's a wheelchair, and I'm opening a bar." This older white man comes to the door. He looked like he could be seventy-five or eighty years old. He's up there, and I'm trying to explain to him that we were about to open a bar. He said, "You say a bar?" I said yes. I was expecting him to say, "Oh man, I'm too old for all that." 
He was like, "You say a bar? I love drinking! Let me sign that thing!" (Laughs out loud)

\section{Enabling Factors Related to Non-Traditional Participation}

Most enabling factors related to the artistic community's participation in New Orleans, though, were related to outlaw citizenship practices. New Orleans' artistic community's outlaw citizenship displays were especially bold and often linked to the city's beloved culture and traditions as mentioned in the section about institutions. That positive connection they made created both local support, as well as support from others outside New Orleans who are familiar with and love its local culture too. Interviewees said that one goal of displays such as the 2014 brass band protest against a proposed noise ordinance was that they were also working to demonstrate to both officials and the public at-large that these cultural practices had value and, especially because they were being threatened, that they should be supported and preserved.

Nevertheless, many in New Orleans' artistic community were bold to the point of being unafraid of being offensive when they were especially angry. This went far beyond simply getting attention and worked to fully communicate the gravity of their situations. New Orleans' artistic community was not meek and did not tread lightly in horrible situations. When situations were especially severe, such what as the artistic community and New Orleanians as a whole faced during the Katrina aftermath, political corruption scandals, and the pumping station flooding in 2017 , the New Orleans artistic community fought back with the same gusto. 


\section{Links to beloved cultural practices}

One major element behind much of New Orleans' outlaw citizenship practices has been links to beloved culture and traditions. Rimmerman (2011) indicates that when those who engage in outlaw citizenship link their cause with something much of the public favors, the outlaw citizens and the cause often get positive public attention. An example Rimmerman (2011) notes is the Civil Rights Movement protestors and how they would dress in church clothes for their events — linking largely positively viewed Christianity to racial equality.

This has been done in New Orleans. For multiple New Orleans outlaw citizenship activities, artistic community members used the beloved second-line parades and jazz funerals, and these are activities that likely aided in public support for their causes (Personal Communication, 2017; Woodward, 2014).

The reason why those involved in the January 2014 brass band noise ordinance protest in city hall did their musical display was to show officials and remind all who were participating and those who were watching not only what they were fighting against but also what they were fighting to keep, Susan, another cultural community advocate, said. She noted that the original plan was not to march into city hall as a second-line parade but to speak first and play music later. Others in the group took at different approach when all were gathered.

Susan: People were asked to bring their musical instruments to, at the end of it, sort of close with a little bit of music, reminding ourselves what it was that we were fighting for - music on the streets.

A trombone player kind of just gestured with his horn and started to move. ... The advocacy groups had legal observers because it's not their first rodeo. They said, "Go with them. Whatever's about to happen, go with them. We don't know 
what's happening. ... So they go to the door, and the city council staff is kind of like, "Hmmmm...." Everybody went through security and quietly in line with their horns and put them through the conveyor belt thing.

And off they went, down the main hallway of city hall, which is very small. It was very loud. The head of the Mayor's Office of Cultural Economy, who has been a very good ally for some of the advocacy groups... He sort of looked down, I guess from the second floor from the mayor's offices, and he sort of gave it a nod and $\mathrm{OK}$.

...They were festiving around in there, playing just the sheer joy, the sort of power of music, and the power of taking over a civic space in that way.

When the city removed four Confederate monuments in 2017, Kingsley said New Orleans' artistic community and many of its citizenry as a whole invoked their culture and traditions again, and they also added the element of significant and beloved places. He said those who supported the removals gathered at New Orleans' Congo Square and marched, with bands and dancers in tow, to Lee Circle the day the Robert E. Lee statue was removed. Lee's statue was the last to go out of the four. Starting the march from Congo Square added a very symbolic element of the city's history, particularly for its black citizens.

Before slavery was abolished, Congo Square was a gathering place for slaves on Sundays, when they had the day off (Mariano, 2017a). However, they did not have a specific meeting place or the right to gather until an 1817 mayoral decree established where they could assemble. Eventually, Congo Square would have "regular gatherings of free and enslaved people of color, some of whom would pound out rhythms on drums while others danced and sang. Around them, others would sell and trade wares" (Mariano, 2017a). Mariano (2017a) noted that these meetings were highly controlled, but these controls were lax compared to other Southern regions "that often did their best to 
prevent meetings of any kind among slaves". Now, Congo Square is part of Louis Armstrong Park and on the National Register of Historic Places (Mariano, 2017a). To this day, some will still gather on Sundays to play drums because the community based group Congo Square Preservation Society will host drum circles as a way to continue those established traditions.

Understanding the controversy behind the Confederate monuments in New Orleans and other cities goes far beyond Civil War history, in all senses of the word. The majority of the United States' Confederate statues were built after the Civil War, with spikes in monument placements in the early 1900s and during the Civil Rights movement (Parks, 2017). The monuments' detractors point to that in arguing that the monuments were built to intimidate black citizens and try to continue to assert white authority. The four New Orleans monuments removed, ones for Lee, Jefferson Davis, General P.G.T. Beauregard, and the Battle of Liberty Place (a post-Civil War deadly fight between white supremacists and the city's integrated police force), were all built after the Civil War, namely during the post-Reconstruction and Jim Crow eras (Litten, 2017a; Simon \& Almasy, 2017). At one point after the Civil War, Congo Square was renamed "Beauregard Square" to both honor Beauregard and discourage black citizens' weekly meetings - that continued anyway (Mariano, 2017a).

Kingsley recalled the day the Lee statue was removed, during which he and other officers had to handle an intense security situation (to be further explained in the next chapter) because of those protesting the Confederate monuments' removal. Citizens that included brass band players and dancers marched to Lee Circle and began their march at Congo Square. Beginning the march to the Lee statue's last stand from Congo Square, 
Kingsley said, was extremely symbolic in terms of what Congo Square meant to New

Orleans culture, particularly for black citizens.

Kingsley: If you know the history of Congo Square, it's a symbolic place to start a march in support of taking down the Confederate monuments. ... Congo Square would be where the slaves would gather on their Sundays off to play music, to socialize, to congregate, and to have a day off from this horrible bondage that they were experiencing. Over the years, it has become a very important, symbolic, and sacred place because that was a meeting place of enslaved persons, and they were kind of allowed to regain some humanity and their socialization during that time.

The fact that they had a march that started at Congo Square, supporting the removal of monuments that were erected to remind African-Americans that they were "inferior" and then march to the monument itself, Lee, to then rally for the cause of taking down the monument... I thought that was a great symbolic march.

Figures 5.18 and 5.19 below show both a musician and a dancer at the Lee statue removal, celebrating, with the trumpet player projecting his sound right at the statue showing how the brass band and dance traditions in New Orleans culture went beyond expression and invoked beloved culture to gain attention for their causes.

Figure 5.18: Trumpet player at Lee statue removal (DeMocker, 2017a)

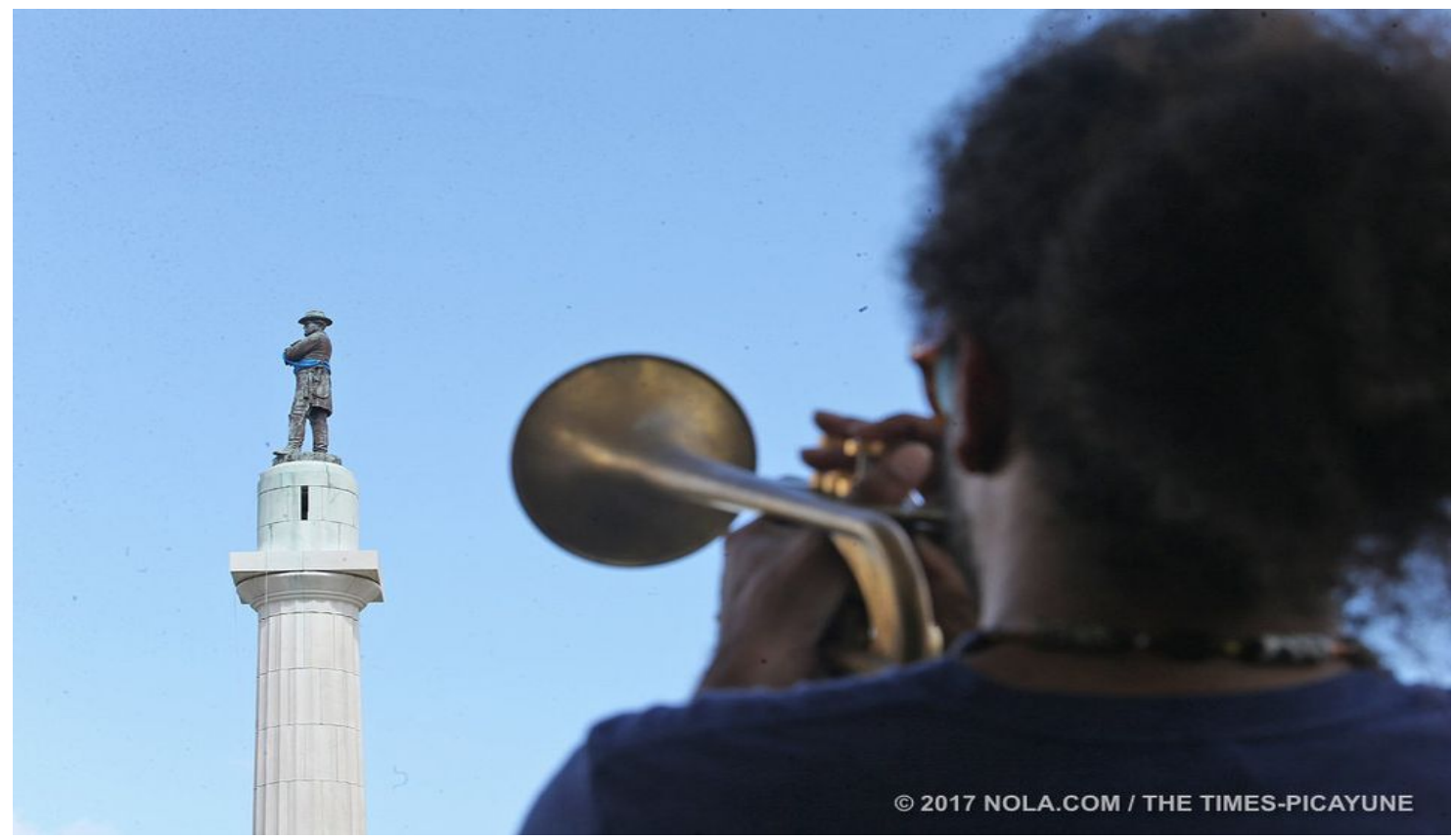


Figure 5.19: Dancer at Lee statue removal (DeMocker, 2017b)

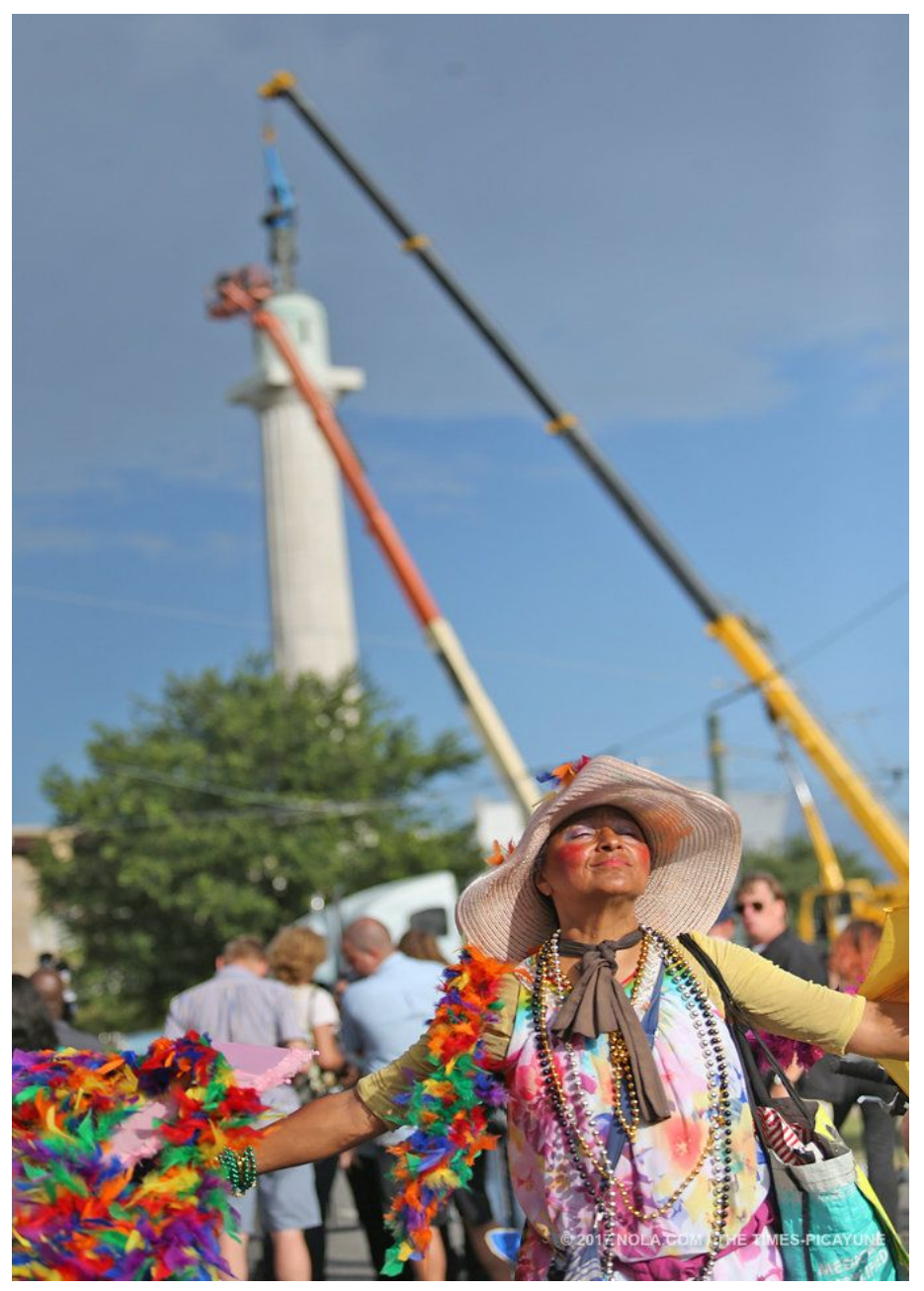

Boldness gains attention and time factor

Susan said that she and other cultural community advocates namely work to help citizens have a voice through traditional participation, rather than outlaw citizenship. The problem was that the December 2013 noise ordinance proposal that led to the January 2014 brass band protest was crafted privately at a time when it would normally not gain attention and moving too quickly to do the preparation work needed for a large showing that would entail such practices. On the day of the protest, a committee vote that could have moved the proposed ordinance to a full council vote was scheduled. Though the city 
cancelled the committee meeting once it realized the growing public backlash, Susan said those who organized the planned rally went forward with their plans anyway because of the process of it being crafted in private, done when little would normally pay attention to it, and in collaboration with city elites - which she called "unacceptable".

Harry, who also worked with the protest group, said that because how little time all the ordinance opponents had, the group had to find something bold, attentiongrabbing, and easier to organize. The protest was bold enough to grab international attention.

Harry: We found out about it. We had to kill it. The easiest way to do that, because we didn't have the time to do anything else, was to have that big protest. It worked. We killed that bad ordinance.

\section{Partnering with other disenfranchised groups}

New Orleans' artistic community has also partnered with other disaffected groups in the city, and artistic community members I interviewed told me they would welcome more collaboration. Many saw groups that namely included service industry workers, as well as adult entertainment workers and the homeless, as kindred spirits who also find themselves at the mercy of wealthy elites. They have joined these other groups in the others' outlaw citizenship techniques and saw the potential for even more powerful and impactful outlaw citizenship with such collaboration.

Artistic community members especially considered service industry workers kindred spirits and had already joined some of the service industry workers' protests in support. Already, service industry workers at businesses such as hotels and restaurants vital to New Orleans' tourism economy, as is the artistic community — have unionized 
and some have staged walkouts (McClendon, 2014; Nolan, 2010; Sayre, 2017c). The service industry workers have grievances about their pay, as well as desires for sick leave, predictable scheduling, freedom from harassment, and health care access (Stromquist, 2017). At some walkouts, bands have joined them to lend support (Nolan, 2010; Stromquist, 2017). Social media posts from the artistic community repeatedly show support for the service industry workers, noting their low pay and how some assert that the city's economic development strategies only add such low-paying jobs (Music and Culture Coalition of New Orleans, 2018).

Musicians and other artistic community members also joined adult entertainment workers during a massive street protest in February 2018 about police raids at adult entertainment venues (Archer, 2018). The adult entertainment workers also brought their concerns to traditional participation venues, as well (Morris, 2018), with a TimesPicayune columnist saying that "'Bourbon Street, Not Sesame Street" has become a common refrain as some city officials want to "clean up" Bourbon and make it "family friendly (Morris, 2018). Cultural community social media posts decried the exotic dancers' and strip clubs' treatment, calling it "Disneyfication" of New Orleans (Music and Culture Coalition of New Orleans, 2017b).

Ginny noted that despite their low pay and treatment from the city's elites, both the artistic community and the service industry workers plus adult entertainment workers have great economic power because of what they provide that fuels the tourist economy. United, these groups could make a serious impact and send a serious message, even it was just for one day, she said. Ginny also noted Europe's practice of general strikes where no one works or spends money to demonstrate economic power (Pridemore, 2018). 
One problem, though, is deciding on a singular concrete message because there are so many issues. Still, she emphasized the power these groups combined with the artistic community have.

Ginny: I'm talking about the bartenders, strippers, bouncers, cooks, waiters, the new hotel employees - everybody who makes the magic happen. Minimum wage in New Orleans is, like, four bucks or something for a server. It's like three or four bucks and everybody lives off of tips. All of that money that gets spent on all of these luxury items goes to the businesses but not the employees.

Amelia: In other words, that $\$ 500$ steak dinner goes to the business, not to the server making four dollars, right?

Ginny: One hundred percent. Yeah, you're eating, depending on which restaurant... Everyone is sort of in the same boat, and I think that is very much by design. That has roots as old as America itself.

If we got together and shut down the city for one day — which we could... It's just so overwhelming because it's hard to just pick one thing. There are so many. Where do you start? Do you start with wages? Do you start with housing? Do you start with transportation? There are so many issues, and I think that's another thing that we need to break down. We need to decide what the common issues are.

But if we could get all those people in a room together, we do have so much power and so much economic power - even if it isn't technically in our pockets.

The street musicians in the focus group, besides voicing support for the service industry workers, also showed support for some of the homeless — for whom they had empathy and who had also done what they could to support the street performers. Like some of the "scruffy" street performers had been treated, they said the homeless had sometimes been automatically deemed criminals — even though one street musician told the story of how one, in particular, stopped a crime. They referred to one particular group of homeless as "crust punks", an affectionate term for those they had really come to like while on the streets together. 
Lucius: A lot of people like the homeless will like to come around and hear the music. And that's awesome to me. They don't have a whole lot of alternatives for entertainment. There is a certain attraction, I think, as they say, the criminal element has to music, but that's not a bad thing. They're not criminals because they're bad. They're criminals because they have lifestyle decisions they make that are an offense to the aesthetics for the wealthy in this town. They are criminals, but they shouldn't be. We see them, and they see us.

...We had a very interesting experience one time because we were playing at a different spot outside, and a younger homeless gentleman just reached both hands in a bucket and drew out two wads of cash. A couple of other homeless gentlemen we affectionately refer to as crust punks in this town saw the injustice, tracked him down, and exacted physical justice on him. They gave us our money back.

Lee: You asked if musicians are considered to be affiliated with those aspects of society, which might be viewed as negative, but it may be the case that the stereotype comes from a negative place. It is often true that there may be some sympathetic respect from a crust punk community and a street musician community, even if we don't necessarily hang out together. We see each other in a similar place and space.

\section{Unafraid of being deliberately offensive when situation warrants it}

On the surface, some of New Orleans' outlaw citizenship techniques that could be seen as offensive and turning people off might seem like a hindering factor. However, one must step back and examine how severe some of the city's problems have been and how the citizenry as a whole have been treated — such as enduring the government failures during Katrina (Kettl, 2007; Krewe Du Vieux, 2006) and the 2017 pumping station flooding (Brasted, 2017; Granger, 2017a, 2017b; Krewe Du Vieux, 2018; Rainey, 2017d, 2017e; Sayre, 2017b), notorious corruption history (Daily Mail Reporter, 2013; Kushner, 2010; Lane, 2016), excessive force from police and murders police officers committed (Hoye, 2014; Mustain, 2014; Personal Communication, 2017; Public Broadcasting Service, 2010; Simerman, 2016), racism and segregation (Personal Communication, 2017; WDSU-TV, 2017 [1982]), and outsider derision (Cooperman, 
2005; MSNBC, 2005; Times-Picayune, 2005). Fighting back with a serious bite and massive burn could be justified, then. This could be especially true because, as interview, focus group, and observational data revealed, the elected government does not listen and continues its collaboration against disaffected groups like the artistic community with wealthy elites.

One of the boldest and scathing displays of deliberately — but purposeful — outlaw citizenship was seen during the Krewe Du Vieux parade in 2018, during which I did a participant observation and physical artifact examination. The theme, "Bienville's Wet Dream" not only conveyed the message of how, after 300 years, the citizens are still failed repeatedly and with the "wet" part referring to the pumping station flooding. The "wet dream" aspect also invoked sexual themes and sexually oriented humor.

As a nod to the city's $300^{\text {th }}$ anniversary, numerous walking group members, male and female, dressed in Marie Antoinette costumes, a nod to the city's French heritage and making a connection to an element of the city's culture that helped bring New Orleans' elaborate, French-style parades. The photos below in Figures 5.20 and 5.21 show some of the "Maries", along with some Louis XVIIs. The costumes are often covered in lights, particularly the ones with tall wigs that the fallen queen made famous. 
Figure 5.20: Krewe Du View Marie Antoinettes at parade arrival (Pridemore, 2018)

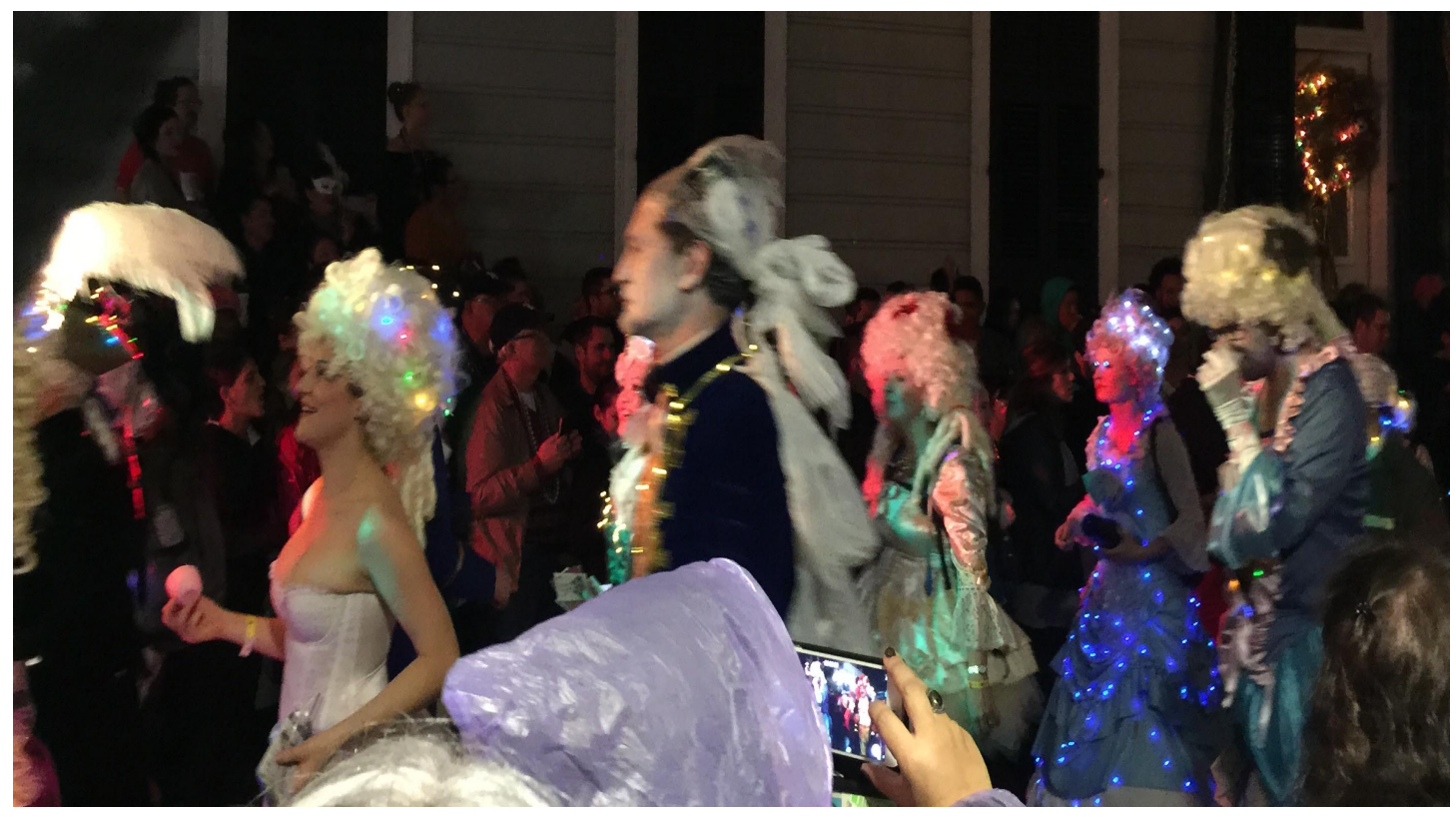

Figure 5.21: Krewe Du Vieux bearded Marie Antoinette (DeMocker, 2018b)

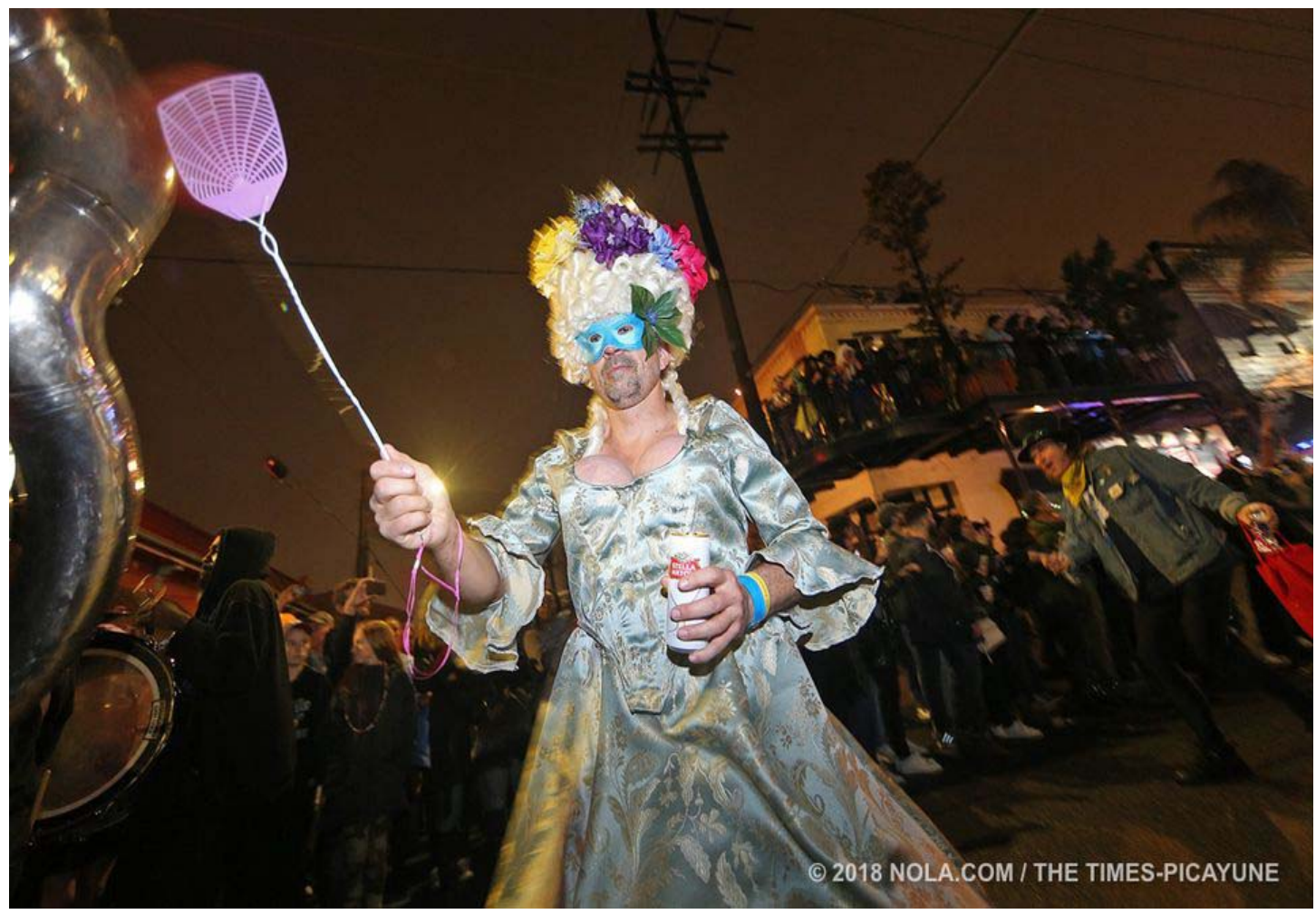


The use of Marie Antoinette was the beginning, though, of local cultural link to edgy material that conveyed citizen anger about both their local and national situations. This fan in Figure 5.22 I examined as physical artifact, designed to mimic the style of elegant French women, communicated the participants' deep displeasure of their situation.

Figure 5.22: Krewe Du Vieux, Let them eat, pink fan (Pridemore, 2018)

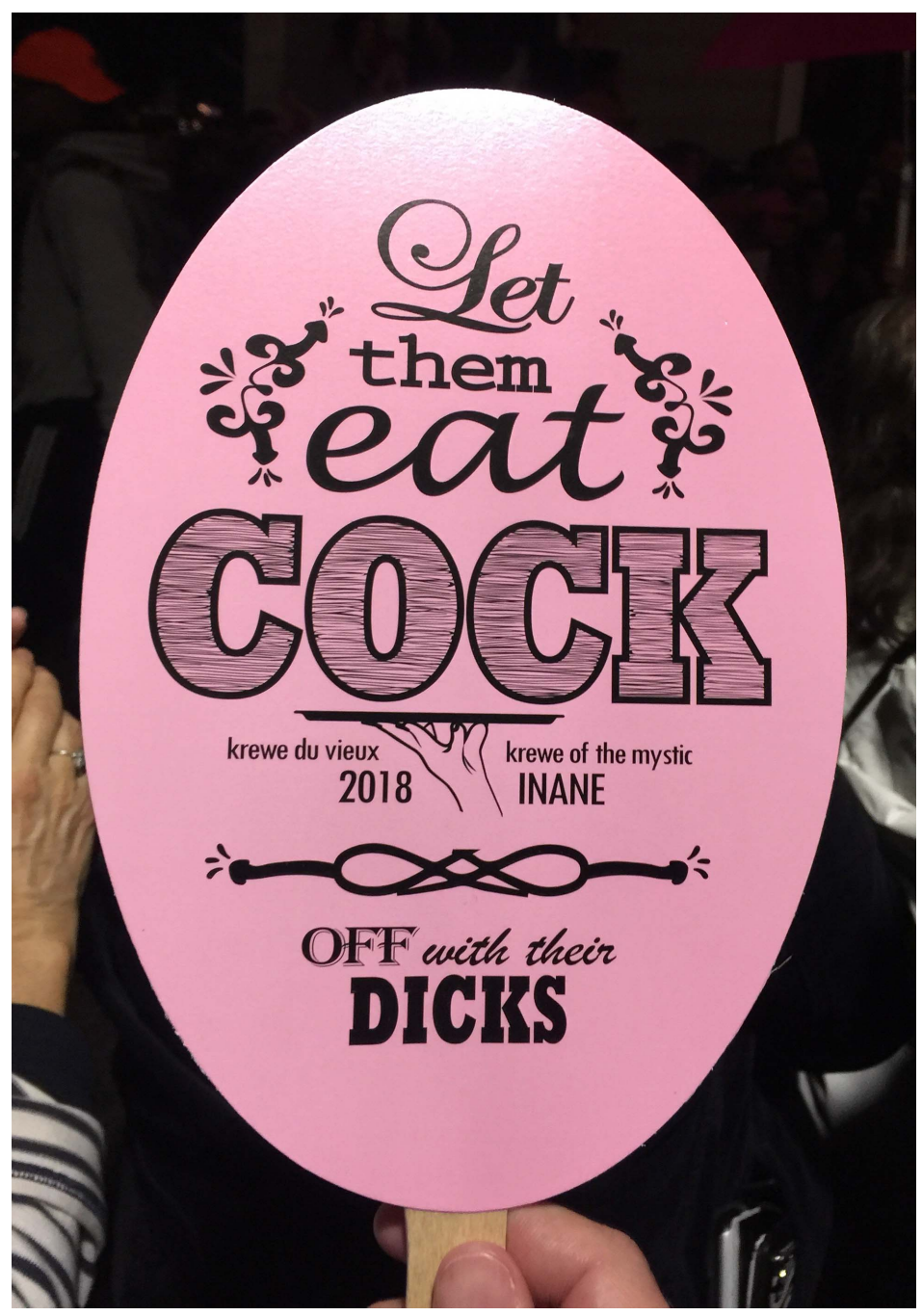

These sexually oriented themes were repeatedly invoked throughout the parade, such as in the "Mitchey's Sewer and Water Whores" float shown in the previous chapter 
that showed Landrieu as a stripper atop a pumping station and accompanied by a walking group dressed as pimps. Another float and walking group featured the local and national controversy about New Orleans' status as a sanctuary city (Clark, 2017). The float "Spanktuary City", featured a bare-assed Statue of Liberty with a walking group clad in Statue of Liberty costumes. Some in the walking group carried wooden paddles and spanked willing revelers in the crowd. The float is shown below in Figure 5.23.

Figure 5.23: Krewe Du Vieux Spanktuary City Lady Liberty butt (Pridemore, 2018)

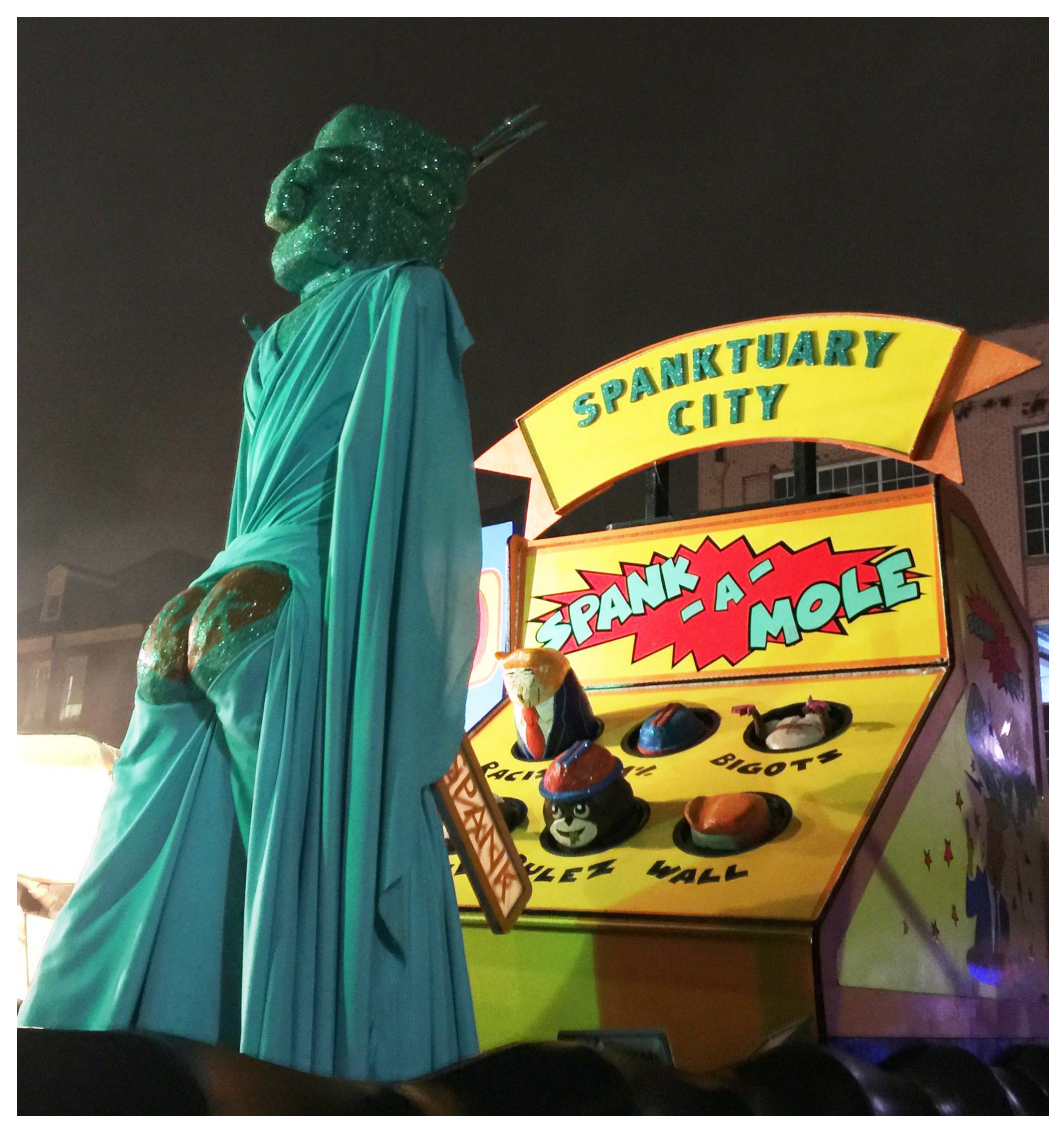

These displays I examined and observed, though, communicated how the federal “spanking" of New Orleans' local policy went against the ideals of the United States being an open and accepting country. The national policy, not the float designers or parade organizers, were baring and corporally punishing both the city and the ideals 
communicated on the statue itself. Just detractors were spanking New Orleans, New

Orleans was spanking back, though. Figure 5.24 below shows a key close-up of the float.

Figure 5.24: Krewe Du Vieux Lady Liberty spanks back (Pridemore, 2018)

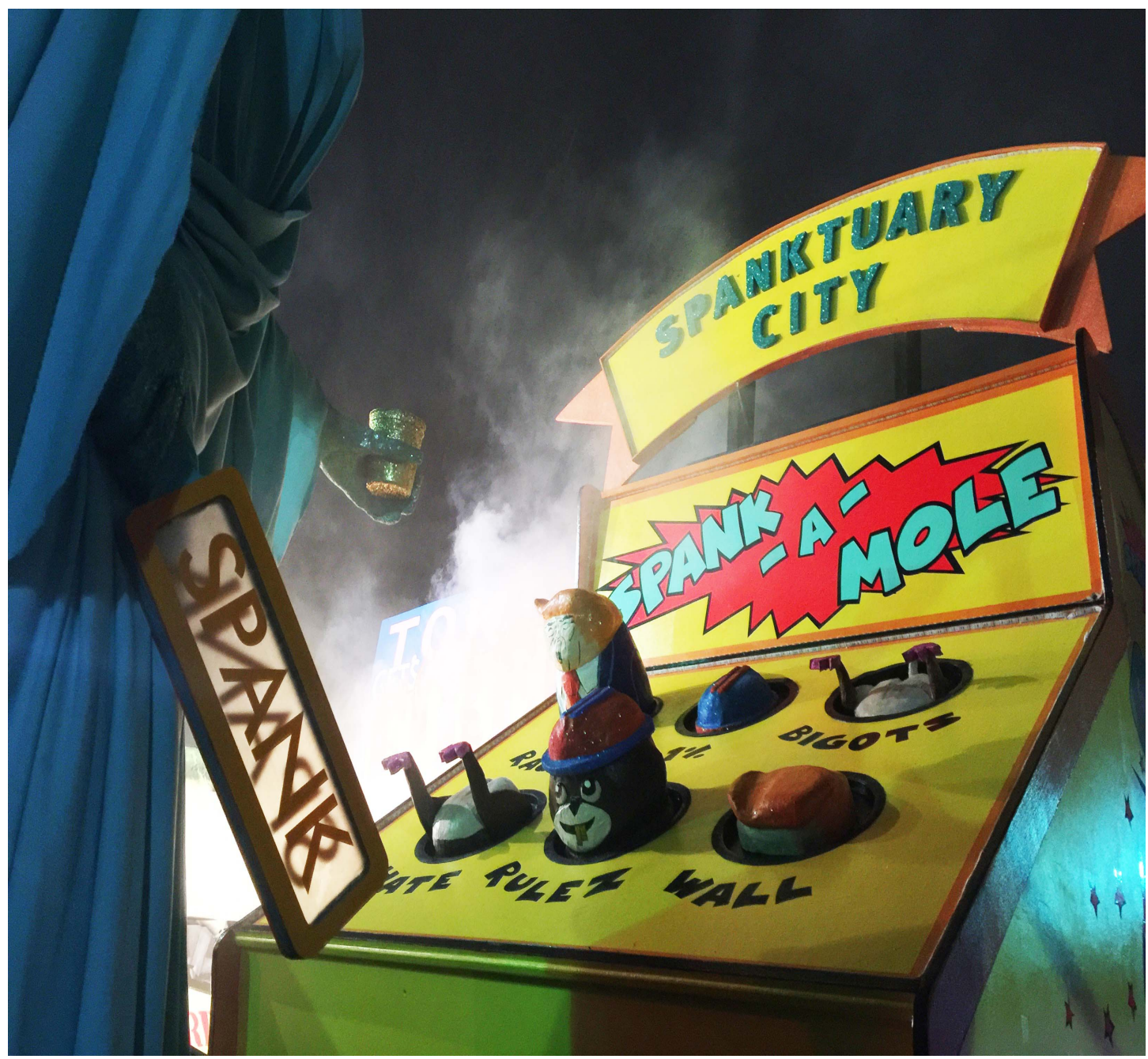

In this photo, the Statue of Liberty, though bare-assed herself, has a paddle in hand and fighting back — much like New Orleans does, given that this version of the Statue of Liberty has a paddle in hand that's ready to spank Donald Trump, bigots, and Trump's border wall with Mexico. At the same time, it shows New Orleans' accepting attitude that, as noted in the previous chapter, has drawn backlash from outsiders and is yet a source of pride for New Orleans. It also shows that New Orleans wants to 
affectionately spank (willing) downtrodden groups seeking refuge in the city and welcome them with a drink in one of the city's signature go-cups, as shown in the Statue of Liberty's left hand. The float featured a New Orleans-oriented parody of the Statue of Liberty's inscription that I examined. It communicated how, as mentioned in the previous chapter, New Orleans would accept even those that others scorned. It read:

Give me your weird, your poor, your huddled asses yearning to be spanked. Send these - the homeless, the health care-lost, to me. I lift my go-cup beside the famous door! (Krewe Du Vieux, 2018)

Besides portraying Landrieu as, literally, a man made of feces, Krewe Du Vieux also invoked purposeful toilet humor more to both point at the sewer controversy (Brasted, 2017; Krewe Du Vieux, 2018) and their being disproportionately affected by climate change. Louisiana's coastline has constantly eroded for several years, and it outright threatens New Orleans' existence (Kennedy, 2017; Pridemore, 2005; Wendland, 2018). Louisiana is the state losing the most coastal areas as time (Wendland, 2018). Wendland's (2018) featured a family in Slidell, Louisiana (just east of New Orleans) that readies its two rowboats every time it rains in case they have to, again, escape floodwaters.

One of the multiple satirical articles in Krewe Du Vieux's Le Monde de Merde (Translated from French: The World of Shit) newsletter for 2018 told the fictional story of an archaeological expedition to an underwater New Orleans on its $400^{\text {th }}$ Anniversary. Part of that article read:

Thanks to coastal erosion, rising sea levels, and the weight of all the Mardi Gras beads in people's attics, New Orleans will sink into the Gulf of Mexico. We knew we were in the right place, though, because of the giant glitter slick on the water's surface. 
...There were some changes. Most of the population, for example, breathed through gills. If you've walked around New Orleans in August, you know we're practically breathing water already, so they said it wasn't too much of a shift. It was about the same amount of pollution too (Krewe Du Vieux, 2018, p. 6).

One Krewe Du Vieux float, a boat called "NOLA's Ark", pointed to both the sewer problem and the eroding coastline. This is a physical artifact examination I did of the float, paying close attention to signs such as "Pooping is not allowed on the poop deck. Sorry for the confusion," pointing to the sewage problems and the lobsters next to them to communicate issues involving the coastline.

Figure 5.25: Krewe Du Vieux, poop deck boat float (Pridemore, 2018)

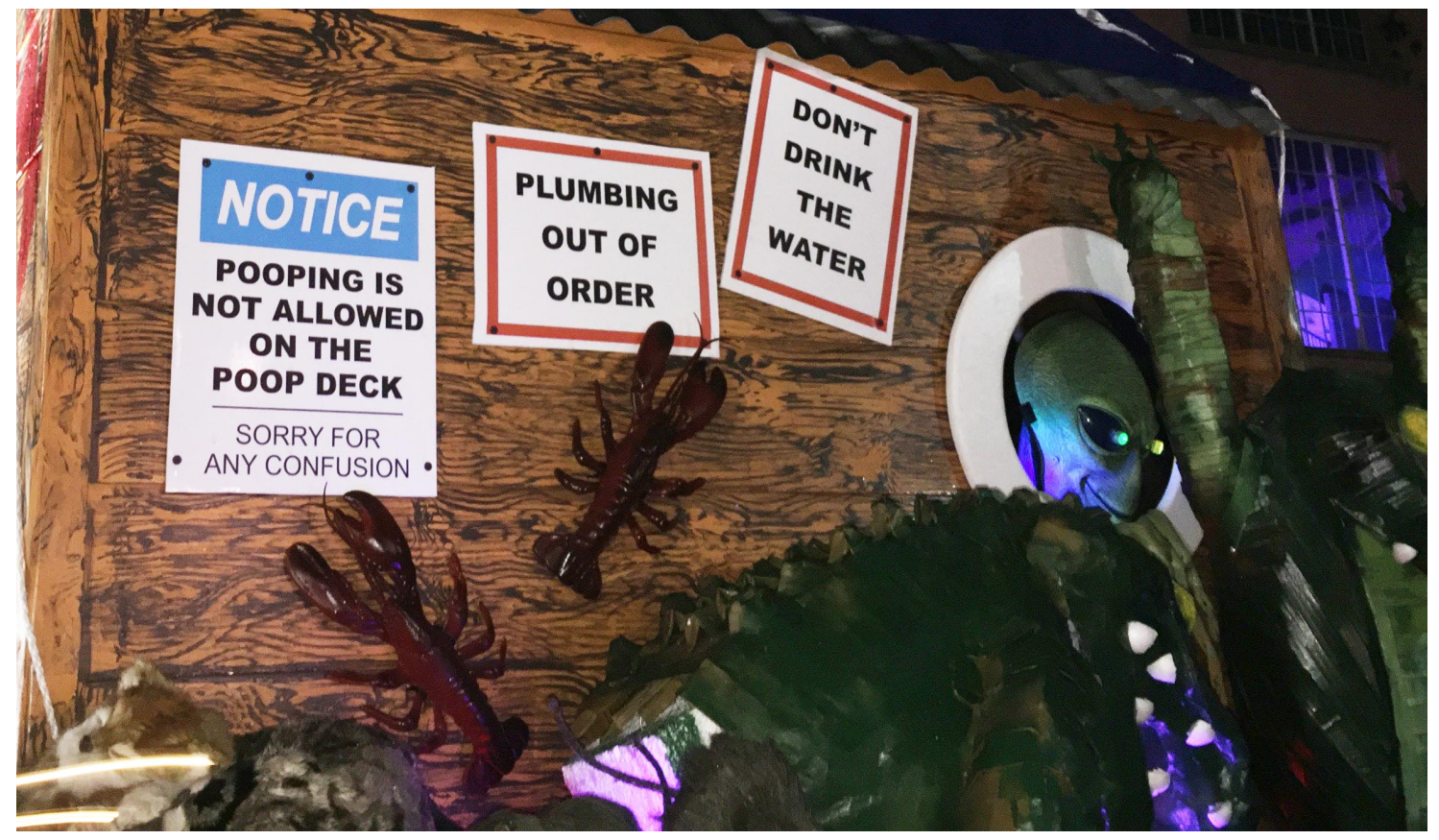

Other floats and walking groups were more focused on the coastline issues, with one float shown in Figure 5.26 I examined communicating that New Orleans would likely be underwater for its $400^{\text {th }}$ anniversary, and a walking group shown in Figures 5.27 and 5.28 I observed following it during the parade dressed in scuba gear. 
Figure 5.26: Krewe Du Vieux, NOLA Underwater at 400 (Pridemore, 2018)

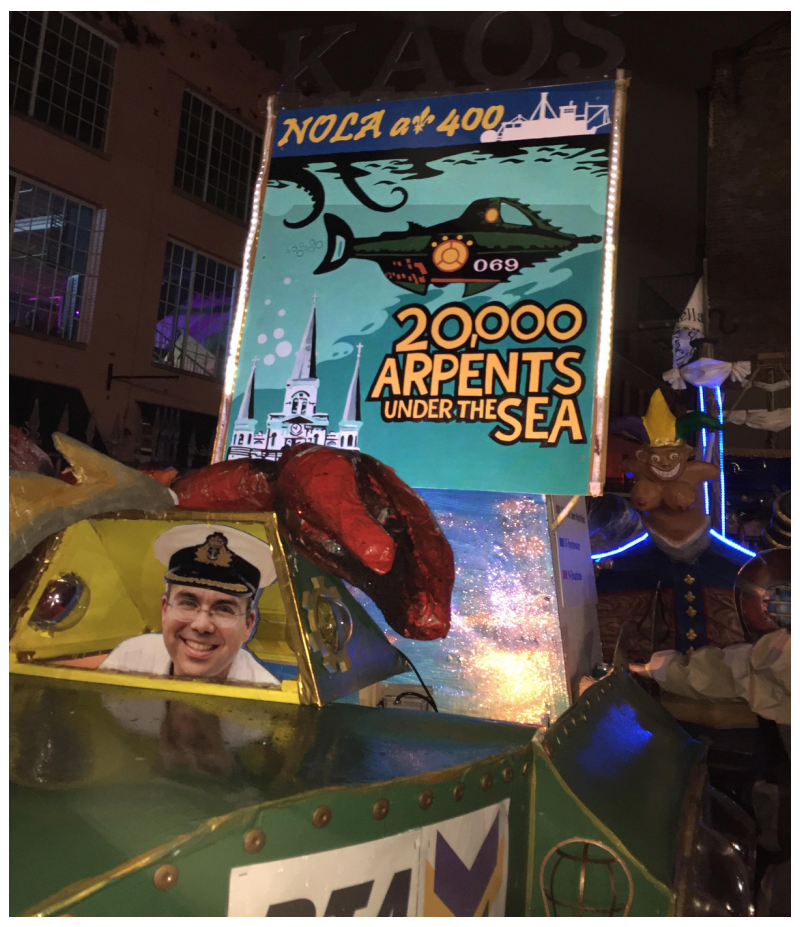

Figure 5.27: Krewe Du Vieux, scuba diver with Rouses bag (Germer, 2018)

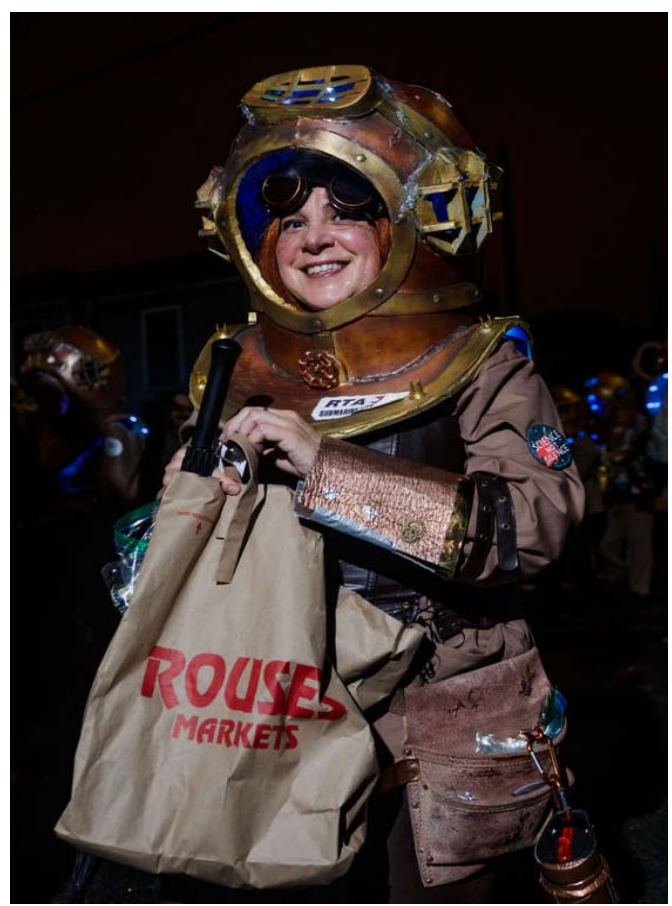


Figure 5.28: Krewe Du Vieux, scuba divers in walking group (DeMocker, 2018c)

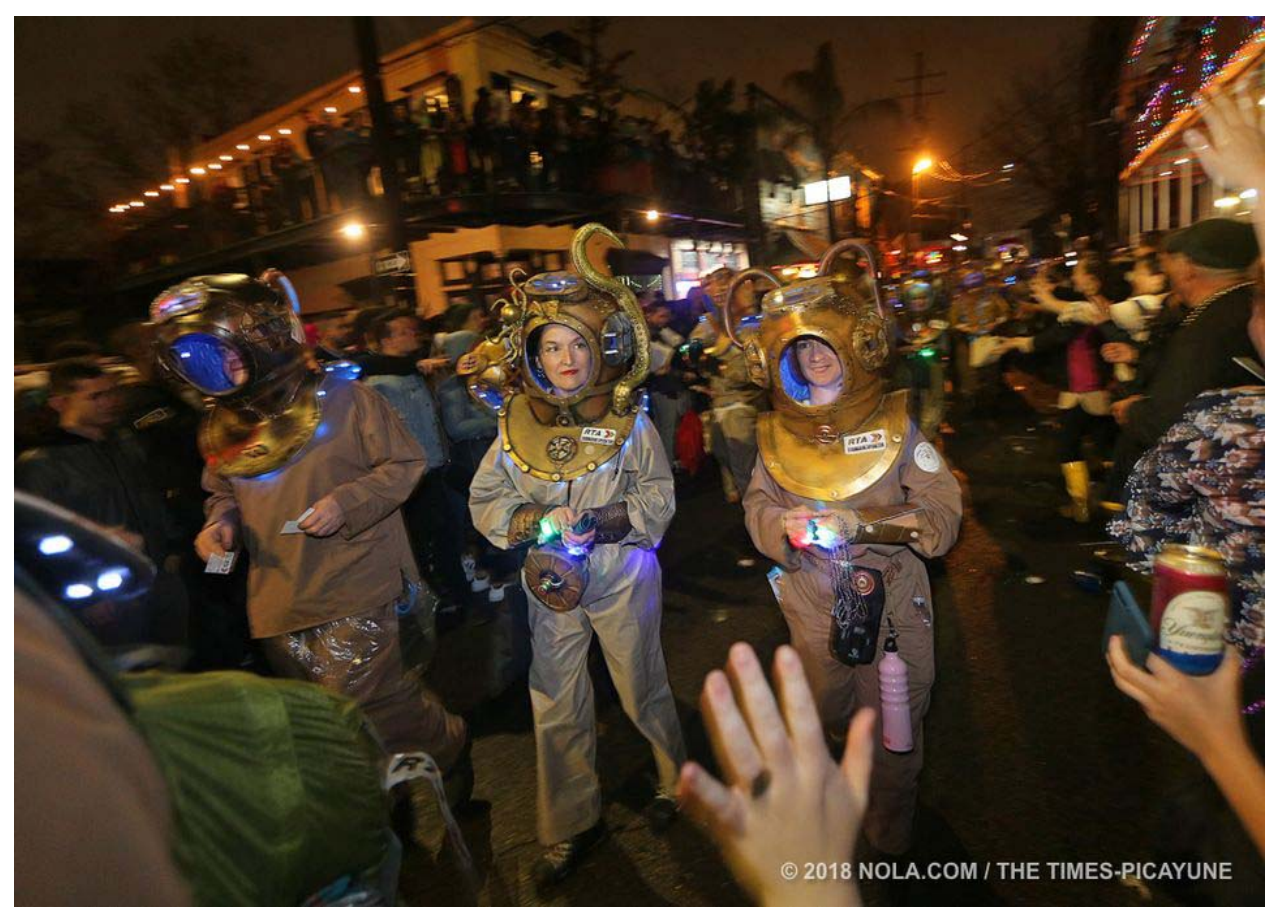

The parade mostly focused on local issues, but it invoked national controversies

as well — as not only a nod to national issues that have affected New Orleanians as well, but also as a way of saying the pot is calling the kettle black, per se, in attacking the longstanding outsider derision. Krewe Du Vieux's newsletter noted the national controversies, such as ongoing sexual harassment and assault accusations against powerful men who include the president of the United States. The newsletter, when discussing the state of the current environment, in part read:

And it's not like things were great again anywhere else. Although ISIS mostly became WASIS, Vladimir kept Putin on the Ritz, meaning it soon became Mueller Time in Washington. As the evidence piled up like missed Congressional deadlines, the Trumpgeizer bunny took a beating but kept on tweeting. The overblown second-grade bully seemed committed to Making America Eight Again. Steve Bannon brought his Not-So-Breitbart racist views to the White House, though like most of the staff, he barely lasted long enough to get investigated. Ultimately, this led the people of Alabama to channel their inner Edgar Allen Poe and quote, "Never Moore." 
The groper-in-chief did manage to avoid the sexual harassment fallout that brought down many powerful and slimy so-called men, but one has to wonder how long he can keep pussygrabbing around the issue (Krewe Du Vieux, 2018, p. $1)$.

Multiple floats and walking groups were dedicated to the sexual misconduct scandals, with walking groups dressed as pigs to communicate their message that the “morons" featured on their floats like Trump, Al Franken, Matt Lauer, and Bill O'Reilly were male chauvinist pigs. Trump, in particular, was the main target and received the most scathing treatment. A float I examined and have shown below in Figure 5.29 had Trump with Marie Antoinette hair, with the same "Let Them Eat Cock" slogan found the fan I collected, as well as "Off with their Dicks". 
Figure 5.29: Krewe Du Vieux, Let them eat Donald Trump float (Pridemore, 2018)

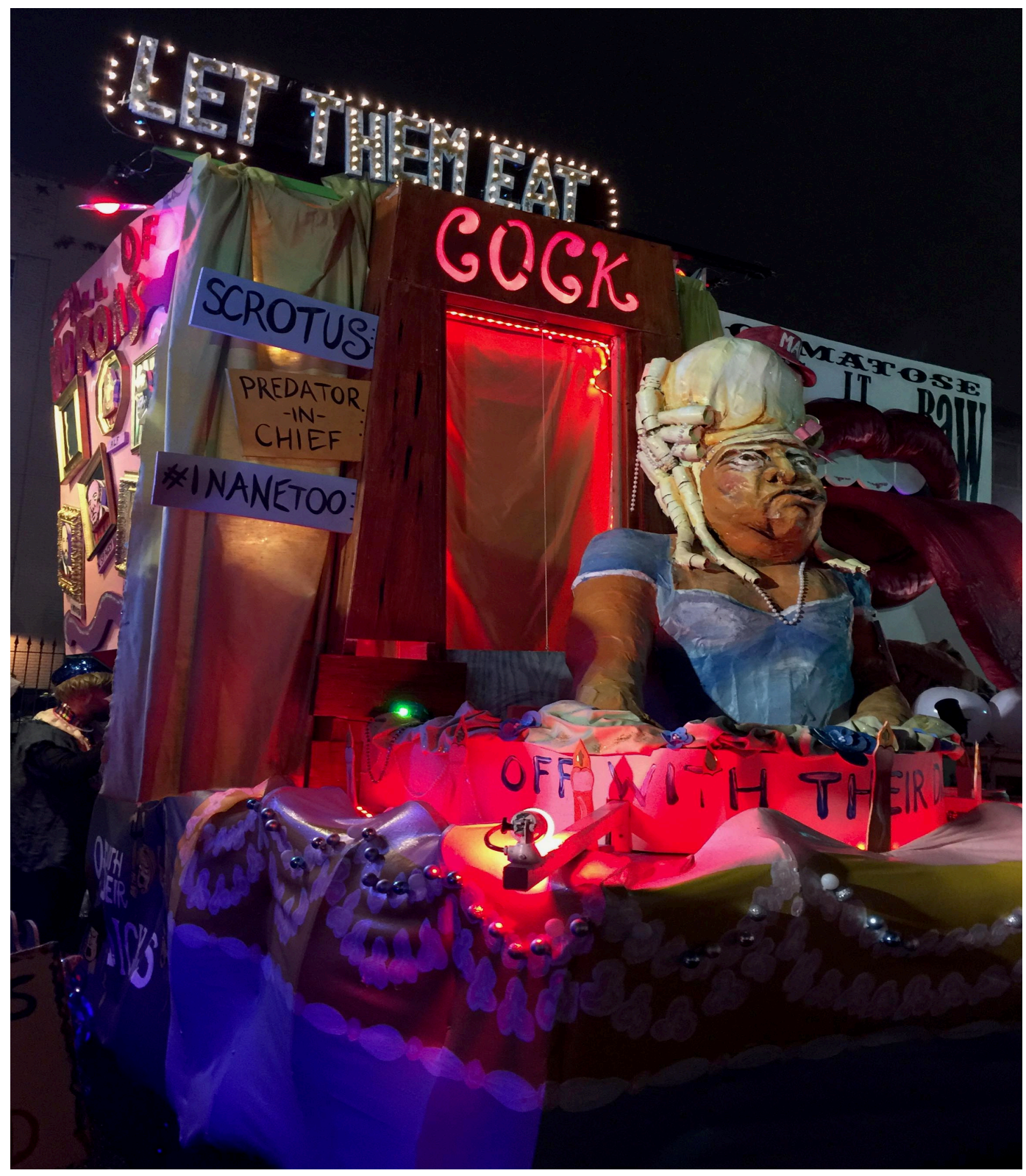

On the surface, such a float may only serve as a joke appealing to prurient interests. However, one must consider some of the specific, sexually oriented, and longstanding outsider derision of New Orleans that especially burned during the immediate Katrina aftermath (Cooperman, 2005; MSNBC, 2005). In particular, the outsider derision has been that New Orleans is a den of sexual immorality, such as 
outsiders' criticism of Storyville a century ago (Karst, 2017) to the Southern Decadence parade (among other social and cultural events and characteristics of the city) in 2005 (Cooperman, 2005; MSNBC, 2005; Times-Picayune, 2005). The Krewe Du Vieux (2018) newsletter also points out the infamous 1862 rule of Union Civil War General Benjamin Butler, who was called "The Beast", among other derogatory names (Pontchartrain, 2014). While Butler was hated in New Orleans for multiple reasons, one of his infamous orders involving women gave him that "Beast" moniker. "Butler decreed that women who hurled insults at federal officers or soldiers would be regarded as prostitutes and prosecuted" (Pontchartrain, 2014).

But like the newsletter reads, "And it's not like things were great anywhere else" (Krewe Du Vieux, 2018, p.1), New Orleans is pointing out that practically no other place truly has room to criticize New Orleans when it comes to "immoral" sexual behavior because the newsletter also points out centuries-old sexual misconduct such as Thomas Jefferson fathering children with his slave Sally Hemmings and present-day scandals like those linked to Trump and Alabama U.S. Senate candidate Roy Moore (Krewe Du Vieux, 2018).

If anything, New Orleans, with its open revelry and occult and witchcraft stores in the open that I documented, demonstrates that it at least does not put on an act. During my observation on a Bourbon Street Saturday night, I witnessed this mix of open nods to the seedy past, outsider condemnation, and countering of that condemnation. New Orleans' 24/7 culture boomed during the Prohibition era, thanks to a mix of its location being ideal for smuggling black market liquor and then-Louisiana Gov. Huey Long 
openly turning a blind eye (Hyde, 2014; McKnight, 2014). On Bourbon, a bar shown in Figure 5.30 bears the era's name - with an advertising slogan that runs counter to it.

Figure: 5.30: Prohibition beers, Bourbon Street (Pridemore, 2017)

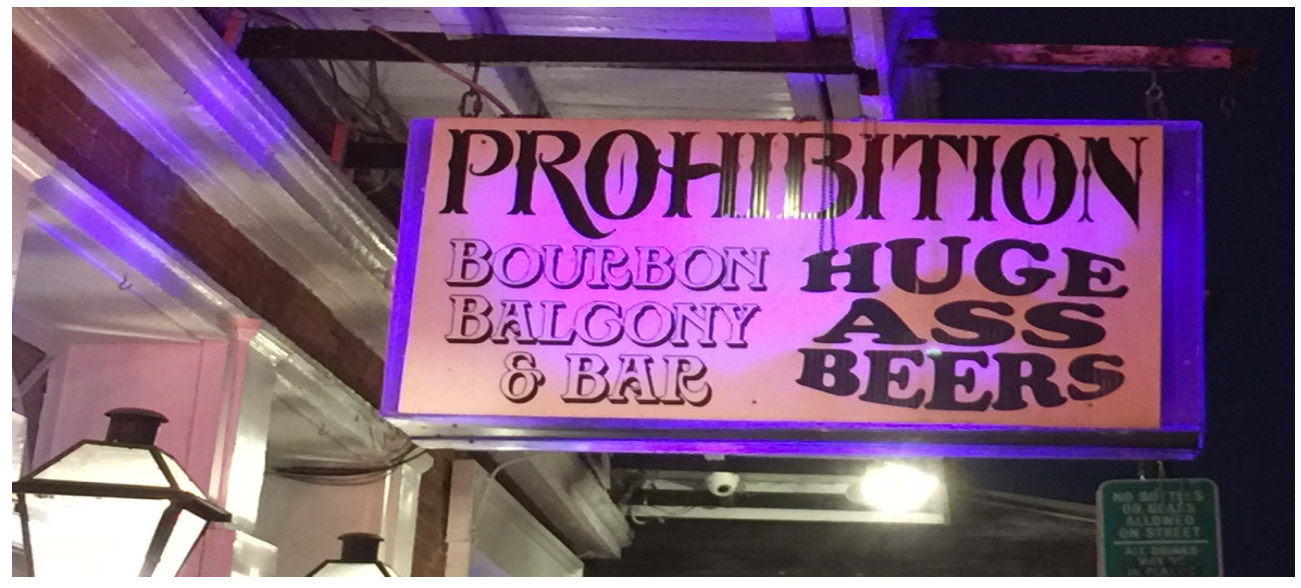

In the middle of Bourbon Street, a man stood with a giant white cross well over six feet tall and shouted over a megaphone that everyone would go to Hell for the sin or sins they were committing on Bourbon Street. His photo is below. I later saw this man walking like a marching soldier, with a stern face, and with the giant cross hoisted over his head. He is shown below in Figure 5.31.

Figure 5.31: Street preacher on Bourbon Street (Pridemore, 2017)

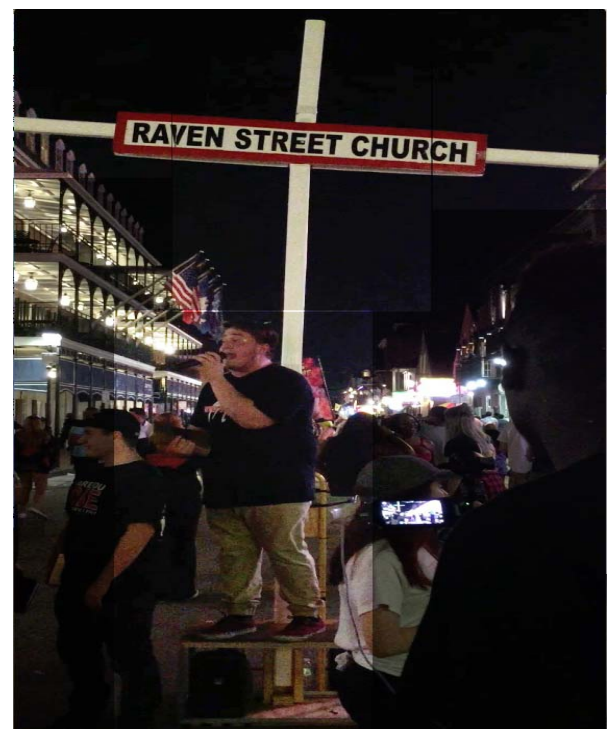


On the flipside, just as I was exiting Bourbon Street that night, I found this woman driving a pedi-cab for revelers. The pedi-cab this colorfully and brightly adorned woman drove was not only covered in flashing lights, but it was also decorated with Bible verses. One she invoked that struck me the most was along the side: "Judge not, for you shall be judged" (Matthew 7: 1-3). New Orleans, in its bold style, had the same message. The woman and her pedi-cab are pictured below in Figure 5.32.

Figure 5.32: Judge not, pedi-cab driver (Pridemore, 2017)

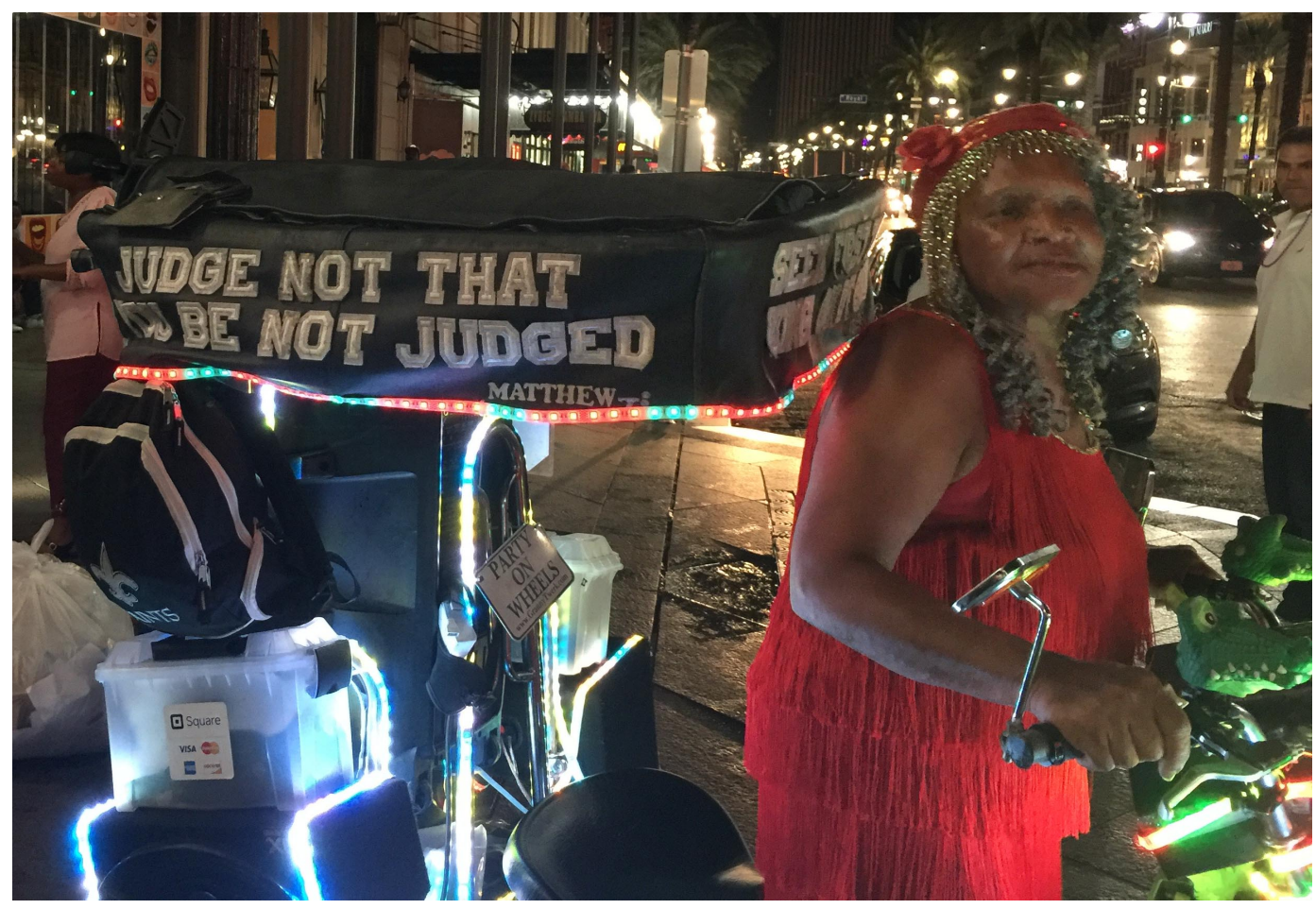

\section{Conclusion}

New Orleans' artistic community, as detailed in the previous chapter, faces a major uphill climb because of its especially egregious and longstanding participation hindering factors. However, it has shown here that even when its wounds appear to be mortal, they are not. New Orleans' artistic community fights back with gusto for the culture it loves. When its detractors bark, the artistic community bites. 
Given this was a negative extreme case and the previous chapter's identified hindering factors were so deep, it may be surprising to someone without the imprint of New Orleans' pavement on her feet and without the imprint of the city's heart and soul in her mind that anything positive could be found. This flipside of my journey through New Orleans shows that these initial perceptions are not reality.

In New Orleans, some bureaucracy members put the "street" in street-level bureaucrat through getting out of their offices and visiting the artistic community venues at their third places — and the artistic communities want to see them there more. This takes third places theory (Oldenburg, 1999) involving place and community building to a new level, given how groups with the amount of longstanding animosity can build constructive relationships in those third places. These findings also both compliment and contradict established scholarship on outlaw citizenship. It compliments through utilizing beloved culture and tradition (Rimmerman, 2011), but also contradicts it in that being offensive and abrasive can be a positive draw. It can mobilize citizens and be a way of feeling empowered again after the artistic community and New Orleans as a whole has faced outsider degradation.

In the next chapter, I will explore the question of who should participate in New Orleans' artistic community. The findings namely include issues of representation, namely having racially diverse participants. It also shows a dark side of partnerships, which are generally viewed as a positive in public administration literature (Pridemore, N.E. Ganapati, \& Revell, 2019). Some interviewees indicated that some potential "partners" would tell them working relationships hinged on the interviewees compromising their personal or organizational ethics — and they had to refuse. The 
chapter also explores social media participation, extremely uncharted territory in public administration scholarship. Social media both helped those organizing outlaw citizenship efforts and literally created a dangerous situation during the 2016 and 2017 Confederate monument removal controversy (Associated Press, 2016; Evans, 2017b, 2017c, 2017d; Kinchen, 2016; LaRose, 2016; Litten, 2017a). 


\section{CHAPTER 6: NEW ORLEANS AND DECIDING WHO PARTICIPATES}

The research question of who participates - the conundrum of balancing out diversity and inclusivity with the need to control the overall dialog to ensure clarity and constructiveness - is what I explore in this chapter. Key findings include issues of representation — namely the need for racial diversity, having and possibly limiting participation to speakers from the groups that policies actually affect, and controlling the overall participants' group size. Major findings also include how partnerships are not always a positive, especially if such an arrangement would force individuals or groups to compromise their ethics.

Social media concerns a major aspect of these findings. Because social media literally opens a global digital door for practically anyone to participate in a policy forum, this produced positive and negative extremes in terms of findings. On one hand, they enabled groups organizing for traditional participation and outlaw citizenship alike to quickly spread their messages and organize. The flipside was that social media opened the door to those who could create an intensely negative dialog from near or afar. In the case of New Orleans' 2016 and 2017 Confederate monument removal controversy, some social media users literally created a dangerous situation involving intense online and offline protests, threats of violence, intimidation, and, possibly, a car being torched (Associated Press, 2016; Evans, 2017b, 2017c, 2017d; Kinchen, 2016; LaRose, 2016; Litten, 2017a).

These findings fill multiple literature gaps. One is that some citizen participation partnerships should be avoided, particularly ones that would require individuals or groups to compromise their ethics. Previous scholarship involving partnerships has namely 
focused on building them and their positive aspects (Pridemore, N.E. Ganapati, \& Revell, 2019). This presents an opposite situation.

This chapter's multiple findings involving social media participation are major literature additions. During an extensive literature review of public administration empirical literature going from 2006 to 2016, Pridemore, N.E. Ganapati, and Revell (2019) only found three articles that explicitly mentioned social media or a social media platform in the title. Covering social media ground also adds to the literature involving online participation because it also covers the use of non-government web platforms. Previous public administration scholarship has mostly examined ones governments provide (Pridemore, N.E. Ganapati, \& Revell, 2019). It also further explores how online participation can move to offline participation — and extremes in that, creating both robust, inclusive dialog and literally dangerous security situations alike.

This is the chapter's structure: First, I will discuss the findings involving representation, such as the need for racial diversity but also controlling size to keep dialog concise and constructive. I will then discuss partnerships, both in how they can benefit artistic communities and governments but also the earlier-mentioned negative flipside of partnerships, showing which ones should be avoided. Afterward, I will discuss social media, which opens the participation door to an extreme. This has major positive aspects, in terms of how it can diversify and quickly organize participants. It can also take a much darker turn because, in the case of New Orleans' Confederate monument controversy, social media users literally created a hostile environment and dangerous security situation. 


\section{Representation}

Representation was a major concern when it came to determining who participates, namely because it created the biggest balancing act for city officials and the artistic community alike. The chief concern in this area was that of racial and ethnic diversity in who participates. Some black interviewees were incensed at the number of white advocates from outside New Orleans who were not culture creators themselves entering the policymaking dialog. White interviewees also wanted more racial diversity because they agreed with black interviewees' statements that so much of the elites' challenges were rooted in race. Size concerns and nuance were two other major concerns. To balance out the need for diversity and to control size so that the dialog is also controlled and constructive, participants suggested starting participation efforts with small groups first and through considering the nuances of exactly who a policy affects the most and exactly who in government should be addressed.

\section{Race and Ethnicity}

Racial and ethnic diversity in deciding who participates was a major concern for interviewees. Being that the New Orleans artistic community and the city as a whole is majority black, interviewees were concerned that, if the artistic community were truncated to a few spokespeople, too many of them (if not all of them) would be white. Both black and white interviewees saw this as a problem, but some who are black found this even more troubling because, they indicated, too much white representation for a majority black population means that too many people who have not actually experienced the challenges the majority of New Orleans artistic community and citizenry as a whole were the ones speaking. 
Michael, a musician who is also black, used the term "Columbusing" when he described white people, often coming from outside New Orleans, who say they are in New Orleans to save its arts and culture and especially ones in relatively new advocacy organizations. One group that he brought up was the Music and Culture Coalition of New Orleans (MACCNO), which he said he had no problem "putting on blast" because some of their ideas for bridging gaps with the cultural community and government will not work for black cultural community members.

Michael questioned the advocacy groups, as a whole, in terms of their intentions because some, sometimes coming from wealthy families, working to boost an entertainment or social entrepreneurship career have come to New Orleans to use the interest in the city to boost their credentials all to leave it behind. The other problem is that the white representatives, he said, often become the ones to whom government officials are more receptive. Black cultural community members, he indicated, sometimes feel like they are treated as someone who is only useful for entertainment — even when they are highly educated, like he is. He used the term "Becky with the Good Hair" to describe white people who act as spokespeople for the black musicians and artists but with their own interests at the forefront.

"Becky with the Good Hair", made especially famous on Beyoncé's Lemonade album track "Sorry" (Gordon, Rhoden, \& Knowles, 2016), is a term, among several other uses (sometimes very derogatory) (St. Bernard, 2016), to describe the woman, quite often white, a black man prefers over a black woman with natural black hair (St. Bernard, 2016; Urban Dictionary, 2016). 
Michael: We know who needs to be at the table. It's those who are suffering. It's those who are getting the short end of the stick. ... (Black members of the cultural community) have educated folks in all of the genres of our cultural community, whether it's the Mardi Gras Indians, etc. We have people who have high intellect, high historical insight, and academic fortitude.

...Maybe we want to be the advocates for us. But, damn, if you (whites) keep hijacking our voice, how can we? You're not allowing us to have the voice. What if we, ourselves, want to organize a forum with the mayor? Why do we need you to do that for us? ... This is the shit that... You have somebody like (local musician and academic) who has been performing in New Orleans music and culture and representing New Orleans music and culture since the 1970s. You have an immense number of elder musicians. You have younger musicians like myself. I busted my ass to get a master's degree and a Ph.D. for that particular purpose.

...Yeah, let's get Becky with the Good Hair. Can you please set us up a meeting? Can you serve as the moderator because we can't speak well? Can you actually ask the questions for us?

But what we'll do is have the Mardi Gras Indians dance when everyone is coming in. We'll maybe let one of the brass bands play a dirge in the middle. And then, we'll all have a second-line at the end. We'll be the cultural performance, but could you really be our voice because we don't have the intellect or academic sensibility to be our own voice and be our advocacy? And that's the way I sense it, and that's the way that many of my cultural peers sense it too.

Harry said that in doing his work, he has to be very conscious of the fact that he himself is a white man and working for a white-male-led organization while in a majority black city with a majority black artistic community. His organization has worked to diversify both its staff and its board so that, organization-wide, it is not majority white and for the reason of having more perspectives that align with the New Orleans artistic community and the citizenry as a whole.

As an individual, Harry said he has to strike a very precarious balance. He has to find ways to utilize his own white privilege as a positive, so that he can access spaces where white elites will use racially coded language they would never use in the presence 
of a black person when the elites are trying to shut down black cultural spaces and practices. He can then use what he sees as evidence about the elites' real intentions, call them out, and let others know too. Simultaneously, when working to organize and bring more black artistic community members into his efforts, his and others working with him being white have turned off minorities.

Harry: I think the key is being very aware, very conscious, and being aware of how my identity can be used to access spaces other people may not and how to make sure that I push for an opportunity for people of color to take in that space or push back against policies that are problematic. One example... I was at a safety and security meeting about the French Quarter, in general. Someone was talking, in coded language, about "those people hanging around outside." I was able to push back on that and sort of derail that conversation. ... I try to use this to push back as best as I can.

...We need to be thinking about inclusion. We need to be thinking about how we dismantle the roadblocks of opportunity for people of color - to own a business in the French Quarter or with policing practices. ... But (for a project) we tried to do sampling early on, and we had that issue of sample bias. We just scrapped the project because we didn't have the capacity to do it. The time and work to develop a fair sample was something we didn't have yet.

Amelia: Was part of the sampling problem people of color just not trusting you?

Harry: Some. Yes. Also, part of that was that because who we had participating in our organization at that time was not representative. So that came through in our sample. We were almost all-white, and there was a sort of split at one point. This was at a meeting when we really weren't a formal organization yet but just a collective of people. There was a split and disagreement, and most people of color stopped coming.

Susan also discussed the issue of, when deciding who participates, racial and ethnic diversity being needed, especially when those who participate use racially coded language in their attacks. In the face of racially coded attacks, racial diversity is needed as a counter and from people with actual life experience providing that counter.

Susan: This gets super, super racial because a lot of the spaces where the music comes from are black communities, and it's popular in black communities. So you 
have this racially coded language and a little old white lady saying, "Well, we just want nice music." Motherfucker, you just want a white jazz trio. Say what you mean because you're not fooling us. When you're looking at that, you might have more representatives from groups like bounce musicians, for instance.

\section{Balancing Diversity and Having Controlled Dialog}

Especially when considering the racial tension involving who participates in New Orleans' artistic community, the challenge of balancing participant diversity and controlling participation efforts so that messages are clear and concise is a major challenge. This becomes even more challenging when anyone opposing the artistic community and cultural practices has much more wealth and power.

New Orleans' government official and bar owner interviewees pointed to advocacy organizations. From government officials' perspective, the advocacy groups provided a concise point of contact for when it needed to reach out to the cultural community as a whole and for when numerous members of the cultural community needed to reach the officials. Those points of contact also informed them of artistic community occupational and technical concerns that the officials needed in policymaking. The bar owners favored the advocacy groups from a different perspective because the groups were able to rally their followers to support the bar owners when far more powerful elites opposed them - using numbers as a counterbalance. MACCNO was a group interviewees mentioned quite often.

One government official also found that truncating citizen participation efforts at the beginning of a program's rollout was very constructive - revealing it to small stakeholder groups first and receiving their thoughts — before presenting it to the news media and general public. This allowed her to get needed feedback and background 
before presenting it on a far-wider scale. Other ideas interviewees presented included having few spokespeople — but packed government meeting rooms for visual effect and considering nuances in issues at hand. With the latter, an interviewee indicated, certain populations are affected more than others, so participants should be narrowed down to those populations.

The advocacy organizations have been a key component of the city police department's efforts to improve relationships with the artistic community, according to Kingsley. Besides the earlier-mentioned attendance at the organizations' meetings, the advocacy groups can serve as central points of contact when either he needs to communicate something to the artistic community or if there is a problem they are having that he needs to address. One such organization that he mentioned was MACCNO.

Kingsley: So one of the ways that you can really engage the community here is to figure out who are those cultural icons and those cultural groups that really lend to the city's feeling and expressions. The things we've done recently and not too recently are reaching out to the leaders of these groups and say, "Look, what are your problems?" So, for instance, take MACCNO. One of the first things I did when I came into this position was seek them out and have a conversation with them. I said, "When you guys have a problems with a police officer who you think is overstepping their boundaries, you need to let me know because I can't fix problems if I don't know about problems."

Kingsley recalled an incident in which having MACCNO, in particular, as an established contact point was key in correcting misguided behavior on the part of an officer that could have further soured relationships with the artistic community after an incident with a group of street poets. It also helped him find a gap in training younger officers and work to fix that problem and likely others before they start, as well. This, 
along with his above-mentioned attendance at the advocacy groups' meetings in their

spaces, has worked to bridge gaps between the police and the artistic community.

Kingsley: MACCNO contacted me and said they had a problem. So, I called them back. I had assigned one of my officers, on an overtime basis, to go to Frenchmen Street and take some enforcement action against illegal vending. I have real concerns with that, even though it might sound silly. Let me give you the context: People that are out there illegally barbecuing and then selling their barbecue and their food and stuff... You have to get a permit for that, but more important than the permit is that you have an open flame next to a 200 -year-old wooden building. You've also set up next to a business that pays taxes, that has permits, and now you've taken away their business because you can undercut them because you have no overhead. So there are a lot of things - just equity.

So I sent some officers out there to deal with unpermitted vendors on Frenchmen Street. Well, one of my officers was young, and he did not have as good of appreciation of the law as some of my other officers would have. And honestly, I, either through my lieutenant or my sergeant, maybe did not do my job and my due diligence to make sure he understood what he was doing.

So he went out there, and he issued four or five poets summonses for illegal vending because they were creating poetry, which is not against the law. Somebody would come up to them for poetry. You give \$5, and they'll type up a poem. You don't need a permit to create poetry. The officer saw that as illegal vending. It's not. Poetry is protected speech. It's artistic expression. It's not illegal vending. But it wasn't the officer's fault. Nobody teaches the vending and permitting laws in the academy. They just don't. ... So when MACCNO contacted me with a problem, I was able to go and look through the officer's body camera. The officer also wasn't rude. He just thought he was doing his job.

I found those summonses he had given. I was basically able to pull those tickets out, have somebody cancel those tickets before they reached court, have somebody write a supplemental report explaining why the tickets were cancelled, and then get back with MACCNO and ask if there were any others who improperly received a summons.

...We can self-correct this before it even reaches the court because we should. If somebody makes a bad enforcement action, it shouldn't be up to the courts to throw it out. I want us to be able to police ourselves. ... I think this officer legitimately made a mistake. He didn't understand the law, so we circled back to him and explained to him that poetry is free speech and how that's not really vending. Now, he understands. We use it as a teachable moment to that officer and his platoon. Everybody who works with him now got that same lesson, and we also use it as an opportunity to fix a problem. 
The poets didn't have to hire a lawyer to fight a bad charge at court. That's what I want. I don't think that all of the nearly one hundred officers that work for me will get it right a hundred percent of the time because I know I'm not going to get it right a hundred percent of the time. But I hope somebody trusts us enough that they can come back to me when there's a problem and give me the chance to fix it before it becomes an issue we have to litigate. That's my hope.

Olympia said that during the health department's smaller meetings before Sound

Check was launched, MACCNO was a good point of contact for when she had the meeting with cultural community members. MACCNO's leadership was able to tell her some of the issues that could arise and challenges she could face, in advance. In turn, she was able to utilize MACCNO to relay information to their constituents so that they could process what she would present in advance. This could have been a reason why the first Sound Check meetings with the cultural community were very constructive. Also, these groups as well as other musician friends she has made let her, someone who does not have a music or arts background, know details about these occupations that she needs to take into account in policymaking.

Olympia: Our first few meetings were really just us listening to people and providing them with an outline of what we wanted to do.... We have seen some really great ideas from the musicians that we've been able to implement that I wouldn't have come up with myself. ... I'm a public health person. I do not have any background in the arts or music, and so I really didn't understand how that world works and I didn't understand the relationship between businesses and musicians before all of this began. And so having some of those individual conversations really allowed the head of MACCNO to explain all of that to me and how that whole world works so that I had a better background when trying to figure out how to please multiple groups.

Dean and Regulus both said MACCNO and its followers were a major help in their work to keep the doors open when wealthy elites worked to shut down their bars. This gave them further strength in numbers because not only did they have their positive 
relationships with neighbors and community organizations mentioned in the previous chapter, but they also had MACCNO's followers and resources to back them, as well. Dean also appreciated the fact that the organization is working to change the ambiguous language in the dated noise ordinance.

Dean: Their mission is to be an advocate of music and culture in New Orleans and they do that. They will find you legal help. They will take on an effort when there's a rich guy that is trying to subvert live music or free expression of art or whatever in a venue for some reason. If that expression is legal, they will take on that cause and make sure that it's being fairly represented.

So I know that a lot of cities have that. In New Orleans, it seems to be a little bit more powerful. I think that might be because most... I mean, New Orleans is like the biggest small town there is. It's got all the advantages of a big town like Houston or Chicago or New York in a small package. So organizations like MACCNO can be more powerful because they don't have as many people to serve. They don't in these other organizations. You might have more constituents pumping in, and so those organizations might have more money in the bigger cities, but they also have all these different venues that they have to protect, and that gets watered down.

...They're also very much advocates of being within the rules. It's like, "OK, well, you need to be within the sound ordinance. You need to understand the rules." But they also work with city council members and the rulemakers to understand what those rules are. They work with them to change the rules so that the rules make better sense. They're working to change the wording so that it's not ambiguous so that, when you do have arguments between a venue and a neighbor, that ambiguity doesn't cause conflict.

Regulus said that advocacy organizations can be a major help and were for him when his business was facing shutdown because, alone, a business owner or artistic community member facing a group can be de-legitimized because of the size of those opposing him or her versus that person as an individual. The disproportion in size, alone, may make the individual automatically look like a problem. So when advocacy groups, like MACCNO in his case too, began supporting him, the numbers evened out. I 
mentioned some of the above-mentioned concerns with advocacy groups, particularly

MACCNO, and whether or not MACCNO does truly help the cultural community. This

was Regulus' response:

Regulus: I say, "God bless them." I don't get the chance to participate in MACCNO's activities as often as I can, but I have been to a lot of meetings. I knew a lot of people and for me, I have to say, "God bless them." They're some good people, and they've been working really hard on behalf of music and culture in New Orleans. From a very, very personal perspective as a business owner... When they began supporting me, it was the first time when I started feeling like a little pressure was being taken off of me. They're the ones who helped me feel that way.

Other interviewees mentioned that balancing out participation level can be done through picking a few spokespeople — but making sure that supporters pack government meeting room chambers to have a visual effect and visually show government officials what the support level is for the artistic community.

Michael: Imagine if the two hundred collective brass band musicians, and the 150 collective Mardi Gras Indians, and the five hundred collective social aid and pleasure club members all showed up together at city hall chambers - then had whomever from the community to represent them. You have eight hundred cultural community participants sitting right there in the chamber. What's the city council going to do at that point? What's the mayor going to do at that point? That's when the mayor is going to listen.

When they went for the noise ordinance, you had the people who were advocating for the ordinance, which were the property owners in the Vieux Carre and these different so and so. They had two hundred people sitting in the audience saying, "The trumpet is noise, and I don't want to hear it after 8 p.m." Then, you had Becky talking on behalf of Johnny and maybe five other musicians or so. What council sees is, "There are two hundred voters sitting right there." At the end of the day, with politics, they're looking at their voters. They want to please their constituency.

Amelia: But if you have eight hundred culture bearers there...

Michael: That means, "I've got eight hundred voters there. I have no choice but to listen." ... The heart of advocacy is not only the message and the voice, but it's 
also the numbers, point blank. We just need folks to show up. That's it. You see folks there, and people are going to take you seriously.

Susan said that when deciding who participates, another factor that should be taken into account is multiple specifics and nuances - finding the specific group that a specific policy or a specific agency that will affect the most.

Susan: That question needs to be broken down much further. That's exactly the point. It's recognizing that these things are not monolithic. You hear, "this city". And I'm like, "Who are we talking about?" You know, there's a department, an office, a person, a process..." It's not this nameless, faceless sort of thing. "The city did this." Well, who did it? Let's find out so we can go and sit down in their office and tell them to stop being an asshole. In other words, is it the police department? Is that the mayor's office? Is that the health department? City council? All of the above?

It varies, and it has to be treated with nuance. In other words, "OK, let's see who this affects. Is it everybody or is it just one group? But also, is it being pushed upon or are people being pulled into a governmental thing or are the people drawing themselves into an issue that they care about? If people want to engage and want to participate, which direction is this coming from?

\section{Partnerships: Positive and Negative Aspects}

Another consideration that the New Orleans participants had to carefully consider in determining who participates was partnerships - which were not always positive.

This was especially true for those doing advocacy work. Some interviewees informed me that partnering with other groups has helped them in terms of providing numbers, resources, and perspectives. Others, though, found that certain potential partnerships would only lead to destructive dialog, only one group making decisions on the overall message, or compromising their ethics and values.

Olympia said that besides MACCNO, another organization with which she has done work is the New Orleans Musicians' Clinic that provides health care for musicians 
and other cultural community members. The health department and this organization, she said, have common goals such as making sure more people have health insurance and protecting performers' hearing. Her sentiments echoed Susan's above, in that she also mentioned the need for specifics when choosing potential partners.

Olympia: I think the other thing that helps with the Sound Check project and others too is just really setting some clear boundaries of, "This is what our focus is," or, "This is how much we can handle," and letting people know where there's flexibility in where you can work together and where the lines are."

...We've had some conversations through (the musicians' clinic) with some of the Mardi Gras Indians and some other groups and looking at ways... People came to us and said things like, "OK, you want to protect our hearing? What about the rest of our health? How can we get health insurance?" So we paired them with our health insurance team. At the time, the Affordable Care Act was the new thing. We did some things like helping people sign up for ACA coverage and providing some other health care benefits that has allowed us to work with some different groups of musicians.

At the same time, Olympia said, there are certain groups with whom she does not choose to work because she wants to keep conversations constructive, and these groups would not likely do that. This is something else that she and her department have had to consider when working to build relationships with the cultural community.

Olympia: We've started choosing who to get involved with and who not to get involved with. ... Some groups, we've intentionally... They haven't reached out to us, but we've also not intentionally reached out to them. There was another group that, right around the time we were talking about launching this or maybe it was right after, they held this big, long community thing. It was going to be live, like on one of the radio shows or something. So we all listened to it but did not show up because, at that point, a few of them knew our faces, and we didn't want to cause disturbances.

But we still wanted to hear the conversation that was going on around it and some of the backgrounds. Listening to that conversation was the first time I had heard that some people felt like some of the music issues were related to race. I had no idea that was being talked about. 
... If any of the other groups had asked to meet with us, we probably would have. But I think when we were looking for ideas, we wanted to keep conversations positive because these can easily derail and lead down other places.

...So we've tried to use social media or other ways to hear what's going on and trying to figure out the most constructive way to do that. MACCNO is the primary organization we've worked with. They seem to be the group that is most engaged with the government and willing to have those conversations with us.

Harry said that in advocacy work, partnering is most often a positive. He

mentioned, for instance, how he wants to do work in terms of social justice issues like racial profiling of black performers by police and how groups focused on that could help him. The problem is that some groups bring him to the table but with their decisions already made and not wanting to treat him or others as partners. This is especially true for cultural community advocates like Harry who have connected with prominent local entertainment figures. Certain groups may want to use these figures to promote their own causes but want to do nothing to help the people Harry's organization serves.

Harry: I think most advocacy organizations, we do work with, but there are other cultural advocacy groups that don't partner. We deliberately try to partner and for two reasons. One, it's crucial to the survivability of New Orleans culture, but, two, we get asked, a lot, about, "Hey, can you get a musician to come and speak on this?"

I think we should flip that too. Why don't you talk to musicians and advocate for what they need rather than try to get a musician to come and record a video for you? Why don't you work with them to get what they need and work to create it?

An example would be... There was a coalition that was trying to push back against AirBnB regulations. They asked us to come to the table, and I did. But it was already clear that they had decided what their position was. They just wanted our voice to lend support to their organization, which I called them out on and said, "Here are our suggestions. You're not using any of them, but you want us to record a video for you."

That's not the way partnership works. So, we backed out of that and worked with other partners to actually address systemic concerns rather than just be a voice. If you really want the cultural community involved, you need to use them as more 
than a mascot for your ideas, which what I think people often try to do. So we need to make sure to continually change that dynamic.

Personal or organizational ethics and values, interviewees said, must also be considered when deciding whether or not to partner with certain groups or individuals. This was especially a concern for advocacy groups. Something that made this an even greater concern was when the other party - and that party sometimes being very powerful — demanded that one change its position on or drop opposition to an issue. For certain groups and individuals, doing this would cross ethical lines. If this were the case with government agencies, then it would be better to continually participate in policy forums but as an outsider.

Harry noted the city's proposed surveillance camera ordinance introduced in late 2017. Litten (2018) wrote that this ordinance would have required "every alcoholic beverage outlet in the city to connect security cameras to a citywide camera monitoring system". This would have added at least 1,500 private business' cameras to the publicly owned network of 350 cameras that were already running (Litten, 2018). This was a part of an anti-crime plan that Landrieu wanted to complete before leaving office. The proposal was withdrawn in March 2018 after civil liberties groups, bar and restaurant owners, and advocacy organizations mobilized and vociferously opposed it, essentially calling any implementation of that policy the creation of a "Big Brother" regime (as cited in Litten, 2018).

Harry's organization was one of those who fought the camera ordinance, and doing so cost him partnerships with a very powerful nonprofit organization and some in city government. Even some government agencies like the Mayor's Office of Cultural 
Economy, with whom his organization has had a positive relationship, were in an

"oppositional space" because of his organization's opposition to the camera ordinance.

Supporting that ordinance or even just backing down would have been unethical, he said,

and he and others in his organization could not do that.

Harry: We were working with the (nonprofit) Convention and Visitor's Bureau to promote some work we were doing that would have really helped the cultural community. As soon as they saw that we were publicly opposing that ordinance, they said it wasn't going to work. Fair. Maybe that wasn't the right fit.

But also, it's a clear sign that... The politically expedient thing to do would be saying, "OK. Let's figure it out so we can get our work out there." The right thing to do is continue to oppose this ordinance because it's terrible. When things break that way, I feel like you have to go with what you know is right. I think that's what sets us apart from a lot of other cultural nonprofits. Some won't take a political stand on issues. They've got their thing. They do it. They don't want to sort of rock the boat. I get it.

...We have to figure out different avenues to get our work done, and do more of an outside strategy instead of an inside strategy. That's where our power base comes from. If we're opposing... We can't have the stance of power respects power. We have to build our power up. We have to show that there's power behind us to get things done. I'd love to have more of an inside track, but right now, no.

\section{Social Media}

In terms of determining who participates, social media was an issue that divided participants or even had some of the same participants having serious mixed feelings

about it. Social media was very much like the participation size issue, but to an extreme. Positives participants discussed were how it has helped reach younger populations and ones who could not attend traditional public forums. It has also helped with in-person mobilization. Monitoring social media channels also allowed government officials to get a better sense of what the overall feelings were on given issues. 
However, this has also caused serious problems because social media opens the door to everyone, including people from outside New Orleans who may decide to come into the city and cause trouble. Some of the dialog during the Confederate monuments debate, for example, was especially poisonous and caused dangerous security situations in the city.

Kingsley earlier acknowledged that some groups would be too intimidated to meet with police at a police station. Besides going to the artistic community's gathering places and spaces, he said social media can be a positive way to reach populations police want to reach who may never go to a police station or any other government-designated time and place for a meeting. This is especially true for younger populations.

Kingsley: My LGBTQ community, especially some of the younger members, are very reluctant to go to a place and at a designated time to meet with any government officials because there's just a real distrust in some of those communities of the police and other government officials. ... A better place to meet them may be online, through the use of social media to have those back and forth conversations with them and through trusted mediators in their community. ... Asking them to meet with me at a specific place and time is probably not the best way to meet them.

Social media can mobilize people to show a massive outpouring of support for a given cause, namely because of its reach and because notifying potential supporters is so much faster, easier, and can become much more widespread. For this reason, Kingsley said social media was "one of the most important things that has happened to democracy in a long time". This can be useful for both traditional forums and outlaw citizenship. An example Kingsley gave was the Women's March, which, in New Orleans, brought out an estimated 10,000 to 15,000 people - possibly 16,000 to 18,000 .

Kingsley: So let me give you some police terms so you can understand what I'm saying. The "lead" (police car) is the first part of a parade. We're very used to 
parades here. So lead cars are usually that first police car you see at the beginning of the parade, and then the "tail car" is the last police car in the parade. Then, there's something called "disband", which is the end of the parade and formation, the ending. The lead car reached disband for the Women's March before the tail left formation. That only happens for Endymion (one of the largest Mardi Gras parades). That's the only parade that's so big and so long and so huge that, that occurs.

And to me, it was really, really powerful to hear that many people came out, and it filled that much of a route and marched so powerfully that the lead car reached... For police officers, it's amazing when the lead car reaches disband before the tail car leaves formation. The police officer understands what that means. "Oh my gosh. The whole route is full of people."

...The Women's March was really, really powerful here and throughout the country. ... I don't say this lightly, but could the Women's March have been possible without social media? I mean, maybe. Look at what Dr. King did in DC, right? ... But could it have happened simultaneously in so many cities throughout America without social media? It's pretty powerful to show the dozens and dozens of American cities that have hundreds of thousands of people, both men and women, showing that they appreciate that women's rights are human rights.

Kingsley did hope, though, that social media enhanced but did not outright

replace in-person dialog and real-time gathering in public spaces, which he believed was

more powerful in the end.

Kingsley: It has just made it easier for people to be open and engaged. I hope it continues to mean that people gather in public spaces to have their voices heard. I am not of the social media generation, but I hope that it doesn't become a substitute for gathering in public spaces because I think that there's just an importance to that, to going out there and having your voices heard. Although social media might give you more ability to reach more people, I think it's more impactful if you get up, get out of your house, and get out to Canal and Royal and lay down in the middle of the street and have a die-in for the "Fight for 15", which is where we had a few, a couple of weeks ago. Snarl traffic every now and then. Just don't killed on the interstate doing it.

Social media can be a positive depending on how one uses it, Olympia said. She said most city social media accounts, like her agency's, are primarily used for one-way communication. People can "like" and share material from it, but they cannot comment. 
Also, the department only allows two staff members to have access to those accounts. That prevents conflicting messages from spreading or having someone post something that just should not be posted. However, it does look at comments from other Facebook pages, as well as other social media channels like Twitter and internet sites like local newspapers', because it does want to get a gauge for what the city's population, as a whole, is thinking or saying.

However, social media had serious downsides and because of that same access and information sharing. Social media participation opened the doors, also, to those who created a poisonous dialog, particularly from those outside the city. This became especially evident during the city's Confederate monument removals and during the legal challenges the city had to face. The Confederate monument debate touched all facets of the city, including the artistic community.

Throughout the legal challenges the city faced after the council voted to remove the four monuments and during the monuments' removals, the social media dialog on both local advocacy groups that supported the removals pages and pages for ones who opposed it was especially profane, with some promoting violence. MACCNO (2016b) shared screenshots from a group opposing the monuments' removal that had commenters suggesting ways of killing a local poet involved in the local Black Lives Matter movement. (The original post shown in Figures 6.1 and 6.2 has since been removed.) 
Figure 6.1: Threats (as cited in Music and Culture Coalition of New Orleans, 2016b)

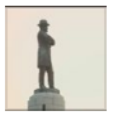

\section{Battle of New Orleans: The Bicentennial Documentary} added 2 new photos.

$3 \mathrm{hrs} \cdot$

This is Quest, the leader of the Nola BLM thuggers. He's like Charles Manson in that he gives the orders and then hides behind the crowd so to not get arrested... he is on the Soros payroll... PUBLIC ENEMY \#1 Arrest him and the Nola BLM thuggers have no more leadership...

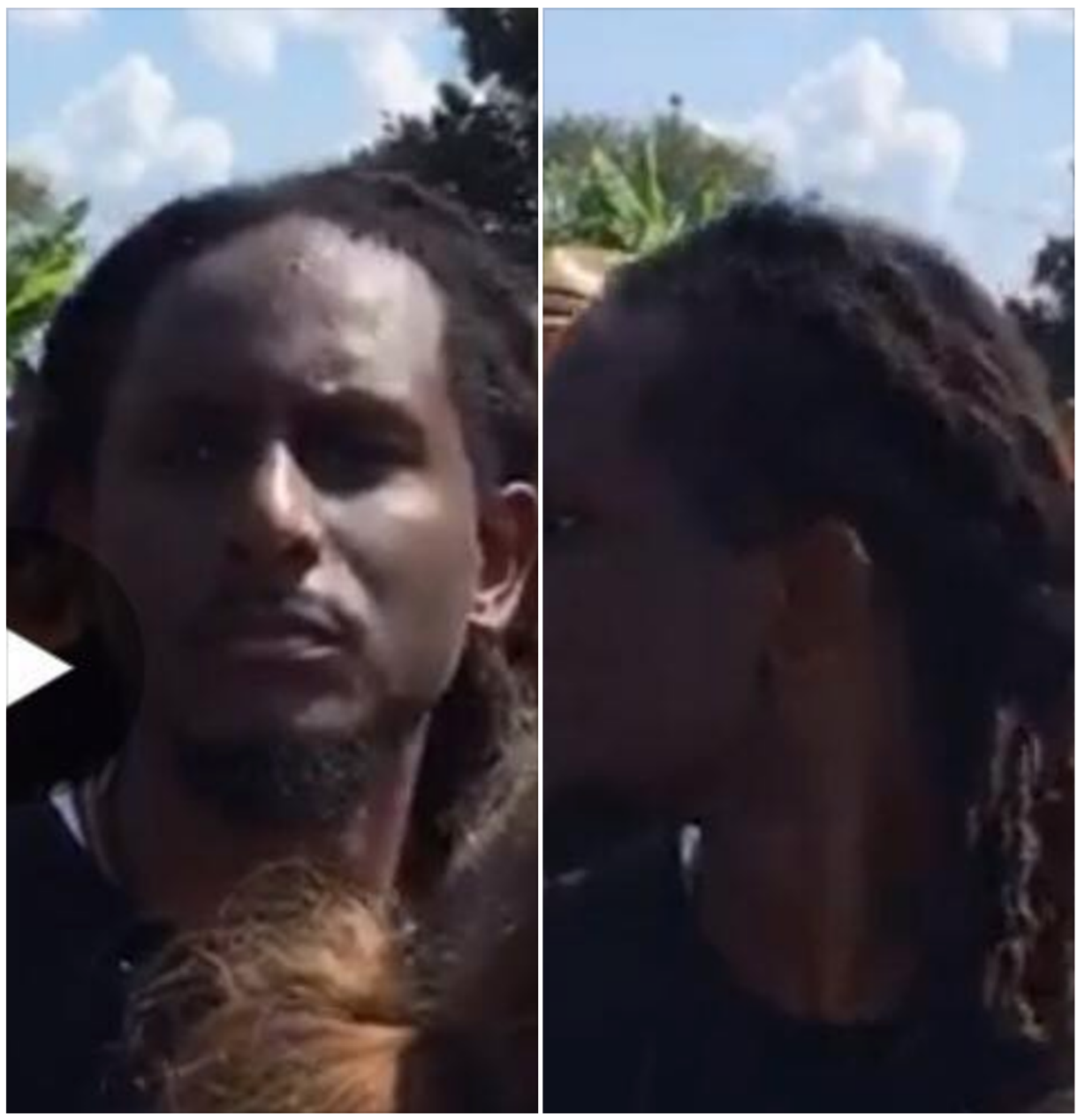


Figure 6.2: Kill Wish (as cited in Music and Culture Coalition of New Orleans, 2016b)
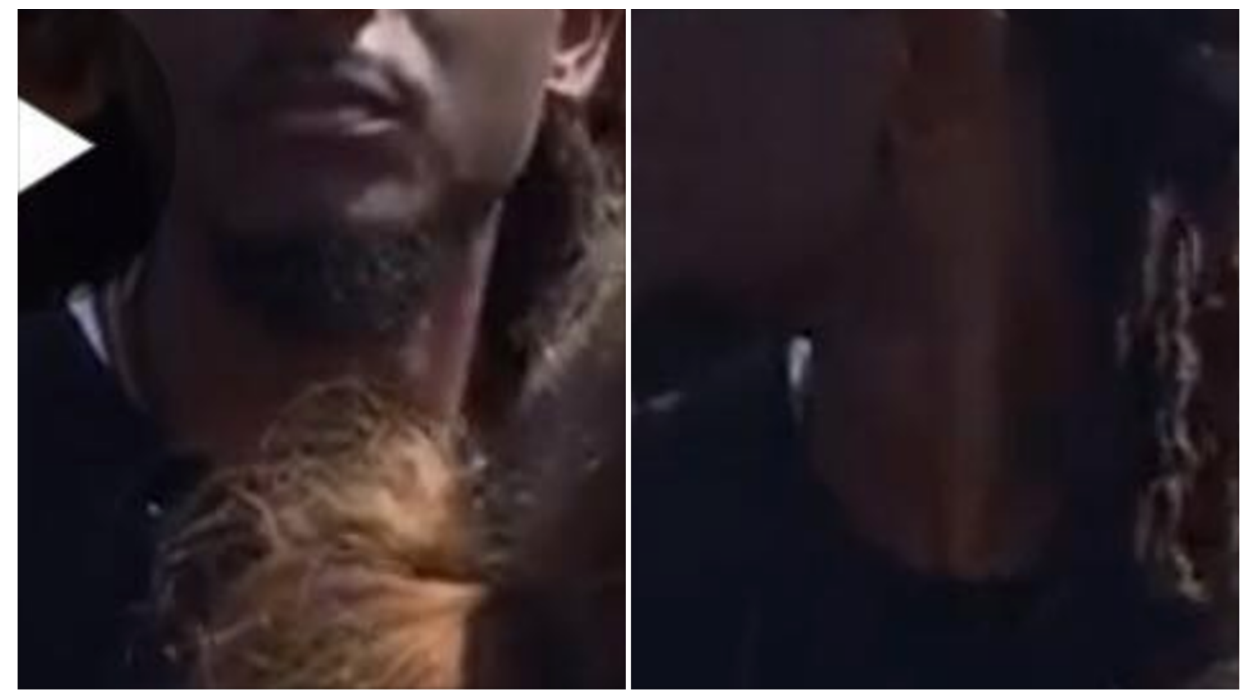

Share

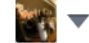

(1) $=2$ Devin McGovern, Clayton Comeaux and 44 others

23 shares

Paul Turnbaugh Don't arrest shoot the sewer rat ass wipe

(1) $5 \cdot 3$ hrs

Raven Foxx No...don't waste the bullet( plus don't wanna cause more gun control issues) GET A ROPE!!!

(1) $2 \cdot 3 \mathrm{hrs}$

Patrick J. Hebert He needs to be taken on a one way boat ride into the swamp.

(1) $3 \cdot 3$ hrs

A. Amy Arneson Cryan Gator bait.

(1) $5 \cdot 3$ hrs

Mimi Stipp Right between the eyes!!

(1) $1 \cdot 2$ hrs

Mark Couvillon pure scum!

$1 \mathrm{hr}$ 
Comments on other pages opposing the monuments' removal shown in Figures 6.3 and 6.4 also invoked violence and resembled the derogatory dialog about New Orleans during the Katrina aftermath (Cooperman, 2005; MSNBC, 2005)

Figure 6.3: Walk over their dead bodies, Facebook comment (Stevenson, 2016)

Andrew Stevenson Very lucky it wasn't me. I will walk over their dead bodies if they try block me.

Like - Reply - $2 y$

Figure 6.4: God sent a warning in Katrina, Facebook comment (Reily, 2017)

Wain Reily God sent a warning to New Orleans in Hurricane Katrina.The next warning may be coming.

Like · Reply - 1y

Even social media pages for those supporting the monuments were not spared, with monument supporters repeatedly taunting those who praised the monument removal with Katrina (and desire for another such event to happen again), the white supremacist rally violence in Charlottesville, Virginia, Trump's election in 2016 and even posting profane graphics and racial slurs. Some of these posts are shown in Figures 6.5 and 6.6. 
Figure 6.5: Post-Charlottesville Facebook taunting (Pendley, 2017a, 2017b)

Ralph Michael Pendley When this hurricane hits. Make sure u call those Antifa Bitches to help u. See how much they really care then. Same way black lives splatter did when they JUST left ur area a week before Katrina hit. Yet NOWHERE to be seen when u really needed some help. I'm getting my popcorn. Let's see how many dead mongrels I can see floating. Them gators gonna get huge

Like · Reply +1y

Ralph Michael Pendley And STILL got ur asses whooped and killed by a handful of Klansman Imfao so fucking funny.

Like · Reply · 1y 
Figure 6.6: Facebook insults, racist meme (Callahan, 2017a, 2017b)

\section{Matt Callahan}

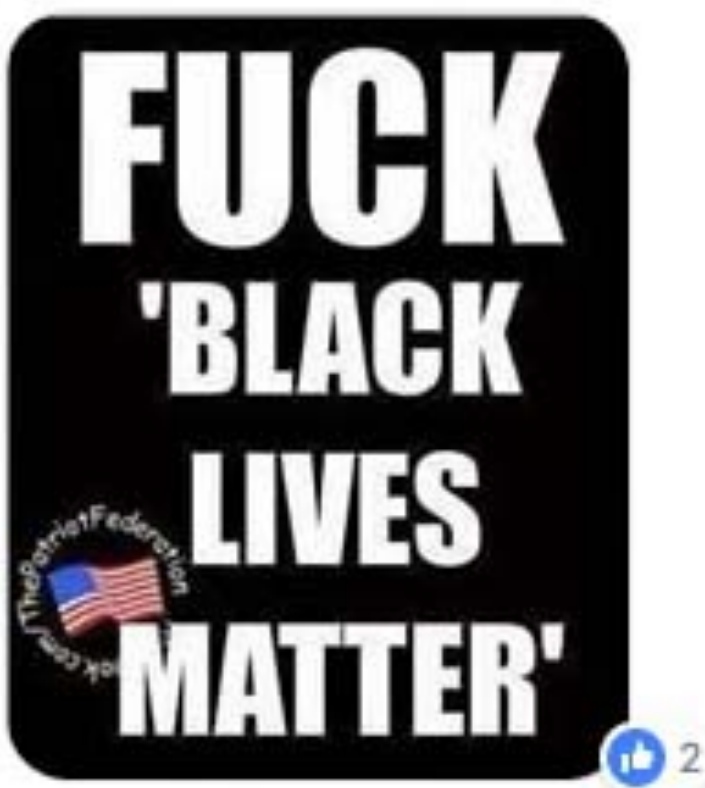

Like · Reply - 1y

\section{Matt Callahan}

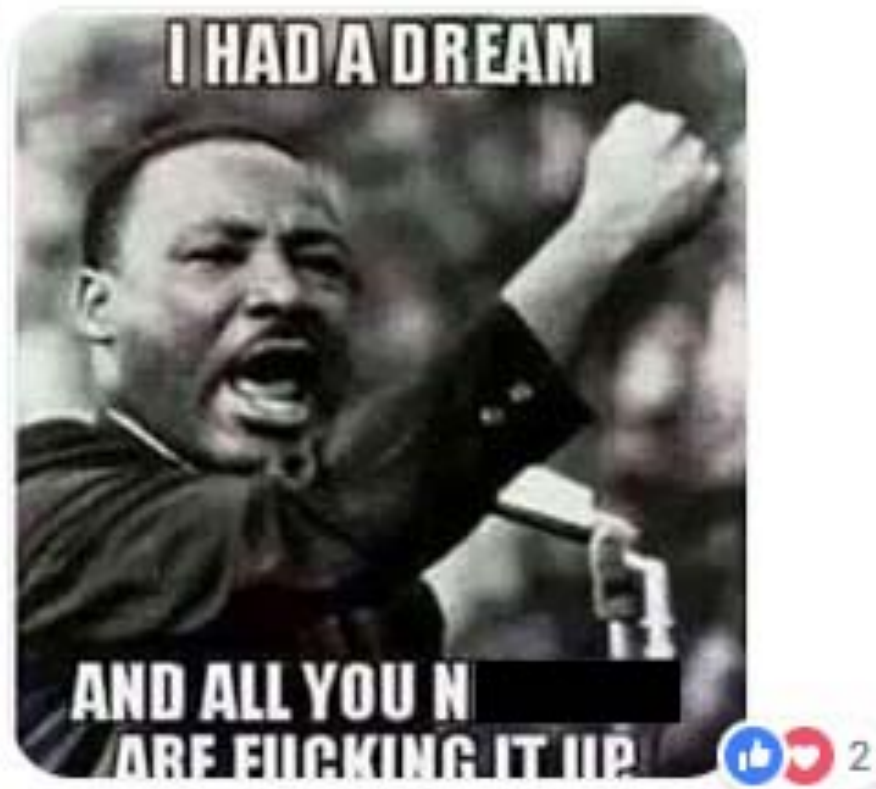

Like - Reply - 1y 
While such activity could be pushed aside as horrible, yet futile, online drivel and trolling, social media activity during the Confederate monument situation had major consequences that created serious security concerns in New Orleans. Social media outrage, along with death threats and the threat of other contracts being cancelled spurred the city's original contractor from Baton Rouge to pull out of the job (Associated Press, 2016; Kinchen, 2016). That still did not stop the business owner’s \$200,000 Lamborghini from being torched.

Fearing death threats and business boycotts, often fueled through social media sharing, the city had few contractors interested in the job and eventually had to seal the bidding process for security concerns (Associated Press, 2016; McClendon, 2016a). When the monuments were removed, the contractors often worked at odd nighttime or pre-daylight hours and had to wear full-body tactical gear to protect themselves and conceal their identities (Evans, 2017b; Rainey, 2017a). After New Orleans city firefighters (but without their specific names) were revealed as ones helping with one monument's removal, some removal opponents "launched a social media manhunt to unmask the people and companies" (as cited in Rainey, 2017a).

I asked Kingsley if what the city and the city police encountered during the Confederate monument removals is an example of how, perhaps, social media can open the citizen participation door too widely. Kingsley relayed what it was like to work at the monuments' removals and protests, particularly at the one for the Lee statue removal. $\mathrm{He}$ and other officers were at the statue site well in advance. When the marchers from Congo Square mentioned in the previous chapter arrived, they were facing down those opposing the statue's removal who had already arrived. He emphasized that especially as a law 
enforcement officer, he cannot let any viewpoint of his own affect how he does his job.

The officers' jobs were not to either condone or condemn anyone's message but to stop anyone from committing acts of violence in spreading whatever that message would be.

Kingsley: So (the removal opponents) got there before the pro-removal people got there, and they had their signs, and they were open carrying (firearms) and some of them dressed like they were... (pause) ...characters on Game of Thrones. They had homemade shields. I'm not even more where you buy a shield nowadays. And they had baseball bats and they looked like they were ready for battle.

But we talked to them and engaged them. A lot of them said, "We're here to have our voices heard. We're wearing this in case the other side wants to fight. But we also don't want any violence."

I will tell you that at one point, we did make about two or three arrests that day of pro-monument people who started fighting. But that was unfair to all of the promonument people. People in that group came to us and said, "We don't condone their behavior. We don't appreciate what they did. We want you to know that once anyone, internally, starts fighting, they're not with us."

When I first asked Kingsley, in general, who should participate, Kingsley walked to his desk and pulled up a copy of the United States Constitution that he keeps there.

Freedom of expression, he said, is a Constitutional right that cannot be denied. It is his job to control criminal behavior and violence in that, not the content. As he reflected on the Confederate monument controversy, he circled back to his thoughts on free expression.

Kingsley: (Kingsley walks behind his desk and shows multiple copies of the Constitution.) I give these to all of my new detectives.

...I don't think there is a limit to free speech. I think that there is a limit to violence. Once speech turns to violence, it's my job as a public safety official to stop it. ... It is not my job to limit a person's speech. I think that the more speech the better. If we all kind of let the world know what we thought, then maybe we would all be better positioned to understand each other's context and where each person is coming from. 
...So to me, and back to the social media aspect... ... I appreciate and understand what social media means. ... I appreciate when people are open and honest in their beliefs and views on Facebook and Twitter and Instagram because now, I don't have to think, "What is their agenda?" They've given me their context. So I can now make a better, informed decision as to whether to, even just as a citizen, whether to appreciate or trust or agree with their point of view.

\section{Conclusion}

Determining who participates is a balancing act that New Orleans' city government and artistic community continually has to strike, one that involves weighing

diversity and democracy on one hand and controlled and constructive dialog on the other. The situation in New Orleans shows that numerous other factors have to be taken into consideration during this balancing act — and especially in dealing with social media, which takes democracy and diffuse participation to such an extreme.

The social media findings are critical literature contributions, given the relative lack of social media scholarship in public administration, period (Pridemore, N.E. Ganapati, \& Revell, 2019). This shows how citizen participation levels can reach an extreme - and how that can simultaneously build or destroy communities. The findings involving the dark sides of partnership provide a challenge to most established scholarship, which tends to point toward its positives and provide advice in building it (Pridemore, N.E. Ganapati, \& Revell, 2019). Here, I present a critical component that artistic communities and government officials must consider when working to build relationships - deciding whether or not the relationship is one that should be entered in the first place, with factors such as personal and organizational ethics and the other party only working to serve its own interests that come into play. Understanding dark sides, though they may be uncomfortable and off-putting for some, is just as critical as studying 
the bright sides. One must know pitfalls as well as opportunities in any policy decisionmaking, and deciding on partnerships is a part of this.

In my dissertation's next three chapters, I will present my findings from my fieldwork in the city of Austin, Texas. While New Orleans either combatted the ghosts of its past or utilized longstanding tradition in their battle to survive, Austin is a city hurling toward the future - possibly, too quickly, as some of my participants there told me. Though it was initially classified as a positive extreme, Austin provided several identical findings to New Orleans' and for better and worse. Austin presented new opportunities and challenges, though, in terms of its city government structure (both in-place and missing), extremely rapid development, policy challenges involving its outdoor music culture, and a group of former rivals sparking one of the most significant policy victories for the artistic community. 


\section{CHAPTER 7: AUSTIN'S PARTICIPATION HINDERING FACTORS}

Extremely rapid development and skyrocketing costs threatening beloved third place arts venues combined with a city government the local artistic community believed took no actions in implementing policies that would allow longstanding music, arts, and culture to survive - especially when the artistic community had already spoken multiple times - were major factors hindering Austin's artistic community's participation in its local government. In this chapter, I explore the negative findings for this case that I had classified as a positive extreme at this dissertation's onset.

Multiple findings in this chapter do a combination of adding to existing scholarship or providing new contexts for that existing scholarship. This chapter has a heavy focus in citizen participation's equity issue, such as how factors including socioeconomic status, occupations, familial status, wealth, and societal privilege affect how well someone participating in traditional government forums will be received, if they are even able to participate at all (Fung, 2006, 2015; Laurian, 2004; Rimmerman, 2011). This also adds credence to some of Arnstein's (1969) criticisms of citizen participation that she saw as ineffective, at best, like surveys and other mechanisms for gathering information — with which governments then do nothing. Additionally, this chapter addresses issues involving the Second Face of Power's "non-decision" exercise, in which not taking action that would benefit a particular group is an exercise in power in

itself (Warner, 2001; Warner, 2011). The Austin findings also move the power dimension scholarship into the Third Face, in which the less powerful withdraw over time because, thanks to constant defeats, it can feel hopeless (Gaventa, 1980; Warner, 2001; Warner, 2011). 
Other findings did not outright contradict existing scholarship, but it did provide new contexts. One major finding involving citizen participation is that citizen participation will never work, no matter how many people come to a public hearing, respond to a survey, or join a citizen board unless the policies crafted from that participation are implemented and implemented well. Scholars have concluded that sustaining participation is difficult (Pridemore, N.E. Ganapati, \& Revell, 2019), but the findings in this chapter show that government inaction after citizens give their time and input is at least one reason why participation levels drop. This chapter addresses instability in the face of rapid social and economic change, but unlike the majority of such studies (Pridemore, N.E. Ganapati, \& Revell, 2019; Simeonova, 2005), it focuses on a city in the United States.

The findings also point to a new element of social construction theory (Schneider \& Ingram, 1993) — place. How the public at-large views a place, for better or worse, will determine whether or not policies will work in the place's favor, as it does for certain target populations (Schneider \& Ingram, 1993). Trust is a major factor in this chapter, but more of its focus on trust involves intermediary advocates and if citizens and government officials alike should trust them, rather than issues of citizens trusting government (Pridemore, N.E. Ganapati, \& Revell, 2019). Findings in this chapter also provide a new angle for organizational culture studies (Shafritz, Ott, \& Jang, 2011) because, in citizen participation, policymakers must consider both formal and informal methods of operation that those they want to engage will use. If it is a polar opposite, as it is with the free-form oriented artistic community versus the traditionally hierarchal bureaucracy (Taylor, 2011 [1916]; Weber, 2011 [1922]), this will require both understanding and adjustment for all 
parties. In terms of arts policy, this chapter provides a different angle in that it shows artistic community preferences for private sector-oriented policy approaches that would create better market conditions (Currid, 2007) instead of traditional arts policy studies that have focused on the nonprofit sector (Rushton, 2013).

The chapter's structure is as follows. First, I will discuss traditional citizen participation's barriers which namely include government inaction after citizen participation initiatives, extremely long meetings, and leadership gaps from long department head vacancies in a rapidly changing city. Afterward, I will discuss the institutional-related factors of "Austin Exceptionalism" — the city presenting itself as a progressive beacon when that it not necessarily the case — and the fact that some people get too comfortable with institutions and do not realize they can fall. Next, I will discuss place-related factors that namely include the social construction of place, like beloved or reviled entertainment districts, as well as transportation issues that involve expensive and limited parking.

Hindering factors from other community stakeholders will follow, and the main aspect of this deals with the attempts to temper longstanding entertainment zones and the very related tension from rapid development and rising property values. It also takes into account some of the negative issues surrounding the literally hundreds of arts nonprofits in Austin, namely several interviewees' belief that there are just too many nonprofits. Then, I will discuss hindering factors involving artistic communities, such as their constantly working because of the affordability crisis and resentment from being an economic recruitment tool for the city while living in dire conditions. I will then discuss factors hindering non-traditional outlaw citizenship in Austin, such as not enough of a 
focus on local issues and how outlaw citizenship displays, especially in this current environment, attract outside agitators that can ruin these participation efforts.

\section{Hindering Factors Related to Traditional Participation}

Traditional citizen participation presented numerous barriers for Austin's artistic community. Through my interviews, observations, and secondary source reviews, I found that public meetings were especially problematic. Meetings were conducted often during peak working hours for some artistic community members, and the fact that some meetings were extremely long — seventeen hours for one city council meeting and several meetings lasting past midnight — meant that some people who would want to participate would likely have to leave before they get the chance to speak. This reflected studies involving citizen participation equity, namely in traditional forums (Fung, 2006, 2015; Laurian, 2004; Rimmerman, 2011).

Hindering factors related to public officials namely stemmed from inaction. Artistic community members informed me that government officials taking no action or having policies get stalled and especially when they spent considerable time in participation forums to help craft these stalled policies infuriated them and made them not want to bother with participating again. A second major problem was Austin's yearlong city manager vacancy and multiple department heads in interim positions during the city manager search. Some blamed the inaction on the vacancies, but most believed that the most serious problem related to this was the lack of permanent leaders and related stability in a city that was outright transforming, with tensions being high. 


\section{Barriers related to formal mechanisms}

Formal participation mechanisms in Austin presented numerous participation hindering factors. Namely, artistic community members found city government meeting times inaccessible because of conflicts with some of their peak working hours, and, meeting length was at an extreme. This presented a serious problem with overall participation equity because individuals, particularly ones with more wealth and political power, had the ability to come to these forums and stay until they were heard, even if it were after midnight. For those in the artistic community, this was simply not doable.

\section{Meeting times conflicting with artistic communities' schedules}

Official government meeting times being scheduled at times when artistic community members could rarely attend was a major participation hindering factor in Austin, reflecting Laurian's (2004) work that noted problems with work schedules when citizens try to access formal participation venues. As I will further explore in a subsequent section, the artistic community members having to constantly work to pay the rising rents made coming to a formal meeting practically impossible as it was, but the particular times certain meetings were scheduled especially conflicted with specific parts of artistic community members' schedules, such as musicians' and other performance artists' gigs.

Hermione (musician): I think a lot of meetings taking place in the evening hours are difficult for musicians to attend because if you're a gigging musician, you've probably got a gig at 7 p.m. and you can't go to a 6:30 p.m. meeting. I think that's kind of a difficulty in general, regardless of what time of day it is. People who are freelancing musicians have very unpredictable schedules a lot of the time, depending on sort of how many different gigs or unpredictable schedules a lot of the time, depending on sort of how many different gigs they're doing or how many different groups they're playing with or if they're teaching lessons on top of that, they may be running around the city to different locations. So thinking, "OK, 
can I fit going to this planning meeting between this rehearsal and this lesson and that gig I have later tonight?" I think just the issue of scheduling and the nature of freelancing and just being busy and already having to run over or around so much, especially when it comes to evening hours being the prime hours that musicians are usually working.

Evening meetings, as Hermione noted, were particularly problematic for artistic community members, and namely those in the performing arts who are usually on-stage or preparing to go onstage in the evenings. Musician interviewees, in particular, noted that when city boards and commissions typically meet around 6 p.m., this is right when musicians are doing pre-gig sound checks or unloading their gear at venues. However, artistic community members also found daytime meetings, such as Austin City's Council's regular meetings at 10 a.m., inaccessible as well, namely because many were working jobs inside and outside of the arts during the day to pay the rising living costs in Austin. Angelina, a city elected official, pointed out the problems with both daytime and evening meetings alike, with the latter being especially problematic also for anyone who has children. She indicated that, especially in reaching diverse groups and populations from whom city government has not heard, public forum time structure is a major barrier.

Angelina: In terms of barriers to participation, some of the meetings for either voluntary boards and commissions or city council... Some of those take place during the day, and people have work commitments. Some of those meetings are at night, and people have work commitments then too. ... As a mom, I know it's really challenging to get to a 5 p.m. meeting, 5:30 p.m. meeting, or a 6 p.m. meeting because that's dinner time, right?

We have to think about the timing of those conversations. A lot of important conversations happen during the traditional workday, and that's going to exclude people who don't have the ability at their job to leave for an hour or two to come here and have a conversation. 


\section{Extremely long meetings}

Extremely long meetings were a major participation hindering factor in Austin.

Government meetings lasting for several hours have been a problem numerous local governments have encountered, but ones in Austin have taken meeting length to an extreme. This problem hinders participation because, if anyone can make it to a traditional participation forum, the meetings' length may make it impossible to stay until one's time to speak.

This problem, for Austin, has two major elements — packed agendas, according to secondary sources (Grumet, 2018b) and too many speakers, according to my interviewees. Having too many speakers, they said, ultimately hinders democracy in the end because those who cannot speak because they cannot be at a meeting as long as others can will most likely be from historically disadvantaged groups. On the flipside, the ones who can stay and regularly attend and speak at meetings often have greater personal wealth and time, two elements that are connected.

According to secondary sources and interviewees, late-night, all-night, and marathon meetings in Austin city government are prevalent and problematic. I mentioned the eight-hour New Orleans public hearing to Albus, an advocate for the artistic community and former member of city boards and commissions in Austin. This was his response:

Albus: So what you mentioned, Amelia... I'm sorry. That's nothing. We have a rule that our boards and commissions have to pass a motion at $10 \mathrm{p} . \mathrm{m}$. in order to continue and that's because of how routinely meetings were going past midnight. ... I've had meetings I chaired when I was on a city commission that started at 6 p.m. that ended after midnight. That's just when we were really making some major changes. But the city council... I think it was an all-night city council meeting when they were taking testimony on a controversial development project, 
and people were just there because they take everybody at three minutes, and they had however many people would take ten hours to talk or whatnot.

In May 2018, an Austin City Council meeting with a 90-item agenda lasted for seventeen hours - from 10 a.m. and ending at 3 a.m. (Hernandez, 2018). However, secondary sources and interviewees noted this problem was both frequent and longstanding. An Austin American-Statesman editorial noted that "barn-burner" meetings were commonplace at a time when critical issues are constantly arising in the changing city and when citizen input is needed (Grumet, 2018b).

Bleary-eyed council members cast important votes while most of the city sleeps, and civic engagement suffers because who can commit that kind of time to being involved?

Austin faces many challenging problems. This shouldn't be one of them (Grumet, 2018b).

Both secondary sources and interviewees indicated the city has constantly worked to shorten meetings, through such measures as having single hearings for especially controversial issues that bring out numerous speakers (Grumet, 2018b) as well as limiting speakers' times. Grumet (2018b) indicates that, for city council in particular, a major problem is that some agendas are stacked with too many items. From May 2017 to May 2018, the meetings that ran past 10 p.m. averaged ninety-eight items per agenda, compared to the overall average of seventy-nine. To make matters worse, these long meetings meant that major discussions were being pushed to extremely late hours, like a debate about rentable scooters starting after midnight and a "critical" discussion about CodeNext, a significant policy piece that could result in a major overhaul in city land use code, going from 2-3 a.m. (Grumet, 2018b). 
Albus said the end result of the meetings being so long is that those from historically disadvantaged groups are the least likely to be heard and the speaker diversity suffers. The long meetings are a problem that city officials, both elected and those appointed to boards and commissions have constantly worked to solve, such as limiting speakers' time, limiting the time even more for subsequent speakers, and allowing speakers to donate time to others to both shorten the number of speakers and avoid repetition.

Albus: It wasn't any effort to close down democracy or anything. It was trying to shorten meetings because it's not democratic if you draw out meetings for a long time, and then the single mom who has to get up early to go to work the next day can't participate. That's not democratic.

...If you talk to a lot of people who have served on different boards and the city council members, you tend to see the same people all the time. There are a core number of civic activists who come to a lot of meetings and speak up at a lot of the meetings. A lot of them are there. I mean, all of them are probably goodhearted, and they think they have the right intent, but they have the luxury, the leisure time. They're now retired. Their spouse makes a lot of money, and they don't. They can spend all their time advocating and lobbying.

The combination of packed agendas and long meetings created a challenge in that meetings, particularly the city council which makes decisions on all areas of city policy instead of the boards' and commissions' specialty areas, had several (if not numerous) items on agendas that were of no concern for artistic community members. They would then have to wait through these other items, which had multiple speakers of their own. The meetings, overall, had little relevance for them and gave them little incentive to attend.

Hermione: We are just so busy, already. Then, it's like, "OK, fitting in this twohour meeting, but who knows if anything is really going to come out of it or what?" ... Then, are they going to be covering all of these other things that maybe 
aren't relevant to me, and I'm going to sit through this two-hour meeting and maybe only fifteen minutes of it is the part I actually care about.

Penelope, a journalist, said that city board and commission meetings, like the city's arts commission and music commission, will not run nearly as long as city council, but they have run late, lasting for three hours or longer on a few nights. Even though three hours is much shorter than seventeen hours, that is still an incredibly long time for people with crammed schedules, and because the boards and commissions typically meet in the evenings, this is hard for artistic community members with gigs and, like Angelina noted, those raising children. This becomes even more challenging because, as Grumet (2018b) noted above, Austin is rapidly changing citywide and in all areas of city policy.

This means there will be deeply interested parties for any given issue.

Penelope: A lot of people don't even realize how long they go, and then they'll show up and be like, "Oh, nevermind." So I think that does discriminate against people who want to participate, while it's also like, "Well, what can you do?" Austin is a huge city. It's got a lot of problems now. ... I just can't imagine how you could get everyone's voices in. It's tough.

\section{Cancelled meetings}

Some interviewees also noted that board and commission meeting cancellations were another major problem. Interviewees indicated this was a problem because even the volunteer boards had trouble with balancing out their professional schedules with the meetings, especially if they were also simultaneously working artistic community members.

Although my review of meeting documents did not turn up many meeting cancellations, interviewees indicated even just a few created long-term participation 
problems. Besides the city literally not having its scheduled forum for someone to be heard, artistic community members carving out the time to attend a meeting all for it to be cancelled discouraged artistic community members from trying to participate again. Furthermore, this exacerbated the problem of long meetings because, when the boards and commissions did meet again, they would be working on items from cancelled meetings on top of the regularly scheduled ones. This happening with special boards and commissions had an additional problem. Some people in the artistic community, interviewees said, would be automatically attracted to a commission specializing in their interest area over a governing body that was all-encompassing. So interest could be much higher all for it to be shut down because of a cancelled meeting.

The Austin Music Commission had two meeting cancellations in 2017 and two more in 2018, according to city documents (City of Austin, 2017b, 2017c; City of Austin, 2018e, 2018f). One of the two music commission meeting cancellations for 2018 was a joint meeting of the city's music and arts commissions, and this was the only cancellation I found for the arts commission during this two-year period. Lack of quorum was the reason why all four were cancelled. Two music commission meetings were cancelled because five commissioners attended, while six were absent. Another was cancelled because five were present and five were absent. For the cancelled August 2018 joint meeting of the music and arts commissions, four music commissioners were present, but seven were absent. The city document announcing the meeting's cancellation did not indicate which arts commissioners were present and which were absent (City of Austin, 2018f). One of the cancelled music commission meetings was my own first time that I had come out for an Austin city forum. 
Penelope indicated that, with the music commission, she has seen meeting cancellations being a more frequent problem over late or extremely long meetings. She personally found the work that the music commission did very engaging and exciting, but cancellations due to slightly more than half of the board being absent was discouraging.

Penelope: The music commission... I saw the music commission meetings get cancelled more than I saw it actually have a long meeting. It's hard for them to get everybody there.

\section{Meeting intimidation}

Another hindering factor related to formal mechanisms was that some artistic community members, particularly younger or poorer ones, found traditional government forums intimidating, reflecting Rimmerman's (2011) work involving how social position and privilege makes traditional participation less intimidating, and vice versa. This was especially true when other speakers, particularly when those speakers were on the opposite side of a policy debate, were wealthier and, because of a greater ability to attend these meetings, more well-versed at speaking at public hearings and addressing public officials. What made some of these forums even more intimidating was confusion related to sign-in procedures and, possibly, technology used at some of the meetings.

Padma, an advocate for the artistic community, noted that some people are just more introverted by nature, and that, by virtue of human nature, they are nervous about public speaking. What makes this situation go beyond that and into a deeper examination of equity in participation, though, is the wealth and power imbalances between some artistic community members and those who typically and frequently show up at meetings.

Padma: There's a real power difference there. If you've got two sides at the table, and one side is a bunch of people who are not necessarily wealthy but well-off enough to be retired and who own their own homes, and the other side of the table 
is people who are just starting out in their careers who are passionate but aren't necessarily eloquent, experienced, or polished... You've got a real power differential before anyone opens their mouths.

Particular setups in the city's official meeting rooms could also be intimidating, especially for a more introverted person. During a music commission meeting, I noted that the city hall meeting room displayed anyone speaking on multiple large screens. While this helped me, as an observer, clearly see who was speaking and with that person clearly identified, I questioned how being displayed on all of those monitors may exacerbate someone's trepidation about participating and quite possibly make them change their minds. The city council chambers showed an even greater hierarchal physical structure in the meeting rooms. While the music commissioners and speakers were seated at a table and at the same height as everyone else in the room, the city council chambers had council members seated on a stage situated well above anyone else in the room, including speakers. It also had about twice as many monitor displays that showed close-ups of those speaking.

Photos of the city council chamber setup from both council's and spectators' views are shown in Figures 7.1, 7.2, and 7.3 below. I have marked the speaker podiums with pink boxes to show the height difference between where council members are seated and where speakers stand while addressing them. 
Figure 7.1: Elevated Austin city council seats (Rodrigues, 2015)

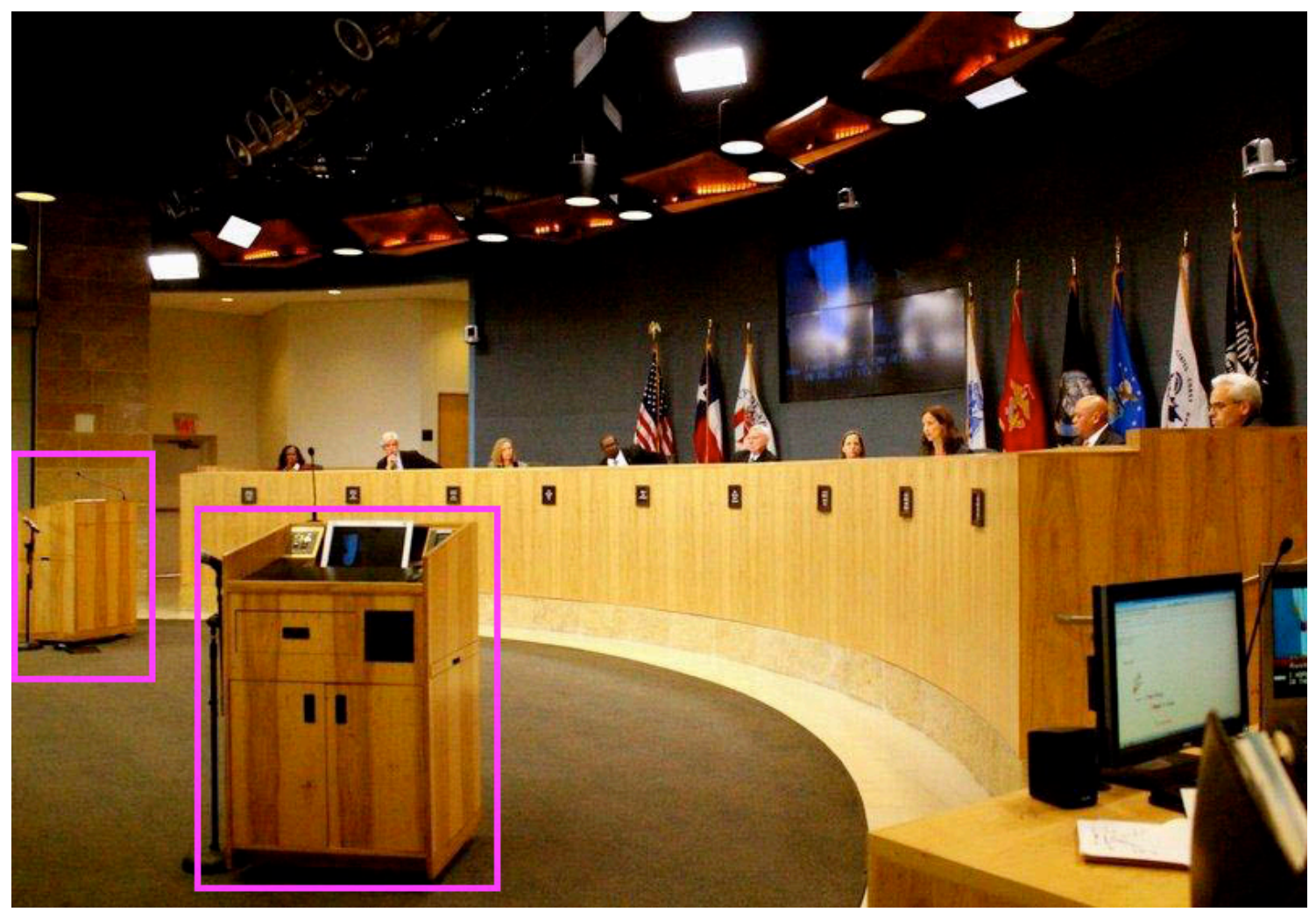

Figure 7.2: Elevated Austin city council seats (back view) (Unknown Photographer, 2015)

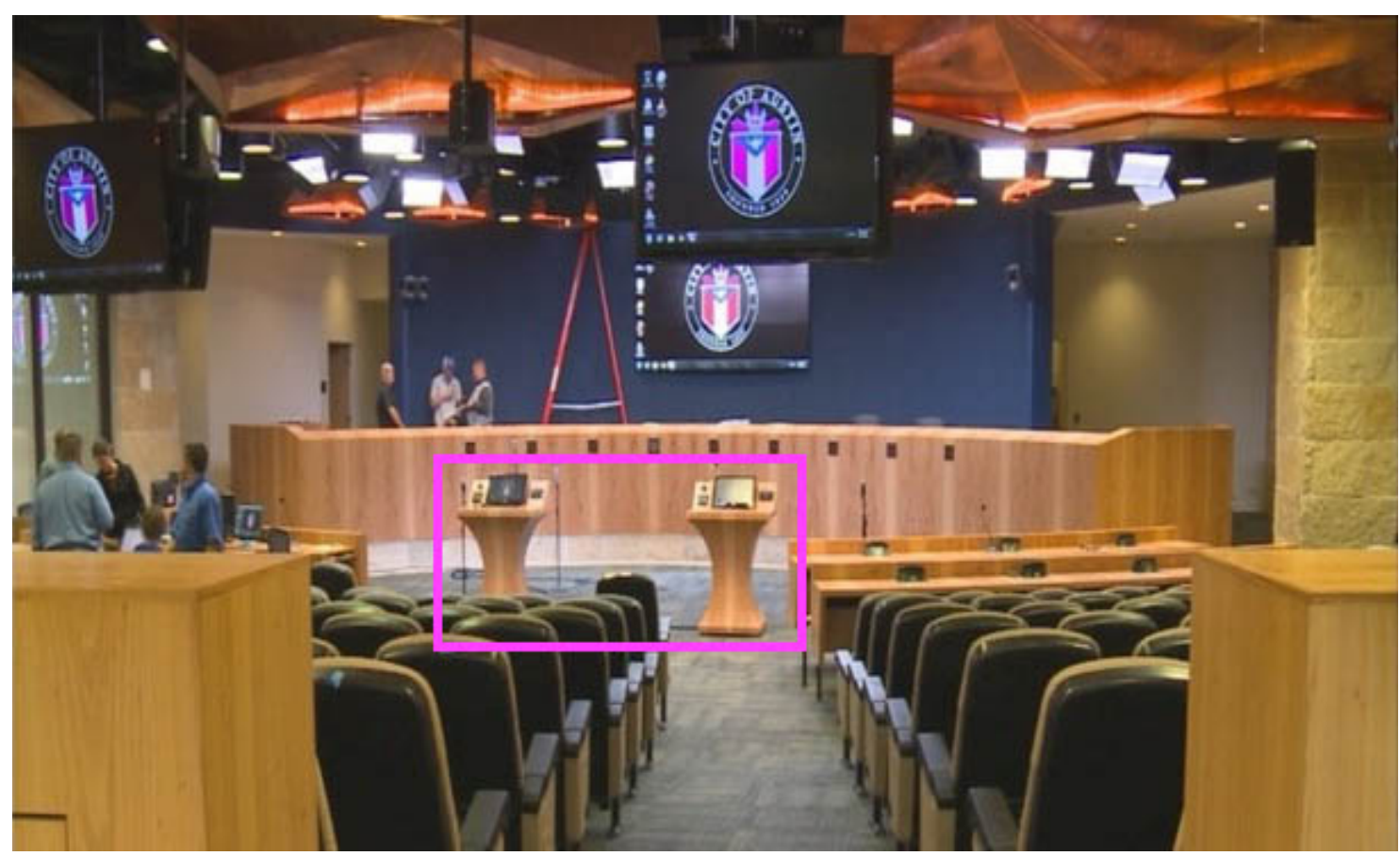


Figure 7.3: Elevated Austin city council seats (council view) (Rodrigues, 2014)

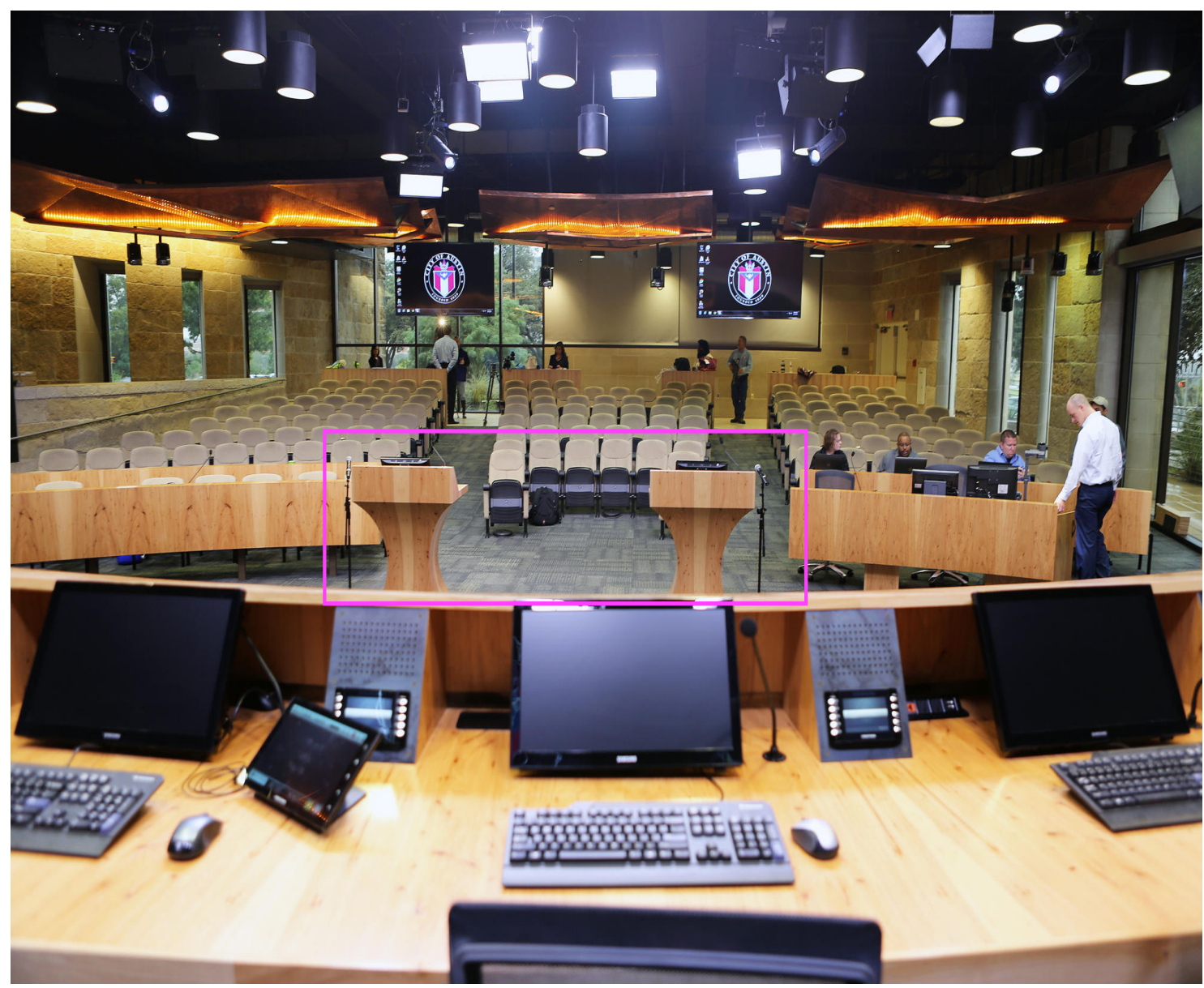

\section{Barriers related to public officials}

Barriers related to public officials namely involved inaction. Artistic community members were infuriated when policies that would aid their situations were stalled or, after they spent sometimes considerable time participating in policymaking forums, the policies recommended would go nowhere. This reflected the "non-decision" aspect of the Second Face of Power, in which those with ability to make change benefitting the less powerful do nothing, as an exercise of power, itself. Another major factor was the long city manager vacancy, during which multiple department heads with major dealings with the artistic community were in the interim. Beside the general uncertainty that new 
leadership brings, a few interviewees believed the inaction came from the vacancy issue and a city manager search that was viewed as bizarre, at best, did not help matters of public trust.

\section{Inaction}

One of the most frustrating points that artistic community members had with public officials was real and perceived government inaction - especially when city government took little to no action from major citizen participation initiatives and little to no action on policies that could help the artistic community. Some of those policies that presently remain in limbo even after years pass are ones that resulted from citizen participation efforts, as well. This hindered participation because the artistic community members believed, and with concrete proof sometimes, that participation was fruitless because city government would do nothing, no matter how much they contributed. This was especially frustrating for people who had already participated before, especially if that past participation was something that took a considerable amount of time, like being a task force or working group member. Interviewees considered future participation fruitless because of all the times this had happened before to either themselves or friends who passed the word along.

Artistic community members found this particularly frustrating or even insulting when city officials would publicly state — sometimes, with great fanfare — that they wanted to help Austin's musicians and artists for city officials to do nothing in the end. This not only made them far less likely to participate again but it also sowed even more discontent when, as interviewees indicated, city officials took no action at all and later asked for input on the same problems repeatedly. 


\section{Inaction after citizen participation initiatives}

Interviewees told me that when inaction continued even when they had given input, it was especially infuriating. One example that multiple interviewees pointed out was the Austin Music Census (formal name: The ATX Music Industry Census and Needs Assessment) released in 2015. While my interviewees, even the ones who were disenchanted with the end result, did not view the census and its undertaking as a negative even now, they still believed that it and participation efforts like it that ultimately led to nothing made artistic community members less willing to participate.

The initiative from the city's Music and Entertainment Division of its economic development department was done to establish a "current baseline" of the city's overall music industry and the people working in it that would "enable policymakers to formulate effective policies for future growth" (City of Austin, 2015, p. 6). The census had two main goals. The first was creating a "comprehensive inventory" of the city's music industry through "three main private-sector categories: live music venues, individual musicians, and music industry workers." (p. 6). Information gathered included demographics as well as answers for a "broad series of questions about how they earn income, what they thought was going well in Austin, and what could be better for themselves and in Austin's music industry, generally”. The second goal was to analyze the census' data to "assess key needs and gaps" and proposing "next steps and key criteria to assist city of Austin policymakers in identifying economic development opportunities."

Stith and Blackstock (2017) wrote that the “census argues that Austin's music industry cannot continue to grow — and in fact, may retract - without a comprehensive 
long-term economic development strategy". Major problems the census found included more than eighty percent of respondents saying that stagnating pay made it "difficult to make a viable income", and the city's issues with declining affordability and rising costs of living compounding the problem even more (City of Austin, 2015). Sixty percent of all respondents were working two or more jobs, both inside and outside the music industry (p. 6), and nearly one-third of musician respondents were living on $\$ 15,000$ or less per year when counting income from all sources (p. 24) It noted:

Musicians and music industry workers are paying more for rent, mortgages, property taxes, and other costs of living. Downtown development of relatively expensive condos and apartments are pushing low- and middle-income artists and industry workers further out of the central city core. There is some indication that musicians are beginning to move out of Austin altogether due to the cumulative effect of affordability issues (City of Austin, 2015).

Besides painting a grim situation for those in the Austin music industry, the Austin Music Census simultaneously showed both frustration with parts of city government and also, at the time, a strong willingness for those in the music industry to participate in the policymaking process. The frustrations included sixty-one percent of venue respondents finding it extremely to moderately difficult to communicate with the proper city officials, and sixty-two percent of venue operator respondents stating "inconsistent information and enforcement" from the city police department regarding the local sound ordinance had an "extreme/strong or moderate" impact on their business (City of Austin, 2015, p. 10-11). However, the census' response showed that, at least at the time, those in Austin's music industry wanted to be a part of creating more conducive policies. The survey garnered nearly four thousand respondents, plus eight focus groups 
and twenty interviews (p. 5). Sixty percent of the music census' respondents were musicians, with the final report stating:

"...it is evident that Austin musicians are very focused on the state of the music economy in Austin. They are eager to articulate the reality of being a working musician in Austin and discuss improvements that can be made as a community" (City of Austin, 2015, p. 20).

Likewise, the city also put forward a desire to listen, then. The report stated that one justification for doing the study — that the city paid Titan Music Group, a music industry oriented economic development and public policy consulting firm, $\$ 45,000$ to do (City of Austin, 2015; Stith \& Blackstock, 2017) — was to improve the Music and Entertainment Division's understanding of the different subsets of "music industry innovators and their needs for future growth of jobs, salaries, and revenues" (City of Austin, 2015, p. 5). Another reason stated in the report was:

Perhaps even more important is that the Austin Music Census was commissioned because of a strong desire to listen to the public, and to find ideas and best practices to provide best-in-class services to the Austin music industry based on a holistic, broad-based view of its participants (City of Austin, 2015, p. 5).

Interviewees that included musicians and journalists, though, pointed out that the city's musicians have yet to truly see any benefit from their participation. The census, according to city government interviewees, led to changes such as a restructuring of the Music and Entertainment Division to better serve its target population and, according to interviews with city officials, journalists, and secondary sources, policy proposals that can alleviate many of these situations once passed. Those measures, to be discussed later in this chapter and in the following chapter alike, though, are ones that the musicians and greater artistic community either know are stalled or, more importantly, are ones that are 
not seen as tangible benefits that directly improve their situations. Furthermore, because developers in the city are moving so quickly — bringing drastically rising rents and property taxes at the same pace - some interviewees believed that any meaningful policy change would come too late. This situation reflected previous work involving the Third Face of Power because, in this dimension, the less powerful constantly being on the receiving and losing end of others' power exercises make the less powerful withdraw over time and because of a sense of powerlessness against those who exercise power over them repeatedly (Gaventa, 1980; Warner, 2001; Warner, 2011). This made many in the artistic community see their past efforts as futile and not want to participate again. 
The narrative map below in Figure 7.4 is from Percy, a musician.

Figure 7.4: Narrative Map (Reality): Percy, Austin musician
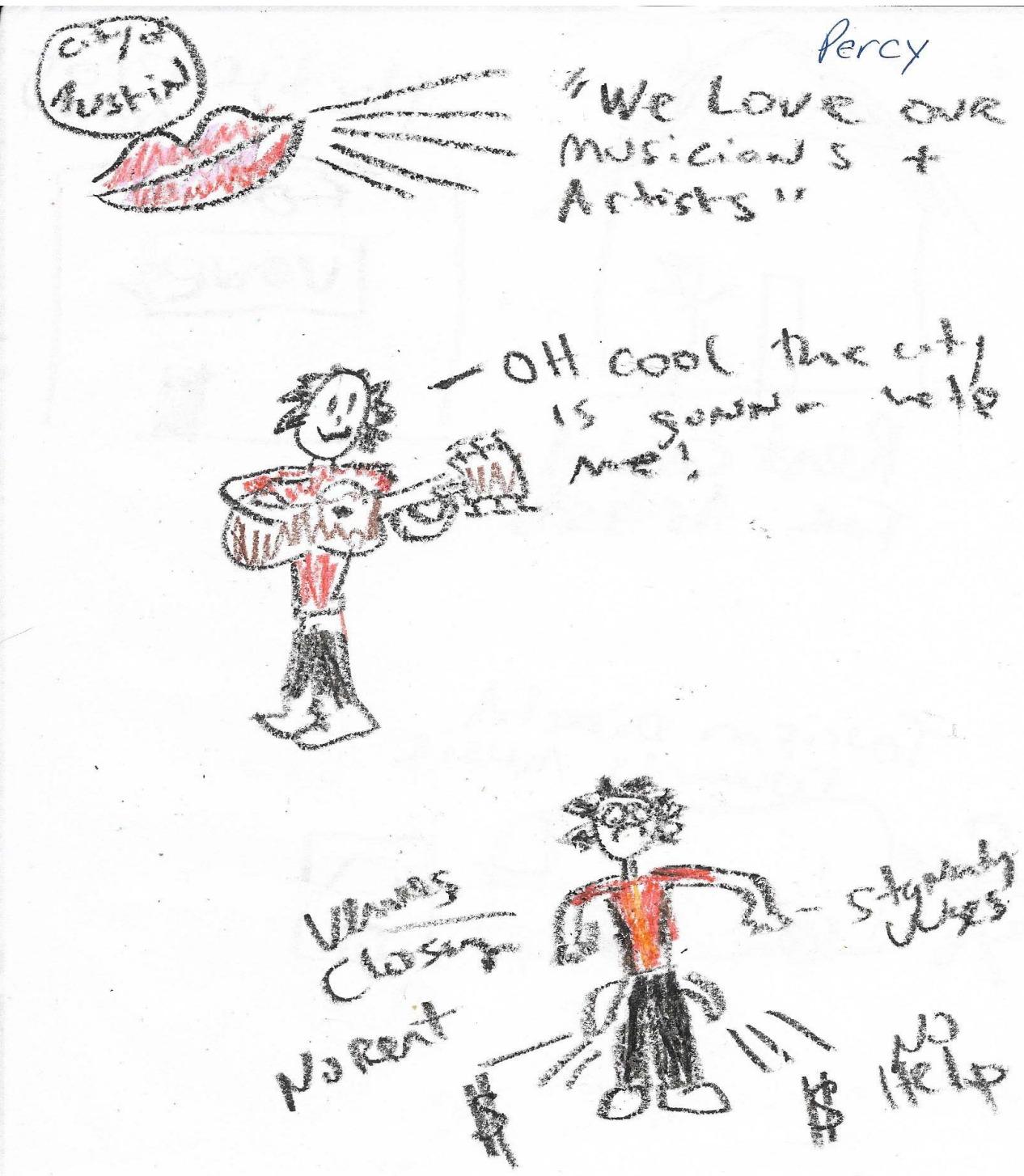

Percy explained that his drawing represents the city providing lip service, as represented at the top, that takes the form of government officials' repeated statements that its musicians and artists are such a critical part of the city's culture and economy and the government's pledges to help them. The musician in the center, he explained, hears this and becomes hopeful that his situation will change for the better. In the end, though, 
this musician (like so many others in Austin's artistic community) is still in a terrible situation, namely in that his earnings are not covering the skyrocketing residential rents, the venues where he performs are closing because they cannot afford the skyrocketing commercial rents or property taxes, and he has no help. He explained that when musicians and artists are let down like this, especially after they have been pumped up and taken sometimes considerable time to provide input, they will not want to take that time out again.

Percy: It used to just seem like the city didn't care. City officials really didn't say much about music, and then, for the last three or four years, there has been a lot of lip service. The city will say, "If we lose our musicians, we lose our culture, and we need to do things to support them." It gets the musicians excited and involved. And then after, I'd say the amount of time that the average musician or venue owner remains involved will be about a year before it has completely drained their give a shit.

...People find the time, and then, they just get disillusioned. I've watched it over and over. Crops of people will say, "We're getting more organized, and we're going to go to all these meetings." They go to the meetings for about a year, and then realize that it's a huge fucking fuck-around. It's a waste of their time. It's just a bunch of people paying them lip service, and then they lose faith. They stop doing it, and they're like, "I'm not going to this anymore."

Percy said that the music census, itself, was not a negative, and he believed that, despite the end result, it did not do more harm than good. The census, he said, provided city employees and elected officials with "all the information they could possibly want" about the music community's needs and suggestions as to how they could address them. The problem was that the city did not implement solutions. He further said:

Percy: There are people who are doing stuff, but the city, as a unit, has no track record of being able to execute these plans. I mean, in 2015, we put out the Austin Music Census. When that came out, everyone (in the music community) was like, "Yeah, we already know this stuff." It still needed to be done because the politicians needed to see it. Musicians already knew everything that was on that. 
They were the respondents. But it was stuff all of us already knew. The census needed to be a roadmap for the city to develop policy. Well, zero aspects of that policy have come to fruition in a positive way. Literally, zero. They tried to do an entertainment license thing that was going to streamline the process and suck up less of a venue owner's time. It backfired so badly. It was written so poorly and almost, like, litigiously, the community was like, "Fuck this. We don't want this. Forget about it."

Interviewees said other initiatives such as surveys, working groups, and stakeholder meetings of any kind seemed to not only fail to create meaningful policy change, but they seemed to be carbon copies of initiatives done before. Helena, a city boards/commissions member, said Austin's quality of life studies focusing on its black citizens are constant repeats. During an observation at a stakeholder meeting where the city was working to get input before changing special event procedures, a woman in attendance loudly told a city official how these meetings were repeats of past efforts in that area. Nymphadora, a film festival organizer with past experience in the public sector, understood the various limitations that those in the civil service face and that procedures and policymaking often take time. At the same time, though, she understood how it would feel for a citizen being repeatedly asked to take the time to give the same input.

Nymphadora: I see both sides. Honestly, if I had been to a bunch of those meetings before and just kept hearing the same thing and the tiers were exactly the same as they've been, I would have been really frustrated as well. Nothing is worse than when someone asks you for your opinion, you say it, and you're like, "Yeah, I did it", for you to step away and have them ask for your opinion again however long later. You're like, "You've already got it!" And you say it again. And they treat it like new information. ... It's, inherently, a really frustrating process.

When examining one city policy area affecting the artistic community and especially minorities and the poor, these assertions from interviewees that citizen input 
efforts go nowhere do have some more concrete backing. The Office of the City Auditor released a special report in January 2018 on Austin city government's efforts to address displacement and gentrification (City of Austin, 2018b). The office identified 541 recommendations and resolutions issued between 2000 and August 2017 related to displacement and gentrification. Once this inventory was compiled, the auditor's office then deemed 133 of those measures "actionable" and having a potential "direct effect" (p. 1). Only fifty-six of the 133 measures were "presumed implemented or reported as implemented" as of January 2018.

One of the more troublesome aspects, though, was that the status of the remaining seventy-three direct and actionable recommendations and resolutions was unknown at the time of the report (City of Austin, 2018b). Of those original 541 recommendations and resolutions, ninety-seven came from task forces, eighty-eight came from community reports, and seventy-seven came from city commissions (generally comprised of citizen members). Judging from these numbers, at least forty-eight percent of these measures came from citizen participation. A key problem the report identified was that "many recommendations are not currently tracked" (p. 1). Furthermore, any measures other than city council resolutions were the ones that were the most difficult to find. It further read: “...based on conversations with city management, staff, and other stakeholders, it appears that there is not a system in place to make this determination or to otherwise track the status of recommendations directed to city council.'

"Additionally, while city council resolutions are easy to locate and review online, the city has not historically shared the actions that have been taken in response to city council resolutions in an easy to access, public format. Without information on city efforts to address council resolutions, task forces and other bodies may repeat analysis and recommendations for actions that have already been requested of city management" (City of Austin, 2018b, p. 6). 
Lily, an advocate who has experience in local government management, said that these recommended solutions not being implemented is wearing down the artistic community.

Lily: The individual city council members do a lot of resolutions and have these resolutions that say, "Be it resolved, such and such issue, and we want the city manager to look into it." Well, those never circulate back to city council, where the staff has looked into the issue or they set up... "We're going to have a task force, and the task force is going to recommend changes," or "We want to do this type of program." And yet, those things in the space of time in the few years that I've been here, I have not always... Things kind of get lost or they end up not implementing the changes that were suggested by the task force. So you really have to push.

...At least from my standpoint, the arts community is learning how to be more politically active, and that's something they're learning on their own. I think they have been in the past. But I think now that they see that there are so many issues with the fact that venues are going away. There was an art gallery and kind of event space that just lost their lease, you know? And every day, there are those types of things happening.

I think now that the expensive housing and the combination of those two things have put such pressure on the arts communities that they have... They, over the last few years, have said, "We really have to get in this game." I think some of them feel frustrated because they feel as if they are not... The council members may be hearing them, but the solutions are not getting implemented, or the request to do something is not being answered the way it should be.

A combination of not really knowing what to do to help the artistic community and the city not brave enough to challenge powerful real estate and development interests (to be discussed later in this chapter), Percy said, often leads to a combination of both repeated participation efforts that seemingly go nowhere and people who work hard to advocate for policies that would help the artistic community burning out and giving up.

Percy: I think what it is... They see the value. They see the cultural value in music and arts, and they know how to make working groups, which is something 
you hear a lot in the city. "Oh, let's get a working group to discuss this." It's like we're the fucking working group capital of the world at this point. You know, it's the creative working group capital of the world, but they don't know how to turn it into policy that benefits musicians in the music industry.

...When we talk about leadership, I think more about the leadership amongst people who are able to pay people to spend their fucking time to fight for music at a political level. We've seen a lot of those people rotate too, man. It's the nonprofits. They're important too because the musicians can't be in there fighting for themselves. All the people who wanted to have tried, and it's a fool's errand. There are nonprofit advocates who are doing a good job. But now, there are so many problems. I just don't see how it will work. Someone needs to do something drastic.

I consider Mayor (Steve) Adler a friend, but I also think he is a real estate-minded person who presents to care about the arts, and maybe he does care about the arts, but knows better how to care about real estate and stuff like that.

What compounds the frustration even more is when interviewees have come prepared with their own proposed concrete policy solutions, often doing research into other cities that have done these successfully. This also comes at a time when developers, rent hikes, and property tax hikes are moving at the opposite speed of city government outright warp speed - managing to threaten, financially cripple, or even close spaces like performance venues and galleries before policy can be enacted to stop this.

Luna, a local theater company member, was operating without a space after her organization was one of multiple theaters and art galleries that lost thousands of square feet in space after a major rent hike. A core principle of her organization and others like it in Austin was keeping shows affordable, and, therefore, they did not want to hike ticket prices to the point where shows were financially inaccessible for many, if not most, citizens to balance their own costs. They asked the city for help in finding a policy 
oriented solution, emphasizing this benefit of greater public access to culture - but they

were still waiting, still working without a space, and still trying to find one.

Luna: Maybe the great answer hasn't been found. It might just be that much. I know, on the part of my company, we have pitched ways we would like to help. We've suggested things like, "If you could give us access to a city owned property for a short- or long-term lease so that we can continue to manage a space with the same values that we used to manage our old one. We're ready." I don't know if that's offering a complication or a solution, but we feel strongly that it would be a benefit. I think there is a lot of good will and desire to find solutions, but I don't think we've nailed it.

...I've had many meetings where I thought we had something. And we still don't have a space.

Percy noted proposed solutions regarding the music venues and individual

musicians but how development's speed and skyrocketing expenses from development were making policy solutions come too-little-too-late.

Percy: Half of it needs to be hands-off. Don't hassle the venues. The venues are a revenue stream for musicians. So part of that is hands-off, and the other half is hands-on. You've got to do things to create more opportunities for musicians. And the city just doesn't know how to do those things. They don't know how to pass them.

...There's a bar where I work a lot... They just got hit with property taxes that more than doubled, going from around $\$ 400,000$ to a million. It's very popular. They do well. But no one can... They rent, but they're responsible for a portion of the property taxes. Nobody wants to see that stuff jump up.

So I'm connecting the owners, who are people who would never want to meet with city officials, with the music and entertainment division, another person from the city, and then, someone from a nonprofit that helps venues. I'm getting everybody at the table. I'm just doing it to help people out and to mediate, kind of, between parties that wouldn't normally sit down next to each other. So, at least they're taking the time to sit down, but all they're going to do is sit down and be like, "We know this is fucked up. We want to listen to you." It'll make the venue owner feel better that they're being listened to, but then, at best, they can expect change years down the road. 
Amelia: And how is that going to help when they have a million-dollar tax bill right now?

Percy: Right.

Severus, another arts community advocate, noted the artistic community knows the situation is critical and something must be done. He, like some of the others above mentioned, feared that any participation would shrink or even end because of the ongoing inaction. He also pointed to the artistic community's and his own frustration with activities like studies, as well as grand announcements from government officials that they were going to help the artistic community with no action to follow. Some of these grand announcements, he said, led many in the artistic community to continually believe the city would do something to help them when the city would not. That, he said, needed to end, and real, concrete policy needed to be put in place.

Severus: Engagement from the arts community is really high right now because we have been in a literal crisis. It's not made up. There have been times in the past where advocates, particularly for music, were sort of like we're crying wolf. This is real at this point. It's incredibly hard to be an artist in Austin versus a decade ago or even five years ago. So engagement is really up.

My worry is that, yeah, they show up at all these meetings, but then they don't see anything substantive happening. There's a lot of firestorm and drawing and bullshit and talk, but no actual programs. ... It's a labyrinth of bullshit from both elected and unelected city staff.

...It's time to do something. The time for studies is over. So fuck Steve Adler. He is the main reason people feel this way because he's the one going to every damn music advocacy event. ... He's going to get up there, and he's going to shake hands and tell everybody, "We're on your side, live music. It's so important to the city." Nobody in the room is going to have the balls to say, "Dude, it's been three years now, and you haven't done anything." 


\section{Stalled Policies}

Another point of contention related to inaction was stalled policies. In some cases, city officials did craft policy that could help the artistic community, particularly as it faced continued economic and social tensions from new development, and those tensions spilled into the public policy realm (The development tensions will be discussed in far more detail in a subsequent section.). Several of these efforts were the result of citizen participation efforts. The problem, there, was that those policies remained stalled for multiple years. This hurt present and future participation because the prolonged and stalled processes to enact policies stemming from early participation efforts made the artistic community believe, again, that their efforts were fruitless and that nothing would be done if they participated again.

One specific stalled policy proposal that interviewees that included city and state government officials, advocates, and journalists all pointed to and pointed to often was "Agent of Change". Agent of Change is essentially a principle of, "Who was here first?" (Curtin, 2018; Personal Communication, 2017, 2018; Swiatecki, 2018). If someone wanted to build or open a business or residential complex that was seemingly incompatible with the existing immediate area — such as hotels or condos being built next door to outdoor live music venues - the new person would be both be informed that something that could be disturbing is within very close proximity and this person would also be required to take these considerations into account with construction, such as making sure the building is soundproofed. Agent of Change also works in reverse. If someone decided to open a business such as a live music venue next to a residential area, they would have to understand that the homes were there first and that they had to 
mitigate their noise, namely through above-mentioned building practices like soundproofing.

Advocates for the music community also wanted to add provisions to Agent of Change that would make the new entity wave its rights to "complain of noise kept within the city's decibel limits" (as cited in Stith \& Findell, 2017). As I will explain in a later section, both situations, residential and hotel development beside live music venues and live music venues opening near residential areas, are major parts of Austin's development-related tension.

Agent of Change has been in effective limbo for about three years, as of 2018 (Curtin, 2018). The proposed policy came its closest, as of this writing, to being enacted in 2017 , but it was pulled before it could go before city council for a vote. The key reasons, according to Percy, and Ron, a journalist, Agent of Change failed then was that the version going before council exempted hotels, one of the biggest sources of complaints against live music venues, and that it did not have the legal teeth that would require the new party to build to mitigate impacts.

Ron: Now, there are people who want to make it so that its, "OK, Mr. Hotel Person, not only do you have to acknowledge that you are moving into an area where music could affect you. You also have to build to that. You have to build in soundproofing so that there's no way that your people are going to call in a nuisance complaint that is going to impact this business negatively." That hasn't happened yet because that's a whole higher standard and layer of expense and rigmarole for the incoming party.

A shitty version of it was being pushed forward by city staff back in June 2017. There was a bunch of outcry of, "If you pass this, it's not going to do anything. It's going to be prescribing penicillin when you've got a broken bone." It wouldn't have prevented legal action. The one that was being pushed through was purely acknowledgement. There were no other teeth to it. There was no building standard required. There was no further shield to these music venues other than the acknowledgement. Well, the acknowledgement could be used in any court 
proceedings, but if you're taking a case like this to litigation, you're talking tens of fucking thousands of dollars to clubs that barely get by on a three-percent margin, so you're probably going to put them out of business anyway.

Percy: The city just botched it. It didn't include hotels, which are the biggest complainers, new hotels complaining about noise. The city was scared. It was written by the economic development division. They're scared shitless of the hotel lobby, and, therefore, that failed.

City officials, themselves, told me that Agent of Change was, as of the time of this fieldwork, still alive but stalled, with Pomona, an economic development office employee saying, "The discussion of Agent of Change has been tabled with no definitive timeline." The present situation with Agent of Change and other stalled policies left some city bureaucracy members in limbo, just as it did with members of the artistic community.

One department that often found its hands tied was the city's police department. Ernie, an Austin police officer, said that the huge influx of new mixed-use development, particularly in downtown Austin, now has residents and businesses side-by-side. This brings challenges in any situation, but this is especially the case in a city where live outdoor entertainment is a major part of day-to-day life. Besides hotels and condos building next to existing outdoor live music venues in locations such as the Red River district, businesses in other parts of the city have wanted to capitalize on this Austin hallmark and have outdoor live music, too. Sometimes, these are in neighborhoods that have been historically residential or at least not live entertainment hotspots. Add the major population boom, as a whole, Ernie said, and the situation calls for multiple policy 
solutions such as Agent of Change and revising the city's noise ordinance. However, these require city council actions, which continues the political limbo.

Ernie: For about eight years and until now, we've pretty much changed and revamped the entire (noise) ordinance because that's when the music and entertainment division came online, as well. We didn't have any ordinances for them. Some of the permitting that they do was not in there. So we had to, within the last six years... Our ordinance has been completely rewritten. Once it's written like that, it's hard to change anything in that ordinance because it has to go through council. It takes a council action to be able to change even a single word in the ordinance. We are going through an ordinance change now. We're writing some ordinances because of all the changes here.

Amelia: Is it a whole new one or just a modification?

Ernie: It's going to be a modification, and it's going to be because of the situations we're finding ourselves in. You've got twenty thousand people that live downtown now, and you have all these bars, and... Well, it's not just downtown. You have every little mom-and-pop shop wanting to have a deck on their back patio and play bands, and it's all over the city.

Seamus, a music venue owner in the Red River district and a musician, also saw the problem of neighborhoods that are not traditionally entertainment areas hosting live outdoor music as a problem too, and he noted a proposed policy that could remedy this, plus other issues involving live music venues who have disputes with neighbors - a zoning designation specifically for live music venues. Currently, the only such land use is for bars and nightclubs that the state provides, Seamus said, and not all bars and nightclubs have live entertainment or have it outdoors. This designation, he said, could both protect existing venues from those who want quiet them and protect more residential areas from those who would disturb them.

Seamus: We've gotten a local lobby group called the Music Venue Alliance that has been created with many of us who are looking to define what a live music venue is simply because the market is so festival-oriented and cultural tourismoriented that anyone who has a freaking taco truck or a bar with a patio can 
suddenly put up a band in front or out back and go, "We're a live music venue." No, there has to be criteria by which one actually qualifies as that.

During an observation at a joint music and arts commission meeting in January 2018, I found that those working on arts and music-related policy in city government are working to have this designation as part of CodeNext. CodeNext is a city initiative to revise land development codes that determine "how land can be used throughout the city — including what can be built, where it can be built, and how much can (and cannot) be built" (City of Austin, n.d.a). CodeNext has been part of city government work to plan for explosive growth and that work began in 2012. The problem with this, Albus said, is that CodeNext, a major multi-policy piece in which music venue designations would be a fraction, at best, faces major opposition from detached single-family home owners who are often wealthier. CodeNext, he said, includes measures to increase population density, which the single-family home owners do not want. CodeNext being stalled is not the only problem. Some citizens are pushing for CodeNext to go to a citywide vote, which means that, should the venue designation be packaged with CodeNext, it could fail in a popular vote.

These stalled policies, particularly Agent of Change, Ernie noted, also tie police officers' hands when it comes to settling noise-related disputes. Ernie pointed to the Westin hotel's nuisance lawsuit against the Nook, a neighboring music venue on Sixth Street. The Nook hosted bands and DJs since opening in 2012, and Westin did not open until 2015 (Curtin, 2017a). Westin filed its lawsuit the following year, which did not end until the two parties reached a settlement on their own in mid-2017 (Findell, 2017d). The photo in Figure 7.5 below of the Nook shows Westin directly in the background. 
Figure 7.5: The Nook, with Westin hotel in the background (Anderson, 2017)

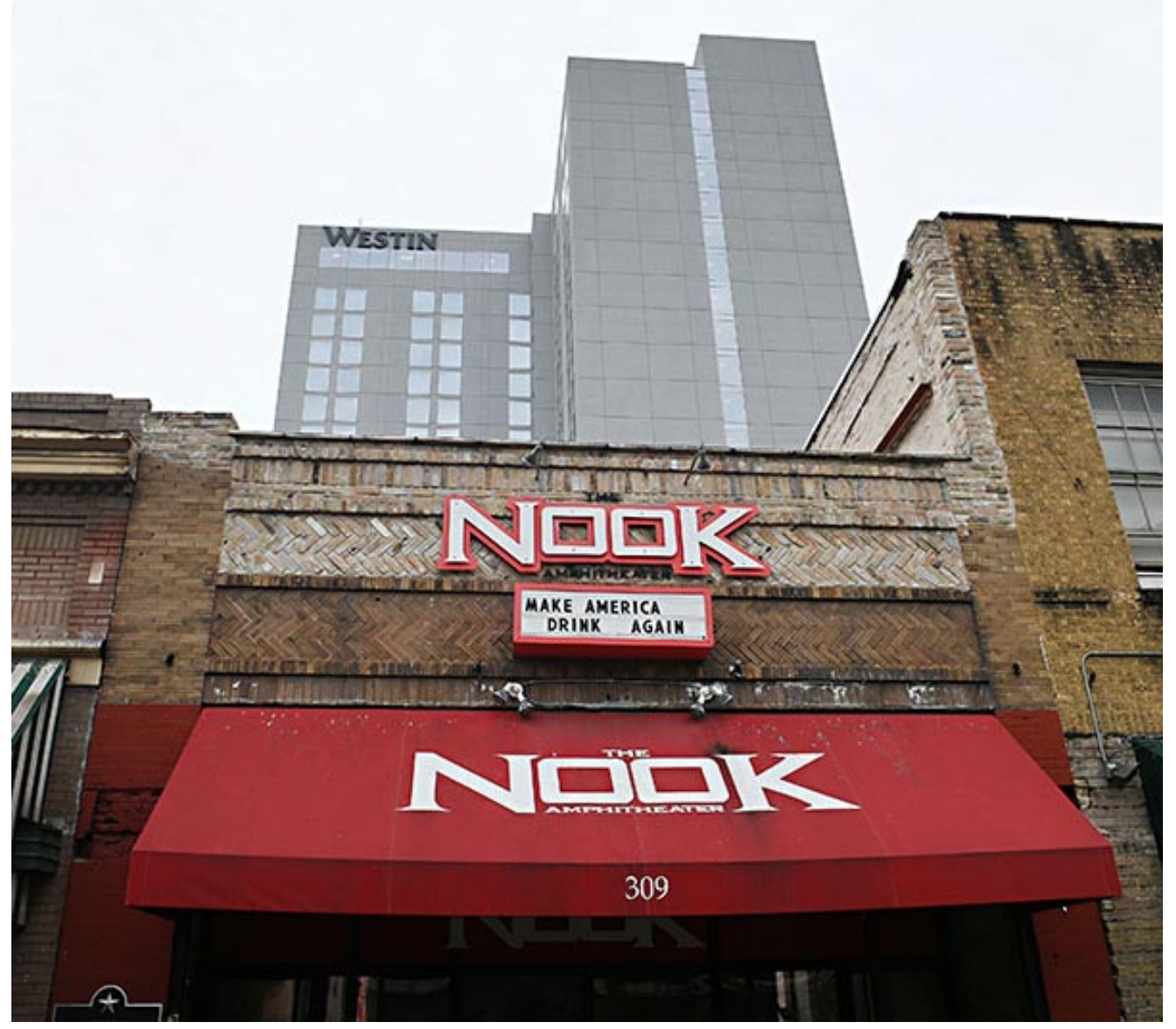

Without new policies like Agent of Change, Ernie said, the police department had its hands tied during the dispute between Westin and the Nook because it only had the existing noise ordinance limits. The Nook was in compliance with those. The situation with Westin and the Nook, though, was just a small example of a major, ongoing, and citywide problem that will not get better unless a solid policy change moves forward.

Ernie: With the Westin and the Nook, we tried to mediate as much as we could, and we just couldn't do any more. It finally got to the point to where they were both just at each other's throats, and for us, it was like, "OK, we're stepping out. This is not a legal issue anymore. This is not a criminal issue. (The Nook) is not breaking the law. I'm sorry you're affected by their noise, but they're within the ordinance. So we stepped out, and they solved it themselves. 
...We've proposed several things - requiring buildings to be built with sound mitigation in it and stuff like that. But again, that has to go through council, and it has to be voted on. The council has to weigh in. It's, "OK are people going to stop building here because we're going to require them to spend more money to build sound mitigation into it? So that kind of got squashed. We moved to Agent of Change to say, "OK, then we'll just make it to where whoever was here first." That's where we're at now.

It is a huge problem. It's a big problem when you have that kind of density and mixed-use. I don't know if there's any real answer to it. ... Agent of Change could take care of this, once we get it done.

Amelia: But it's still in political limbo right now, correct?

Ernie: It is. It is.

\section{City manager vacancy and department heads in the interim}

Another major participation hindering factor was Austin's long city manager vacancy and interim department heads leading multiple city agencies during the city manager search. The lack of permanent position-holders for the city manager and department head positions created or compounded multiple situations. First, there was the general situation involving a rapidly changing city and the uncertainty and anxiety that can bring. Not having a permanent leader to guide the city through those situations could make the situation worse, namely in creating greater instability, interviewees indicated. Then, there were two very interrelated time issues — uncertainty about changes that would accompany a new city manager because they could affect any established relationships with city officials and, while the positions were not filled, interviewees' belief that the multiple vacancies and overall leadership gap made the above-mentioned inaction even worse. 
Background: Austin city manager and department head vacancies and the city's search process for a new city manager

Austin's city manager search began when the previous city manager, Marc Ott, resigned from the position in late 2016 (M. King, 2018a). Chief Financial Officer Elaine Hart then assumed the position on an interim basis. What made the search rocky and sparked the most ire from the public at-large and especially the local news media was the process elected officials followed in their search. The city council voted to hire an outside recruiting firm, Russell Reynolds Associates, a global firm with its main headquarters in New York, to handle the search (Craver, 2017). Russell Reynolds' recommendations that council members followed then became problematic in Austin public sphere.

Following Russell Reynolds' advice, council members opted for candidate secrecy after firm representatives argued that it would give the city a better applicant pool because candidates could apply without any current employers knowing they were searching for work (M. King, 2017; M. King, 2018a). This did not sit well with the citizenry as a whole in Austin because, culturally, the city is one that "highly values transparency and citizen engagement" and where "It is not uncommon for residents to publicly take a manager's decision to task" (as cited in Austin American-Statesman Editorial Board, 2017). The Austin American-Statesman noted that a city manager hired during a secretive process would start his or her job "under a cloud of skepticism", which was behind the "sinking fortunes" of a former local Austin school superintendent hired in the same manner and who went on to operate, the editorial board indicated, in a nontransparent fashion (as cited in Austin American-Statesman Editorial Board, 2017). 
Besides the city and Russell Reynolds and local media outlets battling each other to release the candidates' identities, with the Austin American-Statesman suing the city in October 2017 for the information (Findell \& Jankowski, 2017a; M. King, 2018a), the city had multiple critical department head vacancies - fifteen at one point and more than a quarter of its top positions - during the city manager search (Hernandez, 2017;

Jankowski, 2017b). City officials wanted to have the new city manager, when appointed, to be able to assemble his or her own leadership team, which could prove counterproductive if this is not the case because a new city manager may have a new vision for a given department once in place (Jankowski, 2017b). City officials, in March 2017 article in the Austin American-Statesman, said the city manager search process was expected to take three to six months (Findell, 2017b). It took even longer than that, and combined with the transparency issue, the time factor that, counting the time before the March 2017 announcement after Ott left his position, left Austin without a city manager for about a year weighed heavily on several of my interviewees.

Spencer Cronk, then the city coordinator for Minneapolis, was announced as Austin's choice on December 22, 2017 (Hernandez, 2017). Cronk began the job on February 12, 2018 (Jankowski, 2018a), because, at the time he was chosen for the Austin position, Minneapolis was hosting the Super Bowl in early February 2018, and he had been at the forefront of his now-former employer's preparation for that event (Jankowski, 2018a). He had been encouraged to finish his work on that event before leaving for Austin. Less than one month after Cronk was on the job, a serial bomber put the city in "three weeks of terror" (as cited by Jankowski, 2018b) that had Cronk at numerous 
briefings to watch over the massive manhunt that ended with the suspect blowing himself up as officers closed in on his vehicle (Jankowski, 2018b).

Even before Cronk was chosen and began his job under extraordinary circumstances for any new city manager, interviewees told me that an especially long period without a permanent city manager and without multiple permanent department heads in a city that is outright morphing at warp speed is a dangerous situation. This is an exchange I had with Ron in mid-2017, before Cronk was hired.

Ron: Everything needs work - always. (The bureaucracy) ain't perfect. Things move, but they don't move that fast. There are a lot of key areas that need to be better. The bureaucracy is... Because Austin is such a city in flux and changing, I think the city could use a good reworked, revisited set of priorities. "Here's how we can work best. Here's how we can serve our people best. Here's where we definitely want to make a difference, and these are the points by which we will abide." That needs to happen. The city is growing so fast and changing so quickly.

Amelia: So it needs to revise as Austin revises, per se?

Ron: Yeah, and we haven't had a city manager now for a year. They're still just getting around to interviewing candidates for city manager. You've got about 20 percent of executive-level staff positions that are currently in an interim position right now. So, you've got a whole lot of people just kind of marking time. There needs to be some stability, created with a new city manager being hired. 
The city's organizational chart, as of late February 2018 and after Cronk's appointment, is displayed below in Figure 7.6. Interim department heads are highlighted.

Figure 7.6: Austin February 2018 city government org chart (City of Austin, 2018g)

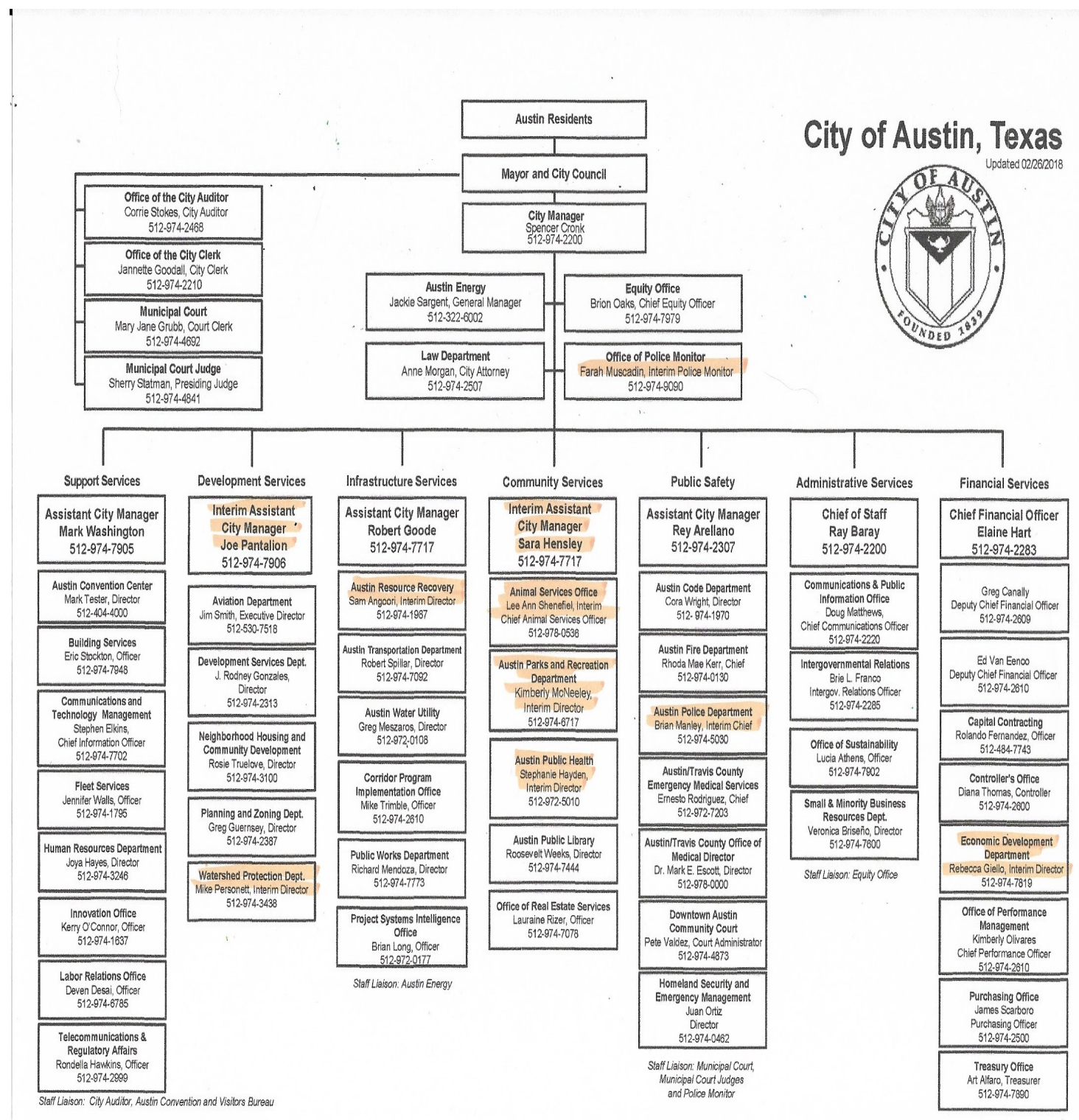

The chart displays ten interim department heads. This chart was created before

Fire Chief Rhoda Mae Kerr left her position in the summer of 2018 (Plohetski, 2018a).

This created yet another department head vacancy. Most of the department heads that 
were in the interim at this point had major effects on the artistic community, such as the economic development department, which houses the Music and Entertainment and Creative Arts divisions, and the police department, which handles sound enforcement at venues.

The artistic community depends on multiple department heads, even those who seemingly do not have a direct hand in arts policy, and the level of coordination that goes into the city's numerous special events is intense. This is especially the case if they are as large as South-by-Southwest. Ron said that thirteen city departments are involved in the coordination of any one special event. A frequent make-or-break, for any city event and even in day-to-day operations, is how well certain departments work together and stay on the same page. I asked Ron, in mid-2017, how well that works in Austin. His response was related to the vacancies.

Ron: Not great, frankly. The communication is pretty sub-optimal. I would say... Again, not to point a finger, but we've got an interim police chief right now because our last police chief left. You can't hire a new police chief until you hire a new city manager. The city manager wants to pick who all of his or her department heads are. You have a ton of people just marking time and not really connecting the dots. You have left hand, right hand - that whole thing. So, it's pretty piss poor in a lot of ways.

\section{Relationship changes with new leadership}

While interviewees indicated that they wanted the city to move forward and have permanent leaders in place, they were still concerned that leadership changes could negatively affect existing positive working relationships they had already built with certain members of the city bureaucracy. Advocates, journalists, and at least one city employee informed me that the real uncertainty begins right when the city manager is 
chosen and much more so than when positions are in interim. A new city manager could see the need for changes and "clean house", as one advocate with government management experience noted. The same could happen when new department heads are appointed. Others pointed out that middle-management or rank-and-file employees who had the most day-to-day contact with the artistic community could be reassigned or leave because they do not like the changes and/or new management.

Nymphadora said her working relationship with the city has been a positive, namely because she has a major point of contact that is extremely helpful even when Nymphadora encounters sudden problems and because her particular event is much smaller-scale compared to others such as the Austin City Limits Music Festival and South-by-Southwest. This combined with the fact that her event has not had major changes with a greater public impact has made the long transition not affect as much as it has others. Still, that situation could change if there are major shifts with new management that was incoming at the time of my interview with her.

Nymphadora: So I think I've been lucky in that it hasn't affected me solely because I haven't done anything like triple in size or decide to bring a Ferris wheel into downtown or do something dramatically different from what I've done in the past. ... This is all under the presumption that things stay the same and my folks don't just hate the new city manager and peace out. I don't think that they will, but they're... Yeah.

...Honestly, the thing that would affect me most is if my current point of contact went away. I wouldn't know what to do.

Ernie, whose department head was an interim police chief at the time of my interview with him (which was also before Cronk's hire), said the situation at his department was essentially business-as-usual. The real question as to how things would change would be when the city manager was hired and, then, that city manager hired a 
new police chief. The interim police chief at the time, Brian Manley, was directly below the former police chief, and during the interim period, operations remained the same. (Note: Brian Manley was made the permanent police chief after the Austin fieldwork period ended, partially because of reasons that will be explained further in this section.). Ernie also noted that others filling positions like interim city manager and some interim assistant city manager positions were also already working in Austin city government, meaning that operations governing the police department and others had essentially remained the same as well. However, the new management would bring changes, and those changes remained to be seen.

Ernie: The management of what those jobs were doing really hasn't changed, simply because the people who moved into those positions in the interim are capable. There's not really any difference in how things are running. ... They didn't bring in somebody new. The person below our former chief came up to that job. Things haven't changed.

...But typically, when a new chief comes in, there's some measure of policy change within the department, with our Standard Operating Procedures (SOPs) or our command structure, depending on where the new chief comes from and what belief system he or she brings. There's typically some kind of change that happens.

...Amelia: Could the new police chief eliminate entire units?

Ernie: Absolutely. The new police chief could eliminate anything he or she wants to, as far as coming in and saying, "We don't like street narcotics anymore. We're going to get rid of that unit. We don't like the sound enforcement division. We're going to get rid of that unit." Of course, they would be advised against it considering the impact that division has on special events and the fact that there are so many venues. That would just never work.

Amelia: But a new chief could come in and do some shakeups, correct?

Ernie: Yeah. To give you an example, when the last chief came in, he changed the uniforms, he changed the cars, and he changed the guns. He changed the policy on the guns that we carry. A lot of those things changed when he came in. Those are big changes, you know, when you change the color of the cars, and you have 
to paint all four hundred cars, and you have to change the patch on your uniform. So everybody has to get new uniforms. I mean, those are big changes.

Amelia: Will things like that happen just about any time you get new leadership?

Ernie: Sure. There's going to be some changes.

I interviewed Lily shortly after Cronk's hire, and she said that with any new city manager hire, major changes could happen because new leaders want management that shares their visions, and they may have already made connections in the field that they already have in mind for hires.

Lily: When the new city manager comes in, he will probably bring some of his own people, and those interim city managers that are here now may leave or go back to the departments they were heading before. We don't know until (Cronk) gets on board. I like to say that a lot of city managers, when they come in, they keep people for about six months to kind of get their feet wet. Then, they start cleaning house, and they bring their own people in. They'll go, "I really liked the guy who was the police chief in Minneapolis or my parks and rec person was really good. So, I'm going to bring them down here, and put them in this. I really liked this ACM (assistant city manager). I know somebody out in the field of city managers and assistant city managers, a good colleague of mine. I'd really like to bring this person in as an ACM."

Albus also noted that, with offices that have built some of the closest working relationships with the artistic community, the history is not a long one as it is. The Music and Entertainment Division was only established in 2010, and it replaced its first director, Don Pitts, with current director Erica Shamaly in mid-2017 (Blackstock, 2017). Kevin Johns, the economic development director who announced Shamaly's appointment, retired four months later, and another interim department head took his place (Clifton, 2017).

Albus: Our music office is around eight years old, and we don't have much history with it. The Cultural Arts Division has been around for a long time, and 
they do have staff members who have been there for a very long time. One of them is getting ready to retire, though.

Interviewees noted that finding out how things would eventually run will take some time because it will take Cronk, himself, time to determine the city's course. Alastor, a state government official in an arts agency, noted that he went through a very similar process when assuming his position. With Cronk taking a position where he already faces so many department head vacancies alone, this can take even more time, and Cronk will certainly have to prioritize which department head positions to fill first.

Alastor: I know that when people actually do come in and start running their shops, they change things. But that's just sort of the nature of it. Honestly, I think those time lapses are just kind of par for the course. ... When new administrations come in, there are changes. There can be a long ramp-up time. It's just the way it is. I'm not saying it's right. I'm just saying that's usually how it is. And honestly, even if they do put someone in quickly, getting that person up to speed and getting that person's arms wrapped around exactly what he or she needs to do long-term takes a while. It really does.

...I can only say from my own experience. It took me months to get my head around exactly what our office could do and started implementing programs based on what I heard, statewide. It's a long process, especially in our case, when we really tried to change what the office did and make it a much more expansive series of programs that we were going to operate. It took a long time, about a year.

At the beginning of Cronk's tenure, though, those I interviewed inside government were optimistic, and the ones outside city government who worked with the city frequently were cautiously optimistic. At the end of the fieldwork period, most in the artistic community did not have much of a chance to find out much about him because of his beginning the position just before South-by-Southwest began on March 9, 2018, when 
the artistic community is extremely busy. The event is large enough to where it often affects everyone in the city to some extent.

Nymphadora: Honestly, I don't know a lot about him. Hopefully, he takes the time to learn all his various systems. This man obviously has a lot on his plate in terms of departments and things. I mean, there's a ton of vacancies. Austin is a very interesting and dynamic city. This sounds really dumb, but it's like half techs and half liberal hipsters. It's a very weird place to be if you're not familiar with it.

I am cautiously optimistic. Again, I think if I had a larger event or a larger impact, a bigger footprint, I would be a little bit more worried. But I'm not. In a world where maybe one day we do assess, if there are new rules, we'll go from there.

If I knew more about him, I might have a more informed opinion. But in a place where I don't, I am excited for him and hope for the best. I may change my mind if you interviewed me in another how many months after he's... I don't know, dissolved half of the departments in the city and started something super crazy. I may have something totally different to say. But he seems like a competent human. So, we'll go from there.

\section{Inaction due to vacancies}

The city not having a permanent city manager and not having several permanent department heads also led to concerns that the earlier-discussed inaction would only get worse. Some interviewees blamed the inaction on the vacancies, themselves, while others only believed the vacancy problem was a contributing factor for a much larger problem. This was part of a related exchange I had with Lily, who believed that accountability, in both following up with policy analysis and crafting and accountability in general was a major issue with the number of interims in place. This includes policies handed to the bureaucracy that, as indicated from interviews and secondary source interviews in an earlier discussion, seem to go nowhere - a "black hole", in Lily's words.

Amelia: So when it comes to the issue of, "no more talk and translating talking to action", how much of a factor has the limbo in city government here, with the open city manager position and interim department heads, been? 
Lily: I think it is a factor because I think one that's one of the reasons why I think the city council members keep doing all these resolutions to get movement on problems. It's because there is a leadership vacuum.

...Yes, I think a lot of stuff has been on hold, and I think the council gets frustrated with that. I mean, if I were on that city council, I would be tremendously frustrated with that.

...I think the other part of that is there's a whole accountability issue from the staff side because, usually, the city council directs the city manager, who then directs his department heads. Right? OK, well, if you really have a city manager in a limbo situation, then where is the accountability for the department heads because they technically have no one really to answer to except an interim city manager who may or may not care because they're also interim? ... So it all kind of rolls downhill, and so when you have those situations, to me, there's a lot of instability, and there's not a lot of accountability.

...To me, coming from looking at it from the governing side of it — true governing - your city manager's job is to take that resolution and keep track of that and go off to the city department heads and say, "OK, you guys, you're supposed to be doing this, you're supposed to be doing this, you're supposed to be doing that."

But to me, they're seeing the resolution situation seems to be a black hole because resolutions get passed and nothing happens, and nothing happens. The date for when the staff was supposed to come back and do stuff passes, and nothing happens, and nothing happens. I think if I were a city council member, I would be incredibly frustrated by that.

Accountability becomes even more urgent in crisis situations — and while asking a follow-up question related to this subject during my interview with Lily, I found my own words haunting me later. I asked how important that accountability becomes when a city is the subject of national and even international attention. During the March 2018 bombings, Austin was that. The brand new city manager was in the background at all the numerous press briefings, in which the interim police chief, Manley, was in the lead. The photo below is a screenshot of the pre-dawn press briefing on March 21, 2018, just after police officers surrounded the bomber's car in nearby Round Rock and shot at the 
bomber as the bomber blew himself up (Weber \& Federico, 2018). Manley is the officer speaking at the microphone, and Cronk is behind him, wearing the purple tie. Months later, Cronk chose Manley to be the permanent police chief, citing Manley's handling of the bombings as key reasons for naming Manley as the sole finalist for the job (M. Wilson, 2018).

Figure 7.7: Interim chief, new city manager, bombing (KTBC FOX 7 Austin, 2018)

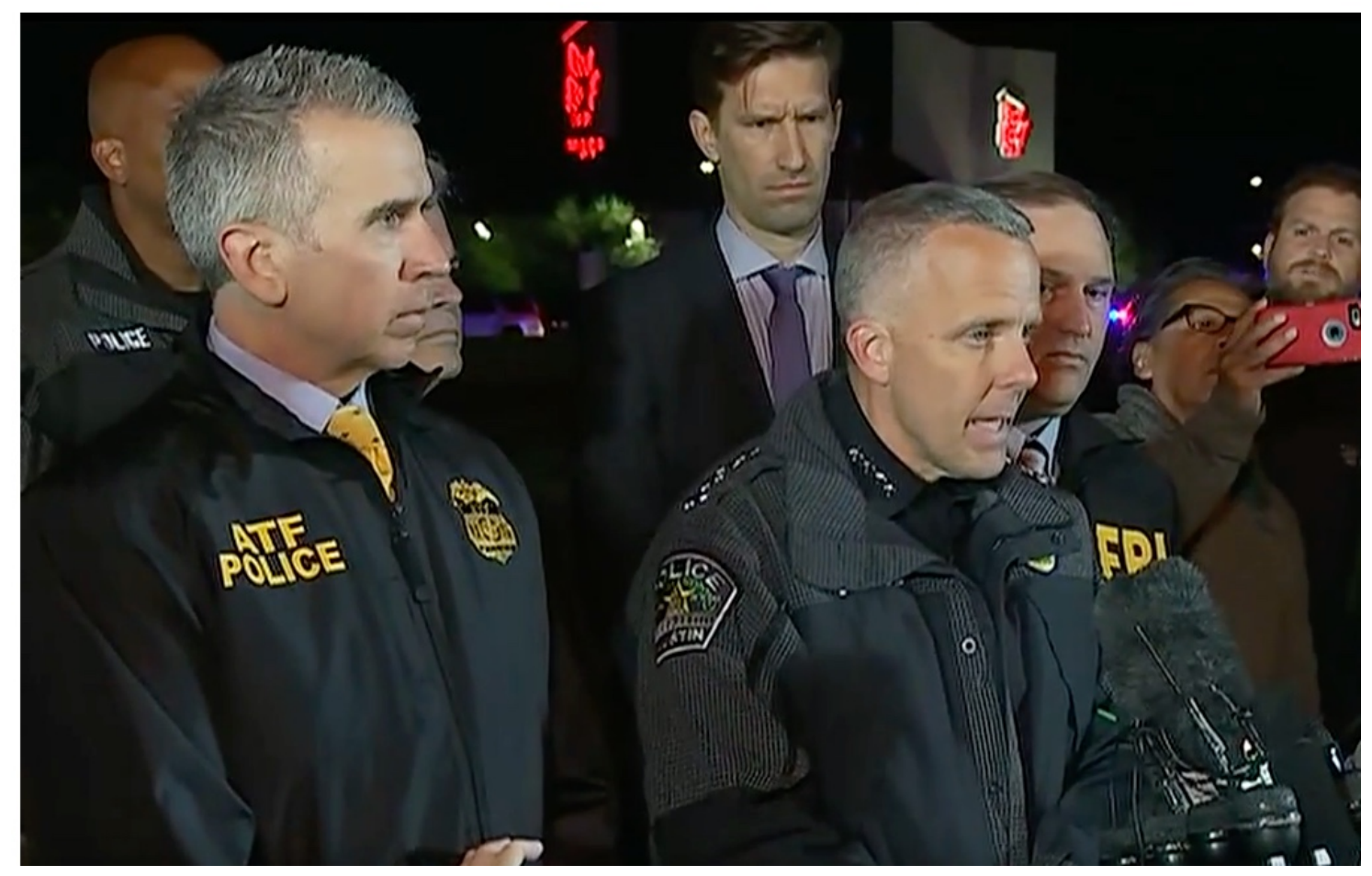

Helena, a city boards and commissions member, believed that both

administration and staff changes alike, not just in the city manager's office, could be a contributing factor in the participation initiatives, like surveys, being repeated, as mentioned earlier.

Helena: I'm not going to say that the city government is full of people who don't care. I'm not going to say that no one cares. I think there are some wellintentioned people. However, you also have some administration changes. When the first African-American Quality of Life study was done, I can't even tell you who was mayor. I don't even know. But I'm saying that if you also have the 
turnover in administration, staffs change so they may not have been engaged, and they're now thinking they're doing something new. It's like the same wheel. You just took it off and put it on a different car. So I think that's built into the problem and the process. Administrations and government and changing staffs and people... It's a hard thing to quantify.

Without a new city manager and permanent department heads in place who could possibly change direction, the city would likely stay in a position where, Luna believed when interviewed months before Cronk was hired, it is solely focused on economic growth and the overall bottom line that has favored the tech industry and not also considering the non-monetary, cultural capital that the arts bring into the city as well as economic growth from it.

Luna: I don't feel like we have an efficient system or certainly an effective system of getting things done that are not connected to economic growth that is apparent because you sold this plot of land, and it becomes part of the tech industry. Seeing, over time, how arts impact can create a good tourism city, can create more jobs for Austinites... This requires a lot of shared vision.

Lily noted that a potential danger for existing permanent employees when there is any new administration change or any new manager is raising one's profile. This meant that having a new permanent city manager in place could make the transition-related inaction continue. In almost any workplace situation, putting oneself in the new manager's spotlight may draw attention to aspects of that employee that the new manager does not like. Then, that person is replaced. Therefore, city employees may be nervous about making changes at this point. This can cause further frustration for those in the artistic community who need their help, she said.

Lily: One of the staff members from an arts advocacy group we work with and I just had a conversation yesterday about how frustrating it is with city staff to get movement on stuff. I don't know if it's because the city staff doesn't want to do 
anything because they've got a new city manager coming in, and nobody wants to get in trouble. Nobody wants to raise their profile because then, they're out the door.

However, Percy believes that the problems with inaction predated the city manager and department head vacancies. The city auditor's report led credence to this claim because the gentrification and displacement report it released in January included recommendations and resolutions going back to 2000, which even predated Ott's hiring in 2008 (Hicks, 2016).

Percy: This kind of inaction, both inaction and allowing and facilitating greed and wealth to dominate, go, I think, much longer than those positions. I think it's complicated, but it is not something I would list as the primary or even secondary factor in it. I don't think that the city of Austin knows how to make the changes that it needs to make. Even if the city officials did, I don't know if they're brave enough to enact drastic policy that does not benefit real estate people.

...I don't think there are any rotating government positions in the last few years that have contributed to that, specifically, in Austin.

\section{Problematic city manager search process}

Besides the issue of vacancies, issues involving how the elected government and its consulting firm conducted the city manager search sparked public outcry with Austin's citizens. Culturally, Austin's citizenry as a whole demands transparency, and city government and the consulting firm's tension with local media outlets went as far as the Austin American-Statesman suing the city because of it not releasing information about the applicants.

For some interviewees in the artistic community, the city manager search, especially its ending, had the artistic community believing the city government's and its consulting firm's actions were bizarre, at best, especially for those who wanted to stay informed about new city leaders who could seriously affect how they operate. This was 
especially true because of the announcement being made during the lead-up to South-BySouthwest. The interviews I show later in this section were done shortly before and shortly after South-By-Southwest.

The secrecy issues surrounding the city manager search persisted, and the related battles between the elected government and the Russell Reynolds consulting firm took a strange turn, especially after the Statesman utilized a Freedom of Information request to city communications about the decision to secretly change the interview location for the second round of city manager candidate interviews conducted on November 2, 2017 (Jankowski, 2017b). Using "sources and social media" the Statesman began identifying some of the nine finalists on October 31, 2017, the first day of interviews (Jankowski, 2017b). This led the consulting firm to change the November 2, 2017, interview location from the Hilton Austin Airport hotel to behind security lines at the Austin-Bergstrom International Airport to avoid journalists.

The interview day in November became "weird", with council members originally arriving at the Hilton and then going "on the lam, giving reporters the slip by escaping in vans and later surfacing in a room behind TSA security checkpoints..." (as cited in Findell \& Jankowski, 2017c). Consultants even suggested that the city manager finalists "don wigs, pretend to be tourists, or possibly even wear Halloween masks after American-Statesman reporters managed to identify several candidates..." (as cited in Jankowski, 2017b). On a more serious note, the meeting's legality was questionable because of it possibly violating the Texas Open Meetings Act (Jankowski, 2017b). At the search's end, city Councilman Jimmy Flannigan said, "It's fair to say that, at times, it was a farce" (as cited in M. King, 2018a). 
Penelope: I know people were really upset about the city manager stuff. I mean, it doesn't help that the city has just been super weird and secretive about that whole process.

Amelia: Like suggesting people wear Halloween costumes at the airport and the like?

Penelope: Yeah. It's just... They're strange.

Nymphadora: With the process being so incredibly secretive that the city did in trying to find the city manager... The process has been going on for a really long time, but we haven't had a name of anyone who was a candidate until recently, and then, they picked one. Honestly, for myself, personally, because of the work I have going on, I like to stay very informed.

...The first half of the year is just a little crazy because it's New Year's nonsense and that kind of stuff. Sometimes, it slows down a little in February, but then, March is all South-By. Even if you know South-By is only a certain number of days, it is all of March. It's in everyone's heart and brains. Then, everything kind of gets going again after that.

... South-By is about to happen. Everything is happening. I haven't had a chance to even google this guy. I couldn't tell you anything about him.

One of the premises behind council-manager government forms is that it

professionalizes day-to-day management of government and keeps the politics to a minimum (Kanin, 2013). Ernie begged to differ.

Ernie: That's not reality. I don't care where you go. Any city, government entity, any election, elected official in any of those things is going to have politics. It's going to have it. You know it's there. Quid-pro-quo is in every official, whether it's a council, mayoral, or whether it's a governmental state - it doesn't matter. There's some element of quid-pro-quo.

\section{Artistic community feeling disconnected from city officials}


Another hindering factor artistic community members identified was a general disconnectedness they felt from city government officials. Some of them felt as if city officials, particularly the elected ones, simply didn't "get" what it was like to be a person working in entertainment and the arts and felt like there was a figurative wall between themselves and officials. Their sentiments included feeling as if the city's arts-friendly stance, particularly toward the commercial music industry, was fake, earlier-noted sentiments that the city cares more for its revenue from real estate and the tech industry, and that it did not understand the needs of working artists and creative businesses like live music venues.

This finding really came out when interviewees did the narrative mapping exercises. Penelope's drawing, in which she depicts the reality of the situation for Austin's artistic community, is below in Figure 7.8.

Figure 7.8: Narrative Map (Reality): Penelope, Austin journalist 

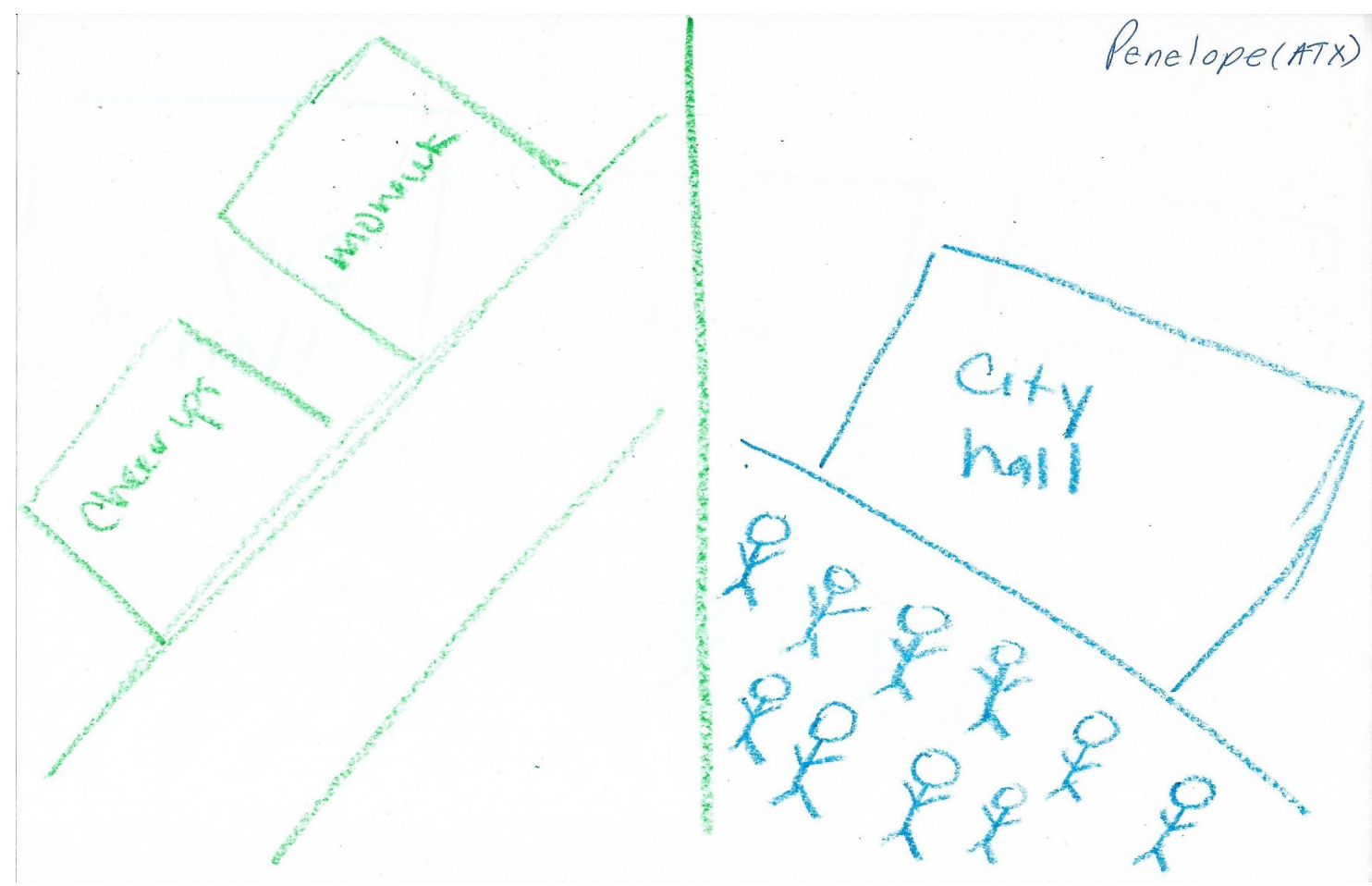

Penelope explained that her drawing showed how the world of those who, as in the example she provided, work in the Red River district (identified by two of its venues, Cheer-Up Charlie's and the Mohawk) and those who work at city hall are separated and disconnected. She used different colors to represent the two groups, to show distinction between them. She did not use blue or green, specifically, for a particular reason, but she did want to use two different colors, whatever they may be, to show that separation.

Penelope: So here, they're pretty separate. I don't see a whole lot of intermingling going on in between.

Amelia: So is that why you have a line drawn?

Penelope: Yeah, even from the people that I know sitting on the council. They're just... There are a couple of people who are really involved in the music scene and get it. But like all of them... I mean, the main guy. His name is... I can't remember. He has, like, a classical orchestra background and seems kind of more familiar and has better relationships with the people on Red River. But there just seems to be a disconnect, for sure.

Amelia: Is there any reason why one group is blue and the other is green? 
Penelope: Just to diversify.

Amelia: Just to show they're not even the same color.

Penelope: Yeah, exactly.

Nymphadora displayed a positive relationship she has with city government in her narrative map shown below in Figure 7.9. However, her drawing still showed an element of disconnect that she would prefer not to have in a very ideal "dream" situation.

Figure 7.9: Narrative Map (Reality): Nymphadora, film festival organizer in Austin (2018)

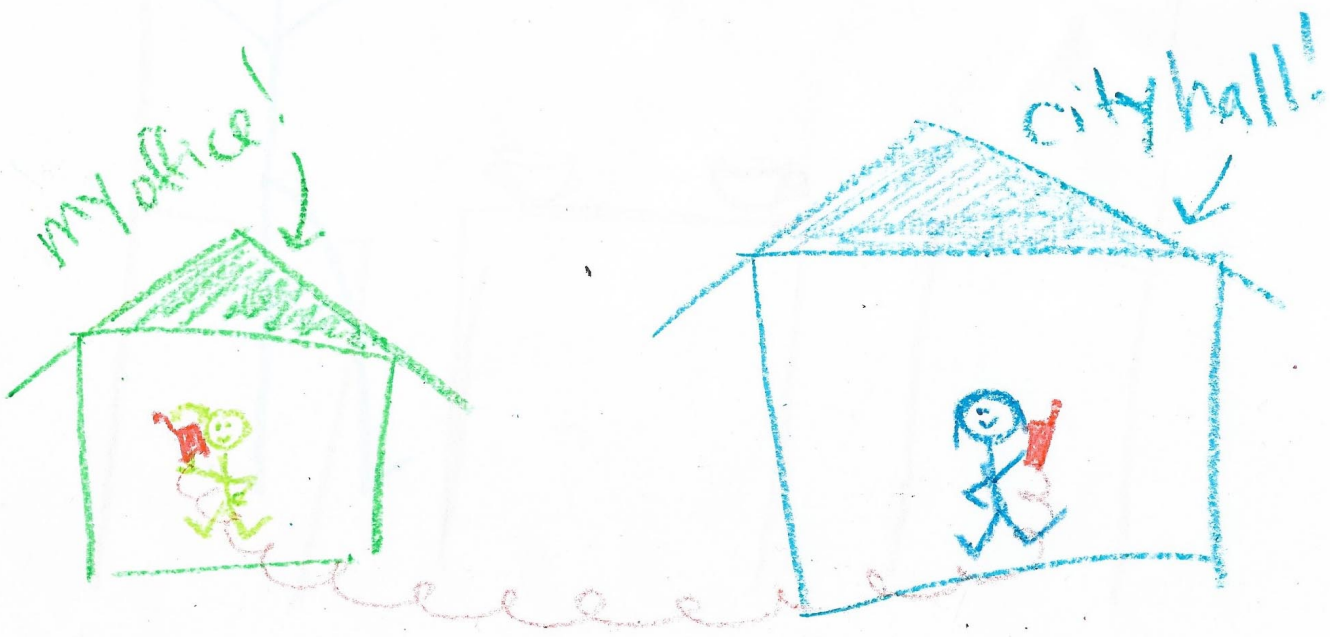

Nymphadora: OK. For the record, I am satisfied with what I have now. It's not like what I have right now is, "Oh that sucks. I hate it."

... So in this picture I've made, it's one of those... It's very interesting. So, we're in two separate places - the city government and me. I am contained within my office, and they're contained within city hall even though my contacts don't actually work in city hall, but you get the gist. So, we're not ever really coming together. There's not a lot of face-to-face interaction, but I do most of my work with them via phone or via email. So I still feel connected, even though it's kind of this isolated connectedness, if that makes sense. It's like we're still having a dialog. I don't feel lost. I don't feel stuck, but I don't necessarily have any kind of meeting together and the shaking of hands and that kind of thing.

\section{Hindering Factors Related to Institutions}


Two major hindering factors emerged with institutions, "Austin Exceptionalism" and some people having too much faith in institutions. Austin Exceptionalism, as it was explained to me, was the belief that the city was a liberal, progressive beacon something city officials promoted — when certain interviewees believed it was anything but that. This was especially the case with some black and Hispanic interviewees who pointed to major issues with racial inequality that have lasting legacies to the present day. The other hindering factor was that some people had too much faith in institutions. Some interviewees indicated that this was dangerous, especially in the face of so much change. Too much faith in institutions, they believed, would make the artistic community rest get a false sense of security and rest on their laurels all to find their institutions of music and art gone.

\section{"Austin Exceptionalism"}

"Austin Exceptionalism" — a widely held belief and city government-promoted image of Austin being a liberal, accepting beacon even when located in a conservative Southern state — was something several interviewees considered suspicious or outright bunk, even infuriating. This hindered participation because hearing this mantra from city government when artistic community members' realities did not reflect this image whatsoever was an immediate turn-off, and this created more tension, especially when minorities, as I will further explain in a latter section, were not represented well at all in the overall policymaking dialog.

This was especially true for some black and Hispanic interviewees. The image,

they said, was especially not the reality for minority residents who have been displaced from gentrification and minorities in the artistic community who believe that their own 
work, and art forms associated with minority groups like hip-hop and Tejano music, and prominent minority artistic community figures are pushed aside to put white artistic community members and art forms with larger white audiences and more white artists like "alt-country" music on higher pedestals.

Some interviewees also noted that Austin should not be exalted as a liberal beacon when other Texas cities such as Houston, El Paso, San Antonio, and Dallas are also very progressive - if not more progressive, especially in how diverse populations are accepted in reality, not just in a promoted image. Furthermore, some interviewees also indicated that, compared to other Texas cities, Austin was lagging behind in creating innovative policies that could better help the artistic community.

When I interviewed Draco, a city boards and commissions member and former working musician. I mentioned previous studies that have shown that traditional citizen participation structures favors those who are wealthier, have more monetary and political power, more socially advantaged, and white (Fung, 2006, 2015). I asked him if this was the case in Austin. This is how Draco, who is Hispanic, responded.

Draco: I think, wholly, that would be the case. The communities that are now creating the gentrification are certainly young Anglo-fluent migrants. That's what I will call them and not immigrants. So, they are coming. I understand we had research recently stating that we have people chiefly from California, San Francisco, and Los Angeles who are now making their way to Austin in very large numbers. That's why we are among the finalists for the new headquarters of Amazon and Apple - because of that equity perception, which is actually a false one.

I mentioned to Draco some of the data, perceptions, and statements regarding Austin's progressive image. The Human Rights Commission's Municipal Equality Index, which ranks hundreds of United States cities on how LGBT-friendly they are in terms of 
public policy each year. Austin generally earns a 100 on the HRC's scale of 0-100

(Human Rights Campaign, 2018). I noted that when Donald Trump announced

transgender people would be banned from serving in the military, Adler tweeted a link to the Austin Police Department application for anyone who is dismissed from the military because of gender identity (Grumet \& Webb, 2017). Austin has repeatedly battled Texas state-level forces over the city's left-leaning policies such as plastic bag bans (Largey, 2018). I asked Draco though, if the policy on paper or the policy promoted in public image is the reality.

Draco: It is not. Again, the platform we stand on, the "Live Music Capital of the World", is certainly a false one in that no one can name a success story engaged or involving the world's most popular genres of music, urban music, hip-hop, and rap. We've had a music industry, I would say a commercial one, since 1965 to the present, almost 50 years. There are zero success stories for the urban colony, way back to funk music or Motown offshoots and to black rock artists like Jimi Hendrix or Prince. No stories exist here.

Latino music? It's the same issue once again. Our Latino artists of any repute are the Americana vein and are not recognized as spokespersons for the Latino market or faces of the Latino market, like Carlos Santana or even Linda Ronstadt. These are elders and contemporary. I'm not sure Camila Cabello... Is that her name? She's one of the latest, and that's very telling that we have statues to Willie Nelson and Stevie Ray Vaughn and murals to Janis Joplin. Rocky Erickson, 13 Floor Elevators... All are profoundly a legitimate Mount Rushmore of music, but that's white, white, and white over 50 years.

So how can a city call itself a progressive community when voices are silenced?

Helena, who is black, echoed his sentiment when, during my interview with her, I recalled a statement from another interviewee who told me what it was like to work in a progressive city in a conservative state. I interviewed Helena not long after I interviewed Draco and another man who also questioned exactly how progressive Austin really was. This was my exchange with Helena. 
Helena: That's absolutely not true. That's absolutely untrue. ... That is a huge fallacy.

...Amelia: You know, others told me the same thing along those lines. I was told that some people here get what one man told me was "Austin Exceptionalism", putting Austin out there as super-progressive. Another man I interviewed, who is Hispanic, told me that was false.

Helena: It is. I agree.

Amelia: When somebody says, "Oh, I've heard Austin is one of the most progressive places in America..."

Helena: I get that all the time when I travel. It's not.

Amelia: If you were to say what it's really like, what would you say it is?

Helena: For a single woman of color, awful. Awful. I leave every chance I get.

Amelia: If you just had to explain it... Can you give me an example of what makes it awful?

Helena: There's no one I would date here. There are very few people who look like me. There's little entertainment and food. There's no culture here. There are only museums. This city is a hard place to live day-to-day.

Amelia: But does it put itself out there in that way?

Helena: If I were a 20 -year-old white kid, this would be fucking nirvana. But I'm not. I tell people that if it's your perspective and that's what you're looking for, it may be all of those things for you. If you're asking me, though, it's not.

Racial inequity in Austin did not happen overnight. In the late 1800s and early 1900s, both black and Hispanic residents lived in pockets dispersed throughout the city (Austin American-Statesman, n.d.). Austin came to be known as a safe haven for freed slaves as thousands of freed slaves migrated toward urban areas after the Civil War (Zehr, 2015a). It was considered a more accepting city "with less of the racial violence that would burn throughout the South for the better part of the next century" (as cited in 
Zehr, 2015a). The influx of black residents still faced private restrictions and municipal zoning policies that limited where they could settle, but at least those pockets were dispersed throughout the city limits.

That dispersement would change and as a direct result of public policy. The U.S. Supreme Court, in its 1917 Buchanan vs. Warley decision ruled that race-based zoning was unconstitutional because it infringed on homeowners' rights to sell their land to whomever they choose (Tretter \& Sounny-Slitine, 2012). After this ruling, Austin and other southern cities started developing new policies for isolating minorities.

One of the most infamous measures for doing this — with its effects lasting to the present day — was the 1928 Koch and Fowler city plan, from a Dallas firm with the same name (Austin American-Statesman, n.d.; Tretter \& Sounny-Slitine, 2012; Zehr, 2015a). The plan proposed creating a "negro district", which was the only part of the city where black residents could access schools and other public services. As Jennifer Jellison Holme, an educational policy and planning professor at the University of Texas at Austin told the Austin American-Statesman, "Koch and Fowler came in and said, 'Let's get a little creative.' Instead of saying you can't live there, they segregated services. 'You can choose to live here, but you're not going to get access to city utilities and services"' (as cited in Zehr, 2015a). A rather notorious section of the Koch and Fowler report recommends using racially segregated city services to the east of what is now Interstate 35. Tretter and Sounny-Slitine (2012) writes that such a plan would save the city money through duplicating other segregated services citywide, and "it would also encourage the spatial separation of blacks from whites" (p. 15). For example, sewer service was 
extended to black residents in East Austin, but black residents in other parts of the city were denied this service.

Hispanic residents were not spared from this racially motivated city planning, either. Before 1920, Austin had a very small Hispanic community. By 1930, Hispanics had become a "considerably sized" community in Austin, about nine percent of the population (Tretter \& Sounny-Slitine, 2012). Immigration fueled these numbers, with "internal unrest, economic dislocation, and decades of instability from the Mexican Revolution between 1910 and 1930, an estimated 10 percent of Mexico's population" ( $p$. 25) left the country, and many fled to Texas. Many were drawn to Texas because of labor scarcity, particularly in the agriculture sector, because large numbers of black residents moved north to work at industrial jobs during World War I (Tretter \& Sounny-Slitine, 2012). Hispanics were also increasingly segregated into a district of East Austin in the 1930s, which was located at the southern border of the "negro district". Their concentration in this area was also linked to public service availability.

The map from the Koch and Fowler plan (1928) that has the minority districts marked off in orange is below in Figure 7.10, with neighborhoods with higher Hispanic populations in pink, located around the southern part of the main minority district. The map from 1928 includes a key at the bottom left side that indicates where the "negro", "negro and Mexican", and "remainder white" neighborhoods are. 
Figure 7.10: (Koch and Fowler, 1928, as cited in Austin American-Statesman, n.d.)

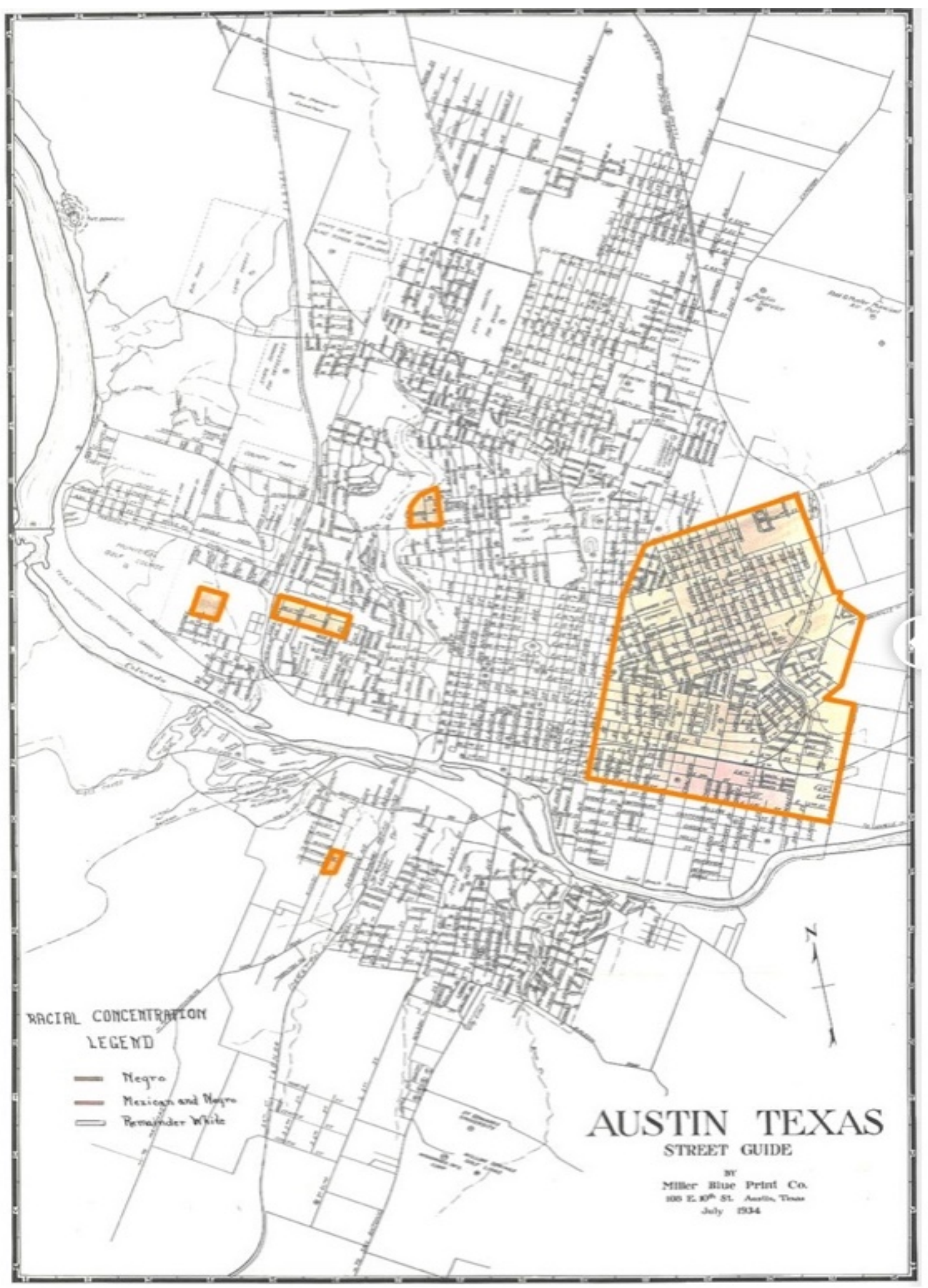


Black and Hispanic Austin residents were not only pushed into these neighborhoods because of others' desire to push them out of the way. They also had to live with less-than-desirable elements that those living in white neighborhoods did not. Zoning laws formalize what can and cannot be located in a given area, and a practice called "covenants" are not policy documents, but are instead are what Tretter \& SounnySlitine (2012) called "private zoning” (p. 17), deed restrictions and agreements between parties that outline what can and cannot be done on a piece of land. These were used to prevent activities that could negatively affect health or neighborhood aesthetics, like raising farm animals. These covenants eventually influenced public law, and white neighborhoods kept protective zoning restrictions.

Neighborhoods reserved for non-white residents were the ones where alcohol could be sold and noxious uses like heavy industry could place (Tretter \& Sounny-Slitine, 2012). Austin did not have a large industrial base, but it did have light industry. As years passed, an industrial zone was built near land only black and Hispanic residents occupied (Tretter \& Sounny-Slitine, 2012). After 1928, the year of the Koch and Fowler plan, a central train station was built and the area around it was zoned for industrial activity. According to the Austin American-Statesman (n.d.), "Koch and Fowler also proposed that the district have the city's weakest zoning restrictions, allowing the development of 'a number of slightly objectionable industrial uses' — essentially, any use that wasn't specifically outlawed". The map, also from the Koch and Fowler plan, shown below in Figure 7.11 shows neighborhoods in pink that did not have zoning protections. Most of these neighborhoods without zoning protections are the black and Hispanic neighborhoods shown in the previous map in Figure 7.10. 
Figure 7.11: (Koch and Fowler, 1928; as cited in Austin Statesman-American, n.d.)

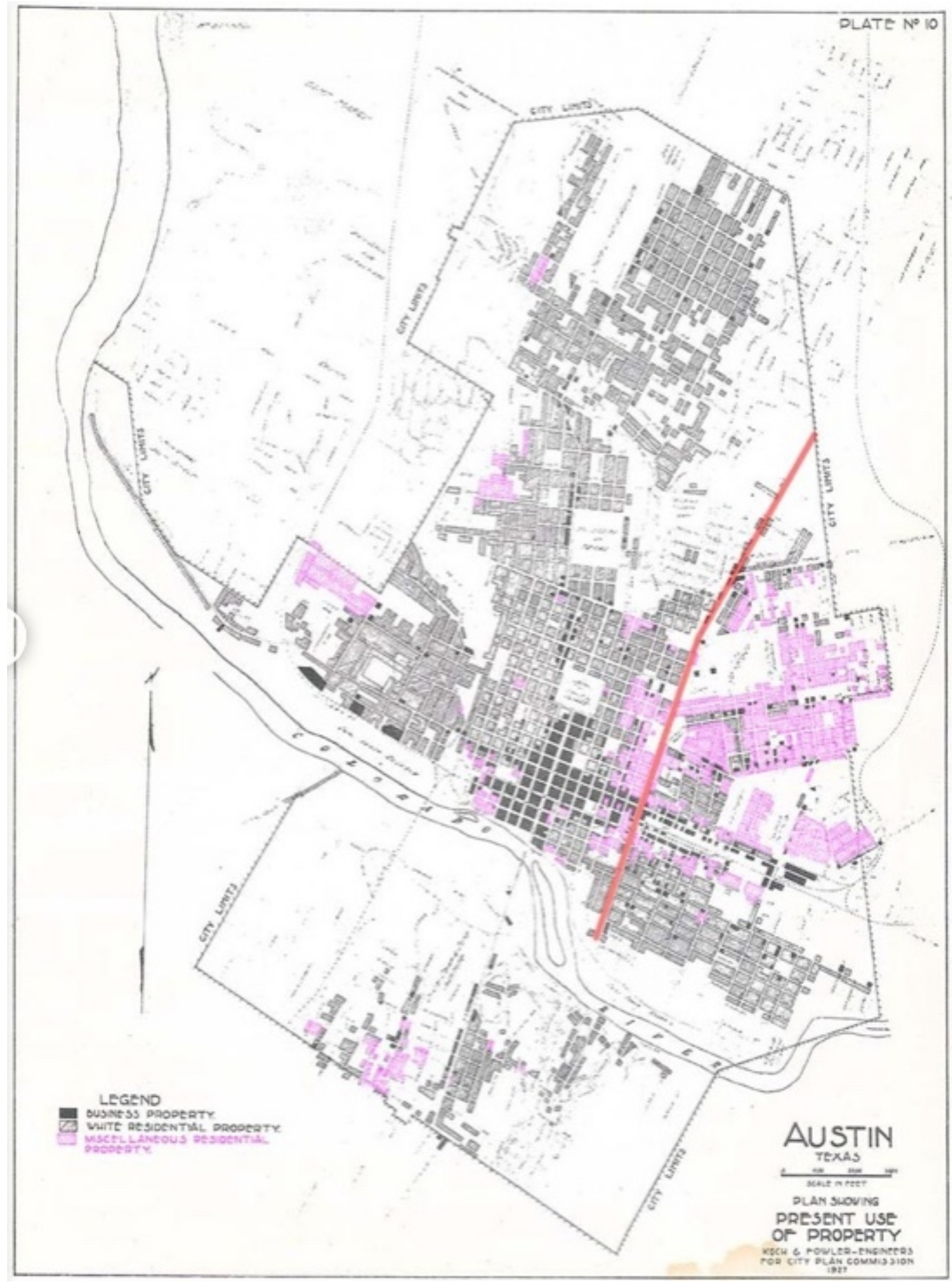


Interviewees said this attitude is still in practice in the present day. I will further discuss the overall issues with skyrocketing property values, property taxes, and displacement issues in another section, but I will note now that minority East Austin residents believe they are hit the worst by this and that this is an attempt to, instead of pushing them into a neighborhood, push them out of the city altogether (Freer, 2018; Prazan, 2016; Zehr, 2015a, 2015c).

Around the early 1990s, Helena estimated, it was evident that even though the tech boom was "just starting to simmer", the city was growing quickly and that growth was not just going to stay in the downtown. There are only so many places where the city could grow, and that new growth moved east. At that same time, brand new houses were being built in Pflugerville, a city in Williamson County to the north of Austin. Real estate agents then marketed these new Pflugerville houses — brand new houses for $\$ 100,000$ to middle-class black families in East Austin.

Helena: A lot of my friends' parents got caught up in it. You can get a brand new house for $\$ 100,000$. That was the draw. It was, "This is dead over here, people are scared to come downtown, and there are drugs." It's anything any other city has experienced, though.

But you had this influx of new build. It was $\$ 100,000$. Here, you had the tech kind of simmer happening. People are making solid money, so a good chunk of the middle-class black and Hispanic families in this particular area went to Pflugerville and Round Rock for a brand new house for $\$ 100,000$. That allowed things to deteriorate a little bit more. And then you started seeing artists moving into the East Side.

Now, again, at this point in time, white folks were like, "Don't go. Don't go east of I-35. You'll die. It's bad. You'll get killed, stabbed, or robbed." There are no statistics that bear that out, at all, ever, in the city. That was the mythology about East Austin, but then you started seeing that the students, artists, and musicians started going to East Austin. That, you know, begins the wave.... And now, you buy a lot - an empty lot - for half a million dollars that's not even five thousand square feet. It's something crazy over there. 
Ron, who is white, agreed with the minority interviewees' assertions that Austin

Exceptionalism is a myth.

Ron: I completely agree. There's a term in certain kinds of... I wouldn't say radical, but fairly leftist circles of how it's more than gentrification. It's a term called "economic violence." That's what we're talking about with regards to those communities being shut off from opportunity, historically, and then, "Oh hey, catch up, because everything is getting fucking expensive in a hurry." It's going to be impossible to feel violated in a certain way when you have that going on in a community or throughout a geographic region.

...I don't have the solution for a half-century-plus of a lack of opportunity for a significant, if not the majority, of Austin's population. If I did, I'd be shouting from the mountaintops, but I think it's tough to deny that is the case.

As her organization continues its search for a new space, Luna noted that she and the others with whom she works knows about how gentrification has priced out people in the artistic community, but also how minorities are disproportionately affected. Given gentrification's associations with artists, they want to be as certain as they can that they will not be a gentrification agent.

Luna: I feel like it's complicated to talk about because I think Austin has a long history of displacement, with its black population in particular. Gentrification is so associated with artists going into a part of town, and then making it palatable for some white person. I can tell you that we're very aware of that as we try to find a replacement space. We do not want to be the ones who cause people to be displaced. We want to keep costs associated with our space at an affordable rate.

Nymphadora, who retained a positive overall viewpoint of Austin, still noted that while Austin may seem safer than some places displayed on the news as being "Trump Country" or not accepting of others, she noted that Austin is not an outright island where those attitudes can be totally avoided. 
Nymphadora: If you look hard enough in Austin, you'll find a ton of that shit too. It's less concentrated, certainly, in more liberal, larger cities. Yeah, I mean that's a whole other conversation about our country and our future and people needing to be better versions of themselves.

I discovered such sentiments that echoed some of the more poisonous aspects of the national political dialog on display in certain places in Austin during observations, namely in graffiti I found in places such as stairwells and restroom stalls. I took the photo below shown in Figure 7.12 inside a parking garage stairwell, with the edited derogatory epithet from the graffiti "counterprotestor" highlighted only to better see what was written.

Figure 7.12: Fuck Trump, Fuck (epithet) stairwell vandalism (Pridemore, 2017)

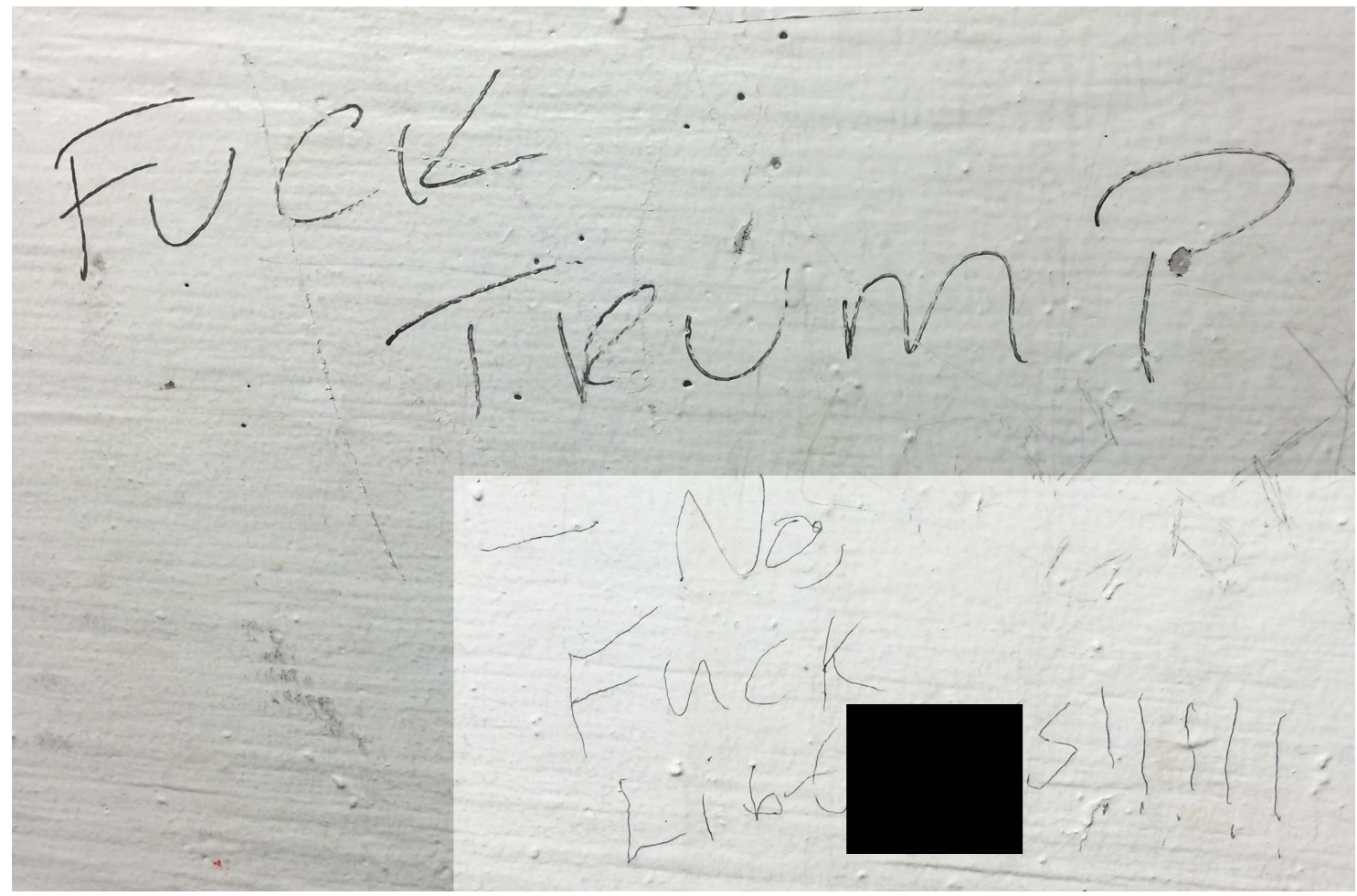

Albus, who did not take a negative viewpoint of Austin, either, was still skeptical about the city being more progressive and more charitable than others. Austin has the 
highest number of nonprofits per capita in Texas, with about fifty-six nonprofits for every 10,000 residents compared to about thirty-nine nonprofits for every 10,000 people in Texas (Brown, Jo, \& Andersson, 2013). However, Austin was ranked at No. 48 out of the fifty largest cities in the United States in terms of discretionary income donated to charity, with arts and culture ranked $12^{\text {th }}$ on a list of eighteen identified needs (City of Austin, 2009). The Austin area did have sixty-eight percent of its residents donate $\$ 100$ or more to charity, according to a 2018 report (Bixler \& Bhandari, 2018), but there was no information as to how that number compared to other cities.

Albus: I think it was somebody just last night about Austin Exceptionalism. What city in America does not consider itself to be exceptional? I love Austin. I think this is paradise. I cannot imagine living anywhere else, but from being a scientist and being totally objective, I have to think that this is same Austin Exceptionalism that they have in Fort Worth about Fort Worth Exceptionalism or in Memphis about Memphis Exceptionalism, or whatnot. So you can say we vote for Democrats here, but I'll tell you that I've been very put off by the fact that we elect city council members who voted against new apartment buildings and vote affordable housing projects and things like that. I'm old. I'm an old guy. I'm cynical. I have to be cynical. That's part of my job as an old guy. I've realized I've done that as part of age and education level.

So when you look at things objectively, you would have to show me some data that shows we're a more altruistic city than other cities. ... Are we any more altruistic than any other cities? ... I don't know. One thing I do know, in terms of philanthropy, Austin is not one of the leaders in terms of raising funds for good causes and whatnot. Part of that is with the tech community and the younger population. Those aren't traditional cohorts for producing charitable contributions. Even though they may be very compassionate people, the young people don't have the means to do a lot of charitable contributions. The tech people? Maybe it doesn't occur to them to do so.

... Again, I'd like to see the data.

Others noted that Austin was lagging behind other Texas cities in terms of both social openness and innovative policymaking, alike. Lily said that, in terms of economic 
policy, other cities such as Dallas, have used economic development tools such as tax increment reinvestment zones for endangered commercial areas like the Red River venues or utilizing older, disused buildings for artist live/work spaces to alleviate the housing situation. Austin, she said, could do these things too. Helena noted the progressive attitudes and politics in other Texas cities.

Helena: If you look at every other urban city in Texas - Houston, Dallas, El Paso, San Antonio - all of those cities are blue, if not bluer than Austin. If you go precinct by precinct, Houston is bluer than Austin, and Dallas is bluer than Austin.

Austin likes to think of itself of being so progressive, but that's not true. As a matter of fact, the state was much more interested in the bill that was in Houston about pay equity, providing benefits to domestic partners of city employees. The whole thing is incorrect. Houston did that first.

Austin has had openly LGBT people in city leadership, such as Flannigan, its first openly gay man on city council (Goldstein, 2017), and now, Cronk, who is also an openly gay man (M. King, 2018b). However, Helena also noted that the Houston measure that sparked Texas state officials' interest was done under Annise Parker, one of the first LGBT mayors in a major U.S. city. To date, Houston is the most populous city in the United States to have voted an openly LGBT mayor into office (Armus, 2017). In the extremely close and widely covered U.S. Senate race in Texas between incumbent Ted Cruz and Democratic U.S. Congressman Beto O'Rourke, O'Rourke did win the Austin metro area — as well as Dallas, Fort Worth, San Antonio, Houston, El Paso (O'Rourke's hometown), and areas near the border with Mexico (Briz, Fisher, Jin, McClure, \& Mihalik, 2018). O'Rourke only lost by 2.6 percentage points. Also, the Human Rights Campaign's Municipal Equality Index, which ranks U.S. cities based on LGBT-friendly 
local policy, on a scale of zero to one hundred, gave Austin a 100 in its latest report (Human Rights Campaign, 2018), but also gave Dallas, Fort Worth, and San Antonio the same score.

\section{Becoming Too Comfortable with Institutions}

One hindering factor related to institutions was people in the artistic community and their supporters becoming too comfortable with institutions - namely the institution of Austin having a deep love for its music and art. This hindered participation namely because it sometimes created an attitude of, "Oh, we will never lose this institution in Austin," and caused people to rest on their laurels. Some interviewees said that this type of thinking was especially dangerous because even when institutions are strong, institutions are not indestructible. This, they said, is especially the case as the city transforms at full tilt.

As noted in the literature review chapter, North (1990) writes that institutions are extremely strong, particularly informal institutions. A major sustaining force of informal institutions, such as love of music and art, is societal culture. However, as also noted in the literature review chapter, some scholars strongly warn against presuming institutions are indestructible (Bachrach \& Baratz, 1962), even when considering their strength. Those who seek to change institutions often begin their work through first changing formal institutions, like public policy (North, 1990). This can eventually wear down an informal institution until it can go away, too.

Interviewees such as Alastor and Seamus, a Red River district bar owner and musician, warned that getting too comfortable with an institution is dangerous, in this specific case, because as business and economic models, public policy, social conditions, 
and cities as a whole continually change, artistic communities must adapt. The same is true for private businesses and public agencies that work with them. Otherwise, those institutions can fall — and that fall can begin with formal institution change (North, 1990), like noise restrictions on outdoor live music venues.

Alastor: I think it is dangerous. It could be my opinion, but I think it's right. I think not constantly re-evaluating what you do for a living, not constantly reevaluating what your organization does to help and who it is supposed to help, and what it looks like... I think that's dangerous. I think that not constantly reevaluating or evaluating what your organization does is going to take you down the wrong path.

Seamus also noted that, as Austin changes, the artistic community and businesses supporting it must adapt with that change both in the present-day and in a way that future generations to whom it is handed will be able to continue the institution, as well, because the city will most likely change during their times, too. Because of the need to preserve this institution, he said, it requires looking at other institutions within the artistic community that are positive and negative alike, in order to face the grueling job ahead. Otherwise, Austin's institutions involving arts and music will fall.

Those who make a living in the arts already encounter a host of informal and formal institutions as a rule, Seamus said. The key is that some of those that seem formal are actually informal, one finds, when a person begins actually doing the work. Informal institutions become a part of life for those in the arts, even for skills that can be taught in formal settings. For the arts, even with formal training such as in a music school, it takes someone really diving into experiences such as self-referentialism that come with putting a part of oneself out there in their art or through constant practice, much like learning a trade. At the same time, surviving takes more than artistic talent. It takes learning 
business and public policy skills such as "the nitty-gritty of math, spreadsheets, top-line, bottom-line, strategy, planning, and politics." While this can be taught formally as well, it still takes years of practice to truly get all of this down pat - just like learning an instrument. Some of the most successful people he has met in the field only have a high school education and not advanced degrees because so much of it is repeated practice and "having a knack".

From his experiences in the music community, Seamus said, there is the added factor of other longstanding institutions that can work against it in the end. Sometimes, musicians and other artists are known to take a rather "anti-establishment" approach. They may choose a music career because they have been disenfranchised from opportunities like education or simply do not want to fit into traditional societal norms. He also noted, "Within our community, there is a higher prevalence of mental illness and addiction alongside of that." These groups combined with those mentioned above who have a "knack" for the arts combined with business and policy knowledge, Seamus said, means that there are both "highly functioning" and "barely functioning" people in the artistic community. The latter can create situations that have major consequences, especially in the long term, because all have to make sure the next generation is fully prepared, and not all are in a good position to do so.

Seamus: To target music and art and say, "Oh this is an institution," I would say is laughable because those who carry on that institution, the art and music community is always changing. So it always needs a broader understanding of art and music and an ability to hand it off to the next generation who understands what's happening now versus then. When folks like the generation before me and under me and myself don't have spaces to run or no longer fight and find it viable, everyone has to start from scratch again, much like the Middle Ages. It's like literally reinventing the wheel, which means the economic impact. 
You have to think: If you have a vibrant art and music community that gets decimated here, I think the combined impact of that is around four billion dollars. This is not just musicians or folks working in a bar. It's hotels, restaurants, and car rental places. I mean, it's cultural tourism.

That's the sort of precarious place that we find ourselves in, not just in Austin, but also worldwide, because as urban density and urban development intensifies, the major cities are seeing huge attrition for art spaces and music spaces. I think London saw about a 70 percent loss within about the last three years. Others have less.

We're kind of on the precipice in Austin of needing to have a moment of truth, deciding if this is who we are as Austin - and if it is really who we want to be. If public policy doesn't align with the cultural tourism, then it will just go away, which is ironic because that's been identified as one of the largest factors of what's driving the economic growth of Austin.

\section{Hindering Factors Related to Place}

Hindering factors related to place for Austin's artistic community had two major prongs - social construction of place and transportation issues. In regards to social construction of place, interviewees slammed the notorious Sixth Street entertainment district, known to locals as "Dirty Sixth". The problem with Dirty Sixth is that the nearby Red River Cultural District, which the locals held in high regard, was experiencing a crime problem. Even though this crime was not inside or even related to the bars, that could still equate Red River with Dirty Sixth in some eyes and a drop in public opinion could result in negative policy targeting for Red River too — akin to Schneider and Ingram's (1993) work involving target populations of people who become negative policy targets based on public opinion. Transportation presented a major issue on multiple fronts, namely because many, if not most, in the artistic community were living on the city's outer edges because they could not afford to live in the city's core, where government buildings and most of the entertainment venues are located. If they had cars, 
they were paying for very expensive and very limited parking and going through heavy traffic to reach it. If not, they had a less-than-ideal public transit system and lived too far away for a practical bicycle ride. This problem exacerbated the above-mentioned issue with extremely long or late-running meetings because artistic community members would not be able to stay for meetings' entirety because they would have to leave early to catch a bus or before running out of money or time for parking.

\section{"Dirty Sixth": Negative Social Construction of Place}

Negative social construction extended to place in Austin, namely with the most notorious stretch of the historic Sixth Street entertainment district — known to the locals as "Dirty Sixth". The stretch of Sixth Street that runs between Congress Avenue and Interstate 35 make up this notorious stretch (Curtin, 2015b) that, according to Curtin (2015b), is "largely perceived by Austin music fans as a wasteland..." My interviewees said contributing factors to that image of Dirty Sixth includes crime, over-the-top debauchery, bands playing cover songs instead of original music from "real Austin", and Dirty Sixth just being an overall tourist trap. Some of my own observations of Dirty Sixth added credence to their claims.

This negative social construction of Dirty Sixth hurt participation on two fronts. First, if venues on Dirty Sixth were threatened in the policy arena, public support would be extremely low. Second, and probably most damaging, is that if venues elsewhere that were beloved were seen as remotely resembling Dirty Sixth, public opinion about them could become more negative. This could ultimately threaten the existence of venues that Austin's artistic community loves. This particular aspect of negative social construction 
of place will be discussed more in the next subsection involving the much-loved Red

River district. Ron gave me an overview of the locals' view of Dirty Sixth.

Ron: There is kind of a turning up of the nose to the Dirty Sixth Street crowd. ... God, if you're on Dirty Sixth, you're there to just get hammered, grab ass, and get lucky for the night. You're not out in Austin for the real Austin. See, the music venues - and I'm going to sound snobby here, and that's fine - on Sixth Street are fairly garbage. Now, there's the Parish, the Vulcan Gas Company, and Dirty Dog, and Cantina 512. Other than that handful, everything else there is just shit cover bands and what have you. It's just purely soundtracks to shot specials. So there is a bit of a great unwashed masses view of the vibe on Sixth Street amongst music fans in other parts of the city.

Amelia: But that's just with the fans, right? Not the musicians themselves?

Ron: No. I think the musicians are part of the, "That's fucked up. That's horrible. Why would anyone do that?"

I conducted an observation on Dirty Sixth on a Saturday night in the summer of

2017. The photo below in Figure 7.13 is an overview of one part of Dirty Sixth.

Figure 7.13: Dirty Sixth overview (Pridemore, 2017)

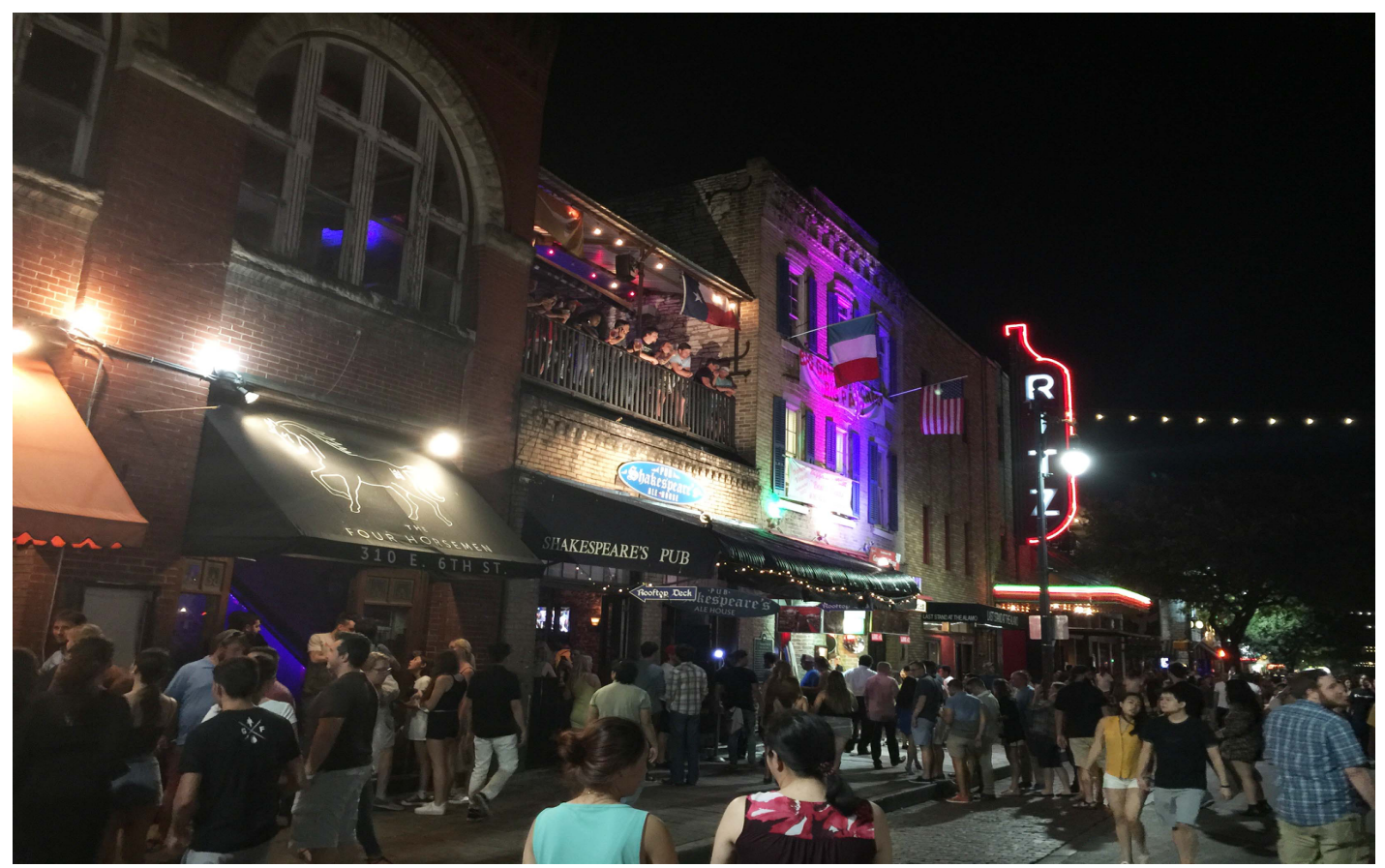


Based on my Dirty Sixth observation, I will confirm that many of my interviewees' and secondary source writers' assertions are true. When I crossed Congress Avenue and made my way onto Dirty Sixth, the street went from relatively quiet to shouting, whooping, yelling, cheering, and all sorts of sounds related to drunken revelry. The debauchery was quite evident, especially as I watched a man walking through the drunken-majority crowd with a giant inflatable sex doll. Vomit was ever-present, such as when I tried to take an elevator but could not take the first that arrived because the bottom was completely covered in reeking, festering vomit. I witnessed several pedi-cab drivers with their vehicles labeled "drunk cycles", and I was literally almost run over by a speeding pedi-cab driver while in a crosswalk. Two men yelling for me to look out and yelling at the pedi-cab driver for his recklessness saved me.

The tourist trap description the locals gave me seemed to definitely fit. Most of the bars I entered on Dirty Sixth had a western theme, but it seemed like, as I put it in my observational notes, "a bad version of the Whitehorse Saloon or something on TNN (The Nashville Network) in the 1990s". There were large signs telling people not to dance on tabletops, and cowboy décor in practically every corner, even in the restrooms. Another bar featured a mechanical bull that could be viewed from a window as crowds cheered for those riding it. A man stood in the street in a cowboy costume standing outside for tips for tourist photos, and there were plenty of T-shirt stores with things such as, "I got drunk on Sixth Street" on them. Like the interviewees told me, most of the music I heard were cover tunes.

Other observers, whose accounts were in secondary sources, noted much of what I did and were far less restrained. Curtin (2015b) wrote about his time observing Dirty 
Sixth for five straight nights. Curtin (2015b) did observe some musicians playing original music that he did not expect to find on Dirty Sixth. However, he also noted bands playing "excruciating" covers, a bar "packed with patrons dancing to trap remixes and three girls who've jumped on the DJ platform to shake their asses", and a man who "vomits up his bar tab". He wondered why Austin musicians would "shelve true creativity" to play on Dirty Sixth, but he also noted the money that was in their tip jars (as cited in Curtin, 2015b). On one of his last nights on Dirty Sixth, a "Sunday bloody Sunday" (as cited in Curtin, 2015b), he did enjoy a docu-concert at the Alamo Drafthouse Ritz theater. However, here were some other aspects of his account that day.

By Sunday bloody Sunday, Dirty Sixth has worn on me, and I'm dreading yet another night on the charmless strip. While fueling up on history's worst slice of $\$ 4.25$ pizza, I admire a new plaque outside the Alamo Drafthouse Ritz. ... Vacating the cinema, my good mood is downturned by the sound of a band on the roof of the Blind Pig performing "Dynamite" by Taio Cruz. I wish I had that $\$ 4.25$ pie crust to jam into my ears. I'm right back where I started on Wednesday - listening to musicians disgracing themselves with garbage pop covers. It's all part of the cacophonous soundtrack of Dirty Sixth (as cited in Curtin, 2015b).

Curtin (2015b) also echoed Ron's statements about how men on Sixth Street behave, with the "2 a.m. cavalcade" (closing time for the Sixth Street bars) and "males with pit bull aggression circling women". This mirrored Penelope's view of how women are treated on Sixth Street.

Amelia: One guy I interviewed early on basically called Dirty Sixth a place to, pardon my French, get shit-faced, grab ass, and get lucky. That's how he put it and not in a positive way.

Penelope: That's sounds like what dudes expect to get on Dirty Sixth. That's for sure. 
Interviewees often told me that Dirty Sixth was not an authentic experience and not the "real Austin". Besides the tourist-oriented aspects I noted above, I also noticed that some parts of Dirty Sixth seemed to be copying New Orleans, with New Orleans' trademark fleur de lis symbols and the names of New Orleans streets on signs and locations. Scantily clad women graced the windowsills of one nightclub, as some did on Bourbon Street. One such location with New Orleans imagery is shown in the photo below in Figure 7.14.

Figure 7.14: New Orleans logo on Sixth Street bar (Pridemore, 2017)

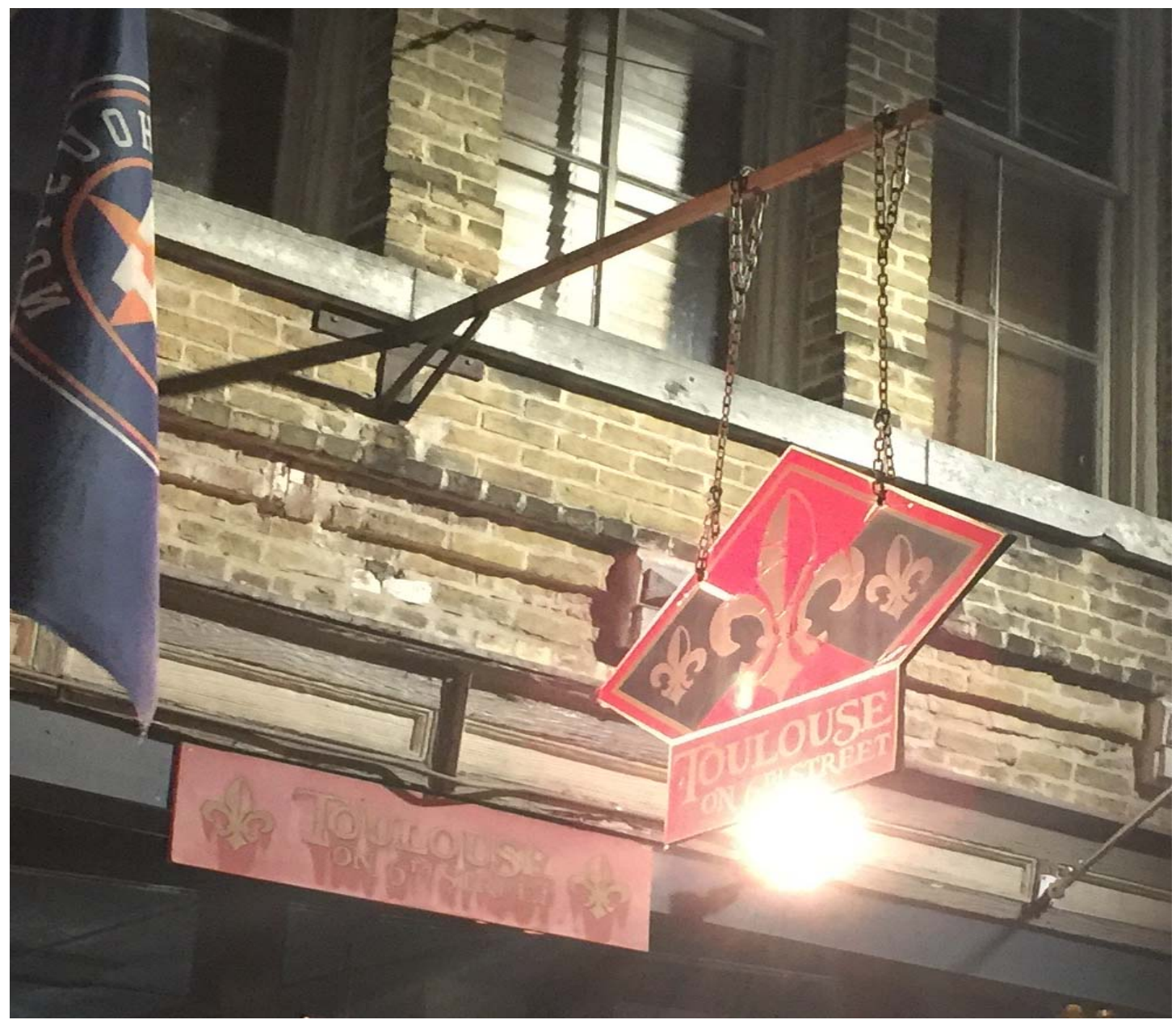


An observation I made, though, was that these parts of Dirty Sixth were not only a copy of New Orleans but also watered-down versions of it. One of the people, like those on Bourbon Street, working to catch the crowd's attention on Dirty Sixth, also carried a live snake, like two people I observed did on Bourbon. However, the snake she carried was far thinner and shorter, practically a necklace, compared to the Bourbon Street snake holders that draped giant snakes across their shoulders that were long enough to reach the ground on both sides. The snake I saw on Dirty Sixth would be, at best, an appetizer for one of the snakes I saw on Bourbon Street.

A couple of stores also resembled some of New Orleans' voodoo stores, such as this storefront in Figure 7.15 that featured several freaky animal masks and books from H.P. Lovecraft, along with stickers that read, "No one gives a SHIT about your band," which seemed to echo some of my interviewees' assertions about the Dirty Sixth cover bands. 
Figure 7.15: Sixth Street animal masks in window (Pridemore, 2017)

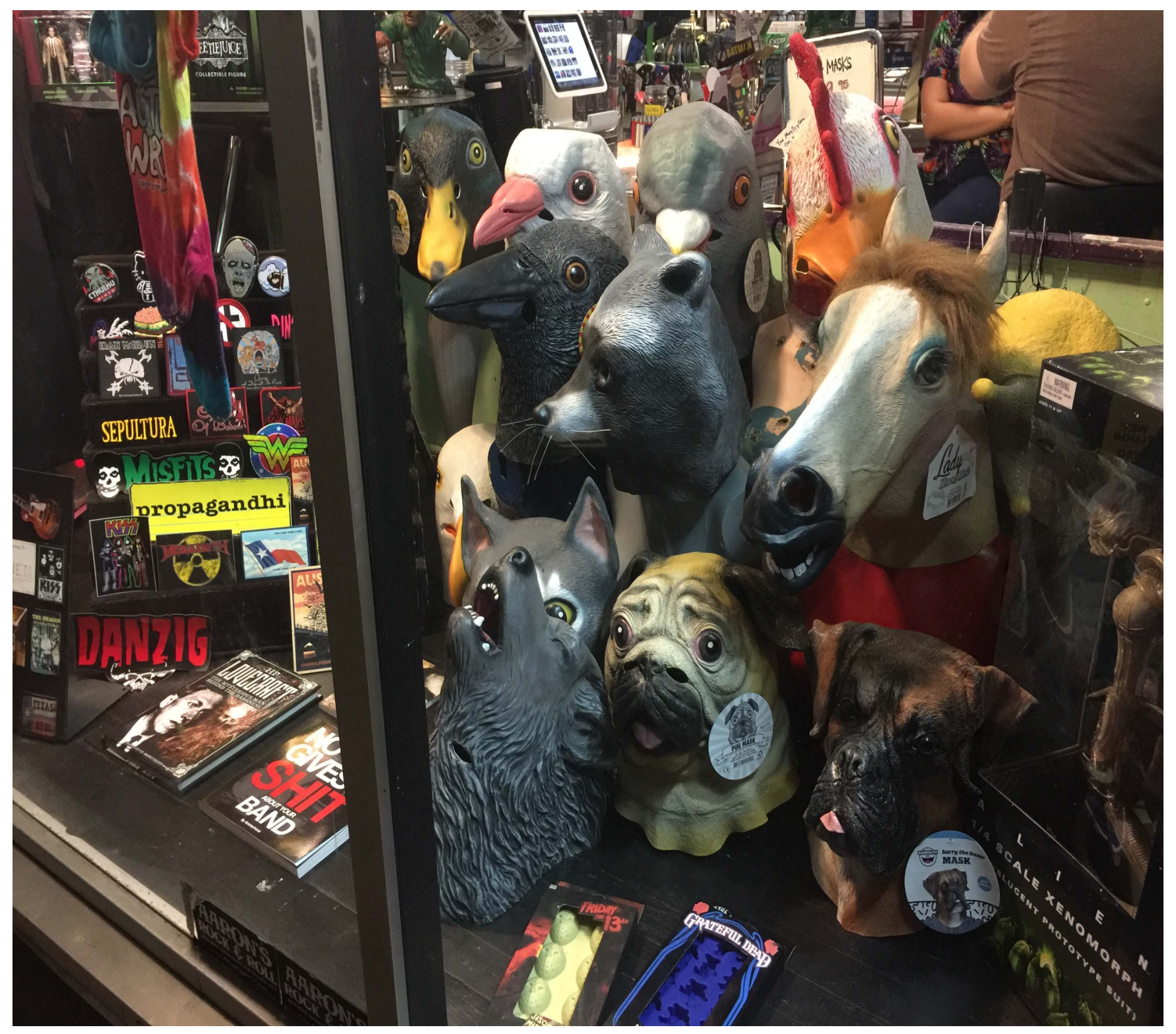

According to Curtin (2015b), Dirty Sixth was not always viewed this way. A man told him that in the early 1990s, "Sixth Street, with venues like Steamboat and Black Cat, was ground zero for original Austin music before eventually being overtaken by cover bands. 'You know the Sixth Street drinking game?' he asks. 'You drink every time you hear a Stevie Ray Vaughn cover"” (as cited in Curtin, 2015b).

Sirius, one of my interviewees and an Austin musician, also noted the negative image of Sixth Street because of its cover bands and tourist trap image. 
Sirius: As a local musician, playing a Dirty Sixth Street gig is assumed to be really playing to tourists trying to find that instead of original music that is more creative and just more fun for the musicians to play. Sixth Street just really is a tourist trap and kind of more of a party scene. So having those more serious venues with original music is seen as very important. It's nice for locals, too, to see their local bands play in these (other) bars.

Lily and Andromeda, a city planner, both said Dirty Sixth had a "frat boy" image.

Lily also noted how Dirty Sixth had changed over the years into something negative and said it was unsafe.

Lily: Dirty Sixth is frat boy land. It used to be very cool, and in my day, when I was younger and would come to Austin, it had great restaurants, great music, really cool stores, all of that. Now, it's just... Don't go. I tell people, "Don't." ... It's dangerous too, by the way. There's a lot of crime. A lot of bad stuff happens.

\section{Red River Crime: Possibly shifting into negative social construction of space}

The interviewees, though, had the exact opposite sentiments about the Red River district. As I will further explain in the next chapter, Red River was seen as a place with "real Austin" original live music from local bands, a more comfortable and tamer atmosphere, and welcoming venues. The problem was that, outside the venues, crime was a problem. This, some interviewees warned, could be the ultimate undoing of the Red River district especially if members of the public at-large connect it with nearby Dirty Sixth - and that could hinder participation that could save Red River if it is continually threatened. If crime makes the Red River venues lose in the figurative court of public opinion, this could make it easier for anyone seeking to profit more from prime real estate on which the old venues stand to shut down the venues with less public backlash or even public support, as Schneider and Ingram (1993) point out about less powerful and 
negatively viewed target populations. Almost all club owners leasing their properties rather than owning them would make this even easier.

Lily said the Red River venue owners work extremely hard to do what they can to make Red River as actually safe and look as safe as possible. This is especially important, she said, when taking the public's view of Dirty Sixth into account. Red River finding itself equated with Dirty Sixth would be consequential, and not in a positive way. They work to keep their casual, third place (Oldenburg, 1999) image (as will be further discussed in the next chapter), while still making sure their buildings are clean and safe.

Lily: I think the venue owners on Red River do have concerns about safety and things like that because they don't want Red River to become Dirty Sixth. They've seen the issues. ... The first time somebody is hurt or killed down there, it will impact all of them. It doesn't matter whether it happened way up there on the edge or in the middle. It impacts everyone. ... People won't come down.

I'll never forget what happened to Deep Element in Dallas, when they had a couple of shootings.... It took a long time for them to bring it back around and beat the perception. I know this from downtown revitalization. It's all about perception.

In an Austin Chronicle story, Red River nightclub owners and managers (as my interviewees did) described trouble not associated with the bars but with transient populations who are "creating an unappealing business environment on the walkable music strip" (as cited in Curtin, 2017b). Red River is located near social service agencies such as the Austin Resource Center for the Homeless (ARCH), but a nightclub owner quoted in the news story emphasized the homeless were not the main problem (Curtin, 2017b). People such as the drug dealers preying on them were. Another Red River owner quoted in the news story shared his concerns, as well. 
My clientele doesn't want to hang out on the street because it's not safe. Ultimately, I don't think we'll be able to survive if the streets stay like this (as cited in Curtin, 2017b).

In his interview with me, Seamus said that crime has been bad in Red River for decades, but it is less in the bars and more on the street now. The business owners, he said, are having stakeholder meetings with city officials and trying to tap into funds for additional police patrol hours on Red River.

The drug dealers preying on homeless and transient populations, according to secondary sources and interviewees, have created a major problem with $\mathrm{K} 2$, originally called synthetic marijuana, but it actually has a much stronger chemical makeup from a substance called "spice" and a much stronger effect on users (Curtin, 2017b; Hernandez, 2018). Hernandez (2018) wrote that K2 "looks like marijuana but gives users a high that's more akin to smoking Drano." In 2016, Austin-Travis County Emergency Medical Services treated 1,611 K2 overdoses (Curtin, 2017b), with fifty-two people who had overdosing K2 in one day — but this was not the "only incident of mass K2 overdosing" that year (Curtin, 2017b). One Red River bar owner reported "seeing both spice and crack get sold every afternoon around the corner from his business" (as cited in Curtin, 2017b).

Penelope said the homeless who are causing the problems on Red River are particularly incendiary, even more so than the ones on Sixth Street. However, she, like others, blames the drug problem and drug dealers who prey on the homeless, especially with K2. A likely factor, she said, is also the skyrocketing rents and property taxes that are forcing people out of their homes, particularly those who used to live in East Austin, and they are now forced to intermingle with those addicted to $\mathrm{K} 2$. 
The crime situation is unnerving, but Penelope said it is especially unnerving for young women like herself who make a good portion (if not all) of their living in Red

River. This reflected related findings in New Orleans about how gender becomes even more of a factor when crime is a problem in entertainment districts.

Penelope: As a young woman walking down Red River, it can be extremely frightening. I rarely do it by myself, or if I do, I call my mom while I walk to my car and with kind of a fast walk. My parents came to visit. I went to a show on Red River, and my parents...... They were just completely terrified that this is where I hang out all the time.

I know everyone is trying their hardest. It's not easy getting a home for every single one of these people, and meeting that need is just impossible. I feel like that's a problem that the city is going to have to deal with.

This is what you get for those property tax hikes in East Austin because, now, we've got this problem and especially the drug problem. That's the most frustrating part for me, knowing that these people were probably perfectly fine before they got poisoned with K2, you know? But I would say it's a big, big factor, I think, for a lot of people.

Percy also pointed out that the crime problem is outside the venues and that this will likely scare away patrons, especially if they are women.

Percy: More so, if you're talking about crime, it is the atmosphere. The ARCH being close to Red River, the homeless shelter and stuff like that... They're close to Red River, scaring off normals from wanting to go to shows there.

Amelia: I was told there have been problems with K2 ODs and things like that.

Percy: Oh yeah. Constantly. Yeah, that's absolutely it. But it's not like someone is going to get shut down. It's just that some dude bros will come to your show, but their girlfriends or groups of girls who don't want to be harassed by homeless people or don't want to see somebody, like, drooling on themselves or whatever aren't. It definitely hurts, for sure. 


\section{Transportation and Infrastructure}

Transportation issues, particularly parking, were hindering factors for Austin's artistic community's transportation. One of their chief complaints was the high cost of parking in areas like downtown Austin, if there was parking to be found at all. The artistic community members, as well as their advocates and even some government officials, noted this problem, plus too few public transit routes (especially late at night) and the city's traffic.

Transportation issues were also a major issue because, thanks to the rents in the city's core where the main entertainment venues and government offices are, most artistic community members were living on the city's outermost edges. The rent was becoming increasingly unaffordable even there, but affording rent near the city's core was impossible. Riding a bicycle, a common transportation mode in Austin, would be impossible for the artistic community much of the time, I was told, given the distance most would have to travel and the weather with temperatures well above 100 degrees in the summer.

Making it to a government office, then, would require artistic community members to leave their homes on the city's outer edges, fight through traffic to make it to the city's core, work to find a place to park, and pay high parking costs once (or if) they found one. This is presuming that they even had a car and would not be living away from a bus route or biking across the city in 100-degree heat. For most, this was too much of a hassle to participate in local government.

On top of this, Red River venue owners and others who worked or spent time in the district noted a major infrastructure issue, dangerous sidewalks. While the Red River 
owners maintained the shabby, casual third place (Oldenburg, 1999) feel, they worked to keep their businesses clean and safe because of the earlier-mentioned social construction issues that could work against them otherwise. However, the hole-riddled sidewalks, which were something the Red River owners legally could not repair because they are city property, were extremely dangerous and could potentially have a negative impact on both revenues and the positive social construction they needed to survive.

Transportation and infrastructure problems also fueled resentment, which hindered participation further, because problems such as expensive parking and finding transportation from the city's outer edges also ate into the artistic community's limited earnings. This was particularly the case for working musicians. Because they have to do load-ins and load-outs with their gear and find a place to park on top of that - which is almost always expensive near the city's venues — for the time they are playing a gig, this created both financial and logistical problems. While infrastructure was, at the time of the study, not sparking as much bad blood as the parking issues, it had the potential to erode relationships between the artistic community and government more over time because not all of the transportation issues were directly tied to government (i.e., Some of the expensive parking lots are privately owned.). Infrastructure problems, like the holeriddled sidewalks in Red River, were ones that were entirely government's responsibility and left the affected populations at government's mercy if they were to be repaired.

\section{Parking}

During my first observations in Austin, I discovered that getting from my car to the observation site was not cheap. To observe one government meeting for which I had to find parking in a private garage, I had to spend \$24 to park. Going through my 
financial records for this dissertation, I discovered I spent about $\$ 11-\$ 12$, on average, each time I had to pay for parking in Austin. That average could have been much higher. The parking pinch became much lighter toward the end of my Austin fieldwork when I found a certain location that, at the time, offered very inexpensive parking — until many people starting buying reserved spots in it. Availability became an issue, as well, with my having to park as far as about a mile or farther away from places where I would do work. This especially became an issue when city council meetings were known to last past midnight. On top of this, some garages closed at certain hours, meaning that someone may have to leave a meeting or lose access to his/her car. Towing policies, which are extremely commonplace, varied, and highly enforced throughout Austin, are something one must consider too.

For members of Austin's artistic community, this is a daily reality and what keeps them from having a greater voice in city policymaking. They literally cannot reach and/or cannot afford to reach venues where they could be heard. To make their situations even worse, parking costs ate their incomes when they would go to work at gigs, which exacerbated the affordability situation.

Narcissa, an Austin musician, explained how the parking situation is especially painful in this exchange I had with her.

Narcissa: I remember talking about this with one of my bandmates... Most people do not necessarily live in central Austin. So you're driving typically downtown, a lot of the time, to Red River to paly a gig at one of the clubs on that street or in that part of Austin. So you have to park, or you have to drop your stuff off, and then park.

Sometimes, I've paid more for parking than I've made off the gig that night. Actually, a lot of times, I've done that. 
Amelia: About how much do you spend on parking every time you have to go to Red River or downtown?

Narcissa: It depends on what time the show is. One time, I had to park in this one spot, which I knew would be super expensive, but it was Saturday and was already super busy. I spent, like, $\$ 14$ or something for parking for about two hours. And I was like, "God this is so stupid."

Amelia: So, if you have to play a gig on Red River multiple nights a week, then you're spending almost $\$ 60$ or so, right?

Narcissa: You could. Hopefully, you will be able to find something on the street. But yeah, that was one thing I know they were discussing - somehow trying to validate parking for musicians, but I don't know how they would go about doing that.

Parking is a factor for Helena when she does anywhere in Austin and for any purpose, period. She saw how this could be a major hindering factor for anyone who wants to participate in local government.

Helena: I won't go into the new library (downtown) because I'm not finding parking. If there is any perception that I may have trouble parking, I'm not going to go there.

Alastor noted that cities must be cautious of policies that may, on the surface, not appear related to artistic communities, such as noise ordinances for music venues, but will nonetheless have a major effect on them. One such issue is parking, especially for people who have to load and unload gear.

Alastor: We definitely need to build a system so people have a way to talk to city government because there are some real policies out there that are not arts-based that are going to affect people who are trying to drive down and load their gear and park, virtually overnight, to do their jobs. It's not an easy situation. That's for certain. 


\section{Public Transit System Issues}

Information from my interviewees, participant observations of my own, and secondary sources revealed major problems with transit in Austin. These problems included people in the artistic community having no bus routes near them, very little light rail transportation, and too few late-night transportation options. This hindered participation, again, because the artistic community members who did not have cars, did not want to ride a bicycle in the extreme heat (if they had bicycles) or could not afford the expensive parking if they did have cars, could not make it to participation venues from their homes that were often in outer-lying areas. For those who did not have cars or could not afford parking, this also created a participation equity issue.

This was exacerbated even further because, as mentioned above, meetings can be extremely long and last well past midnight. Those relying on bus transportation will then likely have to leave before their time to speak comes. Furthermore, artistic community interviewees and a participant observation revealed that ride share services like Uber and Lyft were too expensive, especially when considering so many of them live on the city's outer edges. At one point, Uber and Lyft were not available, anyway, because of a dispute the companies had with city government (Austin American-Statesman Staff, 2017; Wear, 2016). Other ride share services opened in Austin afterward, and Uber and Lyft have returned.

Narcissa said public transit was lacking in the city, especially for people who carry any kind of gear, like musicians. While taking public transit may be logistically impossible, anyway, for those with large instruments like drums, it could be possible for those with more portable instruments like guitars. She has seen this in other cities. Still, 
the lacking transit issue, especially with the lack of light rail, makes taking public transit too much of a hassle for those in the artistic community. A lot of people use ride shares like Uber and Lyft, but those are expensive. Add in the factor of 100-degree (or higher) temperatures in the summer and the distance, and riding a bicycle is also impossible.

Narcissa: I don't know of anyone that takes their stuff on the bus with them. If you're taking just something like your guitar with you or maybe they have a backline. I don't really see that as much here as I do in other large cities. I was in London a couple of months ago, and I saw people all the time with guitars or some sort of instrument, depending on where I was in the city. But you can get to places there. People have their instruments on their backs or carry them. It's not like that here.

In the summer of 2018, Capital Metro, the public transit system that serves Austin and some from surrounding areas commuting to Austin, began its "Cap Remap" revamp of its bus routes (Wear, 2018). It added eight more "frequent" routes, with buses showing up at least every fifteen minutes, seven days a week and 120,000 extra hours of bus service per year, an increase of about ten percent.

Cap Remap did present some problems, even before it started. Although it did have thirteen existing routes offering coverage that reach existing customers by a halfmile that would run more frequently, fifteen routes were eliminated (Wear, 2018). An estimated six hundred regular riders, the agency estimated, will be farther than a halfmile from bus service. Fifty-two routes would change — some, significantly. Capital Metro posted signs at bus stops alerting riders about what would happen to their routes and brought "ambassadors" to stops to answer riders' last-minute questions. Capital Metro provides services such as MetroRapid, which operates faster because it has fewer 
stops, and MetroExpress for people in outerlying areas (Capital Metro, 2018a). However, its MetroRail service only has one route.

One of the biggest points of contention for the artistic community was Capital Metro's lack of late-night transit in terms of routes and hours. Most routes end around midnight. Capital Metro does operate "night owl" routes that run from midnight until 3 a.m. - at the same time as at least one city council meeting ended (Capital Metro, 2018b; Hernandez, 2018). However, there are only five night owl routes. This creates two major problems for the artistic community, for both their participation and for their ongoing economic woes that fuel resentment. With government meetings lasting well past midnight, artistic community members may not be able to catch a bus, especially on a route that runs near their homes, after their time to speak finally arrives. In terms of their working conditions, bars in the city typically close at 2 a.m. This seems like it would just give them enough time to catch a bus, but those who work at these businesses will be doing closing cleanup well after the patrons leave. This means they must have a car and pay the expensive parking, pay for an expensive ride share, hope to get a ride from a friend, or, at worst, wait until the next day's bus routes begin around 5 a.m.

Like Narcissa, Pomona also noted that transit in Austin does not work as well as it does in other cities and noted the parking problems. This, she said, affects both participation and how those in the artistic community make a living.

Pomona: I think that, definitely, one of the barriers (to participation) is that we're becoming less and less of a commutable city. It's not like Chicago or Toronto or other large cities like that. We have a bus line, and we have a metro area, but it's not functioning the way that it should be, and it doesn't touch all the parts of the city. 
If we have stakeholder meetings and things like that, they have to be in kind of a central location with parking, and they will have to be kid-friendly and ADAaccessible, of course. It has to be a number of things. Maybe that would be a barrier.

...If you're talking about Austin proper, we're looking at about a fifteen-mile span, and no disrespect to the public transportation system. It's wonderful. But you know, it's not mass transit the way there is in other large cities.

Transportation is an issue. Even when we do have an event in central Austin, musicians also have to park down there. You have to put your car somewhere, or you have to wait on buses.

Even for those who have the time to stay as late as some government meetings

run, Padma said, lacking bus service can still stand in the way of them being heard.

Padma: It could be that you have the time, but you don't have a car and you don't live on a transit route or the transit route near you doesn't run late at night enough for you to get home. If you did take the bus downtown, you wouldn't be able to get home because, sometimes, city council meetings go until two or three o' clock in the morning.

I decided that I needed to experience this, myself. For observations, I opted to try out Austin's transportation systems, public and private, to reach my South-by-Southwest observations in March 2018 because attendees were warned to not even try to park there. For the first day, I used Lyft, and even though I was not traveling on a peak day and during peak hours, the trip to downtown from my home on the outer edges of Austin (I could not afford the downtown rents, either.) and back cost about $\$ 100$. Knowing that I would go broke after several days of that, I opted to take Capital Metro's bus service that still had its $\$ 7$ rate despite the surge of users. This was quite the experience.

My walk to a bus stop was not an especially long one, as some artistic community members are experiencing. It was not just outside my door, either. A bus arrived not very long after I did, but the problem was with Capital Metro's mobile app that displays the 
bus routes I would have to take to my destination. At first, the app seemed easy to read. A photo of part of that route's screenshot, with information that could identify my residence obscured, is below in Figure 7.16.

Figure 7.16: My Capital Metro route screenshot (Pridemore, 2018)

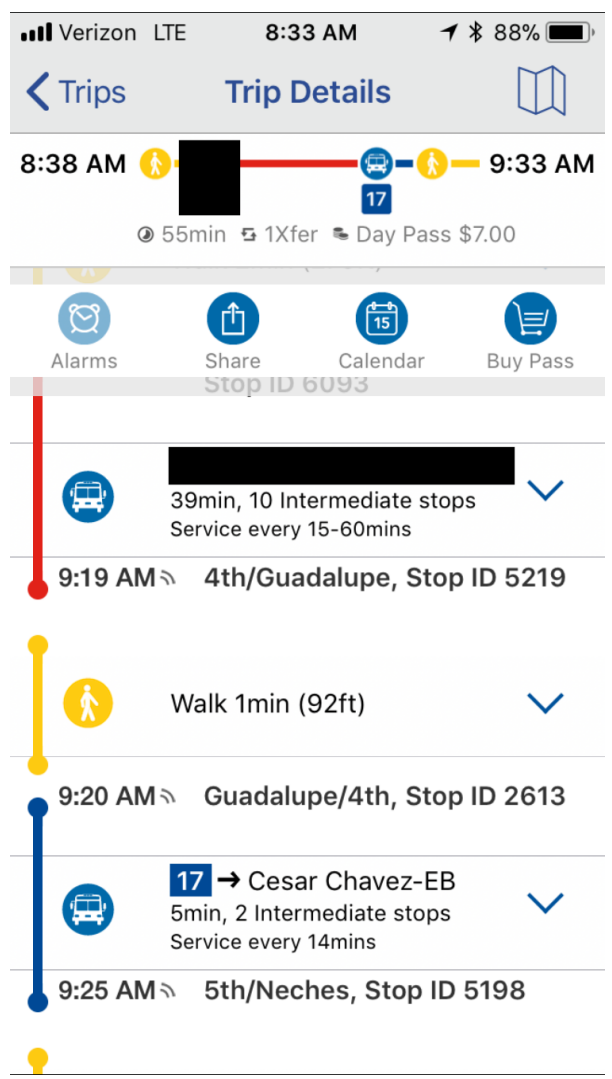

This ride presented two problems, though. First, while I was on the bus, the route on the app constantly changed. Therefore, I was glad that I committed the first listing with four stops to memory because the app constantly suggested new stops. It also, unlike other transit smartphone apps I have used, did not show me where I was on the route in real time. Therefore, I had to rubberneck to look outside bus windows as we sped along to see both what roads the buses were on and where the stops were. I will say that SouthBy-Southwest created an exceptional situation, but even then, I was able to reach the 
event in decent time compared to other transit systems I have used. Still, this was rather hair-raising too.

Going home in the evening was a different story. I opted to take the rail route, and trains were parked outside of South-By-Southwest's epicenter. I found myself crowded onto the train with other passengers groaning as the train slowly slogged along. I wondered if perhaps the bus would have been a better mode of transportation but then I realized I would be in an apocalyptic version of Austin's late afternoon traffic. I did have to take a bus at the end when reaching the MetroRail station closest to my home, and the bus was not entirely easy to find. I also had to wait for the bus to make several rounds around the area where I was living before it came to the nearest stop.

I basically collapsed as soon as I walked through the door — and thought of what it was like for those in Austin for whom taking such a trip was not an option.

\section{Traffic}

If members of the Austin artistic community had cars, then, they had to deal with the city's traffic. Interviewees told me that the city's traffic, particularly on Interstate 35, not only affects their livelihoods but also inhibits their ability to participate in government. For evening forums, if artistic community workers do not have to work then, they will find themselves stuck in heavy commuter traffic if they have to leave a daytime job.

Austin's traffic has been ranked as the $13^{\text {th }}$ worst in the nation (Stone, 2017), and the Interstate 35 corridor between Slaughter Lane and Airport Boulevard (around the south-central area of the city) was ranked the sixth most congested in the United States, with the average travel speed during peak commute times being about 23 miles per hour 
(Stone, 2017). Some interviewees noted, though, that other cities where they have lived or visited, such as New York (ranked third), Los Angeles (ranked first), and Miami (ranked tenth) (Babish, 2017) are worse for traffic than Austin, but the traffic was still a major hindering factor for both participation and for their livelihoods, with the latter, again, fueling resentment about the situation.

Severus echoed earlier comments from Alastor about how policies that may seem unrelated to the arts actually play a major role in the lives of those who work in that field. He also noted the traffic's ties to the fact that so many in the artistic community have had to move out to the city's edges.

Severus: We need to have more of a voice in conversations around land use and transportation. Places I think that, normally, we wouldn't see a role for ourselves, except for the fact that we are citizens... As the city grows, commutes to gigs take longer. That has a material impact on people I know. I know several people who are doing fewer gigs because of transportation.

One of my buddies got cast in a play, but he couldn't make it across town from one rehearsal to another time, so he couldn't do it. That's because he's had to move farther out onto the edges. He doesn't live in central Austin anymore. I have one of those guys who plays ten gigs a week for fifty bucks or a hundred bucks. Basically, as a working musician, that's all he does, and he's just playing happy hour in one place and then running over to be a sideman for another show and running the next day to have a rehearsal and then a show. He was saying it too. He lives way far south, and he can't pick up gigs too far north because the transportation just takes too long. Traffic sucks.

So this opened my eyes to a latent desire in the community for a bigger voice on all kinds of things, not just things that were specifically for us, and we took it to heart and for their words. There are all kinds of policy issues that affect arts. Things you don't think affect the arts like transportation - it's just about anything that affects affordability and quality of life. 


\section{Infrastructure: Red River sidewalks}

One factor that also sparked resentment from the artistic community was infrastructure issues, namely the dangerous sidewalks in the Red River district. These hole-riddled sidewalks both threatened revenues and social construction the venues needed to survive. The major point with this, as well as almost any infrastructure issue, is that these are the direct responsibility of government to repair and it is almost always illegal for citizens to repair these on their own. Therefore, anyone who needs infrastructure repairs are at government's mercy. When this is not repaired and businesses, like artistic venues, are at risk as it is, this only sparks more resentment and ill will.

Seamus said that when combined with the crime situation, the holes in the sidewalks have the greater Red River community "physically walking a gambit of danger", and, for reasons both economic and ethical, they do not want people to feel unsafe when in the Red River district. Lily, when she discussed how perception and perception that an area is safe is a major element in economic development, noted how the Red River owners were working to have the sidewalks repaired because they knew the holes in the sidewalk, especially when considering the earlier mentioned social construction (Schneider \& Ingram, 1993) issues like crime.

Lily: I know the owners are talking about working with the city on repairing a bunch of sidewalks because they're literally dangerous. There are holes and stuff like that. So, we don't want to lose that casual feel, but we do want to do some basic things that are maintenance. We want to keep the area safe and clean and inviting for people to keep coming there.

...That's why I'm saying the Red River venue owners are trying to be very cognizant of what they see on Sixth Street and not let that happen in their area. They'd like the sidewalks repaired, as well as some better street lighting and 
enough to just make sure you get the idea that the area is safe, that you can park down there and your car won't get vandalized, and then you can go to all the different places and hear music.

\section{Hindering Factors Related to Other Community Stakeholders}

One of the most severe hindering factors for the Austin study involved other community stakeholders — attempts to temper entertainment zones. High-end development like hotels and condos, sometimes literally right next to longstanding outdoor live music venues, not only skyrocketed the venues' rents and property taxes but it also caused policy related tension when the wealthier newcomers would fight to quiet down or even silence the venues, despite building next to such a location with the full knowledge it was there first. This infuriated members of the artistic community, but at the same time, it hindered participation because of the uneven power dynamic between artistic community and the developers and the artistic community feeling powerless to stop them, reflecting studies involving the Third Face of Power and how repeated "beating down" of the less powerful will make that group withdraw because they believe they have no power to stop their oppressors (Gaventa, 1980; Warner, 2001; Warner, 2011).

Other problems included issues involving the literally hundreds of arts nonprofit organizations in Austin. These included having too many nonprofits and the fact that some of the organizations had major friction between them. This left artistic community members and some in government wondering who they could genuinely trust, especially when multiple people claimed to be spokespeople for the artistic community as a whole and seemed to be working to serve their own agendas. This presented another dimension 
to citizen participation studies involving trust (Pridemore, N.E. Ganapati, \& Revell, 2019). The main trust issue, here, was whether or not the artistic community members and government officials could trust those who claimed to be advocates with the artistic community's interests truly at heart.

\section{Attempts to Temper Entertainment Zones}

The largest source of tension, frustration, anger, confusion, and hopelessness or some combination of these — came from real estate developers, certain new businesses like hotels, and new residents working to temper historically boisterous entertainment zones and live entertainment venues. Interviewees told me that the Austin's near-complete skyline change just in the last few years has brought high-priced mixeduse developments, new condos, and new hotels into the downtown. Sometimes, these have located right next door to pre-existing live music venues that have outdoor music.

Once construction begins, interviewees told me, the developers will not add elements such as soundproofing into the new construction despite warnings from the city, find the venues bothersome, and either file lawsuits or pursue policies that could negatively affect the venues like more noise restrictions. This created an intense situation especially when the artistic community members loved the venues and made a living there and the raised property values threatened the venues' existence because of skyrocketing rents and property taxes. Furthermore, increased development threatened their own homes because of increased residential property taxes and rents.

This created a major participation hindrance for two reasons - anger and hopelessness. Several interviewees saw city government as being only concerned with the financial bottom line and concerned only with what brought in the most revenues, not the 
historical and cultural values of artistic spaces. The situation became even more heated when the interviewees' beloved Red River district in downtown was threatened with high-end development literally right beside the venues. This fueled animosity and a sentiment among some that, should artistic community members approach city government, none of their efforts would matter anyway, especially when pitted against wealthy and powerful developers that they believed city officials already favored over them.

First, this resembled participation equity issues because of the developers' power and wealth and related greater appeal to public officials (Fung, 2006, 2015; Rimmerman, 2011). The developers' actions resembled the Second Face of Power because of their working through inexplicit power exercises against the artistic community and the artistic community being fully aware that they were responsible (Bachrach \& Baratz, 1962; Gaventa, 1980; Warner, 2001; Warner, 2011). However, the artistic community's response is akin to the Third Face of Power in that it believed it was powerless to stop this powerful group after it repeatedly exercised power against them (Gaventa, 1980; Warner, 2001; Warner, 2011).

Just in Austin's downtown area, fourteen thousand people now live there, a number projected to double by 2040 (Novak, 2018). Only about four thousand lived there in the early 2000s. Contributing factors include the "exponential growth of the tech sector downtown that is continuing with major expansions from companies that include Google, Facebook, and Indeed" (as cited in Novak, 2018). Another factor driving the growth is attractive amenities that include "cultural attractions" (Novak, 2018). Five residential and 
hotel high-rises are set to open in downtown Austin in 2019, with some condos selling for as high as $\$ 6$ million.

The effects go beyond downtown. Between 2016 and 2017, the owner of an “average Austin home” experienced a $\$ 517$ property tax hike (Osborn, Huber, \& Taboada, 2017). Between 2012 and 2017, the average citywide tax increase was about twenty-one percent, an additional \$1,342. Local government entities, like the city of Austin and Travis County, who collect shares of these taxes will point to efforts they have done to offer property tax relief, and most entities in Austin have reduced their rates. However, "they did not reduce them enough to cancel out the effect of rising property values driven by the market demand, and those agencies continue to rake in more money each year" (as cited in Osborn, Huber \& Taboada, 2017).

Economic growth, particularly in the real estate and tech industries, might be cheered elsewhere, but it has Austin residents seething because of their aforementioned skyrocketing rents and property taxes, more crowds and highway congestion, and fear that their local and laid-back culture will be snuffed out (Personal Communication, 2017, 2018; O’Donnell, 2018). This was evident when Austin was a contender for a new Amazon headquarters - that even some city government officials did not want (Herrera, 2018b) - and when, shortly after Amazon chose two other cities, Apple announced that it would build a new campus in North Austin, on the Williamson County edge of the city limits (Sechler, 2018). While Austin city officials did not provide Apple with incentives, Williamson County officials provided Apple with about \$16 million (Cobler, 2018; Sechler, 2018). Some Austin residents were happy about the Apple announcement, but 
others were outraged because of the "prospect of higher taxes, increased rent, and strains on infrastructure" like traffic (as cited in O’Donnell, 2018).

To say this growth and development has hit the artistic community like a ton of bricks is a serious understatement. Some of the most high-profile impacts have been disputes between new residential complexes, mixed-use developments, or hotels and older, pre-existing music venues, particularly those that play their music outdoors. Besides the above-mentioned dispute between the Westin and the Nook on Sixth Street, the venues in the Red River district have fought new high-rise hotels that have been built literally across the street, next door, or just uphill from them (Curtin, 2015a; Findell, 2017a; Personal Communication, 2017, 2018; Stith, 2015a, 2015b). The photos below in Figures 7.17 to 7.20 , most taken during my observations in the Red River district, illustrate this issue in term of how close this new development is to older, more casual, third place (Oldenburg, 1999) music venues that have mostly outdoor shows and gathering places. 


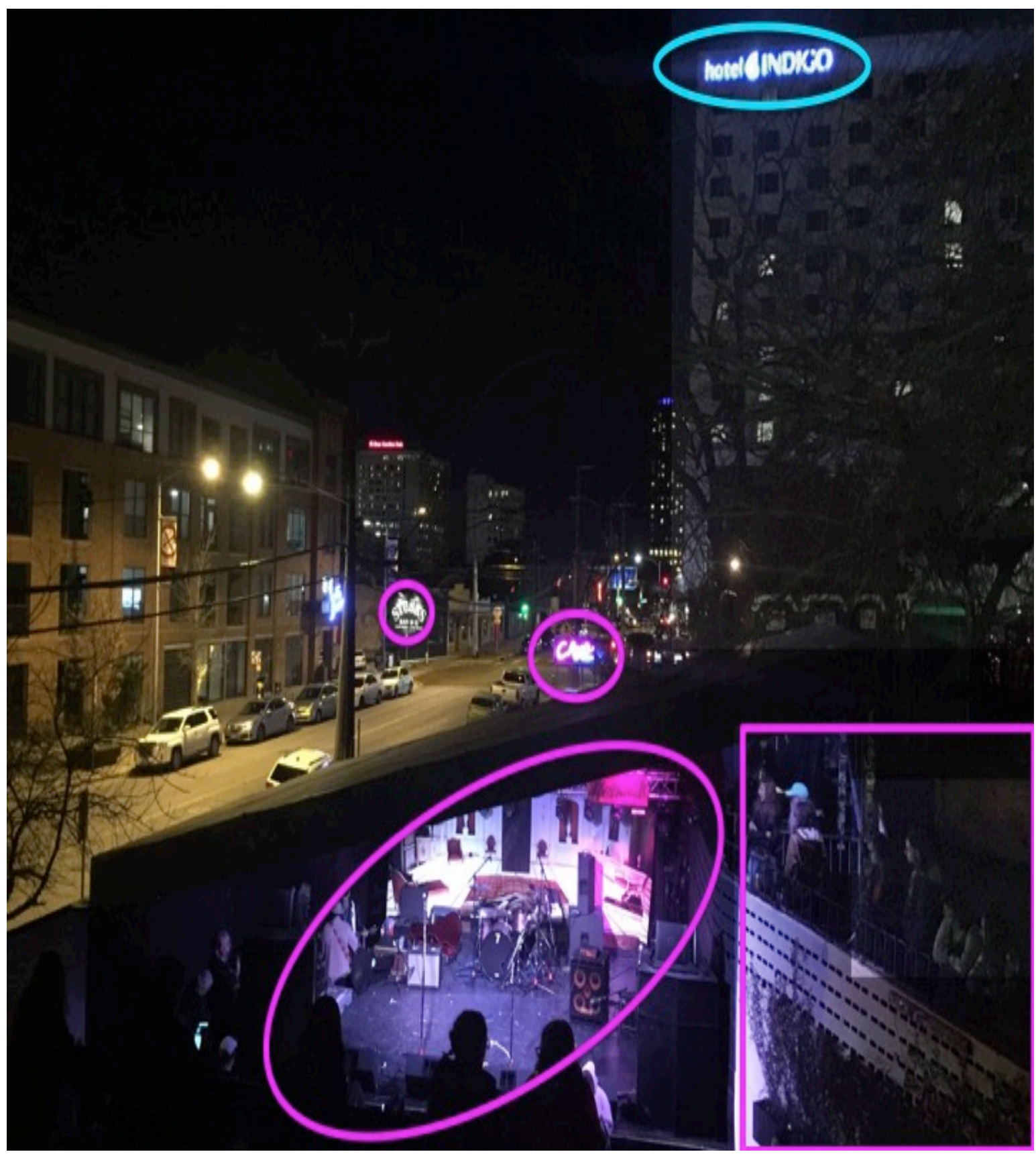

Figure 7.17, shown above, is an overview of part of the Red River district - the bars with outdoor live music and the one of the high-rise hotels that have built right next to them. The bar areas are circled in pink, and the hotels are circled in blue. The bar in the foreground is the Mohawk on Red River Street, which has its main stage covered with an 
awning but still outdoors and most of its spectator/socializing areas in the open air. The Mohawk, which has multiple levels (height-wise) of open-air spectator space, is beside a hill (One of its upper decks is in the pink box at the far right.), as is Cheer Up Charlie's, the bar in the immediate background from the Mohawk (around the center of the photo). Cheer Up Charlie's is Mohawk's next door neighbor and located at the intersection with East Ninth Street. Stubb's (toward the left side, circled in pink), another Red River venue with outdoor music, is on the next block of Red River Street but on the other side of the street. Hotel Indigo, marked in blue, is just across East Ninth Street from Cheer Up Charlie's and is tall enough to hover over the other bars.

Hotel Indigo is not the only hotel looming in the Red River district or even Cheer Up Charlie's and Mohawk, alone, as I will show in two photos below in Figures 7.18 and 7.19 . 
Figure 7.18: Cheer Up Charlie's and two hotels over it (Pridemore, 2018)

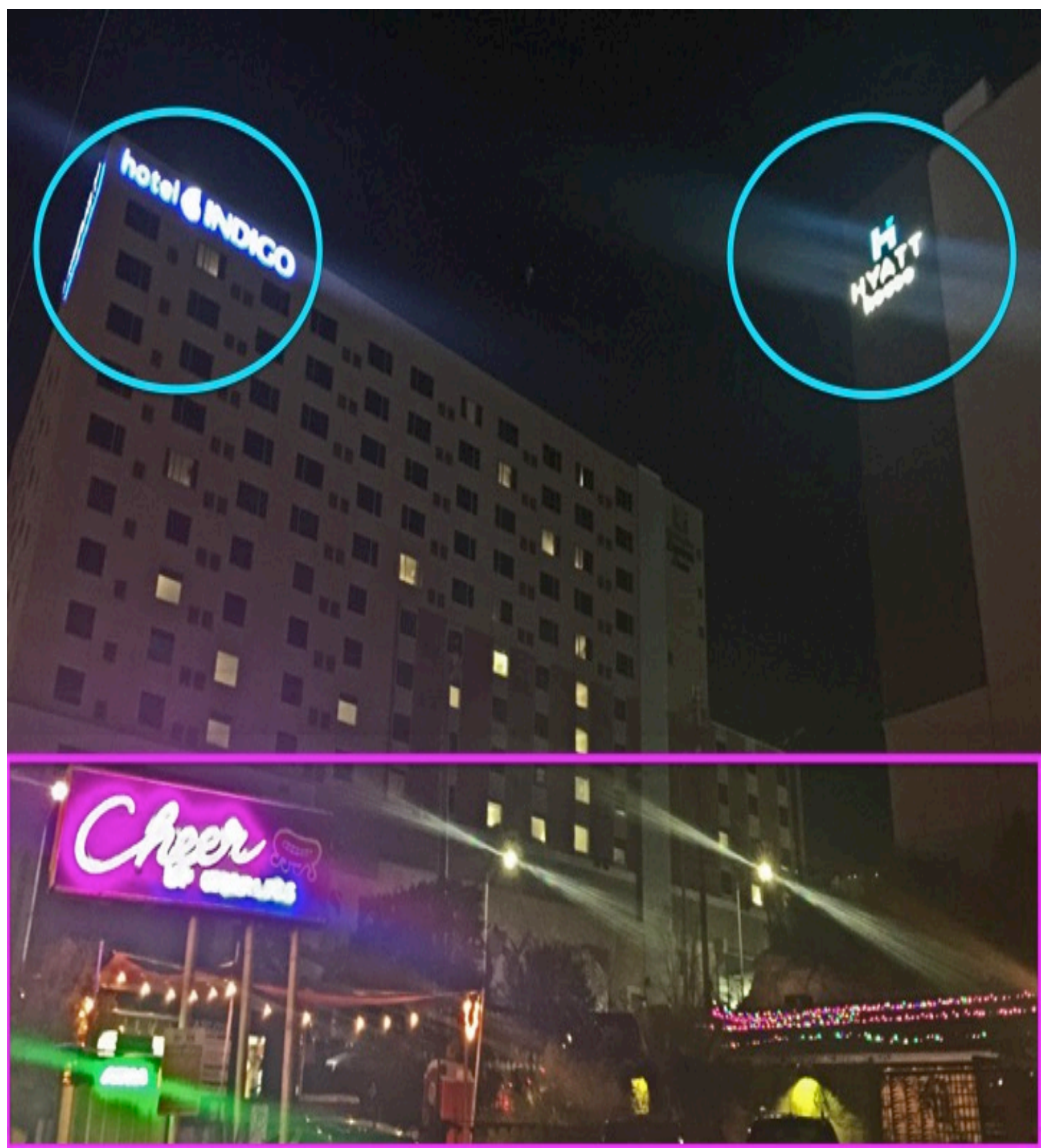


Figure 7.19: Cheer Up Charlie's, Hyatt, and rock wall (Google Street View, 2018)

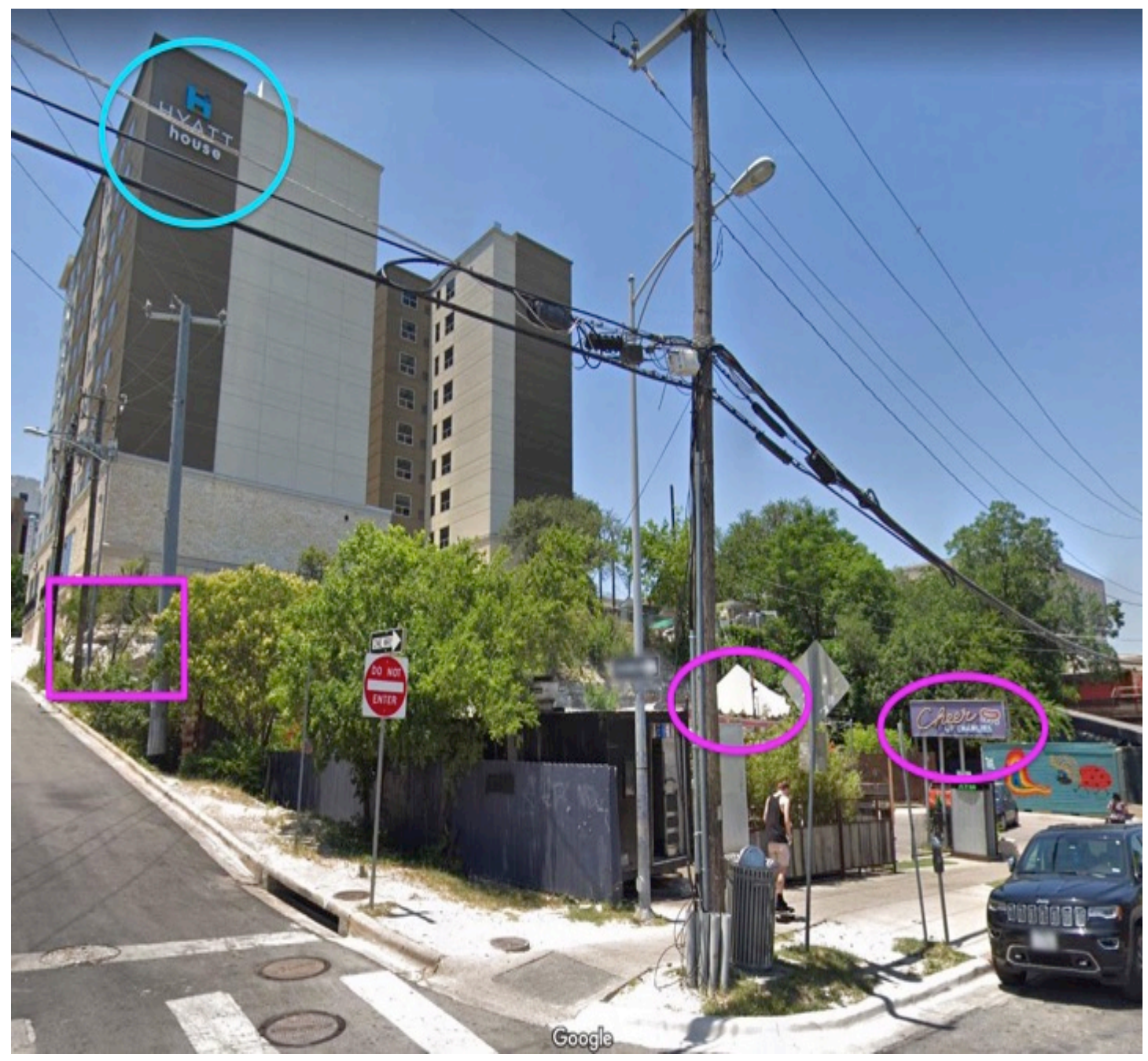

A Hyatt hotel, with its logo circled in blue in the Figures 7.18 and 7.19 shown above is directly behind Cheer Up Charlie's and extremely close to Cheer Ups' neighbor, the Mohawk. It should also be noted that the Hyatt is also uphill from the two bars because East Ninth Street (the street to the left on the second picture) is on an incline. This makes the hotel tower over Red River even more, and hills can make sound waves travel in odd directions. Figure 4.20 below has Cheer Up Charlie's sign in pink, as well as two other key elements of the bar marked in pink. The white canopy in the middle of the picture is used to cover its outdoor stage area and/or the patio near the stage. The pink 
box farthest to the left marks the location of a rock wall with several trees at the top

(which obscure its view here). This is the only separation between Cheer Up Charlie's and the Hyatt, and Cheer Up Charlie's stage is beside the rock wall — as shown below in Figure 4.20 with the canopy and wall marked with a white arrow and a star. Some of the Mohawk's upper-deck spectator areas are also along this same hillside where Cheer Up Charlie's rock wall is.

Figure 7.20: Cheer Up Charlie's outdoor stage, rock wall (Austin Chronicle, n.d.)

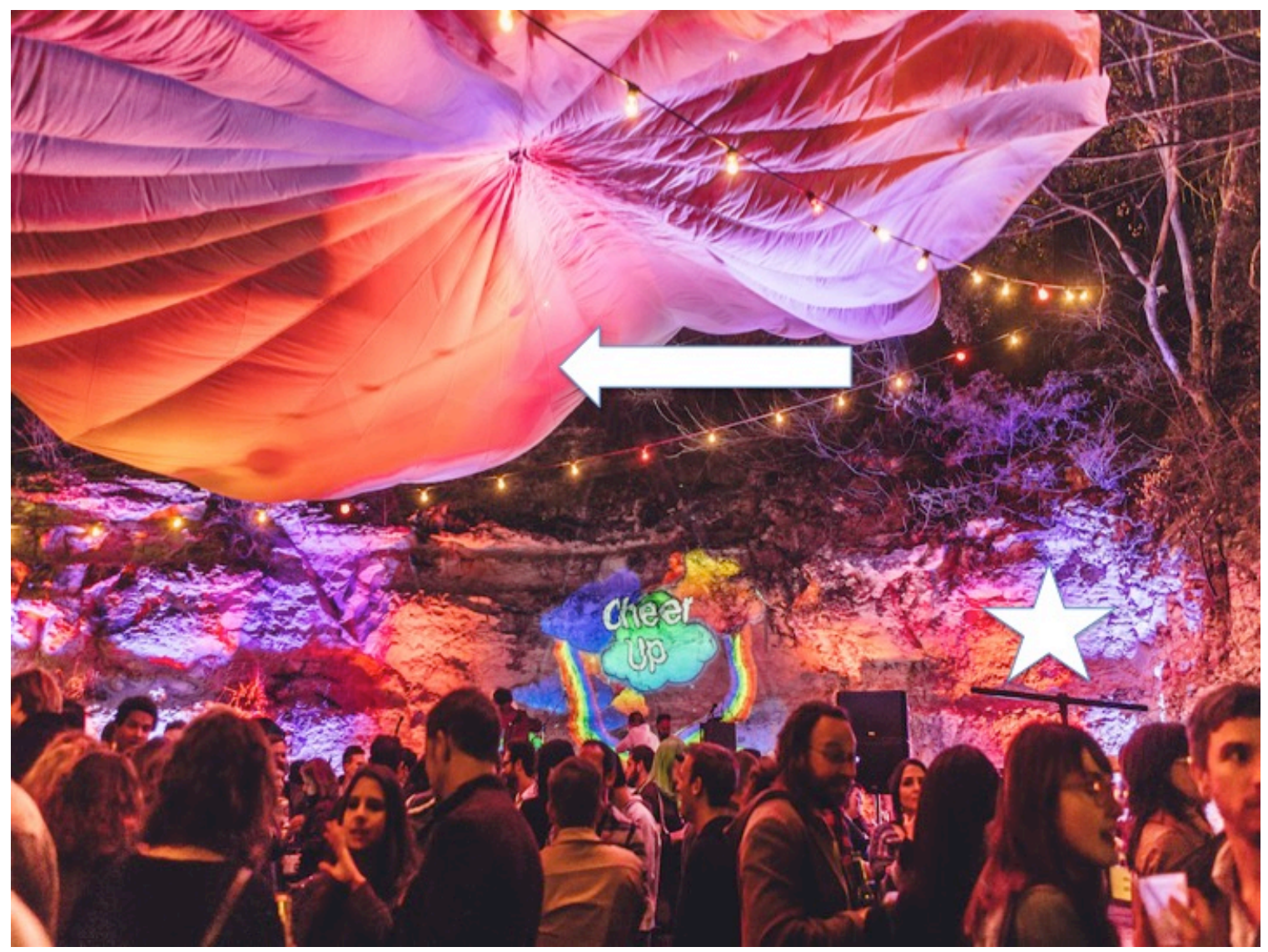

The Hyatt, alone, had an impact on Cheer Up Charlie's and Mohawk's business even when it was still developing. Cheer Up Charlie's landlord allowed the Hyatt to remove parts of the rock wall during the 2015 construction of its parking garage (Curtin, 2015a; Stith, 2015b), and the landlord allowed construction equipment and fences on the 
venue's outdoor area — the venue's main area — during the construction project. Cheer Up Charlie's owners projected that even when considering the per-day compensation they received for the days they could not use their outdoor area, the construction outside would cause them to lose more business than the compensation would cover (Curtin, 2015b). That same year, the Mohawk received a notice to vacate its dumpster space it had used for ten years and shared with Cheer Up Charlie's because the space located in a vacant alley was in a right-of-way — as well as its longstanding upstairs deck (Stith, 2015a). The Mohawk's owner believed this was a direct result of the hotel development.

This was only the beginning, though. The major problems began when the hotels opened and the noise complaints from the hotels and about the pre-existing outdoor music venues began pouring in. Despite none of the businesses receiving violations for violating city noise ordinances, complaints logged within a 1,500-foot radius of the Red River district spiked from forty-three in 2015 to 159 in 2016 (Stith, 2016). City officials attributed at least some of the complaints to new developments in the Red River area, such as the hotels. When the city began a pilot program that would slightly extend the Red River venues' hours (to be further explained in the following chapter) and collect verifiable data on exactly how loud the venues were, some local hotel managers protested the move (Findell, 2017a). This is an excerpt from an Austin American-Statesman story about the city council meeting that led to the program's beginning:

Hoteliers argued the move would hurt their business, saying they already receive too many complaints from guests about loud music at night.

"We still have an exorbitant amount of guest complaints (with music) going until midnight," said Sunni Dupree, manager of Hotel Indigo. "To expand that to 1:30 would impact my business tremendously." 
She added that hotels, while they built next to live music venues knowing there would be music, are seeing more and more corporate guests, who expect to get a good night's sleep (as cited in Findell, 2017a).

The impact on Austin's culture, history, way of life, and attempts to curtail places and practices the locals loved were the first seeds of discontent sown. As I observed in Austin and not just at live music venues like those in Red River, gathering places in the city often have properties that are majority outdoor, with restaurants', coffee shops', and other such business generally having a small indoor space for preparing food and restrooms, and perhaps a few tables. The majority of seating and social areas will be outside in a patio area. Lily, who is a native Texan, explained that the outdoor, open-air entertainment and socializing is a longtime cultural and historical staple, with Nymphadora, an Austin native, noting that Austinites simply "just love our patios".

Lily explained this has been a part of the Austin music scene's draw for many years. Austin's music venues generally began when they found old industrial buildings no one else wanted that they could rent on the cheap. Although several have been lost, many are still operating. The appeal is being able to have a drink and listen to music outdoors, she said, especially when considering the weather in Austin is generally very warm and outdoor music can be played most of the year, with only "a few months out of the year where it's just unbearable". The buildings being older and more casual are also major parts of the draw, too, because of the laid-back vibe. She also pointed to the attitudes toward the development around the Red River bars. Severus also noted the market conditions that are making this situation a harsh reality.

Lily: So you want to move them some place new? Then, what would be the point because the charm of going down there is the old buildings and the venues in and 
of themselves where you can go outside and stuff like that? (Lily puts on a mockingly snooty voice.) "No, and now, we're going to put in a new-mixed use development."

No. It's not the same.

Severus: We're losing spaces because the real estate market is out of hand. When leases are ending, the rents are tripling or quadrupling, or they're not renewing leases because the owner wants to redevelop it as a condominium project or mixed-use development. We've lost two theaters in the last eighteen months. We lost a major 12,000-foot dance studio in South Austin. We're about to lose 30,000 square feet of visual arts studio space in two different facilities, and, not to mention, the innumerable little single-studio spaces or co-ops between four artists in a tiny warehouse or a home.

Hermione drew a view of what she saw as a clash between this growth and the longstanding artistic community and its longstanding traditions when she displayed her view of the city's reality in her narrative map. Her drawing is shown below in Figure 7.21 . 
Figure 7.21: Narrative Map (Reality): Hermione, Austin musician

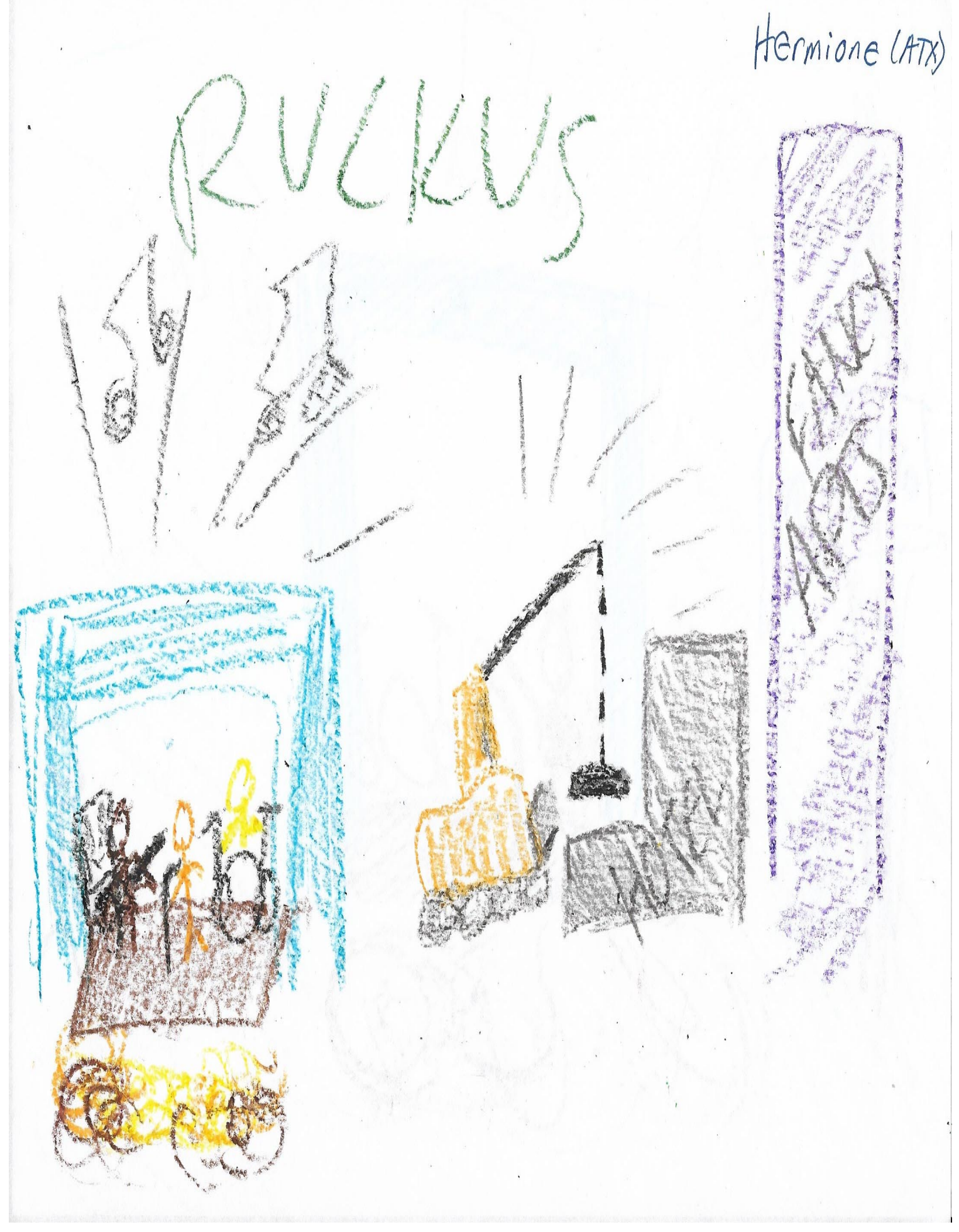


Hermione explained that the "RUCKUS" she wrote at the top of the page displayed the attitude of both the artistic community and developers. The two groups, though, have sharply different opinions on what and who is causing a ruckus.

On the left hand side of the drawing, she drew an outdoor music stage with the different flesh tones used below to represent an ethnically and racially diverse audience. The stage and the audience she drew represents her positive view of her favorite music venues, with her saying she used blue, a favorite color of hers, while thinking specifically about Cheer Up Charlie's rock wall behind its stage and the hotel looming above it.

The stage — and the arts in Austin it represents — is being pushed to the side for construction of hotels and high-priced apartments that are shown on the right, Hermione said. For developers and those in the hotels and high-priced apartments, the arts are causing a ruckus through creating noise that disturbs them. However, the artistic community considers the developers the ones making a ruckus because they are also being noisy but most importantly, creating a social ruckus through working to curtail what the artistic community does, hurt the spaces the artistic community exalts, and what the artistic community loves so dearly. It also represents the related city policy debates. This is part of the exchange I had with Hermione when I was asking her to explain this drawing.

Hermione: It's sort of demonstrates the noisy construction versus the noise of the music. They're different functions and purposes, but it also shows the different ways that they are treated by policy.

Amelia: How would you say this (points to the stage) is treated by policy, and that (points to the construction) is treated by policy?

Hermione: Well, I'm kind of thinking about the conflicts and issues that have arisen in the last few years with new constructions. There was the whole thing 
with a new hotel being built. I don't even know which one it was... And then, they were submitting a noise complaint.

...So yeah, it's just that kind of interesting juxtaposition of hotels and things, themselves, creating a lot of noise and disruption in building their stuff. And then when it comes to noise that is actually part of the culture, then, all of a sudden, they're like, "Oh no! What's that? Shut your noise down! City, help us get rid of this pesky noise!" Well, you just spent the last two years making a ruckus with building this hotel that isn't benefitting the community, necessarily, in the same direct way.

Throughout my travels in Austin, I seemingly found large construction cranes building high-rises in almost every area of the city. This was especially true in or near downtown, but practically no place was immune. Helena noted how East Austin, a historically minority neighborhood, has become "trendy" now, with developers advertising high-end amenities there and raising costs of living for existing residents. Barriers against sidewalks or in the middle of streets were also ever-present. Even in areas like the Red River district, which had venues that would likely have Ray Oldenburg (1999) saying, "Yes, this is obviously a third place," if he so much as put one foot inside the door, higher-end bistros were now just a few doors down from some of the older bars or next door to an older, colorful restaurant. Figure 7.22 below shows just a small portion of the major construction happening in Austin. I took this photo near the city's new central library and during a short walk to city hall. 
Figure 7.22: Downtown Austin construction cranes (Pridemore, 2018)

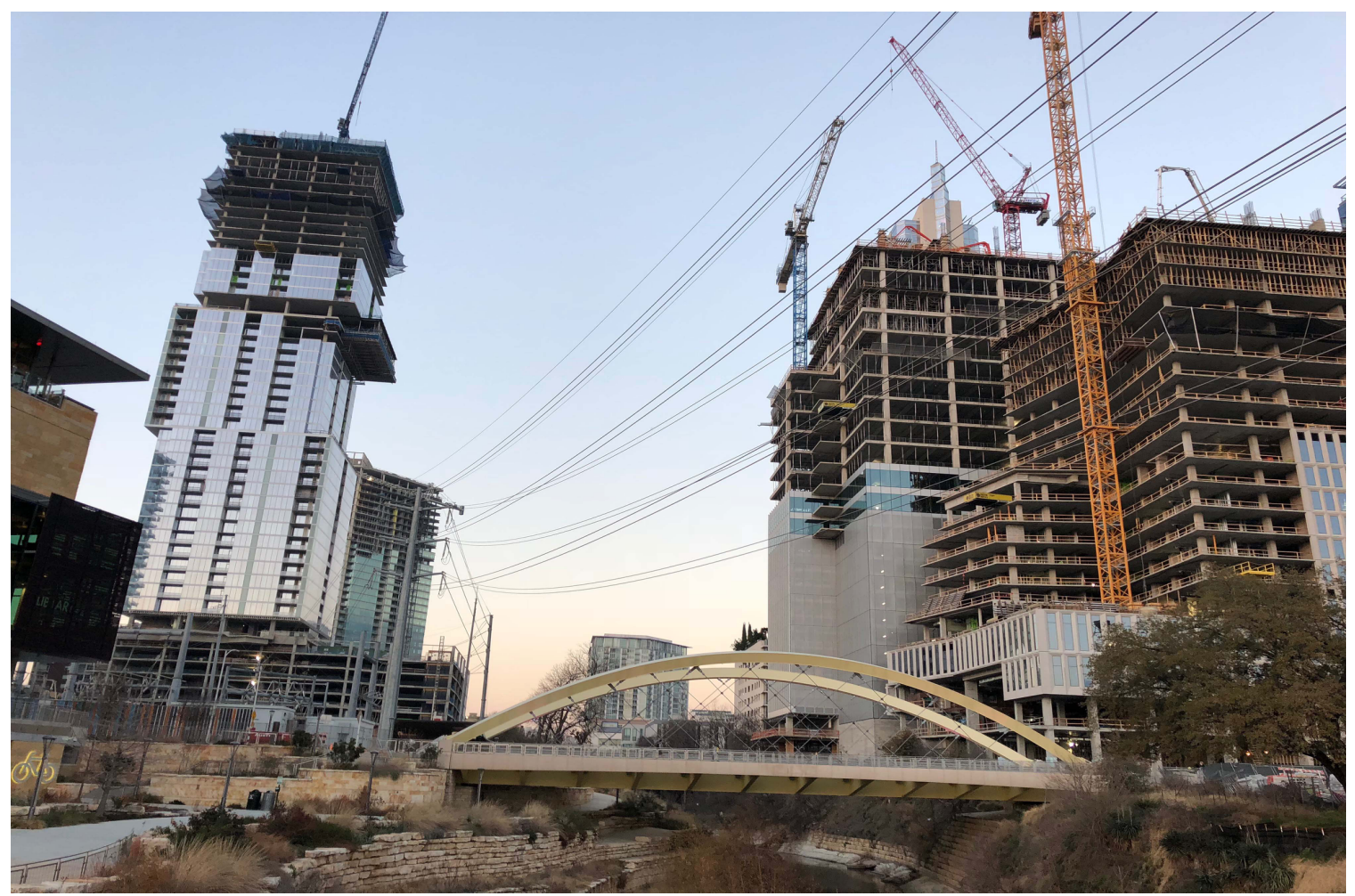

I took the following photos, Figures 7.23 and 7.24, of a billboard in that same area that indicate who these properties are intended to serve and for what purpose - mixeduse development and for wealthy "creative class" (Florida, 2014a, 2014b) workers. The last photo is decorated in spraypainted "tags" (a graffiti writer's signature consisting of the writer's street name). Some scholars and journalists have argued that graffiti is a way for people to reclaim lost public space, particularly when markets claim them (Biel, 2011; Visconti, Sherry, Borghini, \& Anderson, 2010). 
Figure 7.23: Luxury real estate signs (Pridemore, 2018)

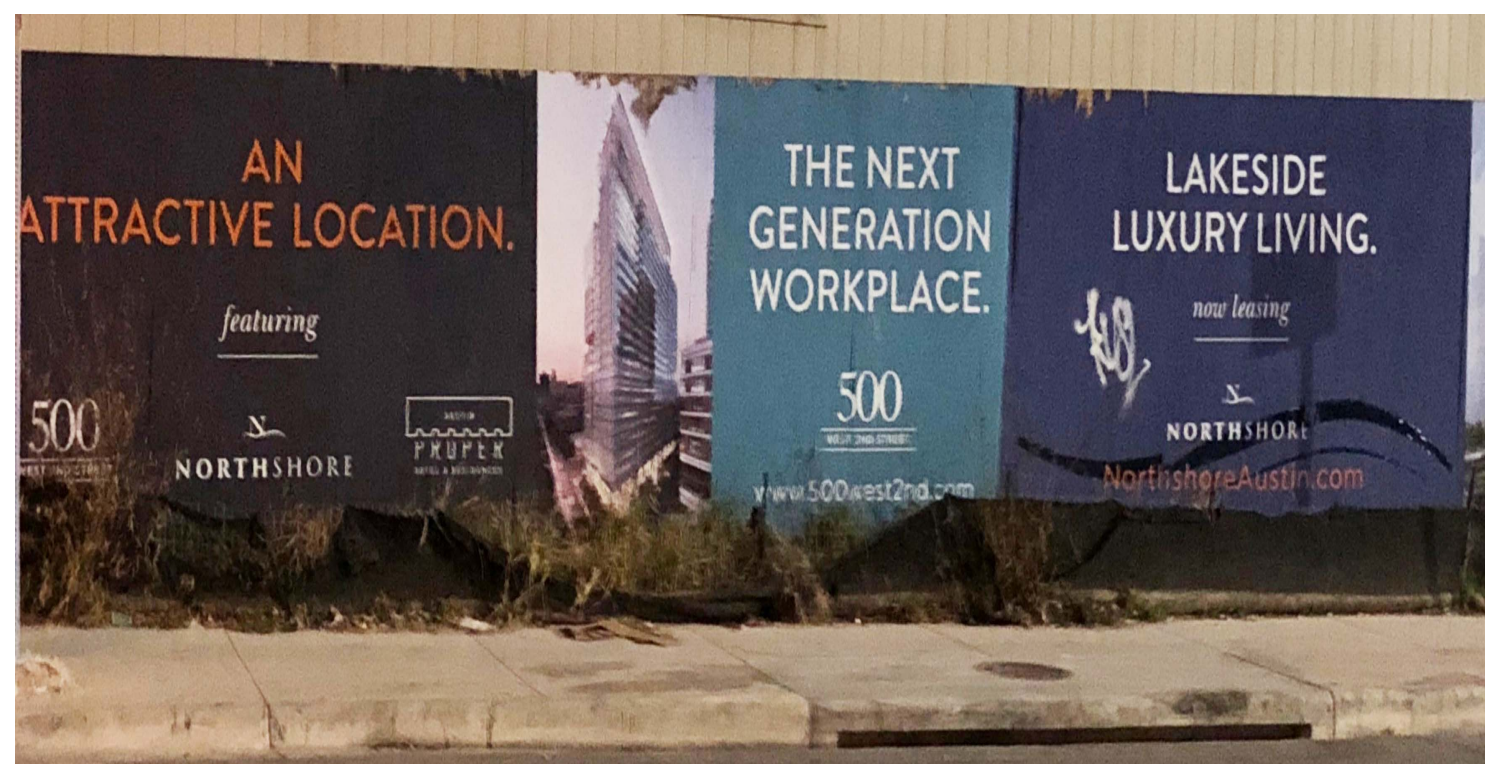

Figure 7.24: Luxury real estate sign covered in tags (Pridemore, 2018)

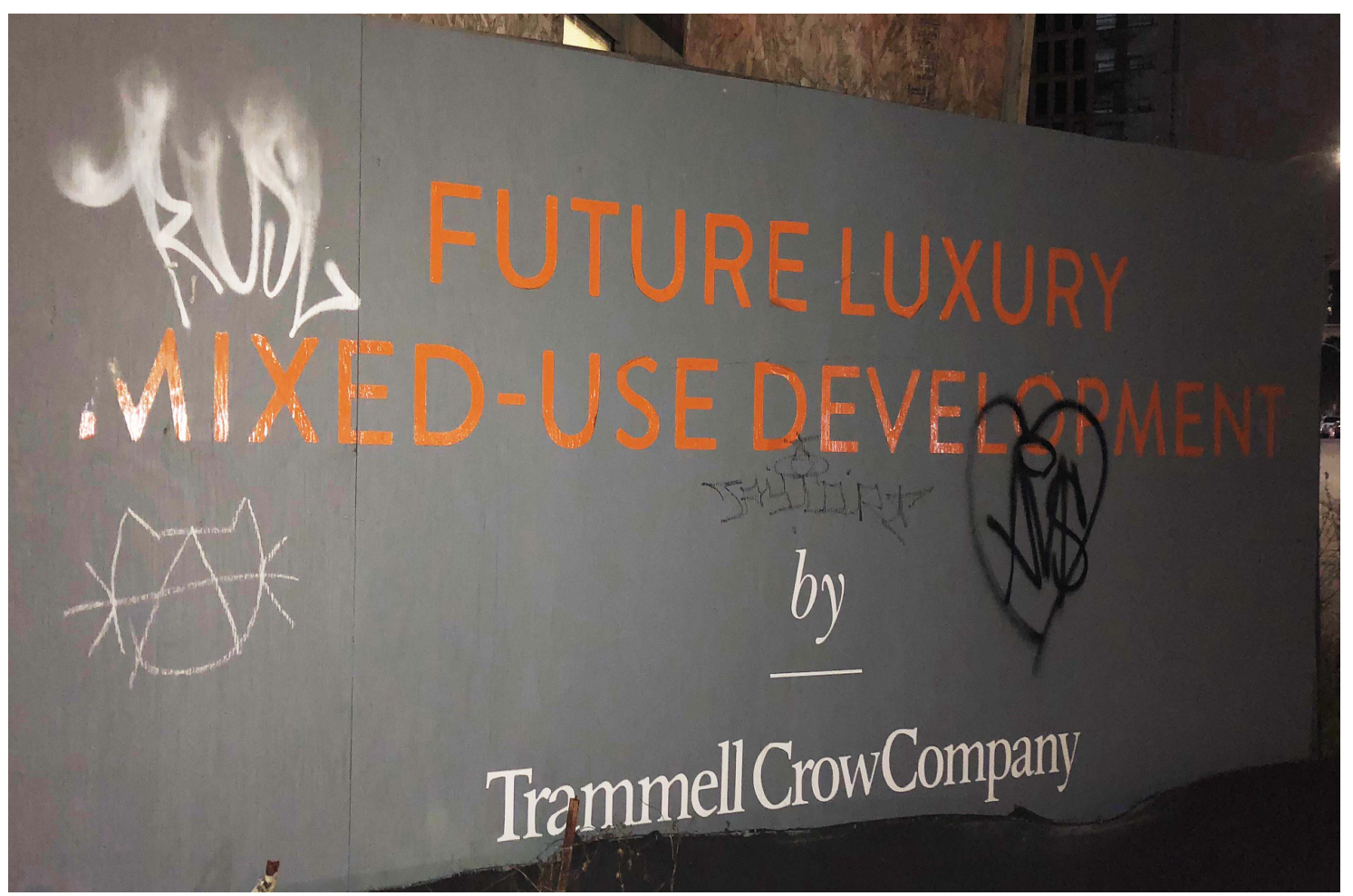

Seamus said that some in Austin have the attitude that art and music is either "disposable" or will not go away. Also, the perception is that if they are priced out of 
their current locations because of the real estate market, they can go elsewhere. Because of the citywide real estate market, growth, and development, there is literally nowhere else in Austin for them to go now. Like Lily, he noted the history of the Austin music venues and overall music scene and reflected cautions about how institutions, like a love of art and music, can still fall (Bachrach \& Baratz, 1962).

Seamus: I think it being considered disposable comes from a general perception that I've run into with folks who are outside of art and music culture who look in on it and see it as observers. Wherever I turn, it's there: "Things come and go. Therefore, things always are." That's kind of what I've seen. It's kind of a generic life perspective without really unboxing things and those of us in the art and music communities are like, "No, art and music have value, not just extrinsically in terms of dollars you should be spending on it, but intrinsically, in terms of how it affects and elevates just the experience of being a human being.

So, when we talked to people about our economic challenges down here, the first response was, "I don't see what the big deal is. Bars have come and gone through the history of Austin. If y'all go away, they'll just pop up somewhere else. And my response to that was... I study history. That's part of my background. If you look at the history of music in Austin, and I grew up here, and if you look at the history of the venues... I've been obsessed with music since I was ten years old. They only appear in the areas that are economically depressed, like warehouse districts or near docks or just in kind of run-down parts of town.

So in large, fast-growing urban areas, you see real estate advancing at a speed that wages and sales can't meet often, and spaces that are used to being in warehouse districts are now considered prime real estate. It's like, "Where would these things pop up?"

As we looked around Austin and what people do, we saw the answer was nowhere because there isn't anywhere in the city limits that, one, is available that's depressed anymore. But also too, there's the friction that is sort of inherently created between bars, venues, or commercial real estate with private neighborhood real estate. So with those two factors being identified as, "Now, if this goes away, it's just like two things can't exist in the same space at the same time. So we won't have a place to go as live music."

When asked why someone would knowingly build next door to a place such as an outdoor live music venue, Andromeda said the venues are actually part of the developers' 
marketing strategy — advertising the neighborhood's amenities, such as bars and nightlife, as well as restaurants like Austin's famous barbecue joints and other attractions. So, some people will move into a place like a condo in downtown Austin because it seems attractive on the surface. Reality then sets in when they actually begin living there, and it only takes one or two residents complaining about activities outside like live music and barbecue smell to have problems arise. She boiled down this overall situation to one word.

Andromeda: It is money. It's economics. It's supply and demand. It starts with someone living in some very lowbrow building, they have high creative ideas, and they attract people to the location. People go, "Oh, I want to be next to this cool location." It becomes popular. The property values go up, and then, all of a sudden, they devolve the building. That coolness killed the place because then it became too expensive to keep those people who are spending $\$ 500$ or $\$ 600$ a month in rent. I could just demolish the building it sell $\$ 800,000$ condos. It's money.

...Council and the planning commission are aware of the situation. The city is aware of the situation, but we're not North Korea. We can't say you can't have anything next to these music venues or that you can't raise the rent on this bar. Travis County assessors, you can't... The property that was worth $\$ 200,000$ is now worth $\$ 1.5$ million, and this bar or restaurant or nightclub that has live music who doesn't own the property can have the landlord tell them to be out in thirty days because they're going to sell it to a condo or hotel developer.

Our skyline has completely changed during the last ten years. Half of the buildings are brand new. ... They're building right now. So most of these live music venues are downtown in one-story, very modest buildings that have parking around them. You can sell those properties and get a lot of money.

Ernie, like Andromeda, noted that the bars were the draw and the developers like those for the hotels, namely the Westin that faces Sixth Street, had police and the music and entertainment division warn them that they would be building next door to an existing outdoor live music venue and advise them that they should mitigate for sound in 
their construction. The city code, though, does not require developers to do this. The only enforcement mechanism the city has, then, is the noise ordinance. If the venues do not exceed the ordinance, city officials' hands are tied. Alastor said that mitigation should be part of city code.

Alastor: They wouldn't triple-pane the glass, and they wouldn't really refocus their HVAC vents away from the venues so that sound didn't travel throughout the building. Then, the noise complaints started. The response from the city ought to be, "We warned you." I think that's how it ought to work. I don't think these places should be able to go about suing these clubs or anything else if they don't take the necessary steps. I think they must be written into code.

Despite these actions from developers that some in the city bureaucracy tried to prevent, interviewees indicated that they did not believe the city would make decisions that would benefit the artistic community if these decisions would have a negative effect on the financial bottom line. Interviewees, particularly in the artistic community, believed that money coming in from the real estate industry was the city's top priority, particularly that of its elected government.

Severus: Adler is a real estate guy. Adler comes out of the real estate industry. Micropolicy teams who were seasoned observers of the local political scene have come to the conclusion that the mayor is using this issue as a shield. He doesn't want to do anything, and he doesn't want to save Red River at all. I believe his wife is connected to the landlord for Cheer Up Charlie's, which means he shouldn't even be voting on these things, but he does. ... It's easy for him to say, "I love wherever we are. We're going to figure it out." While in the meantime, you know, his best friends are making plans to develop Red River.

Amelia: So what's the plan?

Severus: Well, the plan is that the music venues are going to come under a lot of pressure from the innovation district. The innovation district is coming down south. ... Some of it is just a block north from the Mohawk. ... We have a twelveblock area of that northeast corner of downtown that is empty. The plan is for it to become an innovation zone to attract men of tech companies there who can interact with the research at the University of Texas medical school and build our medical technology industry. 
Great. I'm down with that, but the fact is that between the convention center and hotels wanting to move up from the south and innovation zone moving down from the north... Most of the real estate guys I know in town give Red River three to five years unless those guys get smart. Their original plan was to get themselves named a cultural district by the state of Texas. They didn't do that. I'm pretty sure they didn't do that at the urging of the mayor or his fixers, who were probably like, “Oh that's so hard, and it doesn't really give you much."

... So music downtown is really under threat, and what's going on at the surface level where all the politicians and all the city staff are like, "Oh, it's so important," is straight-up bullshit. The real agenda is "Why is music downtown? We don't need it downtown." It's, "Is this the highest and best use of this real estate?"

Even some city board and commission members had this view. The real estate industry and developers had so much sway, Draco said, that they had the ability to sidestep board and commission members whose job it is to be council members' citizen expert in that board or commission's given specialty area. It may be that the business interests fear a conversation leading to race, particularly with a black board member/commissioner or Hispanic board member/commissioner like Draco is. The relatively new 10-1 council system has brought greater diversity to both the council and the boards and commissions alike. The real reason, though, is that the main concern is profit.

Draco: That outside influence from the private sector feels it has the ear of the council and the mayor more so than my commission, the agent of the government. I'm finding out about this marriage, at this hour, from someone who is speaking to "my" council member and going around me. Why aren't you approaching the commissioner, the chief advocate by law, for this specialty to the government?

They don't like those conditions. Why do they not like those conditions? Some of the board members are black or Hispanic, and it's not that (the private sector representatives) are racist, but they don't want to get into that discussion. They just address the bottom line. They just address the welfare of the bottom line. 
City government's viewpoint, according to many of my Austin interviewees, of considering real estate values and profit over cultural and social value, like the hotels versus the Red River venues is akin to Box's (2015) arguments involving neoliberalism and participation, but with more of an economic angle and more of a focus on the end result. Box (2015) writes that neoliberalism principles, when applied to citizen participation, means that how much the public is involved depends on how profitable or costly it is. In this situation involving the Austin real estate market and the artistic community, according to my interviewees, profit and cost are the chief considerations when it comes to whose citizen participation efforts win or lose in the end. Likewise, that neoliberal emphasis is what turns some artistic community members away from participating in government because they may believe that they will never win against someone who has profit on their side of the policy debate.

In the end, this entire situation led to an angry, demoralized, or hopeless artistic community, depending on who was asked. Given the negative impacts on the culture and some developers continually closing in as prices skyrocket — despite the city being well aware of the problems - this led some people in the artistic community believe that the city government was only profit-oriented and would not listen to them if and when they participated. Some were especially angry.

Sirius: A lot of musicians have just burned out, and it's kind of seen as hopeless in Austin. The force of new developments and making Austin kind of just really big city having all these condos, bigger office buildings... It's an unstoppable force that is pushing musicians out. So, I think there could be some sort of resentment and kind of more... I would say, maybe not resentment, but more, just this feeling of hopelessness because musicians don't know how to save themselves, let alone participate in government to try and save the music community. 
Severus: Cheer Up Charlie's is my absolute favorite spot in Austin. It's not the greatest music venue, but I do love the scene access because they have young up and coming acts and baby acts, but it's also just that the owners have done an amazing job of creating an open and inclusive space for everything. If you look on a map, it's a gay bar, but you really wouldn't know. It's just everyone hanging out and just LGBT owned. Everybody is welcome in that kind of place, and I love that. It smacks of the Austin that I came to in the Eighties.

So to me, it's one of the last bastions of really the kind of open, inclusive Austin that I love. So making them vulnerable to fucking hotels is gross. And you know, I think everyone at city hall is like, "We don't want that to happen." But when the rubber hits the road, what are you doing about it? You're talking about it. If Cheer Up Charlie's gets closed due to construction pressure or political pressure, everybody at city hall is going to be culpable because they know this is happening, and they know what actions need to be taken.

\section{Red River lease situation}

What makes the situation even more precarious in the Red River district, specifically, is that all venues of the thirteen except for one (Stubb's) leases and does not own their properties. Therefore, they are subject to not only exponentially higher rents when leases come up for renewal, but they are also subject to not having their leases renewed at all because their landlords could decide to profit from the prime real estate market. Interviewees that included a Red River bar owner, artistic community members, and journalists said this was a much bigger threat to Red River than the crime. Even if the area is crime-free and public opinion remains high, a property owner may not care if they are quoted the right price.

This situation hindered participation even more because this further fueled attitudes that the city was more concerned about the financial bottom line and the real estate industry over the artistic community and cultural spaces. Especially when considering the widespread love of Red River, the fact that the city, in some 
interviewees' viewpoints, would let the real estate market seize this district they love, created an even more negative view of city government officials.

Though he acknowledged crime was a problem, Percy disputed the viewpoint that the crime was the worst problem, saying the leases created a far more dangerous situation.

Percy: The number one issue is leases because everybody just doesn't know what their next markup is going to be on the leases, and that is the thing that will put someone out of business. That has already put so many Red River clubs out of business, or they turn over because of that. That has got to be the Number One fear for everybody there.

Crime? If someone gets shot outside your club... I don't know, to be honest. The only time that has happened in the last decade was on the corner of Red River and Seventh in a club that doesn't exist anymore. A guy got turned away at a hip-hop showcase or something. He and his brother came by and shot people at the thing. That place didn't last, but I don't know if that was even the key factor involving it.

Percy noted the violent car crash incident in Red River during South-By-

Southwest in 2014, where a man driving drunk and evading police passed through barricades and drove into crowds on Red River Street (Fechter, 2016; Lindell, 2017). Four people were killed. The Red River clubs did not face sanctions over this man's actions, though.

Percy: I don't think one shooting, one stabbing, or whatever... Like, who's going to shut them down? They have leases with their landlords. The city can't shut down a club because of an act of violence.

...Red River needs to be protected, and people have been fighting forever. There's a lot of factors, including a few landlords pricing out the tenants. The main thing that was lost was the original Emo's. That was kind of a capital on Red River. Ten years ago, that was THE spot. But you know, there's...

The Mohawk is great, but the Mohawk is not going to be around forever. At some point, it's going to go. It's going to be unaffordable. Cheer Up Charlie's? They have a horrible relationship with their landlord, and their fucking landlord is 
somehow related... The landlord company that owns Cheer Up Charlie's employs Mayor Adler's wife. Stubb's would not be there. I don't know. Stubb's is kind of cool. It's also kind of a piece of shit. It's not incubating bands like the rest of them to make a showplace, you know? Beerland is incredibly important. Elysium is incredibly important for its own weird scene.

Barracuda, Empire... Sidewinders is kind of in flux right now, but you have got to keep at least that many venues on that street for it to be viable, and once they start falling, it's going to be like dominoes. Like, what's the value of paying really expensive rent to be down there if it isn't a music district, and if we don't have that walkable music district?

\section{Issues with nonprofit organizations}

Other issues hindering Austin's artistic community's participation involved the large number of nonprofit organizations in the city. First, some interviewees indicated that there were simply too many nonprofits — so many that even government officials' counts and hardly anyone could find a definitive number of them. Some of these nonprofits had competing claims of being "real" representatives for the artistic community, leading some in the artistic community and government not knowing who a good point of contact was and who could be trusted. The large number also meant that any available funding was divided even more.

How some of the nonprofits came into existence or treated other organizations was even more troubling. A few nonprofits had rivalries with one another, and some came into existence because of an angry split within a previously existing nonprofit. Some all-encompassing arts organizations or ones that did not focus on music felt slighted over the music nonprofits and music, in general. Also, some organizations or nonprofit leaders dropped off or became inactive, largely because they believed that the earlier-mentioned inaction made their efforts futile. This presented another angle to studies involving citizen participation and trust in that instead of focusing on citizens' 
trust of government officials (Pridemore, N.E. Ganapati, \& Revell, 2019), this issue involved whether or not both citizens and government officials alike could trust people who claimed to be advocates and ones that had the artistic community's interests at heart.

\section{Too many nonprofits}

The sheer number of nonprofits created a participation hindering factor, according to some of my interviewees. With, literally, hundreds of nonprofits in the arts alone and a seemingly infinite number of other nonprofits outside the arts taking an interest in the artistic community's plight, the artistic community and the city government were both overwhelmed because the artistic community could not find out who was the best to help them, and government officials sometimes could not clearly identify a few solid point persons to help them reach a wider set of artistic community members. What made the situation even more complex was that multiple organizations claimed to represent or be THE representative for the artistic community, which created a problem with seemingly (or actual) competing spokespeople. It was difficult to tell who was and was not capable and, more importantly, could and could not be trusted if either government officials wanted to use a nonprofit organization to reach the artistic community or the artistic community wanted an organization's help in advocating for more favorable policy.

Finding a definitive answer on how many arts nonprofits there were in Austin proved to be a challenge, namely because even the numbers that city officials had available kept changing. Numbers quoted to me for music, alone, ranged from 130 to 148. So, I conducted a search on the GuideStar network, which "gathers, organizes, and distributes information about U.S. nonprofits" (as cited in GuideStar, 2018), and I found 7,845 nonprofit organizations in Austin. I narrowed the search to 590 that were classified 
as "Arts, Culture, and Humanities". Only seven of those 590 were specifically classified as "Alliance/Advocacy" organizations.

However, one of the trickier aspects of trying to put a number on the number of nonprofits involved with the artistic community in Austin is that organizations not officially classified as being concerned with the arts are working with the artistic community because some of the artistic community's concerns fall under their umbrella, too. For example, Lily mentioned historic preservation organizations' interest in preserving older music venues and art spaces, and Padma noted affordable housing groups' interest in the artistic community's residential affordability crisis. Furthermore, I met arts nonprofit personnel from organizations not classified as advocacy groups contributing to policy discussions when I did an observation at a city stakeholder meeting involving special events policies. So, when considering that plus, as some interviewees reported, the number of nonprofits seemingly grows constantly, finding out exactly how many organizations are doing work with and for the artistic community is practically impossible.

Molly, a city employee in an arts economic development office, explained that the reason behind the number of nonprofits is the "terminally democratic" nature of Austin. Still, the large numbers can cause problems.

Molly: People are very, very socially engaged, and they love causes. They are passionate, and they're involved, and they want to get right in the mix. But you can hit a point where you're oversaturated. I don't know that there's a control on that, necessarily, other than just the natural sort of attenuation rate of nonprofits that make it. Some don't, and some combine over time. I think some of that just happens. 
Pomona had a list of 148 nonprofits for music, alone, and she believed a major problem was that some nonprofits were splintering and becoming overspecialized to the point where it was rather imprudent. Lily, who works for a nonprofit, herself, echoed those concerns, as well, during my interview with her.

Pomona: The number of 148 music nonprofits doesn't help anyone. That number of nonprofits doesn't help the 148 music nonprofits. ... There's a Celtic Music Society, and then there's the Celtic Women's Music Society. The splitting and splintering of these efforts are just so granular and kind of silly, in my opinion.

Lily: It's like you and I could be a nonprofit. And why? ... I mean, do we really need 130 for music? Sometimes, it gets to the point where it's so thin as far as, "We're only interested in pink guitars that are played on the third Wednesday of the month on a full moon." Those kinds of nonprofits where it gets the sector so... It really only benefits ten people or whatever.

Ron, similar to Pomona, mentioned that when so many nonprofits are in one city and working in one specialty area, the nonprofits duplicate efforts. He believed that, instead of starting one's own nonprofit to make a given situation better, that a person who wants to be an advocate or promote a cause join and help an established group.

Ron: There's a group or nonprofit group for just about everything in this town. This town is overrun with creative and artist nonprofits, frankly. There are a lot that are well-intentioned but are kind of trying to address duplicitous issues. There's more than one nonprofit for the same issue.

... There's a little bit of hyperbole here. I think, with a lot of the people in the nonprofit groups, it's a, "Ready, shoot, aim." It's, "Oh, I'm going to go out and establish this nonprofit." They then don't realize that there's one that's kind of the same and working on pretty much the same thing. There's no territorial problem, but there's... If you took the time and resources to dedicating your own nonprofit and instead directed them to this already established group, you'd be doing far more good by joining an already established group before creating your own. 
For interviewees who were former or current government officials, the numerous nonprofits created challenges on multiple fronts. First, they would not know who was a good point person for the artistic community as a whole and who could be trusted, especially if multiple people were making such claims. This was especially the case for Alastor, whose office covers all of Texas, the state with the second-highest population in the nation (about 28.7 million people) (U.S. Census Bureau, 2018b) and the largest state, geographically, in the continental United States. Then, there was the fact that it was impossible for the officials to hear the concerns of so many organizations. This was particularly problematic when government officials were working to make sure they had diverse voices at the table.

Lily: To me, if I were looking in as a policymaker, who do I talk to? Who has the best voice? Who speaks for 130 of those? How do they communicate?

That would be the thing if I'm trying to develop public policy that would help them. Who do I talk to? ... Structurally, it would be easier to deal with... I mean, if I were an elected official or a city staff person trying to craft public policy, who do I go to now?

...You know, if there were twenty, that's more manageable, but 130 to me is like... To me, it kind of dilutes what you're trying to do. ... I never had that many. I never had a situation where I had to communicate to 130 , but you still encounter situations where you're trying to make sure you're getting everything, and you sit there as somebody trying to formulate public policy, you are going, "Oh crap! Did I miss somebody? Did we catch everybody and talk to everybody?" ... I've worked in departments where we did tons and tons and tons of public outreach. That was always the fear that we got. Everyone did.

...You didn't want the random group coming up and saying, "Well, they never talked to us." You wanted to make sure that you tried to get everybody. So, to me, when you have this plethora of nonprofit organizations, it gets a little hard to make sure you're... If you're trying to do your due diligence and make sure that you get these people, and you've been inclusive, and you've listened, and all of that... To me, it gets hard to make sure that you've listened to everybody because of the sheer volume. 
Pomona: We can't serve 148 clients. We can't serve 148 musicians. That's kind of how I feel about it right now. It's just that the nonprofits are like, "We started a new nonprofit. We're doing this, and it's better, and we're doing this, and it's more." It really just seems like it's more of the same.

Amelia: I'm wondering about when you have had to sometimes make a call as to whether or not this person is really a spokesperson. Sometimes, is it just hard to tell?

Alastor: Yeah, I definitely had to do that, for sure, and especially now. Since our office has taken a more statewide role, we've got a lot more visibility in the last couple of years. I've definitely had to make those calls to people who would know about who this person is and who they actually speak for. I'm glad I have, in most cases, made those calls because, a lot of times, yeah, they don't really. They may have at one point worked with an organization or two, that sort of scenario, but they're not actually employed by anybody or they're not actually working for the nonprofit they say they are - a whole list of things. I've run across a lot of that.

Seamus said that when he and the other Red River bar owners were working with city government officials for more favorable policy while hotels and other developers were closing in on them, they made sure to work on their own because they were capable and because of the problem with trust amidst competing representation claims. He said that some who claim to be advocates are really only working to help themselves.

Seamus: The advice we were given early on was that we should know that everyone is trying to speak as our representatives and trying to use that cache to advance their own agendas. It was, "Y'all need to be the ones who own that idea and not let other people do that for you." I mean, one of us came with the credentials of having worked in the industry for ten, fifteen, twenty years. So, it wasn't that we knew everything or had all the answers or could have certainly represented every perspective, but we certainly had the experience to back up what we were talking about. And we talk within ourselves.

It's important when you can get meetings with folks like that, that it is not a cacophony. If you're in a band, everyone has their instruments, and they're 
playing the song together. It's like when people aren't trying to do different things at once because it's about achieving objectives. I mean, it's just basic organization.

\section{Nonprofit stability issues}

Interviewees from government and the artistic community noted that overall stability with the nonprofit organizations was another factor. With established nonprofits, the artistic community members said, some of those advocates and organizations burned out and became inactive. Some of that, they indicated, was linked to the earliermentioned problems with inaction. On the other hand, there was worry that some of the newer nonprofits were not very well-established or lacked capacity and therefore, had little track record on which they could be judged. This was especially concerning if they were working to be an organizer and voice for the artistic community during critical policy debates.

During my interview with Molly, she mentioned her agency’s nonprofit partners. I asked her about how navigating, literally, hundreds of nonprofits was in terms of finding the right partners.

Molly: It's tough because if you look at the quantity, that's one thing. If you look at the capacity, that's a very different thing. So we may have a lot, but when we're looking for partners, we're looking for someone who can help sustain a long-term goal. You have to have some staying power and some resources to do that, and that's not always going to be the young nonprofit or even the middlestage nonprofit that's going to be kind of institutional partners that have been around for a while or have an active board or have a pretty good track record of success and have some resources they can bring to the table.

I would love to see more of those come into being or develop. I think we have a lot of the young or even small guys that are still struggling and trying to make it to the next stage. It's so hard when there are so many out there doing that. I wish it were a little more balanced and sort of a tiered approach so that we could kind of say, "Well, who's doing this specific work, and who's able to bring something to the table so that if we partner with them or if we match some efforts, it doesn't 
feel one-sided?" ... So those nonprofit partners all play a role. But you really have to find someone who can bring some stability to the table.

Some interviewees noted that there are ways of evaluating nonprofits, which include going through their IRS 990 forms and particularly in looking at their financial capacity and records. Just to see this for myself, I searched the Austin arts nonprofits' gross receipts, the total amount of a nonprofit's income from all sources and without subtracting any costs or expenses (Fishman, n.d.). In my GuideStar (2018) search that produced 590 arts nonprofits in Austin, I found that 277 of that 590 (about 47 percent) had gross receipts of one dollar or more - meaning that 313 (about 53 percent) had zero dollars in gross receipts. Two of those 277 with more than zero dollars in gross receipts only had gross receipts of one dollar.

Percy said that, despite the number of nonprofits, he believed that very few of the nonprofits really mattered because some do better work and have greater reach and impact than others, and also because some advocates and groups who were once extremely passionate have burned out over the years.

Percy: It's changing a lot in terms of which ones are actually trying. There was one group that was the leading advocacy organization until about two years ago. The lady who ran it is a really nice person and really sharp. She retired from it because she felt like she had lost support, like people didn't believe in her. She had lost support of the community, you know?

...So there is a lot, but there's not 130 that matter. There are about five that matter.

Severus said he loved his work, despite it entailing wading through messy politics — but even though he actually enjoyed that, he wondered how long he would last, himself. 
Severus: I didn't think I would like it this much. I really do enjoy the politics of it, but for most of our community, this is icky and this is compromising and this is not why they got into being artists - to go and get in the muck with these fucking narcissist sociopaths at city hall. I'm a narcissist sociopath, so that works out. No,

not really. I'm a loving husband and father. But get back with me in two years and see if I'm completely demoralized.

\section{Nonprofit frictions}

Another major problem related to the numerous nonprofits was friction, sometimes, rather intense, between the organizations and/or some of their leaders. A few organizations also had internal strife. During interviews and observations, I found out that several groups had animosity toward others, namely competing claims for being THE representative for the artistic community or segments of it, fracturing and splitting into new nonprofits for various reasons, not collaborating at all or not collaborating well, and better-funded nonprofits not helping smaller nonprofits or other citizen groups when parts of the artistic community were threatened.

This hindered participation namely because government officials and artistic community members did not know how to trust or were simply sick of the strife. The artistic community members often had to rely on the advocates in nonprofit organizations to speak for them because they were time-starved, but they could not be sure as to which organization, if any, truly had their best interests at heart or which ones were trustworthy. Government officials, who also had to carefully consider who to trust, also found themselves working as a referee between those with competing claims. Even the nonprofit organizations' participation efforts were hindered because, especially in the case of smaller organizations with less funding, some organizations wanting all the credit, only wanting to help those within their small sphere, or simply snubbing others meant 
that they did not have as many partners when they tried to do advocacy work for the artistic community.

During the course of my interviews and observations, I met nonprofit leaders who detailed how they began because they split from a dominant nonprofit because the dominant one, they believed, no longer represented them. Some nonprofit leaders I met hinted that many of the nonprofit organizations simply do not get along with others. One of the major point of contention I found was that some of the general arts or non-musical arts nonprofits were not fans of the nonprofits involved with the commercial music industry, saying that the music nonprofits considered themselves "too cool", superior, or overly demanding. Some musicians, though, not only disagreed with this assertion but found some of these arts nonprofit personnel's statements especially grating or offensive.

Ron said that, as I will explore more in the next chapter, the relationships between the rank-and-file members of the different artistic disciplines are very constructive or at least there is no serious animosity, as a whole. With some of the organizational leaders, this is sometimes a different story. A lot of the roots of that, he said, is that the general arts organizations tend to get better funding and have an easier time getting that funding over the music advocacy groups, and the music advocacy groups would like to have that. The arts organizations are irked because they believe the music advocates have a superiority complex from Austin being considered a "music city".

Ron: I can't point to any oil/water type of dynamics between the greater populace and the creative community. There is a little bit among certain components of the music stakeholders, like a (music advocate), and other arts groups as a whole. There's a thought of, "Music built this city. Music should get the bulk of the city resources." And the visual and the other arts are always trying to improve their lot too. There's a little bit of sharpened elbows there. 
Amelia: Meaning the advocacy groups between the other art forms?

Ron: Yeah.

Amelia: Now, on the rank and file end, is there anything between say musicians and visual artists or...

Ron: Oh no. I never saw any evidence of animosity. It was more on the stakeholders, people who make the building blocks move - the decision-maker level. Sometimes, you had a little side-eye and a lot of...

Amelia: In other words, the visual groups are, "Where's our share?" when the music groups are, "Excuse me! We built this place."

Ron: That kind of captures it. Yeah.

Severus said the situation has been changing, but while he did not fault all music advocates, particularly newer ones that have emerged in recent years, he had harsh words for a longstanding core group of music industry advocates, particularly in terms of their overall tone in the artistic community's dialog and their attitude toward the other art forms and other arts organizations.

Severus: For years, the same music advocates were in place. They were known as the "Furious Five" at city hall. There were literally five individuals who were at the forefront of music advocacy for almost a decade and they got nothing achieved because their whole attitude was like, "Dammit! I'm music. You've got to do this for us. We're important. We're the Live Music Capital of the World."

Well that did not sit well with just about anybody, and it caused divisions with the non-music arts, where instead of working together on things that affect them all, like affordable space, incomes, transportation... Music was like, "Ah, we don't need 'little arts' over there. You know, we're music. We're cool," and it's been really negative. 
Individual artistic community members found some of these attitudes grating and concerning, such as when one personnel member from a nonprofit organization referred to some other advocates as "whining bitches".

Hermione: I kind of don't trust anyone who would use that phrase, honestly.

Hermione said that she believed that anyone in any nonprofit organization, musicspecific, general-arts, or one that has nothing to do with the arts, working to be an advocate should be someone doing so because he or she wants to do that — truly be an advocate — and constantly re-evaluate to make sure they are in the right line of work. This is because being an advocate, she said, means working to advance others, not oneself.

Hermione: I definitely feel like a lot of it just comes down to people coming back to the point that... Why are they doing this? Is it for their own egos? Is it actually to make music a more sustainable industry in Austin? You know? I think when people are able to strip down and come back to what their real goals are, it becomes a lot easier to work together. I think people who have been working, especially with organizations for a long time or maybe who's started organizations and are really personally invested in them... It can be easy to kind of lose sight of the bigger picture of what are we all trying to do to make a great sustainable music community in this city.

Lily said a major problem that develops between the nonprofits is a flipside to some of the sustainability statements involving nonprofits. Better-established, betterfunded nonprofits, she said, will often not partner with smaller startups who really are trying to do good work or ones simply without their amount of capital. They will only stick to their small area of focus — while not seeing that there are mutual interests with the less-powerful nonprofits. 
Lily: They get a bunch of money from this. They're very well-funded from the city... I have seen some divisions there where it's like, "Well we have our money and we're good. We get all the hotel occupancy." The arts here can be funded by a portion of the hotel occupancy tax. So yeah, "We get our arts money, and we're in good shape, and we own our venues. Oh, you poor things." But you know, I see some, where it's the older better-established ones that have a good funding stream. And they're like, "Well, yeah, OK. It's a problem. It's an issue."

Amelia: And does it matter if it's nonprofit or for-profit, or is it more for places that get grant support versus the ones who don't?

Lily: Yeah, I think it's, it's the ones that get really good grant support from the city that are older, well-established, have their own place to live... I mean, I think they're like, "Yeah, this is an issue, but it doesn't really touch us as much. You know, it's not like a little theater over in East Austin that just lost their lease. We're older, better-established. We have a funding stream, both public and private." That's pretty strong. I had seen a little of that. Now anything deeper, it's not my bailiwick. I'll be honest. It's just not my bailiwick. But in a couple of cases I've seen it, where it's the more-established, well-funded ones going, "Well, you know, isn't that too bad?"

Lily also pointed out problems with nonprofit organizations and leaders who refuse to partner with anyone else when they approach city government in their advocacy work. This, she said, can happen anywhere, but it is a major concern because when situations are dire, people must stick together.

Lily: I think it's probably the same as all over the US. There are going to be the few holdouts that are like, "No, it's my deal, and I'm going to go do it this way." Well, you know, good luck with that. Good luck with that. You know, see if it works, and when it doesn't, come back and let us know. The other part is that makes me nervous is if you can't get everybody singing from the same page of the hymnbook, that it can hurt the overall cause.

This situation was especially concerning for government officials working to help the artistic community because they did want constructive relationships with local nonprofits. At the same time, they had to be careful about some who did not have the best intentions and mediate some factions. 
Alastor: Well, I think a lot of that is politics too. It's the purest kind of form of grassroots politics. You know, people are fighting over very small pieces of a big pie, and they want to get their voice heard.

Well first of all, if you're in a position like mine where a lot of people are coming to you for help and guidance, that you've really have to work with those people to make them understand where they sit into the whole scene, the whole network. You've got to have some pretty constructive conversations with them about how working together is going to be a lot better in the long run versus working at odds with the people who are in the same city who are trying to accomplish some of the same things. I've had many conversations about that.

People are really anxious to help and sometimes those people are so passionate. While passion is, overall, a good thing, there's absolutely, with a fairly low threshold, a spot where there's too much passion about something. Helping people identify when they've crossed that line or giving them some new ways to think about what they're doing... I find myself doing that quite a bit.

I love that people want to help, but when people make the mistake of thinking that they're the only person that can help or they're the only person who is doing it the right way, then I know I've got an issue.

...Amelia: Have you seen this in Austin or have you seen this less in Austin compared to other cities where you've done work?

Alastor: I think that's a fairly universal thing. I think that's fairly universal situation. It's not necessarily more and more in one place than the other. Austin's got a lot of folks are really fired up to help the music industry, and a lot of folks who are really fired up about doing it only one way. When you run into that, it's a little bit difficult. I don't think that's something that's unique to Austin. I'm dealing with the same people in other cities right now.

...You know, they'll come up to me... This is just my perspective. But they'll come up to be and claim that they know more about the industry than anybody else in the city. And they've got the answers, and I know that's not true because they don't know, say, the ten people I just listened who were working really hard to kind of get some things built, and yes, it's a thing to navigate.

\section{Festival problems}

Issues involving the festivals created challenges for the artistic community and the city government alike. Besides the festivals' growth being seen by some as being out of control, the key was that some of the city's signature events that began as ones by 
locals and for locals were ones that the Austin artistic community and citizens at-large believed they did not own anymore - a time for people from the outside to essentially take over the city. Safety concerns and crowds during the events did not help matters, either.

Two key elements involving festivals affected participation. First, the city promoting the festivals even as they morphed into something that the citizens did not own was further evidence for citizens that city government cared about nothing else than bottom line. Also, it felt like more outsiders were threatening their beloved culture and landscape, which was especially the case with South-By-Southwest adding a technology piece to the festival — which made the city even more attractive for the tech industry. This threat, again, made the artistic community and the citizens as a whole believe the city cared nothing about those who existed and the culture and only about boosting its revenues.

Nymphadora, who is in her 30s, said that she believed the real social and economic shifts started happening in Austin, overall, when South-By-Southwest added its "Interactive" (technology) element in 1994, along with its film component. South-BySouthwest had begun in 1987 as a music festival and one that was geared toward getting more widespread exposure for local musicians (Cofield, 2016; South by Southwest, n.d.).

The festival's organizers believed that they should showcase the other elements of Austin that were innovative, as well (Hoffberger, 2015; South by Southwest, n.d). The tech industry had a presence in Austin since the 1980s when a decline in manufacturing jobs led economic development professionals to look to the technology sector (Long, 2010). Austin attracted companies such as IBM, Motorola, and Texas Instruments and 
provided those companies with a steady skilled labor pool with University of Texas-

Austin graduates. The subsequent Dot Com Boom influenced growth in that sector even more, with more than three hundred companies (mostly technology related)

headquartering or locating their offices in Austin between 1989 and 1999.

Nymphadora said that this shift from the festival being a fun event into an

industry showcase event not only altered the festival but also Austin's overall landscape.

Amelia: So Interactive was when things changed, overall, citywide?

Nymphadora: Yeah, I feel like it was just kind of in conjunction, like the city was ready for it. Well, it maybe wasn't logistically or infrastructurally ready for it, but it was able to support something like that. I think that was a very telling shift in sort of what we were doing and what the market was capable of taking on. The money was coming in, when it came to events and things like that.

Amelia: So the techies were already starting to come in at that point?

Nymphadora: Yeah. We had people who were physically here that would want to go to something like that, but it wasn't just kind of a fun thing you went to see a band or to see a movie, but it was like an industry based kind of a thing.

Amelia: So that was another thing that changed it, when you added into that became an industry.

Nymphadora: Yeah, I think so. South-By is so huge.

The Austin City Limits historic TV show expanding to become the Austin City

Limits Music Festival, as well, was another major shift in the Austin landscape, Nymphadora explained. The TV show began in 1974, as a way to showcase local musicians and the city's burgeoning music scene (Long, 2010). In 2002, the festival began, after the TV show had become one of Austin's best-known assets, with it becoming the longest-running concert program in the United States (Pridemore, 2017).

Nymphadora: Austin, I feel like, has been steadily growing for the past fifty years. It's a weird town and that I feel like it's plateaued a couple times, but it's always 
had upward momentum. Events-wise, I feel like maybe it's just when South-By just got really big. There were a few years when it tripled or doubled in size, which is kind of intense. Once we started having the ACL festival instead of just the ACL music TV show kind of a situation, and there was an actual festival for it. I feel like that was probably the biggest shift as well.

What has caused tension in the city's artistic community and citywide is that many in Austin believe the city has lost ownership of South-By-Southwest and Austin City Limits - moving from something homegrown that showcases its local talent to something that feels like it is only for outsiders and even cuts the locals out. Narcissa explained that South-By-Southwest "pays" its musicians with exposure, but even with that factored in, most of the musicians playing at South-By-Southwest are not local. To top it off, there is a fee to send one's material to South-By-Southwest just to be considered for the festival.

Narcissa: The majority is from outside of Austin. It's not really for... I think it once was for Austin musicians, but now it's mostly for people everywhere, all over the world. I have some friends in Europe who are very familiar with it. It's more from all over the world as opposed to here. I don't know the story, exactly. I don't know exactly what the number is, but the majority, I think, is not from here. Now, a friend of mine played one year, and he played the next year. And then he got rejected the next year, because they don't like having you play consecutive years, I guess. And he's a local guy.

To make matters even more complicated with South-By-Southwest, there is the “special events" permitting process. Besides the festival's main grounds at the city's convention center downtown, numerous other places in the area host smaller "temporary use permit" (TUP) events during the festival (Curtin, 2016a), ranging from what Curtin (2016a) wrote "run the gamut between corporate-sponsored parties and reggae bands playing in parking lots of e-cig shops". However, there is only a set amount of permits for them every year, and they were reduced in 2014 and even further, down to 120, by 2016 
(Curtin, 2016a). A furor resulted in 2016 also when the city announced that applications would be cut off either on an early February due date or when the number of applications hit 120. The latter happened with little warning, catching local promoters off guard and fearing their clients would sue them. The special event permitting created local tension on two fronts - competition for the permits and locals feeling further cut out.

However, a major problem has been the issue of crowd control and safety at South-By-Southwest. Ron said that around the mid-2000s and especially during the early 2010s, there was a problem with what he called the "Spring Breakification" of the festival. Major corporations working to further promote their brands would have parties open to the public, whether those members of the public had purchased a festival badge or not, and these parties were anything but tame.

Ron: All of these big brands were in town with parties open to the general public. All you had to do was RSVP, and you got complimentary booze and all of these great performances. It was, "Let's get every fucking person we can in front of the stage, so we can blitz them with branding." That started creating a negative impact for the people who had bought South-By-Southwest badges, who paid a thousand-dollars-plus for a badge and paid several hundred dollars for a hotel. It started creating a negative experience for those people. One, it was because everything was a hairy damn mess everywhere, and badge-holders were becoming less of a priority for all of these special events that were just general admission. So, it was starting to cannibalize and jeopardize the badge purchases for the festival itself. So the festival kind of started talking to the city about throttling back on special events, and they started making a lot of these events semi-official and badge-only.

The festival gained major black eyes namely because of safety concerns and violence, though. During the 2014 festival, a man driving drunk and evading police passed through barricades, drove into crowds on Red River Street, and killed four people (Fechter, 2016; Lindell, 2017). Two years later, Sixth Street turned into "the terrordome" 
(as cited in Curtin, 2016b [headline]) on the final night of South-By-Southwest, with an angry crowd in a "human traffic jam" in a police barricade, open drug dealing, fights, and a "stampede" after a "22-year-old Killeen resident fired warning shots into the sky after an argument" (as cited in Curtin, 2016b).

Although Albus had lost track of all the incidents that have happened during South-By-Southwest, he could say that the violent incidents have been the largest source of the festival's problems. Problems such as open drug dealing have been the least of them.

Albus: Actually going back before that, it was probably six years ago that, during South-By-Southwest, some fans knocked down a fence to get into a free concert, which is really amazing.

...When I was on one of the city boards, a meeting where a guy who was a crowd management expert, an international crowd management expert came and showed videos of how crowds were managed during the Haaj in Mecca and what had happened at different rock concerts and some of the video that we have of disasters that were crowd-related disasters. And then he talked about all these different things that you can do to mitigate them and break up a crowd.

And so Dirty Sixth Street during South-By is very well-managed in terms of the crowds. Even though there was a shooting where a guy had a gun and he shot somebody, but still...

Amelia: Wasn't there, just two years ago, some craziness that happened when a guy from Killeen fired a shot in the air?

Albus: At South-By?

Amelia: Yeah.

Albus: I heard about a guy who pulled out a gun during a fight and shot somebody who was he was not intending to shoot.

Amelia: Oh, OK. Yeah. I heard about some guy firing shots in the air.

Albus: That could have happened too. I don't know. I don't have a list of all the different bizarre things that have happened. 


\section{Hindering Factors Related to Artistic Communities}

A combination of negative economic and social factors and frustrations with city government were the main hindering factors related to the artistic community in Austin. A major factor was the affordability crisis itself. Artistic community members were constantly working, taking on multiple jobs and constant gigs to afford the skyrocketing residential rents. This factor also had them living in dire conditions, with interviewees discussing how some in the artistic community have trouble affording basic needs like food and how they are living in less-than-ideal conditions. This further reflected participation equity studies (Fung, 2006, 2015; Laurian, 2004). This led to economic resentment, another major hindering factor (Rimmerman, 2011). As the city continually prospered largely in part from using the music and arts scenes as recruiting tools for companies such as technology firms, this infuriated some interviewees because they were living in such conditions and that recruitment, they believed, was adding to their misery because of high-end development and economic and social change.

Other factors involved frustrations with government and citizen participation processes, in general, reflecting Rimmerman's (2011) work on disaffectedness' and outlaw citizenship's roots. Interviewees that namely included advocates and government officials said that some in the artistic community do not understand citizen participation processes, and a particularly bewildering part of that is understanding "governmentspeak" like acronyms and other terminology related to the public sector and Austin's

specific system of government. Interviewees noted that these factors are often the result of social equity factors, with some artistic community members not coming from a 
position of privilege in which they are "trained" in policymaking processes and how they can have their voices heard.

For artistic community members, a major factor was their desire for marketoriented policy solutions that would help them in a changing and challenging market. Their main interests were policies such as Agent of Change or zoning designations for entertainment venues rather than ones that would give them direct government funding. The problem was that because these policies were either being stalled or their own ideas were not so much as being considered, this added to their frustrations about inaction and made them less likely to participate because it was further evidence to them that their efforts would be futile, again reflecting the Second Face of Power's exercises of nondecisions (Warner, 2001; Warner, 2011) and the Third Face of Power and how the less powerful will withdraw because they believe the more powerful cannot be stopped (Gaventa, 1980; Warner, 2001; Warner, 2011).

Also, any encounter between government officials and the artistic community would be a clash of formal and informal "organizational culture", alike, because of artistic communities' more free-form temperament and work style versus hierarchal structures and set procedures for the bureaucracy. This provided a new angle to previous work involving organizational culture (Shafritz, Ott, \& Jang, 2011; Weber, 2011 [1922]) because policymakers who want to engage citizens must consider any conflicting formal and informal work styles that could clash with those of policymakers' if the groups meet.

\section{Affordability crisis itself}

One of the greatest factors hindering the artistic community's participation was the affordability crisis itself. Like the New Orleans artistic community, they were in a 
practically never-ending rat race with having to work more than one job inside and outside of their crafts and take on constant gigs — and this stood in the way of having a voice in policymaking that could potentially ease their situations. Interviewees also noted that besides this, doing their crafts also meant practice and studio time. The constant work not only left them far less time to create more and refine their crafts, but it also left them with practically no time to participate in policymaking. The constant workload is also taking a toll on them in terms of their physical health, with injuries such as damaged vocal chords being a greater risk. The issues involving time with their crafts and injury risks had the potential to either keep them from advancing economically or even destroy a source of their livelihood.

On top of this, some are less than ideal living situations, such as living in overcrowded living quarters or living with far less than ideal people. This is a situation that, interviewees said, calls for some kind of policy remedies, but the artistic community is trapped in this rat race and cannot be heard.

The earlier-mentioned New Orleans tap dancer, who had to dance nonstop on the night before his rent was due, sparked this finding in Austin as well. I mentioned this story to some of my interviewees within the artistic community, asking if the constant gigs and multiple jobs stood in the way of their participation.

Luna: Absolutely, absolutely. Artists are working in the service industries. Artists have all kinds of side jobs, which become their primary jobs in this city. On top of that, we've had this huge tech boom in Austin and these diversions in Austin whether it's food, drink, or party time - I don't know what. They have gone up in price, along with rental rates or if you want to buy a home... Those costs have all gone up, in tandem.

But these industry gigs are paying the same hourly wages as they were years ago. Artists who want to support themselves with a flexible job are still getting priced 
out of their housing. They don't have competitive pricing to be able to make rent in a central area. This is nothing new.

Sirius: That is absolutely the situation. There's so much focus that has to be given to the musician grind that people don't have the time to stay involved in local politics. I know a musician, one of my close friends actually, who is going to leave Austin permanently very soon because it's so unaffordable. To make ends meet, they have to work two other jobs in addition to playing several shows a week.

...You just have to work so hard to create a career here or even just to play any music that you lose sight of that kind of thinking. You just have to go, almost week by week, day by day, and just figure it out. You get so sucked into this grind that you're not going to have the time to research these groups that are here to help musicians. ... I think if people were aware of these resources and aware of the places, they would use them, if they could. Also, it takes time to use these, and time is not something a lot of musicians have.

...It's, "I don't have time to deal with the hierarchy." They have to work. You have to work two jobs and play gigs. You don't have time to go to town hall meetings or reach out to the music and entertainment division, as an individual.

Narcissa explained that a local band becoming popular that will draw a good crowd could make a living only from their craft in other cities, but that is not a feasible way to survive for most Austin musicians. Some of the most popular musicians can make a living off of their crafts through heavy touring, and the recording industry has other ways for musicians to make profits, like through streams or having a song licensed.

Narcissa: But as far as getting paid, your average local whoever band, which is me - you don't get paid shit.

Narcissa explained the myriad of factors that determine how much musicians like herself will get paid from gigs - and they can vary wildly. Bars can give bands a "guarantee", which is a set fee for the band's performance, or they will give bands a cut 
of the night's bar sales, typically around ten to fifteen percent. Usually, the band will get to decide on which option to take. The most she typically makes on a gig is around $\$ 200$, which is split three ways among her two bandmates and herself. That would be on a busy night at a popular location. Gigs at places like coffee shops, which do not have alcohol markup like bars, will typically only have a guarantee or possibly have a tipping system. One advantage of a coffee shop gig, though, especially in terms of earning tips, is that the coffee shop gigs may be longer than those at bars and may pay more in the end.

Sirius also illustrated how unpredictable the gig income was.

Sirius: It really depends. Some shows, like cover bands, will have shows that pay $\$ 100$, and if the venue has a lot of confidence, they will pay more. I've also played shows where I've earned $\$ 15$ or less. It's very unpredictable.

This especially becomes a problem when, overall, Austin has major issues with income inequality. Molly pointed to a 2015 study from the Toronto-based Martin Property Institute that Richard Florida oversaw that evaluated the United States' “350plus metro areas based on individual and combined measures of income and educational and occupational segregation, plus an overall economic segregation index" (as cited in Selby, 2018). Economic segregation measures essentially show how many people of similar income levels "clump" together in a given region (Selby, 2018). That study showed that the Austin-Round Rock-San Marcos area was the country's most economically segregated metro area with a population of one million or more (Selby, 2018). Multiple researchers Selby (2018) contacted in 2018, which included Florida, noted that the Austin area is still one of the most economically segregated cities in the United States, although at least a few have taken higher spots on that ranking now. 
Molly: So that divide is unfortunately separating a lot of the artists into the bottom half of the economic prosperity in Austin. There are a lot of people who can't afford to live here anymore, can't pay property taxes, can't pay market rents for their homes, apartments, and places where they create work and perform work.

So we're in this, I think, amazing dichotomy of amazing development boom and prosperity on one hand, but on the other, we're sort of descending into this place where we are intentionally, in some cases, I think and maybe unintentionally, causing this exodus of our creative class and our service class who can't continue to compete with the economic pressures that we have here. I think there are a lot of barriers that are associated with just keeping your doors open.

Padma said the cost of living rising as it is becomes even worse for artists, who have traditionally lived at the bottom of the economic strata, anyway. She and other interviewees gave strong examples of how dire the living conditions are.

Padma: In Austin, it's certainly becoming a significant concern because as the city has become more of a popular destination for business, it has become less and less affordable. So, while a few years ago, $\$ 25,000$ might have been enough for you to live a nice, modest lifestyle, now, those same musicians might be older. They may have children, and they're still making the same amount even though their rent has tripled or something else has happened.

It's always a concern, certainly as you look at any society, because the artists are going to be at the bottom of the food chain in terms of compensation. As cities become more and more expensive, it becomes a more sensitive issue. Artists have definitely seen an increase in the cost of living.

Ron: There's this band in town, and their two core members are also in another band. They are two of the best bands in town and two of the busiest people in the city. They're phenomenally talented. One of them had to count her calories upward. They were recording videos that involved dancing, but she didn't have a lot of money for food. She still had to have enough calories in her to do the dancing to record the videos. She was paying just enough money for food to be able to exert the energy. One of the two bands she was in had a new record then.

That's an example of how dire the money situation is. She was working as a waitress, I believe, but she had to quit that because she's in two bands that tour. They have rehearsals and shows. You can't have a work schedule when you're 
doing that stuff. The bands, for that time period, were it for her. Things were pretty damn tight.

Padma: I was just in a meeting yesterday. Somebody was saying, "Hey, can you recommend any restaurants around here?" People were recommending this, this, and this... He said, "Well, I would like some decent food, but I can't spend more than seven dollars." There are those costs that are being weighed very carefully for a lot of people. .... I can absolutely understand the thought process behind it, saying, "My body is a tool. This is how I'm going to make my living. I'll give it just enough fuel, but not any more because I also need to have money for medicine, rent, gas for my car, and that kind of thing."

Living conditions, given the high rents, were a major challenge because of the rents. A typical situation, interviewees said, were artistic community members living in crammed living spaces. Something more dangerous, though, was that some were living in dangerous situations because desperation to quickly find someone with whom to split the rent led them to live with dangerous people - a situation far worse than typical roommate friction. Augusta, a multi-disciplinary artist who is biracial, had a former roommate move someone else into their apartment to discover this man had decorated his room in Nazi symbols.

Narcissa: Our drummer lives with four people, and yeah, most people have to live with at least two people to make rent. One of my friends lived in a one-bedroom with a friend of his, and he had his bed in the living room.

Interviewees also highlighted the reality of what it is like to handle other jobs on top of gigs. Narcissa said that one advantage of working at a job such as one in the service industry or retail, like she and many of her musician and artist friends do, is that at least they do not have to take their work home with them when a shift is done. Still, even that is extra work. Padma noted that besides having a full-time job, some in the 
artistic community with children might not have child care or be able to afford child care.

Those doing shift work may not be able to take breaks. Molly said survival, for many in the artistic community, takes precedence over participation.

Narcissa: The joke here is that you could ask one of the baristas at any coffee shop, and at least one of them is a musician. Ask half of the people in any coffee shop. Probably a couple of them are in a band.

Amelia: One of the Austin musicians I've interviewed said that if you go into any given coffee shop here, you'll have baristas who are musicians.

Albus: Yes. That's quite literal. I go to a coffee shop five days a week with one of my co-workers. He is a musician. I'm actually going to his show tonight, but he's one of my co-workers. So he has a nice forty-hour-a-week job. He doesn't have to rely on his musicianship, but every time we go to a coffee shop, and there's a new guy there, he says, "Hey, do you play anything?" because he likes to connect with other musicians. About half the time, it's somebody who is a hip-hop guy, or guitar player, or does something in music.

Molly: You can't get to a meeting if you have a full-time job or if you need child care, and you can't get those things figured out. So I think there are just some things that especially affect artists whose art work is not their full-time job that gives them a paycheck or their primary paycheck. Perhaps those are the things that I think they struggle with the most because, first and foremost, comes their ability just to survive in the city. That has to come from some sort of standing source of income.

Percy also highlighted the point that those working in the arts have to spend time

on not only other jobs and their gigs, but on other aspects related to their crafts like band practices.

Percy: There are not just gigs, but, always, as an artist, you need to be creating. I spend several days of a month in a studio, which eats up a lot of time. ... I'm in bands. I do scoring for films. I do all kinds of shit. There are a lot of things that eat up your time. Band practice eats up your time. 
With schedules like this, people in the artistic community not only find themselves unable to meet government officials or go to public hearings, but they have little to no time to meet with one another to organize. I mentioned the in-group competition finding from New Orleans to Ron, but he said that in Austin, the problem was the time factor, not in-group tension.

Ron: Someone threw a statistic at me that Austin, compared to other music cities like Nashville and Los Angeles, is a solo entrepreneur or small business-focused economy, with "small business" meaning less than five people. Everyone is so focused on doing their own thing and keeping their lights on and keeping their heads above water that they don't really have too much bandwidth to look around them and see the greater landscape of where they could maybe find people with common causes. So, I think that is kind of a proven dynamic of the economy here in Austin.

Everyone is paddling so fast in the water flow that they don't really have too much time and opportunity to look beyond themselves. That's not to say that they won't. It's just that they don't really have the deep bandwidth to do that. So there's not really an animosity. It's more just lack of opportunity.

Albus and Padma both pointed out that problems with income inequality and the interrelated problem of who can participate in policymaking and who cannot go beyond the arts.

Albus: It's not just about artists, per se. It's single moms. There are people who work for hourly wages that are at minimum wage. It's the people who are in debt because of college debt or medical expenses or things like that. So those things cut across the entire population.

...The same thing happens in the arts as it's happening in other professions, where you're getting this drawn-out effect where the top one percent makes fifty percent of the income. When you think about music, it is a person like anybody who's playing at the Erwin Center or whatnot. All of your Taylor Swifts, and your Beyonces, and people like that are making a huge percentage of the income of all the revenue that goes to artists. With regard to painting and whatnot, the heavy hitters have their stuff in galleries in New York City or San Francisco or London. Those are the visual artists who make the big, big incomes. 
The same thing is happening in other professions. In dentistry, the people that are doing the very high-end stuff are making more money in dentistry, as a practice. So the top one percent is making twenty percent of the income. So there are all of these statistics out there that are happening within our society about greater segregation economically, and it's happening in the arts. It's very obvious that it hurts when you cannot make your income from something that you really love and you have to have another job or two jobs.

Padma: It's not just for artists. That's for teachers. That's for social workers. There are an awful lot of people who aren't retired. They don't have the luxury of telling their bosses, "Hey, I'll be back in a couple of hours. I have to contribute to the life of my community." That's a luxury that many, many, many people don't have. And yes, part of the reason why it's a luxury is because the cost of living is so high.

\section{Market challenges and desire for policy/market solutions}

The problems went beyond the never-ending work schedules, though.

Interviewees in the artistic community were encountering major market-related challenges even when not factoring in the development-related affordability issues and tension. Most of them sought policy remedies akin to Adam Smith (1982 [1776]) approaches - having government not totally control what they do or even pay for what they do, but instead having government enact policies that would create more favorable market conditions for them and reflect their current market challenges. This reflected Currid's (2007) work that included similar findings but provided something different from the dominant nonprofit research in arts policy (Rushton, 2013). These policy preferences also included some controls on other markets, namely real estate. Some of these such as Agent of Change were stalled, and for other potential policy solutions, some advocates believed city officials would not listen to some potentially innovative solutions that addressed those market concerns. 
While these challenges could be merely chalked up to the market and not policy or participation, they did have an effect on policy and participation. Because of either inaction on proposed market-oriented policies, which some noted would not cost the city much or any money, or having their ideas ignored, this also made some artistic community members feel that their efforts were futile or at least added to their deep frustrations.

The commercial music industry, city employee and musician interviewees said, has always been one to consider itself a private-sector operation. However, work that one would believe is publicly funded or is relegated to the nonprofit realm is also considered a private-sector venture. In a city report largely focusing on arts occupations outside the commercial music industry, those surveyed in most disciplines other than the performing arts wanted more information resources not regarding the nonprofit sector, but information specific to the arts and creative industries and specific to small businesses (City of Austin, 2016a). Albus said one example of policy related challenge affecting one's ability to stay competitive in the market outside of commercial music is zoning laws that would keep people such as visual artists from selling work from their homes. Padma said that even those who work in large arts centers, like symphonies, generally only have seasonal jobs and often have to making a living as solo or small business entrepreneurs too.

Padma: Not every visual artist is going to have an exhibit at a museum or even a gallery. They may be selling prints out of their living rooms or making their prints into greeting cards. It's just an entirely different model. We used to call them SOBs - symphony, opera, and ballet. ... Even in Austin, we've got a lot of union musicians who play for the symphony, but even that is not a steady, 52-week-ayear job. They also do other kinds of music. They also do teaching. They also do insurance sales. They've got day jobs. 
In the Red River district, Seamus said, the bar owners want to have third places (Oldenburg, 1999) — open, inclusive, and casual spaces where all people feel welcome and enjoy the live music too. The challenge is that not only are the owners facing skyrocketing costs related to the real estate market, but they also want to make sure the musicians are being paid, too. Having musicians play for free and be "paid" with "exposure" is a common practice, nationally, but one that musicians decry. Besides the personal and business ethics of paying people for their work, paying the musicians is even more critical in a situation that the Austin venues are facing with the real estate market threats. If a venue is endangered, one that pays its musicians will get those musicians' support, plus that of the musicians' fans. Ones that do not pay its musicians will be considered "good riddance". This was part of the exchange I had with Seamus.

Amelia: How do you balance being accessible and open to people, paying the bands for their work - and while your rents keep going up?

Seamus: Yeah. Our property value just doubled, too, this year.

Amelia: Really?

Seamus: Our taxes doubled. (Laughs, knowingly)

Amelia: How do you balance that? How do you even stay in the black when you have that challenge ahead of you?

Seamus: Oh, it's two steps forward, one-and-a-half steps back, constantly. It's incredibly... Just from a rational business perspective, it's pretty grim. Let's just say that there's never a pop-a-bottle-of-champagne-open moment. It's like you have growth in a month, and then the next month, there are challenges. It's just a constant, balancing, kind of walking on a tightrope wire.

We've had kind of an identity crisis in Austin because, almost like a side parallel to what I've said about there not being any formal school of business or how to be creative in music... From that, people have emerged with a variety of creative 
ways on how to run live music businesses. Some of them are fascinating. Some of them are just downright impractical. So part of our identity crisis in Austin, currently, is figuring out how one creates a smarter, tighter, more fiscally responsible business model that celebrates explosive, passionate, creative moments - while understanding that, to be sustainable, everyone who is working needs to be paid. It's this idea of, "Oh, you're having fun. This world is better than a desk job, so be happy that you're an intern or something."

Yeah, that doesn't put food in your belly.

The challenge on top of that, though, is that the current consumer market, namely the younger segment that grew up during the digital age, does not want to pay for music and art - believing that it should all be free, Seamus and Padma said. Online music piracy slammed the commercial music industry (Timberg, 2015). Such a problem has happened in other artistic industries, too, like film scripts being leaked online as it happened to Quentin Tarantino's The Hateful Eight before its release (Nadkarni, 2015) and Twilight Saga author Stephenie Meyer shelving the spinoff story Midnight Sun after it was also leaked online (Ashley Hamilton, 2015).

Seamus: It's a challenge because the expectation from the culture and the youth culture is, "Free, free, free!" - free music, free online shows, free everything. And so if one goes with the flow... You know, some people are like, "Well, we'll just make our cover free, and then we'll come up with some sort of percentage at the bar, or we won't pay people at all. They get to have a tip jar or something like that. But for those of us who are doing live music, like, five, six, or seven days a week, it's like when you run the bar, money is all fixed and variable in terms of the costs that come out of it. The more you make, the more costs are there, whether it's labor costs, costs of goods, or insurance, etc.

...So in a way, local music is a labor of love because you're willing to develop bands and develop music scenes and have this sort of third place idea that you're exploring. Hopefully, those bands can then grow on the different sized stages that are around town and ended up opening for festivals and these sorts of things. But they really are more of a labor of love than a revenue generator.

Our scheme is a door cover charge because you absolutely have to have one for touring bands. If you're setting expectations for the guests, it's confusing to folks. 
Then, there's a hurdle people have to jump to actually want to come in and participate in your business rather than going, "No. There's always a cost at the door because the bands have to get paid." You like music. So why wouldn't you pay for that?

Padma: It's much more volatile to behavioral trends. If you look at Red River, there are about thirteen clubs. You think, "Oh, this is going to be great. Every four years (with University of Texas' incoming students), you have a new batch of potential customers." This current generation of customers has been raised to believe that music should be free. They're not going to spend $\$ 75$ on a ticket to see a band, even if they had that discretionary income, which they don't. The audiences skew much younger for live music than for some of these professional companies that are working year-round. The kinds of crowds you find in a club either can't afford a five-dollar cover or doesn't believe in the principle of a fivedollar cover. It's very different from someone who is going to be a season ticketholder to the chamber music company. That matters to the artist.

Public policy, some of it being low-cost or no-cost and only minor adjustments, can create a market more favorable for the artistic community — something that most in the artistic community would prefer, interviewees said. They noted different solutions they and others have proposed to do this, but many of them get stalled or ignored.

Seamus pointed out how the proposed specific zoning designation for live music venues, rather than the ones that could be applied to any bar or nightclub, would not only curb neighborhood problems, as he mentioned above, but such zoning would also create a business model more conducive in this current market. One of the criteria of such a designation would have a business model providing a revenue stream to pay for performances.

Another policy idea that Severus suggested was finding at least some developers and partnering with them to provide low-cost cultural space or affordable housing in exchange for something attractive to the developer like being able to build a slightly taller 
building — that would still give them more space they could use for making more money. City officials I interviewed noted that the state of Texas does not allow inclusionary zoning, which would require developers to have a certain number of their units be affordable housing. Severus, though, noted that some of the developers are willing to work to help the artistic community voluntarily if given the incentives. It could replace some of the spaces that have been lost. This, plus the extra revenue from development for the city, he said, could be a win on multiple levels. The problem is that some elected officials and powerful interest groups are dead-set against it.

Severus: I work with a lot of developers. Some are greedy assholes who don't care, but there's many, many of them who are interested in the long, long haul and see a return in the next, not just five years, but twenty years if they do it right. That's what we're trying to do.

...I'm not giving up on the city because we need the city to implement policies to help with this real estate market. But our whole scene and world has to turn away from this idea that the only solution is through the city because that's not the case.

...But this probably won't happen because of the neighborhood associations. ... Some of these are tools a lot of cities in Texas have used. Not here. It's another function of our dysfunction.

\section{Economic resentment}

The artistic community also heavily resented that they were major — if not the top - reason why Austin, as a whole, prospered when they were doing anything but that. Aspects they cited were the artistic community and overall creative scene being heavily used to attract businesses like tech companies. Yet, they were living in the conditions as described earlier. This hindered participation because, although the artistic community and their advocates agreed that policy change was needed to alleviate this situation, they felt that they were not a priority — even though they were such a huge recruitment tool 
for people and businesses they believed were making their lives miserable. Therefore, they were averse to working with a government who they believed was responsible. This again reflected Rimmerman's (2011) work that indicated disaffectedness' and outlaw citizenship's roots and how those participating in outlaw citizenship work against, and not with, government to disrupt policies they believe are unjust.

Penelope: I feel like people are more willing to get together and talk more than people think. But I also think that they're feeling pretty disgruntled at this point. I feel like there needs to be more one-on-one interactions with people. ... I think people are just not agreeing on what to do and what the next steps will be. It just amazes me because I feel like other cities have some sort of plan for how to help local businesses and local property owners maintain where they live, like some sort of incentive or tax break or something. I'm surprised that we don't have something like that here.

...It's very frustrating. We have to figure this out. ... I feel the tension every day. Are we going to lose where we work? I think there are a lot of feelings of animosity, and feelings that the city doesn't care about them but just cares about making money and tourism.

In early 2018, the music commission and arts commission had a joint meeting to bring together those who represent all of Austin's artistic community, with the chairman of the music commission beginning the meeting by saying, "I am so glad that we could both be here today because the city is trying to bring in Amazon and Apple on the backs of our people."

I later asked Draco if he agreed with this statement.

Draco: It's the quality of life that sells the city of Austin. Its identifier is the music industry, and that's what separates us from Silicon Valley, and Denver, and Portland, other centers of culture like Seattle, San Francisco, Los Angeles... Austin can weigh the factor of the music industry to underscore its creativity because we only have one major university, even though it's a Public Ivy. To compare to Los Angeles or Seattle or San Francisco is still a chore. So, how do we sell it? We sell it on the progressiveness, which is explored in our history of music dating back to the 1960s and psychedelic rock and heroes like Janis Joplin, 
Rocky Erickson, 13 Floor Elevators coming out of the Austin music scene and followed in the 1970s by Willie Nelson, Stevie Ray Vaughn, and everything that has come since.

Besides the "creative class" (Florida, 2014a, 2014b) oriented real estate signs shown in photos earlier, other interviewees also backed up the claim that the artistic community was the city's major selling point.

Ron: I think everyone is aware or at least buys that dynamic in a lot of ways. I think it has a lot of truth to it. They're selling the artists to these companies. Companies want talented workers, and by and large, the talented workers of the $21^{\text {st }}$ Century are attracted to cities that are dynamic, vibrant, and creative. The talent is attracted by the creativity more than the companies are. They are attracted by the creativity. So, there are a couple of links in that chain, but the end result is still the same. The creative community here is what's leading Austin to become America's boomtown.

The problem, though, was that while the city was using the artistic community for marketing, it was not helping sustain it in the market conditions that same growth was creating, interviewees indicated. Ones in the artistic community were incensed, with some considering leaving the city. It was even more frustrating for those who noted that the development that often came from this marketing was the development that, as mentioned earlier in this chapter, led to noise complaints against venues or priced out performance and other creative spaces.

Amelia: Austin markets itself as the "Live Music Capital of the World". But how can the city retain both its identity and what they're using to bring in money if they don't find solutions for the arts community?

Lily: Well, and that's the $\$ 64,000$ question. I kind of call it "squeezing the puppy", you know? We are loving it to death. Everybody loves music, and everybody wants to move to Austin. One of the reasons why all the young creatives who make over $\$ 100,000$ a year working for all the high-tech companies move to Austin and why they love it is, "Oh wow! I'm going to move to Austin and work for XYZ High-Tech Company!" Well, yeah, it's got a great music scene. What's not to love here? 
...I know from listening to the arts community here that they feel the same way. "You're making money off of us, but you're not helping us stay here."

Severus: The city really loosely markets its cultural vibrancy but doesn't effectively invest in it. I mean, that's our brand in the world. I don't go to New York or San Francisco for a conference and have people start asking about our amazing convention center or cool hotels. It's about, "Oh dude, you know, this film and that band I saw the last time I was there..." So the city does use that as a recruiting tool for these tech companies.

Hermione: So, it's like, well, this is clearly a huge part of the culture that you're capitalizing on to expand the tourism industry here and put money into your own pocket. But then you're actually making it more difficult for the musicians to survive - like with finding living spaces, finding rehearsal spaces, and even just performing without being fined.

When interviewing Percy, I noted a February 2018 Facebook posting from the city’s Cultural Arts Division that showed the city’s “creative industries” making $\$ 3.2$ billion between 2015 and 2016 (City of Austin, 2018c). Besides the fact that some of the businesses, like full-service restaurants (the businesses with the highest earnings) being included as a creative business is debatable, the greater issue was that while the industries showed high profits, it was questionable as to how much went to individual artistic community members versus the businesses. He believed that the city, for too long, had worked to cater to and benefit industries like real estate and tech, and that focus needed to shift to the artistic community that draws those industries.

Percy: Every year, they have the annual South-By economic impact report, which is in the millions. And I'm actually a pro-South-By person when a lot of people aren't because, I think, for me and for people who do it right, it really does create a lot of opportunities.

But musicians don't make any money off of it. A new ACL Fest generates a lot of money in the account, like from people coming in and staying in hotels and shit 
like that. None of that or very little of what's generated by the creative industries actually goes to musicians, actual creatives.

...It's almost like if someone needs to... We need a Robin Hood. That's the only way. We need somebody in power who is a true Robin Hood - someone who would get up there and be like, "The hotel people have been eating. We don't need to feed them anymore. Music people are starving. We need to prioritize them and say, "Fuck these people and disappoint them - disappoint the hotel lobby, to disappoint the developers, disappoint the real estate, even the people who are on their own boards, like the park land task force and all that kind of shit." There are a lot of people fighting for more money who have plenty of money or fighting for more opportunity who have plenty of opportunity. Meanwhile, musicians just don't have much.

\section{Not understanding participation processes}

The artistic community not understanding or having difficulty navigating policymaking processes was another major hindering factor. Interviewees said that those who have not regularly engaged with government before can find the process intimidating, confusing, or just especially difficult. Furthermore, some may not know that addressing public officials is permitted or proper and not know about the music and arts commissions, either. Some in the artistic community are also unaware of other nongovernmental resources available, such as with the advocacy organizations. A few interviewees, like Rimmerman (2011) noted that social equity issues such as race and socioeconomic background are the roots of whether or not someone in the artistic community — or anyone, for that matter — will have the knowledge and comfort level needed to address government officials.

Sirius said that among his fellow musicians, apathy is not the problem. There is serious desire to find policy solutions that can help in the affordability crisis and other challenges the artistic community faces. The problem is that on top of their earlier- 
mentioned time constraints, they do not know how to navigate city government, policymaking, or know what resources such as the music commission or Music and Entertainment Division are available.

For the city to truly be inclusive in participation processes, Lily said, the artistic community — and all citizens, for that matter — need to be trained in how to navigate these processes.

Lily: I think that the city of Austin, as a friend of mine puts it, has an "illusion of inclusion". I think from the arts community side, they have not always known how to be engaged. I know from working in local government for almost forty years that you have to teach them to become engaged. You have to make it so it's easy for them to become engaged. You do this so that when a building gets torn down that they love, they understand how to go forward in being effective with working with their city council members, the landmark commission, city staff how to get into this process and who to know.

I think that although the city of Austin prides itself on having all this open communication and all these meetings, I don't know that, at the staff level, this translates into true change and to true engagement.

Besides its two eleven-member commissions for arts and music, Austin has eighty-seven other boards and commissions, plus fifty-one departments other than the city manager's office. Several of those departments have multiple divisions, such as the economic development department having both the Cultural Arts and Music and Entertainment division underneath it. This also does not include the mayor's and ten city council members' offices. Interviewees indicated that either they or people in the artistic community said they did not even know that there were such governmental entities such as two commissions and two economic development offices related to the arts. City government, once all of it is put together in an aggregate, Ron said, seems like this huge, confusing monolith for the artistic community. 
Ron: How would you go and talk to a monolith? It may be a wondering of, "How would I even get involved? Who would I even talk to? How do I even begin the process of engaging with my city government to try to change things or get my voice heard?"

One meeting I observed, a joint meeting of the music and arts commissions, had the sign-up sheets for those who wanted to speak on a given issue prepared in advance, labeled, and even with a pen ready for each. All was at a table with "Citizens' Communication" in two places and in large print. What I questioned, though, was how a person less experienced in speaking at public hearings and especially those who were inexperienced would know what to do when presented with six different sign-up sheets.

Photos of the sign-in area are below in Figures 7.25 and 7.26.

Figure 7.25: Six sign-up sheets for one meeting (Pridemore, 2018)

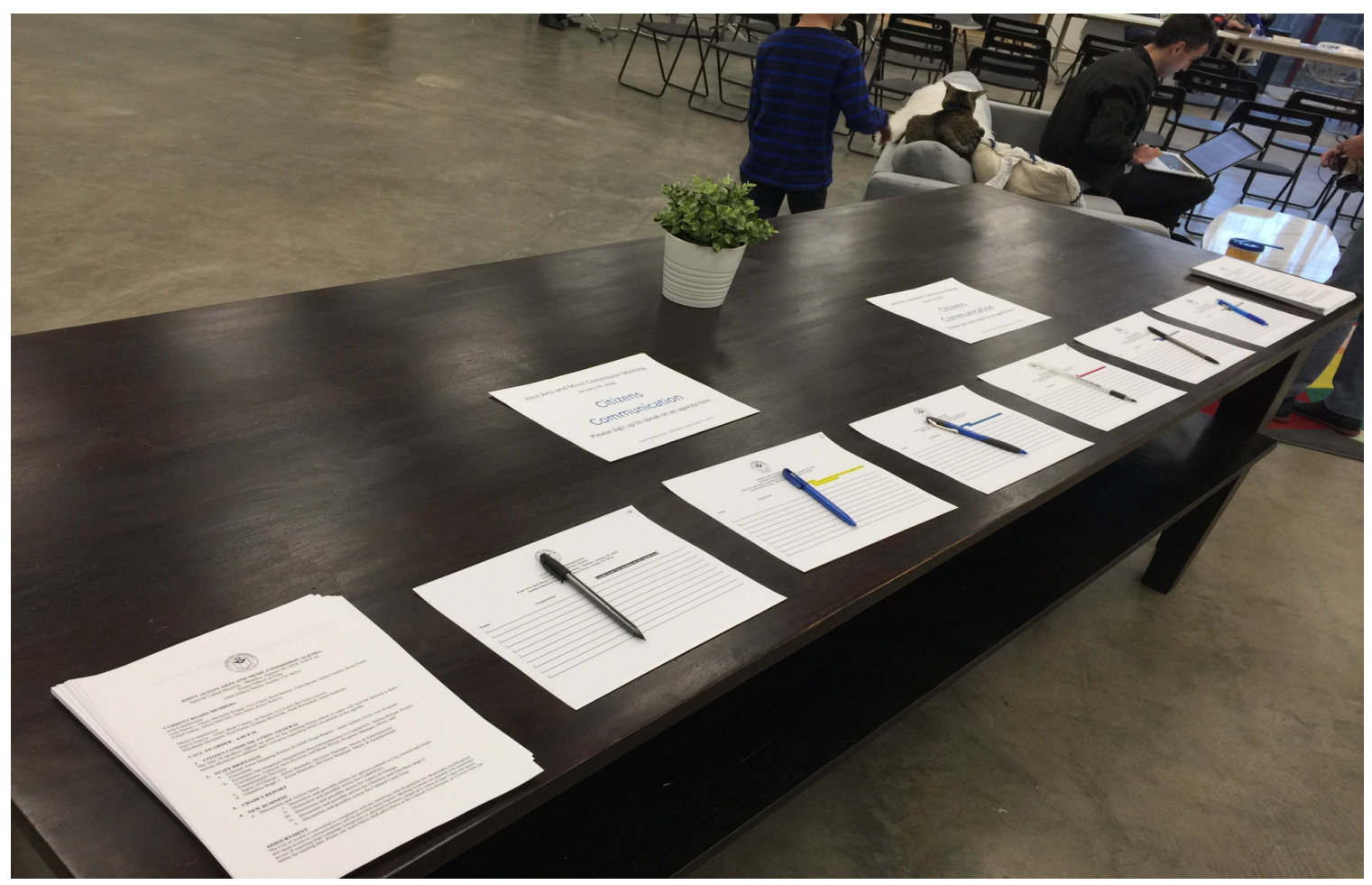


Figure 7.26: Sign-up sheet close-up (Pridemore, 2018)

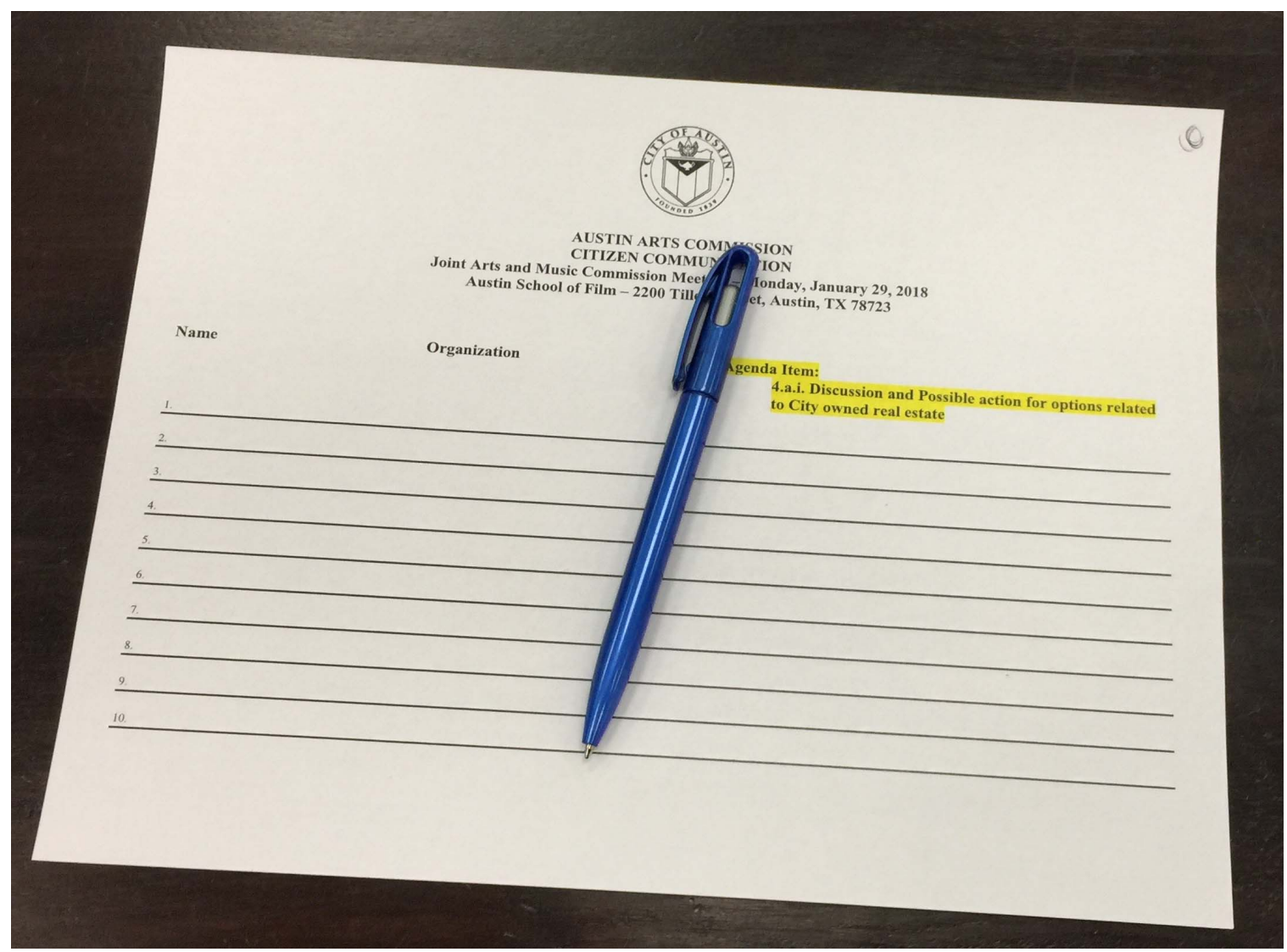

Pomona said that those in her office, once people know to get in touch with them, find out that reaching them is easy. However, not everyone in the artistic community knows policy processes and government terminology. Like Lily, she said that this needs to be taught, which she works to do. Still, government itself, can be scary for someone not accustomed to its inner workings, and not everyone has been able to find available resources. Like Sirius, she said this is not apathy but just a learning curve. She also noted that the Music and Entertainment Division of the economic development office is the first of its kind in a city government, meaning that some may not know such a novel office is there to help. 
Pomona: If we have a stakeholder meeting at city hall, not everyone has been to city hall before. Not everyone knows the process and the name of the game. I think once you get access and you realize how easy it is to get a hold of myself or even our managers, I feel like when someone is in, they're kind of in. They know where to contact us and how to contact us.

But I think one other thing is maybe just kind of the general fear of the government and not knowing what it means to contact someone within the city government. Our city council members and their staffs do a wonderful job of letting us know when someone is reaching out about a problem or issue.

...I know that it's hard. It's challenging for us to engage with creatives who are not used to having to provide their input to the government or not even put a little support behind what it is they do. So I wouldn't call it apathy, but it's definitely...

We have the first music office to exist within a city government. The first thing it does... So honestly, it's more brand recognition than anything. It's really just letting people that we're here. It's not that they don't care. They just don't know. When people do realize we're here and that we're not going anywhere and that we are here to provide support, and that, while we can't reach out to people as much as they would like for us to, we're really going to do what we can do. We will do everything we can to try to help people know that we're here to support them.

I wouldn't call it apathy. I would call it discovery.

Some people may not even know that addressing public officials is even permitted or considered proper, interviewees indicated.

Angelina: Those factors are going to be true for, really, all residents, not specific to the arts community. Some of the barriers to participation include a lack of information about how and when a person can participate. I remember when I first started paying attention to local issues, I wasn't aware that a resident of Austin could pick up the phone and call a council member or email a council member. I didn't have an understanding of how the process of how to communicate with my local elected officials. I didn't know that there were opportunities in every council meeting, for example, for anybody to sign up and communicate on something that was posted or with a little bit more pre-planning, to communicate on an issue not on the agenda through citizens' communication.

I think most Austinites are just not aware of how it's not just acceptable, but definitely part of the process for them to communicate in those ways. And if they know about some of those opportunities, they don't probably know about all of 
them. ... Those are just not always immediately apparent for people who aren't already involved.

...It's pretty specialized in some ways. It's a specialized group of knowledge, and not everybody has it or knows how to go about finding it. ... I mean, I had to ask a friend, "Is it acceptable for me to reach out to a council member?" And they're like, "Absolutely. You should." I just didn't know that we could contact the city council outside of meetings.

That specialized knowledge is particularly a concern when people from historically disenfranchised groups are working to have their voices heard. Albus noted that those who did not grow up in more socioeconomically advantaged homes may not be "trained" in citizen participation, and especially when considering diversity and in hearing from those who are socioeconomically disadvantaged, this should be both considered and remedied. This also goes beyond artistic communities.

Albus: Barriers to participation probably has a lot to do with a lack of knowledge about how to communicate with public officials. It's not just about artists. Earlier today, I met with another person from the minority community who is active in politics about the fact that young people, people who have to work two jobs, single moms, persons for whom it's not a tradition in their families... It's not clear to them. It's not obvious to them. It's not easy for them to get involved in public policy.

...It's of great benefit to young people to be involved in public policy and whatnot because of the fact that pension funds are run down and job opportunities are not as prevalent as they were for my generation. And yet if it's not part of their culture and upbringing, and it's not made obvious to them or impressed on them through their education to become involved, then many of them do not become involved.

So it's not that we lock the doors. It's not that we try to divert people. It's that it's not part of the culture for people to be involved in public policy. It's more along the ideas about business where the business of business is business. The business of artists is art. The business of young people is experience and living. So where does that bring them into the public arena? It has to be made. They have to be drawn into it because somebody has to help them realize that it's in their best interest. 


\section{"Language barriers"}

Another hindering factor in the Austin artistic community's participation was that of figurative, two-way language barriers (Herranz, 2015) between it and city government. The artistic community found itself confounded by the language and practices of government. Likewise, interviewees reported that some in city government did not understand the artistic community's practices and their related needs in terms of public policy. If the two parties came together, collaboration was sometimes lost in translation.

Pomona noted how "government-speak" can be very intimidating for those outside of government, particularly because of how government officials often utilize acronyms as part of their regular lexicon. For someone like her who works with both the artistic community and inside government, this requires effort to first explain what the terminology is to artistic community members before any policy oriented dialog can even begin.

Pomona: Government-speak can be very intimidating if you don't have a day-today understanding or even a pedestrian understanding of what city codes mean, and ordinances, what the difference between a council recommendation and resolution is...

When we have interns come in or people come in who are at the basic level of city government understanding, I will always take the time and be like, "Listen, we have ten council members. There is district representation. Here is what district representation is..." Breaking it down in a way that is easy to consume is very important.

I would definitely consider that a barrier. I wasn't thinking about it because I'm so used to using the acronyms, and some of our council members hate our acronyms. But RCA, "Request for Council Action", and just different city acronyms is definitely a barrier. If you don't know the council and the city government-speak, it could definitely be something that's overwhelming. You could get halfway down the process of doing something that you could have skipped fifteen steps to do. 
Penelope said that in Austin, citizens as a whole tend to be more well-informed than "a lot of people would expect", such as ones in the artistic community and their allies who have rallied behind the Red River district. However, she believed that there were only a handful of exceptionally well-informed citizens who are prepared to navigate citizen participation processes. Most others do know what is happening, but do not know exactly how to move forward. Those in the latter group may not show up to a public hearing because they do not know what to do when going to such a meeting could help them start learning.

Penelope: I think that because there's so much controversy around Red River and the hotels that are moving in here... You know, everybody has their "Defend Red River" t-shirt, and I think in that aspect, people are pretty well aware of what's going on in city hall. But I don't know if they feel like there's a way for them to contribute. I mean, as a person who has been to these meetings, I can tell you that people never show up unless they're there to speak. That can be kind of frustrating because it would be nice to see if it was just to show up to learn more. I learned so much at those meetings about the music scene that I didn't know about before. But when only the speaker shows up and there's no one except the city council members to hear it, it's hard to get everything kind of translated to everyone.

\section{Artistic temperament versus bureaucracy's hierarchal structures}

Some in the artistic community also noted that city government, particularly the bureaucracy, was the exact opposite in terms of thought processes, ethos, culture, and operations when compared to artists. Those in the artistic community and some of their advocates said that super-hierarchal and highly structured bureaucratic offices (i.e., Max Weber [(2011 [1922])] style) were a turn-off for artistic people who prefer a looser, more free-form approach as to how they do their jobs and operate in society, at-large. This presented a hindering factor in that a combination of government officials and artistic 
community members together meant that there were two parties who did not understand and more importantly, operate in, each other's formal and informal organizational cultures, per se.

This was especially true because, interviewees said, many artists tend to lean on the anti-establishment side as it is, but there are some, such as punk or metal musicians, who outright exist to oppose establishments and formal structures. This was very related to the "language barrier" issue in that two groups, the artistic community and government, not only had two sets of lingo but two methods of operation, and these were an automatic turnoff to some in the artistic community.

Hermione said that "government" as a whole, is off-putting for creative, free-form people, but when that is combined with a rigid operational structure, this can turn off artistic people even more. That structural element was more bothersome than government, itself, and more than public officials, themselves.

Hermione: I think people look at that bureaucratic system, especially people who are maybe more used to working in collaborative, kind of open-ended contexts where there's not so much kind of set structure and process and hoops to jump through... With us, it's really everybody contributing ideas and working together to create something. People who are used to working in kind of a more creative, collaborative context can look at this bureaucratic governmental structure and say, "OK, well, that's not how I work. I don't see myself making an impact on that because that's just not how I would structure things or move things along."

...Amelia: So it's just not how creative people operate, right? It's not necessarily a reaction of, "Oh they're a bunch of crooks!" It's just seen as this onerous, crazystructured system when you do things on a more free-form level, right?

Hermione: Right. I would say it's less about the individual people in government, although I think there is also some level of distrust with "the kind of people", quote unquote, who would choose to go into government and politics. I think, to some extent, there is maybe a little bit of, "Well, if these people are choosing to become politicians or whatever, then they clearly buy into this system." So am I going to be able to get anything out of them or have a working relationship with 
this person who thinks that this system is working or is a cog in the system, if my ultimate goal is to really restructure and get outside of that bureaucracy in the first place?

When Hermione told me this, I immediately recalled a narrative map from the New Orleans focus group that seemed to echo these feelings. Anti-hierarchal attitudes were not a major, overall finding in New Orleans, but at least one person vividly displayed his preference for a far more free-form society at-large, including in the government, when he displayed his idealized relationship between artistic community members like himself and the local government. Lee, a street musician who was in the focus group who drew this, told me that chaos was not necessarily a bad thing.

I brought this up with Hermione when I returned to Austin. Hermione's perspective was in line with Lee's - but she noted that what one would view as chaotic is relative, with the artistic community looking at the hierarchal, organized bureaucracy as the one that is chaotic. One note I made about her response, here, was her use of the word "efficient" — considered an "Old Public Administration" value (Frederickson, 1997a) - but noting how artistic people like Hermione view what it is in a polar opposite fashion.

Amelia: One of the musicians I met in New Orleans drew, for his ideal, this smorgasbord of everything and everybody all over the place. I asked him what was going on there, and he said it was chaos.

Hermione: (Laughs)

Amelia: He said it was chaos, but that it was good chaos because everyone is all together, collaborating and everybody is just being chaotic together and not so organized. Is a little chaos not such a bad thing?

Hermione: I definitely don't have a problem with some good, creative chaos. 
Amelia: (Laughs loudly)

Hermione: I think that's the thing that's a little bit ironic. Bureaucracy is also chaos, a lot of the time, or it's certainly not by any means, the most efficient or productive way of, again in air quotes here, "getting things done". I think it's interesting that we are kind of trained to think about those two ends of a spectrum - bureaucracy as being organization and then kind of a lack of bureaucracy or more of a collaborative space being chaotic. Yeah, to some extent, maybe that's true, but I don't think it's necessarily the element of chaos that is a) exclusive to the lack of bureaucracy because, again, I think that bureaucracy is, in some ways, also always chaotic or b) that chaotic element is a deterrence to progress or productivity, necessarily.

Ron said that some artistic community members, given the nature some of them have, might find themselves being reluctant to engage with anyone they believe is "the man". This could make them be labeled a sell-out. Remus, a metal musician, agreed that in subcultures like his, taking an oppositional stance against dominant society structures that include government is very culturally ingrained. Albus agreed that governmental structure could be off-putting for a creative person, too.

Albus: It has to do with the difference between the idea of art and creativity falling along the line about chaos and randomness and the fact that you get a spur of the moment idea that translates into your art, versus the well-planned, organizational-type factors. There are policies or procedures that we try to follow where we have procedures and meetings and stakeholder groups and focus groups and legal departments that vet language, etc.

So the city falls along more of a mechanistic, formulaic pattern. Whereas with art, we hope you can follow along more of a natural path. This could be a contrast between nature and industrialization, basically where government is industrial and art is natural or something like that.

Sirius noted that while organization may be an affront to artistic nature, understanding how bureaucracy works is essential when working toward change.

Sirius: I guess that's built into the whole rock and roll thought process. But I think it's an essential part of working within the rules of local government. Even though 
it may be counter to their artistic temperament, it's a necessary thing to be able to work toward change and understanding that bureaucracy and working with it.

\section{Hindering Factors Related to Non-Traditional Participation}

Two key hindering factors emerged when it came to Austin's barriers to nontraditional outlaw citizenship. One was that while the Austin citizenry, as a whole, did not shy away from outlaw citizenship displays and very creative, arts-oriented ones, they did not do this much for even the most pressing local issues and instead opted to focus ones at the federal and state level. Another factor was that outlaw citizenship displays, largely because of the current heated political and social environment, often attracted outside agitators who went beyond mere counterprotesting and worked to derail certain groups' outlaw citizenship efforts or ruin the image of those who participated in these. Some participants, themselves, created hindrances because even if just one person in a group engaged in appalling behavior, it created a negative image for all involved.

\section{Not enough done for local issues}

The Austin citizenry, as a whole, was one that did not shy away from outlaw citizenship. The problem was that most outlaw citizenship efforts focused on federal or state government policies and not much on local policies. Local policy was certainly not ignored, as I will detail in the next chapter, but those doing outlaw citizenship displays were focusing much less on local issues - even when the local issues were urgent. Austin being the state capital meant that most outlaw citizenship activities took place at the capitol building versus city government sites, taking place out of the local outlaw citizenship context, as well. 
Albus: I've been to political rallies indoors at different clubs on different issues. We've had a march here. But it's funny that there's not really... There may be some. There may be a protest about CodeNext. I don't know. There are a lot of angry people out there. But there really hasn't been a local issue that was so divisive or that we needed to speak to our public officials so loudly. Actually, back in the early 1990s, I participated in an environmental protest outside of city hall that led to an all-night meeting. There was a period there.

Helena also noted that most outlaw citizenship activities she sees in Austin move to the capitol complex versus city hall, minus the Occupy movement of the early 2010 s.

Helena: (Occupy) had a forum, and there was a rally and people got some information out there, but typically, that does not happen in Austin. ... If they're going to have a march, people are going to be marching toward the capitol versus city hall.

One display I observed during my Austin fieldwork period was a Christmasthemed protest against the Republican tax bill in Congress in December 2017. Protestors dressed in Santa caps, reindeer antlers, and elves wrote their grievances and their zip codes - to show that they are registered voters in Texas - on black sheets of paper to resemble lumps of coal. As people sang Christmas carols outside U.S. Senator Ted Cruz's and then U.S. Senator John Cornyn's offices, a protest leader dressed as Santa collected the "lumps of coal" and brought them into the senators' offices in giant stockings. Photos of the protest are below in Figures 7.27, 7.28, and 7.29. 
Figure 7.27: Santa caps at tax bill protest (Pridemore, 2017)

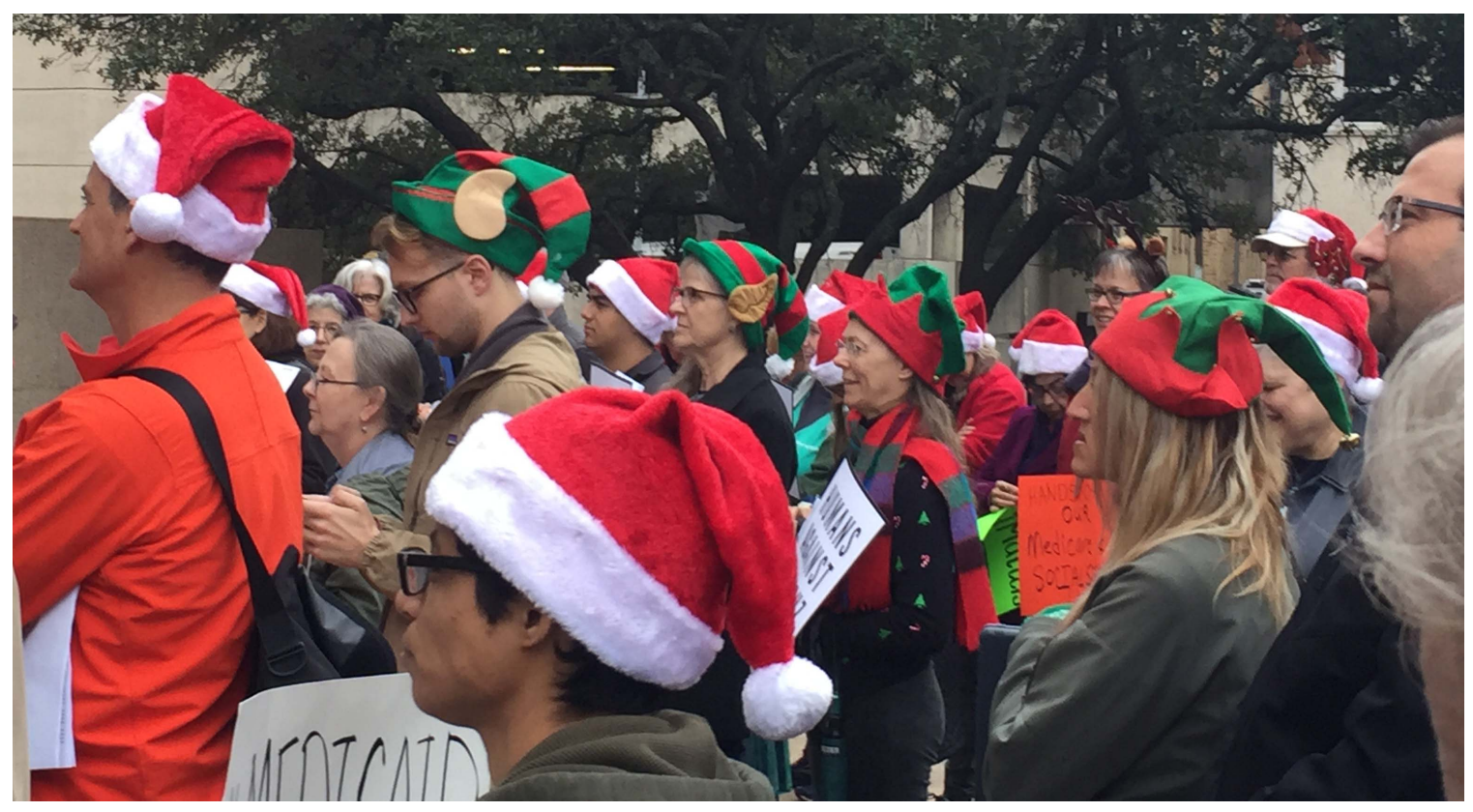

Figure 7.28: Santa at tax bill protest (Pridemore, 2017)

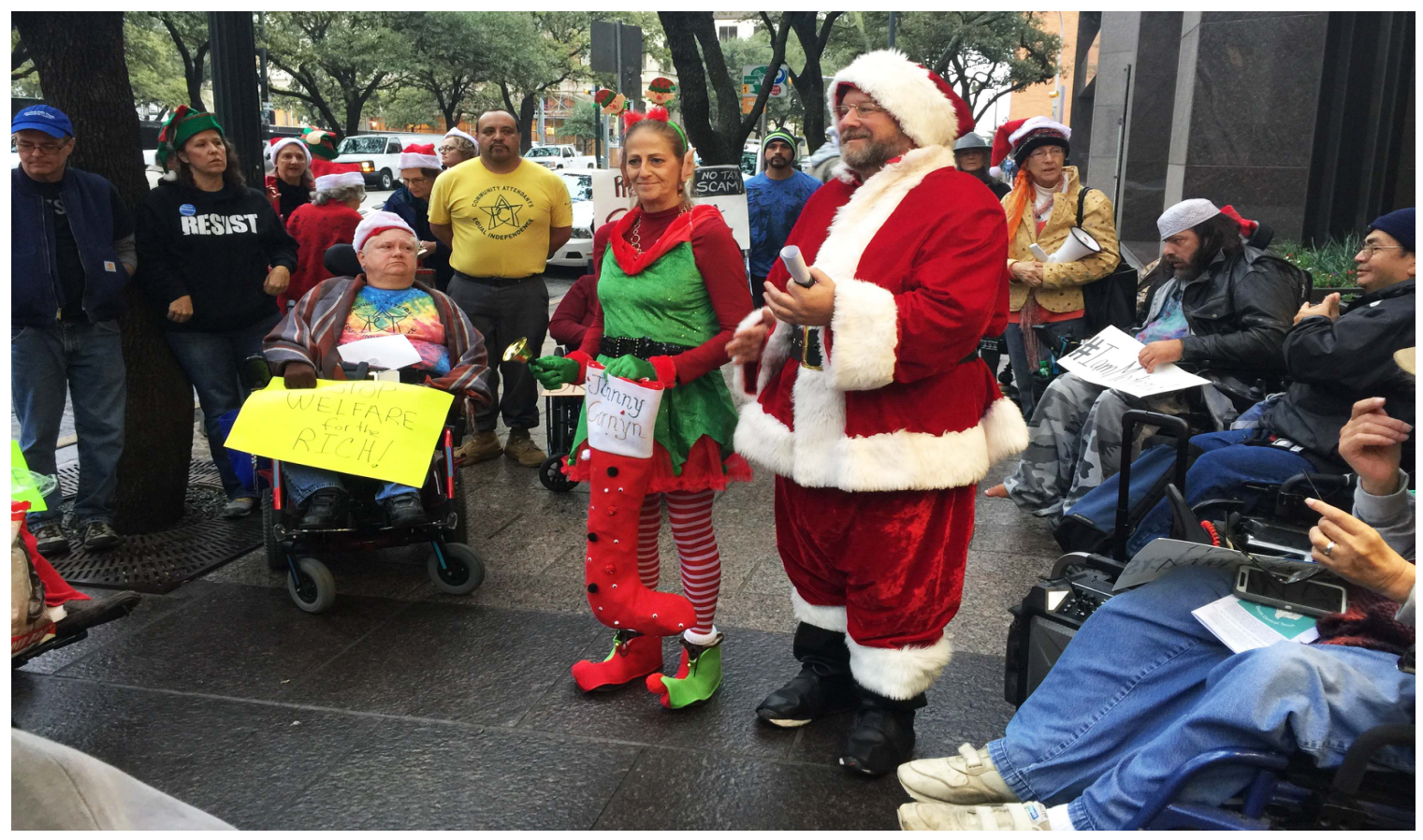


Figure 7.29: Lump of coal for senator at Christmas protest (Pridemore, 2017)

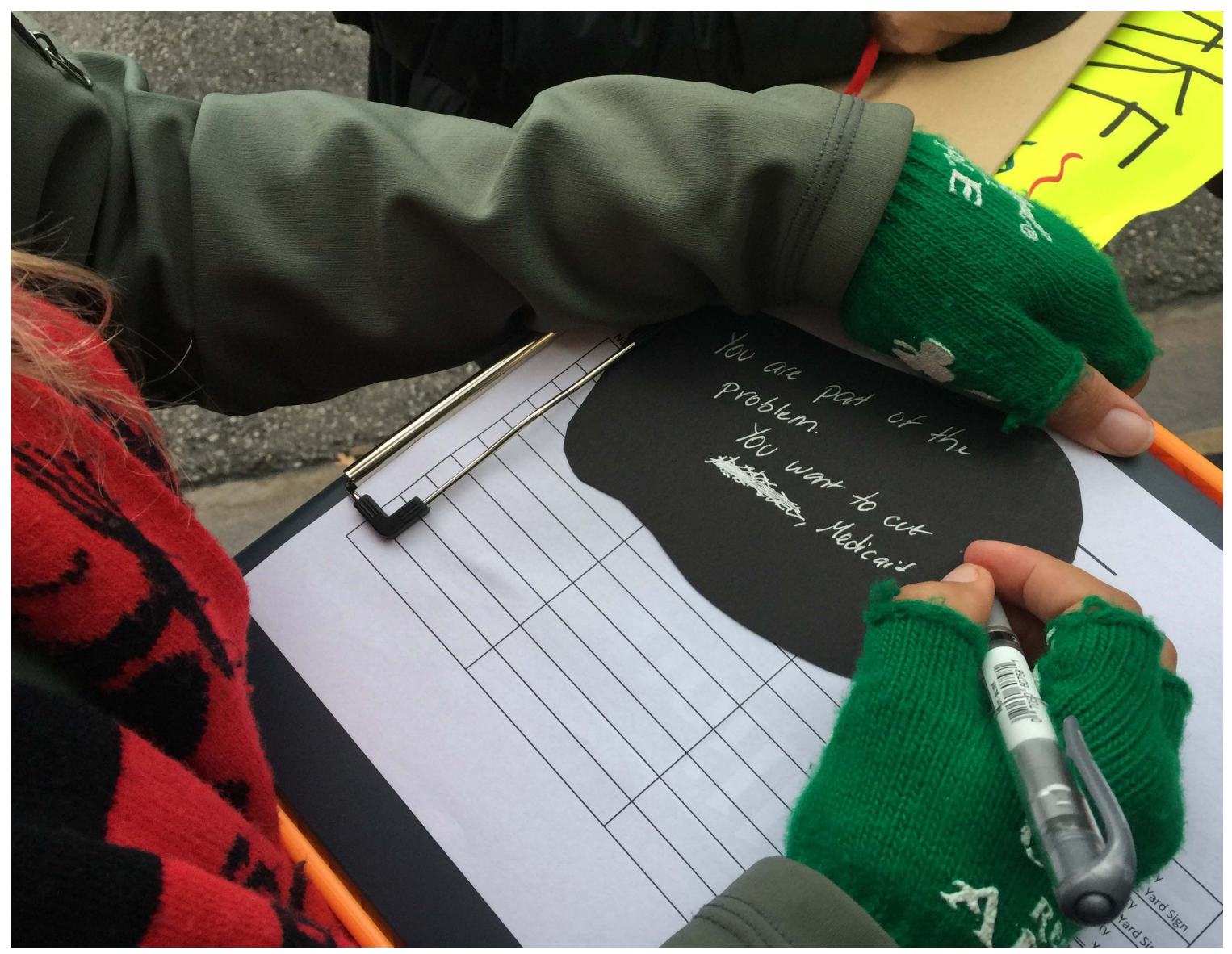

Something that struck me about this event though, did not hit me until I was

walking back to my car after the protest ended. It made me wonder that, while federal and state issues are indeed important, if these made people miss what was happening in their own backyards.

Blocks away from where the protest had taken place, I saw a man sleeping on a sidewalk outside of a church. From what I could tell from a sign on the church door, it provided services to the homeless but only during certain times. The man's dog was cuddled next to him, not leaving his side. I did not take his picture, though I knew the image would be powerful. I just could not do it for personal, ethical reasons. It made me 
think of what interviewees had told me about the issues involving housing prices and

displacement that are happening locally, along with the drug dealers like those selling K2 who are preying on the homeless around Red River. After such a display about a federal issue, I wondered if what was happening locally needed a display of its own - maybe an even larger one.

Ron noted that with some federal issues, particularly when involving extraordinarily polarizing public figures like Donald Trump, the narrative is easier than complex local issues, such as the stalled Agent of Change policy.

Ron: It's easier to get attached to or get involved when an issue has a face or an easy narrative. How long did it take me to explain Agent of Change to you? Four minutes? And I know the issue. Try to construct a two-sentence, quick narrative about Agent of Change that Joe Public can 1) understand and 2) pick a side on and care about. It ain't happening.

That's the thing. Donald Trump is an easy narrative, whether you see him as a positive or a negative. It's easy to talk about. ... If you could do that on a local level, kind of crack that nut and turn Agent of Change and cost of living and affordability and any of these other issues into easy narratives that can be pulled apart and argued about vociferously... In the long run, that might be better for everybody, but how do you do that?

\section{Attracting agitators, protestors repelling people from their causes}

Outlaw citizenship displays, especially if they are about extremely heated topics that are polarizing, often attract outside agitators like angry counterprotestors or people working to ruin outlaw citizenship participants' images. What makes matters worse is when certain people involved in outlaw citizenship do things on their own that makes everyone involved in their cause be viewed unfavorably — which, as Rimmerman (2011) argues, hurts their cause in the end. The current, fractious political environment makes 
the problem of outside agitators more commonplace and can hinder outlaw citizenship efforts even more.

Ernie said that in the current political environment, particularly at the federal level, he and other police officers have had to deal with a larger influx of protests, as well as ones that attract counterprotestors that he and other officers will have to make sure stay separated. However, most demonstrations, which involve state or national issues, will move from city property and go straight to the state capitol complex, where the Texas Department of Public Safety has jurisdiction. Still, this has created a more tense security situation that city police have to monitor.

Outside agitators, given the rise of extreme politics, are even more common and when some of the most infamous of them are locally based, they are more likely to show up and try to make outlaw citizenship scenes chaotic. During the Christmas carol protest, a "correspondent" from the controversial, far-right conspiracy theorist broadcast InfoWars arrived and asked protestors inflammatory questions. InfoWars is based in Austin. The InfoWars correspondent is shown below in Figure 7.30, at the portion of the protest outside Cruz's office. 
Figure 7.30: InfoWars at Christmas protest (Pridemore, 2017)

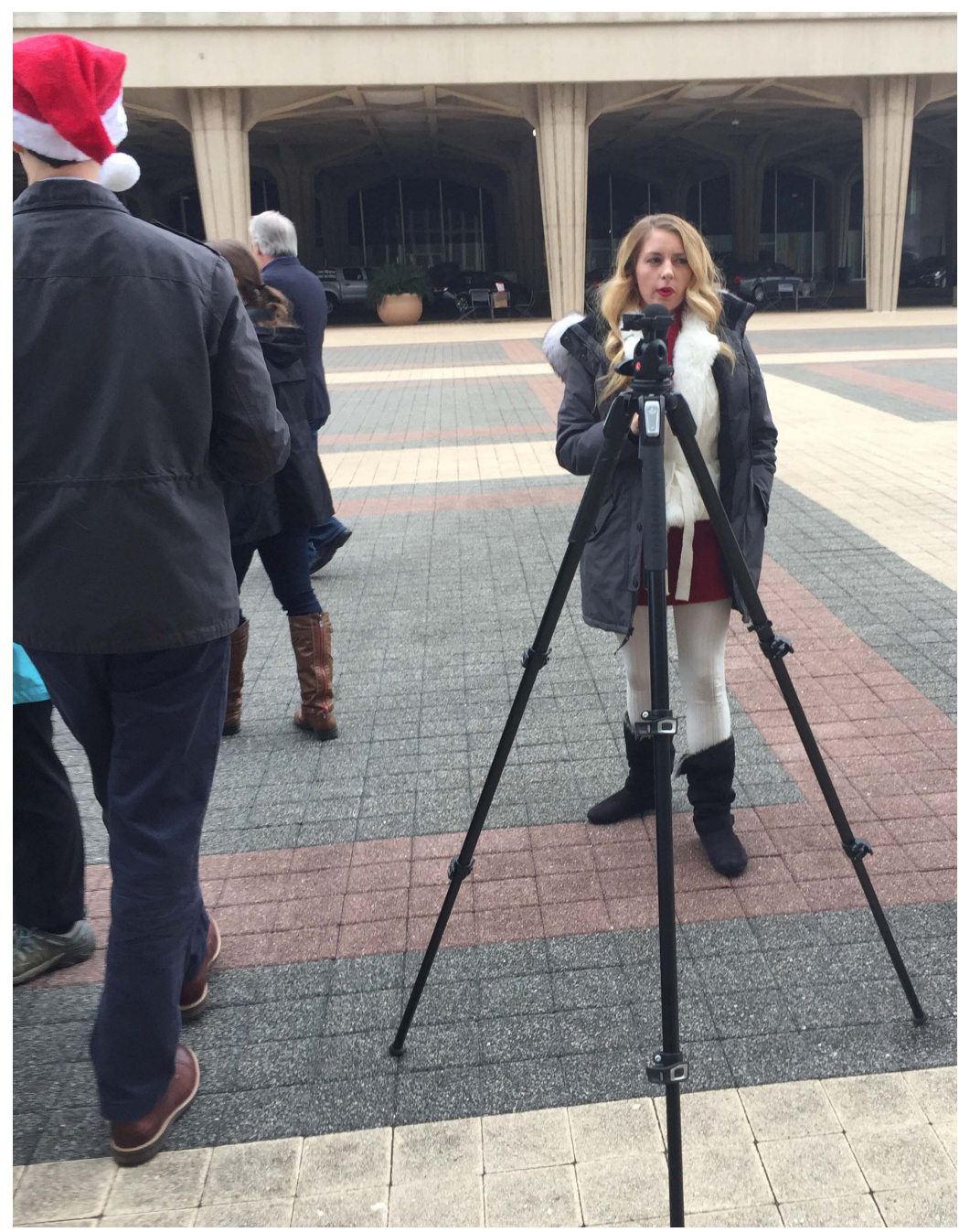

These are commonplace on the lighting rod host Alex Jones' broadcast's "field pieces", like Jones himself used to taunt U.S. Senator Marco Rubio (Daugherty, 2018). InfoWars is known for material such as Jones' assertions that the federal government was both responsible for chemicals that make frogs gay and working to control the weather (WatchMojo.com, 2018). In the current political environment, though, agitators like Jones are not alone, and outlaw citizenship can attract them.

Another factor that hinders outlaw citizenship is when certain participants engage in activities that turn off anyone who might be otherwise attracted to their cause. 
Sometimes, it just takes the actions of a few or even one person to do so. Helena's

recollection of the Occupy protests at city hall reflected this.

Helena: That was probably the last public, non-legal activity I can recall. They were camped out at city hall. They were all over that whole public area, blocking the sidewalks, defecating everywhere. They were mixed in with the homeless. It was a mess. It got people's attention.

\section{Conclusion}

Austin is a city practically changing at the speed of light, and it is outright careening like a car with no brakes — and the artistic community believes it will not be able to get the policy tools they need that could help them stop them before a crash. The hindering factors to the artistic community's citizen participation presented in this chapter, such as government inaction, facing down wealthy and powerful developers who seek to temper entertainment areas, an affordability crisis that prevents them from engaging in policymaking forums, and negative social construction of place possibly

moving to their beloved arts-oriented neighborhoods that I have addressed in this chapter are ones that they believe make a dangerous situation worse and leave them powerless to stop it.

Some of the Austin findings presented here add to existing scholarship. This chapter provides an additional step for citizen participation studies. Public administrators who seek to bring citizens into policymaking must go beyond bringing them into the fold and having a dialog and actually follow through and implement the policies citizens help craft. Otherwise, the citizen participation that can be difficult to retain as it is (Pridemore, N.E. Ganapati, \& Revell, 2019) will certainly drop off or even end. This is especially true for policymakers working with disaffected populations. Not following through after 
citizens have worked to create solutions means that not only citizens will believe their efforts were in vain, but it will also create greater resentment and unrest. The findings also further confirm other scholars' work involving inequities in citizen participation processes, such as more powerful and privileged populations having greater access to forums and officials while those on the opposite end of the social strata having less because of factors such as less flexible work schedules and longstanding racial inequality (Fung, 2006, 2015; Laurian, 2004; Rimmerman, 2011). The findings here also compliment Arnstein's (1969) lesser-cited but arguably greater focus on how certain citizen participation forums and methods governments use can be akin to bread and circuses - simply placating citizens and making them feel better without actually taking their input and making it a concrete policy that actually makes their lives better.

This chapter's findings also add to scholarship involving multi-dimensional power exercise (Bachrach \& Baratz, 1962; Gaventa, 1980; Schattschneider, 1983 [1960]; Warner, 2001; Warner, 2011) in that they not only involve issues involving the Second Face of Power, but also the Third Face of Power. The Second Face of Power exhibits itself with power exercises with the aim of changing "rules of the game" (Warner, 2001; Warner, 2011), like hotel developers' work to quiet live music venues — exercising power even when they do not have the ability to explicitly do so - and with venue owners, the artistic community, and patrons knowing who is responsible. The Second Face also exhibits itself, in the Austin findings, with "non-decisions" (Warner, 2011, p. 1) when ignoring someone or refusal to make decisions in that person's favor is a power exercise, too. 
These findings cross into the Third Face of Power (Gaventa, 1980; Warner, 2001; Warner, 2011) because of how the artistic community's constant beatdowns from powerholders inside and outside government has made some in the artistic community feel powerless to stop a situation they know works against them. Also, they may not know all who are truly responsible, as is often the case with the Third Face of Power, given some city officials' posturing (Personal Communication, 2017, 2018).

The findings also give existing scholarship new dimensions. Place can be socially constructed (Schneider \& Ingram, 1993), and in the vein of Schneider and Ingram's (1993) work involving groups of people, places can also be targeted for helpful or punishing public policies, depending on overall public opinion about them. Studies involving trust as a citizen participation factor have namely focused on citizens' trust in government (Pridemore, N.E. Ganapati, \& Revell, 2019). However this chapter has noted trust issues involving intermediary advocates and how citizens and government officials alike must be careful as to whom they trust. This chapter's finding also provides a new dimension to organizational theory studies, as well as that of citizen participation. When bringing citizens to the table, policymakers must understand that certain groups, like freeform-oriented artistic communities, may have drastically different working styles and preferences than those working the bureaucracy, especially if, as in the case with artistic communities, the group in question is not oriented toward formal structures and hierarchies, like the bureaucracy (Shafritz, Ott, \& Jang, 2011; Taylor, 2011 [1916]; Weber, 2011 [1922]). In terms of artistic communities policy preferences, this chapter showed artistic community's policy overall preferences geared more toward the private sector and enabling market conditions to work in their favor (City of Austin, 2016a; 
Currid, 2007; Personal Communication, 2017, 2018) rather policies geared toward than the wider-studied nonprofit arts realm (Rushton, 2013).

Studies involving citizen participation challenges during tumultuous social and economic change (Pridemore, N.E. Ganapati, \& Revell, 2019; Simenova, 2005) are not new, but the findings in this chapter focuses on a city in the United States unlike most from the past. A very interrelated finding challenges notions about institutions' strength, even for informal institutions. While these remain strong (North, 1990), the findings presented in this chapter show that, as Bachrach and Baratz (1962) cautioned, institutions are not indestructible and, as North (1990) wrote, those who seek institutional change will work to do so by first changing formal institutions, such as public policy governing music venues' noise levels. The findings here also show the danger of putting too much faith in institutions. Institutions can be especially vulnerable in the face of unprecedented and extremely rapid change.

The practical warp speed at which the social and economic landscape in Austin is changing combined with the real and perceived snail's pace any policy remedy to mitigate this is happening will make overcoming these participation challenges extremely difficult. Especially when considering the rapid changes, there may not be enough time now to remedy the situation before more arts and entertainment venues close and more artistic community members are priced out of the city.

In the next chapter, however, I will present enabling factors for Austin's artistic community's citizen participation. I show how some in Austin's artistic community have certainly not given up, despite what seems to be an avalanche rolling straight into their paths. Two key factors are former rivals — some of them, people one would never 
imagine building a positive working relationship — burying hatchets they have because they realize that their survival requires strength in numbers. The other factor involves unique offices in the bureaucracy that both work to serve the artistic community and bring a private-sector orientation in their approaches. Austin's challenges may seem insurmountable, especially at the speed in which they fly in the faces of the artistic community. As I will explore in the next chapter, not all have given up. 


\section{CHAPTER 8: AUSTIN'S PARTICIPATION ENABLING FACTORS}

Place being a critical element in conducive and constructive citizen participation, the importance of government officials meeting disaffected citizens where and when they gather, disaffected citizens creating positive in-group relationships within their own groups and pushing aside rivalries, and weighing out creative fun versus necessary boredom were key enabling factors in the Austin artistic community's citizen participation. In this chapter, I explore the positive findings for this case that I had classified as a positive extreme at this dissertation's onset.

This chapter provides multiple contributions to existing scholarship, working to fill some of the gaps scholars who examine both citizen participation and arts and cultural policy have identified. It also contributes to the literature in terms of providing new angles for existing scholarship and showing how certain theories work in present-day practice.

One major contribution is how place is a major enabling factor for constructive and conducive citizen participation, not just for artistic communities, but for historically disenfranchised and underrepresented groups in general. My findings show that artistic communities want government officials to come to them and at the places and times the artistic community gathers, not the other way around. The major element of how this was conducive is this became a demonstration that government officials "got it" - that the officials truly took a genuine interest in the artistic communities' concerns and were willing to experience what the artistic communities did. Also, this created greater equity in terms of countering problems with meeting times and work schedules (Fung, 2006, 2015; Laurian, 2004), as well as countering intimidation factors from formal government 
meetings and these formal meetings not being conducive, period, for historically disenfranchised groups (Rimmerman, 2011).

The artistic community believed that officials coming to their places not only demonstrated that public officials showed genuine interest in their condition, but it allowed them to see the issues affecting them and their spaces first-hand. This knowledge led to more effective public policy, both they and government officials told me. Learning first-hand from the citizens who are affected most by a given policy is part of established scholarship (Elias \& Alkadry, 2011), but this chapter provides an addition to that because it shows how place can be a critical, if not the most critical, factor in having such a conversation and having it be constructive and open.

This major finding also showed how third places theory (Oldenburg, 1999) can work in practice and provide more contributions to how social construction theory (Schneider \& Ingram, 1993) can be applied to place. When city officials and Austin artistic community members would meet in locations like third places, the socially level (Oldenburg, 1999) and less-structured environments created an environment that was more conducive to having critical conversations. With less intimidation or discomfort, the artistic community members were able to openly express their concerns and in a way that felt more natural to the more free-form-oriented artists. Social construction theory (Schneider \& Ingram, 1993) also came into play in terms of how positively constructed places, like beloved entertainment districts and historic creative spaces, can become the targets for more favorable public policy, just like positively constructed people can be, as well (Schneider \& Ingram, 1993). This happened in Austin when the artistic community pulled both public officials and the public at-large to the places and activities more often, 
sometimes considering barriers on the general public's part in doing so, and demonstrating that these spaces and activities had value and meaning — and were worth fighting to save.

Private-sector orientation in city arts policy, was part of city government "getting" the artistic community and another major literature contribution in terms of arts and cultural policy. In Austin, two city arts offices in the economic development department were oriented more toward the private sector and business development, something that most in the artistic community, particularly those in commercial music, were thrilled to see. The employees of these offices having experience in private-sector arts and privatesector creative business development was another major plus for the artistic community and in relationship-building between the artistic community and the city government. This addresses concerns that scholars in arts policy have put forward about how the dominant nonprofit arts discussions have resulted in undercounting of those who participate in local arts and cultural activities (M. Jackson, Herranz \& Kabwasa-Green, 2002; Rushton, 2013) and how individuals working in the arts have said that their work, though it is a creative endeavor, is still that of an independent business (Novoselic, 2004).

The importance of citizen groups' in-group relationships — namely with former rivals becoming allies - is a major contribution to the literature that this chapter provides. Citizen participation scholarship has accounted for conflicts between particular groups as major participation challenges (Pridemore, N.E. Ganapati, \& Revell, 2019). However, this chapter provides insight on how relationships within citizen groups are critical in participation, namely because those who want to effectively work for positive change have to settle or at least put aside any conflicts, rivalries, or tribalism within their 
own ranks before approaching government officials. Otherwise, their efforts will fall apart. One rather remarkable example of this, detailed in this chapter, is how nightclub owners in a highly competitive entertainment district united and initiated successful policy change efforts, even when their opponents were extremely powerful and wellfinanced.

Another contribution this chapter makes is detailing the importance of citizen self-sufficiency in participation efforts. Artistic community members taking initiative on their own, being their own spokespeople, crafting their own arguments and proposing their own solutions were all critical in their being heard, their message being wellreceived, and having policy solutions that worked. This went further than favorable reception, though. It also countered the issue explained in the previous chapter of the artistic community having numerous organizational leaders, some with serious rivalries, competing to be its spokespeople. Being their own spokespeople meant that the artistic community did not have to face its serious policy challenges and determine who could and could not be trusted at the same time. Part of this self-sufficiency also addresses issues noted in outlaw citizenship (Rimmerman, 2011) and power theory (Gaventa, 1980; Warner, 2001, 2011), namely because it requires some in the artistic community to drop an oppositional stance disaffected populations often adopt (Rimmerman, 2011) for survival and defeat power structures described in the Third Face of Power (Gaventa, 1980; Warner, 2001, 2011) because working with government means that they have to break out of a mindset that government is an enemy not to be trusted. Those mindsets being ingrained are part of longstanding power structures holding down disaffected 
populations, and this chapter details how some in the Austin artistic community have overcome that.

Scholars have also noted the problem of retaining citizen involvement in multiple citizen participation studies (Pridemore, N.E. Ganapati, \& Revell, 2019). This chapter provides a contribution to that literature and that involving outlaw citizenship at the same time because it provides an answer as to how this can be done - making participation enjoyable, creative, and even fun. Outlaw citizenship provides such opportunities. Interviewees noted that traditional citizen participation outlets, especially for younger artistic community members, are often extremely boring. Outlaw citizenship allows them to express themselves unrestrained, be creative, and do something enjoyable while also drawing attention to the serious problems it faces. Likewise, creative and fun outlaw citizenship activities can, as this chapter demonstrates, can create that needed abovementioned positive social construction of creative spaces that is needed for positive policy targeting (Schneider \& Ingram, 1993). Also, like the competing bar owners in Red River becoming unlikely allies, the city government had the potential to be one in outlaw citizenship, namely because of the state government's constant eroding of local control, which has had effects on the artistic community.

Elements of how power structures can be defeated and in real-time are found throughout this chapter, namely with the accounts of the successful Red River district's extended hours. In this effort, the Red River owners, as Gaventa (1980) balanced selfreliance with partnerships - developing their own course and taking the lead but through also uniting with people having the same grievances, clearly identifying problems, anticipating counterattacks and developing strategies for responding to those, taking 
action on their own, and through breaking deeply ingrained negative thought patterns with roots in socioeconomic power imbalances. An additional contribution I make is that the latter, breaking the thought patterns, is likely the most difficult for disaffected artistic communities and, likely, disaffected populations as a whole. Likewise, another contribution is that this has to be done before any of the other actions in breaking power structures can take place. One of those is realizing how certain groups, like rival business owners or government can be allies and working to bury hatchets to make that critical organizing element work.

This chapter's structure is as follows. First, I will discuss enabling factors related to traditional citizen participation, which namely included the two arts economic development offices that artistic community members highly regarded for having bureaucracy members who "get" what it is like to be in the private sector arts and because of the offices' private-sector orientations. Another key factor with those two offices was that they were integrated into the city's civil service and not a political initiative, meaning they were far less vulnerable to political whims. Afterward, I will discuss the institutional enabling factors that namely include the city's love for its music and arts and a flipside on social construction (Schneider \& Ingram, 1993) based on appearance. In Austin, a more casual and more "rock "n roll" appearance was favored over something more "buttonedup" because it was seen as attractive, approachable, and being true to self rather than putting on an act. Enabling factors involving other community stakeholders will follow, and these namely include the positive side of Austin having numerous nonprofits and improvements festivals such as South-by-Southwest have made. 
Enabling factors related to place will follow, and much of this is linked to how third places can be extremely conducive environments for meaningful conversation between public officials and artistic communities, namely because of their ability to "level" social standing (Oldenburg, 1999). It also shows how positive social construction of place can lead to a place being targeted for policy that helps it, just as it can for positively constructed people (Schneider \& Ingram, 1993). Then, I will discuss enabling factors related to artistic communities, which namely include their above-mentioned positive in-group relationships and self-sufficiency. In the final section, I will discuss enabling factors for outlaw citizenship, namely because the non-traditional activities retain more interest over time from being creative and fun and also how outlaw citizenship can empower artistic communities by giving them back figurative ownership of activities they believed were lost to outsiders, like festivals.

\section{Enabling Factors Related to Traditional Participation}

Major elements of traditional participation namely included tangible policy remedies, government officials going to artistic communities at the artistic communities' times and places, and building upon common causes both citizens and government had. These efforts had numerous benefits that included a more positive view of city government that made artistic communities want to engage with it more or at least find that their efforts were not in vain. Specifically, with the two arts economic development offices, interviewees in the artistic community believed that employees in those offices "got it", with their experience as working artists and musicians and the private-sector orientation that most of the artistic community wanted. Furthermore, building on common causes between the city government and the artistic community, such as both 
parties wanting tangible policy to both mitigate noise complaints from music venues but still allow the venues to do their jobs, strengthened citizen participation efforts.

\section{Enablers related to formal mechanisms}

Three major enabling factors related to formal participation mechanisms involved tangible policy remedies - a counter to the problem involving inaction mentioned in the previous chapter. This namely involved the Red River district's successful efforts to extend the hours that they could play live music. One key element in this, which I will discuss further in another section, was that the Red River owners came to city government on their own, with evidence-based arguments and proposed solutions that

they crafted on their own. Self-initiation and with one's own course are two key elements in breaking old power structures and overcoming powerful opponents (Gaventa, 1980).

Advocate interviewees argued that any successful forums must be specific about their scope — what the specific policy is and who it would specifically affect and attract. With this, the people who are most concerned about this topic will be more willing to come and have better firsthand experience. It also curbs the problem, mentioned in the previous chapter, of having artistic community members sit through forums that mean nothing to them and not returning to ones for which they could make a serious contribution.

Interviewees and secondary sources indicated that the 10-1 city council representation not only provided city council members from historically underrepresented groups such as racial minorities, but it also diversified the council-appointed city boards and commissions and provided more of a voice for those who gentrification was affecting the most. 


\section{Tangible policy remedies}

Artistic community members managing to actually get policies not only crafted but also implemented was a major participation enabling factor, both in terms of creating a more positive view of city government, participation in policymaking, and in terms of their continued participation. When their work with city government and policy ideas crafted with city government became reality rather than an idea not acted upon, this also created a counter to the major hindering factor of inaction mentioned in the previous chapter.

A major victory for the artistic community in Austin was extended hours for playing live music in the Red River district. In September 2018, the city council approved allowing the Red River venues to play music one hour later — until midnight on Thursdays and until 1 a.m. on weekends (Findell, 2018). This came after a pilot program lasting for one year that ended with greater revenues for the venues and their staff, and musicians, plus decreased complaints about the venues to the city's 311 . Even a neighborhood association leader who had strongly opposed the pilot program when it was approved in January 2017 and began in May 2017 supported it in the end (Findell, 2017e; Neely, 2017b).

In January 2017, the city council approved what was known as the Red River pilot program, which, for a six-month period running from May through November of that year, allowed venues to play amplified music outdoors for those three extra hours, total (Craver, 2017a; Swiatecki, 2017b). During the program, city staff would constantly monitor the noise levels at the venues and interiors of surrounding hotels and residences to ensure the venues did not go over the city's 85-decibel noise limit (Cagle, 2017; 
Findell, 2017a, 2018). Venue owners explained that extended hours would both allow for longer shows and higher alcohol sales, plus, especially for summer months, allow shows to attract larger crowds by starting later because Austin's summer temperatures are still around one hundred degrees as late as 7 p.m. (Swiatecki, 2017b). Furthermore, longer shows would mean that the venues could book more local artists for additional openers for touring acts (Stith, 2016).

Additionally, the Red River owners noted, the sound monitoring would allow the city to collect measureable data on the noise complaints and better understand which areas are affected most (Findell, 2017a). Besides the hotel developers mentioned in the previous chapter, complaints had also come from residents living to the venues' north because of sound traveling up nearby Waller Creek. One of the Red River managers quoted in Findell's (2017a) story said, at the time:

The pilot program will provide us the opportunity to create jobs, to create more opportunities for musicians, to address growing and untenable costs, and to collect data to finally find solutions for some of the contentious issues (as cited in Findell, 2017a).

When I interviewed Ernie, an Austin police officer, during the pilot program, he said the pilot program began when the Red River owners came forward with a proposed solution first, just as Gaventa (1980) writes is necessary for a less powerful group to break longstanding power structures. Ernie noted at the time I interviewed him in 2017 that the program was going well. Only one venue, he said, was going over the 85-decibel limit consistently. The rest, though, were "on target", and the pilot program allowed his department and other city officials to get "real-time, live measurements". The city council later voted to extend the pilot program for another six months after even its initial 
opponents "agreed the program was going swimmingly" (as cited in Findell, 2017e). A neighborhood association leader who had strongly opposed the program in January 2017 said, by October 2017, that "the decrease in noise trespass has been noticeable" since the pilot program began, and she supported it (as cited in Findell, 2017e).

The pilot program, according to a city staff evaluation, also increased the venues' revenues, and the venues were in turn able to pay staff and musicians more (Findell, 2018). Mixed beverage sales increased eight percent, staff pay increased by three percent, and musician pay increased by five percent during the pilot program's first six months, when compared to the same time period in 2016. On top of this, sound monitors showed "no quantifiable sound impact" to residents north of the district, and complaints to 311 decreased (as cited in Findell, 2018). Only two venues, Sidewinder and Empire Control Room, went above 85 decibels during the program's first month, with Sidewinder surpassing the limit five times and Empire, twice, but never more than a complete decibel (Cagle, 2017).

During my observation at South-By-Southwest's “Austin Y'All” panel about how the Austin music scene is working to survive, one of the venue managers said a key aspect of policy related success the Red River venue owners have had is they "started talking math" - providing evidence-based, hard data when presenting their arguments to city council members. In this case, the data and evidence-based arguments gave them the backing to make the extended hours permanent and create a tangible policy implementation that has worked. 


\section{Being specific about forums' scope and splitting them up}

Interviewees that namely included advocates and journalists informed me that specificity is a major enabling factor when working to enable participation. First, one must be extremely specific about who a forum targets. This means that participation will be higher when a group knows this will address issues related to them, specifically, and likewise, keep others from being disenchanted after going to forums and feeling as if nothing mattered to them. Likewise, the government agencies that are involved in such a matter need to be targeted, specifically, so that those who can best address concerns are present. The second element of specificity is keeping the scope of forum's topics narrow and targeted to that particular group. That way, those who are concerned about it most will show and find it constructive, and likewise, those who are not so much will not be too discouraged to come to another forum where they would benefit more from attending and they could provide stronger input.

Padma, an advocate for the artistic community, said one event she conducted had heavy participation namely because it targeted a specific segment of the population metal musicians, in this case. It was attractive both because the group knew it specifically concerned them, and the other reason was that, according to those who attended, it also showed that those hosting the events actually wanted to hear from a group they believed was often pushed aside. This countered the problems with artistic community members feeling frustrated by sitting through extremely long meetings full of topics that did not concern them and some of the problems with participant diversity.

Padma: We had one that was just around metal. That was probably one of the best-attended ones we had. We even had a band show up, volunteering by playing on the sidewalk. Then, they came in and played some Black Sabbath — on tubas. 
It was a brass band. A whole bunch of people showed up because, as they said, "Nobody ever asks metal what we think." We had a host for the event who was a DJ for a very well-respected local metal broadcast. We had some of our younger city council members, one of whom was a huge Black Sabbath fan, so he was super-happy.

If we had sent out an e-mail saying, (puts on a fake uppity voice), "We want to talk to you about civic issues as to how it relates to musicians...", we were not going to get people to show up. We said, "Look, we're having an event at Kick Butt Coffee, and it's for the metal community. We want you to come out and tell us how we can fix Austin music." That got participants.

When working to gather feedback about city policy, overall, Padma said she and others sliced events up by not only genre, but also geographic region. One strategy was also having events in all ten city council districts. This eased the transportation-related burdens mentioned as participation hindering factors in the previous chapter.

Padma: I think, in Austin, the key for us, when we were working to gather feedback on major city policies, was slicing things and having multiple events. I think that's the first thing - giving people multiple opportunities to participate. Don't just have one town hall and try to solve it. ... We didn't ask people to come downtown. We just asked people to come to a place that was, maybe, within a fifteen-minute drive. Certainly, you want to meet people where they are.

During my conversation with Padma, I recalled Herranz's (Personal Communication, 2015) statement during my research's preliminary stages that organizing musicians was like "herding cats" because, sometimes, people do not know who the other musicians or artists were unless they played gigs together. This was an exchange I had with Padma, during which she explained that keeping the topic's scope, as well as the population's scope, was critical in both gaining participation and sustaining it in the long term.

Amelia: In an environment that (Herranz) described to me as "herding cats" how did you manage to herd those cats? 
Padma: I think the key was to have a very specific scope for that day. We had a very finite list of objectives for each day and each event, for all parties. We would say something like, "We're having a candidate forum. We want you to attend. We want you to meet the candidate afterward and ask questions. We want you to give us your email address so we can follow up with you later. Or, we would say, "We need for you to show up at city hall at this time. This is the issue we're talking about. This is the item number it is on the agenda. We anticipate it will come up at X time. We will all meet up beforehand at the coffee shop that's next door to city hall, and we'll all walk over together. We'll all sit down together."

We didn't just say, "Come and tell us your thoughts on the music industry." We said, “Tonight's discussion is about pay-to-play. Tonight's discussion is on accessory dwelling units. Tonight's discussion is on short-term rentals. Tonight's discussion is on safe late-night transportation." We tried to make it as small as possible, and then give them something very specific to do. That way, the people who showed up had a general concept of what was expected of them, and you were attracting people for whom that topic is interesting.

Amelia: Versus someone saying, "Well, all they talked about was housing, when I care about transit, and I'm not coming again." Right?

Padma: Yes.

Amelia: So, in other words, when you were deadly specific, you not only got who wanted to come, but you got the right people to come? And you not so much avoided the wrong people from coming, but you didn't discourage the right people from coming to the right event later, correct?

Padma: Right. The last thing you want is for someone to finally leave their house and come to your event but have it be a negative experience for them. You're never going to get them back.

Along the same lines as Padma's statements, Ron, an Austin journalist, added that a major element besides an event being as specific as possible was ensuring that any meetings were specifically structured.

Ron: I think the big part of it is how you frame the discussion. If you can structure the conversations - the questions, the issues - that clearly set guidelines for what you want to get or what kind of answers you want... What's the question we're trying to answer here? What's the problem we're trying to solve? If you structure it the right way, I think that can make things much more productive. 


\section{0-1 Council System and Representation}

A major change to Austin's city government in recent years, a shift to its "10-1" and "Mayor At-Large" city council representation, was seen as a positive for the interviewees in terms of participation. The key aspect of it was that certain groups, particularly minorities, low-income residents, and other historically disenfranchised populations had both better representation on city council and, as a result, the city's numerous boards and commissions because each council member and the mayor all had appointees for each board and commission. This aided participation and overall attitudes toward city government namely because those feeling the effects of policies leading to further gentrification, for example, had better voices and specific points of contact.

Before 2014, six council members and a mayor were elected citywide (Velasquez, 2016). Now, one council member is elected from ten different geographic regions of the city (Personal Communication, 2017). The mayor is elected at-large, but the mayor, under Austin's council-manager system has a vote on council, as well. With the change, minority residents had proportional representation for the first time, and certain neighborhoods had a representative from their part of the city for the first time in several years (Velasquez, 2016). Previously, many of the at-large council members lived in West Austin and the city's urban core. Interviewees informed me, as explained in the previous chapter, that the artistic community members tended to live on the city's outer edges, namely to the north and east, because of the rents being unattainable in the urban core. West Austin, they told me, is where the city's wealthiest residents tend to live. 
Ron said that one positive from the change is that the greater minority representation and certain neighborhoods gaining representation means that certain groups who have experienced disproportionate negative effects of the city's intense development will have a representative now.

Ron: I tend to think that a district council, with members from the different regions of the city will bring more representation from areas that are being affected by gentrification forces. It seems that, over the medium-to-long-term, that's going to play out better.

Draco, a city boards/commissions member who is also Hispanic, told me that the new system brought greater representation for minority communities. Speaking about the music commission, in particular, he said:

Draco: The music commission is finding its way again. It once was six commissioners as hired guns by maybe one entity that could create a monopoly on what the music industry represented and what it stood for. Now that it's 10-1, they are literally from all over the city. There are some Republicans, even. There are liberals and conservatives side-by-side.

Helena, a city boards/commissions member who is also black, said that a large part of her motivation to serve was that diversity needed to improve, in general, and also pointed to the music and arts scenes' diversity issues, as other interviewees did in the previous chapter.

Helena: I really do care about what my commission does very much. Really, my goal here was to represent because of the lack of diversity. I keep putting that in the front. We're dealing with a lot of other stuff, but I am going to keep reminding them. Guess what? We don't have diversity here. Someone has to be there to do that. I hope whoever succeeds me, whether my council member is there or not, that there will be someone to keep that reminder present on our commission. 
Although he did have some concerns about the 10-1 system, Ernie still favored the change. Sometimes, he said, the district system means that council members may be only focused on their districts and not the city as a whole. Nonetheless, the improved representation has been a positive, he said.

Ernie: I think it's a little better process than what is was before, when you're representing this huge chunk, and you live over here and you don't even live over there. So the 10-1 district, I think, is better.

\section{Enabling Factors Related to Public Officials}

Major enabling factors related to public officials included the work of the two arts economic development offices, government officials going to the artistic community where and when it gathers, building on common causes, and government officials providing free parking for any events for which it wants to attract artistic community members. The arts economic development offices, the Music and Entertainment Division and Cultural Arts Division, received high marks from the artistic community namely because it had employees with experience in the arts and "got it", along with the privatesector orientation they desired. A key point that government officials namely pointed out was that the two offices were integrated into the city's civil service rather than being political initiatives. This meant that the offices were less subject to political whims.

Government officials going to the artistic community where and when it gathers was a major enabling factor, as well. It demonstrated to the artistic community care and concern and created positive attitudes that made the artistic community want to engage with their government more. It also showed government officials, firsthand, what 
challenges the artistic community faced, such as infrastructure and crime concerns in the Red River district.

Building on common causes was another major element in that both government officials and the artistic community wanted workable policy solutions that mitigated noise complaints about music venues but still allowed music venues, who have to have high enough decibel levels to operate, to do their jobs and stay open. Other common causes included youth development and safety at special events like festivals.

Another enabling factor was the city frequently validating or providing free parking for events for which it wanted to specifically attract the artistic community. This not only reduced costs for the artistic community and attracted more to events, but this also helped to counter the transportation equity issues mentioned in the previous chapter.

\section{Music and Entertainment and Cultural Arts economic development offices}

Interviewees, as a whole, gave the city Economic Development Department's

Music and Entertainment and Cultural Arts divisions high marks in terms of enabling the artistic community's participation and their work to improve the artistic community's situations, overall. A major factor was that those who had the chance to work with these offices felt that both the offices, and the city by proxy, "got it", in terms of understanding their particular needs or at least believed that the city offices were moving matters in the right direction. Four major factors related to these offices enabled participation: Privatesector orientations, breaking "language barriers" between other government officials and those in the artistic community, the offices' civil service integration (over a political initiative), and local artist support. 


\section{Background: Music and Entertainment Division and Cultural Arts divisions' history}

Austin took major steps, starting in the early 2000s, to have its local public policy involving the arts to have more of an economic development and private-sector approach, being one of the first cities to take such steps (Personal Communication, 2017, 2018). This was especially true of the commercial music industry. This was done because, as interviewees informed me, the city recognized and through citizen input, that most artists work as small businesses or solo entrepreneurs. Molly, an employee in one of the city's arts economic development offices, noted that this "grassroots", local-citizen-driven approach over a "consultant's stamp" in shaping these offices was a major point in helping these offices gaining local support, connecting with the local artistic community, and further developing the arts in the city, as a whole.

Interviewees informed me that, before, the Parks and Recreation Department oversaw cultural functions. Cultural Arts, which oversees art forms outside of commercial music and entertainment (i.e., visual arts, theater, etc.), was moved from Parks and Recreation to the Economic Development Division. Although it does provide funding support for certain arts activities, interviewees still informed me that Cultural Arts is strongly focused on activities such as small business incubation, development support, and developing artists' business acumen.

The Music and Entertainment Division, as compared to most other bureaucratic offices, is very new, and it exists because of local, "grassroots" citizen participation efforts. Interviewees informed me that the pre-existing city music commission created a live music task force, and, in 2009, the top priority that came from that citizen participation was creating a city music office. The division officially opened in 2011 with 
a staff of two and one intern, and it operated in this way for about two more years.

Eventually, it grew to a staff of four, and by my fieldwork's commencement in 2017, it had a staff of eight. It has two major divisions, within — programming and permitting. The programming staff works namely with individual musicians on areas such as business development. The permitting staff works more with entertainment venues in areas such as noise regulations and in mediating disputes between venues (as well as special events like music festivals) and their neighbors.

\section{Private-sector orientation}

The office's private-sector versus nonprofit orientation was welcomed, particularly by those in commercial music, which almost never receives grant support. Still, even those outside that artistic discipline are most often small businesses or solo entrepreneurs, meaning they need assistance that understands how those operations work. At the same time, the city employees working in that office understood the creative side of their work as well. The fact that many, if not most, of those working in these offices had private-sector arts experience before taking these jobs was also seen as a positive too. This enabled participation because these employees who better understood their needs and had often been in their shoes connected with the artistic community well. That positive connection laid the groundwork for the divisions and the rest of city government to get needed input from those in the artistic community.

During an observation, at a joint arts/music commission meeting in January 2018, I noticed that when presenters discussed mapping the city's cultural assets, they noted for-profit facilities just as they did with nonprofit ones, as well. Solely focusing on the nonprofit arts facilities (particularly well-funded ones) and audience participation in them 
has been noted as a major gap in arts policy scholarship (M. Jackson, Herranz, KabwasaGreen, 2003; Rushton, 2013). In Austin, the for-profit facilities were gaining just as much attention in developing cultural policy.

While interviewing Molly, I mentioned former Nirvana bassist Krist Novoselic's (2004) statement that if some eighteen-year-olds form a band, they are a small business. I asked Molly if such, if artists and musicians like them require business acumen and support geared toward private-sector entrepreneurs. Molly responded:

Molly: Yeah, individual artists are a small business. They're solo entrepreneurs. So, they have just as many responsibilities to look at their books and in the same way that an independent business owner would do. They are just kind of a business of one. They're a small business owner.

In terms of the commercial music industry, Pomona, another arts economic development city employee said, it is not only one that needs to be in economic development but also one that needs to be on its own. Namely, the music industry has numerous financial and legal nuances that musicians, industry professionals, and venue owners face. For example, a venue in Austin has to have anywhere between seven to eighteen permits to open its doors and operate, and many of these permits, which come with costs, have to be renewed annually. Nymphadora said that in her former public sector arts job, she regularly worked with those in the private sector just as much as those in the nonprofit sector.

Nymphadora: It was kind of half-and-half. It just depended on anything that sort of touched the media industries, which I would say is half industry, half sort-of service/nonprofit arts-based. I would work with a nonprofit film society one day on a thing, and then, I would work with a for-profit camera rental company the next day. I was totally toddling back and forth. 
When the Music and Entertainment division was created, Pomona said, its first director made a "very calculated approach" in deciding who to bring into the fold, and, those he sought out included those in the private sector music industry.

Pomona: He was afforded the very fortunate opportunity to be the first manager of that division, and to also build his team the way he wanted it to look. So, he brought in a music industry person. He brought in a veteran musician to work with the venues, and he brought a former radio executive director. He got to build his own team from the ground up, which is whatever government employee wants to do. It was, "Who or what from the private sector could I pull into my team to do this if I could?"

Pomona noted her own experience in the private sector before she entered the city bureaucracy, and she has leveraged this experience in her new role in working with the artistic community.

Pomona: I've worked in the music industry, myself, so I kind of started inventing an entry point for myself there. That's what I did before I worked for the city. I kind of prided myself in being one of those people who literally did every single job in the industry so that I knew how this was done before I entered government. I think that I was placed in my position because I knew how to create the most hands-on relationships with these artists.

Others within or who worked with the artistic community also believed these two offices, particularly because of their private-sector approaches and employees with that experience, were an asset to the city and its artistic community. Penelope, an Austin journalist, said:

Penelope: I was really excited when Erica Shamaly started running the music office. I was excited when she came on board because she did marketing for ACL Live, and she's done (the) Levitation (music festival). She really knows it. Those are two brands that are really well-known in the city. So, I think it proved that she understands how to reach out to people and get people interested. It really does seem like she cares and has a stake in helping to bridge all these... She wants to bring film and music together more, and she has friends in the music industry. 
So, it was so heartening to see someone like her coming into that office because you kind of got the feeling that they finally got an expert who understands how to do outreach. It seemed like she was really involved, and it was cool to see someone with a marketing background who could maybe figure out how to appeal to more people.

Besides reaching the artistic community, Pomona noted, those in the economic development arts offices who have those connections to or knowledge of the arts industries nationally and internationally can inform other city departments as to what they can expect when touring acts arrive, such as security concerns.

Pomona: Especially during South-By, seeing what talent is coming and determining whether or not it could be a potential risk for security, whether we need to let the police know or not... That is one place where it is a skill set and oversight that the music office has that no other department within the city government may have. It is their jobs to read Rolling Stone. It is their jobs to read Pulse and see who is at the top of the charts right now.

...To give you a very broad example, two or three years ago, we had a musician come into town to play a venue who literally incited a riot. People were knocking down fences. That was one of the venues and one of the artists that the music office was asked to provide some oversight on, and they told the city it was going to be an issue.

Unfortunately, this happens more often than not - city governments don't realize it's an issue until it is a critical mass-type, serious issue and have to stop this person in the airport and arrest them for disorderly conduct. So that is one skill set and asset that the music office staff who are on the programming side has. It's one thing that makes them invaluable assets to the city.

While a government office whose staff has a largely private-sector background might be a concern for some who may question their ability to navigate a sector that is new to them, Albus, an artistic community advocate, had two counterpoints. First, those who would supervise such offices would likely have greater public sector experience. Second, lines between the public and private sector are not exactly firm because, from 
what he has observed, people in the public sector are often working to learn more about the private sector's operations and apply those to their jobs.

Albus: There is a safeguard there that, even if you didn't bring in somebody who had great government or municipal planning expertise or whatnot, you do have somebody else in leadership who does. So you can hire someone as that subject matter expert, and then they can get help from human resources help from the HR department and help from the accounting office on other things. It's more about hiring a good leader.

...There are programs for mid-career professionals to get their MBAs.... Two friends of mine who were city of Austin employees were working on getting specializations with an MBA. One guy was with the fire department, and his had to do with facility planning for the fire department. Another guy is a guy who was in the cultural arts division.

\section{Translating "language barriers"}

Interviewees noted that those working in the two arts economic development offices can help translate "language barriers" (Herranz, 2015), per se, which could counter the hindering factor of the same name in the previous chapter. Because of their knowhow in working in the private-sector arts, employees in these offices can communicate occupational and related policy needs to others in city government. Likewise, they can communicate policy language to the artistic community. This was a major enabling factor for participation because the arts economic development employees could act as "translators" during a dialog with other city officials and the artistic community.

Alastor, a Texas state arts office employee who is also a former working musician, said that being able to translate policy language and artistic language was critical in forming a constructive dialog. The employees in those two economic 
development offices and related commissions, as well as other such offices he has seen in his travels, are major components of that.

Alastor: They've got to be able to speak two languages. That's really the thing. The folks that they're talking to don't know the music industry by heart, unless they're a rare case. It's important for those people on the music commission and the people in the music office to have that background, and they can draw from that so they can accurately translate those needs to folks in city government that aren't going to really know what they're talking about. That's for certain.

Language barriers (Herranz, 2015) between city government and the artistic

community can go two ways, Pomona said, and the reason why offices like the two economic development arts offices are vital. She gave the example of the Music and Entertainment Division and how it has worked to be a "translator".

Pomona: So, there are definitely barriers on both sides. ... I think that the establishment of the music office and the intention with the establishment of the music office was to kind of limit those barriers and have people in the city government who can speak fluent musician. I always joke that I speak fluent musician so when I say musicians will be here at 5:15, that means they'll show up with their car parked at 5:15, but they won't be ready to play right at 5:15. I think that was part of the reasoning why the music office was established - to limit communication barriers between city government and musicians.

More often than not, we hear from musicians or venue owners who say, "You didn't tell us this part. This is confusing," or, "You didn't tell us about this." We did tell you about this. But of course, the way the city government goes or with the way that government sometimes goes, it's just that the way it was explained isn't always the most detailed. It's all factual, but it's not very intricately explained.

It's the same thing on the opposite side. The city government doesn't realize that when you hire a musician, you have to tell them to be there, but if you want them to play at 5:45 and get them to be there... It's not just plugging in a microphone and doing sound check. It's load-in and different things. It's not just a thing when the musician shows up and music is there. 
Penelope also appreciated the work these offices do, particularly when the Music and Entertainment Division was a large part of the successful push to have extended hours in the Red River district. Having city employees who "get" what it is like to work in the artistic community, she said, can create not only a better dialog but provide greater backing to artistic community members' claims.

Penelope: I think that having someone who can explain to people, "No. This musician isn't really just talking out of his ass. This is how it will help," can be a huge help.

Alastor provided details on some of the methods he uses to be a translator and how others can re-frame their arguments in terms that government officials understand and also find more appealing. A major part of this is providing hard evidence, such as that found in economic studies.

Alastor: The people, by and large, on the elected leadership front are not knowledgeable about our industry at all. I think it's vital that we translate our business into data that they can understand. I do that through economic impact studies that I use to help reset the conversation about what the music industry actually is. That's just how they go about doing business.

\section{Encouraging Participation and Educating on Participation Process}

Another positive of the two arts economic development offices was that both worked to not only encourage participation but also educate artistic community members on participation processes to make them less confusing or intimidating. As Pomona noted in the previous chapter, she will explain "government speak" to artistic community members before policy forums begin. Molly noted the same and how important it is for city officials to hear directly from someone in the artistic community and how her office 
works to, despite any nervousness from the artistic community members, "embrace the fact that their voices are valuable and need to be heard."

Molly: People don't always know what civic literacy means or how to access things or how to navigate that process. And so that's just a whole other world. So, you need a little bit of a helping hand sometimes to know how to enter that system. We try to do it a little bit to get people to come to a commission meeting, go to city council, write an email... But there are some lines there. We can't really direct them necessarily, but if they are interested in how the process works, we're there all day. "This is how it works. This is who you need to talk to here. He represents you. Here's why it's important for them to know who you are."

I'll talk about that all day with everybody because it's really important for them to know why the artists matter in Austin, and it's better to have that come straight from an artist than from a third party any day.

\section{Cultural Arts and Music and Entertainment divisions integrated into civil service}

The Cultural Arts and Music and Entertainment divisions are integrated into the city of Austin's civil service rather than being a mayoral or other political initiative. This meant that both offices could not be shut down because of mere political whims.

Interviewees indicated this enabled participation because the employees having more security allowed them to do their jobs that included engaging the artistic community without severe political trepidation. Such a structure also allowed for internal stability and stronger, long-term relationship building with the artistic community.

The state of Texas, Alastor noted, has a "Music Friendly Community" certification program for cities. According to information from the Texas Music Office, this program "provides Texas communities with a network for fostering music industry development and sends a clear message to industry professionals that certified communities are serious about attracting and developing music industry growth" (as cited in Texas Music Office, n.d.). Austin is one of the seven cities with this designation, and 
three more are working through the certification process. Alastor explained that one of the guidelines for earning this certification is that either an office or an officer responsible for developing a city's music industry is in the civil service.

Alastor: We're trying to build systems and initiatives that are lasting. So when we're trying to build these systems around the state, one of the guidelines the state sets for certification is that the cities create an office or officer that exists in an administratively enforceable position. Once that is created, it will not go away when those serving in office do. They may not find the support they've enjoyed or maybe don't enjoy today, but their positions would not go away with the elected leadership. That's why the state has put that guideline into the certification process to become a music-friendly community.

Even if an office that is a political initiative is not outright eliminated, Alastor noted, cities' offices created by such an initiative may have trouble having their voices being heard unless the elected officials are receptive.

Alastor: Austin has some real systems built so that whoever holds office, they have assistance built for the commercial music industry in Austin. They can plug in to whomever comes in. That's not something that an individual would have to rebuild and repair relationships to keep going. That situation is not the case in other spots. The cities of Denton, right now, and Fort Worth and San Antonio have started to build those systems, which is good. But the ones that haven't, unless they're friendly with whoever gets elected, getting their voice heard is going to be really difficult.

Pomona said that offices like the two arts divisions of economic development do

have strong mayoral support. Still, the civil service protection is a major positive.

Pomona: I know I can definitely rest easier. I think we can all definitely rest easier now. To be honest with you, our office budget is so small. It's hardly a blip on the radar for a council who might not like what things we're doing to slash at any point. Our staff definitely goes to work resting easier, knowing that they're going to have a job for years to come. 
Besides overall job security, Molly noted that her office's work and what it does

for the city remains constant, as well, with the civil service protection.

Molly: I think we're fortunate to be embedded into a city department that is very much part of the fabric of what the city of Austin's government chooses to allocate to support the community. There's a little more security in our programs to survive the waxes and wanes of the economic cycle that may hit other departments or kind of freestanding entities or mayoral appointments more heavily. So we're a little more insulated from dips in the economic cycle or the whims of policymakers or politicians that may have a different agenda.

So in that way, it helps us because there's continuity to say we're very much kind of a part and parcel of how we deliver economic development to the city. It's not a standalone. It's not a separate initiative. It's part of what we do to look at the fabric of how we support our economy in Austin. ... So in that way, it's really great to have it be business as usual and to have the arts be part of that.

\section{Local artist support}

The two arts economic development offices enabled participation through local artist support, and the common thread most of their activities had was helping the artistic community help themselves. First, it worked to combat the financial difficulties and problems with business acumen mentioned in the previous chapter through workshops and other activities designed to improve their business knowledge of the arts business.

Second, they also worked to spur collaboration — working to ease the problem of "herding cats" (Herranz, 2015) — through bringing artistic community members together so that those artistic community members could organize and work to find solutions on their own. This mirrored the "hands off" approach those in the artistic community wanted in terms of government support, as detailed in the previous chapter. This enabled participation not only in terms of enabling organization but also in terms of showing that, 
despite the problems with inaction mentioned in the previous chapter, there were some in government who were indeed working to move policy in a more favorable direction.

During my interview with Molly, I noted issues that other interviewees brought up about how there are social equity related problems of people who are entering a extremely complex business - one with royalties, copyrights, liabilities, and the like when, growing up, they did not learn how to balance a checkbook, as Padma said. I asked Molly what the arts economic development offices are doing to help bridge that gap.

Molly: We do what we can. We're trying to do more because one of our other divisions, along with Cultural Arts and Music and Entertainment, is small business and also global business and our redevelopment staff. So we sort through all the work that we're doing. We want them to succeed as businesses. A lot of the training has been focused for the small business group. They did one-on-one coaching with artists. They now have a kind of dedicated staff person to provide that. They do workshops all the time. A lot of it is geared more toward traditional for-profit businesses, which may not necessarily share all of the same aspects and mechanisms of a nonprofit.

There's a little bit of distinction here, but a lot of it is very similar. You need to have a business plan, and you need to know how much you're spending every year. You need to know that you're accounting for things in QuickBooks. You need to have a marketing staff. You need to know how your audience profile works in terms of your revenue. What are your revenue streams? These are all shared areas. How does the tax code work? What are your legal restrictions? What are your insurance needs?

So I think we're always trying to shift their mindset and into thinking like a business. They do have a mission, most of them, so they're a little bit different and that they're putting money back into their business and not sharing with stakeholders. They also don't have the same bottom line. But when it all comes down to it, you want to be making a profit that you can live on and be consistent in your practice or your organization over time. So you're building that capacity over time, and that does that. You can't just be overspending. You need a board that functions for you. You need all these things to come into play. So we're trying to build that capacity through all of that. 
Molly also noted that having to learn this is extremely difficult for those in the arts, who, if they did have formal training, did not have business skills as part of their educational programs. Therefore, they need that additional support.

Molly: They're typically not taught that if they've gone through an academic program where they have a BFA or MFA. Business is not really the focus of those programs. They may touch on it, but there's not really enough so that they can emerge feeling like they're prepared to enter that world. A lot of that is learned from peers or on the job or from a nonprofit or the government. That's just kind of life lessons, which are so hard because you're balancing, especially if you're an emerging artist, your practice, your paycheck, and maybe a family — and all of those things about living in Austin. All of these things have to find a way to make it into your piece of the pie. And it's really hard when you don't have an actual structural support system.

However, some in the artistic community were taking advantage of that support. During my fieldwork period, I attempted to go to the Music and Entertainment Division's free workshops related to different areas of business skill development. Most spaces were filled before the day of the announcement ended - sometimes, within a few hours of them being posted to social media. Cultural Arts' workshops spaces were filled rather quickly, as well. Hermione, an Austin musician, was working to start a business at the time of my interview with her, and although, she was just getting off the ground, she knew that Austin's city government, particularly the two economic development arts offices, were working to provide professional development activities. A number of them, she believed, would not be in most other cities. Ron pointed out that offices like Music and Entertainment, as well as some of the nonprofits, provide resources for artists and musicians to learn how to better profit from their work. More just needed to take advantage of it. 
Ron: There are lots of resources out there, and I think if you talked to the folks at the Austin Music Foundation or the music office or any group that is driven or whose mission is to improve the lot of artists, they'll tell you that they wish more people knew about them or were aware of the resources that they have and how they would love to be able to help more people through adding more people walking through their door.

\section{Music Survey did have impact}

Although the artistic community members who commented on the inaction during the previous chapter pointed to the Austin Music Census survey as further proof of government inaction, city officials were quick to point out that action has been taken, namely in restructuring the Music and Entertainment Division to better serve and engage the music community.

The major point that has come out of the music survey that has already been enacted has been the restructuring that divided the office into programming and permitting divisions. Ron pointed out that the Music and Entertainment Division was created to support and enhance the music scene, but it quickly became the "sound police" because it was saddled with mediating disputes between venues and neighbors so much that it could not do the functions for which it was created.

Ron: It was, “Oh you've got a sound complaint? All right. We've got a music office. Go to them." It should be the police that handle all of the noise ordinances. (The first Music and Entertainment Division director), for years, was really this noise cop, dealing with all the permutations of noise issues and not focusing on the economic development component of the office, which is why it was created in the first place.

Pomona said the response, alone, was "unprecedented", with about four thousand representatives from the music community participating in the study when only one thousand were expected. Respondents were "everyone from door guys to bartenders to 
musicians to music lawyers - everyone who has their hands on and who makes money based on live music performances in Austin." The results showed the crisis situation, namely with rising real estate values and related costs, detailed in the previous chapter. On top of that, the live music venues informed the city that the permitting process was arduous and difficult.

Pomona: With the release of that study, it was kind of... It wasn't frowned upon, but it's definitely something that our colleagues in city government looked at us going, "What the hell are you doing? You're letting everyone see all of your ugly. You're basically taking the Halloween mask off and saying, 'Oh my God. We are in a crisis. We're intubating one."”

It forced us to look at all of the things we were doing that weren't serving our constituents. ... Even though we separated the music community into three different groups - musicians, industry professionals, and venue owners - as a whole, they were all telling us, "We are struggling. Help us. Help us. Help us!" So it forced us to kind of change the dynamic. When this one came out, there were five employees in the music office, and all were working on the same things. When we hit the tipping point, we kind of divided them off. It forced us to refocus the entire office. For the last two years, we've been doing that.

A large part of the problem, as Ron also noted, was the Music and Entertainment Division being bogged down with complaint mediation. Pomona agreed and said that the music survey helped shift the office into one that has a better focus on their music community's well being.

Pomona: It was part of the survey, correct. Yet it took us a while to figure it out. But it is literally like a black napkin and a red napkin. The red napkin is the programming piece - music programming, music business development, and the outreach staff. ... Then, there are some who work specifically in permitting. Part of that entails doing the mediation. There is the group of people who are sitting there at the ACL festival in the neighborhoods, holding up sound meters going, "Now, I know you're upset, and I know that you think this is very loud, but they're well within the rights of what they said they were going to do, and they stopped when they said they were going to stop." 
That mediation piece... I do not envy the people who have to do that job.

...Before, it was like everyone had to do everything. Before, it was all hands on deck because we didn't have a direction or just kind of like squeaky wheels getting the grease. It was definitely one of those things where they would come into the office and try to program the music series but also have to sit in on permitting meetings and sit in on meetings and provide oversight to Sixth Street venues, like, "OK, here's six hundred collective impact plans. Can you do a writeup on these?" And that includes everything from determining where they are in terms of the entertainment district, what their decibel limitations are, what their time limitations are...

Ron urged caution in determining whether or not the impact, over time, will be positive. He said that with the music office being split now, it should start having a greater impact on the populations it was designed to serve, particularly in terms of helping them with their financial well-being and careers. The problem, now, is the namely the affordability problems are so huge that it will take what he called a "cocktail" of fixes such as music industry development outside of live music and festivals. The newly enhanced Music and Entertainment Division is working on this, but one office, alone, cannot solve all of this. Furthermore, it will literally take years to determine exactly how much of an impact any such development and, as a part of that, the music office had.

Ron: It's a five-year or ten-year horizon. ... You can't test for what's not there. It would be nice to see that it had an impact, and it could have a positive long-term impact. But are they going to be able to save $\mathrm{X}$ number of musicians from having to move to Lockhart because of cost of living or whatever? I don't know.

\section{Going to the artistic community}

Government officials going to the artistic community rather than merely leaving a door open for them was a major participation enabling factor. Artistic community 
members, business owners, advocates, journalists, and government officials themselves believed that coming to the artistic community where and when it gathers was not only a critical piece of building a positive working relationship. It was also government officials' duty. If government officials were seen as not doing this enough, interviewees who had this opinion wanted to see it happen more.

This enabled participation on multiple fronts. First, this created a positive attitude toward public officials, meaning that artistic community members were much more receptive to continually working with them. Second, it eliminated problems of government buildings and formal meetings feeling uncomfortable and stifling, plus the transportation problems. It also worked to better counter the time and scheduling factor on the artistic community's part, given that government officials were catering to the artistic community's schedules instead of the opposite situation happening. Most importantly, though, government officials coming to the artistic community's "home turf" better showed that their interest in improving the artistic community's situation was genuine and it gave them the chance to see the problems certain groups faced first-hand and meet with the people these problems affect first-hand. That first-hand knowledge, interviewees believed, led to more informed and, consequently, effective policy. It should be noted that third place locations were a major enabling factor tied to this, but this, specifically, will be explored in a subsequent section.

Going to where the artistic community is, versus waiting for them to show up, can help on multiple levels, Angelina, an Austin elected official, said. This can help in terms of participation equity and diversity, in particular. The latter two were barriers mentioned in the previous chapter. 
Angelina: In terms of structuring stakeholder feedback, we can't always wait for people to show up. We need to be more intentional about being proactive and inviting particular people to be part of those conversations, especially if they're members of traditionally underrepresented groups. We have to really get more knowledgeable about who trusted community voices are and who the trusted community organizations are and invite them to be present. I sense improvements in that area. There's definitely a recognition that we need to do better on this front, so it's not always easy to recognize success in those efforts, I will say.

As the city rapidly and radically changes, this is especially critical, she noted. City departments will, quite often, come to large community gatherings like festivals as part of general outreach, but they will do targeted outreach too. For example, one city department came to a neighborhood night out meeting to find out what local university students believed was needed for a safer environment, like better lighting. Rather than ask them to contact the city government, the city government came to the students and engaged with them one-on-one, asking for feedback on-site.

Angelina: So, it's just a good example of how, as a city, we're really trying to move. We're really trying to get out to where people are. We're not waiting for them to come. We're not waiting for them to come to us with feedback either online or in meetings, but trying to get out to try and partner with those organizations that are having events in their communities.

As mentioned before, Pomona's experience in the music industry already gave her an entry point to the artistic community. She believed that engaging the artistic community where they are is crucial, in general, but this is especially the case because they are in a crisis situation.

Pomona: Certain people have more community interactions than others. I'm doing some of the most. I probably talk to people in the community more than anyone else, and I talk to other people in government less than anyone else.

...The music division is only a few years old, so it was a new thing. I still think that there are people who work with my colleagues in city government who still 
think they kind of just come into work and listen to music all day and hang out. But the musicians they work with and know are at a critical tipping point. They are in a crisis. They can't afford to live in a city that they want to work in. I think that if we were just working in cubes and we weren't on the ground at South-By and other special events like the ACL festival... If we were separated from that, the model wouldn't work.

Like Pomona, Alastor said he makes going to artistic communities where they are a major part of his work, and he believes that this not only sends a positive message, but doing this is also a part of solid public policy. Doing this means he stays informed about what is actually happening and uses that to craft policy that works.

Alastor: If a public official wants to make a statement that he or she is willing to come to the place of work for the constituency, I think that's good policy.

Ask anybody. I'm out a lot. People see me out a lot all over the state. I am mostly where people do their work, not the other way around. ... For me, that's my job. I've got to be out talking to people, so I know what's actually going on. I can get all the reports I can from the folks in the bureaucracy who are supposed to be doing that, but I get the other half of that information from being out among those folks. So, I'm out a lot, and I think it's important that I am. I'll keep doing it.

... I think it's vital that the music industry sees elected leadership out, too. If the elected leaders find it important to go talk to them, I think that's a huge win. ... You know, the people I've heard from that really appreciate the support they get from their various cities talk about how they see their mayor out enjoying a show from time to time. Well, I think it's just good policy to be out doing things in your community like that.

I conducted an observation at a meeting a local nonprofit hosted at the Spider House Café and Ballroom nightclub in 2017, where the gathering's topic was "Can the tech industry save the music industry?" One of the Red River venue owners was a panelist. He insisted that anyone who works to find a solution for a struggling group has to first consult that struggling group before and while crafting solutions. Otherwise, 
whatever solution they craft, no matter how grand, will not work. Specifically addressing the tech professionals gathered at this meeting, he said:

The thing I would say as a cautionary note... For every great idea I hear about transforming a live music space or the bar experience, there are probably ten really terrible ones. Probably every single one of those ten terrible ones comes from someone who hasn't taken the time to spend and work with folks whose quote/unquote "lives" they're trying to change. I think that's important ... to understand. ... I'm approachable. The folks with me are approachable. We'd love to talk about our problems and help you to help us solve them.

Seamus, a Red River venue owner, and Penelope demonstrated how coming to the artistic community where it gathers could better inform policymaking. Meeting the artistic community where it gathers can not only build relationships, but it can also show, in real time, what the concerns are. Seamus and Penelope both mentioned the situation in the Red River district, such as crime and safety issues mentioned in the previous chapter and infrastructure concerns, like the hazardous sidewalks that the owners want repaired.

Seamus: I think when we're trying to share our challenges, whether they're safety or infrastructure or economics, it's helpful for them to come and walk a day in our shoes and see what we're looking at. And sometimes, we in Red River have been successful in having folks doing that, and other times, people have been more hesitant to do that.

But I think it's important for public officials, particularly, but also city staff to come and see what's actually going on because theory and concepts are one thing, but when you're physically walking a gambit of danger and things like holes in the ground and things like feeling unnerving about the smell of urine and freebasing in the area... People go, "Oh! This is really uncomfortable. I want to get out of here." We're like, "Exactly! Can you help us with this?" because that's the opposite feeling of what we want people to have down here.

Penelope: I'd like to know that they're going out and experiencing music and understanding what it's like. I'd like to know how they would tackle trying to park on Red River on a Friday night or just all the different factors like how walking down the street is like or getting into venues and know that they're going 
through the same things that we are, as members of the community. They represent us and even having them just go out to the venues and talk to people more... I would be delighted if one of them came to a meet-up I was hosting. I would say, "Yes! Please come!"

Advocates echoed these sentiments, especially for government officials who are new. This also created a system in which the power balance between officials and the artistic community were equal, if not one that had the artistic community in the more powerful position, as opposed to the social and physical structures at government buildings noted in the previous chapter.

Padma: I really think that going out into the community as opposed to trying to get people to come to city hall is going to be your best bet if you're starting from scratch. This is something we did when the council went from an at-large system to a district system. There were seventy-four candidates for ten seats. We went into each district, and we had our candidate forums at a bar. We went into the bars. Part of that was getting the candidates to come. It wasn't, "Come to the meeting room at the library." It was, "No, we're going to have this at the bar during happy hour."

Not only did this engage people on their home turfs where they felt confident, but they also felt like they were the experts. We also got a lot of people who didn't even know this was happening but were hanging out at the place. So it was a bonus. Not only do you get a Lone Star (local-favorite beer), but you also get to meet these council candidates who are now in your community. That was huge because, then, when those people got elected, music was a group that they were already very familiar with because we had hosted them at a candidate forum. We had our people go up and talk to them and introduce themselves.

By the time the council was sworn in, they knew this was a community stakeholder group that was going to have opinions on things. They needed to be engaged. It had that additional benefit. It wasn't just introducing the people, but also introducing the candidates, the potential decision-makers, to a population that had earned the right to be heard.

Nymphadora portrayed a similar sentiment, having a casual, friendly, and more personal contact - and one that is about building a positive relationship rather than 
dealing with problems — with government in her narrative map in Figure 8.1 showing her ideal relationship with city government. My exchange with her, during which she explained the drawing, follows.

Figure 8.1: Narrative Map (Ideal): Nymphadora, film festival organizer in Austin

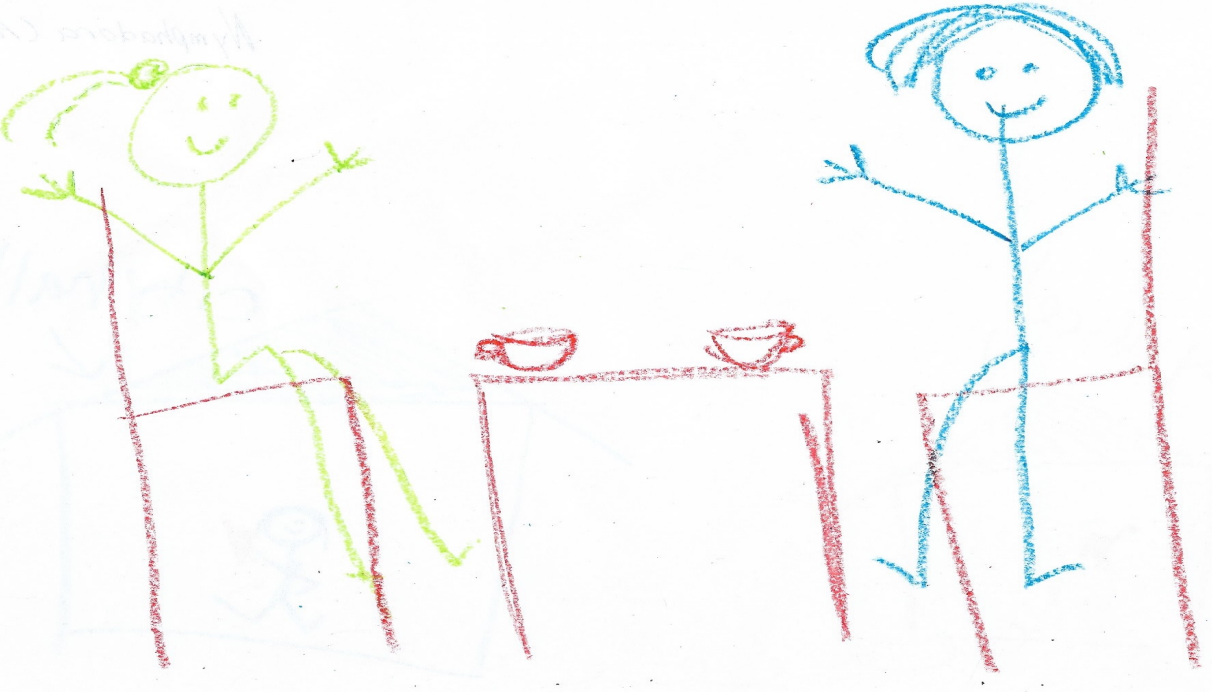

Nymphadora: So what I've just drawn now is myself and my city contact having a cup of coffee. I'm a former government employee, so I understand when you are doing that type of work, there are things like not being able to take a present. There are definitely lines, but it would be nice to... I feel like I have a good personal relationship with my point of contact, but to be able to... I like to have good social relationships with people I work with. I like to have partners as opposed to just contacts. So having someone that felt more like a partner, I think, would be the ideal. That would be the jam.

...Amelia: I see that you and your government person seem to be very happy here.

Nymphadora: We are. It's a little bit like getting to know someone on a personal level because maybe if we're not talking about business right now, maybe we were discussing something interesting that happened, especially... I have so many meetings with partners and contacts that start out with very casual conversation. That's always a good entry point for folks that I ended up working with - to be able to chat and then say, "OK. I had a quick question about blah, blah," or 
"How's the permit coming? Have you or anyone else heard from so and so?" It's that kind of thing and being able to go from there. ...

...Amelia: And when you're interacting with your government, it's not over a problem, correct?

Nymphadora: Yeah, it's kind of more of a status, a checking in. I like a check-in meeting, just checking in to see how things are going. "How are you feeling? I'm feeling good." I like that kind of thing as opposed to, (takes on a more serious tone of voice) "We have something we need to discuss and something we need to correct."

Amelia: So it's not (puts on mockingly serious voice), "Dun, dun, dun..." (Scary music commonly used in horror films.)

Nymphadora: Yes. In other words, there's no scary music associated with what's happening.

\section{Common Causes}

City government officials and the artistic community acting together for common causes was another real and potential enabling factor in Austin. In this section, I will discuss some involving workable public policy, safety, youth development, festivals running smoothly, and city policy. For some groups and city government who have either had no relationship before or had an acrimonious relationship, these were seen as major entry points for beginning a dialog first on the common concerns and then moving to others. I will note that the major common cause between the city government and the artistic community — working to support those struggling with mental illness and substance abuse — will be discussed in a later section involving third places.

Having fair, workable, and enforceable public policy was a major desire that both city officials and the artistic community alike wanted, according to interviews and secondary sources. This was especially true for the police and the live music venue 
owners, who wanted to quell disputes with neighbors, have clear guidelines for operations (namely, noise limits), and have ones that are not so restrictive that they cannot operate. This was a centerpiece of the Red River district bar owners' argument during the debate involving the extended hours. When the pilot program was first approved in early 2017 , the owners said the program would both boost their businesses, enable them to create both jobs and greater opportunities for musicians, and collect noise complaint data that could be used to solve disputes (Findell, 2017a).

Ernie echoed these sentiments. He said the biggest challenge that police in entertainment-oriented cities like Austin have that other cities do not is heavy mediation between entertainment venues and other residents and businesses. Having viable public policy in place to where police and entertainment businesses alike do not have their hands tied is critical. One must also take into account the unique needs of an entertainmentoriented business, such as how loud they need to be, as well.

Ernie: Literally, mediation is the biggest challenge we have, and you have to make sure you have a viable ordinance and one that's not so restrictive that the businesses can't do business. You've got to be aware of their needs, as well as the needs of the people affected around them. That's probably the biggest thing writing a good ordinance and applying that ordinance fairly and then being able to mediate.

Youth development was another cause on which artistic community members and government officials saw common ground. Involving young people in the arts was seen as a positive, by both groups, because new generations were becoming interested in cultural activities that the artistic community enjoyed when they were young and that they were becoming involved in something constructive that kept them out of trouble. In Austin, both groups were working to facilitate this. The city government and various 
officials supported youth activities in various capacities, including the Cultural Arts

Division funding them. Pomona noted activities such as the "Daybird" concerts, put on during earlier hours, allowed families and children to enjoy the city's live music, without the concern of late hours or having underage children at a bar.

Some of the multiple jobs the artistic community worked involved youth development, but despite their crammed schedules, many artistic community members carved out their time to volunteer. Hermione noted that the skills she and others doing this in both paid and unpaid capacities were ones that could be used beyond the arts something that city officials and artistic community members alike could definitely get behind.

Hermione: I think that this not only keeps the young people busy, but it also provides creative outlets for them and empowers them to create things. That's really important, and that's something that is really lacking in the kind of standard structure of our public education and some other kinds of extracurricular activities. Kids don't often have a lot of agency in the activities they're doing and yes, money for these activities is an issue too. We need to make programs accessible to kids all over the city.

They're about giving kids the tools and showing them, "Look, you can make whatever you want. It doesn't have to sound pretty. It doesn't have to fit into any of these boxes." Music is my way of doing that, but I think, for all of us who work in any of these kinds of organizations that are centered in arts education, our end goal is that it's not only the attitude kids have toward the arts. It's the attitude they have toward life, in general - that they feel empowered to think outside the box, to create new solutions, to work together as a group and to kind of pool their skills and resources and ideas to make something better.

...Every Saturday, I work with a youth ensemble and just getting to see them kind of take songs that they like and kind of figure out their own ways of doing it, and deciding who's going to sing or play bass or play drums... It's just really cool to see kids getting to make creative choices and decisions for themselves and then, hopefully, use that same thought pattern in other situations. 
Nymphadora knew that a major common concern she and others who put on or were involved with festivals had with city officials was having safe, successful events with safety being the top priority. For both parties, this meant greater viability and a boosted reputation. This is especially true for "home-grown" events that Austin-based entities put on, versus ones from outside promoters.

Nymphadora: Most of the events I work with or have worked with in the past are pretty much film festivals and other film-related, creative-sort-of events. It's all about public safety. You have so many people on the street, and you want to be sure that they're safe from cars and from humans. You want to make sure that they have a good experience because, one, they're humans and they deserve to be safe and have a good time. But two, as an entertainment business, that's how you get them back. You can't throw a festival and have no one come. So, you need those attendees to show up.

That, to me, is the cause. That's what the city is looking out for, for the most part. That's what fire codes are about. That's why we have various permitting issues on sidewalks and right-of-way - public safety issues for the most part. If you have this many people, you need to have this kind of security, and you need to think about your waste management strategy. It's all about keeping people safe and happy. To me, that seems like the common interest and common goal.

It's just really interesting watching organizations, events, and stuff that are actually located in Austin because you are more invested. Not only are these your attendees that you need for your business, but they're also your mom or your neighbor. There's a connection there. It's like a friend of a friend.

\section{Free parking}

While this may not seem like a major enabling factor for participation, Austin's parking and transportation issues detailed in the previous chapter definitely make this a positive. At various city events in which it worked to attract citizen participation in general and, specifically, from the artistic community, city officials would validate parking. This meant that the artistic community, who were already having to come from the city's outer edges, at least did not have to pay for the city's expensive parking to be 
able to participate. I benefitted from this, myself, when attending at least one city engagement event. Additionally, when the city had a joint arts/music commission meeting in January 2018, it did so at a location with free parking.

When doing a search for engagement events on the various city office Facebook pages in Austin, any event where parking will be free or validated is advertised. Major examples come from the Music and Entertainment Division's page advertising its events that fill up sometimes within hours. The screenshot of a Facebook post in Figure 8.2 below shows that validated parking is a selling point (as it is on other posts for other events). 
Figure 8.2: City music workshop, parking validated (City of Austin, 2018)

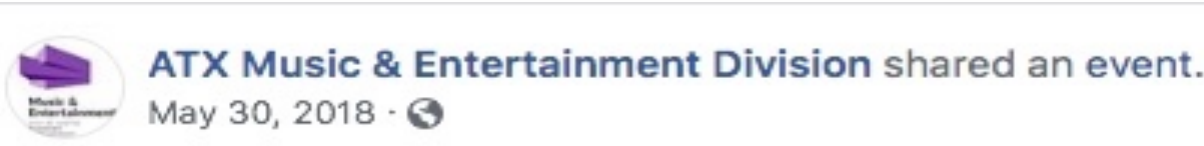

We're excited to host the Musician Compensation Sector Summit tomorrow at Austin City Hall (301 W. 2nd Street) from 2pm-4pm! Staff will present information on programs specific to generating revenue for musicians including the Street Performance Pilot Program, Dipjar, Music on Hold, The Daybird Music Series.

Event is free and open to the public! RSVP:

https://www.eventbrite.com/e/musician-compensation-sector-s...

Parking will be validated.

Tag a musician below!

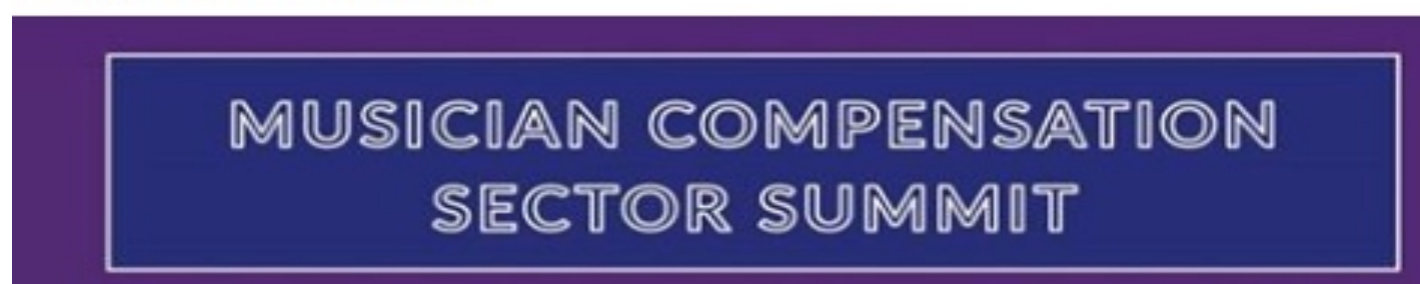

Monday, June 18, 2018 | 2pm - 4pm

AUSTIN CITY HALL

$301 \mathrm{~W}$ 2nd Street

Austin, TX 78701

MON, JUN 18, 2018

Musician Compensation Sector Summit

Austin City Hall · Austin

$\star$ Interested

- You like ATX Music \& Entertainment Division

\section{Enabling Factors Related to Institutions}

Austin's deep love of its music and art, reverse social construction in terms of appearance, and the city's society not being as stratified as others' were institutional factors that enabled the artistic community's citizen participation. The love for the city's 
music and art, a major part of its overall identity and history, was a drive for those in the artistic community and their supporters to fight for the spaces and activities that they loved. Austin's reverse social construction (Schneider \& Ingram, 1993) in regards to appearance — preference for a more casual and/or "rock 'n roll" look versus a professional/business one — was an enabler because, in Austin, participants showing that they were true to self and not fake and the content of one's message was, overall, more important than the participants' looks. A key point was that, compared to other cities, Austin's society was not as stratified. Social circles existed in government, the artistic community, and society at-large, but one could enter them through showing intelligent arguments. In this changing city, fresh perspectives were both desired and preferred.

\section{City's deep love of music and art}

Austin, as a whole, having a deep love for its music and art was a major participation enabling factor related to institutions. This longstanding, core element of what interviewees told me is a major fabric of the city's and their own personal histories drives them to fight for the spaces and activities they love so much. Likewise, some also believed that not all city government officials were ready to quickly and blindly allow the real estate market to outright destroy historic venues, like the ones on Red River, and it was because of this institution.

Austin becoming an arts hotbed and becoming the city it is today because of past

decades' affordable rents, Luna, an Austin theater company member, said. The financial situation has outright morphed, but the city's character remains the same. The artistic community still loves it and still wants to be a part of it. This is what she and others will work to impart on residents to get them to join the artistic community's cause. 
Luna: The arts in Austin was made possible because of what Austin offered early on, like affordable rental rates, and it's a great lifestyle city where you can hang out and have a more relaxed evening. It's not a hyper city.

...We are one set in a big tapestry of artists in the city. This is our way of saying that we're itinerant right now. There are a lot of theaters that are itinerant right now.

Meanwhile, Luna said, she is hopeful that city policy will work to help them and other arts operations find new spaces and continue. Despite her challenges and that of others, she noted that she loves being with the artistic community of Austin and its people who love it. This was my exchange with her.

Luna: I think Austin, in particular, has an incredible love for the arts. Artists in Austin: They're badass! We're always looking for feedback for the things we do, and we take that put that into all future work that we do. The audiences are extremely engaged and collaborate on our pieces. The feeling in Austin is really exciting because, for the most part, you're not in theater with people who are sleeping. They want to be there. They came because they bought a ticket and they want to be there. You can have good work and bad work, any time and anywhere. The goal is then to do better work the next time. Personally, I love making theater, collaboration, creating a reality or a fantasy, an ideal for an ephemeral moment...

Amelia: Like a little moment to get away from your world?

Luna: Not so much an escape, but a chance to sit with another option. I think there's an electricity here that's really cool. It's a shame that there are fewer places to connect to that current.

Amelia: Do you believe that current is what will keep you alive and be the push to give you and everyone else what you need?

Luna: I don't know. When the bills come and I think, "Maybe I should go into this!" I have had the fortune to continue making art. I think that when it comes to survival, it comes to survival. There are other people who have had to weigh that more than I have. I'm not going to say, "Oh my God. Art saved me." I think other people are finding ways to get saved in this situation. ... There's a soulful, spiritual, philosophic, and physical exploration that's connected to the human experience that I love and that art allows. I can't say it's the one and only way, and it shouldn't be. 
Molly said that the love of the arts in Austin as an institution has become its brand and why people recognize the city. This institution, an organic and homegrown one, has grounded itself strongly enough to have serious staying power.

Molly: It's what we're known for: This creativity, innovation, taking creative risks, and working together collaboratively as a creative place. It doesn't hurt that we have some pretty outstanding international and national recognitions that have come from that, and it doesn't hurt that we've kind of created this as a grassroots effort and not sort of as a top-down kind of artificial, "Oh, look at us now. We're the city of whatever." It has come from the people who have lived here and put their sweat equity into creating that vibe and that scene. And that doesn't go away as easily as something that's created by a consultant's stamp onto a city.

Money will not always win, Ron said, when it threatens a cultural institution, Ron said. It will always be a factor, but finances are not the only consideration.

Ron: Look. Money is going to get you listened to, but it's not the only thing that matters, frankly.

Amelia: To city government or Austin, in general?

Ron: In general. I don't think it has a corrosive or pathogenic level of influence. I could just be a little Pollyanna myself. It is certainly a way to get a conversation started, but it's not the only factor. There's a ton of stock in cultural preservation, the "Keep Austin Weird" vibe - all that stuff. All of those things aren't necessarily combatting each other. I think there's a cocktail where I think money is a sizeable ingredient in that cocktail, but it's not the only one.

....There are going to be artists and jaded folks in this town who will say, "Absolutely. That's the way it happens." But from watching things work, no. There's a lot of oversight and lots of people checking every box and going through the process. So, there's not much in the way of money buying or peddling influence.

In the long term, Ron plans to stay in Austin, despite its changes. In fact, the changes are ones he sees as potential opportunities — new people with new ideas and 
new opportunities. He pointed to cities such as former industrial hubs that did not innovate and are paying a hefty price for it. Austin, he said, is doing the opposite.

Ron: I came down for South-By-Southwest in 2002. As I was just enjoying the city, I thought, "All right. I kind of don't want to leave." It's still very much that, even though it's changed with time, and, yes, things are more expensive and there are things that go away that I miss. Even though Austin is changing, there is a ton of opportunity here. Grab it. That's something I find pretty attractive, and it's still got music. It's still got amazing music. It's got amazing people. There's a complete overflow of things to do and things to enjoy. So, yeah, that's a part of the list of why I'm staying.

I am someone who places a ton of importance on social interaction and being in lots of rooms with lots of people and doing lots of things - the social cocktail. Austin is an amazingly effervescent social cocktail bringing in so many new people, new ideas, and new things to do together, pretty much constantly. In the United States, there's no better place for that.

\section{Casual appearance preferred: Reverse social construction}

One participation enabling factor was that social construction (Schneider \& Ingram, 1993) regarding appearance worked in reverse in Austin. Dressing casual or in a "rock in roll" style, like having visible tattoos or men having long hair, was considered a draw and not a turn-off in citizen participation forums, for the most part. Interviewees said this was a characteristic of Austin's historically laid-back vibe, but more importantly, being seen as true to oneself versus being fake was more attractive and more conducive to having one's message register with fellow citizens and even government officials.

This opinion was not a unanimous one, with some interviewees decrying how some artistic community members dressed too casually at government forums. However, most interviewees had a different viewpoint. Ron said that there are some situations where one does have to be somewhat more "buttoned-up", but there is also an 
understanding that people in the artistic community may be a bit off-the-cuff. More importantly, though, is a person's knowledge, preparation, and personality — and that casual appearance can be part of an effective and well-received delivery.

Ron: I think if you kind of have your own style or your own way about doing things while also being one hundred percent on top of your game and professional, your appearance should not be too much of a hindrance. A guy who's on the music commission, Graham Reynolds, is an internationally regarded composer and career musician, also has very much his own distinctive style and flair. He's not a very loud personality, but he definitely has his own thing going on. But he's very well-regarded. He's the mayor's appointee to the music commission. He has gray hair, kind of long-ish hair. He just has his own thing going on. When you're someone like him, you can do that because he carries himself well. He's sharp as a tack on the issues, but he's also very much his own guy.

I think if you're your authentic self and just bringing it when you need it, professionally, I think that matters far more. People can smell when you're inauthentic, and that's worse than anything. So just be yourself and watch your language and everything, obviously. But just be smart. Be on point with everything you need to be, but also just be authentic because if it starts ringing false, then people start to have suspicions and then you can't get anything done.

Ron gave the example of a well-known Red River bar owner who dresses very casually for most events but is also well-known as being extremely knowledgeable about both the business and policy challenges that the Red River district faces and known for presenting these issues exceptionally well, such as during the debate involving the extended hours.

Ron: Let's use him as an example. Part of the reason I believe he is so effective is, one, he is smart as a whip, and he's got great insights on everything. But then, I think his message carries because he's got this persona of someone who's been through the wars with regard to life in the music industry. If you rip that way, and all of a sudden, he has slicked-back hair and a suit, they're going to call bullshit on him. It doesn't carry the same kind of velocity. Obviously, if he did, for whatever reason, move into a phase of his life where he was wearing dress clothes and had less of a shaggy haircut or whatever, if he did that authentically, it would 
still work. It's like if you just do that for the sake of doing that, you're trying to put on a costume. People can tell it's weird.

Seamus recalled when he tried to enter policymaking and he realized that authenticity was far more important, at least in Austin. Also, he said that, in Austin, there seems to be a draw toward people who appear to be "cool". He acknowledged, though, that this might not be the case elsewhere, especially when I noted the opposite finding in New Orleans during my conversation with him.

Seamus: You know, I think I tried this both ways when I first started getting involved with politics. I thought maybe I needed... I know I'm not going to suitand-tie it because quite frankly, I have, like, one suit. That would just seem kind of cheesy. But I tried to doll it up a little, and then I found the longer I played in the pool with people, that people listened to me and were interested in getting meetings with me, not because I knew how to cover my tattoos up or not wearing a shirt that said "Fuck you" or something.

It was because I was like an exotic mythical beast and came from a world that they didn't fully understand but they thought was cool that they were talking to someone from this world. So one of our political assets is just being real and being ourselves because, as an observer, we're kind of just like orientalism we're "the other", you know? And then people find cache with that and they feel cool being around other people that they think are cool. Whether or not I'm cool is neither here nor there. It's just what they think, you know? (Laughs)

So you've got to use the assets you have, and if that means wearing what you would wear normally, I think that's a pretty easy decision to make. Now, wearing shirts that say "Fuck you" or the like are not productive. I would avoid that. But that's also the Austin market. I mean, things can be different in New Orleans. Things would be different in Waco. So, I wouldn't give that as blanket advice, but it seems that policymakers want to hear the perspective of someone genuinely representing that perspective — not a poser or someone trying to be like them.

Penelope said that sometimes, walking into Austin City Hall means that someone who dresses casually will still be taken less seriously — but that should not be the case and, seemingly, it is becoming less of the case in Austin and the state of Texas. She 
pointed to Democratic U.S. Senate candidate Beto O'Rourke, who lost to Ted Cruz by an extremely slim margin. O'Rourke's past in a punk band actually bolstered his popularity, she noted. The Austin Music Commission also has "some punks on there" who "definitely dress like cool guys". So, even if they may be looked down upon, people in such subcultures as punk and hip-hop "know what's going on" and should get the warranted attention.

The reverse social construction regarding appearance sometimes had government employees who worked with both elected officials and the artistic community scrambling when it came to their wardrobe choices. Nymphadora was one of them in her former job. Deciding what to dress, from her perspective, was part of working to meet the people government serves where they are, just as those who mentioned physical meeting places did in a previous section.

Nymphadora: When I was working in government, and in what I did previously, I worked with government folks and legislative people, but, as well, I worked with filmmakers. Honestly, even just finding a dress code to where I could still be taken seriously by government folks and legislative staffers but also not looking like a narc when I would go talk with a filmmaker because I might be wearing a pencil skirt and heels... It's really a fine line of being trusted by both - by what you're wearing, how you talk, where you go, what you do, that kind of thing.

It's actually something you have to think about, which seems really strange, but it's true. If you want to be able to have a really good conversation with someone, you meet them where they are, and then you're able to do that.

\section{Society not as stratified}

While Austin was not free of societal power structures, Austin's society was, overall, not very stratified at all compared to other cities like New Orleans. From my observations and interviews, finding an "in" with Austin government and society at-large 
was not extremely difficult. Austin was, compared to other cities like New Orleans, not very cliquish and not as closed off to new people with new perspectives. In fact, given the city's issues with extremely rapid change, fresh perspectives were desirable. This enabled participation because, as a whole, people were not as averse to working with new individuals and groups and not as averse to new perspectives.

During much of my observations through this fieldwork period, I would do what I called the "sit solo" test, during which I would sit by myself when observing. I would then wait to see how long it took for someone to come and sit with me or talk with me on his/her own, if anyone did at all. I did this to get a feel for how open or closed a given environment would be. I employed this method while observing a local nonprofit's “CodeNext Game Night”. Not long at all after I sat down, a man joined me at my table. Not long afterward, two others, a woman and another man, came to join us. We asked if the latter two knew each other, and it turned out that they had only met just about a minute beforehand while coming in the door and decided to find a place where they could sit together.

The goal was to gather people to play a Lego game designed to put participants in a policymaker's shoes in deciding how to handle growth, much like Austin is experiencing (Glasshouse Policy \& Austin Monitor, 2018). The game had four scoring criteria - accommodation, money, political capital, and green spaces. The situation my group faced was that 500,000 new people were planning to move to Austin, and we were to accommodate them while also balancing different interests - namely financial concerns and political capital (i.e., keeping our existing citizens happy or at least not hating us so much). The beginning game board and information sheets both we and the 
other small groups had in front of us are in the photo below in Figure 8.3. The board is a square representation of an Austin city map, with the different colors corresponding to the ten different council districts.

Figure 8.3: CodeNext Game Night board, documents (Pridemore, 2018)

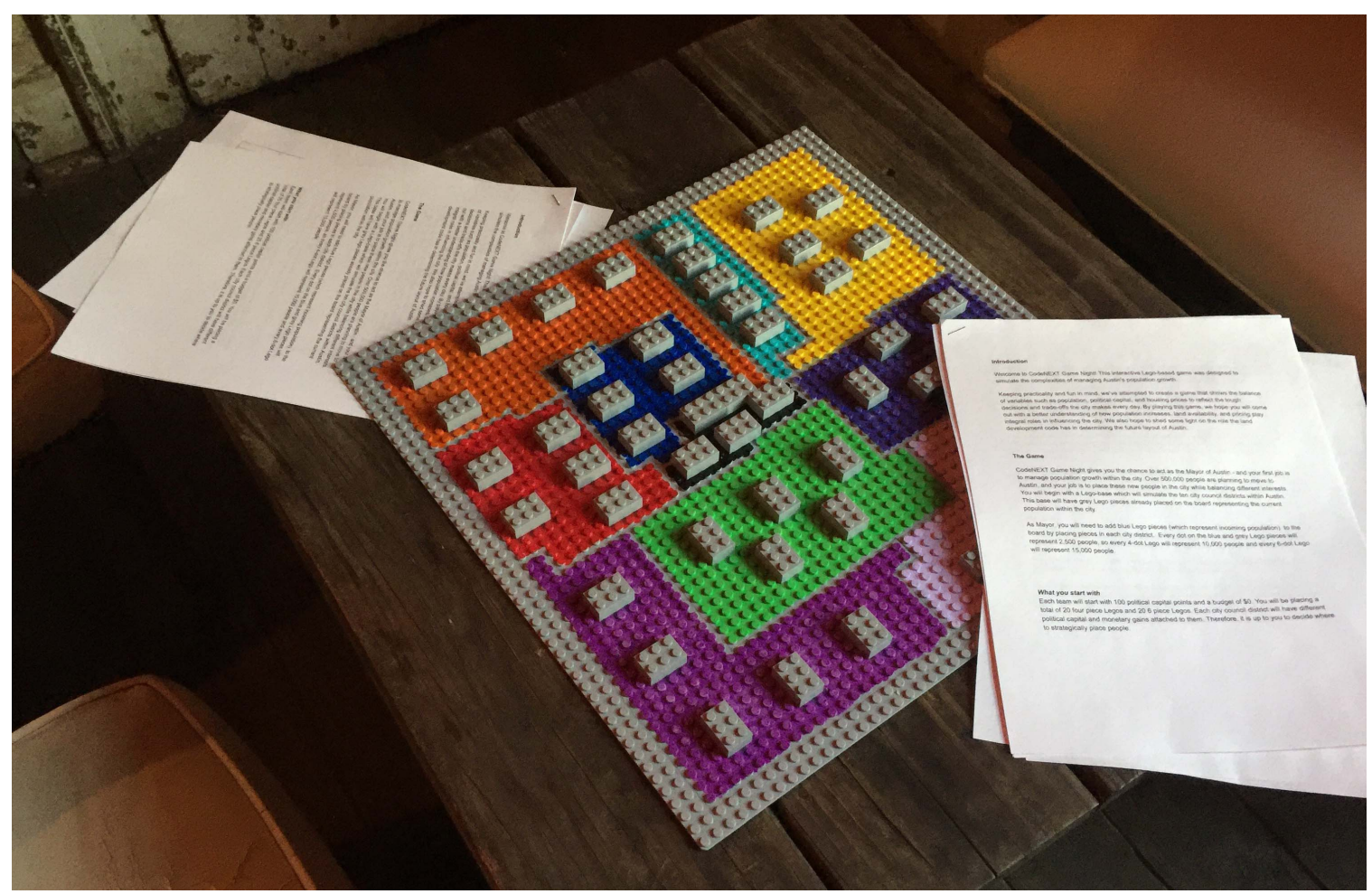

All were given bags with different sizes of blue blocks (four-dot and six-dot) and green blocks that looked like leaves. The blue blocks stood for two things, money and accommodation. Each time we placed a blue block, we accommodated new residents, ten thousand for the four-dot blocks and fifteen thousand for the six-dot ones. This also meant we earned money, which was critical for our city in remaining financially solvent. However, each time we placed a block, we also lost political capital, meaning that existing residents were not happy with the new development we were allowing. 
The question of how much money we gained and how much political capital we lost depended on the council district in which we placed blocks. This is how the game became far more complex and forced us to make some extremely difficult decisions, often re-thinking and revising them as we went along. The map below in Figure 8.4 shows the amount of money we gained per district and the political capital lost, per district. 
Figure 8.4: CodeNext Game map (Glasshouse Policy \& Austin Monitor, 2018)

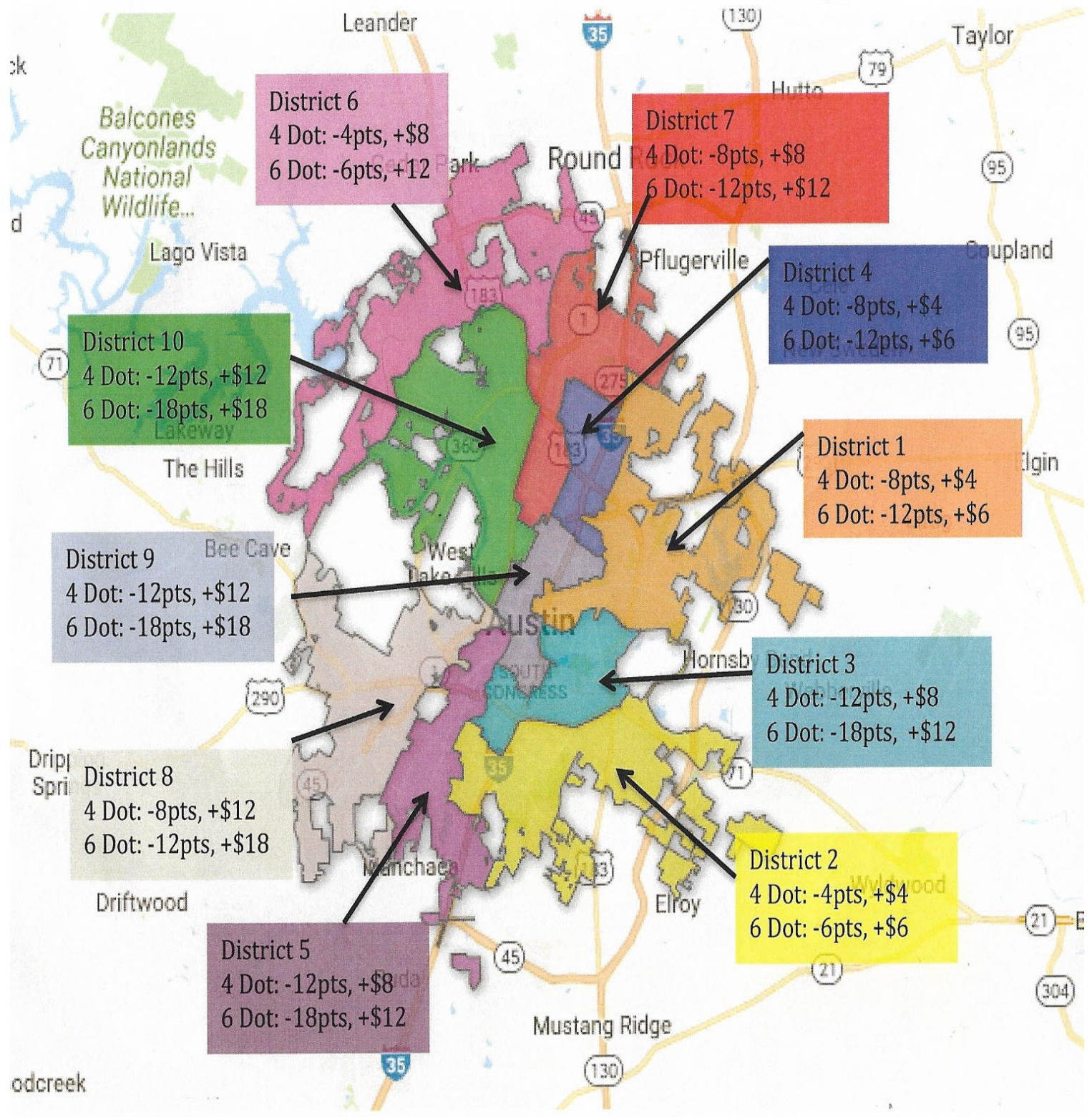

As shown above, some areas of the city would bring us serious financial gains but cost us dearly in the figurative court of public opinion. Organizers at the event said they based their scoring namely on real estate data in these districts and council members' statements that either favored or disdained the development and population influxes. 
One mental note that I made, given my previous interviews, secondary source reviews, and observations before this time, was that the districts that tended to have less political capital loss were ones east of Interstate 35 - historically, minority neighborhoods were, thanks to the Koch and Fowler Plan of 1928, black and Hispanic residents were forced to live if they wanted to access public utilities (Koch and Fowler, 1928; Tretter \& Sounny-Slitine, 2012; Zehr, 2015a, 2015b). Also, the ones with greater political capital loss were wealthier ones, particularly ones where residents tended to live in single-family detached homes like District 10, according to my interview with Albus, who also had played the same game at another location. The minority residents in East Austin, as noted in the previous chapter, have been historically disenfranchised and underrepresented (Personal Communication, 2017, 2018; Tretter \& Sounny-Slitine, 2012; Zehr, 2015a), and, as noted in the previous chapter, the single-family homeowners tend to dominate city public hearings and have more time and financial ability to do so (Personal Communication, 2018).

The game's fourth scoring criterion, green spaces, was not only a way we could benefit the city but also a way we could save face, politically. Green Lego pieces that resembled trees stood for parks. If we put a park in a given district, we would increase our political capital by fifteen points (Glasshouse Policy \& Austin Monitor, 2018). The parks, though, cost us $\$ 30$ from our budget.

Another element besides parks could cost us some serious money, as well failure to accommodate some of the 500,000 new people. We were allowed to make the call as to whether or not we would place the new people inside the city limits, placing them outside the city limits and into the figurative suburbs (Glasshouse Policy \& Austin 
Monitor, 2018). Doing this would penalize us by $\$ 1$ for every dot we placed outside the city because we would lose various tax funding (i.e., property taxes) yet still have increased infrastructure costs and traffic because those new people would still be coming into the city.

We were all given a rubric that determined how well we did, based on the scores in the four categories. A photo of the rubric is below in Figure 8.5.

Figure 8.5: CodeNext Game rubric (Glasshouse Policy \& Austin Monitor, 2018)

\begin{tabular}{|c|c|c|c|c|}
\hline & 1 & 2 & 3 & 4 \\
\hline Political Capital: & $\begin{array}{c}\text { Your political capital is not only too } \\
\text { low to win reelection, but Austinites } \\
\text { are constantly calling for you to } \\
\text { resign. You might want to consider } \\
\text { moving to a new city soon. } \\
\text { Political capital: } 0-20\end{array}$ & $\begin{array}{c}\text { You have some political capital left, } \\
\text { but you will almost definitely lose } \\
\text { reelection. Better start sending out } \\
\text { your resume! } \\
\text { Political capital: } 20-40\end{array}$ & $\begin{array}{c}\text { You have enough political } \\
\text { capital left to win reelection, } \\
\text { but just barely. } \\
\text { Political capital: } 40-60\end{array}$ & $\begin{array}{l}\text { The city loves you! You will win } \\
\text { reelection easily. They might even } \\
\text { throw a parade in your honor. } \\
\text { Political capital: 60t }\end{array}$ \\
\hline Green Spaces: & $\begin{array}{c}\text { Your city is now a sad, concrete } \\
\text { jungle without any parks. Where will } \\
\text { the children play now? } \\
\text { Parks in } 0 \text { districts }\end{array}$ & $\begin{array}{l}\text { You have some parks, but they are } \\
\text { limited to only a few districts, so } \\
\text { very few people benefit from these } \\
\text { services. } \\
\text { Parks in 2-5/10 districts }\end{array}$ & $\begin{array}{c}\text { The majority of the districts } \\
\text { have parks, which means that } \\
\text { there's a good amount of } \\
\text { green space around the city. } \\
\text { Nice job. } \\
\text { Parks in 6-9/10 districts }\end{array}$ & $\begin{array}{l}\text { There is at least one park in every } \\
\text { district. The city is green and lush, } \\
\text { and people can be seen frolicking } \\
\text { in their local parks. Looks like } \\
\text { somebody has a green thumb! } \\
\text { Parks in all } 10 \text { districts }\end{array}$ \\
\hline Accommodation & $\begin{array}{l}\text { Barely anyone is accommodated in } \\
\text { this new plan. All of these } \\
\text { newcomers' tax dollars will go to the } \\
\text { county instead of the city, but you } \\
\text { will still carry the burden of providing } \\
\text { transportation and services for } \\
\text { them, thus hurting your budget. } \\
\text { What were you even trying to do } \\
\text { here in the first place? } \\
\text { People accommodated: } 0-99,999\end{array}$ & $\begin{array}{l}\text { Some people are accommodated, } \\
\text { but a majority of the people moving } \\
\text { to the Austin area will have to live } \\
\text { outside of the city limits. } \\
\text { People accommodated: } 100,000 \text { - } \\
399,999\end{array}$ & $\begin{array}{l}\text { Most of the people who will } \\
\text { move to the area will be able } \\
\text { to live in the city, giving you all } \\
\text { of their tax dollars! } \\
\text { People accommodated: } \\
400,000-499,999\end{array}$ & $\begin{array}{l}\text { Congrats, you placed all } 500,000 \\
\text { people within the city limits! Your } \\
\text { city budget will thank you once the } \\
\text { money starts rollin' in. } \\
\text { People accommodated: } 500,000\end{array}$ \\
\hline Money: & $\begin{array}{l}\text { The city government is in a financial } \\
\text { crisis. Does the word "budgeting" } \\
\text { mean anything to you? } \\
\$ 0-20 \text { left }\end{array}$ & $\begin{array}{l}\text { The city's budget is looking a little } \\
\text { lean these days, but things should } \\
\text { turn out ok in the end. } \\
\$ 20-40 \text { left }\end{array}$ & $\begin{array}{l}\text { You've got some money in the } \\
\text { bank! Your budget is looking } \\
\text { better than normal! } \\
\text { \$40-60 left }\end{array}$ & $\begin{array}{l}\text { Nice job! The city of Austin is } \\
\text { loaded and in good shape } \\
\text { financially. Guac for everyone! } \\
\$ 60+\text { left }\end{array}$ \\
\hline
\end{tabular}


So while this game seemed like a fun time to play with blocks on the surface, the truth was that we had to model the extremely difficult decisions with serious consequences that policymakers in growing cities have to tackle every day — and in reality, too. In this situation, I was not only watching to learn from the game, but also whether or not four perfect strangers from four different professional backgrounds ones, I might add, were all derided in some fashion in Austin - could collaborate in making extraordinarily complex policy decisions (even if it were just a mock setup).

We did it.

The group sponsoring the event gave each group a spreadsheet file on which we could track our overall scores, and only one among us who brought a laptop worked to track our scores. Throughout our gameplay, we did not clash; however, I did notice our perspectives were different in terms of what score one person would watch more than another. The two who were not keeping score were watching the financial situation a little more than me, and I was watching the political capital situation more than the others. Nonetheless, we all still recognized the value of all four elements we had to track - especially the man who was watching the spreadsheet and saw how District 10, the single-family homeowner district Albus had mentioned to me in an interview, had grown to outright despise us, given how it was devouring our political capital score. We gave District 10 two parks, and even that did not help us, overall.

“Guys! Ten is killing us! They HATE us!” our scorekeeper said, as he watched the spreadsheet. 
We took away one of District 10's parks and saved some money, then.

As we moved forward, we realized that so many options presented to us had no happy endings. In the end, we made the decision not to place all 500,000 people in the city limits and take the financial hit that brought. Otherwise, no amount of parks was going to quell the citizen discontent that kept rising. We were going to have miserable, angry people even if our coffers were brimming. Our completed game board is shown below in Figure 8.6.

Figure 8.6: Code Next Game Night completed game board (Pridemore, 2018)

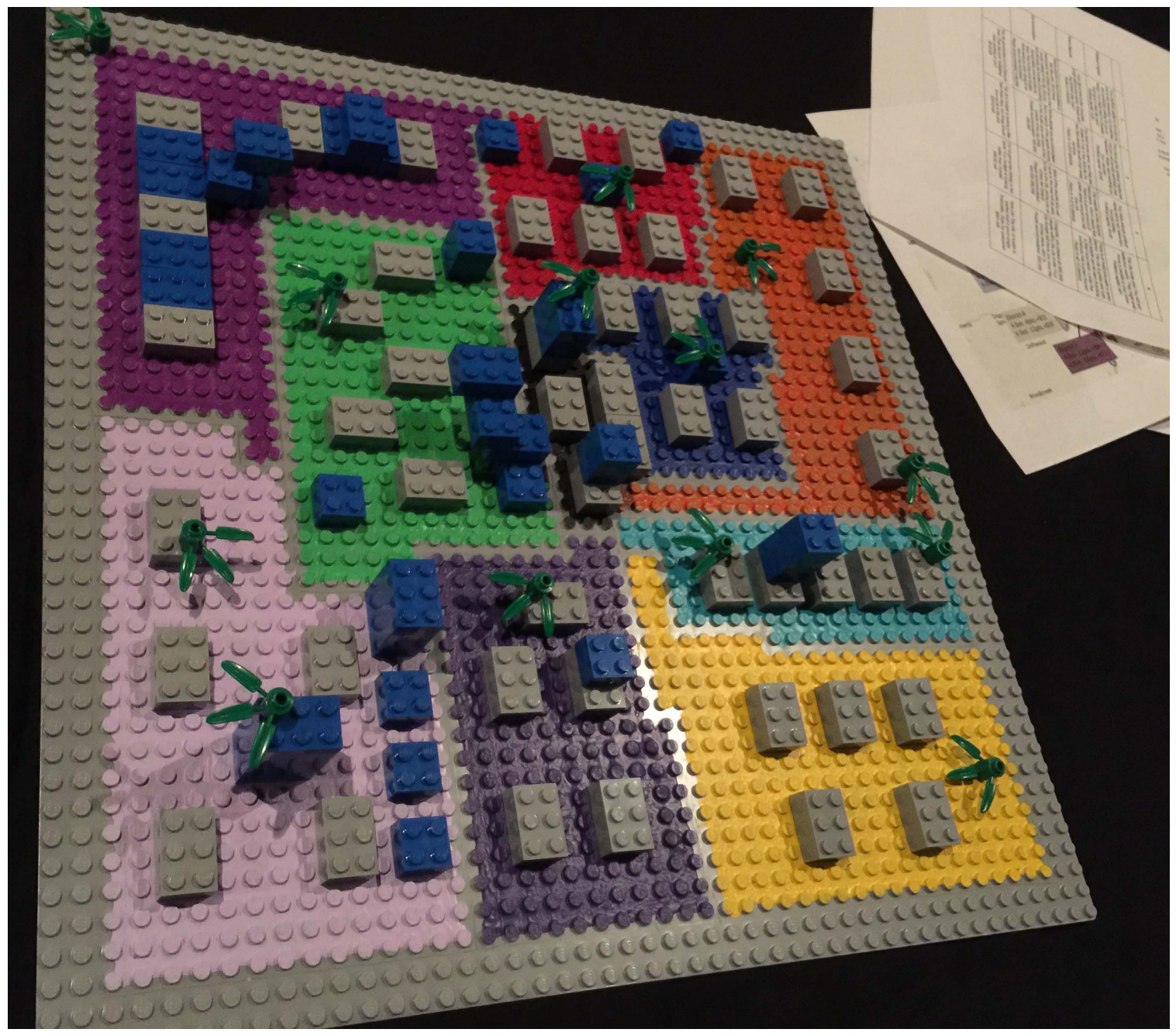


The lesson I learned here was not only related to development and population influx issues — and ones of power and citizen discontent — but also, that at least in Austin, there were people who were open, willing to have serious discussions with disparate groups, and could have these discussions without a brawl erupting. Now, the question remained as to how a group of policymakers, merged with citizens, could have such a calm discussion when facing "the real thing". However, Austin not having rigid social strata in which someone who did not fit in some sort of defined social order (or orders) made this situation easier. Ron noted this during an interview, in which he said proving oneself, is how someone gets "in", with Austin. Granted, some defined social circles exist, but the social environment is not stratified to the point where someone with newer ideas is snuffed out.

Ron: If you can get into a specific circle and kind of prove that you've got the intellectual muscle or the muscles to belong and stand out and show your value, then I think those barriers kind of wither away pretty quickly. ... In Austin, one of the best things and one of the great things that is so attractive about it, is there's a pretty open kind of intellectual meritocracy.

So yeah, social circles determine where you most frequent and where you most have it. And so you'll have to make some jumps and burn some calories getting into different social circles, but it's not like anyone has really gotten a ton of disdain for people in other social circles. It's not a pathology. It's more of just a dynamic thing.

There's no perfect situation, but I think there's far less of a malevolent attitude toward people in other circles. It's more just like, “Oh, I've never seen this guy before, but if I have a conversation with this guy or this gal, when we first start clicking, then, hey, that's great. I've just met some new people, and this is awesome." It's more of that rather than, "Oh, they don't go to the country clubs, so I can't give them the time of day."

So, I think that's kind of what I've observed. And I say that from a position of white male privilege, so who can say whether I have a great perspective on it or not, but that's just what I've seen in my nearly ten years here. 


\section{Enabling Factors Related to Place}

Place was a major enabling factor in the artistic community's participation — and when done properly, it was probably the strongest enabling factor I found in the Austin study. Interviewees, particularly from the artistic community, wanted to meet public officials at their venues and at times that worked for them, rather than government buildings at scheduled public hearing times, as mentioned in a previous section. But specifically, the vast majority specified that they really had the desire to meet any public officials in casual, comfortable third places. Besides the inherent comfort level of being in familiar and casual environments, the artistic community interviewees believed that conversations in such meetings could be less structured rather than the formal structure of public hearings that some believed were off-putting (as mentioned in the previous chapter). Policy oriented meetings that government officials or other groups had in such venues were especially well-attended, sometimes to the point where, literally, finding a place to stand was difficult.

It also conveyed a message that government officials either understood the artistic community's needs or wanted to understand them. Furthermore, coming to venues that were held in such high regard — but were endangered, like the Red River district venues - created both conductive conversation and again, showed that the city government cared.

\section{Third Places}

During the Austin study, third places were a major participation enabler on multiple fronts — personal comfort and ease, love for them from the artistic community and the city as a whole, Austin having figurative ownership of them, and most 
importantly, conducive environments for having deeply serious conversations about issues facing the artistic community and city as a whole. This was especially true in the Red River district, which, despite its economic perils detailed in the previous chapter, Austinites valued and wanted to save. This enabled participation because there was serious drive to save the third places and because the third places were the ideal spaces for participation to happen.

Physical artifact examinations, observations, and interviews gave me needed background to explain why such locations, as opposed to a government building, would be a more comfortable environment. During observations in the Red River district, I visited venues that, as I mentioned in an earlier section, Ray Oldenburg (1999) would likely say, "Yes, this is a third place," upon setting a single foot in the door. Despite appearances that would make a more high-brow people turn up their noses, I felt at home — and felt that these were fertile ground for discussing the extremely difficult situation the artistic community faces. The situation is an uncomfortable one in which hard truths will have to come to the forefront — so, it is imperative that the setting in which those discussions take place do not make a tense situation far worse.

Yes, the buildings in Red River were older. Yes, some of the bathrooms were not exactly a concierge-type at a luxury wine bar (although none were outright filthy). Bathroom stalls were covered in various forms of vandalism, and patrons had stuck numerous stickers all over the walls, posts, and other locations over time. Still, I felt that the environments were likely some of the least stifling and most comfortable and freespirited places I had ever encountered. I even felt like the shabby bathrooms and vandalism added to the overall relaxed feel. At one venue in particular, the Mohawk, I 
saw a sign right at the entrance that clearly stated that this was an open, "leveler" (Oldenburg, 1999) environment.

Figure 8.7: Mohawk, All Are Welcome sign (Pridemore, 2018)

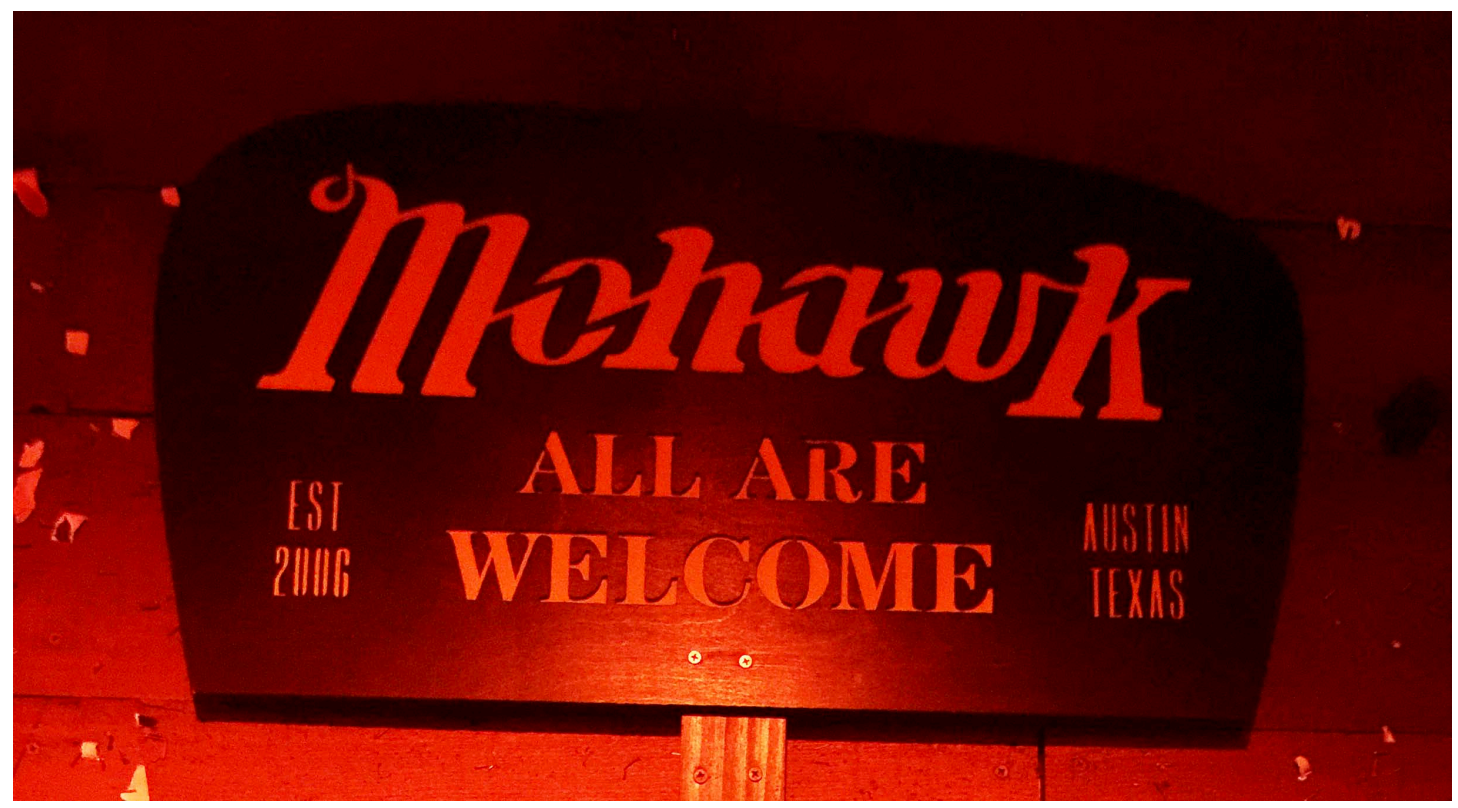

Like Oldenburg (1999) writes, third places are where an interesting mix of characters gave a city its identity. Besides the Red River district's longstanding history in Austin, the Mohawk and other venues showed it was definitely a place with character and for characters - such as this taxidermy bear living a colorful afterlife at the bar shown below in Figure 8.8. 
Figure 8.8: Mohawk, taxidermy bear in rhinestone suit (Pridemore, 2018)

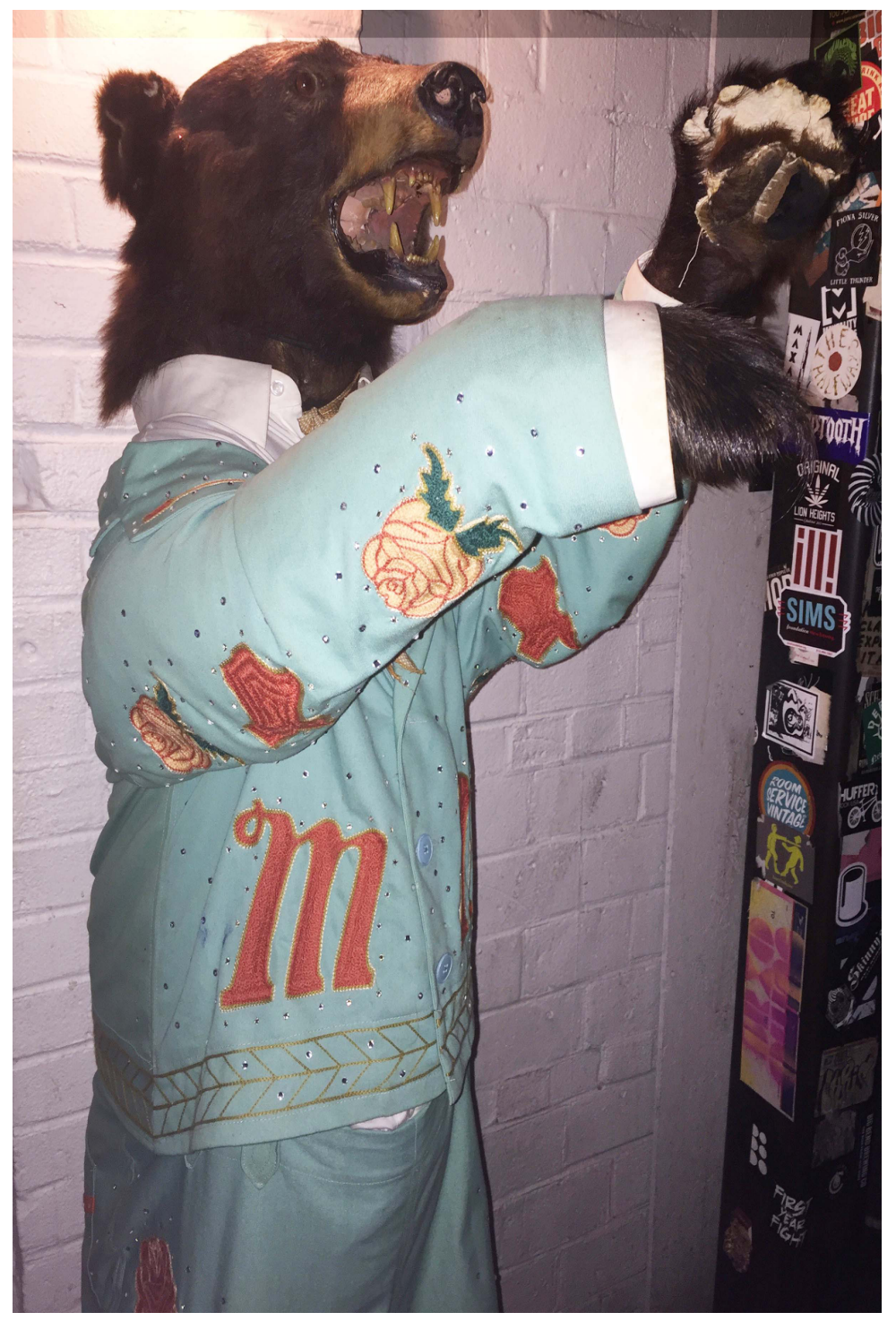

The Red River venues also captured the freedom one experiences at a third place as Oldenburg (1999) writes - a place to let oneself go, no matter how silly or crazy that person may look, because doing so is permissible in a third place, versus a workplace where such behavior would get someone fired. Seamus noted the "welcome", level, and free atmosphere in Red River, too, and inadvertently echoed material Oldenburg (1999) wrote about how taverns were places where ideas leading to social change were born. 
Seamus: It's interesting because a lot of art and revolutionary ideas came out of third places in the turn of the $20^{\text {th }}$ Century in places like salons, coffee houses, and beer houses where socialists and beatniks met. And in fact, the Japanese referred to sake as "wisdom tea" because it levels. The Japanese have such a highly codified, hierarchal social structure, traditionally, that it creates an opportunity and spaces for, regardless of one's class, for all to just be idiots together. That's the wisdom of it, you know? (Laughs out loud)

This large display of bathroom vandalism shown below in Figure 8.9 included a message that the Mohawk and other Red River bars were also a place where society's misfits — even the damned — could find like-minded people and escape from the pressures of home and work, much like Oldenburg (1999) notes about third places.

Figure 8.9: When in Rome, when in Hell, bathroom vandalism (Pridemore, 2018)

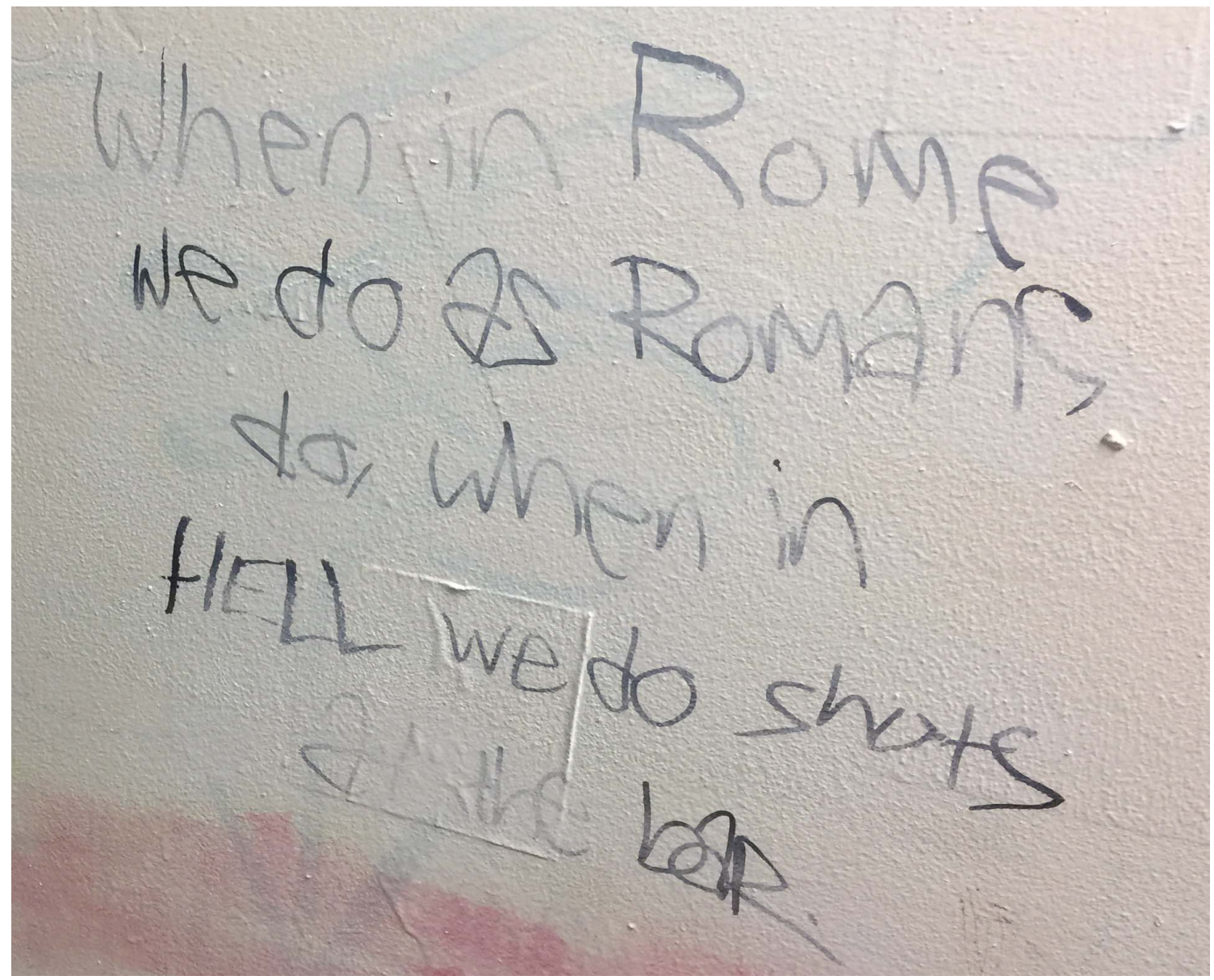


I asked Seamus about the "All are welcome" sign I saw at the Mohawk and how that seemed to set the tone for the Red River district. He indicated it is both a mix of history and change because, historically, Austin venues were laid-back, but they were also very genre-centric. Now, as part of being diverse and inclusive in the ethical sense, they have also worked to make venues diverse and inclusive because it makes good business sense not to shut off other particular groups who do other forms of music and art.

Seamus: It kind of has, for us, double meaning here in Austin. One is that, in the history of venues, Austin has a really long-standing history of having genrecentric venues. Say, you've got the reggae bar, you've got the metal club, you've got the blues players, and so on and so forth. With having traveled the U.S. pretty extensively, this was not the case I found anywhere else. And that was true, I don't know, from at least the 1970s up until the early 2000s - a thirty-year stretch.

Then so, we made a break with that through creating an atmosphere in Red River that said, "All are welcome," by saying, "Hey, it's kind of crazy. I mean, it might be neat to create these micro-communities, but having a space where people who enjoy a variety of music feel don't feel comfortable is just crazy. Plus, just embracing the art, the progressive culture, and spirit - that's also what "All are welcome" means to us. It's just embracing all people, and all diversity of identity and being, you know?

Also, from a business point of view, it's crazy. Music is an insanely niche thing. People who like to see live music are also very niche. We take for granted that live music is this ubiquitous experience. A lot of people don't care about music, I've discovered and to my surprise. So not only for the creative, sort-of lifeaffirming side of it that wants to embrace everyone, but on the other hand, from the business side of it, it's the only sensible way to progress is like a niche business model. So I like to juxtapose common sense and idealism when they kind of correlate in and run parallel to one another. It's a beautiful thing. You can convince people who have values in both camps. That's a good idea.

I found a similar welcoming environment when I visited Cheer Up Charlie's, but here, I additionally experienced what Oldenburg (1999) writes about the "commended 
stranger" - the person one meets at the third place who generally remains only in the third place, but that person is fascinating and engaging, with the third place adding to their overall allure. Cheer Up Charlie's, as interviewees told me, clearly conveyed that it was an inclusive environment not only because of its casual appearance but also its heavy use of rainbow colors throughout, colors traditionally used in LGBT pride flags, indicating it was LGBT friendly. Still, like other interviewees told me, Cheer Up Charlie's was a place that, although it might be labeled a "gay bar", it is not an LGBTonly destination. Like the Mohawk's sign, Cheer Up Charlie's décor conveyed, “All are welcome". Photos of Cheer Up Charlie's sign, outside mural, and indoor bar area with its rainbow lighting are shown below in Figures 8.10, 8.11, and 8.12.

Figure 8.10: Cheer Up Charlie's lit-up sign (Pridemore, 2017)

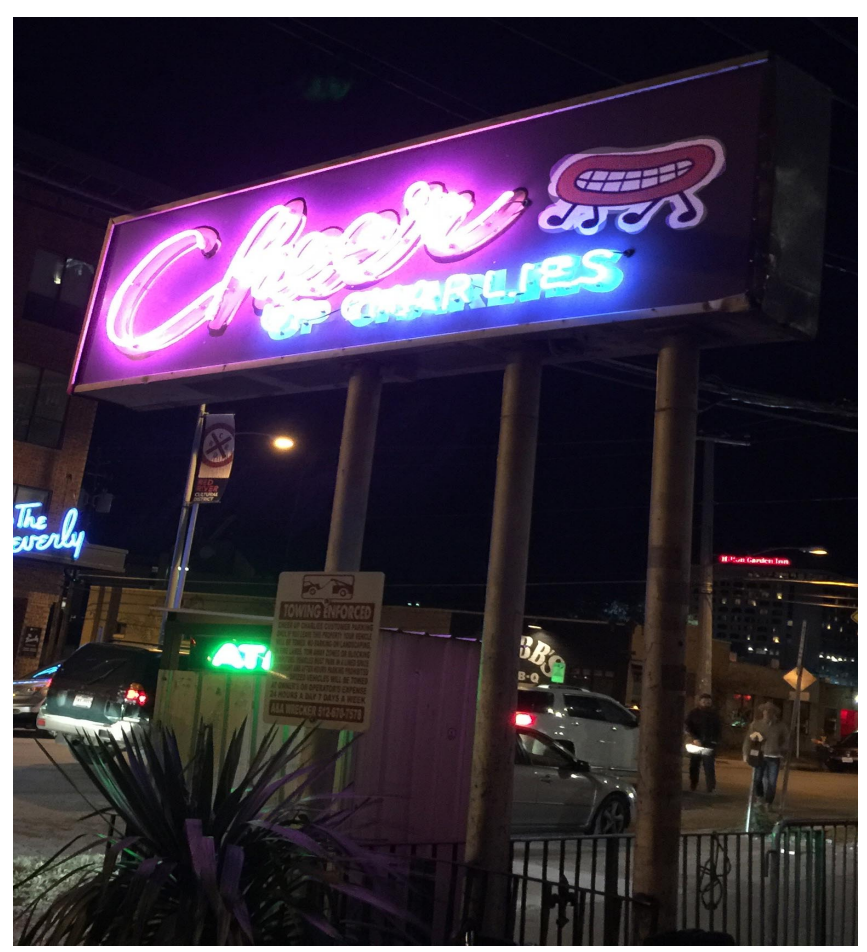


Figure 8.11: Cheer Up Charlie's outside mural (Pridemore, 2017)

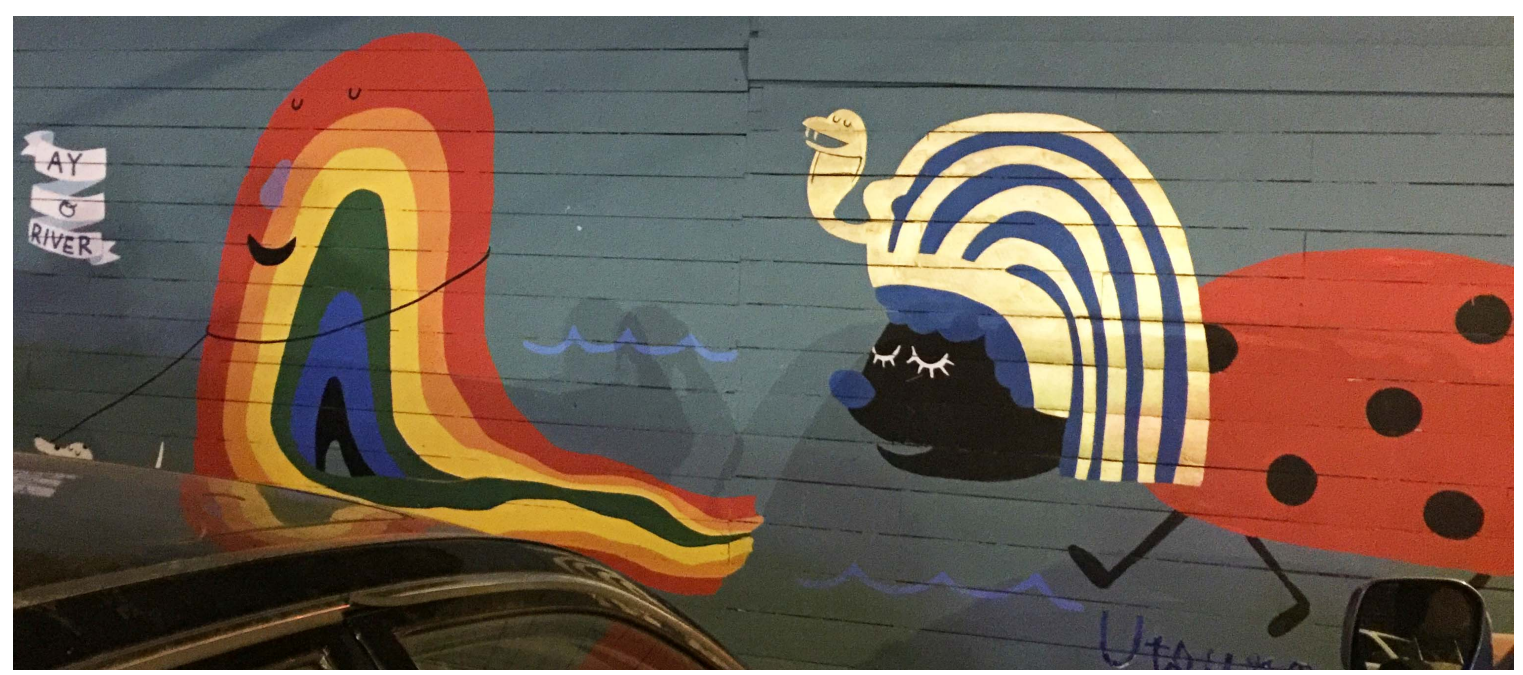

Figure 8.12: Cheer Up Charlie's rainbow bar area (Pridemore, 2017)

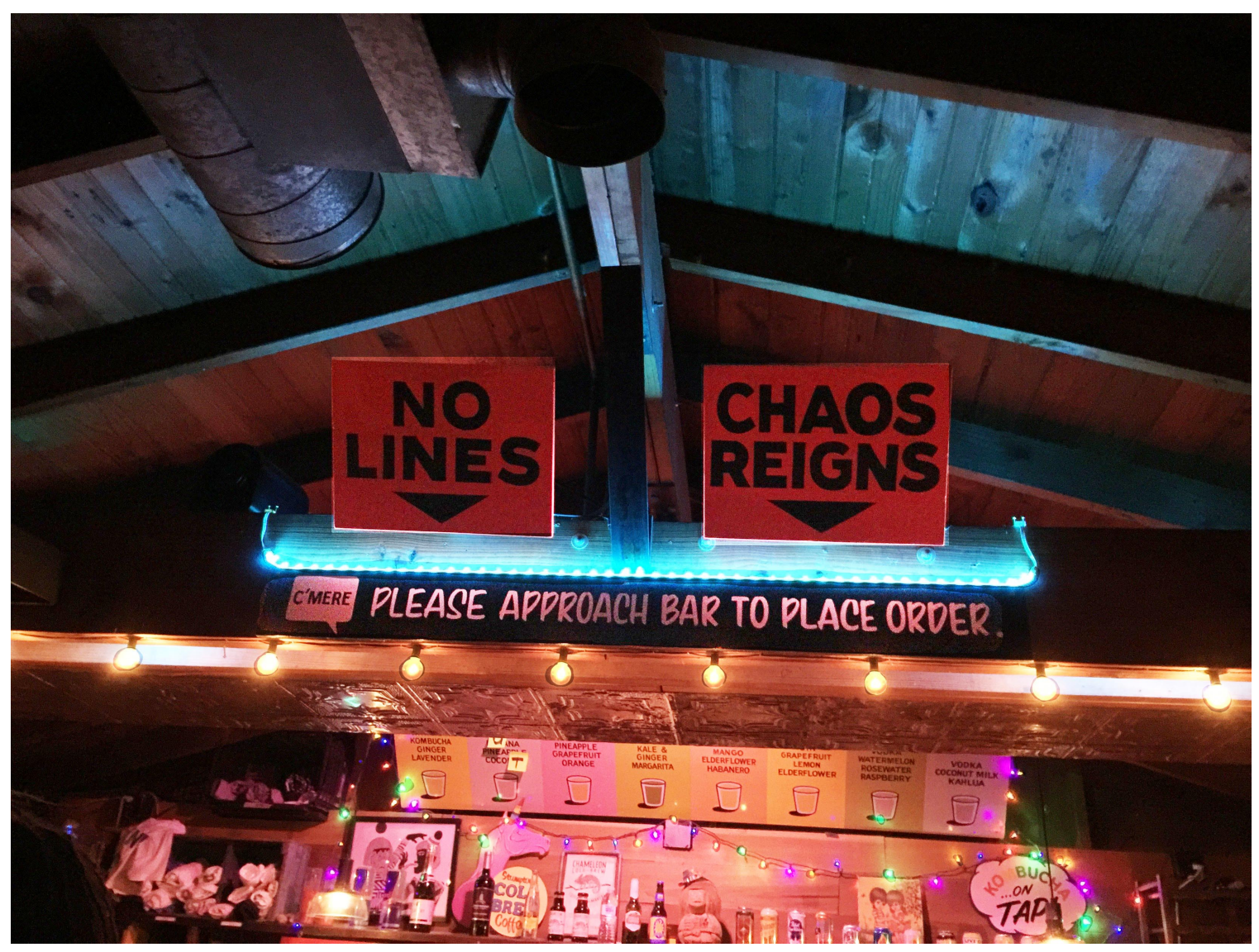

Outside, in Cheer Up Charlie's patio area, I definitely found the spiritual tonic and commended strangers that Oldenburg (1999) writes about. I could not exactly do my 
"sit down solo" test here, but elements of it still worked, in a way. All tables were taken, except for one where a woman was sitting alone. I asked her if I could sit there, and when she said it was OK, I pretended to just sit quietly. Then, she started a conversation with me - and two young men neither of us knew came to join us.

While were talking, I mentioned my love of Harry Potter, how I considered myself a hybrid of the series' Gryffindor (the brave and bold) and Ravenclaw (the intelligent and creative) houses, and that I was an academic. The young man who sat beside me, also a Harry Potter fan, joked that he would presume an academic to be in Slytherin (the ambitious, cunning, "means to an end" - has a reputation for turning out dark wizards). I promised him that there were good people among us. I was also able to let go a bit when a drunk friend of the woman who had been sitting alone came to join us, too, and when I mentioned I train in Brazilian Jiu-Jitsu and he thought it was cool, I showed him in the safest way possible without a large mat, how to do a simple takedown. I was able to let myself go - and not break my wallet in half while doing that. Besides the fact that the bar had no cover that night, water was free here. At some bars and nightclubs where I had gone in other cities and in the past, water was as expensive as three-to-four dollars a bottle. Just being able to get free water was a positive for me, and, for me, conveyed that this is a far less pretentious space than some others who want to charge $\$ 3$ (or more) for water, plus not allow goofy Harry Potter fans to demonstrate JiuJitsu moves. The place was shabby, with old wooden picnic tables, but it was well-lit, and, according to the notes I wrote that night, "It wasn't a rowdy, obscene place where people were busting beer bottles over each others' heads." I felt safe there in the physical sense too, and judging from anything from the décor to the lighting, I believed that the 
owners were working to ensure that feeling (and reality) for their patrons. It was like Lily, an advocate, mentioned in my interview with her in which she said the Red River owners were working to keep the shabby, casual feel but make sure the venues are clean and safe, with elements such as good lighting.

While outside in Red River, I took note of a "word mural" the Elysium nightclub's outside wall. Figures 8.13 and 8.14 are photos I took of the mural, which I had to do in more that one shot because of its size and the area being on a slight incline.

Figure 8.13: Elysium word mural, left side (Pridemore, 2017)

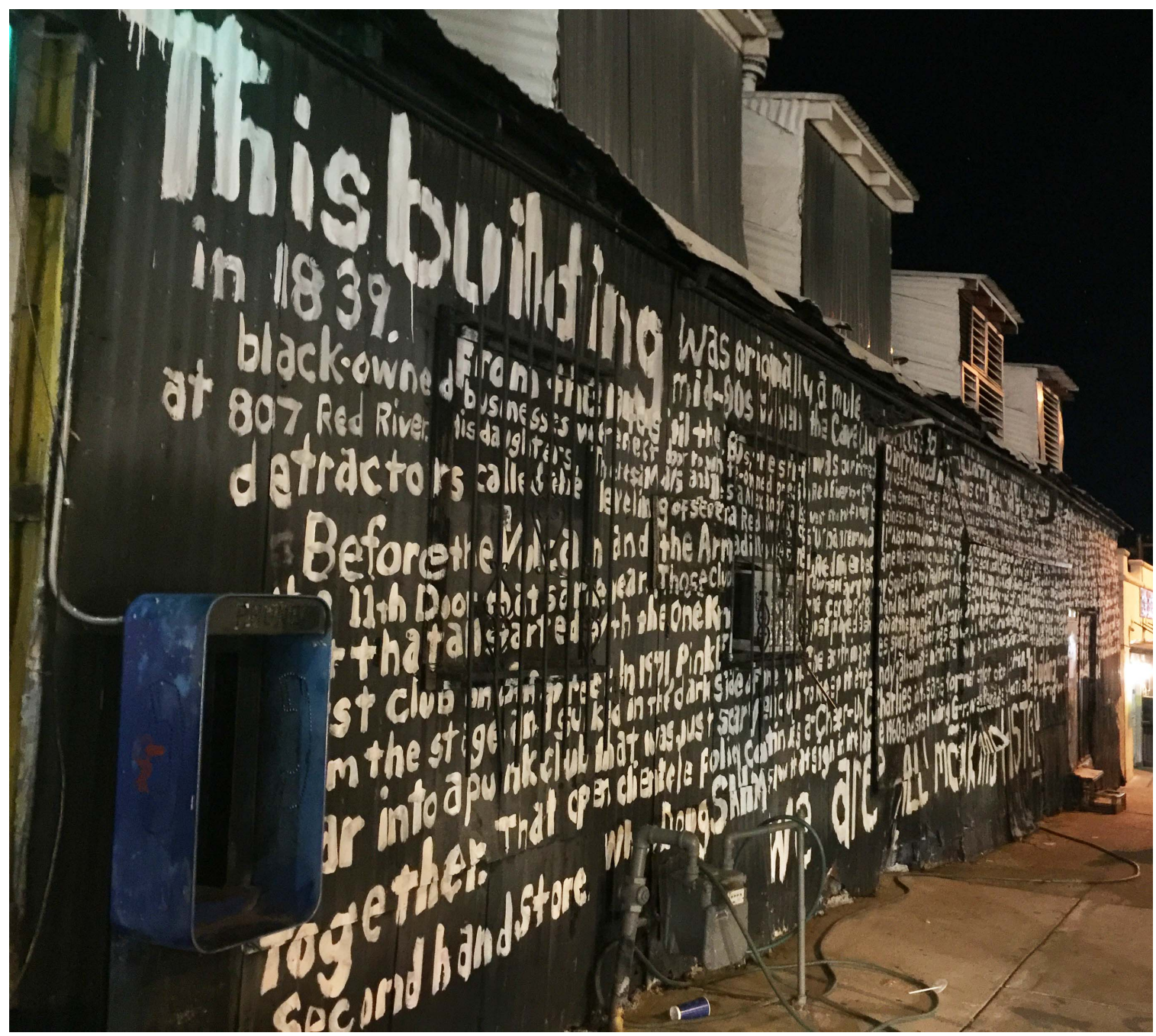


Figure 8.14: Elysium word mural, right side (Pridemore, 2017)

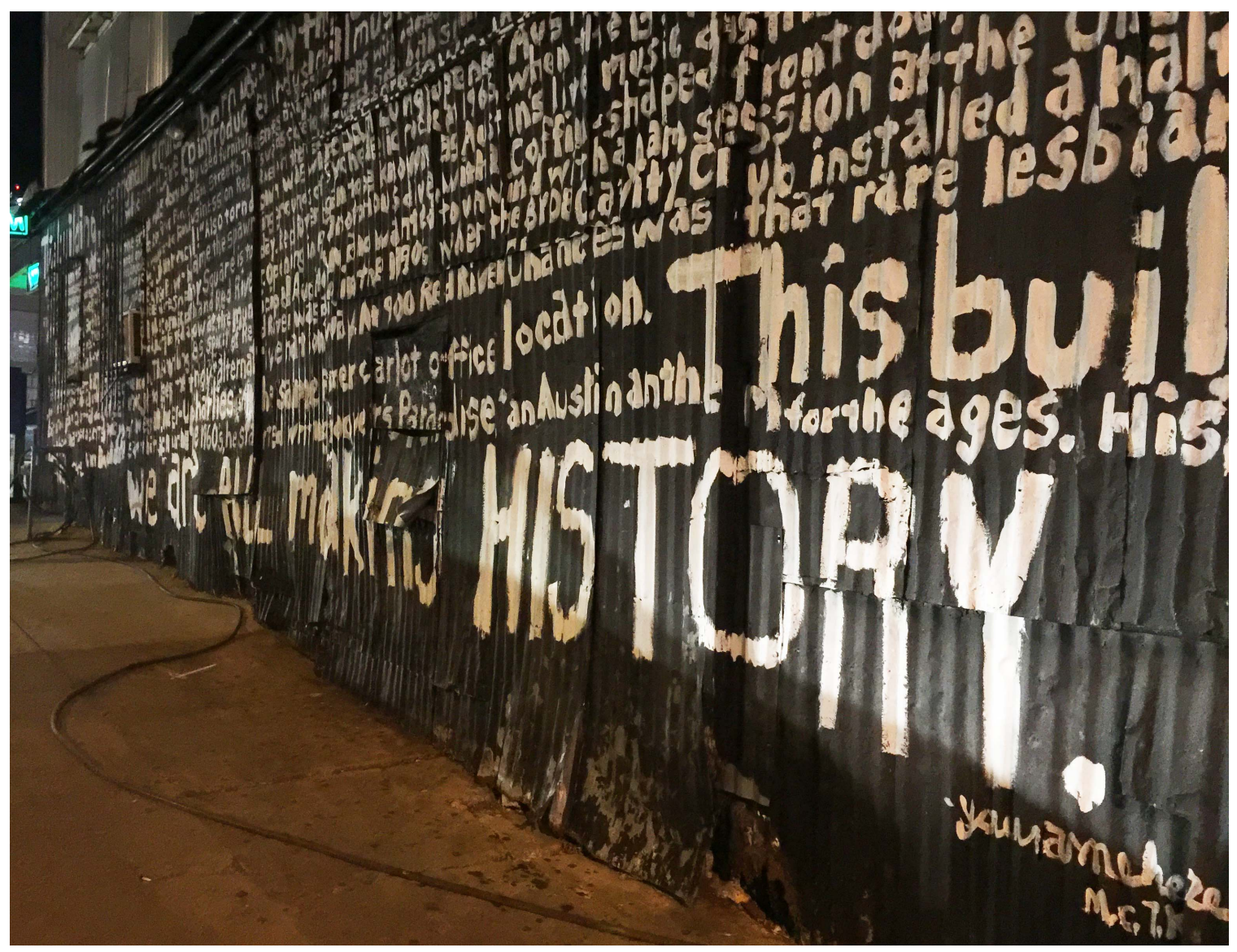

The mural, done by artist Tim Kerr (City of Austin, 2017a; Goldenstein, 2017b) is

one that literally tells the story of the Red River district's history, with the full text shown below.

This building was originally a mule barn, used by the U.S. Army during WWI, housed various secondhand stores, and then live music venues since the mid-80s when the Cave Club introduced industrial music to Texas. Red River Street was the eastern edge of Austin when the street plan was laid out by Edwin Waller in 1839. Because it was flat, not uphill from Sixth, it became a major N-S thoroughfare. From the 1940 s 'til the ' 80 s, the strip was dominated by used furniture stores and junk shops with names like J.B. Branton, Williams Do-Rite Swap Shop, Fairyland Antiques, Dutch Meyer's Trading Post, Red River Rats, and Hurt's Hunting Grounds.

During the era of segregation, black-owned businesses were next door to whiteowned ones on Red River from Sixth to 15th Streets. This was as close to the East Side, both spiritually and physically, as you could get in downtown Austin. Simon 
Sidle, a son of freed slaves, helped establish Red River as "antique row" when he opened his first shop in 1917 at 807 Red River. His daughters Theresa Mays and Ilesta Alexander also went into the family business, but their shops were torn down in the early ' 70 s as part of the Brackenridge Urban Renewal Project. Since many of the displaced businesses were black-owned, detractors called the leveling of several Red River blocks "urban removal." Also torn down was the building at 1128 RR where Sam Lung, whose Cantonese father moved to Texas in the 1890s to work building railroads, opened Austin's first Chinese restaurant in 1946. Lung's Chinese Kitchen gave birth to Austin's ethnic/exotic food scene.

Before the Vulcan and the Armadillo opened, Red River was the spawning ground of psychedelic rock in 1966, when the 13th Floor Elevators debuted their first single "You're Gonna Miss Me" at the New Orleans Club. Janis Joplin sang just steps away at the 11 th Door that same year. Those clubs were where Symphony Square is today. Red River began to be known as Austin's live music district in the 1990s, with Emo's and 801 Red River leading the way for the Mohawk, Beerland, Club DeVille and others, but that all started with the One Knite at 801 Red River. Opening in 1970, the notorious dive with a coffin-shaped front door, hosted the Vaughan brothers and other blues savants years before Clifford Antone opened his first club on Sixth Street. In 1971, Pink Floyd had just played a show at the Municipal Auditorium and wanted to unwind with a jam session at the One Knite. When they said they didn't know any Freddie King, they were turned away from the stage and sulked in the dark side of the room.

The anything goes spirit of Red River was alive in the 1990s, when the BYOB Cavity Club installed a half-pipe for skateboarders. Miss Laura of the Blue Flamingo turned her drag bar into a punk club that was just scary enough to keep the trendy "alternative nation" away. At 900 Red River, Chances was that rare lesbian bar that booked indie rock bands, a wild hybrid that brought different cultures together. That open clientele policy continues at Cheer-Up Charlie's in the same former car lot office location. This building, the current Elysium, was once the home of Snooper's Paradise secondhand store. When Doug Sahm saw that sign in the late '60s, he started writing "Groover's Paradise," an Austin anthem for the ages.

History never gets old. Time is time was NOW. We ARE ALL MAKING HISTORY (Kerr, 2017; as cited in the City of Austin, 2017a; Observation, 2017).

During an observation at South-by-Southwest, a Red River venue owner explained that the district as it stands now had "accidental" success namely in that the buildings were abandoned former brothels and stables that certain people decided were ideal and affordable spaces for live music. I did some digging in secondary sources after 
arriving home from my observation at Cheer Up Charlie's to find out some context behind why this mural was done in this fashion and about what it had to say. Tim Kerr, an artist and musician, was asked to create a mural describing Red River's history and to be painted on Elysium, the district's oldest building (Goldenstein, 2017b). Kerr said:

When I saw it, I thought, "Man, let's not do anything to it. Let's just leave it as is, and let's just write the history in white paint." Fill the whole wall with history, and I'm pretty sure somebody's going to stop and read it (as cited in Goldenstein, 2017b).

Goldenstein's (2017b) story highlighted the district's history, particularly in terms of how it was diverse when diversity was not even legal. Plus, it highlighted work the Red River venue owners were doing to draw people in and keep their patrons there, given the economic challenges they face from the real estate market and the crime, as I mentioned in the previous chapter. My interviewees discussed why Red River was important to them, namely because of what they saw as authenticity and Austin's ownership of them, on different levels, often using words like "real" and "serious" to describe them. This included the Red River venues hosting local Austin musicians playing original music and in a walkable, multi-venue district. Furthermore, they believed it provided a much more positive contrast for the city as opposed to Sixth Street, which, among the numerous problems with "Dirty Sixth" mentioned in the previous chapter, includes it being a tourist trap that does not cater to locals. Percy, a journalist and musician, Sirius, a musician, and Lily all commented on how the locals love Red River but deride Sixth Street.

Percy: Red River is the most important thing. It's like, even as we're seeing areas of the city... East Sixth used to be a music street in the Nineties. Now, just one or 
two places have original music on the whole street. The rest of it is mostly cover bands or DJs.

Red River is so unique. I travel all the time. I've been in bands that are on tour. There are not very many places in America where there's a concentration of a whole of clubs on a street where you can walk from club, to club, to club and go to four shows in one night. It's incredibly, incredibly rare. The only reason they can do the Levitation festival, which is all in clubs, is because they're all close by.

Sirius: Especially as a local musician, I can tell you that having those more serious venues with original music is seen as very important. On Red River, we get to play original music that is more creative and just more fun for the musicians to play. It's nice for the locals too, to see their local bands play in these bars. Playing a Dirty Sixth Street gig is assumed to be really playing to tourists. Sixth Street just really is a tourist trap and kind of more of a party scene.

Lily: Red River is a place that has what I consider more serious venues, with Cheer Up Charlie's, Stubb's, and places like that, which are pretty wellestablished, get good acts, and acts that I've actually heard of. I listen to all sorts of music, but they'll get somebody in a good local band.

...Red River has real clubs who have real musicians who play things that you've heard of or from the local scene that you want to support. ... Dirty Sixth? I don't want to go to Frat Boy Land, you know?

\section{Conducive environment}

Interviewees relayed how a third place, especially one in a beloved or at least familiar and casual location, would be much more conducive meeting spaces. Their key points were comfort level and less intimidation, successful meetings at such places in the past, government making a positive statement that it "gets" the artistic community, and that gathering in such places could attract a more diverse crowd and from historically disenfranchised groups. 
During the summer of 2017, I conducted an observation at a popular live performance venue in central Austin, Spider House Café and Ballroom, that a nonprofit organization conducted. It posed the question of, "Can the tech industry save the music industry?" When I arrived at the event, I could hardly find a place to stand. The venue was small, but it was still practically wall-to-wall with people, with one of the event organizers estimating about one hundred people came, total. I eventually had to cram myself beside the sound booth in the back to be able to watch. Although Albus said that such an event typically attracts more in the tech industry because they like to network, I did meet several members of the local artistic community at this event. Some were members of the hip-hop scene, which interviewees told me is an underrepresented group even inside the artistic community itself.

Conversely, I attended a city sponsored meeting about special event permitting procedures at the new central library's auditorium in January 2018 and despite its enormous room size, I counted only thirty people there. Harsh winter weather and the meeting previously being cancelled for it could have been a factor in the low attendance, I will note. While some advocates and one venue owner did attend, I did not see any rank-and-file artistic community members there.

I also did the "sit solo" test at this meeting, and no one came to my table until one man arrived just before the meeting started. It was a city official who invited us to join a larger crowd. Before this one man arrived, I wrote in my notes, "Now, I know what it's like to feel like the stinky kid at school." At this huge auditorium, pictured below in Figure $8.15 \ldots$ 
Figure 8.15: Austin Central Library's auditorium (City of Austin, n.d.c)

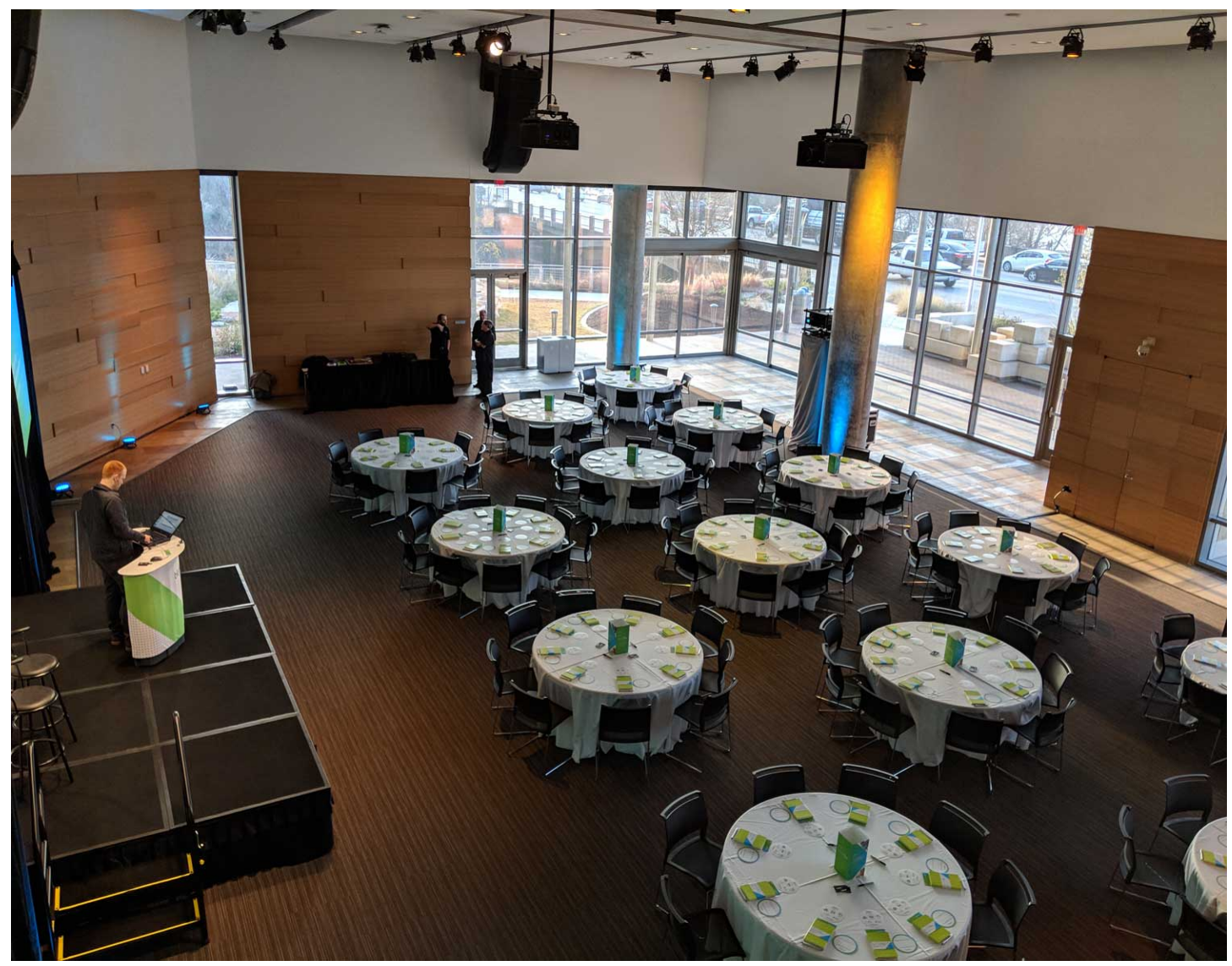

...I sat alone for quite some time until one man showed up and a city official intervened.

This was a totally different experience from when I was at the CodeNext Lego game venue pictured below in Figure 8.16... 


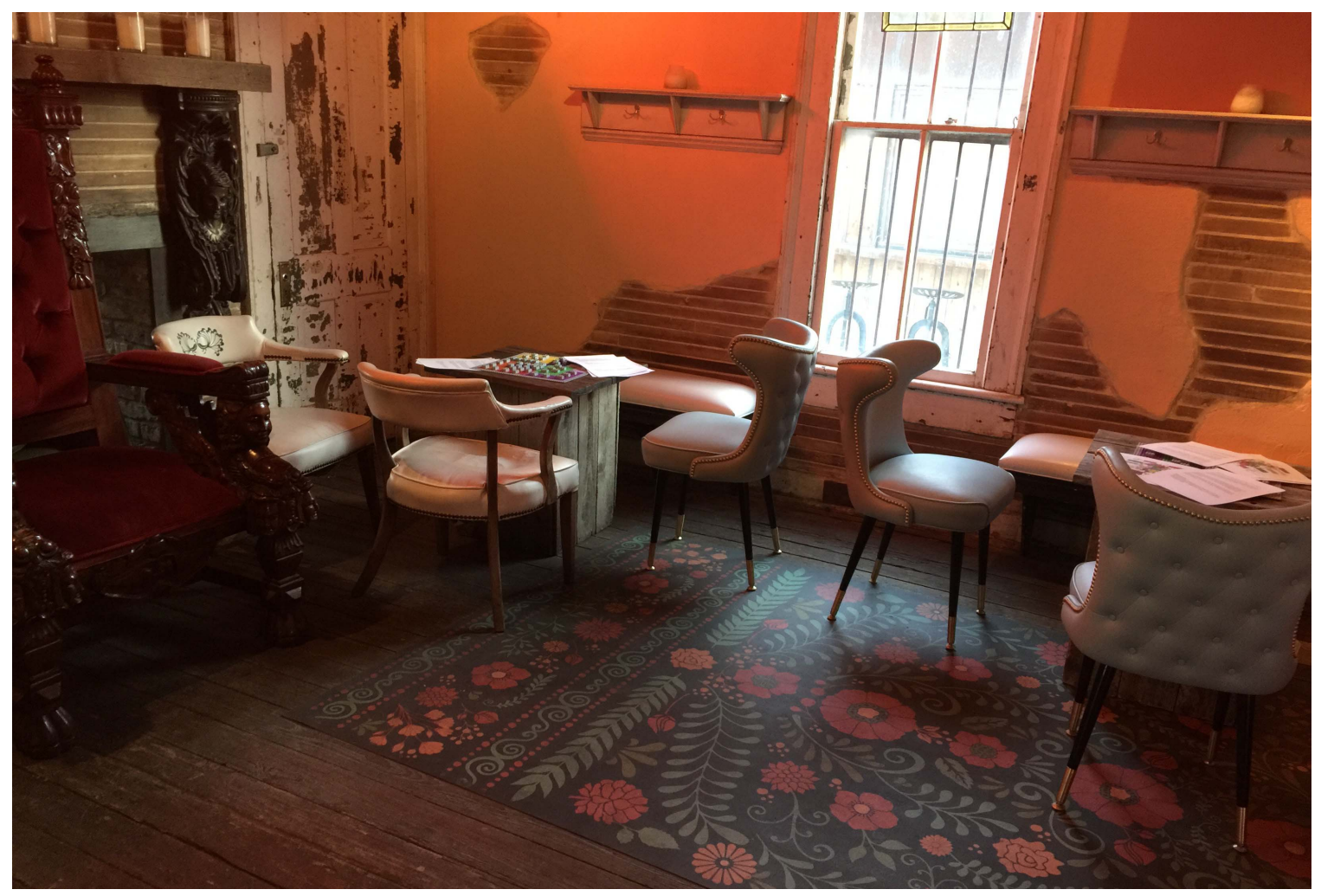

... an older neighborhood bar, where three total strangers joined me almost immediately.

I mentioned the Spider House and city library events to Hermione, who told me

Spider House was one of her favorite venues. This was her response.

Hermione: I think you've hit on something huge, which is venue. I think holding meetings in a music venue, where musicians already know where it is... They know. They've played there, and they've gone to shows there. I think it's a lot easier for people to envision going and having a conversation about something like (policy) at a venue that they're already familiar with versus this auditorium at the library or a conference room at city hall or a city building or whatever.

I think that the venue itself makes a huge difference toward accessibility for musicians. It's somewhere familiar, somewhere they are comfortable with, and there's not this additional thing of, "OK, I'm going to have to go find this city building - find the building, figure out which building it is... Then I have to go in and maybe go through security, potentially, or check in at a desk or something, and then find a room in this building... Then, what if I'm five minutes late and the meeting has already started? If I'm walking in, then, it's extra awkward because I haven't been able to find this room and this building. So I think, yeah, 
just having discussions in a familiar venue that functions already as a place musicians work will be better.

Another aspect of third places like music venues, Hermione noted, is that they're less off-putting for people in artistic communities who are averse to rigid structures. As Hermione mentioned in the previous chapter, government buildings, official policy procedures, and especially formal public hearings, for more free-form artistic community members, represent everything they abhor. A third place would be far more conducive and attractive.

Hermione: I think another one of the things that is so off-putting is this idea that this is going to be some bureaucratic meeting. It's going to be probably led by some city official. They're probably going to open stuff up for comments at some point, but it's going to be a pretty structured meeting. It's going to feel kind of slow and pointless.

Whereas, I feel like if you hear something like, "Oh, there's this conversation - a talk on this topic that's going on at Spider House," I feel like people are going to presume already that it's going to be more of a conversation. It's going to be more collaborative. They're not envisioning it being run by some city official with an agenda and they're just going dot, dot, dot, down the list. I think they are probably going to envision it as being more of the kind of free-form community conversation that they're already used to participating in.

So I think just the kind of connotation of the venue also adds a lot. You're getting away from this place that's so associated with this kind of bureaucracy and boredom and dryness and putting it into a place where people, I think, are going to expect to participate in more, actually.

A key word that Hermione used in this statement was conversation. This led to another point she and others made. During such a meeting in a third place, artistic community members would want a two-way, face-to-face, and even dialog with public officials - not a session like a public hearing or stump speech where the officials do most, if not all, of the talking. 
Hermione: In these spaces that are comfortable and familiar to musicians, they're going to expect more of an exchange of ideas rather than being talked at by an official and then maybe having a comment period. I think kind of structuring kind of an open forum would be really effective. Absolutely.

Nymphadora knew from her time as a government employee that having a forum in a third place or any place that is not government property could be dicey on two fronts. Budget-wise, the city likely gets to use facilities like the library auditorium for free. Then, in the figurative court of public opinion, “Taxpayer Number One Who Doesn't Care About Any Kind of Festival or Any Kind of Arts Situation", she said, may complain about city officials meeting certain groups outside of city facilities, and there could be even more issues if the place outside city facilities serves alcohol. However, given her past and present experience with creative people like filmmakers, she said:

Nymphadora: Meetings and meeting folks, especially for creative people who are super uncomfortable in various formal environments or kind of scary places that seem too buttoned-up or whatever... Absolutely, I think that would help. ... I think it's an amazing idea. It's all about when you're trying to find common ground.

...The library feels neutral to me. ... For event organizers in the city, having people meet at a library that's really beautiful and brand new, that kind of feels like a neutral space. Still, for organizers... If you want to get people like filmmakers and musicians in there and loop in the artists, it does skew more city friendly that it does artist-friendly. Definitely.

I mentioned Hermione's remarks about the Spider House meeting versus the one at the library, and Sirius shared her sentiments. One note that he made was that the city coming to and listening to the artistic community at a third place venue with which it is familiar would demonstrate that both the venue the artistic community loves supports this idea and that the city supports the artistic community. 
Sirius: I would totally go. I would much rather go to a meeting that was at Spider House than at a library downtown. ... One, it would be a place where I would just go to, casually. If there's nothing going on that night, I might just end up there. It's also showing that the music venue, especially one that's so known and loved like Spider House, that's loved by local musicians... If they're hosting a government's meeting, then I would feel that the venue is really supporting the cause for that meeting.

Where maybe having it at the library... It's like it's more disconnected from the music scene. ... Having it at the Mohawk or some place like that is going to, I think, be seen in a more positive light than a meeting at the library or wherever, where it's just to talk and nothing's going to happen. If it's happening at the right music venues, and it helps to impact, I think it's going to be more well-attended.

Penelope pointed out not only the comfort factor, but also the fact that

underrepresented groups, like racial minorities or artists who are somewhat on the fringe, would be more likely to come to a casual venue versus a government building. She mentioned an event she attended at the central library versus ones she has attended with a meet-up group at local venues like those in Red River.

Penelope: I remember when a community organization here recently did an event at the library. The attendance was pretty low, compared to previous ones they've had. It was still great, but they've always packed out places. Last year, they had it at Spider House, and it was the same thing. You could hardly get people who could still stand, and they had three different rooms going on at the same time.

I was talking to the woman who runs it, and she was saying that she felt like a lot of the community members felt like there was an intimidation factor in having it at the library. You know, there's police force all around, and it's pretty clean and tidy and very official and doesn't really get people feeling comfortable enough to maybe open up and talk.

...They were working with minority communities, who do feel extremely intimidated by police force. So I think that played a big factor. One of their speakers usually doesn't wear shoes. She got in trouble with the library for not wearing shoes. It's stuff like that, where it's just things that would not have happened at Spider House or another venue that would have been more OK about that sort of thing. I think they felt like it was less casual. People felt less comfortable because of that. 
...Whereas like a place like Spider House, it's just... It's more casual and laidback, like Mohawk or Cheer-Up Charlie's. I had a meet-up at Cheer Up's, actually, a couple of weeks ago. It was great. They were super-happy to have people there, and it was pretty much dead there, aside from us. So that was nice. Cheer Up's is LGBTQ friendly and much more laid back. They have the food truck there, and it was just more chill.

\section{Successful events at third places}

In Austin, such gatherings were not a hypothetical. They had been done and had worked well — sometimes, smashingly well. Some of these gatherings had managed to draw in people from the artistic community, fans, business owners, elected officials, the bureaucracy - practically everyone who needed to be involved in a conversation about how to improve the situation for the artistic community as a whole. The main attraction was when, as mentioned in an earlier section, the gatherings in the third places centered on common causes.

Ron told me that in 2016 , the city was contemplating different policy proposals related to the artistic community and had community sessions in the ten districts and at community gathering places like restaurants.

Ron: I only went to one of them, but it was fairly well-attended. I think it had about forty people, and this was one of ten they had that all had a pretty decent turnout. Yeah, that's an example of where place can matter.

In January 2018, I saw serious potential for this when I observed a benefit at the Mohawk centered on mental health called “ 'Hi, How Are You?' Day: A Celebration of Music, Art, and Mental Wellness". The key takeaway from this event was that when there is a combination of a common cause and a beloved, comfortable place, governments and artistic communities could be together in the same room, do so in a 
constructive fashion, and in the name of doing something about a serious problem the artistic community faces.

Besides what was then the newly formed Hi, How Are You Project, the Mohawk, and Austin's SIMS Foundation that focuses on musician mental health, the city's Music and Entertainment Division was a co-presenter for the event, as well (Hi, How Are You Project, 2018). The Hi, How Are You Project funds mental health awareness, research, and education and also works through "inspiring new conversations around mental health issues by funding and creating thoughtful media content, projects, and events" (as cited in Hi, How Are You Project, n.d.).

The event's inspiration came from Daniel Johnston, a legendary, underground lofi folk musician and visual artist who began his career as an Austin music scene staple and the creator of what has now become a symbol synonymous with Austin (Blackstock, 2018; Blais-Billie, 2018; Flanagan, 2018; M. Hall, 2005; Hi, How Are You Project, n.d.; Prince, 2018). During the event, local Austin musicians played covers of Johnston's songs. Likewise, Johnston, himself, symbolizes a major struggle within the artistic community that Seamus noted in the previous chapter. Johnston, like so many others in Austin's artistic community, has battled mental health issues, schizophrenia and bipolar disorder in his case, which have led to his multiple stays in psychiatric facilities (L. Berg, King \& SIMS Foundation, 2018; Blais-Billie, 2018; Flanagan, 2018; M. Hall, 2005; Hi, How Are You Project, n.d.; Personal Communication, 2018; SIMS Foundation, n.d.)

The SIMS foundation website explains why musicians, in particular, are an at-risk population (L. Berg, King \& SIMS Foundation, 2018; SIMS Foundation, n.d.) - namely with roots in the affordability crisis that has been this dissertation's roots. Research from 
the Dell Medical School's Department of Psychiatry and the SIMS Foundation indicates that "musicians who specifically reported high levels of work insecurity ... were over five times more likely to report higher levels of depression and anxiety" and that "over two thirds of those" of those this study surveyed "rated their financial stress as high or overwhelming” (L. Berg, B. King \& SIMS Foundation, 2018).

Live music is the heart and soul of Austin, but living as a musician can be a real challenge. Musicians and music professionals are at higher risk for mental illness and substance abuse, working under the stress of an unstable income, a skyrocketing cost of living, erratic tour schedules, distance from family and support, and constant proximity to drugs and alcohol (SIMS Foundation, 2018).

...Musicians have significantly higher rates of depression and suicide than the general population. Many attribute this to the often-repeated myth of the tortured artist, which assumes musicians are assisted in their creativity by despair and pain and embrace emotional suffering as a prerequisite to musical inspiration. What most people do not appreciate is that musicians struggle with multiple work stressors, including unpredictable work opportunities, low wages, and holding multiple jobs to support their music careers (L. Berg, B. King, \& SIMS Foundation, 2018).

Some of Johnston's visual art has become synonymous with Austin, as a whole. Johnston drew a frog named "Jeremiah the Innocent" for the cover of his 1983 cassette album Hi, How Are You: The Unfinished Album (Blackstock, 2018; Flanagan, 2018; Prince, 2018). A photo of the frog is below in Figure 8.17. 
Figure 8.17: Daniel Johnston's frog drawing (Johnston, n.d.)

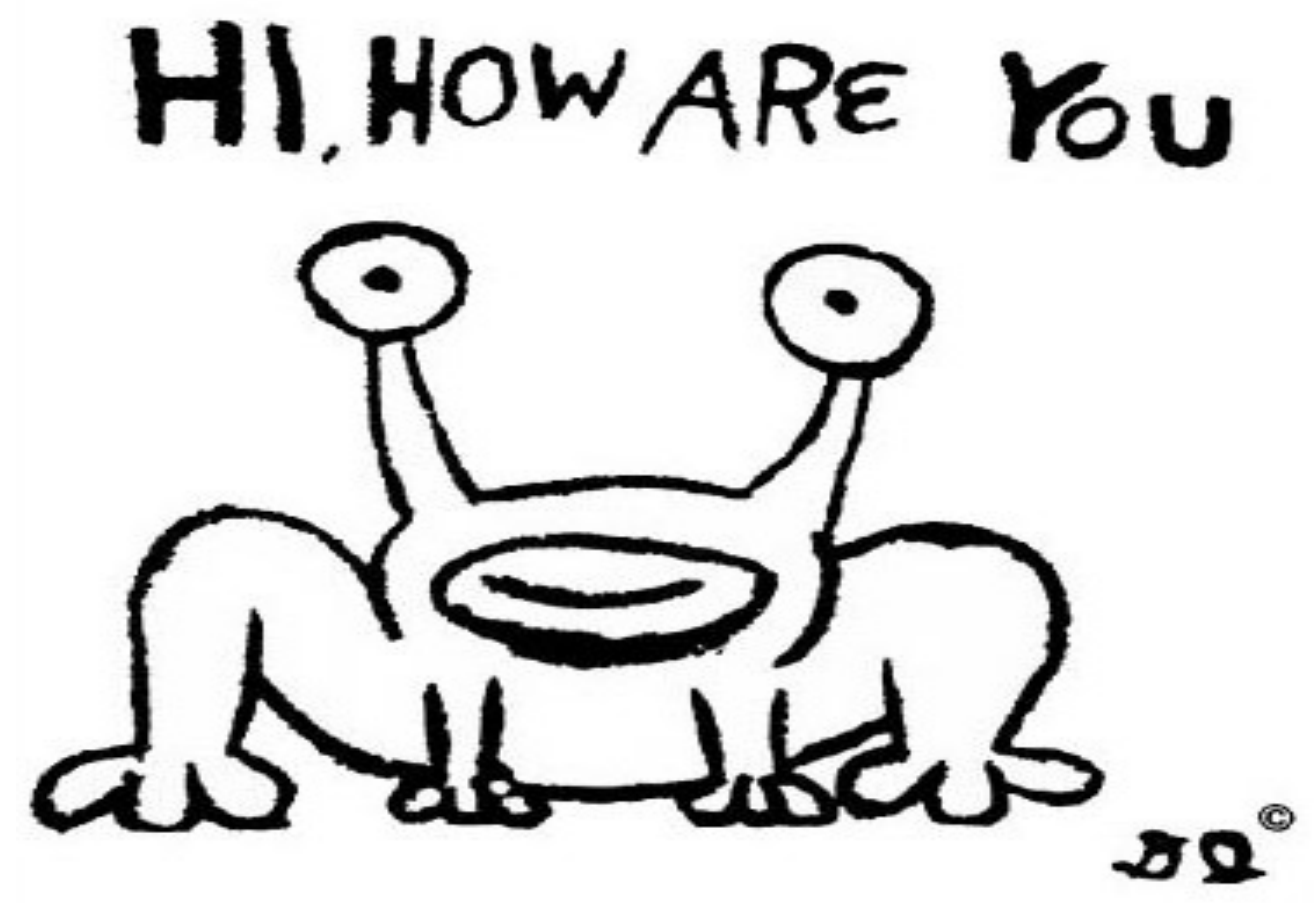

Jeremiah appeared on t-shirts that later exploded in popularity. The late Nirvana frontman Kurt Cobain became a fan of Johnston's work (Gotrich, 2011) and wore a shirt with the iconic frog on it at the MTV Video Music Awards in 1992, at the height of Nirvana's fame, and wore the same shirt at photo shoots (M. Hall, 2005). This sparked greater and national interest in Johnston's work. One year after this, the Sound Exchange record store on the corner of $21^{\text {st }}$ and Guadalupe streets, which sold Johnston's cassettes, commissioned Johnston to make a mural of his music — and Johnston painted Jeremiah on the store's outside brick wall (Blackstock, 2018; Prince, 2018). Jeremiah, like Johnston, became an icon of the Austin music scene, and arguably, the city as a whole (Hi, How Are You Day, n.d.; Prince, 2018). The mural I observed and photographed later is pictured below in Figure 8.18, along with a statement from Mayor Steve Adler about 
its meaning that goes beyond visual art — one he said, at the event, shows so much about "who we are" as a city.

Figure 8.18: Daniel Johnston's frog mural (Pridemore, 2018)

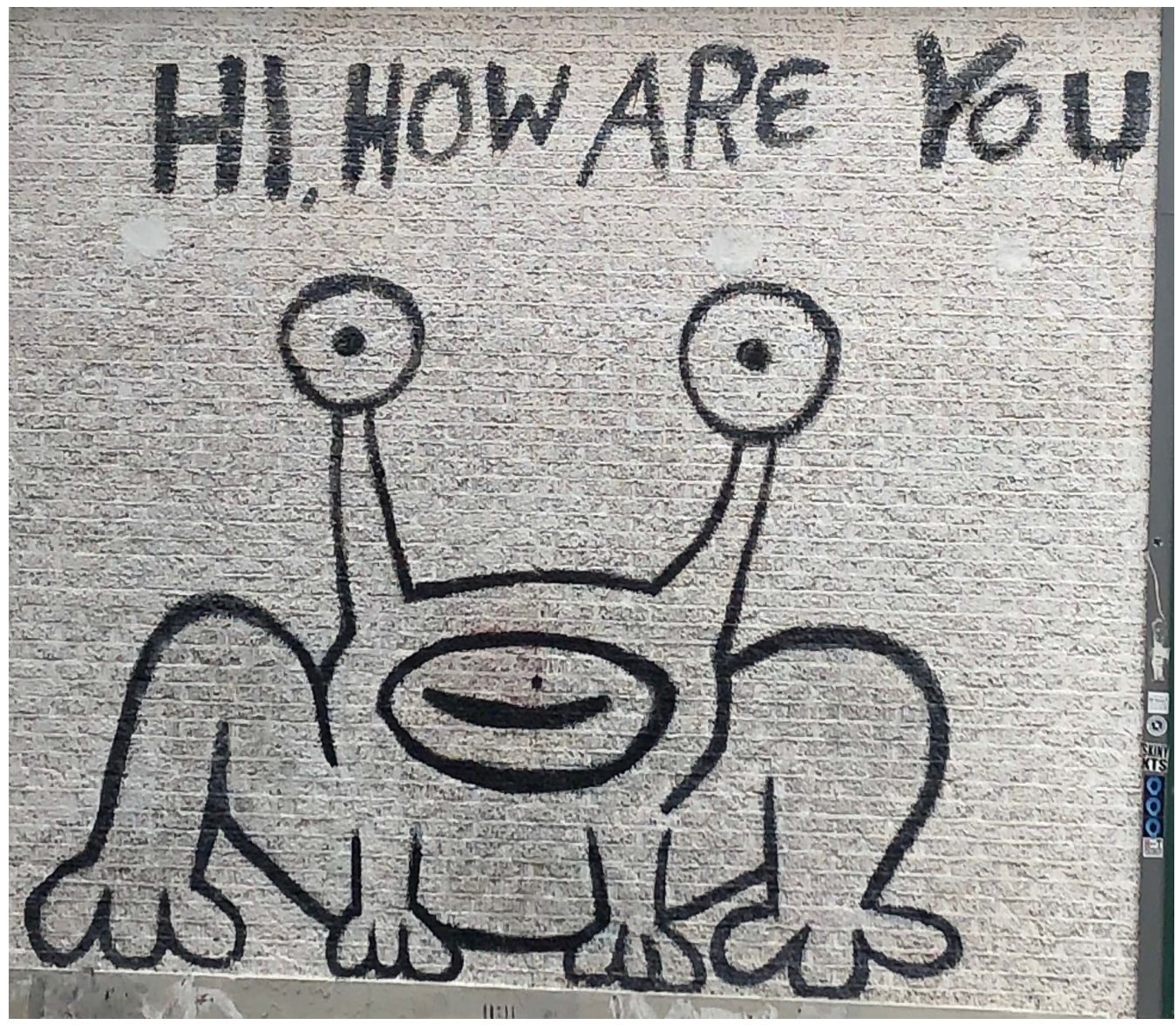

"Hi, How Are You?" is more than one of Austin's most iconic murals. It's a reminder to reach out to our friends and neighbors to see if they're OK, and for those experiencing mental health issues, it's a reminder that you've got a whole community that can handle an honest answer because we want to help you get the help you need (as cited in Flanagan, 2018).

Community organization kept the frog mural alive. Sound Exchange went out of business and a restaurant named Baja Shrimp moved into its space and intended to remove the mural (Prince, 2018). Incensed locals banded together to save the mural that had so much historical resonance within the local community. When the local pressure 
became too much, Baja Shrimp left the building, leaving Jeremiah unscathed. The owner of a Thai restaurant that now occupies the building, called "Thai, How Are You?" not only witnessed how that mural impacted his business success, but he also decided to pay licensing fees for use of the image. Jeremiah the Innocent can now be found in multiple Austin locations, such as at the bottom of this sidewalk art in downtown in Figure 8.19 that I observed during South-By-Southwest in March 2018.

Figure 8.19: Daniel Johnston's frog at bottom of SXSW mural (Pridemore, 2018)

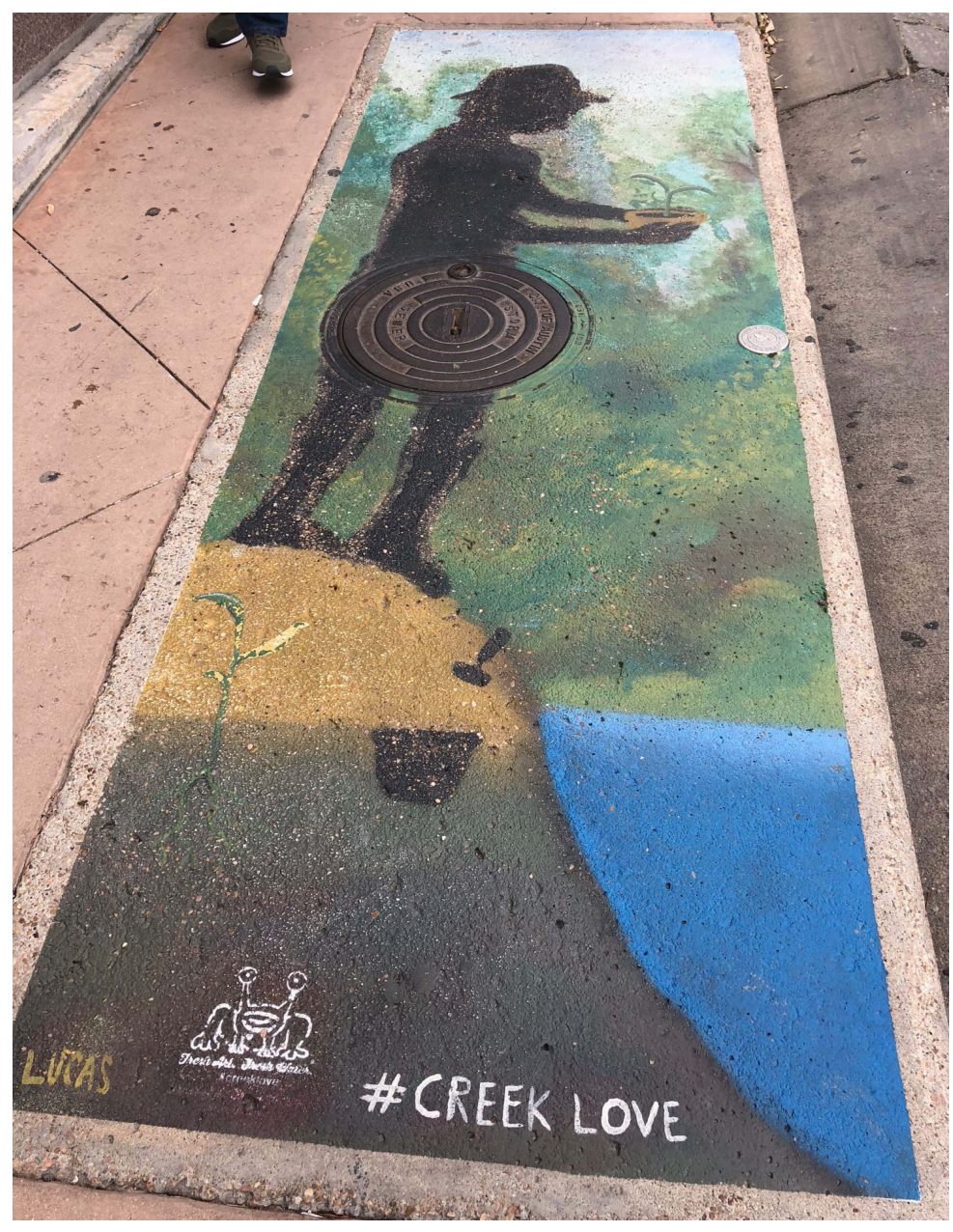


The frog also made it onto the event's sign and it became the evening's cake for

Daniel Johnston, whose birthday was on that date (Staff Writer, 2018a). The sign and the cake are shown below in Figures 8.20 and 8.21.

Figure 8.20: Hi, How Are You Day sign, with frog (Pridemore, 2018)

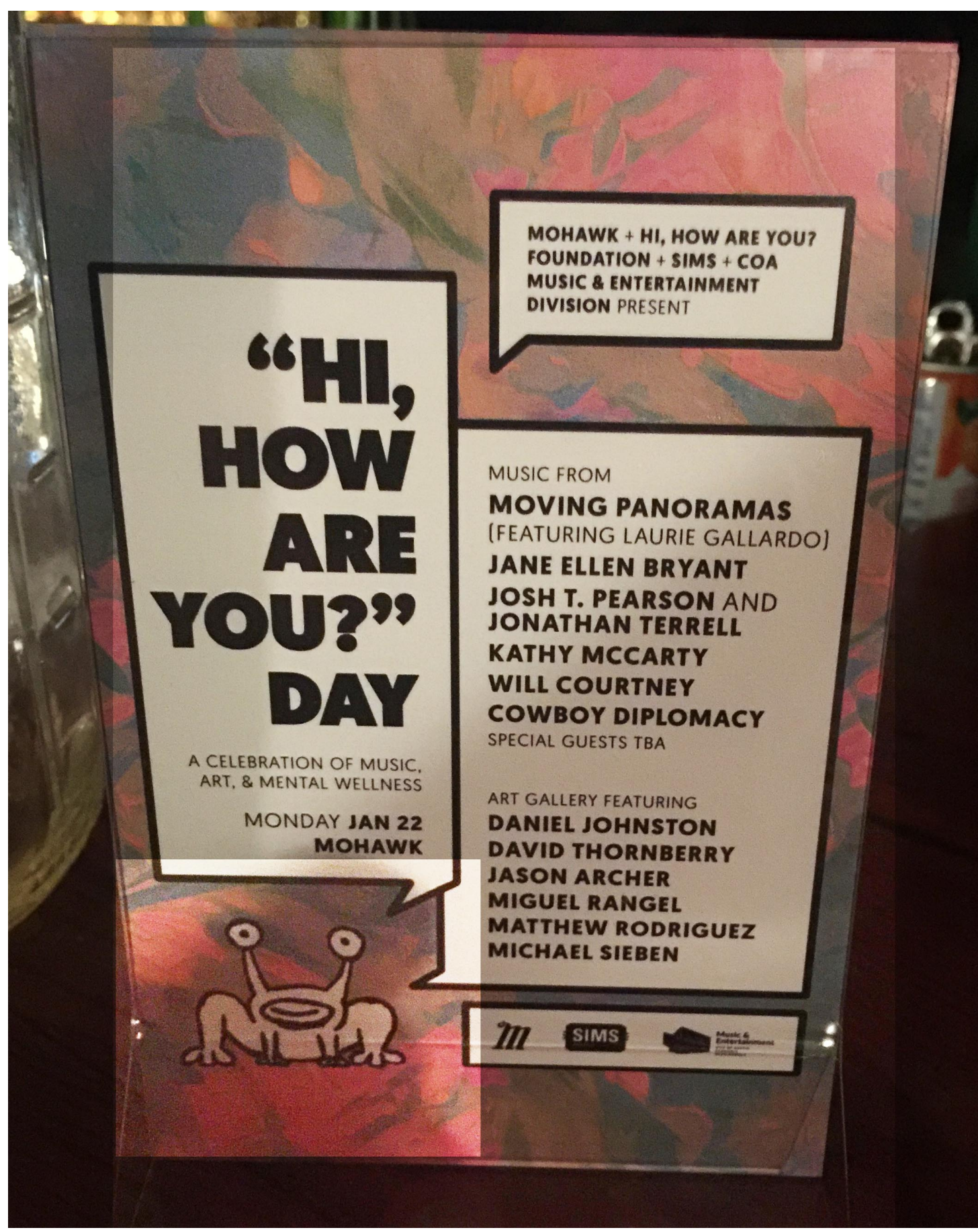


Figure 8.21: Hi, How Are You Day frog cake (Pridemore, 2018)

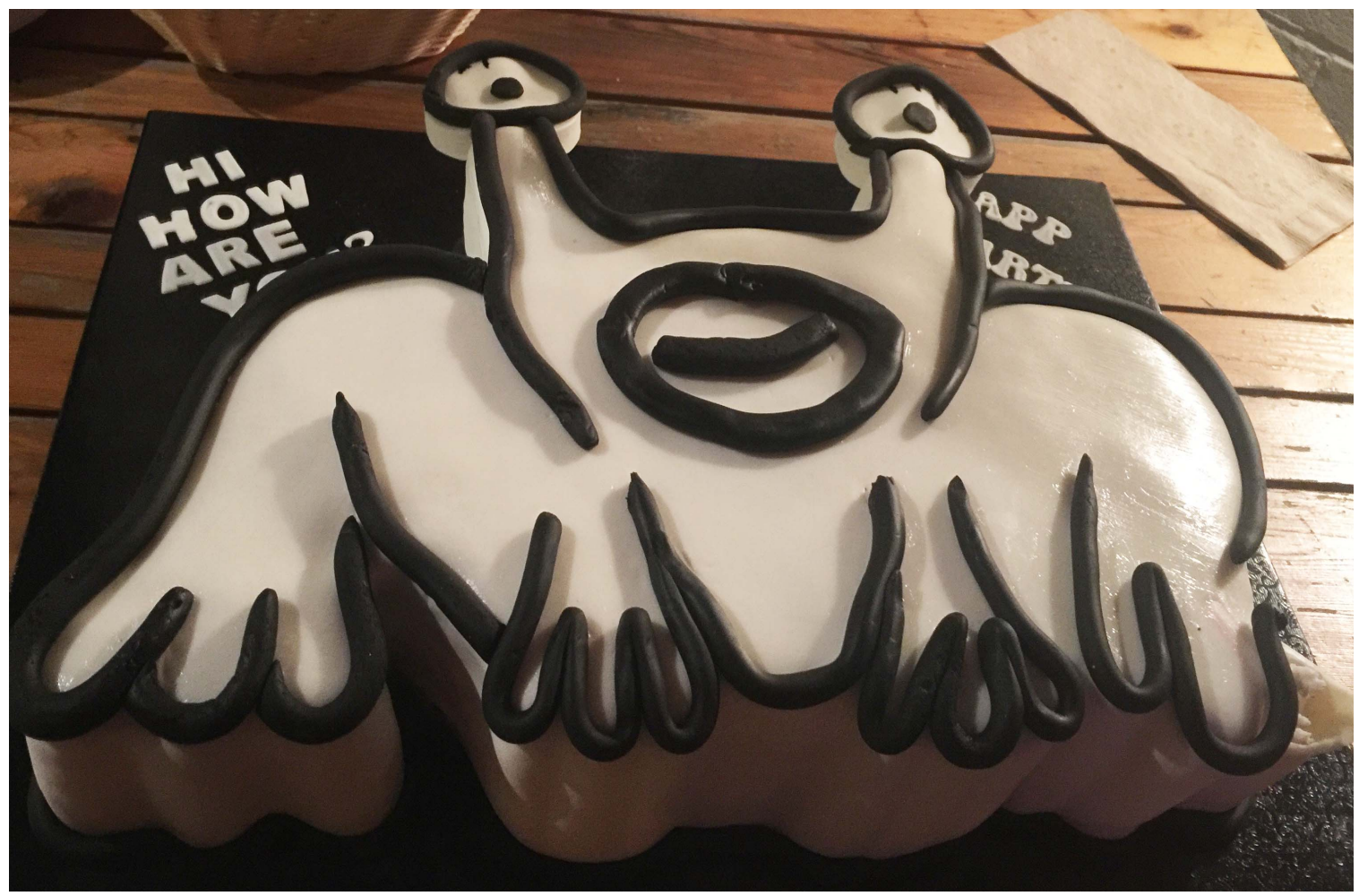

At the Mohawk, I found a group, who, judging on the surface, would normally never associate with one another, and yet they were all gathered in the same music venue for the same cause. While I was at the event, I made sure to work to blend in with the crowd as much as possible, so I would not alter the observation's conditions. Given the Mohawk was a causal and musical venue, I opted to wear a heavily DIY-altered Alice in Chains T-shirt and jeans with a slight bleach stain, but after I arrived, I saw that I could have worn just about anything that was not terribly, terribly dressy to fit in with this crowd. The only way I could have fit in more was wearing one of the shirts featuring Jeremiah the Innocent, which at least half of this crowd of people practically from age twenty to age eighty was wearing. 
Practically anyone who needed to be involved in a greater conversation about anything involving the artistic community and the issues it faces was present - the Music and Entertainment Division's employees, elected officials, representatives from major nonprofit organizations, local-favorite musicians, and fans. Pieces from local visual artists were being sold in an adjoining room. Judging from who I saw as I intermingled with the crowd, I saw anyone from people in their early 20 s wearing clothes even more DIY than my own to elderly people, including a few men with waist-length white beards, plus some people in business suits or more high-end casual clothes. Some photos of the crowds, on multiple levels of the Mohawk's outdoor space, and performers are shown below in Figures 8.22, 8.23, and 8.24.

Figure 8.22: Overview, Mohawk, Hi How Are You Day (Pridemore, 2018)

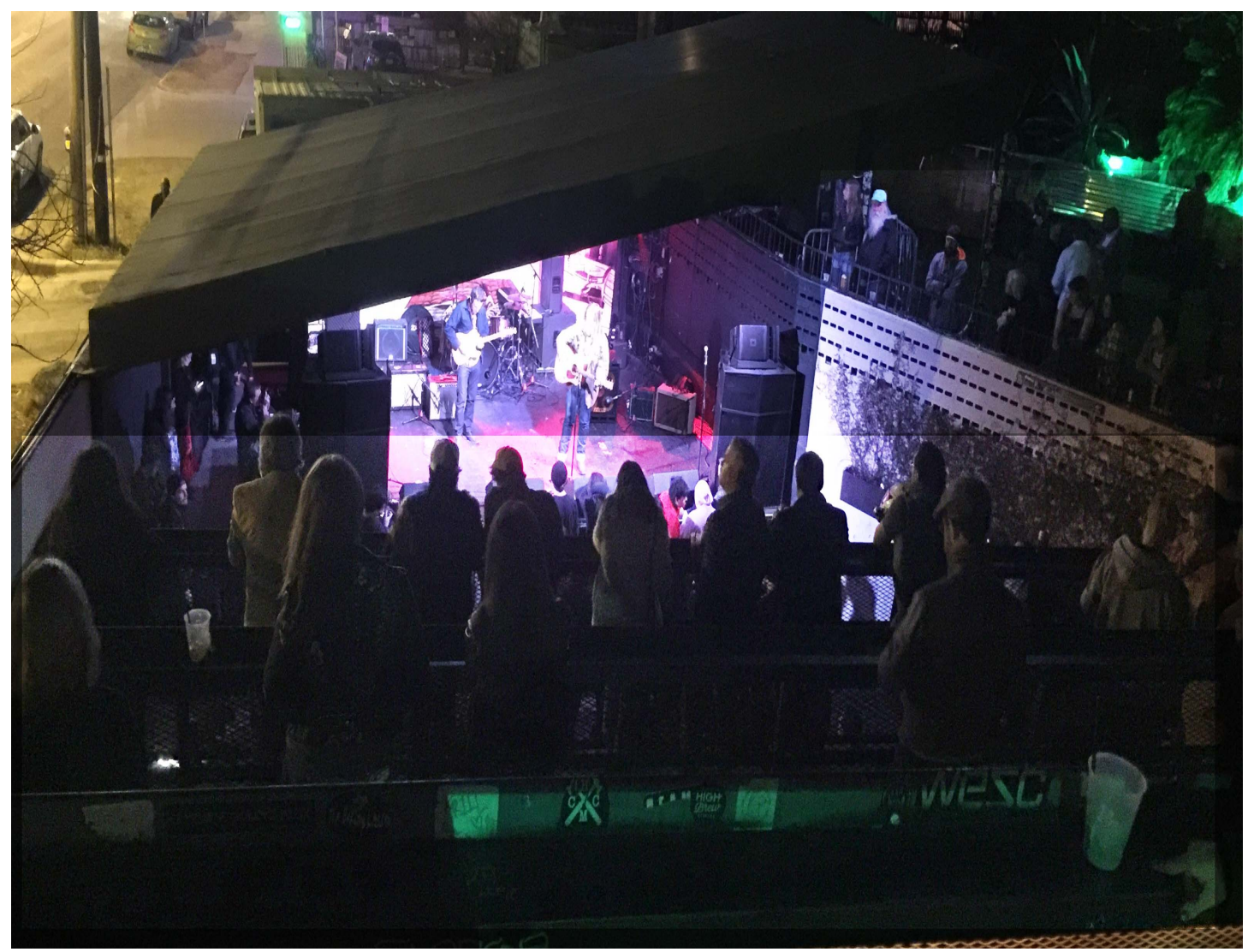


Figure 8.23: Ground level concert pit, Mohawk (Pridemore, 2018)

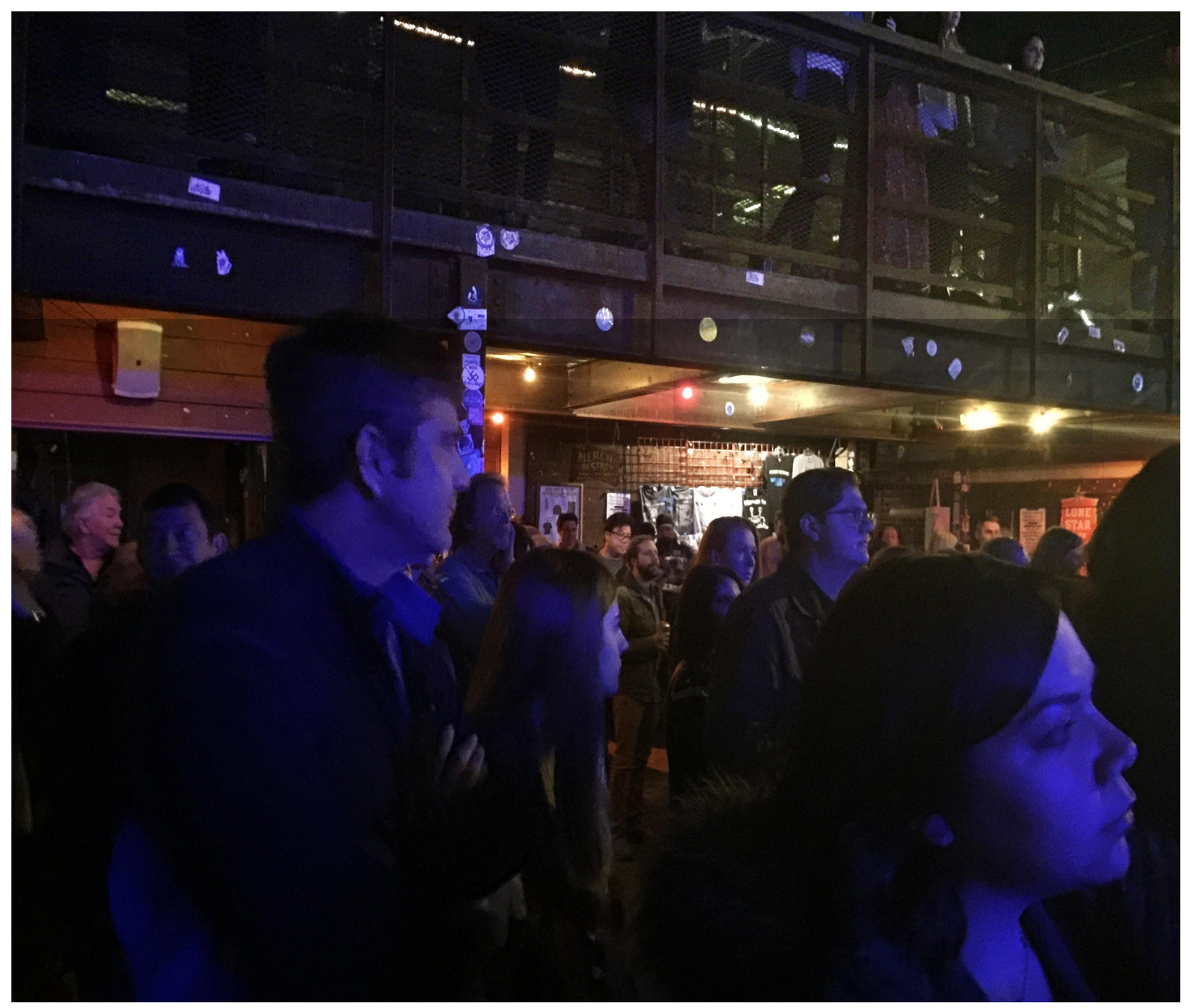


Figure 8.24: Band and crowd, Mohawk, Hi How Are You Day (Pridemore, 2018)

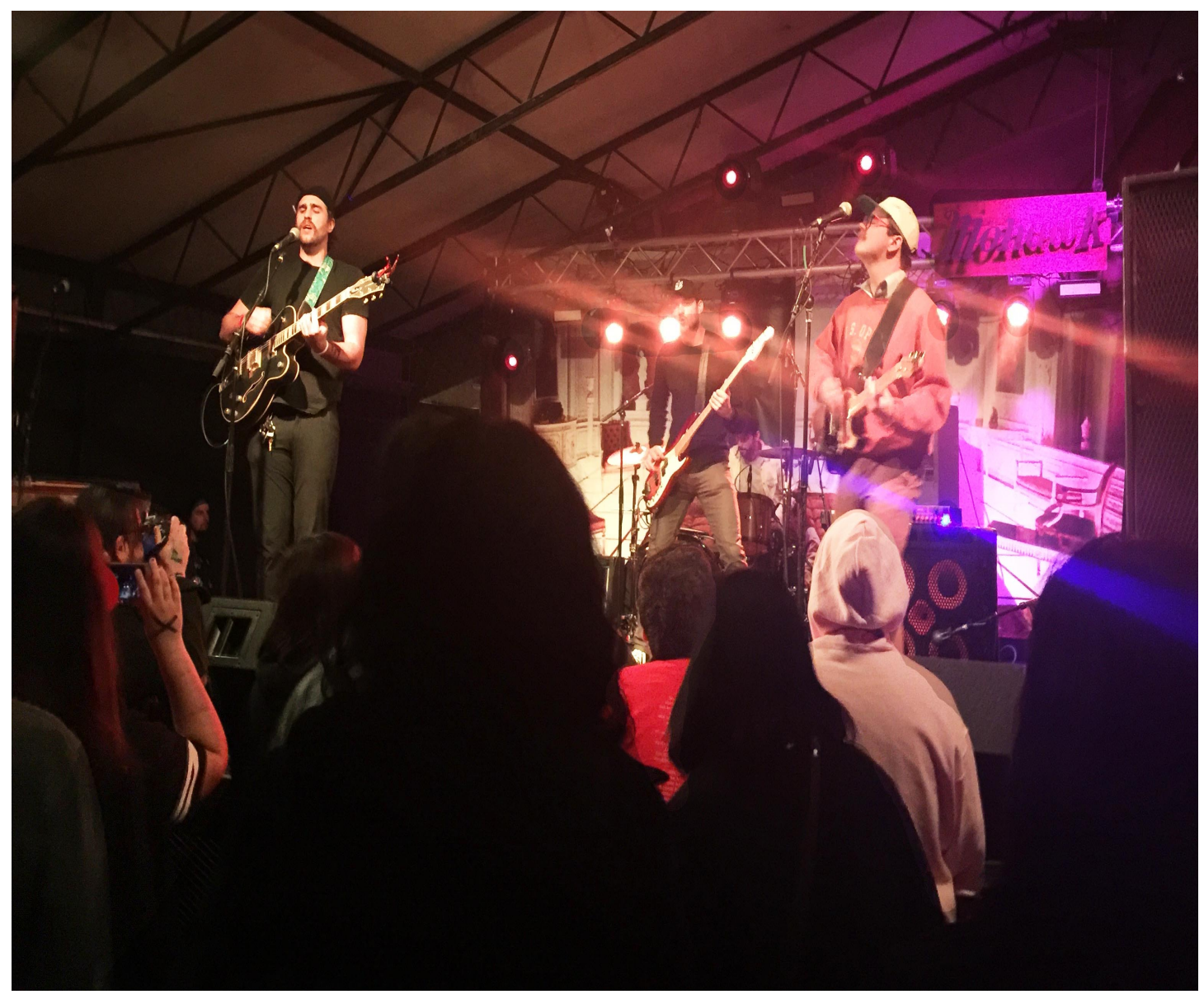

I found a group who was also extremely open and not closed-off to an "outsider". If I found myself in a conversation, I was almost never the one who started it. Also being mindful of a situation I did not want to alter, I kept my notepad hidden except during times I was walking to different areas of the venue or the few times I was alone. In doing this, I also made sure to stand in the middle of the concert's pit (General admission "pit" style is when there are no chairs and people simply stand when and where they find a space.) when in front of the main stage area, rather than a corner alone. This not only showed the crowd I was "all in" but also the fact that I was watching them was far less obvious. 
Not bringing up the subject myself, I had some people tell me about their own struggles with mental health or that of their friends or family members. Some attendees, particularly younger ones, excitedly asked me if I was a Daniel Johnston fan. The fact that I had learned about Daniel Johnston's work from Canadian singer-songwriter Matthew Good, who had covered Johnston's "True Love Will Find You in the End" on his Hospital Music album Good had recorded after his own bipolar diagnosis (Newton, 2007) seemed to really resonate with those with whom I spoke, particularly when it was someone younger or another musician - even more so than my being a musician, myself, in this situation. I also had no trouble socializing with the more professional crowd, either, with several of them asking me about my research after one saw me attempting to take a selfie with the Mohawk's dead stuffed bear. That led to a lively conversation with his friends and him.

Like Alastor mentioned earlier, about how heartening it was for local artistic community members to see government officials out at their shows, and how the interviewees wanted to see government officials to come to the venues and see shows, the city government did that. Multiple officials did attend this event, including Adler, who proclaimed that day, "Hi, How Are You? Day" in Austin, alongside Johnston and Hi, How Are You Project creators Courtney Blanton and Tom Gimbel. Figure 8.25 below is a photo of that moment, with Adler speaking at the far left and Johnston in the foreground and at the far right. Blanton is the second from the right and Gimbel is between Blanton and Johnston. 
Figure 8.25: Mayor, organizers, Hi How Are You Day (Pridemore, 2018)

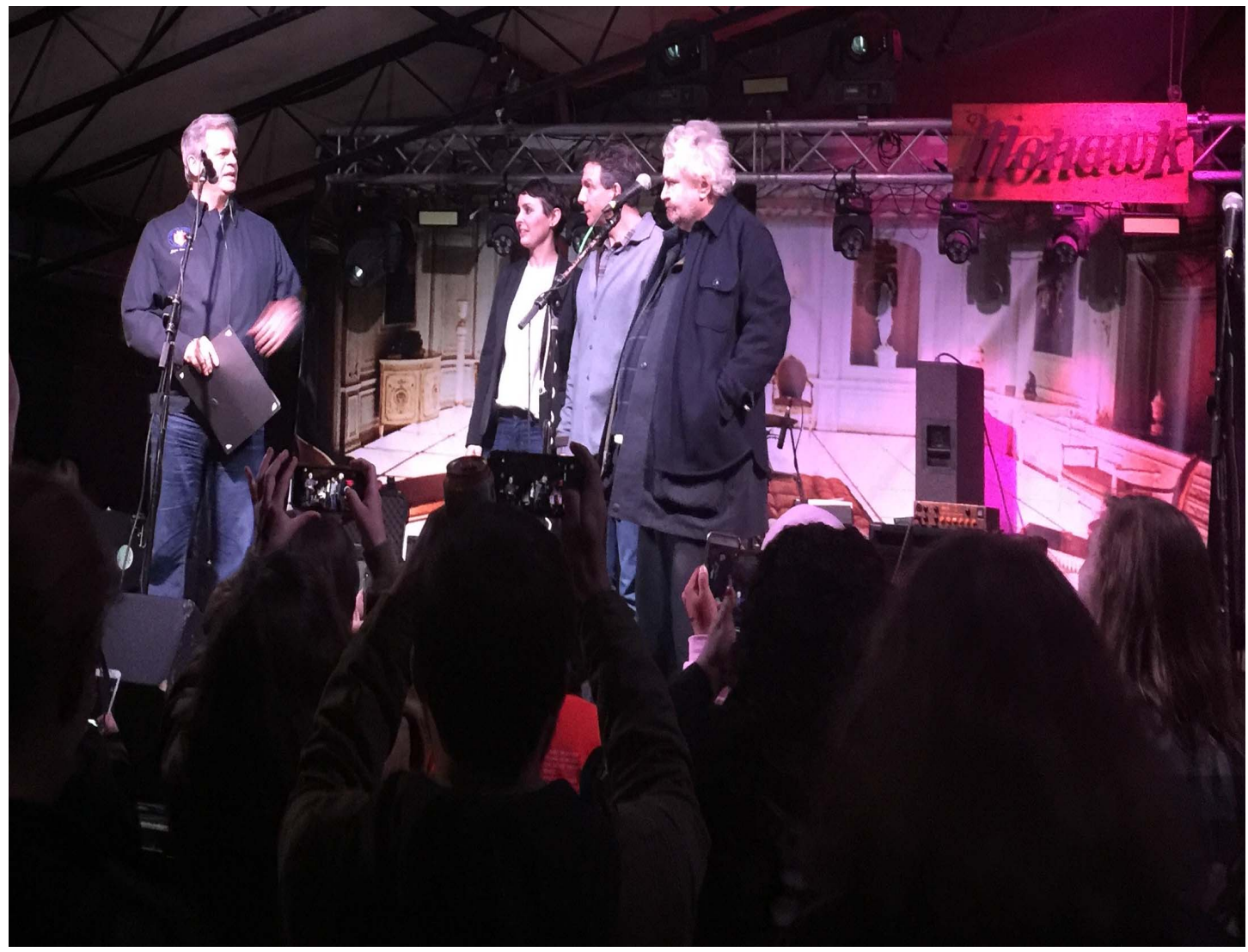

Visual art also made it to the forefront, namely with original works from multiple artists that included Johnston being sold to benefit the project and available for viewing throughout the evening. Some of the Johnston drawings I observed are shown below in Figures 8.26 and 8.27. 
Figure 8.26: Johnston's art, auction (Pridemore, 2018)

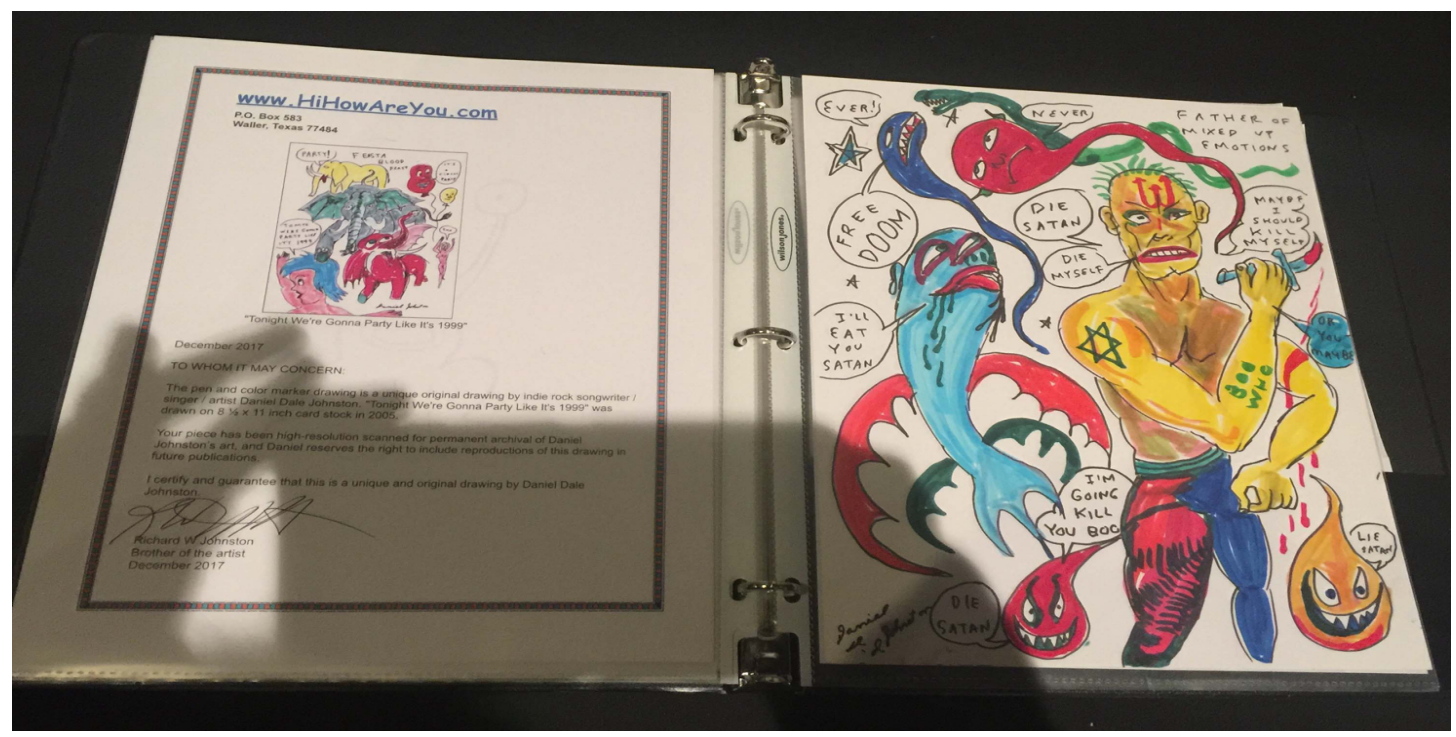

Figure 8.27: Johnston's art, auction (Pridemore, 2018)

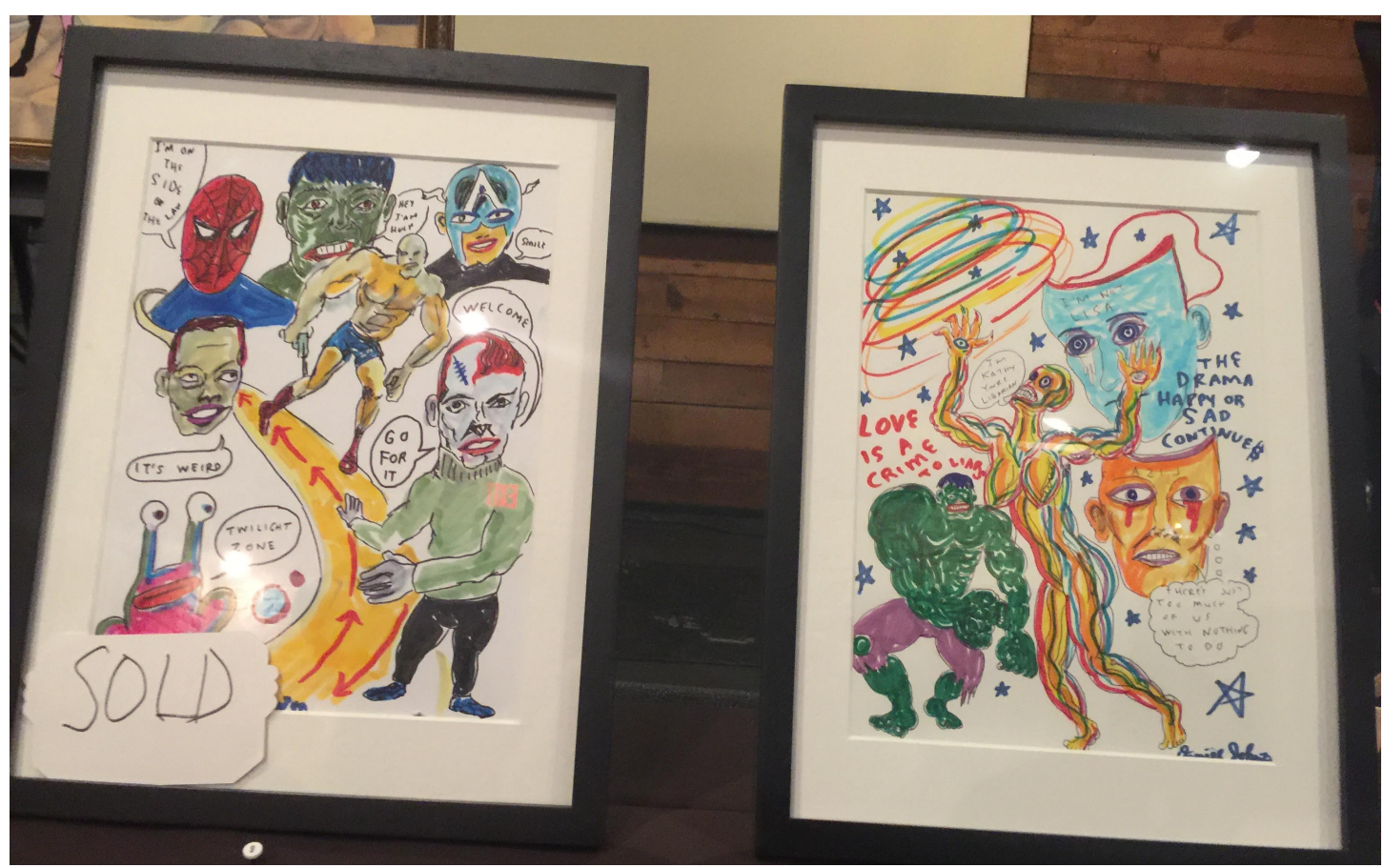


When I would walk away for some moments when I was largely alone, some of the notes I wrote that night included:

This is it!

The Mohawk's sign says, "All are welcome." I see that's definitely the case here tonight. Everyone is welcome here. Everyone wants to be here. The government, both elected and bureaucratic, the rich and the poor, the younger and the older... They're all here. They all give a damn. They're in the right PLACE.

During my interview with him, I asked Albus about whether or not he believed a more casual venue and one popular with the artistic community would be more conducive. Albus mentioned that he had been at this same event at the Mohawk, himself. While he still questioned whether or not a meet-up about policy would bring out a crowd, especially one as large and diverse as the one that came to the Mohawk, he believed it would be a starting point. He noted that the Mohawk event provided entertainment, and a meet-up that provided this in spots could possibly attract a younger crowd.

Albus: That was an excellent example at the Mohawk. Yeah, I was hanging out with people from the city music office, and I talked to the mayor, and it was a very mixed crowd.

...Amelia: Do you think that's an example of how a casual event and just a casual venue alone can be the spark that brings people together?

Albus: Yes. The question is, "Could this bring them together for a meeting?" It's one thing about going to a fundraiser or an arts performance or music performed, a live music performance. It's another thing if they're going to discuss the policy about the sound ordinance or parking requirements and whether we're going to allow busking and to what extent artists can sell stuff out of their own homes. And there is all of the bevy of the large number of individual issues that are important to artists and musicians.

...There was this thing I went to... They actually had in the set list, for the set times for the different performers, a little five-minute slot for a chemist to get up there and give a talk about the research that she's doing in psychedelic medicine. This guy I talked to there was just chatting up someone. He was telling me about 
what a fan he is of organization maps, which have been around since 1986, that I've never heard of before. But I went because I liked the bands that were performing and I love the venue, the Barracuda.

...Amelia: So maybe you kind of bait them with the music but, in turn, also have a discussion about mental health, scientific research, or whatever it may be?

Albus: Yeah. Yeah.

Two other moments struck me during the event, in terms of what I was studying with this dissertation overall, and what those who had positive reactions to my work, during this study's course, had told me. One was the moment when I was re-checking the event's Facebook page, explaining the event's purpose and inspiration. For me, it not only reminded me of the night's cause, but the desires of the artistic communities I had met in both Austin and New Orleans alike. It read, in part:

It's time to inspire new and different conversation around mental well-being.

However people are, whatever they are dealing with, you could be the turning point in that moment. Sometimes, we just need to be HEARD.

We all have times in our life when we need support. In this moment, you can be that lifeline for someone. Our goal is shifting the mental well-being conversation from the clinical to the personal; empowering each one of us to stand with others who are in crisis or who just need an ear.

On January 22, we invite you to ask your friends, family, co-workers, and loved ones - "Hi, how are you?" You probably say that a lot, but this time, we want you to mean it. "How are you really doing today? Are you OK?" Just by listening, getting curious, standing in compassion and empathy, you can be the catalyst in changing a person's life (Hi, How Are You Project, 2018).

I was reminded of the same when local Austin musician Jane Ellen Bryant performed a cover of Johnston's "Peek-A-Boo" that night as I sat on the top-level 
bleachers both listening the music, observing the crowd - and looking up to see the two high-rise hotels looming over Mohawk and Cheer Up Charlie's. The lyrics include:

You can listen to these songs

Have a good time and walk away

But for me, it's not that easy

I have to live these songs forever

Please hear my cry for help (Johnston, 1982; Johnston \& Bryant, 2018).

\section{Enabling Factors Related to Other Community Stakeholders}

Enabling factors related to other community stakeholders did provide some flipsides to some of the factors mentioned in the previous chapter. The large number of nonprofit organizations meant that there were numerous organizations from which the artistic community could seek help for both personal and financial issues and could provide some elements that government could not, namely in providing or potentially providing artist housing. Government could not single out a particular group for a benefit like that because of other groups needing the same, but nonprofit agencies, as well as the private sector, had that ability. Likewise, the splintering and fracturing of some organizations, on the flipside, meant that some groups realized they were not being represented and/or their needs were not being met and taking action.

Another enabling factor was that the festivals, namely South-By-Southwest had made improvements, namely in terms of controlling its size and crowds, and the caliber of speakers and entertainers it brought to the city gave the city a favorable view from outsiders. Also, the festivals being so large meant that it provided needed economic boosts for struggling creative spaces, namely the music venues. 
Both directly or indirectly providing a better well-being for the artistic community and better image for the city did improve artists' financial situation. This enabled participation because an even worse financial situation meant that they would have far less opportunities to participate, individually, and businesses would be under threat even more - possibly not even surviving.

\section{Positive side of nonprofit numbers}

Austin's large number of nonprofits was also seen as a participation enabling factor namely because they provided services that improved the artistic community's overall situation, socially and financially. While Austin may have numerous nonprofits, Albus said that the opposite situation would mean that the artistic community's situation would be far worse.

Albus: Look at what's on the other end of that spectrum. You're in a community that does not have nonprofits - that does not have a HAAM (Health Alliance for Austin Musicians), or SIMS Foundation, or an Austin Music Foundation, or whatnot. You're screwed there.

We have a cornucopia of opportunities. Your challenge is to figure out which ones that's... You've got riches from which to choose. Now, the internet makes it easy to find. I mean, I can imagine someone who is an artist, who concentrates on that and who doesn't generally go out and look for help, being confounded. But people with friends and people who are similar, who are familiar with how to look things up, ought to be able to find somebody that can help them by 2018 easier than they could have ever before, in a city like this with Austin, with so many opportunities and nonprofits and whatnot. It should be easier today than it ever has been before.

Like Albus noted with the number of nonprofits, Padma also pointed out that the numbers also bring choices and opportunities for someone seeking help and in whatever area they need help. She noted this is especially the case for those who need help in 
building their business acumen and understanding a complex business like the recording

industry, which also has numerous legal concerns, like contracts and copyrights.

Padma: The Austin Music Foundation is a nonprofit. All of their services are free. They have regular workshops. They have mentors. They have drop-in coaching that could do, that will help you with all of this kind of thing — with reading a contract, deciding if you're ready for your first tour, and how you make those numbers work, how many stops you need to have on that route for you to make your money back. That's a resource that's available.

There's Texas Accountants and Lawyers for the Arts. They do regular free workshops on how to read a contract and determining whether contracts are needed in certain situations. They teach you how to protect your copyright and how to deal with streaming. The third local organization is called Foundation Communities. They have people who specially trained to do tax returns for artists. Artists are mostly self-employed, and they're usually not going to be worried about a house payment. Foundation Communities has people who are specially trained artists. Those services are free.

Austin has an embarrassment of riches, from my perspective. I can see, from a musician's perspective, that they may not have heard of any of those things. But from my privileged position on the inside, I see a ton of support available for artists who are interested in that sort of thing or maybe they don't even know they're interested yet, but they need to do it if they're going to build their business.

The main issue of concern with the nonprofits is not numbers, but whether or not they are fulfilling their mission and meeting the needs of the people they serve, Helena said.

Helena: Quantity is never the problem. It's whether or not they are meeting the needs and if someone here can find one that meets his or her needs. I mean, if there are five thousand, but they're serving and fulfilling their mission, that's all they're here to do. That's why you're a nonprofit. Are you fulfilling your mission? We could have a million of them. Quantity is not the problem.

With that concern about mission over quantity, comes a flipside on the issue of nonprofits having splits or breaking off, sometimes, not in an amicable fashion. Helena 
said that if a group is no longer representing the people it is supposed to serve, someone breaking away to create their own group is not a negative.

Helena: If my needs aren't being met, then I'll figure out where they can be.

Nonprofit organizations, as well as the private sector, also have an ability to help with the affordability crisis that the public sector does not. Multiple interviewees noted that when it comes to public funds for something such as affordable housing, justifying why public dollars are used to help one group over another (i.e., artists instead of public school teachers) is dicey, if not impossible. Nonprofits and the private sector do not have to worry about this. Alastor used the example of the Ellis Marsalis Center Musicians' Village in New Orleans, spearheaded by prominent New Orleans musicians Harry Connick Jr. and Branford Marsalis, to bring musicians back to New Orleans after Hurricane Katrina (Ellis Marsalis Center Musicians’ Village, n.d.).

Alastor: I tend to think private groups are going to do a better job of that. Affordability is something I get asked about all the time, and, unfortunately, I don't have great answers for it. But I think that because cities are kind of tasked to help a broad range of people, affordability in the music community is something that's going to have to be a project of a private organization, like Connick's foundation in New Orleans. I think that's a good example. His organization is a good example of deciding they're going to help a particular group of people and going and helping them. And that's who I think is going to be more effective.

\section{Festival improvements}

Major festival improvements included better efforts to control their sizes and have tighter organization. Both of these created favorable views of not only the festival, but also the city as a whole. Likewise, the high-profile events meant that the festivals managed to bring high-profile or extremely interesting personalities, which also created a 
more favorable view of the city. Also, the economic benefits from the festival, even though some considered it a headache, was that the artistic community reaped its overall benefits. This namely included the creative spaces, like music venues, who were struggling to survive. Some believed they would not be able to survive financially without South-by-Southwest, alone.

\section{Size control and organization}

Key improvements for South-By-Southwest included what they did to curb the increasingly unpopular and problematic unofficial free events during the festival, and the main event's intricate organization system — seen as absolutely necessary for one that brings more than 400,000 people.

One improvement that Ron pointed out was that South-By-Southwest realized that problems with the festival were a mutual problem for both the city and themselves. The unofficial special events throughout the city taking place during the festival that were open to anyone, whether they were a badge-holder or not, devalued the badge that their paying customers had purchased for around $\$ 1,000$ or more. It also jeopardized those badge purchases, period, as well as creating a "hairy damn mess everywhere". So besides talking to the city about cutting back on special events permitting, the festival also started making some of the smaller events "semi-official" through making them badge-only. This meant that just the badge holders, and not "masses" of people who had not paid, a potential customer base. I noticed during my own observation of South-By-Southwest that many events outside the main area at the Austin Convention Center, such as ones in bars, were badge-only. 
The festival's crowd control techniques might seem complex or stifling to someone visiting as an outsider, but Nymphadora, who saw South-By's system noted that this was critical for a festival, given her current job of organizing a festival of her own. Both she and others in her line of work constantly monitor other festivals and make careful note of the specific mistakes that disastrous festivals made, such as Woodstock 1999 (Kreps, 2014; Pridemore, 2017) and the 2017 Fyre Festival. One of the numerous (but not one of the worst) mistakes the former made was access control (Kreps, 2014) and the latter made was not giving attendees nearly what they paid for — in that case, up to $\$ 100,000$ for luxury accommodations only to find disaster tents and cheese sandwich meals (Baggs, 2019).

Nymphadora said that such organization of an event that more than 400,000 people attend, she said, is absolutely needed to both keep the event under control and to make sure attendees have a positive experience. Otherwise, the festival will get a major black eye like those mentioned above. This could give a host city one, by proxy, too.

South-By-Southwest, which I observed as a participant in 2018, has four different badges — "Platinum", "Interactive", "Film", and "Music". Interactive is designed for those primarily interested in the technology events, and the film and music badges are designed for those whose primary interest are in those disciplines. Platinum badges are ones that give greater access to all of the festival's events, which I will further explain, moving forward. All badges are color-coded and attendees must wear their badge at all times while on the festival's grounds. Figures $8.28,8.29,8.30$, and 8.31, shown below, are of my own green music badge lanyard, and the other three badges' lanyards. These 
were taken with the respective attendees' permission and without their faces being shown.

Figure 8.28: South-By-Southwest green music lanyard (Pridemore, 2018)

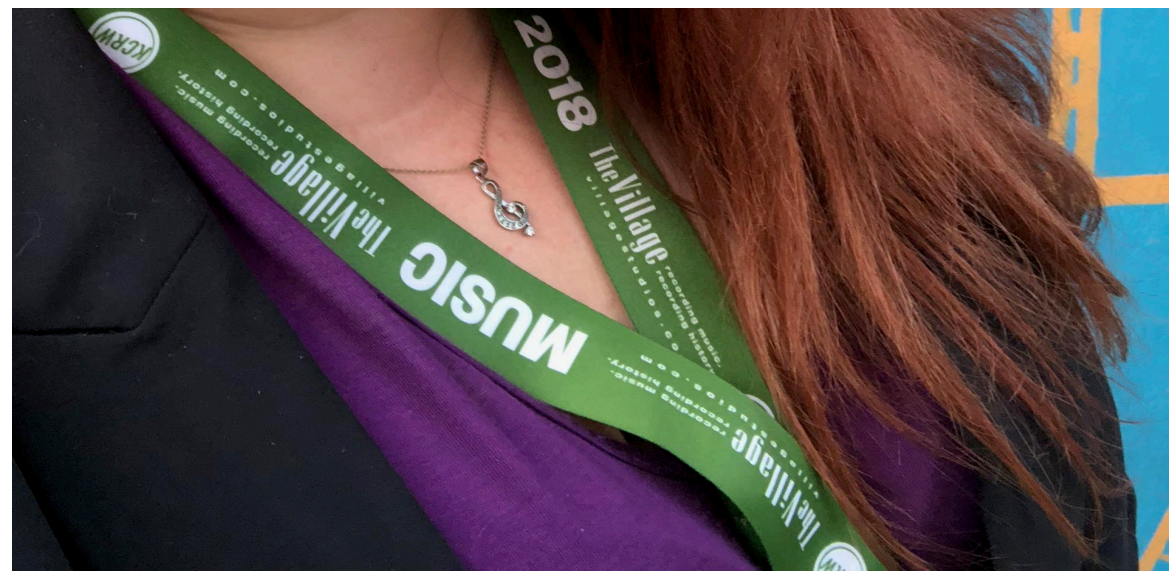

Figure 8.29: South-By-Southwest orange interactive lanyard (Pridemore, 2018)

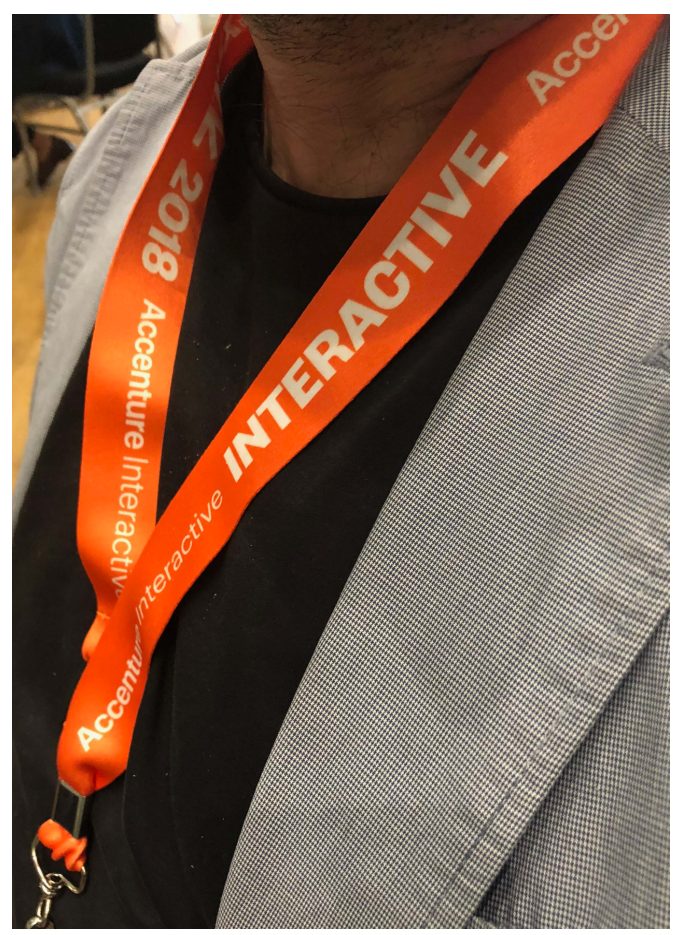


Figure 8.30: South-By-Southwest blue film lanyard (Pridemore, 2018)

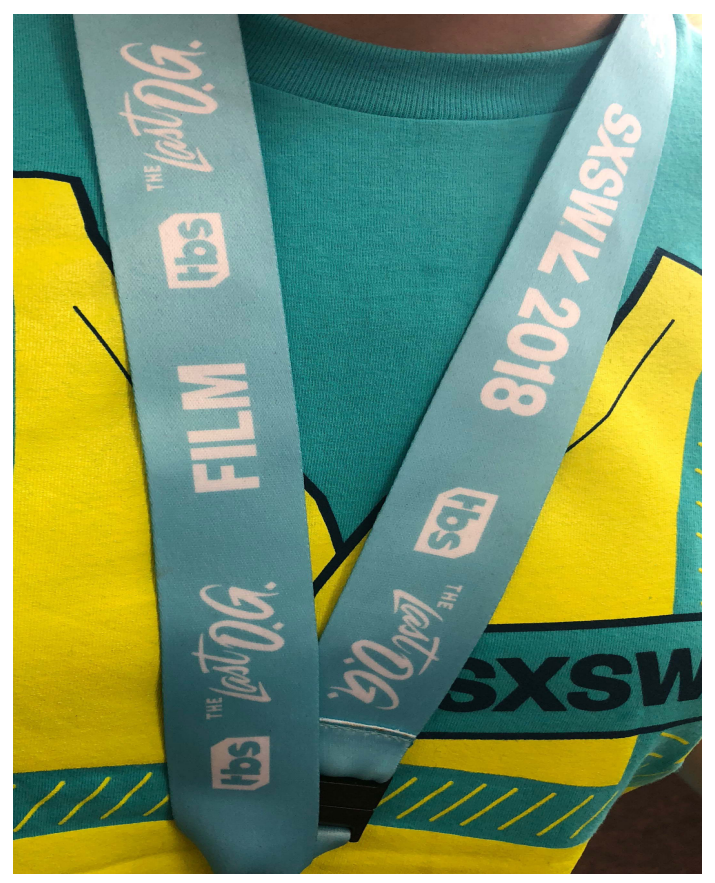

Figure 8.31: South-By-Southwest gray platinum lanyard (Pridemore, 2018)

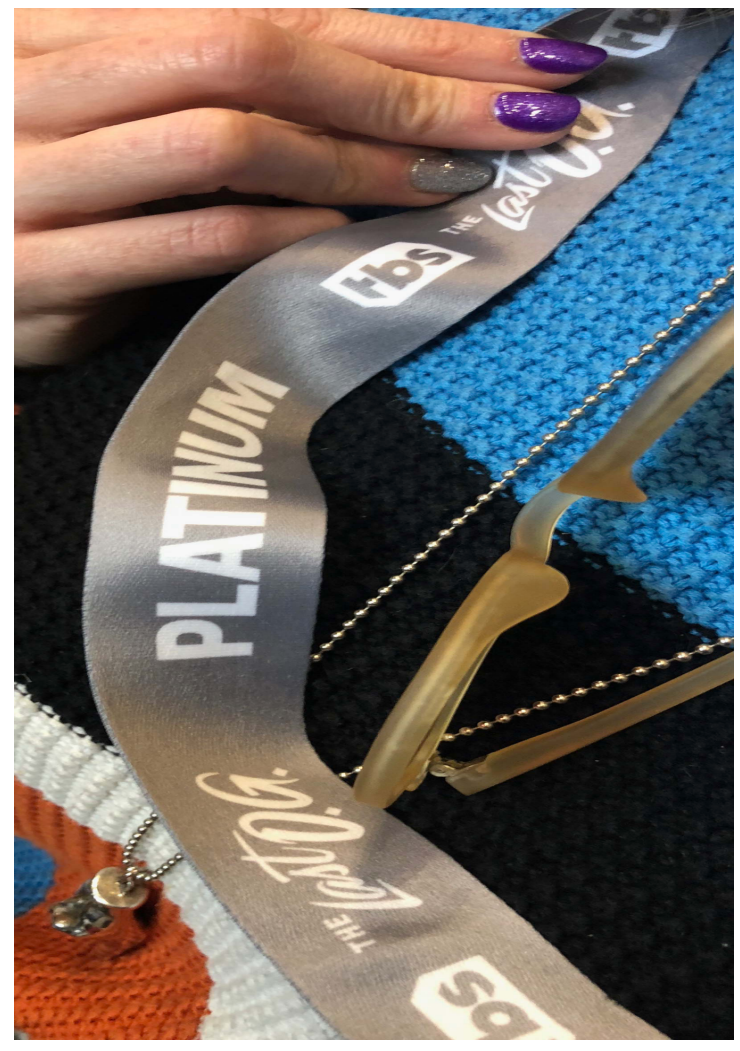


South-By's numerous, simultaneously occurring events taking place both at the main grounds at the convention center and throughout much of downtown Austin are mostly categorized as focusing on film, music, or technology. Some of them are extremely popular, but a given event will only hold so many people in a room. Therefore, South-By creates "primary access" and "secondary access" lines for all events. Those with a badge corresponding to that event's category (i.e., a music badge for a music event) are given primary access, meaning that once an event's doors open, those with primary access get in first. Those with secondary access, like someone with a film badge wanting to attend a technology event, would only go in after the primary access badge holders are inside. Platinum badge holders get primary access to all events, regardless of category. Naturally, they pay much more to get such a badge. Figure 8.32 below shows the different South-By access gates.

Figure 8.32: South-By-Southwest access gates (Pridemore, 2018)

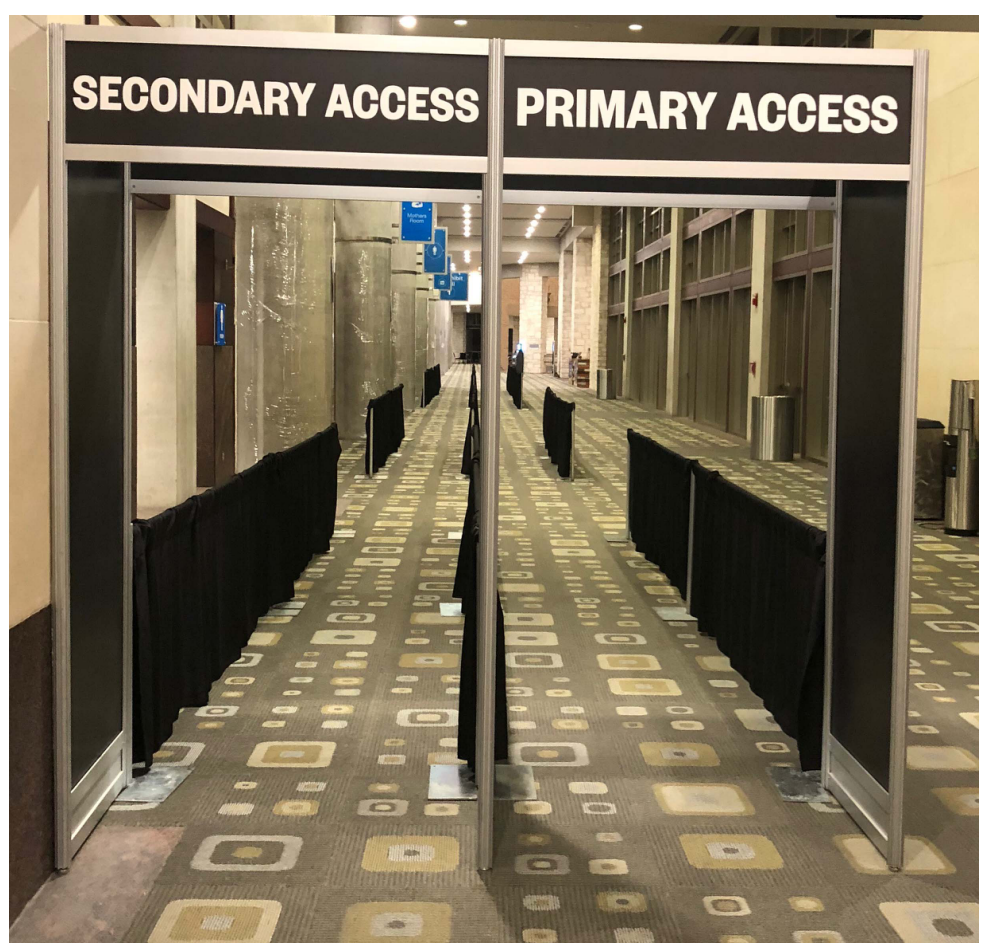


I benefitted from this, myself, when I wanted and needed to observe a forum on how Austin's music industry was working to survive given the challenges it faces. This was categorized as a music event, and South-By organizers outside the doors while I was waiting moved several people without music or platinum badges out of the way and into a secondary line. This ensured that music badge holders like myself and platinum badge holders were not slighted over those who did not pay for such access. The prominent lanyards and badges with their bright color coding helped the organizers quickly see who had primary access and who did not — and likewise, had no access at all, in the case of events in buildings built to the street.

Nymphadora explained that besides keeping the event as organized as possible and allowing attendees to get what they paid for, this also helps attendees who are often running from event to event and choosing between the extremely wide variety of them. It helps the latter namely because the attendees are far less likely to waste their time waiting to get into an event that they will not be able to attend.

Nymphadora: For me, as a logistical person, it makes a ton of sense because when you have a bunch of people in line, you can see if they should be in this line or if they're not. So it's an easy way to say, "Hey friend, you have an orange lanyard. I know you have an interactive badge. You're actually in this line, and let me tell you that you're in the wrong line so you don't waste your time. So shortcutwise... ... I really like the lanyard colors. If I had a conference that had four different types of badges that had different access levels, I would want that immediate sort of, "Hey buddy, you're know that you're in the wrong spot," because, literally, nothing makes an attendee angrier than when they waited in line for an hour, and then they can't get in because they were in the wrong line.

South-By lines are really long, and you can be in them for a really long time. I respect their line logistics. It's very complicated, and it is sort of like you are here, you are not here... It's a lot. But they also have, like, a jillion attendees trying to go to everything at once, and they're trying to open it up to access to everyone, so they're doing what they can. 
There's a ton of people, and so you need to have as short of a hand as possible to help them get where they need to be, so they're able to see what they want to see. That's the whole point. ... It seems over-the-top, and you're like, "Oh my God, this is ridiculous. But once you get there, you see they have to apply this kind of insane badge line to everything to make everything run as smoothly as possible. There's only so much space, and you have to make sure that people are lined up correctly. If you're outside, there's only so much space you can take up on the sidewalk. There's a ton of stuff, and you have to deal with it yourself even on a small-scale level.

\section{Successful festivals creating positive view of the city, economic benefits}

During my time in Austin, I found that the festivals, namely South-by-Southwest, were seen as blessings or curses. Those who were on the "blessing" side of South-BySouthwest, in particular, noted that one major benefit was a positive image for the city, as a whole. These benefits included the economic impact, which some business owners said was literally how they were still surviving financially, and the fact that a festival with international recognition that brings major public figures, interesting personalities, and up-and-coming entertainers comes to the city puts the city in a positive light.

The economic impact from South-By-Southwest, alone, was something that the city should not pass up, Ron said, noting he had moved from a city with severe financial difficulties — "the complete opposite end of the prosperity spectrum", as he put it. The other factor is how individuals can benefit from it economically, too, given the potential for exposure and the sheer numbers of people in Austin during that time.

Ron: It's an absolute blessing. Yes, it is a big, hairy disruptor. I'm not going to say it doesn't throw everything into a damn blender for an entire month, but that's good. ... If I'm going to take tens of thousands of people or tens of millions of dollars or hundreds of millions of dollars flocking into my city for a few weeks, reliably, yeah, I'm absolutely going to do that.

I think the biggest groups that complain about South-By-Southwest are the folks who can't find a way to capitalize on such an opportunity. If you're a musician, 
this is a chance to get in front of A LOT of different people who can help your career. Maybe it's not with a traditional record deal, but maybe you'll find people who can help you book tours or get a sponsorship deal. There are tons of different ways to have a recording career these days. You've got to try and play a dozen shows and look at it as a business expense and treat yourself like a business.

During my observation at the South-By-Southwest forum on the Austin music scene, one of the Red River bar managers indicated that sixty percent of his business' revenues come from South-By, which is critical as the rents accelerate. Seamus agreed with this assertion and noted that a significant portion of his business' revenue also comes from the festival. Also, he pointed out that the city as a whole and he, personally, has benefitted from the additional revenues.

Seamus: I think it's important not to be a grouchy old man who's saying, "Get off my lawn." This is the reason I was able to go to college. South-By-Southwest money went toward my tuition. Some people are out of their minds if they think that the city is sustainable without it. So it's incredibly, incredibly important to the ecosystem here.

While I was observing South-By-Southwest, I took note of where attendees were coming from, either through seeing their entity's locations on their badges or casual conversation. The event was literally bringing people from around the world, namely from Asian countries or the United Kingdom. One person from the latter was presenting invaluable pieces of music history, some of which had never been seen before. This man's name was Alec Byrne, and decades ago, he photographed some of the most iconic musicians of the modern era, often when they were just launching their careers. His subjects included the Rolling Stones, Jimi Hendrix, a very young David Bowie, and Bob Marley, and he inadvertently became the first person to photograph Mick Jagger and Jimi Hendrix together. That portion of the program is shown below in Figures 8.33 and 8.34. 
Figure 8.33: South-By-Southwest British rock photographer (Pridemore, 2018)

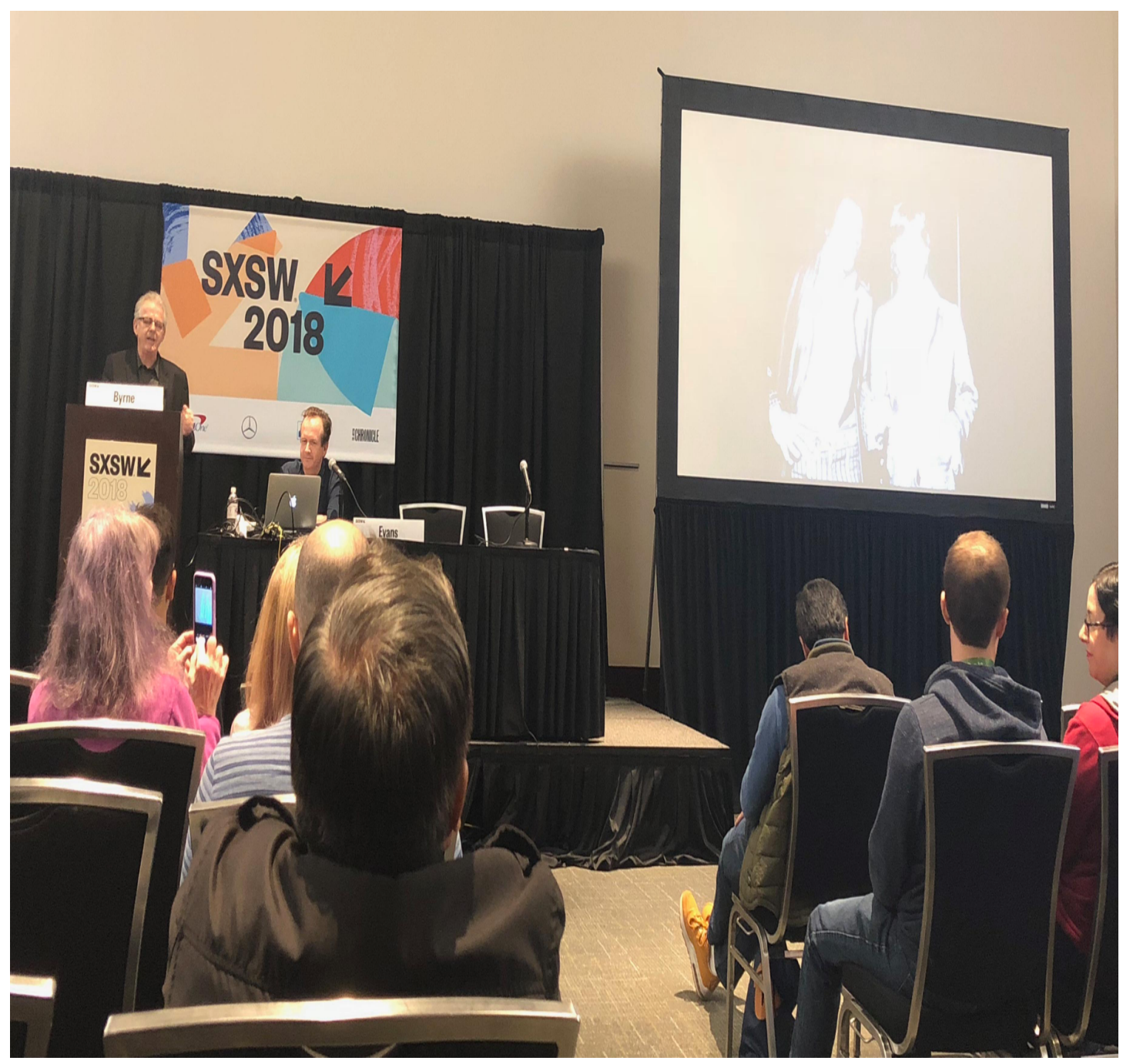


Figure 8.34: SXSW, first photo, Hendrix and Jagger (Pridemore, 2018)

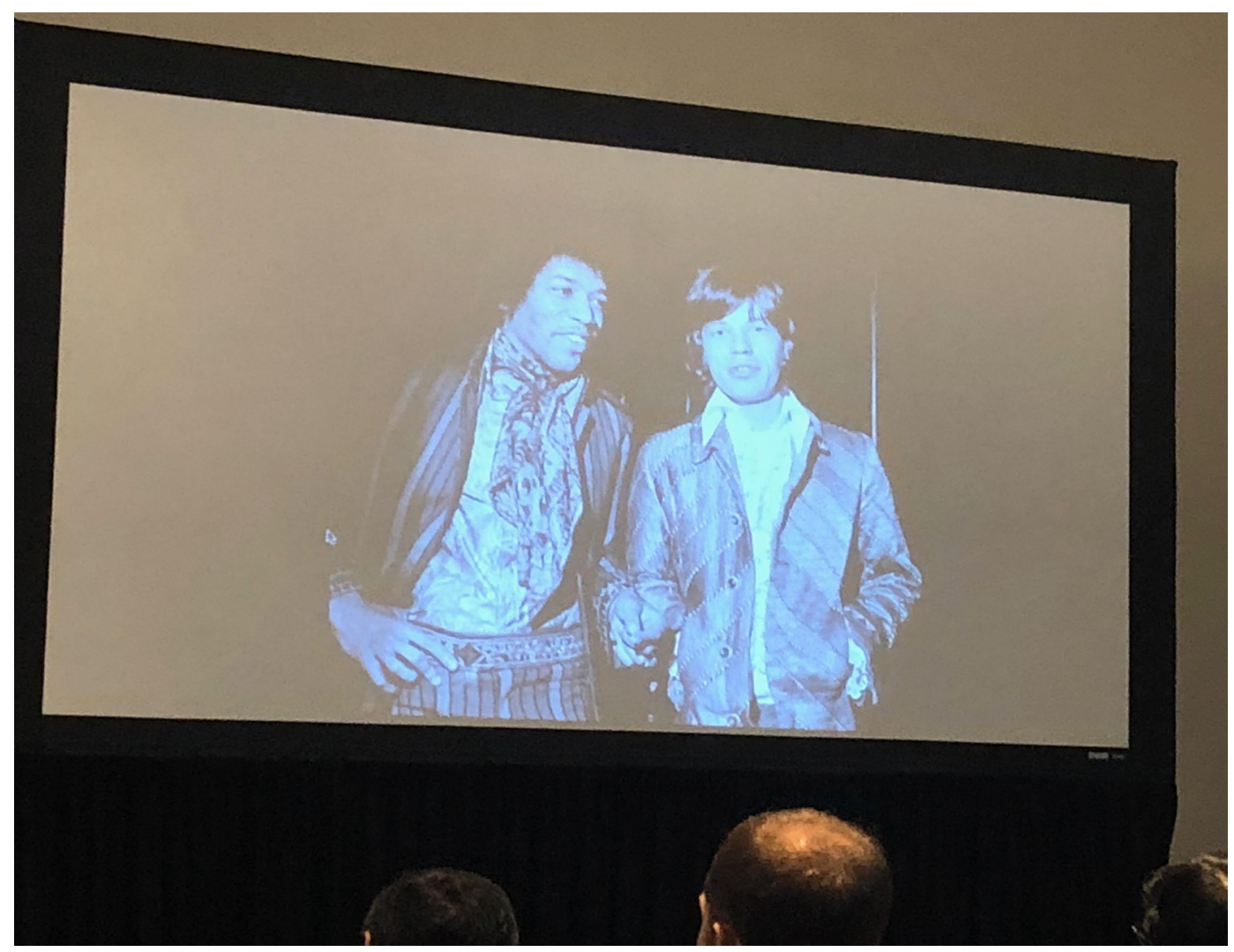

Byrne told stories of his work with these icons, which, I noted at the time, I probably would never have had the chance to hear without an event of this caliber coming to Austin. I also had a chance meeting, while just stopping to check my notes, with an actress, originally from Canada, who was promoting her new TV show pilot. This made me wonder if I would soon be able to say, "I knew her when," as well as, "Yes, I was the one who loaned her my makeup compact before her South-By-Southwest interview." Someone else there could have had similar chance meetings, too, and those profound meetings happened in Austin.

Nymphadora, noted that though the event is overwhelming, seeing such caliber in her Austin hometown is wonderful for her. 
Nymphadora: I love it, but I think it's because I'm used to it and because I'm able to ride the wave, for lack of better words. ... It's just really nice because everyone's in town. I live here, so I get to go home and sleep in my own bed, but I still get to participate in this internationally, well-known conference that I love. They bring in really great speakers. They do a really good job for the amount of people that they're bringing in and all the stuff they have going on.

So, I think people really get overwhelmed with the amount of stuff and it's like when you're not going to go to one of the $20^{\text {th }}$ of the stuff and just in one of the conferences... So, as long as you kind of embrace that as someone who has terrible FOMO (Fear of Missing Out) - I have a hard time with that — and just kind of let it go for South-By because there's just no way to see everything or talk to everyone. And that's OK.

\section{Enabling Factors Related to the Artistic Community}

Two major, overarching factors that were participation enabling factors related to the artistic community were positive in-group relationships and self-sufficiency. In those positive in-group relationships, a major factor was former rivals and competitors burying any hatchets they had and coming together to achieve a common goal and to confront major challenges they all had in common. This was especially the case with the Red River district venue owners who were in a highly competitive environment but opted to make those competitors allies — and the result was one of the biggest policy victories the artistic community has seen thus far.

While some of those who led organizations, namely some of the nonprofits, did not get along with those representing different disciplines (or get along, in general), rankand-file artistic community members got along extremely well, with different disciplines regularly collaborating with one another and without excessive cutthroat tribalism seen in other cities. This enabled participation because, with these groups already having existing 
positive, collaborative relationships, they could enter policy debates and concentrate on their powerful outside opponents, like developers, and not have infighting tear that apart.

Self-sufficiency was another key enabling factor for the artistic community. Those who worked to participate in government would often approach officials on their own and did their own research on policy challenges, possible solutions, and participation processes, despite huge learning curves for some, on their own. This self-sufficiency allowed government officials to directly hear from those policies directly affect, created a positive view of the artistic community members who came well-prepared, and helped them avoid the problem of trying to determine which third party they could trust to actually speak for them.

\section{Positive in-group relationships}

Burying hatchets: Rivals becoming allies in policymaking

Besides place, one of the major enabling factors in the artistic community's participation in Austin was former rivals burying hatchets and becoming allies in policymaking. This not only created policies that worked in their favor in the end, but it also enabled participation through these groups settling any of their own differences and removing the barrier of in-group tribalism and outright squabbling and, then, coming to city government as a collective rather than individuals with disparate interests.

This was especially the case in the Red River district when the diverse venue owners - working side-by-side in a competitive entertainment district, as major entertainment districts anywhere tend to be - did this and in a city government plagued with the inaction mentioned in the previous chapter, scored a major victory with the permanent extended hours for playing live music. Interviewees told me what the Red 
River owners did was important on three fronts — working past in-group rivalry was critical in creating and implementing workable public policy and that if highly competitive bar owners can come together to help create effective public policy, almost anyone can do the same.

During my observations in both Austin and New Orleans, I noticed that the bars and entertainment venues working side-by-side - thirteen in the Red River district, alone - were in an extremely competitive environment and working to ensure that potential customers walking through the entertainment districts came into their venues instead of the ones next door. Not only did I notice that this was far less pronounced in Austin over New Orleans, I noticed that when listening to, observing, and interviewing those in the Red River district, the key was that the bar owners were working as a collective and no longer against one another. At the technology and music event at Spider House Café and Ballroom I observed in 2017, one of the Red River venue owners explained:

We're past the point, at least in the cultural district, but probably even in Austin... All of us who are in this live music business recognize that there is a giant threat to the livelihood and it's no longer acceptable to stand in the tower with your binoculars and flip off the guy across the way. We all have to work together to keep what we have going.

The venue owners were the ones who took the initiative in creating the Red River Cultural District, as well as the Red River Merchants' Association for the owners, according to interviewees and secondary sources (City of Austin, n.d.b; Personal Communication, 2017, 2018). The largest reason behind it was that the owners realized 
that they needed to present a united front and work together, both on their own and in the policymaking arena, to address the numerous challenges they face.

Seamus explained that the venue owners, some of whom had known one another for ten to twenty years, were not at outright war with one another, but recognized one another as direct competitors and in a highly competitive environment. However, the challenges they faced made them all realize that they needed to band together if they were to survive.

Seamus: While we were aware of one another and were cordial, I think it's fair to say that we saw each other as direct competitors. So, at best, it was kind of a competitive sort of respect that we had. But we're all also involved in a live music culture down here and sort of live music incubator culture that necessitates all of the different capacity sizes of each other's venues. So, we see each other as filling our own niche in the ecosystem. That's a little bit different if we were just bars, and it's just drinking.

So, I think that coupled with some of the evolving world of live music venues, like the threshold for participating in one and maybe owning or running one was that you had the cash to open it and maybe a high school diploma. Live music is sort of the brand of Austin. So, it's highly competitive here.

But this has required all of us to sort of level up in terms of our professionalism and our maturity and not only, like I commented, seeing each other as a healthy part of the ecosystem as a whole, but also that we needed one another in order to survive because, in some ways, we were seen as disposable and ubiquitous at the same time, where many people go, "Oh, art is always there. Look at history. They're always going to be around. There's no need to really give it any second thought. It's always accessible," but that's really not the case. If one does really look at history, that's certainly not the case. And because only one of our venues down here owns their land, we started taking a look really quickly at some of the economic pressures that we're grinding up against because we're all very costheavy businesses - like ninety-five to ninety-eight percent, if we're doing a really good job.

So I think that just allowed us to look at ourselves in the mirror and kind of level up and quit thinking, "Oh, this guy down the street or this gal across the street is out to get me." It's like, "How are we going to keep doing this and preserve not only our ability and our staff's ability to pay rent and make a living, but how are we going to preserve the unique culture of Austin going forward? 
Interviewees indicated this united front from the Red River venue owners was the key in a major policy victory for the Red River district — the extended hours for which they can play live music. In January 2017, Austin City Council voted to allow a sixmonth pilot program in Red River that would run from May 2017 to November 2017, during which the venues would be able to play live music for three extra hours each week (one extra hour each night) — until midnight on Thursdays and until 1 a.m. on weekends. The pilot program's purpose was twofold — to have measurable data on the economic impact the venue owners believed it would have and measurable data on which and how many venues went over the city's 85-decibel limit and how often (Craver, 2017a; Findell, 2017a; Findell, 2018; Neely, 2017a; Staff Writer, 2018b; Swiatecki, 2017b). Five venues were covered in this - Stubb's BBQ, the Mohawk, Empire Control Room and Garage, Cheer Up Charlie's, and Sidewinder.

The first four bars' locations are marked with pink circles on the map in Figure 8.35 below. (Note: Sidewinder has since closed.). Besides the hotels mentioned in the previous chapter, the bars are also located near the Waller Creek waterway. Residents living north of the Red River district have often reported noise from music traveling up Waller Creek (Findell, 2018). 
Figure 8.35: Red River district map, venues circled (Google Maps, 2019)

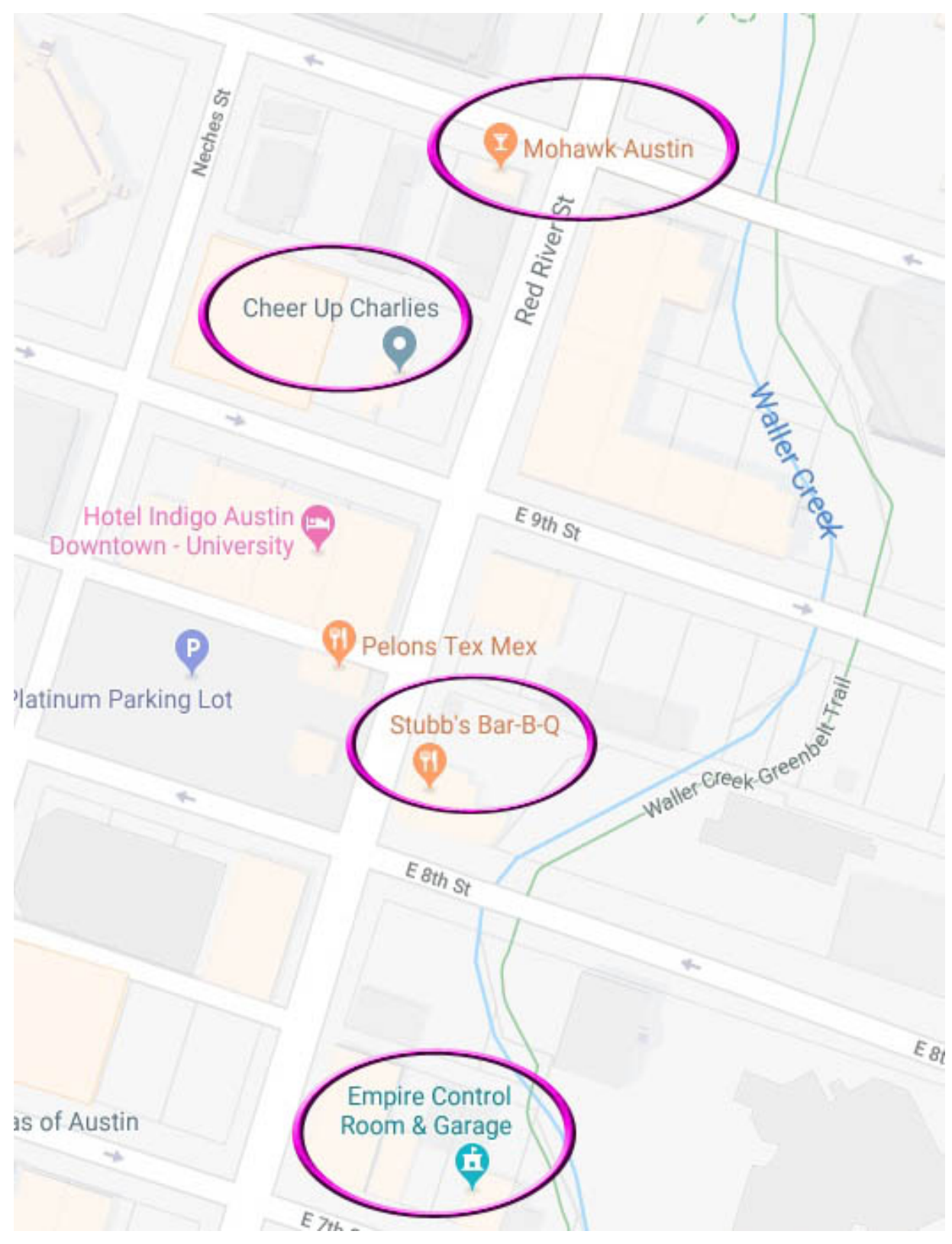

In the long run, the venues believed that this would lead to additional revenue for all parties involved - themselves as they faced the challenge of rising rents, increased pay for local artists, and being able to create more jobs through hiring more staff (Findell, 2017a; Findell, 2018; Neely, 2017a; Staff Writer, 2018b). However, this pilot program 
had strong opposition from nearby hotels, as mentioned in the previous chapter, as well as neighborhood associations (Findell, 2017a; Neely, 2017a).

The venues, though, had to subject themselves to consistent sound monitoring from city officials - but they welcomed it, with the owners saying it would allow the city to collect data on noise complaints to better understand which areas are affected the most (Findell, 2017a). The pilot program both required the venues to stay in the 85decibel limit and also strengthen their sound mitigation efforts (Neely, 2017a; Swiatecki, 2017b). Voluntarily welcoming and asking for the sound monitoring was akin to Gaventa's (1980) assertion that less powerful groups have to anticipate challenges and know, in advance, how to respond.

The pilot program was such a success that the city council gave it a six-month extension, which allowed the hours to stay in place through May 2018 (Neely, 2017b). Parties that included the Red River owners, city staff — and the neighborhood associations — provided positive feedback during the October 2017 council meeting that extended the hours. Economic data showed revenue boots, and the pilot program turned at least some former detractors into supporters, with the president of the Austin Neighborhoods Council, who had opposed the pilot program in January 2017, voicing strong support for it nine months later (Findell, 2017e; Neely, 2017b).

In late April 2018, the council voted to make the extended hours permanent (Findell, 2018), namely after the data the Red River owners wanted to gather showed positive impacts both economically and in terms of resident quality of life. City staff evaluated the pilot program and found that, from May to December in 2017, compared to the same period in 2016, showed that the five affected venues made more "revenue 
during the extended hours and, in turn, were able to pay staff and musicians more" (as cited in Findell, 2018). "Mixed beverage sales ... increased eight percent, ... rising from $\$ 4.2$ million to $\$ 4.5$ million. ... The total amounts paid to staff and musicians ... increased three percent and five percent, respectively" (as cited in Findell, 2018).

The positive impact went beyond the economic one, with noise complaints to the city's 311 decreasing, with those monitoring sound showing "no quantifiable sound impact to residents north of the district" (as cited in Findell, 2018). City officials "attributed the drop to better communication between the neighborhoods and the venues, plus the addition of night and weekend staff to address complaints in real time" (as cited in Findell, 2018). This will continue because the "city created a division in early 2017 that focuses on enforcing music venue sound restrictions" (as cited in Findell, 2018). Government inaction was cited as a major participation hindering factor in the previous chapter. When the Red River extended hours were made permanent, Adler's statement in the Austin American-Statesman showed how the Red River extended hours work created an opposite situation.

This issue of music and hours and impacts on neighborhoods has been a point of contention in this community going back decades. Quite frankly, this is one of the first times I've seen where we were able to constructively move this ball forward (as cited in Findell, 2018).

Interviewees indicated that the key to this success was the Red River owners' collaboration and cooperation, first with one another, before they approached city officials - and they were the ones who first made the approach, Ernie said. The owners, working together, were the ones who got the pilot program started, through first 
communicating with one another and deciding on their major talking points, and then sending a representative to the police department.

Alastor indicated that the Red River venues' approach was not only correct for them but that approach was also something that other venues elsewhere facing same situation should take. Given the challenges the live music industry faces, now is not the time for business competitions, even the nastiest ones, to derail favorable policymaking.

Alastor: What does your rivalry as a bar owner and with another bar owner, in the grand scheme of things, have anything to do with anybody? I mean, if there are real tax issues facing 150 venues like you, why are you so special that you should pull out of that conversation? I think being professional rivals is fine, but having mutual respect and actually having enough perception to understand when it's time to put that away and actually go to work together? Yeah, that's absolutely vital.

Look, the music industry is faced with a whole lot of things right now that are going to take some very, very smart people working together to approach. And frankly, I'm not a get-off-my-lawn type. But I don't care about rivalry. I don't really care about that. The main impact we can make is when a bunch of really smart folks who are survivors in the industry get together and work on a couple of key issues. You've got to put all that petty stuff aside and grow up. I've had this conversation with people who were lifers in the industry, and the conversation starts to veer toward, "Well, this guy did this, and I don't want to work with them for this purpose."

It doesn't matter. For what we're talking about, leave it at the door. Let's be professionals here. Later, you can go take a swing at him in the parking lot for all I care.

During an observation at South-By-Southwest, one of the Red River owners said reaching out to the other owners, as well as the other venues' staff was critical. Yes, the person next door was a competitor, but it was important to not behave like a "petulant child" toward one another. When music and arts communities are facing the struggles that they are, he said, it is important for these communities to take initiative themselves 
but, simultaneously, not divide the community. This is not a time for artistic communities and businesses supporting them to be "us and them".

Much like Seamus indicated, the competition between the Red River owners was not particularly nasty, Ron said. However, they were not collaborating before, and when they did, this was a major step in a positive direction.

Ron: It wasn't like they were trying to slash somebody's tires, but everyone kind of had their heads down, just doing their own things. But now, it's, "We're all in this together. ... This thing works because we're all in here together." There is certainly such a feeling and an atmosphere there. They have a camaraderie of cooperation. Everyone kind of digs what everyone else is doing and realizes that everyone brings their own flavor and unique approach to what's going on.

Other interviewees noted that this collaboration of Red River "competitors" was critical not only for the past and present, but also as they move forward and face new challenges and work to tackle both policies that have yet to be implemented and its issues with infrastructure and crime.

Pomona: Banding together is always better. There's that old African proverb: If you want to go somewhere far, you travel together. If you want to go somewhere fast, you travel alone. So I think a good thing that has happened with the Red River Cultural District is that a lot of these bar owners are realizing that they have the same issues. We all have issues. We all have issues with our bathrooms. We all have issues with fire, police, and code compliance. They're the same issues.

We are all looking at this big, bad hotel going up next to us, and we're all going to have to compete with that Agent of Change concept of who was here first. I don't know about the Red River businesses to call it a rivalry, but I would definitely say that they were doing similar things and realized that, "Hey, you're doing this. I'm doing this, also. Why don't we do this together? Why don't we try to tackle these challenges we have together instead of separately?

Lily: The Red River folks are pretty savvy. ... My perception is that they are trying to be proactive. ... I think they're trying to come together as a united front and be proactive and be kind of circumspect about what they're doing and how 
they do it. If that's what they do, they stand a better chance politically, and they see that.... They want to make sure that the area is safe and that things are going well because they can use that, then, to go back to the city council and say, "You know, we're doing our job," or "We're trying to keep it safe and trying to keep things cleaned up.... We're doing all of these things. Now, we need you to... Let's put some bond money into fixing the sidewalks, and we want to talk about parking management" or whatever it is.

Much like Alastor, other interviewees noted that what the Red River owners did could be a model for other music venues facing the same challenges - or any other types of groups and in any city who, perhaps compete with or just do not like each other, but face a mutual threat of any kind.

Lily: You can hate each other after you get the policy implemented. You have to. Everybody has to be adults about this, and buck it up, buttercup. Everyone has to say, "OK, we generally agree on the following five things, and so we're all going to go and do this." And I think there are groups that are trying to hold their noses and work with each other despite... I think there are other ones that are sabotaging, but I think there are some that are going, "Yeah, it's the greater good. You have to look at the greater good."

There are some people in my line of work that I don't particularly care for, but if something I truly care about is being threatened, I'll be singing 'Kumbaya' with them faster than anybody. We don't all like each other, but when it comes to the big stuff, we buck it up. We all get together and say, "Yeah, we've got to say this. We've got to do this. This is what we have to do."

\section{Different disciplines working well together}

In the last chapter, problems involving the plethora of nonprofit organizations in Austin were identified as hindering factors - one of those problems being animosity between organizations focused on the commercial music industry and those focusing on the general arts. These conflicts included, but were not limited to, ill feelings between some of the commercial music and general arts nonprofits. Interviewees indicated that the general arts nonprofits believed those involved in the commercial music industry 
considered themselves "too cool", superior, or overly demanding. On the other hand, the general arts organizations, they said, tend to get better funding over the commercial music groups, and the music groups would like to have that.

This situation, though, was the opposite for the rank-and-file members of the artistic community. Even though some of those who led advocacy organizations had discord between their organizations and artistic disciplines, the individual members of the artistic community, overall, had positive relationships with one another, did not hold severe grudges, did not engage in heavy tribalism, and regularly worked with those in other artistic disciplines. Several were co-curricular, meaning that they engaged in more than one type of artistic activity. This was a participation enabling factor because the existing positive relationships within the artistic community meant that they were already willing to work with one another in citizen participation efforts, with some even taking the initiative on their own outside of government and the nonprofit organizations.

As he mentioned in the previous chapter, Ron said that the rank-and-file musicians and artists got along well, and that the problematic relationships were namely between some of the nonprofit organizations' leadership.

Ron: I never saw any evidence of animosity. It was more on the decision-maker level, the leaders of the different advocacy groups.

...Amelia: But the individual theater person, musician, writer...

Ron: They're not really even keyed into that dynamic of resource scarcity. They just want to do their shit, collaborate with whomever they can collaborate with, and do whatever they can do. Your average workaday musician and artist are fine. There's no animosity.

Amelia: Is there a lot of collaboration here between the artistic disciplines?

Ron: A fair amount, yeah. That happens. 
Amelia: Is there a fair amount of co-curricular types, like me?

Ron: Yeah, that's not unusual at all?

Amelia: So with the rank-and-file, everyone is OK, right?

Ron: It seems like it. I've never caught wind of any real tension or beefs.

Hermione said that cross-discipline collaboration regularly, if not always, happens when musicians like herself work in arts programs in public schools, which the city's Cultural Arts division often funds. Artistic community members multiple jobs often include such work in public schools during the day. She and other artistic community members work with organizations that work with public school teachers on incorporating art-based, outside-the-box teaching strategies. Hers are the ones rooted in music, but others do the same for other disciplines. Another example she gave included musicians who are parts of puppet shows in public schools - the shows need music, but they also need visual artists to design sets and create the puppets or theater-oriented people to do the voice acting and dialog. Regularly, she and musician friends engage in other creative ventures, such as coloring or designing their CD covers and DIY (Do It Yourself) crafts. These are all often display at shows.

Hermione: People, I think, upon meeting each other, tend to be really open and excited to kind of connect with new people and exchange ideas. One thing along those lines that I think is so cool is just how much you see sort of different elements of arts coming together within specific events. So, a lot of times at Cheer Up's, you'll see not only bands playing, but you'll also see things like people vending vintage clothes or DIY stuff that they made at shows or doing DIY paintings. You'll see people creating art at shows.

...It's interesting to hear about the issues involving some of the other nonprofits because what I've been seeing, especially this last year, is a lot of different organizations who are actually sort of overlapping or doing mutually conducive 
things. On the education side, I feel like we're seeing a lot of organizations coming together to try and kind of do the same things - pooling resources and also kind of making sure that those resources are being used efficiently.

...I personally have ill will toward very few people unless they're fucking with other people. But yeah, I definitely wouldn't say that it is a sentiment I have encountered much with my musician friends, either. If anything, I would say almost kind of the opposite. At least within my circle, it's very common for these kinds of different arts communities to come together and collaborate. A lot of the groups I'm working with now are trying to collaborate with other disciplines too.

Sometimes, Hermione said, those in other art forms do feel slighted over music,

but the artistic community, themselves, is not doing this. Rather, if it happens, it is on the part of the public at-large.

Hermione: My roommate is more of a visual artist, and he's a musician as well, but he's primarily a painter. I know he kind of feels like art gets subsumed by music. There's a lot good art that gets made here. But these are things like paintings for shows or posters for shows, and other art that gets made for the music that gets the most attention. If you have a gallery show, and you have a band playing there, the focus is more on the band than the art, typically. I know he feels kind of like the visual art kind of gets overshadowed or eaten up by the music industry.

But from the other way, I would definitely say I've never heard of any musicians express antagonism toward any other artists.

I asked Nymphadora about some of the general arts organizations' attitudes toward the commercial music ones and if, from someone who works in the greater artistic community outside of music, she agreed with that. She noted her role was not as a content creator, like a filmmaker herself, but she believed Austin's city government has shifted into a more encompassing attitude toward cultivating other artistic disciplines and those working in those disciplines that may not be considered "artists".

Nymphadora: I feel like Austin does a relatively good job of trying to encompass things. As a city, the Cultural Arts Division at some point decided to stop saying "artists", and they started saying, "creatives" to encompass more people and to be 
able to encompass, maybe, sort of the technical side of filmmaking, for example. It doesn't feel like an artist, but it feels creative. It's a good sort of umbrella word, which I like.

I feel like everyone is going to feel inclined to feel like they're not being supported enough. I feel like if you talk to some musicians, they would not agree with that.

One key city document backs up Nymphadora, and that is the Music and Creative Ecosystem Omnibus Resolution or the Music and Creative Ecosystem Stabilization Recommendations, commonly referred to in Austin as just "the omnibus". Agent of Change, which would seriously benefit the music community is part of the omnibus, but the issue of affordable space — something affecting all disciplines — is mentioned as a major priority and the first individual one discussed (City of Austin, 2016b).

Another positive aspect of the Austin artistic community's in-group relationships is that interviewees told me the overall environment is not hyper-competitive to the point where the individual musicians and artists are tearing one another down. Even when there is competition, the overall environment among them is one that wants one another to succeed.

Sirius thought that such attitudes were not only present, but also critical given the development-related challenges the artistic community and its spaces have.

Sirius: I think Austin is very unique because there is a very community oriented aspect of its musicians. Everyone is kind of in this together. I do see how it would be easy to be more tribal and just say, "OK, this doesn't really affect my career. It's going to affect others, but things are totally working for me." I think that is trying to think on a smaller scale, and some musicians might have to think that way. It's saying, "I'm struggling. I need every gig I can get.” But I think having everyone's interests in mind is best for the whole community, in terms of the community growing as a whole rather than just you, from one week to the next, getting more shows. 
Amelia: Are you seeing more of a community oriented atmosphere in Austin?

Sirius: I would say so. I think Austin's music community is very tightly knit. There are so many different circles, but everyone can kind of jump in, really without much competition now. There is still competition for those shows, but I don't think it's ruthless. I'm not thinking, "That drummer broke his leg, and I can take all of his gigs now." I wouldn't. I wouldn't think that was good for everybody if it was just for the individual.

I think that's a key thing that Austin music has. I think that's important to keep that as the music scene grows or as just the city grows, because, if that splinters, there is no way we're going to stay in the downtown area.

Penelope said that those in the Austin artistic community also collaborate on their business-related challenges, which have been discussed as a major obstacle for the artistic community's overall survival. Together, they will share what they have learned in terms of business acumen. Like Sirius, she believed that Austin was a place that was much more supportive and collaborative and not cutthroat.

Penelope: So, becoming a licensed business owner is on my mind right now. It's tax season, so taxes are on my mind. I'm talking a lot with my peers about how to tackle those issues because I feel like that's one thing that school just doesn't teach you. Why did we never have a class on how to file our taxes? It amazes me.

It's the same with musicians or people who work in media. There are the nitty gritty things that I feel just aren't taught. So there's definitely a lot of idea exchange and helping build one another up. None of us wants to see each other fail. It's not as competitive, even with the media realm and in other such industries that can be very competitive in other cities. In Austin, I feel like everyone is kind of on the same time.

Separately, both Hermione and Penelope gave the example of Raw Paw, a multidisciplinary Austin arts collective (Raw Paw, n.d.), that had an arson fire destroy its headquarters in January 2018 (Brenner, 2018; Personal Communication, 2018). Raw Paw is an integral and beloved part of the Austin artistic community, both said, and this is why 
it strongly rallied in support of Raw Paw, particularly when it had a benefit in March

2018. In a secondary source, D.B. Hall (2018) wrote that "hundreds" showed up to

support Raw Paw, writing:

When tragedy befalls an artist or group of artists - such as the January 2 fire started by a still-at-large arsonist that burned down Raw Paw's headquarters full of irreplaceable art - it isn't just an affront to those particular people. It's an attack on the entire creative community. Yet, such a widespread feeling of pain and loss is likewise often the rallying cry for a mass movement toward healing, as was the case during the art collective's Saturday evening arson benefit held at Spokesman and St. Elmo Brewing Company, which drew hundreds of supporters for a showcase of local bands and the sale of art saved from the flames (as cited in D.B. Hall, 2018).

Penelope said the rallying around Raw Paw was a major example of how the

Austin artistic community works to build one another up and not tear one another apart.

She noted that this was especially critical because those in powerful positions, in the artistic community's view, are working against them.

Penelope: I went to their benefit show, and it was so great to see the community come together and raise money for them. You can tell there's just no real competition there. People just want to help each other succeed because I think there's a collective feeling that the system right now is working against us. Working together means we're stronger in a force rather than all separate.

The collaborative and not hyper-competitive environment is a major reason why

Hermione has chosen to stay in Austin.

Hermione: It was that element of this community that I've seen here more so than any other places where I've lived or spent a lot of time. The music community here doesn't feel like people are trying to compete against each other. It really feels like everyone is kind of working together to create a great music scene and to make it sustainable for musicians as possible. 
Another point Narcissa, a musician, made was that Austin is not outright

jealously-free or competition-free. However, this is not all consuming simply because she and others believe that actively working to tear one another down is simply pointless, especially, as other interviewees have noted, because everyone in the music community is facing the same challenges.

Narcissa: I think we all get bitter and jealous and everything, but then, also, you have to think about it logically and not be an asshole. You have to think that if you were gaining the same amount of success or whatever, then you would want people to be happy for you more than just being like, "Oh, fuck you, now that you're doing well." ... I'm not saying that doesn't occur because it does happen anywhere. ... You know, yeah, there's definitely more competition, a lot more competition, which does create some tension, maybe.

But — when I say this, I'm not trying to say I'm a fucking saint — I don't think it should be directed outwardly at any other musicians because they're just in the same boat as you. I have friends that are considerably more successful, and I don't wish for them not to be successful (Laughs). I just want to make a living, as well.

Sometimes, I'm sure it's like, "Oh that group made it out," or whatever. But I don't know. If some bands are successful, tons of people from Austin will go see them. A lot times, they're good bands. They might not be my cup of tea.... You always have that, "Shit, man, I wish I had that." ... But ultimately, it's just a fucking waste of time. I'm not saying I don't get that way, but it's a fucking waste of time. It's not going to do anything besides make you bitter or angry.

\section{Self-sufficiency}

Another major enabling factor for some in Austin's artistic community is that many of its members were extremely self-sufficient in working to find policy solutions that would improve their situations. This included approaching city government on their own, doing their own policy research even though many of them had larger learning curves, and working to learn policymaking and citizen participation processes on their own. This enabled participation not only because public officials heard directly from 
those that policy directly affects, but it also helped artistic community members avoid the problem of determining which third party to trust, and, when they made their case well and on their own, it put them in a more positive light and created a much more constructive relationship with city officials. A key point in any of their successful efforts was use of evidence-based arguments and coming prepared with possible solutions.

As mentioned in the previous chapter, Seamus said the Red River owners decided early to be their own representatives and to take the initiative themselves rather than work through a spokesperson - acting on advice from others who informed them that some people were trying to speak as their representatives but only to advance their own agendas. Another major reason they did this was because they knew they had the experience — and a major element key, evidence — to back up their arguments regarding both their problems and the solutions they proposed, like the pilot program. During South-By-Southwest, the Red River bar manager on the panel about Austin's live music scene said that having data on items such as revenue and evidence-based arguments that they brought forward on their own was a major step forward in having policy that worked for them, saying, "We had to talk about math and not emotion before we were ever taken seriously."

Seamus noted that even with issues that are outside the Red River owners' legal control, such as crime outside of their bars and the dangerous sidewalks, they are working with the city to find solutions and proposing their own. They have even gone as far as working to help government officials find funding sources the officials could use to remedy the problems, like grants for additional police patrols. 
Alastor said this sentiment is correct, and it is something he must do as someone working to translate the "language barrier" (as mentioned in the previous chapter) (Herranz, 2015) between government officials and the arts in his position. To do this, he often relies on numbers — namely, economic impact studies. Speaking from a position that government officials understand, such as revenues and jobs, before speaking from a position of passion is critical not only for him but also for anyone who is working to have their arguments resonate with public officials. I recalled both the South-By-Southwest observation and Olympia's statement in New Orleans about how evidence-based arguments can work to transcend politics. This was my exchange with Alastor, during which he noted that artistic communities, not just the bureaucracy, could use this as an effective strategy.

Alastor: A lot of times when folks go to visit city leaders or they go to visit people in private industry to ask for help, they talk out of a position of passion for what they do. That's fine, but mostly, those elected leaders and private industry individuals deal with issues without passion. They've got a wide, wide range of topics they have to cover. So, as you can reshape the conversation about the music industry, in our case, and to a form that they can understand, namely jobs and numbers, you can have that other conversation about why, culturally, it's important. You have to start with the same bedrock principles that they listen to every day about why they should support the health care industry, why they should support oil and gas, or whatever else it is. That's just how they go about doing business.

Amelia: One of the officials I interviewed in New Orleans mentioned that one way she works to, at least on her part, transcend politics, is stick to evidencebased arguments. Would you agree with doing that, as well?

Alastor: If there were a more than one hundred percent yes to that, I would give you a 110 percent yes. That's correct. Why put that much added pressure on a decision maker you're trying to get on your team? Imagine the kind of conversation people in something like trade organizations or citizen groups could have, if they came with an evidence-based argument and if they arrived at that office with a concise, evidence-based solution and an evidence-based issue and 
constituency - and some proposed solutions that were not out of the realm of possibility. That is absolutely something that decision maker would love.

The people that the music industry is trying to convince to help them out whether that is Congress, a state legislature, city council members, and mayors... These people have a whole list of issues they're trying to tackle, and a lot of people that they've got to be accountable to. Just to be quite frank about it, the music industry is pretty far down that list. If you don't tackle immigration, if you don't tackle the budget, if you don't tackle defense, and on, and on, and on, the music industry is just flat out not going to exist anyway.

So if we do need help, then we ought to be really concise about our issue, the singular issue we need help with, and we need evidence to back our case up. We need to be able to convey, accurately, why our industry is important to support, and then, we should have a proposed solution for it.

Honestly, that last part is done incorrectly quite a bit. There are these things when bills are put forward called fiscal notes, and if you don't have a clear and concise person trying to assist when a lawmaker goes to write a bill, and then it goes through the budget office of the city or statehouse, that fiscal note makes it impossible for the bill to move forward anyway because you haven't clearly defined your affected class. So you've got to be clear and concise. You've got to have data to back up your relevancy, and then you've got to have that solution in hand.

Outlaw citizenship challenge: Disaffected breaking power structures, not activity, creates the outlaws

I noticed that, especially in the case of the Red River policy victories, a flipside is that outlaw citizenship exercise may not necessarily depend on what is being done, but, rather, who is participating and even if that is in a traditional setting. Before some members of this group could even begin, they had to defeat longstanding in-group messaging in their own social circles that kept them in an oppositional mindset against government. These longstanding messages, common among less powerful groups, were often started by powerholders and passed on through generations (Gaventa, 1980). Just as there is messaging in one's own group to defeat, there are the identified barriers from 
powerholders too (Gaventa, 1980; Warner, 2001, 2011) and namely ones that keep the less powerful from entering traditional venues (Arnstein, 1969; Fung, 2006, 2015; Rimmerman, 2011).

Therefore, less powerful groups managing to enter traditional venues and especially when they find a way to become victorious over powerholders could be the real "outlaws". They defied both their own communities and longstanding power inequity and found a way to use processes that created hindering policies now create ones to work in their favor.

The Red River owners' situation, namely with the district's extended hours victory, has multiple elements of Gaventa's (1980) assertions on how power structures can be broken. Working on their own and with their own strategies, evidence, and proposed solutions as they did demonstrated the needed self-sufficiency. Likewise, their mobilizing with people who have the shared problem and, in their case, putting aside any rivalries, added the needed mobilizing effort. Volunteering to have their sound monitored was part of anticipating challenges from those with more power. It also required breaking old thought patterns and overcoming old messaging — but the key, I found with Red River, was that this was the most difficult to overcome and had to be done first.

During these processes, not only did some artistic community members overcome a major learning curve but they also had to learn how and when to let go of "antiestablishment" subcultural stances and work with government officials and present evidence-based arguments in doing so. For those who are seasoned veterans in industries such as nightlife and live music, this is not easy, Seamus said. This can be especially true 
for especially oppositional subcultures, such as those in punk, his main subculture, or metal, what he called his "gateway drug" into music.

Seamus: Oh, it's a big deal. I think that's a reason why a lot of folks haven't stepped out of bars and venues and kind of thought about a bigger picture thing because the ideas and the approaches that one finds successful in music subculture and on the street, like being confrontational and oppositional and hyperaggressive can be really good survival strategies. It's not only in music, but also in street culture and lower economic situations.

But those are the tools that work against you when you're looking at thinking more than a week ahead and trying to understand more complex systems and how they're designed in order to game them and create desirable outcomes for yourself. So, I found, for myself, that this was a maturity issue. It was, "Oh well, I don't want to do it this way. I want to do it this other way," and, you know, I'd say "the system" and other sort of tired teenage tropes.

And then I realized, "Wait a minute. This is the fifteen-year-old me." That person isn't going away, but that person just needs to chill out and go to their room because they're not going to help everyone keep their jobs (Laughs). Arguing with some "man", whether "the man" is my boss or the mayor, it's not going to work out in my favor because that's just not how grown-ups get desired outcomes with one another, unless you're a professional boxer. You know? (Laughs)

One common thread I heard throughout the course of this entire dissertation was how difficult it was for a person without formal policy training to grasp "governmentspeak", navigate policymaking, and be someone who works to both work past and translate "language barriers" (Herranz, 2015) between artistic communities and governments.

I asked Seamus, whose formal education was not in public policy, how he managed to do this. The answer he gave was tied more to mindset rather than a straight path - but that mindset had to be changed before he could step onto that path in the first place. Essentially, he said, he had to drop an ingrained, oppositional stance against government first. This may sound simple to someone who does not come from, as he 
mentioned above, a historically disaffected group. However, according to part of the Third Face of Power, powerholders rely on the disempowered retaining a mindset that a group who could help them out is the enemy and is not to be trusted (Gaventa, 1980; Warner, 2001, 2011). These mindsets are extremely difficult to break, especially when those around such a person continually reinforce this.

The key for him, Seamus said, was striking a balance between authenticity and adaptation - being true to self in terms of retaining entrenched, and still-positive ethical credos like those gained from being part of a subculture while also evolving to adapt to social change. This was especially true when that social change is positive.

He used the example of punk and metal cultures, which have been simultaneously questioning authority and embracing outside-the-box thinking and diversity — and yet have numerous people in those subcultures holding strict codes of conduct and strict definitions of what punk and metal can be and who can be its key figures. This was a key example for him, especially, because of his being immersed in them for decades. The former was appealing, and the latter, he found unnerving. On the other hand, as times have changed, artists and fan bases have overall changed for the better, namely in terms of racial and gender diversity and acceptance of that diversity. He said these changes have been done over the figurative angry shouting of the holdouts who hang on to those old conduct codes and strict definitions — but this is a positive. The questioning and outside-the-box thinking remains, but the old guard is losing to people who "flip the script”.

Just like the punk and metal cultures are simultaneously remaining authentic yet adapting and for the positive, he has had to do the same. He has kept the positive punk 
credos of celebrating creativity and diversity, thinking outside the box, and challenging norms and presumptions, but he has accepted change when it has either been a positive or necessary. This is how someone in the live music world managed to take the dive into public policy, continually work to plow through it, and find policy solutions that worked even when he and his colleagues were faced with powerful opponents and in an increasingly challenging live music industry.

Seamus: It's a grinding industry. The hours are miserable. (Laughs) The work is never-ending. As soon as one gets a formula that works, the next year, it doesn't anymore. It's like a new thing one has to engage with. It requires a lot of resilience, determination, and willingness or even excitation to change. My observation, now that I'm in my forties, is that people including myself, hate change. Even if someone was like, "Guess what? This great opportunity here has arisen, but it's going to require you to do X, Y, and Z, but it's going to be so good for you." The impulse is that, whether it's good change or bad change, we just don't like it. We get comfortable in our patterns.

So, for me, accepting that the only way to survive was to adapt and the only way to thrive was to adapt, as well, helped me kind of confront myself and those challenges I had about wanting to do things a certain way or thinking about how things are supposed to be done from a perspective of twenty years ago versus the music industry of today.

\section{Enabling Factors Related to Non-Traditional Participation}

Creative ventures to regain spaces and boost support, retaining participant interest, and taking back events after the Austin artistic community lost figurative ownership of them were the major enabling factors for non-traditional outlaw citizenship. With the creative ventures, artistic community members would perform in odd places and in numerous city locations to not only gain financial support, but also, and more importantly, unite the city around its artistic community and the arts that made the city 
what it is and what brought so many of its residents (and finances) to Austin. This was critical because of these institutions, activities, and spaces being threatened.

Some of this provided a challenge to outlaw citizenship literature. A flipside some of these outlaw citizenship activities, namely ones that were aimed at demonstrating value, is that, although these participation methods were outside the norm, it was designed to unite with fellow citizens and government rather than being confrontational and adversarial.

These arts-oriented outlaw citizenship activities also helped to retain participant interest because, certain interviewees said, traditional participation forums can be dull and boring, and more fun, creative events that also allowed people to fully express any anger (if they wanted to be confrontational) kept interest high instead of having participation drop. Also, some in the artistic community were reclaiming figurative ownership of artistic events, allowing them to showcase local talent and in spaces dear to them.

Just like the competing Red River bar owners became unlikely allies, outlaw citizenship, traditionally thought to be an activity for working against government (Pridemore, 2018; Rimmerman, 2011), had the potential to unite the artistic community and the city government in another form. This was namely because of the state government's constant eroding of local control, and on some policies with a direct effect on the artistic community and arts economic development projects. Given an increasingly irritated and stomped-upon city government, both the citizenry in Austin and the city government had a level of disaffectedness in this regard. This echoes Box's (2017) 
writing on how local-level policy and government can be critical in pulling citizens through "regressive" eras.

All of this enabled participation because these presented attractive, fun, and creative activities that held participant interest and empowered the artistic community when it had lost power before, making it more of a force for reckoning. It also provided a way for disaffected citizens to unite with city government, to both demonstrate their artistic activities' value and resist as the state and federal government bear down on the city. I will note, here, that much of Austin's locally oriented outlaw citizenship was being done over social media and other technology outlets. These elements will be covered much more when I reach the next chapter and have a much more extensive discussion about citizen participation and social media.

\section{Creative ventures to regain spaces, garner support}

Some artistic community members who had lost their spaces refused to back down and refused to quit, launching creative participation efforts in their work to both regain space and to gather support for their causes. This enabled non-traditional participation because, especially when these events were prolonged done in different locations, they reached more people because of transportation and scheduling issues. With some of the locations and performances being rather non-traditional, themselves, this created more interest in their activities. Their unwillingness to back down even when it appeared as if they were finished garnered positive media and public attention, as well.

Like the Red River owners worked to do, some of the other artistic community members were working to remind Austin society and government of what it had, and they attracted people to their message with creativity. One major element of it was some of 
this was being done not to go against government and others in society at-large but to unite, which is a flipside to outlaw citizenship literature (Pridemore, 2018; Rimmerman, 2011). They worked to remind government and fellow citizens of what they had, how it had value, and, as a result, why it needed to be saved.

Rude Mechanicals (also known as "Rude Mechs"), an Austin theater company, was one of multiple artistic venues that has lost space in recent years, losing a space due to "pricing out" for themselves and other Austin artists that used it (Rude Mechs, 2017). Therefore, the company launched its "crushAustin" initiative. The company traveled and performed in all ten Austin city council districts, not only to help its own fundraising efforts but to, most importantly, unite the city that helped the company begin and develop and help the city understand where it should go and what it should be in at the same time as it changes so rapidly. This also addressed artistic community interviewee concerns that the city was only concerned about financial gains from real estate development instead of its creative spaces. The website for Rude Mechs' kickstarter campaign states:

We want to insert our creativity into every nook and cranny of Austin with the very best new independent cultural productions. Not palatable fare, but the kind of shit that curls your toes and takes your breath away and makes you lose your mind. We want to scour its backside for inspiration in sites of actual cultural production and join forces with others in making work that matters. We want a forum for conversations between artists and audiences about the shape of things to come.

crushAustin will focus on "the city" as a collective and as a collaborative structure. Austin has raised us, made us who we are, but now, it needs some looking after, some care, and some attention as Austinites try to figure out what kind of city we want to be, what we value, and what our civic life should be.

When space is valued in dollars and cents, when the future is reduced to capital accrued, then our most important contribution as an arts organization is to provide alternative ways of engaging in the now (as cited in Rude Mechs, 2017). 
Not only did the Kickstarter campaign raise four thousand dollars more than its ten thousand-dollar goal, crushAustin featured performances in a variety of orthodox and unorthodox spaces ranging from performance spaces and coffee shops to private homes (Rude Mechs, 2018). At last check, Rude Mechs has an eighteen-month lease in the Austin American-Statesman warehouse. With a new campaign, Rude Mechs is also working to erase the negative feelings that have developed in Austin as it changes but while still concentrating on its serious problems. The campaign is called "flushAUSTIN", with the intent of flushing away negativity. Rude Mechs' website explains what it will do as part of this campaign will be encouraging people to come to performances to both support culture and show Austin its value and continue its work in the previousinterviewee-mentioned government common cause in youth development. It also wants to inspire all people to create their own work and provide opportunities for "kids that don't accept the dominant design that they are handed and build their own" (as cited in Rude Mechs, 2018). Also, Its statement reads, in part:

Austin has a big problem! If you listen to the way we talk about our city, there's too much shit-talk going on. Maybe it started as a tricky defense mechanism to scare off unwanted newcomers who might move here and besmirch the beauty of our violet crown. But now, we've internalized our pottymouth and somehow, it's gotten cool to not love this place. But if that's true, then Rude Mechs thinks it's not cool to be cool anymore.

...Of course, shit's far from perfect now. The long train of abuses and usurpations is well-documented elsewhere - everywhere. But what's clear is greed got us into this place. If greed is the condition of feeling like you lack and can't ever get enough, then it seems like the only antidote is feelin' flush - so the Rudes are mandating an economy of abundance.

Count your blessings! That's what our upcoming season, flushAUSTIN, is about - turning this train around by looking at how rich we are. Austin's so rich rich with talent, rich with beauty... We're surrounded by brilliant minds, incredible people, and we're absolutely overrun with rich people flush with cash 
to bankroll all the utopias we can dream up. Austin's even rich with space. There's culture getting created every day, all over this metropolis. And believe it or not, the "vibe" is still strong. We won't let the stingy mindset of the moneygrubbing developers infect us. (Or that of the nationalists that what to "protect our country".) We know there is more than enough to go around!

...We CAN flush away all the stupid shit that makes our city suck: homelessness, displacement, traffic...

And soon enough, we'll all be living in flushAUSTIN (as cited in Rude Mechs, 2018).

\section{Retaining interest}

One participation enabling factor for outlaw citizenship is that it helped retain participant interest, especially through policy debates and processes that were particularly long. Interviewees indicated that traditional participation generally means sitting through long, dry meetings that do not allow them to fully express their anger when it is rather intense - and that these can be extremely boring. Outlaw citizenship, especially when dispersed throughout long traditional participation processes, can be much more fun and interesting for people and also allow them to be able to express themselves freely if what they believe they need to say is not nice. Also, it allows participants to freely express themselves if they want to be especially boisterous and creative.

As noted in the previous chapter, the Austin artistic community has not engaged in outlaw citizenship on local issues as much as state or national ones. This was especially true when compared to New Orleans. However, one group of musicians and artists put on a colorful display — namely through, as Faires (2016) wrote, "borrowed from our sisters and brothers in New Orleans". Like two New Orleans protests, the Austin artistic community did a protest in the style of a New Orleans jazz funeral. 
In September 2016, seventy-five Austin musicians and artists marched in a jazz funeral second-line parade to city hall urging the city government to "Save our spaces," — doing so with a brass band first playing the religious hymn "Just a Closer Walk With Thee" (Faires, 2016). Marchers carried a flower-covered casket labeled "Save Our Spaces", but unlike the New Orleans jazz funerals, the "dead" arose. The band stopped and local dancer emerged from the casket and proceeded to "twirl and high-kick her way around the other marchers" (as cited in Faires, 2016). The photos below in Figures 8.36, 8.37, and 8.38 show the casket and dancer emerging during the march.

Figure 8.36: Save Our Spaces protest casket (D.B. Hall, 2016)

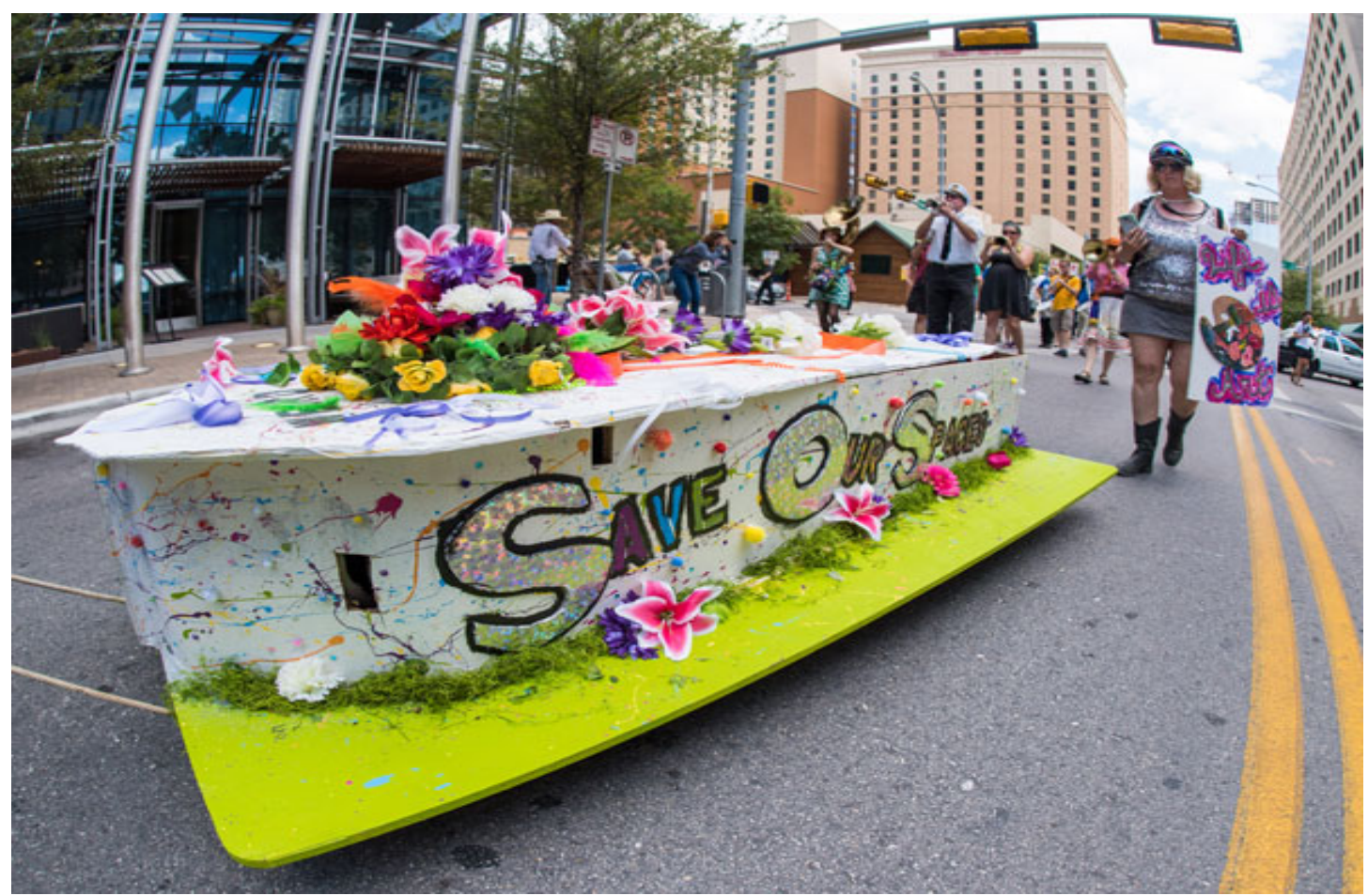


Figure 8.37: Save Our Spaces, dancer rises (Austin American-Statesman, 2016)

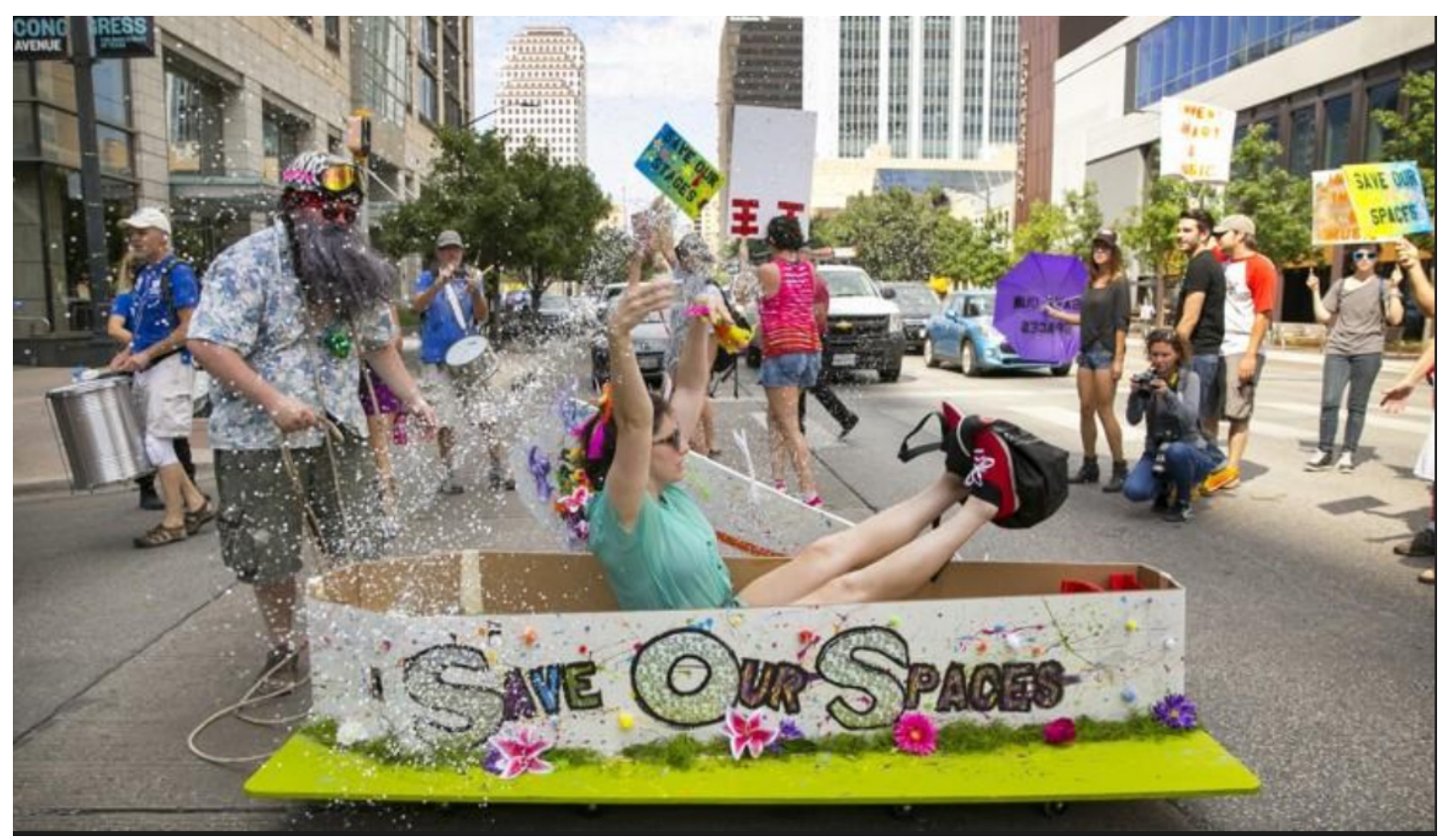

Figure 8.38: Save Our Spaces protest, dancer comes out of casket (D.B. Hall, 2016)

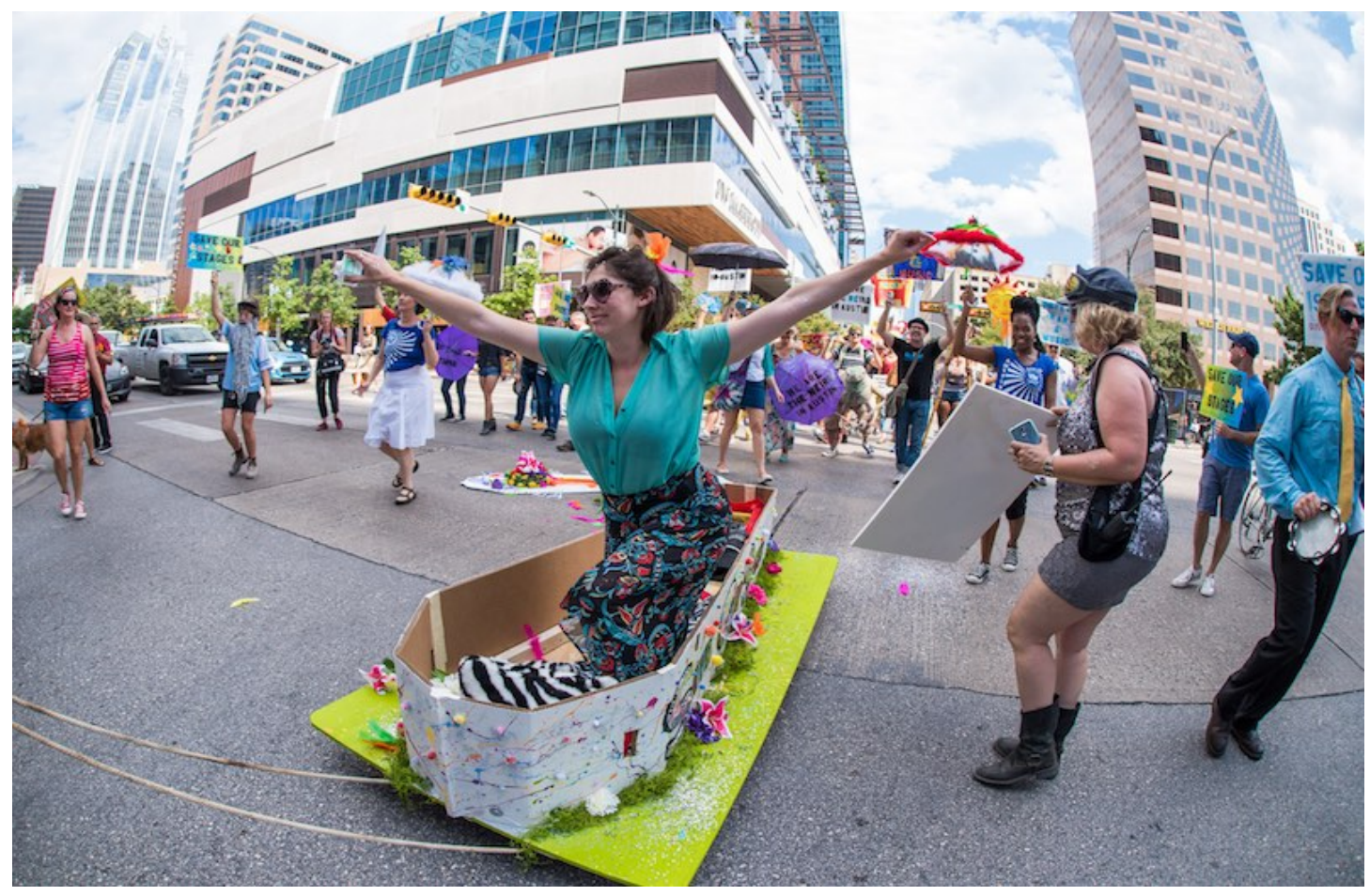

Like New Orleans jazz funerals do once the dead is buried (City of New Orleans,

2013; Kunian, 2007), Austin's band switched and played an upbeat version of a spiritual 
song, this one being "Down by the Riverside". "Down by the Riverside" has roots dating back to the pre-Civil War era and has been a New Orleans jazz staple since the 1920s (Preservation Hall Foundation, 2018). Besides numerous legendary musicians such as Elvis Presley, Louis Armstrong, and Sister Rosetta Tharpe (Mormon Tabernacle Choir, 2015; Wald, 2004) recording it, the song "has been used as an anti-war protest song, especially during the Vietnam War" (as cited in Preservation Hall Foundation, 2018). This time, though, it was done when the dancer arose from the dead, per se.

Besides the dancer's resurrection, the Austin marchers added some of their own flavor to this New Orleans practice. Namely, dancers were dressed much more casually as compared to New Orleans' second-line organizers being dressed extremely sharp exhibiting Austin's version of positive social construction based on appearance. While marchers did carry parasols and items associated with New Orleans second-lines, they also brought signs such as "We are the weird in Austin" (Austin American-Statesman, 2016; D.B. Hall, 2016; Faires, 2016), dressed in casual clothing such as sneakers and ripped jeans, as well as wearing some strange dinosaur-like costumes. Also, some marchers brought dogs. Dog-related events, and much more dog-friendly spaces, and dogs, in general, are Austin mainstays (Auber, 2018). Photos showing more of the Austin-oriented looks are shown below in Figures 8.39, 8.40, and 8.41. 
Figure 8.39: We Are the Weird in Austin (as cited in D.B. Hall, 2016)

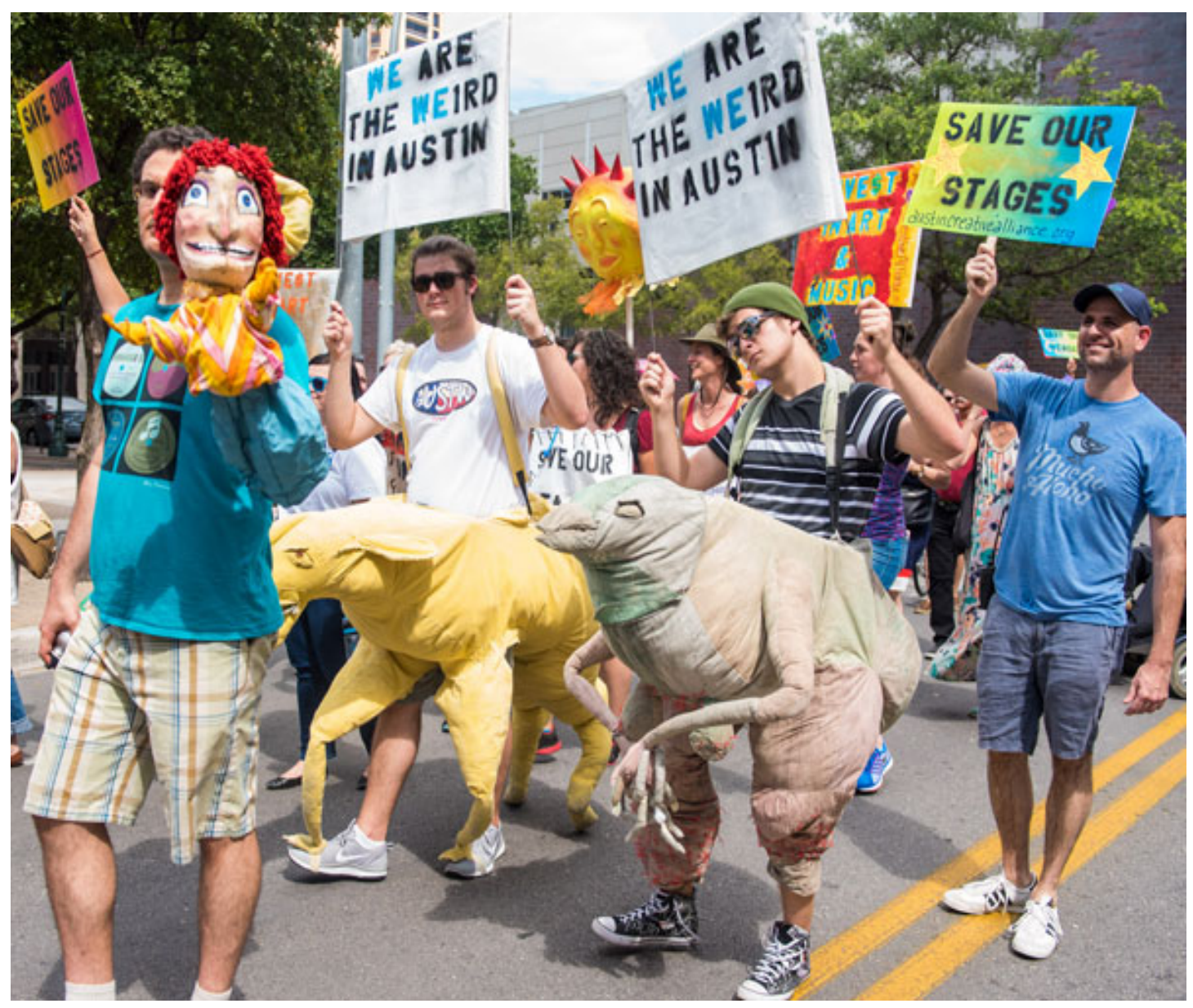


Figure 8.40: Save Our Spaces protest, Jester (as cited in D.B. Hall, 2016)

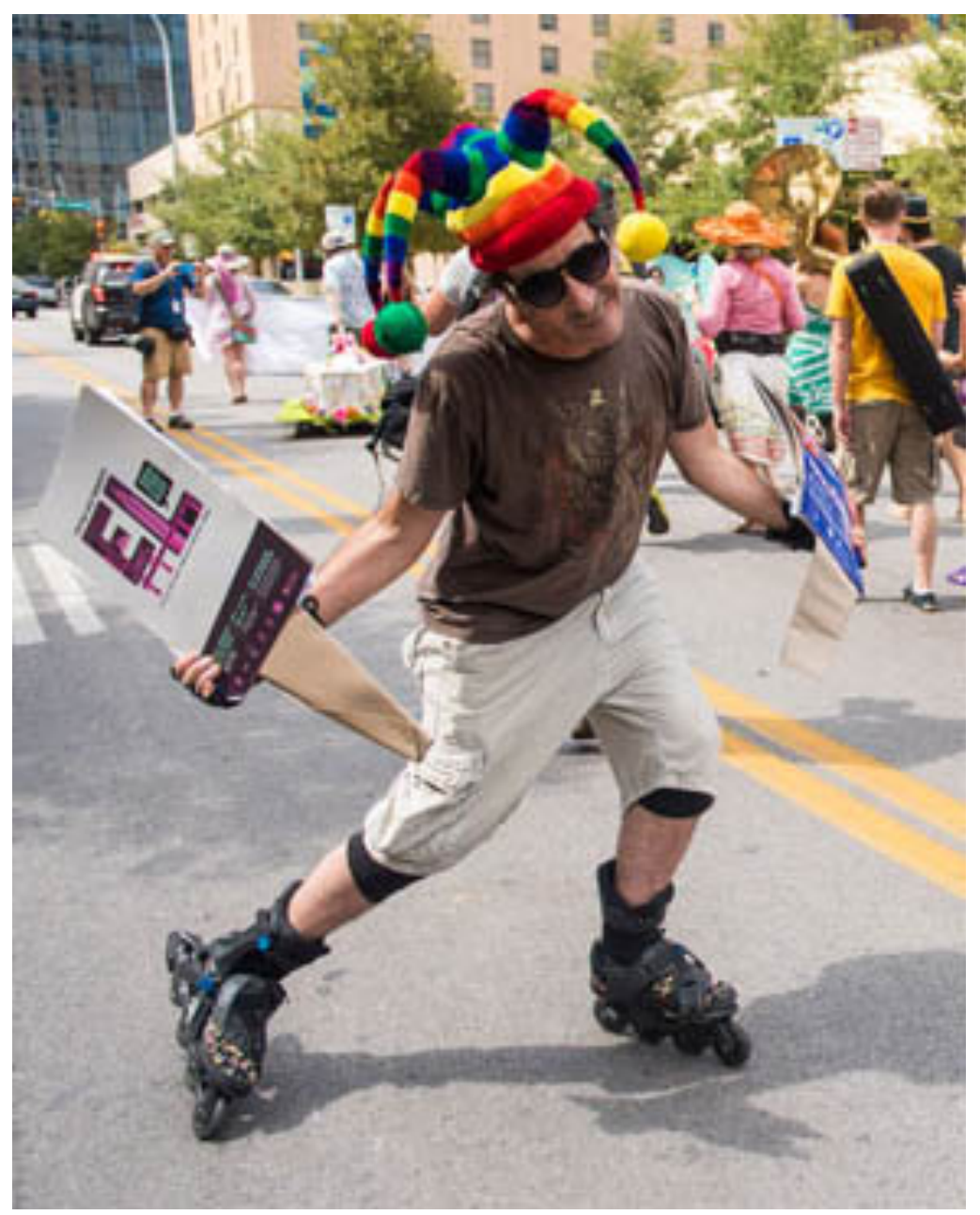


Figure 8.41: Dog walker and dancer (as cited in D.B. Hall, 2016)

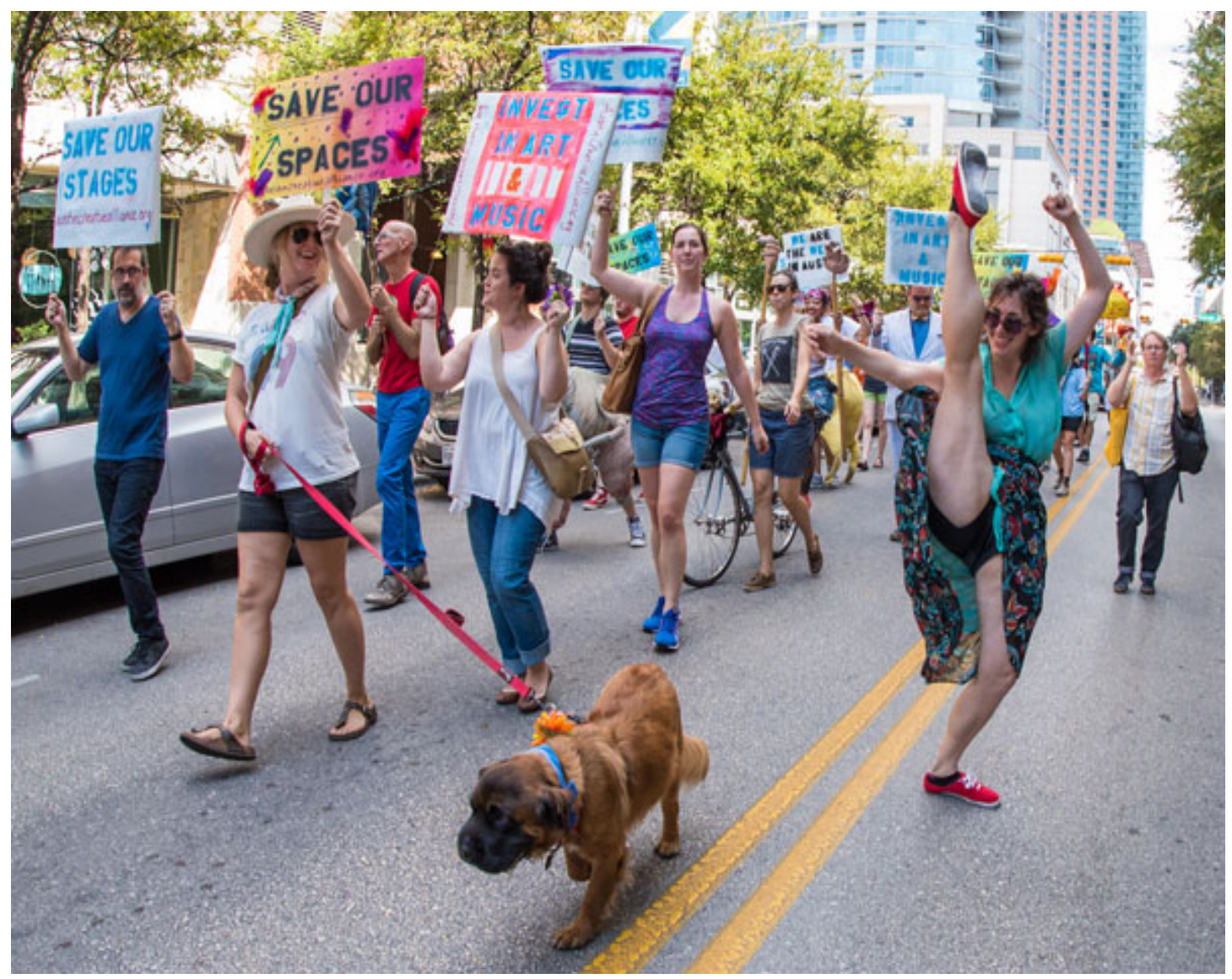

Despite the fun, though, the marchers had a serious message, with two leaders of

Salvage Vanguard Theater, a local theater company, reminding the marchers and the city government as to how the arts were a building block of Austin and to tell the city government some of their ideas on how artistic space could be preserved — and, thereby, demonstrating that its care for the artistic community is not just lip service (Faires, 2016).

We as artists are resourceful, but the arts are not a resource. We are a necessity. We teach our communities, and we heal our communities. Our work may appear to be fruits on the tree of Austin, but we're really the roots. Make no mistake about it. The arts are a part of those roots (as cited in Faires, 2016).

In 2012, the city drafted an Imagine Austin plan. Well, imagine an Austin without us. So, we ask the city council to give us the keys. Give us the keys of an underutilized building, perhaps one in your city center that's just housing toilet 
paper. Give us the keys to an underused rec center, one that is not being used at night or on weekends. Give us a ninety-nine-year lease. Give us a below-market, sustainable business rate.

Give us a sign that you give a shit whether we stay or go (as cited in Faires, 2016).

One of the other protest leaders also mentioned how the arts were a draw for the industries like tech, as Draco did, and the chair of the music commission did during my observation in January 2018. Because of that, the protest leader said that it was time for the city to invest in the arts that drew these companies to Austin.

Tech is coming because of us. I want all of you to call your city council person tomorrow, email them, and remind them that arts and music are what brought tech to Austin. Arts and music brought all this wealth to Austin. Arts and music brought all these people to Austin, and it's time to invest.

When the city thinks the core of the city is in trouble, they build a hotel. When they think the tech industry is in trouble, they give it $\$ 70$ million in tax abatements. I'm not saying those are bad investments at all. I'm saying that we're in a crisis. Now is the time. Invest in arts and music (as cited in Faires, 2016).

Events such as these, Severus said, allow people to "bust a cap" — vent their anger in a way that would not be acceptable in a traditional setting and do something fun and creative, the latter being especially important to people in artistic communities. They also counter the problem that artistic community members noted in my other interviews of sitting through long meetings with several items that are of no concern to them. These go far from being cathartic, though, and retain interest in participation efforts, something that scholars have consistently noted is a constant problem in citizen participation (Pridemore, N.E. Ganapati, \& Revell, 2019). Noting the 2016 protest that he observed, Severus said: 
Severus: Most of this groundwork is laid in one-on-one meetings with staff. So that's where you really get the chance to make the argument to people who work for a council member about value capture, about mitigating the market, about the rate of increase versus the rate of revenue expansion, and policy wonk shit that they kind of respect and understand. If you don't have that, you're not going to be heard anyway. But you can go raise hell if you want.

There was some anger there and a woman who had just lost her theater. She gave a pretty angry speech, but her point was that the city actually has a lot of space. In fact, the city owns performing arts spaces, and they're closed all the time because they haven't allocated employee budgets to have somebody who can open the doors and stay through performances. So what she was angry about at the steps of city hall was that there are empty spaces right now.

There was some anger and some passion and some passion and some passion and some fun and creativity in that march. I would not be able to keep people motivated if all we did was go to city hall and speak very politely about wonky policy. Every now and then, you have to let them bust a cap out and express that anger and make a scene.

You have to have a draw for them to do it. If I had to get everybody to come to city hall every other week and sit there quietly for four hours waiting for an unknown time for an agenda item, that would dwindle very quickly. So in the interim, we have meetings at our office, we talk a lot, and we basically have some pep rallies. It keeps the people happy with bread and circuses so that they do want to show up when it's time to be boring and dry. We're taking a serious policy approach here, and that's the tone. Not only do we modulate it toward the way to political culture talks in Austin, which is very evasive and elusive and not blunt at all. It's frustrating because I'm a blunt guy, but the arts community's message is getting known.

During my time in Austin, I often mentioned some of the outlaw citizenship activities related to local government and the artistic community in New Orleans, such as the January 2014 brass band protest and the Krewe Du Vieux Mardi Gras parade. Some interviewees praised New Orleans' artistic community, with a few of them suggesting that they take New Orleans' more aggressive stance, given that their working in traditional participation, in some minds, does not seem to work in Austin. Noting that Austin's outlaw citizenship, as I will detail more in the previous chapter, is mostly done 
online, some in the artistic community believed that taking outlaw citizenship to the streets would be far more effective.

Percy: I think online political shit is masturbatory at best, often. I hate to say it, but it's like if Austin musicians wanted to make a movement... I don't think striking would work, but if they really wanted to really freak out some politicians, taking it to the street would be way more effective than doing it online.

\section{Taking back local events after losing ownership}

As mentioned in the previous chapter, there were feelings that some home-grown events, particularly South-By-Southwest and the Austin City Limits Music Festival, no longer belonged to locals and were instead overtaken by outside entertainers and attendees. Some groups within the artistic community began organizing "alt" festivals during these events as a way to have their own local-oriented events again and reclaim that event time.

Hermione mentioned Raw Paw's “Ditch the Fest”, which Siciliano (2018) writes is a yearly event designed to "highlight some of Austin's most badass local talent" (as cited in Siciliano, 2018) and because of it taking place at ACL weekend, it is "even more of a reason to put Austin talent front and center". The 2018 event took place at the earlier-mentioned Cheer Up Charlie's in the Red River district (Siciliano, 2018), which the local artistic community considers beloved and a place for "real" Austin local music. (Personal Communication, 2017, 2018).

Hermione: It's a day-long thing of local bands - a sort of answer to the big festivals. During South-By, I'm sure (Raw Paw) will be putting on lots of showcases and stuff that are mostly made up of local bands and artists.... I definitely think that's sort of become their role, just to be a general creative support system and facilitator of the local art scene. 
Other "alt" festivals included Goat by Goat West (Blue Tongue, 2018) and Peach by Fuzz Fest (Peach by Fuzz Fest, 2018), as answers to South-By-Southwest, which was both free or very low in cost, especially when compared to South-By-Southwest's badge prices that can cost more than $\$ 1,000$. Ron noted another such event during ACL called the "Austin Corn Lovers Fiesta", with the same ACL acronym. According to its producer's website, this festival was also born from ACL not featuring enough local talent (Saustex Records, 2018). The event has expanded to allow regional acts, but the event is still locally focused. The organizers' website states, in part:

The annual floating club, mini-festival is hosted by Saustex Records and local cowpunk anti-heroes, the Hickoids.

The festival was spawned on the fly in the band's touring vehicle, "The Freak Van", on the way home from a West Coast tour. After reviewing the lineup for the upcoming behemoth ACL, they wondered aloud why there wasn't more local talent featured, and a little monster was conceived. Originally, it was a four consecutive night lineup, but followed suit to the much larger provocateur ("the other ACL")..." (as cited in Saustex Records, 2018).

During my interview with Ron, I noted some other "alt" groups in Austin previous interviewees had mentioned, some of which were conceived with an antagonistic stance against a more dominant group in mind. Unless the "alt" group is acting with antagonism for others and, instead, simply wants to present a different option that appeals to more people, this is a benefit, according to Ron.

Ron: If all you're doing is trying to throw shade at somebody else, that's silly. But if what you're doing is using it as a way to gather other people and kind of build your own tribe for the improvement of the lot and the life of everyone involved in your group, then that's fine. The more, the merrier. I can see the concern, but I think as long as that's just the starting point so everyone can kind of laugh at and maybe have a little bit of fun with it rather than it being an antagonistic thing, then I think that benefits everybody. 


\section{Outlaw City Government}

One potential enabling factor for outlaw citizenship in Austin was the city's increasing stance as an outlaw city government — one that fought back against policies from ideologically polar opposite state and federal governments, and with that state government inside its city. While some of Austin's progressive stances were seen, in the last chapter, as "Austin Exceptionalism" - the idea that Austin is a equality oriented progressive bastion when there are serious social inequities were happening — as a participation hindering factor, the city government had some sharp policy differences with the state and federal government that included ones involving the arts. Interviewees indicated that these and the state government chipping away at Austin's local control, which sparked serious ire, believed this was common ground for the city government and its citizens to fight back and together.

The Texas state government, alone, has namely used a combination of legislative action and court cases to erode numerous aspects of the city's local control. These include (but are certainly not limited to) the state legislature passing a bill to overturn an Austin ordinance meant to help low-income renters with federal housing vouchers and later prohibiting use of certain building fees for building more affordable housing (Watson, 2018), Governor Greg Abbott stripping Travis County (which contains the majority of the Austin city limits) of $\$ 1.5$ million in criminal justice grants for refusing to cooperate with federal authorities on immigration policy (Jarvie, 2017), the Texas Supreme Court striking down Austin's and some other Texas cities' plastic bag bans (Lindell, 2018a, 2018b), and a state appeals court striking down an Austin city ordinance requiring most businesses to pay employees sick leave (Lindell, 2018c). Interviewees 
from both inside and outside of city government say that they believed Austin's overall way of life was being threatened. This could enable non-traditional participation and more locally oriented because both city government and the artistic community (as well as much of its at-large citizens) see a mutual threat.

Pomona referred to Austin as a "blueberry in a bowl of tomato soup" and noted how the city "got in trouble with the big, bad governor of Texas" because of it being a "sanctuary city" in terms of immigration policy. While, as detailed in the previous chapter, other Texas cities such as Dallas and San Antonio have become markedly more progressive, Texas remains a very conservative state, overall. I definitely noticed this in my travels throughout the state as I drove between Austin and New Orleans and on different routes during my fieldwork. Austin prohibited firearms at city hall, but a state district judge ruled, in a lawsuit the state attorney general's office filed, that the city violated state open carry laws when it blocked a licensed firearm holder from entering city hall in 2016 (Autullo, 2019). The city was fined $\$ 9,000$. Austin city government's attitude toward firearms was markedly different from other areas in the state, given what I saw on physical artifacts such as pro-gun bumper stickers, giant shotgun windshield decals with "Come and take it!" on them, and this merchandise displayed in Figures 8.42 and 8.43 that I saw for sale at a gas station in northeast Texas. 
Figure 8.42: Texas gas station gun T-shirt (Pridemore, 2017)

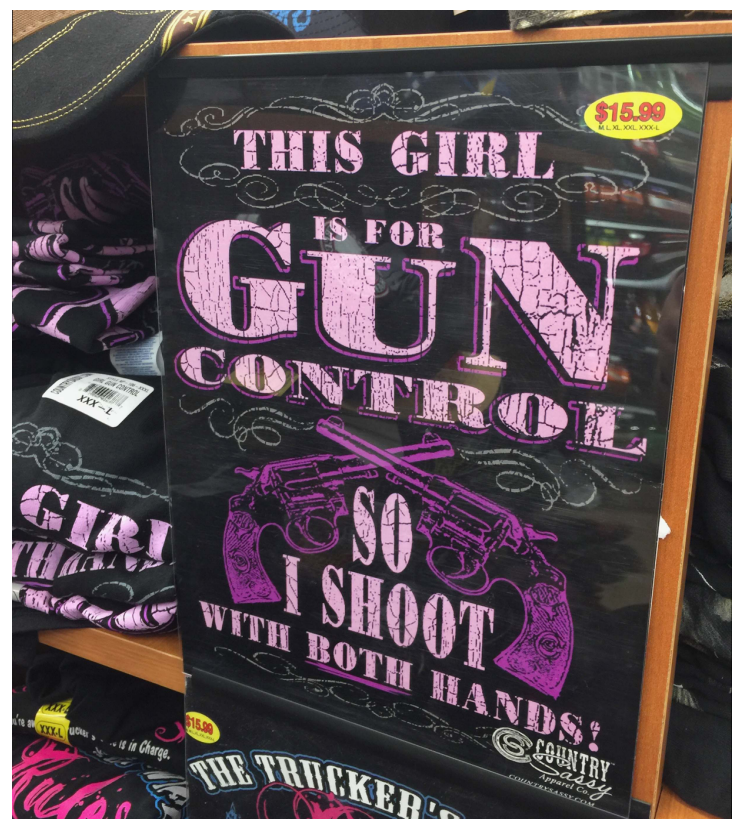

Figure 8.43: Texas gas station gun, God, America T-shirt (Pridemore, 2017)

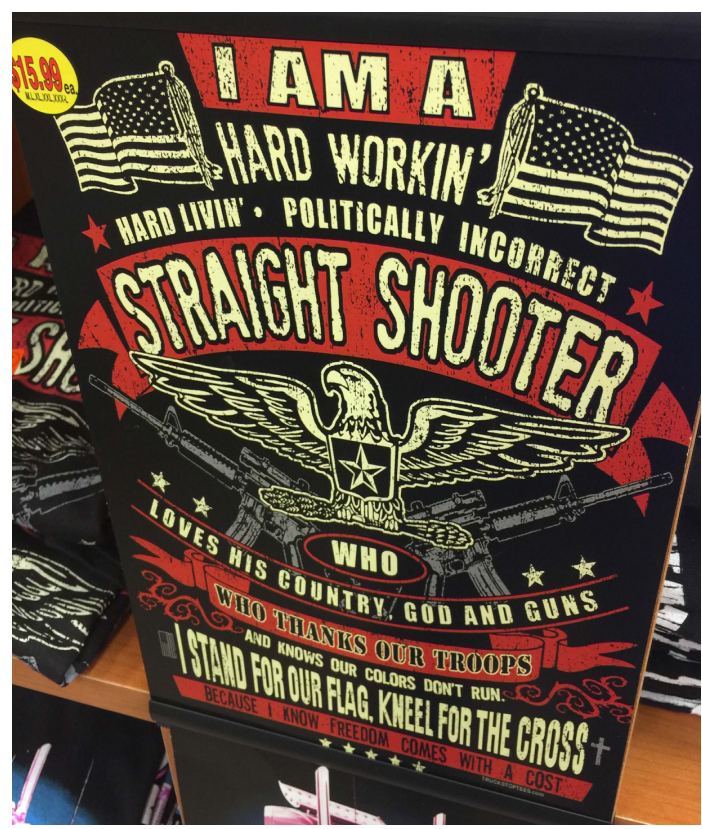

Noting the state government's frequent eroding of Austin's local control, in

general, Pomona said:

Pomona: We're going to march to the beat of our own drum, always. I think that the state- and federal-level government hurdles that are putting up barriers right 
now are definitely... I don't want to get too dramatic, but they're threatening our way of life, and they're threatening the way we operate, normally. I think we have a very strong-willed and very opinionated mayor who is going to do his best to make sure that the way of life in Austin and integrity of the people who live here is maintained.

Amelia: But is it going to be a hard fight with the federal and state changes happening?

Pomona: Definitely.

...Pomona: Without diving too deeply into my personal politics, it's been a funny thing to watch when it's like, "Oh, now the governor things they can do this because the president told him he could do this, and this is perfectly fine." But you know, I know that the city of Austin is going... The day after the presidential inauguration, one of the largest Women's Marches in the country was assembled in Austin. It's definitely interesting to watch and interesting to see what's happening around us to kind of wake up every morning... I feel like I live on completely different planets and what's going on...

Definitely, living in Austin, it just feels like... I was born and raised here, and I definitely wake up some mornings and feel like I live on a different planet than the rest of my state, which is very weird. But you know, sometimes, all you can do is kind of watch and be like, "Well, I hope that things work out in our favor." It's definitely been interesting to watch, to kind of be an outside spectator of the rest of the state.

City officials I interviewed noted that finding affordable housing solutions, a challenge for the artistic community, can be extremely difficult namely because of Texas state law. Andromeda, a city planner, said that some cities facing affordability issues like Seattle have implemented "inclusionary zoning", in which the state grants local governments the option of requiring developers to put affordable options in their developments. The state of Texas does not allow this. States such as Texas depend on Community Development Block Grant (CDBG) money for affordable housing. Usually, a nonprofit partner is the one who builds the affordable units. 
Andromeda: We have the state government literally a mile down the road from us, and they especially watch us. They love watching Austin and seeing what we're doing.

One hit for the artistic community and the city's arts economic development work Molly noted was the state's cuts on film project incentives, meaning that film projects have now left Texas for other states.

Molly: One of the big issues we've seen change in the past several years was that the state has basically sort of gutted its film incentives, which makes it really hard for attracting film projects to Texas, where there used to be sort of a competitive aspect to attracting projects, where you could give tax relief or some sort of funding to kick back to these projects that they choose to film here. And that's not really there anymore.

That has really impacted projects being filmed here. We used to have several TV shows that were sort of based here, plus several films. They've gone to other states. Georgia has a really robust program. Michigan, I think, has a really robust one. It's been really frustrating for us to be able to... We had a companion creative content incentive program, and it's just basically been now kind of a shell of what it was, which is really disappointing because the film sector is one of those where, typically, they rely on a lot of private support. If you can build in some public support, that's a great way to get some projects off the ground.

Amelia: Do you know why this was cut?

Molly: I just think that, maybe, there was the view that film was not as essential as some other programs. I don't know. The profile maybe couldn't compete with other programs. Maybe some lawmakers felt like it was sort of a frill, or a throwaway, or luxury, or it was not worth the state's investment. I think it has kind of made me more aware. I think there's a lot of perception, unfortunately, where the facts are not on par with how people maybe perceive a certain creative industry. I don't know. There was one particular lawmaker who was sort of on a warpath, but unfortunately, I think when it comes to the state level, a lot of those discussions don't necessarily take into account a lot of the things that are happening around the state, which are not happening at the legislature. So there are special interests I think it kind of elevated. 
Hermione said she favors more of a community-based, self-sufficient approach.

However, she believes the city was going to be an "essential" part of countering state policy that affects the artistic community and life in Austin, in general.

Hermione: As much as I say, "We can do it all ourselves!", we do absolutely need the city to put some policies into place. Some are already in the works, like ones to keep rent affordable for galleries and venues in developing neighborhoods. I know that's one they're working on right now.

Absolutely, we need those kind of institutional structures in place if we're going to have the same kind of diversity and size and quality of music community that we currently have because, otherwise... I think one of the things that makes Austin so unique is that we have all of those nonprofits and organizations and stuff, but I think as soon as those start to fail in doing their jobs and in keeping music as a sustainable profession for musicians, we're going to lose a lot of people to other cities that are maybe improving faster in those areas. I think Austin has a lot of things existing, but it's going to be an issue, as well, of course - continuing to keep those things relevant and active and to ensure that there's just as much nonprofit and city support as there is development coming in.

\section{Conclusion}

Though Austin changes at a blinding pace, the artistic community refuses to give up without a fight. Hallmarks about Austin's artistic community enabling factors are that the artistic community knows the proper place, proper allies, and proper opponents for this fight. Casual, level third place (Oldenburg, 1999) gatherings with local government officials versus ones in city buildings created a conducive environment for productive and less intimidating conversation, especially for those from underrepresented groups. It also led to more effective public policy and better relationships with the government and artistic community, simultaneously, because officials demonstrated genuine concern by walking out of the door rather than simply opening it and it gained first-hand knowledge of what the artistic community's challenges are. 
Likewise, the positive in-group relationships within the artistic community some of which developed from rivals becoming allies — ensured that when the artistic community approached city government, it had a united front and did not have infighting ruin their efforts. They recognized that their fellow musicians, fellow visual artists, fellow business owner, or a person from another discipline was not the enemy. They also knew how to be self-sufficient while doing so, avoiding the problem of determining which third party could be trusted. It also meant that some people, in their self-sufficient efforts, had to drop deeply ingrained Third Face of Power-related (Gaventa, 1980; Warner, 2001, 2011) thought patterns that government was the enemy before it could do so, as well. In this, they followed Gaventa's (1980) trajectory in defeating power structures. The artistic community also recognized that the general public was a needed ally, and it worked to remind it of why cultural activities and creative spaces under threat in Austin mattered and worth fighting for - and did so in an attractive way that was creative and fun.

One of the major contributions this chapter has provided is how vital place is when considering enabling (and hindering) factors for citizen participation. It showed how Oldenburg's third places (1999) concepts such as these spaces being social levelers, being comfortable and free-spirited, and being birthplaces for new ideas not only manifested themselves in real-time but also worked to create conducive environments for citizen participation, especially for disaffected groups. It also aided in the problems with formal meetings being intimidating for historically disenfranchised groups (Rimmerman, 2011) and with meetings being in inconvenient places and times, especially in terms of work schedules (Fung, 2006, 2015; Laurian, 2004). Place provided an addition to social 
construction scholarship (Schneider \& Ingram, 1993) because, place, in this chapter was shown as socially constructed, and, as such, could be a positive policy target if that social construction was and remained positive.

A key contribution to citizen participation literature in this chapter was its findings regarding in-group citizen relationships. Previous scholarship in citizen participation has noted competition between different groups (Pridemore, N.E. Ganapati, \& Revell, 2019), but, here, it notes the importance within citizen groups as a make-orbreak. The account of the Red River venue owners who work side-by-side in an intensely competitive entertainment district deciding it was time to, as one put it, stop "giving the finger" to the other business owners and come together with a united front was critical in demonstrating that any internal issues had to be either settled or at least pushed aside if critical policy change was needed. This was especially true when mutual opponents had much greater power and financing.

Citizen group self-sufficiency is another major contribution. Previous scholarship, as noted in preceding chapters, has largely viewed partnerships as ideal and as a positive (Pridemore, N.E. Ganapati, \& Revell, 2019). However, the Austin artistic community stepping out on its own, especially when presenting its own policy solutions and its own evidence-based arguments, garnered a positive response because of that self-sufficiency and it did not have to worry about which third party could be trusted.

Likewise, they showed how they reached this point through breaking one of the bindings of the Third Face of Power - letting go of ingrained beliefs that another group, government in this case, is the enemy (Gaventa, 1980; Warner, 2001, 2011). This is a major addition to studies involving disaffected citizens' participation because these 
ingrained beliefs are often part of an oppositional stance one needs to survive in societally disadvantaged situations (Personal Communication, 2018). Oppositional stances and being a socially disadvantaged positions are key elements of outlaw citizenship (Rimmerman, 2011; Pridemore, 2018), but this demonstrates that breaking from that thought pattern is not impossible, but it is easier said than done.

All of these factors provided two major challenges to notions of outlaw citizenship — how it is not necessarily confrontational against government and how outlaw citizenship can hinge on who is participating rather than what is being done. The artistic outlaw citizenship that was designed to remind fellow citizens and government officials that the activities had value and to rally them in support. This participation was outside the traditional sphere such as public hearings (Pridemore, 2018; Rimmerman, 2011) was done to unite, not confront. The other challenge is that when someone from a disaffected and historically underrepresented group enters traditional participation, the fact that they are defying both in-group messaging that government is the enemy and powerholders who would rather they stay away makes them challenge longstanding power imbalances (Gaventa, 1980; Warner, 2001, 2011) on two fronts.

This chapter simultaneously addresses the concerns of private-sector versus nonprofit arts scholarship and figurative community "ownership" of something, such as a home-grown festival. The chapter did provide additions to the arts policy literature (M. Jackson, Herranz, \& Kabwasa-Green, 2002; Rushton, 2013) about how private-sector orientation of government arts offices can work extremely well and mesh better with individual artistic community members. A key factor in these, as well as "alt" events replacing ones believed to be lost to outsiders, was that the artistic community had 
ownership of them. They were home-grown and the product of citizen participation. Traditional participation involving public officials and outlaw citizenship activities like "alt" events having a common thread seems rather strange, but, as Molly said, these, like the arts in Austin, being locally created and not with a "consultant's stamp", were major participation enabling factors also because they truly belonged to the Austin artistic community.

While this may seem trivial, the importance of fun and creativity in citizen participation is a major element, and this is something outlaw citizenship can readily provide. As policy scholars, policymaking and its forums are elements to which we have literally devoted our lives. Because of that, we may forget that many of those outside of our field, such as artistic community members and especially younger ones, consider traditional policymaking forums mind-numbingly boring. Existing scholarship has shown that public administrators constantly struggle with retaining citizen involvement (Pridemore, N.E. Ganapati, \& Revell, 2019). One solution to this problem is possibly finding ways of making citizen engagement fun, engaging, and creative. This can be especially effective with engaging younger populations. The finding that the city government can be an ally in outlaw citizenship because of its increasing disaffectedness over the state government eroding its local control and it fighting back (Jarvie, 2017) means that disaffected citizens could potentially work with and not against the local government, anyway, which is a major flipside to outlaw citizenship scholarship (Pridemore, 2018; Rimmerman, 2011).

Austin may be struggling to determine when and how to apply the figurative brakes as it continually morphs and the city, as a whole, is constantly facing an uncertain 
future as it changes so much and so quickly. Still, a strong artistic community that has linked arms, even with former rivals, and worked to remind its government and the public at-large as to why it and its spaces matter and need to stay will not back down without a fight — and against the right parties — will use its creativity and self-sufficient drive to do it.

In the next chapter, I will pose the question of "Who participates?" in Austin's artistic community. This will work to answer this dissertation research question that seeks to balance out diversity and inclusivity with incoherent noise. A key element in this chapter is a deeper exploration of social media participation, which is in its relative infancy in government use, and is an outright newborn in public administration citizen participation scholarship (Pridemore, N.E. Ganapati, \& Revell, 2018). This is where the extreme event of the 2018 Austin serial bombings filtered into this dissertation findings, as Russian trolls worked to sow discord in Austin while the city was being terrorized for almost a month (Herrera, 2018a). Social media may provide great outreach opportunities, and cause outright chaos at the same time. Therefore, governments who want to use it must approach with extreme caution. 


\section{CHAPTER 9: AUSTIN AND DECIDING WHO PARTICIPATES}

Social media's extremely diffuse democracy and potential for outright mayhem, having a robust dialog and having too many speakers drowning out underrepresented groups, and participants' racial and ethnic diversity were numerous balances that both government officials and artistic communities had to strike when determining who participates in policymaking. In this chapter, I explore both the problems and solutions that in determining who among Austin's artistic community participates in local government. Government officials and artistic communities alike consistently worked to strike this balance between democracy and incoherent noise that could drown out the less powerful.

The largest contribution that this chapter's findings provide is greater insight into social media participation, which is practically a newborn in public administration scholarship. The Austin case study provides exceptional insight into this issue, given that some city government entities are doing live citizen participation forums and hosting live meetings over social media. Pridemore, N.E. Ganapati, and Revell (2019) found that in a sample of empirical public administration articles from 2006 to 2016, only three explicitly mentioned social media or a social media platform in the title. Online participation has been a popular topic in public administration scholarship in recent years, but most of its content has been related to government websites. This chapter provides insight into how social media takes democracy to an extreme, inviting literally any person with an internet connection to participate in local government. This countered problems shown in the literature and some of my own findings involving participation equity, such as finding transportation to and from public hearings and dealing with work and family 
responsibilities. It also gave local governments to connect with artistic communities where they virtually congregate.

At the same time, that extreme democracy had major drawbacks because it invited outside agitators to both derail critical conversations and erode citizens' faith in their cities' institutions and trust in one another. What made social media participation even more vexing for local government is that it was on platforms the government did not ultimately control, meaning that there were unruly citizen behaviors during participation that, in some circumstances, it could not stop. On top of that, local government had to keep up with that technology's extremely rapid changes and changes made before technical glitches and bugs could be resolved. The high-tech world of social media and its issues with democracy's doors being opened so widely echoed James Madison's 232year-old concerns in The Federalist Papers (2001 [1787]), where he warned that "factions" consisting of a majority, an especially loud minority, or even "an obnoxious individual" would drown out the voices of the less powerful.

Other key contributions in deciding who participates involve participation equity and the issue of increasing participant diversity. Like Fung $(2006,2015)$ has pointed out, the findings in this chapter indicate that a major problem is that those who typically attend traditional public hearings are a more privileged set, with few racial minorities and those from poorer socioeconomic backgrounds. An addition this chapter makes is that another contributing factor to participant inequity is having too many participants at a given venue - cutting into underrepresented groups' time to be heard through dragging out meeting times to a point when those with more restrictive work schedules or lacking transportation can no longer stay. Likewise, this chapter builds on Fung's $(2006,2015)$ 
recommendation of selectively recruiting more diverse groups and ones a given policy affects the most by stating how this can be done for artistic communities. Namely, it involves physically going to their gathering places and having a constructive one-on-one conversation first.

This chapter's first section involves determining who participates with in-person participation. I begin through discussing problems with who participates, which include public hearing speakers not being representative of the population, lacking racial and ethnic diversity, and having too many speakers. Then, I present solutions in determining who participates. These namely include selectively targeting diverse and underrepresented populations and narrowing participation down to a few spokespeople so that dialog is more controlled, concise, and constructive.

In the second section, I discuss the social media in terms of who participates. Social media was such a complex and uncharted topic that it warranted a section of its own. The positive findings include its greater accessibility, how often the targeted artistic population uses it, and its data tools governments can use to gauge participation. However, the largest section of this comes afterward, which are the negative sides of social media being so diffuse in terms of who participates. Because social media opens the doors so widely, it opens the doors to and even encourages those who want to create a destructive dialog, one that erodes relationships with government, within groups, and faith in city institutions. Those who engage in this are often outside agitators, who purposefully seek to make situations worse in a crisis, as Russian trolls did during the Austin serial bombings in March 2018 (Herrera, 2018a). Other problems include the fact that government use of social media is in its relative infancy, and the technology 
constantly changes on this platform in which tech companies are ultimately responsible for the participation ground rules.

\section{In-Person Participation}

\section{Problems with who participates (in person)}

The traditional public hearings' speakers not being representative of the artistic community, a lack of racial and ethnic diversity, and meetings having too many speakers — which drowned out the voices of underrepresented and less powerful groups on multiple levels — were major problems that Austin was facing in terms of deciding who participates. These problems ultimately hurt democracy, even when participation seemed robust on the surface, because too many participants from far more advantaged populations overtook the policy dialog and chaotic "town hall" forums produced no meaningful results because of literal and figurative incoherent shouting — sometimes making negative situations worse.

Public hearings' speakers not representative of the city, artistic community

A key problem in Austin in terms of who participates, interviewees informed me, was that those who were heard much more often were not representative of the artistic community or city as a whole. Namely, those who participated the most in traditional public hearings were wealthier, single-family homeowners, and participants were overall very majority-white. This created inequitable participation in terms of factors such as race and socioeconomic status, and, like Fung $(2006,2015)$ argues, more privileged groups had a disproportionate impact on the policymaking process.

Albus, an advocate and a former member of multiple city boards and commissions, said that in his former role in the city, he noted that at a given meeting, 
numerous people from one constituency would come out to speak in favor of or against a given policy. However, that did not mean the entire city supported or opposed that policy. Rather, this was a group of self-selected participants, something that Fung $(2006,2015)$ notes is an issue with the traditional public hearing format. Like Rimmerman (2011), Albus also noted the problem that historically underrepresented groups like those with low socioeconomic status are generally not raised in a culture where voicing concerns to government officials is emphasized or encouraged.

Albus: When you're on a board or commission, you are trained. Part of that training should be about recognizing who it is you're listening to. When we hold a public meeting and we allow people to come up and testify, I would want my members of, say, the planning commission to ask, "Are these all single-family homeowners who are trying to keep out renters? Or are they people coming up with legitimate concerns about parking and traffic and flooding? Are they just trying to be exclusive about who lives near them?"

So I don't know if I got that in my training. In my training, I got stuff about open meetings, rules, and open records, and Robert's Rules of Order, and things like that. But what I learned over time was just a question - Who was testifying? Was it always the same people? Was it always detached single-family homeowners who were trying to keep others out or practice some exclusive housing policy? Was it always the same environmentalists who were concerned about something? Was it always the same business people who wanted to reduce regulation? I mean, there are so many special interests out there.

It's not a vote. If everybody comes up and is against something, that does not mean that the citizenry as a whole is against it.

Amelia: It was just whoever came to the meeting, right?

Albus: Yeah. That would drive me crazy when my colleagues would say something like, "Well, we've heard from most people, and they don't like this." And I would say, "Well, you didn't hear from most people. You heard from the people that are here." I didn't say it like that, but it's the realization that, one, single moms, the people who have to work hourly jobs at minimum wage, the seniors who can't get around without ambulatory aids - you don't hear from a lot of people because they can't get to the meeting and they don't know about it. It's not a part of their culture, either. 
The single-family detached homeowners, Albus said, are not necessarily wealthy, but they are an affluent set with mortgages and pensions and/or higher-paying jobs. This is the group that comes out the most to public hearings and to at-large city elections. With the latter, there is a higher political price to pay, should officials cross them. He said that when it comes to change in general and change that would benefit the artistic community, this group tends to be one of the most vocal opponents. He said their motivation is namely NIMBY (Not in My Backyard) issues, such as a neighbor selling visual artwork from his/her home or noise from a music festival. This becomes especially problematic when this group dominates forums. He also emphasized that in the grander scheme of societal problems, these NIMBY complaints should not be such a concern.

Albus: They tend to be the most adverse to change and stand in the way of us making more affordable communities and allowing artists to sell things out of their homes or allowing a new music venue to go in or complaining about a music festival nearby where people park on the street and things like that.

The key to success in a lot of what we're trying to promote is increased tolerance. ... I wish people were more tolerant. That would help us boost the arts more and more.

...I think people don't like a stranger parking in front of their house. They don't like the fact that people are coming and going next door, and they don't know what's going on inside. They're worried about the fact that they can hear something inside their house even though it doesn't disrupt conversation or prevent them from sleeping. They don't want to hear that bass coming in, so it's these minor annoyances that rise to the level that somebody will vote a particular way, or make a phone call to a public official, or send an email to a public official, or whatnot when they're just... Who cares?

...It's a public street. Why would you care that your neighbor is selling art out of their house? It's their house, and it's not keeping you up at night. It's not preventing you from sleeping or eating or coming and going from your own house.

And yet, that's the disproportionate number of people who turn out. 
Like Albus noted with the voter representation, Ron, a journalist, pointed out that most voter turnout in the city does come from the wealthier districts, toward the western part of the city. Lim (2015) wrote that the 2014 city council elections, the first with the 10-1 Representation, had the highest overall turnout in Districts 8 and 10, which are in the west. Turnout was lower in Districts 1,2,3, and 4, toward the east and where, historically, heavier concentrations of black and Hispanic residents have lived. So when certain groups appeal to elected officials in particular, Ron said, any bias those officials have is generally not a dislike of underrepresented groups but, rather, a preference for those who are definitely represented because of political capital.

Ron: I think there's probably a sentiment that politicians only cater to rich people. But the thing is that more rich people are the ones who vote. That's where it is. It's not a class thing. It's an activity bias.

Ernie, an Austin police officer, pointed out that turnout is not the only factor in terms of participation equity. Another factor is wealth and power, which can defeat numbers. So even if a true majority is opposed to a given policy, if the single person or entity that wants it is powerful enough, that person or entity can still emerge victorious. This does not necessarily mean someone in the artistic community will always lose. Austin is home to some large entertainment corporations, as well as struggling freelance musicians and artists. Certain large entertainment entities, which are extremely powerful, can even override wealthier homeowners and neighborhood associations. So when factoring in those large entities, some in the artistic community can override others because of power and wealth, just like some wealthy homeowners can. Also, those can 
lose include the bureaucracy, whose evidence-based claims may not weigh as much in elected officials' decision-making as an entity's power and wealth.

He gave the example of C3 Presents, an Austin-based entertainment company that produces the Austin City Limits Music Festival — and the Lollapalooza music festival in Chicago and numerous other events. ACL takes place in Austin's Zilker Park in the southwestern part of the city, which is located near some residences. In 2017, Ernie said, the city police and residents took issue with C3's request to extend its footprint because this would involve blocking emergency lanes. This was part of the exchange I had with Ernie.

Ernie: ACL is very... I mean, $\mathrm{C} 3$ is the promoter for ACL, and they are a very, very large organization. They run Lollapalooza and work in Paris and Germany and all over the place here in the United States. And they lobbied city council and said, "Hey, we want..." They did it (in 2017) and said, "Hey, we want to extend our footprint." We said, "No, you can't do that. You can't do it. You're going to block the emergency lanes." City council said, "Yes, you can do it." So guess what? They get to do it.

Now you've got emergency lanes blocked. You've got an entire street that's blocked that nobody can go down. They're like, "Well, OK. We're going to figure it out. But (city council) let them have it. That's the politics of it. We can't go against what city council said when city council said they could have it. They can have it. Now, we just have to work with it.

Amelia: So you had your input and told council these were emergency lanes, but they sided with $\mathrm{C} 3$.

Ernie: Yes. Absolutely.

Amelia: And likewise, is it often the same when a huge neighborhood association is up against a little neighborhood bar?

Ernie: Absolutely. Big lobby. If they've got an entire neighborhood going, and you've got this little bar that's all by itself and it's not part of an association, it's a disadvantage for the bar. Yes.

Amelia: So is there both power in numbers and power in money? 
Ernie: Yes.

Amelia: What would you say is the deciding factor - the power in numbers, the power in money, or some combination of them...

Ernie: It could be one or the other. I mean, it could be a single person that has a lot of money that is the voice. There's power in that. It could be the association, a large number that basically means there's a lot money involved there too. But it depends on the situation. I mean, we've had instances where it was one person that was there complaining. But it just happened to be a very powerful person, a very well-to-do person, and council listened. So it could be either one.

\section{Lacking racial/ethnic diversity}

As detailed in Chapter 7, racial and ethnic representation in policymaking decisions was extremely low, despite Austin's image as a progressive city in a conservative state. This was an image minority interviewees and some white interviewees said was false namely because of how minorities have been and still are treated. In terms of who is currently participating and who is not being heard, participants are overwhelmingly white. This is in a majority-minority city that, according to 2018 U.S. Census data, is only 48.6 percent non-Hispanic white and 34.5 Hispanic, 7.6 percent black, seven percent Asian, and 3.1 percent "two or more races" (U.S. Census Bureau, 2018a). This was a major problem in terms of balancing out who participates and especially concerning to the interviewees because minority residents have disproportionately borne the weight of the skyrocketing costs of living with the city's rapid development.

Draco, a city boards/commissions member who is also Hispanic, drew the narrative map below to show his ideal relationship between the city government and artistic community. 
Figure 9.1: Narrative Map (Ideal): Draco, city boards/commissions member

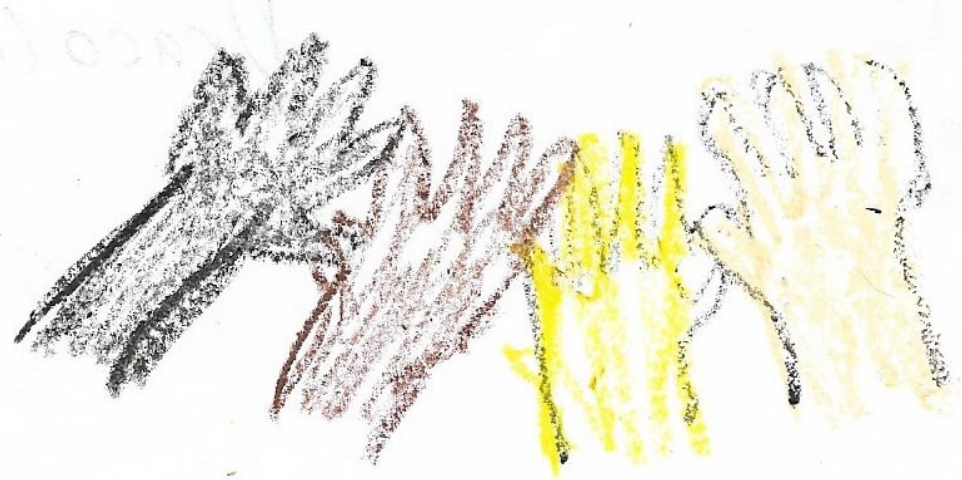

Draco explained that his drawing represents a desire for greater racial and ethnic representation with both the artistic community members the city exalts and in terms of who is heard in policymaking. The latter is very interconnected because the art forms and artists who are promoted, namely white artists from "cowboy/Americana/blues" music, are the ones who have a greater standing in city government, he said. On top of this, the legacy of segregation policies, such as those that came from the 1928 Koch Fowler Plan (Koch and Fowler, 1928; Tretter \& Sounny-Slitine, 2012; Zehr, 2015a, 2015b, 2015c), is still evident because the city's minority populations are still heavily concentrated east of Interstate 35 . This is especially troublesome because the city cannot truly progress and have a positive outside view if the city's residents remain segregated and much of the city's population is not represented and is not heard. He said:

Draco: Black and brown people are missing in our city. This drawing is a bit racist probably because I'm using colors to match, quote, "flesh", but we are missing diversity from our music industry, and diversity in general.

Our city is one of the least diverse creative capitals in the world. Its doors are closed to people of color and communities of color - Latino, African-American, Asian. ... It's not that the music industry in of itself has any racist tenets, but this community is so self-segregated that we will never achieve the status of Los Angeles, New York City, or Miami until we address this issue. 
...Have you seen a statue or mural of a Mexican-American musician anywhere in the city? No. There will be none found.

Minority artistic community members are continually underrepresented in policymaking, interviewees such as Padma, an advocate for the artistic community, told me. Like Albus, she pointed out the issues of how participation forums generally leave out historically disenfranchised groups (Fung, 2006, 2015) and often because of longstanding mistrust of government officials - a tenet of the Third Face of Power. Those from historically disenfranchised groups are taught that certain groups who could help them, like government officials, are the enemy, and those disenfranchised groups do not trust them and/or work to oppose them (Gaventa, 1980; Warner, 2001, 2011). Those who come from more advantaged backgrounds, like Rimmerman (2011) writes, are more at ease in government settings.

Amelia: One of the key questions I'll be asking is who participates...

Padma: Oh, it's the white people. It's definitely... It's the twenty-something white people. It's not the 40-or-50-year-old artist, generally speaking. It's the young artists who are, perhaps, not that far out of college. I rarely... I very, very rarely see artists of color at any of these events, whether it's an artist or a fan speaking on behalf of the art they love. I believe that goes back to social equity. There are people who feel very comfortable and safe in the so-called halls of power, and there are other people for whom those are not attractive destinations. They don't have a lot of trust in that system.

The stakes are so much higher for minority communities because of their higher displacement, Penelope, an Austin journalist, said, that if participation is to be limited in any way for conciseness, then it should be limited to minorities.

Penelope: It's entirely possible to get people in a room and have them come to some sort of agreement. But I would almost rather they just have less white 
people because I feel like minority communities are the ones that have more at stake and have the most to lose. So why not let them make some more choices on these issues? Even as a white person, I would just be so sad to see even more black people leave the city because they feel like they don't have a voice. I mean, we are already still becoming the least diverse while growing the fastest.

So, I'd almost rather the people who are being marginalized make more decisions then, if that's what it comes down to. If we have to limit people, limit it to the marginalized.

\section{Too many speakers}

As noted in Chapter 7, one major participation hindering factor has been extremely long meetings. One reason interviewees cited for government meetings, which frequently last past midnight, has been too many speakers, which presented a major problem in terms of balancing out democracy and too much figurative (or literal) noise. This meant certain groups' time to speak could come way too late for them to stay, particularly if they are relying on public transit, cannot afford to have a car parked longer, or have to go to work. It created a major participation equity issue. Another problem that interviewees noted is that having too many speakers creates nothing but outright noise too much shouting and to the point where the message is diluted. This echoes concerns of James Madison in the Federalist Papers (2001 [1787]) and Hirschman (1970) who warned that less powerful people could be drowned in the noise (Alexander Hamilton, Jay \& Madison, 2001 [1787]) or those in power may be turned off because they find the noise harassing (Hirschman, 1970).

Ernie illustrated the problem with too many participants creating too much noise. Earlier efforts to mediate disputes between businesses such as live music venues and entertainment companies and other groups such as hotels and neighborhood associations 
were open to any affected person, and they were not successful at all because of the clamor. They possibly made bad situations worse.

Ernie: We have tried efforts where we had a large number of people affected in an open forum meeting, and, basically, nothing gets done. It turns into a gripe session. ... If it's a large open forum, it doesn't work.

...There were definitely some heated tones. It is literally just a gripe session - a bitch session, you know? You don't actually get to give any information or try to get a consensus as to how many people are for something, against something, or really don't care. You don't even get to that because you never get that far during an open forum. It's just shouting.

Just as this was a problem in terms of whose viewpoints were represented and whose were not, the number of speakers created a problem in terms of who was heard both because of underrepresented groups' constraints and also because of repetition, Albus said. This repetition was not only in terms of the number of people who spoke about the same issue at a given meeting but the ones being heard being the same people, a "core of civic activists" over and over again and at meeting after meeting. After he had mentioned a government meeting that lasted past midnight, he mentioned how he and government officials during and after his tenure have struggled with keeping an open dialog with citizens while also working to limit speakers to make sure certain groups are not cut out in the end.

Albus: Mayor after mayor and commission chairperson after commission chairperson has tried to figure out how to make the meetings shorter. We instituted a rule when I was serving on one of the commissions where, instead of everybody having three minutes, the first speaker would have five minutes, the next three speakers would have three minutes each, and then everybody after that would have one minute. You could trade your time if people would donate their time to you. But we were trying to get as fewer people to talk because of the repetition. 
...We try to be fair. We try to say that everybody will have a chance to speak, but your speaking time will be limited if you're just repeating the same argument over and over again because we're trying to balance giving everybody a chance to talk and getting the meeting done in a timely manner. But it's very often the case that you see the same people all the time.

Penelope noted the difficulty of limiting speakers namely because, whatever time speakers are given, they will use it if individual time limits are the only constraints. Austin's size and growth makes this even more of a challenge, but at the same time, finding a way to ensure certain groups are not cut out of the overall dialog can be extremely difficult.

Penelope: I've covered a good amount of board meetings in my life. I can say that if someone is given too much time to talk, they will use it, and they will use every second of it. But it's hard to figure out because you want everyone to have a voice, and in a city like Austin, it's just monstrously huge. How does New York do it? I just can't imagine how you get everyone's voices in. So, it's tough.

Grumet (2018b) writes that the city council has tried multiple efforts to shorten meetings, such as having separate hearings on "specific high-interest issues" like the city police contract and CodeNext, utilizing online message boards for council members to ask city staff questions so that they are not asked during meeting times as often, and "steering more public comment and policy crafting into committee meetings" (as cited in Grumet, 2018b) However, the meetings still run late, and the committee meetings "merely created more meetings without making the full council gatherings any shorter" (as cited in Grumet, 2018b). About the balancing act between democracy and conciseness, Grumet (2018b) writes:

Don't get me wrong: I don't want meetings to be too efficient. If everything is predetermined and meetings merely serve as a rubber-stamp function, the public misses the opportunity to influence policy and understand how city decisions are 
made. But there's got to be a happy medium that doesn't turn democratic participation into an endurance challenge (as cited in Grumet, 2018b).

\section{Solutions to who participates (in person)}

Targeting populations and narrowing down participants were major solutions when Austin's city government and artistic community worked to determine who participates. One key was selective recruitment, working to find underrepresented groups affected most by a given policy where they gather first, then bringing that targeted population to the forefront. Another measure that saw major success was narrowing down a given group's presentations to a few spokespeople. This was particularly useful not only in countering the problem of having too many speakers, but it was also conducive when multiple groups who had negative relationships with one another in the past needed to work out their differences. Fewer people in the room — but those people being representatives who determined their message with their comrades in advance — led to a more constructive and concise dialog that has solved contentious issues.

\section{Targeting groups policies affect the most}

As noted in Chapter 8, interviewees indicated that specificity is needed in terms of deciding who participates and, in that, participants should be recruited based on how much a given policy would affect them. The ones who would benefit or be hurt the most should be who participates, they said. This meant that the participant pool would be one that brings first-hand knowledge of the situation at hand and, for the participants, it would be something that encourages them to participate more because their input mattered and their time mattered. Interviewees also noted the importance of considering groups inside 
the artistic community who play a significant role but are not in the spotlight, literally or figuratively, as often as others.

Ron said that targeted recruitment for participants is vital engagement and engagement that moves dialog forward. In doing that, governments must realize that older ways of reaching people, namely through broadcasting widespread messages to a general audience, do not work as well as finding ways to target the different groups they need.

Ron: There are tactics and platforms and tons, and tons, and tons of ways to reach people effectively. You just have to be one. You have to realize what doesn't work. You kind of have to give up your marriage to the old ways of trying to reach people and keep trying new things and have standards. Don't just be willing to do the good enough.

Have standards and demand that if we can get that library ballroom full of one hundred people, then we should have the right people - not just one hundred people, but one hundred people who matter. Part of it is that government is created for the masses. But I think with regard to engagement, you've got to kind of choose your audiences and narrow your cast a little bit because if you narrow cast, we can find your little niches a lot easier and communicate a much more effective message than if you just try to bullhorn to everybody who's gone by on the street.

Interviewees also noted the importance of considering groups inside the artistic community who play a significant role but are not in the spotlight, literally or figuratively, as often as others. Padma, in noting the race and income challenges mentioned earlier, pointed out groups that need to be engaged that also included those who are definitely vital parts of the artistic community like blue-collar workers but do not get the attention that groups such as performers have. While they are part of the artistic community, they have different concerns that need to be heard, as well, especially if a given policy would affect them more. 
Padma: You want people who are hardly considered a part of the artistic conversation. We're a big festival community, and sound engineers and people who build stages - those people are really important. It's a blue-collar workplace backstage. The blue-collar folks generally don't get engaged in the conversation because they're not the ones onstage. They're the ones with the steel-toed boots, but they're just as vital to an entertainment economy or a creative economy as the artists themselves.

In some ways, they're closer to city policy. They're the ones affected by rules from the health department, rules from the transportation department, or parks, or right-of-way, code enforcement... Those are the people who get hit with it much earlier in the process than an artist like the drummer is going to get hit by it. It's going to be the door guy who has to deal with something, some kind of emergency, because the doors are locked or the sprinkler isn't working. That's going to fall on someone very different from the artists, but it's still part of the same ecosystem.

\section{Narrowing down to a few spokespeople}

One solution some officials and artistic community members have found in being democratic, yet controlled, is narrowing down conversations between different stakeholder groups to a few spokespeople — having each group, before meeting with city officials and divergent groups, decide on their key talking points among themselves and then appointing a spokesperson. This has led to more concise and more constructive conversation because of far less crowded rooms. This has especially been the case when the groups involved have had less-than-friendly interactions.

Ernie said this is the police department's general approach in mediation, something that was done with the Red River venue owners and with the Austin City Limits Music Festival's management and the neighbors. The department has done this for about five years, as of my interview with him in 2017. This, he said, has produced much more constructive dialog.

Ernie: So what we do is we get a representative for, let's say, a condo building. Let them decide what their overall vote is on the whole thing. They can figure that 
out and send their representative. There's no reason for us to do that. Or if they need information, they'll send a representative, and we'll give all the information that we can give and let them go back and tell the others. Then, they can vote.

...We have stakeholder meetings when we're doing something on Sixth Street. Even when Sixth Street is just being Sixth Street, we'll gather stakeholders if there's a problem and mediate that issue.

Amelia: Have you noticed a difference for better or worse in between relationships with all parties since you've been having the stakeholder meetings?

Ernie: Oh, it's absolutely for the better. There is a lot more transparency, plus the residents and the neighborhoods get to communicate to the person or people that are putting on the event or running the venue. With ACL, we have people who talk with our transportation and parks departments and with the people who run ACL about how many roads are going to be shut down, how they're going to get into their neighborhoods, how to keep people from parking up the whole neighborhood... It's absolutely a positive effect.

...It's absolutely a lot calmer with a lot less complaints. ... There's more participation from $\mathrm{C} 3$, which runs ACL, and the neighborhood. They have their own agreements. They've made agreements, and they have their own communication. So, we're not always in the middle of it because they got together, and they have their own communication.

Severus, an advocate for the artistic community, said that during some public hearings, artistic community members will bring about thirty people for the visual effect of having a number of supporters. However, a strategy he and others devised was having only twelve speak and do so in a "measured and informed way".

Severus: I was told I got all kinds of notes of congratulations from across city hall because we did it really, really well. We didn't piss anyone off in the process. We didn't come at it as though we were entitled. We talked about it reasonably, and it was just, "This market is moving too fast for arts and cultural businesses, and we all agree that the arts and culture gives us an edge in other economic realms. So can you guys help us build a tool kit to mitigate that market?"

Lily, another advocate, noted that while narrowing down speakers is effective, in itself, groups who are working to have a voice in policymaking must be strategic as to 
who their speakers are. Sometimes, choosing someone with more stature is effective, but what works best is having a good cross-section of speakers. Like Ernie noted, a critical point, Lily said, is having the group agree on their message in advance. To avoid the repetition problem mentioned above, she suggested having the chosen speakers bring up different issues that the group has agreed are their core — and with proposed solutions.

Lily: Although my issues here and this person's issues here may not be exactly the same, as long as we're saying, "I'm in the arts. These are the issues that my group is encountering. And so we have banded together with all these other people. We feel that this is our issue. We've all decided on the five issues." You know, you've only got three minutes. So, everybody takes an issue that they're going to talk about, and I'm number five. I say, "You know, I agree with all of the other issues that have been presented, and our final issue is this one. We feel that the following things are something you should take into consideration, and we think some of the solutions are — bam, bam, bam, bam, bam — Thank you very much."

\section{Increasing participant diversity}

Increasing participant diversity should be a goal in determining who participates, interviewees told me. Interviewees noted that when working to increase participant diversity and include the viewpoints of those who have been underrepresented, there are strategies one can undertake. This namely involved what Fung $(2006,2015)$ noted was selective recruitment, working to specifically target populations who have been left out of vital policymaking processes who have a greater stake than others. In Austin, as interviewees noted was desirable in Chapter 8, this has involved going to where the artistic community gathers and starting conversations with potential new participants there rather than simply opening a door and waiting. On public officials' parts, interviewees also noted that officials need to be willing to work with someone with 
whom they do not agree because although that viewpoint is the opposite, it should still be heard.

Albus said reaching historically underrepresented groups, such as the working class and other historically underrepresented populations, is very difficult, but it is not impossible. The key is finding them in-person and engaging with them face-to-face first. Angelina, a city elected official, echoed these sentiments.

Albus: That's where you have to go out and have the stakeholder groups, appoint stakeholder groups, and make sure that you appoint people from those communities to your boards and commissions. Make sure that you go out to public meetings at churches and schools. The PTA, civic events... Show that you're present and willing to talk to citizens. The best officials are the ones who will go outside of city hall to talk to people and find out what they need and what their concerns are.

Angelina: I think there are more intentional strategies at the city level to try to get diverse voices involved. ... Just in the time I've been involved in lots of conversations with a certain group that is seriously struggling, most organizations are talking about the importance of and are acting on getting individuals with lived experience involved in the conversation.

Helena, a city boards/commissions member, said a key is that city officials must not only find participants reflective of the city itself, such as considering factors like race, but also be willing to listen to and work with those with whom they disagree.

Helena: City government staffers, officials, all of those people have to be very conscious and inclusive because you don't want the same faces. I think that's where it's important. You have to recognize that, while it may be easier to work with the same folks in these processes, you have to be inclusive and reflective of the city you live in.

Amelia: When you start hearing the figurative warning bells of, "This group is getting a little too exclusive here," what are some things you can to do to put the brakes on that? 
Helena: First and foremost, I think when people start telling you things, listen to them. When people start saying, "Hey, well, what about this? What happened to this idea?" Listen to them. I think staffers and officials have to be willing to listen to people who absolutely do not agree with them or their ideology, or it's moving in the direction they may not want to go. But hey, they're here to represent their entire constituency. That doesn't mean they're going to do that, but you have to at least listen to folks who have something different to say than what you may or may not believe.

\section{Social Media Participation}

Social media participation took the issue of balancing out democracy and incoherent noise to an extreme on the democracy side, creating an especially vexing problem for the city government and the artistic community alike. It opened the doors to literally anyone with an internet connection. This had serious advantages namely because engaging artistic communities where they virtually congregated was an effective way to reach them and counter issues involving transportation and work schedule issues. It used the target population's tools and simultaneously created greater access.

However, the negative aspects of social media did outweigh the positive in these findings. The most prevalent social media finding, period, was the problem of general chaos and bad behavior. The doors being opened so widely and on a platform social media companies, not governments, ultimately controlled, opened the door to those who wanted a destructive dialog, which ranged from online trolling and fights to outside agitators like Russian trolls working to erode relationships within communities and faith in institutions, like the news media and law enforcement. This was made far worse during the March 2018 serial bombings, which had the city in a state of terror even without factoring in the agitation. The problems also include just the fact that government use of 
social media is in its infancy and even when government becomes well-versed, the technology and tools change yet again.

Interviewees informed me that, despite the challenges, some balances can be struck with social media participation. The key takeaway was that it was good for notification, but not engagement. Engagement, they said, had to move offline to in-person forums - whether it be a traditional public hearing or an informal in-person gathering at a third place venue (Oldenburg, 1999). The notification would reach a wider audience but those who genuinely wanted to positively engage, were truly part of a given city or community could come, and the in-person interaction provided a greater social accountability. In-person interaction meant that someone would be far less tempted to use internet anonymity to be vicious to one another.

Austin provided unique insight into social media citizen participation and how it can spur a more democratic dialog and create chaos. During this study, I conducted observations of two Facebook Live meetings that two different city offices - the Music and Entertainment Division and CodeNext conducted. I chose the former, done in January 2018, because of a segment of the artistic community being its core audience, and I chose the latter, done in December 2017, at random to have a second department to which I could compare it. I did this to see if the two departments experienced common or divergent positive and negative aspects of their social media participation outlets so that this did not narrowly target the Music and Entertainment Division for better or worse and to see if I could discover issues involving social media live engagement that could be transferred to studies involving a broader range of public agencies. I will utilize 
information I gathered from these Facebook Live meetings throughout the rest of this social media section.

I will also note that finding online forums for the artistic community that I could ethically use was difficult for Austin because most of the artistic community's forums that I discovered were in closed groups - meaning that any data I pulled from those groups could be considered unethical evidence gathering. However, this closed group situation was a finding, namely because those in the Austin artistic community were working to avoid problems with outside agitators and trolling.

\section{Positive Aspects of Social Media Participation}

Social media participation had some positive aspects, namely in terms of providing a more democratic selection of participants. One of the more pertinent positive findings for social media was access. This gave populations that may not be able to access traditional forums because of issues like work schedules and transportation greater ability to engage with the local government. Social media was also the tools of the targeted population, which allowed governments and advocacy groups the ability to virtually go to where their populations congregated.

Accessibility

One positive aspect of social media participation that interviewees pointed out was greater accessibility to policymaking forums and government officials, as well as officials' ability to reach the artistic community with specific information and question and answer sessions about topics that were of major concern. In determining who participates, this created a more democratic dialog overall. It helped counter issues 
involving the artistic community's work and personal schedules and transportation issues, both of which hindered their participation in other formats.

Pomona, a city economic development employee, pointed to a regular session the Music and Entertainment Division has over Facebook Live called "ATX Music Talks". During these sessions, a panel of industry professionals who are experts in the topic the office chooses both discusses the issue in real time and audience members who are logged in can ask questions in real-time, as well. These sessions are recorded so anyone who wants to watch it at a more convenient time can do so. ATX Music Talks was done because of accessibility issues that the office wanted to counter.

Pomona: What we've run into quite a bit on our end is people saying, 'I can't meet at the time that you're having a meeting. I can't meet at 5:00 in the afternoon because I have my kid. I can't meet on Saturday in the morning because I had a gig the night before." It's just different things for different reasons.

We're never going to capture everyone, so we figured if we could provide an opportunity for people to watch the Facebook Live channel and tune in online or tune in later and reach out to us... It's all in an effort to reach a wider audience. We have a social media following on Facebook allowing up to 10,000-plus. We're getting closer to 11,000 as we speak. So, we have a huge audience, and it's a venture that has been quite successful for us because of the audience that we have and because the subject matter is impactful and relevant for us.

While she believed in-person conversation was preferable, Penelope said that Facebook Live meetings such as ATX Music Talks was still a good opportunity for more people to have access to government officials and what offices like the Music and Entertainment Division have to offer.

Penelope: It would be nice if people showed up in-person instead. ... But I think it bridges the gap for people who can't make it to meetings or have to be at work or something. I do feel like it gives an opportunity for people who can't be there to still learn. 


\section{Data tools}

Social media participation also provided government officials with data tools for which they could gauge both engagement levels and real-time reactions to certain points of their meetings. It can give government officials more information as to how well their message is spreading, as well as how it is being received by the population it serves.

During both of the city's Facebook Live meetings I observed, I was able to see how many Facebook users were tuned in and at what times, seeing if participation was picking up or if people were tuning out. This number is shown at the top left hand corner of the broadcast video and highlighted with a pink box, shown in Figure 9.2 for the CodeNext meeting.

Figure 9.2: Facebook Live's viewer counter (as cited in City of Austin, 2018a)

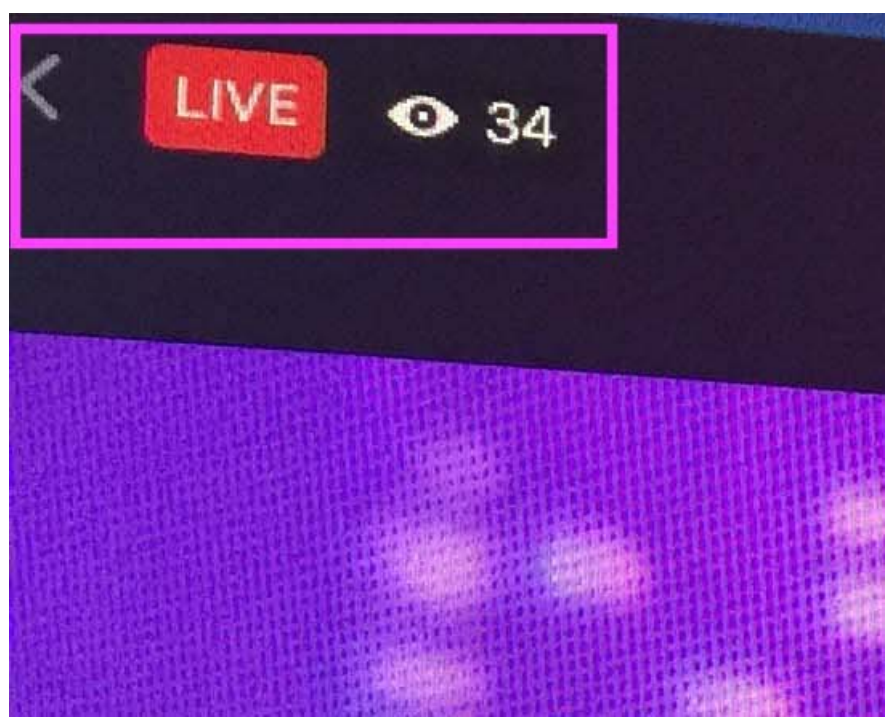

One caveat is that at any given point, determining why people were tuning in or tuning out was almost purely presumptuous because that would require finding them and asking — and from my observer's view, I could not see the names of those tuned in unless they were making comments. 
Another tool that Facebook Live provides is a way to gauge participants' realtime reactions and perceptions of what is being discussed, thanks to Facebook's six different reaction types that users can show — a "like" (a thumbs-up sign), a "love" (heart), a "haha" (laughing emoji), a "sad" (crying emoji), and an "angry" (angry emoji). So, for example, if something is being well-received, it could receive numerous "likes" or "loves", indicated by those symbols going across the screen at that time. Conversely, something that receives a negative reaction could receive a sad or angry emoji, if not numerous ones. A photo of the emojis, at the bottom of the screen for users to utilize in real-time, is shown in Figure 9.3.

Figure 9.3: Facebook Live's real-time emojis (as cited in City of Austin, 2018a)

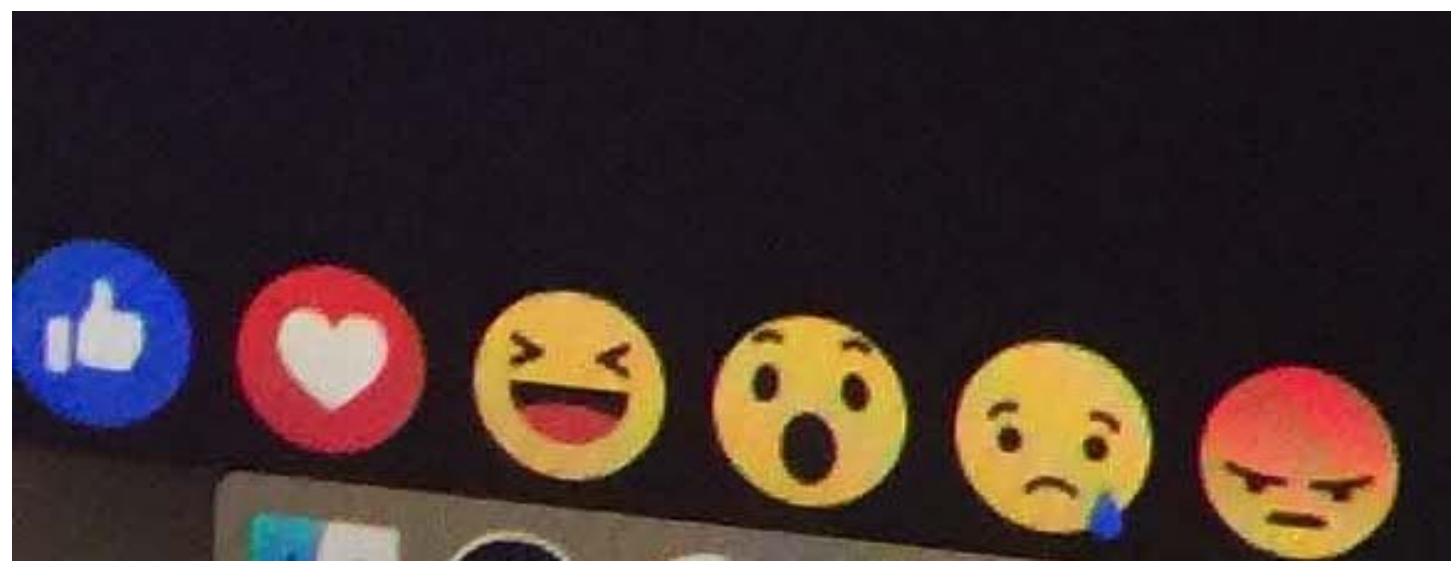

However, this can be rather subjective, as well. First of all, the laughing emoji could be used if someone finds something humorous in a good way, like if someone on the meeting said a joke that was meant to be funny. On the other hand, it can be seen as likely mocking someone too, which is a not a positive reaction. Furthermore, some may find the use of cartoon-like symbols out-of-place in a public policy discussion, especially if the matter has major implications. CodeNext, for example, is highly controversial and could completely redo Austin's city land use codes and outright alter the landscape even 
more than it already has been altered (Personal Communication, 2017, 2018). Therefore, emoji use during a discussion of such a policy may be seen as out-of-place.

\section{Using the tools of the target population}

Interviewees indicated that social media is a major communication tool the artistic community in Austin uses, meaning that anyone working to reach them is figuratively going to where their target population is rather than merely opening a door.

Besides reaching the artistic community at their gathering places, like bars and music venues, Sirius said that using social media is probably one of the best tools in both reaching the artistic community and city government having greater visibility in terms of the work that they do and what they have to offer. He estimated that about ninety-five percent of his fellow musicians are active social media users, and this is how they network among themselves, especially if they are freelance musicians doing "hired gun" shows, a one-off performance with a given band as opposed to playing as a regular member of an established band.

Padma said that social media use in reaching the artistic community is much like working to translate figurative "language barriers" (Herranz, 2015). Early in social media's advent, others did not want to use these platforms, but she found it successful. One has to shake off the fact that, although social media may not be their figurative cup of tea, it is the cup of tea for the target population. She also noted overall shifts away from Facebook and onto other social media platforms, such as Instagram, and how some of the target population may not be instantly attracted to a government agency's or advocacy organization's page. 
Padma: I think that one of the things is understanding the tools those you're wanting to talk to use to communicate - speaking to them in their language. When I started this, no one wanted to deal with social media. It turned out that we got our best turnouts for events when we promoted on Twitter and later on Instagram, where we posted pictures of people at events, where we had people engaged and talking.

That's not where I hang out, but it doesn't matter where I hang out. It matters where the people I'm working to engage hang out. I think that using the tools that they use instead of trying to convert them to using the tools that you want them to use is key. I always say you've got to meet them where they are, and they're on Twitter.

They're not on Facebook. You put all the events you want and reach a couple of people, but you're not going to get the engagement that you want. The people we met in Austin... That's not where they made their choices of what events they chose to engage in. They made their choices based on recommendations of friends and through Twitter and Instagram - not necessarily a city page or an organization page that invited them on Facebook. So, we adjusted.

\section{Negative Aspects of Social Media Participation}

However, the majority of social media findings in the Austin case study were especially negative. The most prevalent finding for the entire social media part of this study was that chaos and bad online behavior was a major problem that had to be considered when deciding who participates. Social media taking diffuse participant access to an extreme meant that it opened the door to those who worked to agitate Austin citizens and during one of its most harrowing months — the March 2018 serial bombings — and, in general, worked to stoke longstanding racial divisions, erode trust among citizens, and erode faith in city institutions (Alliance for Securing Democracy, n.d.c; Grumet, 2018a; Herrera, 2018a; O’Donnell \& Webb, 2018). Many of those outside agitators were Russian trolls who, as they have done in other localities, taken 
longstanding local problems and used them to sow discontent (Chen, 2015; Grumet, 2018a; Herrera, 2018a).

Other problems namely included government use being in its relative infancy, meaning that social media was uncharted territory for governments. Furthermore, some of its tools constantly changing and on a platform that tech companies, not governments, controlled, meant that governments continually had to keep up with the changes that tech companies did not always make for the better.

\section{General chaos and bad behavior}

This finding involving social media participation in Austin was seen as the most prevalent negative finding - and most prevalent finding in social media participation, period. These issues included online fights and trolling, which created ill feelings toward one's own fellow citizens, and the fact that some engaged on Austin-based social media discussions were outside agitators, namely Russians, whose goal it was to create discord among citizens. This became especially egregious during the March 2018 serial bombings in Austin, when fear and ill feelings about longstanding social inequities reached a fever pitch.

All of this created a dilemma in terms of who participates because social media opening the door to an extremely diffuse population, which can also hide behind false identities or mere user names, means that it opens the doors to people whose idea of citizen participation is extremely toxic and not only stall needed dialog but also create an extremely negative one that erodes any positive relationships government officials have built with the artistic community and, possibly, ones artistic community members have built with one another and with others in the city as a whole. 
Rimmerman (2011) noted that one major problem with online participation is that, unlike face-to-face interaction, is that online participants are not held accountable for their positions. Social media interactions, interviewees told me, can take that to an extreme. Almost every interviewee said they have witnessed social media users being outright disgusting to one another in comment sections. They said social media users attacking someone from behind a screen rather than to that other person's face — and therefore, not having to deal with in-person consequences — make being vile easier for someone to do, both logistically and emotionally.

Narcissa (musician): It's so much easier to verbally shit on someone in the privacy of your own home than it is in person, or it's at least easier for people who want to tear someone down or tear some thing down. It's easier to be sort of the invisible person on the Internet as opposed to face-to-face with someone. ... You probably wouldn't say that to whoever is reading that tweet to his face.

Penelope: It's very easy for people to be rude and mean. ... I would definitely never tell someone, "Oh, I think you should do a Q\&A on Facebook. Things would go great," because people will say crazy things on the Internet and because it's the Internet.

Penelope noted that some will go as far as starting social media accounts entirely devoted to attacking a person or group. These can be especially vicious and literally dangerous. She mentioned the Austin nonprofit Boss Babes, an organization that, among other aims, works to boost women's entrepreneurship in occupations such as the arts (Boss Babes, n.d.). One group that, upon my working to find it online in early 2018, had been taken offline since was rather sadistic.

Penelope: There's now a hate group that's literally focused on Boss Babes in Austin, called "Kill Your Boss Babes". They've got a Facebook group, and they have a Twitter account. I don't know if they still do because I reported them. It's 
not even just against the founders of Boss Babes, but they go against different women in Austin that they don't like.

Amelia: Is it an anti-feminist group?

Penelope: Actually, it isn't. It's another form of feminism, but it's like people who think that Boss Babes doesn't do enough. Like, they think that it's inappropriate to be asking women to become bosses. I don't completely understand it, but they... To me, it's not very positive for the feminist movement because I feel like it's just attacking each other when we could just be working together. But they were really angry because they don't like Counterbalance ATX.

...Counterbalance is completely black-woman-run, and it's an activist group. They call it the global majority because black people are the global majority, and it's basically a way to uplift women in the global majority. And they were extremely, extremely helpful during Hurricane Harvey, literally giving everything they had to helping victims who were the people who were forgotten about in Houston. For whatever reason, they have a lot of haters. Any time black women are powerful, it seems to be that people like to come back and have backlash. So when Boss Babes had a community caucus, there were death threats against them for hosting Counterbalance and giving them a platform. Honestly the commentary... There was a picture of one of the women hugging a police officer at a vigil, and (the hate group) was saying things like, "Oh, Counterbalance is propolice," because they're really hard on police.

When social media opens the doors, it also opens the doors to outside agitators solely working to sow discord in a given country — or state or city — and this is not isolated to federal-level governments. This creates a serious problem for local governments and citizen groups in terms of weighing out democracy versus controlled dialog because social media opens the door to anyone with digital access, whether they are a part of a given city or community or not. Not all visitors are kind digital houseguests. In fact, some actively work to destroy relationships within communities and are extremely skilled at it, namely through finding existing tensions and exploiting them. 
During Austin's March 2018 serial bombings, Russian bots and trolls worked to stir discord, locally, as the city was being terrorized (Herrera, 2018a). The strategy, after a review of secondary sources, a database compiling Russian-linked tweets linked to the Austin bombings, and social media traffic during the bombings, show that the apparent Russian strategy was building on the still-burning legacy of Austin's racial inequality that namely includes the Koch and Fowler Plan (1928), which forced black and Hispanic residents to live east of Interstate 35 (Tretter \& Sounny-Slitine, 2012; Zehr, 2015a; Zehr, 2015b). That local legacy spilled into local forums and overall dialog (Alliance for Securing Democracy, 2018a, 2018b, 2018c, 2018d, 2018e, 2018f, 2018g; Grumet, 2018a; Jean, Ramsey-Ford, West, Vasquez, \& Appice, 2018; O’Donnell \& Webb, 2018). Another tactic was, as been done in other Russian trolling operations, working to erode locals' faith in longstanding institutions, namely in the local news media and law enforcement (Alliance for Securing Democracy, 2018a, 2018b, 2018c, 2018d, 2018e, 2018f, 2018g; Grumet, 2018a; O’Donnell \& Webb, 2018; Schafer, 2018). These tactics were also rooted in the city's longstanding racial divisions, both physical and social (Alliance for Securing Democracy, 2018a, 2018b, 2018c, 2018d, 2018e; Austin American-Statesman, n.d.; O’Donnell \& Webb, 2018; Zehr, 2015a, 2015b).

Herrera (2018a) writes that the Alliance for Securing Democracy, “a bipartisan nonprofit that monitors six hundred Twitter accounts linked to Russian influence agencies" reported that "Russian bots and trolls were tweeting heavily about the Austin bombings at the height of the manhunt" in mid-to-late March 2018. The organization also "reported a spike of almost two thousand tweets" from the "Russia-linked accounts" on March 20, 2018 (as cited in Herrera, 2018a). On that date, a fifth package bomb bound 
for Austin exploded at a FedEx facility outside San Antonio, a sixth bomb was found but disarmed at a FedEx facility in Southeast Austin — and the serial bombings ended during the very early morning hours of March 21, 2018, when suspect Mark Anthony Conditt blew himself up in his vehicle in Round Rock as police closed in (Chang, 2018). Conditt left a video behind, confessing to all the bombings (Osborn, Huber, \& Walsh, 2018).

In Austin, the Russian-linked accounts, Herrera (2018a) wrote, "were helping push false narratives that the bombings were not covered by the news media because the first four bombing victims were black and Hispanic" and "that police did not take "the bombings seriously until they involved white victims". The overall online dialog also included whether or not Conditt, who was white and reportedly came from a "Christian background, was being treated differently than if he had been a person of color or a Muslim" (as cited in Herrera, 2018a).

The Alliance for Securing Democracy has a searchable database available of "known and suspected Russian-linked Twitter accounts" from its Hamilton 68 project that worked to track this activity since August 2017 (Schafer, 2018). Additionally, the database includes tweets from "Twitter's release of more than 3,800 Internet Research Agency (IRA) accounts" (as cited in Schafer, 2018). The IRA has "become known for employing hundreds of Russians to post pro-Kremlin propaganda online under fake identities" (as cited in Chen, 2015) and, also, the IRA has "aggressively deployed" against "Russia's perceived enemies" (as cited in Chen, 2015).

What makes the work of the IRA even more concerning for local officials in the United States, though, is that the agency's work goes beyond sowing discord at the national or global level and has worked to find ways to target localities, with one report 
Goldberg (2018) cited stating that social media posts from multiple major platforms turned over to Congress showed a "nuanced and deep knowledge of American culture, media, and influencers in each community the IRA targeted". This meant that it understood such nuances in Austin, as it would for any other locality.

I searched the Hamilton 68 database, myself, to get an overview of the IRAlinked tweets about the Austin bombings. In these twenty-one tweets I found, a common thread was that the tweets primarily worked to capitalize on Austin's longstanding racial divisions and legacy of racial inequality (Alliance for Securing Democracy, 2018a, 2018b, 2018c, 2018d, 2018e). They also targeted a politically liberal American audience, with user names created like "Resistance Girl", that utilized criticisms of Donald Trump and, besides claims that Conditt received kinder treatment for being white and Christian, claimed Conditt was a white nationalist (Alliance for Securing Democracy, 2018e, 2018f, 2018g). This was never confirmed (O’Donnell \& Webb, 2018). Besides Trump, other targets included both Austin-based and national news media and law enforcement, which can fall under the Russian technique of attacking institutions (Schafer, 2018).

This was an example, according to Schafer (2018), of the Russian technique of creating fake social media accounts targeting both liberal and conservative audiences alike, working to use pre-existing divisions to stoke discord within the targeted community. Also, just as the Russians did during the aftermath of the 2017 mass shooting in Las Vegas, they used the Austin bombings — an "event that was of no particular importance to Russia from a policy perspective" as a way to take existing debates and divisions to "pick at the scabs" and "spread fear-mongering messages and antigovernment conspiracy theories" (as cited in Schafer, 2018). 
The Austin American-Statesman worked to confirm, refute, or clarify social media claims made during the bombings (O'Donnell \& Webb, 2018). Two major claims were that the bombings were racially motivated hate crimes and that news media outlets did not cover early events surrounding the bombings. The IRA-linked tweet in Figure 9.4 below suggests both, and it was retweeted more than eight thousand times.

Figure 9.4: Eight Thousand Retweets (Alliance for Securing Democracy, 2018c)

\section{Luisa Haynes}

Another explosion in southwest Austin, Texas! Why these bombings ain't a bigger story? Oh yes... all of the victims have been black...

\section{$8146 \quad$ C14701 2018-03-19}

The first three bombings, one on March 2, 2018, and two explosions just hours apart on March 12, 2018, were east of Interstate 35, the current home of a major portion of Austin's black and Hispanic populations and the historic dividing line from the Koch and Fowler Plan (Koch and Fowler, 1928; O’Donnell \& Webb, 2018; Tretter \& SounnySlitine, 2012; Zehr, 2015a, 2015b). Two black men were killed in the first two explosions, and a Hispanic woman was injured in the third (O'Donnell \& Webb, 2018). The bombings' locations and the victims' ethnicities led numerous social media users to theorize that the attacks were racially motivated, and the police did investigate that the bombings could be hate crimes.

The widespread and extremely diffuse nature of social media meant that the Austin bombings' social media posts were wildly and quickly circulated and caught the attention of those with major influence - which made social media messages spread at a 
breakneck pace. Recording artist Chance the Rapper, who has more than eight million Twitter followers (Chance the Rapper, 2019), tweeted about the Austin bombings on March 20, at the height of the social media furor (O’Donnell \& Webb, 2018). His tweet, shown below in Figure 9.5, was retweeted more than 57,000 times.

Figure 9.5: Chance the Rapper tweet, Austin bombings (Chance the Rapper, 2018)

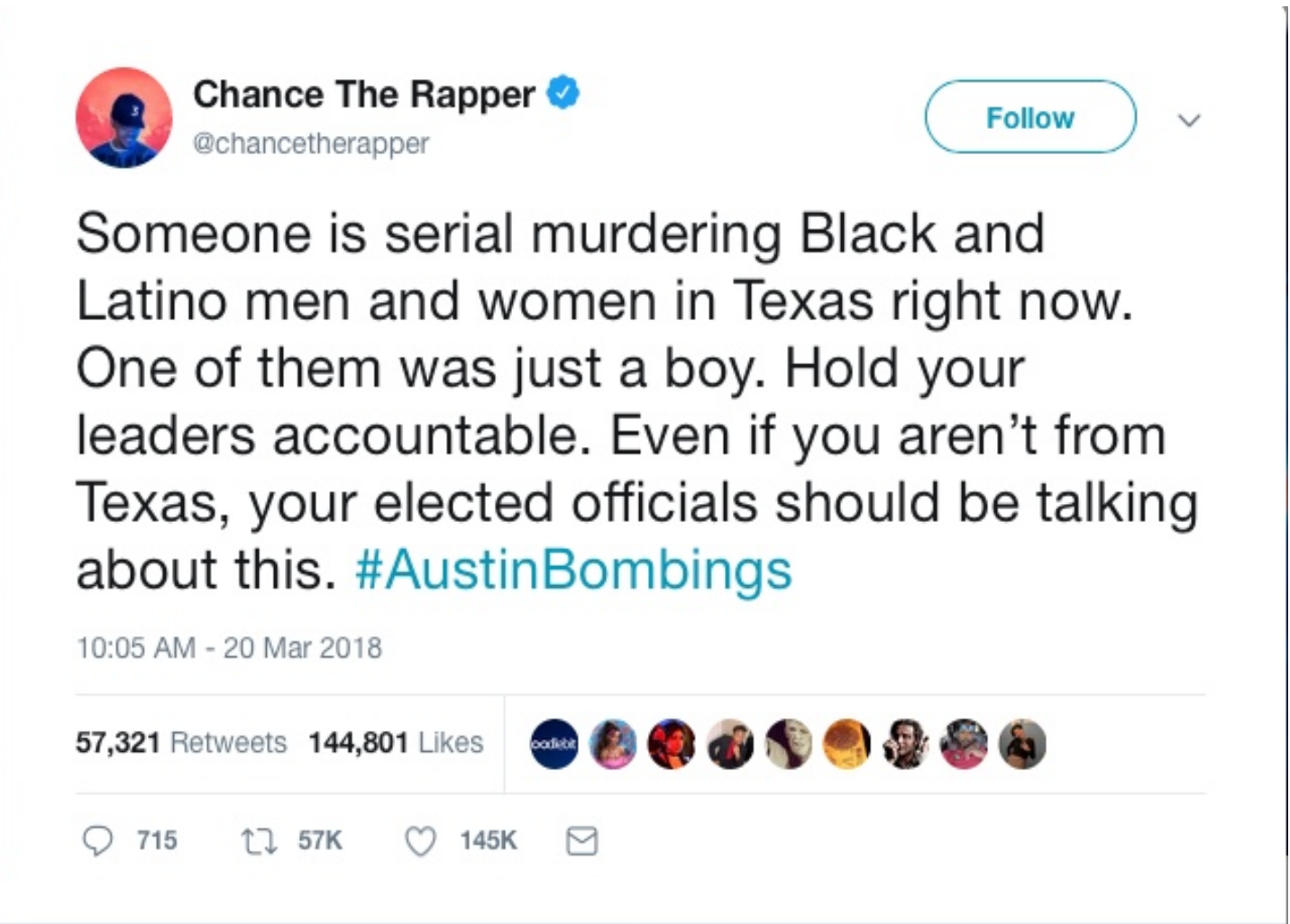

However, official releases, social media dialog, and overall fear were ratcheted with the fourth explosion, which was a trip wire-triggered bomb that injured two men on March 18 (Chang, 2018; O'Donnell \& Webb, 2018). The key aspect of this bombing in terms of the extremely diffuse social media participation is that it created more divisions and more heated dialog in terms of race. The fourth bombing having a trip-wire setup and law enforcement statements that it showed the bomber was more sophisticated than originally presumed and that he was moving toward much more random attacks (Chang, 
2018; O’Donnell \& Webb, 2018; Wangemann, Walsh, \& Plohetski, 2018) increased the city's collective anxiety levels even more than a fourth bombing, alone, would have. However, circumstances behind it in terms of victim ethnicity and location, combined with that anxiety, made the social media dialog even worse.

This took place in a predominately white subdivision in Southwest Austin, and the two victims were white (O'Donnell \& Webb, 2018; Wangemann, Walsh, \& Plohetski, 2018b). This gave detractors of those who insisted the bombings were targeting minorities an angle for attack and left those, including law enforcement and media, who only stated that the bomber's motivation could not be confirmed open to attack, themselves (Chance the Rapper, 2018). The Russian IRA tweets continually pushed a narrative that the attacks were racially motivated and that the victims were being ignored by those in power because of race after the fourth bombing (Alliance for Securing Democracy, 2018a, 2018b, 2018d), as shown below in Figures 9.6, 9.7, and 9.8. One took it further through also connecting the Austin bombings to other national-level controversies involving racial inequality that included the Flint, Michigan, water crisis and black voter suppression.

Figure 9.6: Russians, bombings, race (Alliance for Securing Democracy, 2018d)

\section{Kanisha J}

There has now been 4 bombings in Austin Texas. A serial bomber is targeting men \&amp; women of color. This is domestic terrorism. \#AustinBombings

\section{, $231 \quad 358 \quad 2018-03-19$}


Figure 9.7: Russians, bombings, Trump (Alliance for Securing Democracy, 2018b)

Resistance Girl

4 bombings happened in Austin, TX, all of them targeted minorities. If the targets were White Christian males Trump would turn this into a National talking point \#AustinBombings

$\leftrightarrows 102 \bigcirc 212 \quad 2018-03-19$

Figure 9.8: Russians, bombings, race (Alliance for Securing Democracy, 2018a)

Jemisha

Just a reminder that: - Majority black Flint, Michigan still has drinking water that will give you brain damage if consumed. - Republicans are still trying to keep black people from voting. - A terrorist has been targeting black families for assassination in Austin, Texas.

$\leftrightarrows 299 \bigcirc 357 \quad 2018-03-18$

Meanwhile, the fourth bombings' victims being white caused other social media discussions to become heated because of some users' continued insistence that the attacks were racially motivated and others who cited the two white victims as evidence that they were not and attacking those with another opinion (Chance the Rapper, 2018). This happened on national forums, like from replies to Chance the Rapper's (2018) tweet shown below in Figure 9.9, and local ones, such as the Facebook feed shown in Figure 9.10 from an Austin American-Statesman (2018) story shown after that. The divide, with social media adding fuel to the fire, kept it alive. 
Figure 9.9: Chance the Rapper's tweet replies (Kane, Heffler, \& Wendigobeach, 2018)

eddie kane @kungfudenne · 20 Mar 2018

Show me someone other than black and Latino person having a bomb on there porch
Q 18
$\uparrow \downarrow 2$
O 41

A. Heffler @Aheffler24 · 20 Mar 2018

Not on there porch. However same guy set up a bomb with trip wires.

$9: 524$

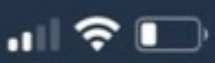

Tweet

JacquelineSarkissian

@JSarkissianFOX7

\section{BREAKING: @chief_manley has}

\section{confirmed both men injured in this}

latest explosion are white.

\#AustinBombings

3/19/18, 7:49 AM from Austin, TX

\section{Retweets 9 Likes}

Q $10 \quad \uparrow\urcorner \begin{array}{lllll}14 & \text { 1 } & 270 & \square\end{array}$

Wendigobeach @wendigobeach · 20 Mar 2018

Isn't that just because they exploded accidentally en route to their intended target.
Q 14
七】 1
O 120

1 more reply 
Figure 9.10: Racism or Not (Jean, Ramsey-Ford, West, Vasquez, \& Appice, 2018)

Tiffany Jean Everyone has "personal issues." Most people don't go around blowing up people of color, though.

Like - Reply - $48 \mathrm{w}$

^ Hide 16 Replies

Tiffany Jean The random ones. Not the intentional ones. Actions speak louder than words.

Like - Reply - $48 \mathrm{w}$

Q Ruth Ann Ramsey-Ford Why is there always someone that's gotta bring up skin color? These people who bring it up must be the true racist.

Like - Reply - $48 w$

69 Tiffany Jean Pretending racism doesn't exist doesn't help racism not exist, Ruth.

Like - Reply - $48 w$

Kathy Sampson West Pretending it exists in actions where it doesn't perpetuates the problem also, Tiffany

Like - Reply - $48 w$

Ricky Vasquez It's the truth white ones were only hurt due to the bomb going off early that's FACTS FACTS FACTS all the addresses were minority's they won't even call him a terrorist

Like - Reply - $48 w$

-

Tiffany Jean Except in this case, it did. Kathy. (D) 4

Like - Reply - $48 w$

Kelly Davis Appice Tiffany Jean all were random. He didnt know who lived at any of the places he took boxes,

Like - Reply - $48 w$ 
Figure 9.11: Sugar coating, poo emoji (Boudreaux, 2018)

PauLo Boudreaux They've been sugar coating mysterious bombs as if there's an invisible target. Like everyone is being bombed. C'mon stop sugar coating 8 . Don't be afraid to say it. Churches are being bombed again now "particular" residents in Austin. Stop whitewashing the bombing

Like · Reply · $46 w$

Some of the more vicious attacks, much like Figure 9.11 shown above were reserved for the news media, though, attacking this institution. During the bombings, some social media users (including the first tweet shown above from a Russian IRA account) claimed there was no news coverage of the bombings, "focusing their ire on 'mainstream' or national outlets” (as cited in O'Donnell \& Webb, 2018). O’Donnell and Webb write that the Austin American-Statesman and other local news outlets began "extensively" covering the bombings on March 2, the day of the first explosion. When the second and third bombs exploded on March 12, national outlets began taking notice, as well. The ire directed at the news media continued even after the bombings and it seemingly became worse when local outlets countered attacks on their coverage and revealed the Russian social media influence. Such a Facebook comment on the Austin American-Statesman's story about the Russian meddling is below in Figure 9.12.

Figure 9.12: Facebook, media, bombings (Barnes, 2018)

Greg Barnes The United workers at the un-american statesman are the Russian bots.

Like · Reply $\cdot 45 w$ 
Other social media users attacked the media, in general, through also using Facebook forums about the Austin bombers to attack the media for what they perceived as unfair attacks on Donald Trump, even though the real or perceived attacks many of them pointed out did not involve the Austin bombings. Screenshots are shown below in Figures 9.13 and 9.14. Users also proceeded to attack one another in the process. 
Figure 9.13: Facebook, media, bombings (Cox, Blakley, Bolton, \& Macry, 2018)

Terri R Cox I only watch FOX the rest lie and push their agenda Like - Reply $46 w$
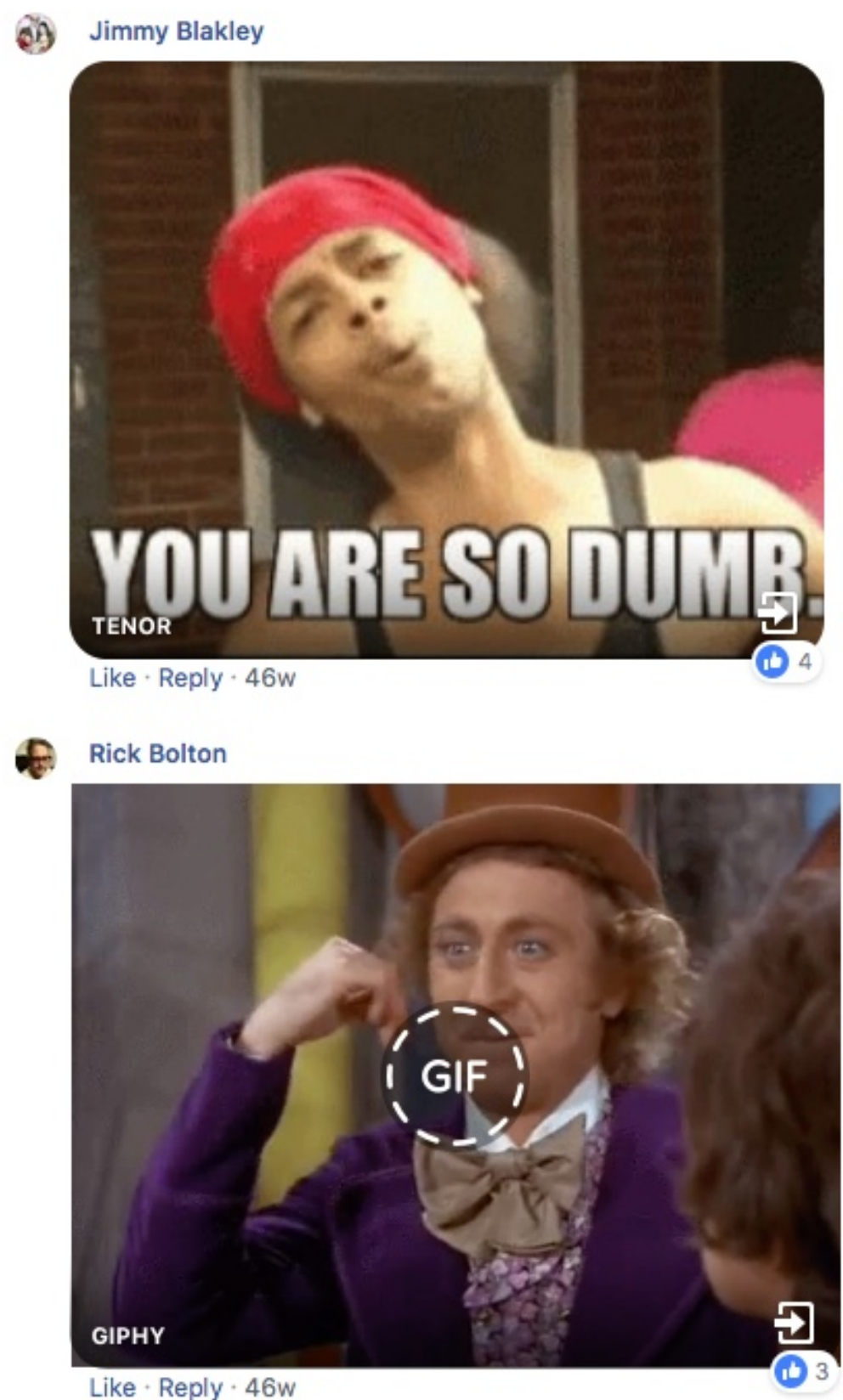

Like · Reply $466 \mathrm{w}$

Q Joseph Macry Fox lies and pushes their agenda. Like · Reply $\cdot 46 w$ 
Figure 9.14: (Bennett-Ashcraft, Bynum, Parkhill, Lenhart, Garza, \& Schell, 2018)

Cheryl Bennett-Ashcraft They only report on Trump and now this supposed affair when he wasn't even president.

Like - Reply - $46 \mathrm{w} \quad \because D=7$

Dan Bynum Trump traitors are just sad and sociopathetic.

Like - Reply - $46 w$

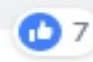

Kristen Parkhill Yeah, cuz that makes it better. I'm sure you would've given Obama a pass if he'd had an affair with a porn star before he was elected, right? $\Theta$

Like - Reply - 46w 14

D Marty Lenhart But Obama didn't have any affairs, porn star or otherwise. Your point?

Like - Reply - 46w

(1) Beto Garza I think the president has done a fantastic job the economy continues to grow because of what he set forth. It bothers me that anyone will post anything bad about this president that I speak of. He is intelligent sophisticated classy and a great father who also happens to be a great husband to his beautiful wife. So please raise your hands if you agree with me that the best president ever is with no questions of any scandals what so ever, President Barack Hussein Obama. We miss you. its

Like - Reply $\cdot 46 w$

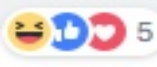

$\Theta$ Chip Schell Your news sources are obviously very limited. Here's one from the BBC. That's in England, which is across the Atlantic Ocean, that big body of water off the east coast, or to your right as you look at a map. http://www.bbc.com/news/world-us-canada-43453237

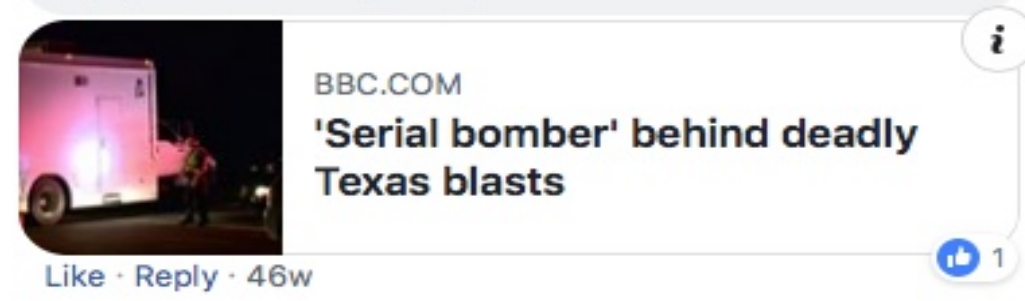

Other narratives that the Russians pushed included speculation of Conditt's

motives, which, as of this writing, have not been confirmed and may never be (Plohetski,

2018b; Walsh \& Plohetski, 2018). Social media users began claims that besides the 
bombings being racially motivated hate crimes, Conditt was "motivated by radical political and religious beliefs" (as cited in O'Donnell \& Webb, 2018). Media reports did indicate that he wrote blogs posts for a community college government course he took as teenager, in which he describes himself as "generally conservative" but "not that politically inclined" and argued "against gay marriage and abortion and in favor of the death penalty" and proposed "ending the sex offender registry" (as cited in O'Donnell \& Webb, 2018). He was also reportedly home-schooled, raised in a Christian home, "ran in conservative survivalist circles" and, as a friend told another BuzzFeed, those circles “were into weapons and stuff” (as cited in O’Donnell \& Webb, 2018).

Law enforcement has said nothing in Conditt's confession indicated that his political and religious beliefs played a role (O'Donnell \& Webb, 2018). Furthermore, police said that the confession did not state any clear motive for the bombings at all or provide any insight into how he chose his victims. Nonetheless, the Russian social media accounts pounced on these reports about Conditt's past to spread a narrative about Conditt that claimed, among other things, that he was a white nationalist and a religious fanatic and that he was being treated more kindly for being white and reportedly Christian (Alliance for Securing Democracy, 2018e, 2018f, 2018g; Herrera, 2018a). Also, the Russian tweets, with three shown below in Figures 9.15, 9.16, and 9.17, used the occasion to take digs at Trump. 
Figure 9.15: Russians, white nationalism (Alliance for Securing Democracy, 2018e)

\section{Kanisha J}

The Austin bomber, Mark Anthony Conditt was a white man. Call him what he was: a domestic terrorist. A white, male, bigoted, hateful terrorist, radicalized by the surge of white nationalism. https://t.co/LtWA7vrbCe

$\leftrightarrow 123 \bigcirc 224 \quad 2018-03-21$

Figure 9.16: Russians, fanaticism (Alliance for Securing Democracy, 2018g)

\section{Resistance Girl}

The Austin bomber went to survivalist camps as a teen. Much more about him as white straight religious fanatic. Terrorism: Incites fear; political motives BS; grievances BS. Austin bomber incited FEAR. Terrorist.

\section{乌54 ○166 2018-03-22}

Figure 9.17: Russians, conservative (Alliance for Securing Democracy, 2018f)

\section{Resistance Girl}

It turns out that the Austin bomber, Mark Anthony Conditt, was a Conservative who proposed ending the sex offender registry. I'm going to guess our alleged sex offender-in-chief will not make another tweet or comment about his capture. Just a guess...

\section{$\hookrightarrow 343 \odot 955 \quad 2018-03-21$}

Another side effect of the Russian meddling is that some social media users who may actually live in a given city and may have first-hand knowledge of certain events 
could be presumed to be Russian and have their viewpoint discarded. This was shown at the end of a Facebook feed, displayed in Figure 9.18, from the Austin American-

Statesman, and Albus commented in an interview that took place before the bombings that this presumption creates a major problem in the dialog overall. This is especially the case if participation remains online and does not move offline, as I will further discuss in a later subsection.

Figure 9.18: Accused Russian (Garza, Schell, \& Epps, 2018)

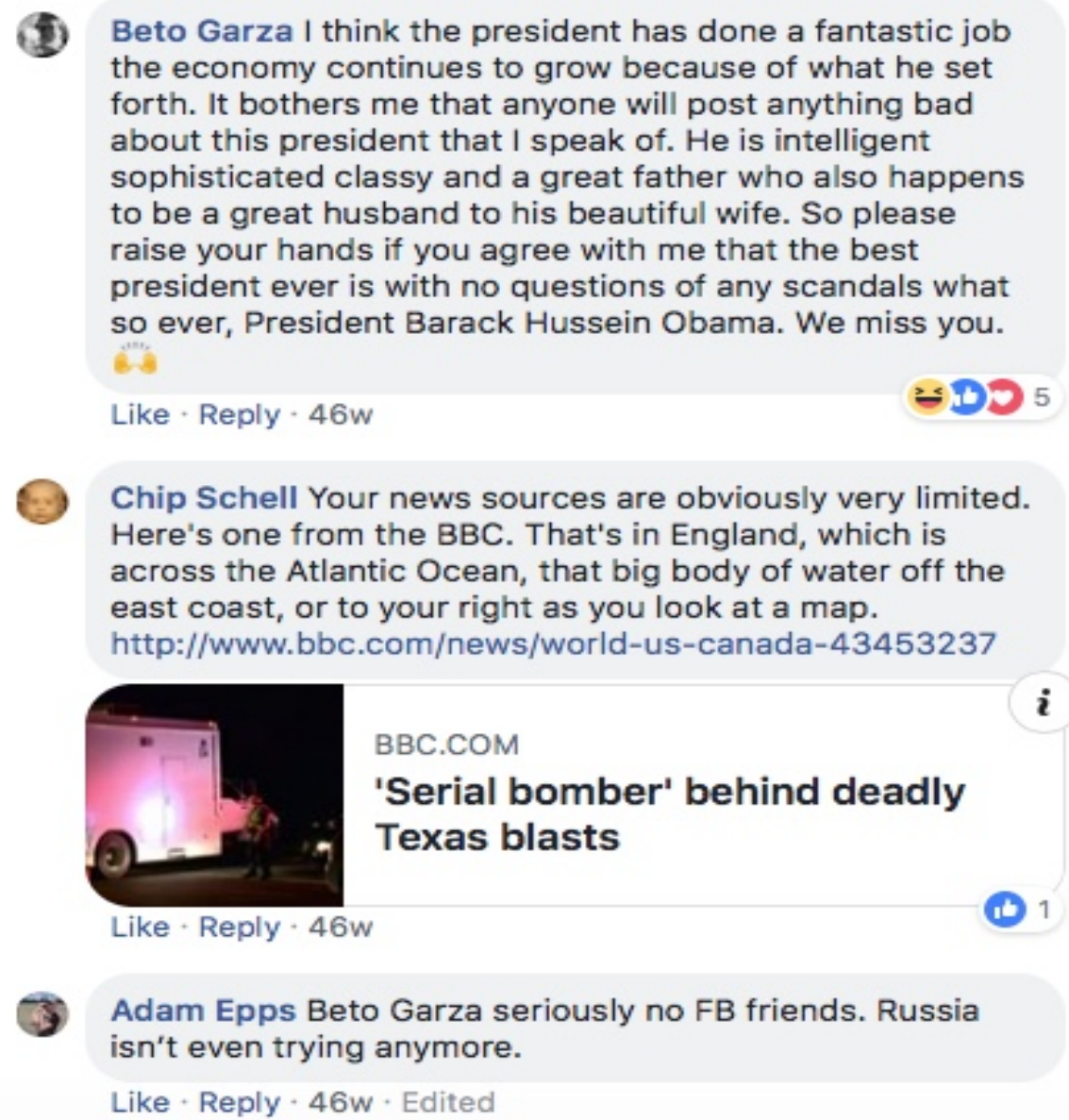

Albus: There are Russian bots out there writing all those comments. They come from Russian bots. It's not your fellow Americans. It's sowing discontent in America. They're Russians. It's all true. 
But that would be the knee-jerk response now to talk about the Russian conspiracy. It's not the CIA. It's the Russians!

\section{Government use in its infancy}

Besides the issues of how others abuse social media, government agencies, in considering how and if they would use social media participation, must consider that social media is a relatively new, uncharted frontier — a figurative Wild West — in the public sector and its capabilities and limitations continually and rapidly change. This means that any learning curve government agencies have is indefinite. Furthermore, social media outlets being a non-governmental space means that government agencies are on someone else's changing turf and that other party is the one ultimately in charge of how social media platforms work, not government agencies. In determining who participates, this becomes a vexing issue for government agencies who may desire a more controlled dialog but are on a platform that does not allow it and any tools they could use in making the dialog more controlled or diffuse alike could be changed at the will of a social media company.

Pomona noted the Music and Entertainment Division's Facebook Live forums and she believes that they have, overall, been a success. She did acknowledge that social media technology is new and ever-changing and how government cannot control some elements, such as what users will post in a live forum.

Pomona: It is a little bit of the Wild West, and the Music and Entertainment Division is a government entity. So the division has some limitations on what it can do. It's going pretty well, but it is definitely the Wild West. You can't really filter questions that people are going to ask, and not all the questions that people ask make it to the independent panel moderator. But the division staff tries its best to make sure that it gets questions over to those professionals. It's easy access, and we get those questions over to the panelists in a diplomatic and efficient way. 
...We work for the government. So I always like to say that we are the starting point for the folks who have a lot to say. We have to make sure that every person who reached out to us has been heard and feels their voice has been heard. That is the new process. So because we chose to work in government, we have to make sure that all of our customers are being served.

So, for me at least, it's part of the process and part of having to vet what's realistic and what's not. The division sometimes doesn't get to respond to and address everyone. Unfortunately, people do use a government forum for things that it is not necessarily meant for sometimes. We all have to be diplomatic and disciplined or at least acknowledge people will not go without being acknowledged anymore.

Facebook Live, for example, has only been available for all Facebook users since April 2016 (Castillo, 2017). Media outlets have reported that the project was rushed because some live video users were moving away from Facebook and to competitors like Snapchat, and Facebook has already dealt with problems such as livestreamed violence and other crime. The CodeNext Facebook Live meeting I observed had some Facebook users upset that their questions were not answered during the broadcast, but it only lasted for shy of eighteen minutes (City of Austin, 2018a). Some staff stayed behind and answered questions after the broadcast, however. Still, CodeNext only had twenty-five comments in their feed versus seventy-eight in the Music and Entertainment Division's Facebook feed (City of Austin, 2018d) and twenty-one more on Twitter for its Facebook Live meeting that I observed.

The technology is so new and ever-changing that, although some people make working in social media and studying it their full-time job, no one will probably know its true impact for many years, Ron said. He noted the opportunities for greater access to forums versus the above-mentioned trolling and problems with outside agitators. 
Ron: That's the kind of time we live in. I don't think there's anyone who has really... We're kind of figuring this thing out as we go, or we don't ever really know the full scope of what that animal looks like. So, to what are the healthy normative limits of that versus what's unhealthy and makes you ripe for disinformation and propaganda? I don't know. Famous last words... I think I can tell the difference.

But I don't know. You raise an interesting point, but I don't have a strong answer on that one. I think we're going to probably find out ten years down the road. What was good? What was bad? At this point, you really don't know why you're doing it.

Like Ron, Albus said that social media largely remains a great unknown, even to academics. Although researchers are continually working to find answers in this domain, he noted that, if their findings show especially negative impacts of social media, social media has spread so much that it may be too late to stop it or control it.

Albus: I know there's a lot of research out there now, where people are pulling down all of the tweets, and the postings, and whatnot, and doing word searches, and interpretations of language, and the frequency of different keywords, and word clouds, and things like that. So, they should tell us: Should we pay attention? Is it $\mathrm{OK}$ to let people vent because it can lead to more violence or mental illness? Or are people happier because they can vent now in different forms, and they don't resort to violence because they can vent in an online chat? I don't know, but there are experts out there who can look at those things and tell us because we're not going to regulate it.

It's too late. The horse is out of the barn now.

\section{Conversations easily overtaken}

One major problem involving social media participation is that because someone can take space on a comment feed as quickly as hitting a return key or a tweet button, a few or even just one person can take over an entire feed if government agencies or any other group engages the artistic community or any other group via social media. This is the very modern-day and extreme version of James Madison's concerns in The Federalist 
Papers, in which he argued that, if democracy was not controlled, factions that included "an obnoxious individual" could overpower others and drown out others in the overall social and political dialog (2001 [1787]).

This was evident during the city of Austin's Facebook Live meetings, especially for the Music and Entertainment Division's meeting that I observed. The topic of discussion for this meeting involved how musicians can better utilize social media to market themselves, and it featured a moderated panel that included popular personalities in the Austin music scene.

During that meeting, one user posted around twenty-five of the meeting's fortythree comments (roughly fifty-eight percent). Seven more comments came from a business with which the repeat user was apparently associated, which would bring this person to being responsible for about seventy-four percent of all Facebook comments for this meeting. The photo below shows this user's comments, the bottom four in this photo in Figure 9.19, as almost the entire feed. This was the case for much of the hour-long meeting. 
Figure 9.19: Repeated posting (as cited in City of Austin, 2018d)

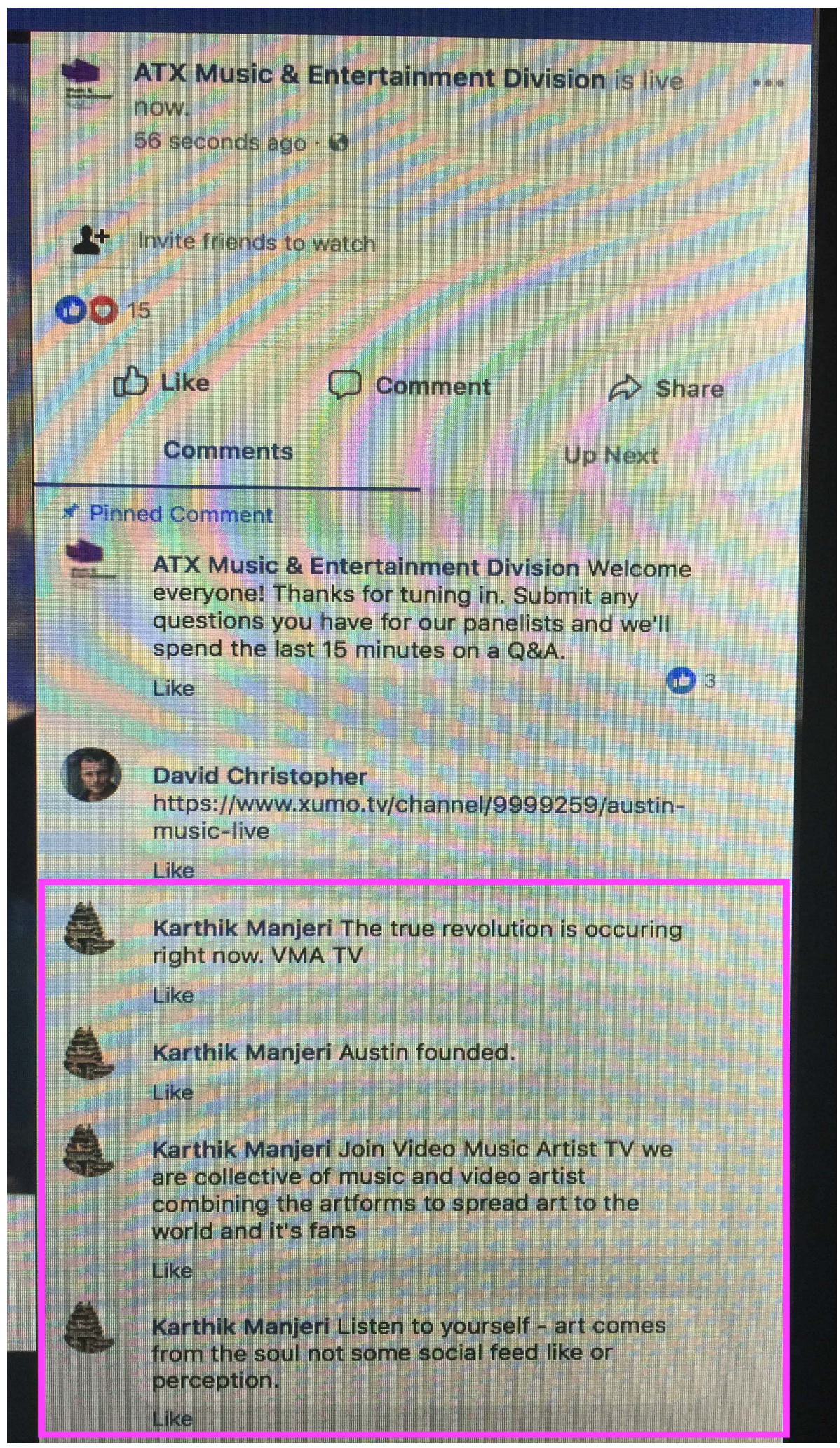


This person, as did some others, posted comments in an extremely rapid-fire fashion and drowned out others who had questions for the assembled panel. This became an even larger issue when, as I will discuss later, the users who were repeatedly taking up the social media feeds were posting content completely irrelevant to the meeting's topic at hand. Some questions that were relevant then disappeared from an observer's view. The photo below in Figure 9.20 shows another user's question that dealt with the meeting's topic. It disappeared from my view after approximately two seconds. That comment is in the pink box, and two comments at the bottom, in a blue box, come from the most prevalent repeat poster's business and the repeat poster himself. 
Figure 9.20: Repeats drown out relevant (as cited in City of Austin, 2018d)

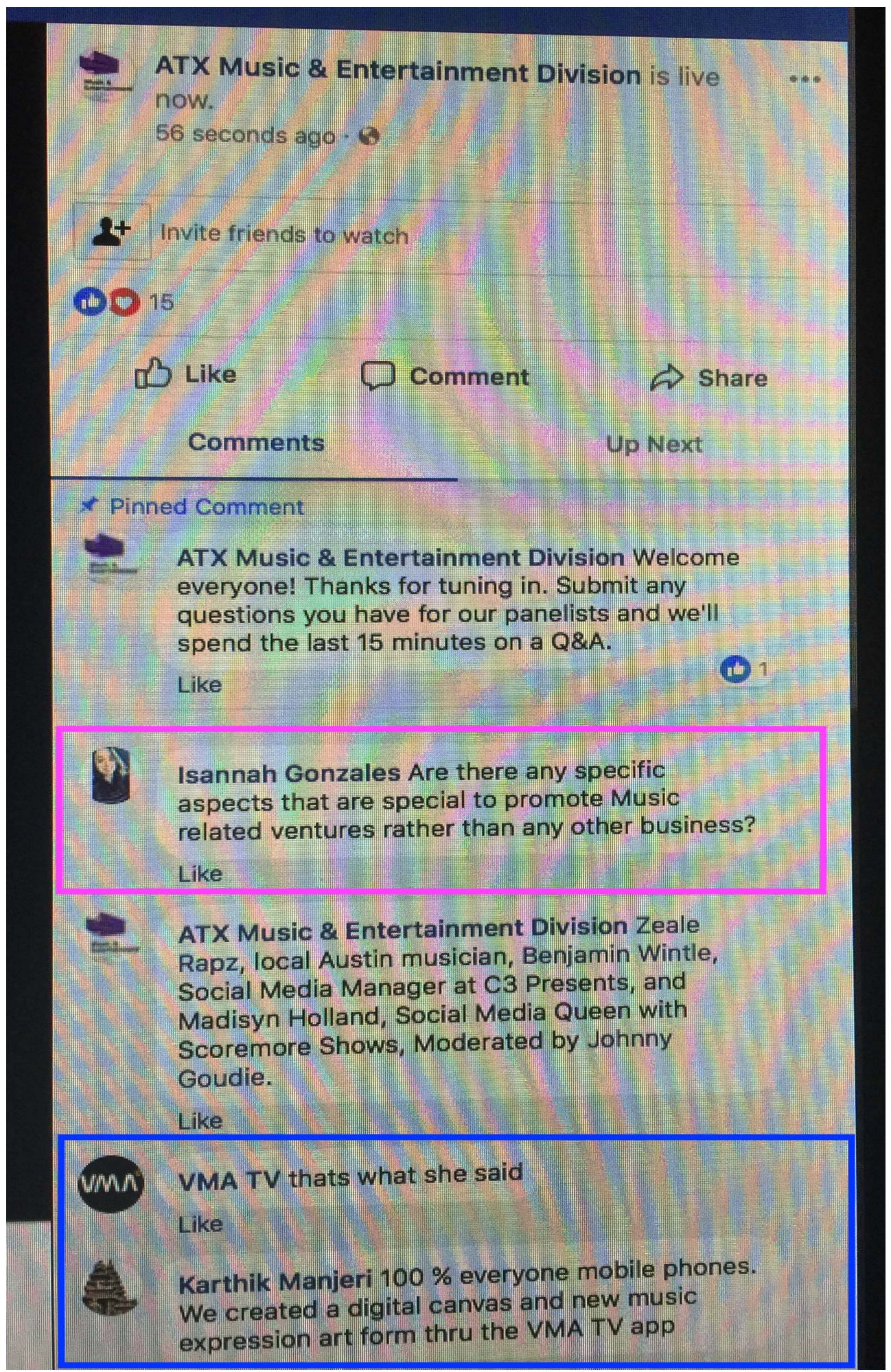


This problem was not unique to the Music and Entertainment Division's

Facebook Live meeting because the CodeNext meeting had similar issues, though not as severe. However, CodeNext's meeting only lasted for just shy of eighteen minutes versus the hour for the Music and Entertainment Division, meaning that users for CodeNext did not get as much of a chance to repeatedly post. Still, out of the twenty-five comments posted during this meeting, ten of them, just under half, came from two people. Another seven came from CodeNext, itself, but five of those were CodeNext's responses to users' questions that they could not answer during the short broadcast. This meant that nine questions or comments out of twenty-five (about thirty-six percent) came from someone other than CodeNext or one of the two users who repeatedly posted. It should also be noted that the Music and Entertainment Division was dealing with one person on its forum who, within that time frame that was four times the length of CodeNext's, was taking repeat posting to an extreme.

Irrelevant dialog

Another inherent problem with social media dialog in government affairs was the fact that citizen participation was taking place in the same digital venues in which people have their personal, marketing-oriented, and entertainment-oriented conversations - and those personal, marketing-oriented, and entertainment-oriented conversations seemed to cross over into forums meant for citizen participation. This created an issue in terms of who participates because social media's doors being opened so widely meant that the doors were opened to people who used citizen participation venues as they would for interacting with their friends, potential customers, or favorite celebrities. It made matters 
worse for when, as noted above, such participants drowned out those who were asking constructive questions or making constructive comments about the topic at hand.

One common problem I observed during the Music and Entertainment Division's meeting was that some commenting - the especially dominant repeat commenter, in particular - were using the forum to promote themselves or their business ventures. When I went through the comments from Facebook, I noted that twelve comments of the seventy-eight were self-promotion. Some of the self-promoting posts are shown in Figures 9.21 and 9.22 below.

Figure 9.21: Self-promotion (as cited in City of Austin, 2018d)

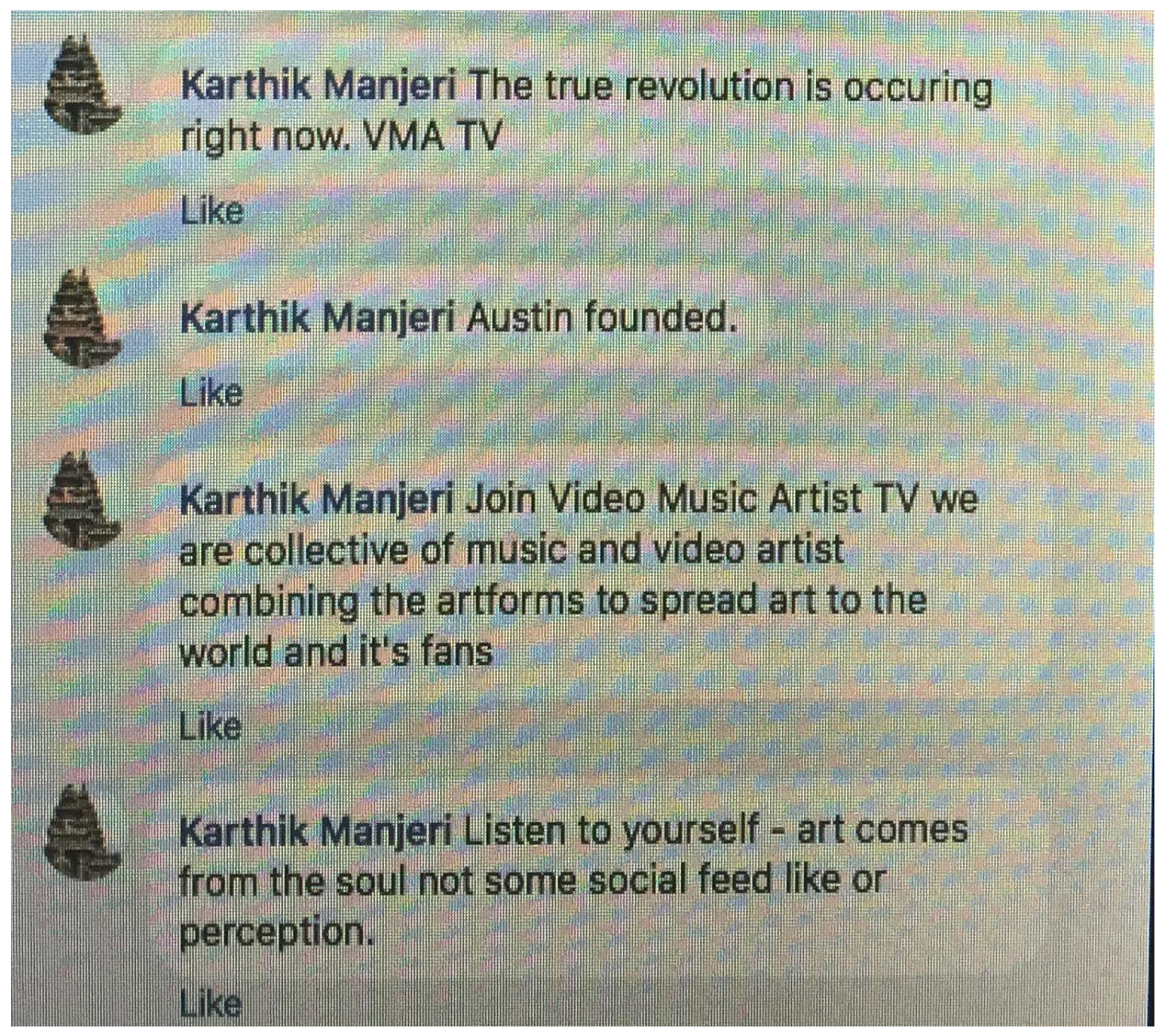


Figure 9.22: More self-promotion (as cited in City of Austin, 2018d)

Karthik Manjeri What tech social background do any of yall have?

Like

Karthik Manjeri I thought this was about musix

Like

Karthik Manjeri Hit me.up if you want

social.media 101. VMA TV HOUR BAND 4 LIFE.

Like

Karthik Manjeri We did rock b4 u zeale. HOUR

BAND 4 LIFE.

Like

C Camille Wright Xavier Omär kills the social media game and is from San Antonio!

Like

Karthik Manjeri Zeale is an artist. Join VMA

\section{Like}

Besides strange comments I observed such as "art comes from the soul", I noticed that some of the meeting's participants were fans of some of the personalities on the panel and used the meeting's feeds on both Facebook and Twitter to give "shout-outs", a common phrase for giving recognition to or devotion to someone like a favorite celebrity. During this time, I counted twelve shout-outs on Facebook and two more on Twitter. 
Some of these comments are posted below in Figures 9.23, 9.24, and 9.25. One I will especially note is Figure 9.23, in which the writer says, "not sure what you are talking about" (as cited in City of Austin, 2018d), meaning that the writer was, most likely, not engaged in the meeting's intended content.

Figure 9.23: Not sure what you're talking about (as cited in City of Austin, 2018d)

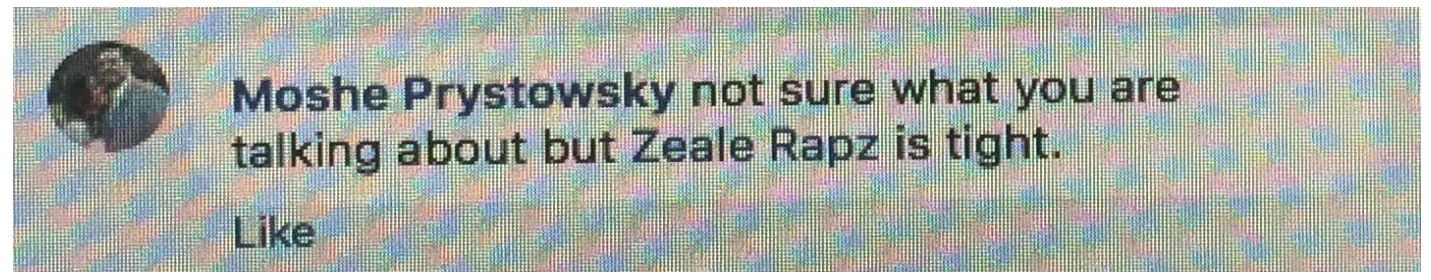

Figure 9.24: Panelist fan love (as cited in City of Austin, 2018d)

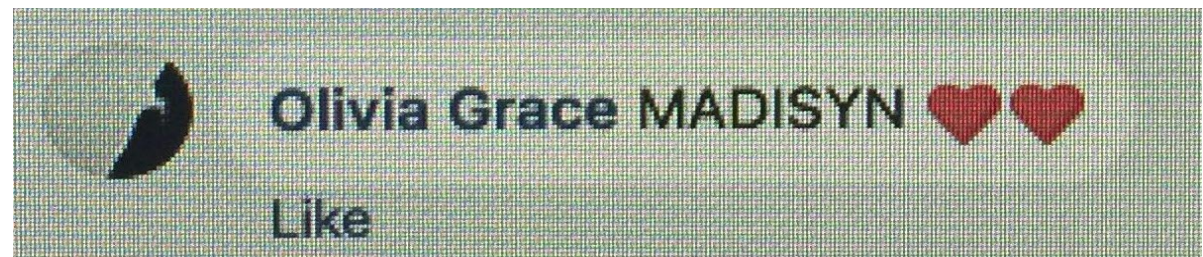


Figure 9.25: Fan love for panelist on Twitter (Cam Mysterio, 2018b)

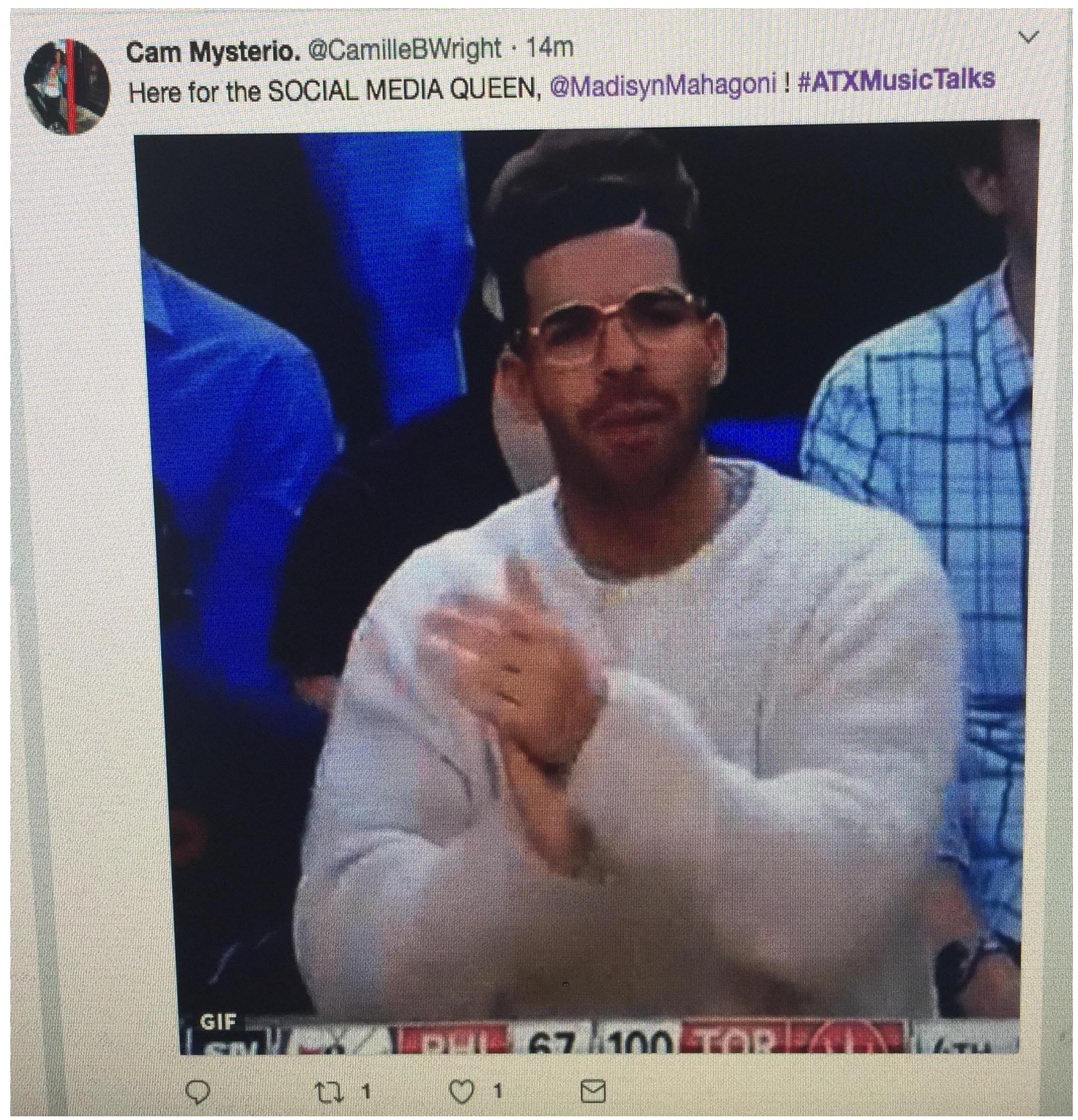

While the CodeNext meeting had little problems with shout-outs, I did observe at least one person using it to make repeated fringe political posts about "raping" Austin's green space and rail against the city's development and developers, posting a New York Times story's screenshots afterward. This is shown below in Figure 9.26. 
Figure 9.26: Sharp political comments (as cited in City of Austin, 2018a)

Jane Joseph - $0: 00$ It seemed obvious he
tried not to come right out and say "in order
to do whatever we can to make the
developers happy, we no longer are going to
deal with flooding via the best way possible
for the community ie. Preserve green space,
we are going to deal with it by killing green
space, let developers have their way and
require developers to come up with a man
made way to deal with flooding. It's
egregious.. it's an awful outcome and there
are better ways to deal with affordable
housing than raping the precious asset austin
has that attracts people here. Build a subway
to outlying affordable areas. Ensure each area
is required to have a mini metro (not those
dying subdivisions but villages with stores,
restaurants, etc. the New York Times
explained it beautifully. Imagine is asinine.
Like - Reply - 1y - Edited

Two differences must be considered when comparing some of the near-topic or off-topic conversation during these two meetings. The CodeNext discussion did not involve prominent entertainment personalities, meaning that it was far less likely to bring out fans who wanted to virtually connect with their favorite entertainers than the Music and Entertainment Division's. However, the Music and Entertainment Division's topic at hand was not as controversial as CodeNext has been, overall (Personal Communication, 2018), meaning it would be less likely to bring out those who wanted to use the forum to express their political views. Nonetheless, both showed how, when opening the doors as 
widely as social media does, it could open the door to people who can steer conversations off-course. Sirius, a musician, noted the same during my interview with him.

Sirius: It's easy to get derailed on social media. I think that especially something like Facebook Live could do that. ... I think putting those kinds of meetings on Facebook is a great idea, but maybe using Facebook Live and streaming them live isn't the best idea.

\section{Technical difficulties}

Because some social media technologies are relatively, if not very, new, some bugs and glitches may not be resolved or even anticipated. If citizen participation takes place over a very new technological outlet and unanticipated operational problems emerge, this can derail citizen participation efforts. This echoed previous literature that indicates functionality with technology enabled participation is critical if that participation is to work (S. Ganapati, 2011; Zheng, 2015).

During the Music and Entertainment Division's Facebook Live meeting I observed, at least one participant shown in Figure 9.27 was already showing frustration after twenty minutes, writing:

Figure 9.27: Asking is it over (as cited in City of Austin, 2018d)

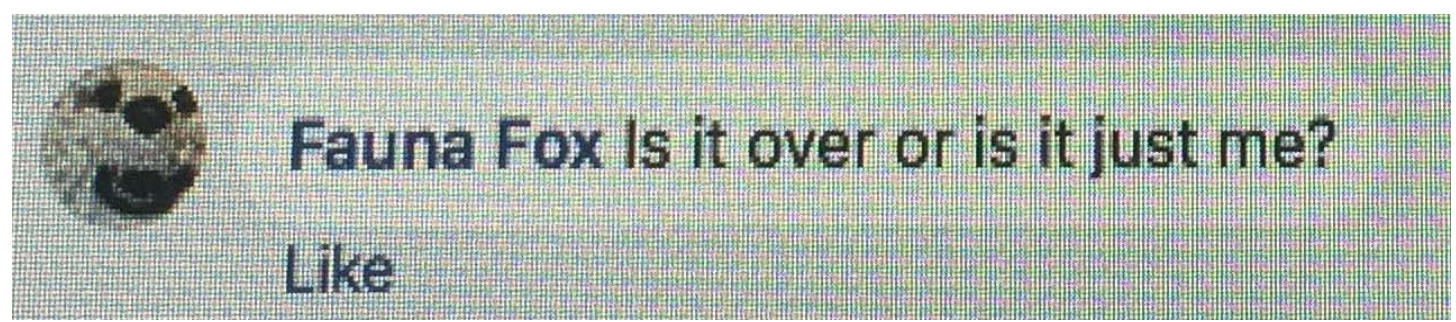

Shortly thereafter, major problems emerged with the video quality, with the feed repeatedly cutting in and out and with the images appearing garbled at points. A shot of the screen, taken halfway into the meeting and during this point, is shown below. (Note: 
The photo in Figure 9.28 is extremely blurry on purpose, not altered to be such, and is being used to show what happened to the broadcast feed.)

Figure 9.28: Broadcast cutting out (as cited in City of Austin, 2018d)

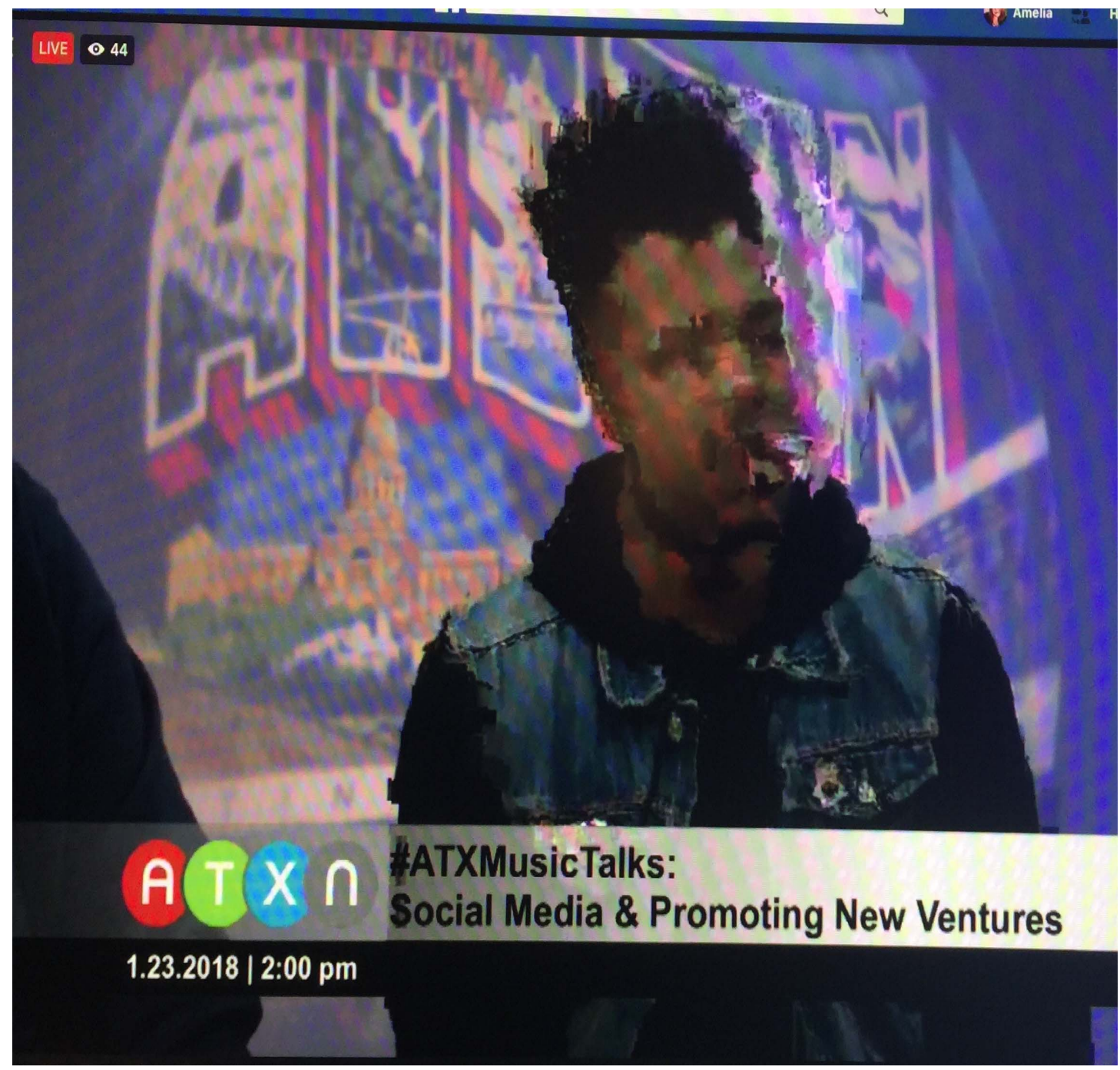

Some users began showing their frustration about the technical issues, such as this person who tweeted with an animated gif of a man repeatedly slamming a laptop in frustration. This is shown in Figure 9.29. 
Figure 9.29: Frustrated Twitter user, laptop gif (Cam Mysterio, 2018a)

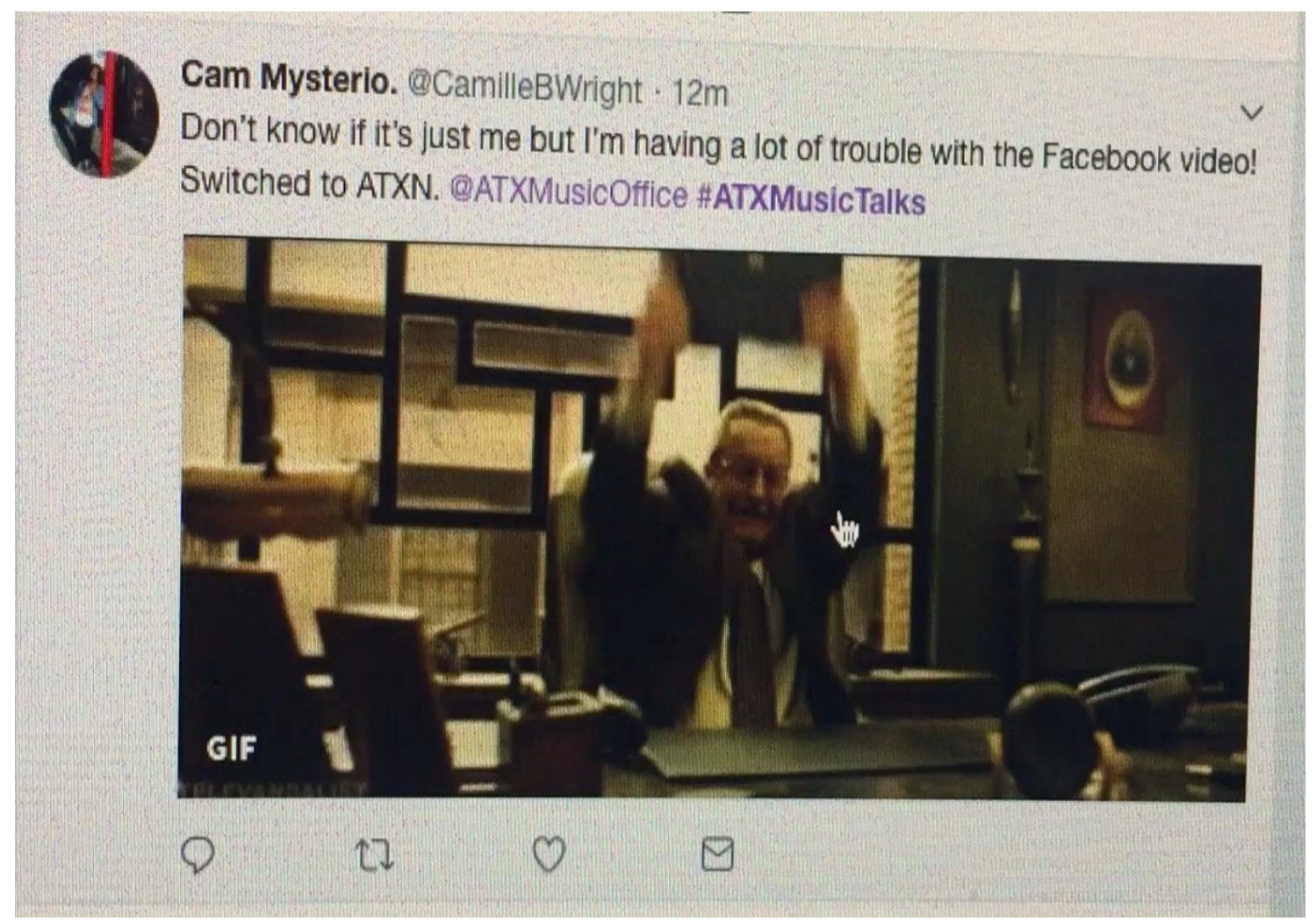

The technical difficulties may have been the reason behind a drop in the number of participants, judging by the Facebook Live numbers, as the meeting moved forward. At the meeting's beginning at 1:30 p.m., fifty-four people were tuned in over Facebook Live. After a half hour and when the technical problems began, that number dropped to forty-four by 2 p.m. - and then twenty-four by 2:05 p.m. Then, at 2:10 p.m., the feed went completely black, as shown in Figure 9.30. 
Figure 9.30: Tech problems, video goes black (as cited in City of Austin, 2018d)

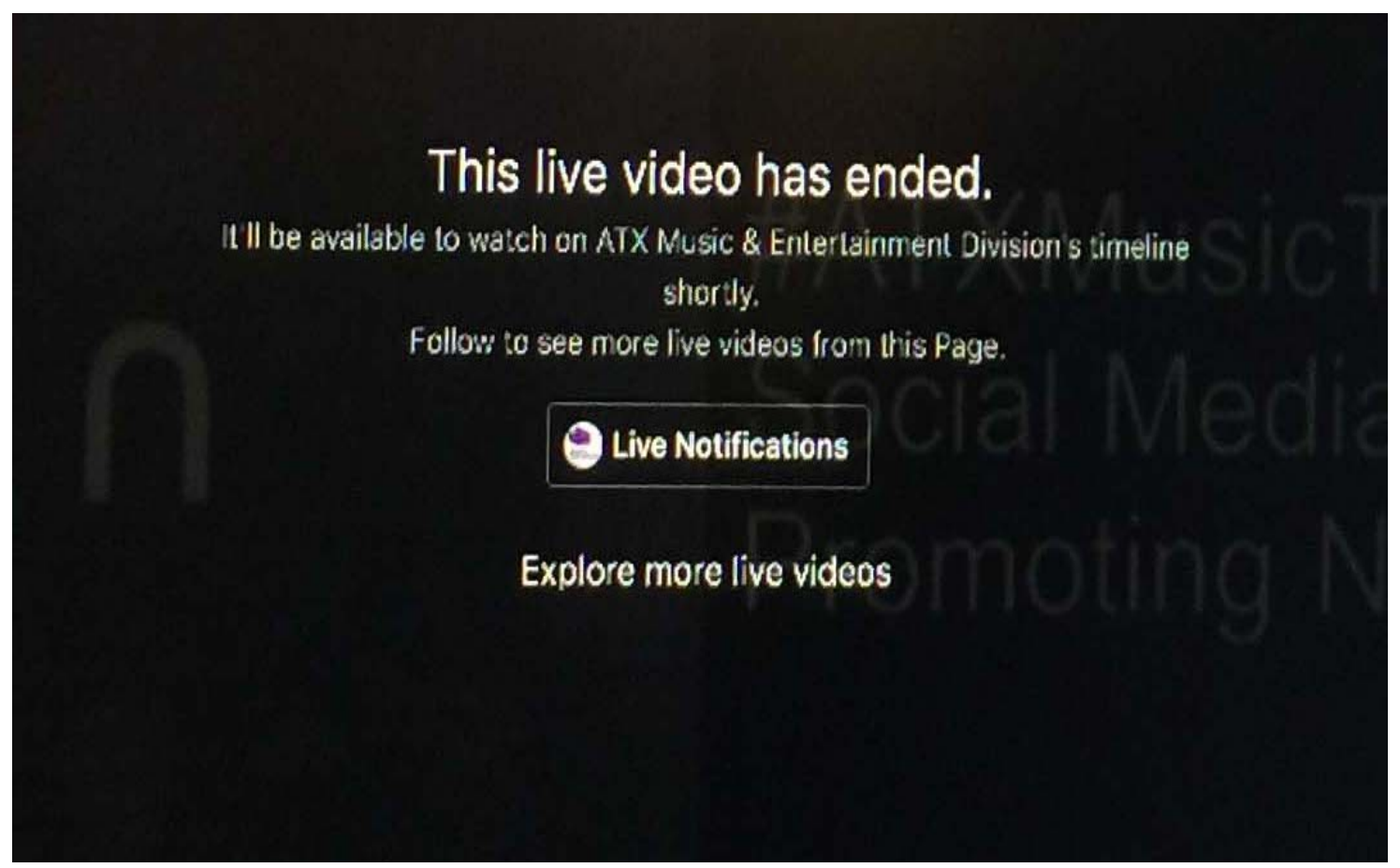

Those gathered were directed to the city's online television network, ATX TV, to watch the rest of the forum. No technical issues emerged there. The numbers dropping may not necessarily indicate that people left the session entirely. As the Twitter user indicated above, some may have just left Facebook's broadcast and opted to use the city's website. Still, this shows that technical difficulties can emerge when using very new and still-evolving technology — and, as the Music and Entertainment Division did in this case, it was vital to have multiple backups, such as the city's channel and Twitter.

Otherwise, its effort to engage its target audience would have ended with the Facebook video feed.

Cannot be used for some government functions

Namely because of certain legal requirements, as well as logistical ones, some interviewees pointed out that some government functions and interactions cannot be done 
over social media. One of the major issues that emerged here was that social media networks are private channels, and open records laws forbid official government communication over private channels.

Angelina said that a prior council adopted an ordinance that requires officials to forward any communication about city business to their official government email accounts, should it come to a personal one. She noted high-profile controversies about public officials using personal email accounts for official business and that she fully understands she cannot put herself into such a position — even if some constituents would rather interact over social media. She also pointed out time constraints that she has and how she already has to manage her time well with official communication.

Angelina: That's exactly why we have that policy. I have to constantly make assessments about how I'm using my time, which are the taxpayer resources, and so if I'm communicating with somebody on Facebook messaging and I have to take the time to forward each and every one of those text messages to my email, it's not a good use of taxpayer resources. We have to communicate in a way that is practical.

I get emails on my private accounts anyway, and then I have to forward them and write back to people. There's a certain amount that happens by mistake. I just can't have another avenue that happens outside the city that has to become city business. The logistics of it would be a nightmare.

...I cannot get into a conversation with somebody on Facebook Messenger about a city issue because, then, I have to send each individual message to my city email. It's just not a mechanism. If I don't remember to check my messages every day on Facebook, I'm missing a potential constituent issue. With my city account, if I miss it, usually, my staff will notice it and we can address it that way. If someone picks up the phone and calls my office, we've got a process for handling those kinds of calls. I also just don't have the capacity in my private life to manage constituent issues and concerns coming in through Facebook.... When people message me, I'll usually message them back and tell them to please contact me at my official email address. I don't engage and ask them to contact me at my official email address. That's my usual way of communicating that. 


\section{Consensus: Social media better for notification, not for engagement}

The viewpoint most of the interviewees in Austin had was that the healthiest possible balance between the above-mentioned open dialog and democracy of social media and its potential for destructive chaos is that governments and citizen groups should use it for notification but not as the actual forum for engagement. That notification should work to let people who are on social media know about in-person gatherings where much more conducive face-to-face engagement can take place. This would allow a combination of reaching a wider audience and still avoiding trolls, irrelevant dialog, and outside agitators. Some of the interviewees also pointed out that Facebook group controls, which can limit those who enter a given forum, could be utilized more to control dialog and make it more constructive.

Alastor said social media could be a valuable tool to spread the message of what a government agency does and what it has to offer people in artistic communities. This has been the case with his office. He occasionally finds valuable information concerning his constituencies but believes engaging face-to-face is much more conducive. Also, people who do show up for in-person gatherings are the ones who tend to demonstrate the greatest care and concern for the issues at hand.

Alastor: I don't think accessing Facebook should give you access to a meaningful conversation that's happening on a policy level. I think it's a valuable tool. We use it quite often and with great effect at our office to spread information about what we're doing and what our programs are, but very, very rarely would I ever consult a social media platform to take cues about how I'm going to proceed.

Look, I don't want to paint people with an ad hominem attack, but it's not an adult way to communicate. If you're willing to show up and state your position, and you're angry about it, that's fine. I'm going to listen to every word you have to say. But if you don't take the time to do that, and you feel like Facebook is your way to get your point across, then you've already kind of lost. The folks who 
do get together, who do take the time to get together and come to those kind of open forums and talk in-person about what's important to them - they should have their voices heard. Maybe there's a time limit on that, but they get to have their voice heard. Those groups that listen to those concerns and translate them down to that one person who's going to take them forward have to put their blinders on about social media.

Penelope said she prefers in-person meetings when discussing serious issues as well and finds that much more conducive too. Social media, though, can work to help citizen groups gain more like-minded people for their cause who may not have known about those groups otherwise. She knows this because of her work with others who organize via Facebook.

Penelope: I think it's better as an invitation for things like our meet-ups. We do it so that we can reach a wider audience on it. Honestly, the audience was too wide for our first meeting. We did not expect that many people would be interested, but it was a good way to get people to show up. I don't think it would have been as powerful if it had just been something that happened online, like if we just met on the Facebook group instead of doing something in real life.

Through witnessing multiple social media meltdowns, some interviewees have been extremely careful about how they engage, and one tool most of the artistic community's groups on social media were using was closed group controls — with group admins working to personally vet anyone who wants to join. Often, they said, they can set up automated questions for anyone who requests to join, such as details as to who that person is and why they want to join. Noting some of the issues with the city's Facebook Live discussions, Hermione suggested that, perhaps, a closed group discussion could be more conducive for policy discussions.

Hermione: In that way, you hopefully eliminate the random Russian trolls, and it hopefully is made up of people who are actually in and involved and concerned with the community. 
Penelope and her co-organizers opted to do this for their own group.

Penelope: Just seeing that breakdown on social media has been really interesting, and I think it's helped me learn some best practices for moderating our own group. We ask questions before you come in to try and figure out why you want to join. We also do that so we can cater what we focus on to understand what people are trying to get out of this group when they join.

The only complicated part about that has been that there are only three of us moderating. So I rarely see when people answer. I go home, and I'm like, "Oh there's more people in the group now. But we were prepared for it, which is why we have a statement at the top. It tells people to be positive, not to say anything rude, that this is an open space for people of all races and try to be careful and proactive in that sense. We haven't had any problems yet.

\section{Conclusion}

The issue of who participates within Austin's artistic community is a precarious balancing act, and social media has now taken that balancing act to an extreme. Government officials and artistic community members alike must work, in outlets that are in-person and virtual alike, to ensure that voices are not silenced but, in doing so, making sure that that an unrestrained democracy does not silence the less powerful essentially having democracy snuff out democracy, itself.

The key literature contributions are the social media findings because public administration remains in its infancy in terms of its social media scholarship (Pridemore, N.E. Ganapati, \& Revell, 2019). However, the fact that social media in government use is in its infancy is a finding, itself, and at the rate social media fluctuates and with governments not being able to restrain this non-governmental internet platform, it may be a subject that practitioners and scholars alike will find themselves learning well all to have to start from scratch. Given its threat to local government civility and stability, it 
becomes an even greater priority because outside agitators like the Russians are utilizing their strategies of using existing discord to wreak havoc to the local level and not just national or global levels (Chen, 2015, Herrera, 2018a).

Social media was not the only major finding in this chapter though. Another point of consideration in terms of who participates is that concise participation is needed. Otherwise, diverse and underrepresented groups will not be heard because forums will be overtaken by too many speakers from more affluent groups and diffuse forums with too many participants can descend into chaos, even when done with the social accountability of in-person interaction. Conversely, a succinct and concise forum with interested groups choosing prepared spokespeople who have agreed-upon talking points can create much more constructive dialog. This is a major addition to studies involving participation equity because it shows that a controlled democracy results in greater democracy in the end. 


\section{CHAPTER 10: CONCLUSION}

\section{Part 1: Introduction}

Public policy scholars and public administrators must pay close attention to policy challenges artistic communities face and, likewise, some of the outlaw citizenship practices both they and other disaffected citizens practice. Rapid development and related conflict from social and economic change has put longstanding local-level artistic communities in a crisis situation (Long, 2010; Timberg, 2015). Rising residential and commercial rents have created an affordability crisis, and the new development has brought major social tension namely from newcomers who seek to temper historically boisterous entertainment neighborhoods. While this may seem like a market-oriented challenge on the surface, public policies such as stricter noise ordinances in longstanding entertainment-oriented districts are the driving force behind these changes. Therefore, scholars and administrators must understand the implications of their actions that can cause these situations and listen to those who are affected the most.

Local artistic communities, who are major elements of these arts-oriented cities'

culture, history, quality of life, and economies, are working to enter public policymaking to remedy this situation, but longstanding harsh feelings between them and local government, such as disputes over noise and longstanding racial tension (Rainey, 2014; Woodward, 2014; Tretter \& Sounny-Slitine, 2012; Zehr, 2015a, 2015b, 2015c), have them entering as a disaffected group. They face numerous participation barriers that I found, such as crammed work schedules to afford the rising rents, and many in these communities are turning to outlaw citizenship. 
For this dissertation, I developed three research questions:

- What factors hinder artistic communities' participation and how?

- What factors enable artistic communities' participation and how?

- Who among artistic communities should participate and why?

The findings in my dissertation both shed more light on this situation and provide some challenges to existing to literature. The major finding in terms of both enabling and hindering factors for participation and in both cities was that place was critical. The venue in which participation took place either created a socially level (Oldenburg, 1999) and helped create a conducive and constructive dialog between artistic communities and local government officials or reinforced feelings of intimidation and powerlessness among historically underrepresented groups. Three of the major findings involving outlaw citizenship, include much of it being done among threatened artistic communities is to remind the public of their value and what could be lost, that displays that could be considered offensive can be attractive in certain contexts, and, depending on the context, whether or not a practice is considered outlaw citizenship depends on the participant, possibly more than the type of participation activity.

One major enabling factor involving enabling factors for artistic communities' participation involved partnering with kindred spirits and unlikely allies. These kindred spirits were fellow disaffected populations who shared the same grievances. The unlikely allies were groups with which artistic community members had done battle before, such as rival bar owners, police, and some government officials — but those groups also had common concerns and goals. Another key point is that policymaking can be difficult to someone not trained in it, but anyone can learn participation and policymaking 
processes. Doing so for groups like those with less socioeconomic privilege creates a steeper learning curve, but it is not impossible to overcome. However, one of the biggest challenges artistic communities face, overall, largely does not come directly from government, but from elites using multi-dimensional power exercises to control less powerful artistic communities. This is how powerful groups outside of government, such as wealthy developers and longtime elites, manage to exert power over artistic communities, even though they do not have the legal power to give direct orders.

The structure of this chapter is as follows. First, I will give a deeper summation of my most critical findings that involve artistic communities and non-governmental actors, which namely include how place can be both major enabling and hindering factors for participation, depending on the venue chosen. Afterward, I will then present my policy conclusions that namely include how, on multiple levels, traditional citizen participation venues simply do not work for artistic communities. Then, I will present my main contributions to the literature, which, besides the importance of place, also include contributions involving participation sustainment and challenges to outlaw citizenship literature. I will follow with policy recommendations, my dissertation's limitations and strengths, and then, recommendations for future studies. I will conclude with my final thoughts.

\section{Part 2: Summation of Findings (Artistic Communities)}

\section{Participation Hindering Factors}

Artistic communities being in a figurative rat race — working constantly to afford the skyrocketing rents and therefore being unable to take the time to engage with government officials to solve their new challenges — was a major hindering factor this 
dissertation revealed. One crisis fed another, with the unaffordability and participation inequity making each other worse. This echoed studies involving participation equity concerns that less privileged groups participated less not because of apathy but because they faced too many barriers (Fung, 2006, 2015; Laurian, 2004). This went further, though, because not only did it show how this concern specifically affected artistic communities, but also how underrepresented groups are in a vicious cycle, with policy concerns themselves keeping those concerns from being addressed. This, like Fung (2006, 2015) writes, had policy outcomes often favoring more privileged groups that had greater economic ability to participate.

One of the most sinister findings this dissertation unveiled was how multidimensional power structures helped powerful, non-governmental parties like local elites and wealthy developers exert power over artistic communities and work to temper longstanding entertainment neighborhoods and cultural practices even though they did not have the direct authority to do so. Much of this mirrored the Second Face of Power, where the elites managed to manipulate policymaking processes and "the rules of the game” (Bachrach \& Baratz, 1962; Gaventa, 1980; Warner, 2001, 2011) to have policies work in their favor.

This namely manifested itself in government-elite collaboration, where policy decisions were made at private gatherings in New Orleans or with the "non-decision" (Warner, 2001, 2011) power exercises in Austin, where those in government, influenced by powerful outside interests, quite often did not make decisions benefitting the less powerful artistic community. It also mirrored the Second Face of Power because the artistic community knew what the elites were doing (Warner, 2001, 2011), but with one 
difference between the cities being that the elites in New Orleans tended to be much more brazen. The Third Face of Power, in which artistic communities withdrew or became hopeless after constant defeats (Gaventa, 1980; Warner, 2001, 2011) or inaction, began exhibiting itself more in Austin — with the repeated power exercises against the artistic community making some community members believe their actions were futile.

Infighting and negative in-group relationships were a third major hindering factor I identified. Some artistic community members, namely in New Orleans, found themselves battling one another for a myriad of reasons ranging from economic competition, to stylistic and taste conflicts, and to personal feuds. This presented a major problem because an artistic community that refused to work together or could not put aside its differences would have its citizen participation efforts fall apart.

Another important note about the in-group relationships involves the nuances in the artistic communities. Tension arose when either more prominent individual artistic community members or more well-funded arts and cultural advocacy groups were, in multiple interviewees' minds, not team players, per se, in solving the crisis situation that could ultimately affect all. For New Orleans, it was more at the individual level, as interviewees noted that some entertainers are considered "royalty" and regularly push less fortunate ones away because the more prominent ones consider the others inferior (Personal Communication, 2017). In Austin, it was more at the organizational level, with interviewees pointing out that other organizations, namely larger and far more wellfunded nonprofits, showed little to no interest to helping smaller organizations or less prominent artistic community members. Also, interviewees noted that the income gaps between musicians and artists are an outright chasm, making this situation even more 
unbalanced. This ultimately hurt their participation in the end because, as mentioned before, not presenting a united front when approaching government officials meant that participation efforts would likely fail.

\section{Participation Enabling Factors}

Place, in terms of physical participation venue, being an enabling factor was one of the most significant and prevalent findings for this entire dissertation. This was especially true if a given participation venue was a beloved third place (Oldenburg, 1999) such as a local music venue. Much like Oldenburg (1999) indicates, the artistic community members I interviewed found third places to be socially level, in terms of them being casual and less intimidating, as opposed to elegant buildings or government meeting rooms that featured officials seated high above them and, generally, a higher police presence. Third place environments enabled an even and open conversation and one that was constructive. This also mitigated the problem of organizing artistic community members being likened to "herding cats" (Herranz, 2015), meaning that their packed schedules make it difficult to find time to organize. Having conversations at a place where they would be, anyway, and when they would be there helped alleviate this problem.

Positive in-group and out-group relationships were another major enabling factor. The larger point in this was that, when positive relationships were built in advance or any differences were settled in advance, artistic communities were ready to organize and plan their strategies when they faced a policy challenge. It also provided them with allies at the onset. Austin's Red River bar owners, despite years of competition, coming together 
to successfully craft the extended hours pilot program and manage to get it implemented is an example of how having in-group issues settled can lead to a resounding success.

Likewise, the owners of the two New Orleans bars I interviewed pointed toward positive relationships they built in advance through working to be a good neighbor or a good citizen in the city at-large were critical to their survival when they were targeted for shutdown. Without those relationships, all of those business owners would have either faced challenges from significantly more powerful interests on their own or had any collective efforts collapse.

Using evidence-based arguments, proposing one's own policy solutions, and being one's own spokesperson were three major enabling factors that were very intertwined. Interviewees indicated that breaking the language barrier between themselves and government officials was presenting arguments based on evidence and not emotion. In particular, they recommended making those arguments based on what appealed to government officials the most, like revenues, jobs created, and economic impact studies. Additionally, a major finding was that proposing one's own policy solutions was critical. This first allowed artistic communities to find something fair and workable that would also benefit them rather than leaving it up to chance with someone else. Also, it gained more positive attention for artistic communities because it showed officials that the artistic communities had done their homework, and this saved government officials time when they were dealing with numerous competing priorities. All of this made government officials take artistic communities who did this more seriously. 
Likewise, artistic community members being their own spokespersons was a major enabling factor on multiple fronts. First, it showed greater initiative on their parts. Government officials also learned from the parties affected most, first-hand. Also, it eliminated the problem both artistic communities and government officials alike faced with the problem of competing interests working to be spokespeople - or the spokesperson - for the artistic community, and not all were to be trusted.

For some in the artistic community, the learning curve in terms of figuring out policymaking and participation processes could be steep. Still, it was not impossible. The most difficult aspect of this was not a lack of intellectual fortitude. For some of those coming from lower socioeconomic backgrounds, overcoming this curve meant defeating multiple power structures holding them down, which was easier said than done and much more difficult than understanding dense wording of a city ordinance. It required defeating both powerholders and elites who wanted to keep them out of the overall dialog and those from within their own communities who emphasized oppositional stances against government, an entity they were taught was an enemy. The latter, some interviewees told me, was often more formidable than the former. Nonetheless, some in artistic communities managed to defeat these power structures and, in the words of Arnstein (1969), learn the "Mickey Mouse game" (p. 218) in government to have policies implemented in their favor.

\section{Who Participates?}

Those a given policy affects the most should be the artistic community members who participate. Interviewees told me that those who have either the most to lose or gain and who have that first-hand knowledge policymakers need to hear should be ones who 
are heard. When making such a decision, nuance and specifics should be considered. For example, policies regulating $\mathrm{C}$-weighted music, which is bass (Personal Communication, 2017), would affect those in bass-heavy genres like hip-hop much more than others. The danger in ignoring nuance and specifics, I found, is that not only those affected the most may go unheard but also that those who show up for a forum on something that is not a major concern for them may consider policymaking, in general, a waste of time. Then, that group will not show up to discuss issues that do concern them more and for which they do have major first-hand knowledge.

Two other major findings in terms of who participates is a balancing act. Diversity, especially in terms of race and ethnicity, should be considered when deciding who participates among artistic communities. Interviewees indicated that those participating in forums involving the artistic community (especially traditional venues) are very majority white. Especially when considering historical inequity and from minorities being disproportionately affected by gentrification, racial diversity is crucial. Conversely, narrowing down participants to a few spokespeople was also recommended. Interviewees indicated that when a given group came together on their own in advance, agreed on talking points, and then appointed a spokesperson, this created a much more concise and constructive dialog. Gathering too many people together created either a literal or figurative shouting match that achieved nothing.

Social media being a positive for notification but not for participation was the general consensus involving the vexing issues involving social media and its taking participation access to an extreme. Interviewees told me that social media's reach helped galvanize more supporters but, until those supporters showed up for either traditional or 
non-traditional participation in person, nothing was achieved. It was successful, though, when it brought more participants out en masse, creating powerful imagery and, especially when gaining more media attention, putting more pressure on powerholders.

\section{Part 3: Policy Conclusions}

\section{Traditional participation mechanisms just do not work for artistic communities}

On multiple levels, traditional citizen participation mechanisms did not work for artistic communities. The most prevalent issue besides the rat-race scheduling issue was also that of place. In a reverse scenario of Oldenburg's (1999) third places theory, places such as elegant rooms and government meeting rooms were a mix of intimidating and stifling. Overall, these settings could be uncomfortable for those with lower socioeconomic standing, who are already working to defeat ingrained messaging that they do not belong in and should not be in government halls of power (Gaventa, 1980). They also hurt underrepresented groups', particularly minorities', participation because they tended to have a heavier police presence. Elements such as having officials seated high above citizens in a figurative god-like appearance visually and psychologically reinforced uneven power dynamics. It did this even more when officials could use furniture and furniture placement, such as high-back chairs, to literally turn their backs to citizens who were speaking and create a wall between themselves and the citizens.

A second reason why these forums did not work for artistic communities, particularly those coming from lower socioeconomic backgrounds, was that traditional public hearings were extremely long — often, too long for them to stay until it was their turn to speak. When faced with meetings that lasted literally the entire day and 
sometimes through the entire night, issues such as work obligations and transportation problems kept them from being heard. However, those of more privileged means could stay and be heard.

\section{Venue matters}

One major policy conclusion I reached is that venue matters in terms of whether or not artistic communities will be heard. Just as they must accept that the earliermentioned issues of government buildings are an obstacle, policymakers must also understand that going to the artistic community and where and when it gathers - and not merely opening their doors - is what it must do to engage this population. First, it demonstrates that government officials care, and it helps build positive relationships. This is especially true for groups that would never enter a government building and for certain government officials, like police, whose buildings invoke fear or anger. This may mean going to a less posh location and at witching hours, but it is necessary. Furthermore, it leads to better policies in the end. It allows policymakers to see issues facing the artistic community, such as crime in entertainment districts, first-hand and learn from those with first-hand experience.

\section{Bureaucracy that "gets it"}

Having bureaucracy members who "get it" — who understand what it is like to be a working artist or, if they do not, learn what this is like, is a policy finding that can create better relationships with and better policies involving local artistic communities. One method, as seen in Austin, is having bureaucracy members who have worked as artists and musicians and understand their specific and unique needs. A large part of that is private sector-orientation in terms of the policies most of these communities want and 
need, like clear and fair noise ordinances that allow them to conduct business or regulations on development, as opposed to the dominant nonprofit arts discussion. These bureaucracy members can work as "translators" for the "language barriers" (Herranz, 2015) between artistic communities and other government officials. To enable these in the bureaucracy to do their jobs without fearing political whims and have artistic communities build more stable relationships with these staff members, these employees and their offices need to be integrated into local government's civil service over a political initiative, as is the case in Austin. Otherwise, a new council or even a single new mayor can eliminate positions or even an entire office, as is the case in New Orleans.

\section{Up-to-date, workable, and fair policies}

Another major policy conclusion is that local governments must have up-to-date, workable, and fair policies — and constantly update existing policies or create new ones as city landscapes, economies, and societies change. These policies must be based on evidence, such as health research on healthy noise levels and be specific and clear. With this, government officials have an enforcement tool and can mediate neighborhood disputes. Businesses and artistic community members have clear guidelines as to how they can operate. This also leaves fewer doors open for a challenge from someone who would use an outdated or unfair policy to his/her advantage in shutting down what would be a lawfully operating business under a fair ordinance. A fair and enforceable ordinance is also one that gives businesses and self-employed artists, especially pre-existing ones, the ability to operate as well as keep the peace. 


\section{Leadership matters}

The most relevant policy conclusions about leadership from this dissertation deal with relationships and stability. When leadership transitions are long and with prolonged uncertainty, this leaves artistic communities in limbo as to whether or not an official with whom they had built a positive relationship would be in his or her position when the new leaders came on board. Not knowing when or if a new leader would assume office made the limbo even more exhausting. Furthermore, not knowing who the new leaders would be, such as when Austin had no permanent city manager and several interim department heads, made the uncertainty even worse.

The second point relating to stability has to do with changing city landscapes or city landscapes that, in some ways, need to change. With Austin, the city's constant changes created enough anxiety, but not knowing who would guide them through this made the situation more chaotic. In New Orleans, the city was changing but namely mired in longstanding inequality and government misconduct — which plagued the city long before Hurricane Katrina. The corruption-weary citizens, though doubtful the situation would change, still wanted to know who could possibly guide them. When cities are in figurative rough waters, the situation becomes far worse when they do not know who their captain will be.

\section{Cautions about government social media use}

Government use of social media is practically in its infancy, as are public administration studies about it (Pridemore, N.E. Ganapati, \& Revell, 2019). Two major concerns that governments should have about utilizing social media with engaging its citizens is that it creates an extremely diffuse participation open door, and, unlike 
government websites, social media sites are platforms that government does not ultimately control.

The participation door is open to, literally, anyone with an Internet connection with social media. While this can help reach a wider audience, especially with artistic communities that tend to be active social media users, my study showed that the problems tended to outweigh the positives. Namely, these included non-constructive or even dangerous dialog. Social media participation also opens the door to trolling, derailed conversations in general, fights, and even threats. As was the case in Austin with the serial bombings and New Orleans with the Confederate monument removals, social media created major security situations and opened the door to outside agitators. Local government had to take extra precautions, namely in New Orleans, to handle the onslaught.

While social media sites offer some controls that governments can utilize if they choose, such as turning off comments, third-party technology companies ultimately control what tools are available, what tools are not, and if any tools will be added or taken away. Quite often, this happens before anyone, even those technology companies, can understand their capabilities or if they have bugs and technical problems. Worse yet, there is far less capability, as opposed a government website with a platform officials can fully control, to control bad online behavior. Therefore, using such platforms such be approached with extreme caution, and continued and constant education is needed to keep up with new controls. 


\section{Part 4: Literature Contributions}

Place

The place element contributed to almost every set of literature I covered in my review - enabling factors, hindering factors, and challenges for artistic communities. This contributes to the literature both in demonstrating how Oldenburg's (1999) third places theory, namely about generating ideas that can improve society, can become a reality. It can not only counter intimidation affects, which I will explain later in this section, from government buildings, but the free-form, and free expression-promoting atmosphere at third places is more attractive to artistic people, particularly those who engage in more fringe expression.

The socially level environment in third places (Oldenburg, 1999) is critical, as well, because it creates an even dialog. Furthermore, they are more conducive for gathering diverse participants, especially if they are farther from police stations. Participant equity in terms of racial diversity is a major concern for scholars (Fung, 2006, 2015), not only because population subsets are not being heard but also because officials are not hearing first-hand information from those affected most. Meeting officials in third places (Oldenburg, 1999) could remedy that. When certain city agencies in both Austin and New Orleans have done that, this has been a success. Hearing from those with firsthand experience can create more solid and workable policy (Elias \& Alkadry, 2011), and this takes scholarship a step further to show both how and where this could happen.

A literature contribution I make in terms of place is how Oldenburg's (1999) third places theory can work in reverse with government buildings and elegant locations. It also takes Rimmerman's (2011) points about how traditional public hearings can 
intimidate socioeconomically disadvantaged populations further in demonstrating another element that adds to that intimidation, should they try to enter policymaking. This also takes Fung's $(2006,2015)$ findings involving participation equity in terms of racial and ethnic minorities further. It provides additional information as to why disadvantaged groups are intimidated and what elements, besides factors other scholars have identified such as a lack of advertising in minority neighborhoods (Fung, 2006, 2015) create that inequity, particularly in terms of race.

\section{New perspectives on partnerships}

Another contribution this dissertation makes to the literature involves partnerships. Namely, this contribution shows that old enemies are sometimes the best allies and that "friends" may turn out to be anything but that.

Previous scholarship has mostly focused on partnerships between citizens and government, and, most importantly for this section, how those can be a positive and how they can be built (Pridemore, Ganapati, \& Revell, 2019). Also, previous studies have focused on trust, but most of them have focused on citizens' trust in government (Pridemore, Ganapati, \& Revell, 2019). This contribution shows that partnerships are not always a positive, and that, in some cases, they should be avoided. Also, a negative partner could be a government agency, an advocacy organization, or certain segments of the artistic community, and ones that all of the three aforementioned groups must be careful about joining, lest they enter an unholy alliance. This adds to the trust literature because parties other than citizens can and/or should be suspicious of someone who seems to be especially eager to help and claims to be a representative for or the representative for the artistic community. 
The reasons behind this include a potential partner only wanting to boost his/her personal stature or making a condition of a partnership one that compromises personal or organizational ethics. For artistic communities and both government and nonprofit agencies that specifically work with them, there is an additional concern because some of these groups have access to popular local entertainers. The other group may want to use those entertainers as mere spokespersons but without doing anything to help this entertainer or his/her fellow artists and musicians.

Likewise, the fact that old enemies can be valuable partners - even some of the best partners - is a major contribution. Previous scholarship has noted how some governments and citizens have worked to repair relationships after extreme conflict (Pridemore, Ganapati, \& Revell, 2019). Some of those old enemies that have been valuable partners are indeed government agencies. However, this dissertation adds that rivals outside of government, such as bar owners in a highly competitive entertainment district, can be one's best allies when facing a challenge. The root is common causes and working toward a greater good for all involved. Furthermore, this dissertation explores either extreme conflict or extreme social change — and how partnerships are emerging during and after these intense situations - in American cities when most studies have focused on this in international locations (Pridemore, Ganapati, \& Revell, 2019).

\section{Participation sustainment}

Participation sustainment, both in why it is difficult to achieve and how it can be done, is another contribution this dissertation makes. Previous scholarship has noted that sustaining participant involvement is difficult (Pridemore, Ganapati, \& Revell, 2019). This dissertation reveals why it is difficult to maintain and offers some suggestions as to 
how it can be maintained. First, past bad actions from government, especially when it has been sordid and longstanding, and government inaction and government, in citizens' minds, doing nothing with work done from their participation, can cause citizen participation to drop. Governments that find itself in repeated scandals or engaging in practices that are dubious at best can push engaged citizens away because the citizens want nothing to do with officials they believe are corrupt. If the history is longstanding, they may never want to engage at all. In terms of inaction, this can turn off citizens just as much because they believe their actions were useless before, and they do not want to waste their time again.

Another factor that, as public administration scholars, we might find it hard to admit is that traditional citizen participation venues like public hearings can be mindnumbingly boring. This is especially true for governing bodies like city councils that have items covering a myriad of issues on its agenda, and some artistic community members do not care about those that do not directly affect them. The fact that public hearings can literally last all day (or longer) makes this matter even worse.

The keys to participation sustainment I found were providing results and having participation activities that are more fun and engaging, which is generally achieved in outlaw citizenship. I will discuss the latter in my following section dealing with outlaw citizenship and focus on the results at this time. When citizens work to craft a policy, it is important that the policy be implemented and one that is not a watered-down version that has no effect. There must be follow-through. During that process in between citizen engagement and implementation, the participation results must be tracked and not lost with systems in place for tracking. If citizen participation only results in citizens 
figuratively shouting into the air, they will see their efforts as wasted time and not participate again.

\section{Challenges to outlaw citizenship and artistic communication literature}

My findings regarding outlaw citizenship and artistic communication literature challenge much of the scholarship surrounding both. Namely, those challenges include artistic communication being done because artistic communities want to demonstrate the value of what they do - not because they lack ability to speak with rational argument or prefer not to use rational argument. Offensive displays, given the context, can be empowering and be received positively, and outlaw citizens whose activities backfire are the ones who manage to attract outside agitators who make creating a negative public image their goals. Also, whether or not participation is outlaw citizenship may depend not just on what type of participation is being done but who is participating, even if that is in a traditional forum.

Scholarship involving artistic communication has shown that historically disenfranchised groups prefer artistic communication over rational argument because the change from oral to literate societies meant that rational argument, the style preferred by middle-class and upper-class white men, became preferred more (Love, 2006). Historically and due to being cut off from learning this new communication style, historically disenfranchised groups have preferred artistic communication (Love, 2006).

While this dissertation does not dispute these historical roots, it does provide a challenge as to why artistic communities use the arts as political and social commentary and in outlaw citizenship. I discovered that the artistic communities I encountered were doing this to demonstrate the value in what they did - namely to their cities' quality of 
life and culture and history — to their fellow citizens and public officials. Because they were under threat, the artistic communities were also working to demonstrate what could be lost. Additionally, this outlaw citizenship was often being done to connect with government, as well as fellow citizens, rather than work against it. The activities were outside of the normal public hearing settings and even their own facilities, making them non-traditional, but the tone used was one of bridging, not fighting.

Artistic communities engaged in rational argument speech just as often, and one of their points of contention was that they believed governments and some advocacy groups only saw their value as entertainment, not as serious and articulate spokespeople. This was especially grating for minority artistic community members when officials and/or advocacy group leaders were white.

Displays that could widely be considered as offensive being empowering for disaffected populations is another challenge to the outlaw citizenship literature. Rimmerman (2011) writes that offensive displays, namely violent ones or ones involving hate speech, can turn the public at-large off from outlaw citizenship activities, and, most importantly, their participants and messages. While I do not dispute that violence and hate speech can be a turn-off, I provide a challenge in that offensive displays that are extremely angry and involve material such as profanity and sexually explicit material can be empowering. For citizens who feel as if their governments have outright knifed them in the back — ones who feel they have been egregiously wronged — lashing out with their level of ire and with little restraint can make displays and participants attractive. Essentially, these fight fire with fire. Societal norms and government wrongdoing's level of severity must be considered. Less permissive societies than the two case study cities in 
this dissertation and governments with less egregious actions than New Orleans' may create backlash for offensive outlaw citizenship. However, being non-offensive may be considered too weak in the eyes of a citizenry feeling deep betrayal, and such behavior from government could warrant an equal response.

However, this provides a challenge to outlaw citizenship literature in terms of what can cause negative backlash, and that is action from outside agitators. Outlaw citizenship scholarship points to behavior within protest groups as a main cause of public backlash (Rimmerman, 2011). While I do not outright dispute this, both what I have found in my fieldwork and the present-day political environment, as a whole is shifting this. Outlaw citizenship activities, I discovered, often attract outside agitators such as counterprotestors or conspiracy theorist online broadcasts working to counter them, especially if they are deeply opposed to the outlaw citizens' views or simply want to ruin the outlaw citizens' image. The heated environment in the present-day social and political sphere (Box, 2017; Pridemore, 2018) sparking outrage, confrontation, and spite among citizens could make outside agitators even more of a problem for those engaging in outlaw citizenship.

The other challenge I make for outlaw citizenship is that it can depend on who is participating more than what is being done. Disaffected and less powerful populations defy both powerful in-group messaging (often started by powerholders) (Gaventa, 1980) that government is the enemy (Personal Communication, 2018) and powerholders who see them as a potential threat and want to keep them away (Gaventa, 1980) if they enter traditional participation. They also have to devise effective strategies that appeal to government officials and that use established processes that have historically worked 
against them to now work in their favor — defeating powerholders with some of their own weapons, per se. This combination of defiance on two fronts and with learning powerholders' "game" (Arnstein, 1969; Warner, 2001, 2011) and playing that same game but being the victor instead could, I argue, make these groups not only defeat power structures (Gaventa, 1980) but be even greater "outlaws" than ones who engage in nontraditional participation.

\section{Transportation and infrastructure}

Transportation was a somewhat expected finding for this dissertation, but infrastructure was definitely not - and it is a contribution in terms of both participation hindering factors and outlaw citizenship's roots. Transportation as a hindering factor is an addition to the literature, given that issues such as expensive parking and inadequate public transit create more participation equity issues. Citizens with lower socioeconomic status will struggle with this more, meaning that policies can favor the more privileged (Fung, 2006, 2015) because the less fortunate may literally be unable make it to a public hearing.

However, infrastructure was rather unexpected, and interviewees who mentioned this as a hindering factor tended to be some of the angriest at local government officials. This, as a result, became a much greater hindering factor in terms of citizens' ill feelings toward government officials. The infrastructure problems could exacerbate the participation hindering factors more in the long-term. The key aspect about infrastructure that should be noted here is that, in most cases, taking care of infrastructure is not only a government responsibility but also problems such as dangerous street pavement 
throughout New Orleans and on Austin's Red River district sidewalks are literally illegal for citizens to repair on their own. Citizens are essentially at their governments' mercy.

Infrastructure problems also created the most scathing outlaw citizenship display I observed during this dissertation. In the case of New Orleans' sewage and drainage problems and flooding, this created enough anger for those in the 2018 Mardi Gras Krewe Du Vieux parade to create multiple giant parade floats about it, with one depicting the then-mayor as a man made of excrement. Shortly after my New Orleans fieldwork ended, at least one fed-up neighborhood group turned to vigilante pothole repair (Brasted, 2018).

As I will further discuss below with social construction, the Red River district's business owners and patrons strived to keep their casual feel but still make sure their properties were clean and safe. This was to maintain public and government support when they were already struggling. Still, they could do nothing about the dangerous sidewalks. Infrastructure issues, I found, were two-pronged because they not only prevented people from attending participation forums, but they also sparked discontent that did lead to outlaw citizenship.

\section{Social construction}

A contribution this dissertation makes is two major additions to social construction scholarship — place and appearance. Like certain groups of people, depending on whether their social construction is positive or negative, can be targeted for positive or negative policy (Schneider \& Ingram, 1993), place and appearance can be socially constructed and make a place or a person the target for positive or negative policy too. 
Place was the major addition. Factors such as crime or reputation for over-the-top debauchery could make a given place, like an entertainment district, fall out of favor in the public's eyes. Likewise, it could be the target for negative public policy, such as noise restrictions or even being shut down, especially if public outcry is loud enough. However, a place being beloved, iconic, and a major piece of a community's culture and history can make it positively constructed and targeted for positive public policy, like a person or group of people can be (Schneider \& Ingram, 1993). One key aspect of this, though, was the places' owners and patrons working to keep any positive social construction intact, and a challenge they faced was working to handle activities that were largely or totally outside of their control. Two related common thread both cities had was crime and the earlier-mentioned infrastructure issues. Even if the business owners and their patrons worked to maintain safe environments inside, certain factors in dealing with their outside environments were out of their control, although they were working with city government to remedy these. With their spaces' existences being threatened, the artistic communities knew social construction of those places was a make-or-break in terms of their survival.

Artistic community members' personal appearances were an addition to social construction literature, as well. This point highly depended on both individual perspective and overall city perspective. Some in New Orleans' artistic community slammed artists and musicians who were dressed too casually, given how the city's traditional performers are known for dressing extremely sharp even for seemingly casual gigs like street performance. Those who did dress casually said that their being "scruffy" made them a target for both low opinions from the influential elites and negative attention from police. Conversely, Austin's artistic community largely praised those who were more casual and 
had a more "rock and roll" look, such as long hair on men and visible tattoos. This, in Austin, was seen as being more true to self, not being fake, being less stiff, and being attractive because they were "cool". Just as "scruffy" artists were targeted for negative policy action (Schneider \& Ingram, 1993) in New Orleans, Austin's artistic community members who were more casual had some of the most significant policy victories, like the Red River district's extended hours. So while appearance itself is a contribution, the element of local context should be a factor in considering social construction, as well.

\section{Institutions and multi-dimensional power exercises}

Literature contributions in terms of institutions and multi-dimensional power exercises that this dissertation makes are namely dire warnings that institutions can fall and how multi-dimensional power exercise works to help non-governmental actors who do not have direct authority over less powerful groups can still exert power over them. It also makes a contribution in terms of power exercises because it demonstrates what someone must do to break free of longstanding power inequities.

Institutions being changed and warnings not to become too comfortable have been noted in the literature (Bachrach \& Baratz, 1962; North, 1990). However, I take this a step further and show exactly how fragile institutions can be when societies are in serious flux and with unprecedented socioeconomic inequality. This can be connected with Florida's (2017) writing about how the present-day gentrification is more devastating than it has been in the past. The economic means between new urban residents who are behind much of these skyrocketing rents and those who are being priced out is far wider than it has been with gentrification of years' past. 
Interviewees informed me that this gives those with more economic capital greater ability to shift both real estate markets and related public policy, a formal institution (North, 1990). With greater ability to change formal institutions, which North (1990) writes are the first targets for those seeking institutional change, this can have a domino effect on informal institutions like cities' love of music and art. Interviewees warned that having too much faith in institutions, in the wake of what they are facing in artistic communities now, is outright dangerous.

This dissertation also contributes to literature regarding multi-dimensional power exercises, namely in demonstrating how non-governmental actors with no direct authority over less powerful artistic community members can still exert power over them. As is done with Second Face of Power (Bachrach \& Baratz, 1962; Gaventa, 1980; Warner, 2001, 2011), interviewees informed me that wealthy elites will manipulate policymaking and the overall "rules of the game" to work in their favor or refuse to make decisions that would work in their favor - which Warner $(2001,2011)$ indicates is a power exercise in itself. These findings also demonstrate how the Third Face of Power works because constant exercise of the First and Second faces, particularly in Austin, has led to widespread hopelessness and even withdraw from participation (Gaventa, 1980; Warner, 2001, 2011) on the artistic community's part, for some. Another aspect of the Third Face of Power is that the less powerful will teach one another that groups such as government are the enemy, often because of messaging actually started by the powerholders (Gaventa, 1980). These are nonetheless passed onward through generations. My interviewees added that taking on "anti-establishment" and "oppositional" stances are not 
only common in lower socioeconomic strata but are also needed for survival when living in those circumstances.

However, this dissertation also demonstrates how the less powerful are still able to overcome these structures and emerge victorious in policymaking. Gaventa (1980) writes that for B (the less powerful) to overcome A (the powerholders), B must mobilize “action upon issues" that overcome A's "mobilization of bias against B's actions" (p. 24). B must also "develop its own resources" and mobilize others with the same "clearly conceived and articulated" grievances (p. 24). This, interviewees told me, was the strategy that the Austin Red River district owners employed during the successful extended hours measure. They worked with others facing the same issue — putting aside any differences when doing so — acted as their own spokespeople, countered wealthy developers' and hotel operators' arguments, and presented their own evidence-based arguments. One informed me that reaching this point was extremely difficult because of the mindset he had to first overcome, and this was no easy task. Before he could begin this process, he had to overcome longstanding messaging from powerholders and within his own social circles that policymaking and working with "the man" should be avoided, as Gaventa (1980) has noted as an obstacle for the less powerful. This was an example of how breaking power structures requires conquering longstanding messaging from both powerholders and one's own community.

\section{Social media}

Social media itself is a literature contribution because of it being in its infancy in public administration literature (Pridemore, N.E. Ganapati, \& Revell, 2019). One of its most ironic contributions is that this new technological frontier, a digital Wild West, 
mirrors so much of James Madison's warnings in The Federalist Papers 232 years ago. A chief concern for Madison (2001 [1787]) was development of "factions", a group of citizens who can be a majority of citizens, an especially loud and/or powerful minority, and even "an obnoxious individual" (p. 46). Factions, he wrote, are a threat to liberty itself even if they are a majority and the rights of those they threaten are a minority.

Social media took this situation to an extreme, with its vastly diffuse participant pool - one that opened the participation door to anyone with an internet connection. Issues I discovered that included repeat posters overtaking comment feeds and outside agitators, with this greater ability thanks to technology, entering a local dialog for the sole purpose of sowing discord (Alliance for Securing Democracy, n.d.c; Herrera, 2018a) demonstrated what Madison (2001 [1787]), should he be alive today, warned about democracy becoming too diffuse, writing, "Liberty is to faction, what air is to fire, an ailment, without which it instantly expires" (p. 43). Like Madison (2001 [1787]) suggested about controlling the overall dialog, some government officials and artistic community members were working to control social media participation through methods such as turning off comments on government offices' social media pages or artistic communities communicating in closed groups, where group administrators can vet those who want to join.

Still, social media's speed and unlimited access showed how, as was done during a Facebook Live forum that the city of Austin (2018d) hosted and I observed, it only took two seconds for a repeated poster to make a relevant question disappear from view in the comment feed. It also opened the doors so widely that the social media dialog led to major security situations becoming even worse, as they did during New Orleans' 
Confederate monument removal (Associated Press, 2016; Evans, 2017b, 2017c, 2017d;

Kinchen, 2016) and the Austin serial bombings (Alliance for Securing Democracy, 2018a, 2018b, 2018c, 2018d, 2018e, 2018f, 2018g; Herrera, 2018a). The fever pitch social media on social media, even when cities are not in crisis as Austin and New

Orleans were during these time periods, demonstrates some of Madison's (2001 [1787]) warnings centuries ago about how the desire for a diverse dialog has a serious side effect of personal passions, once unleashed and unrestrained, possibly turning citizens against one another. He writes:

A zeal for different opinions concerning religion, concerning government, and many other points, as well of speculation as of practice; an attachment to different leaders, ambitiously contending for pre-eminence and power; or to persons of other descriptions, whose fortunes have been interesting to the human passions, have, in turn, divided mankind into parties, inflamed them with mutual animosity, and rendered them much more disposed to vex and oppress each other, than to cooperate for their common good (p. 44).

\section{Part 5: Policy Recommendations}

In this section, I will propose policy recommendations. First, I will provide them for government officials, and I will follow by doing the same for artistic communities. In this, I will offer recommendations for participation, in general, but at the end of each subsection, I will offer some specific recommendations connected to outlaw citizenship. Key recommendations include use of third places as socially "level" participation venues, use of evidence-based arguments when working to craft policy, and proceeding with extreme caution when utilizing social media. 


\section{Recommendations for Government Officials}

Participation venue and time must be carefully considered

One of the most pertinent policy recommendations for government officials is that participation venue is a key component in reaching disaffected populations that include artistic communities, as well as underrepresented groups. This is a component of a proactive approach to creating more constructive relationships with these communities and reaching a more diverse population. It is not enough to merely open a door. Officials must walk out the door to reach disaffected populations.

My research has found that coming to casual locations where artistic communities gather and when they gather can have a major positive impact on relationships with government officials. First, it allows for more effective policies in the end because officials can receive first-hand information from the affected population and see what their challenges are first-hand as well. It is also a gesture of good will on officials' parts to come to these communities where and when they gather, and being there at the time they gather also mitigates problems involving crammed work schedules. During leadership transitions, this can help begin relationship building on a positive note between new leadership and the population that leadership will serve. This can help officials reach a more diverse population, as well. Coming to, for instance, a traditional minority cultural space or a place where lower-income citizens gather can balance out the issues involving participation inequity.

Furthermore, coming to a venue such as a casual third place, like an older and beloved music venue, not only allows officials to reach the population they want but it also provides a way to have a more comfortable, less intimidating conversation with 
artistic communities, as well as other disaffected populations. Third places provide a laidback and socially "level" environment where those gathered are on the same social footing (Oldenburg, 1999). This is a stark contrast to government buildings or elegant locations, which can be especially intimidating for underrepresented groups in terms of appearance and structure. Another important note in this area is that groups like racial minorities can be intimidated or turned off by government buildings that have a heavy police presence. Meeting in third places provides a stark contrast, which could even help police who are working to build more constructive relationships with artistic communities, as well as other disaffected populations - as this has done for the New Orleans Police Department. Given this has helped bridge gaps between a police department that has such a sordid past and the artistic community in New Orleans, this shows how considering participation venue can have a major positive impact.

This is also critical because, as my research has found, traditional participation mechanisms, as well as venues, simply do not work for artistic communities. Besides the issues involving place, meetings are often scheduled during times when artistic community members are working, such as late afternoon and early evening sound checks for musicians. Furthermore, because of the artistic communities constantly working to afford higher living costs, they cannot attend most government meetings anyway. As I will further explain in another subsection, extremely long meetings exacerbate this problem because even if artistic community members can attend a traditional public hearing, they may have to leave for work before their time to speak. 
Having up-to-date, workable, and fair policies implemented

Policies such as noise ordinances and zoning ordinances must be constantly updated and re-evaluated, especially in growing and rapidly changing cities and as cultural changes, like emergence of new performance genres, present new policy needs. Otherwise, government officials like police officers will have no ability to enforce statutes and clearly know who is in the right or wrong when disputes arise. Likewise, providing cultural businesses and artistic community members clear information about what they can and cannot do provides them with the information they need and also desire to stay within the law.

In crafting the policies, they must be specific and clear and based on evidence and not emotion, or personal and political beliefs. For example, noise limits should be based on what public health researchers have determined are safe and what those in fields like sound engineering have determined is high enough for artistic businesses and performers to effectively do their jobs. This should not be, as a New Orleans official detailed to me, based on whether or not a performance genre or content offends someone's personal tastes or beliefs. In these policies, vague language, such as whether or not noise would disturb a "reasonable" person, as was the case in at least one part of the New Orleans noise ordinance, needs to be eliminated and replaced with specific, evidence-based language.

Two other major points emerge with policy development. Policies must be fair and, most importantly, implemented. For example, policies cannot narrowly target certain businesses, such as the New Orleans measure that would have sound measured at the alleged source's property line - for places built to the street as they are required to be in 
urban historic districts like the French Quarter (Personal Communication, 2017).

Likewise, they cannot narrowly target cultural practices, such as putting too-severe limits on C-weighted sound (bass), which is associated with minority-centric music like hip-hop and Latin.

When fair, evidence-based, and specific policies are crafted, they must be implemented. Policies are nothing more than figurative bread and circuses for the people they could help if they are not implemented. If government officials, elected or bureaucratic alike, craft policies and raise hopes — all for those policies to become mired and in limbo or watered-down to something with no impact — this increases citizen ire toward government officials. This becomes even worse when citizens have taken their time to participate in policymaking forums all for, in their minds or in reality, their efforts to lead to nothing. This was one of the major findings in the Austin case study, where policy measures developed after participation efforts were stalled, and, as shown by the Austin city government's own study of gentrification policy recommendations and resolutions, seventy-three proposed policies' statuses were unknown and apparently not even tracked (City of Austin, 2018b). If citizens who take their time to participate in policymaking see their participation as being nothing more than placating them, not only does their participation achieve nothing, but also, they will most likely never participate again.

Private-sector arts policy orientation and civil service protection for arts offices

Two recommendations for government officials also deal with internal structures and staffing. Namely, I recommend that local-level arts policy should also adapt a 
private-sector approach alongside the dominant nonprofit one and that those working in local governments' arts offices have civil service protection.

During my study, I found that the majority of those working in the arts and not just those in the music and recording industry want policies that enable private-sector arts businesses and solo entrepreneurs to both survive and thrive. Rather than more grant funding, they desired more urban-oriented policies such as less restrictive noise and zoning ordinances that allowed them to perform their jobs — or not more of such restrictions that could outright shut them down. Likewise, they desired more market controls, such as ones controlling the development that was causing property taxes and rents to skyrocket. This is not to say that nonprofit arts should be shoved aside and ignored. Rather, this policy recommendation is one putting forward a two-pronged approach that caters to the different needs of those in artistic communities. Just as government staff members who can aid artistic community members in finding funding opportunities are needed, so are ones who can better develop artistic communities' business acumen. The latter, interviewees in both cities informed me, is especially needed for musicians.

With that concern in mind, those who staff such offices should look toward those with private-sector arts experience who understand these unique concerns. On top of the fact that those in the private-sector arts have business-oriented concerns, their business is a complex one with factors such as royalties and licensing involved. Therefore, those who understand this business should be recruited. This can also help governments have "translators", per se, for the "language barriers" (Herranz, 2015) that they may have with those in the artistic community. Likewise, these employees can translate often- 
intimidating or confusing "government-speak", as such an employee in Austin told me, to artistic communities.

To solidify and protect relationships that such employees can build with the artistic community, they need civil service protection and to not be part of a political initiative. The civil service protection, such as what the arts economic development employees in Austin had, allowed for relationships they built with the artistic community to be more stable because the employees and the offices themselves were not subject to political whims. Conversely, the cultural economy office in New Orleans was a mayoral initiative, meaning that a single mayor could eliminate the entire office at any time he or she wished. Especially long leadership transitions in both cities created uncertainty as to not only who would lead but also if current relationships with the bureaucracies would remain intact. A major difference was that Austin's arts economic development employees being integrated into the civil service versus being part of a political initiative gave the two arts economic development offices and the relationships the employees had built more stability. These structural differences for arts offices are not unique to Austin and New Orleans. Therefore, when cities are considering how to structure such offices, ones that give employees civil service protection should be the choice because they provide much more stability — both internally and for the people those offices serve. Have stronger controls on meetings' length

Although I have detailed how traditional mechanisms largely do not work for artistic community members, one major improvement that government officials can make is instituting stronger controls on meeting length. Namely, these include avoiding packed agendas, not having two public meetings back-to-back, and doing more to limit speakers' 
time. These measures to control public meeting length are ones that, according to my findings, create a more democratic citizen participation process in the end. More people with crowded schedules, as artistic community members and other underrepresented groups have, are able to stay and be heard, just as those who can literally afford to stay longer.

Long and even extremely long meetings were major problems in both cities. One cause behind Austin's city council meetings that would run past midnight was that agendas were packed, with some having ninety items or more (Grumet, 2018b; Hernandez, 2018). Likewise, the city of New Orleans had its public comment period on its Master Plan amendments that I observed tagged onto the end of a regular city council meeting. This made the meeting drag onward to the point where citizens and officials alike were extremely frustrated and weary, and several people signed up to speak left before their turn. On top of this, Austin was also dealing with numerous speakers at its meetings (Grumet, 2018b; Personal Communication, 2018).

While the number of people showing up for a meeting cannot legally be controlled, certain elements of the meeting structure can be altered to mitigate this problem. One is not packing agendas. With, literally, ninety or more items on a given agenda, which could have citizens and officials commenting on all, any meeting will inevitably be extremely long. Therefore, officials should be cognizant about how many items are on a given agenda.

Likewise, officials should avoid tagging additional hearings — particularly on major and/or controversial issues like New Orleans' Master Plan — at the end of regular meetings. This makes the problem of long meetings far worse. Any major and/or 
controversial issues, as Austin has worked to do to try and control its meetings' length, should have their own hearing because of the number of speakers that will inevitably want to be heard. Speakers are another issue. Public officials, artistic community members, and advocates alike in this study have all recommended groups together deciding on their talking points and appointing a few spokespeople. However, not allowing a person to speak during a public hearing would present a legal challenge for officials, meaning that this cannot be policy. What could work, though, is doing more to limit speakers' time, providing that all speakers have the same time limits.

Approach social media with extreme caution

Governments entering the social media sphere are entering largely uncharted and potentially dangerous territory. The key policy recommendations I will make for government officials related to social media is to proceed with extreme caution, stay upto-date on tech companies' changes to these platforms, and to be mindful of social media's extremely diffuse participation window - which can open the door to those who use it to create rancor and even security risks.

A key difference between most previous citizen participation work in public administration scholarship and the new frontier of social media is that most previous work involved government websites (Pridemore, N.E. Ganapati, \& Revell, 2019). These, governments can control. With social media, governments have far less control over their online participation. Third-party tech companies control social media platforms and can provide, deny, or significantly change these platforms' operations whenever the tech companies choose. This means that tools governments have can significantly change, and what governments can do with social media largely depends on what the tech companies 
choose to offer. Likewise, how functional or problematic new social media technologies such as Facebook Live can be is also under the tech companies' control. Essentially, governments who choose to utilize this are at tech companies' mercy.

Findings involving social media in this dissertation were largely negative, and they provide sobering or even chilling lessons for government officials who choose to use it. This is largely because of bad behavior and creation of community tension thanks to behavior like trolling, and its diffuse nature means that anyone with an Internet connection - which includes outside agitators - can enter a local forum. Therefore, governments who utilize social media must understand these platforms' controls, such as turning off comments, and keep up with new developments and any functionality concerns, such as those involving Facebook Live. If the public is to be engaged over social media, governments should make sure that the engagement tools work. Social media channels should also be monitored not only for abusive dialog, but also ones that point to security concerns, such as those that arose from social media during the New Orleans Confederate monument removals and the Austin serial bombings.

As I will further detail in my recommendations for artistic communities, I found that social media is good for notification but not for actual participation. Online participation must go offline to be effective in the end. Interviewees indicated social media can reach more potential participants, but those participants must show up whether a given event is a traditional public hearing or an outlaw citizenship activity to make that participation effective. 


\section{Outlaw citizenship recommendations (for government officials)}

Many of the recommendations I will provide for government officials regarding outlaw citizenship are linked to ones I have discussed. These include proactive outreach approaches to possibly avoid outlaw citizenship from erupting in the first place, having policies resulting from outlaw citizens' demands being implemented, utilizing the morerelatable street-level bureaucrats as those to interact with disaffected citizens, and even finding ways to join outlaw citizens in their efforts.

One of my core arguments regarding outlaw citizenship is that public administrators should not be shocked when encountering outlaw citizenship (Pridemore, 2018). Outlaw citizenship is not spontaneous, but, rather, a buildup of citizen frustration that finally reaches a breaking point. Therefore, a proactive approach — finding out what those longstanding grievances are and finding meaningful and workable ways to fix them now - can potentially avert crisis-level situations in the future. What I recommend is, again, public officials walking out the door instead of merely opening it. To find out what the problems are and what could potentially fix them, government officials must go to the affected population where and when it gathers. Those level and more relaxed conversations on the affected population's ground are critical.

Conversations will have no impact in the end, though, unless policy proposals from them are implemented. This is especially true if officials have to take a reactive approach to outlaw citizenship. Therefore, it is critical that conversation leads to action, which then ends with policy put in place. Otherwise it is mere bread and circuses — and citizens like those I interviewed in the Austin and New Orleans artistic communities know it. If policies crafted with the affected population's input do not become reality, 
citizens' ill feelings could become worse, and any existing outlaw citizenship, should it have already erupted, could escalate.

I also recommend that those who work to build relationships with disaffected citizens should be street-level bureaucrats rather than elected officials or even high-level appointed ones. Especially when working with populations in lower socioeconomic strata, those in the bureaucracy can be more relatable namely because the civil servants who have more face-to-face interaction with artistic communities and other disaffected groups are most often not living like millionaires. Interviewees within government shared that they are also struggling with rising costs of living and, sometimes, in the face of budget cuts or salary freezes. Likewise, some artistic community members believed that the bureaucracy was more relatable because they had common oppressors, such as elected officials or wealthy elites. Furthermore, the longer tenures in the bureaucracy versus elected office means that those in the bureaucracy can form more stable, longerlasting relationships. The bureaucracy, namely the street-level bureaucrats, should be the ones to make the first move in positive relationship building.

Likewise, public officials can build relationships with disaffected citizens through, in some cases, joining their efforts and becoming an "outlaw local government". This opportunity, in the current political and social environment, has presented itself as certain cities have become more progressive while the federal government and some state governments have shifted in the opposite direction. Joining citizens who are fighting back against state and federal policies they believe are unjust — while state and federal governments are sometimes working to undermine local policies with which they do not agree — can build a bridge. This can go further than a mere visual display, though. An 
especially effective way of being an outlaw local government is through policymaking and policy implementation that runs counter to federal and state policy. Presenting outlaw citizens a concrete policy that sharply contradicts federal and state policy that outrages local citizens can both show a greater commitment on the part of local officials and give the citizens the counterattack they desire.

\section{Recommendations for artistic communities}

Build and maintain positive in-group relationships

Building positive in-group relationships — or a lack of doing so — was a major point of divergence between the two case study cities' artistic communities. This also provides a major lesson for artistic communities in any city. While it should be noted that this was not the only factor, those in Austin who built more positive in-group relationships, even with former rivals, managed to have concrete policy implemented that worked in their favor. While this was not the only component of any victories, it was surely the foundation. Conversely, New Orleans' artistic community's infighting and tribalism made some of their efforts toward positive change fall apart because they had not settled their own longstanding differences enough to where they could formulate plans and then address public officials.

This provides a lesson to artistic communities anywhere that in-group problems must be solved or at least temporarily pushed aside if they are to help craft policies that work in their favor. The challenges that artistic communities face now, such as affordability and social changes that have led to attempts to temper historically boisterous entertainment neighborhoods, are greater than any rivalries such as bar owner 
competition or dislike of someone's performance style. Also, the opponents that all artistic community members face are especially strong and well-financed.

Therefore, it takes a united front and ideas from, as a Texas state official in the Austin case put it, "survivors" in the music industry and the arts to provide enough pushback. Even if the parties involved cannot outright dismiss their personal dislike of a fellow artistic community member, those differences should at least be pushed aside temporarily until policies are crafted and implemented. As an Austin advocate and former government official said, "You can go back to hating each other after the policy is implemented," and as a Texas state official interviewed for the Austin case said, "For what we're talking about, leave it at the door. Let's be professionals here. Later, you take a swing at him in the parking lot for all I care." If this does not happen, an artistic community divided is bound to, together, fall.

These positive in-group relationships, though, can be critical to have in place if faced with a policy challenge, such as a restrictive noise ordinance or a wealthy individual working to shut down a cultural business like a music venue. As two New Orleans business owners learned when the businesses they built were endangered, the positive relationships they built with others in the artistic community — as well as groups such as their neighbors - meant that they had a ready-made group of supporters ready to rally to their sides. While some relationships will never be positive, establishing as many positive relationships in advance means that more time can be spent on other needed strategies in fighting for helpful policies or against hurtful ones, such as deciding on a workable policy proposal to bring to government officials' attention. 
Nuances of the artistic community make this situation more complex — but those nuances are part of a problem that artistic communities must work past to have policies work in their favor. Within these in-group relationships, real or perceived hierarchy within artistic communities should be shoved aside — with more prominent and wealthier artistic community members and better-funded and more prominent arts organizations becoming team players. The opposite was a problem in both cities, but more with prominent individual artistic community members in New Orleans and betterfunded organizations in Austin.

A select few artistic community members and a select few organizations were doing well, if not extremely well, while the majority were in crisis. The consensus among advocates from smaller nonprofits and artistic community members in both cities was that the few certain individuals and organizations who were doing well did not want to be team players and contribute their considerable societal and/or financial capital to help the artistic community as a whole. They noted that if the smaller, less powerful individuals or groups will fall, the larger ones would be next. Therefore, any artistic community should know that a threat against one - whether it is a rival or someone considered insignificant in the social strata - is a threat against all.

\section{Being one's own spokesperson, evidence-based arguments, and proposing solutions}

While in-group relationships are critical, artistic communities must make sure to not be overly dependent on others. The key policy recommendations I will make in this subsection is rooted on self-reliance and fact-checking. These include artistic community members being their own spokespeople, using evidence-based arguments when doing so, and proposing their own policy solutions. 
Artistic communities being their own spokespeople has multiple benefits. First, policymakers hear directly from the affected population, and the policymakers will most often appreciate and respect artistic communities for making a serious effort to create positive change. It also shows initiative on the artistic communities' parts. The other factor that artistic communities must note in this area is that they should be their own spokespeople because certain third parties, like some (not all) advocacy groups, may claim to have the artistic communities' interests at heart or represent the artistic community. The reality, I found, is that some of these groups do neither. The additional factor that artistic communities, specifically, have to watch is their celebrity factor, per se. Individuals' and groups' connections to prominent local entertainers may mean that potential partners only want a local celebrity to promote themselves and have no interest in helping that local celebrity's less fortunate colleagues. Any group working to create major policy change would have to be wary of this, but artistic communities must be even more careful.

When being one's own spokesperson, artistic community members should also come prepared with their own evidence-based arguments. Throughout this dissertation, particularly in the Austin section, interviewees indicated that instead of relying on emotion, artistic communities should rely much more on hard evidence, such as revenues, jobs created, and economic impact studies. Such arguments not only carry more weight but they also catch the attention of government officials more, especially when financial figures become part of the presentation. This can also work to break the figurative language barrier (Herranz, 2015) artistic communities often have with government 
officials because they can speak to government officials in the language that government officials understand more.

To bolster artistic communities' positions further, they should come prepared with their own proposed policy solutions when approaching government. Interviewees indicated that this saves officials time and shows initiative, but this also allows artistic communities to have greater control of their own destiny. Through proposing their own policies rather than having someone else do the job, there is a greater chance that artistic communities will get what they want. It should be noted that proposing policy solutions is no guarantee that artistic communities will get all that they want or anything they want at all. Still, their desires are clearly articulated. Likewise, when crafting the policy solutions, artistic communities must make sure they would have an impact, consider their costs and how these measures could be funded, and make sure they are doable, overall.

This may seem daunting for someone who is not a public policy practitioner or scholar. Still, interviewees indicated, this is not an impossible task. Rather, artistic communities may just have a steeper learning curve and may need more time to learn, as would any citizen without formal policy training. Once overcoming that, though, they can still navigate the often murky and exhausting policymaking process. If they still have trouble, the earlier-mentioned street-level bureaucrats can be the, as an Austin music venue owner told me, "smartest people in the room" who can help them figure out oftencomplex processes.

It should also be noted that when artistic community members are working to break participation barriers, some of their greatest challenges come from within their own social and socioeconomic circles. I found that longstanding in-group messaging that 
government, a.k.a. "the man", is the enemy could create a barrier between artistic communities and government even before they ever interact. Breaking out of that thought pattern is the key, and a Red River music venue owner in Austin who had to do this informed me this is extremely difficult because such messaging is deeply ingrained. However, both he and a New Orleans police supervisor indicated that dialog about not wanting to work with "the man" had to stop — with artistic communities being willing to approach government for a constructive relationship and not turning away officials when officials approach artistic communities to try and build the same. Just as artistic communities must work together because they face strong outside opponents, artistic communities must also handle the extremely difficult task of standing out on their own and countering negative messaging within their socioeconomic spheres.

\section{Participant selection, diversity, and nuance}

As detailed in both chapters about deciding who participates, balancing out diversity and democracy with conciseness and clarity are constant struggles. Still, I offer policy recommendations to artistic communities in this area. The key factor is nuance finding out exactly who has first-hand knowledge of an issue or exactly who would have a greater interest in a given, extremely specific policy matter. With that question being answered, artistic communities can then determine who would be the best spokespersons or what forums and events they should attend, especially when considering their crammed schedules. At the same time, the interested group should still be a diverse one, taking in perspectives of underrepresented groups even within the artistic community.

Specificity for participants is critical for not only better policy to be created in the end, but also for sustaining participation. As interviewees noted, someone who comes to 
a forum that does not interest him or her will find it a waste of time - then not come to a forum that would be of greater interest and where they can make a major contribution. Likewise, when groups such as advocacy organizations or other artistic community members are working to organize, they must make sure that any forums they create themselves are extremely specific as well and for the same reason.

I also recommend that artistic communities narrow down their participants to a few spokespeople or even just one spokesperson but after all agree on what the core issues are and what the talking points should be. This not only makes any dialog with government officials more concise, but it also eliminates some chaotic displays shown in some public meetings where the topic is especially controversial. Likewise, meetings are more constructive when more controlled. As interviewees have indicated in both cities, I recommend that while only a few are chosen as speakers, artistic communities should work to pack any policy forum with as many supporters as possible for visual effect.

While participants must be specific and messages must be concise, the flipside is that they must, at the same time, be a diverse, representative group. The key here, as Fung (2006) notes is important in participant selection, is selective targeting. For example, to reach more minorities in the artistic community, going to a historically minority cultural space to find participants could help. Reaching a diverse population is especially critical when minority populations in artistic communities would be affected most, such as the performers in the majority-minority hip-hop and Latin music circles who would have the most to lose with tighter regulations on $\mathrm{C}$-weighted sound. 


\section{Social media participation}

For artistic communities, they too face some of the same above-mentioned problems that government officials have with social media participation. Social media is littered with trolling, bad behavior, divisive dialog, and those who desire nothing more

than to cause trouble. Still, it also provides opportunities with its widespread reach. As I did with government officials, my main policy recommendation to artistic communities with social media participation is that online participation must move offline to be effective in the end.

Social media participation can be a valuable tool in spreading messages about traditional and outlaw citizenship participation events alike, and social media can be a good originating point for discussion when closely monitored for problems such as trolling. It can also provide a valuable access point for those with crammed work schedules. But the key word is "originating". Participation does not have the impact online as it would offline, especially with outlaw citizenship activities. Visuals and inperson interaction are key components in participation efforts that work. Likewise, inperson interaction has a greater social accountability element because those who want to cause trouble find it easier to hide behind a screen and internet alias. When dialog is done in person, that social accountability factor can be a major point that enables civility and constructive discussion. So, social media is an effective way to begin dialog, but staying behind a computer screen or a smartphone at all times will leave policy problems in first gear. 


\section{Consider local context}

Just as nuances must be considered with participant selection, local context must be considered when devising participation strategy — even down to what chosen participants wear. What is acceptable or appealing in one city may be appalling in another. This was the case in my findings about social construction of artistic community members based on their appearances. For Austin, a casual, "cool", and "rock and roll" appearance was seen as attractive and true to self, but New Orleans' artistic community, with its more longstanding members known for dressing extremely sharp even for casual events, decried this. Therefore, artistic communities must consider local context in all aspects of its participation activities when they are planning. What may be acceptable in both Austin and New Orleans may be totally unacceptable in Nashville or Seattle, and vice versa.

\section{Outlaw citizenship recommendations (for artistic communities)}

Outlaw citizenship on the part of artistic communities can be risky but quite effective if done properly. Displays that are not strong enough could be ignored or even mocked for being useless, causing less people to participate in the end. Displays that are too bold, especially if activities are illegal, can lower both government officials' and the public at-large's opinion of the artistic community.

So outlaw citizenship requires striking a precarious balance that involves considering how severe the problem is, how effective traditional participation and relationship building with government has been, finding the proper like-minded disaffected citizens from other groups, being watchful of outside agitators, deciding how bold a display will be, and most importantly, having a clearly articulated grievance and 
goal for these activities. Also, a major draw in gaining public support is not only linking outlaw citizenship to beloved cultural practices, but in doing that, show the public atlarge, as well as officials, what stands to be lost without greater support.

Being bold is critical to gaining attention, but how bold should depend on the issue and the local context. For example, New Orleans' Krewe Du Vieux parade in 2018 featured floats with especially brazen and even intentionally offensive (in other cities' contexts, most likely) language and imagery. However, the parade organizers' main target was the city government they and other citizens believed were responsible for the city repeatedly flooding because of constant and longstanding sewer and drainage problems. The city's $300^{\text {th }}$ anniversary and continued issues with corruption even after three centuries also added fuel to the fire. Although the messages involving corruption were rather broad, the messaging behind the sewer problems and how citizens felt about their government's actions was both bold and clear, such as when they depicted the thenmayor as a literal piece of excrement.

So in this case, it was critical for the display to match the situation. If working to have a message resonate with other angry citizens, the displays need to match that anger. Otherwise, it will seem watered down and useless. At the study's onset, I had classified New Orleans as a negative extreme because of its rancor and Austin as a positive extreme because, on the surface, relationships between the local government and artistic community seemed far more constructive. One challenge I had to this classification once I obtained IRB approval to enter the field in both cities was that New Orleans' activities in outlaw citizenship seemed to be the most favorably viewed and effective. Austin interviewees, particularly those who were familiar with New Orleans' activities, 
suggested it was time to take a cue from New Orleans because, in some minds, trying to have a friendly dialog in traditional forums with officials was not working. Traditional efforts, they believed, were exhausted. For them, it was time to stop playing nice. For other cities' artistic communities facing similar situations, the time may come or it may already be past time to stop playing nice, as well.

This may seem like the worst policy recommendation a public administration scholar could ever put forward, but I will recommend that anyone who wishes to organize and participate in outlaw citizenship should consider options that may break the law. Doing this is obviously extremely risky in terms of not only legal troubles but also public opinion. One thing that must be considered is whether or not the action is violent or destroys property. Generally speaking, if neither is the case, outlaw citizenship that breaks the law has less risk of lowering public opinion about artistic communities. The New Orleans brass band protest with a second-line parade storming city hall was not legally permitted. Still, the powerful photos of the event resonated with citizens both inside and outside New Orleans, and, most importantly, the more restrictive proposed noise ordinance that was the clearly defined target was pulled after this event. In fact, negative treatment of those who engage in outlaw citizenship like non-violent civil disobedience who do face negative government responses like excessive police force [as was the case during the Civil Rights Movement (Rimmerman, 2011)], tend to get more of the public on their sides and to fight the same policies.

Outlaw citizenship activities can be stronger too, if artistic communities find likeminded groups who share similar or even the same grievances. For example, the New Orleans artistic community saw groups such as the service industry workers as kindred 
spirits because the service industry workers were major elements of the largely tourist economy - yet the service industry workers profited little from it too. The artistic community already participated in the service industry workers' rallies. A key element that an interviewee noted is that both groups have considerable economic power, even if they do not have financial capital in hand, because of their contributions to the local economy. As this street poet said, if the artistic community members and service industry workers united for just one day to stop work, they could "shut down" the city and send a strong message as to how vital they are. The potential is there, as long as the groups are appropriate for a given message and that partnerships are equal.

Just as outside groups can be major allies, outside groups can also seriously derail outlaw citizenship efforts. In fact, as I found in this study, the current social and political environment has created an environment to which outlaw citizens have to be mindful of outside agitators possibly even more than their own in-group behavior. These agitators can cause participants to lose their tempers and act out when cameras are rolling or make an otherwise peaceful activity violent. One recommendation I would make in this regard is monitoring social media channels and other communication from groups who would counter certain outlaw citizenship methods. With this, artistic community members can be prepared and work to keep their image intact. If the outside agitators threaten violence, the outlaw artistic community members can notify law enforcement agencies that usually monitor such activities. This makes the artistic community the more constructive partner in government's eyes, even if they are working against certain public policies.

Another form of outlaw citizenship that could be highly effective is working to ones working to bridge gaps between artistic communities and government offiicals, as 
well as the public at-large. A major way of possibly accomplishing this that I will recommend is utilizing the music and arts these groups provide.

Earlier literature showed that, sometimes, artistic communities use their art as preferred communication because, historically, underrepresented groups were denied educational opportunities (Love, 2006). In this particular study, I found that most artistic community members were perfectly comfortable with speaking with governmentpreferred rational argument. When they used their art as a way to get their message across, it was often a way to unite more than fight. In the case of the New Orleans brass band protest in 2014, interviewees informed me that the purpose was to not only fight against policy they beliveved was unjust but also to rally others to support them and remind the group as to what they were fighting to protect. Austin theater performers who lost their spaces were traveling to do their performances but did so to bring people in and, like New Orleans did, remind people of what was at stake. Outlaw citizenship's disruption of the status quo does not always have to require an oppositional stance.

\section{Part 6: Limitations and Strengths}

One major limitation in terms of study credibility (Yilmaz, 2013) is majority white samples, especially for New Orleans. Dependability (Yilmaz, 2013) is another concern because of the shifting situations in both cities, particularly with its leadership changes, and extreme events happening in both cities during the course of this study. Having only two case studies and the heavy influence of the case studies' cities context is a concern for transferability. Other cities' context would likely affect any findings there.

However, this study has multiple strengths. For credibility (Yilmaz, 2013), it features multiple methods I used to verify findings, with different methods adding 
credence to or providing contrasts to previous information I had collected. Additionally, my use of more judgment sampling helped me learn rival explanations, rather than the perspectives of only one group. With this, feuds and tribalism was a finding itself, but it did not have a serious impact on my findings as whole. I was also able to reach more fringe and unheard populations, such as those in punk, metal, and hip-hop subcultures.

For confirmability (Yilmaz, 2013), the multiple triangulated methods helped, again, because they provided checks and balances on findings from any given method. Additionally, my asking those who did narrative maps about their drawings' elements helped confirmability because I did not read into elements that did not matter or miss something significant. Interviewees also had the opportunity to confirm or refute findings through my reporting back, and the unstructured interview format's ability to ask followup questions allowed me to further fact-check statements. My personal background as a musician and writer also aided in this because I could utilize it in questioning and observing, such as when I noticed less-than-ideal transportation methods for people with large equipment like I have hauled, myself, or understood the high injury risks, such as vocal damage, for overworked performers. Likewise, that combined with my policy background helped me also work as a "translator" for the language barriers (Herranz, 2015) that appeared throughout this dissertation.

For dependability (Yilmaz, 2013), I made sure to clearly define my role as a researcher for the multiple situations in the two cities, documenting every field situation down to how I dressed, every time. I made checks on findings not just from one method, but also certain informants' claims. I was also cognizant of how my background as not only a musician and writer, but also as a journalist who had covered Hurricane Katrina in 
2005 , could negatively or positively affect interviewees. I took great care in what I revealed and, if so, when I did.

In terms of transferability (Yilmaz, 2013), much of this study can be applied to other disaffected groups, particularly those with lower socioeconomic status or less societal power, in general. These groups can include service industry workers or striking public school teachers. It also provides insight for multiple disciplines, given its literature contributions in not only public administration, but also urban studies, political science, and arts and culture.

\section{Part 7: Future Studies}

Future studies should entail researchers working to spend more time building trust and relationships with disaffected groups if working to reach them. This is especially needed for white researchers working in majority minority settings, as was the case for me. While I took my time and worked to build trust, time constraints did not allow me to take as much time as I likely needed, given the challenges in working with any disaffected population. Disaffected populations, as I frequently found, are often turned off by academic research, in general. One possible solution for this is not only taking more time to build relationships but also having multiple researchers working in a team and those researchers coming from different racial, ethnic, socioeconomic, and professional backgrounds.

Researchers should also explore the particular nuances of other disaffected populations. The current political and social climate has given rise to multiple outlaw citizenship movements (Pridemore, 2018). These groups include and are certainly not limited to minorities, service industry workers, and public school teachers. Just as artistic 
communities had their own particular policy concerns, other disaffected groups will, as well. This should explored, too.

This work should also be done with artistic communities in other arts-oriented cities. Other arts-oriented cities' artistic communities are facing similar struggles with affordability and social and economic change. Their cities' contexts could provide new findings, perspectives, and, possibly, solutions in terms of how artistic communities can be heard and do so in a way that results in positive policy outcomes.

Future research should also examine the place element much more, given its ties to multiple research questions I examined and on multiple disciplines and literatures. Additionally, more work should be done on social media, namely because it is very new territory, in general, and it continually changes. Furthermore, governments are now handling the challenge of working on third-party platforms that they ultimately do not control.

More research should be done on the nuances of outlaw citizenship, especially because it continues to rise in the current political and social environment (Pridemore, 2018). Given their links to artistic communities' participation hindrances and disaffectedness that I found, more work should be done on how multi-dimensional power exercises and how they happen in practice.

\section{Part 8: Final Thoughts}

Although positive change will not happen overnight for artistic communities, it is not impossible. The key to their survival as economies and societies change and seemingly want to sweep them out of the communities and spaces they created is having a constructive dialog, both within their group, with kindred spirits, and even old enemies 
inside and outside of government. Having this dialog requires overcoming language barriers (Herranz, 2015) between artistic communities and governments, working to organize even though it is akin to herding cats (Herranz, 2015), and burying some hatchets and healing some festering old wounds.

Artistic communities face numerous barriers, but they should never doubt their ability to formulate effective public policy that works in their favor. Governments and outside groups should never doubt the artistic communities' abilities either. They already come armed with first-hand knowledge, which governments do need for more effective policy (Elias \& Alkadry, 2011). The challenge that many of them have, which is maybe even greater than practical barriers like work schedules and transportation, is working to overcome messaging from both powerholders and within their own communities that policymaking is not for them because they may be too "scruffy", government is the enemy, and that they will never defeat someone who has more power, money, and social standing. This has to be done before anyone in this situation can move on to formulate evidence-based arguments and create concise messages that resonate with officials which artistic communities have done - and can do - even when facing powerful opponents.

This leads me to again argue that outlaw citizenship is much more multi-faceted than I had previously learned from my pre-fieldwork research. Outlaw citizenship is more than an activity and the context of who participants are should be considered. Those who overcome tremendous power structures, many of them being extremely longstanding (Gaventa, 1980; Warner, 2001, 2011), could be outlaws for entering traditional participation venues, with structures that can work against underrepresented groups, and 
especially if they emerge successful. Outlaw citizenship, also, may not be a confrontational and angry activity, but rather, one that reminds fellow citizens and public officials that arts and artistic communities have value and what could be lost without further support. Outlaw citizenship can be used to pull in like-minded people and draw in new allies but, rather than having an oppositional stance, it can unite disparate groups and for a cause rather than against it. Just as I learned that Austin and New Orleans were not neatly dichotomous case studies that were clear positive and negative extremes, neither is outlaw citizenship, itself.

Dear reader, I have run with outlaws and herded cats to bring you these findings. I have walked for miles on Austin's and New Orleans' streets to demonstrate what obstacles artistic communities have in being heard and what they are doing to overcome them. To make my contribution to my discipline, to the knowledge body as a whole, and to, I hope, demonstrate how public policymaking can be more accessible for artistic communities, I have sat with street performers on dirty sidewalks and inside crammed cars, have nearly been struck by garbage trucks at least twice, slept in my car both at an abandoned gas station and beside a cow pasture, twerked though I totally looked ridiculous doing so, and headbanged.

For other researchers, this would be torture. For me, I eagerly dove in and would do so again in a heartbeat. More importantly, I believe I have reached a group the public administration discipline has rarely touched, and I hope this creates a continued and more widespread dialog between artistic communities and policy scholars. Artistic communities may be in crisis, but their strength and gusto are amazing — even when 
facing what some may consider imminent doom. May other scholars and the public atlarge utilize the lessons they impart as I will do forever. 


\section{REFERENCES}

Adelson, J. (2018, January 18). Orleans, Jefferson Officials Hopeful Water Systems, Schools Will Return to Normal by Monday. New Orleans Advocate. Retrieved from https:/www.theadvocate.com/new_orleans/news/article_27b4751c-fc7511e7-a974-bf61e0f2829a.html

Adickes, S. (2002). Sisters, not demons: The influence of British suffragists on the American suffrage movement. Women's History Review, 11(4), 675-690.

Akram, S. (2014). Recognizing the 2011 United Kingdom Riots as Political Protest: A Theoretical Framework Based on Agency, Habitus and the Preconscious. British Journal of Criminology, 54(3), 375-392.

Allcott, H., \& Gentzkow, M. (2017). Social Media and Fake News in the 2016 Election. Journal of Economic Perspectives, 31(2), 211-236.

Alliance for Securing Democracy. (n.d.a). Hamilton 68 Version 2.0 - COMING SOON. Retrieved from https://securingdemocracy.gmfus.org/hamilton-68

Alliance for Securing Democracy. (n.d.b). In IO-A - Information Operations Archive. Retrieved from https://www.io-archive.org/\#/

Alliance for Securing Democracy. (n.d.c). Mission Statement. In About Us. Retrieved from https://securingdemocracy.gmfus.org/about-us\#mission

Alliance for Securing Democracy. (2018a, March 18). [Just a reminder that: Majority black Flint, Michigan still has drinking water that will give you brain damage...]. (Original alias used: Jemisha). Retrieved from Hamilton 68, Information Operations Archive database: https://www.io-archive.org/\#/

Alliance for Securing Democracy. (2018b, March 19). [4 bombings happened in Austin, TX, all of them targeted minorities...]. (Original alias used: Resistance Girl). Retrieved from Hamilton 68, Information Operations Archive database: https://www.io-archive.org/\#/

Alliance for Securing Democracy. (2018c, March 19). [Another explosion in southwest Austin, Texas! Why these bombings ain't a bigger story? ...]. (Original alias used: Luisa Haynes). Retrieved from Hamilton 68, Information Operations Archive database: https:/www.io-archive.org/\#/ 
Alliance for Securing Democracy. (2018d, March 19). [There has now been 4 bombings in Austin Texas...]. (Original alias used: Kanisha J). Retrieved from Hamilton 68, Information Operations Archive database: https://www.ioarchive.org/\#/

Alliance for Securing Democracy. (2018e, March 21). [The Austin bomber, Mark Anthony Conditt was a white man...]. (Original alias used: Kanisha J). Retrieved from Hamilton 68, Information Operations Archive database: https://www.ioarchive.org/\#/

Alliance for Securing Democracy. (2018f, March 21). [It turns out that the Austin bomber, Mark Anthony Conditt, was a Conservative.... . (Original alias used: Resistance Girl). Retrieved from Hamilton 68, Information Operations Archive database: https://www.io-archive.org/\#/

Alliance for Securing Democracy. (2018g, March 22). [The Austin bomber went to survivalist camps as a teen...]. (Original alias used: Resistance Girl). Retrieved from Hamilton 68, Information Operations Archive database: https://www.ioarchive.org/\#/

American Association of Colleges of Osteopathic Medicine. (2015, July-August). Climbing the Ladder: A Look at Sherry R. Arnstein. Retrieved from https://www.aacom.org/news-and-events/publications/iome/2015/july-august2015/Arnstein-bio

Anderson, J. (Photographer). (2017, January 6). [The Nook music venue with a Westin hotel in the background]. Austin Chronicle. Retrieved from https://www.austinchronicle.com/music/2017-01-06/playback-the-westin-suesthe-nook-over-sound/

Ankrum, N. (2010, April 23). Earth Day -- Austin's Political Ecosystem: Scott Swearingen's 'Environmental City' Tells the Inner Story of Austin Politics. Austin Chronicle. Retrieved from https://www.austinchronicle.com/news/2010-0423/1018722/

Ansolabehere, S. \& Iyengar, S. (1996). The Craft of Political Advertising: A Progress Report. In D.C. Mutz, P.M. Sniderman, and R.A. Brody (Eds.), Political Persuasion and Attitude Change (pp. 101-124). Ann Arbor, MI: The University of Michigan Press.

Archer, L. (2018, February 6). Criminalizing strippers' work makes young women more vulnerable [Editorial]. Times-Picayune. Retrieved from https://www.nola.com/opinions/index.ssf/2018/02/bourbon_street_strip_clubs.htm 1 
Armus, T. (2017, December 9). Former Houston Mayor Annise Parker to lead LGBTQ Victory Fund. NBC News. Retrieved from https://www.nbcnews.com/feature/nbcout/former-houston-mayor-annise-parker-lead-lgbtq-victory-fund-n827746

Arnstein, S.R. (1969, July). A Ladder of Citizen Participation. Journal of the American Institute of Planners, 35(4), 216-224.

Associated Press. (2005, September 1). Hastert: Rebuilding New Orleans Under Sea Level Makes No Sense. Fox News. Retrieved from http://www.foxnews.com/story/2005/09/01/hastert-rebuilding-new-orleans-undersea-level-makes-no-sense.html

Associated Press. (2006, February 6). States Move to Bar Protests at Soldiers' Funerals. NBC News. Retrieved from http://www.nbcnews.com/id/11206458/ns/us_news-life/t/states-move-barprotests-soldiers-funerals/\#.WzqDpC-ZOsp

Associated Press. (2016, March 25). Confederate statue removal in New Orleans turns nasty. Times-Picayune. Retrieved from https://www.nola.com/politics/index.ssf/2016/03/confederate_statue_removal_in. html

Associated Press. (2017, August 9). Hot Words After New Orleans Flood, Pump Problems Revealed. Times-Picayune. Retrieved from https://www.nola.com/politics/index.ssf/2017/08/hot_words_after_new_orleans_f 1.html

ATX Music. (n.d.) Music and Entertainment Division: About Us. Retrieved from http://www.austintexas.gov/about-atxmusic

Auber, A. (2018, August 18). 50 restaurants where you can take your dog in Austin. Austin American-Statesman. Retrieved from https://www.austin360.com/ENTERTAINMENT/20180818/50-restaurantswhere-you-can-take-your-dog-in-Austin

Austin American-Statesman. (n.d.) Overview: Inheriting inequality. Austin AmericanStatesman. Retrieved from https://projects.statesman.com/news/economicmobility/index.html

Austin American-Statesman. (2016, September 15). 'Save Our Spaces' protest march, 09.14.16. Austin American-Statesman. Retrieved from https://www.statesman.com/photogallery/TX/20160915/PHOTOGALLERY/3091 $59796 / \mathrm{PH} / 1$ 
Austin American-Statesman Editorial Board. (2017, March 31). Austin abandons transparency in search for a new city manager [Editorial]. Austin AmericanStatesman. Retrieved from https://www.statesman.com/NEWS/20170331/Austinabandons-transparency-in-search-for-a-new-city-manager

Austin American-Statesman Staff. (2017, December 26). No. 8 story of the year: Uber and Lyft return to Austin. Austin American-Statesman. Retrieved from https://www.statesman.com/news/20171226/no-8-story-of-the-year-uber-and-lyftreturn-to-austin

Autullo, R. (2019, January 17). Austin unlawfully blocked gun holder from City Hall, judge rules. Austin American-Statesman. Retrieved from https://www.statesman.com/news/20190117/austin-unlawfully-blocked-gunholder-from-city-hall-judge-rules

Axtman, K. (2002, May 1). Austin Asks Just How Loud 'Live Music Capital' Has to Be. Christian Science Monitor. Retrieved from http://www.csmonitor.com/2002/0501/p02s01-ussc.html

Bachrach, P., \& Baratz, M.S. (1962, December). Two Faces of Power. The American Political Science Review, 56(4), 947-952.

Baggs, M. (2019, January 18). Fyre Festival: Inside the world's biggest festival flop. BBC News. Retrieved from https://www.bbc.com/news/newsbeat-46904445

Balli, C., \& Texas Monthly. (2013, February). What Nobody Says About Austin. Texas Monthly. Retrieved from https://www.texasmonthly.com/politics/what-nobodysays-about-austin/

Barnes, G. (2018, March 28). [The United workers at the un-american statesman are the Russian bots.]. In Austin American-Statesman. Retrieved from https://www.facebook.com/pg/statesman/posts/?ref=page_internal [Facebook update].

Bennett-Ashcraft, C., Bynum, D., Parkhill, K., Lenhart, M., Garza, B., Schell, C., \& Epps, A. (2018, March 19). [They only report on Trump and now this supposed affair...]. In Austin American-Statesman. Retrieved from https://www.facebook.com/pg/statesman/posts/?ref=page_internal [Facebook update].

Berg, L., King, B. \& The SIMS Foundation. (2018). The Nightlife Ain't No Good Life. In The SIMS Foundation. Retrieved from https://simsfoundation.org/berg-study/

Berg, B.L., \& Lune, H. (2012). Qualitative Research Methods for the Social Sciences (8th ed.). Upper Saddle River, NJ: Pearson. 
Berson, M. (2007, October 26). Theater Resurging on Capitol Hill. Seattle Times. Retrieved from http://www.seattletimes.com/entertainment/theater-resurging-oncapitol-hill/

Beyer, S. (2016, March). In the Birthplace of Jazz, Noise Complaints Get Louder. Governing. Retrieved from http://www.governing.com/columns/urbannotebook/gov-new-orleans-noise-complaints.html

Biel, E. (2011, October 27). Revolution Graffiti: Reclaiming Public Space, Reclaiming Freedom in the New Egypt. The Yale Globalist. Retrieved from http://tyglobalist.org/in-the-magazine/online-exclusive/revolution-graffitireclaiming-public-space-reclaiming-freedom-in-the-new-egypt/

Bixler, R.P. \& Bhandari, E.E. (2018). 2018 Greater Austin Civic Health Index. Austin, TX: RGK Center for Philanthropy and Community Service, University of Texas at Austin.

Black, L. (2018, June 20). The Stranger's Guide for First Time Pot Buyers in Seattle. The Stranger. Retrieved from https://www.thestranger.com/visitorsguide/2017/05/10/25140530/the-strangers-guide-to-first-time-pot-buyers-inseattle

Blackstock, P. (2017, July 11). City selects Erica Shamaly as Music \& Entertainment Division manager. Austin American-Statesman. Retrieved from https://www.statesman.com/news/20170711/city-selects-erica-shamaly-as-music-entertainment-division-manager

Blackstock, P. (2018, January 19). Hi, how are you? We'd like to tell you about 'Hi, How Are You?' Day. Austin American-Statesman. Retrieved from http://music.blog.austin360.com/2018/01/19/hi-how-are-you-wed-like-to-tell-youabout-hi-how-are-you-day/

Bland, G. (2011). Overcoming a Decade of Crisis: Zimbabwe's Local Authorities in Transition. Public Administration and Development, 31(5), 340-350.

Blais-Billie, B. (2018). Austin Honors Daniel Johnston With "Hi, How Are You?" Day. Pitchfork. Retrieved from https://pitchfork.com/news/austin-honors-danieljohnston-with-hi-how-are-you-day/

Blue Tongue. (2018). Goat By Goat West. Retrieved from https://www.facebook.com/events/203412883738093/ [Facebook event page]. 
Brenner, W.A. (2018, January 8). Raw Paw's Chris Dock Talks About the Fire that Destroyed Their HQ. Austin Chronicle. Retrieved from https://www.austinchronicle.com/daily/arts/2018-01-08/raw-paws-chris-docktalks-about-the-fire-that-destroyed-their-hq/

Briz, A., Fisher, T., Jin, B., McClure, J., \& Mihalik, L. (2018). Texas Senate Election Results: Live Midterm Map by County \& Analysis. Politico. Retrieved from https://www.politico.com/election-results/2018/texas/senate/

Brown, W., Jo, S., \& Andersson, F. (2013). Texas Nonprofit Sector: Describing the Size and Scope. College Station, TX: The Bush School of Government \& Public Service, Texas A\&M University.

Brydon, M., \& Vining, A.R. (2016). Combining Citizen Participation and Expert Analysis: A Wild, Wild Horses Problem in British Columbia. Local Government Studies, 42(1), 75-96.

Bryer, T.A. (2013). Public Participation in Regulatory Decision-Making: Cases from Regulations.gov. Public Performance \& Management Review, 37(2), 263-279.

Boss Babes. (n.d.) What We Do. Retrieved from https://www.bossbabes.org/programming

Boudreaux, P. (2018, March 19). [They've been sugar coating mysterious bombs as if there's an invisible target...]. In Austin American-Statesman. Retrieved from https://www.facebook.com/pg/statesman/posts/?ref=page_internal [Facebook update].

Box, R.C. (2015). The Citizenship Role of the Public Professional: Imagining Private Lives and Alternative Futures. In C.S. King (Ed.), The Government is Us 2.0 (pp. 59-75). New York: M.E. Sharpe.

Box, R.C. (2017). Into a New Regressive Era: Implications for Public Administration. Public Integrity, 19(6), 576-592.

Brasted, C. (2017, August 10). New Orleans Pumps Crisis by the Numbers. TimesPicayune. Retrieved from https://www.nola.com/weather/index.ssf/2017/08/new_orleans_drainage_pumps_ 1.html

Brasted, C. (2018, March 20). After a pothole sat unfixed for a year, neighbors team up for vigilante repair. Times-Picayune. Retrieved from https://www.nola.com/traffic/index.ssf/2018/03/diy_pothole_filling_new_orlean.h tml 
Bucy, C. (n.d.). A Short History of the Creation of Metropolitan Government for Nashville-Davidson County. In Metropolitan Government of Nashville \& Davidson County, Tennessee. Retrieved from https://www.nashville.gov/Portals/0/SiteContent/Government/docs/MetroHistory Bucy.pdf

Burns, K., \& Novick, L. (Director). Ward, G. C. (Writer). (2011). Prohibition [Motion picture]. Washington, DC: Florentine Films.

Bullington, J. (2015, May 11). French Quarter Crime Task Force to Get City Help Pending Tax Vote, City Hall Says. Times-Picayune. Retrieved from https://www.nola.com/crime/index.ssf/2015/05/french_quarter_task_force.html

Bullington, J. (2016, June 2). French Quarter off-duty police patrol '2.0' launched with Sidney Torres' backing. Times-Picayune. Retrieved from https://www.nola.com/crime/index.ssf/2016/06/french_quarter_task_force_20_1.ht $\mathrm{ml}$

Cafe Lafitte in Exile. (n.d.). About Us. Retrieved from https://www.lafittes.com/about2

Cagle, T. (2017, June 30). INTERACTIVE: See which Red River Street venues surpassed the legal noise level in June. Community Impact. Retrieved from https://communityimpact.com/austin/central-austin/artsentertainment/2017/06/30/interactive-see-red-river-street-venues-surpassed-legalnoise-level-june/

Callahan, M. (2017a, April 19). [Graphic: I had a dream and you...]. In Take 'Em Down NOLA. Retrieved from https://www.facebook.com/pg/TakeEmDownNOLA/posts/?ref=page_internal [Facebook update]

Callahan, M. (2017b, April 19). [Graphic: F UCK 'BLACK LIVES MATTER']. In Take 'Em Down NOLA. Retrieved from https://www.facebook.com/pg/TakeEmDownNOLA/posts/?ref=page_internal [Facebook update]

Cam Mysterio. (2018a, March 20). [Don't know if it's just me but I'm having a lot of trouble...] Retrieved from: https://twitter.com/CamilleBWright [Twitter update].

Cam Mysterio. (2018b, March 20). [Here for the SOCIAL MEDIA QUEEN...] Retrieved from: https://twitter.com/CamilleBWright [Twitter update].

Capital Metro. (2018a). Late Night Services. Retrieved from https://www.capmetro.org/latenight/\#! 
Capital Metro. (2018b). Schedules and Maps. Retrieved from https://www.capmetro.org/schedmap/

Carrizales, T., Melitski, J., Manoharan, A., \& Holzer, M. (2011). E-Governance Approaches at the Local Level: A Case Study in Best Practice. International Journal of Public Administration, 34(14), 935-945.

Castillo, M. (2017, March 6). Mark Zuckerberg put employees on 'lockdown' for two months to launch Facebook Live: Report. $C N B C$. Retrieved from https://www.cnbc.com/2017/03/06/zuckerberg-put-employees-on-lockdown-tolaunch-facebook-live-wsj.html

CBS News. (2018). Murder Map: Deadliest U.S. Cities. In Murder in America. Retrieved October 5, 2018, from https://www.cbsnews.com/pictures/murder-mapdeadliest-u-s-cities/60/

Chance the Rapper. (2018, March 20). [Someone is serial murdering Black and Latino men and women in Texas right now...] Retrieved from: https://twitter.com/chancetherapper/status/976097408684785664?ref_src=twsrc\% 5Etfw [Twitter update].

Chang, J. (2018, March 23). 3 WEEKS OF TERROR: How 7 Austin bombing incidents unfolded. Austin American-Statesman. Retrieved from https://www.statesman.com/news/20180323/3-weeks-of-terror-how-7-austinbombing-incidents-unfolded

Chen, A. (2015, June 2). The Agency. New York Times. Retrieved from https://www.nytimes.com/2015/06/07/magazine/the-agency.html?module=inline

Choi, J.W. (2007). Governance Structure and Administrative Corruption in Japan: An Organizational Network Approach. Public Administration Review, 67(5), 930942.

City of Austin. (n.d.a) What is CodeNext? In CodeNext. Retrieved from http://www.austintexas.gov/department/what-codenext

City of Austin. (n.d.b). Red River District. Retrieved from http://austintexas.gov/page/red-river-district

City of Austin. Austin Public Library. (n.d.c). Special Event Center. In Event Space Rental. Retrieved from https://library.austintexas.gov/rental/special-event-center

City of Austin. Economic Development Department (n.d.d). Music and Entertainment Division. Retrieved from http://www.austintexas.gov/department/musicentertainment-division 
City of Austin. Cultural Arts Division. (2009). Create Austin: Cultural Master Plan. Prepared by The Metropolitan Group. Retrieved from https://www.austintexas.gov/sites/default/files/files/Redevelopment/createaustin cultural_master_plan.pdf

City of Austin. (2012). The Economic Impact of the Creative Sector in Austin - 2012 UPDATE. Prepared by TXP. Retrieved from https://austintexas.gov/sites/default/files/files/creative_sector_impact2012.pdf

City of Austin. Music \& Entertainment Division. (2015). The Austin Music Census: A Data-Driven Assessment of Austin's Commercial Music Economy. Prepared by Titan Music Group LLC. Retrieved from http://www.austintexas.gov/sites/default/files/files/Austin_Music_Census_Interact ive_PDF_53115.pdf

City of Austin. Cultural Arts Division. (2016a). Building Austin's Creative Capacity: Creative Sector Needs Assessment. Prepared by C. Harris (Christine Harris Connections) \& J. Carnwath (WolfBrown). Retrieved from http://www.austintexas.gov/sites/default/files/files/EGRSO/BuildingAustin_sCrea tiveCapacity_Compilation.pdf

City of Austin. Economic Development Department. (2016b, June). Music and Creative Ecosystem Stabilization Recommendations. Retrieved from https://www.austintexas.gov/sites/default/files/files/EGRSO/Music_and_Creative _Ecosystem_Stabilization_Recommendations_June_2016_.pdf

City of Austin. (2017a). "Time was NOW" by Tim Kerr [Video file]. Retrieved from https://www.youtube.com/watch?v=C7hPDuoo8i8

City of Austin. Music Commission. (2017b, March 7). Meeting cancellation notice. Retrieved from http://www.austintexas.gov/edims/document.cfm?id=272938

City of Austin. Music Commission. (2017c, August 7). Meeting cancellation notice. Retrieved from http://www.austintexas.gov/edims/document.cfm?id=281654

City of Austin. CodeNext. (2018a, January 10). CodeNext LIVE: Flooding [Facebook Live broadcast]. Retrieved from https://www.facebook.com/austincodenext/videos/vl.150359265751217/1884144 $638550623 /$ type $=1$

City of Austin. Office of the City Auditor. (2018b, January). City Efforts to Address Displacement and Gentrification. Retrieved from https://www.austintexas.gov/sites/default/files/files/Auditor/Audit_Reports/2_Dis placement_and_Gentrification_AS17103_January_2018.pdf 
City of Austin. Cultural Arts Division. (2018c, February 26). [Did you know that there are 3,000 more creative jobs in Austin since 2015? ...]. Retrieved from https://www.facebook.com/CityofAustinArts/photos/a.128319030516112/197174 3129507017/?type=3\&theater [Facebook update]

City of Austin. Music and Entertainment Division. (2018d, January 23). \#ATXMusicTalks: Social Media and Promoting New Ventures [Facebook Live broadcast]. Retrieved from https://www.facebook.com/ATXMusicOffice/videos/vl.842901502560703/10167 $51691805595 /$ type $=1$

City of Austin. Music and Entertainment Division. (2018e, May 30). [We're excited to host the Musician Compensation Sector Summit...]. Retrieved from https://www.facebook.com/pg/ATXMusicOffice/posts/?ref=page_internal [Facebook post].

City of Austin. Music Commission. (2018e, August 6). Meeting cancellation notice. Retrieved from http://www.austintexas.gov/edims/document.cfm?id=303186

City of Austin. Joint Arts and Music Commission. (2018f, August 29). Meeting cancellation notice. Retrieved from http://www.austintexas.gov/edims/document.cfm?id=304847

City of Austin. Office of the City Manager. (2018g). City Organizational and Department Chart. Retrieved March 1, 2018, from http://austintexas.gov/service/city-organizational-and-department-chart

City of New Orleans. New Orleans City Council. (2013, August 5). New Orleans Sound Ordinance and Soundscape Evaluation and Recommendations, New Orleans, Louisiana. Prepared by Oxford Acoustics Inc. (Project No. 11-01883-01).

City of New Orleans. Office of Cultural Economy. (2016). 2016 New Orleans Cultural Economy Snapshot.

City of New Orleans. (2018a, June 7). 2016 Master Plan Amendment Process. Retrieved from https://www.nola.gov/city-planning/master-plan/mpamendments/

City of New Orleans. (2018b, June 29). Master Plan. Retrieved from https:/www.nola.gov/city-planning/master-plan/

City of New Orleans. (2018c, August). In Office of Cultural Economy. Retrieved from https://www.nola.gov/cultural-economy/

City of Sydney. (2013). Live Music Matters: Planning for Live Music and Performance in Sydney. Sydney: City of Sydney. 
Clark, M. (2017, October 13). DOJ and New Orleans Officials Spar Over "Sanctuary" Immigration Policy. Times-Picayune. Retrieved from

https://www.nola.com/politics/index.ssf/2017/10/nopd_fully_compliant_with_fed e.html

Clifton, J. (2017, November 29). Kevin Johns announces retirement. Austin Monitor. Retrieved from https://www.austinmonitor.com/stories/whispers/kevin-johnsannounces-retirement/

Cobler, N. (2018, December 18). Williamson County approves \$16 million incentive package for Apple. Austin American-Statesman. Retrieved from https://www.statesman.com/news/20181218/williamson-county-approves-16million-incentive-package-for-apple

Cockroach, A. (Photographer). (2006a, February 11). [Krewe Du Vieux. Mardi Gras 2006. New Orleans. K.A.O.S. Grand Marshal Michael Brown: Out to Dinner] Flickr. Retrieved from https://www.flickr.com/photos/boxchain/98900689/in/photostream/

Cockroach, A. (Photographer). (2006b, February 11). [Krewe Du Vieux. Mardi Gras 2006. New Orleans. FEMA Condom.] Flickr. Retrieved from https://www.flickr.com/photos/boxchain/98900557/in/photostream/

Cockroach, A. (Photographer). (2006c, February 11). [Krewe Du Vieux. Mardi Gras 2006. New Orleans. Home is Where the Tarp Is.] Flickr. Retrieved from https://www.flickr.com/photos/boxchain/98900311/in/photostream/

Cockroach, A. (Photographer). (2006d, February 11). [Krewe Du Vieux. Mardi Gras 2006. New Orleans. Fix Everything My Ass.] Flickr. Retrieved from https://www.flickr.com/photos/boxchain/98596706/in/photostream/

Cofield, A. (2016, September 8). A Brief History of South By Southwest (SXSW). The Culture Trip. Retrieved from https://heculturetrip.com/northamerica/usa/texas/articles/a-brief-history-of-south-by-southwest-sxsw/

Commerford, T., de la Rocha, Z., Morello, T. \& Wilk, B. (1992). Killing in the Name. [Recorded by Rage Against the Machine]. On Rage Against the Machine [CD]. Van Nuys, CA; Studio City, CA; North Hollywood, CA: Epic.

Cooperman, A. (2005, September 4). Where Most See a Weather System, Some See Divine Retribution. Washington Post. Retrieved from http://www.washingtonpost.com/wpdyn/content/article/2005/09/03/AR2005090301408.html 
Coviello, W. (2011, June 21). History of Bounce. Gambit. Retrieved from http://www.bestofneworleans.com/gambit/the-history-ofbounce/Content?oid=1812825

Cox, T.R., Blakley, J., Bolton, R., \& Macry, J. (2018, March 19). [I only watch FOX the rest lie and push their agenda]. In Austin American-Statesman. Retrieved from https://www.facebook.com/pg/statesman/posts/?ref=page_internal [Facebook update].

Craver, J. (2017a, January 27). Council approves extended hours for five Red River music venues. Austin Monitor. Retrieved from https://www.austinmonitor.com/stories/2017/01/council-approves-extendedhours-five-red-river-music-venues/

Craver, J. (2017b, February 10). Council selects search firm to find new city manager. Austin Monitor. Retrieved from https://www.austinmonitor.com/stories/2017/02/council-selects-search-firm-findnew-city-manager/

Crockett, E. (2017, March 7). The "Day Without a Woman" Strike, Explained. Vox. Retrieved from https://www.vox.com/identities/2017/3/3/14721468/internationalwomens-day-strike-a-day-without-a-woman-march-8

Currid, E. (2007). How art and culture happen in New York: Implications for urban economic development. Journal of the American Planning Association, 73(4), 454-467.

Curtin, K. (2015a, June 24). Cheer Ups Cheerless Over Development. Austin Chronicle. Retrieved from https://www.austinchronicle.com/daily/news/2015-0624/cheer-ups-cheerless-over-development/

Curtin, K. (2015b, July 17). Playback: Five Nights on Dirty Sixth [Editorial]. Austin Chronicle. Retrieved from https://www.austinchronicle.com/music/2015-0717/playback-five-nights-on-dirty-sixth/

Curtin, K. (2016a, February 12). Playback: Permitting Nightmare Precedes SXSW [Editorial]. Austin Chronicle. Retrieved from https://www.austinchronicle.com/music/2016-02-12/playback-permittingnightmare-precedes-sxsw/

Curtin, K. (2016b, April 8). Playback: Welcome to Terrordome: Sixth Street During SXSW [Editorial]. Austin Chronicle. Retrieved from https://www.austinchronicle.com/music/2016-04-08/playback-welcome-toterrordome-sixth-street-during-sxsw/ 
Curtin, K. (2017a, January 6). Playback: The Westin Sues the Nook Over Sound [Editorial]. Austin Chronicle. Retrieved from https://www.austinchronicle.com/music/2017-01-06/playback-the-westin-suesthe-nook-over-sound/

Curtin, K. (2017b, February 3). Red River Clubs Grapple With Downtown Homelessness. Austin Chronicle. Retrieved from https://www.austinchronicle.com/news/2017-02-03/red-river-clubs-grapple-withdowntown-homelessness/

Curtin, K. (2018, October 19). Playback: Agent of Change Returns [Editorial]. Austin Chronicle. Retrieved from https://www.austinchronicle.com/music/2018-1019/playback-agent-of-change-returns/

Daily Mail Reporter. (2013, March 27). The Girls of Storyville: Haunting Pictures From New Orleans' Red-Light District Reveal How Prostitutes Lived 100 Years Ago. Daily Mail. Retrieved from http://www.dailymail.co.uk/femail/article2299994/The-girls-Story

Daugherty, A. (2018, September 5). InfoWars' Alex Jones insults, touches Marco Rubio outside U.S. Senate hearing. Miami Herald. Retrieved from https://www.miamiherald.com/news/politics-government/article217851000.html

DeBerry, J. (2017, November 24). New Orleans' first Vietnamese council member plans to make everybody proud [Editorial]. Times-Picayune. Retrieved from https://www.nola.com/opinions/index.ssf/2017/11/cyndi_nguyen_vietnamese.htm 1

DeMocker, M. (Photographer). (2017a, May 19). Statue of Robert E. Lee Taken Down (a). Times-Picayune. Retrieved from https://www.nola.com/politics/index.ssf/2017/05/confederate_gen_robert_e_lee_s _1.html

DeMocker, M. (Photographer). (2017b, May 19). Statue of Robert E. Lee Taken Down (b). Times-Picayune. Retrieved from https://www.nola.com/politics/index.ssf/2017/05/confederate_gen_robert_e_lee_s -1.html

DeMocker, M. (Photographer). (2018a, January 27). [Krewe Du Vieux Pimp Walking Group]. Times-Picayune. Retrieved from https://www.nola.com/mardi_gras_nola/2018/01/krewe_du_vieux_delusion_roll_ s.html

DeMocker, M. (Photographer). (2018b, January 27). [Krewe Du Vieux Marie Antoinette with fly swatter]. Times-Picayune. Retrieved from 
https://www.nola.com/mardi_gras_nola/2018/01/krewe_du_vieux_delusion_roll_ s.html

DeMocker, M. (Photographer). (2018c, January 27). [Krewe Du Vieux scuba diver walking group]. Times-Picayune. Retrieved from https://www.nola.com/mardi_gras_nola/2018/01/krewe_du_vieux_delusion_roll_ s.html

Denhardt, J.V., \& Denhardt, R.B. (2015). The New Public Service: Serving, Not Steering. New York: Routledge.

Dennis, B. (2009). Acting Up: Theater of the Oppressed as Critical Ethnography. International Journal of Qualitative Methods, 8(2), 65-96.

Denzin, N.K. (1997). Interpretive Ethnography: Ethnographic Practices for the $21^{\text {st }}$ Century. Thousand Oaks, CA: Sage.

Dinges, G. (2016, August 16). Mayor unveils plan to boost Austin's music industry. Austin American-Statesman. Retrieved from https://www.statesman.com/business/20160816/mayor-unveils-plan-to-boostaustins-music-industry

Driscoll, M.T. (2012). New Orleans Brass Band Traditions and Popular Music: Elements of Style in the Music of Mama Digdown's Brass Band and Youngblood Brass Band (Doctoral Dissertation). (Retrieved from University of Iowa Research Online). http://ir.uiowa.edu/cgi/viewcontent.cgi?article=3288\&context=etd

Editorial Board. (2018, March 23). Bomber is dead, but case not over with many questions that linger [Editorial]. Austin American-Statesman. Retrieved from https://www.statesman.com/news/20180323/bomber-is-dead-but-case-not-overwith-many-questions-that-linger

Eilperin, J., Rein, L., \& Fisher, M. (2017, January 31). Resistance From Within: Federal Workers Push Back Against Trump. Washington Post. Retrieved from https://www.washingtonpost.com/politics/resistance-from-within-federalworkers-push-back-against-trump/2017/01/31/c65b110e-e7cb-11e6-b82f$687 \mathrm{~d} 6 \mathrm{e} 6 \mathrm{a} 3 \mathrm{e} 7 \mathrm{c} \_$story.html?utm_term $=. \mathrm{a} 34 \mathrm{aebc} 4829 \mathrm{c}$

Eggler, B. (2013, January 17). Mayor Landrieu to Receive Award for Promoting the Arts. Times-Picayune. Retrieved from https://www.nola.com/news/index.ssf/2013/01/mayor_landrieu_to_receive_awar. $\mathrm{html}$

Elías, M. V., \& Alkadry, M. G. (2011). Constructive Conflict, Participation, and Shared Governance. Administration \& Society, 43(8), 869-895. 
Ellis Marsalis Center Musicians' Village. (n.d.). In About: Musicians' Village. Retrieved from https://www.ellismarsaliscenter.org/musicians-village

Emerson, K., \& Nabatchi, T. (2015). Collaborative Governance Regimes. Washington, D.C.: Georgetown University Press.

Estrin, J. (2012, August 14). Criminalizing Photography. New York Times. Retrieved from https://lens.blogs.nytimes.com/2012/08/14/criminalizing-photography/

Evans, B. (2017a, March 21). New Orleans Put on List of Cities That "Limit Cooperation" with Immigration Authorities. Times-Picayune. Retrieved from https://www.nola.com/politics/index.ssf/2017/03/immigration_report_new_orlean s.html

Evans, B. (2017b, May 2). Confederate monument protestors clash at Jefferson Davis statue. Times-Picayune. Retrieved from https://www.nola.com/politics/index.ssf/2017/04/confederate_monument_protest_ j.html

Evans, B. (2017c, May 7). For Confederate monuments protest, guns banned, Lee Circle streets closed. Times-Picayune. Retrieved from https://www.nola.com/politics/index.ssf/2017/05/confederate_monuments_police prepare.html

Evans, B. (2017d, May 7). Confederate monument protestors in New Orleans clash at Lee Circle. Times-Picayune. Retrieved from https://www.nola.com/politics/index.ssf/2017/05/confederate_monument_new_or lea.html

Evans, B. (2017e, July 20). Royal Street 'Pedestrian Mall' Closed During Bourbon Construction. Times-Picayune. Retrieved from https://www.nola.com/traffic/index.ssf/2017/07/royal_street_pedestrian_mall_c.ht $\mathrm{ml}$

Evans, B. (2018, May 8). New Orleans City Council touts diversity, experience in first meeting. Times-Picayune. Retrieved from https://www.nola.com/expo/erry2018/05/165e3eb10d6455/city_council_new_members_take.html

Evensi. (2018). Peach by Fuzz Fest. Retrieved from https://www.evensi.us/peachfuzz-fest-spider-house-cafeballroom/249966772?fbclid=IwAR0bzj_U74QheGgrYPeBXbqECVwy1YCwfqbi -Fc7XNC1rUBjqjfE06TE10c 
Evon, D. (2018, July 9). Does this Video Show 8 Supernatural Car Crashes? Snopes. Retrieved from https://www.snopes.com/fact-check/video-8-supernatural-carcrashes/

Faires, R. (2016, September 15). Save Our Spaces March: "Give Us the Keys!". Austin Chronicle. Retrieved from https://www.austinchronicle.com/daily/arts/2016-0915/save-our-spaces-march-give-us-the-keys/

Farmer, D.J. (2010). Public Administration in Perspective: Theory and Practice Through Multiple Lenses. New York: Routledge.

Fayyad, A. (2017, December 20). The Criminalization of Gentrifying Neighborhoods. The Atlantic. Retrieved from https://www.theatlantic.com/politics/archive/2017/12/the-criminalization-ofgentrifying-neighborhoods/548837/

Fechter, J. (2016, January 2). Driver who killed 4 in SXSW crash in 2014 convicted, sentenced to life in prison. San Antonio Express-News. Retrieved from https://www.mysanantonio.com/news/local/crime/article/Driver-accused-in-fatalSXSW-crash-gets-life-in-6615676.php

Fenwick, J., \& McMillan, J. (2012). Public Participation and Public Service Modernization: Learning from New Labor?. International Journal of Public Administration, 35(6), 367-378.

Ferretti, M.P., \& Lener, M. (2008). Lay Public or Experts? E-Participation in Authorization for GMO Products in the European Union. Review of Policy Research, 25(6), 507-525.

Findell, E. (2017a, January 26). Austin council extends Red River live music hours for a six-month test. Austin American-Statesman. Retrieved from https://www.statesman.com/NEWS/20170126/Austin-council-extends-Red-Riverlive-music-hours-for-a-six-month-test

Findell, E. (2017b, March 23). Austin will keep city manager search a secret. Austin American-Statesman. Retrieved from https://www.statesman.com/NEWS/20170323/Austin-will-keep-city-managersearch-a-secret

Findell, E. (2017c, June 1). 'AGENT OF CHANGE': Why Austin music venues say proposal isn't enough. Austin American-Statesman. Retrieved from https://www.statesman.com/news/20170601/agent-of-change-why-austin-musicvenues-say-proposal-isnt-enough 
Findell, E. (2017d, July 12). New soundproofing, bass limits end Westin Hotel's lawsuit against Nook. Austin American-Statesman. Retrieved from https://www.statesman.com/news/20170712/new-soundproofing-bass-limits-endwestin-hotels-lawsuit-against-nook

Findell, E. (2017e, October 20). Later live music hours to continue on Red River, at least until April. Austin American-Statesman. Retrieved from https://www.statesman.com/news/20171020/later-live-music-hours-to-continueon-red-river-at-least-until-april?_ga=2.124983503.411505412.15470522561283944473.1486637597

Findell, E. (2018, April 26). Longer live music hours on Red River will remain in place. Austin American-Statesman. Retrieved from https://www.statesman.com/NEWS/20180426/Longer-live-music-hours-on-RedRiver-will-remain-in-place

Findell, E., \& Jankowski, P. (2017a, November 1). Statesman sues city of Austin over city manager secrecy. Austin American-Statesman. Retrieved from https://www.statesman.com/NEWS/20171101/Statesman-sues-city-of-Austinover-city-manager-secrecy

Findell, E., \& Jankowski, P. (2017b, November 1). Reversing on secrecy, Austin announces six city manager finalists. Austin American-Statesman. Retrieved from https://www.statesman.com/news/20171121/reversing-on-secrecy-austinannounces-six-city-manager-finalists

Findell, E., \& Jankowski, P. (2017c, November 3). A van getaway, a maybe-illegal meeting, secret manager candidates. What the heck happened Thursday? [Blog post]. Austin American-Statesman. Retrieved from http://cityhall.blog.statesman.com/2017/11/02/can-you-help-id-austins-next-citymanager/?_ga=2.195721900.1839698095.1545284486-1283944473.1486637597

Fischer, F. (2006). Participatory Governance as Deliberative Empowerment: The Cultural Politics of Discursive Space. The American Review of Public Administration, 36(1), 19-40.

Fishman, S. (n.d.). Small Nonprofits: Qualifying for Tax-Exempt Status Without Filing an IRS Application. NOLO. Retrieved from https://www.nolo.com/legalencyclopedia/small-nonprofits-qualifying-tax-exempt-status-without-filing-irsapplication.html

Fix My Streets NOLA. (Photographer). (2015, May 21). ["Fix My Streets" Heel in Pothole]. New Orleans Advocate. Retrieved from https://www.theadvocate.com/new_orleans/news/article_56cfff6e-5194-5703a649-31824a2fb00a.html 
Flanagan, A. (2018, January 22). Austin Establishes 'Hi, How Are You?' Day To Encourage Mental Health Support. NPR Music. Retrieved from https://www.npr.org/sections/therecord/2018/01/22/579715885/austin-establisheshi-how-are-you-day-to-encourage-mental-health-support

Floeckher, R.J. (2010). Fuck Euphemisms: How Heavy Metal Lyrics Speak the Truth About War. In N.W.R. Scott (Ed.), The Metal Void: First Gatherings (pp. 233244). Interdisciplinary Press: Oxford, United Kingdom.

Florida, R. (2014a). The Creative Class and Economic Development. Economic Development Quarterly, 28(3), 196-205.

Florida, R. (2014b). The Rise of the Creative Class--Revisited: Revised and Expanded. New York: Basic Books.

Florida, R. (2017). The New Urban Crisis: How our Cities are Increasing Inequality, Deepening Segregation, and Failing the Middle Class - And What We Can Do About It. New York: Basic Books.

Fraser, N. (1997). Justice Interruptus, Critical Reflections on the "Postsocialist" Condition. New York: Routledge.

Frederickson, H. G. (1997a). New Public Administration (pp. 13-47). Tuscaloosa, AL: University of Alabama Press.

Frederickson, H. G. (1997b). The Spirit of Public Administration (Vol. 80). San Francisco: Jossey-Bass Publishers.

Friedenthal, A. (2017, August 22). Theater collective Rude Mechanicals has the ultimate plan to crush Austin. TimeOut Austin. Retrieved from https://www.timeout.com/austin/news/theater-collective-rude-mechanicals-hasthe-ultimate-plan-to-crush-austin082217?fbclid=IwAR1YdKp3bWzCpcCXFle0yuw7BwH_noymD5eWRTMf3kz51fhAS1rUE8kgOg

Freer, E. (2018, May 29). Austin property appraisal protests expected to hit record high in 2018. Community Impact. Retrieved from https:/communityimpact.com/austin/central-austin/features/2018/05/29/austinproperty-appraisal-protests-expected-to-hit-record-high-in-2018/

French Quarter Citizens. (2014). Quality of Life. Retrieved from http://www.frenchquartercitizens.org/1-quality-of-life/

French Quarter Management District. (2016). Welcome!. Retrieved from https://www.fqmd.org 
Freund, H. (2014a, July 16). New Orleans Lawyer Charged with Cyberstalking in French Quarter Noise Ordinance Feud. Times-Picayune. Retrieved from https://www.nola.com/crime/index.ssf/2014/07/new_orleans_lawyer_accused_of. html

Freund, H. (2014b, September 9). Lawyer Pleads Guilty to Cyberstalking Charge in French Quarter Noise Ordinance Feud, Gets Probation. Times-Picayune. Retrieved from https://www.nola.com/crime/index.ssf/2014/09/new_orleans_lawyer_accused_of_ 1.html

Frith, S. (1996). Music and Identity. In S. Hall \& P. DuGay (Eds.), Questions of Cultural Identity (pp. 108-127). London: Sage Publications.

Fung, A. (2006). Varieties of Participation in Complex Governance. Public Administration Review, 66(S1), 66-75.

Fung, A. (2015). Putting the Public Back into Governance: The Challenges of Citizen Participation and Its Future. Public Administration Review, 75(4), 513-522.

Gabbatt, A. (2017, May 8). Anti-Protest Bills Would 'Attack Right to Speak Out' Under Donald Trump. Guardian. Retrieved from https://www.theguardian.com/world/2017/may/08/donald-trump-anti-protest-bills

Gabriel, D. (2013, March 17). Inductive and Deductive Approaches to Research. Dr. Deborah Gabriel: Academic, Media, and Equality Specialist. [Blog Post] Retrieved from http://deborahgabriel.com/2013/03/17/inductive-and-deductiveapproaches-to-research/

Ganapati, S. (2011). Uses of Public Participation Geographic Information Systems Applications in E-Government. Public Administration Review, 71(3), 425-434.

Garza, B., Schell, C., \& Epps, A. (2018, March 19). [I think the president has done a fantastic job...]. In Austin American-Statesman. Retrieved from https://www.facebook.com/pg/statesman/posts/?ref=page_internal [Facebook update].

Gasnier, L.J. (Director), Hirlman, G. (Producer), Esper, D. (Producer [Re-release]), Hoerl, A. (Screenwriter), \& Meade, L. (Story writer). (1938 [1936]). Reefer Madness (formerly Tell Your Children) [Motion picture]. United States: Motion Picture Ventures.

Gaventa, J. (1980). Power and Powerlessness: Quiescence and Rebellion in an Appalachian Valley. Chicago: University of Illinois Press. 
Germer, S. (Photographer). (2018, January 27). [Krewe Du Vieux scuba suit with Rouses shopping bag]. Times-Picayune. Retrieved from https://www.nola.com/mardi_gras_nola/2018/01/krewe_du_vieux_delusion_roll_ s.html

Geurtz, C., \& Van de Wijdeven, T. (2010). Making Citizen Participation Work: The Challenging Search for New Forms of Local Democracy in the Netherlands. Local Government Studies, 36(4), 531-549.

Glasshouse Policy \& Austin Monitor. (2018). CodeNext Game Night.

Goldberg, M. (2018, December 17). Yes, Russian Trolls Helped Elect Trump [Editorial]. New York Times. Retrieved from https://www.nytimes.com/2018/12/17/opinion/russia-2016-election-influencetrump.html

Goldie, R., \& Murphy, J. (2015). Belfast Beyond Violence: Flagging up a Challenge to Local Government?. Local Government Studies, 41(3), 470-488.

Goldenstein, T. (2017a, March 3). Flannigan has tearful moment after LGBTQ advocate addresses council. Austin American-Statesman. Retrieved from https://www.statesman.com/NEWS/20170303/Flannigan-has-tearful-momentafter-LGBTQ-advocate-addresses-council

Goldenstein, T. (2017b, July 16). Red River district mural spotlights history as hotbed of Austin music. Austin American-Statesman. Retrieved from https://www.statesman.com/NEWS/20170716/Red-River-district-muralspotlights-history-as-hotbed-of-Austin-music

Gooden, S.T. (2014). Race and Social Equity: A Nervous Area of Government. New York: M.E. Sharpe.

Google Street View. (2018). [Cheer Up Charlie's]. Retrieved from https://www.google.com/maps/@30.2694167,97.7360957,3a,75y,314.63h,93.76t/data=!3m7!1e1!3m5!1sLBhfSQXmxASaALb m0mGOdw!2e0!6s\%2F\%2Fgeo0.ggpht.com\%2Fcbk\%3Fpanoid\%3DLBhfSQXm xASaALbm0mGOdw\%26output \%3Dthumbnail\%26cb_client\%3Dmaps_sv.tactil e.gps $\% 26$ thumb $\% 3 \mathrm{D} 2 \% 26 \mathrm{w} \% 3 \mathrm{D} 203 \% 26 \mathrm{~h} \% 3 \mathrm{D} 100 \%$ 26yaw\%3D6.1487904\%26 pitch\%3D0\%26thumbfov\%3D100!7i16384!8i8192

Google Maps. (2018). [Red River Cultural District]. Retrieved from https://www.google.com/maps/place/Red+River+Cultural+District,+Austin,+TX+ 78701/@30.2696032,97.7375601,17z/data=!3m1!4b1!4m5!3m4!1s0x8644b5a68651259b:0xf507b5bd5 fe45924! $8 \mathrm{~m} 2$ ! $3 \mathrm{~d} 30.2684271 ! 4 \mathrm{~d}-97.7355595$ 
Google Maps. (2019). [Red River District]. Retrieved from https://www.google.com/maps/place/Mohawk+Austin/@30.270157,97.7382304,17z/data =!3m1!4b1!4m5!3m4!1s0x8644b5a40259a1d5:0x406f3c3c3 $6 \mathrm{a} 295 \mathrm{bb} ! 8 \mathrm{~m} 2 ! 3 \mathrm{~d} 30.2701524 ! 4 \mathrm{~d}-97.7360364$

Gordon, W., Rhoden, S., \& Knowles, B. (2016). Sorry [Recorded by Beyonce]. On Lemonade [Digital audio]. Los Angeles: Columbia.

Gotrich, L. (2011, September 19). 50 Artists Who Inspired Kurt Cobain. NPR Music. Retrieved from https://www.npr.org/2011/09/19/140487084/the-mix-50-artistswho-inspired-kurt-cobain

Granger, C. (Photographer). (2014, January 17). Musicians march into N.O. City Hall. Times-Picayune. Retrieved from https://www.nola.com/news/index.ssf/2014/01/new_orleans_noise_ordinance_ra. html

Granger, C. (Photographer). (2017a, August 8). [Citizen Holding “LIES” Sign]. TimesPicayune. Retrieved from https://www.nola.com/politics/index.ssf/2017/08/floods_blame_sewerage_water_ bo.html

Granger, C. (Photographer). (2017b, August 8). [Purple Plunger at City Hall]. TimesPicayune. Retrieved from https://www.nola.com/politics/index.ssf/2017/08/floods_blame_sewerage_water_ bo.html

Gregory, S. (2011, March 3). Why the Supreme Court Ruled for Westboro. Time. Retrieved from http://content.time.com/time/nation/article/0,8599,2056613,00.html

Grumet, B., \& Webb, E. (2017, July 27). Mayor Adler: Transgender and kicked out of military? Join Austin police force. Austin American-Statesman. Retrieved from https://www.statesman.com/news/20170727/mayor-adler-transgender-and-kickedout-of-military-join-austin-police-force

Grumet, B. (2018a, March 20). Viewpoints: Race, Russian bots and the angst around \#AustinBombings [Editorial]. Austin American-Statesman. Retrieved from http://viewpoints.blog.statesman.com/2018/03/20/viewpoints-race-russian-botsand-the-angst-around-austinbombings/?_ga=2.93538709.92654936.15495829131283944473.1486637597 
Grumet, B. (2018b, May 11). Grumet: Late-Night Council Meetings Hurt the Cause of Open Government [Editorial]. Austin American-Statesman. Retrieved from https://www.mystatesman.com/news/opinion/grumet-late-night-council-meetingshurt-the-cause-open-government/wqMgXX5IPHSFaLZedaZ4YM/

GuideStar. (2018). About Us. Retrieved from https://learn.guidestar.org/about-us

Hale, L., Hottinger, J. \& Stevens, S. (2015). I Am the Fire [Recorded by Halestorm]. On Into the Wild Life [Digital Audio]. Nashville: Atlantic.

Hall, D.B. (2016, September 15). ACA's Save Our Spaces Second Line March \& Rally. Austin Chronicle. Retrieved from https://www.austinchronicle.com/photos/acas-save-our-spaces-second-linemarch-and-rally/17/

Hall, D.B. (2018, March 2). Snapshot: Raw Paw Arson Benefit. Austin Chronicle. Retrieved from https://www.austinchronicle.com/arts/2018-03-02/snapshot-rawpaw-arson-benefit/

Hall, M. (2005, February). He's Daniel Johnston, and he was gonna be famous. Texas Monthly. Retrieved from https://www.texasmonthly.com/articles/hes-danieljohnston-and-he-was-gonna-be-famous/

Hamilton, A. [Alexander], Jay, J., \& Madison, J. (2001 [1787]). The Federalist Papers. Eds. G.W. Carey \& J. McClellan. Liberty Fund: Indianapolis.

Hamilton, A [Ashley]. (2015, October 9). Stephenie Meyer Reveals Another Reason Why She Won't Finish 'Midnight Sun'. BookBub. Retrieved from https://www.bookbub.com/blog/2015/10/09/why-stephenie-meyer-wont-finishmidnight-sun

Hardy, A. (2016, February 8). Why Method of Selecting Carnival Royalty Varies by Krewe. New Orleans Advocate. Retrieved from https://www.theadvocate.com/new_orleans/news/article_d5f95858-dbf7-532daf62-fffbde8f0e7a.html

Hazell, R., Bourke, G., \& Worthy, B. (2012). Open House? Freedom of Information and its Impact on the UK Parliament. Public Administration, 90(4), 901-921.

Hernandez, N. (2017, December 22). Spencer Cronk Named City Manager. Austin Chronicle. Retrieved from https://www.austinchronicle.com/news/2017-1222/spencer-cronk-named-city-manager/ 
Hernandez, N. (2018, March 16). The Problem With K2, Downtown Austin's Most Dangerous Drug. Austin Chronicle. Retrieved from https://www.austinchronicle.com/news/2018-03-16/the-problem-with-k2downtown-austins-most-dangerous-drug/

Herranz Jr., J. (2015, February 23). Personal Communication.

Herrera, S. (2018a, March 31). Russian bots and the Austin bombings: Can factchecking offset division, misinformation? Austin American-Statesman. Retrieved from https:/www.statesman.com/news/20180331/russian-bots-and-the-austinbombings-can-fact-checking-offset-division-misinformation-

Herrera, S. (2018b, November 13). After Amazon closes HQ2 door, Austin shrugs and moves on. Austin American-Statesman. Retrieved from https://www.statesman.com/news/20181113/after-amazon-closes-hq2-dooraustin-shrugs-and-moves-on

Hi, How Are You Project. (n.d.). In About Us. Retrieved from https://www.hihowareyou.org/aboutus/

Hi, How Are You Project. (2018, January 22). Hi, How Are You Day. In Facebook [Event Page]. Retrieved December 31, 2018, from https://www.facebook.com/events/170585770223370/

Hicks, N. (2016, September 15). Austin City Manager Marc Ott leaving for Washington job. Austin American-Statesman. Retrieved from https://www.statesman.com/NEWS/20160915/Austin-City-Manager-Marc-Ottleaving-for-Washington-job

Hirschman, A. O. (1970). Exit, Voice, and Loyalty: Responses to Decline in Firms, Organizations, and States (Vol. 25). Cambridge, MA: Harvard University Press.

History Channel. (2014). In 2 Live Crew Members are Acquitted of Obscenity Charges. Retrieved November 25, 2014, from http://www.history.com/this-dayin-history/2-live-crew-members-are-acquitted-of-obscenity-charges

History.com Editors. (2017, May 31). Stonewall Riots. In History Channel. Retrieved from https:/www.history.com/topics/gay-rights/the-stonewall-riots

Hoffberger, C. (2015, March 8). The History of South by Southwest Interactive. The Kernel. Retrieved from http://kernelmag.dailydot.com/issue-sections/featuresissue-sections/12033/sxsw-tech-history-keynote/

Hong, S. (2015). Citizen Participation in Budgeting: A Trade-Off between Knowledge and Inclusiveness?. Public Administration Review, 75(4), 572-582. 
House of Blues New Orleans. (2016, July 22). The Quarter in the Rain. Vader in the Quarter. Retrieved from https://www.facebook.com/HOBNewOrleans/videos/10153948526448167/ [Facebook update]

Hoye, S. (2014, November 20). Still Awaiting Justice, 20 Years After a Crooked Cop had her Mother Killed. Al-Jazeera America. Retrieved from http://america.aljazeera.com/watch/shows/americatonight/articles/2014/11/20/new-orleans-cop-orderedmotherkilled.html

Human Rights Campaign. (2018). Municipal Equality Index: A Nationwide Evaluation of Municipal Law. Washington, DC.

Hyde, S.C. (2014, January 30). Prohibition (1920-1933). In KnowLA: Encyclopedia of Louisiana. Retrieved December 12, 2016, from http://www.knowla.org/entry/847/

Ivanović, M.D. (2012). The Application of Information Technology and Environmental Protection. International Review of Administrative Sciences, 78(4), 692-709.

Jackson, M., Herranz, J., \& Kabwasa-Green, F. (2003). Art and Culture in Communities: Unpacking Participation. (Policy Brief No. 2 of the Culture, Creativity, and Communities Program). Washington, DC: The Urban Institute.

Jackson, T. (Photographer). (2014a, September 10). Lakeview: Fleur De Lis Drive at $36^{\text {th }}$ Street. Times-Picayune. Retrieved from https://www.nola.com/traffic/index.ssf/2014/09/road_worriers_5_carcrushing_n.html

Jackson, T. (Photographer). (2014b, September 10). Mid-City: St. Louis Street. TimesPicayune. Retrieved from https://www.nola.com/traffic/index.ssf/2014/09/road_worriers_5_carcrushing_n.html

Jacobs, J. (1992 [1961]). The Death and Life of Great American Cities. New York: Vintage Books.

Jankowski, P. (2017a, June 24). HELP WANTED: City manager search leaves several top city jobs in limbo. Austin American-Statesman. Retrieved from https://www.statesman.com/news/20170624/help-wanted-city-manager-searchleaves-several-top-city-jobs-in-limbo 
Jankowski, P. (2017b, December 7). Diversions and disguises: Behind Austin's city manager search. Austin American-Statesman. Retrieved from https://www.statesman.com/news/20171207/diversions-and-disguises-behindaustins-city-manager-search

Jankowski, P. (2018a, January 11). Incoming city manager aims to take reins of City Hall in February. Austin American-Statesman. Retrieved from https://www.statesman.com/NEWS/20180111/Incoming-city-manager-aims-totake-reins-of-City-Hall-in-February

Jankowski, P. (2018b, May 23). In his first 100 days, Cronk's 'listening tour' interrupted by a crisis. Austin American-Statesman. Retrieved from https://www.statesman.com/news/20180523/in-his-first-100-days-cronkslistening-tour-interrupted-by-a-crisis

Jarvie, J. (2017, April 14). As Trump and Texas Crack Down on Illegal Immigration, the City of Austin Rebels. Los Angeles Times. Retrieved from http://www.latimes.com/nation/la-na-immigration-austin-20170414-story.html

Jean, T., Ramsey-Ford, R.A., West, K.S., Vasquez, R., \& Appice, K.D. (2018, March 22). [Everyone has “personal issues”. Most people don't go around blowing up people of color, though.]. In Austin American-Statesman. Retrieved from https://www.facebook.com/pg/statesman/posts/?ref=page_internal [Facebook update]

Jewell, C., \& Bero, L. (2007). Public participation and Claimsmaking: Evidence Utilization and Divergent Policy Frames in California's Ergonomics Rulemaking. Journal of Public Administration Research and Theory, 17(4), 625650.

Jewson, M., \& Maldonado, C. (2015, August 28). Hurricane Katrina, 10 Years Later: The Myths That Persist, Debunked. Slate. Retrieved from http://www.slate.com/articles/news_and_politics/politics/2015/08/hurricane_katri na_10_years_later_the_myths_that_persist_debunked.html

Jimenez, B.S. (2013). Raise Taxes, Cut Services, or Lay Off Staff: Citizens in the Fiscal Retrenchment Process. Journal of Public Administration Research and Theory, 24(4), 923-953.

Johnston, D. (Artist). (n.d.). Hi, How Are You. Rebloggy. Retrieved from http://rebloggy.com/post/true-love-will-find-you-in-the-end-daniel-johnston-lesigh-daniel-johnston-audi/30015298389

Johnston, D. (1982). Peek-A-Boo [Recorded by Daniel Johnston]. On The What of Whom [Cassette]. Self-released. Austin, TX. 
Johnston, D. (Songwriter), \& Bryant, J.E. (Performer). (2018, January 22). Peek-ABoo. Live performance at the Mohawk, Austin, TX.

Jun, K.N., \& Bryer, T. (2016). Facilitating Public Participation in Local Governments in Hard Times. The American Review of Public Administration, 0275074016643587

Kamb, L. (2018, June 21). AG Ferguson: Washington, Other States to Sue Trump Administration Over Separating Immigrant Families at Border. Seattle Times. Retrieved from https:/www.seattletimes.com/seattle-news/ag-fergusonwashington-other-states-to-sue-trump-administration-over-zero-toleranceimmigration-policy/

Kane, E., Heffler, A. \& Wendigobeach. (2018, March 20). [Show me someone other than black and Latino person having a bomb on there (sic) porch...] In Chance the Rapper. Retrieved from: https://twitter.com/chancetherapper/status/976097408684785664?ref_src=twsrc\% 5Etfw [Twitter update].

Kanin, M. (2013, November). Is this city hall's most powerful leader under Austin's change to 10-1? KUT-Radio. Retrieved from http://www.kut.org/post/city-hallsmost-powerful-leader-under-austins-change-10-1

Karst, J. (2016a, May 16). The 1934 Standoff Between Huey Long, New Orleans in Never-Before-Seen Photos. Times-Picayune. Retrieved from https://www.nola.com/politics/index.ssf/2016/05/the_1934_standoff_between_hu ey.html

Karst, J. (Photographer). (2016b, May 16) [Long Standoff 1]. Times-Picayune. Retrieved from https://www.nola.com/politics/index.ssf/2016/05/the_1934_standoff_between_hu ey.html

Karst, J. (Photographer). (2016c, May 16) [Long Standoff 2]. Times-Picayune. Retrieved from https://www.nola.com/politics/index.ssf/2016/05/the_1934_standoff_between_hu ey.html

Karst, J. (2017, November 19). The Fight to Save Storyville. Times-Picayune. Retrieved from https://www.nola.com/vintage/2017/11/the_fight_to_save_storyville.html

Kelly, C. (2014, October 3). Hip-hop's Big Freedia brings a bouncy beat to Howard Theatre. Washington Post. Retrieved from https://www.washingtonpost.com/entertainment/music/hip-hops-big-freedia- 
brings-a-bouncy-beat-to-howard-theater/2014/10/03/3af65ade-4aec-11e4-a4bf794ab74e90f0_story.html?utm_term=.bd4d10f086c9

Kennedy, M. (2016, November 21). Police, Protesters Clash Near Dakota Access Pipeline Route. WBUR-Radio. Retrieved from http://www.wbur.org/npr/502865857/police-protesters-clash-near-dakota-accesspipeline-route

Kennedy, M. (2017, April 20). Louisiana's Governor Declares State Of Emergency Over Disappearing Coastline. National Public Radio. Retrieved from https://www.npr.org/sections/thetwo-way/2017/04/20/524896256/louisianasgovernor-declares-state-of-emergency-over-disappearing-coastline

Kerr, 2017. (Artist and Writer). [Red River district wall mural at Elysium]. Observed in November 2017.

Kettl, D. F. (2007). System Under Stress: Homeland Security and American Politics (2nd ed.). Washington, DC: CQ Press.

Key, V.O. (1966). The Responsible Electorate: Rationality in Presidential Voting 19361960. Belknap Press of Harvard University Press.

Kinchen, D. (2016, January 20). \$200,000 Lamborghini found burned in Baton Rouge raises questions about possible link to New Orleans Confederate monuments debate. New Orleans Advocate. Retrieved from https://www.theadvocate.com/baton_rouge/news/article_81c06007-0df9-5d4ab15d-ae228fd939a3.html

King, C.S. \& Nank, R. (2015). The Context: Citizens, Administrators, and Their Discontents. In C.S. King (Ed.), The Government is Us 2.0 (pp. 3-16). New York: M.E. Sharpe.

King, C.S. (2015). Citizens and Administrators: The Possibilities and Dilemmas. In C.S. King (Ed.), The Government is Us 2.0 (pp. 7-27). New York: M.E. Sharpe.

King, M. (2017, December 8). Point Austin: Double Top Secret Probation: City council goes on a snipe hunt and is left holding the bag. Austin Chronicle. Retrieved from https://www.austinchronicle.com/news/2017-12-08/point-austindouble-top-secret-probation/

King, M. (2018a, January 5). The Council and the City Manager: Tracking back on a long, complicated search. Austin Chronicle. Retrieved from https://www.austinchronicle.com/news/2018-01-05/the-council-and-the-citymanager/ 
King, M. (2018b, February 23). New City Manager Spencer Cronk: "Engagement and Transparency". Austin Chronicle. Retrieved from https://www.austinchronicle.com/news/2018-02-23/new-city-manager-spencercronk-engagement-and-transparency/

Koch and Fowler [Firm]. (1928). A city plan for Austin, Texas. Edited by the Department of Planning. Austin History Center.

Kovalick, W.W., Walts, A., \& Wells, S. (2015). The EPA Seeks its Role in Communities: Evolutionary Engagement. In C.S. King (Ed.), The Government is Us 2.0 (pp. 119-146). New York: M.E. Sharpe.

Kreps, D. (2014, July 31). 19 Worst Things About Woodstock '99. Rolling Stone. Retrieved from https://www.rollingstone.com/music/music-news/19-worst-thingsabout-woodstock-99-176052/

Krewe Du Vieux. (2006). Le Monde de Merde: Krewe Du Vieux Says “C'est Levee”. 15(1). New Orleans.

Krewe Du Vieux. (2018). Le Monde de Merde: Krewe Du Vieux Explores “Bienville’s Wet Dream”. 27(1). New Orleans.

KTBC FOX 7 Austin. (2018, March 23). Full news conference on Austin bombings suspect 3/2018 [Video file]. Retrieved from: https://www.youtube.com/watch?v=a5mm0bZC1b4

Kunian, D. (2007, February 6). 'A Positive, Cultural Thing'. Gambit. Retrieved from http://www.bestofneworleans.com/gambit/a-positive-culturalthing/Content?oid=1247141

Kurniawan, M., \& de Vries, W.T. (2015). The Contradictory Effects in Efficiency and Citizens' Participation When Employing Geo-ICT Apps Within Local Government. Local Government Studies, 41(1), 119-136.

Kushner, A. B. (2010, March 10). Is Louisiana the Most Corrupt State? Newsweek. Retrieved from http://www.newsweek.com/louisiana-most-corrupt-state-69541

Landau, E. (2014, January 27). Storyville (1897-1917). In KnowLA: The Encyclopedia of Louisiana. Retrieved December 12, 2016, from http://www.knowla.org/entry/739/

Lane, E. (2016, May 19). Inside the Ray Nagin Investigation: A \$50K Bribe, a Call from NJ, and a Mayor's Downfall. Times-Picayune. Retrieved from https://www.nola.com/crime/index.ssf/2016/05/ray_nagin_fbi_tip_new_orleans.ht $\mathrm{ml}$ 
Lapum, J.L., Liu, L., Hume, S., Wang, S., Nguyen, M., Harding, B., ... Yau, T.M. (2015). Pictorial Narrative Mapping as a Qualitative Analytic Technique. International Journal of Qualitative Methods, 1-15.

Larino, J. (2015, March 9). Fest-Goers, Older Vacationers Boost New Orleans Tourist Count in 2014. Times-Picayune. Retrieved from https://www.nola.com/business/index.ssf/2015/03/new_orleans_tourism_count_2 014.html

Larino, J. (2016, July 18). 'Trash King' Sidney Torres IV is Back in the New Orleans Disposal Business. Times-Picayune. Retrieved from https://www.nola.com/business/index.ssf/2016/07/sidney_torres_iv_returns_trash. html

Largey, M. (2018, July 3). Austin Says It Will No Longer Enforce Plastic Bag Ban, After Texas Supreme Court Ruling. KUT-Radio. Retrieved from http://www.kut.org/post/austin-says-it-will-no-longer-enforce-plastic-bag-banafter-texas-supreme-court-ruling

LaRose, G. (2016, January 14). Contractor working on Confederate monuments project quits after death threats. Times-Picayune. Retrieved from https://www.nola.com/politics/index.ssf/2016/01/contractor_working_on_confede r.html

LaRose, G. (2018a, February 6). New Orleans Delays Master Plan Changes Until After Mardi Gras. Times-Picayune. Retrieved from https://www.nola.com/politics/index.ssf/2018/02/new_orleans_delays_master_pla n.html

LaRose, G. (2018b, May 3). Jeff Landry and LaToya Cantrell Differ on Status of Credit Card Probe. Times-Picayune. Retrieved from https://www.nola.com/politics/index.ssf/2018/05/latoya_cantrell_jeff_landry_in.ht $\mathrm{ml}$

LaRose, G. (2018c, June 26). How Does Sidney Torres Find the 'Next Hot Neighborhood'? Times-Picayune. Retrieved from https://www.nola.com/business/index.ssf/2018/06/sidney_torres_next_hot_neighb o.html

Laurian, L. (2004). Public Participation in Environmental Decision Making: Findings from Communities Facing Toxic Waste Cleanup. Journal of the American Planning Association, 70(1), 53-65 
Lawton, A., \& Macaulay, M. (2014). Localism in Practice: Investigating Citizen Participation and Good Governance in Local Government Standards of Conduct. Public Administration Review, 74(1), 75-83.

Levin, S. (2017, February). Army Veterans Return to Standing Rock to Form a Human Shield Against Police. Guardian. Retrieved from https://www.theguardian.com/us-news/2017/feb/11/standing-rock-army-veteranscamp

Lim, A. (2015, November 3). We finally know what voter turnout was in the 10 council districts. Austin Statesman-American. Retrieved from http://cityhall.blog.statesman.com/2015/11/03/we-finally-know-what-voterturnout-was-in-the-10-council-districts/

Linde, J., \& Karlsson, M. (2013). The Dictator's New Clothes: The Relationship Between E-Participation and Quality of Government in Non-Democratic Regimes. International Journal of Public Administration, 36(4), 269-281.

Lindell, C. (2017, November 22). Court upholds murder conviction in SXSW crashes that killed 4 in 2014. Austin American-Statesman. Retrieved from https://www.statesman.com/NEWS/20171122/Court-upholds-murder-convictionin-SXSW-crashes-that-killed-4-in-2014

Lindell, C. (2018a, June 22). Texas Supreme Court Rules Against City Bag Bans. Austin American-Statesman. Retrieved from https://www.statesman.com/news/city-bag-bans-violate-state-law-texas-supremecourt-rules/ZRd93xYQUkvZkHIEQX9yrM/

Lindell, C. (2018b, June 25). City bag bans violate state law, Texas Supreme Court rules. Austin American-Statesman. Retrieved from https://www.statesman.com/news/20180625/city-bag-bans-violate-state-lawtexas-supreme-court-rules?_ga=2.116090053.274557549.15486894931283944473.1486637597

Lindell, C. (2018c, November 26). Appeals court voids Austin's paid sick leave ordinance. Austin American-Statesman. Retrieved from https://www.statesman.com/news/20181116/appeals-court-voids-austins-paidsick-leave-ordinance

Litten, K. (2016, September 27). Neighborhood 'Mourners' Want New Orleans ShortTerm Rentals Regulated. Times-Picayune. Retrieved from https://www.nola.com/politics/index.ssf/2016/09/short_term_rental_demonstratio. html 
Litten, K. (2017a, May 19). Confederate Gen. Robert E. Lee statue removed in New Orleans. Times-Picayune. Retrieved from https://www.nola.com/politics/index.ssf/2017/05/confederate_gen_robert_e_lee_s - 1.html

Litten, K. (2017b, October 3). Negative Campaigning in New Orleans Mayor's Race Led by Two PACs. Times-Picayune. Retrieved from https://www.nola.com/politics/index.ssf/2017/10/desiree_charbonnet_attacks_pac. html

Litten, K. (2017c, October 5). Prominent New Orleans Business Leaders Behind AntiCharbonnet PAC. Times-Picayune. Retrieved from https://www.nola.com/politics/index.ssf/2017/10/desiree_charbonnet_notforsalen. html

Litten, K. (2017d, October 25). LaToya Cantrell, Desiree Charbonnet to Meet in Runoff for New Orleans Mayor. Times-Picayune. Retrieved from https://www.nola.com/politics/index.ssf/2017/10/new_orleans_mayoral_race.html

Litten, K. (2017e, November 25). Mitch Landrieu is Mayor for Another 6 Months. Here is Why LaToya Cantrell has to Wait. Times-Picayune. Retrieved from https://www.nola.com/politics/index.ssf/2017/11/latoya_cantrell_transition_lan.ht $\mathrm{ml}$

Litten, K. (2017f, December 13). Neighbors Win Crusade Against Sidney Torres' Noisy Church Venue - For Now. Times-Picayune. Retrieved from https://www.nola.com/politics/index.ssf/2017/12/sidney_torres_rampart_church.h tml $\% \%$ STOP $\% \%$ ath=\% $\%$ eval $\% 20$ lower $\% 20 \$ m d 5 \_$email $\% \%$

Litten, K. (2018a, January 17). N.O. Used Overflow Shelter for Homeless Tuesday; Officials Urge Caution. Times-Picayune. Retrieved from https://www.nola.com/politics/index.ssf/2018/01/mitch_landrieu_hard_freeze.htm 1

Litten, K. (2018b, March 20). The N.O. ordinance requiring bars to install cameras is dead. Times-Picayune. Retrieved from https://www.nola.com/politics/index.ssf/2018/03/bar_camera_monitoring_council .html

Long, J. (2010). Weird City: Sense of Place and Creative Resistance in Austin, Texas. Austin, TX: University of Texas Press.

Love, N. S. (2006). Musical Democracy. Albany, NY: SUNY Press.

Lukes, S. (1974). Power: A Radical View. London: Macmillan Education. 
Mallone, L. (2017, February 24). Photo of the Week: The Dakota Access Pipeline Protest Ends in Flames. Wired. Retrieved from https://www.wired.com/2017/02/photo-week-dakota-access-protest-camp-endsflames/

Manoharan, A., \& Bennett, L.V. (2013). Opportunities for Online Citizen Participation: A Study of Global Municipal Practices. Journal of Public Management \& Social Policy, 19(2), 137.

Mansbridge, J.J. (1983). Beyond Adversary Democracy (2nd ed.). Chicago: University of Chicago Press.

Mardi Gras New Orleans. (n.d.). A Colorful Conundrum: The Truth About the Purple, Green, and Gold of Mardi Gras. In Mardi Gras Colors. Retrieved from http://www.mardigrasneworleans.com/mgcolors.html

Mardi Gras New Orleans. (2018). Krewe Du Vieux. Retrieved from http://www.mardigrasneworleans.com/schedule/parade-info/krewe-du-vieux.html

Markusen, A., \& Schrock, G. (2006). The Artistic Dividend: Urban Artistic Specialization and Economic Development Implications. Urban Studies, 43(10), 1661-1686.

Markusen, A. (2014). Creative Cities: A 10-Year Research Agenda. Journal of Urban Affairs, 36(s2), 567-589.

Mariano, A. (2017a, June 14). Drumbeats of History: The legacy of Congo Square in New Orleans. Times-Picayune. Retrieved from https://www.nola.com/300/2017/06/congo_square_history_new_orlea.html

Mariano, A. (2017b, September 5). Decades of Decadence: How New Orleans' "Gay Mardi Gras" Got Started. Times-Picayune. Retrieved from https://www.nola.com/300/2017/08/post.html

Marshall, C., \& Rossman, G.B. (2011). Designing Qualitative Research (5th ed.). Thousand Oaks, CA: Sage Publications.

McClendon, R. (2014, September 26). Hospitality union, Teamsters, quietly negotiating contract with Harrah's after employees unionize. Times-Picayune. Retrieved from https://www.nola.com/business/index.ssf/2014/09/hospitality_union_teamsters_q u_1.html 
McClendon, R. (2015a, August 27). Busing in the Band: Will New Orleans Culture Survive the Post-Katrina Boom? Times-Picayune. Retrieved from https://www.nola.com/katrina/index.ssf/2015/08/bussing_in_the_band_will_new_ o.html

McClendon, R. (2015b, September 22). City Health Department to begin investigating noise complaints this week. Times-Picayune. Retrieved from https://www.nola.com/politics/index.ssf/2015/09/city_health_department_to_begi. html

McClendon, R. (2016a, February 2). Crane company says city never hired it to move Confederate monuments. Times-Picayune. Retrieved from https://www.nola.com/politics/index.ssf/2016/02/crane_operator_says_the_city_n. html

McClendon, R. (2016b, March 1). "Sanctuary City" Policy Puts an End to NOPD's Immigration Enforcement. Times-Picayune. Retrieved from https://www.nola.com/politics/index.ssf/2016/03/sanctuary_city_immigration_ne w.html

McKnight, L. (2014, December 16). 'Through the Whiskey Glass': A Brief New Orleans History Lesson. Times-Picayune. Retrieved from http://www.nola.com/drink/index.ssf/2014/12/through_the_whiskey_glass_a_br.h tml

McManus, R.M. \& Perruci, G. (2015). Understanding Leadership: An Arts and Humanities Perspective ( $1^{\text {st }}$ ed.). New York: Routledge.

Morris, T. (2018, February 7). Bourbon Street doesn't have to be Sesame Street [Editorial]. Times-Picayune. Retrieved from https://www.nola.com/opinions/index.ssf/2018/02/bourbon_street_strippers.html

Newton, S. (2007, September 19). Dark times inspired Matthew Good's Hospital Music. Georgia Straight. Retrieved from https://www.straight.com/article110502/dark-times-inspired-matthew-goods-hospital-music

Nolan, B. (2010, October 7). Sodexo workers stage one-day walkout at Tulane, demand better wages. Times-Picayune. Retrieved from https://www.nola.com/education/index.ssf/2010/10/cafeteria_workers_walk_out_ at.html

Novoselic, K. (2004). Of Grunge and Government: Let's Fix This Broken Democracy! New York: RDV Book/Akashic Books. 
Oldenburg, R. (1999). The Great Good Place: Cafes, Coffee Shops, Bookstores, Bars, Hair Salons, and Other Hangouts at the Heart of a Community. New York: Da Capo Press.

Miller, H.T. (2012). Governing Narratives: Symbolic Politics and Policy Change. Tuscaloosa, AL: University of Alabama Press.

Milman, O. (2016, October 26). Dakota Access Pipeline Company and Donald Trump Have Close Financial Ties. Guardian. Retrieved from https://www.theguardian.com/us-news/2016/oct/26/donald-trump-dakota-accesspipeline-investment-energy-transfer-partners

Morin, D. (2016). Democratic Accountability During Performance Audits Under Pressure: A Recipe for Institutional Hypocrisy?. Financial Accountability \& Management, 32(1), 104-124.

Mormon Tabernacle Choir. (2015, March 24). A Brief History of "Down by the Riverside". In Mormon Tabernacle Choir Blog. Retrieved from https://www.thetabernaclechoir.org/articles/down-by-the-riverside-history.html

Morton, T. (2011, March 2). Matthew Shepard Funeral Put Westboro Baptist Church on the Map. Billings Gazette. Retrieved from https://billingsgazette.com/news/state-and-regional/wyoming/matthew-shepardfuneral-put-westboro-baptist-church-on-the-map/article_fa10936e-cb5b-5170afd8-e7eaa0a43aa8.html

Mott-Smith, T. (2014, October 16). LGBTQ History \#11: Bounce Music Originates in New Orleans. Tagg Magazine. Retrieved from http://taggmagazine.com/artsentertainment/entertainment/bounce-music-originates-new-orleans/

MSNBC. (2005, October 5). Katrina: Wrath of God? MSNBC. Retrieved from http://www.nbcnews.com/id/9600878/ns/msnbc-morning_joe/t/hurricane-katrinawrath-god/\#.W3IVIi-ZOso

Mucha, M. (2015). A Case of Transformational Change: Making Sustainability Real in the City of Olympia. In C.S. King (Ed.), The Government is Us 2.0 (pp. 174-184). New York: M.E. Sharpe.

Murray, E. (2014, March 10). 'Musicians Priority Loading Zones' Come to Seattle A City of Music Partnership to Increase Safety and Access for Local Musicians. In Office of the Mayor: Mayor Edward B. Murray. Retrieved from http://murray.seattle.gov/musicians-priority-loading-zones-come-to-seattle-a-cityof-music-partnership-to-increase-safety-and-access-for-local-musicians/ 
Music and Culture Coalition of New Orleans. (2015, September 16). This promises to be a great conversation with French Quarter service industry workers tonight. Retrieved from https://www.facebook.com/pg/MACCNOpage/posts/?ref=page_internal [Facebook update]

Music and Culture Coalition of New Orleans. (2016a). Guide to New Orleans Street Performance. Retrieved from https://static1.squarespace.com/static/5839e0cf8419c204f71e961c/t/585c2929035 96e058c4262c9/1482434859986/MACCNO_street_performance_guide.pdf

Music and Culture Coalition of New Orleans. (2016b, September 26). [Last night, a Facebook page called the Battle...] Retrieved from https://www.facebook.com/MACCNOpage/posts/1125598644189881?_xts_[0] =68.ARBWjer9gtJg_5t9JbrM76TWPVXuXp9KT8vtZ4p8xHgYmkhwBsVvdlF58 FVizdUA2mglyOoyT2RjKkCBwdES8XngeWWkmxd753WQRMwPHpm_4kxd 6hFKqkAXLRrCfifUVxieZZRKO3XbphAIrH7_pxsJmiXG4LqOmzTt0PI2TXgSvStr8L2LChVUlDgvmsEkEuCniZPIf6FvhvEpPsEZsvgzGn7UZac7XgHHZn_QEsM4epDSfFuy7d5WTczPT1gSDpokD1yxOwwTssfCk1KmZt 7MltM4UJPxzKnnTyyjWYkz7myfoMs92FKeU\&_tn__ $=\mathrm{H}-\mathrm{R}$ [Facebook update]

Music and Culture Coalition of New Orleans. (2017a, March 11). [ATTENTION STREET PERFORMERS... Attorney General Landry's "violent crime task force"...]. Retrieved from https://www.facebook.com/pg/MACCNOpage/posts/?ref=page_internal [Facebook update]

Music and Culture Coalition of New Orleans. (2017b, October 21). [Buried in the story is the fact that Jim Kelly... live entertainment (not just adult entertainment)...]. Retrieved from https://www.facebook.com/pg/MACCNOpage/posts/?ref=page_internal [Facebook update]

Music and Culture Coalition of New Orleans. (2018, January 27). [Interested in helping the entertainers and service industry workers? ... losing jobs and incomes due to the crackdown on Bourbon St clubs? ...]. Retrieved from https://www.facebook.com/MACCNOpage/?_tn__ $=\mathrm{kC}$ -

R\&eid=ARBgbpxsImr45DogtULlPp4Ap067ropwbz0UifqxyF8kLVTRD4az79Lx6umGoE-U0Xd_Pnd67ZtXaf\&hc_ref=ARTqNH8UoflKSXJFraT1rGN1OPg8--ESNnRF0C7YqoOGqiQYYCqbXHxhIVtUZeUt0g\&_xts_[0]=68.ARC_wmbdzG 4kxKGH3HSVmV6U2NP182oRAWXjSqnpjvXTj0ApqwHoKyGEZ34X_NT4_3 yJ8SdGe1_j4Gwr1T5Lnmx-pP-_nDj-O2n6IHmusJ0G- 
1kJqRWhxjXZ4JZGktCxDIDN7vzI3m1WCmz1XRMtC_EpPq-

6062PpB9Xmt_Rau4Tft4gA83mPNNzBLoIJUdIKqTeip4m1KGtzuPxeFpjkjrzNs vGoDbavfJdKQXFtc6QDwS2pFP-tWujrw-

K1XRoSVcX_SGQoJ9qREcck0DtEBJY06Y2KZxOPrN8Ys5ZqtDpXqiiwcIjpsy qMGDxtbNflt2oqIgzVRhE1utKGl-mVNd6vGI [Facebook update]

Musso, J., Weare, C., Bryer, T., \& Cooper, T.L. (2011, January). Toward "Strong Democracy" in Global Cities? Social Capital Building, Theory-Driven Reform, and the Los Angeles Neighborhood Council Experience. Public Administration Review, 102-111.

Mustain, J. (2014, October 15). A murder 20 years ago marked low point for NOPD. New Orleans Advocate. Retrieved from https://www.theadvocate.com/new_orleans/news/article_1c89036b-ab8e-5f5b863a-e01129b85cbf.html

Nadkarni, R. (2015, December 8). Who Leaked The Hateful Eight Script? Jimmy Kimmel Investigates. GQ. Retrieved from https://www.gq.com/story/hatefuleight-script-leak-jimmy-kimmel

Neely, C. (2017a, January 26). Austin council members approve extended music curfew pilot program at Red River Cultural District. Community Impact. Retrieved from https://communityimpact.com/austin/central-austin/citycounty/2017/01/26/austin-council-members-approve-extended-music-curfewpilot-program-red-river-cultural-district/

Neely, C. (2017b, October 19). Austin City Council extends music curfew pilot program at Red River Cultural District. Austin Chronicle. Retrieved from https://communityimpact.com/austin/central-austin/citycounty/2017/10/19/austin-city-council-votes-continue-extended-music-curfewpilot-program-red-river-cultural-district/

Neshkova, M.I., \& Guo, H. (2016). Policy Target Populations and Public Participation in Agency Decision Making. International Public Management Journal, 1-29.

New Orleans Brazilian Jiu-Jitsu. (2018a). Our Logo. Retrieved February 13, 2018.

New Orleans Brazilian Jiu-Jitsu. (2018b). Welcome to NOLA BJJ. In About Us. Retrieved October 7, 2018, from https://www.nolabjj.com

New Orleans Tourism Marketing Corporation. (n.d.). In Social Aid and Pleasure Clubs. Retrieved from http://www.neworleansonline.com/neworleans/multicultural/multiculturaltradition s/socialaid.html 
New York State Police. (n.d.). Motorcycle Unit. Retrieved from https://www.troopers.ny.gov/Specialized_Services/Motorcycle_Unit/

NOLA Community. (2013, September 20). Loyola University New Orleans College of Law Donor Honored With a Sculpture of his Likeness. Times-Picayune. Retrieved from http://blog.nola.com/new_orleans/2013/09/loyola_university_new_orleans.html

North, D.C. (1990). Institutions, Institutional Change and Economic Performance. New York: Press Syndicate of the University of Cambridge.

Novak, S. (2018, December 20). Downtown Austin: A building boom that won't stop. Gatehouse Media. Retrieved from https://gatehousenews.com/downtowndevelopment/

Oakes, S., \& Warnaby, G. (2011). Conceptualizing the Management and Consumption of Live Music in Urban Space. Marketing Theory, 11(4), 405-418.

O'Donnell, A. (2018, December 13). 'I hear Michigan needs 5,000 jobs': Apple announces Austin expansion and residents react. Austin American-Statesman. Retrieved from https://www.statesman.com/news/20181213/i-hear-michiganneeds-5000-jobs-apple-announces-austin-expansion-and-residents-react

O'Donnell, A., \& Webb, E. (2018, March 22). Austin bombings: The facts about 5 claims from social media. Austin American-Statesman. Retrieved from https://www.statesman.com/news/20180322/austin-bombings-the-facts-about-5claims-from-social-media

O’Donoghue, J. (2017, January 10). John Bel Edwards: Jeff Landry Must Work With Others on New Orleans Crime. Times-Picayune. Retrieved from https://www.nola.com/politics/index.ssf/2017/01/landry_new_orleans_crime.html

O'Dowd, P. (2016, November 24). Standing Rock Protestors Vow to Stay Despite Hypothermia, Violent Clashes. WBUR-Radio. Retrieved from http://www.wbur.org/hereandnow/2016/11/24/standing-rock-violent-clashes

Oldenburg, R. (1999). The Great Good Place: Cafes, Coffee Shops, Bookstores, Bars, Hair Salons, and Other Hangouts at the Heart of a Community. New York: Da Capo Press.

Oliver, A. (2007, December 29). Super Sunday: Weekend parades showcase dozens of Mardi Gras Indian gangs. Times-Picayune. Retrieved from https://www.mardigras.com/news/2007/12/super_sunday_weekend_parades_s.ht $\mathrm{ml}$ 
Osborn, C., Huber, M., \& Taboada, M. B. (2017, October 21). Average Austin property tax bill hits \$7,600, up \$517 from last year. Austin American-Statesman. Retrieved from https://www.statesman.com/news/20171021/average-austinproperty-tax-bill-hits-7600-up-517-from-last-year

Osborn, C., Huber, M., \& Walsh, S. C. (2018, March 22). THE SUSPECT: Mark Conditt driven by personal issues - not hate, cops say. Austin American-Statesman. Retrieved from https://www.statesman.com/news/20180322/the-suspect-markconditt-driven-by-personal-issues--not-hate-cops-say

Ouellet, N. (2016, December 3). Standing Rock Protesters Gear Up for Winter. National Public Radio. Retrieved from https://www.npr.org/2016/12/03/504244425/standing-rock-protesters-gear-up-forwinter

Park, M. (2018, March 9). Teachers in West Virginia went on strike -- and won. Now, teachers in other states may follow their lead. $C N N$. Retrieved from https://www.cnn.com/2018/03/09/us/teachers-union-movement/index.html

Parks, M. (2017, August 20). Confederate Statues Were Built To Further A 'White Supremacist Future'. National Public Radio. Retrieved from https://www.npr.org/2017/08/20/544266880/confederate-statues-were-built-tofurther-a-white-supremacist-future

Pascaru, M., \& Ana Buţiu, C. (2010). Psycho-Sociological Barriers to Citizen Participation in Local Governance. The Case of Some Rural Communities in Romania. Local Government Studies, 36(4), 493-509.

Pendley, R.M. (2017a, August 20). [When this hurricane hits. Make sure u (sic) call those Antifa Bitches to help u (sic)...] In Take 'Em Down NOLA. Retrieved from https://www.facebook.com/pg/TakeEmDownNOLA/posts/?ref=page_internal [Facebook update]

Pendley, R.M. (2017b, August 20). [And STILL got ur (sic) asses whooped and killed by a handful of Klansman lmfao (sic) so fucking funny.]. In Take 'Em Down NOLA. Retrieved from https://www.facebook.com/pg/TakeEmDownNOLA/posts/?ref=page_internal [Facebook update]

Plohetski, T. (2018a, February 8). Austin's first female fire chief, Rhoda Mae Kerr, takes job in Florida. Austin American-Statesman. Retrieved from https://www.statesman.com/news/20180208/austins-first-female-fire-chief-rhodamae-kerr-takes-job-in-florida 
Plohetski, T. (2018b, April 9). Why Austin bomber Mark Conditt's confession may be kept secret - forever. Austin American-Statesman. Retrieved from https://www.statesman.com/news/20180409/why-austin-bomber-mark-condittsconfession-may-be-kept-secret--forever

Pontchartrain, B. (2014, December 8). Why do people here hate Union Gen. Benjamin Butler? Gambit. Retrieved from https://www.theadvocate.com/gambit/new_orleans/news/blake_pontchartrain/artic le_6e8e4665-bd3e-5434-a1dc-edb910847939.html

Pope, J. (2017, November 15). 100 Years Ago This Month, New Orleans Closed the Book on Storyville. Times-Picayune. Retrieved from https://www.nola.com/300/2017/11/when_did_storyville_close_new_orleans_111 52017.html

Prazan, P. (2016, June 21). East Austinites say they're hit hardest by property tax increases. $K X A N-T V$. Retrieved from https://www.kxan.com/news/local/austin/east-austinites-say-theyre-hit-hardestby-property-tax-increases/1049748231

Preservation Hall Foundation. (2018). Down by the Riverside. Retrieved from https://www.preshallfoundation.org/downbytheriverside/

Pridemore, A.A. (2005, October 9). Hurricanes Katrina, Rita turned city into war zone. Register-Herald, pp. 1A, 8A.

Pridemore, A.A. (2008, May 16). Video Poker Parlor in Beckley Robbed. RegisterHerald. Retrieved from http://www.register-herald.com/news/local_news/videopoker-parlor-in-beckley-robbed/article_92444ef0-8f6c-5ff2-bba79b676275ffc $7 . h t m l$

Pridemore, A.A. (2010, February 24). Man Charged in Pizza Delivery Driver Robbery. Register-Herald. Retrieved from http://www.registerherald.com/news/local_news/man-charged-in-pizza-delivery-driverrobbery/article_9acec486-4894-5bb8-88a0-0209fe55cdcc.html

Pridemore, A.A. (2017). Crank It to Eleven: Music Festivals Breathe New Life into Cities. In L.N. Hersey \& B. Bobick (Eds.). Handbook of Research on the Facilitation of Civic Engagement through Community Art (pp. 524-543). Hershey, PA: IGI Global.

Pridemore, A.A. (2018). Outlaw Citizenship. In A. Farazmand (Ed.) P. Prysmakova \& D.R. Vienne (Section Eds.). Global Encyclopedia of Public Administration, Public Policy, and Governance. Springer International Publishing. DOI: https://doi.org/10.1007/978-3-319-31816-5_3359-1 
Pridemore, A.A., Ganapati, N.E., \& Revell, K.D. (2019). Citizen Participation is Shifting While Public Administrators Lock Down: A Citizen Participation Literature Review for Public Administration. Manuscript submitted for publication.

Prince, J. (2018, February 15). Everything You Don't Know About the Best Murals in Austin. The Austinot. Retrieved from https://austinot.com/best-murals-in-austin

Prose, F. (2017, January 30). Forget Protest: Trump's Actions Warrant a General National Strike [Editorial]. Guardian. Retrieved from https://www.theguardian.com/commentisfree/2017/jan/30/travel-ban-airportprotests-disruption

Raeburn, B.B. (2007, December). 'They're Trying to Wash Us Away': New Orleans Musicians Surviving Katrina. Journal of American History, 94, 812-819.

Rainey, R. (2014, April 24). Bourbon Street Noise Ordinance Proposal Silenced by New Orleans City Council. Times-Picayune. Retrieved from http://www.nola.com/politics/index.ssf/2014/04/new_orleans_city_council_bourb. html

Rainey, R. (2016, October 5). Ray Nagin Exhausts Appeals as Supreme Court Refuses Jailed Ex-Mayor's Case. Times-Picayune. Retrieved from https://www.nola.com/crime/index.ssf/2016/10/jailed_exmayor_ray_nagin_exha.html

Rainey, R. (2017a, April 26). New Orleans firefighters helped remove Liberty Place monument, union leader says. Times-Picayune. Retrieved from https://www.nola.com/politics/index.ssf/2017/04/firefighters_helped_remove_lib. html

Rainey, R. (2017b, July 14). Last day for Sidney Torres' Dance with New Orleans Mayor's Race. Times-Picayune. Retrieved from https://www.nola.com/politics/index.ssf/2017/07/last_day_for_sidney_torres_dan. html

Rainey, R. (2017c, July 14). NOLA Votes 2017: Sidney Torres Won't Run for Mayor. Times-Picayune. Retrieved from https://www.nola.com/politics/index.ssf/2017/07/nola_votes_2017_clock_ticks_f o.html

Rainey, R. (2017d, August 23). New Orleans braces for Harvey with some pumps still out. Times-Picayune. Retrieved from https://www.nola.com/weather/index.ssf/2017/08/new_orleans_braces_for_harve y.html 
Rainey, R. (2017e, October 5). New Orleans prepares for Tropical Storm Nate. TimesPicayune. Retrieved from https://www.nola.com/weather/index.ssf/2017/10/new_orleans_braces_for_what_ co.html

Rainey, R. (2017f, October 28). Cantrell Used City Credit Card for \$8,952 She Later Repaid From Campaign, Personal Accounts. Times-Picayune. Retrieved from https://www.nola.com/politics/index.ssf/2017/10/latoya_cantrell_credit_card_ch.h tml

Raw Paw. (n.d.). About. Retrieved from http://www.rawpaw.ink/about/

Reckdahl, K. (2010, March 8). Mardi Gras Indians concerned about police antagonism. Times-Picayune. Retrieved from https://www.mardigras.com/news/2010/03/mardi_gras_indians_say_police.html

Red River Cultural District. (n.d.). About. In Facebook. Retrieved from https://www.facebook.com/pg/redriverculturaldistrict/about/?ref=page_internal

Reily, W. (2017, April 27). [God sent a warning to New Orleans in Hurricane Katrina... In Sons of Confederate Veterans. Retrieved from https://www.facebook.com/pg/SCVOfficialPage/posts/?ref=page_internal [Facebook update]

Rimmerman, C.A. (2011). The New Citizenship: Unconventional Politics, Activism, and Service (4th ed.). Boulder, CO: Westview Press.

Robbins, M.D., Simonsen, B., \& Feldman, B. (2008). Citizens and Resource Allocation: Improving Decision Making with Interactive Web-Based Citizen Participation. Public Administration Review, 68(3), 564-575.

Rodrigues, F. (Photographer). (2014, November 6). The new city council chamber opens today and features an expanded dais and upgraded audio-video equipment. KUT-Radio. Retrieved from http://www.kut.org/post/austin-city-council-returnsrenovated-chambers-today

Rodrigues, F. (Photographer). (2015, January 6). New council, new dais: The Austin City Council dais was revamped to accommodate the new 10-member council. But what do Austinites want to see from the 10-1 council? KUT-Radio. Retrieved from http://www.kut.org/post/listen-what-do-austinites-want-see-new-city-council

Rothman, L. (2015, February 17). How Mardi Gras Became a Party for Everyone. Time. Retrieved from http://time.com/3703165/mardi-gras-crewhistory/ 
Rossmann, D., \& Shanahan, E.A. (2012). Defining and Achieving Normative Democratic Values in Participatory Budgeting Processes. Public Administration Review, 72(1), 56-66.

Royo, S., Yetano, A., \& Acerete, B. (2013). E-Participation and Environmental Protection: Are Local Governments Really Committed? Public Administration Review, 87-98.

Rude Mechs. (2017). crushAustin. In Kickstarter. Retrieved from https://www.kickstarter.com/projects/rudemechs/crushaustin

Rude Mechs. (2018). 2018/2019 Season: flushAUSTIN. In The Work. Retrieved from https://rudemechs.com/thework/20182019_season/

Rushton, M. (2013). Introduction. In M. Rushton (Ed.), Creative Communities: Art Works in Economic Development (pp. 1-11). Brookings Institution: Washington, D.C.

Sarlin, B., Patulla, S., \& Peterson, M. (2016, June 20). The United States of Trump: How Donald Trump Took Over the Republican Party. NBC News. Retrieved from https://www.nbcnews.com/specials/donald-trump-republican-party

Saturday Night Live. (2018 [1981]). Mr. Bill Visits Los Angeles. In Watch Saturday Night Live Highlight: Mr. Bill. Retrieved October 7, 2018, from https://www.nbc.com/saturday-night-live/video/mr-bill/n8854

Saustex Records. (2018). Austin Corn Lovers' Fiesta. Retrieved from http://www.saustex.com/AUSTIN-CORN-LOVER-SFIESTA.html?fbclid=IwAR09AkJGHSrDV-4wKI8YLoH6IzWXVIB7BocBy2EKvKrwb_uwshvrr-eRhc

Sayre, K. (2017a, July 10). Changes are Coming for the New Orleans Master Plan: 4 Amendments to Watch. Times-Picayune. Retrieved from https://www.nola.com/politics/index.ssf/2017/07/affordable_housing_density_ma s.html

Sayre, K. (2017b, August 8). Here's Why New Orleans Flooding Was So Bad, and Why People are Being Fired Over It. Times-Picayune. Retrieved from https://www.nola.com/politics/index.ssf/2017/08/floods_blame_sewerage_water_ bo.html

Sayre, K. (2017c, August 24). Hospitality union negotiating contract with Hilton Riverside, city's largest hotel. Times-Picayune. Retrieved from https://www.nola.com/business/index.ssf/2017/08/hilton_riverside_union.html 
Schafer, B. (2018, November 9). A View from the Digital Trenches - Lessons from Year One of Hamilton 68. In Alliance for Securing Democracy. Retrieved from https://securingdemocracy.gmfus.org/a-view-from-the-digital-trenches-lessonsfrom-year-one-of-hamilton-68/

Schattschneider, E.E. (1983 [1960]). The Semisovereign People: A Realist's View of Democracy in America. Orlando, FL: Holt, Rinehart, and Winston.

Schatz, F. (2013). Fighting Corruption with Social Accountability: A Comparative Analysis of Social Accountability Mechanisms' Potential to Reduce Corruption in Public Administration. Public Administration and Development, 33(3), 161-174.

Schleifstein, M. (2017, September 5). New Orleans, State Reviewing Irma Evacuation Plans, Just in Case. Times-Picayune. Retrieved from https://www.nola.com/hurricane/index.ssf/2017/09/new_orleans_state_reviewing _ir.html

Schneider, A. \& Ingram, H. (1993). Social Construction of Target Populations: Implications for Politics and Policy. American Political Science Review, 87(02), 334-347.

Sechler, B. (2018, December 13). Apple plans new \$1 billion Austin campus, 5,000 more jobs. Austin American-Statesman. Retrieved from https://www.statesman.com/news/20181213/apple-plans-new-1-billion-austincampus-5000-more-jobs

Selby, W. G. (2018, June 1). PolitiFact: Austin among most economically segregated cities. Austin American-Statesman. Retrieved from https://www.statesman.com/news/20180601/politifact-austin-among-mosteconomically-segregated-cities

Shafritz, J. M., Ott, J. S., \& Jang, Y. S. (2015). Classics of Organization Theory ( $8^{\text {th }}$ ed.). Boston: Cengage Learning.

Siciliano, D. (2018). Reasons to Ditch the Fest. In Raw Paw. Retrieved from http://www.rawpaw.ink/3-reasons-to-ditch/?fbclid=IwAR13Hile_rXFWSP4yO0p7YcAil6AbiZrcBKwmuenmVHjug_JCgv6njpCPA

Siegel, R. (2005, January 11). Tipper Gore and Family Values. NPR Music. Retrieved from http://www.npr.org/templates/story/story.php?storyId $=4279560$

Simeonova, E. (2005). The Bulgarian Crossroads: The Political Crisis. In K. Engelbrekt \& M. Förberg (Eds.). Managing Political Crises in Bulgaria: Pragmatism and Procrastination. (pp. 45-74). Stockholm: CRISMART, Swedish National Defense College. 
Simerman, J. (2016, January 9). Appeals Court Overturns New Trial for Rogers LaCaze in Infamous 1995 Triple Murder. New Orleans Advocate. Retrieved from http://www.theadvocate.com/new_orleans/news/article_092826ee-269e-57f0bad2-2238a39e9151.html

Simon, D., \& Almasy, S. (2017, May 19). Final Conderate statue comes down in New Orleans. $C N N$. Retrieved from https://www.cnn.com/2017/05/19/us/new-orleansconfederate-monuments/index.html

SIMS Foundation. (n.d.). In About Us. Retrieved from https://simsfoundation.org/about-us/

Sisk, A. (2016, October 28). Police Arrest Protesters at North Dakota Pipeline Site. WBUR-Radio. Retrieved from http://www.wbur.org/hereandnow/2016/10/28/north-dakota-pipeline-arrests

Smith, A. (1982 [1776]). An Inquiry into the Nature and Causes of the Wealth of Nations. R.H. Campbell, A.S. Skinner, \& W.B. Todd (Eds.). Indianapolis: Liberty Classics

Smith-Spark, L. (2017, January 17). Women's March: Protestors Rally Worldwide in Solidarity. CNN. Retrieved from https://www.cnn.com/2017/01/21/politics/trumpwomen-march-on-washington/

Snyder-Young, D. (2010). Beyond "an Aesthetic of Objectivity": Performance Ethnography, Performance Texts, and Theatricality. Qualitative Inquiry, 16(10), 883-893.

South by Southwest. (n.d.). History -- SXSW. In South by Southwest. Retrieved from https://www.sxsw.com/about/history/

Spanos, B. (2015, August 10). Tom Morello on Ferguson Visit: "I'm Not a Humanitarian. I'm a Hell-Raiser". Rolling Stone. Retrieved from: http://www.rollingstone.com/music/features/tom-morello-on-ferguson-visit-imnot-a-humanitarian-im-a-hell-raiser-20150810

St. Bernard, T. (2016, April 29). What Becky with the good hair is telling our black daughters [Editorial]. Café Mom. Retrieved from https://thestir.cafemom.com/parenting_news/197718/what_becky_with_the_good

Staff Writer. (2018a, January 23). Hi, how was it? Here's what 'Hi, How Are You?' Day at the Mohawk was like. Austin American-Statesman. Retrieved from https://www.statesman.com/news/20180123/hi-how-was-it-heres-what-hi-howare-you-day-at-the-mohawk-was-like 
Staff Writer. (2018b, April 3). City staff, Austin Music Commission recommend later curfews for Red River Cultural District. Austin American-Statesman. Retrieved from https://www.statesman.com/news/20180403/city-staff-austin-musiccommission-recommend-later-curfews-for-red-river-cultural-district

Stevenson, A. (2016, July 20). [Very lucky it wasn't me...] In Battle of New Orleans: The Bicentennial Documentary. (2016, July 20). Retrieved from https://www.facebook.com/pg/battleofneworleansdocumentary/posts/?ref=page_i nternal [Facebook update].

Stith, D. S. (2015a, June 20). Development around new Hyatt House could disrupt Red River clubs, Mohawk owner says. Austin American-Statesman. Retrieved from http://music.blog.austin360.com/2015/06/19/development-around-newhyatt-house-could-disrupt-red-river-clubs-mohawk-owner-says/

Stith, D. S. (2015b, June 22). Hotel development could affect outdoor features at Cheer Up Charlie's, owners say. Austin American-Statesman. Retrieved from http://music.blog.austin360.com/2015/06/20/hotel-development-could-affectoutdoor-features-at-cheer-up-charlies-owners-say/

Stith, D. S. (2016, December 12). Venue owners say Red River curfew extension could bring big benefits to Austin music. Austin American-Statesman. Retrieved from http://music.blog.austin360.com/2016/12/12/venue-owners-say-red-rivercurfew-extension-could-bring-big-benefits-to-austin-music/

Stith, D. S. (2017, February 14). City music manager Don Pitts resigns while on administrative leave. Austin American-Statesman. Retrieved from https://www.statesman.com/NEWS/20170214/City-music-manager-Don-Pittsresigns-while-on-administrative-leave

Stith, D. S., \& Blackstock, P. (2017, October 24). Austin Music Census finds city at tipping point as Live Music Capital. Austin American-Statesman. Retrieved from https://www.statesman.com/NEWS/20171024/Austin-Music-Census-finds-cityat-tipping-point-as-Live-Music-Capital

Stith, D. S., \& Findell, E. (2017, June 1). Music industry backlash may delay vote on 'toothless' loudness policy. Austin American-Statesman. Retrieved from https://www.statesman.com/news/20170601/music-industry-backlash-may-delayvote-on-toothless-loudness-policy

Stocks, M. (2015, April 13). Track-by-Track: Halestorm -- Into the Wild Life.

TeamRock. Retrieved from http://www.teamrock.com/features/2015-04-13/trackby-track-halestorm-into-the-wild-life?identifier $=66656174757265$ 552ba00eb5f3e3.14462984 
Stokes, S. (2010, August 28). Cross Our Hearts: In Detail. Times-Picayune. Retrieved from https://www.nola.com/homegarden/index.ssf/2010/08/cross_our_hearts_in_detail. html

Stromquist, K. (2017, September 16). At rally and march, New Orleans service industry workers call for better treatment. Gambit. Retrieved from https://www.theadvocate.com/gambit/new_orleans/news/the_latest/article_beff06 be-27d8-51ff-ba9b-1a3ffd35e 5b5.html

Suddath, C. (2011, April 5). Robert Mapplethorpe: Top 10 Persecuted Artists. Time. Retrieved from http://content.time.com/time/specials/packages/article/0,28804,2063218_2063273 _2063220,00.html

Sunstein, C.R. (2017). \#Republic: Divided Democracy in the Age of Social Media. Princeton, NJ: Princeton University Press.

Swearingen, W.S. (2010). Environmental City: People, Place, Politics, and the Meaning of Modern Austin. Austin: University of Texas Press.

Swenson, D. \& Times-Picayune Staff. (Infographic). (2015, August 19). X Marks Your House. Times-Picayune. Retrieved from http://media.nola.com/hurricane_katrina/photo/katrina-X-spray-paint-graphicb9c53bee2f123960.jpg

Swiatecki, C. (2017a, April 21). Red River Music Venues Face '11th Hour' Endangerment. Austin Monitor. Retrieved from https://www.austinmonitor.com/stories/2017/04/study-red-river-music-venuesface-11th-hour-endangerment/

Swiatecki, C. (2017b, May 4). All Ears on Red River as Noise Curfew Pilot Program Kicks Off. Austin Monitor. Retrieved from https://www.austinmonitor.com/stories/2017/05/ears-red-river-noise-curfew-pilotprogram-kicks-off/

Swiatecki, C. (2018, December 4). Austin looks to other music cities as 'agent of change' ordinance develops. Austin Monitor. Retrieved from https://www.austinmonitor.com/stories/2018/12/austin-looks-to-other-musiccities-as-agent-of-change-ordinance-develops/

Take 'Em Down NOLA. (2017, May 3). [ALL OUT SUNDAY, MAY 7TH...]. Retrieved from https://www.facebook.com/pg/TakeEmDownNOLA/posts/?ref=page_internal [Facebook update] 
Taylor, F.W. (1967 [1911]). The Principles of Scientific Management. New York: W.W. Norton and Company.

Taylor, F.W. (2011 [1916]). The Principles of Scientific Management. In J.M. Shaftritz, J.S. Ott, \& Y.S. Jang (Eds.), Classics of Organization Theory ( $8^{\text {th }}$ ed.) (pp. 65-76). Boston: Cengage Learning.

Texas Music Office. (n.d.). Music Friendly Communities. Retrieved from https://gov.texas.gov/music/page/music-friendly-communities

[THE FADER]. (2009, October 7). Big Freedia - Interview. [Video File]. Retrieved from https://www.youtube.com/watch?v=03T9esCldFg\&t=194s

Theroux, L. (2007, March 31). God's Squad. Guardian. Retrieved from https://www.theguardian.com/media/2007/mar/31/tvandradio.usnews

Thijssen, P., \& Van Dooren, W. (2016). Who You Are/Where You Live: Do Neighbourhood Characteristics Explain Co-Production?. International Review of Administrative Sciences, 82(1), 88-109.

Timberg, S. (2015). Culture Crash: The Killing of the Creative Class. New Haven, CT: Yale University Press.

Times-Picayune. (2011, November 5). 1932: Huey Long Dominated Louisiana. Times-Picayune. Retrieved from http://www.nola.com/175years/index.ssf/2011/11/1932_huey_p_long_dominated _lou.html

Times-Picayune. (2014, May 28). With Noise Ordinances Up in the Air, Brass Bands and Businesses Forced to Work Out Their Differences on Frenchmen Street. Times-Picayune. Retrieved from https://www.nola.com/music/index.ssf/2014/05/with_noise_ordinance_up_in_the. html

Times-Picayune. (2017, November 19). Who is LaToya Cantrell? The backstory of New Orleans' mayor-elect. Times-Picayune. Retrieved from https://www.nola.com/politics/index.ssf/2017/11/who_is_latoya_cantrell_new_orl .html

Times-Picayune Staff. (2005, November 20). An Editorial: It's Time for a Nation to Return the Favor [Editorial]. Times-Picayune. Retrieved from http://www.nola.com/katrina/2005/11/an_editorial_its_time_for_a_na.html 
Times-Picayune Staff. (2016, January 26). What is Mardi Gras? And Everything Else You're Too Scared to Ask. Times-Picayune. Retrieved from https://www.mardigras.com/news/2016/01/what_is_mardi_gras_faq_new_orl.htm 1

Tretter, E.M. \& Sounny-Slitine, M.A. (2012). Austin restricted: Progressivism, zoning, private racial covenants, and the making of a segregated city. Geography, 512, 471-5116.

United Press International. (2001, May 23). Jury Hits Exxon with \$1B Verdict. United Press International. Retrieved from https://www.upi.com/Archives/2001/05/23/Jury-hits-Exxon-with-1bverdict/3668990590400/

Unknown Photographer. (Photographer). (2015, January 22). [Austin city council chambers]. In A. Inns (Reporter). Austin City Council members may cut pay. $K X A N-T V$. Retrieved from https://www.kxan.com/news/local/austin/austin-citycouncil-members-may-cut-pay/1049490874

Urban Dictionary. (2016, May 30). Becky with the Good Hair. Retrieved from https://www.urbandictionary.com/define.php?term=Becky\%20with\%20the\%20go od\%20hair

U.S. Census Bureau. (2018a). Austin, city: American Community Survey, Demographic and Housing Estimates. Retrieved from https://factfinder.census.gov/faces/tableservices/jsf/pages/productview.xhtml? src= $\mathrm{CF}$

U.S. Census Bureau. (2018b). Texas: 2018 Population Estimates. Retrieved from https://www.census.gov/searchresults.html?q $=$ population + of + texas \&page $=1 \&$ stateGeo $=$ none\&searchtype $=$ web $\& \operatorname{cssp}=$ SERP\&_charset_ $=$ UTF- 8

U.S. Department of Justice. (2015). Investigation of the Ferguson Police Department. United States Department of Justice Civil Rights Division.

U.S. Department of Labor. (2017, May). Occupational Employment Statistics: Arts, Design, Entertainment, Sports, and Media Occupations [Data file]. Retrieved from https://www.bls.gov/oes/current/oes270000.htm

Velasquez, J. J. (2016, October 26). Local organizations weigh in on how Austin's 101 council is faring 2 years in. Community Impact. Retrieved from https://communityimpact.com/austin/city-county/2016/10/26/local-organizationsweigh-austins-10-1-council-faring-2-years/ 
Visconti, L. M., Sherry Jr, J. F., Borghini, S., \& Anderson, L. (2010). Street art, sweet art? Reclaiming the "public" in public place. Journal of consumer research, 37(3), 511-529.

Weber, M. (2011 [1916]). Bureaucracy. In J.M. Shaftritz, J.S. Ott, \& Y.S. Jang (Eds.), Classics of Organization Theory ( $8^{\text {th }}$ ed.) (pp. 77-82). Boston: Cengage Learning.

Wagenaar, H. (2007). Governance, Complexity, and Democratic Participation: How Citizens and Public Officials Harness the Complexities of Neighborhood Decline. The American Review of Public Administration, 37(1), 17-50.

Wald, G. (2004). "Down by the Riverside" -- Sister Rosetta Tharpe with Lucky Millinder and His Orchestra (1944). In Library of Congress. Retrieved from https://www.loc.gov/programs/static/national-recording-preservationboard/documents/DownByTheRiverside.pdf

Walsh, S. C., \& Plohetski, T. (2018, May 15). Inside the Austin bomber's life:

Questions of friends, faith, sexuality. Austin American-Statesman. Retrieved from https://www.statesman.com/news/20180515/inside-the-austin-bombers-lifequestions-of-friends-faith-sexuality

Wangemann, J., Walsh, S. C., \& Plohetski, T. (2018, March 23). 4th Austin bomb more sophisticated than others, leaves city on edge. Austin American-Statesman. Retrieved from https://www.statesman.com/news/20180323/4th-austin-bombmore-sophisticated-than-others-leaves-city-on-edge

Warner, J. (2011). Power Tools. [Course handout]. Department of Political Science, Marshall University, Huntington, WV.

Warner, J. (2018, March 4). Personal Communication.

Warner, J.B. (2001). Laughter and the Tactics of Forgetting (Doctoral Dissertation). Pennsylvania State University. State College, PA.

WatchMojo.com. (2018, January 10). Top 10 Ridiculous Alex Jones Moments [Video file]. Retrieved from: https://www.youtube.com/watch?v=kgUDbvKYbWk

Watson, K. (2018, December 1). Commentary: Hating on the state's most prosperous city [Editorial]. Austin American-Statesman. Retrieved from https://www.statesman.com/opinion/20181201/commentary-hating-on-statesmost-prosperous-city 
WDSU-TV (2017, September 8 [1982]). 1982: Rose Tattoo on Tchoupitoulas receives a bomb threat from the Ku Klux Klan. WDSU-TV reports. In Almost Ready: The Story of Punk Rock in New Orleans. Retrieved from: https://www.facebook.com/pg/almostreadymovie/posts/?ref=page_internal [Facebook update].

Wear, B. (2016, September 15). Final Prop 1 tab for Uber, Lyft tops $\$ 10$ million. Austin American-Statesman. Retrieved from https://www.statesman.com/news/20160915/final-prop-1-tab-for-uber-lyft-tops10-million

Wear, B. (2018, June 1). Cap Metro, riders brace for bus system overhaul that arrives Sunday. Austin American-Statesman. Retrieved from https://www.statesman.com/news/20180601/cap-metro-riders-brace-for-bussystem-overhaul-that-arrives-sunday

Weber, A., \& Federico, S. (2018, March 22). Here's A Timeline Of The Austin Bombings. KUT-Radio. Retrieved from http://www.kut.org/post/heres-timelineaustin-bombings

Webster, R.A. (2014a, January 16). City Council Slams the Brakes on Proposed New Noise Ordinance. Times-Picayune. Retrieved from https://www.nola.com/politics/index.ssf/2014/01/city_council_slams_the_brakes. html

Webster, R.A. (2014b, January 16). New Orleans City Council Committee Set to Consider Controversial Noise Ordinance Friday. Times-Picayune. Retrieved from https://www.nola.com/politics/index.ssf/2014/01/new_orleans_city_council_set_t. html

Webster, R.A. (2014c, February 20). Lawyer in New Orleans Noise Ordinance Debate Accused of Intimidation. Times-Picayune. Retrieved from https://www.nola.com/politics/index.ssf/2014/02/lawyer_in_new_orleans_noise_o r.html

Webster, R.A. (2015a, March 17). Bourbon Street Noise Ordinance Resurrected by City Council. Times-Picayune. Retrieved from https://www.nola.com/politics/index.ssf/2015/03/new_orleans_noise_sound_musi c.html

Webster, R.A. (2015b, December 30). Save the Royal Street Pedestrian Mall: 700 Sign Petition Sent to Councilwoman Ramsey. Times-Picayune. Retrieved from https://www.nola.com/politics/index.ssf/2015/12/save_the_royal_street_pedestri.h tml 
Webster, R.A. (2017, May 3). Two arrested at Confederate monuments protest. Times-Picayune. Retrieved from https://www.nola.com/crime/index.ssf/2017/05/two_arrested_at_confederate_mo. html

Wendland, T. (2018, January 4). Louisiana Says Thousands Should Move From Vulnerable Coast, But Can't Pay Them. WWNO and National Public Radio. Retrieved from https:/www.npr.org/2018/01/04/572721503/louisiana-saysthousands-should-move-from-vulnerable-coast-but-cant-pay-them

Wilson, M. (2018, June 14). Austin City Council makes Manley's interim police chief role permanent. Austin American-Statesman. Retrieved from https://www.statesman.com/news/20180614/austin-city-council-makes-manleysinterim-police-chief-role-permanent

Wilson, W. (1887). The Study of Administration. Political Science Quarterly, 2(2), 197-222.

Woodward, A. (2014, January 17). Noise Ordinance Opponents Rally Inside City Hall. Gambit. Retrieved from http://www.bestofneworleans.com/blogofneworleans/archives/2014/01/17/noiseordinance-opponents-rally-inside-city-hall

Woodward, A. (2016, October 19). 'Uninhabitable' Storytelling Showcase Sheds Light on New Orleans Housing Issues. Gambit. Retrieved from http://www.bestofneworleans.com/thelatest/archives/2016/10/19/uninhabitablestorytelling-showcase-sheds-light-on-new-orleans-housing-issues

Worland, J. (2016, October 28). What to Know About the Dakota Access Pipeline Protests. Time. Retrieved from http://time.com/4548566/dakota-access-pipelinestanding-rock-sioux/

Worthy, B. (2010). More Open but Not More Trusted? The Effect of the Freedom of Information Act 2000 on the United Kingdom Central Government. Governance, 23(4), 561-582.

Wynn, J. R. (2011). [Review of the book Environmental City: People, Place, Politics, and the Meaning of Modern Austin, by W.S. Swearingen]. Great Plains Research: A Journal of Natural and Social Sciences, 21(1), 121-123.

Yang, Y., \& Wu, J. (2013). Are the "Bigger Fish" Caught? China's Experience of Engaging Citizens in Performance Measurement System. Public Administration Quarterly, 144-182. 
Yetano, A., \& Royo, S. (2017). Keeping Citizens Engaged: A Comparison Between Online and Offline Participants. Administration \& Society, 49(3), 394-422.

Yilmaz, K. (2013). Comparison of Quantitative and Qualitative Research Trajectories: Epistemological, Theoretical, and Methodological Differences. European Journal of Education, 48(2), 311-325

Yin, R.K. (2014). Case Study Research: Design and Methods (5th ed.). Washington, DC: Sage Publications.

Zehr, D. (2015a, January 18). Austin's history of segregation threatens economy's future. Austin American-Statesman. Retrieved from https://projects.statesman.com/news/economic-mobility/wealth.html

Zehr, D. (2015b, January 18). How Austin isolated Latinos with a unique form of segregation. Austin American-Statesman. Retrieved from https://projects.statesman.com/news/economic-mobility/latino.html

Zehr, D. (2015c, January 18). The price of wider gaps and weaker links. Austin American-Statesman. Retrieved from https://projects.statesman.com/news/economic-mobility/divide.html

Zheng, Y. (2015). Explaining Citizens' E-Participation Usage: Functionality of EParticipation Applications. Administration \& Society, 49(3), 423-442. 


\section{Appendix A: New Orleans' Background Information}

New Orleans' noise ordinance: New Orleans' noise ordinance is the policy piece at the root of much of the policy oriented battles, threats toward the artistic community, issues involving unequal power structures, and issues with the political environment standing in the way of positive change. The noise ordinance that is on the books as of this writing was first passed in the 1950s and with a few updates in the 1980s. For both those who want the artistic community and boisterous neighborhoods to flourish, those who want to temper those activities, and the bureaucracy charged with trying to enforce it, the noise ordinance is outright nightmarish. There are elements that are unconstitutional, such as how it narrowly targets music. Parts of it are too ambiguous. Other elements are extremely confusing, such as having zones with numerous different noise restrictions, with ten zones (seven of them being in the entertainment-oriented French Quarter and Marigny neighborhoods, alone) for the whole city, with some zones only having one narrow street separating them. It also has a controversial curfew on street performers, which is likely unconstitutional, as well. Attempts to update or replace the noise ordinance have resulted in protests, outright nasty political and neighborhood spats, and assertions that certain proposed noise restrictions are designed to narrowly target beloved cultural practices or are racist. During the New Orleans fieldwork period, any action on the noise ordinance was stalled largely because of upcoming city elections (Freund, 2014a, 2014b; Music and Culture Coalition of New Orleans, 2016a; Personal Communication, 2017; Times-Picayune, 2014; Webster, 2014a, 2014b, 2014c)

Second-line parades: A longstanding New Orleans traditional parade that typically consists of a military style brass band, followed by a "second line" of dancers and/or revelers, often carrying colorful items such as parasols. Modern-day second-lines often have revelers intermixing with the bands. This combines the traditions of European military bands that white settlers brought and West African dance that came with African slaves (Kunian, 2007; City of New Orleans, 2013).

Jazz funeral: A specific form of second-line parade, reserved for funerals. These involve a brass band mournfully playing a religious hymn as it follows the deceased's casket, and mourners are the second line behind the band. When the casket is lowered, the band switches to a jazzy, up-tempo version of religious hymns, and the mourners become rejoicing revelers. All is done to celebrate the deceased person's life rather than only mourn his/her death. This combines the European and African traditions of second lines with those of Caribbean voodoo. The voodoo practitioners believed that evil spirits would become vengeful if mourning did not quickly change into merriment (Kunian, 2007; City of New Orleans, 2013).

Social Aid and Pleasure Club: The second line parades originated in social aid and pleasure clubs. These organizations grew from benevolent societies in the mid-to-late 1800 s that began with the fall of slavery. Insurance companies often refused to write policies for newly freed slaves, leaving them helpless when faced with unexpected expenses like burial and health care costs. Benevolent societies filled the gap through 
helping its dues-paying members defray those costs. Members earned a jazz funeral when they died, with the clubs hiring bands to play these. New Orleans' social aid and pleasure clubs became community staples through hosting social events and doing charitable work. While they may not serve all the benevolent societies' functions of the past, they work to unify communities and are a major source of cultural pride for the city's black citizens. Their parades are known for club members who dress in sharp, bold, oftenelaborate, coordinated suits and hats who are also part of the "first line" with their second-line parades' bands. Being a part of one is not exactly cheap, with club dues costing in the hundreds per year along with the clothing costs for the suits. Pre-Katrina, New Orleans" social aid and pleasure clubs "numbered in the forties" with a different club having a parade every Sunday except during summers (as cited in New Orleans Tourism Marketing Corporation, 2018). Now, the clubs are struggling, but some still parade. (City of New Orleans, 2013; Kunian, 2007; New Orleans Tourism Marketing Corporation, n.d.).

Pumping stations and related 2017 flooding: The city's constant problems with malfunctioning pumping stations and related frequent flooding during the fieldwork period caused ire between the New Orleans citizenry as a whole and its city government. The low-lying city, for more than 100 years, has had multiple pumping stations that pull water out of the low-lying city when it rains. In 2017, multiple pumps that are more than 100 years old and running on an outdated electrical system malfunctioned and flooded the parts of the city multiple times during rain events. City government mismanagement during and before the situation created even more discontent. The situation became especially dangerous during the 2017 hurricane season, when even a non-direct strike from Hurricanes Harvey and Irma could have been devastating. Citizens' rage was reflected in visual art, music, costuming and dance performance through most of the satirical Mardi Gras parade, Krewe Du Vieux in 2018 (Krewe Du Vieux is detailed below.) (Brasted, 2017; Granger, 2017a, 2017b; Krewe Du Vieux, 2018; Pridemore, 2005; Rainey, 2017d, 2017e; Sayre, 2017b; Schleifstein, 2017)

Krewe: These are organizations that put on parades or balls during Mardi Gras season, and they participate in social events throughout the year. Originally, the balls and the krewes were male-only and only for the most elite of the city's elite, with only five clubs before 1900 . During the $20^{\text {th }}$ Century, others began forming their own krewes, with fortynine krewes by 1949 including ones for women. This did not mean that Mardi Gras became inclusive at all. Krewes were still separated by gender, race, ethnic, and religion and were such for decades. In December 1991, the city council voted to require the estimated sixty krewes to integrate by 1994 or lose the right to have parades. This was extremely controversial, even with many black voters opposing the change because of tradition. It was enough to keep some of the oldest and most tradition-minded krewes from ever having another parade, and the number of integrated krewes continued to expand. In the present day, some very new, contemporary krewes that have come with the city's diversifying cultural landscape have caused friction within the artistic community and the city itself (Personal Communication, 2017; Rothman, 2015). 
Krewe Du Vieux: Krewe Du Vieux is a 40-year-old Mardi Gras krewe known for its displays of biting political satire and comedy and very adult themes. Every year before the parade, it releases its newsletter "Le Monde de Merde" (Translated from French: The World of Shit) and unveils its theme. It gained national attention in 2006 when it became the first parade to march after Katrina and how it kept its lightheartedness and willingness to "go there" by invoking how city residents were feeling after Katrina. The January 2018 Krewe Du Vieux parade I observed had the theme "Bienville's Wet Dream". It made light of the city's $300^{\text {th }}$ anniversary by visually invoking the city's French heritage (dancers of both genders in Marie Antoinette costumes, etc.), the city's sordid corruption history, and the city's severe pumping station, sewer, and related flooding in 2017 in an overall message of "Three hundred years later: Things are still horrible." (Mardi Gras New Orleans, 2018; Krewe Du Vieux, 2006; Krewe Du Vieux, 2018; Personal Communication, 2018).

Go-Cup: New Orleans' bars frequently serve alcohol in cups that one can legally take outside the bar with them, consuming alcoholic beverages on the streets. This is considered a staple of New Orleans local entertainment culture, but it and other such practices have come under scrutiny as newcomers turned off by such practices have arrived (Personal Communication, 2017).

Master Plan: The Master Plan (Formal Name: The Plan for the $21^{\text {st }}$ Century) was a major New Orleans city policy piece adopted in 2010 with a goal being recovering from Hurricane Katrina and then moving forward, carrying the city into 2030. The main goal was handling zoning and land use, but it has expanded to numerous facets of city policy that includes arts and culture. The city's charter requires the Master Plan be reviewed at least once every five years, and the city's planning commission decided amendments were needed, with interested individuals and groups invited to submit amendments for consideration. The public was invited to comment on the chosen amendments in January 2018, but a final city council vote, as of this writing, has been delayed (City of New Orleans, 2018a, 2018b; LaRose, 2018a; Sayre, 2017a).

January 2014 Brass Band City Hall Protest: When faced with a proposed noise ordinance that it deeply opposed in December 2013, members of New Orleans' artistic community stormed city hall with a full brass band in January 2014 to do a New Orleansstyle mock jazz funeral for the noise ordinance. Whether or not this was successful in the end is debatable, according to my New Orleans informants. The noise ordinance did not pass, and the display caught attention from the outside. However, the problematic existing noise ordinance remains on the books and the artistic community and city government alike are left with policy that is a mixture of problematic, unconstitutional, and too vague to even use (Personal Communication, 2017; Woodward, 2014)

Royal Street Pedestrian Mall: Royal Street in the French Quarter has shut down to vehicular traffic between $11 \mathrm{a} . \mathrm{m}$. and 4 p.m. on weekdays and 11 a.m. to 7 p.m. on weekends since 1971, per city code. It brings together numerous street musicians, visual artists, poets and others working to earn money from their crafts. It has created major 
tension between some French Quarter business owners and street performers. The practice has run into problems in recent years. The city opened Royal up to traffic at all times in 2017 because of extensive construction on neighboring Bourbon Street (which was a major controversy) and related traffic congestion. NOPD also shut down the pedestrian mall for traffic in 2015 after the Nice, France, vehicular terrorist attack. That same year, a coalition of business owners worked to permanently shut down the pedestrian mall. No formal announcement has been regarding the pedestrian mall's status since June 2017, but the pedestrian mall had periodically started again while I was in the field in New Orleans (Evans, 2017e; Personal Communication, 2017, 2018; Webster, 2015b).

Sound Check: Sound Check is an initiative the New Orleans Health Department began in 2015 as the city worked toward regulating noise as a public health matter and having a noise ordinance that had elements such as decibel limits based on scientific data - and not the extremely problematic noise ordinance from the 1950s that is still on the books. Sound Check began with an educational approach, with health department officials trained in sound measurement going to music venues and meeting with artistic community members like gigging musicians and street performers. The health officials would encourage them to use hearing protection and maintain healthy sound limits. The work was a success, with complaints going down and the health department making some positive inroads with the artistic community. However, the department largely lacked enforcement tools and the ability to penalize anyone because a political environment that also included city elections and controversies involving strip clubs stalled crafting and passage of a workable noise ordinance (McClendon, 2015b; Personal Communication, 2017).

Storyville: A district adjacent to the French Quarter that, between 1897 and 1917, had legalized prostitution. The district featured glamorous prostitutes and elegant brothels (as well as far less glamorous but more budget-friendly "cribs" on the district's edge) that provided New Orleans' musicians, black jazz performers in particular, with performance venues. It provided black women with income they used to start businesses. Certain madams became beloved pillars of the community, and the district became a very popular visitor destination. Storyville's legacy influenced music, literature, and theatrical pieces that came from New Orleans and last to the present day. It also contributed to how outsiders' image of New Orleans is still either romanticized and beloved, namely as a haven that welcomes societal outcasts, or is a modern-day Sodom and Gomorrah reeking of sin and vice. Critical outsiders ultimately pushed city officials shut down Storyville at the dawn of World War I because New Orleans is port city, and there were restrictions against prostitution in close proximity to military facilities. Despite it being closed down literally one hundred years before the dissertation study period, Storyville's legacy was invoked often to demonstrate issues involving citizen participation and public policymaking, in general (Daily Mail, 2013; Landau, 2014; Personal Communication, 2017; Pope, 2017; Karst, 2017). 
Prohibition in New Orleans: The Prohibition era during the early $20^{\text {th }}$ Century was a major driver for New Orleans becoming the cultural and entertainment epicenter that it is today. Geographically, New Orleans was the perfect location for receiving smuggled liquor because shipments from abroad could go into Louisiana via the Gulf of Mexico, then into Mississippi River. More isolated rural areas surrounded New Orleans, and these became perfect places to stash the goods until they could be eventually smuggled into the city. State-level politics also created such an environment. The legendary (for better or worse, depending on who is asked) Louisiana Governor Huey Long, when asked what he was doing to enforce Prohibition, reportedly replied "Not a damn thing!" New Orleans was ranked the "wettest" city during Prohibition. Its lively $24 / 7$ entertainment combined with abundant black market alcoholic beverages made it a natural draw for visitors (City of New Orleans, 2013; Hyde, 2014; McKnight, 2014).

Bounce: Bounce is an energetic, up-tempo hip-hop subgenre native to New Orleans. This developed around the 1980s, with black LGBT artists (The LGBT artists are often called "sissies" in this culture.) being some of its most prominent figures, especially as Bounce's popularity has spread beyond New Orleans. It also features the rump-shaking "twerk" dance style that produces very lively shows in which the audiences twerk along with the performers. (Coviello, 2011; FADER, 2009; Kelly, 2014; Mott-Smith, 2014).

Mayoral transition note: Mitch Landrieu was still New Orleans' mayor during the study's fieldwork period. LaToya Cantrell, a city councilwoman at the time, was elected as the city's first female mayor during the fieldwork period, but she had yet to take office when the fieldwork period ended in early 2018. 


\section{Appendix B: Austin's Background Information}

Outdoor Live Music Venues: The majority of Austin's live music venues are partially, if not mostly outdoor spaces, and most of the music is played outdoors. This is a longstanding staple of local culture because the venues once found these properties, in then-less-desirable areas, at a low price, and the environments provide a casual, welcoming place to enjoy music and socialize in Austin's warm weather. However, those in new developments such as hotels that have built literally next door to these longstanding venues have complained about the venues' noise and consider them disturbing, despite the venues being there first and the city informing them about the outdoor live music (Personal Communication, 2017, 2018).

Red River Cultural District: The Red River Cultural District, located in downtown Austin on Red River Street and between the intersections of Seventh and Twelfth streets, contains a conglomerate of thirteen longstanding live music venues, most of them playing music outdoors. The venues formed a merchant association in early 2016 and have worked to get Texas state historical designation. Red River is largely beloved in Austin and by its artistic community because the welcoming venues feature "real" Austin music and original music versus cover bands. However, the venues are threatened because of noise complaints from those opening new developments, skyrocketing property values, the fact that all but one leases and does not own their properties in a prime real estate area, and because of crime outside of and not associated with the bars taking place in the area. Red River provides remarkable lessons involving citizen participation because it involved intense competitors and seemingly unlikely policymaking participants - rival bar owners located side-by-side - putting their differences aside and entering policymaking processes to preserve their existence and have seen major policy success even with intense challenges (City of Austin, n.d.b; Personal Communication, 2017, 2018).

Sixth Street and "Dirty Sixth": Sixth Street is Austin's historic entertainment district in downtown, but despite its popularity with tourists, it has fallen out of favor with the locals that include artistic community members. It contains a notorious stretch between Congress Avenue and Interstate 35 known to locals as "Dirty Sixth". Dirty Sixth is derided for its real and perceived over-the-top debauchery, safety concerns, "tourist trap" image, and music from cover bands versus original and "real" Austin music. A fear associated with Dirty Sixth that the artistic community has is that if the Red River district, located not far from Dirty Sixth, becomes associated with Dirty Sixth because of Red River's crime problems outside the bars, it could fall out of favor in the eyes of the public and fall victim to negative social construction of place - making actions that work against it either not spark much opposition or even be seen as favorable (Curtin, 2015b; Personal Communication, 2015) 
A map showing the locations of the Red River district and Dirty Sixth is below.

Figure B1: Map of Red River district and Dirty Sixth (Google Maps, 2018)

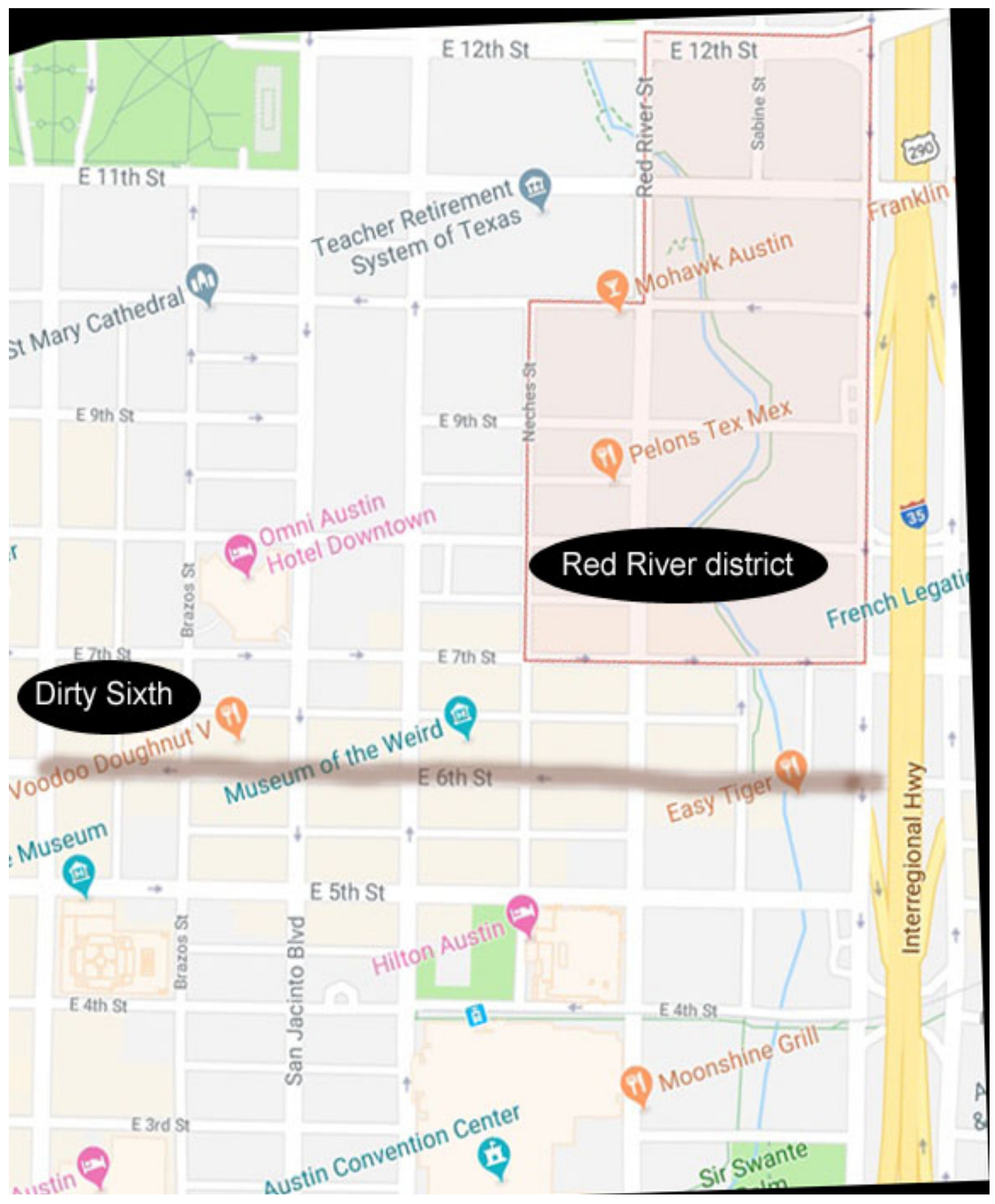

South-by-Southwest ("South-By" or "SXSW"): South-By-Southwest is a threepronged festival with the goal of showcasing Austin's innovative signatures, as a whole. It has "Interactive" (technology), music, and film segments, and in 2017, the festival had 
almost 422,000 people counted as participating in the festival. "South-By", as the locals most often call it, also attracts big-name celebrities and public figures. South-By began in 1987 as a small music festival designed to showcase local music talent. It added its technology and film portions in 1994, and some locals note that as one of the major turning points in Austin society as a whole namely because its transformation as a fun event to an industry showcase attracted throngs of tech professionals and, with those, high-end development. South-By is an extremely polarizing event among locals and even within Austin's artistic community. On the negative side, South-By is blamed for the affordability crisis, has created major public safety concerns (namely because of violence during the event), is seen as being inaccessible to locals because of the festival badges' high costs (as much as \$1,300), "paying" musicians only with "exposure" and charging them just to be considered, few musicians being local, and the festival's extremely large footprint. However, local bar owners support the festival because South-By is the only reason why some of them end a given year in the black, local musicians and their supporters favoring it because of its positive economic impacts and especially for the local venues, and some in the city viewing it as a way to showcase their hometown and bring high-profile people to the city (Cofield, 2016; Curtin, 2016a, 2016b; Fechter, 2016; Hoffberger, 2015; Lindell, 2017; Personal Communication, 2017, 2018; South-BySouthwest, n.d.)

Austin City Limits: This historic TV show began in 1974 as a way to showcase local musicians and what was then a burgeoning local music scene. It has become one of Austin's best-known historic assets, with it becoming the longest-running concert program in the United States. It also spawned the Austin City Limits Music Festival (further explained below) that began in 2002 (Long, 2010; Pridemore, 2017).

Austin City Limits Music Festival ("ACL"): The Austin City Limits Music Festival began as a way to further showcase Austin's music through utilizing the historic TV show's recognizable brand. The festival, often referred to by locals as "ACL", also worked to showcase other aspects of Austin culture, such as having local vendors serve the food and having local artisans sell their works. However, local artistic community members now see the wildly popular festival as something that is no longer their own or that the city owns. Instead, they believe, it is something made for outsiders. The festival expanding its footprint in the city's popular Zilker Park has not set well with those living nearby, either. Like some of the evolutions with South-by-Southwest, the festival developing from the longstanding TV show is seen as marking one of the overall shifts in Austin, as a whole. Some artistic community members have responded by creating their own small-scale "alt-ACL" festivals so that they can have an event that is their own, again (Personal Communication, 2017, 2018; Pridemore, 2017)

\section{Economic Development Department's Cultural Arts Division and Music and}

Entertainment Division: The city of Austin's Economic Development Department has two divisions, the Cultural Arts Division and the Music and Entertainment Division, that focus on the arts but more from a economic development/small business private-sector perspective rather than a nonprofit one. The Cultural Arts Division assists those in sectors 
such as visual arts, film, and public art displays, funds cultural programs in the city, and offers workshops that teach artists business skills such as marketing. The Music and Entertainment Division is very new, only beginning in 2010 and with its second director appointed in 2017. Its focus is on the non-classical, commercial music industry in the city, offering programming services such as professional development and entrepreneurship for musicians and entertainment services such as promoting safe nightlife and venue preservation. Besides their private-sector orientations, these offices are unique from most others like them in larger cities because they are also integrated into the city's civil service versus being a political initiative. This means the employees have civil service protections, and the offices are not especially vulnerable to political whims. As a whole, these offices also receive high marks from those in the local artistic community and their events' slots can literally be filled in less than a day (ATX Music, n.d.; City of Austin, n.d.d; Personal Communication, 2017).

Agent of Change: Agent of Change is a proposed city policy that is essentially a principle of "Who was here first?" Under this policy, someone building a structure seemingly incompatible with the existing immediate area — such as hotels or condos being built next door to outdoor live music venues or outdoor live music venues being built near residential areas - would both be informed of this incompatibility and be required to take these considerations into account with construction, such as making sure a building is soundproofed. In the case of a hotel or residence that knowingly built near a live entertainment venue, it would also make the new entity waive its right to complain about noise that remains in the city's legal limits. This has been proposed as a way to handle Austin's major problems with clashes between new developments and longstanding artistic venues. However, Agent of Change has been in effective limbo for about three years, as of 2018 (Curtin, 2018: Personal Communication, 2017, 2018; Stith \& Findell, 2017; Swiatecki, 2018)

Austin Music Census: The Austin Music Census was a major research initiative the city's Music and Entertainment Division undertook and released in 2015. This was done to get data such as income levels, attitudes about city government, and overall conditions for those in the music community, such as musicians and venue owners. This was also done to, once data was gathered, begin formulating public policy that would help the local music industry. The data showed dire conditions for the music community, such as nearly one-third living on $\$ 15,000$ or less per year, even when factoring in most of them working at least one other job other than their work in music. It also showed that being in Austin was unaffordable, particularly in the city's core, and some were already leaving the city because they could not afford to live there. However, participation was extremely high, with four thousand people responding to a survey, plus eight focus groups and twenty interviews. The report detailed that both the music community wanted to work to create better conditions for itself and that the city wanted to listen to them and help them. The problem was that, according to interviewees from the artistic community, nothing was done to help them after that major participation effort. This created further resentment of city government and made them much less likely to participate in future 
policymaking efforts (City of Austin, 2015; Personal Communication, 2017, 2018; Stith \& Blackstock, 2017).

"Live Music Capital of the World": This is a slogan the city of Austin uses to market itself and namely its longstanding music scene. However, disaffected artistic community members have utilized this often in slamming out they feel treated by city government and in citizen participation efforts they believe do nothing to help them in the end. One example is an interviewee calling Austin, "The Working Group Capital of the World," because participation efforts also seemingly get repeated while no action is taken (Personal Communication, 2017, 2018).

CodeNext: CodeNext is an Austin city initiative to revise land development codes that determine "how land can be used throughout the city - including what can be built, where it can be built, and how much can (and cannot) be built" (as cited in City of Austin, n.d.). CodeNext has been part of city government work to plan for even more explosive growth, and that work began in 2012. One aspect of CodeNext that many in the artistic community favor is that it would have a special zoning designation for live music venues, which could help with neighborhood tensions. The problem is that CodeNext is a major multi-policy piece in which that music venue designation would only be a fraction (at best), faces major opposition from detached single-family home owners who are often wealthier. CodeNext includes measures to increase population density, which the singlefamily, detached home owners do not want. Some citizens are pushing for CodeNext to go to a citywide vote, which means that, should the venue designation be packaged with CodeNext, it could fail in a popular vote (City of Austin, n.d.; Grumet, 2018b ; Personal Communication, 2018).

10/1 Council Representation/ "Mayor At-Large" system: This is the system for representation on Austin City Council that has been in place since 2014. The city is divided into ten districts that elect one representative, each, to council. An eleventh elected position is the mayor, chosen by voters citywide, but the position is more akin to an at-large council member because of Austin having a council/manager system and because the mayor has a vote on council. This system replaced one in which six council members and a mayor were all elected citywide. The new system has garnered praise because it has increased diversity of not only council members but with the city's sixty volunteer boards and commissions for which each council member has an appointee from their district and the mayor has a citywide pick. This has allowed for more minorities on the council and on the boards because historically minority and low-income neighborhoods are better assured representation. However, some critics have noted that the district system has created a council only concerned with their own constituents and not with the interests of the city, as a whole (Personal Communication, 2017, 2018; Velasquez, 2016)

Austin serial bomber: Between March 2, 2018, and March 21, 2018, a serial bomber terrorized the city of Austin, with three package bombs (two exploding within hours of each other on March 12) and one tripwire bomb that killed two people and injured four. 
Additionally, another package bound for Austin exploded at a FedEx facility near San Antonio, and a package ready for an explosion was found at another FedEx location in Austin. This terrifying rampage also included fake bomb threats at South-by-Southwest that was happening through much of the time period, panic after an unrelated blast, and residents living in fear citywide. The rampage ended on March 21 when police closed in on the bomber in nearby Round Rock, and the bomber blew himself up in his own car as police opened fire on him. The bomber left a confession video behind. During the bombings, Russian trolls worked to cause discord online, namely through exploiting and working to spike racial tension and poison public opinion about the local news media, as well as the police. These incidents also highlighted Austin's year without a permanent city manager and multiple major department heads in an interim position because of the city manager vacancy. Austin City Manager Spencer Cronk had been on the job for about a month before the bombings began, and the city's interim police chief Brian Manley was leading the manhunt and its main spokesperson. However, Cronk was ever-present at the briefings, and Manley's performance was, overall, highly praised. Cronk later appointed Manley as the permanent police chief (Jankowski, 2018b; Hernandez, 2017; Herrera, 2018a; Personal Communication, 2018; Weber \& Federico, 2018)

Koch and Fowler Plan: This 1928 city plan from a Dallas firm with the same name created segregated neighborhoods in the city where black and Hispanic residents were only able to access public utilities if they lived east of what is now Interstate 35 . These neighborhoods reserved for non-white residents also, by design, did not receive the zoning protections that white neighborhoods did, meaning they were used more for noxious uses like industrial work and alcohol sales were allowed. The legacy of the Koch and Fowler Plan exists to this day because many minority Austin residents see the city's progressive stance as a farce. Also, because minority residents in East Austin have been harder-hit by gentrification and skyrocketing property taxes, this burn is even worse in the present day (Austin American-Statesman, n.d.; Koch and Fowler, 1928; Personal Communication, 2018; Tretter \& Sounny-Slitine, 2012; Zehr, 2015a, 2015b, 2015c). 


\section{Appendix C: Data Analysis}

The following appendix contains my most frequently occurring subject matter I found through my NVivo data analysis. I will present charts with the most frequently occurring codes for each research question and in each city.

Table C1: Austin, Hindering Factors, Data Analysis

\begin{tabular}{|l|l|l|}
\hline Finding & Sources & References \\
\hline $\begin{array}{l}\text { Attempts to temper } \\
\text { longstanding entertainment } \\
\text { neighborhoods }\end{array}$ & 54 & 80 \\
\hline $\begin{array}{l}\text { Artistic communities } \\
\text { finding government } \\
\text { intimidating and/or } \\
\text { frustrating }\end{array}$ & 56 & 78 \\
\hline $\begin{array}{l}\text { Government inaction (Real } \\
\text { and perceived) }\end{array}$ & 71 & 113 \\
\hline $\begin{array}{l}\text { Artistic communities' } \\
\text { economic and social factors }\end{array}$ & 38 & 62 \\
\hline $\begin{array}{l}\text { Negative social construction } \\
\text { of place }\end{array}$ & 25 & 38 \\
\hline
\end{tabular}

Table C2: Austin, Enabling Factors, Data Analysis

\begin{tabular}{|l|l|l|}
\hline Finding & Sources & References \\
\hline $\begin{array}{l}\text { Artistic community's } \\
\text { positive in-group } \\
\text { relationships }\end{array}$ & 28 & 49 \\
\hline $\begin{array}{l}\text { Comfortable meeting } \\
\text { environments in third places }\end{array}$ & 41 & 69 \\
\hline $\begin{array}{l}\text { Positive aspects of the city } \\
\text { economic development } \\
\text { department's unique Music } \\
\text { and Entertainment and } \\
\text { Creative Arts divisions }\end{array}$ & 32 & 47 \\
\hline $\begin{array}{l}\text { Public officials going to the } \\
\text { citizens }\end{array}$ & 13 & 26 \\
\hline $\begin{array}{l}\text { Positive aspects of the } \\
\text { numerous nonprofits }\end{array}$ & 23 & 31 \\
\hline
\end{tabular}


Table C3: Austin, Who Participates?, Data Analysis

\begin{tabular}{|l|l|l|}
\hline Finding & Sources & References \\
\hline $\begin{array}{l}\text { Social Media: General } \\
\text { chaos and bad behavior }\end{array}$ & 11 & 20 \\
\hline $\begin{array}{l}\text { Social Media: Government } \\
\text { use in relative infancy }\end{array}$ & 12 & 19 \\
\hline $\begin{array}{l}\text { Appointing few } \\
\text { spokespeople from } \\
\text { interested groups }\end{array}$ & 5 & 7 \\
\hline $\begin{array}{l}\text { Problem: Few speakers not } \\
\text { representing the majority }\end{array}$ & 7 & 12 \\
\hline $\begin{array}{l}\text { Recruiting people that given } \\
\text { policies affect most }\end{array}$ & 4 & 4 \\
\hline
\end{tabular}

Table C4: Austin, Breaking Participation Barriers, Data Analysis

\begin{tabular}{|l|l|l|}
\hline Finding & Sources & References \\
\hline Policy remedies & 12 & 16 \\
\hline $\begin{array}{l}\text { Artistic communities \& } \\
\text { Government working on } \\
\text { common causes }\end{array}$ & 10 & 13 \\
\hline $\begin{array}{l}\text { Quickly building } \\
\text { relationships with new } \\
\text { leaders }\end{array}$ & 3 & 4 \\
\hline $\begin{array}{l}\text { Clearly demonstrating how } \\
\text { and why an issue matters }\end{array}$ & 4 & 4 \\
\hline $\begin{array}{l}\text { Translating language } \\
\text { barriers between } \\
\text { government and artistic } \\
\text { communities }\end{array}$ & 4 & 7 \\
\hline
\end{tabular}

Table C5: New Orleans, Hindering Factors, Data Analysis

\begin{tabular}{|l|l|l|}
\hline Finding & Sources & References \\
\hline Tribalism \& Social Order & 43 & 63 \\
\hline
\end{tabular}




\begin{tabular}{|l|l|l|}
\hline $\begin{array}{l}\text { Transportation \& } \\
\text { Infrastructure }\end{array}$ & 40 & 48 \\
\hline Negative social construction & 39 & 51 \\
\hline $\begin{array}{l}\text { Hyper-political } \\
\text { environment }\end{array}$ & 26 & 46 \\
\hline Corruption history & 26 & 39 \\
\hline
\end{tabular}

Table C6: New Orleans, Enabling Factors, Data Analysis

\begin{tabular}{|l|l|l|}
\hline Finding & Sources & References \\
\hline $\begin{array}{l}\text { Artistic community is tough } \\
\text { as nails }\end{array}$ & 81 & 112 \\
\hline $\begin{array}{l}\text { Old enemies having } \\
\text { common causes }\end{array}$ & 22 & 32 \\
\hline $\begin{array}{l}\text { Having common causes } \\
\text { with other disaffected } \\
\text { groups }\end{array}$ & 14 & 21 \\
\hline $\begin{array}{l}\text { Government going to the } \\
\text { people }\end{array}$ & 12 & 18 \\
\hline $\begin{array}{l}\text { Government improving } \\
\text { relationships }\end{array}$ & 10 & 16 \\
\hline
\end{tabular}

Table C7: New Orleans, Who Participates?, Data Analysis

\begin{tabular}{|l|l|l|}
\hline Finding & Sources & References \\
\hline $\begin{array}{l}\text { Representation \& Advocacy } \\
\text { issues }\end{array}$ & 23 & 31 \\
\hline $\begin{array}{l}\text { Social Media: Negative } \\
\text { Effects }\end{array}$ & 16 & 25 \\
\hline $\begin{array}{l}\text { Social Media: Positive } \\
\text { Effects }\end{array}$ & 13 & 19 \\
\hline $\begin{array}{l}\text { NOT partnering can be best } \\
\text { route }\end{array}$ & 2 & 4 \\
\hline $\begin{array}{l}\text { Strength in numbers } \\
\text { providing powerful visual }\end{array}$ & 2 & 2 \\
\hline
\end{tabular}


Table C8: New Orleans, Breaking Participation Barriers, Data Analysis

\begin{tabular}{|l|l|l|}
\hline Finding & Sources & References \\
\hline $\begin{array}{l}\text { Government educating } \\
\text { artistic communities on } \\
\text { policy issues }\end{array}$ & 7 & 17 \\
\hline New leadership & 5 & 7 \\
\hline $\begin{array}{l}\text { Advocacy organizations } \\
\text { educating artistic } \\
\text { communities on policy } \\
\text { issues }\end{array}$ & 2 & 5 \\
\hline $\begin{array}{l}\text { "Carrot" approaches over } \\
\text { "stick" approaches }\end{array}$ & 2 & 4 \\
\hline $\begin{array}{l}\text { Institutionalizing positive } \\
\text { practices }\end{array}$ & 1 & 1 \\
\hline
\end{tabular}




\section{Appendix D: Participant Index}

New Orleans

Alicia: Visual artist

Anthony: Street musician

Dean: Bar owner

Fleur: Street musician

Frank: Street musician

Garrick: Street musician

Ginny: Street poet

Harry: Advocate for artistic community

Kingsley: New Orleans Police Department supervisor

Lavender: Advocate for artistic community

Lee: Street musician

Lucius: Street musician

Michael: Musician

Minerva: Non-resident academic working in city

Neville: Filmmaker

Olympia: New Orleans city health official

Parvati: Advocate for artistic community

Regulus: Bar owner

Rolanda: Art gallery owner and visual artist

Rubeus: Street musician

Susan: Advocate for artistic community

Austin

Alastor: Texas state government official, arts office

Albus: Advocate, artistic community; former city boards/commissions member Andromeda: City planner

Angelina: City elected official

Augusta: Multi-disciplinary artist

Draco: City board/commission member

Ernie: Austin city police officer

Helena: City board/commission member

Hermione: Musician

Lily: Advocate; former local government manager

Luna: Theater company member

Molly: City Arts/Economic Development employee

Narcissa: Musician

Nymphadora: Film festival organizer; former government arts office employee Padma: Advocate, artistic community

Percy: Musician 
Penelope: Journalist

Pomona: City Arts/Economic Development employee

Ron: Journalist

Remus: Musician

Seamus: Red River Cultural District bar owner

Severus: Advocate, artistic community

Sirius: Musician 
VITA

AMELIA A. PRIDEMORE

Born: Huntington, West Virginia

2003

B.A., Journalism

Marshall University

Huntington, West Virginia

2005-2010

Police beat reporter

The Register-Herald

Beckley, West Virginia

2011

M.A., Political Science

Marshall University

Huntington, West Virginia

2013-2014

AmeriCorps VISTA

Coalfield Development Corporation

Wayne, West Virginia

2014

Writing Tutor

Mountwest Community and Technical College

Huntington, West Virginia

2017

Morris and Anita Broad Fellowship, Steven J. Green School of

Public and International Affairs, Florida International University

2017 Doctoral Evidence Acquisition fellowship: University Graduate

School, Florida International University

2018

Dissertation Year Fellowship: University Graduate School, Florida International University

2019 Founders' Fellow: American Society for Public Administration

2019

Ph.D., Public Affairs

Florida International University

Miami, Florida 


\section{PUBLICATIONS AND PRESENTATIONS}

Pridemore, Amelia A. (2018). “Outlaw Citizenship.” In Global Encyclopedia of Public Administration, Public Policy, and Governance, ed. A. Farazmand. Section eds. P. Prysmakova \& D.R. Vienne. Springer Reference Editorial.

Pridemore, Amelia A. (2017). "Crank it to Eleven: Music Festivals Breathe New Life into Cities". In Handbook of Research on the Facilitation of Civic Engagement through Community Art, eds. Leigh Nanney Hersey \& Bryna Bobick. (Hershey, PA: IGI Global, 2017), 524-543.

Pridemore, Amelia A., Ganapati, N. Emel. \& Revell, Keith.D. "Citizen Participation is Shifting While Public Administrators Lock Down: A Citizen Participation Literature Review for Public Administration" (Under Revise and Resubmit Status by American Review of Public Administration)

Pridemore, Amelia A. \& Neshkova, M.I. "Municipal Arts Policy and Concentration of Arts and Entertainment Professionals: A Panel and GIS Analysis of the Miami MSA" (Article-length manuscript). (In Progress).

Pridemore, Amelia A. "The Cultural Rat Race: Local-Level Music and Arts Communities' Obstacles in Local Government Participation" (Article-length manuscript.) (In Progress)

Pridemore, Amelia A. "Kindred Spirits and Unlikely Allies: Breaking Barriers to Music and Arts Communities' Citizen Participation in Local Government." American Society of Public Administration conference (as a Founder's Fellow). March 2019. Washington, DC.

Pridemore, Amelia A. "The Cultural Rat Race: Local-Level Music and Arts Communities' Obstacles in Local Government Participation." Urban Affairs Association conference. April 2018. Toronto.

Pridemore, Amelia A. "Soundtracks to Social Upheaval: The Cases of the United States Vietnam War Protests and the Bulgarian Post-Communism Revolutions." Trans-Atlantic Dialogue Conference 13. April 2017. Miami.

Pridemore, Amelia A. "Outlaw Citizenship and the Fine Arts: The Case of New Orleans." Third Annual Public Administration Colloquium, Doctoral Students in Public Administration. Florida Atlantic University. March 2017. Boca Raton, Florida.

Pridemore, Amelia A. "Crank it to Eleven: Music Festivals Breathe New Life into Cities." Southeastern Conference for Public Administration. October 2015. Charleston, South Carolina. 